\title{
Ein Blick hinter die Kulissen: Deutschsprachige Dramatikerinnen im 18. und 19. Jahrhundert
}

Susanne Kord

Follow this and additional works at: https://scholarsarchive.byu.edu/sophnf_nonfict

Part of the German Literature Commons

\section{BYU ScholarsArchive Citation}

Kord, Susanne, "Ein Blick hinter die Kulissen: Deutschsprachige Dramatikerinnen im 18. und 19. Jahrhundert" (1992). Prose Nonfiction. 235.

https://scholarsarchive.byu.edu/sophnf_nonfict/235

This Article is brought to you for free and open access by the Nonfiction at BYU ScholarsArchive. It has been accepted for inclusion in Prose Nonfiction by an authorized administrator of BYU ScholarsArchive. For more information, please contact scholarsarchive@byu.edu, ellen_amatangelo@byu.edu. 
Ergebnisse der

Frauenforschung
Susanne Kord

Ein Blick

hinter die Kulissen

Deutschsprachige

Dramatikerinnen

im 18. und 19. Jahrhundert 
Gedruckt mit Unterstützung der Freien Universität Berlin

Gedruct mit Untestüzung der Freien Universiat Berlin

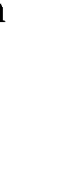
"Es ist außerordentlich schwer, vergessene Stücke aus früherer Zeit wie-
der einzubürgern. Selten sind sie durch Zufall vergessen worden ..."

Heinrich Laube

(Das Wiener Stadttheater)

„For most of history, Anonymous was a woman."

Virginia Woolf

„Alles vergibt euch die Welt, sei’s Reichtum, Stand - ja selbst Laster, Immer zur Nachsicht geneigt, findet sie Jugend und Reiz.

Für eines nur hofft ihr umsonst Vergebung im Leben und Tode:

Nimmer verzeihn wird die Welt Erfolge der dichtenden Frau."

Charlotte Birch-Pfeiffer

\section{Die Deutsche Bibliothek - CIP-Einheitsaufnahme}

\section{Kord, Susanne:}

Ein Blick hinter die Kulissen: deutschsprachige Dramatikerinnen im 18. und

19. Jahrhundert / Susanne Kord. - Stuttgart: Metzler, 1992.

(Ergebnisse der Frauenforschung; Bd. 27)

ISBN 3-476-00835-5

NE: GT

\section{ISBN 3-476-00835-5}

Dieses Werk einschließlich aller seiner Teile ist urheberrechtlich geschützt. Jede Verwertung außerhalb der engen Grenzen des Urheberrechtsgesetzes ist ohne Zustimmung des Verlages unzulässig und strafbar. Das gilt insbesondere für Vervielfältigungen, Ủbersetzungen, Mikroverfilmungen und die Einspeicherung und Verarbeitung in elektronischen Systemen.

(c) 1992 J. B. Metzlersche Verlagsbuchhandlung und Carl Ernst Poeschel Verlag GmbH in Stuttgart Einbandgestaltung: Willy Löffelhardt, Stuttgart

Druck: Gulde-Druck GmbH, Tübingen

Einband: Franz Wilhelm Held, Rottenburg 
I. WER ZÄHLT DIE HÄUPTER, NENNT DIE NAMEN?

ANSTELLE EINES ForSCHUNGSBERICHTS

II. Die Pfosten sind, Die Bretter aufgeschlagen:

TheATERPRAXIS DES 18. UND 19. JahrhunderTS

III. WIE ENG GEBUNDEN IST DES Weibes GLÜCK ...

Komödien Und Schauspiele $\ldots \ldots \ldots \ldots \ldots \ldots \ldots \ldots \ldots \ldots \ldots . \ldots 2$

A. Ende gut, alles miserabel: Ehegeschichten aus dem 18. Jahrhundert _. 42

1. „Sitzengeblieben" und noch mal Glück gehabt

Luise Adelgunde Gottsched $\ldots \ldots \ldots \ldots \ldots \ldots \ldots \ldots \ldots 4$

2. Der "Lohn" der Tugend:

Rührstücke von Rupp, Reitzenstein, Teutscher, Seyler . . . . . . . 48

3. Die Bekehrung des Tyrannen: Titzenhofer, Berlepsch, Bandemer . . 52

B. Gebildete Frauen und Kobolde: Ehegeschichten bis 1850 . . . . . 57

1. Nur eine Komödie: Johanna Franul von Weißenthurn $\ldots \ldots \ldots 58$

2. Was ist ein Mann gegen einen Brillantschmuck?

Amalie von Sachsen $\ldots \ldots \ldots \ldots \ldots \ldots \ldots \ldots \ldots \ldots$

3. A la recherche du bonheur: Charlotte Birch-Pfeiffer $\ldots \ldots \ldots \ldots, 70$

C. Wo ist der Posten der Frau? Komödien und Schauspiele nach $1850 \ldots 76$

1. Damenwahl: Ehekomödien nach 1850

Hillern, Cornelius, Young,

Ebner-Eschenbach, Levi, von Schlichtkrull . . . . . . . . . . . . . . 77

2. Berufstätige Frauen $\ldots \ldots \ldots \ldots \ldots \ldots \ldots \ldots \ldots \ldots \ldots$

a. Künstlerinnen oder Dilettantinnen? Breden, Hoffmann, Günther. . 78

b. Ärztinnen oder Quacksalber? Günther, Bernstein . . . . . . . . 82

c. Schriftstellerinnen oder Blaustrümpfe?

Droste-Hülshoff, Günther; Bernstein . 
A. Tauber Himmel: Gottsched, Huber, Pernet $\ldots \ldots \ldots \ldots \ldots \ldots .94$

B. Blinde Leidenschaft: Schlegel, Thon . . . . . . . . . . . 100

C. Himmlische versus irdische Seligkeit: Artner . . . . . . . . . 105

D. Über die Abhängigkeit des Weibes: Günderrode, Droste-Hülshoff . . . 109

V. VERGESSENHEIT, DAS IST DER WAHRE TOD!

Historische Dramen zur Geschichte der Frau,

mit einem Nachwort auch zUr Geschichte des Mannes . . . . . . . 122

A. Historische Tragödien $\ldots \ldots \ldots \ldots \ldots \ldots \ldots \ldots \ldots \ldots \ldots \ldots$

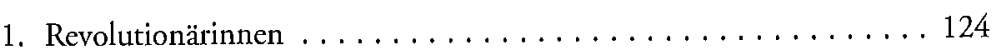

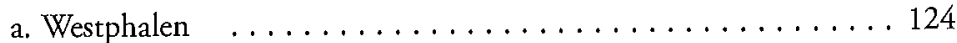

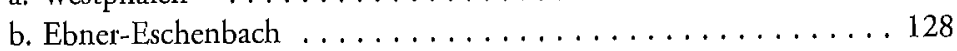

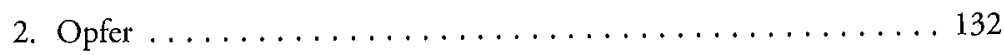

a. Elisabeth von Rumänien und Kremnitz . . . . . . . . . . . . 132

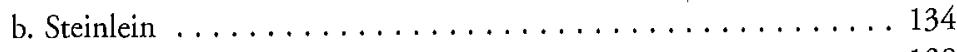

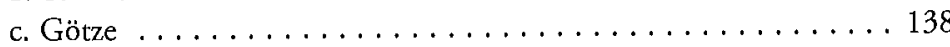

B. Historische Dramen $\ldots \ldots \ldots \ldots \ldots \ldots \ldots \ldots \ldots \ldots \ldots \ldots$

1. Königinnen und solche, die es werden sollten $\ldots \ldots \ldots \ldots \ldots 143$

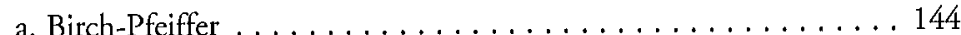

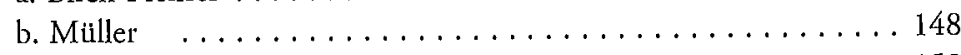

c. Wickenburg ....................... 153

C. Nachwort auch zur Geschichte des Mannes

Pichler, Franul von Weißenthurn, Wesendonck, Schmidt . . . . . . 155

VI. Pygmalions Erben:

Dramen Úber KÚnstler und Musen $\ldots \ldots \ldots \ldots \ldots \ldots \ldots \ldots \ldots 157$

A. Schriftsteller: Westphalen, Schmidt $\ldots \ldots \ldots \ldots \ldots \ldots \ldots \ldots 158$

B. Maler: Birch-Pfeiffer, Pierson . . . . . . . . . . . . . 168

C. Architekt: Elisabeth von Rumänien $\ldots \ldots \ldots \ldots \ldots \ldots \ldots \ldots 174$
VII. Die Emanzipation vom Mythos der Machtlosigkett:

Mythologische Dramen und Bibelbearbeitungen . .

A Mythologie: von Stein, Bernstein, Prellwitz, Wesendonck . . . . . . . 180

B. Biblische Dramen: Kraft, delle Grazie . . . . . . . . . . . . . 189

VIII. ES WAR EINMAL/EINMAL WIRD ES SOWEIT SEIN:

MÄrCHEN UND ALLEGORISCHE UTOPIEN

A Märchen von der Zaubermacht der Liebe:

Seyler, Krones, Günther, Bernstein .................... 196

B. Die Utopie von der Allmacht der Dichtkunst: Neuber, delle Grazie . . 209

IX. Und die Moral von der Geschicht.

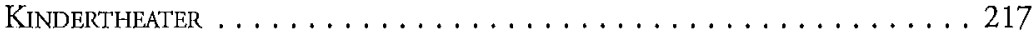

A. Braun, Hölder, Hofmann, von Sydow, Franz . . . . . . . . 217

X. DurCh die Hinterturr: SCHLUSSWORT

ANHÄNGE

A. Kurze Biopraphien der behandelten Autorinnen $\ldots \ldots \ldots \ldots \ldots \ldots 243$

B. Liste der Autorinnen, Dramatischen Werke und Pseudonyme . . . . 323

SiglenVERZEICHNIS $\ldots \ldots \ldots \ldots \ldots \ldots \ldots \ldots \ldots \ldots \ldots \ldots \ldots \ldots \ldots \ldots 442$

LITERATURVERZEICHNIS

DANK .506 
Diese Arbeit, ursprünglich meine Dissertation, ist keine Literatur-„Geschichte“ im herkömmlichen Sinne. Sie stellt eine Auswahl aus der reichhaltigen dramatischen Produktion deutschsprachiger Autorinnen im 18. und 19. Jahrhundert vor. Da es sich hier um weitgehend unbekannte Texte handelt und Dramen weiblicher Autoren noch kaum in unser literarisches Bewußtsein gedrungen sind, ist "Vorstellen" hier nicht gleichbedeutend mit „Analysieren“: diese Arbeit will lediglich die Voraussetzung für kritische Analysen liefern. Deshalb habe ich vor allem versucht, Interesse am Material zu wecken; dagegen hoffe ich, daß es mir gelungen ist, Wertungen jeder Art zu vermeiden. Solange diese Dramen noch nicht einem breiten Publikum zugänglich sind - eine Anthologie von einigen Stücken erschien $1991^{1}$-, fühlte ich mich weder berufen, die se oft recht eigenwilligen und seltsamen Texte in die uns bekannte Literaturgeschichte einzuordnen, noch berechtigt, sie nach Maßstäben der "hohen" oder Trivial-Literatur zu bewerten. Bei meinen Interpretationen galt für mich vor allem ein Gesetz: das Material hat Vorrang vor der Interpretation.

Aus dieser Verfahrensweise ergibt sich ein Korpus von Material, der - zunächst? außerhalb der Literaturgeschichte, wie wir sie kennen, steht. Schon allein diese Tatsache wirft Fragen an die Literaturgeschichte und an unser literarisches Bewußtsein auf: gibt es eine Literaturgeschichte (unsere) oder zwei (eine für Frauen und eine für Männer)? (Schlimmer noch: gibt es eine Geschichte oder zwei?) Wenn es nur eine Literaturgeschichte gibt, was fehlt in ihr? Was und wer (welche Gruppen) wurde nicht in sie aufgenommen? Warum nicht? Wenn es zwei gibt, kann und soll die weibliche Literaturgeschichte in die männliche integriert werden? Um diese Fragen herum sind inzwischen mehrere theoretische Ansätze entwickelt worden. Hier soll nicht versuch werden, sie zu beantworten. Daß sich dagegen solche Fragen beim Lesen dieser Arbeit aufdrängen werden, halte ich für einen Vorteil

Die Suche nach verschollenen Autoren (weiblichen und männlichen) beginnt mit der Suche nach dem Namen. Bei weiblichen Autoren wird dieses Unternehmen erheblich erschwert durch die Vielzahl der Namen, dic sich durch Scheidungen, Wiederverheiratungen, Namensänderungen und vor allem durch den Gebrauch von Pseudonymen ergibt. Ein großer Teil dieser Arbeit besteht daher aus der Basisinformation, die Voraussetzung für alles andere ist, aus Namen und Daten. Dieser (noch) unbelkannte Hintergrund, vor dem meine Interpretationen stattfinden, findet sich in den Anhängen. Anhang $A$ gibt kurze biographische Informationen über die fünfzig Autorinnen, deren Dramen hier mehr oder weniger ausführlich behandelt werden; sowie Angaben zu ihren nichtdramatischen Werken (eine Dramenliste findet sich in Anhang B) und weiterführende Literatur. Anbang $B$ ist eine Liste aller Dramatikerinnen beider Jahrhunderte, soweit ermittelt, mit Namen (d. h.: Mädchennamen, sämtliche Ehenamen, Bühnennamen, Pseudonyme), Daten, Geburts- und Sterbeorten, dramatischen Werken und Standorten der Dramen, soweit ermittelt. Dieser Anhang wurde gegenübe der ursprünglichen Fassung in der Dissertation erheblich erweitert und um deutsche 
österreichische und Schweizer Standorte bereichert. Im Text selbst wurden die Lebensdaten der Autorinnen und die Entstehungsdaten der Dramen bei der ersten Erwäh nung angegeben.

Bei Zitaten habe ich mich streng an dic Orthographie der zitierten Texte gehalten, auch im Bezug auf Groß- oder Kleinschreibung. Ein Verzeichnis der zitierten Werke und weiterfïhrender Literatur findet sich am Ende der Arbeit. Bei Angaben zu Dramen aus Gesamtwerken wurde im Literaturverzeichnis die Sammlung und danach ein Inhaltsverzeichnis nur der dramatischen Werke angegeben. Wo im Literaturverzeichnis Texte von Autorinnen angeführt werden, die unter einem Pseudonym (oder unter einem abgekürzten oder geänderten Namen) veröffentlicht wurden, wird außer dem vollen Namen der Verfasserin (in eckigen Klammern) das Pseudonym oder die Abkürzung des Namens bzw. Namensänderung wie im Originaltext angegeben. (Beispiel [Götze, Auguste]. Vittoria Accoramboni. Tragödie in fün Aufzügen von A. Weimar [Pseud.]. Leipzig: Breitkopf \& Härtel, 1890.) Ebenso wird verfahren, wo eine Autorin ihren Mädchennamen im Werktitel nennt; d. h. hier wird der Verfasserinnenname doppelt genannt. (Beispiel: Pichler, Caroline. Ferdinand der Zweyte, König von Ungarn und Böbmen. Historisches Schauspiel in fünf Aufzügen. Von Caroline Pichler, gebornen von Greiner. Leipzig: Fleischer, 1816.) Der Grund: mir schien wichtig, festzuhalten, wie Autorinnen aus diesem Zeitraum ihre Werke veröffentlichten. Sehr viele benutzten Pseudonyme oder veröffentlichten anonym; andere dagegen hatten, vielleicht als Reaktion auf diese (übliche) Veröffentlichungsmethode, mit Anonymität so wenig im Sinn, daß sie sich durch Nennung von Extra-Namen, so vorhanden, „über-"identifizierten. In den meisten Fällen ist die Weglassung bzw. Hinzufügung von Namen in Werktiteln durchaus aussagelkräftig, und ich wollte diese Aussagen den Leserinnen und Lesern nicht vorenthalten.

\section{KAPITEL I}

\section{WER ZÄHLT DIE HÄUPT'ER, NENNT' DIE NAMEN?}

\section{ANSTELLE EINES FORSCHUNGSBERICHTS}

Über Dramatikerinnen des 18. und 19. Jahrhunderts und ihre Werke gibt es bis heute nur einige wenige Studien über cinzelne Autorinnen und drei umfassendere Arbeiten die sich auf wenige Jahre beschränken: die Arbeiten von Wurst, Scholtz-Novals und von Hoffs Dramen des Weiblichen. ${ }^{2}$ Eine bibliographische Zusammenstellung von Autorinnen und Dramen gibt es nicht. Wer sich also mit Dramenautorinnen in diesem Zeitraum beschäftigt, ist weitgehend auf allgemeine Werke und bibliographische Angaben zur Frauenliteratur angewiesen. Dabei stellen sich hauptsächlich zwei Probleme: erstens ist bei allgemeinen Werken oder Bibliographien zur Frauenliteratur nicht auf Anhieb feststellbar, in welchem Genre die behandelten Autorinnen schrieben, und zweitens sind biographische Daten über Schriftstellerinnen oft widersprüchlich.

Von den vielen Lexika, in denen man Angaben zu Autorinnen in diesem Zeitraum finden kann - Goedeke, Kosch, die Allgemeine deutsche Biographie, Pataky, Schindel, Brümmer, Meusel, Reden-Esbecks Deutsches Bühnen-Lexikon, Philipp Steins Deutsche Schauspieler, Richels The German Stage, die Gallerie von Teutschen Schauspielern und Schauspielerinnen u. v. a. - sind in der Regel diejenigen verläßlicher, die sich ausschließlich mit weiblichen Autoren beschäftigen. Pataky und Schindel bieten Kurzbiographien, Werkangaben und Angaben zu Pseudonymen, und sind im Bezug auf Lebensdaten wesentlich zuverlässiger als Goedeke. In Gisela Brinker-Gablers Deutsche Dichterinnen und ihrem Lexikon deutschsprachiger Schriftstellerinnen, herausgegeben in Zusammenarbeit mit Karola Ludwig und Angela Wöffen, finden sich kurzgehaltene Lebensläufe der Autorinnen; im Lexikon außerdem ausführliche Bibliographien zur Primär- und Sekundärliteratur. Für Namen, Pseudonyme und Lebensdaten ist Elisabeth Friedrichs' Die deutschsprachigen Schriftstellerinnen absolut unentbehrlich; Friedrichs gibt außerdem Hinweise auf andere Werke, in denen die jeweilige Autorin behandelt wird. Da Angaben zu Namen und Daten, insbesondere in Lexilka des 19. Jahrhunderts, zum Teil sehr voneinander abweichen, ist es bei der Suche nach biographischen Angaben anzuraten, in mehreren Lexila nachzuschlagen.

Allgemeine Literaturgeschichten zur Frauenliteratur aus diesem Zeitraum behandeln in der Regel lediglich eine Auswahl von Autorinnen und sind in biographischer Hinsicht oft noch unzuverlässiger als Lexika. Robinson, die unter dem Pseudonym „Talvj“ Autorinnen des 18. Jahrhunderts bespricht, biographiert teilweise ausführlich und bietet Werkanalysen. Heinrich Groß' Deutschlands Dichterinen und Schriftstellerinen, nicht zu verwechseln mit seinem dreibändigen Werk Deutsche Dichterinen und Schriftstellerinen, in denen er außer Angaben zu Lebensdaten auch Werkauszüge liefert, ist eine Fundgrube für Namen und Werktitel; allerdings beschränkt er sich auf einige wenige Sätze pro Autorin und ist in seinen Angaben zu Lebensdaten oft recht ungenau. 
Adalbert von Hanstein behandelt in Die Frauen in der Geschichte des deutschen Geisteslebens eine ausführliche Liste von Autorinnen, wobei er sich in der Regel um biographische Daten nicht kümmert und bei der literarischen Einordnung der Autorinnen, phische Da lotte von Stein [II, 421-40] tritt Goethe wesentlich prominenter auf als sie selbst). In den meisten Allgemein-Literaturgeschichten über Frauen fallen die Informationen über die Autorinnen äußerst spärlich aus, so daß es auch hicr hilft, so viele Quellen wie irgend möglich an der Hand zu haben. Da viele Dramatikerinnen auch in anderen Genres schrieben, lohnt es sich bei der Forschung über Dramenautorinnen durchaus, in Werken nachzuschlagen, die Romane oder Novellen von Frauen behandeln (Brausewetter; Touaillon).

Studien über einzelne Autorinnen sind noch seltener. Abgesehen von wenigen Büchern, Artikeln oder auch nur einleitenden Bemerkungen über Gottsched (Richels Luise Gottsched; Schlenthers Frau Gottsched; Sanders, „Ein kdeiner Umweg"), Neuber (Sasse; Reden-Esbecks Caroline Neuber), Ebner-Eschenbach (Alkemade), Birch-Pfeiffer (Hes), Günderrode (Kastinger Riley), Huber (Köpke), Krones (Rabenlechner) und Anneke (Wagner; Ruben; Gebhardt) herrscht Schweigen.

Mit Ausnahme der wenigen Einzelstudien beschränkt sich die Mehrzahl der angegebenen Werke auf das Nötigste: im günstigsten Falle kann die Leserin sich hier übe Namen, Daten und Hauptwerke informieren; bei vielen Werken ist, wie gesagt, im Bezug auf die Korrektheit der Namen und Daten Mißtrauen angebracht. Wer sich dafür interessiert, wann, wo und wie oft Dramen von Frauen aufgeführt wurden, muß sich die Mühe machen und endlose Dramenlisten in zeitgenössischen Almanachen durchsehen, die, nach Jahr und Bühne geordnet, meistens nur den Dramentitel, nicht durchsehen, die, nach Jahr und Bühne geordnet, meistens nur den Drater oder des Autors angeben. Wer tiefergehende biographische Details benötigt, kann sich nur an eine der raren Einzelstudien halten. Oder man hat Glück und forscht einer Autorin nach, die Briefe, Tagebücher oder gar eine Autobiographie verfaßt hat (Berlepsch, von der Recke, Chézy, Pichler, Gottsched). Daß sich hier methodologische Probleme ergeben, muß nicht erst erwähnt werden.

Für Dramen von Frauen gilt dasselbe, was sich von fast allem von Frauen Geschriebenen in diesem Zeitraum behaupten läßt: sie sind wesentlich schwerer zugänglich als die Werke ihrer männlichen Kollegen. Die Dramenliste in Anhang B enthält bestenfalls einen Bruchteil der dramatischen Produktion weiblicher Autoren. Da es bis weit in 19. 19. Jahrhundert weder Copyright noch Auffuhrungsrechte gab, war es durchaus nich immer im Interesse einer Autorin, die ihr Stück aufgeführt sehen wollte, es zu verö fentlichen. Daraus erklärt sich (nur) teilweise die geringe Anzahl gedruckter Stücke und die große Anzahl derer, die verlorengegangen sind. Noch seltener sind Gesamtausund die große Anzahl derer, de ungeheure Popularität (Birch-Pfeiffer), ein Schwager, gaben: dazu gehörte entweder ungeheure Popularität (Birch-Pfeiffer), ein Schwager, der selbst Verleger war (Pichler), oder königliche Intervention (Amalies Dramatsche Werke wurden - posthum - im Auftrag des Königs Johann von Sachsen herausgegeben).

Auch die Autorinnenliste in Anhang $B$ ist aufgrund der unvollkommenen Forschungslage lediglich eine vorläufige. Die 315 angeführten Dramatikerinnen waren fast ausnahmslos Angehörige des Adels und des Bürgertums: Frauen, die die Ausbildung, die Zeit, den Mut und die nötigen Finanzen besaßen, um für die Bühne ode den Druck zu schreiben. Obwohl die meisten dieser Autorinnen sozial und finanziell privilegiert waren, war ihre literarische Betätigung auch für sie ein Wagnis. Anonyme oder pseudonyme Veröffentlichungen waren wesentlich häufiger als Veröffentlichungen unter dem Namen der Verfasserin. Von 151 der 315 Autorinnen wurden die Pseudonyme ermittelt; die Zahl der Autorinnen, die unter einem Decknamen oder anonym veröffentlichten, liegt mit Sicherheit wesentlich höher. Von den insgesamt 265 ermittelten Decknamen sind fünf Pseudonyme geblieben: wer sich hinter Kreopola, Richa Mara L. verbirgt, ist bis heute nicht geklärt, ebensowenig wie die Identität der Verfasserin der Ortinde (1792) oder der Vorname der Frau von Mauritius (ihr Name? ih Pseudonym?). Viele Frauen behielten ihr Pseudonym auch dann bei, wenn hinreichend bekannt war, wer sich dahinter verbarg: eine Schriftstellerin, die auf ihren Ruf hielt, erhielt den Schein der Anonymität aufrecht. Ein Pseudonym hatte oft die Nebenfunktion, dem Geschriebenen Glaubwürdigkeit zu verleihen: unerkannt zu bleiben, dabei aber bekannt zu werden, scheint das Ziel vieler Autorinnen gewesen zu sein. So nennen viele Frauen in ihren Pseudonymen gern bereits veröffentlichte Werke („Verfasserin de Philosophie eines Weibes“, „Verfasserin des Julchen Grünthal“, „Verfasserin der Charlotte Corday"), die sie unter Umständen auch fälschlich zu Übersetzungen degradieren („Miß Jennys Übersetzerinn"). Andere definieren sich als Familienangehörige oder Freundinnen anderer literarischer Größen („Tochter der Karschin“, „Freundin Goethe und Schillers aus Heidelberg") oder verweisen auf ihren sozialen Status („Adliches Frauenzimmer in Schlesien"). Im 18. Jahrhundert bestehen die Frauen trotz ihrer Anonymität darauf, als weiblich erkannt zu werden: sie nennen sich Jerta, Jenny, Glycere, Minna, Nina, Therese. Obwohl diese Tendenz bis ins 19. Jahrhundert weiterbesteht, steigt die Popularität männlicher Pseudonyme zwischen 1800 und 1900. Zwischen 1850 und 1900 überwiegen die männlichen Pseudonyme die weiblichen bei weitem, z. T. betont männliche wie Ernst Ritter; R. Edmund Hahn, Max Stein, Lork Alban, Willibert von Herrigau, Julius Willborn, Franz Fels, Werner Kraft, Josef Trieb. Während im 18. Jahrhundert der Zweck des Pseudonyms hauptsächlich der ist, die Identität zu verhüllen, liegt jetzt die Betonung auf der Verhüllung des Geschlechts der Autorin: die Erkenntnis macht sich breit, daß unter männlichem Pseudonym veröffentlichte Werke eher eine Chance haben, ernstgenommen zu werden.

Auch bei Pseudonymen, die Initialen verwenden, läßt sich eine Entwicklung zur Männlichkeit hin verzeichnen. Während im 18. Jahrhundert das Pseudonym meistens entweder ganz aus Initialen besteht (L. A. V. G., W. v. G., E. T. P. A.) oder der Nachname hinter einem Buchstaben verschwindet (Eleonore F., Susanne von B.), steigt im 19. Jahrhundert die Tendenz, den Vornamen abzuküizen: P. v. Husch, F. S. Koch, K. Ph. Zianitzka, C. Wedi, H. Salkkorausch, A. Freese. Autorinnen, die solche Pseudonyme benutzten, rechneten wahrscheinlich damit, daß der Durchschnittsleser hinte einem abgekürzten Vornamen einen männlichen Autor vermuten würde.

Viele Autorinnen hatten eine Reihe von Pseudonymen zur Hand, die sie nach Belieben (oder Genre) einsetzten. Katharina Zitz zum Beispiel schrieb unter mindestens 
15 verschiedenen Pseudonymen, darunter Initialen, Männer- und Frauennamen einmal legt sie sich sogar einen Doktortitel zu (Dr. Schmid). Teilweise definierte eine Autorin sich durch ihr Pseudonym als Komödienautorin (Amalic Heiter) oder Märchenautorin (Fittchersvogel, Allerleih Rauh).

Aus der weitverbreiteten Anonymität oder Pseudonymität weiblicher Autoren und der Flut von Namen, die sich aus dem häufigen Gebrauch von Pseudonymen, aus Verheiratungen, Scheidungen und Wiederverheiratungen ergeben, erklärt sich ein guter Teil der Schwierigkeiten bei der Forschung, wie auch die widersprüichlichen Angaben in Nachschlagewerken über Schriftstellerinnen. Von 74 der Autorinnen in Anhang $B$ fehlen entweder Geburts- oder Todesdaten oder beides. Bei anderen finden sich widersprüchliche Angaben zu Lebensdaten, Geburtsorten und Schreibweise der Namen, wie B. im Falle Regina Frohberg, geb. Salomo (Groß, Deutschlands Dichterinen: Salomon), angenommener Name Saling (Goedeke: Saaling), verheiratete Friedländer, geno 1850 (Godeke, Groß in Deutschlands Dichterinen: nach 1858). Aus diesen Namen den "richtigen“ zu bestimmen - zur Auswahl stehen der Mädchenname, de Name des ersten Ehemannes, der Name des letzten Ehemannes, der Name, unter den die Autorin am bekanntesten war, der Name, unter dem sie am häufigsten veröffentdie Anto lichte -, scheint ein Ding der Unmoglichkeit. Eine Schriftstellein beim " Namen zu nennen, war daher oft nur begrenzt möglich. ${ }^{3}$ Aus der Vielzahl der Namen für dieselbe Autorin entstand oft eine Verdoppelung, wenn nicht eine Vervielfachung der Autorin selbst, denn eine Autorin, die über eine Reihe von Jahren hinweg veröffentlichte, konnte durchaus bei jeder ihrer Publikationen den Namen wechseln. Of vermuteten spätere Biographen hinter jedem dieser Ehenamen oder Pseudonyme vermer oder mehr. ${ }^{4}$ Erst wenn sich herausstellt, daß beide Autorinnen dasselbe ungewöhnliche Pseudonym benutzten, daß sich ihre Namen ähneln und beide in demselben Zeitraum lebten, erst dann beginn man zu ahnen, daß es sich z. B. bei Christiane von Breden, geboren 1839, und Christine Bredow, geboren 1844, um ein- und dieselbe Autorin handelt (Pseudonym: Ada Christen). Zweifel kommen einem dagegen, wenn die Autorin Elisabeth Müller in zwei verschiedenen Werken mit um Jahrzehnte abweichenden Lebensdaten angegeben wird (Friedrichs: 1866-1932; National Union Catalog: 1827-1898). Einig sind sich beide allerdings über das Pseudonym der Autorin (E. Meruell), so daß die schon gefaßte Überzeugung, es handele sich um zwei verschiedene Autorinnen, letztendlich doch keine ist.

Ein Pseudonym war für viele Autorinnen mehr als nur ein falscher Name, der dazu diente, die Identität der Autorin zu verhüllen: es war vor allem ein Schutzmantel für den guten Ruf. Ich halte es für völlig verfehlt, anzunehmen, daß Schriftstellerinnen aus den guten Ruf. Tch halte es fir dieser Zeit unerkannt bleiben wollten: viele, wahrscheinlich die Mehrzahl, wollten durchaus (an)erkannt und bekannt werden. Dic Vielzahl der recht offensichtlichen Pseudonyme (wie "Tochter der Karschin") spricht dafür. Für viele war ein Deckname lediglich eine Konzession an die öffentliche Meinung. Laddey stellt noch 1873 fest, daß die Gesellschaft einer Frau Alles leichter [vergibt], als daß sie versucht, die Feder zu führen. Für die größte Hälfte der Menschheit (nicht nur der Männer) ist eine schreibende Frau ein unbeschreiblich grauenvolles Etwas, ein Wesen, das zwischen Mann und Frau stehend betrachtet wird [...]. Dieses Vorurtheil veranlaßt denn leider viele tüchtige Schriftstellerinnen sich einen Männernamen beizulegen, unter dessen Schutz sie ihr Werk dann ganz getrost und weit weniger ängstlich in die Welt hinaus senden können. Solches Verbergen aber, das Verleugnen des Frauennamens wird gerade bei diesen Talentvollen zum Unrecht an ihrem Geschlechte: wie soll man diesem je etwas zutrauen, wenn seine besten Leistungen den Männern zugeschrieben werden? (270 f).

Solange die gesellschaftliche Konvention die Frau in Küche und Schlafzimmer verbannte, begab sich eine Schriftstellerin auf soziales Glatteis und setzte sich der öffentlichen Kritik aus: Kritik nicht etwa an der Qualität des Geschriebenen, sondern allein an der Tatsache, daß sie schrieb - Kritik an ihrer sogenannten „Weiblichkeit“. „Oeffentlich als Verfasserinn aufzutreten, - dieser Schritt ist gewagt“, schreibt Franul von Weißenthurn in ihrer Vorrede zu ihren Schauspielen (I, III), und weiß, daß sie der kritischen Welt „ein Messer in die Hand“ gibt, ,indem ich meine Stücke mit meinem Nahmen in die Welt schicke" (v). Aber auch Frauen, die pseudonym veröffentlichten, fühlten sich hinter ihrem Decknamen keineswegs sicher: kaum eine Autorin, die nicht in ihrem Vorwort auf das zeitgenössische Vorurteil gegen weibliche Schriftstellerei eingeht oder darauf anspielt.

Auf diese Vorurteile reagierten viele Autorinnen mit Taktiken, die ich als „pseudonymes Verhalten" bezeichnen würde. Pseudonymes Verhalten könnte man definieren als den Versuch einer Autorin, ihre Leserschaft trotz ihrer „unweiblichen“ Beschäftigung des Schreibens von ihrer Weiblichkeit zu überzeugen. Ein Deckname allein reichte dazu oft nicht aus: viele Autorinnen sahen sich außerdem genötigt, ihr Werk als Werk des Zufalls hinzustellen, die offensichtlichen Mängel des eigenen Werkes im Vorwort hervorzuheben (Seyler, Die Entfiibrung, Vorbericht 3), um dic Nachsicht der (männlichen) Kritiker zu bitten (Bürger, Gedichte, Vorrede XvII f; Titzenhofer, Lausus und Lydie, Nacherinnerung $91 \mathrm{f}$ ), oder zu versichern, sie könnten mit der Nadel vie besser umgehen als mit der Feder. Viele berufen sich auf eine subjektive inspiratorische Schreibweise, nach der das Werk „sich selbst" geschrieben habe, und lehnen so die Verantwortung für das Geschriebene ab (Bürger, Gedichte, Vorrede XVII). Andere stellen von vornherein fest, sie hätten keine Kunstwerke im Sinn gehabt (Hofmann, Vorerinnerung 7), sondern lediglich „bescheidene Beiträge“ (Gerhard, Vorwort III). Oft artet die so demonstrierte weibliche Bescheidenheit in harte Selbstkritik aus (Titzenhofer spricht im Nachwort zu Lausus und Lydie von der "Mißgeburt meines Witzes", 92) oder auch in demonstrative Anerkennung männlicher Überlegenheit: „Hätte ein Mann diese Blätter geschrieben, sie würden vorzüglicher seyn" (Woltmann, Ueber Natur, Bestimmung, Tugend und Bildung, Vorrede v). Manche Autorinnen berufen sich gerade auf den unerwarteten Erfolg des Werkes und rechtfertigen dadurch eine Neuauflage (Arndts, Vorwort, unpag; Levi, Durch die Intendanz, Vorwort $3 \mathrm{f}$ ). Wieder andere 
erklärten sich als Nur-Herausgeberinnen bzw. Übersetzerinnen ihrer eigenen Werke (Christiane Friederike Huber in Cleveland; von Rupp in Marianne). Bei der Vielzahl der ungenauen Angaben (typisch sind „nach dem Französischen“, „aus dem Englischen", "bearbeitet nach Destouches") ist oft nur schwer feststellbar, ob es sich tatsächlich um eine Übersetzung oder um eine Form pseudonymen Verhaltens handelt. Ich habe daher bei angeblichen Übersetzungen und Herausgaben angenommen, daß es sich nicht um Originalwerke handelt (obwohl das meiner Ansicht nach keineswegs überall anzunehmen ist), und sie nicht in diese Arbeit eingeschlossen.

Eine weitere sehr beliebte pseudonyme Taltik ist die (angebliche) Veröffentlichung Wen Willen und ohne das Wissen der Autorin (Levi, Durch die Intendanz, Vorgegen den Willen und ohne das Wissen der Autorin (Levi, Durch 3 f ${ }^{5}$ Oft wurde wort 3; Christiane Karoline Schlegel, Vorbericht des Herausgebers 3 f). ${ }^{5}$ Oft wurde das Werk angeblich nicht zum Zweck der Veröffentlichung oder Aufführung geschrieben (und das sollte bei einem Drama Mißtrauen erregen), sondern „bloß zum Vergnügen einiger Freunde" (Titzenhofer, Lausus und Lydie, Nacherinnerung 93; ähnlich Franul von Wcißenthurn, Die Drusen, Vorwort 207, und Das Waisenhaus, Vorrede 203). Di Debatte in Vor- und Nachworten über die Frage, ob die Autorin es wagen dürfe, das Werk drucken zu lassen, ist teilweise unglaublich ausfuhlich. Berlepsch beispielsweise schreibt darüber ein 28seitiges filktives "Gespräch als Vorrede“ (zu ihrer Sammlung kleiner Schriften), in dem die fiktive Verfasserin Eugenie sich mit dem Gedanken quält, ob ner Schiften in es gerechtfertigt sei, "die kleinen, einzelnen Schöpfungen sammeln und sie der Welt vorzulegen" (v) und von Philotas mühsam dazu überrede werden muß. Philotas, der als Mann wesentlich sicherer auftreten kann, hat zu Eugewe nies größtem Schrecken sogar mehrene Băd in Sinn (xxvi). Le ihrer Anonymität belich läßt es bei ihrer Erstausgabe der Pietisterey nicht allein bei ihrer Anonymität bewenden, sondern rechtfertigt die Veröffentlichung des Stückes durch eine „Vorrede de Herausgebers", der sie eine "Antwort des Verfassers [sic] an den Herausgeber" folgen Herausgers", der sie en "An läßt. Der Herausgeber, der den Verfasser als „Hoch-Ehrwürdigex, Hochgelahrter" Herr tituliert (Die Lustspiele I, 442), entschuldigt sich kniefälligst für den Druck des Werkes ohne Erlaubnis und Wissen des Verfassers. Er berichtet, er habe das Stück bei eine Gesellschaft vorgelesen, worauf es ihm von begeisterten Zuhörern aus den Händen gerissen worden sei, ,und es war mir nicht möglich, dasselbe wiederum in meine Hand zu bekommen" (444). Die "gescheidesten Köpfe" besagter Gesellschaft faßten daraufzu beksommen zu veröffentlichen, sonhin nicht nur den spontanen Entschluß, das Work ungeh dern finanzierten auch den Druck. Alle Einwendungen des Herausgebers fruchteten nichts, und der Druck ging so schnell vor sich, daß er vollendet war, bevor der Herausnichts un in seinem Antwortschreiben seine äußerste Bestürzung über das Vorgefallene aus und versichert, er habe das Stück „bloß zu meiner eigenen Vergnügung, und höchstens zur versichert, er habe das Stur " bey müßigen Stunden aufgesetzet" (446). Da es allerdings „nicht mehr bey mir stehet, den Druck derselben zu hindern“ (448), ergibt er sich schließlich seufzend in sein Schicksal, unter der Bedingung, daß seine Anonymität gewahrt bleibt. Weiterhin besteht der Autor auf einer öffentlichen Erklärung des Herausgebers, daß der Autor weder am Druck beteiligt war noch seine Einwilligung dazu gegeben hatte; und auf eine möglichst beschränkte Auflagenzahl (449). Daß beide Briefe von Luise Gottsched stammen und sowohl „der Autor" als auch der Herausgeber fiktive Personen sind, ist stark anzunehmen. Abgesehen von einer geradezu aufdringlichen Wahrung der Anonymität der Verfasserin (und dem Verhüllen der Tatsache, daß es sich um eine Frau handelt, denn ihr fiktiver Anonymus ist eindeutig ein Mann) erfüllen diese Briefe einen weiteren Zweck: der Herausgeber sowic dic begeisterte Gesellschaft, die an dem Malheur schuld ist, bürgen für die Qualität des Stückes und empfehlen es so gewissermaßen den Lesern weiter, während "der Autor" sich weiterhin in bescheidene Anonymität hüllen darf und nicht in die peinliche Lage kommt, sein eigenes Stück loben zu müssen.

Nur sehr wenige Autorinnen waren angesichts der gängigen Vorurteile weiblichen Schriftstellern gegenüber selbstbewußt genug, ohne Pseudonyme, Anonymität, ständige Selbstverleugnungen, Selbstkritiken, Entschuldigungen und Bitten um Nachsicht auskommen zu wollen. Die, die es konnten, oder meinten, es zu können, kamen meist aus einem Stand, in dem man es sich erlauben konnte: entweder waren sie Schauspielerinnen und aufgrund dieser Tatsache in sozialer Hinsicht suspekt (Seyler, Neuber; Franul von Weißenthurn, Birch-Pfeiffer), oder sie waren Angehörige des Hochadels obwohl auch Kaiserinnen und Königinnen oft nicht in den Ver-Ruf der Schriftstellerei kommen wollten. Katharina II. von Rußland veröffentlichte unter einem Kürzel, das offensichtlich genug war: „Von I[hrer] K[aiserlichen] M[ajestät] d[er] K[aiserin] a[ller] R[eussen]"; Prinzessin Amalie von Sachsen dagegen benutzte Pseudonyme (Amalie Heiter, A. Serena, Verfasserin von „Lüge und Wahrheit"); desgleichen Elisabeth, die Königin von Rumänien (Carmen Sylva, Dito, C. Wedi). Die Schauspielerinnen dagegen schrieben meist nicht nur unter ihrem eigenen Namen, sondern nahmen sich oft auch die Freiheit, die Situation weiblicher Schriftsteller zu kommentieren. Karoline Neuber läßt in ihrem Vorwort zu Ein deutsches Vorspiel keinen Zweifel daran, daß sie nicht daran denkt, sich für ihre Profession oder ihre Schriftstellerei in irgendeiner Weise zu entschuldigen. Mit herausforderndem Ton gibt sie ihren Lesern ihr Stück in die Hand:

Hier hast du was zu lesen. Nicht etwan von einem grossen gelehrten Manne; Nein nur von einer Frau, deren Namen du aussen wirst gefunden haben, und deren Stand du unter den geringsten Leuten suchen mußt: Denn sie ist nichts, als eine Comödiantin [...]. Fragst du: Warum sie auch schreibt? So antwortet sie dir das, dem Frauenzimmer gewöhnliche, Darum! Fragt dich jemand: Wer ihr geholfen hat? So sprich: [...] Es könnte doch wohl seyn, daß sie es selbst gemacht hätte (3, Hervorhebung der Autorin).

Daß auch Karoline Neuber viele ihrer Stücke nicht drucken ließ, lag nicht an ihre Angst vor dem Urteil der bürgerlichen Gesellschaft, sondern an ihrer Angst vor de Konkurrenz, die ihre Stücke, einmal gedruckt, ohne Erlaubnis der Verfasserin aufführen konnte (vgl. Kap. II). Allerdings können die zeitgenössischen Vorurteile während beider Jahrhunderte für den größten Teil der verlorengegangenen Werke und heut 
vergessenen Autorinnen verantwortlich gemacht werden. Die meisten Autorinnen im Anhang sind heute unbekannt; viele waren es immer. Die Zahl der Schriftstellerinnen, die unbekannt bleiben werden, ist mit Sicherheit viel größer als die Zahl derer, die noch in mühsamer Kleinarbeit, unter Vergleich von zahllosen und meist widersprüchlichen Informationsschnipseln ausgegraben werden können. Die Zahl der Stücke, die endgültig verlorengegangen sind, ist wesentlich höher als die Zahl derer, die noch über

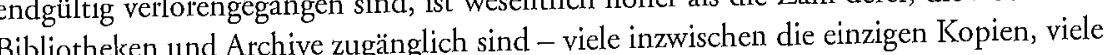
in kaum noch lesbarem Zustand.

Diese Arbeit ist vor allem ein Versuch, das Interesse an einigen dieser Autorinnen Diten Werken wieder zu wecken, und ihnen den Platz iteraturgeschichte zuzubilligen, der ihnen schon lange zusteht. Das bedeutet nicht, daß hier versucht wird, die Dramen weiblicher Autoren in die deutsche Literaturgeschichte einzuordnen; im Gegenteil werden Vergleiche zwischen Dramen männlicher und weiblicher Autoren Im Gegentil weitgehend die weiblicher vermieden. Die Geschichte weiblicher Dramatiker - und weigehend die weiblicher Autoren überhaupt - muß zunächst einmal unabhängig von der uns bekannten männlichen Literaturgeschichte geschrieben werden; solange sie noch nicht geschrieben ist, Wer wäre ein Vergleich zwischen Diamen wciblicher und mantich früht. Die Einteilung in verschiedene literarische und philosophische Epochen (Aufklärung und Empfindsamkeit, Sturm und Drang, Klassik, Romantils, Biedermeier und Vormä Realismus und Naturalismus) baut auf Werken männlicher Literaten und Philosophen auf. Eine glatte Einordnung der Literatur von Trauen in dieses Muster is unmöglich. Schon in der Wahl des Genres zeigt sich eine Divergenz zwischen der Literur von Frauen und der von Männern: wo das Drama als die höchste literarische Gar von Frauch un me meisten FrauGattung galt (Klassik), finden sich nur wenige Dramen von Fraten. Die endramen entstanden während literarischer Epochen, in denen Roman und Novelle die vorherrschenden Genres waren (Biedermeier und Realismus). Die Diskrepanz zwi(ie Sozialgeschichte der Frauen zu den literarischen und philosophischen Tendenzen und Bestrebungen de Männer in direktem Gegensatz steht. In literarischen Strömungen, die das unbedingte (maing (männliche) Genie propgiecen (Sturn und Drestich Weltordnung gilt (Klassilk) oder Erlösung verheißt (Frühromanti), finder wenige Schriftstellerinnen; noch auffallender ist ihre Abwesenheit in betont politischtendenziör Literatur (Vormärz und Junges Deutschland). Selbst Schriftstellerinnen, (wie Charlotte Birchdie enge Beziehungen zu Vertretern dieser Richtung unterhielten (wie Charlotte BirchPfeiffer zu Heinrich Laube), nahmen nicht selbst an dieser literarischen Tendenz teil. Weibliche Autoren, von politischer Tätigkeit ausgeschlossen, in ihrer künstlerischen Ausübung eingeschränkt, konnten den politischen und künstlerischen Erlösungsmodellen männlicher Literatur nur skeptisch gegenüberstehen. Wo dagegen das Gefüls zur Triebfeder der Handlung (Empfindsamkeit) und der Schoß der Familie zum Schauplatz wird (Biedermeier), sind Frauen sehr stark vertreten: auf dem Gebiet der Empfindungen und der Familie galten sie schon immer als Expertinnen, und diese Themen und die entsprechenden dramatischen Genres - Komödie und Schauspiel, vorwiegend das Familienstïck - waren ihre hauptsächliche dramatische Domäne.
Aus diesen Gründen halte ich eine thematische Untersuchung der Dramen für angebrachter als beispielsweise eine historische oder literarhistorische, in der die un bekannte männliche Literaturgeschichte zum Bezugspunkt für die weibliche würde. Für eine solche Studie wäre überdies eine strilkt chronologische Einteilung der Dramen wesentlich zweckmäßiger, und die wird schon dadurch erschwert, daß die Entstehungs- oder Veröffentlichungsdaten vieler Dramen nicht mehr feststellbar sind. Vielmehr werden hier die Hauptthemen einzelner dramatischer Genres (Komödien und Schauspiele, Tragödien, historische Dramen, Künstlerdramen, mythologische Dramen und Bibelbearbeitungen, dramatische Märchen und Allegorien, Kindertheater) untersucht und die sich daraus abzeichnenden Entwicklungen aufgezeigt, und zwar unabhängig davon, ob sie sich von den Tendenzen des zeitgenössischen Dramas männlicher Autoren unterscheiden oder nicht. Innerhalb der Genres wird weitgehend chronologisch vorgegangen. Als Hintergrund und Bezugspunkt für die thematischen Untersuchungen wird über die Theaterpraxis beider Jahrhunderte berichtet. Als Forschungshilfe finden sich in den Anhängen biographische Informationen über die 50 Autorinnen, die hier ausführlicher behandelt werden (Anhang $A$ ) und eine umfassendere Liste der ermittelten Dramatikerinnen, in der Namen und Daten, Pseudonyme, Bühnen- und Mädchennamen, dramatische Werke und Standorte, soweit mir bekannt, wiedergegeben werden (Anhang B). 


\section{KAPITEL II}

Die Pfosten sind, die Bretter aufgeschlagen:

THEATERPRAXIS DES 18. UND 19. JAHRHUNDERTS

Ein Blick hinter die Kulissen des damaligen Theaters ist schon deshalb angebracht, weil viele der hier behandelten Dramatikerinnen auch Schauspielerinnen waren, und well viel der hier butorinnen von der damaligen Theaterpraxis weil die dramatische Produktion vieler Autorinnen von der damaligen Theaterpraxis bestimmt war.

Theater im 18. und 19. Jahrhundert ist nicht gleich Theater. Zwischen Hof-, Stadt-, Unternehmer- und Wandertheatern bestanden finanzielle, soziale und bühnenpraktiUnternehmer und Wandertheaten bestanden fühnenhierarchic sche Unterschiede, die eine veritable Hierarchie ausmachten. Diese Bühnenhierarchie reicht von den Hoftheatern über Stadt- und Unternehmertheater bis hinunter zu den Wanderbühnen. Die Hoftheater wurden von ihren adligen Gönnern enorm subventioiert: die fürstliche Unterstïtzung betrug of bis zu 50\% des Gesamtetats oder mehr niert; die fürstliche Unterstützung betrug oft bis zu $50 \%$ mit Hilfe dieser Subventionen Die meisten Hoftheater in Leipzig, München, Berabgedeckt werden konnten. Kustner, Direk jer Jahr seiner Abrechnung: das Berline lin und Darmstadt, zieht dieses Fazit in jedem Jahr seiner Abrechnung. das Berliner Hoftheater, 1830 das am höchsten subventionierte Theater in Deutschland, wurde be 170000 Talern Einnahmen mit 230-240 000 Talern bezuschußt; der Ausgabenetat 170 400000 Taler (Rückblick 320). ${ }^{6}$ Stadt- und Unternehmertheater dagegen mußbetrug 400000 Taler (Ruckblick 320). Stadt- und Uno ten ausschließlich von den Kasseneinnahmen überleben und hohe Abgaben an dic Stadt zahlen, die sich von Konzession und Theaterpacht (Martersteig, Das deutsche Theater 378; Küstner, Taschen- und Handbuch 167) bis zu Benefizvorstellungen für die Armen erstreckten (Küstner, Taschen- und Handbuch 274-81). In Anbetracht der Tat sache, daß selbst die Hoftheater nur mit Hilfe von enormen Subventionen finanziel uiberleben konnten, war es kein Wunder, daß viele Stadttheater sich nur wenige Jahre hielten. Das Leipziger Stadttheater, 1817 eröffnet, machte 1827 während der zweimaligen Landestrauer, während der Spielverbot herrschte, 16000 Taler Schulden und mußte im folgenden Jahr schließen (Küstner, Rückblick 298 f). Die Wandertheater schließlich waren finanziell am unsichersten, weil sie an jedem neuen Ort um Spielschlesh nachsuchen und dazu noch mit der Konkurrenz anderer Wanderbühnen oder lokaler stehender Theater kämpfen mußten. Allerdings hielten sich viele Wanderoder loka 1866-7 zählt Paldamus 67 reisende Gesellschafbühnen bis ins 19. Jahrhundert: um 10 als finanziell abgesichert (99).

Während die reisenden Gesellschaften ständig den Spielort und damit das Publikum Wruppe spielte im Jahre 1730 in acht verschiedenen wechselten Städten (Hans Devrient, Johann Friedrich Schönemann 303); - sahen sich die stehenden Bühnen, die am selben Ort ihr Publikum unterhalten wollten, gezwungen, cin abwechslungsreiches Repertoire aufzustellen. Küstner gab 1833-42 am Hoftheater München durchschnittlich 225 Vorstellungen im Jahr, davon 160 verschiedene Stücke und 41 Neuaufführungen (Vierunddreißig Jahre 142); während seiner Berliner Direktion 1842-51 gab er 460-470 Vorstellungen pro Jahr in Berlin, Potsdam und Charlotteriburg (Vierunddreißig Jabre 185). Auch Wandertheaterdirektoren, die irgendwo eine längerfristige Spiclerlaubnis erhielten, sorgten für Abwechslung im Spielplan: Karoline Neuber gab vom 8. 4. bis zum 5. 12. 1735 in Hamburg insgesamt 203 Vorstellungen; von den aufgeführten Stücken wurden nur die erfolgreichen wiederhol (Reden-Esbeck, Caroline Neuber 107-10). Gespielt wurde also fast jeden Tag, jede Woche wurde ein neues Stück aufgeführt. Daß bei diesem helktischen Tempo nicht viel Zeit für Proben blieb, leuchtet ein. Karoline Schulze-Kummerfeld lernte 1758 be Ackermann ihre Rollen, ohne den Rest der Stücke zu kennen, und mußte sich ihre Abgänge vom Souffleur andeuten lassen; wenn es sich um „alte" Stücke handelte, wurde überhaupt nicht geprobt (Schulze-Kummerfeld I, $106 \mathrm{f}$ ). Daß Schauspieler oft bei der Aufführung von Stücken nur ihre Rollen kannten, war keineswegs ungewöhnlich: in der Regel ging unter den probenden Schauspielern eine Ausgabe des Stückes herum, aus der sie ihre Rollen abschrieben, ohne natürlich dabei den Rest des Stückes mitzukopieren (Laube, Briefe 56). In Schröders Hamburger Theater der 1770er Jahre fand lediglich eine Leseprobe und eine Probe statt, oft am Tag vor der Aufführung (Paul Hoffmann 265; Schulze-Kummerfeld II, 59; Rötscher, Dramaturgische Probleme 33; Löhn-Siegel, Vom Oldenburger Hoftheater 36 f), „so daß die Schauspieler eine Stunde nach der Probe des einen Stückes das andere spielen mußten" (Gerber 33). Die 1808 in Wien erlassenen "Gesetze für das deutsche Schauspiel" schrieben zwei Lese- und zwei Gedächtnisproben, bei der der Souffleur Stichworte gab, vor (Kindermann, Thedtergeschichte 499). Friedrich Ludwig Schmidt, Mitdirektor des Hamburger Stadttheaters, empfiehlt 1820 drei Proben und eine Leseprobe, wobei er impliziert, daß im Normalfall weniger geprobt wurde (Dramaturgische Aphorismen 109-14). Heinrich Laube, seit 1869 Direktor des Leipziger Theaters, probte vor jeder Aufführung immerhin fünf bis sieben Mal (Das norddeutsche Theater 148). Wenn ein Stück unerwarteter Weise zu kurz ausfiel, d. h. nicht „abendfüllend" war, wurde nach der Vorstellung oft kurzerhand ein Nachspiel angesetzt, für das gar nicht geprobt wurde. Det Schauspieler Brandes berichtet von einer solchen kurzfristigen Zusatzvorstellung, bei der er auf die Bühne gestellt wurde, ohne zu wissen, welches Stück gespielt werden sollte, und auf seine Fragen von seinem Direktor Schuch die Antwort erhielt: „Schwatz der Herr nur von Liebe, das übrige wird der Herr schon erfahren" (zit. Eloesser, Aus der großen Zeit 34). Selbst in Goethes Weimarer Theater wurde vor jeder Aufführung nur drei bis vier Mal geprobt; was Satori-Neumann für die Regel „bei [...] mittleren Truppen“ hält (272).

Was gespielt wurde, hing sowohl von den Finanzen als auch von den künstlerischen Ansprüchen der jeweiligen Theater ab, und auch hier gab es krasse Unterschiede zwischen Wanderbühnen und stehenden Theatern. Eduard Devrient sieht einen der großen Fortschritte des Theaters im 19. Jahrhundert darin, daß von der Hofbühne herab moralisch belehrt werden könne, während die Wandertheater sich nach Publikumswünschen richten müßten (Geschichte der deutschen Schauspielkunst I, 479 f). Die Trennungslinie zwischen Unterhaltungstheater und der Bühne als moralische An- 
talt betrachtet ist also die zwischen Hoftheater und Wanderbühne. Aufgrund dieser Unterscheidung versuchten die meisten Stadt- und Unternehmertheater, sich den

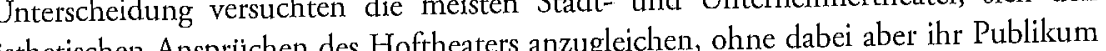
zu verlieren. Ein Mittel dazu schien die Abgrenzung zur Wanderbühne. Wanderzu verlieren. Ein Mittel dazu schien dit Ausnahme der Neuberschen, galten als reine Unterhaltungstheater, die hauptsächlich sogenannte „Haupt- und Staatsaktionen“" im Repertoire führten (Prutz 188. Küsner. Rückblick 198), tatsächlich aber alle Genres spielten, von Trauerspiel, Lustspiel und Possen bis zur Oper, aus denen die publikumswirlksamsten ausgewählt wurden. „So sind es denn weit weniger die wirklich guten Trauerspiele, welche zur Aufführung kommen, sondern die Stücke von Kotzebue, Babo, Auffenberg, Weißenthurn fuhrung kommen, sondern die Stucke von Konden im Repertoire etc." (Paldamus 150). Auch Goethe- und Schilleraufführungen standen im Repertoire der Wanderbühnen, weil die Magistrate, die die Spielgenehmigungen erteilten, sich oft die Spielpläne vorlegen ließen, „da müssen denn auch ein paar klassische Stücke darauf die Spie (Pald stehen" (Paldamus 150). Die "klassischen" Verteter auf dem Spielplan wurden popularisiert, sowohl inhaltlich als auch im Titel: so wurde aus Schillers Räubern „Die Räuber in den böhmischen Wäldern“, und Kabale und Liebe wurde umbenannt in „Kabale und Liebe oder die verhängnisvolle Limonade" (Paldamus 151).

asseneinnahmen Die Stadt- und Unternehmertheater, die ausschließlich von ihren Kasseneinnahmen existierten, richteten sich bei der Aufstellung ihrer Spielpläne nach dem Geschmact des Publikums, die Hoftheater nach dem ihrer adligen Gönner. In Stadttheatern waren Komödien und Schauspiele die vorherrschenden Genres, in Hoftheatern die Komödie und die Oper. Der Almanach für Freunde der Schauspielkunst (1845) führt für die Zeit vom 1. 10. 1843 bis zum 31. 3. 184427 in Berlin aufgeführte Lustspiele und nur vem 1. 10. 1843 bis 2 ) 31.3 . 184427 in Ben 1851 an den vier Thensechs Tragödien an (538); Küstner fuhte zw tern unter seiner Direktion dreimal soviele Lustspiele wie Tragödien auf (Vierunddre Big Jahre 327; Rückblick 240); Klingemann zählt $1822 \mathrm{mehr}$ Lustspiele als andere GenBühnen (Allgemeiner deutscher Theater-Almanach 132) und Laube stellt in jedem Jahr seiner Abrechnung fest, es werde „dem Lustspiele stark gefröhnt" (Das Burgtheater 239 und 389). Die Tragödie galt zwar als die höchste Form des Schauspiels, war aber keineswegs die publikumswirksamste, denn das Publikum des Schauspiels, war aber keineswegs dic pulikis will „mehr belustigt als erschüttert sein“ (Küstner, Rïckblick 241; vgl. Laube, Das Wiener Stadt-Theater $64 \mathrm{f}$ ), und ein Theater, selbst ein Hoftheater, mußte vor allem überleben. Laube faßt das Überlebenspostulat des Theaters kurz: „Die Mehrzahl de Menschen will nicht belehrt werden, nein, sie will unterhalten sein. Sie hört auf den Hanswurst" (Erinnerungen IX, 444). Dementsprechend suchte Laube vor allem nach Lustspielen - „neue Wendungen über das Duett von Hans und Grete" (Erinnerungen IX 423) klagte über ,die geringe deutsche Produktion im deutschen Lustspiele (Erinnerungen IX, 423) und fragte sich „[...] besorgt, ob sich denn auch neue Dramatiker finden würden, welche imstande wären, Lustspiele zu schreiben“ (Theaterkritiken I, 177). Wie abhängig er sich von Lustspieldichtern fühlte, zeigt eine Bemerkung über Charlotte Birch-Pfeiffer: „Wäre die fleißige Fabrilkantin in Berlin, die Birch-Pfeiffer nicht da, die für den Markt arbeitet, die Schauspielhäuser müßten geschlossen werden" (Theaterkritiken I, 172).
Die Vorliebe des Publikums für die Komödie beeinflußte auch das Repertoire an Hoftheatern, obwohl die adligen Gönner teilweise die literarische bzw, moralischästhetische Funktion des Theaters betont wissen wollten und den Spielplan dementsprechend festlegten. So z. B. Kaiser Joseph II. im Wiener Burgtheater der 1780er Jahre: „Unerschütterlich hält er daran fest, das höhere Schauspiel und Trauerspiel aufgeführt zu sehen [...]. Das Publicum theilte diese Vorliebe nicht" (Laube, Das Burgtheater 68). Und den Ruin des Berliner Hoftheaters in den 1850er Jahren erklärt Laube ironisch damit, es sei „über die Marmorstufen der Klassilk“ gefallen (Das Burgtheater 393)

Bei der Aufstellung des Spielplans konnte ein Theaterdirektor nicht nur über die Stufen der Klassils stolpern, sondern auch über die der Zensur. In dieser Beziehung waren Hoftheaterdirektoren bei der Aufstellung des Spielplans wesentlich abhängige als die Direktoren von Stadt- oder Wanderbühnen, eine Abhängigkeit, die sich schon aus den hohen Subventionen der Hoftheater ergab. Ein Theaterdirelktor an einem Stadt- oder Wandertheater, in der Regel der Unternehmer selbst, hatte weitreichende Befugnisse; er war verantwortlich für Einstellung und Entlassung des Ensembles und bestimmte die Bezahlung der Schauspieler, Stückewahl und Rollenverteilung und führte oft auch Regie. Bei Hoftheatern dagegen wurden die Kompetenzen der Direktion oft vom Hof beschnitten. Küstner, langjähriger Intendant von sowohl Hof- als auch Stadttheatern, spricht aus Erfahrung von den Nachteilen, „denen ein Hoftheaterintendant gegenüber einem selbständigen und unabhängigen Unternehmer ausgesetzt ist" da „freie Bewegung [...] den Hoftheatervorständen selten oder nicht im nöthigen Um fange gewährt wird" (Vierunddreißig Jabre 94 f). Am Burgtheater der 1850er Jahre lag die oberste Direktion in den Händen des Oberkämmerers Graf Lanckoronski, de auch sämtliche Verträge abschloß; Laube war lediglich künstlerischer Direktor ohne reale Befugnisse (Laube, Erinnerungen IX, $403 \mathrm{f}$ ) und wesentlich zensurabhängiger als der Direlktor eines Stadt theaters.

Die frühesten Zensurbestimmungen richteten sich gegen die Wanderbühnen und deren improvisierte Schauspiele. In Wien gab es seit 1542 Verordnungen gegen "vagabundierende Künstler" (von Weilen/Teuber I, 113). Herumziehende Schauspiele mußten sich anmelden, eine Spielerlaubnis vom Magistrat erhalten und Abgaben zahlen ${ }^{8}$ "dabey aber bey Leib und Guts-Straff das Gotteslästern, Fluchen und Schwören, wie auch einige unzüchtige Reden, Gebärden und Vorstellungen nicht zugestatten (Kaiserliche Verordnung, 1665, zit. von Weilen/Teuber I, 114). Dieser Erlaß wurde $1671,1716,1724,1731$ und 1746 wiederholt (von Weilen/Teuber I, 114). Obwohl diese Zensur allgemeiner gehalten war als später die Zensur an Hoftheatern, stellte sie eine Bedrohung dar, die durchaus ernstgenommen wurde. Johann Carl Eckenberg, Inhaber des Privilegs für die Berliner Bühne ab 1732, fragte sicherheitshalber an Allerhöchster Stelle an, „wie ich mich, um alle Scandala zu evitiren, bei meinen Actionen aufführen solle" (Brief an König Friedrich Wilhelm I. vom 24. 10. 1741 [sic!]; zit. in Almanach 1848, 159).

Bei Stadt- und Hoftheatern wurde zunächst das Extemporieren zensiert. Daß besonders Hoftheater das Improvisieren auf der Bühne strikt untersagten, war nicht nur ein 
Qualitätsmerkmal bzw. eine Abgrenzung zur Wanderbühne, sondern das Resultat einer praktctischen Überlegung: auf der Bühne Improvisiertes war schwer zu zensieren, während geschriebene Stücke vor der Aufnahme in den Spielplan dem Zensor vorgelegt werden konnten, der über Aufnahme oder Ablehnung entschied (Laube, Das Burgtheater 11). 1752 verbot Maria Theresia in Wien jegliches Improvisieren auf der Bühne (Kindermann, Theatergeschichte 224); der erste Verstoß wurde mit Verweis, der zweite mit vierzehntägiger, der dritte und „schwere" Verstöße (Grobheit oder Unsittlichkeit) mit lebenslänglicher Festungshaft geahndet (Martersteig, Das deutsche Theater 108; von Weilen/Teuber II, 60). Joseph II. wiederholte dieses Edikt, als er 1776 das Wiener Theater zum Hof- und Nationaltheater erklärte und kategorisch bestimmte, am Burgtheater solle „von nun an nichts als gute regelmäßige Originale und wohlgeratene Übersetzungen aufgefuihrt werden" (Kindermann, Theatergeschichte 198). Das Improvisieren war damit erncut untersagt; strengere Zensurmaßnahmen folgten mit der visiö Karl Hägelin, von 1770 bis 1805 Theaterzensor in Wien, stellte 1795 einen Leitfaden für die Theaterzensur in Ungarn zusammen, und zwar „mit Verwertung aller Grundsätze, die bis dahin für die Wiener Bühnen maßgebend waren" (Lothar 40). Nach diesen Bestimmungen waren von der Darstellung oder Erwähnung auf der Bühne unter anderem ausgeschlossen: sämtliche Staatsinstitutionen, Königtum und Behörden, das Parlament Gesetze oder Gesetzgebung eines Staates, Religion, die Konfessionen, das Militär, die Kreuzzüge, die Ehe, Moral, Vorgänge aus dem Leben oder Namensnennung von lebenden oder toten Angehörigen des Königshauses, Erwähnung von nichtmonarchischen Staatsformen, Hinrichtungen von Regenten, religiöse oder politische Vorurteile, biblische oder lkatechische Ausdrücke, unsittliche oder grobe Ausdrücke, alle Wörter, die ein geistliches Amt bezeichnen, die Darstellung einer wilden Ehe, und die Wörter "Sünde“, „heilig", "Tyrann", „Despotismus", „Unterdrückung", „Freiheit", "Gleich "Seit", "Aufklärung", "Gott", „Kirche“, „, beten“" sowie Gleichnisreden aus der Bibel, wie z. B. "stumm wie ein Fisch" (Martersteig, Das deutsche Theater 275; Lothar 40-43) Weiterhin hatte die Zensur „darauf zu sehen, daß nie zwey verliebte Personen mitein ander allein vom Theater abtreten“ (Karl Hägelin, "Grundsätze der Censur", zit. Lothar 40-43). In Preußen wurden persönliche Beleidigungen, Aufforderungen zum Hochverrat, Beschimpfungen einer anerkannten Religionsgemeinschaft, unzüchtige Handlungen, Darstellungen von Mitgliedern des königlichen Hauses und Stoffe aus biblischen Geschichten zensiert (Martersteig, Das deutsche Theater 276). Die Liste der verbotenen Stücke war endlos; auch Goethe, Schiller und Shakespeare wurden nich verschont. ${ }^{10}$ In Wien wurde 1815 die Aufführung von Caroline Pichlers Ferdinand II. untersagt (Winkler 88); 1836 folgten Friederike Lohmanns Die Mühle an der Elbe, Charlotte Birch-Pfeiffers Die Günstlinge, Ferdinand Avelli der Flüchtling, Die Flucht nach London, Die Engländer in Paris, Der Glöckner von Notre-Dame, und Margarethe Bernbrunns Der Reisewagen des Flüchtlings (Mayer 18-29). Da im Reisewagen „die gräßlichen Szenen gemildert wurden", wurde das Stück später „nachträglich zur Aufführung zugelassen" (Mayer 29). 1830-38 waren in Wien 251 Stücke verboten (H. Devrient, Archiv I, 18 f)
Die Zensurbestimmungen in Deutschland waren so divers wie die Gesetzgebung der 39 Staaten: „Was in Preußen verboten wurde, blieb in Baden erlaubt; wer hie ausgewiesen wurde, flüchtete zum Nachbar" (Laube, Erinnerungen VIII, 147). Im katholischen Wien war die Zensur zu Beginn des 19. Jahrhunderts strenger als im protestantischen Berlin (Weil 125); trotzdem mußte Iffland in Berlin "selbstverständlich alle etwas zu lebhaft geäußerten Gefühle für Freihcit und vor allem Wendungen gegen Feudalismus und Königtum tilgen" (Weil 117). Fast überall wurde die Zensur zur Selbstzensur: der geschickte Theaterdirektor, der das Eingreifen der Zensur voraussah, strich selbst, wo nötig. Unter diesen Voraussetzungen wagte Laube es sogar, im lkatholischen Wien Albert Lindners Die Bluthochzeit, ein Stück über die Bartholomäusnacht, aufzuführen. Obwohl ihm Zweifel bezüglich der Zensur kamen, war er der Ansicht, ssie würde nicht Nein sagen, wenn ich hie und da an den mißlichsten Stellen den nacksten Ausdruck einer Unthat ein wenig bekleidete, und nur den Sinn rettete" (Laube, Das Wiener Stadt-Theater 108). Laube behielt Recht: das Stück kam durch. Da bei strikter Befolgung der Zensurbestimmungen ein Repertoire nicht leicht aufzustellen war, denn die Zensur verbot „so ziemlich alles, was wesentlich Stoff zum Drama ist“ (Martersteig, Das deutsche Theater 276), versuchten viele Theaterdirektoren, die Zensur zu umgehen. „[...] wir fügten uns immer nur dem unwiderstehlichen Drucke. Sobald sich nur ein Luftloch offnete, waren wir auch augenblicklich wieder da mit unserem verbannten Kinde" (Laube, Das Burgtheater 160). Laubes Taktik war allerdings nur begrenzt wirksam: Mitte des 19. Jahrhunderts wurden insgesamt drei Burgtheaterdirektoren wegen Schwierigkeiten mit dem Hof entlassen - Schreyvogel, Burckhard und Laube selbst (Lothar 48).

1848 wurde die Zensur am Burgtheater pro forma aufgehoben (Martersteig, Das deutsche Theater 368), aber damit war sie noch lange nicht vorbei. Als Laube ein Jah später das Burgtheater übernahm, fand er „ein sehr langes Verzeichnis von Stücken, welche nie mehr gegeben werden sollten" (Laube, Das Burgtheater 156). Nach der 1848er Revolution konzentrierte sich die Zensur vornehmlich auf Politisches: 1851 wurde ein Schauspieler wegen nicht näher bezeichneter "Ungebührlichkeit" vorgeladen und ein anderer verklagt, weil er „politisch aufregende" Verse zu überzeugend vorgetragen habe (E. Devrient, Eduard Devrient 566). In den 1860er Jahren wurde Marie von Ebner-Eschenbachs Marie Roland am Burgtheater abgelehnt, weil „die französische Revolution denn doch ein zu naheliegendes Ereignis sei und der Name der Königin in dem Stücke erwähnt werde" (Lothar 132). Noch um 1880 berichtet Laube, das Kasseler Hoftheater unterliege „bis in die neueste Zeit [...] strengster Zensur. Die populärsten Stïcke durften dort nicht gegeben werden, weil dieser oder jener unscheinbare Zug Serenissimo mißfallen könnte" (Erinnerungen VIII, 75).

Während die Theaterdirektoren mit unzureichenden Etats und der Zensur zu kämpfen hatten, hatten die Schauspieler und Schauspieldichter andere Schwierigkeiten, vor allem mit den Direktionen ihrer Theater. Ein Vertrag zwischen Schauspieler und Theaterdirektor war darauf ausgerichtet, den Schauspieler möglichst abhängig vom Direktor zu machen. Die Theaterdirektion stellte nicht nur das Personal ein und bestimmte Repertoire und Rollenverteilung, sie hatte auch Disziplinargewalt über da 
Personal (Paul Hoffmann 249) und legte die Bestimmungen in Theaterverträgen fest. Dementsprechend willkürlich waren oft die Verträge. Gerber klagt 1865 über die vertraglich festgelegte Ausnutzung der Schauspieler: „[...] ein Dienstbote hat's oft viel

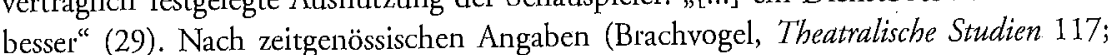
Küstner, Vierunddreißig Jahre 284-6) war der folgende Theatervertrag im 19. Jahrhundert nicht untypisch:

Contract.

Stempel reservirt.

Zwischen dem Theater-Director Herrn (Thespis zu U.) ${ }^{11}$ und dem Schauspieler Herrn (Sylpho) ist heute folgender Contract verabredet und geschlossen.

$\$ 1$.

Herr Director (Thespis) engagirt bei seinem Unternehmen, wo und wann er auch Vorstellungen zu geben für gut findet, Herrn (Sylpho) für die Zeit (vom 1. Juli 1862 bis 1. Juli 1863); jedoch steht dem Director (Thespis) das Recht zu, diesen Contract in allen seinen Theilen am (1. September 1862) durch eine vorherige (vier-) wöchentliche Kündigung wieder aufzulösen, falls wider Voraussetzung Herr (Sylpho) in seinen artistischen Leistungen den gehegten gerechten und billigen Erwartungen des Directors (Thespis) nicht entsprechen sollte.

\section{$\$ 2$}

Herr (Sylpho) verpflichtet sich zur Uebernahme aller Rollen im Fache (der ersten jugendlichen Helden), verspricht aber auch, alle anderen Rollen, welche seiner Individualität nicht zuwider sind, zu übernehmen und auszuführen, ganz wie solches die Direction im Interesse des Instituts für angemessen erachtet.

$$
\$ 3 \text {. }
$$

Herr Director (Thespis) zahlt an (Herrn Sylpho) eine monatliche Gage von (Fünfzig Thalern) in halbmonatlichen Raten am 1. und 16. jedes Monats, postnumerando zahlbar.

$$
\$ 4
$$

Herr Director (Thespis) stellt für Herrn (Sylpho) alles Costüm, mit Ausnahme der modernen Französischen Garderobe, Tricots, Federn, Schmuck, Fußbekleidung und Handschuhe, die derselbe aus eigenen Mitteln herzustellen hat.

[Dieser Paragraph gilt nur für die männlichen Mitglieder des Theaters. Wenn Herr Thespis eine Frau Sylpha cinstellt, lautet der Paragraph wie folgt:

$$
\$ 4 \text {. }
$$

Herr Director (Thespis) stellt für (Fräulein Sylpha) nur die männlichen Costüme, sobald sie solche zu ihren Rollen bedarf, alle übrigen Costüme hat sich dieselbe aus eigenen Mitteln anzuschaffen, soweit selbige nicht etwa im Garderobe-Inventarium vorhanden sind.]

\section{$\$ 5$}

Herr (Sylpho) unterwirft sich nachfolgenden Theatergesetzen und sieht sie als einen integrirenden Theil dieses Contractes an, entsagt auch ausdrücklich allen dagegen zu machenden Einwendungen.

$$
\$ 6
$$

In allen Streitigkeiten zwischen den beiden Contrahenten, welche die Entscheidung eines Gerichts erforderlich machen, unterwirft sich (Herr Sylpho) der Gerichtsbarkeit des Kgl. Stadt-, resp. Appellations-Gerichts zu X. und zwar so, daß (Her Sylpho) bei diesen Gerichtshöfen sich auf die Klage einlassen, oder Contumazialverfahren gewärtigen muß, selbst wenn (er seinen) Wohnsitz anderswo im In- oder Auslande hat, oder nehmen sollte.

$$
[\$ 7 .
$$

legt die Kündigungsfrist des einjährigen Vertrages auf drei Monate fest.]

$$
\$ 8 \text {. }
$$

Tritt Brand des Schauspielhauses, Krieg, ansteckende Krankheit, Landestrauer, politische Umwälzung oder sonstige Calamität ein, die die Schließung des Theaters nöthig macht, so ist der Director (Thespis) berechtigt, diesen Contract sofort und ohne jede Entschädigung in allen seinen Theilen aufzulösen.

[\$9

bestimmt ein zur Monatsgage zusätzliches Spielhonorar, die sogenannten „Alkzidentien", auf die weiter unten eingegangen wird.]

$$
\$ 10 .
$$

Sollte Herr (Sylpho) diesen Contract brechen, nicht rechtzeitig antreten oder früher, als derselbe zu Ende gegangen ist, das Engagement verlassen, so verfällt (der-) selbe in eine sofort zu zahlende Conventionalstrafe von (900) Thlr.; jedoch hebt die Zahlung der Conventionalstrafe die Rechtsbeständigkeit dieses Contracts nicht auf, und behält sich Herr Dir. (Thespis) seine diesfälligen Rechtsansprüche auf Erfüllung des Contracts oder auf Schadenersatz nach seinem Ermessen vor, und begiebt sich (Herr Sylpho) des Einwandes, daß die stipulirte Conventionalstrafe das Doppelte des wirklichen Interesses übersteige.

$$
[\$ 11 .
$$

bestimmt das Herrn Sylpho gewährte Benefiz, d. h. eine Aufführung, deren Einnahmen an ihn gehen, auf die halbe Einnahme nach Abzug der Tageskosten.

$$
\$ 12 .
$$

enthält dic Schlußformel ohne weitere Klausel.] (zit. in Brachvogel, Theatralische Studien 117-144).

Für neue Mitglieder an Herrn Thespis' Theater bedeutete das folgendes: zunächst wurden sie auf zweimonatige Probezeit angestellt, während der der Direktor eine beliebig festzusetzende Kündigungsfrist hatte; danach wurde ihr Vertrag auf weitere zehn 
Monate verlängert, mit dreimonatiger Kündigungsfrist für die Direktion. Sie selbst konnten weder während der Probezeit noch während des Vertrags kündigen und durften sich nicht weigern, eine Rolle zu spielen. Frauen waren für ihre gesamte Garderobe ten sich nicht Garderobe selbst anselbst verantwortlich; Mannner mußten sich sur einen Teil der Garderobe selbst anschaffen. Die "nachfolgenden Theatergesetze“, denen Sylpho sich in $\$ 5$ unterwirft, bestehen an Herrn Thespis' Theater aus 50 Paragraphen, die die Schauspieler dazu anhalten jede ihnen vorgelegte Rolle ohne Zusätze oder Änderungen zu spiclen; ihnen die Änderung des Kostüms verbieten; sie zwingen, sich auch während ihrer Freizeit in der Nähe des Theaters aufzuhalten; ihnen untersagen, in öffentlichen oder Privatvereinen zu

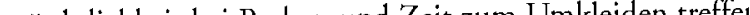
Krankheit, Versäumnis, Unpünktlichkeit bei Proben und bei Verstößen mit Gehaltskürrzung oder Entlassung drohen. In $\$ 47$ verpflichten sich die Schauspicler im Voraus zur Beachtung aller noch künftig zu erlassenden Gesetze und Vorschriften (Brachvogel, Theatralische Studien 128-35). Laut $\$ 8$ des Hauptvertrags lsonnten Schauspieler jederzeit fristlos entlassen werden.

So oder ähnlich sah ein Theatervertrag aus, „der heutige moderne Contract, wie er uns vorliegt und durchweg, mit wenigen Ausnahmen, geschlossen wird" (Brachvogel, Theatralische Studien 117). Die von Vohs und Willms in Weimar erlassenen Theatergesetze vom 7.3. 1793 treffen ähnliche Bestimmungen (Satori-Neumann 74 f). An den meisten Theatern wurden neue Schauspieler auf Probezeiten verpflichtet, nach denen die Direktion, nicht aber das Mitglied, den Vertrag lösen konnte; ein Direlktor konnte z. B. durchaus 18 Mitglieder auf Probe engagieren und nach dem Probemonat 17 au die Straße setzen (Martersteig Das deutsche Theater 394 f; Löhn-Siegel, Vorn Oldenburger Hoftheater 14). Eine unter $\$ 8$ erwähnte „sonstige Calamität“ für den Schauspieler konnte auch ein Wechsel in der Theaterleitung sein: es gab keine Bestimmungen, die einen neuen Intendanten dazu anhielten, das Ensemble des alten zu übernehmen (Kilian 127-162). Bei Wanderbühnen waren die Verträge oft noch willkürlicher, die Kündigungszciten lagen zwischen drei und sechs Wochen (Martersteig, Das deutsche Theater 155).

Trotz der finanziellen Unsicherheit und der Rechtlosigkeit der Schauspieler, die in derartigen Verträgen institutionalisiert wurde, hätte Frau Sylpha oder Herr Sylpho bei dem oben zitierten Vertrag noch Glück gehabt. Da neue Mitglieder meist über weite Entfernungen hinweg engagiert wurden, machten sich viele arbeitsuchende SchauspieW Weg au einem weit entfernten Theater. Dort ler auf bloße Versprechungen hin auf den Weg zu einem weit entfernten Theater. Dort wurde ihnen nicht selten mitgeteilt, daß die „mißlichen Zeitverhältnisse und sonstig unverschuldete Unglücksfälle eine Herabsetzung der Gage gebieten und die Direktion stellt ihnen dic traurige Alternative, den Kontrakt zu verändern und sich mit einer weit geringeren Gage zu begnügen, oder die kostspielige Rückreise anzutreten" (Gerber 32). Teilweise wurden auf diese Weise ganze Schauspielerfamilien engagiert, von denen dann den besten Schauspielern gleich zu Beginn des Engagements gekündigt wurde; die schlechteren Schauspieler in der Familie wurden behalten. Mit Rücksicht auf das Engagement der Familienmitglieder versuchten dann die entlassenen Schauspieler, bei dem Theater
Gage wieder genommen wurden (Gerber 32). Teilweise wurden Schauspieler auch unter Geltendmachung irgendwelcher Vertragsklauseln ohne Gage angestellt (Gerber 33). Ein arbeitsloser Schauspieler ging also auf der Suche nach neuen Engagements erhebliche Risilken ein. Karoline Schulze-Kummerfeld reiste mit ihrer Familie 1751-2 aufgrund falscher Versprechungen von einem verschuldeten Prinzipal zum anderen und durchquerte in diesem Jahr auf Engagementssuche sieben Städte (Schulze-Kummerfeld I, 32-50). Dieses ständige Wanderdasein war auch für viele Schauspieler an stehenden Theatern eher die Regel als die Ausnahme: stehende Theater waren im Sommer geschlossen und gaben auch Vorstellungen in umliegenden Orten. Gastspicle von fest engagierten Schauspielern waren auch deshalb häufig, da sie in der Regel besser bezahlt waren als Festanstellungen und außerdem oft die einzige Möglichkeit boten, ein neues Engagement zu erhalten (Küstner; Vierunddreißig Jahre 262).

Das Format der Theaterverträge und die miserablen Praktiken vieler Direktionen zwangen die Mehrzahl der Schauspieler in eine absolute Abhängigkeit. Vertragsbrüche waren an der Tagesordnung, obwohl sie mit Entlassung und teilweise auch mit $\mathrm{Haft}$ bestraft wurden (Kindermann, Theatergeschichte 499). Da auf Versäumen einer Vorstellung, egal aus welchen Gründen, dieselben Strafen standen, spielten viele Schauspieler auch unter extremen Bedingungen. Karoline Schulze-Kummerfeld spielte trotz Lungenentzündung die Sara Sampson (Schulze-Kummerfeld I, 166-171); ihre Mutter spielte noch im achten Monat ihrer Schwangerschaft und am Abend nach dem Tod ihres neugeborenen Sohnes (I, 21-5). Zu den natürlichen Krankheiten kamen die Berufskrankheiten des Schauspielers: „Empfindsamkeit der Nerven, Überanstrengung des Gedächtnisses, Auszehrung, Vergiftungserscheinungen infolge Gebrauchs schädlicher Schminkfarben, Erkältungen und Fieberanfälle" (Satori-Neumann 188). Im letzten Jahrzehnt des 18. Jahrhunderts starben zwei Drittel aller Schauspieler vor ihrem 40. Lebensjahr "physisch (oder wenigstens artistisch)" (Satori-Neumann 189).

Mit Ausnahme einiger weniger gutsubventionierter Hoftheater waren die Ensembles an den meisten Theatern sehr klein, um Schauspielergagen zu sparen, so daß die meisten Schauspieler an fast jeder Aufführung mitwirken mußten. Dazu wurden die Mitglieder des Ensembles oft vielseitig verwertet: bei Wandertheatern war ein Schauspieler oft gleichzeitig Maschinist, Zettelträger oder Dekorationsmaler (Paldamus 124; Rötscher, Dramaturgische Probleme 33); an anderen Wanderbühnen und stehenden Theatern fungierte ein Schauspieler, je nach Begabung, zusätzlich als Tänzer, Opernoder Chorsänger, Statist und Komparse; viele arbeiteten auch im technischen Personal mit oder verkauften Eintrittskarten (Almanach 1809, 125 f; Satori-Neumann 214, Küstner, Rückblick 26 f; Martersteig, Das deutsche Theater 154; Kindermann, Theatergeschichte 527 f; Laube, Das norddeutsche Theater 58 f). ${ }^{12}$ Brandes war 1757 an der Schönemannschen Truppe als Schauspieler engagiert, schrieb aber auch Rollen, soufflierte und figurierte in Rollen für ein minimales Gehalt (Eloesser, Aus der großen Zeit $30 \mathrm{f}$ ). Auch Karoline Schulze-Kummerfeld weiß von der Überbelastung der Schauspieler ein Lied zu singen: von den von März 1781 bis zum Februar 1782 in Innsbruck aufgeführten 172 Stücken spielte sie in 123 mit; von den insgesamt 84 Rollen, die sie in diesen elf Monaten spielte, waren 56 neu; außerdem tanzte sic widerwillig im Ballett 
(II, 114) - das alles für 12 Taler pro Woche (II, 106). Da die meisten Schauspieler am Innsbrucker Theater gleichzeitig Tänzer waren, konnte sie nicht konkurrieren und wurde schließlich entlassen (II, 119).

Die Gagen der meisten Schauspieler, seltene Berühmtheiten ausgenommen, fielen recht ärmlich aus. Während die berühmte Sophie Schröder bei einem Gastspiel in Dresden 1817100 Taler pro Rolle verlangen konnte (Schröder, Briefe 1813-1868 158 f), verdiente Karoline Schulze-Kummerfeld in ihrer jahrzehntelangen Schauspielerlaufverdiente Karoline Schulze-Kummerfold für spielte und tanzte sie und ihr Bruder tanzte (Schulze-Kummerfeld I, 236). Bei Wandertheatern mußten sich die Schauspieler „damit begnügen, wenn sie nur wirklich (Palch 125 ); die Direktoren erwicen sich in puncto $Z$ ahsatt werden lsönnen" (Paldamus $125 \mathrm{f}$ ); die Direktoren erwiesen sich in puncto Zahlung oft als unzuverlässig, und Profite wanderten in die Tasche des Direktors (Paldamus 125). Die Gehälter bewegten sich auf einer breiten Skala: 1786 war das höchste Schauspielergehalt in Döbbelins Truppe in Berlin 1040 Taler im Jahr, das niedrigste 104 der Durchschnitt lag zwischen 300 und 400 - Direktor Döbbelin selbst verdiente in diesem Jahr 1300 Gulden (Brachvogel, Die Königl. Oper 11-13). Karoline Neuber in dien 1727 zwei Gulden pro Woche für Anfänger; im Durchzahlte ihren Schauspielern 1727 zwei Gulden pro Woche fünete Schauspieler (RedenEsbeck, Caroline Neuber 57). 1733 verdienten Schauspieler in Eckenbergs Truppe moEatich zwischen acht und 34 Taler. (Brachvogel, Das alte Berliner Theater-Wesen 78). 1754 lag die Höchstgage für Schauspieler um 44 Gulden pro Woche, das Niedrigstgehalt um 12. Um diese Zeit verdiente Prehauser, der berïhmteste Hanswurst seine Zeit, 40 Gulden pro Woche; Karoline Neuber verdiente trotz ihrer Doppelfunktion als Schauspielerin und Direktorin der Truppe 15, also genau drei Gulden über dem Niedrigstgehalt (von Weilen/Teuber I, 164). Die niedrigen Gehälter wurden teilweise durch Haushaltswaren aufgebessert: Ekhofs Höchstgage in Hamburg bestand aus 600 Talern und einem Klafter Holz im Jahr (Martersteig, Das deutsche Theater 153); die Schauspieler der Neuberschen Truppe bekamen außer ihrem Gehalt freie Kost, die Schauspielerinnen Kost und Logis (Reden-Esbeck, Caroline Neuber 57). Am Burgtheater der (780 in jener Zeit", rangierten die Gehälter von 2550 Gulden (für Ludwig Schröder) bis 300 Gulden im Jahr und lagen im Schnitt um 1200-1400 (Laube, Das Burgtheater $60 \mathrm{f}$ ).

Fhepare oder ganze Schauspielerfamilien wurden in der Regel en gros bezahlt, was meistens hieß: schlechter als einzelne Schauspieler. Goethe, Direlstor des Weimarer Theaters der $1790 \mathrm{er}$ Jahre, der äußerst bescheidene Gehälter zahlte (Satori-Neumann 181; Laube, Das norddeutsche Theater 60), zahlte unverheirateten Schauspielern fünf Whe Eheparen acht bis zwölf, Anfängern fünf. Ein ledige bis acht Taler pro Woche, Eheparen ach bis zöf, Anfinge finf Schauspieler an Goethes Theater verdiente demnach mindestens fün Taler in der Woche und höchstens acht, ein verheirateter mindestens vier und höchstens sechs, einen Taler über dem Anfängergehalt. 1779 verdiente Seyler als Direktor des Mannheimer Theaters zusammen mit seiner Frau, einer berühmten und gefeierten Schauspielerin, 2000 Gulden (Iffland, Briefe 1772-181438). Bei gleicher Teilung verdienten also beide weniger als Direlstor Döbbelin 1786. Eine gleiche Teilung ist uibrigens keineswegs

anzunehmen: allein aus der Sitte, Ehepaare niedriger zu bezahlen als ledige Schauspieler, läßt sich schließen, daß die Gehälter für Frauen niedriger lagen. Teilweise, wie z. B. im Wiener Erlaß von 1807, war die niedrigere Bezahlung von Frauen gesetzlich verankert. Eine Ausnahme, wenn nicht zur gemeinsamen Bezahlung von Ehepaaren, so doch zur niedrigeren Bezahlung von Frauen, bildet die Schauspielerin Sacco: sie bezog 1781 am Burgtheater 1965 Gulden pro Jahr und einen Gulden pro Tag als Lebensunterhalt für ihren Mann (von Weilen/Teuber II, 30).

Obwohl man von einem durchschnittlichen Schauspielergehalt kaum überleben konnte, waren viele Theaterdirektoren wegen der knappen Etats ständig bemüht, die Gagen zu senken, und suchten nach anderen Mitteln, das Ensemble am Theater zu halten. Ein Promemoria am Gothaer Hoftheater legte am 17. Juli 1775 Schauspielergagen auf höchstens 125 Taler in der Woche fest (Kindermann, Theatergeschichte 526f); ein ähnlicher Erlaß bestimmte 1807 in Wien das Maximalgehalt für Schauspieler als 2500 Gulden im Jahr für Männer und 2000 für Frauen (Martersteig, Das deut sche Theater $153 \mathrm{f}$ ). Um sich gegen die zahlreichen Vertragsbrüche von Seiten der Schauspieler abzusichern, verlegten die Direlstoren einen Teil der Gehälter auf die Vorstellungen selbst. Das Burgtheater zahlte in den 1820er Jahren außer den üblichen Wochengagen Spielhonorare zwischen fünf und zwanzig Gulden pro Aufführung (Klingemann, Kunst und Natur II, 162). Teilweise waren diese Spielhonorare sogenannte „Akzidentien“" d. h. Bezahlung von „außergewöhnlichen Leistungen“ während der Aufführung, die bei Verhinderung wegfielen und zur Disziplinierung der Schauspieler gestrichen werden konnten (Martersteig, Das deutsche Theater 153). Eine "außergewöhnliche Leistung" konnte alles sein von Gesangs- und Tanzeinlage bis zu Ohrfeigen erhalten und mit Wasser begossen werden (Martersteig, Das deutsche Theater 153); die Bezahlung richtete sich nach dem Grad der Mißhandlung, die der Schauspieler über sich ergehen lassen mußte. Eine Ohrfeige z. B. brachte Mitte des I8. Jahrhunderts einen Gulden ein, ein Sprung ins Wasser nur 30 Groschen (von Weilen/Teuber I, 164). Die Schauspieler, die aufgrund der niedrigen Gehälter ständig auf der Suche nach Nebenverdienst waren, nützten diese Zulagen natürlich weidlich aus. Karoline Bauer zitiert eine typische Schauspielerrechnung aus der Mitte des 18. Jahrhunderts:

Diese Woche 6 Arien gesungen à $1 \mathrm{fl}$.

Ein $\mathrm{Mal}$ in die Luft geflogen

Ein Mal in's Wasser gesprungen

Ein Mal begossen worden

Ein Mal Prügel bekommen mit zwei

blauen Flecken à $34 \mathrm{Kr}$

Zwei Ohrfeigen erhalten

Ein Fußtritt erhalten

Drei Verkleidungen à I fl.

$$
\begin{aligned}
& 6 \text { Fl. } \quad-\mathrm{Kr}^{13} \\
& 1 \text { Fl. }-\mathrm{Kr} . \\
& 1 \text { Fl. } \\
& \text { - Fl. } 34 \mathrm{Kr} .
\end{aligned}
$$

- Fl. $68 \mathrm{Kr}$

1 Fl. $8 \mathrm{Kr}$ :

- Fl. $34 \mathrm{Kr}$

3 Fl. $-\mathrm{K}$

Summa 13 Fl. $44 \mathrm{Kr}$.

worüber dankbarlichst quittire

(Bauer, Komödianten-Fabrten 29) 
Die finanzielle Situation des Schauspielers bestimmte oft sowohl seine Spielweise als auch seinen sozialen Status. Der Schauspieler war teilweise nur wenige Schritte vom Hofnarren entfernt und wurde auch weitgehend als solcher angesehen. Obwohl der Schauspiclerstand an sich als fragwürdig galt, wurden auch hier Unterschiede gemacht: die soziale Hierarchie verlief parallel zur finanziellen, von den Hofbühnen über Stadttheater bis zu reisenden Gesellschaften. Wanderbühnenkomödianten wurden mit Taschenspielern, Dieben und Vagabunden auf eine Stufe gestellt (Tieck II, 319), die Bürgersfrau „nahm die Wäsche von den Stricken [...], wenn die Komödianten kamen“ (Kindermann, Theatergeschichte 518). Mit der Stabilisierung des Theaters in Form von stehenden Bühnen wurde der soziale Stand des Schauspielers etwas "würdiger" (SatoriNeumann 177), aber das allgemeine bürgerliche Vorurteil gegen den Stand war ein Neumann 177), aber das allgemeine bürgertiche (Löhn-Siegel, Vom Oldenburger Hoftheater 90). Nach bürgerlichen Begriffen war ein Schauspieler eine öffentliche Persönlichleeit, der die Verstellung zu seinem Metier machte und sich zu diesem Zweck schminkte und kostümierte - der personifizierte Gegensatz zum bürgerlichen Ernst des Lebens (Almanach 1842, 42) und zur christlichen Dolstrin der Jenseitigkeit (Mund 56). Schauspieler, egal an welchem Theater, nahm man „für Unehrliche" oder „nich für voll“, man hielt „jegliche persönliche Berührung mit den Schauspielern für sittlich gefahrvoll und unter der Würde des Bürgers. Der Adel aber betrachtete sie als Spielzeug, Zeitvertreib, Schachfiguren" (Kindermann, Theatergeschichte 518). Dazu kam, im Gegensatz zu anderen Künstlern, das völlige Fehlen einer formalen Ausbildung (Schebest) und das ständige Wanderdasein auch der Hofschauspieler (Kindermann, Theatergeschichte 519 und 533). Das Spiel als Gegensatz zur existierenden Wirklichlkei bot außerdem die Möglichkeit, eine (noch) nicht existente Wirklichkeit auf die Bühne zu bringen. Nicht nur politisches Theater, sondern Theater überhaupt wurde daher oft als potentiell staatsgefährdend empfunden - laut Clemens von Alexandrien beginnen Vollssempörungen oft auf dem Theater (Mundt 56).

Diesen Vorurteilen setzten Theaterdirektoren und Schauspieler den Versuch entgegen, ihren Stand „ehrwürdig" zu machen. Beredter Beleg dafür ist die Vielzahl der meist kurzlebigen Schauspieler- und Bühnenvereine, die den Zusammenhang zwischen der finanziellen Unsicherheit und mangelnden Ausbildung des Schauspielers und seinem niedrigen sozialen Status deutlich erkannten und alle ein Ziel hatten: die soziale Hebung des Schauspielerstandes durch Versittlichung, Ausbildung und iestanden meist aus in regelmäßigen Zeitabständen gewählten Ausschüssen, die die Schauspieler am sittlichen Gängelband hielten, aber auch versuchten, Schauspielschulen und Pensionsfonds zu grïnden, die lebenslängliche Anstellung von Schauspielern durchzusetzen, die Anzah der Proben vor jeder Aufführung zu vergrößern und dem Metier - der Schauspielkunst - einen theoretisch-wissenschaftlichen Unterbau zu geben. Löwen schlug 1767 eine Verbindung von Schauspielern vor, die „Vorlesungen, gemeinschaftliche Berathungen, Kunst-Kritils, innige Verbindung mit Gelehrten und Schriftstellern, ein besonderes Sittengericht" einschließen sollte und in der auch eine Pensionskasse für Schauspieler vorgesehen war; wobei die Höhe der Rente nicht vom Gehalt, sondern vom Betragen und Lebenswandel der Schauspieler abhängen sollte (Vor und binter den Coulissen 361 f). Ähnliche Ziele hatten Elkhofs Alkademie für Schauspieler 1753, der 1782 in Dalbergs Mannheimer Theater gegründete Schauspielerverein, der „Löffel- Gabel- und Messer-Orden" in Berlin, der Verein dramatischer Künstler in Berlin 1834, der 1845 von Küstner gegründete bundesweite Bühnenverein und zahllose andere (Vor und binter den Coulissen 349-79; H. Devrient, Archiv II, 95-150 und Jobann Friedrich Schönemann, Anhang XXX, 336-40; Löwen 68-71; Brachvogel, Das alte Berliner Theater-Wesen 158; Almanach 1836, 133-9; 1848, 171-6; Küstner, Vierunddreißig Jahre 230-44). Die meisten dieser Vereine gingen nach wenigen Jahren wieder ein; die angestrebten Ziele blieben in der Planung stecken: die. Klagen .über die mangelhafte Ausbildung der Schauspieler ziehen sich bis tief ins 19. Jahrhundert (Schebest; Gerber 36 f; Rötscher, Die Kunst 12 f; Laube, Das norddeutsche Theater 252 f), und bis 1860 hatten nur sehr wenige Theater eine Pensionskasse für Schauspieler: (E. Devrient, Geschichte der deutschen Schauspielkunst II, 385; H. Devrient, Archiv II, 132; Küstner; Vierunddreißig Jahre 53-6, 75 f, 236 f, 354-63; Taschen- und Handbuch 28, $36 \mathrm{f}$, 41-3, 119, 141, 147, 158, 163, 169, 304, 315-18). Auch wo Pensionseinrichtungen existierten, waren sic ein gefährdetes Unternehmen. Bei Hoftheatern waren sie von der Allerhöchsten Gnade abhängig (Küstner, Vierunddreißig Jahre 236 f); bei Stadttheatern waren Pensionen in der Regel eine theaterinterne Einrichtung und wurden daher aus der Theaterkasse gezahlt (Kindermann, Theatergeschichte 547). Wenn das Theater geschlossen werden mußte oder bankrott machte, ging die Rente für den Schauspieler verloren.

Besonderen Wert legten Vereine, Theatergesetze und Polizeierlasse auf die „Versittlichung" der Schauspieler. Da herumzichende Schauspieler auf der untersten Stufe der bürgerlichen Achtung standen, entwickelte sich bei stehenden Theatern die Tendenz der Abgrenzung zu den Wanderbühnen. Der Schauspieler an einem stehenden Theater wurde als Schauspieler, der reisende Schauspieler als Komödiant bezeichnet, und die Bezeichnung "Komödiant" wurde an stehenden Theatern zum Schimpfwort. "In die Klasse von Komödianten gehörten die Schauspieler, die weder von Ehre noch Pflich noch bürgerlicher Ordnung wissen wollten" und „nach der Gewohnheit fahrender Schauspielergesellschaften" überall Schulden hinterließen und „moralitätswidrige Streiche" machten. Der brave Schauspieler dagegen empfahl sich durch "gutes sittliche Betragen, Conduite" (Goethe und Pasqué, zit. Satori-Neumann 178). E. Schütz, Hofschauspieler an der Herzoglichen Bühne in Braunschweig, warnte seine Kollegen vor der Beifallsucht, „denn so entstehen die naturwidrigen Subjecte, die man mit dem Schimpfnamen Comödianten bezeichnet" (Almanach 1842, 37; Hervorhebung des Autors). Diese entschiedene Abgrenzung zu den Wanderbühnen hatte jedoch mehr Wirkung auf das Selbstbewußtsein der Schauspieler an stehenden Theatern als auf die Achtung der Bürger vor dem Stand. Iffland, 1785 Schauspieler in Mannheim, beklagt sich: „Man spricht gar nicht mit uns, sondern zu uns. Oft gar [...] zu uns herab“ (Fragmente 117). Goethe versuchte zwar, den Schauspielerstand zu heben, indem er "der Welt zeigte, daß ich sie eines gesellschaftlichen Verkehrs mit mir wert achtete" (zit. Laube, Erinnerungen VIII, 199), aber auch seine Weimarer Hofschauspieler; die in 
den „angesehensten Häusern“ verkehrten, blieben für die Dorfbewohner „die Bande“, vor der sie eiligst ihre Hühner versteckten (Satori-Neumann $187 \mathrm{f}$ ).

Da insbesondere aus der sittlichen und geistigen Hebung des Standes, oft irrtümlicherweise, die soziale abgeleitet wurde, hatten Schauspieler moralisch bewußter zu leben als jeder andere, und das möglichst sichtbar für die Augen der zweifelnden Bürger. Schon Karoline Neuber hiclt bei ihrer Truppe auf strikte Trennung der männlichen von weiblichen Mitgliedern, duldete keinerlei ,zarte Beziehungen“ und nahm die unverheirateten Schauspielerinnen sicherheitshalber ins eigene Haus auf (Martersteig, Das deutsche Theater 148). In Bremen erschien zu Ackermanns Zeiten eine Polizeiverordnung, in der die Schauspieler ausdrücklich ermahnt wurden,

sich anständig zu benchmen und „geziemende Kleidung“ zu tragen, sich „alles familiären und verdächtigen Umganges mit jungen Leuten zu jeder Zeit sorgfältigst zu enthalten", keinerlei öffentliche Lokale zu besuchen, ihre Wohnungen abends nach enthalten“, keinerlei öffentliche Lokich ür nicht zu verlassen, und „,ich überhaupt in keinerlei weitläufige Conversationen oder Ausschweifungen einzulassen, noch weniger dazu einige Anleitung zu geben" (Kindermann, Theatergeschichte 532).

Diese Verordnung mußte von jedem Theatermitglied unterschrieben werden. Ähnlich die 1766 angekündigten „Vorläufige Nachrichten von den zu Ostern 1767 vorzunehmenden Veränderungen des Hamburger Theaters", die vom Schauspieler „die strengste, edelste und untadelhafteste Aufführung, die besten und liebenswürdigsten Sitten vere, ed erste Pflicht eines jeden Schauspielers" sollte „die ungeheuchelte Got tesfurcht, der Abscheu an allen, der bürgerlichen Gesellschaft so gefährlichen Lasterm, tesfurcht, der Abscheu an allen, der bürgerlichen Geringsten Verdacht befreyte Lebensart" sein (Löwen $87 \mathrm{f}$. In den Theatergesetzen der Hamburger Bühne zu Ludwig Schröders Zeiten finden sich sogar Absätze, die das Küssen auf der Bühne verbieten (Zimmermann, Neue dramaturgische Blätter I, 328)

Diese aufoktroyierte moralische Korrektheit bezog sich vornehmlich auf Frauen. Fü Frauen galten prinzipiell am Theater andere Gesetze als für Männer; so waren z. B. die Höchstgagen an vielen deutschen Theatern für Frauen wesentlich niedriger angesetzt als für Männer (Martersteig, Das deutsche Theater 150 und $153 \mathrm{f}$ ), und die vertraglichen Bestimmungen waren in der Regel härter für Schauspielerinnen (vgl. $\$ 4$ des oben Den zitierten Vertrages). Selbst männlichen Geschlechtes können der Tugend Schlingen legen, Versuche und sträfliche Anträge machen; allein ein Frauenzimmer kann nie, wäre es auch nur zum Scheinc cinwilligen" (Hägelin, Grundsätze der Zensur", zit. Lothar 41). Kein Wunder also, daß Frauen von der „Versittlichung" der Schauspieler besonders betroffen waren, insbesondere da sie für viele die Unmoral des Theaters versinnbildlichten. Kirche und Staat wurden immer dann ausgesprochen theaterfeindlich, [...] wenn das Weib wiede auf der Bühne erschien " (Martersteig, Das deutsche Theater 147). Als den Frauen im 16. Jahrhundert der Auftritt auf der Bühne gestattet wurde (H. Devrient, Archiv II, 8; Dawson, Frawen und Theater" $421 \mathrm{f}$ ), war dieser Schritt „begleitet [...] von einem
Sinken der Moral, weil die Frau auf dem Theater eben von Anfang an, und selbst vor dem Gesetz, als Dirne erschien" (Martersteig, Das deutsche Theater 147). Die allgemeine Annahme war, „es müsse dem Weib, das sich berufsmäßig dazu hergibt, allabendlich erotische Regungen und Leidenschaften auf der Bühne vorzutäuschen, auch ,berufsmäßiges' Bedürfnis sein, zu lieben und geliebt zu werden" (Martersteig, Das deutsche Theater 148). Das Bild der Schauspielerin als Prostituierte war gängige Münze (Löhn-Siegel, Vom Oldenburger Hoftheater 20-5). „Wenn die Primadonna der Hofoper in neun von zehn Fällen zugleich die Kurtisane des hohen Herrn gewesen war, so gab es sich als naturgemäß, in dem Weib auf der Bühne überhaupt ein Wesen von wohlfeiler Geschlechtsehre zu erblicken“ (Martersteig, Das deutsche Theater 124). Eine am Theater beschäftigte Frau mußte in Sachen „Sittenstrenge von den ersten Geistern“ sein (Martersteig, Das deutsche Theater 147); trotzdem gab es im 18. und 19. Jahrhundert wohl kaum einen Theaterskandal, -streit oder-konkurs, für den nicht direkt oder indirekt eine Frau verantwortlich gemacht wurde (E. Devrient, Geschichte der deutschen Schauspielkunst I, 482, 569; II, 322; Brachvogel, Das alte Berliner Theater-Wesen $200 \mathrm{f}$ Iffland/Seume 118 f; Almanach 1852, 98-101; Martersteig, Das deutsche Theater $294 \mathrm{f}$ und 299).

Frauen auf der Bühne waren moralisch von vornherein suspelts; im Publikum dagegen repräsentierten sie den Bestandteil, der von Kunst nichts verstand und für die Fülle billiger Komödien oder sentimentaler Rührstücke verantwortlich zu machen war: Goethe berichtet in seinen Gesprächen mit Eckermann von Schillers Idee, ein Haus nur für Tragödien zu bauen, „auch jede Woche ein Stück bloß für Männer zu geben“, denn

was tun unsere jungen Mädchen im Theater? Sie gehören gar nicht hinein, sie gehören ins Kloster [...]. Mit den Männern der Weimarischen Gesellschaft mochte es noch angehen, [...] schlimmer sah es mit den Frauen aus, die über den Geschmack der Zeit zum Sentimentalen nicht hinauszuziehen waren (zit. Martersteig, Das deutsche Theater 183-7).

Die Frauen waren allerdings aus dem Theaterpublikum des 18. und 19. Jahrhunderts nicht hinwegzudenken: das weibliche Publikum war in der Regel stärker vertreten als das männliche. Über die Aufführung des Schauspiels Cordemann schreibt Goethe 1798 an Kirms: "Wenn er den Frauen gefällt, bin ich schon zufrieden; die Frauen sind schon mehr als ein halbes Publicum" (zit. Satori-Neumann 283). Auch Laube wußte, daß "die Theatererfolge bei den Frauen [...] die breitesten" waren (Das Burgtheater 109), und spekulierte, daß ein Theater von einem rein männlichen Publikum nicht überleben könnte: „Das wäre der Untergang des Theaters in Deutschland, wenn die Frauen vom Theaterbesuche ausgeschlossen würden. Sie bilden ja das eigentliche Stammpublikum" (Laube, Erinnerungen IX, 421).

Der große Anteil der Frauen im Publikum wurde in beiden Jahrhunderten häufig von Zeitgenossen für die kü̈nstlerische Anspruchslosigkeit des deutschen Theaters verantwortlich gemacht, mit der Begrïndung, daß die Direktionen dadurch veranlaßt 
würden, weniger anspruchsvolle Stücke aufzuführen. Paldamus ist nicht allein, wenn er Klagt, daß bei Wandertheatern eher Kotzebue, Babo, Auffenberg und Franul von WeiBenthurn aufgeführt würden als „die wirklich guten Trauerspicle" (150). Kotzebue und Babo waren auch an Stadt- und Hoftheatern wesentlich populärer als Goethe und Schiller, und am erschütterndsten für die Zeitgenossen war wohl, daß unter den erfolg reichsten Schauspieldichtern im 19. Jahrhundert Frauen waren: Charlotte Birch-Pfeiffer, Amalie von Sachsen, Johanna Franul von Weißenthurn. Ihre Stücke wurden bei jeder Gelegenheit kritisiert, verrissen und belächelt, aber vom Spielplan konnten sie nicht vertrieben werden - ich erinnere nur an Laubes Zitat über Birch-Pfeiffer, ohne

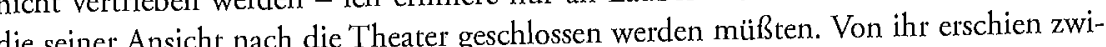
die seiner Ansicht nach die Theater geschlossen werden mußsten. Von ihr erschien zwischen 1830 und 1860 jedes Jahr mindestens ein Stück, das auf jedem deutschen Theater mit großem Erfolg gespielt und regelmäßig wiederholt wurde. Am Stadttheater Börnstein 1846-7 der am häufigsten aufgeführte Schauspieldichter; seine Stücke wurden in diesem Jahr $22 \mathrm{Mal}$ aufgeführt - von insgesamt 266 Vorstellungen in diesem Jahr. Es folgten Friedrich mit 17, Gutzlkow mit 16, Birch-Pfeiffer, Feldmann ind wurde im selben Jahr nur drei Mal aufgeführt (Almanach 1848, 93). Für Schiller war das ein außergewöhnlich erfolgreiches Jahr: Stücke von Charlotte Birch-Pfeiffer und Amalie von Sachsen wurden bundesweit in den 1840er Jahren weit häufiger aufgeführt als die von Schiller oder Goethe. Dieses Fazit ist nicht ein Zeichen für die Abneigung des Theaters oder Publikums gegen „höhere" Schauspiele und Trauerspiele, sondern einfach ein Ergebnis bühnenpraktischer Umstände: Birch-Pfeiffer und Kotzebue, di einfach cin Eollen schrieben, waren leichter aufführbar als einer Schauspielerin, die fast jeden Tag ine andere Rolle Goethe und Schiller. Von einer Schauspielerin, die fast jeden spielte, zu verlangen, sozusagen über Nacht und nach einer einzigen Probe die Mari Stuart auf die Bühne zu bringen, fiel nur wenigen Direktoren ein. Auch die Zensu bzw. das Improvisierverbot spielte hier eine Rolle. Nach nur einer oder zwei Proben war es natürlich, daß die Schauspieler Leerstellen trotz Verbot aus dem Gedächtnis ergänz ten, was bei Versdramen fast unmöglich war. Außerdem fiel bei bekannten Stïcken jede Abweichung vom Text auf, und Schauspieler und Direktoren waren bei Goethe-

oder Schilleraufführungen wesentlich anfälliger für das Eingreifen der Obrigkeit.

Die Schauspieldichter mußten sich beim Schreiben nach theaterspezilschen Bedingungen richten und alles in Betracht ziehen, was das Theater ausmachte: Budget, Zensur, die Beliebtheit der Komödie, die geringe Probenanzahl und die Zusammensetzung des Publikums. Daraus ergab sich in ihrer Produktion die große Anzahl der Lustspiele tic hä politische Vorsichtigkeit besonders des Theaters der Restauration und nach dic häufige politische Vorschigket besond 1848, die Konzentration vieler Schauspieldichter auf Familienstïcke, und die Vielzahl und Kürze der Rollen. Dramenautoren schrieben Stücke für finanziell unsichere Theater die ständig auf der Suche nach „Zugstücken“ waren, Rollen für überarbeitete Schauspieler, die kaum geprobt werden konnten, und Theater für cin vorwiegend weibliches Publikum. Vor allem schrieben sie direlkt für das Theater, da sich an Auffuhrungen wesentlich mehr Geld verdienen ließ als an gedruckten Stücken: Lesedramen waren nicht rentabel und entsprechend seiten.
Das Repertoire war für den Theaterdirektor die billigste Investition im ganzen Unternehmen, und das letzte, wofür er bereit war; Geld auszugeben. In finanzieller Hinsicht waren Schauspieldichter ebenso abhängig von der Direltion wie die Schauspieler bis 1870 gab es kein Copyright für Theaterstücke in Deutschland, bis 1841 keine Aufführungsrechte (Martersteig, Das deutsche Theater 399 f; Küstner, Vierunddreißig Jahre 287 und 296). Vor der gesetzlichen Einführung der Druckrechte 1870 wurde ein gedrucktes Stück als nationaler Besitz angesehen und konnte von jedem Theater aufgeführt werden, ohne daß man die Erlaubnis der Verfasser einholte oder sie in irgendeiner Weise entschädigte. Der Druck von Theaterstücken brachte wenig ein, da Theaterschriftsteller wie Romanautoren per Bogen, also nach Länge des Manuskripts, bezahlt wurden; die Honorare für Theaterstïcke lagen daher wesentlich niedriger als die für Romane. Bei Aufführungen dagegen wurden lediglich ungedruckte Stücke bezahlt, und auch das nur spärlich: die Dichterhonorare stellten „häufig kaum mehr als eine Entschädigung der Kopierkosten dar" (Martersteig, Das deutsche Theater 399). Der Autorenanteil an erfolgreichen und oft aufgeführten Stücken existierte seit Mitte des 18. Jahrhunderts, bürgerte sich aber erst um 1850 langsam ein (Almanach 1852, $114 \mathrm{f}$ ); bis dahin bekamen Autoren ein einmaliges Honorar für das Manuskript und hatten damit jedes Recht an ihr Werk verloren. Das hieß auch, daß ein Theaterdirektor ein Stück nach Belieben verändern oder umschreiben konnte, ohne daß die Autoren Einspruch erheben konnten (Schmidt, Neue Hamburger Bühne, Einleitung v).

Bühnenschriftsteller schickten ihre Stücke entweder direkt an die Theaterdirektion, die sie im Manuskript kaufte (Satori-Neumann 219), oder versuchten, ihre Dramen durch Vermittlung einer Theateragentur auf die Bühne zu bringen. Im 19. Jahrhundert gab es eine Vielzahl von Agenturen, die gegen einen Prozentsatz der Gage oder des Honorars Gastspiele, Engagements und Aufführungen neuer Stïcke vermittelten (Anzeigenteil in Almanach 1848, 443-9; 1849, 354-7; 1851, 398-405; 1852, 489-501) Viele Theaterintendanten entwickelten den Grundsatz, nur gedruckte Stücke aufzuführen, denn die bekam man umsonst (Winkler 124-8; Satori-Neumann 219). Die Honorare für Theaterstücke hingen von der jeweiligen Theaterdirektion und der Länge des Stückes ab, lagen aber im Schnitt bis Mitte des 19. Jahrhunderts um 100 Gulden für ein „abendfüllendes" Stück (von Weilen/Teuber II, 125; H. Devrient, Archiv II, 222; Lothar 93). Für Einalkter, Vor- und Nachspiele belsamen Bühnenautoren ein Drittel bis die Hälfte (Küstner, Vierunddreißig Jahre 288-90). Bei Opern wurden nur Komponisten bezahlt, die die Librettisten nach eigenem Ermessen entlohnen sollten; Librettisten konnten keine Ansprüche an das Theater stellen (Küstner, Vierunddreißig Jahre 289). In Wien lagen die Honorare doppelt so hoch wie üblich, weil dort die Zensur so streng war, daß die Dichter ihre Stücke gar nicht erst einreichten (Martersteig, Das deutsche Theater 399). Nach 1850 bekamen Autoren eine Tantième, d. h. einen Anteil am Ertrag der Aufführungen. In der Regel bekamen Bühnenschriftsteller für ein abendfüllendes Stück zwischen zwei und zehn Prozent jeder Einnahme, für Vor- und Nachspiele entsprechend weniger, oder die Einnahme der achten, zehnten und danach jeder zehnten Aufführung (Martersteig, Das deutsche Theater 402-4). Ob ein Stück wiederholt wurde oder nicht, wurde meistens bei der dritten Aufführung entschieden; 
über diese dritte Aufführung kamen nur sehr erfolgreiche Stücke hinaus. Die Bezahlung der Autoren hing also vor der Einführung der Tantième von der Aufführung eines Stückes, nach der Tantième von der Anzahl der Aufführungen, sprich: vom Erfolg des Stückes ab.

Um ein Stück also finanziell zu verwerten, versuchten die meisten Bühnenautoren, es so oft wie möglich aufführen zu lassen, bevor es gedruckt wurde. Bei vielen der mi zugänglichen gedruckten Stücke von Frauen findet sich die Anmerkung: „Den Bühnen zugänglichenl gedruckten Stücke von Aufführungsrecht behielt sich die Autorin vor. Für Autorinnen wie Karoline Neuber, die gleichzeitig Schauspieldirektorinnen waren, bestand die einzige Möglichkeit, sich die Aufführungsrechte ihrer Werke zu sichern, darin, sie gar nicht drucken zu lassen (Schmid, Chronologie 44); das ist einer der Gründe, warum von Karoline Neuber nu drei Stücke im Druck erschienen. Andere Autorinnen, die gleichzeitig Schauspielerinnen waren, wie Charlotte Birch-Pfeiffer, machten aus der Not eine Tugend und brachten auf Gastspiclen ihre eigenen Stücke so oft wie möglich auf die Bretter: Gastschauspieler konnten in der Regel ihre Rollen selbst bestimmen (Schröder, Briefe 1813-1868 12; Lothar 136). In den Jahren 1842, 1844, 1848 und 1851 gab sie 13 Gastspiele an ebensovielen Bühnen und spielte fast ausnahmslos in ihren eigenen Stücken (Martersteig, Das deutsche Theater 508; Almanach 1842, 260 und 355; 1844, 46, 255, 304, $325,340,361 \mathrm{f}$ und $424 ; 1848,367 \mathrm{f} ; 1849,137 ; 1851,273)$.

Die Vielzahl weiblicher Dramatiker - siehe Anhang $B$ - und die ungeheure Bekanntheit und Popularität der Birch-Pfeiffer, Franul von Weißenthurn, Amalie von Sachsen und vieler anderer paßt schlecht zu der vielzitierten „Traditionslosigkeit weiblicher Dramatiker". Die Begründung dafür, daß sie heute relativ unbekannt sind, kann nicht einfach damit abgetan werden, daß sie für ein spezifisches Theater schrieben, das heute in dieser Form nicht mehr existiert - das taten auch Goethe und Schiller. Für Dramenautorinnen gilt in verstärktem Maße, was sich über Literatur von Frauen allgemein sagen läßt: geschrieben haben viele, in der Werkauswahl, die wir heute als „Literatur" empfinden, erscheinen nur wenige. Dramen von Frauen im 18, und 19. Jahrhundert sind schon deshalb heute nicht ein selbstverständlicher Teil unseres Literaturverständnisses, weil sie es auch damals nicht waren: indem sie schrieben, taten sie einen Schritt über die seit dem 18. Jahrhundert fest definierten Formen der Weiblichkei hinaus, und in der Regel waren sie sich dieser Tatsache deutlich bewußt und taten ih Bestes, um bekannt zu werden, dabei aber unerkannt zu bleiben. Kaum eine Frau, die nicht mehrere Pseudonyme zur Verfügung hatte, sich nicht hinter einer fiktiven Herausgeberfunktion versteckte oder die sich nicht angehalten fühlte, bei einer Veröffentlichung unter ihrem Namen zu beteuern, das Stück sei ohne ihr Wissen und gegen ihren Willen gedruckt worden. Kaum eine Schriftstellerin, die den Bruch des WeiblichkeitsWillen gedruckt worden. Kaum eine Schriftstellerin, die den Bruch des Weiblichkeitsals die Feder".

Bei Dramen weiblicher Autoren sind anonyme und pseudonyme Veröffentlichungen wesentlich häufiger als bei Veröffentlichungen in anderen Genres. Die Verfasserinnen von Bildungstraktaten beispielsweise, die gerade als Frauen eine gewisse Berechtigung besaßen, die zeitgenössische Frauenbildung zu kommentieren, setzten fast immer ihren vollen Namen unter ihre Werke. Einige dieser Verfasserinnen empfanden manche literarische Genres als „weiblicher", d. h. subjelstiver als andere, wie z. B. Gedichte, Briefe und Briefromane, Tagebücher, Autobiographien und Reiscbeschreibungen. So z. B Caroline de la Motte-Fouqué (1773-1831): „Poesie, solche, die elegisch oder idyilisch dem Herzen entströmt, gehört auch dem Herzen“, sie „ist der weichern klangreichen Frauennatur innerlich ebenso verwandt, als das Epos und das Trauerspiel ihr freme bleiben“ (250 f). Gedichte statt Trauerspiele zu schreiben, wurde nicht nur als „weiblicher" propagiert, sondern war aus eben diesem Grund weniger risikoreich: bei Gedichtveröffentlichungen konnte die Verfasserin immer vorschützen (und der Leser annehmen), sie seien ursprünglich nicht zur Veröffentlichung bestimmt gewesen. Viele Dramatikerinnen behaupteten zwar dasselbe, aber bei Dramen klang diese Behauptung weitaus unglaubwürdiger. Eine Frau, die im stillen Kämmerlein nach der Hausarbeit nicht zur Veröffentlichung bestimmtc Briefe oder Gedichte verfaßte, war allemal akzeptabler als eine, die sich schon durch die Wahl ihres Genres auf das Gebiet der Of fentlichkeit begab (Theater) oder sich zur Autorität auf einem von Männern besetzten Gebiet erklärte (wissenschaftliche Abhandlungen). Autorinnen, die in diesen Genres schrieben, gaben sich oft nicht mit der Benutzung eines Pseudonyms zufrieden; eine Art pseudonymes Verhalten - eine zumindest oberflächliche Anpassung an in der männlichen Literatur etablierte Traditionen, Themen und Vorstellungen - läßt sich häufig auch in ihren Texten selbst nachweisen. Die Vermutung liegt nahe, daß der Zwang zur Anpassung je nach Genre variierte, d. h. daß Frauen, die in tabuisierten Genres schrieben, das Korsett enger schnallen mußten als andere. Mit diesem Wissen oder zumindest mit diesem Verdacht sollten ihre Werke gelesen werden; der Versuch sollte gemacht werden, die Zugeständnisse an patriarchalische politische und soziale Zustände zumindest anzuzweifeln, und zu lesen, was trotzdem gesagt wird. 
soweit ihnen ihre finanzielle Lage oder ihr sozialer Stand das erlaubte (Prinzessin Amalie von Sachsen), oder sie waren geschieden, teilweise mehrfach (Seyler). Die Mehrzah von ihnen war berufstätig, als Berufsdramatikerinnen, die für die Bühne oder den Druck schrieben, teilweise auch als Schauspielerinnen. Schauspielerinnen waren bi weit ins 19. Jahrhundert hinein Mitglieder eines verachteten Standes, und die berufsmäßige Produlktion von Theaterstücken hing weitgehend von der Protektion der Theaterdirektoren ab: die Stïckse mußten aufgefïhrt werden, wenn sie ihre Frau ernähren sollten, da sich vor der Einführung der Druckrechte mit gedruckten Stücken nichts verdienen ließ.

Obwohl sich bei Frauen, dic einen so unsicheren Beruf ergriffen, ein gewisses Maß an Unabhängigkeit vermuten läßt, wrurde diese selten in ihren Stücken offen prolslamiert. So lehnten sie z. B. die Institution der Ehe in ihren Stücken nie ab und stellten auch keine „emanzipierten“ Frauen auf die Bühne, die sich etwa aus Gründen der persönlichen Unabhängigkeit weigern zu heiraten. Denn abgesehen von der ständigen Notwendigkeit, die Stïcke beim Theater anzubringen und die Zensur zu umgehen, schrieben sie, wenn nicht innerhalb, so doch im Bezug auf eine bestimmte literarische Tradition und paßten sich ihr an. Daher läßt sich in Dramen von Frauen ein paradoxes Phänomen beobachten: die Zweifel werden versteckt hinter dem dicken Mantel ostentativer Anpassung; erst die überdeutliche Anpassung an die Komödien- oder Schauspicltradition ermöglicht die subversiven Untertöne. Oft ist das Thema Liebe lediglich Scheinthema des Stückes; das heißt, es wird im Titel oder in der Exposition in den Vordergrund geschoben, während es im Stück selbst um völlig andere Probleme geht: um die Misere erzwungener Ehen, das Fehlen jeglicher Alternativen, die Auseinandersetzung der Frau mit der männlichen Autorität (Vater) im Kampf um die Wahl des zukiunftigen Besitzers (Ehemann), oder um Probleme innerhalb einer bereits geschlossenen Ehe. Der väterliche/männliche Status als Stellvertreter Gottes auf Erden und der korrespondierende weibliche als ewige Untertanin wird zwar aus der Tradition iibernommen, aber nicht kritiklos. Die väterliche Macht und die weibliche 'Tugend, die diese Macht aufrechterhält, werden konsequent bezweifelt.

Im 19. Jahrhundert taucht eine mögliche Alternative zu der sich tugendhaft der männlichen Autorität unterordnenden Frau auf - die gebildete Frau, die sich den kïnftigen Herrn und Gebieter selbst aussucht. Das yon den Gesetzen der Komödie vorgeschriebene Happy End, die Verheiratung des Pärchens, wird oft relativiert, ironisiert, nur angedeutet oder fällt ganz weg. Bei alledem wird der Schein der Anpassung erfolgreich aufrechterhalten: die väterliche Autorität wird nur dann untergraben, wenn sie eine tyrannische ist, die Frau begehrt nur zu Zwecken der Selbsterhaltung gegen sie auf, und am Ende des Stückes wird nach wie vor geheiratet. Wo nicht, wird der Widerstand der Heldin gegen die Ehe oder die Verhinderung der Eheschließung auf eine dem Zuschauer alkzeptable Weisc erklärt, ohne daß der Unabhängigkeit der Frau direkt das Wort geredet wird. Wenn geheiratet wird, ist das Happy End oft alles andere als ein gliickliches Ende, sondern erscheint so stark relativiert, daß es klar als das von der Tradition aufgesetzte Komödienende erkennbar ist: die Verlobung am Schluß bedeutet nicht das große Glück, oder sie wird durch Unwahrscheinlichkeiten und Zufälle 
herbeigeführt, oder sie hat mit dem Stück selbst nichts zu tun und muß schnell eingeschoben werden, weil das Gesetz der Komödie es so will.

Wenn es eine Komödientradition von Frauen gibt, dann ist es diese Relativierung des traditionellen Happy Ends, mit allen damit verbundenen Zweifeln an der Ordnung, die in der Komödie dargestellt wird: der Lohn der Tugend, die Bestrafung des Lasters, die Gottgewolltheit der väterlichen Autorität und der weiblichen Unterwerfung. Es lohnt sich also, einige der vielen stilistischen und dramatischen Methoden zur Relativierung des Happy Ends zu untersuchen.

\section{1. „SITZENGEBLIEBEN“ UND NOCHMAL GLÜCK GEHABT:} LUISE ADELGUNDE GOTTSCHED

In den Lustspielen der Luise Adelgunde Gottsched (1713-1762) besteht das Happy End meist nicht in einer Verlobung, sondern in der Verhinderung einer Verlobung; die Ehe wird nicht als großes Glück, sondern als finanzielle Transaktion dargestellt. Gottsched ${ }^{15}$ schrieb „Verbesserungskomödien" im Sinne der Frühaufklärung, in denen die Figuren in der Regel mit einem Fehler identifiziert werden. Aufgabe der Komödie ist es, diesen Fehler anzuprangern, die davon befallene Figur davon zu kurieren und den Zuschauer vor derartigen Verfehlungen zu warnen. Dieser traditionelle Teil der Themenwahl in ihren Stücken war sehr stark von ihrem Mann beeinflußt; abgesehen von der Pietisterey im Fischbein-Rocke (1736) besteht ihr gesamtes dramatisches Werk aus Auftragsarbeiten ihres Mannes für seine Deutsche Schaubühne. Sie hielt sich bei derartigen Auftragsarbeiten streng an die von ihm aufgestellten dramatischen Regeln (drei Einheiten, fünf Alkte, möglichst wenige handelnde Personen), ließ sich verschiedentlich Themen von ihm aufoktroyieren (wie in der Hausfranzösinn, 1744, und in der Pietisterey) und schlug für ihn Schlachten gegen seine Kritiker auf der Bühne (Der Witzling, 1745). Trotzdem sind viele ihrer Themen unverkennbar ihre eigenen.

Eins davon ist ihr Mißtrauen gegenüber der Ehe als traditionelles Happy End der Komödie, wie man von einer Frau erwarten könnte, die ihre eigene Heirat jahrelang hinauszögerte (Briefe I, 12 f, 42 f, 53 f, 86 f, 97 f, $114 \mathrm{ff}, 120$ f). Die Vertreterinnen der Vernunft in ihren Stücken äußern meist den Entschluß, unverheiratet zu bleiben, und lsönnen der Stimme der Vernunft oft deshalb folgen, weil die Autoritätsfigur der Familie eine Person mit beschränkter Macht ist: die Mutter (Die Pietisterey im Fischbein-Rocke), die Tante (Das Testament, 1745), oder der Vormund (Der Witzling). In ihrem Erstlingswerk, der Pietistereys wird Jungfer Luisgen durch die Ankunft ihres Vaters, der wahren Autoritätsperson, vor der von ihrer Mutter geplanten Zwangsehe gerettet, da der Vater glücklicherweise mit Luisgens Wahl des Herrn Liebmann einverstanden ist. Die Handlung des Stückes dreht sich, abgesehen von der Lächerlichmachung de Pietisten, weniger um die Verheiratung Luisgens mit Herrn Liebmann als um die Verhinderung der Ehe zwischen Luisgen und Herrn von Muckersdorff. Die EheschlieBung selbstbeschränkt sich auf wenige Zeilen, in denen der Geschäftscharakter der Transaktion betont wird: „Der Contract ist schon [...] fertig, wir dürffen ihn nur unterschreiben“ (Die Lustspiele I, 572) ${ }^{16}$ Luisgen kommentiert ihr Glück mit keinem Wort.
Wie willkürlich der Zusammenhang zwischen Liebe und Ehe dargestellt wird, äußert sich im väterlichen Versprechen an die ältere Tochter Dorgen, die um jeden Preis heiraten will, und der der Vater so bald wie möglich (irgend)einen Mann verspricht (573).

In Gottscheds nächstem Lustspiel, Die ungleiche Heirath (1744), ist das Ziel der Handlung die Verhinderung der bereits im Titel verpönten „ungleichen“" Heirat zwischen Fräulein Philippine von Ahnenstolz und dem bürgerlichen Herrn Wilibald. Während Philippine als Tochter des Hauses dem Willen ihrer Eltern nachgeben muß und dieser Wille zwingt ihr den verachteten bürgerlichen Bräutigam auf - - , hat Amalia, als Stiefschwester der Frau von Ahnenstolz, keinerlei Autorität über sich und kann es sich daher erlauben, die Handlung und die Personen zu kommentieren und ihren Einfluß zu benutzen, um die Hochzeit diskret zu hintertreiben. Aber auch die elterliche Autorität über Philippine ist begrenzt: Philippine ist zwar bereit, sich dem elterlichen Gebot zu beugen und Wilibald zu heiraten, will aber ihren derzeitigen Liebhaber, Herrn von Zierfeld, als ständigen Hausfreund beibehalten, im Vertrauen auf das Verständnis ihrer Eltern, die „ihrem Kinde [...] so gram nicht seyn [werden], daß sie ein Fräulein zwingen sollten, einem Bürgerlichen treu zu seyn" (Die Lustspiele I, 31).

Ähnlich wie Amalia, vernünftig, ehrlich und mit allen bürgerlichen Tugenden ausgestattet, als charakterlicher Gegensatz zu Philippines losen Moralvorstellungen und adliger Arroganz fungiert, sind die Anwärter auf Philippines Hand einander entgegengesetzt. Wilibald ist der vernünftige Bürger, der durch Erbschaft und ehrliche Arbeit so wohlhabend geworden ist, daß die Familie von Ahnenstolz ihn für würdig erachtet, als Philippines Ehemann ihre Schulden zu bezahlen. Herr von Zierfeld dagegen ist der adlige Geck, der keinerlei moralische oder intellektuelle Qualitäten aufzuweisen hat und nicht einmal vorgibt, Philippine zu lieben, obwohl er sie heiraten will. Daß eine Heirat keineswegs auf Zuneigung irgendwelcher Art basiert, wird im Stück zur Genüge hervorgehoben. Der Austausch zwischen Zierfeld und Philippine beschränkt sich auf vorformulierte Schmeicheleien seinerseits, auf die sie kaum reagiert und ihn dadurch wiederholt zu aufgebrachten Ausbrüchen veranlaßt: „Zum Henker! gnädiges Fräulein, bewundern Sie doch meine Artigkeit!“ (54 f) Wilibald dagegen besitzt zwar sämtliche bürgerlich-vernünftigen und moralischen Qualitäten, hat sich aber nach eigener Aussage „die Grille in den Kopf gesetzt [...], mich durch ein Fräulein über meines gleichen zu erheben" (87).

Amalia betont die Tatsache, daß Geld bei Eheschließungen immer der ausschlaggebende Faktor ist (28); während Philippine Wilibald in aller Deutlichkeit mitteilt daß sie ihn lediglich aus Eigennutz heiratet und diesen Beweggrund als einzig möglichen darstellt. „Ein jeder hat seine Ursachen warum er heirathet, und diese gründen sich immer auf den Eigennutz; er sey nun beschaffen wie er wolle" (38). Im Bezug auf sämtliche Personen des Stückes hat sie zweifellos recht. Da der Eigennutz hier auf beiden Seiten ein finanzieller ist (Wilibald will sich durch die Heirat einen Adelstitel kaufen, während die Familie Ahnenstolz nur darauf aus ist, ihre Schulden zu bezahlen) wird die Ehe - und keineswegs nur diese Ehe - als Geschäft dargestellt, als eine Transaktion, bei der der Vater (derzeitiger Besitzer) dem Bräutigam (zukünftiger Besitzer) mehr oder weniger teuer eine Frau verkauft. 
Diese Auffassung der Ehe scheint für alle handelnden Personen eine Selbstverständichkeit. Das Problem, das es erforderlich macht, die ungleiche Heirat zwischen Philippine und dem vernünftigen Herrn Wilibald zu verhindern und ihr stattdessen den eitlen Zierfeld zuzuschanzen, besteht lediglich darin, daß Herr Wilibald „sich für sein Geld ein immerwährendes Unglück an den Hals kaufet" (28). Amalias Befürchtung, daß Wilibald „sich die Braut gar zu theuer verlkaufen“ läßt (54), bewahrheitet sich in der fünften Szene des dritten Alktes, in der Wilibald entsetzt feststellen muß, wie teue die Braut tatsächlich ist (66-72). Als Amalia Wilibald sein künftiges Unglück ausmalt, impliziert sie, daß sogar eine standesgemäße Ehe unter Bürgerlichen keineswegs eine Liebesehe wäre, sondern nichts weiter als ein vernünftigerer Frauenkauf. Denn „für Ihr "res Vermögen", mit dem Geld also, das er zum Ankauf Philippines anwendet, hätte er sich ,unter Ihres gleichen, die vortrefflichste Person in und außer Landes [...] wählen können" (52).

Wenn die Ehe in einem anderen Zusammenhang erwähnt wird als in dem der finanziellen Transalktion, wird sie als Machtkampf dargestellt, der sich in ewigen Zänkereien äußert. Philippine verwahrt sich gegen Wilibalds Beschuldigung ihrer Untreue mit dem Hinweis, er habe noch keine Autorität über sie: „Ich möchte doch wissen, was Sie sich über mich für Gewalt herausnehmen? Sind wir denn etwa schon verheirathet? Sie sind doch nichts mehr, als nur mein Bräutigam?" (59) Sowohl Herr als auch Frau von Ahnenstolz schen derartige Zwistigkeiten als typisches Merkmal der Ehe an sich. Frau von Ahnenstolz, die in diesen Streit hineinplatzt, bemerkt dazu: „Wie zankt Ihr euch so? Es ist nicht anders, als wenn Ihr schon verheirathet wäret" (60); Herr von Ahnenstolz entsprechend: „Ihr guten Kinder fangt zu frühe an! Nach der Hochzeit A habt Thr noch Zeit genug zut sie wird, wie Herr von Zierfeld es ausdrückt, „in Ihrer Mama Fußstapfen treten" (107). Daß Gottsched unter solchen Umständen die Ehe nicht zustandekommen läßt, aberrascht nach dem Gesagten kaum: Amalia entlarvt das heimliche Verhältnis zwischen Zierfeld und Philippine und bringt Wilibald zur Vernunft, d. h. sie verhinder eine Ehe die für ihn ein schlechtes Geschäft gewesen wäre. Die logische Konsequenz, (a) nämlich die Heirat zwischen Philippine und Zierfeld, ist duchaus unnicher Herr von Ahnenstolz, der halbherzig zustimmt, muß zunächst das Einverständnis seiner Frau einholen, und in dieser Hinsicht kann er am Ende des Stückes „noch nichts gewisse versprechen" (122). Amalia dagegen muß noch einen Heiratsantrag von seiten Herrn Wilibalds ablehnen, der trotz aller Erfahrungen mit adligen Fräuleins noch nicht kuriert ist. Selbst in dieser Szene zwischen den beiden Vertretern der Vernunft wird das Thema The nicht ernsthaft angesprochen: Wilibald bezeichnet seinen Antrag als „den einzigen Dank, den ich gegen Eu. Gnaden fähig bin“" (123) - als Gegenleistung für einen Gefallen also. Amalia dagegen bemerkt dahinter sofort eine neue Äußerung seine alten Grille“, sich einen Adelstitel zu kaufen, lehnt den Antrag aus sozialen Paritätsgründen ab und gibt ihm gratis noch den guten Rat, er solle sich „den Appetit zu den Fräuleins vergehen" lassen. Was er auch tut: er verläßt die Bühne mit einem herzempfundenen "So hole doch der"Henker alle Fräuleins" (124).
Ein Jahr später spricht Gottsched in Das Testament (1745) das Thema Ehe als Geschäft erneut an. Caroline und Amalie, die Heldinnen des Stückes, sind elternlos, d. b. olnne wirkliche Autorität, und in der Obhut ihrer reichen Tante Frau von Tiefenborn. Amalie will um jeden Preis heiraten; ähnlich wie bei Jungfer Dorgen in der Pietisterey wird ihre Heiratswut als negativer Charakterzug dargestellt. Sie versucht, mit Hilfe ihres verschwendungssïchtigen Bruders, Herrn von Kaltenborn, ihre Tante in ihrer Hypochondrie zu bestärken, um dafür zu sorgen, daß sie möglichst bald ihr' Testament macht. Gleichzeitig umschmeichelt sie sie in der Hoffnung, sie zu beerben. Caroline dagegen glaubt nicht an die fingierte Krankheit ihrer Tante, die diese in der Tat nur spielt, um den Charakter ihrer Zöglinge zu testen, und versichert Frau von Tiefenborn bei jeder Gelegenheit, sie sei völlig gesund und werde noch alle ihre Erben überleben. Für Amalie bedeutet die Erbschaft die finanzielle Möglichlseit, sich zu verheiraten; da sie die Erbschaft als das einzige Mittel zur Ehe und die Ehe als einzige Lebensmöglichkeit der Frau sieht, ist das Testament eine wahre Existenzfrage für sie. Sie wehrt sich gegen die finanzielle Abhängigkeit von ihrer Tante, bei der sie versorgt ist "wie ein Kind im Hause. Ich habe alles was mir gegeben wird, und was ich erbetteln muß" (Die Lustspiele I, 323). Caroline dagegen ist damit zufrieden; sie will nichts vom Leben als „Wasser und Brod, und die edle Freyheit, daß ich einem jeden meine Meynung unverholen sagen darf" (295). Von dieser Freiheit macht sie ausgiebig Gebrauch, sowohl ihren Geschwistern als auch ihrer Tante gegenüber. Sie vertritt die Stimme der Vernunft im Stïck und ist mit ähnlichen Charakterzügen ausgestattet wic viele vernünftige Gottschedsche Frauenfiguren: sie ist ehrlich, spöttisch, und kommentiert mehr, als daß sie an der Handlung selbst teilnimmt. Caroline warnt Amalie wiederholt vor einer Heirat mit einem Mann, der sie nur wegen des Geldes nähme, und unterstellt dieses Motiv ihren beiden Freiern, dem Hauptmann von Wagehals und dem Herrn von Kreuzweg. Beide geben Amalie gegenüber unverblümt zu, daß sie sich nur ihrer Erbschaft wegen um sie bewerben, und machen sich nach Amalies Enterbuing erwartungsgemäß davon. Daß Geld das einzige Motiv dieser Werbungen ist, wird erneut betont, als Kreuzweg um Caroline anhält, weil diese im Testament gut bedacht worden ist. Caroline lehnt selbstverständlich seinen Antrag ab und äußert außerdem den Entschluß, überhaupt nicht zu heiraten, solange ihre Tante lebt - von der sie, wie gesagt, hofft, daß sie ihre Erben überleben wird.

Die Tante selbst scheint auch keineswegs mit ihrem baldigen Ableben zu rechnen: sie ist die einzige, die sich tatsächlich verlobt. Auch sie ist sich bewußt, daß ihr Reichtum ein Heiratsmotiv ihres Verlobten ist. Die Schmeichelei, daß er sie für zwanzig Jahre jünger hält als sie ist, kommentiert sie ironisch: „ich habe ihn immer für einen Cavalier gehalten, der Verstand genug hat, die Aenderung einzusehen, die ein großes Vermögen in eines Menschen Verstand, Alter und Vorzügen machen kann" (301). Was Amalie in allem Ernst behauptet - „Wer reich ist, der ist allein klug" (262) -, ironisier Frau von Tiefenborn hier in einer Weise, die anzeigt, daß sie sich diese überlegene Haltung sowohl ihrem Vermögen als auch ihrer Verlobung gegenüber erlauben kann. Denn mit ihrer Ehe gibt sie keineswegs ihre finanzielle Unabhängigkeit auf: ihr Zukünftiger wird lediglich als Erbe nach ihrem Tod eingesetzt - bis dahin aber bleibt sie 
Herrin ihres Vermögens, mit ihren Worten: „Frau in meinem eigenen Hause“ (329). Sie folgt lediglich dem von Caroline in II, 1 vorweggenommenen Rat: „Wenn ich an ihrer Stelle wäre, ich heirathete noch einmal, und genösse mein Vermögen recht" (271). Mit einem Wort: anders als Caroline oder Amalie, deren Mitgift in den Besitz des Zukünftigen übergegangen wäre, kann Frau von Tiefenborn sich die Ehe leisten.

2. DER „LOHN“ DER TUGEND:

\section{RÜHRSTÜCKE VON RUPP, REITZEENSTEIN, TEUTSCHER, SEYLER}

Nach Gottscheds dramatischer Produlktion herrscht zwanzig Jahre lang Schweigen: zwischen 1750 und 1770 sind nur wenige Dramen von Frauen ermittelt. In den darauf folgenden zwanzig Jahren melden sich mehrere Dramatikerinnen zu Worte, deren Lustspiele und Dramen in der Tradition und im Stil der Empfindsamkeit geschrieben sind. In vielen dieser Rührstücke sind 'Teile der Handlung direkt aus Richardsons Romanen entlehnt: In Friederike Sophie Seylers (1738-1789) Die Familie auf dem Lande (1770) und Victoria von Rupps (ca. 1755 bis ca. 1824) Marianne, oder Der Sieg der Tugend (1777) entführt ein wollïstiger Lord eine sozial unter ihm stehende Unschuld, die ihre Tugend dadurch unter Beweis stellen muß, daß sie ihn entrüstet abweist. In Sophie Mariane von Reitzensteins (1770-1823) Die seltene Beständigkeit (1792) und Marie Antonie Teutschers (1752-1784) Fanny, oder Die glückliche Wiedervereinigung (1773), die beide nach der Eheschließung zwischen dem (hier edlen, aber irregeleiteten) Lord und der tugendhaften Heldin angesetzt sind, wird die Ehe durch böswillige Verleumdungen auseinandergebracht. Ziel der Handlung ist es, die Liebenden durch gegenseitige Treuebeweise wieder zusammenzuführen. In von Rupps Jenny, oder Die Uneigenniutzzigkeit (1777) geht es um die Hindernisse einer Ehe zwischen einem Lord und einem vermeintlichen Bauernmädchen, die glücklicherweise dadurch beseitig werden können, daß das Bauernmädchen sich als Adlige entpuppt. Mit Ausnahme von Reitzensteins Stück spielen alle diese Stücke in England; alle spielen auf dem Land; in allen wird der Gegensatz zwischen Tugend und Laster weitgehend mit dem zwischen Land und Stadt gleichgesetzt. Die weiblichen Protagonisten werden bereits im Tite mit den Tugenden identifiziert, die sie im Stück unter Beweis stellen müssen: in von Reitzensteins Stück ist Elise die personifizierte seltene Beständigkeit, ebenso ist Jenny das Sinnbild der Uneigennützigkeit und Marianne das der Tugend. Bedroht sind die Tugenden, die durch diese Figuren versinnbildlicht werden, nicht allein durch Verleumdungen von außen oder Nachstellungen lüsterner Adliger, sondern auch nicht zuletzt durch das Fehlen oder die Inkompetenz einer familiären, oft männlichen Autoritä (Vater), die imstande wäre, sie zu verteidigen: keines dieser Stücke hat ein vollständiges Elternhaus aufzuweisen. In Seylers Stïck werden die Töchter von der verwitweten Mutter aufgezogen; bei Teutscher ist der Vater alt und krank und Fanny Alleinernährerin der Familie; bei von Reitzenstein und von Rupp (Marianne) wird die weibliche Hauptperson lediglich in die Familie aufgenommen; von Rupps Jenny ist mutterlos.

Die Identifizierung der weiblichen Hauptpersonen mit einer "weiblichen“ Tugend zwingt sic in die Passivität: die bedrohte Tugend darf nicht selbst in das eigene Schick- sal eingreifen. Daher müssen die Autorinnen die Herbeiführung des glücklichen Ausgangs - und das ist in diesen empfindsamen Stücken immer die Stiftung oder Rettun einer Ehe - den männlichen Protagonisten, dem Zufail oder der Vorsehung überlassen. Das in dieser Form aufgesetzte glücleliche Ende erscheint oft dementsprechend unmotiviert und unüberzeugend: die Unglücksfälle, die in Verbindung mit einer geradezu unglaublichen Leichtgläubigkeit der handelnden Personen die Trennungen der Paare herbeiführen, sind um nichts glaubwürdiger als die Zufälle, dic die bedrohten Ehen wieder kitten. Noch aufgesetzter erscheinen die Verlobungen am Ende der anderen Rührstï̈cke. Die Autorinnen tun nichts, um die Unglaubwürdigkeit des vorformulierten Endes zu mildern: daß die weibliche Tugend am Ende doch noch belohnt wird, widerspricht aller Wahrscheinlichkeit und wird in ihren Stücken - m. E. bewußt - als unglaubwürdig dargestellt.

Darauf ist es wohl auch zurückzuführen, daß es meist offen bleibt, ob das so herbeigeführte Happy End in Form einer Heirat tatsächlich ein glückliches ist. In Seylers Familie auf dem Lande (1770), 1771 umgearbeitet und neu veröffentlicht unter dem Titel Die Entfiuhrung, oder Die zärtliche Mutter, wird die entlaufene Caroline in alle Form von ihrer Mutter, der Lady Danby, verstoßen. Ihr tränenreicher Kummer um ihre vom Pfad der Tugend abgewichene Tochter - „Gott! [...] verbirg dieses Kind auf immer vor meinen Augen, wenn ihr Herz von dem Laster befleckt worden ist!" (17) hindert sie allerdings nicht daran, umgehend Heiratspläne für ihre zweite Tochter Charlotte zu schmieden, die sie mit dem Grafen Drummond verheiraten will. Charlotte liebt Carl, den Adoptivsohn der Lady, der seinerseits ebenfalls in sie verliebt ist, aber in einem Anfall unbeherrschter Leidenschaft Caroline die Ehe versprochen hat. Da Caroline mit einem anderen Mann geflohen ist, glaubt er sich von seinem Versprechen entbunden und macht Charlotte den Hof. Es stellt sich allerdings heraus, daß Caroline keineswegs geflohen, sondern von Lord Ogliby entführt und derartig bedrängt worden ist, daß sie darüber den Verstand verloren hat. Carl wird in aller Form mit Charlotte verlobt und prompt wieder entlobt, weil Caroline, deren Geistesverwirrung diesen Verstoß gegen weibliche Zurückhaltung hinreichend entschuldigt, Ansprüche auf ihn stellt. Da Carl zudem noch in den Verdacht gerät, an der Entfiuhrung Carolines beteiligt gewesen zu sein, wird auch er von der Lady verstoßen. Außer diesen an der Handlung direkt beteiligten Figuren spielen zwei Männer eine tragende Rolle, die sich sozusagen den Part des nicht existenten Vaters und Familienoberhaupts teilen. Der vernünftige Graf Drummond, ein Freund der Familie, ist immer bemüht, zwischen Lady Danby und ihren Kindern zu vermitteln und Mißverständnisse aufzuklären. Der jähzornige Lord Hamilton, Bruder der Lady, führt das gesamte Unglück der Familie darauf zurück, daß die Kinder von weiblicher Obhut „verzärtelt" werden, rät der Lady strenge Maßnahmen den Kindern gegenüber an (die Verstoßung Carls und Carolines und die Zwangsverheiratung Charlottes mit Lord Drummond) und enterbt die Töchter, weil Lady Danby sich seinen Anordnungen widersetzt.

Während das Stück auf der Oberfläche weibliche Tugenden propagiert, werden eben diese Tugenden konsequent bezweifelt und negiert. Die Haupttugend der Lady Danby, die Liebe zu ihren Kindern - in der späteren Bearbeitung, Die Entfiihrung oder 
Die zdrtliche Mutter, wird diese Tugend zum Thema des Stückes -, scheint durchaus zweifelhaft, da die Lady ihre Liebe von der vermeintlichen Tugend/Untugend oder $\operatorname{dem}$ Zustand ihrer Kinder abhängig macht. Bereits in I, 3 stellt sie fest, daß sie Caroline tugendhaft oder gar nicht wiedersehen will (17), in III, 10 ist ihr eine verrückte Tochter lieber als eine lasterhafte (49), in III, 11 kann sie den Anblick ihrer geistig verwirrten Tochter nicht ertragen (51). Wenn der Graf in V, 1 bei der Lady für Cart eintritt und ihre Tugend mit den Worten definiert: „Ihre erhabene Tugend ist unfähig, jemanden zu verdammen, ohne ihn gehört zu haben" (72), klingt das wie blanke Ironie, da die Lady sowohl Caroline als auch Carl verstoßen hat, ohne beiden auch nu die geringste Chance zu geben, sich zu rechtfertigen. Caroline muß ihre Tugend mit dem Verlust ihres Verstandes, Charlotte die ihre mit dem Verlust ihres Glücksanspruchs bezahlen. Denn am Ende des Stückes wird Charlotte mit dem Grafen verlobt (in der späteren Bearbeitung bittet sie sich Bedenkzeit aus, s. Entführung, 88) Caroline wird Carl versprochen, „sobald der Himmel ihre zerstörten Sinnen wieder geheilt hat" (85). Im Klartext heißt das: Charlotte heiratet einen Mann, den sie nicht liebt, und verliert den Geliebten; Carl verliert die Frau, die er liebt, und verlobt sich mit einer Geistesgestörten; Caroline ist und bleibt geistig verwirrt. Der einzige, der hier auf Glück Anspruch machen darf, ist der Graf, der seine Freude folgendermaßen äußert: „O, Charlotte, sie machen mich zu dem glücklichsten Menschen". $\mathrm{Daß}$ ausgerechnet die geistesgestörte Caroline aus dieser Äußerung auf Charlottes Glück schließt, ist bezeichnend: „So ist denn meine Schwester auch glücklich? Und ich auch?" (86) Noch in ihrer geistigen Verwirrung bezweifelt sie das eigene Glück und muß es von der Mutter bestätigt bekommen. Deren Vorsehungsglaube „Der Himmel, der uns genug geprüft hat, wird deine Vernunft zurücke bringen, und dann werden wir alle glücklich seyn" (86) - wird im Stück selbst durch nichts unterstützt.

Ähnlich zweifelhaft scheint das Happy End in von Rupps Stücken. In Marianne oder der Sieg der Tugend (1777) sucht die elternlose Marianne Schutz vor ihrem adligen Verführer, dem Lord d'Ambri, bei der ihr völlig unbelzannten Familie Worthi. Sic erregt dabei zunächst die Eifersucht der Frau Worthi, weil diese sich ihre Anwesenheit im. Haus nicht erklären kann, und gerät in das Intrigennetz der Bedienten Sally, die von Lord d'Ambri dafür bezahlt wird, Mariannes Entführung zu arrangieren. Sämtliche männliche Beschützer des Stückes, Sir Worthi, Lord Welton, ein Freund der Familie, und der Obrist Beaumont, der tugendhafte Bruder des Verführers, sind unfähig, die Entführung zu verhindern. Mariannes Rettung gründet sich auf zwei Zufälle: in III, 4 unterbricht der unerwartet auftretende Sohn Worthi die Vergewaltigung Mariannes durch d'Ambri; in III, 15 wird Marianne von Lord Welton aus d'Ambris Händen gerettet. Durch die Wahrung ihrer Tugend werden diese beiden Männer als diejenigen definiert, die Anspruch auf den Besitz Mariannes haben, zumal beide in sie verlieb sind. Lord Weltons Frage, „ob mich Marianne lieber zum Vater oder zum Gemahle haben mag" (80), wird dadurch beantwortet, daß Marianne sich als seine verlorenc Tochter herausstellt; Worthi junior wird in der letzten Szene ziemlich plötzlich mit Marianne verlobt.
Die Möglichkeit einer Verlobung wird zum ersten Mal in III, 10 angesprochen, sechs Szenen vor dem Ende des Stückes. Hier stellt Worthi junior seiner Schwester Henriette den Obristen Beaumont vor, der sich in ihr Bild verliebt hat, sie besucht, um „das Original zu sehen“ (70) und dem Original in den ersten an sie gerichteten Worten einen Antrag macht. Als Henriette Ausweichendes von Hochachtung und Freundschaft redet - verständlicherweise, denn sie sieht ihn hier zum ersten Mal -, reagiert ihr Bruder entrüstet: „Was, Schwester? nur Hochachtung und Freundschaft? Ja, heute erlaube ich dir noch, so zu reden; aber in einigen Tagen - " (70). Auf diesen brüderlichen Verweis reagiert Henriette mit dem Hinweis, auch sie habe für den Bruder "gesorgt", und er werde weniger als „Tage lang brauchen, um mehr für Mariannen als Freundschaft zu fühlen" (71). Ihre Vermutung erweist sich als richtig: sechs Szenen vorher (III, 4) sieht Worthi Marianne zum ersten Mal, sechs Szenen später (III, 16) ist er mit ihr verlobt. Mariannes Jawort wird ebenso vorausgesetzt wie Henriettes; direkt nachdem Welton sich als Mariannes Vater entpuppt, übernimmt Worthi senior die väterliche Autorität über sie und verlobt sie mit seinem Sohn, wobei er das Einverständnis seines Sohnes, seiner Frau und Lord Weltons einholt (in dieser Reihenfolge). Worthi junior bejubelt sein Glück, bittet dann um Weltons Erlaubnis und erst dann um Mariannes, bzw. er setzt sie mehr voraus, als daß er darum bittet. Marianne kennt ihn nicht und ist offensichtlich nicht von der Liebe auf den ersten Blick befallen, die ihn für sie cinnimmt; seiner Familie dagegen ist sie für den Schutz verbunden, den sie ihr gewährt. Mit dieser Verbundenheit begründet sie die Tatsache, daß sie seinen Antrag annimmt, das heißt: sie heiratet ihn nicht als Mann, sondern als Familienmitglied, sie heiratet im Grunde nicht ihn, sondern seine Familie. „Sie sind der Sohn dieser würdigen Eltern, der Bruder meiner Henriette, wie können Sie mir gleichgültig seyn?" Ih künftiges Eheglück ist kein ausschließlich auf ihn konzentriertes; im Gegenteil: die anderen Familienmitglieder treten darin ebenso prominent auf wie der künftige Ehemann. In ihren eigenen Worten will Marianne „in abwechselnden Umarmungen meiner Freunde [...] glücklich seyn" (83). Daß Marianne ihn lediglich aufgrund seine „würdigen" Familie heiratet und ihm versteckt klarmacht, daß er sie mit dieser Familie teilen muß, relativiert das Happy End ebenso wie die plötzliche Entwicklung der Liebesgeschichte überhaupt.

Marianne, ein „rührendes Lustspiel in drey Aufzügen“, ist ein fast tragisches Stück um die Zweifel an und Gefährdung von Mariannes Tugend mit künstlich aufgesetztem Komödienende in Form einer Verlobung. Daß die Autorin dieses Ende dem Stück bewußt lkünstlich aufgesetzt hat, zeigt sich im Vergleich mit ihrem zweialktigen Drama Jenny aus demselben Jahr. Jennys im Titel proklamierte Uneigennützigkeit besteht darin, daß sie zwar bereit ist, den armen Sir Henrich zu heiraten, sich aber weigert, als dieser sich als der reiche Milord d'Angby entpuppt, obwohl sie ihn liebt, und den Geliebten nur durch väterliche Vermittlung des Lord Arminster doch noch "lkriegt". D'Angbys Antrag an sie wird als Motiv des rührenden Lustspiels definiert, als er sich unter Vorspiegelung zweier falscher Tatsachen um sie bewirbt: unter einem falschen Namen und indem er ihr eine Antragsszene aus einem rührenden Lustspiel erzählt. Jenny ist ihm gegenüber im Nachteil, da sich für sie der Unterschied zwischen 
Rührstück und Realität verwischt. Die Szene, die d'Angby erzählt, kann als StandardLiebesszene der Comédie larmoyante gelten: der junge Mann erklärt dem Mädchen seine Liebe und seine Verzweiflung, das Mädchen schämt und ziert sich und verweist auf die Pflicht des väterlichen Gehorsams, er macht physische Annäherungsversuche (Ergreifen der Hand, Kuß), worauf sie ihn zurückstößt, er klagt sie der Grausamkeit an und droht mit Selbstmord, worauf sie ihm zart ihre Zuneigung andeutet, aber erneu auf die väterliche Autorität verweist. Beiderseitiges Erröten und Niederschlagen der Augen; der Liebhaber küißt ihr die Hand, die sie ihm überläßt. Bleibt noch übrig, den Vater zu fragen, der selbstverständlich in das junge Glück einwilligt (17-20). Genau dasselbe spielt sich in Telegrammkürze ab, als d'Angby der von seiner Erzählung gerührten Jenny gesteht, der Liebhaber stünde vor ihr: Jenny will fliehen, d'Angby klagt sie der Grausamkeit an, Jenny protestiert halb weinend, d'Angby macht ihr einen formellen Antrag, Jenny verweist weinend in abgehackten Satzfetzen auf den Vater und flieht, woraus d'Angby schließt, daß sie seine Liebe erwidert (20 f).

Obwohl in diesem Drama, anders als in Marianne, die Liebesgeschichte Haupthandlung des Stückes ist, wird sie hier mehr als deutlich als von den Gesetzen der Komödic vorgeschriebenes Pflichtthema ironisiert: in der Komödie wird geheiratet, und zwar auch dann, wenn - wie in Marianne - die Liebesgeschichte nichts mit dem Stück selbst zu tun hat und kurz vor Schluß noch schnell eingeschoben werden muß. Andererseits ist klar; daß die Heirat keineswegs mit dem Glück gleichzusetzen ist, das am Ende aller dieser Stücke als gerechter Lohn der Tugend beschworen wird: die Tugend, die an Marianne, Jenny und den anderen weiblichen Figuren demonstriert wird, heißt Standhaftigkeit im Unglück. Ob sie diese Standhaftigkeit in der Ehe weiter beweisen müssen, geht in der Regel aus dem Stück selbst nicht hervor.

\section{DIE BEKEHRUNG DES TYRANNEN: TITZENHOFER, BERLEPSCH, BANDEMER}

Parallel zu diesen empfindsamen Dramen, die sich auf die Darstellung weiblicher $\mathrm{Tu}$ gend konzentrieren und in denen die Liebesgeschichte allenfalls nebenher läuft, existiert eine Schauspieltradition, die die Liebesgeschichte zur Haupthandlung und die Liebenden zu Titelheld/inn/en macht. Anders als in den empfindsamen Tugend- und Moralstiicken stellen hier die Figuren, auch die weiblichen, Anspruch auf persönliches Glück: anstatt von den Eltern einfach zusammengegeben zu werden, wählen sie sich selbst ihre Partner, und zwar in der Regel gegen den Willen des Vaters. Der Vater is hier die ausschließliche Autoritätsfigur - Mütter gibt es in diesen Stücken nicht - und meist mit doppelter Autorität ausgestattet: er ist gleichzeitig König, Kaiser oder Richter. Da die väterliche und königliche bzw. exekutive Gewalt mißbraucht wird, bewegen sich diese Dramen hart an der Grenze zur Tragödie. Die Tragödie wird in allen Fällen durch eine recht plötzliche Metamorphose abgewendet: der grausame, teilweise sogar sadistische Patriarch verwandelt sich unvermutet - und völlig unbegründet - in den gütigen Vater, der die Liebenden großmütig zusammengibt.

In Sophie Eleonore von Titzenhofers (1749-1823) Lausus und Lydie, einem Ver's- drama in drei Akten, 1776 anonym veröffentlicht, scheint dieser Gegensatz am krassesten dargestellt. Lydie ist die Kriegsbeute des Königs Mezenz von Tyrrhen. Sie lieb Lausus, den Sohn des Königs, und wird von ihm wiedergeliebt, allerdings zunächst heimlich, da Lydie richtig vermutet, daß Mezenz sie ebenfalls heiraten will. Als Palmenor, Mezenz' Vertrauter, dem König die Liebe zwischen Lydie und Lausus hinterbringt, beschließt Mezenz augenblicklich, seinen Sohn zu töten, und mildert das Urteil auf Anraten Palmenors in Verbannung. Mezenz schickst Lausus mit allen Anzeichen väterlicher Huld zu dem Heer, das die Landesgrenzen bewacht. Auf Anraten und mit Hilfe Phanors, seines Freundes und Vertrauten, versteckt sich der Prinz in der Nähe, während Phanor für ihn Kundschafterdienste übernimmt. Phanor wird von Palmenor erwischt, als er Lydie einen Brief von Lausus übergeben will, und zum Tode verurteilt. Mezenz' Tyrannei zeigt sich nicht nur an der Schnelligkeit und Gefüllllosigkeit, mi der er Todesurteile fällt, sondern hier auch in einem Anfall von Sadismus: Phanors Hinrichtung, inszeniert als Arenakampf gegen einen Löwen in altrömischem Stil, soll an Mezenz' Hochzeitstag mit Lydie stattfinden und dem Volk zur Belustigung dienen. Lausus rettet Phanor, indem er sich in der Verkleidung eines Sklaven ins Gefängnis schleicht und Phanor überredet, mit ihm die Kleider zu tauschen, in der Hoffnung, daß Mezenz' Vatergefühle beim Anblick des eigenen Sohnes in der Arena erwachen würden. Obwohl diese Annahme nach allem Geschehenen sehr naiv scheint, läßt sich auch Phanor von dieser Hoffnung überreden. Unerwarteterweise erwacht die väterliche Huld tatsächlich, und zwar etappenweise: aus Rücksicht auf die Gefühle der Prinzessin zwingt Mezenz sie nicht, die Exekution mitanzusehen, und sieht auch selbst nicht zu - dieser Umstand dient gleichzeitig dazu, die Spannung zu erhöhen, da Lausus' Hoffnung auf die väterliche Begnadigung dadurch vereitelt wird. Als Mezenz von Phanor erfährt, daß Lausus in der Arena mit dem Löwen kämpft, ruft er in abgehackten Sätzen um Hilfe, die, wie sich herausstellt, unnötig ist, da Lausus allein mit dem Löwen fertig wird. In der letzten Szene begnadigt Mezenz seinen Sohn und Phanor und verheiratet Lausus und Lydie.

Während Lausus den aktiven Part zur Rettung seiner Liebe übernimmt, übt sich Lydie in passivem Widerstand. Sie ist eine Sklavin ohne den geringsten Einfluß auf ih eigenes Schicksal und kann sich Mezenz nicht einmal widersetzen, da sie ihrem Vater Gehorsam schuldet - denn der belsommt durch diese Heirat die verlorenen Ländereien zurück. Andererseits besteht sie darauf, daß die anderen Figuren zugeben, daß ihr Zwang angetan wird. Thre Sklaverei versteht sie nicht nur als ihre reale Gefangenschaft, sondern auch als die ihr aufgezwungene Ehe mit Mezenz, die sie wiederholt als „Fessel“ bezeichnet $(34,52)$. Demgegenüber stehen Palmenors Anspielungen, daß der Glanz der Krone sie bald mit ihrem Schicksal aussöhnen werde, und Mezenz' Versuche, sic mit der königlichen Macht zu ködern. In diesem Zusammenhang ergibt sich eine seh interessante Szene zwischen Lydie und Mezenz: Mezenz legt ihr eine mystische Scheinmacht (über sein Herz) bei - die einzige Macht, die der Frau allgemein zugestanden wird -; Lydie dagegen macht ihm unmißverständlich klar; daß diese Scheinmach keine reale Macht darstellt und zu ihrer Unterdrückung beiträgt ( $45 \mathrm{f}$ ). Das heißt: Mezenz versucht, seine Gewalttaten ihr gegenüber dadurch zu mildern, daß er sie zur 
mystischen Überwinderin stilisiert; Lydie dagegen besteht auf ihrem Skllavenstand, weil sie nur dadurch verdeutlichen kann, daß ihr Gewalt angetan wird. Daß ihr die politischen Machtverhältnisse klar sind, drückt sie allein durch ihre Benennung ihrer selbst sche Mönigs aus: ihre häufigste Umschreibung für sich selbst ist „Sklavin“ $(6,35$, 45, 49, 54), Mezenz bezeichnet sie in der Regel als "Tyrann" $(32,36,53 \mathrm{f})$ bzw. „Barbar" $^{\prime \prime}(53 \mathrm{f})$.

Die plötzliche Bekehrung des Tyrannen zum gütigen Landesvater am Ende hat ihre Begründung weniger in Mezenz' plötzlich erwachter Vaterliebe als in einem Umschwung politischer Macht. Denn Lausus' erfolgreicher Kampf mit dem Löwen macht ihn auch in Mezenz' Augen zum „Sieger" (76); gleichzeitig verlicrt Mezenz an politischer Macht, da das Volk auf Lausus' Seite steht: wie Physokrates berichtet, „[...] wapnen Tausende zu Lausus Rettung sich" (75). Lausus läßt Mezenz die Möglichkeit, die Rolle des gütigen Vaters zu spielen, indem er sich seinem Urteil unterwirft, d. h., er 作 gesteht Mezenz eine Macht zu, die er tatsachlich bereits nicht meer hat Mezenz reagiert darauf mit Begnadigung, väterlichem Segen und Einsicht: sein Loblied der Tugend macht ihn erneut zum Vorbild der Kinder (Lausus und Lydie), die das Gesagte lediglich wiederholen und sich so als zukünftige (gütige) Landeseltern etablieren.

Emilie von Berlepsch (1755-1830) behandelt in Eginhard und Emma (1787) dassel-

be Thema: Karl der Große will seine Tochter Emma an den von ihm besiegten Tassilo verheiraten, um die Versöhnung zu vervollkommnen; Emma dagegen liebt Eginhard, Karls Schreiber: Da Emma, wie Lydie, nicht gefragt, sondern lediglich informiert wird, empfindet auch sie die Ehe als „Slklaverey [...] am Hochaltar" (Sammlung kleiner Schriften 174). Anders als Lydie hält sie den Gehorsam dem Vater gegenüber nicht für eine Pflicht, sondern will Eginhard heimlich heiraten und schmiedet mit ihm Fluchtpläne, falls der Vater die Einwilligung nachträglich versagt. Vor die Alternative gestellt, „Entlaufene" (185) oder "Sclavin" (186) zu sein, entscheidet sie sich für die Flucht, und das ohne jedes Anzeichen von Reue. Emma hofft zwar auf die (nachträgliche) väterliche ohne jedes Anzeichen von Reue. Emma hofft zwedings klar, daß sie zu ihrem gemeinsamen Glück nicht eben nötig ist. Obwohl Emma auf Eginhards Schutz vor dem tyrannischen Vater baut ( sey der Retter der Tochter; wenn er [der Vater, S. K.], von Stolz verblendet, ihr Mörder, ihr Tyrann seyn will“, 187), ist sie es, die im Notfall die rettende Idee hat. Als Eginhard Emmas Zimmer nicht unbemerkt verlassen kann, da gerade frischer Schnee gefallen ist, sieht er den Selbstmord als einzige Möglichleit, gerade fischer Schnec gefal ist, such (191). Sie dagegen, weniger um ihre Ehre be Emmas „jungfräuliche Ehre“ zu retten (191). Sie dagegen, weniger um the be sorgt als er und nicht geneigt, so leicht aufzugeben, trägt ihn auf ihrem Rücken übe den Schloßhof, so daß nur ihre Fußspuren sichtbar sind.

Unglückllicherweise wird sie dabei von Karl beobachtet. Karl hält daraufhin einen langen Monolog, in dem er die verschiedenen Möglichkeiten als Vater und Landesvater, die im Falle Mezenz' ausgespielt werden, theoretisch durchexerziert. Zunächs ver Tassilo mit Gründen der Staatsraison. In zwei Sätzen sorgt er sich um Emmas Schick- [... w wenn Emma ihn haßte? wenn dieses Bündniß die Pein ihres Lebens wäre (195 f) schlägt sich aber derartige "Grillen und Sorgen" (196) schnell aus dem Kopf
An dieser Stelle entdeckt er Emma, die Eginhard über den Schloßhof trägt, und bedenkt seine Tochter mit sämtlichen Ausdrücken, die enttäuschte Väter, Liebhaber und Ehemänner den Frauen in solchen Fällen beizulegen pflegen: „[...] schändliche Heuchlerin! Verworfene! [...] Die Heilige, die Reine! das Mädchen mit dem Engelblick!“ (197) Von da bis zum Beschluß, beide hinrichten zu lassen, ist nur ein kleiner Schritt (198). Glücklicherweise fällt direkt nach diesem Entschluß sein Blick auf das Kruzifix, das ihn an seine Pflichten als Christ und Vater erinnert. Der Beschluß, die Liebenden zu begnadigen, folgt auf dem Fuße, zumal Karl sich an seine verstorbene Frau erinnert, die er ebenfalls gegen den Willen ihres Vaters entführen mußte (200).

Diese Begnadigung kann allerdings nicht über die Bühne gehen, ohne daß Karl den Kindern eine Lektion erteilt. Karl demonstriert seine Macht, indem er Eginhard vor die Wahl stellt, zu sterben oder eine Verschleierte zu heiraten; Eginhard weigert sich standhaft; Karl entschleiert die Unbekannte (Emma), und nimmt den überschwenglichen Dank der Kinder entgegen. Aber Karls Güte, die von den Kindern mit den entsprechenden Bildern belegt wird - Eginhard: „Edelster, großmüthigster Mann! mein Fürst, mein Retter"; Emma: „O, mein Vater! [...] der Gottheit Bild auf Erden“ (210) -, ist ebensowenig wie Mezenz' Großmut ganz in seinem Charakter. Denn dieser großmütige Fürst war nach eigener Aussage nahe daran, zum Tyrannen zu werden, und verzeiht den Liebenden nur deshalb, weil er im Grunde - trotz aller Racheschwüre - mit Emmas Wahl einverstanden ist. „Ich schwur euch Tod und Verderben - [...] Dein Herz hat edel gewählt, meine Tochter. Hättest Du einem schwachherzigen Buben Dich hingegeben, nie hätte Dein Vater Dir verziehn" (211). Im Grunde genommen geht es also nach wie vor nicht um Emmas Wahl, sondern um Karls, und die Liebenden haben bei dieser zufälligen Übereinstimmung lediglich Glück gehabt.

Susanne von Bandemers (1751-1828) Dreiakter Sidney und Eduard, oder Was vermag die Liebe? (1792) spielt auf sozial niedrigerer Ebene: der grausame Vater ist nicht König, sondern Friedensrichter in London; die Strafe für die ungehorsamen Kinder besteht nicht in der Todesstrafe, sondern in Verstoßung und Enterbung. Sir Georg Woodberry hat nicht nur seinen Sohn Eduard für die unerlaubte Heirat mit Sidney verstoßen, sondern will auch seine Tochter Fanny zwingen, den alten geizigen Sir Gilbon zu heiraten, obwohl sie in Sir Robert verliebt ist. Während Fanny und Sir Robert die Flucht und heimliche Heirat planen - denn auch hier ist die "Selbsterhaltung" (14) eine stärkere Pflicht als Gehorsam dem Vater gegenüber -, leben Sidney und Eduard in größter Armut, „verstoßen von beiden Vätern" (21). Sir Robert adressiert einen an Fanny gerichteten Liebesbrief an Sidney, um eine Entdeckung zu verhindern; der Brief fällt in Eduards Hände, und Eduard, von Sidneys Untreue überzeugt, faßt sofort den Entschluß, Sir Robert (im Duell) und Sidney (durch Gift) zu töten. Sir Robert wird im Duell nur verwundet; Sidney überlebt den Anschlag ihres Mannes, weil der Apotheker; den Eduard um Gift bittet, Verdacht schöpft, und ihm statt Gift ein harmloses Pulver verkauft. Eduard wird für seine Taten vor Gericht gestellt; der Richter ist sein Vater. Wie Mezenz und Karl wird auch Sir Woodberry in dem Augenblick schwach, als er das Todesurteil seines Kindes sprechen soll, und wandelt sich zum reuigen Vater, der ohne jede Überredungskunst seine Verirrungen zugibt (85 f), Sidney als Schwieger- 
tochter alszeptiert und Fanny und Sir Robert zusammengibt (88 f), um künftig derartigen Katastrophen vorzubeugen. Die Reue Sir Woodberrys wird ausführlicher geschildert als die Mezenz' oder Karls - er bezeichnet sich selbst als „Tyrann Eurer aller Neigurtgen" (90) und bittet seine Kinder wiederholt um Verzeihung. Gleichzeitig wird er fast ausschließlich durch diese Reue charalkterisiert, da er als reuevoller Vater die Bühne betritt: seine vorherige Grausamkeit wird lediglich berichtet. Der Vater geht sogar soweit, den Ungehorsam der Kinder nachträglich zu rechtfertigen, denn „wenn ein Vater sich gegen sein eigenes Gefühl empöret, o dann ist es kein Wunder, wenn alle Welt sich gegen ihn verbindet" (92). Das Stiick schließt mit einer moralisierenden Warnung vor allzugroßer väterlicher Strenge - einem Appell an alle Tyrannen also.

Fanny und Sidney, die weiblichen Protagonisten, sind eine seltsame Mischung aus Gehorsam und Widerstand: der Widerstand richtet sich in beiden Fällen gegen den Vater, der Gehorsam gilt bei beiden dem Mann bzw. Verlobten. Fanny, die, wie gesagt, nach den Gesetzen der Selbsterhaltung handelt, plant mit Sir Robert die Flucht auf sein Betreiben hin; Sidneys Verhalten Eduard gegenüber ist von wahrhaft blindem Gehorsam gekennzeichnet: als Eduard ihr den vermeintlichen Giftbecher reicht, trinkt sie 政 trotz ihres vagen Verdachtes, denn "Von der (61). Während in den empfindsamen Schauspielen der weibliche Gehorsam dem Vate gegenïber strikt eingehalten werden muß, weil diese Unterwerfung unter das väterliche Gebot dem kiunftigen Ehemann eine folgsame Frau garantiert, basiert hier Gehorsam oder Widerstand auf dem eigenen Willen - wie Eduard feststellt, gehorcht man den Befehlen, die den eigenen Wünschen entsprechen, am liebsten (21 f). So mann sam berufen: sobald er glaubt, sich in ihr geirrt zu haben, vertauscht er seine Rolle als Ehemann mit der des gehorsamen Sohnes. „Weib! nicht dein Erwählter sprach: das, sondern Georg Woodberrys Sohn. - Fluch, dem Tage, an welchem ich durch meinen Ungehom aüdig zu seyn! - Nun bin ich ihm wieder gegeben " Ungehorsam aufhörte, seiner wirdig zu s (46 f). Ebenso führt Sidney Eduards ihr unerklärliches Verhalten auf den Fluch ihre Vaters zurück (47 f). Allerdings ist hier Sidney, die auf der Treue zu ihrem Mann und ergo im Ungehorsam beharrt, das Identifikationsmodell; und wie am Ende vom Vater selbst festgestellt wird, ist dieser Widerstand gegen die väterliche Gewalt durchaus vertretbar (92). Der Gehorsam, den ein Vater fordern darf, ist also - sehr im Gegensatz zu den empfindsmen Stiicken - kein unbedingter, sondern kann in Extremfällen verweigert werden.

Diese neue Relativierung der unbedingten kindlichen Gehorsamspflicht bedeute ine Einshränkung der väterlichen Macht, obwohl nach wie vor in keinem diese en Stücke das glückliche Ende ohne väterlichen Segen mach ist. Der Tyrann, dessen Grausamkeit die Ursache für die (Fast-)Tragödie ist, muß bekehrt werden und verhält sich gegen Ende des Stückes unbegründeterweise äußerst großmütig, wofür er von den lïck Kindern vor allem mit der erneuten Anerkennung seiner väterlichen Autoglücklichen Kindern vor allem mit der enteuten Anekennung sein vaterich rität belohnt wird. Das künftige Ehegliick muß nach wie vor durch Unwahrscheinlichkeiten und Zufälle herbeigeführt werden: daß sich die väterliche Autorität nach den Neigungen der Kinder richten muß, ist schon an sich wenig wahrscheinlich; die
Darstellung der plötzlichen väterlichen Großmut betont die Unglaubwürdigkeit eher, als daß sie sie kaschiert.

Von der Aufllärung bis zur Jahrhundertwende durchläuft die Behandlung des Themas Ehe und Liebe verschiedene Stadien: zunächst hat die Frau die Freiheit, nich heiraten zu müssen; später muß sie ihre Tugend unter Beweis stellen und existiert pralstisch nur noch als Sinnbild der Tugend, kann also auch widerspruchslos an den (nächst-)besten Freier vergeben werden; schließlich stellt sie Ansprüche auf freie Wahl des Partners. Wo die väterliche Autorität nicht existiert, kann das verschiedene Konsequenzen haben: Gottscheds weiblichen Figuren gibt ihre Vaterlosigkeit einen gewissen Handlungsspielraum; in den empfindsamen Stücken bedeutet die Vaterlosigkei Schutzlosigkeit dem Verführer der Tugend gegenüber, und später wird die Vaterrolle häufig pro forma von einem der anwesenden Herren übernommen, damit die Tochter an einen Freier vergeben werden lkann. Wo Väter auftreten, ist ihre Rolle überall dicselbe: der Vater ist der Zerstörer des Glückes seiner Kinder; bringt das Stück an den Rand der Katastrophe und gibt in der letzten Szene urplötzlich nach.

Allen Stücken gemeinsam ist das Thema der Zwangsehe oder Vergewaltigung in anderer Form (durch Entführung), das auch im 19. Jahrhundert eins der großen Themen der Komödie und des Schauspiels bleibt, und die teilweise offensichtliche Widersprüchlichkeit des glücklichen Endes, sooft es durch eine Heirat ausgedrückt wird. Gottsched steuert das Happy End via Heirat meist gar nicht erst an: im Gegenteil verhindert sie Ehen (Die ungleiche Heirath), verschafft ihren Figuren finanzielle Unabhängigkeit (Das Testament) oder gibt ihnen ausgiebigst Gelegenheit, sich über die Anwärter auf ihre Hand lustig zu machen (Der Witzling). In vielen empfindsamen Stücken hat das Heiratsmotiv mit dem Stück selbst nichts zu tun; die Möglichkeit einer Verlobung oder Eheschließung wird meistens erst in der letzten Szene des Stückes angesprochen und dient dazu, eine Tugend zu „belohnen“, die als Standhaftigkeit im Unglück definiert wird. Dementsprechend stellt die Personifizierung dieser Tugend auch in der letzten Szene keine Ansprüche und äußert sich kaum zu ihrem Glück: sie „erträgt" es wic vorher alle Nachstellungen und Verleumdungen. Wo die Heirat tatsächlich das Happy End des Stückes ausmacht, erfolgt sie mit Hilfe einer Umkehrung der Weltordnung: der Wille der Liebenden richtet sich gegen den der väterlichen Gewalt, und der Stärkere gibt nach.

\section{B. Gebildete Frauen und Kobolde: Ehegeschichten bis 1850}

Im 18. Jahrhundert ist die dramatische Produlttion von Frauen sehr verstreut: die Mehrzahl der Dramatikerinnen veröffentlichten nur wenige Stücke; wieviele sie schrieben, ist heute kaum noch feststellbar. Jedenfalls scheint es kaum einer Frau gelungen zu sein, aus ihrer dramatischen Produlktion eine Profession zu machen. Das neunzehnte Jahrhundert dagegen hat drei Dramatikerinnen aufzuweisen, die nicht nur außerordentlich viel produziert haben, sondern deren Stücke auch enorm erfolgreich waren: Johanna Franul von Weißenthurn, Amalie von Sachsen und Charlotte Birch-Pfeiffes: 
Thre Stïcke beherrschten das Theaterrepertoire an den meisten Bühnen Deutschlands über Jahrzehnte hinweg; von allen gab es Gesamtausgaben noch zu Lebzeiten. Während Amalies soziale Stellung es ihr erlaubte, aus Liebhaberei zu schreiben, mußten Franul von Weißenthurn und Birch-Pfeiffer, die gleichzeitig Schauspielerinnen waren, von ihren Dramen leben, d. h. sie versuchten, ihre Stücke vor dem Druck so oft wie möglich aufführen zu lassen. Ihre umfangreiche dramatische Produlstion (im Falle Franul von Weißenthurn ca. 60, im Falle Amalie 85, im Falle Birch-Pfeiffer um 100 Stücke) besteht daher hauptsächlich aus Komödien und Schauspielen - laut Laube die populärsten Genres auf dem Theater -, die alle deutlich mit dem Gedanken an di Aufführung geschrieben sind: sie verlangen wenig Ausstattung und Requisiten und im Falle Franul yon Weißenthurn und Amalie wenige Darsteller. Die meisten ihrer Stücke sind Familienstücke, eins der großen Genres des Biedermeiertheaters.

Die Stücke dieser Autorinnen in eine literarische Richtung - Biedermeier oder Vormärz - „einordnen" zu wollen, hat wenig Sinn: der Biedermeierkomödie, die "vergnüglich“ die Weltordnung aufrechterhält und der lediglich „Einzelne satirische Ausfälle [...] erlaubt" sind (Sengle, Biedermeierzeit II, 407), passen sie sich nur der Form nach an; politische Tendenz- und Oppositionsstücke gibt es von Frauen überhaupt nicht. Wenn man den formellen und thematischen Ähnlichkeiten dieser Stücke mit der Biedermeierkomödie nachgeht, stößt man auf Ungereimtheiten. Denn das „Biedermeier, das an eine väterliche Ordnung Gottes glaubt“, in dem „die glücklichen Wendungen des Lustspiels symbolisch die Liebesordnung [offenbaren], die der Welt Wendungen des Lustspiels symbolisch die Liebesordnung loffenbaren], die der Welt mejerzeit II, $406 \mathrm{f}$ ), existiert in Stücken von Frauen nicht widerspruchslos. Was ihre Stücke charalkterisiert, ist mehr als vereinzelte satirische Ausfälle: hier steckt der Widerspruch oft bereits im Ansatz.

1. NUR EINE KOMÖDIE:

JOHANNA FRANUL VON WEISSENTHURN

Bei Johanna Franul von Weißenthurn (1772-1847) scheint dieser Widerspruch besonders ausgeprägt, weil er sich durch ihr gesamtes Werk zicht. In Stücken, in denen sic die Figur eines Landesvaters direkt auf die Bühne bringt (Künstler-Dank, 1815; Johann, Herzog von Finnland 1810; Die Schweitzerbütte am Rheinfall, 1813; Totila, König de Gothen, 1804; Unterthanenliebe, o. J.; Der Wald bey Herrmannstadt, 1807), erhält sie die absolute Macht des Königs als Stellvertreter Gottes auf Erden geradezu ostentativ aufrecht. In ihren Familiendramen allerdings (Das Nachspiel, 1800; Der Reukauf, 1802, Die Erben, 1803; Das Frühstück, 1810; u. v. a.), in denen die „väterliche Ordnung Gottes" durch den Familienvater charakterisiert wird, wird diese Autorität oft unterwandert - und zwar weder thematisch noch in der Charalsterisierung der guitigen Vaterfigur, sondern in der Form. Anders als in den vorrevolutionären Stücken des 18. Jahrhunderts sind hier die Vaterfiguren präsent und wohlwollend; das Liebesglück des Paares am Ende ist vollkommen und muß weder erzwungen noch durch Unwahrscheinlichleeiten herbeizitiert werden. Im Gegenteil: oft brauchen die Liebenden den gütigen Vater nur um ihr Glück zu bitten; das ganze Problem der Komödie besteht in dem mangelnden Vertrauen der Liebenden zum Vater. Aber davor, diese heile Welt der Komödie mit der Welt außerhalb des Theaters zu identifizieren, warnt sie, indem sie ihre Komödien unmißverständlich als Komödien definiert: innerhalb ihrer Stücke findet in der Regel eine Komödie statt, meist von der väterlichen Autorität inszeniert; und nur durch diese Komödie innerhalb des Lustspiels kann das glückliche Ende zustandekommen. Der gütige Vater in ihren Stücken ist selbst cin Komödiant, das glückliche Ende - dic Aufrechterhaltung der Liebesordnung - ist nur gespiclt; das Ganze ist letztendlich doch „nur" eine Komödie.

Franul von Weißenthurns Einakter Das Nachspiel (1800) spielt in einem Schriftstellerhaushalt: Baron Berg schreibt regelmäßige Stücke nach Johann Christoph Gottscheds Regeln, seine Nichte Leonore - seiner Ansicht nach - schlechte Verse. Leonore ist in den Baron Willburg verliebt, der ebenfalls Theaterschriftsteller ist und dessen Stück am Abend aufgeführt wird. Während Berg die Aufführung besucht, unterhält sich Leonore mit dem Autor des Stückes am Fenster. Berg kommt sehr erregt zurück und sagt Mißverständliches, aus dem Leonore schließt, daß ihre Liebe entdeckt ist bis sich herausstellt, daß Berg lediglich Willburgs Komödie beschreibt. Gleich darauf spielt Leonore ihrem Onkel eine vor, indem sie vorgibt, sich nicht an Willburg zu erinnern, bis sie feststellt, daß Berg eine hohe Meinung von Willburg hegt, und in dessen Lobeshymnen über ihn einstimmt. Bergs Mißtrauen über ihr plötzliches Erinnerungsvermögen verstärkt sich noch, als er einen Brief von Willburg erhält, in dem dieser ihn um eine Unterredung bittet, da sie beide an ähnlichen „Plänen" arbeiten - unausgesprochen impliziert sind Pläne zu einer Komödic. Daß Willburg dabei von seinen Plänen im Bezug auf Leonore spricht, ist Berg vollkommen klar: „[...] kommen Sie nur mein Herr Autor, weil Sie mich für einen Komödienonkel halten; ich will mitspielen und Sie sollen erfahren, ob es eine so leichte Sache ist, mein Neffe zu werden" (Schauspiele II, 188).

Der Onkel ist selbstverständlich der, der das nun folgende Stück inszeniert: er erzählt Willburg von seinem "Plan“ zu einem einalstigen Lustspiel, „nur ein Nachspiel“ (190), mit demselben Personenverzeichnis wie Franul von Weißenthurns Nachspiel „Ein Vormund, seine Mündel und der Liebhaber der Mündel“ (191), und natürlich derselben Handlung: der Liebhaber "sucht Zutritt bey seiner Schönen - kömmt in Haus" (191). Zunächst werden die Entwicklungsmöglichkeiten des Stückes theoretisch diskutiert - Willburg ist „sehr für die geheime Unterredung" zwischen Liebhaber und Mündel, Berg hält es für „,besser, daß der junge Mensch unter den Augen des Vormunds handle" (192); dann entschließt man sich, das Stück zu spielen. Leonore wird hinzugezogen; die Rollen werden verteilt und definiert: Willburg „scheint es ganz und gar nicht nöthig, daß das Fräulein viel spreche. Dieß überlassen wir dem Liebhaber" (196). Leonore ist dementsprechend in der Aussprache mit dem Liebhaber ganz Sittsamkeit und gehorsame Nichte: sie weiß, wie sie ihre Rolle zu spielen hat. „Nicht wahr, lieber Onkel! ich muß schüchtern, verlegen seyn, und das ist, glaube ich, Alles, was meine Rolle fordert?" (198) Das Stück läuft nach belkanntem Muster ab - Liebeserklärung, Entdeckung durch den Onkel - bis zu Willburgs Schluß, in dem das Paar die 
Verzeihung des Onkels erhält und von ihm vereinigt wird. In Bergs Version dagegen fordert die "Moral" des Stückes eine Standpauke des Onkels an die Liebenden, in der der Vormund perfekt die Rolle der hintergangenen väterlichen Autorität spielt. Leonore und Willburg wollen nach verschiedenen Seiten fliehen, in der festen Úberzeugung, die Komödie sei vorbei, werden aber von Berg zurückgehalten: „Wartet! es folgt noch ein Auftritt. [...] Du mußt weinen, bitten. - Sie müssen verzweifeln; immer in den Hauptsituationen happerts bey euch" (203). Nachdem das Paar auch diesen Tribut an die väterliche Autorität noch abgetragen hat, werden sie endlich von dem Onkel zusammengegeben.

Daß der Onkel in dieser Aufführung von Anfang bis Ende das Heft in der Hand hat, wird nirgends bezweifelt, denn als väterliche Autorität ist er der Autor des Stückes. hat, wird nirgends bezweifelt, denn als väterliche Autortät ist er der Autor des Stuckes. spielt: die des schüchternen und verlegenen Fräuleins, das nicht viel zu sagen hat und sehr an die tugendhaften Frauenfiguren der Komödie des 18. Jahrhunderts erinnert. In "Wirklichkeit" dagegen - in der Wirklichkeit der Rahmenkomödie - ist Leonore weder schüchtern noch verlegen, wie sich in der ersten Szene mit dem Onkel zeigt, in dem sie ihm ungefragt Ratschläge für sein Drama gibt. Während sie im Possenspiel des Onkels, eingedenk ihrer Rolle, kaum etwas sagt, kann sie sonst durchaus den Mund aufmachen: von der Unterhaltung zwischen ihr und Willburg am Fenster hört der Zuschauer ausschließlich ihren Part; was der Liebhaber, dem sie - in ihrer Rolle als schüchternes Fräulein - das Reden überlassen soll, sagt, kann man nur aus ihren Antworten schließen (181-3). Die Tugend, die sie in der Komödie ihres Onkels mimt, ist in der Rahmenkomödie ersetzt durch Verstand: wie ihr Onkel ist sie Schriftstellerin, ihre hauptsächliche Beschäftigung ist die mit Büchern und der Theaterbesuch (180 f). Der Onkel selbst hält die literarische Beschäftigung von Frauen für eine Tugend und ärgert sich noch, daß Leonore „so wenig Geschmack für alles Wissenschaftliche hat (175). Während Leonores Rolle in der Rahmenkomödie sich von der in der Komödie ihres Onkels beträchtlich unterscheidet, bleibt die Rolle des Onkels in beiden Fällen gleich - und selbstverständlich auch der glücllliche Ausgang, der von der Komödie des Onkels in die Rahmenkomödie hinübergespielt wird.

In Der Reukauf, Lustspiel in zwei Alkten (1802), soll Henriette von ihrem Vater an Baron Hügel zwangsverheiratet werden, obwohl sie Wallen, einen Freund der Familie, heimlich liebt. Der Vater, Baron Hochberg, baut dabei auf den Gehorsam seiner Tochter, da sie „immer ein gutes Kind“ war (Schauspiele I, 178). Sowohl Henriette als auch Wallen, der Henriette ebenfalls liebt, fühlen sich aus Pflichtgefühlen Hochberg gegenüber außerstande, ihm ihre Liebe zu gestehen oder die väterlichen Pläne in irgendeiner Weise zu hintertreiben. Âmalie dagegen, die Nichte Hochbergs, als „kleiner Wildfang charakterisiert (179), ist von keinen derartigen Skrupeln geplagt; sie fädelt eine Komödie ein, in der die Heirat zwischen Henriette und Hügel verhindert werden und deren Ende die Liebesordnung wiederherstellen soll. Wie sie selbst dabei andeutet, usurpiert sie hier die väterliche Autorität: „Der Vater will, Henriette soll Hügels Frau werden, und meine Hoheit, sie soll Frau v. Wallen werden" (190). Daher wird es für sie nötig, „die Intrigue zu leiten. Geschwind also die handelnden Personen aufgesucht! [...] da kommt die Hauptperson mir entgegen" (191). Dieser Hauptperson, Henriette, redet sie zu, aus der weiblichen Rolle zu fallen: Henriette soll Wallen ihre Liebe erklären. Da diese aber die „Achtung [...], die ich meinem Geschlecht schuldig bin“ (193), nur soweit vergessen kann, ihm ihre Liebe zart anzudeuten, besinnt auch Wallen sich auf seine „Pflicht" (200) und entsagt. Als Henriette sich als letztes Mittel endlich ihrem Vater anvertraut, erklärt ihr dieser, sein Plan, sie mit Hügel zu verheiraten, sei nur eine Komödie - nicht ohne sie vier Seiten lang zappeln, bitten und flehen zu lassen (201-5).

Dieses „Possenspiel“ (205) hat er eingefädelt, um „dich und ihn zu zwingen, mich zu eurem Vertrauten zu machen" (207) - ihr Vertrauen hat er nun, aber das Wallens muß noch erzwungen werden. Er legt Henriette also strengstes Stillschweigen auf und macht sie zu einer Figur in seinem Stück: sie soll die unglücklich Verlobte weiterspielen, bis Wallen sich endlich erklärt. Mittlerweile spielt Amalie, die von alledem natürlich nichts weiß, ihre eigene Komödie weiter: als Hügel auftaucht, spielt sie ihm verschleiert eine reiche Gräfin vor, die rasend in ihn verliebt ist und ihn zu sofortiger Flucht überreden will. Hügel, der auf eine reiche Partie aus ist, ist nicht abgeneigt; aber die Flucht wird durch das Auftreten Hochbergs, Wallens und Henriettes verhindert. Amalie kann aus Furcht, daß Hochberg ihre Stimme erkennen könnte, nicht laut sprechen, und sagt Hügel das Nötige vor, der ihr getreulich nachspricht. Die Schauspielerin Amalie fungiert hier also gleichzeitig als Souffleuse und als Autorin der Komödic, denn Amalies Worte in Hügels Mund bringen die Auflösung des Stückes: Hügel erklärt die Anwesenheit der unbekannten Dame, legt Wallen das langersehnte Liebesgeständnis in den Mund und entsagt seinen Ansprüchen auf Henriettes Hand. Alles, was Wallen zu tun bleibt, ist, seine Liebe zu Henriette nicht abzustreiten, und der Vater kann die beiden endlich miteinander verloben.

Falls die Zuschauerin trotz allem Spiel im Spiel vergessen hat, daß es sich bei diesem glücklichen Ende letztendlich doch nur um ein Komödienende handelt, wird sie in der letzten Szene daran erinnert: Hochberg und Amalie streiten sich um die Frage, wessen Komödie das gute Ende herbeigefühıt hat - Amalies „Intrigue“ oder das väterliche „Possenspiel“. Amalies Behauptung: „[...] - ich hab’ Ihr ganzes Project ïber den Haufen gestürzt" wird von Hochberg zwar laut zugegeben, Amalie gegenüber aber abgestritten: „Es ist wahr. (leise) Du hast dich umsonst bemüht; denn es war nie mein Ernst, ihm meine Tochter zu geben“ (234). Dafür usurpiert Amalies „Hoheit“ wenig später erneut die väterliche Autorität: sie übernimmt die Rolle des Vaters, und zwar ausgerechnet in der Paradeszene des gütigen Vaters im Kreise der glücklichen Kinder. Denn Amalie, nicht der Vater, legt laut Bühnenanweisung „tragisch [sic!] Henriettens Hand in Wallens seine“ und übernimmt die dazugehörige väterliche Rede: „Kinder! der Himmel segne euch! seyd glücklich!" (235)

Ähnlich wie Leonore können Henriette und Amalie als Auseinandersetzung mit den tugendhaften Frauengestalten der Komödien des 18. Jahrhunderts gesehen werden: Henriette ist „gebildeter als andere Mädchen in ihrem Alter, auch bey der sorgfältigsten Erziehung zu seyn pflegen" (176); wie bei Leonore ersetzt hier also der Verstand die Tugend. Daß Henriette sich vieles von der tugendhaften Frauenrolle bewahrt hat man erinnere sich an Leonores Definition im Nachspiel: Schüchternheit, Verlegenheit, 
Schweigsamkeit -, würde sie um ihr Glück bringen, wenn ihr Vater der wäre, den er spielt. An der Stelle, in der das väterliche Possenspiel fast in eine Tragödie umschlägt, erfolgt bei inr die entsprechende Einsicht, nämlich die, „daß ich selbst an meinem Unglück Schuld bin" (203). Amalie wäre das eindeutig nicht passiert: während Henriette das Stück damit verbringt, zu gehorchen - erst der vermeintlichen Pflicht, dann dem Vater -, betätigt sich Amalie, wie der Vater, als Autorin, und übernimmt verschiedem dentlich seine Rolle. Das kann sie sich auch entuben, denn obwohl sie und Hochberg verschiedene Stücke schreiben, ist das vorgesehene Happy End in beiden Fällen dasselbe - die Verlobung zwischen Henriette und Wallen. Die Autorität des Vaters als Aut weil Amalies Intrige überflüssig ist, wie er behauptet, sondern deshalb, weil er auch in der Rahmenkomödie die väterliche Autorität spielt - die einzige Figur also, die das Happy End herbeiführen darf, auch wenn Amalie diese Rolle ebenfalls gern spielt.

Figuren wie Leonore, Amalie und Henriette leiten einen Trend ein, der sich durch Ten Zweifel an der traditionellen Frauenrolle. Die Tugenden der Passivität und Nachgiebigkeit, die die Frauen der Komödie des 18. Jahrhunderts charakterisieren, werden hier als teilweise gefährlich dargestellt; die neuen Tugenden der Frau heißen Verstand, Wissen, Ausbildung. Julie, die Heldin in Franu von Weißenthurns Die Erben (1803), ist intelligent, gut erzogen, und widersetzt sich den väterlichen Plänen nachdrücklich. Nicht einmal Schönheit ist mehr eine unentbehrliche Qualität der Frau: August, der sich in Julie verliebt, schwärmt seinem Freund Withen gegenüber weder von ihrer Schönheit noch von ihrer Tugend, sondern von ihrem Verstand Dabei benutzen beide genau dasselbe Vokabular, das die Helden des 18. Jahrhunderts für Schönheit und Tugend reservierten: was fruher die Trau in ein halb mystisches Wesen verwandelte, das sich in höheren Sphären bewegte, verwandel sich jetzt in direkte Anspielungen auf ihr Wissen.

August. [...] Withen - war das eine Erscheinung, oder ein körperliches Wesen? WITHEN Ich halte es für ein körperliches, aber doch dabey sehr geistiges Wesen. August. Withen - das Mädchen ist ein Engel!

WITHEN. Das find ich auch, sie lebt in höheren Sphären.

August, Bey so viel Weiblichkeit - so viel Verstand. [...] So viel Anmuth. - Sie is eben keine Schönheit.

WITHEN. Nein, das ist sie nicht.

August. Aber sie ist so einnehmend - sie hat -

WITHEN. Dich eingenommen (Schauspiele III, 58).

Diese verständigeren (und selbständigeren) Frauen unterwerfen sich der väterlichen Autorität nicht mehr unbedingt. Julie z. B. macht ihrem Vater klar, sie sei „bereit, in allen billigen Dingen den Befehlen meines Vaters zu folgen, mit Aufopferung zu folgen - aber diese Befehle müssen nicht ihn und mich erniedrigen" (35). Wo die väterliche Autorität mißbraucht wird - thematisch heißt das meist: Zwang zur Heirat -, wird dieser Machtmißbrauch anders dargestellt als im 18. Jahrhundert: damals sprach die
Tochter von ihrer Pflicht (des Gehorsams), jetzt spricht der Vater von Zwang, in eine Weise, die auf den Zuschauer, und insbesondere auf die Zuschauerin, empörend wirken soll. So Julies Vater Henning: „[...] haben muß sie ihn, wenn er sie will - das ist der Haken, wenn er sie will; denn sie muß, so wahr ich Henning heiße" (37).

So spricht kein gütiger (Landes-)Vater, mit dessen Figur sich dic allgütige göttliche Ordnung demonstrieren ließe. Henning ist auch in der Tat ein Usurpator, der das ihm anvertraute gräfliche Gut eigennützig verwaltet und auch als Familienvater seine Macht mißbraucht. Der wahre (Landes-) Vater, Graf Bihlen, taucht in der Maske eine Pächters auf und stellt in einer Doppelkomödie die Ordnung wieder her: der vermeintliche Pächter wird von Henning dazu uberredet, den Grafen zu spielen - der Graf spielt also einen Pächter, der seinerseits den Grafen darstellt; die Komödie des rechtmäßigen Besitzers findet innerhalb der des Usurpators statt. Selbstverständlich entthront der Landesvater am Ende den Usurpator und verheiratet dessen Tochter Julie an den Richtigen, d. h. er übernimmt auch seine Autorität als Familienvater.

Was die Väter als Vertreter der göttlichen Ordnung angeht, ist die politische Implikation die der Biedermeierkomödie, nämlich die, daß nur der gütige Landesvater von seinen Kindern bzw. Untertanen Gehorsam erwarten darf. Damit die göttliche Ordnung aufrechterhalten werden kann, muß der Vater also ein gütiger sein und darf den Tyrannen allenfalls spielen. Allerdings bleibt die Frage offen, wie ernst man die väterliche Ordnung Gottes als politische Aussage nehmen kann, wenn sie von einem Komödienonkel gespielt wird, und wie glaubhaft ein gespieltes Happy End, das unversehens zu dem des Stückes selbst wird, scheinen soll. Die Frauenfiguren dagegen müssen zwar wegen der letztendlich doch gütigen göttlichen Ordnung ihre neue Selbständigkeit noch nicht unter Beweis stellen und dürfen weiter gehorchen, aber sie fangen an, sich von den weiblichen Tugenden der Passivität und der unbedingten Gehorsamspflicht zu emanzipieren, und spielen diese Rolle nur noch, wo nötig - meist in der vom Vater inszenierten Komödie. In diesen Komödien bleibt natürlich alles beim Alten, da die Rollen vorgeschrieben sind: der Vater spielt den Gütigen oder den Grausamen, jedenfalls aber die unbeschränkte Autorität; die Tochter spielt die passiv-tugendhafte Heroine, die sie außerhalb des väterlichen Possenspiels längst nicht mehr ist - und diese Kombination aus Autorität und Gehorsam ermöglicht das vorgeschriebene Happy End, die Ehe.

Die Relativierung des Happy Ends (im 18. Jahrhundert durch bewußte Unwahrscheinlichlkeiten, hier durch dic unmißverständliche Definition als Komödienende) ist zu Franul von Weißenthurns Zeiten bereits ein altes Thema. Was bei Franul von WeiBenthurn neu ist, ist die Darstellung der Bildung als neue Frauentugend, und zwar in direktem Gegensatz zu den aus dem 18. Jahrhundert überlieferten Frauentugenden des Gehorsams, der Pflichterfüllung und der Passivität. Die gebildete Frau wird auch für viele andere Autorinnen zum Ideal, und da diese Figur in Komödien und Schauspielen bis zur Jahrhundertmitte erstaunlich oft auftaucht, lohnt es sich, sie etwas eingehender zu beschreiben.

Was genau Bildung für Frauen bedeutet, ist oft nur angedeutet; in den meisten Fällen äußert sich die Bildung der Heldinnen in den zwei Faktoren, die auch Franul von 
Weißenthurn anführt: Belesenheit und cine gewisse Entschlossenheit, Kontrolle über das eigene Schicksal - d. h. die Gattenwahl - auszuüben. Was gelesen wird, ist wichtig: Romane werden nach wie vor als verbildend dargestellt, da sie in der Leserin unrealistiRome Glückserwartungen erwecken. Wünschenswert dagegen ist die Kenntnis der griesche Gluckserwartungen erwecken. Wünshenswert dagegen ist die Ken (renannt wird chischen Klassiker und einiger weniger anerkannter moderner Autoren (genannt wird in der Regel Goethe) verbunden mit einer Kenntnis von Fremdsprachen und Musilk. ${ }^{17}$ Mit diesen neuen Ansprüchen an die Frauenfiguren der Komödie ändern sich selbst-

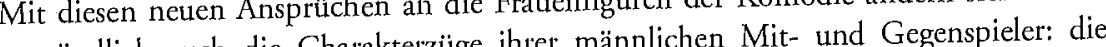
verständlich auch die Charakterzüge ihrer männlichen Mit- und Gegensieler die Kenntnisse einer Frau werden jetzt, wie im 18. Jahrhundert die Tugend der Pflichterfiillung, zum Heiratsgut für die positiven Helden; ein guter Vater ist der, der seiner Tochter eine gute Bildung zukommen läßt, ein tyrannischer Vater ist der, der sie von Büchern fernhält. Die Kenntnisse der Frau sollen teilweise nur dazu dienen, sie zu Buch en far sich durch einer Gesplächspartnerin furr den Zukunntigen zu ceine Mann versorgen zu lassen, ihre Bildung selbst ernähren könnte, statt sich von einem Mann versorgen Zu lassen, wird noch nirgends behauptet. ${ }^{13}$ Dementsprechend erwirbt sie sich ihre Bildung nicht, wien nängt sie aus väterlicher Hand: lesen darf sie zwar, aber nur unter männlicher sie empang sien astehen, aber nicht, um ihren Anleitung; sie ist zwar klug genug, um das Gelesene zu versthen, aber Lesestoff selbst zu bestimmen. Daß die Kenntnisse der Frau oft lediglich als Mitgift gesehen werden, wird schon daraus deutlich, daß die Bildung der Frau selbstverständlich auch die Beherrschung sämtlicher häuslicher und wirtschaftlicher Tugenden einchließt. Aber immerhin bedeutet das Auftreten der belesenen Heldin das Ende der saster passiven Tugend, der Verstand der Frault, wesentlich mehr Selbe aibs sich aus der Situation, Selbstbestimmung, was das Heiraten betrifft. Teilweise ergbt sich aus der Situron, daß die Heldin nicht heiraten müßte, wenn sie nicht wollte. In diesem Sinne wird das neue Bildungsideal zum ersten Faktor in der Unabhängigkeit der Frau - zumindest in der Komödie.

\section{WAS IST EIN MANN GEGEN EINEN BRILLANTSCHMUCK?} AMALIE VON SACHSEN

Amalie von Sachsen (1794-1870) definiert diese relative Unabhängigkeit der Frau eindeutig. die Freibeiten, die ihre weiblichen Figuren demonstrieren, haben sie aufgrund deutig: die Freiheiten, die ihre weiblichen Figuren demonstrere finanzielle Unabhängigkeit enthebt sie der Notwendigkeit, aus Versorgungsgründen zu heiraten; aufgrund ihres Verstandes wehren sie sich dagegen, einfach über sich verfügen und sich vom Vater Verstandes wehren sie sich dagegen, einalie, selbst hochgebildet, finanziell unabhängig einen Mann bestimmen zu lassen. Amalie, selbst hoch nach wie vor heiraten, aber sie und zeitlebens unverheiratet, laßt ihre Herdinnen zur werden, läßt sie nicht mehr verheirate wion besteht nur für Frauen, die nicht genug Verstand haben, sich Unbelesene (1838).

ihre Kompetenzen zu wehren - so z. B. für Sophie in Die Unbelesene (1838). Sophie steht unter der Fuchtel ihres sechzigjährigen Vormundes, des Herrn von Pleißner, der sie bewußt in Unwissenheit gehalten hat und sie wegen ihres beträcht- lichen Besitzes heiraten will. Um sie bewerben sich der Baron von Sommerfels, der sich zu diesem Zweck als Bedienter verkleidet hat, und der gelehrte Herr von Thurneck, der ihr Gut besucht, um die Bibliothek des Anwesens zu besichtigen. Sophies absolute Ahnungslosigkeit ist nicht mit Dummheit zu verwechseln - in dieser Hinsicht unterschätzen sie die meisten Figuren des Stückes -, sondern besteht aus zwei Aspekten: einerseits ist sie ein Resultat ciner bewußt vernachlässigten Erziehung (Unbelesenheit), die jetzt dem Vormund dazu dienen soll, sie finanziell zu übervorteilen. Wie Madame Kurt, die Wirtschafterin, feststellt, ist „Das Mädchen [...] dumm genug, um auf seinen Antrag mit einem Knix und einem -- ,wie Sie befehlen" - zu antworten" (OriginalBeiträge V, 7). Während hier Sophies Unwissenheit als Gefahr erkannt wird, hält der Baron gerade das für eine weibliche Haupttugend: „Ein Mädchen [...] braucht nichts zu wissen. Ihr gefährlichster Reiz ist gutmüthige Beschränktheit, holde Naivetät" (9).

Allerdings irren sich sowohl von Pleißner als auch der Baron in der Annahme, daß sie aufgrund von Sophies holder Naivität leichtes Spiel mit ihr haben würden, denn der zweite Aspekt ihrer Unwissenheit besteht in ihrer Ahnungslosigkeit im Bezug auf die Welt (der Männer), und gerade diese Ahnungslosigkeit macht es den Männern schwer, mit ihren Anträgen bei ihr anzulcommen. Da sie sich in der Sprache der Männer nicht auskennt, nimmt sie schlicht alles wörtlich und macht dadurch dic Antragsteller - und die traditionelle Liebesszene der Komödie - in höchstem Maße lächerlich. Die Liebesseufzer des Barons hält sie für Brustbeklemmungen und versucht sie mit Tropfen zu heilen; als der Baron feststellt, daß er mit zarten Anspielungen nicht weit bei ihr kommt, läßt er die Maske fallen, gibt sich als Baron zu erkennen und macht ihr einen Antrag, den Sophie ebensowenig versteht wie seine Seufzer.

BARON. Sprechen Sie ein freundliches Wort, bewahren Sie mich vor Verzweiflung.

SOPHIE (zurückweichend). Ja, was soll ich denn sagen? (für sich) Er ist toll!

BARON. Daß sie mich nicht hassen -

SOPHIE (wie oben). Nun, ich hasse Sie nicht.

BARON. Daß ich hoffen darf

SOPHIE (immer ängstlicher). Hoffen Sie in des Himmels Namen.

BARON (wirft sich auf die Knie). Reizendes Geschöpf - lassen Sie mich das noch einmal hören.

SopHIE. Jetzt konnten Sie die Kniescheibe brechen (53 f).

In der Antragsszene des Vormunds stellt sich heraus, daß Sophie nicht einmal mit den elementarsten Gesetzen der Männerwelt vertraut ist, nämlich mit dem Umstand, daß Frauen - wohlgemerkt: in der Interpretation des Vormunds - nur mit Mann überlebensfähig sind. Der Vormund begründet die Notwendigkeit der Heirat unter anderem mit der Gefahr, daß Sophie „sitzen bleiben“ könnte - und da kann Sophie, mit Recht, nur staunen.

SOPHIE. $\quad$ Ist es denn ein Unglück, sitzen zu bleiben?

Pleissner. Das größte Unglïck von der Welt. Ein Mädchen, das keinen Mann bekommt, ist über alle Maßen zu beklagen. 
SOPHIE. So?

PLEISSNER. Wird nicht beachtet, nicht geliebt und nur von Jedermann betrogen und bestohlen.

SOPHIE. Das hätte ich nicht gedacht.

PleISSNER. Und kann doch gar nicht anders sein, denn Ihr seid alle einfältig von Natur, und wenn ein Mann Euch nicht zur Seite steht, so wißt Ihr Euch weder zu rathen, noch zu helfen -

SOPHIE (blickt ihn erstaunt an) (28 f).

Während diese Unkenntnis männlicher Rhetorik ihr einen gewissen Schutz vor ihren Bewerbern verleiht, liefert die andere Seite ihrer Unwissenheit, ihre mangelnde Bildung, sie ihrem Vormund aus. Daß in der Ehe mit dem Vormund, der sie nur Rechnungen lesen lassen würde (32), ihre Unbelesenheit permanent werden würde, ist von Anfang an klar: der Vormund will Sophies Bibliothek an von Thurneck verkaufen. Sophie, die sich wegen ihrer mangelnden Bildung schämt und jeden Belesenen beneidet, stiehlt heimlich den Schlüssel zu ihrer eigenen Bibliothek und trifft dort auf von Thurneck, den sie bittet, ihr Lesematerial zu empfehlen. Schon hier wird also das LehrerSchülerin-Verhältnis in der künftigen Ehe festgelegt, denn von Thurneck ist immerhin soweit Patriarch, um festzustellen, ein Mädchen dürfe „nur lesen, was ihre Vorgesetzten ihr in die Hände geben“ (43), und hält sich für berufen, „den Geist des Mädchens auszubilden" (44). Sophie dagegen bietet sich hier die Möglichkeit, zu wählen. Da sie reich ist, ist sie, von Thurneclss Ansichten entgegen, keineswegs gezwungen zu heiraten; dennoch macht sie das Geschäft mit ihm: „schlagen sie ein, Fräulein Sophie (111). Sie investiert sozusagen in ihre Ausbildung.

Die Ehe mit von Thurneck bedeutet für sie zwar immer noch die Abhängigkeit vom Mann, über die sie in der Szene mit von Pleißner so erstaunt war, aber auch das Ende der Unwissenheit, die sie nach eigener Aussage „so demüthigt" (40). Der Patriarch von dem Sophie in Zukunft abhängig sein wird, ist zumindest ein wohlwollender sehr im Gegensatz zu den potentiellen Unterdrückern von Pleißner und Sommerfels, die ihr jede Möglichkeit zu einer Bildung absprechen und sie finanziell ausnutzen wollen. Denn von Thurneck ist zum Unterdrücker einfach nicht männlich genug, und zwar wegen seiner Bildung. Madame Kurt beschreibt ihn als „überstudiert [..., ] ein Weiberfeind und ein wahrer Bär" (12); der Baron fürchtet ihn nicht als Nebenbuhle bei Sophie (112) und läßt sich ungestraft von ihm beleidigen, weil er als Gelehrter satisfaktionsunfähig ist (114). Die Bildung, so scheint es, ist von Thurnecks Männlichkeit abträglich; Sophie dagegen befreit sich aus der demütigenden Unwissenheit, die der Baron als Idealtugend der Frau sieht.

Was Amalie hier an einem negativen Beispiel darstellt, an einer Ungebildeten nämlich, wird an ihren gebildeten, wohlhabenden oder entschlossenen Frauenfiguren in anderen Stücken deutlicher: je gebildeter und/oder wohlhabender die Frau, desto unabhängiger wird sie; umgekehrt verlieren die männlichen Figuren jeweils an Entscheidungsfreiheit, was die weiblichen dazugewinnen. In einigen ihrer Stücke werden die weiblich-männlichen Charaktermerkmale aufgrund der Erziehung oder materiellen
Unabhängigkeit der Frau so weit verwischt, daß die sozialen Rollen der Geschlechter vertauscht werden: nicht die Frau wird aus materiellen Gründen zwangsverheiratet, sondern der Mann.

So z. B. in Das Fräulein vom Lande (1836), in dem der tiefverschuldete Ferdinand von seinem Freund Reinsperg dazu getrieben wird, um das Landpflänzchen Dorothea anzuhalten, obwohl er in die Gräfin Aurelie verliebt ist. Sowohl Dorothea als auch Aurelie sind hochintelligente Frauen mit eigenem Vermögen; Aurelie ist mit 22 Jahren verwitwet und hat daher völlig freie Hand, Dorothea hat einen zerstreuten Vater, der lieber die Sterne beobachtet, als seiner Tochter einen Mann zu verschaffen. Während Dorothea und ihr Vater Bragenau soeben aus der Provinz angekommen sind und sich daher, ebensowenig wie Sophie, in der großen Welt (d. h.: in der Stadr) auskennen, ist Aurelie die grande dame des gesellschaftlichen Lebens, die sich von mehreren Männern umwerben läßt, ohne sich festzulegen. Weil nur eine schleunige Verlobung mit einer reichen Erbin Ferdinand vor dem Schuldturm retten kann, versucht er, von Aurelie das Jawort zu erhalten, bevor er sich um Dorothea bewerben muß - denn Reinsperg hat Dorothea und Bragenau eigens zu diesem Zweck in die Stadt gelotst. Aurelie allerdings verhält sich abweisend und gesteht ihm allenfalls, daß er der Mann sei, der „mich vor der Hand am meisten interessiert" (Original-Beiträge IV, 301). Sie besteht darauf, daß Ferdinand seine Schulden bezahlt, bevor er sich um sie bewirbt, und zwar nicht aus Geiz, sondern aus Angst vor dem Verlust ihrer Unabhängigkeit - und aus Angst vor der alten Auffassung der Ehe als finanzielle Transaktion. „Ich habe Geld, das ist wahr, aber ich brauche es auch, und fühle mich nicht geneigt, meinen Brautstand mit Schuldenbezahlen anzufangen. Nehmen will ich Sie, Ferdinand, nehmen recht gern, aber kaufen nicht" (300). Ferdinand macht darauf Dorothea einen Antrag, auf den sie ähnlich reagiert wie Sophie auf die ihrer Bewerber (323-7). Ferdinand stempelt sie aufgrund ihrer Unkenntnis männlicher Rhetorik zur dummen Landpflanze ab, muß aber später feststellen, daß dem nicht so ist: Dorothea ist nicht nur „eine ganze Landwirthin", sondern auch „gelehrt dabei, gelehrt! Sie lies't Bücher und spricht französisch, auch den Flügel kann sie spielen" und fungiert außerdem als Medilkus der Landgemeinde (339). Dorotheas Bildung ist, zusammen mit ihrem Vermögen, ein Faktor ihrer Unabhängigkeit; ein weiterer besteht, wie in Die Unbelesene, in ihrer ablehnenden Haltung Männern gegenüber. Aurelies Freiheit beruht auf genau denselben Faktoren, nur daß Aurelie die etwas leichtfertigere Stadtversion desselben Phänomens darstellt. Dorothea ist voller Bewunderung für Goethes Tasso - „die schöne Dichtung" -, während Aurelie ins Theater geht, um sich zu amüsieren - ein für Dorothea völlig fremdes Konzept (403). Aurelie hält ihre Liebhaber kurz und besteht auf ihrer Unabhängigkeit, während Dorothea von männlichen Anträgen nach eigener Aussage „nicht ein Wort“ versteht (324).

Der alte Tugendbegriff taucht hier in einem anderen Kontext auf: Tugend ist eine ländliche Eigenschaft und bedeutet hauptsächlich Bildung, Wohltätigkeit, und Natulverbundenheit. Abgesehen von der Liebe zum Landleben als Gegensatz zum Trubel der Stadt beruht Tugend also auch hier auf Verstand und finanziellem Vermögen (als Voraussetzung zur Wohltätigkeit). Deshalb spielt Ferdinand bei seiner Bewerbung um 
Dorothea unter Reinspergs Anleitung den tugendhaften Jüngling, der gute Noten auf der Akademie bekommt und aus lauter Wohltätigkeit in Schulden geraten ist, und gewinnt Dorotheas Zuneigung tatsächlich. Gleichzeitig belkommt er bei diesem Spiel Gelegenheit, sich in Dorotheas gleichgeartete Tugenden zu verlieben. An diesem Punkt wird es für Aurelie ernst: Reinsperg, der sich ebenfalls für sie interessiert, macht ihr unmißverständlich klar, daß Ferdinand entweder verschuldet oder gar nicht zu haben ist. Reinspergs Vokabular degradiert Ferdinand zum käuflich erwerbbaren Besitz, zum Heiratsgut. "Wenn Sie ihn haben wollen, so zahlen Sie die dreitausend Thaler. Für dreitausend Thaler ist er zu erwerben, anders nicht“ (391). Und später: „Es lkommt [...] nur darauf an, ob Sie den Ferdinand so hoch anschlagen wollen, oder nicht" (392). Hier wird der Mann verhandelt wie sonst die Frauen, und diese (weibliche) Rolle wird Ferdinand auch später noch einmal beigelegt, diesmal von Dorothea. Denn als diese von Ferdinands gleichzeitigen Bewerbungen um sie und Aurelie erfährt, interpretiert sie seine Anträge an sie als die Selbstopferung, die im 18. Jahrhundert als weibliche Tugend bzw. Pflicht galt. „[...] Ihr Vater wünschte Sie von Aurelien getrennt, weil er Sie mit mir verbunden wünschte, und Ihrem Vater haben Sie sich opfern wollen" (415).

Ferdinands Tugendschwindel und Doppelwerbung wird nicht von jedem so wohlwollend interpretiert wie von Dorothea, besonders als sich seine guten Noten auf der Alkademie als Erfindung und seine Wohltätigkeit als Spielschulden herausstellen. Da Dorothea viel zu pragmatisch ist, um ihm die Leviten zu lesen, wird diese Aufgabe Dorothea viel zu pragmatisch ist, um ihm die Leviten zu lesen, wirf Ferdinand lautstarl seinen Heiratsschwindel vor und läßt sich nicht von ihm zum Schweigen bringen. „Nun will er mir gar noch das Reden verbieten? Das Reden, die einzige Waffe, die der Himmel den Unterdrückten gegeben hat. Aber das soll er nicht, das kann er nicht, das kann nicht einmal mein Mann" (410). Dieselbe Veronica platzt noch einmal ins Spiel als das Happy End schon fast seinen Lauf genommen hat: Dorothea hat inzwischen Ferdinand ohne dessen Wissen mit einem Brillantschmuck losgekauft, um ihm die Ehe mit Aurelie zu ermöglichen; Ferdinand dagegen wirft sich ihr (bekehrt und schuldenfrei) zu Füßen und bittet sie, meine Schritte zu leiten“ (450). Während Dorothea noch uberegt und Vater Bragen schwankt, tritt Veronica auf und meldet, daß de noch überlegt und Vater Bragenau schwankt, tritt Veronica auf und Brillantschmuck vermißt wird. Auf Vater Bragenaus Versuch, sie loszuwerden - "Wi sind eben mit wichtigen Dingen beschäftigt" - reagiert sie, indem sie Prioritäten setzt: Und wenn Sie die Verlobung des Fräuleins feierten, meine Angelegenheit ist wichti"ger. Männer finden sich überall. Was ist ein Mann gegen einen Brillantschmuck?" (454)

Veronicas Worte bringen die Alternative Ehe versus materielle Sicherheit zum letzten Mal aufs Theater. Das Happy End ist ein bedingtes, verständlicherweise, da nich die Frauen, sondern die Männer heiraten wollen, die Frauen aber sich aufgrund ihre finanziellen Unabhängigkeit entscheiden können. Aurelie lehnt Reinspergs Antrag im dritten Akt ab, und Reinsperg wettet mit sich selbst, daß er doch noch ihr Mann wird - damit verschwindet diese Affäre aus dem Stück. Dorothea kommentiert Ferdinands Antrag mit keinem Wort, ihr Vater gibt seufzend seinen Segen und stellt dabei klar, daß Ferdinand lediglich zur Probe angenommen wird: „Ich sehe es ein, wie jetzt die Sachen stehen, so werden wir es wol mit Ihnen versuchen müssen" (454). Im Endeffekt werden hier also die traditionellen Männer- und Frauenrollen vertauscht: Ferdinand muß heiraten, um versorgt zu sein, Dorothea und Aurelie müssen das keineswegs; Aurelie entscheidet sich gegen die Ehe, Dorothea übernimmt in ihrer Ehe die männliche Rolle, das heißt, sie macht sich die Mühe, Ferdinands Schritte zu leiten (450).

Der Rollentausch der Geschlechter, der hier durch eine finanzielle Überlegenheit der Frau ermöglicht wird, basiert in Amalies Vierakter Der Unentschlossene (1837) auf der geschlechtsuntypischen Erziehung des Titelhelden und der Protagonistin. Marianne ist die resolute Tochter eines verwitweten Offiziers, ihr Verlobter, der Assessor von Dahlen, ist der ewig zögernde Sohn einer Witwe. Während die Unentschlossenheit des Assessors ein Ergebnis seiner "heillose[n] Weibererziehung" (Original-Beiträge III, 427) ist, hat der Oberst von Traunsfeld seine Tochter „so männlich erzogen, daß sie mir beinahe über den Kopf gewachsen ist" (404). Da der Assessor sich nicht entschließen kann, Marianne endlich zu heiraten, inszeniert Marianne heimlich eine Verlobungszeremonie, um ihm die Entscheidung abzunehmen. Ihr ist klar, daß sie in der Ehe die Männerrolle übernehmen wird - und das ist für sie der Hauptgrund, ihn zu heiraten: sie will „für ihn denken, für ihn sorgen. - Ein Mann, wie so manche meiner Mitschwestern sich ihn wünschen, ein ganz sich selbst genügender Mann, der mir nichts zu schalten übrig gelassen, hätte für mich nicht getaugt" (368). Der Assessor seinerseit scheint tatsächlich jemanden zu brauchen, der für ihn denkt: er hat keinerlei Kontrolle über seine Dienerschaft, in seinem Haus geht es drunter und drüber, und seine Entschlußk kraft reicht nicht einmal soweit, daß er sich entscheiden kann, in welche Komödie er gehen will. Zur Ehe kann er sich noch weniger entschließen, denn obwohl er Marianne liebt, bedeutet die Ehe für ihn genau das, was sie traditionellerweise für Frauen bedeutet: das Ende seiner Herrschaft über sich selbst (381). Als er mitren in der Zeremonie ausreißt, schwört Marianne fürchterliche Rache - anstatt, wie man von einer Frau erwarten darf, in Tränen auszubrechen oder in Ohnmacht zu fallen. Zusammen mit dem Forstmeister von Fernau, einem Freund des Assessors, inszeniert sie eine zweite Verlobungsszene, in der sie sich zum Schein mit Fernau verlobt. Der Assesso wird selbstverständlich dazu eingeladen und zeigt sich hinreichend zerknirscht, worauf Marianne, resolut wie inmer, die Versöhnung befiehlt.

Diese zweite Verlobungsszene wirft ein interessantes Licht auf die Ehe im allgemeinen und auf die Ehe zwischen Marianne und dem Assessor im besonderen: trotz aller Ängste, die der Assessor deswegen aussteht, ist die Verlobung sehr leicht rückgängig zu machen, denn angesichts seiner Reue will Marianne den bereits unterzeichneten Kontrakt einfach zerreißen. Es stellt sich heraus, daß das nicht nötig ist, da Fernau (absichtlich) als Zeuge und der Assessor (aus Versehen) als Bräutigam unterschrieben hat und so doch alles seine Richtigkeit hat. Wer hier also wen heiratet, ist reiner Zufall und nur abhängig von einer Unterschrift auf der richtigen oder falschen Linie. Da der Assessor zufälligerweise auf der richtigen Linie unterschrieben hat, ist er am Ende des Stückes „verheiratet, ohne die Mühe gehabt zu haben, deßhalb einen Entschluß zu 
fassen" (443) - eine ironische Beschreibung der üblichen Situation der Frau. Marianne dagegen gibt während der Verlobung eine Kostprobe ihres Entschlusses, in der Ehe fü ing er sich nicht dazu entschließen konnte, hat sie heimlich seine finanziellen Angelegenheiten übernommen und ihn um 20,000 Taler bereichert (440).

Nicht alle weiblichen Protagonisten in Komödien des 19. Jahrhunderts treten so forsch auf wie Marianne, und nicht alle erkämpfen sich dieselbe Machtstellung. Aber seit Verstand zu einer weiblichen Tugend geworden ist, hat sich die Stellung der Frau in der Komödie merklich verändert. Von Pflicht und Tugend ist nirgends mehr die Rede; weibliche Bildung wird auch von männlichen Protagonisten als positive Eigenschaft gewertet. Die Männer, die gegen die Bildung der Frau angehen, sind gleichzeitig die, die sie finanziell ausnutzen wollen. Bei Amalie gebrauchen Frauen ihren Verstand keineswegs nur, um eine bessere Gesprächspartnerin für den Mann abzugeben, sondern hauptsächlich, um ihr Vermögen zu verteidigen oder um sich den Mann auszusuchen, mit dem es sich am besten leben läßt. Der Zwang zur Ehe besteht für Frauen nicht mehr, sobald sie materiell abgesichert sind; in diesem Fall können sie es sich leisten, den Mann zu heiraten, der ihnen die meiste Bewegungsfreiheit (Die Unbelesene) oder gar die gesamte Kontrolle überläßt (Das Fräulein vom Lande, Der Unentschlossene). Je mehr „männliche“ Eigenschaften die Frauen besitzen - wie Bildung (Dorothea, Aurelie, Marinne), Reichtïmer (Sophie, Dorothea, Aurelie) oder Entschlossenheit (Dorothea, Marianne) -, desto mehr übernehmen sie die männlichen Rollen. Die männlichen Heroen dagegen - satisfaktionsunfähige Gelehrte, leichtsinnige Spieler der entieren an Männlichkeit und Kontrolle, was die Frauen dazugewinnen, und können beruhigt geheiratet werden, da sie sich nicht zum Ehetyrannen eignen.

\section{A LA RECHERCHE DU BONHEUR: CHARLOTTE BIRCH-PFEIFFER}

Bei Charlotte Birch-Pfeiffer (1800-1868) ändert sich das Bild. Während alle bisher genannten Autorinnen sich mit der Ordnung des Dramas - und damit mit der politischen und sozialen Ordnung, die das Drama symbolisiert, auseinandersetzen, enthält sie sich scheinbar jeglichen Kommentars. Die Heldinnen ihrer Familienschauspiele sind entweder nach dem Muster des 18. Jahrhunderts geschneiderte Tugenden oder „natürliche Töchter", die aufgrund ihrer Wildheit verfemt und mit entsprechenden "Vorurteilen belegt werden (Hexe, Kobold, Grille), immer aber sind sie tugendhaft, gottesfürchtig und königstreu. ${ }^{19}$ Ihre männlichen Helden sind entsprechend musterhaft; ihre Bösewichter zerfallen in žwei Klassen: die edlen, aber irregeleiteten Verbrecher aus verlorener Ehre oder verhärtete Bösewichter, die aus purer Lust am Bösen vor keine Schandtat zurückschrecken.

Bei derart krasser Zeichnung der Charaktere könnte der Zuschauer Stücke erwarten, in denen das Gute mit dem Bösen in dramatischem Kampf liegt, wobei das Gute siegt und das Böse vernichtet wird. Diese Erwartung würde aber zumindest, was den letzten
Punkt betrifft, bitter enttäuscht. Denn bei Birch-Pfeiffer funktioniert die poetische Gerechtigkeit nur halb: wie extrem die Schandtaten der Bösewichter auch sind, am Ende des Stückes wird zwar durch irgendeinen enorm unglaubwürdigen Zufall die Tugend bestätigt und durch die obligate Verlobung „belohnt", aber das Laster läßt die Autorin, mit einer einzigen Ausnahme, ungeschoren davonkommen. In den ausführlichen Versöhnungsszenen, mit denen sie ihre Stücke schließt, geht der Groll gegen die Bösewichter in allgemeiner Zufriedenheit unter.

Hinter diesem halben guten Ende - das immer in der Verlobung der tugendhaften Charaktere besteht und durch hanebüchene dramatische Unglaubwürdigkeiten herbeigezogen werden muß -, versteckt sich etwas mehr als das Phänomen des unglaubwürdigen Happy Ends, das wir aus dem 18. Jahrhundert krennen. Denn um die Tugend belohnen zu können, ohne das Laster bestrafen zu müssen, schaltet Birch-Pfeiffer ein Element aus ihren Dramen völlig aus, und zwar das Merkmal des Dramas überhaupt den dramatischen Konflikt. Das tut sie mit Vorliebe während ihrer Glanzzeit, in der politisch und literarisch keineswegs konfliktarmen Zeit zwischen 1840 und 1855. In ihrer gesamten dramatischen Produktion, ca. 100 Stücke, findet sich nur eine einzige Tragödie, und auch die trägt ihre Bezeichnung zu Unrecht (Hes 59 f), da ihr jeder tragische Konflikt fehlt. Obwohl Birch-Pfeiffer in jedem dramatischen Genre schrieb romantische und historische Dramen, Lustspiele und Possen, Familiendramen und Ritterstücke -, verfaßte sie weitaus weniger Lustspiele als Schauspiele. Das könnte zu der Annahme verleiten, daß sie die Gegenüberstellung der Tugendheld/inn/en und der Bösewichter in extremeren Farben auf die Bühne stellen wollte, als die Komödie es zuließ, obwohl sie keineswegs vorhatte, daraus einen Konflikt zu machen oder ihn gar zu lösen. Ein weiterer Anhaltspunkt für ihre Vermeidung jeglichen dramatischen Konflikts ist ihre Wahl der Stoffe: Birch-Pfeiffer schrieb mit Vorliebe dramatische Romanadaptationen, und die Handlung dieser Stücke ist meist um nichts dramatischer als die der Romanvorlage. Der Ausgang ihrer Stücke allerdings ist immer ein guter; auch wenn der Roman tragisch endet und sie sich sonst so genau an die Vorlage hielt, daß der Autor einer ihrer Vorlagen sie des Plagiats beschuldigte und gerichtlich verklagte. ${ }^{20}$

Wenn Birch-Pfeiffer in ihren Romandramatisierungen Änderungen dem Original gegenüber vornimmt, dann immer mit dem Blick auf das glüclliche Ende, sprich Verlobung, am Schluß. Sämtliche Konflikte, die in ihren Vorlagen das Happy End erschweren oder verhindern, werden von ihr geschickt ausgeschaltet. Ihr romantisches Drama Der Glöckner von Notre-Dame (1830) übernimmt die Handlung aus Victor Hugos Roman bis zu dem Punkt, an dem das glückliche Ende unmöglich wird. In ihrem Stück wird Esmeralda, wie im Roman, als Kind von Zigeunern entfühtt und taucht Jahre später als Straßentänzerin in Paris auf, wo sich der Priester Claude Frello in sie verliebt. Sie verliebt sich ihrerseits in Phöbus, der von dem vor Eifersucht wahnsinnigen Claude bei einem Stelldichein mit Esmeralda erstochen wird. Esmeralda, der der Mord angelastet wird, wird als Hexe zum Tode verurteilt und muß noch im Gefängnis Claudes Annäherungsversuche abwehren, der sie befreien will, wenn sie seine Liebe erwidert. Kurz vor der öffentlichen Hinrichtung wird sie von Quasimodo aus Dankbarkeit für ihr früheres Mitleid mit ihm in die Kirche Notre Dame gerettet, 
deren Asyl unantastbar ist. Als die Zigeuner die Kirche stürmen, um Esmeralda zu befreien, wird sie von Claude entführt und erneut bedrängt. Soweit die Haupthandlung, die Birch-Pfeiffer unverändert von Hugo übernahm und die sowohl im Roman als auch im Drama den größten Teil der Handlung ausmacht. Das Ende ist denkbar unterschiedlich: bei Hugo folgt die Katastrophe, bei Birch-Pfeiffer der glatte Übergang ins große Glück.

Der Hauptumstand, der ihr diesen Umschwung ermöglicht, ist die Uminterpretation des Geliebten Phöbus, bei Hugo ein brutaler Wüstling mit adliger Verlobter, der Esmeralda nur benutzt. Bei Birch-Pfeiffer wird er zum ehrbar liebenden Jüngling, der Esmeralda heiraten will und bei jeder sich bietenden Gelegenheit sein Leben für sie riskiert. Diese Änderung einer einzigen Figur ermöglicht Birch-Pfeiffer die Auflösung des fast tragischen Stückes in Wonnewolken, ohne dabei die Handlung in mehr als Einzelpunkten ändern zu müssen. Phöbus überlebt Claudes Attentat sowohl bei Hugo als auch bei Birch-Pfeiffer. Bei Birch-Pfeiffer rettet er Esmeralda und flieht mit ihr und der wiedergefundenen Mutter in ein fernes Land, wo sie vor Hexenverfolgung sicher ist (nach Deutschland); bei Hugo heiratet er seine adlige Braut und sieht Esmeraldas Hinrichtung ungerührt mit an. Entsprechend verändert sich das Schicksal der anderen Figuren: im Roman stirbt Esmeraldas wiedergefundene Mutter aus Verzweiflung über den Tod ihrer Tochter, während sie im Stück am Glück ihrer Kinder teilnimmt und so für jahrelange Leiden entschädigt wird.

Während bei Hugo der tragische Ausgang unvermeidlich ist, wird bei Birch-Pfeiffer das schließliche Liebesglück im Stück selbst durch ein einziges Motiv erklärt: durch die Güte Gottes. "Gott ist groß!" (84) lautet die Einsicht des Zigeunerchors in der letzten Szene, in der sie Esmeralda im Triumph von der Bühne tragen. Trotzdem lassen sich Zweifel an der göttlichen Güte nicht ganz vermeiden. Hier sind sie personifiziert in der Figur der Gervaise, Esmeraldas Mutter, deren Charakter aus zwei Bestandteilen zusammengesetzt ist: aus ihrem Haß auf die Zigeuner, die ihr Kind entfïhrt haben, und aus ihrem Versuch, ihren früheren moralisch zweifelhaften Lebenswandel (Esmeralda ist ein „Sündenkind“, 6) in entbehrungsreichem Büßerleben zu sühnen. Direkt nach Esmeraldas Entführung aus Notre Dame schickt Gervaise ein zweiseitiges Gebet gen Himmel, in dem sie Gott anfleht, ihr ihre Tochter wiederzugeben. Ihre Anklagen "[...] du hast mir mein Kind genommen!" - wcichen schließlich der Hoffnung auf die göttliche Güte: „Du bist ja unser aller Vater, und hat ein Vater nicht Erbarmen mit seinen Kindern?" (73) Bei Birch-Pfeiffer hat er das: Gervaises Bitte wird prompt erhört. Denn kaum hat sie ihr Gebet beendet, tritt Claude mit Esmeralda auf und übergibt sie Gervaise zur Bewachung, bis er mit Häschern zurückkommt. Diese hält Esmeralda tatsächlich fest, in schierer Unkenntnis der göttlichen Fügung, bis sich die beiden endlich erkentnen und Gervaise sie vor den Häschern zu verstecken versucht (hier erfolgreich, im Roman vergeblich). Dic glückliche Auflösung erfolgt nach der Einsicht der göttlichen Güte Schlag auf Schlag: kurz hintereinander treten Phöbus und Zigeuner, Claude und Quasimodo auf. Phöbus und Esmeralda finden sich wieder und planen die Flucht; der Gaunerkönig Clopin, Oberhaupt der unterweltlerischen Zigeunerbande, gelobt angesichts der rührenden Szene, cin ehrlicher Kerl zu werden.
Claude, der die Szene ebenfalls mitansieht, will fortschleichen, um die Häscher zu holen, wird aber von dem auf die Bühne stürzenden Quasimodo daran gehindert. Claude ersticht Quasimodo und wird von diesem noch kurz vor seinem Tod getötet. Esmeralda und Phöbus bedauern den treuen Quasimodo mit wenigen Worten, und das Stück endet mit dem erwähnten Triumphzug. Das Ganze nimmt nur ca. anderthalb Seiten in Anspruch.

Claude ist meines Wissens der einzige Birch-Pfeiffersche Bösewicht, der - wie im Roman - für seine Schurkereien büßen muß. In ihren späteren Romanadaptationen gehen ihre Schurken in der Regel frei aus. In Nacht und Morgen (1842), einer Bearbeitung von Edward Lytton Bulwers Night and Morning, sind die Bösewichter ebenso kraß gezeichnet wie Claude im Glöckner, während die Vertreter der Tugend fünf Akte lang ihre grenzenlose Ausdauer im Leiden unter Beweis stellen. Lord Philipp Beauforr hat seine Ehe mit Katharina Morton zwanzig Jahre lang geheimgehalten, um sich eine Erbschaft zu sichern, und bricht sich ausgerechnet an dem Tag, an dem er sie vor aller Welt legitimieren will, den Hals. Da der Trauschein nirgends gefunden werden kann, verliert Katharina das Erbe und wird mit ihren Kindern Philipp und Sidonie ins Elend verstoßen. Die Schurken des Stückes sind Robert Beaufort, der Bruder des Toten, der die Familie aus Habgier aus dem Haus jagt, und Lilburne, der Robert aus purer Lust am Bösen dazu ermutigt. Philipp nimmt Dienste bei einem Buchhändler, während Mutter und Tochter sich kümmerlich von ihrer Hände Arbeit ernähren. Am Sterbebett der Mutter treffen sich Philipp, Robert und sein Sohn Arthur wieder. Arthur wußte nichts von Katharinas Elend und verspricht, für ihre Kinder zu sorgen; Philipp, der wiederum von dieser Szene keine Ahnung hat, verflucht sowohl Arthur als auch Robert und flieht nach Frankreich, da er des Diebstahls verdächtigt wird. Dort tut er sich mit dem edlen, aber irregeleiteten Falschmünzer Gawetry zusammen, der durch eine namenlose Schurkerei Lilburnes unverschuldet ins Unglück geraten und zum Verbrecher geworden ist. Durch Gawetrys rechtzeitigen Tod und durch Eugenie, die sich in ihn verliebt hat, wird Philipp aus dem Sumpf des Verbrechens gerettet. Mit Eugenies Hilfe kommt Philipp zu Stand und Ehren und in die Lage, verkleidet nach England zurückzukehren, um seine Schwester Sidonic zu suchen. Arthur hat sich inzwischen, seinem Versprechen gemäß, sowohl Sidonies als auch Katharinas (die nur scheintot war und im zweiten Alkt wiederauferstanden ist) angenommen. Lilburne entführt Sidonie, um sie zu vergewaltigen, wird aber von Eugenie, die sich als seine alte Beschließerin verkleidet hat, daran gehindert. Sidonie findet das Versteck des Trauscheins und legitimiert so Katharina als rechtmäßige Witwe und Erbin ihres verstorbenen Mannes.

An diesem Punlst werden sämtliche Hauptpersonen des Stückes zur glücklichen Auflösung auf die Bühne zitiert: Robert erscheint, weil er Philipp erkannt hat und sich bei Lilburne Rat holen will, Philipp, Arthur und Katharina treten kurz darauf auf, um Sidonie zu retten. Die glïckliche Auflösung erfolgt ebenso schnell wie im Glöckner (auf knapp zwei Seiten): die seit Jahren getrennte Familie wird wiedervereinigt, Eugenie gibt Philipp den Trauschein, der beide zu ehelichen Kindern und reichen Erben macht, Eugenie und Philipp, Arthur und Sidonie werden ein Paar, und den Schurken Robert und Lilburne wird keine andere Strafe zuteil, als all. dieses Glück mitansehen zu müssen. 
Der glückliche Ausgang ist hier; wie in fast allen Stücken Birch-Pfeiffers, teils von unglaublichen Zufällen abhängig, teils von entsprechenden Änderungen des Originals. Bei Bulwer stirbt Katharina, Birch-Pfeiffer erweckt sie wieder zum Leben, um das Happy End durch ihre Gegenwart zu vervollkommnen und sie, anders als Bulwer, schon zu Lebzeiten zu legitimieren. Der Trauschein wird im Stück durch einen Zufall gefunden - Sidonie zeigt Eugenie einen Mechanismus an einem Bild, an den sie sich aus ihrer Kindheit erinnert, und hinter diesem Bild findet Eugenie den Trauschein. Dieser Zufall wiederum wird durch einen weiteren Zufall ermöglicht, nämlich durch den, daß Sidonies und Philipps Elternhaus von Robert an Lilburne abgetreten wurde und daß es dieses Haus ist, in dem Lilburne die entführte Sidonie versteckt hält. Daß Eugenie Lilburne ein halbes Jahr lang mit ihrer Verkleidung als die alte Madame Claire, die Lilburne nach eigener Aussage sehr gut kennt, täuschen kann, ist reichlich unwahrscheinlich, aber notwendig, da Eugenic nur so Sidonie vor Lilburnes Nachstellungen retten kann.

Sidonie selbst existiert im Roman nicht - bei Bulwer hat Katharina zwei Söhne -, aber die Rolle ist zum Happy End unerläßlich, da die entzweiten Verwandten durch die Ehe zwischen Arthur und Sidonie versöhnt werden. Eugenie schließlich stirbt im Roman, im Stück heiratet sie Philipp. Diese so zwanghaft herbeigeführte Belohnung der Tugend - Katharinas Wiederauferstehung, ihre Legitimierung durch den endlich gefundenen Trauschein, und dic Doppelverlobung - wird nicht durch eine Bestrafung der Bösewichter ergänzt. Robert bricht zusammen und wird von Arthur umsorgt; da er nur wortlos das Gesicht bedeckt, bleibt es dem Zuschauer überlassen, ob er diesen Zusammenbruch als Reue interpretieren will. Lilburne dagegen, der Erzschurke, der an dem jahrelangen Unglück der Familie schuld ist, sieht sich das Ganze ruhig an und wird nicht einmal aus dem Schoß der glücklichen Familie verwiesen. Dramatisch gesehen bleibt ihm das letzte Wort, denn das Stück endet mit der Bühnenanweisung: „Lilburne (lehnt an dem Diwan und betrachtet die Gruppe mit einem höhnischen Lächeln)" (125). Das ist nicht eben die Pose eines Besiegten.

In ihrer erfolgreichsten Romanbearbeitung, Die Waise aus Lowood (1853), einer Bearbeitung von Charlotte Brontës Jane Eyre, kreiert Birch-Pfeiffer das Happy End mit ähnlichen Mitteln und merzt auch hier alles allzu Tragische erfolgreich aus, wie in den vorangegangenen Beispielen hauptsächlich durch Änderung einer Figur. Die Wahnsinnige im Turm ist nicht, wie im Roman, Rowlands ${ }^{21}$ Frau, sondern die Frau seines verstorbenen Bruders, für die er aufopferungsvoll sorgt. Mit dieser simplen Änderung erspart sich Birch-Pfeiffer alle Hindernisse, die der Verbindung zwischen Jane und Rowland im Wege stehen, ebenso wie alle tragischen Ereignisse im Roman, die es relativieren. Der Tod der Wahnsinnigen und Janes entbehrungsreiche Jahre in Lowood, bei Brontë ausführlich geschildert, fallen im Stück ganz weg, ebenso wie die Trennung zwischen Jane und Rochester und Rochesters Erblindung. Erstaunlicherweise tritt, nachdem die Autorin so vorsorglich alle Steine auf dem Weg zu Janes Glück aus dem Weg geräumt hat, doch noch ein Hindernis auf: Jane selbst kann sich plötzlich nicht zur Ehe entschließen. Rowlands Überredungskünste nehmen in der letzten Szene äußerst bedrohliche Töne an: dảs Vokabular, mit dem er sie bedrängt, läßt ihr eindeutig nur die Wahl zwischen Tod und Gefangenschaft.

JANE. [...] lassen Sie mich, ich habe meine Gesinnung ausgesprochen, nun sann ich gehen, wohin ich will!

ROWLAND (sie fester an sich drückend). Das kannst du nicht mehr, Jane Eyre, das Netz schlug über dir zusammen, du bist gefangen.

JANE (sich rasch von ihm losmachend). Ich zerreiße es! Ich bin ein freies Wesen mit unabhängigem Willen.

Rowland. Und du glaubst, ich würde dich lassen, nachdem du so zu mir gesprochen? (Umfaßt sie plötzlich mit beiden Armen.) Weißt du, daß ich dich brechen kann wie Rohr, kleines Mädchen, ehe ich dich von mir gehen lasse? (85, Hervorhebung der Autorin).

Es folgt die Aufklärung von seiten Rowlands, in der er Jane klarmacht, daß sogar die Komplikation seiner Fast-Verlobung mit Georgine nur eine Farce war, die Janes Starrsinn durch Eifersucht brechen sollte. Der Ehe steht nun nichts, aber auch wirklich nichts mehr im Wege - und trotzdem zögert Jane, bis Rowland sich zu einer neuen Drohung hinreißen läßt.

RowLAND. [...] Jane, nimm mich zum Gatten, nimm mich schnell, bedenke es nicht lange - sage: ,Rowland, ich will dein Weib sein, Rowland, ich will dich lieben!' Sag's schnell oder meine Fibern reißen, und etwas Schreckliches geschieht! (86, Hervorhebung der Autorin). ${ }^{22}$

Solche Worte aus dem Munde des liebenden Helden sollten stutzig machen, besonders wenn man sich daran erinnert, daß Claude Esmeralda gegenüber ein ganz ähnliches Vokabular benutzt. Nachdem Birch-Pfeiffer sich solche Mühe gegeben hat, das Happy End zum perfekten zu machen - Rowland, der Erwählte, ist weder Bigamist noch blind -, stellt sie eine Szene auf die Bühne, in der der Erwählte die Ehe so unmißverständlich als Gefangenschaft definiert, daß er Jane zwingt, noch einmal verbal ihre Freiheit zu verteidigen, bevor sie sie unter dem Druck der Drohung schließlich aufgibt Warum hier keine empfindsame Liebesszene mit Kniefall und Handkuß? Erinnern wir uns an ihre früheren Stücke: im Glöckner ermöglicht sic das Happy End, indem sie eigens den perfekten Liebhaber für Esmeralda erfindet und diese durch Veränderung der Handlung vor der Hinrichtung rettet. Dann allerdings macht sie klar, daß man ihr dieses Ende nur mit einer gehörigen Portion Gottvertrauen abkaufen kann - und dieses Gottvertrauen wird kurz vor dem Ende in Gervaises Gebet ausgiebig bezweifelt. In der darauffolgenden Szene wird Esmeralda bei Hugo von den Häschern gefaßt, bei Birch-Pfeiffer lassen sie sich von Gervaise abwimmeln, und alles wird gut. In Nach und Morgen wird das gute Ende durch eine ganze Serie von Zufällen ermöglicht, die so unglaublich und für den Zuschauer so durchsichtig sind, daß die Unwahrscheinlichkeit des Ganzen klar auf der Hand liegt. Der erfahrenen Dramatikerin hätte hier sicher etwas Besseres einfallen können, wenn sie ein Interesse daran gehabt hätte, das End 
für den Zuschauer glaubwürdiger zu machen. Aber direkt nachdem sie alle diese Widersprüche ins Stück einführt, läßt sie sie kommentarlos wieder fallen, und das Happy End, die Versöhnung, Wiederfindung, Verlobung findet auf so eng gedrängtem Raum statt, daß der Zuschauer kaum Zeit hat, sich dieser Widersprüche bewußt zu werden.

Birch-Pfeiffers Neigung, den dramatischen Konflikt zu vermeiden, die Allmacht des Zufalls in vielen ihrer Stücke, die Unwahrscheinlichkeiten und ihre einseitige Einteilung der Figuren in Gute und Böse wurde von vielen, auch von Else Hes, als dramatischer Mangel empfunden: Birch-Pfeiffers Stücke wurden zeit ihres Lebens von Kritikern erbarmungslos verrissen. Das Publikum dagegen genoß ihre versöhnlichen Stücke und nahm für das glückliche Ende auch die gröbsten Unglaubwürdigkeiten hin. Und um das gute Ende kam sie nicht herum: sie wußte sehr wohl, daß hauptsächlich davon die Popularität ihrer Stücke abhing (Briefwechsel mit Heinrich Laube 160). M. E. ist Birch-Pfeiffer der Höhepunlat der Tendenz dramatischer Autorinnen, das Happy End zu relativieren - denn sie experimentiert mit genau dieser Tradition. Das erklärte Ziel aller ihrer Stücke scheint es zu sein, ein solches Ende herbeizuführen; das Experiment besteht in dem Versuch, alle Konflikte, Hindernisse und Beeinträchtigungen des glücklichen Ausgangs von vornherein zu beseitigen. Ist der Konflikt nicht zu lösen, wird er einfach weggelassen. Trotzdem war sie nicht imstande, das so mühsam aufgebaute Glücksgebäude widerspruchslos stehenzulassen; das Happy End scheint in ihren Stülkken verzerrter als bei vielen anderen Autorinnen.

C. Wo ist der Posten der Frau?

Komödien und SCHaUSPiEle NACH 1850

Abgesehen von den neuen Bildungsansprüchen im 19. Jahrhundert bleibt die Komödien- und Schauspieltradition von Frauen bis zur Mitte des 19. Jahrhunderts in etwa die gleiche: der Vater fungiert als Autoritätsfigur, die Tochter als Untertanin; die Ehe ist unweigerlich das bittere Ende der Komödie. Diese Gleichförmigkeit der Schauspieltradition erklärt sich zum Teil aus der politischen Ereignislosigkeit dieser anderthalb Jahrhunderte, denn die Revolutionen von 1789, 1830 und 1848 hatten auf die soziale Stellung der Frau kaum Einfluß. Auch während der liberalsten Bestrebungen für soziale Änderung blieb die Hauptforderung für Frauen eine bessere Ausbildung - zu Privat-, nicht zu Berufszwecken. Politische Gleichberechtigung für Frauen wurde nur vereinzelt - und erfolglos - angesprochen; eine berufliche Arbeit der Frau überhaupt nicht. Die Ehe blieb nach wie vor der einzige „Beruf" der Frau. So blicb auch den Schauspielautorinnen nur übrig, dieses gesellschaftlich vorgeschriebene Komödienende aufzunehmen und daraus das Beste zu machen - oder auch nicht. Um die Mitte des 19. Jahrhunderts fand zum ersten Mal eine Entwicklung statt, die sich auch auf die Rolle der Frau auswirkte: mit der Industrialisierung verlagerte sich die gesellschaftliche Vormachtstellung vom Feudaladel auf das Großbürgertum; man wurde nicht mehr in eine Stellung geboren, sondern hatte sie sich zu erringen; Macht wurde zum ersten Mal nicht als gottgegeben, sondern erwerbbar betrachtet.
Gleichzeitig wurde Frauenarbeit zum ersten Mal institutionalisicrt. Dic Frauen, dic gezwungenermaßen in Fabriken dazuverdienten, waren keineswegs identisch mit denen, die finanziell sicher genug dastanden, um sich den schriftstellerischen Beruf erlauben zu können, aber das Phänomen Frauenarbeit wurde auch von ihnen beobachtet. Die Konsequenz, dic daraus gezogen wurde, war einfach: wenn Frauen plötzlich arbeiten mußten, folgte daraus, daß sie arbeiten durften; wenn es der Frau überhaupt erlaubt war zu arbeiten, mußte es auch möglich sein, ihre Berufschancen zu verbessern. In den 1860 er Jahren wurde die Frauenfrage zum erstenmal öffentlich gestellt; Hauptpunkt auf dem Programm der Frühfeministinnen war eine Ausbildung der Frau zu einigen wenigen ausgesprochen „weiblichen“ Berufen wie Krankenschwester und Lchrerin. ${ }^{23}$ Obwohl auch die Frühfeministinnen nur Berufe im Auge hatten, die Frauen nicht in den Verdacht bringen konnten, mit Männern konkurrieren zu wollen, obwoh politische Gleichberechtigung nach wie vor außer Frage stand, bedeutete schon die Idee einer erwerbstätigen Frau, egal in welchem Beruf, einen wichtigen Einschnitt in ihrer Geschichte: die Ehe war nicht mehr der einzig mögliche Beruf für sie, denn bei entsprechender Ausbildung auf anderen Gebieten hatte sie die Möglichkeit, ledig zu bleiben.

In Dramen von Frauen zwischen Jahrhundertmitte und Jahrhundertwende läßt sich dementsprechend ein klarer Einschnitt feststellen. Seit der Jahrhundertmitte existiert eine doppelte Schauspieltradition, die deutlich die Frage reflektiert: Wo ist der Posten der Frau? Eine dieser Traditionen beschäftigt sich nach wie vor mit der Frau als künftige Ehefrau, die andere mit der Möglichkeit der berufstätigen oder kunstausübenden unverheirateten Frau. Die erste Tradition ist weitgehend eine Weiterführung des von Franul von Weißenthurn und Amalie angeschlagenen Themas der gebildeten, unabhängigeren Frau, die sich den von ihr bevorzugten Mann entgegen der väterlichen Wünsche erwählt oder erspielt. Sie soll daher nur kurz beschrieben werden.

\section{DAMENWAHL: EHEKOMÖDIEN NACH 1850 HILLERN, CORNELIUS, YOUNG, EBNER-ESCHENBACH,} LEVI, VON SCHLICHTKRULI

Während der 1870er Jahre existiert eine Lustspieltradition, die sich stark an Franul von Weißenthurns Nachspiel anlehnt: in diesen meist einalktigen Komödien fuihrt eine Frau eine Komödie auf, um sich den Geliebten von der elterlichen Autorität zu erspielen. Die elterliche Autorität - in Wilhelmine von Hillerns (1836-1916) Guten Abend (1872) der Onkel und Adoptivvater, in Auguste Cornelius' (1826-1891) Nur ein Held (1877) vier Tanten - muß am Ende ihren Widerstand auf- und die Liebenden zusammengeben. Im Unterschied zu Franul von Weißenthurns Nachspiel, in dem der Onkel der Autor des Spiels im Spiel war und Leonore lediglich Figur in seinem Stück, werden diese Komödien von der Frau inszeniert; dic Autoritätsfiguren spielen nur die von ihr vorgesehenen Rollen. In Betty Youngs (1832-1887) Ein amerikanisches Duell (1872) heilt Helene durch ein ähnliches Spiel ihren Mann von seiner rasenden Eifersucht. Der Frauentyp, der in den Komödien bevorzugt wird, ist der des kecken, unabhängigen, 
etwas koboldhaften Mädchens (so in Marie von Ebner-Eschenbachs [1830-1916] Das Waldfräulein, 1873), meist kontrastiert mit dem traditionelleren sanft-nachgiebigen Frauentyp (so in Aline von Schlichtkrulls [1832-1863] Wie ein Staat gerettet wird, 1871 zuerst veröffentlicht; Elise Levis [1832-1892] Durch die Intendanz, 1878 und Der Erbonkel, 1887; und Marie von Ebner-Eschenbachs Männertreue, 1873). Die unkonventionelle Haltung dieser Figuren wird meistens durch einen Faktor entschuldigt bzw, erklärt: die Frauen sind entweder sehr jung (Hedwig in Levis Durch die Intendanz) oder außerhalb der Gesellschaft aufgewachsen (Sarah in Ebner-Eschenbachs Waldfraulein und Carry in Levis Erbonkel). Das ändert allerdings nichts an der Tatsache, daß gerade ihre Intelligenz und Unabhängigkeit ihre Hauptanziehungskraft darstellt: verschiedentlich sorgen sich die Mütter sogar um die Heiratschancen ihre Töchter, da diese unabhängigeren Frauenfiguren eine gefährliche Konkurrenz für die sanfteren und daher langweiligeren Töchter darstellen (Levis Erbonkel). Geheirate wird immer gemäß den Wünschen der Frau; die elterliche Autorität existiert nur noch im Bezug auf den sanften Frauentyp, der sich ihr unterwirft. Wo die nachgiebige Frau in Gefahr ist, ihren Wünschen entgegen zwangsverheiratet zu werden, wird ihr durch cine Intrige der unabhängigeren Frau der Weg zur Vereinigung mit dem Geliebten geebnet (Levis Intendanz und Erbonkel).

Ein weiteres Thema in Frauenkomödien dieser Jahre, vor 1850 äußerst ungewöhnlich, dreht sich um Probleme innerhalb einer bereits geschlossenen Ehe. ${ }^{24}$ Während die meisten Komödien vor 1850 entweder mit der Eheschließung enden oder die Probleme innerhalb der Beziehung (meist in empfindsamen Komödien des 18. Jahrhunderts) durch Verleumdungen Außenstehender herbeigeführt werden, werden jetzt oft ernstere Probleme angesprochen, wic Untreue des Mannes (in Ebner-Eschenbachs Männertreue), Vernachlässigung der Frau durch den Mann (in Bertha Hoffmanns [1816-1892] Ja, oder die Königin der Nacht, 1892), oder unbegründete Eifersucht des Mannes (in Youngs Ein amerikanisches Duell und Louise von François' [1817-1893] Der Posten de Frau, 1881). In allen Fällen erwägen die Frauen, ihre Männer zu verlassen (bei Ebner und Hoffmann) oder tun es tatsächlich (bei Young und François). Da der Posten der Frau aber nach wie vor im Haus des Mannes ist, bleiben sie oder kehren zurück, nachdem sie ihre Männer entweder bekehrt (Ebner, Young) oder mit ihnen erträglichere Bedingungen ausgehandelt haben (Hoffmann, François).

\section{BERUFSTÄTIGE FRAUEN}

a. Künstlerinnen oder Dilettantinnen? Breden, Hoffmann, Günther.

In Schauspielen zwischen 1870 und 1900 setzt sich verstärkt eine Tradition durch, in der die Frau berufstätig ist: als Schauspielerin (Bertha Hoffmanns Der Strohkranz, 1889), als Sängerin (Christiane von Bredens [1839-1901] Faustina, 1871), als Künstlerin (Maria Günthers [1854-1916?] Dilettanten und Kïnstler, 1892), als Schriftstellerin (Elsa Bernsteins [1866-1949] Wir Drei, 1891; und Günthers Sammelfieber, 1887), oder gar als Ärztin (Günthers Die beiden Hausärzte, 1889; und Bernsteins Dämmerung, 1893). Wie unterschiedlich diese verschiedenen weiblichen Berufe von Frauen gewertet werden, wirft ein interessantes Licht auf die Frage, welche Berufsmöglichkeiten für Frauen als akzeptabel dargestellt wurden und welche nicht.

Wo eine Frau künstlerische Ambitionen zeigt, handelt es sich nach wie vor um eine Verirrung, die furchtbar bestraft wird (Hoffmann, Breden), falls ihr nicht rechtzeitig Einhalt geboten wird (Günther). Christiane von Bredens fünfaktiges Drama Faustina 1871 unter dem Pseudonym „Ada Christen“ veröffentlicht, ist eine Uminterpretation von Goethes Faust, komplett mit einem hier machtlosen Mephistopheles, der Faustina als Werkzeug dient (Capitaine von Norrent) und einer männlichen Gretchenfigur namens Heinrich. Faustina ist eine gefeierte Sängerin, schön und unnahbar; dazu wird sie noch „bestrickender“ (8) durch ihre für eine Frau ungewöhnliche Ausbildung: sie hat Chemie und Naturwissenschaften studiert (8). Wie sich am Ende des Stückes herausstellt, ist ihre glänzende Karriere jedoch keineswegs das Ergebnis künstlerischen Ehrgeizes, sondern das ihrer persönlichen Gretchentragödic: Faustina bekam in ihrer Jugend ein uneheliches Kind, wurde von dem Vater des Kindes verlassen und kehrt jetzt zurück, um sich an dem gewissenlosen Verführer zu rächen. Während sie glaubt, ihr Kind sei tot geboren worden, hat der Verführer, der angesehene Kaufherr Warren, das Kind großgezogen. Faustinas Rache besteht darin, Warren seinen Sohn Heinrich zu nehmen, indem sie ihn den väterlichen Plänen entzieht. Heinrich soll wie Wilhelm Meister Kaufmann werden und wird von Faustina betört, eine Karriere als Sänger in Angriff zu nehmen, obwohl er nicht das geringste Talent dazu aufweist.

Faustinas Rachepläne sind von vornherein zum Scheitern verurteilt, da sie sich gegen ihr eigenes Kind richten und da zudem Warren den Sohn haßt und ihn nur widerwillig aufgezogen hat, weil er ihn an seine Jugendsünde erinnert. Faustinas diabolisches Rachebedürfnis wird am Ende des Dramas angemessen bestraft: Heinrich verliebt sich in Faustina und wird aus Scham über den von ihr inszenierten lkünstlerischen Mißerfolg wahnsinnig; Faustina stirbt an der Erkenntnis, daß Heinrich ihr Sohn ist, und aus Entsetzen über dessen inzestuöse Verliebtheit in sie; Warren überlebt. Da Faustinas ungewöhnliche Intelligenz und ihr Erfolg lediglich Ergebnis ihrer Rachepläne sind bewertet sie ihre Qualitäten entsprechend: das Leben der Künstlerin empfindet sie als glänzendes Elend, ein Motiv, das noch verstärkt wird dadurch, daß sie es als angemessene Strafe für den Vater empfindet, den Sohn in dieses Elend hinabzuziehen. Ihre Frage, ob „doch des Weibes Geist zu schwach“ (50, Hervorhebung der Autorin) sei, bezieht sich nicht auf die mögliche Konkurrenz mit Männern auf geistigem Gebiet, sondern auf die Möglichkeit, sich an ihnen zu rächen.

Besonders sprechend sind in diesem Zusammenhang ihre Äußerungen über die Frauenemanzipation, die sie zu einem Zeitpunkt macht, bevor ihre Rachepläne dem Publikum unterbreitet werden. Im ersten Akt ist sie, nach dem Informationsstand der Zuschauerin, lediglich die schöne, tugendhaft-unnahbare, gebildete und ungeheuer gefeierte Sängerin, die durchaus als Identifikationsmodell für Frauen gelten kann, und als solche äußert sie sich wie folgt:

ach, wie viel von innerlichster Weiblichkeit, von weichem Fühlen, stillem Glück läßt jede Frau auf jenen Wegen fallen, die zu dem Ruhm, zur echten Kunst sie 
führen. Ich lache jener Thörinnen, die für Gleichberechtigung der Frau fechten, denn es sind Unglückliche, die mit prahlenden Worten ihren Jammer zu verdekken suchen, Gescheiterte, an ihres Hauses Frieden Verzweifelnde, Einsame oder Abenteuerinnen oft der feinsten Sorte, Weiber, die die Sitte drückt, die nun für Freiheit keck plaidiren, weil unter Gleichberechtigung sie Zügellosigkeit verstehen. Glauben Sie mir Eines, jede Frau, die ihren engen Kreis verlassen, die herbes Schicksal, tolle Laune, heißes Fühlen, ein starker Geist aus ihren Grenzen trieb, [...] ist halb sich selbst entrissen, des Beifalls Sturm, der um sie tobt, kann sie betäuben, doch sie beglücken kann er nie und nimmer (25, Hervorhebungen der Autorin).

Faustina spricht aus Erfahrung; der starke Geist, der sic aus ihren Grenzen tricb, treib sie folgerichtig in den Tod. Der Wissensdrang, der Faust verderblich wird, der von sich behauptet, „alle Schätze/ Des Menschengeists auf mich herbeigerafft“ zu haben (Goethe, Werke III, 60, meine Hervorhebung), besteht für Faustina einfach in dem Bedürfnis, etwas zu wissen oder zu sein. Ganz wie im 18. Jahrhundert, man erinnere sich an Orsina, Marwood und Lady Milford, wird weibliche Intelligenz zum sichersten Zeichen verfehlter Bestimmung.

Bertha Hoffmann (1816-1892) behandelt das Thema in ihrem vieralktigen Versdrama Der Strobkranz (1889) auf ähnliche Weise. Hier stehen sich zwei professionelle Schauspielerinnen gegenüber, dic sanfte unterwürfige Nancy und die entschlossene Intrigantin Anna. Als der König einen Preis für die beste Darstellung der Ophelia aussetzt, gerät Anna in eine haßerfüllte Konkurrenz zu Nancy. Ihr schauspielerischer Eifer hat allerdings, ähnlich wie im Falle Faustina, nichts mit professionellem Ehrgeiz zu tun, sondern mit weiblicher Eifersucht: Anna liebt Nancys Verlobten Henry und setzt alles daran, die beiden auseinanderzubringen. Sie nutzt ihre schauspielerischen Talente beiden gegenüber zu übelsten Zwecken und fälscht schließlich eine schriftlich Liebeserklärung Henrys an sie, dic Nancy in die Themse treibt. Nancy wird gerettet und ins Irrenhaus Bedlam gebracht, wo Henry sie wiederfindet; sie erhält schließlich den Preis für ihre Ophelia, und Anna endet im Wahnsinn.

Nancy und Anna werden von anderen Figuren im Stück sowohl als Frauen als auch als Schauspielerinnen ununterbrochen einander entgegengesetzt, ein Vergleich, der sehr zu Ungunsten Annas ausfällt. Die üblich gebrauchten Gegensatzpaare für die Pole Anna-Nancy sind Unke und Nachtigall (4) oder Schlange und Taube $(21,42)$. Nancy hat hehre Vorstellungen vom Beruf einer Schauspielerin; für sie ist ihr Beruf eine Religion, ihr Zweck die ästhetische Erziehung des Menschen (7). Anna dagegen spielt ihre Rollen sowohl auf dem Theater als auch ihren verschiedenen Verehrern gegenüber und äußert sich entsprechend illusionslos über das Leben am Theater. Nancys entscheidender Vorteil Anna gegenüber ist die völlige Identifikation mit ihrer Rolle. Bereits in der zweiten Szene, in der Henry sie begeistert als Ophelia begrüßt und ihr bezeichnenderweise von der Selbstmordszene vorschwärmt, ist ihr, „als zögen mich die Fluthen tief -l weise von der Selbstmordszene vorschwärmt, ist ihr, , ,als zögen mich die Fich Ophelia" (8, Hervorhebungen der Autorin). Genau in dieser Identifikation liegt die Aufgabe der vollendeten Künstlerin, denn den Preis erhält die, die ,jene Zartheit einer Liebenden/ Zum Leben zaubern kann, daß man das Spiel/ Vergißt" (5).

Die Identifikation, die Nancy zu Ophelia macht, bezeugt die Echtheit ihrer Kunst, während Anna die Rolle nur spielt; die Aufgabe der vollendeten Schauspielerin ist nicht zu spielen, sondern zu sein. Auf persönlicher Ebene gilt selbstverständlich das gleiche: Anna intrigiert/spielt, um Nancy aus dem Weg zu räumen und Henry zu gewinnen, während Nancy ganz ,ist“ „ „[...] was ist des Weibes/ Bestimmung? Linde Trösterin des Mann's/ Zu sein!" (45) Nancy „ist“ Ophelia, indem sie deren Geschichte zu ihrer eigenen macht (durch ihren Selbstmordversuch in der Themse und ihre temporäre Geistesverwirrung in Bedlam), und darf in der letzten Szene die Rolle nicht mehr spielen, da sie durch ihr "Sein" die Wahrheit bereits gesagt hat (72). Anna dagegen betritt dic Bühne mit Ophelias Wahnsinnslied auf den Lippen und verfällt beim unerwarteten Anblick Nancys in echten Wahnsinn - in den der Lady Macbeth. Annas Ausruf bei Nancys Anblick - „- bist Du - Ophelia!!!? [...] Bin ich in sie gefahren, - sind wir zwei?" (74) deutet auf die Teilung der Opheliarolle in Ergebung und Entsagung (Selbstmord) und Leidenschaft (Wahnsinn). Der der Frau angemessene Part ist selbstverständlich der entsagende, die „Zartheit einer Liebenden“, die den leidenschaftlichen Teil der Rolle völlig ausschließt. Diese Rollen werden am Ende des Stückes entsprechend verteilt, gemeinsam mit dem Lohn und der Strafe, der jeder Rolle angemessen ist. Während Anna Ophelias Strohkranz (Wahnsinn) übernimmt, verwandelt sich der Strohlsranz für Nancy in Lorbeer (Ruhm), und, was wichtiger ist, Myrthe (Ehe), und dic zart Liebende entkräftet den Fluch, den Henry Anna nachschickt, mit den versöhnlichen Worten: „Henry, sei sanft! Laß Liebe walten [...]. Ich hab’ ja Dich, mein Alles, neu gefunden!“ (75)

Während in Schauspielen dieser Jahre häufig das schreckliche Schicksal dargestellt wird, das Frauen befällt, die „ein starker Geist aus ihren Grenzen trieb“, konzentrieren sich die Lustspiele mehr auf die Unvernunft der Ausbildung künstlerischer Ambitionen in Frauen. In Maria Günthers (1854-1916?) Dilettanten und Kilnstler (1892) werden Cäcilic und Editha von ihrer ehrgeizigen Mutter Hortense unfreiwillig zu Sängerinnen ausgebildet; die Mutter selbst schreibt unter einem männlichen Pseudonym schlechte Romane. Diesen Dilettantinnen gegenüber stehen die echten Künstler; Regine, eine Malerin, und ihr Bruder Erich Hammer, Dirigent und Komponist, der sich als Musiklehrer sein Brot verdienen und sich täglich von Edithas und Cäcilies Gesang die Ohren beleidigen lassen muß. Die Handlung des Stückes dreht sich um die Verheiratung der Töchter und um ihre Bekehrung von ihrem Kunstdilettantismus zu wahrem Hausfrauentum. Denn während künstlerische Betätigung beim Mann als positive Eigenschaft gilt, ist sie bei der Frau bestenfalls unschuldiger Dilettantismus, schlimmstenfalls Verstellung und vertreibt „den armen Mädchen höchstens die Freier, wird sie womöglich noch zu alten Jungfern machen" (68).

Die Frau, um die ein Mann sich beruhigt bewerben lkann, sicht anders aus: „Klein, unbedeutend, talentlos und unverdorben? Das gefällt mir! Nichts Schrecklicheres als eine talentvolle Frau! Ein Naturkind will ich haben, frisch und ungekünstelt, dem jede Lüge und Verstellung fernliegt" (14). Obwohl das Stück auch eine weibliche 
Künstlerin (Regine) und einen männlichen Dilettanten (Stembuleff) aufzuweisen hat, sind beide Nebenfiguren und an der Handlung, deren Akzent eindeutig auf der Bekehrung der Dilettantinnen liegt, kaum beteiligt. Regine und Stembuleff sind die Ausnahmen, die die Regel bestätigt: Kunst ist Männersache. Daß dem so sei, wird im Stück durch den sozialen Ab- bzw. Aufstieg der Dilettantinnen und Künstler demonstriert: Hammers künstlerische Begabung führt ihn zu Ruhm und Ehren, Hortenses Dilettantismus sie und ihre Familie in den finanziellen Ruin. Cäcilie und Editha befreien sich schließlich von den ihnen mütterlicherseits aufgedrungenen Ambitionen, entdecken ihr wahres Talent "Zur guten Hausfrau“ (70) und begeben sich in die der Frau vorgeschriebenen Grenzen zurück: Cäcilie „malt" zwar immer noch - aber nur noch Kaffec; Editha singt weiter - aber nur noch Wiegenlieder (78). Die Künstlerin der das Todesurteil gesprochen wird, ersteht als Haus- und Ehefrau des männlichen Künstlers wieder auf. "Für Dich allein will ich fortan leben, in Deinem Ruhm will ich mich sonnen! Um den Platz an Deinem Herzen gebe ich alle Triumphe, alle Huldigungen der Welt dahin!“ jubelt die bekehrte Editha (80).

\section{b. Ärztinnen oder Quacksalber? Günther, Bernstein}

Ähnlich erfolglos verläuft in Schauspielen von Frauen die Karriere der Frau als Ärztin. Maria Günther erbringt in Die beiden Hausdrzte (1889) den schlagenden Beweis dafür daß Frauen zum Studium der Medizin denkbar ungeeignet sind. Das Stück spielt in Hermine von Langfelds Pension, in der mehrere Frauen vom Gifthauch der Emanzipation befallen sind. Allen voran steht das Schreckbild der Philologiestudentin Irma, die raucht, trinkt und in äußerst burschikoser Sprache für die Emanzipation der Frau eintritt, sich selbst dem wissenschaftlich unwiderlegbaren Argument verschließend, daß das Gehirn der Frau um 220 Kubilkzentimeter kleiner sei als das männliche (3). Von ähnlichen Phantastereien genarrt, hat Hermine ihre Nichte Bianla zum Medizinstudium gezwungen, damit endlich der Beweis erbracht ist, daß Frauen befähigt sind, Ärztinnen zu werden. Unter den „Pensio-Närrinnen“ (22) findet sich außerdem die „halbe Gelehrte“ (24) Georgine, die zwar reich und schön ist, aber auch intelligent, und sich etwas darauf einbildet, sich nicht von einer Uniform beeindrucken zu lassen. Es scheint also, als ob einer ganzen Reihe von Damen hier eine gründliche Lektion erteilt werden müßte. $\mathrm{Zu}$ diesem $\mathrm{Zweck}$ finden sich mehrere vernünftige männliche Helden bereit: Major Krause, Hermines Bruder, der „die emanzipirten Frauenzimmer, Schriftstellerinnen, Malerinnen und Alles, was dahin gehört, nicht ausstehen" kann (24); Doktor Schönhut, der gegen die Narrheit der Pensionärinnen kämpfen muß, um ihnen die Gesundheit zu erhalten; Lieutenant Oswald Freistedt, der Georgine von ihrem Antimilitarismus heilt und sie zur gebührenden Bewunderung uniformierter Helden bekehrt, und Hellmuth, Hermines Sohn, der auf dem Standpunkt steht, eine Frau solle höchstens die Hälfte von dem wissen, was der Mann weiß (14).

Ein guter Teil der Verwirrungen wird durch Hermines Regiment und ihren Einfluß auf andere Figuren angerichtet. So bringt sie z. B. ihren Sohn Hellmuth dazu, Georgine zu umwerben, weil diese reich ist, obwohl er sich vor deren Gelehrtheit fürchtet und in die weniger bedrohliche Alice verliebt ist. Ebenso verfehlt ist Hermines Plan, anhand von Biankas Medizinstudium die wissenschaftliche Befähigung der Frau zu beweisen Bianka hat bereits nach dem ersten Semester das Studium der Medizin aufgegeben und stattdessen Kunst und Photographie studiert, weil sie beim ersten Betreten des Seziersaals in Ohnmacht gefallen ist. Da Bianka sich nicht traut, ihrer Tante gegenüber ihre Unfähigkeit zum Arztberuf zuzugeben, nimmt das Schicksal unabänderlich seinen Lauf: Hermine entläßt Doktor Schönhut als Hausarzt der Pension und stell stattdessen Bianka ein, obwohl diese beim Anblick von Blut in Ohnmacht fällt und den Medizin- gelegentlich mit dem Mallkasten verwechselt. Der gewesene Hausarzt Schönhut, der überall wiedergutmachen muß, was Bianka verpfuscht, verliebt sich in sie, ist aber zu entsetzt über ihre anmaßende Berufswahl, um sich uin sie zu bewerben. So muß Bianka zunächst von ihren Ambitionen - die nicht einmal eigene, sondern die Hermines sind - kuriert werden. Krause und Schönhut kurieren sie dadurch, daß sie die Gefahr jeder Krankheit ins Maßlose übertreiben und sie so in ständige Angstzustände versetzen. Schließlich zeigt sich Biankas Unfähigkeit in ihrem vollen Umfang, als sie ein harmloses Pülverchen mit Morphium verwechselt und dadurch drei ihrer Patienten in tiefen Schlaf versenkt, der ihr gegenüber zur Lebensgefahr stilisiert wird. Bianka wird schließlich ab- und Schönhut in seine Rechte wieder eingesetzt; und damit ist der Moment gekommen, in dem er sich um ihre Hand bewerben kann - nicht ohne ihr die obligatorische Standpauke zu halten, mit der weibliches Streben belohnt wird.

SсHÖNHUT. Warum sind Sie aus den Schranken Ihrer holden Weiblichkeit herausgetreten?! Meinen Sie denn, daß es so leicht ist, Kranke zu kuriren? Dazu gehört die ganze Energie, die volle geistige Kraft des Mannes! [...] Gehen Sie in sich, entsagen Sie diesem Berufe, den Sie nie hätten erwählen sollen! [...] Kind, bedenken Sie, wenn Sie so fortfahren, sterben die Menschen unter Ihren Händen ja wie die Fliegen! (77)

Auf Biankas Frage, was sie stattdessen machen solle, erfolgt erwartungsgemäß die Antwort: „Heirathen Sie. Das ist Ihr wahrer Beruf. [...] Es wird sich schon Einer finden, sagen Sie nur nicht, daß Sie Arzt sind“ (78). Jetzt lkann Bianka freudig zugeben, daß sie gar keiner ist, jetzt kann Schönhut sich überglücklich um ihre Hand bewerben, jetzt folgt die glückliche Auflösung mit Biankas Bekenntnis zu ihrem neuen "Beruf" als „Deine Hausfrau" (78).

In ganz ähnlicher Weise wird Georgine eine Lektion für ihren Hochmut - d. h. den Stolz auf ihre Intelligenz und ihre Verachtung für uniformiertes Heldentum - erteilt, bis sie sich in Oswald verliebt und sich dem Mann der deutschen Truppe „Auf Gnade und Ungnade" ergibt (72). Die ausführlichen männlichen Standpauken, die ihren Triumph über die weibliche Widersetzlichkeit begleiten, sind im Grunde reichlich überflüssig, da das Unabhängigkeitsbestreben der Frauen meist genauso unecht ist wie Biankas medizinische Tätigkeit. Ebenso wie Bianka die Ärztin spielt, spielen die Pensionärinnen die Emanzipierten; tatsächlich aber befinden sich fast alle auf Männerfang. Sie ergehen sich in Eifersüchteleien, spielen die Kranken, um den Arzt einzufangen, 
und streiten sich bei einer Männerparade um die besten Fensterplätze, von der aus sie ihre Helden mit Blumen und Kußhändchen überschütten (39 f). Selbst die emanzipierte Philologiestudentin Irma kommentiert die Verlobung zwischen Bianka und Schönhut in einer Weise, die deutlich macht, daß sie trotz aller emanzipatorischen Rhetorik nur ein Ziel verfolgt: sich selbst schnellstmöglich an den Mann zu bringen.

IRMA. Ich begreife Sie nicht, Fräulein Doktor! Der Wissenschaft entsagen eines Mannes wegen! Das würde ich nie thun!

HABERSTROH (zu Bianka halblaut). Weil sie keiner will!

BianKA. Ich bin einmal nicht dafür geschaffen! (Zu Schönhut). Aber daß ich kein Arzt sein kann, ist noch kein Beweis, daß nicht andere Frauen die Befähigung besitzen, erfolgreich mit Euch zu konkurrieren!

ScHONHUT. Dann heirathen wir eben unsere Rivalinnen! (Umarmt Bianka).

KraUSE (lachend). Die beste Art, sie unschädlich zu machen!

IrMA (kokett). Wüßten Sic nicht vielleicht Jemand, der mich unschädlich macht? (78 f, Hervorhebungen der Autorin)

Diese kurze Passage ist vollgepackt mit Themen, die heute noch nicht überholt sind: die Alternative Beruf oder Ehe für die Frau, da beides unvereinbar scheint; die Vorstellung von der emanzipierten Frau als Jungfrau älteren Kalibers, die „keinen abgekriegt“ hat; die Konkurrenzängste vicler Männer, sobald Frauen sich in von ihnen besetztc Berufe wagen. Hier werden die meisten dieser Themen nur leise angesprochen; die Frage z. B., ob alle Frauen, wie Bianka, auf wissenschaftlichem Gebiet zum Versagen verurteilt sind, wird nur kurz angetippt und ertrinkt im Gelächter der männlichen Sieger.

Die Moral des Stückes ist relativ simpel: die Ehe ist, nach wie vor, der Hauptberuf der Frau - vgl. Dilettanten und Künstler. Die Frau darf sich allenfalls in einige wenige „weibliche“ Berufe versteigen: während Biankas gespielte Tätigkeit als Ärztin „ein Nonsens, ein Unding“ ist, ebenso wie die gesamte "sogenannte Frauenemancipation" (14), scheint ihr Kunststudium weitaus akzeptabler. Vor allem aber bestätigt das Stück Hellmuths erklärte Ansicht: wenn eine Ehe glücklich sein soll, muß der Mann die Oberhand behalten, vor allem auf geistigem Gebiet. „Es ist gar nicht schön, wenn Frauen so gelehrt sind. Nur fähig müssen sic sein, unserem Gedankenfluge zu folgen; im Uebrigen sind und bleiben sie doch immer nur das schwache Geschlecht!" (14, Hervorhebungen der Autorin) Deshalb bekommt Hellmuth die nachgiebige und nicht besonders helle Alice, die allenfalls klug genug ist, sich dümmer zu stellen, als sie ist, um dem Mann das Bewußtsein seiner Überlegenheit zu erhalten; deshalb bekommt Bianka, die immerhin, aber eben doch „nur" Kunst studiert hat, einen Arzt; deshalb muß die intelligente Georgine vor ihrem Krieger Oswald in den Staub sinken: in allen Fällen kann der Zuschauer die beruhigende Versicherung mit nach Hause nehmen, daß $e r$ mit $i h r$ fertig wird. In diesem Kontext läßt sich Biankas bißchen Hobbymalerei und -photographic allenfalls verkraften - ähnlich wie Hammer Editha erlaubt, „Ihre liebliche Stimme in meinem Heim [...] ertönen [zu] lassen" (Dilettanten und Kïnstler 80)
Irmas Philologiestudium, Georgines intelligenzbegründeter Hochmut und Hermines medizinische Ambitionen für Bianka dagegen werden als der Gipfel weiblicher Verstiegenheit und, da es sich um eine Komödie handelt, der Lächerlichkeit dargestellt. Die Frauen, die sich durch entsprechende Lektionen vom Sockel der Hochmut herunterholen lassen, werden durch die Ehe mit einem Anhänger des starken Geschlechts unschädlich gemacht; Irma dagegen, die wieder keinen „abkriegt“, bleibt zum einsamen Emanzentum verurteilt.

Eine ernsthaftere Darstellung einer berufstätigen Frau findet sich in Elsa Bernsteins (1866-1949) naturalistischem Drama Dämmerung (1893). Sabine ist eine äußerst fähige Augenärztin, die die Tochter des Komponisten Ritter behandelt und sich zunächst gegen seine Vorurteile gegen gebildete Frauen durchsetzen muß. Er hält das Studium der Frau für „moderne[s] Sauzeug" (46) und die Frau für geistig minderbemittelt: "Wie kann denn so ein Unterrock Verstand haben. Fingerhutverstand - höchstens" (29). Als sie ihm durch ihre kompetente Behandlung seiner Tochter Isolde das Gegenteil beweist, verliebt er sich in sie - und sie sich in ihn. Damit beginnt Sabines erstaunliche Verwandlung, denn auch Ritter hält nichts von allzu intelligenten Frauen „Machen Sie doch nicht ein so weises Gesicht. Es steht Ihnen viel besser, wenn Sic ein bißchen erschreckt aussehen und dumm" (109) -, und nährt heimlich die Hoffnung: „Vielleicht gewöhnen Sic sich's noch ab - das Kritische" (109). Sabine nimmt bei ihm Gesangsstunden und läßt sich von ihm tyrannisieren, bis von ihrem ehemals kompetenten Auftreten wenig übrigbleibt. Als sic eine Forschungsstelle in Berlin erhält, macht er ihr einen Heiratsantrag - über den sie vor Freude in Ohnmacht fällt und den sie, nachdem er ihr versichert, sie sei „gut genug" für ihn, "voll namenlosen Glücks" annimmt (112). Mit dem namenlosen Gliick befällt sie eine gewisse Lethargie - „Jetzt ist mir alles recht" (112) -, die sie befähigt, ihren Beruf aufzugeben und sich in der Ehe zu ihrem Glück zwingen, unter Umständen auch prügeln zu lassen:

RiTTER. [...] Ist das nun nicht hunderttausendmal schöner als die ganze lumpige Medizinkomödie?

Sabine (den Kopf an seine Schulter gelegt): Schöner - ist es.

RITTER. Ich werde dich lehren glücklich sein. Schläge kriegst du, wenn du nicht glücklich bist. Und den Verstand treib' ich dir aus.

SABINE. Ich will ganz dumm werden - ganz glücklich dumm (113 f).

Das wird sie auch müssen, denn Ritters Auffassung der Ehe erlaubt keinerlei Alternative. „Du wirst mir überhaupt folgen. Neumodische Mucken gibt's nicht" (112). Selbst das kurz zuvor gegebene Versprechen, sie „weiter doktern“ zu lassen, scheint er jetzt zurücknehmen zu wollen: "Meine Braut ist eine Dame, kein Doktor" (115). Weiter bestchen bleibt dagegen ihre Rolle als seine Musikschülerin, denn in der Rolle des Maestro geht er geradezu auf. „Du hast noch viel zu lernen, mein Kind. Und nun Takt halten. Eins zwei - cins zwei“" (115).

Das Ehe-Glück, das Sabine droht, scheitert an Isoldes Eifersucht, die den Vater mi aller Gewalt für sich behalten will und ihn durch einen Selbstmordversuch und ihre 
schließliche Erblindung völlig an sich fesselt. Am Tag vor Sabines Abreise nach Berlin unternimmt Sabine einen letzten Versuch, ihre Liebe zu retten: sie fleht Ritter an, sie als Pflegerin ins Haus zu nehmen, ohne sie zu heiraten. „Ich will meinen Beruf aufgeben. Ganz. Ich will mit dir gehen - und sic pflegen. Ich will gar nichts für mich brauchen. Ich will so sparsam sein. Ich will alles thun, was sie will. Nur daß ich bei dir bin. Nur daß ich bei dir bin" (134 f). Aber Ritter kann dieses Opfer nicht annehmen, denn Isolde würde „sich verzehren und verzehren“ (135). Sabines Ausbruch - „Aber ich sterbe ja, ich sterbe ja -" (136) - beantwortet er mit einem Vertrauen in ihre Standhaftigkeit, die sie längst verloren hat. Letztendlich lernt sic die Kunst der Entsagung von ihm: in einem Moment der Leidenschaft ist er kurz davor, ihr Opfer anzunehmen, und hält sich im letzten Moment zurück. „[...] wie darf ich denn dir so was thun. Dir!" (137). Die Größe seiner Entsagung überwiegt die Tatsache, daß sie ihren Beruf und die Hoffnung auf eine Ehe mit ihm aufgeben wollte, bei weitem, denn Entsagung, für Frauen eine Selbstverständlichkeit, macht Männer zu Heiligen - und gibt den nur menschlichen Frauen den Mut, ihrem großen Beispiel zu folgen.

SABINE (aufschreiend): Heinrich! Du heiliger Mensch - (Wie ein Kind mit seitwärts geneigtem Kopf und verschlungenen Händen zu ihm aufsehend) Nun hab ich Frieden. Nun geh' ich (137, Hervorhebung der Autorin).

Obwohl die Fähigkeit der Frau zu beruflicher Tätigkeit hier nicht angezweifelt wird, wird doch eins unmißverständlich ausgedrückt: für die Frau ist der Beruf nicht der Weg zum Glück.

Zu Beginn des Stückes ist Sabine kompetent, anerkannt, offen oder widerwillig bewundert, eine Kapazität auf ihrem Gebiet - aber glücklich ist sie nicht. Im Gegenteil empfindet sie ihren Beruf nicht als Quelle der Befriedigung, sondern als Entsagung, als Dienst an anderen. Daß das Glück für sie, nach ihrer eigenen Auffassung, in einer Ehe mit Ritter bestanden hätte, ist klar; ebenso daß sie in dieser Ehe ihren Beruf hätte aufgeben müssen, um "ganz glücklich dumm“ zu werden. Die Tragödie am Ende des Stückes für sie besteht in der erzwungenen Rückkehr zu ihrem Beruf, nachdem sie das „namenlose Glück“ kennengelernt hat.

"Glücklich dumm" ist keineswegs eine Ironisierung der Autorin, sondern eine objektiv gemeinte Umschreibung des weiblichen Dilemmas: eine Frau kann berufstätig sein oder verheiratet, intelligent oder glücklich, beides zusammen kanı sie nicht. Mit etwas Phantasie kann man sich vorstellen, welchen Eindruck das tragische Ende des Stiickes, das dieses Ultimatum formuliert, auf eine Zuschauerin gemacht hätte, die mit dem Gedanken spielte, ins Ausland zu gehen, um dort zu studieren (in Deutschland waren Frauen bis um die Jahrhundertwende vom Hochschulstudium ausgeschlossen). Weibliche Fähigkeiten werden bei Bernstein zwar nicht lächerlich gemacht - wie z. B. bei Günther -, aber als ebenso gefährlich dargestellt: bei Breden treiben das Talent und der Ehrgeiz der Frau sie in den Tod, bei Hoffmann in den Wahnsinn - hier führen sie in die Einsamkeit. c. Schriftstellerinnen oder Blaustrïmpfe? Droste-Hülshoff, Günther, Bernstein.

Die Frage, warum viele Frauen so vehement gegen eine lkünstlerische oder berufliche Tätigkeit der Frau eintraten, kann nur durch Spekulationen beantwortet werden. M.E. bestcht Grund zu der Annahme, daß ein guter Teil dieser Vehemenz auf die Angst der Autorinnen zurückzuführen ist, als „Blaustrümpfe" verfemt zu werden, weil sie schriftstellerisch tätig waren. Daraus ergibt sich zweicrlei: zum einen das Bedürfnis, die eigenen proklamierten Ansichten denen der Machtgruppe anzupassen (indem man beispielsweise die Frau ins Haus verweist), zum anderen das Bedürfnis, von der eigenen beruflichen Tätigkeit abzulenken - indem man andere Berufe als „unnatürlich“ bzw. "unweiblich“ darstellt. ${ }^{25}$ In Stücken, in denen Schriftstellerinnen dargestellt werden, ändert sich der Ton: hier wird oft gegen das verbreitete Vorurteil angegangen, das eine Schriftstellerin zum „Blaustrumpf“ erklärt. Teilweise demonstriert die dargestellte Autorin ihre Weiblichkeit und Vernunft dadurch, daß sie die sogenannten "Emanzen" in schärfsten Tönen verdammt. Daß der Beruf der Schriftstellerin nicht gegen die Weiblichkeit der Frau verstößt, zeigt sich darin, daß die Schriftstellerin, anders als die Künstlerin oder Ärztin, oft sogar heiratet, ohne ihren Beruf aufgeben zu müssen.

Das gängige Vorurteil gegen schreibende Frauen behandelt schon Annette von Droste-Hülshoff (1797-1848) in ihrem Einakter Perdu! oder Dichter, Verleger, und Blaustrümpfe (1840). Die Unterscheidung zwischen Dichter und Blaustrumpf ist denkbar einfach: ein Schriftsteller ist ein Dichter, eine Schriftstellerin ein Blaustrumpf. Im Personenverzeichnis stehen drei Dichter (Sonderrath, Willibald und Seybold) und ebensoviele Blaustrümpfe: Frau von Thielen, „Blaustrumpf von Stande", Claudine Briesen, „naiv-gefühlvoller Blaustrumpf", und Johanna von Austen, „Blaustrumpf DU BON VIEUX TEMPS“ (Dramatische Versuche 3, Großschreibung der Autorin). Über die schriftstellerischen Ambitionen von Frauen wird recht einmütig geurteilt: laut Verleger Speth sind Schriftstellerinnen „abgetakelte Fregatten“ (11), in der Beschreibung seiner Frau sind sie alternde, häßliche, lächerliche Figuren, die liederlich herumlaufen.

Die Implikation ist in beiden Interpretationen die gleiche: ein Blaustrumpf ist cine alternde Frau, unfreiwillig unverheiratet geblieben, und eine schlechte Hausfrau. Ähnlich äußert sich Sonderrath über Briesen („Satan von einem Weibe“, 45) und von Austen (,alte wacklige CARCASSE“, 46, Großschreibung der Autorin). Willibald hält wenig von "Weiberarbeit", bei deren Anblick ihm „schon ganz miscrabel" wird, und hält dafür, die Frauen sollten „bei ihrem Strickstrumpfe bleiben“ (17). Verständlich, daß er sich ärgert, als Speths Tochter Ida ihm über seine Verse das Kompliment macht, sie seien weich und einfühlsam, ,so als wenn sie allenfalls von einem Frauenzimmer herrühren könnten" (22); kein Wunder, daß cr sich beeilt, sie in die Schranken zu weisen: „ich glaube um dic Gedichte so recht - ich meine so in tiefstem Grunde aufzufassen, muß man doch wohl - ein Mann seyn" (22, . Hervorhebung der Autorin). Zunächst scheint nichts dieses althergebrachte Vorurteil zu widerlegen: von Austen zitiert schaudernd Grabeslyrik; Briesen beschreibt Landschaften in pathetisch-empfindsamer Sprache, liest ihr jüngstes Werk halblaut, um sich zu profilieren, und läßt es von Willibald erbarmungslos zusammenstreichen, weil sie sich von ihm eine gute Rezension erhofft. 
Die einzige Frau, die als ernstzunehmende Schriftstellerin in Frage kommt, ist Frau von Thielen, und die tritt nur ganz am Ende kurz auf und wird ansonsten von ihrem Bewunderer Seybold beschrieben. Seybold muß sich seinem Freund Sonderrath gegenüber dic üblichen Vorurteile verbitten, die auch Männer angehen: denn wenn eine schreibende Frau cin Blaustrumpf ist, ist ein Mann, der ihr Talent anerkennt, logischerweise ein Pantoffelheld (48), der sich „einen Blaustrumpf angeschnallt" hat (47). Nachdem das ausgestanden ist, versucht Seybold, von Thielens Gedichte bei Speth anzubringen. Der aber will sie nicht verlegen, obwohl er ihr „einiges Talent" gar nicht abspricht (55), weil Gedichte, zumal von einer Frau, immer ein Verlustgeschäft sind. Seybold verpflichtet sich, ihm die Kosten der Veröffentlichung zu ersetzen, und so kommt das Geschäft doch noch zustande. Gleich darauf tritt die Autorin selbst auf: laut Bühnenanweisung „eine große schöne Frau, von sehr vornehmen Anstande, sie ist einfach aber reich gelkleidet“ (57). Das ist so deutlich gehalten, um das gängige Vorurteil zu widerlegen, das Schriftstellerinnen mit sitzengelassenen Vogelscheuchen identifiziert (schon vorher bezeichnet Seybold sie als eine „Juno, nur viel anmuthiger", 48). Außerdem wird in dieser Beschreibung von vornherein klargestellt: wenn eine Frau von Thielen ihre Gedichte veröffentlicht, dann zu ihrem Vergnügen, finanziell hat sie’s nicht nötig. Dementsprechend zieht sie die Veröffentlichung zurück, sobald sie errät, daß Speth ein Verlustgeschäft fürchtet, und verursacht damit einen neuen Ausbruch von seiten Speths: „hochmüthige CREATUR! - behalt deine Gedichte und ließ sie dir selber vor, dann hast du ein Publikum das dich anbethet!" (59, Großschreibung der Autorin) ${ }^{26}$

Was Droste-Hülshoff hier kurz gefaßt auf die Bühne bringt, ist das Dilemma der Schriftstellerin: sie kann entweder veröffentlichen, indem sie sich der Lächerlichkei aussetzt, Verleger bekniet und sich ihre Werke von männlichen Kollegen zusammenstreichen läßt (Briesen), oder sie kann der Schande entgehen, indem sie für die Schublade schreibt. Denn der Grund, aus dem Frau von Thielen sich gegen die Veröffentlichung ihrer Gedichte entscheidet, liegt weniger in ihrer Sorge um Speths geschäftliche Einnahmen als in der Angst vor der Mißachtung ihres Werkes, die in seinen Worten liegt und die durch eine Veröffentlichung allgemein würde.

Frau von Thielen. Sie fürchten Schaden bei dem Unternehmen?

SPETH (ganz verwirrt). O der könnte doch nur gering sein! es ist ja nur ein kleines Bändchen, - gleichsam cine BAGATELLE -

Frau von Thielen (feuerroth). Darauf darf ich es doch nicht ankommen lassen. Herr Seybold, wollen Sie die Güte haben sich das MANUSCRIPT wieder auszubitten? (58, Großschreibungen der Autorin)

Das ist in etwa die Wahl, die der Schriftstellerin 1840 gelassen wird: entweder sie schreibt unveröffentlichte Gedichte oder veröffentlichte Bagatellen. In der öffentlichen Meinung existiert sie entweder als „Blaustrumpf" oder als "hochmüthige Creatur", die selbst ihr einziges Publikum ist oder ihre Gedichte ihrer Kammerjungfer vorliest (wie Briesen und, in Speths Ausbruch, Frau von Thielen).
Ein halbes Jahrhundert später wurde verschiedentlich der Versuch gemacht, das Zwittergeschöpf Blaustrumpf in die Gesellschaft zu integrieren, indem man es zur. guten Hausfrau und potentiellen Ehefrau erhob. In Maria Günthers Sammelfieber (1887) ist die Schriftstellerin Marianne Schmidt nur eine Nebenfigur; die Haupthandlung der Komödie dreht sich um die Heilung des Rentiers Ebersberg von seiner unseligen Sammelleidenschaft durch Frau und Schwiegermutter, und um die Bekehrung von Ebersbergs Schwester Lconore von der literarischen Schwärmerin zur genügsamen Hausund Ehefrau. Leonore hat sich literarisch in einen Schriftsteller verliebt und will mit ihm einen Briefwechsel à la Goethe und von Stein anfangen. Das erregt schwere Sorgen bei ihrem Verlobten Otto: „Wieder am Schreibtisch? Werden Sie nur kein Blaustrumpf? (Für sich.) Damit es mir nicht geht wie Bruder Karl!“ (12) Bruder Karl war nämlich vor langen Jahren mit einer Schriftstellerin verlobt, die sich unglücklicherweise weigerte, ihren Beruf bei der Heirat aufzugeben, und mußte die Verlobung selbstverständlich lösen. Die Angst vor gleichem Schicksal verleitet Otto schließlich zu folgendem Ausbruch:

Vermehren Sie nicht die Zahl der überspannten Frauenzimmer, die - aus schlech angebrachter Begeisterung für einen Talmidichter - schließlich selbst - o Graus! anfangen zu schreiben! Auf solche Art entstehen die Blaustrümpfe, die die Welt mit schlechter Prosa und noch schlechteren Versen überschwemmen, anstatt als treue Gattinnen und Mütter die Fersen der Strümpfe ihrer Männer und Kinder zu stopfen! O Leonore! Stopfen Sie! Stricken Sie! (32 f).

Diese männliche Panik vor weiblicher Intelligenz ldingt lächerlich - und soll auch so klingen -, obwohl Leonore am Ende des Stückes doch noch sein „liebes, liebes Bräutchen" wird und ihm fest verspricht, alles zu unterlassen, „was Dir mißfällt" (86). Denn eine Schriftstellerin kann durchaus auch eine „echte Frau“, sprich Haus- und Ehefrau, abgeben, zumindest nach Ansicht der meisten weiblichen Figuren im Stück. Die Diskussion um die Frage, ob Weiblichlkeit und Schriftstellerei miteinander vereinbar sind, illustriert das physische Schreckbild des Blaustrumpfs recht deutlich: ein Blaustrumpf ist mehr Hexe als Frau - man erinnere sich an Droste-Hülshoffs „alte Carcasse“.

LeONORE. [...] Nur fürchte ich, daß Sie sowohl Schönheit wie Liebenswürdigkeit bei Blaustrümpfen vergeblich suchen werden!

THEKIA (kopfschüttelnd). Nicht jede Schriftstellerin muß ja zugleich auch ein Blaustrumpf sein, von erschreckender Magerkeit, mit kurz abgeschnittenen Haaren und einer Brille auf der, aus Wissensstolz möglichs hochgetragenen Nase!

BERTHA. Ich behaupte sogar, daß sich echte Weiblichkeit mit dem Berufe der Schriftstellerin sehr wohl vereinigen läßt!

Rudlorf. Ah bah, die Hand, die gewohnt ist, die Feder zu führen, wird schwerlich mit der Nadel und dem Kochlöffel umzugehen verstehen!

EBERSBerg. Ja, entweder Schriftstellerin oder Hausfrau! (40, Hervorhebungen der Autorin). 
Nachdem einmal klargestellt ist, was genau ein Blaustrumpf ist - nämlich eine Reinkarnation der mittelalterlichen Hexe -, ist noch die Frage zu lösen: ist eine Schriftstellerin notwendigerweise ein Blaustrump?? Und siehe da - das ist sie nicht. Schön, liebenswürdig, anmutig und bescheiden, eine aufDenn Marianne ist jung, schon, liebenswurdig, anmutig und bescheiden, ein aufopfernde Christin und gute Wirtschafterin, die unsäglich unter dem Vorturteil leidet, „das einer schriftstellerndeñ Frau die Befähigung abspricht, einen Gatten glücklich zu "das e "(43). The Werufstätige Frauen in machen" (43). Thre Weiblichkeit beweist sie, wie viele and Stücken dieser Zeit, durch einen haßerfülten Ausbruch gegen die wahren Blaustrümpfe, die Emanzen. Denn bei aller Unabhängigkeit „hasse ich selbst die falsche Emancipation, die es dem Manne gleichthun will, und [ich] habe die Häuslichkeit nie ich vernachä ne nächste Szene zeigt sie am keiner weible Kein Wunder, daß Bügelbrett. Kein Wunder, daß ihr ehemals

ihr geirrt hat, und sic doch noch heiratet.

Während Günther den Beweis antritt, daß Schriftstellerinnen auch Frauen, d. h. Während Günther den Beweis antritt, daß Sch Mütter Strümpfe zu stopfen, endet
durchaus imstande sind, als treue Gattinnen und die Autorin in Bernsteins Wir Drei (1891) ebensowenig im Hafen der Ehe wie ihre Augenärztin Sabine. Im Gegenteil muß sie ihrem Beruf das opfern, woran ihr am meisten liegt: ihre Freundschaft zu dem Ehepaar Agnes und Richard. Agnes ist das genauc Gegenteil von Sascha, ihrer schriftstellernden Freundin: sie ist sanft und nachgiebig Gerëtert ihren Mann und gehorcht ihm widerspruchslos in allem. Sascha dagegen ist ein Freigeist, beruflich erfolgreich, finanziell unabhängig, völlig unsentimental, und ein Schriftstellerei unbeeindruckt: für sie ist Schreiben „etwas Jämmervon ihrer eigenen Schriftstellerei unbeeindrucke. Aur sie ist Scheiben „twas Jammer liches", und sie tut es nur deshalb, weil sie "das Schreiben so wenig lassen [kann] wic das Essen“ (37). Ihre Unabhängigkeit äußert sich in einer Zügellosigkeit, die ihrc Freunde schockiert: für sie ist Vernunft gleichbedeutend mit Langeweile, Leben gleichFreunde schockiert. fur sie ist Ver dicke Falstaff? Das ist mein Ideal! bedeutend mit Extremen. „Lustig bin ich! Wie der dicke Falstafn. Das ist mein Ideal! Lügen, fressen, saufen und... Ein göttliches Schwein! Ich möcht' ihn heiraten!" (35) Wie Wie sie ihre eigene bzw. die weibliche Unaberăngigke schließen.

Schön ist sie. Eine schöne Dirne. Aber eine, die ihre Schmach trägt wie eine Krone. Schön ist sic. Eine schöne Dinch Denken Sie sich - so ein Geschöpf aus Weil und Gold und ganz Ruhe - schön,

Nacktheit unter'm Nachthimmel - ganz Trunkenheit und ganz Ruhe
schön - um das himmlische Sternenlicht zur Anbetung zu zwingen ( $58 \mathrm{f}$ ).

Vine Schriftstellerin ist demnach nicht mehr die abgemagerte alte Hexe, die keinen Eeltsame Mischung aus Hure und GötMan für Männer äußerst attraktiv - und daher doppelt gefährlich. Der Mann, der dietin, für Männer ăußerst attraktiv ser Frau verfällt, reagiert entsprechend: entweder mit Anbetung der Göttin oder mi Vergewaltigung und Ermordung der Hure. Im Stück verwandelt sich Richards Anbetung Saschas die sich in Bewunderung ihrer literarischen Erfolge äußert, in eine im betung Saschas, die sich in. der er völlig die Kontrolle verliert - auch über die Sprache. Er will „haben, dich haben... fassen... fühlen... dich - zerreißen“" (60), er will "dir wehthun, du, du, du!" (61) Trotz Saschas Ablehnung verläßt Richard Agnes, obwohl sie - wovon weder Richard noch Sascha etwas wissen - schwanger ist. Monate später erfährt Sascha von Agnes' Schwangerschaft und nimmt sie zu sich, damit sie bei ihr das Kind bekommen kann und so wird schließlich auch in Saschas Haushalt der Schreibtisch durch den Wickeltisch ersetzt (86).

Saschas Motive sind eine Mischung aus Schuldbewußtsein Agnes gegenüber und Liebe zu Richard, den sie wenigstens in Form seines Kindes um sich haben will; dabei wird ihr der Kontrast zwischen Agnes' leidvoller Entsagungsfähigkeit und ihrer eigenen selbstsüchtigen Liebe schmerzlich bewußt.

Können - über sein Herz können - aber können - durch sein Herz - das ist mehr. Sie hat es gekonnt. Ueber ihr Herz gekonnt. Sie hat ihn gehn lassen. Armes Schneewittchen. Und ich kann es nicht einmal über dieses lumpige Herz. Da ist es - neben mir - rot und glänzend - und will Freude, Freude, Freude! (91)

In der Nacht, in der Agnes das Kind zur Welt bringt, kehrt Richard zurück und macht Sascha erneute Anträge, bis die Haushälterin Betty atemlos die Nachricht bringt, daß Agnes „soweit“ ist. Die Tatsache, daß er Vater, bzw. daß Agnes Mutter wird, bekehrt Richard schlagartig: in Sekundenschnelle schrumpft er zum Bilderbuchbeispiel des werdenden Vaters zusammen, der auf Händen und Knieen an der Tür zum Geburtszimmer kauert, und Agnes ist wieder „Mein Weib! Mein Weib!“ (101) So einfach allerdings ist die Ehe nicht zu kitten: das Kind wird tot geboren, und Agnes.wird darüber völlig apathisch. Ihr Schmerz äußert sich nicht, wie der Saschas es täte, in wahnsinnigen Leidenschaftsausbrüchen, sondern in einer Art "geduldige[m] Wahnsinn" (106): Agnes antwortet nur in einsilbigen Wörtern oder wiederholt das Gesagte, will weder leben noch sterben, will nichts und denkt nichts und hat nur einen einzigen Wunsch „Es soll schr still sein“ (106). Aus dieser Apathie wird sie von Richard erweckt, der ih ewige Liebe schwört, und die beiden können neu anfangen. Sascha dagegen schließt sich selbst aus der Gemeinsamkeit, dem "Wir drei“, aus, weil sie weiß, daß sie diese Gemeinsamkeit durch ihre Unabhängigkeit zerstören würde. „Zwei sollt ihr sein, eins sollt ihr sein. Ich bin zu stark, um jedem von euch nicht ein Stück Leben zu nehmen. [...] Ich gehe. Ich werde mir keine Freunde mehr suchen" (112). Die Konsequenz ihrer Unabhängigkeit, ihrer Stärke, ist nicht nur die Aufgabe ihrer Liebe zu Richard, sondern auch die Aufgabe ihrer Freundschaft zu beiden und der Freundschaft überhaupt Für Sascha bleibt nur die völlige Einsamkeit und der Neid auf Agnes und Richard.

Die Glïcklichen! ([...] preßt die Hände auf die Brust.) Weh thut's da - und wird immer weh thun. (Sie hat welke Blätter aufgehoben und läßt sie gedankenvoll wicder aus der Hand gleiten.) Das Blatt da - ob es nicht auch seine Tragödie hat? Ich will arbeiten - wenn mir etwas einfällt. ([...] Ueberwältigt ausbrechend.) O Leid, Leid! (112) 
Das einzige was ihr in ihrer Einsamkeit bleibt, ist ihre Arbeit, wenn ihr etwas einällt - eine Arbeit, die für sie kein Glück bedeutet, sondern eine Tragödie, ein welkes Blatt, ein Leid, Leid", die Antithese zur "Freude, Freude, Freude!" der erfüllten Liebe Was Breden zwanzig Jahre vorher dem weiblichen Publikum durch Faustina mitteilen ließ, gilt noch immer: eine Frau, die „ein starker Geist aus ihren Grenzen trieb, $[. .$.$] ist halb sich selbst entrissen, des Beifalls Sturm, der um sie tobt, kann si$ betäuben, doch sie beglücken kann er nie und nimmer".

Bei Bernstein wird zum erstenmal eine Erkenntnis ausgesprochen, die in Komödien and Schauspielen beider Jahrhunderte das Happy End der Ehe so effelktiv unterminiert: des Weibes Grenzen sind zu eng gezogen. Denn daß die Ehe weder für Sabin mo eine reine „Freude“ wäre, dringt zwar nicht ins Bewußtsein der Figunoch für Sascha eine reine „Freude ware der Autorin mehr als deutlich. Gegen Ende des ren selbst, wird aber in der Darstellung der Autorin mehr als deutlich. Gegen Ende des
Jahrhunderts fällt das Happy End - nicht nur in dieser Form, sondern überhaupt - oft weg, und das "Schauspiel“", bis 1850 noch naher Verwandter der Komödie, wird häufig we

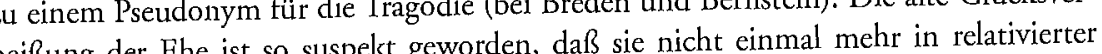
Form

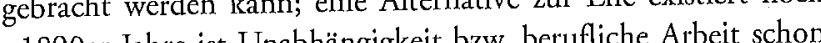
kaum. In Dramen der 1890er Jahre ist Unabhängigkeit bzw. Berufliche Arbeit schon deshalb kein Ersatz für das verlorengegangene Ehe-,Glück“, weil sie die Frau von jeder menschlichen Beziehung ausschließt, weil die Frau durch ihren Beruf ebenso ausschließlich definiert wird wie vorher durch die Ehe. Ebenso suspekt ist die bisher einzischließlich definiert wird wie vorher durch die Ehe. Ebenso suspekt ist die bisher glück" der Frau. Die Frauen, die hier entsagen, finden keine mystische Befriedigung gluck mehr in der Aufgabe "Entsagung" durchaus als das zu verstehen, was das große Wort im 18. Jahrhunder bemäntelt: als völlig prosaisches Unglück. So werden die Versuche, das Glück au die Bühne zu zwingen, allmählich aufgegeben. Statt der Lösung oder vergeblichen Lösungsversuchen steht jetzt das Dilemma selbst im Vordergrund des Dramas - eine Tradition, die im 20. Jahrhundert von Frauen (Fleißer) und Männern (Wedekind) weitergeführt wird.

\section{KAPITEL IV}

\section{GERECHTIGKEIT ERWARTET NICHT: TRAGÖDIEN}

Tragödien waren bei Frauen kein populäres Genre. Gegenüber ca. 1000 Komödien und Schauspielen konnten in beiden Jahrhunderten nur 86 Tragödien ausfindig gemacht werden. Davon sind 30 historische Tragödien, neun sind Bearbeitungen von Mythologien und Bibelgeschichten, acht verleugnen die Zugehörigkeit zum tragischen Genre unter der Bezeichnung „Drama“ oder "Schauspiel“ (wie Bredens Faustina). Von den 39 übriggebliebenen „reinen" Tragödien gibt es kaum eine, die sich nicht in ein pseudo-historisches Gewand kleidet, sich auf mehr oder minder obskure Chroniken beruft, oder das Stück als Darstellung einer tatsächlichen Begebenheit bezeichnet. Mit sehr wenigen Ausnahmen spielen alle Tragödien in geographischer oder zeitlicher Hinsicht "weit weg". Obwohl es also sehr wenige Trauerspiele von Frauen gibt und bei den wenigen, die es gibt, eindeutig der Versuch gemacht wurde, sie durch die Autoritä historischer oder realer Begebenheiten zu legitimieren, scheinen Frauen durchaus Geschmack am Tragischen gefunden zu haben: viele Frauen (z. B. Amalie von Sachsen, Luise Gottsched, Elisabeth Kulmann, Catharina Link, Malwine Maltzan, Henriette Montenglaut, Karoline Paulus, Caroline Schlegel-Schelling und Katharina Zitz) übersetzten mit Vorliebe die Tragödien männlicher Dichter; bei einigen (Paulus, Zitz) machte diese Übersetzertätigkeit ihr dramatisches Gesamtwerk aus.

Für die scheinbare Unbeliebtheit der Tragödie gibt es verschiedene Gründe, von denen einige auch männliche Dramatiker betrafen. Am Theater, für das die meisten Tragödienautorinnen schrieben, war die Komödie nach wie vor die beliebteste Gattung; Lustspiele kamen beim Publikum besser an und waren leichter durch die Zensur zu bringen. Denn Johann Christoph Gottscheds Ansicht, daß die Tragödie „lauter vornchme Leute", die Komödie dagegen „ordentliche Bürger, oder doch Leute von mäßigem Stande" darstellen solle (Critische Dichtkunst 647 und 651), galt zwar nich mehr als bindend, aber die Praxis der Klassentrennung im Genre hielt sich bis Mitte des 19. Jahrhunderts. Die Zensur interessierte sich weit mehr für die Darstellung „vornehmer Leute" - und die Bearbeitung von Geschichte - als für die in der Komödie dargestellten Liebesgeschichten der „Leute von mäßigem Stande“. Die Vorsicht dramatischer Autorinnen und Autoren der Zensur gegenüber ist wahrscheinlich auch der Grund dafür, daß viele ihrer Tragödien in der geschichtlichen oder fiktiven Vergangenheit oder am anderen Ende der Welt spielen. Oft war die Flucht in ein anderes historisches oder geographisches Klima der einzige Weg, „vornehme Personen“ überhaupt auf die Bühne zu bringen - man erinnere sich an das Wiener Zensurverbot, Angehörige des Königshauses im Theater darzustellen oder zu erwähnen.

Die Vergangenheit im historischen Gewande verlieh dem Ganzen eine Aura der Glaubwürdigkeit; unter dem Schutz dieser Glaubwürdigkeit und der Angabe: „Das Stiick spielt im Jahre 1299“ konnte man gefahrloser auf die politische Gegenwart Bezug nehmen. Für Frauen kam noch ein Grund dazu, der vielleicht ihre außerordent- 
liche Vorliebe für historische Tragödien erklärt: die Dramatisierung der Vergangenheit war fiur sic der einzige Weg, Frauen in politischen Machtpositionen zu zeigen, denn in ihrer Gegenwart waren Frauen von politischer Betätigung völlig ausgeschlossen.

Auch in nichthistorischen Tragödien von Frauen wird die Rolle des tragischen Helden oft von einer Frau übernommen, so z. B. in Gottscheds Panthea (1744); Luise (1742-1801) Seline, 1770; Eleonore Thons (1753-1807) Adelheit von Rastenberg, 1788; Droste-Hülshoffs Bertha, 1814; und Mathilde Wesendoncks (1828-1902) Genovefa, 1866. Oft spielt die Tragödie in der Vergangenheit (Panthea; Adelheit von Rastenberg: Genovefa), in geographisch weit entfernten Regionen (Seline, Panthea; Christiane Friederike Hubers [?-1799] Cleveland, 1756) oder versucht sich Panthea; Cleveland; Christiane Karoline Schle[1739-1833] Dïnd wragödiendichterinnen hielten sich gels [1739-1833] Danal wnd Chane wesentlich genauer an die vorgegebene Tradition als Komodien- und Schauspielautorinnen: bis Mitte des 18. Jahrhunderts werden die drei Einheiten in ihren Tragödien streng beachtet, die Versform ist der Alexandriner; gegen Ende der $1770 \mathrm{er}$ bis Ende der 1780 er Jahre folgen einige wenige Prosadramen; im 19. Jahrhundert wechseln Prosamit Jambendramen.

Auch der philosophische Hintergrund ihrer Trauerspiele fällt zeitlich mit den philosophischen Konzepten zusammen, die in Dramen männlicher Autoren eine Tradition sophischen Konzepten zusammen, dërüng waltet in Dramen von Frauen die Vorsehung unumschränkt; zur Zeit des Sturm und Drang ist die Macht der menschlichen Leidenschaft Thema der Tragödie. Im 19. Jahrhundert schließlich wird das historische Trauerschaft The spiel zur beliebtesten Tragödienform. Da die meisten Schriftselleinn personliche Tragik anders darstellten und interpretierten als geschichtliche, sollen historische Tragödien hier gesondert behandelt werden (in Kapitel V).

\section{A. Tauber Himmel: GotTsched, Huber, Pernet}

Parallel zur männlichen Dramentradition spielt in Tragödien von Autorinnen der Frühauflärrung die Vorsehung die Hauptrolle. Sehr im Kontrast zum vielbeschworenen Optimismus der Aufklärung allerdings versagt in ihren Tragödien die Vorsehung: der Glaube, daß der Himmel den vernünftigen und tugendhaften Heldinnen beisteht, wird hier gründlich widerlegt. Umso häufiger beschwören die Figuren der Tragödien die hier gründlich widerlegt. Umso hâuiger beschwor gütige

In Gottscheds fünfalktigem Trauerspiel Panthea (1744), dessen Figuren und Hand lung zum großen Teil aus Xenophons Cyropaedia übernommen sind (Richel, Luise lung zum gontrast zwischen dem menschlichen Vertrauen in die Gottsched 96), zeigt sich der Kontrast zwischen dem menschlichen Vertrauen in die Vorsehung, das einen guten Teil der Definition der Tugend ausmacht, und dem Versagen der Vorsehung am deutlichsten. Cyrus, der tugendhafte König der Perser, hat a Aenommen. Am Morgen vor der Schlacht gegen dic Assyrer macht er Abradates zu seinem Alliierten und gibt ihm Panthea zurück. Der persische Edelmann Araspes, der sich in Panthea verliebt hat, und der Feldherr Hystaspes, der sich durch Cyrus' Aufmerksamkeit für Abradates zurückgesetzt fühlt, fassen den Entschluß, Abradates in de Schlacht zu ermorden. Cyrus zieht mit Abradates in die Schlacht und läßt Panthea in Araspes' Obhut zurück; Abradates fällt in der Schlacht, Panthea ersticht sich. Nachdem der böse Plan des Araspes entdeckt ist und dieser ein Geständnis seiner Untaten abgelegt hat, begeht er ebenfalls Selbstmord - auf dieselbe Weise wie Panthea -; Hystaspes dagegen, der an dem Mordplan beteiligt war, geht frei aus.

In dieser Geschichte finden sich mehrere Ungereimtheiten. Zunächst verstößt Gottsched empfindlich gegen das von ihrem Mann rezipierte aristotelische Prinzip, ein tragischer Held solle weder vollkommen gut noch vollkommen böse sein (Critisch Dichtkunst 606-8). Die Einteilung in die guten, vernünftigen, vorsehungsgläubigen (Panthea, Cyrus, Abradates, Gobrias, Nikothris) und die bösen, leidenschaftlichen, vorsehungsverachtenden Figuren (Araspes, Hystaspes) ist äußerst kraß; Panthea und Cyrus sind wahre Muster weiblicher bzw. männlicher Tugenden. Pantheas Haupttugend ist die unbedingte Treue zu ihrem Mann; Cyrus' Tugend äußert sich etwas vieldimensionaler in seiner Großmut, Tapferkeit, und in dem unbedingten Glauben an die gütige Vorsehung. Weitaus der größte Teil der Tragödie wird mit Lobeshymnen au Pantheas und Cyrus' Tugenden ausgefüllt; immer wird dabei der berechtigten Hoffnung Ausdruck gegeben, daß der Himmel solche Tugend belohnen müsse.

Diese direkte Beziehung zwischen menschlicher Tugend und göttlichem Lohn wird zu Beginn der Tragödie als generelles Diktum, als philosophischer Rahmen des Stückes wiederholt angesprochen. Cyrus ist überzeugt, daß der Sieg nur von seiner und der Tugend seiner Soldaten abhinge $(7,41)$; in seinem Rat an Panthea spricht er dieselbe Überzeugung aus: „Sey ferner; wie du thust, der reinsten Tugend hold;/ Der Götter hohe Gunst ist ihr gewisser Sold" (17). Panthea gibt diese Philosophie an Nikothris weiter: „Prinzeßinn, fahre fort/ Der Tugend treu zu seyn; sie lohnet hier und dort" (52). In diesem Glauben vertraut sie den gütigen Göttern unbedenklich ihren Mann an, denn „da des Himmels Arm die Tugend nie verläßt;/ So wird er auch gewiß in allen andern Sachen,/ Für Abradatens Wohl und für sein Siegen wachen./ Der Götter hohen Schutz trau ich mein Lebenlang" (20).

Am häufigsten wird die gütige Vorsehung beschworen, kurz bevor das menschliche Vertrauen in sie enttäuscht wird. So befiehlt z. B. Abradates Panthea in der Ab schiedsszene vor der Schlacht, in der er umkommt, nicht an dem glücklichen Ausgang der Schlacht zu zweifeln, denn „Wer nicht verderben will, der muß den Himmel trauen" (45). Aber daß des Himmels Arm die Tugend nie verläßt, wird schon zu Beginn des Stückes als zweifelhaft dargestellt, unter anderem dadurch, daß die Vertreter de Lasters die göttliche Fügung teils auf ihrer Seite, teils auf der der Tugend vermuten Hystaspes z. B. glaubt an Cyrus' Sieg, denn Cyrus „ist ein Sohn der Tugend;/ Und diese schützet stets des Himmels hoher Arm" (23). Araspes dagegen nimmt den himmlischen Beistand für seine Rache an Panthea in Anspruch: „Der Himmel aber wird dein undankbares Hassen,/ Womit du mich verfolgt, nicht ungerächet lassen“ (61) Der Ausgang des Stückes scheint ihm recht zu geben: Panthea negiert ihren vorherigen 
Vorsehungsglauben völlig durch ihren Selbstmord, der von den anderen Vertretern der Tugend als Heldentat gesehen wird.

Mit dem Glauben an die göttliche Güte wird der an die göttliche Gerechtigkeit neMit im Falle Panthea und Abradates "gebricht/ Des Himmels Retterarm" (67); von den beiden Bösewichtern, die die Katastrophe herbeiführen, wird nur Araspes bestraf den beiden Bosewichtern, die dugendhafte Panthea ereilt. Daß Hystaspes' Beteiligung - durch dasselbe Ende, das die tugendhafte Panthea ereilt. Daß Hystaspes Beteiligung an dem Mordplan nicht entdeckt wird, widerspricht dem Glauben, daß der Himme Lohn und Strafe gerecht verteilt (62), vollkommen - der Himmel versagt nicht nur im Lohn und Strafe gerecht vertent sich im Bezug auf das Laster strafbar. „Die Gottheit, Bezug auf die Tugend, er macht sich im Bezug auf das Laster strafbar. „Die Gother die wir kennen, / [...] muß sich selber strafbar nennen, / Wofern sein Arm hinfort solch eines Wüthrichs schont/ Und nicht der Frevelthat mit Fall und Unglück lohnt", meint einer von Cyrus' Bundesgenossen (30). In der fehlenden Bestrafung des Bösewichts, mehr noch als in dem Tod der tugendhaften Heldin, liegt eine absolute Absage an den Vorselohnte Tugend noch allenfalls als den Menschen orsehungsglaun unergründlicher gottlich Zimmels - und daher in Tragödien männlicher Autoren Laster ein Vergehen des Himmels - und daher in Tragodien männichen Autoren äußerst untiblich. ${ }^{27}$ So endet das Stücls mit Cyrus' Zweifel an der göttlichen Güte Wie reimt sich deine Huld mit so viel herben Wehe?" (67) - und mit seinen relati "Wie reimt sich deine Huld an den Toten wiedergutzumachen, was die Vorsehung an wirkungslosen Versuchen, an den indem er an den Leichen Pantheas, Abradates' und den Lebenden verpfuscht hat, ind

Araspes' Lohn und Strafe verteilt.

Es werd indeß so gleich ein Ehrenmahl bestellt,

Das Pantheen und auch den Abradat umschliesse;

Damit dieß Par die Ruh in einer Gruft geniesse.

(Auf den Araspes zeigend):

Du Mörder aber, spür auch nach entwichnem Geist,

Daß jedes Lasters Schuld die Fürsten strafen heißt;

Und daß das strenge Recht von Cyrus Königsthrone

Auch an der Leiche nicht des Lebens Boßheit schone (72).

Ebenso wirkungslos nimmt sich die Vorsehung in Christiane Friederike Hubers (? 1799) Alexandrinertragödie Cleveland dritter Theil, oder: Die redliche Untreu (1756) (t) aus. Ähnlich wie Panthea macht das Stück Anspruch auf historische Glaubwurdigkeit aus. Ahehandelt einen Abschnitt aus dem Leben des von Cromwell vertriebenen Philosoes behandelt ein phen Cleveland -; formell werden zwei der drei Einheiten bech (dic Elnheit des Ortes wird durch die Episode auf der Insel gebrochen). Cleveland leidet unter der unbegründeten Fifersucht seiner Frau Fanny, die seinen intellektuellen Umgang mit de gelehrteren Lallin falsch interpretiert, und versucht, sie durch den Umgang mit seinem

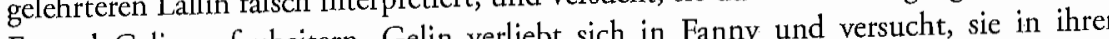
Freund Gelin aufzuheitern. Gelin verliebt sich in Faneden. Fanny gibt schließlich Eifersucht zu bestärken und zur Flucht mit ihm zu überreden. Fanny gibt schießlich nach und läßt sich von Gelin auf eine Insel bringen; Cleveland verfall durch ihre Flucht in solche Verzweiflung, daß er versucht, sich und seine beiden Söhne zu töten.
Da diese um ihr Leben bitten, gibt er den Plan auf; sein Bruder Bridge ubberredet ihn zur Verfolgung der Geflohenen. Auf einer Insel trifft Bridge auf Gelin und verlangt Fannys Freilassung. Als Gelin sich weigert, fordert Bridge ihn zu einem Zweilkampf heraus, in dem Bridge tödlich verwundet wird, worauf sich der reuige Gelin ohne Gegenwehr von Clevelands Dienern töten läßt. Bridge wird zu Cleveland gebracht, dieser will erneut Selbstmord begehen, wird aber von Bridge davon abgehalten. Bridge stirbt; der Plan, nach Fanny zu suchen, wird als zu gefährlich aufgegeben, und Cleveland flieht ziellos von der Insel.

Die Vorsehung wird hier als ebenso allmächtig empfunden wie in Panthea; ebenso wie in Gottscheds Stück herrscht hier die Auffassung, daß die Vorsehung den Menschen zur Tugend anhält. Daß die Vorsehung diese Tugend auch belohnt, ist allerdings nicht mehr die logische Konsequenz, sondern lediglich Hoffnung und Wunsch der Vertreter der Tugend. Oft nimmt die Vorsehung die Wünsche der tugendhaften Figuren zu wörtlich und verkehrt sie in der Erfüllung in ihr Gegenteil, wie z. B. Bridges Wunsch, den er zu Beginn des Stückes Cleveland gegenüber äußert; „Kann man durch Wünschen sich, was künftig ist, erwerben:/ So laß mich Gott einmal an deiner Seite sterben!" (unpag.) Nur einmal erhält die Vorsehung ausdrücklich die Gelegenheit, das Unheil abzuwenden. Als Fanny letzte Anstalten zur Flucht trifft, befallen sie Zweifel an der Untreue ihres Mannes; gleichzeitig berichtet ihr ihre Kammerfrau Rem, Cleveland schlafe im Garten. Fanny macht darauf ihr Schicksal von einem Wink der Vorsehung abhängig: wenn Cleveland aufwacht, würde sie, dem Wink gehorchend, ihre Fluchtpläne aufgeben. „[Text fehlt] leicht kan Cleveland nicht aus dem Schlaf erwachen./ [Text fehlt] mich wird Unschuld stark! ihm Wollust trunken machen - - - [Text fehlt]zt, daß er erwacht; so will die Vorsicht nicht,/ [Text fehlt] ich entfliehen soll." Obwohl Rem sich ihren Bitten anschließt - "Gott! laß es nicht geschehen, / [Text fehlt] meine Frau entflieht! durch deiner Vorsicht Hand,/ [Text fehlt]cke diesesmal den armen Cleveland" -, bleibt der Himmel taub. Cleveland erwacht pünktlich nach Fannys Abgang von der Bühne und interpretiert das Geschehene als Traum -- „Im Schlafe sah ich sie sehr schnell von mir verschwinden“ -; er hält dann einen langen Monolog über seine Liebe $z u$ ihr und endet ihn mit einer bereits abgeschlagenen Bitte an die Vorsehung: „[Text fehlt]rsicht tödte mich! nur Fanny nihm mir nicht.“

Clevelands Verzweiflung bringt selbst den unbeirrbaren Bridge dazu, an der himmlischen Güte zu zweifeln: „Ist Qual, und Tod der Lohn, den wahre Treu erwirbt?" Cleveland hadert mit Gottes Grausamkeit und beschließt den Selbstmord, Gottes Einverständni vorausgesetzt. „Ja Herr! du kannst gewiß den Vorsatz nicht verfluchen./ Mein Mord erzürnt dich nicht, sonst wärst du ein Tyrann. "Im Gegenteil glaubt er sich von der Vorsehung zum Selbstmord und zum Mord an seinen Söhnen ermutigt, denn wenn die Vorsehung beim Vater versagt, tut sie es sicherlich auch bei den Kindern, und denen will er ein Leben in einer durch eine böswillige oder ohnmächtige Vorsehung regierten Welt ersparen. „Nähm sich die Vorsicht nicht bedrängter Eltern an,/ So wird das Unglück auch noch an den Kindern kleben." Clevelands Entschluß scheitert an den Bitten seiner Söhne, und auch seine schnelle Sinneswandlung interpretiert er als „der Vorsicht Hand“, der er sich künftig unterwerfen will. Clevelands Vorsehungsglaube negiert 
(Sterben und Überleben) den göttlichen Willen sehen kann, wird ihm nur dadurch ermöglicht, daß dic Ven) den gottich

Von nun an ergibt sich das gleiche Muster wie in Panthea: die Vorsehung wird immer kurz vor der nächsten Katastrophe beschworen. Die Verfolgung Fannys und 烈 Gelins, die Cleveland noch mit allen Anzeichen "-, endet mit Bridges Tod im Duell, Gott barmherzig ist, muß en uns Gluck ench und kurz bevor Bridge sterbend auf die Bühne getragen wird, gibt Cleveland zum letzten Mal seinem Vorsehungsglauben Ausdruck - der sich darauf gründet, daß ihm in allem Elend sein Bruder geblieben ist. „[...] ich habe noch im Elend Trost gefunden./ [Text fehlt]er Vorsicht strenger Rath gönnt mir noch einen Freund." Nach Bridges Tod beibt ihm nur noch die Flucht, „wohin? das ist verborgen“. Daß das Stück trotz aller erwiesener Unfähigkeit oder Grausamkeit der Vorsehung mit einem Gebet Clevelands, in in der Ambivalenz zwischen Verzweiflung und selbst begründet als in den Plänen der Autorin zu einer Fortsetzung, in der sich das Schicksal Cleveland gewogener zeigen sollte: „,...] erhält dieses fremde Werk einen Scrwünschten Beyfall, so wird dieser berühmten Geschichte in Kurzen der vierte und crwünschen "(Vorbericht). Im dritten Teil findet sich letzte Theil ein vergnügtes Ende verschaffen " (Vorberich). In driten Teil find allerdings kein Hinweis auf ein vergnügtes Ende; der vierte Teil ist meines Wissen nicht entstanden.

Luise von Pernets (1742-1801) Seline, ein komisches Trauerspiel in Versen (1770) ist eine Tragödie im Stil Gottscheds und Christiane Friederike Hubers (Alexandriner; eine Tragor Wahrung der Einheit der Handlung, stet Ans "komisch" ist daran nur das höchst unwahrscheinliche Happy End. Seline wird auf einer Reise nach Byzanz von ihrem Mann Jardin getrennt und dem tugendhaften Türken Talman als Sklavin verkauft. Auf ihre Bitten hin entschließt er sich, ihren Mann Seline liebt. Loran, ein Christ und Vertrauter Talmans, verliebt sich ebenfalls in Seline und versucht, Talmans großmütige Pläne zu vereiteln: er gibt dem Renegaten Berset den Auftrag, Jardin zu töten, und überredet Seline zur Flucht ins Vaterland. Seline den Auftrg, Jadin a mißtraut Talman, weil dieser ein Türke ist, und theht mit Loran und ihrer Vertrauten Elmire. Talman verfolgt die Geflohenen und erfährt Lorans Verrat von Berset, der Jardin in die Sklaverei verkauft hat, weil er es nicht über sich bringen konnte, ihn zu töding ten. In einem echt heidnischen Grausmkeisanfall dabei von Seline, Elmire und Loran, die in einem Gebüsch versteckt sind, beobachtet. Seline, die Berset für Jardin hält, ist nun von Talmans Schurkerei und Lorans Ehrlichleit fest überzeugt, bis Talman, der Jardin inzwischen freigelsauft hat, sie am Hafen keit fest Uberzent, bis Talme wiedersieht und sie eines Besseren belehrt. Ein letzter Versuch Lorans, Seline mit Hilfe des Sultans an sich zu bringen, scheitert an einer List Almets, eines Vertrauten Talmans, und sämtliche Vertreter der Tugend (Talman, Seline und Jardin, Elmire und Almet) schiffen sich fröhlich ins Land der Christen ein.

Die Vorsehung spielt hier allenfalls eine Nebenrolle; wo die Götter angerufen we den, handelt es sich meist um Bitten, die dem guten Ausgang des Stückes abträglich wären, wic Selines „Stärktt, Götter; Loran doch" (Versuch in Fabeln und Erzählungen 106). Die weltlichere Verwandte der Vorsehung, das Glück, begünstigt laut Talman nur die Bösewichter: „O ungerechtes Glück!/ Du bist dem selten hold, der treu und redlich denket,/ Der seine Absicht nur auf reine Tugend lenket" (86). Auf die Vorsehung ist ebensowenig Verlaß wie auf das launische Glück; der Ausgang des Stückes hängt letztendlich, wie in vielen Komödien, von unglaubwürdigen Zufällen ab. Denn nachdem Jardin gerettet ist und Talman mit Mühe Seline von seiner Tugend überzeugt hat, nachdem alle Mißverständnisse aufgeklärt sind und die Geretteten fröhlich Vorkehrungen zur Flucht treffen $(\mathrm{V}, 3)$, bricht die Tragödie noch einmal in die lustspielhafte Freude ein. Auf Betreiben Lorans fordert die Wache des Sultans Selines Herausgabe von Talman, und Talman, der permanente deus ex machina des Stückes, de bis dahin für den guten Ausgang des Stückes alleinverantwortlich ist, ist plötzlich außerstande, Seline zu schützen. Da er ihr wiederholt versprochen hat, ihre Ehre zu schützen, will er Seline, wie Odoardo Emilia, töten, ohne allerdings ihr Einverständnis abzuwarten. Im letzten Moment kommt Almet dazwischen, verhindert den Mord und klärt Talman darüber auf, daß die Wache, die Seline inzwischen fortgezerrt hat, von ihm bestochen wurde, sie nicht Loran auszuliefern, sondern sie zu Jardin zu bringen.

Daß im letzten Moment durch eine Unwahrscheinlichkeit das glückliche Ende gesichert bzw. das tragische Ende abgewendet wird, ist ganz im Sinne der Komödientradition. Die Tragödientradition dagegen, die Absage an den Vorsehungsglauben, wird wie in Panthea dadurch eingehalten, daß der Bösewicht entkommt. Ähnlich wie in Gottscheds Stück handelt es sich hier um einen bewußten Verstoß gegen die poetische Gerechtigkeit, denn Lorans Schicksal scheint im Vergleich mit dem seines Helfershelfers Berset doppelt ungerecht: während Loran die Intrige, die an der Fast-Tragödie schuld ist, eingefädelt hat, ist Berset nur sein durch die Aussicht auf die Freiheit verführtes Werkzeug. Zudem ermöglicht Berset das Happy End, indem er Jardin verschont und ithn in die Slklaverei verkauft, aus der Talman ihn schließlich befreit. Loran hat keinerlei Skrupel, Jardin zu töten, Berset dagegen schlägt das Gewissen. „Die Hoffnung ist auch groß, mich bald befreyt zu sehen;/ Allein, ich soll dafür cin Meichelmörder seyn?/ [...]/ Nein, dieses thu ich nicht" (104). Während Loran am Ende ohne Strafe davonlrommt, wird Berset von Talınan auf grausamste Weise getötet. Weitere Widersprüche ergeben sich aus der Tatsache, daß Berset, nicht Loran, als „de[r] größte[...] Missethäter“ (117) bezeichnet wird, und daß sein Ende von allen anderen Figuren des Stückes als gerecht empfunden wird - auch von Loran (149)

Trotz dieser Verstöße gegen die poetische Gerechtigkeit, trotz der unglaubwürdigen Zufälle, die schließlich das Happy End ermöglichen, machen die Vertreter der Tugend am Ende des Stückes die Vorsehung für den guten Ausgang verantwortlich - bzw. die eigene Tugend, die so von der Vorsehung belohnt wird. Elmire belohnt Almets erfolgreiche Bestechung der Wache durch ihre Hand - „Es ist ein Lohn, den dir die Tugend heut verliehen" (174) -; und Talman äußert mit derselben Logik die Ansicht, daß diese Tugend auch weiterhin zum Besten aller walten wird. „Die Tugend, die bisher uns stets beschüzet hat,/ Führ uns auch noch durchs Meer in eure Vaters Stadt" (174). Dic 
Tragödie, die im Versagen der Vorsehung besteht, wird im letzten Moment durch einen komödienhaften Zufall abgewendet, und das glückliche Ende der Vorsehung zugeschrieben, die - in der Komödie - die Tugend stets belohnt.

\section{B. Blinde Leidenschaft: Schlegel, Thon}

Stïcke von Frauen, die zeitlich parallel zum Sturm und Drang liegen, konzentrieDer Serderblichkeit der menschlichen Leidenschaft. Da ren sich auf die Darstellung der Verderblichkeit der menseinen Anspruch auf historidiese Stücke sich in der Privatsphäre abspielen und daher' keinen Anspruch auf histort
sche Glaubwürdigkeit machen lrönnen, rechtfertigen dic Autorinnen das Dargestellte meist durch die Anmerkung, es handle sich um eine wahre Geschichte. Diese Geschichten sind oft Lustspiele, die anders ausgegangen sind, d. h. die tragische Alternative, die im Lustspiel den guten Ausgang gefährdet - wie z. B. die Zwangsehe mit native, die im Lustspiel den gi hier durch cespielt, ohne daß der Frau ein glüclicher 政 Zufall zu Hilfe kommt. Hauptthema der Tragödie ist die Frage, wie eine Frau sich männlicher Leidenschaft gegenüber zu verhalten hat, wenn aus dieser Leidenschaft . keine Ehe werden kann. In mer Leidlung seiner Liebe bebereits verheiratet; der Man sich oder muß überredet werden.

tie Interessant sind diese Stücke vor allem deshalb, weil in der Rrädie liebt. In den Beziedie Handlung verwickelt ist, die ebenfals den ungeliebten Frau werden verschiedene Reakhungen zwischen der geliebten und der ungeliebten Frau werden verschied Frau aus Eifertionsmöglichlkeiten durchgespielt: entweder wendet sich die ungeliebte Frau aus Eifertion Geliebten Bevorzugte und führt ihren Tod herbei, oder die beiden Frauen unternehmen Versuche, sich gegen den Mann zu verbünden. Nirgends allerdings findet sich die Konstellation, die aus Dramen von Männern bekannt ist: dic Ko

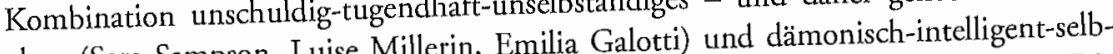
chen (Sara Sampson, Luise Mille - Frau (Marwood, Lady Milford, Gräfin Orsina). Die ständige - und daher ungeliebte - Frau (Marwood, Lady Milfor, Greichen Stand und Frauen, die hier einander gegenüberstehen, sind in der Rege vong gle von derselben Schwäche befallen - der Liebe zu dem Mann -; teilweise find nicht nicht einnal bemerkenswertion auf die $\mathrm{Zu}$ - oder Abneischied zwischen beiden Frauen besteht oft in ihrer Reaktion auf die 'Zngung des Mannes - und dieser Unterschied fällt kaum ins Gewicht: das Stuck endet immer mit dem gewaltsamen Tod der vom Mann geliebtn Frat wendhaft reagiert. ob sie auf die verbotenen Anträge des Mannes nachgiebig oder tugendhaft reagiert.

Christiane Karoline Schlegels (1739-1833) bürgerliches Trauerspiel Düval und Charmille (1778), zu dem ihr "Eine sehr bekannte und leider! sehr wahre tragische Charmille (1778), zu dem ihr "Eine sehr bekannte ting Geschichte [...] den Stoff" lieferte (Vorbericht, 3), stellt das Unglaubliche auf die Buhne: ein verheirateter Mann verliebt sich in eine andere Frau und un ne: in visenen Haus; seine Frau läßt es sich aus Liebe zu ihrem Mann und Freund-

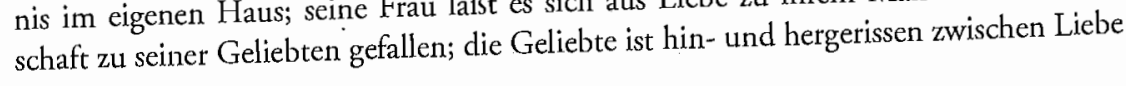

zum Mann und Freundschaft zu der Frau. Düvals Frau Mariane findet sich vor allem deshalb mit seiner Liebe zu Amalie von Charmille ab, weil er durch den Umgang mit Amalie sanfter geworden ist und Mariane nicht mehr mißhandelt, seit er Amalie kennt. „Er ist nicht mehr derselbe. - Wie er sonst dräute, tobte, schäumte, schreckte!" (14) Auch Düval sieht diesen wohltätigen Einfluß Amalies als eine Rechtfertigung seiner Liebe. „Ist nicht schon mein Herz weicher und besserer Eindrücke fähig, seitdem ich dich liebe? Ist nicht Mariane [...] seitdem glücklicher und besser mit mir zufrieden?" (24)

Schon in dieser Gleichheit der Interpretation wird klargestellẗ, worin die Tragödie eigentlich besteht: sowohl Frau als auch Mann gestehen dem Mann das uneingeschränkte Recht zu, die Frau auf alle erdenkliche Art zu mißhandeln, und rechtfertigen diese Mißhandlung, wo sie können. Aber von Seiten Marianes steht dahinter keineswegs die Blindheit der Liebe, sondern eine sehr realistische Einschätzung männlicher Macht und der eigenen Ohnmacht. Da der Mann legal uneingeschränkte Rechte über die Frau besitzt, ist Mariane sehr wohl bewußt, daß sein Verhältnis mit Amalie für sie schlimmere Folgen haben könnte. So wehrt Mariane die höheren Ortes unternommenen Versuche, Düvals außereheliches Verhältnis zu beenden, ab, und zwar mit Hinweis darauf, wie weit die Gewalt des Mannes über die Person und den Besitz der Frau tatsächlich gehen kann. „Ihr [Amalie, S. K.] hatte ich meine ruhigern, friedsamern Tage zu danken, die ich, seit sie ihn beherrschte, genossen. Durft' er nicht mich verlassen, hintergehen, mein Vermögen an andre verschwenden, mir hart begegnen? Niemand strafte ihn!“ (40) In ihren Worten wird deutlich, daß die Lösung, die verschiedene Figuren des Stückes anstreben - nämlich Düval zur Rückkehr zu seiner Frau zu bewegen -, für Mariane keine Lösung ist, da sie von ihm bestenfalls weitere Mißhandlungen zu erwarten hat. Im Bewußtsein dieser uneingeschränkten männlichen Macht gilt ihre Hauptsorge im Stück nicht Düval, obwohl sie ihn liebt, sondern Amalie, die sie wiederholt vor ihm warnt.

Armes, betrogenes Kind! - Dein süßer Traum - ach! er wiegte einst auch mich ein! Ich bin von ihm erwacht. Bereite dich auf dein Erwachen, daß es nicht zu schrecklich sey! Suche keine Treue, keine Zärtlichlkeit in seinem Herzen! Es ist Stolz, Eitelkeit, Wollust und unmenschliche Verrätherey! Du bist nicht sein Erstes - wirst nicht sein letztes Opfer seyn! (19 f)

Amalie dagegen, die die Erfahrung, aus der Mariane spricht, noch nicht gemacht hat, sicht die Lösung in einer mystischen Vereinigung der beiden Frauen zum gemeinsamen Liebesobjekt des Mannes: „Laß unsre Herzen eins werden, darinnen er lebe!“ (39) AuBerhalb von Düval existiert sie nicht als Person; sie hat, wie Düval befriedigt feststellt, keinen Anspruch, keine Leidenschaft, keinen Wunsch, als ihn zu lieben (67). Selbst ihre Freundschaft zu Mariane ist über ihn definicrt, sie liebt sie „um seinetwillen“ (17). So überrascht es nicht, daß ihre Äußerungen die Düvals reflektieren, wiederholen oder vorwegnehmen: die mystische Vereinigung der drei ist auch ein Traum Düvals. "Könnt' ich euch in Ein und mich mit euch zu Einem Wesen vereinigen!" (80) Als 
Düval Amalie schließlich zum Doppelselbstmord überredet, taucht dieser Gedanke (ie die wieder auf: Düval spielt mit dem Gedankame Sohn, „braucht [...] eine Mutter“ (125). Dritte zu sein - aber Franz, der gemeinsame Sohn, " kratennengelernt hat, wäre zu einer Mariane, die in ihrer Ehe die Brutalies auch kaum imstande, und warnt Amalie vor diesolchen Mystiffzierung eines Morchönigenden Worten von der ewigen Vereinigung im ser Brutalität, die sich unter beschonigenden Worten von der ewigen Vereinigung in Tode versteckt. „[...] hüten Sic Sich vor Duval. Er seiner Leidenschaft nie Meister - - ein Wütrich, wenn er ... St!" (78) Da der Wüterich seiner Leidenschaft nie Meister - eitrit, kann Mariane ihre Warnung nicht vollenden, in diesem Moment die Bühne betritt, kann Markane

In In sic zum Selbstmord mit ihm zu überreden (114-124); endlich gibt sie nach - unter um sic zum Selbstmord dem Gewicht eines ihr von Düval in den Mund gelogten Bewegg nicht: aber du willst - ja du kannst mich nicht allein gehen lassen! Du liebs mich vie nu sehr - Amalie würde mich überleben wollen - können?" (124) Sobald sie sich zuzu sehr - Amalie whrde rückzieht, um letzte Vorbereitungen zu treffen, zweifel er an ihrem Todestut, da er sich wohl bewußt ist, daß der Entschluß nicht von the sonder beschließt, sie zur Sicherheit vor seinem Selbstmord zu töten. Was sich dann auf de beshe Bühne abspielt, ist keine mystische Vereinigung zweier Lien im Kabinett - woraus die prosaischer Mord: die Diener hören lautes, erregtes Reden im Kabinett - woraus die Zuschauerin schließen kann, daß Amalie sich zumindest jetzt zur Wehr setzt. Schließlich wankt Amalie sterbend auf die Bühne; ihre letzten Worte bestätigen nicht Düvals Selbstmörders aus Leidenschaft, sondern Marianes Sicht Düvals als Selbstdefinition des Selbstmörders aus Leidenschaf, sondern Saij Mörder. Diese Interpretation wird von sämtlichen Inguen des Stickes wedect Dic Bedienten, die sich um Amalie bemühen, hören den Schuß, mit dem Düval sich umbringt, und interpretieren ihn als Mordversuch: „Himmel! Er schießt nach uns, weil wir ihr helfen“ (137). Franz befürchtet angesichts der längst fälligen Ohnmacht Mariawir ihr helfen "(137). Franz beflrchtet angesichts der längst falligen Ohn nes einen zweiten Mord des Vacts (138) Düvals Selbstmord schließlich wird als Mord rezipiert. "Düval - sein ciges Mörder!" (139) Obwohl viele andere Stïcke aus dieser Zeit die Leidenschaft des Mannes als tödlich für die Frau darstellen, findet sich nirgends eine deutlichere Entharvung der mystisch-männlichen Leidenschaften als Mißhandlung und Ermordung der Frau.

We Wie Schlegel betont Elconore 'Thon (1753-1807) dic Aut spiels Adelheit von Rastenberg (1788) durch die Anmerkung "wahre Geschiche : "Das Sujet dieses Trauerspicls ist eine wahre altdeutsche Familiengeschichte, woran nur dic Namen geändert, und kleine Züge erdichtet sind" (Vorbericht, 253). Anders als bei Schlegel riden den Anträgen des geliebten Mannes. Adelheit ist von Schlegel widersteht hier de ihrem Vater zur Ehe mit dem ungel Hohenburg, sich auf einem Kreuzzug befand. Der während ihr Geliebter, Adelbert von Hohenburg, sich auf einem Kre sz sie - seiner Ankehrt nach Jahren zurück und fordert sie auf, mit ihm zu fliehen, da sie - seince Ansicht nach - vor Gott mit ihm verheiratet ist (260). Adelheit weigert sich standhaft, willigt aber in ein Rendezvous in Gegenwart eines Einsiedlers ein. Inzwischen hat Ber- wurde, Rastenbergs Sohn Franz zum Werkzeug ihrer Rachepläne gemacht, und verspricht, ihn zu heiraten, wenn er Adelheit vergiftet. Franz aber ist von seiner Leidenschaft für Bertha nicht hinreichend geblendet, um einen Mord zu begehen, und will Adelheit zur Flucht verhelfen. Er informiert seinen Vater über das geplante Stelldichein der Liebenden; Adelheit und Hohenburg werden entdeckt, es kommt zum Duell zwischen Ehemann und Liebhaber, das beide durch „einen Wink der Vorsicht" (282) überleben. Um Adelheit zur Flucht zu bewegen, erfindet Franz einen Mordplan Rastenbergs; Adelheit flieht, trifft vor dem Schloß auf Hohenburg, und wird von Bertha erstochen. Bertha begeht Selbstmord, und Rastenberg und Hohenburg versöhnen sich an Adelheits Leiche. Der Einsiedler entpuppt sich in den letzten Szenen als Rastenbergs ehemalige Frau Franziska, die ihn vor langen Jahren wegen eines Licbhabers verlassen hat, und stirbt nach vollzogener Versöhnung.

Die Moral von der Geschichte läßt sich schon aus dem Ausgang des Stückes entnehmen: die männlichen Figuren überleben ohne Ausnahme; die weiblichen sterben, mit einziger Ausnahme der Vertrauten Adelheits, die in keinerlei Liebeshändel verwickelt ist. Da die Gefahr der Leidenschaft im Stück weit häufiger von Männern kommentiert wird als von Frauen, scheint es fast, als sei diese Leidenschaft den männlichen Protagonisten weitaus gefährlicher. Diese Gefahr wird bereits in der ersten Szene von Wenzel, Hohenburgs Vertrautem, umrissen: „Ein schönes Weib ist [...] der Feinde gefährlichster" (255). Das Thema wird kurz darauf wieder aufgenommen, als Rastenberg Franz die schaurige Geschichte von der untreuen Ehefrau Franziska erzählt. Besondere Betonung legt Rastenberg darauf, daß er zeitweise den Tücken der Liebe entkam - bis er durch Adelheit wieder in den Sumpf der Leidenschaft gezogen wurde. „Fünf Jahre lang floh ich das ganze weibliche Geschlecht - o, hät ich's ewig geflohn! aber ich sah Adelheit, sie riß mich unwiderstehlich hin" (264). Als Franz von der Liebe zwischen Adelheit und Hohenburg erfährt, bedauert er seinen Vater, der „dazu bestimmt [scheint], das Spiel falscher Weiber zu seyn" (273). Aufgrund seiner Erfahrung mit Bertha sieht er die Männer als völlig vom Einfluß der Frau abhängig, wodurch er sie implizit für sein Tun verantwortlich macht. „Weiber, Weiber, was könnt ihr aus uns machen! Wir sind edel oder grausam, je nachdem Eure Leidenschaften unsere Seelen stimmen" (288).

Hier wird zum ersten Mal deutlich ausgesprochen, was jede männliche Figur des Stückes impliziert: die gefährliche Leidenschaft ist eine Eigenschaft der Frau; der Mann kann dem drohenden Verhängnis nur dadurch entgehen, daß er sich von Frauen fernhält. Darin besteht Rastenbergs Lehre an seinen Sohn nach Adelheits und Berthas Tod: „Laß mein Beyspiel und deine kurze traurige Geschichte mit Bertha dich lehren, die verführerischen Reize der Lieb und Wohllust zu fliehn. Ihre Becher schäumen von Süßigkeit; aber in der Neig ist Gift" (310). Nur diese Einstellung macht die völlige Versöhnung der Todfeinde Rastenberg und Hohenburg verständlich - denn beide befanden sich in den Netzen der „Lieb und Wohllust"; beide sind durch Adelheits Tod dem nicht näher erläuterten Verhängnis entgangen und haben ihre Lehre daraus gezogen. Adelheit wird dadurch zu nichts weiter als einer Erfahrung, ciner Lehre für beide Männer, die einander großmütig ihren Tod verzeihen: 
HohEnburg. Du verzeihst mir also, daß ich dir Adelheit rauben wollte, daß meine unbesonnene Leidenschaft sie dem Tod entgegen führte?

RAstenBerg. Verzeihst du mir, daß ich sie zuerst dir raubte?

HOHENBurg. Von Herzen.

RASTENBERG. Nun so sind wir versöhnt auf ewig.

HohEnburg (führt ihn Franzen zu). Und nun vergiebst du deinem Sohn (309).

Die männliche Versöhnung ist allseits vollkommen, der Seufzer der Erleichterung ist fast hörbar. In diese Versammlung der erleichtert trauernden Männer bricht noch einmal die Leidenschaft in Form des Weibes, als der Einsiedler hereinstürmt, die Maske mal die Leidenschaft in Form des Wiederaufnahme fleht. Rastenberg vergibt, lehnt aber, weiser geworden, die erneute Verbindung mit einer Frau ab; Franziska stirbt, nachdem sic ihren Sohn umarmt hat Verbindung mit einer Frau ab; Die Gefahr der Leidenschaft wird am Ende des Stückes von allen Männ
gebannt: Rastenberg zieht sich ins Kloster zurück; Hohenburg und Franz in den nächsten Kreuzzug.

Dieser männlichen Rhetorik der Gefährdung des Mannes durch die dämonische Leidenschaft des Weibes widerspricht nur eines: die Tatsache, daß, im Gegensatz zu den versöhnten Männern, die gesamte weibliche Besetzung des Stückes stirbt - und 列 sterben muß, da das Stuck ihnen keine Alterine läß. Dabei hat ihr lod nichts mit ihrer Reaktion auf die männliche Leidenschaft zu tun, sondern einfach mit der Tatsache, daß die Frau in sie verwickelt ist. Auf eine verbotene oder gescheiterte Liebe können Frauen zwar unterschiedlich reagieren, aber das für sie stets tödliche Ende könen Fraucn zwar un scheint unabwendbar. Jede der möglichen Reaktionen wird hier personifiziert: Frauen können entweder dulden und sterben (Adelheit); sie lsönnen sich rächen und sterben (Bertha), oder sie können fehlen, bercuen und sterben (Franziska). Eine Überlebensmöglichkeit existiert nicht einmal vom technischen Aspekt des Stückes, denn Bertha möglichkeit existiert nicht einmal vom technischen Aspekt des Schort Hohenburgs lediglich zuvor (303). Ob das kommt mit ihrem Selbstmord dem Schwert Hohenburgs lediglich zürer ist, ob, wie BerWeib, wie Adelheit, die "ther ob sie, wie Franziska, etwas tha, ein "Unnatürliches, absc schlichter als „armes Weib“, „gutes Weib“ (314f) auftritt - das Resultat ist fin Frauen in jedem Fall dasselbe. Ähnlich wie bei Schlegel steht hier dieses Resultat in krassem Gerorik: offensichtlich werden nur Frauen von der KataGegensatz zur män die von sämtlichen männlichen Figuren des Stückes ununterbrochen strophe betroffen, die von sämtlichen männlichen Figuren des Stückes ununterbrochen beschworen wird, und zwar alle Frauen - egal,

Die Idee daß die tugendhafte Frau dem Verhängnis entgeht und eventuell sogar

Die Idee, daß die tugendhafte Frau dem Verhängnis entgeht und eventuell sogar Anspruch auf Glück stellen darf, wurde schon in Lustspielen von Frauen nur mißtrauisch rezipiert. In ihren Tragödien bricht dieses Konzept völlig zusammen - je nach literarischer Richtung auf unterschiedliche Weise. In den Stücken der Auflaarung appellieren Tugend und Vernunft vergeblich an dic Vorsehung, oft vergeblicher als das Laster. In den Tragödien der 1770 er und $-80 \mathrm{er}$ Jahre wird, wie in vielen Stücken männlicher Dramatiker, die Leidenschaft der Vernunft gegenübergestellt und als gefährlich, dämonisch, unbedingt dargestellt -- nur daß es hier unwichtig ist, wie sich die Frau der Leidenschaft gegenüber verhält. Die aus männlicher Literatur bekannten Rettungsringe - gütige Vorsehung, Beherrschung der Leidenschaften, Entsagung, Bekämpfung des Schicksals - versagen in Tragödien von Frauen mit erstaunlicher Regelmäßigkeit. Da das Schicksal der Frau in Tragödien von Frauen als vorherbestimmt und durch nichts abwendbar interpretiert wird, fehlen hier die meisten Konzepte, die in Tragödien männlicher Dichter unentbehrlich sind: der positive Charakter mit einer Schwäche, die seinen Fall herbeiführt, die Entwicklung der Charaktere, die tragische/ moralische Notwendigkeit, der Glücksumschlag. Während in Tragödien männlicher Dichter meist genau feststellbar ist, ab welchem Punkt die Tragödie unabwendbar ist, fehlen diese Anhaltspunkte bei Frauen völlig.

Der Grund für den Bruch dieser Tradition in Traucrspielen von Frauen ist derselbe wie der für den unausbleiblichen Tod der Frau, ob Hexe, Hetäre oder Heilige: er lieg einfach in der Tatsache, daß der Heldin aufgrund ihrer Abhängigkeit vom Mann oder von vom Mann geschaffenen Umständen keine Kontrolle über ihr Schicksal zugestanden wird. Daher gilt in Trauerspielen von Frauen die Freiheit, das eigene Schicksal oder auch das eigene Verhängnis zu schaffen, nur für männliche Charaktere, denn die Willensfreiheit der Frau ist durch die von Männern geschaffenen Umstände zu stark eingeschränkt, um ihr eigenes Verhängnis verdienen zu können (Gottsched, Thon, Schlegel). Damit entfallen die meisten Konzepte der Tragödientradition: der positive Charakter z. B., dessen Schwäche seinen Fall herbeiführt, hat immer eine Wahl; der Glücksumschlag ist in der Regel die Konsequenz der falsch ausgeübten Entscheidungskraft des Helden; die moralische Notwendigkeit besteht in der Katastrophe als Folge der falschen Entscheidung. Am deutlichsten zeigt sich die Unanwendbarkeit dieser Konzepte auf Frauen da, wo sie versuchsweise eingehalten werden, $d$. h. wo der tragische Held - nicht aber die tragische Heldin - sich sein Verhängnis selbst schafft und es durch fehlgeleitete Ausübung seiner Willensfreiheit verdient.

\section{Himmlische versus irdische Seligkeit: Artner}

In der Vorrede zu ihrem fünfaktigen 'Trauerspiel Die That (1817) erklärt Therese von Artner (1772-1829), daß diese Willensfreiheit, die Möglichkeit, das eigene Schicksal zu beeinflussen, als Menschenrecht anzusehen sei. Ihr ist es wichtig, daß „dieses Stück eine in sich begründete moralische Nothwendigkeit habe, daß es, ohne die Willensfreyheit zu beschränken, ein verdientes Verbängniß darstelle - denn nur ein solches läßt die christliche Poesie gelten" (Vorrede vii, Hervorhebung der Autorin). Dementsprechend versucht sie, in ihrem Stück, das die Vorgeschichte zu Adolph Müllners Die Schuld (1813) behandelt, Lohn und Strafe gerecht zu verteilen. Zu diesem Zweck muß sie sich den von Johann Christoph Gottsched und Gotthold Ephraim Lessing rezipierten aristotelischen Regeln anpassen, und die alten Konzepte der tragischen Notwendigkeit, des mittleren Charalkters, des Glücksumschlags erstchen in ihrem Stück wieder auf. 
Daß aber die Regeln des Trauerspiels, an die Artner sich erklärtermaßen so streng Daß a ihrer Teilung der handelnden Persohalten will, nen in diejenigen, die iht Verhängnis durch verfehlte Ausubung incer Willensferen verdienen, und diejenigen, die in dieses Verhängnis mit hineingezwngen werden, ohne ihre eigene Stimme dazu abgeben zu können. Auf der einen Seite stehen die ohne ihre elgene Stimer Carlos und Hugo) und eine Hexe (die Sibylle/Hexe Gorgo); auf Măn (dic Brider Cargos Schwester Ruffina). Drehder anderen die Frauen (Carlos Phau Elvire und Gorgos Schwor und Angelpunkt des Stückes ist die Sibylle Gorgo, gleichzeitig die cinzige frei effundene Figur des Stückes, über die die Autorin sich in der Vorrede nicht weiter äußert, da 作 mich dabey leitete" (x)

Gorgos Mutter wurde vor langen Jahren unschuldig als Hexe verbrannt, von Donn aura angezeigt, vom Einsiedler Jeronimo verurteilt. Gorgos Lebensziel ist es, ihren Tod an dem Einsiedler und an Iauras Söhnen Carlos und Habei lod an dem Einsiedler und an Lauras Sohnen Cander in serbechen der Henimmt sie die poetische Gerechtigkeit in Anspreh, indemt sie lernt hexen und taucht an xerei, für das ihre Mutter verurteilt wurde, selbst begeht: sie lernt hexen und taucht an entscheidenden Stellen im Leben ihrer Opfer auf. Die Umstande, die dic Tragotie herbeiführen, sind ausschließlich ihr Werk: Laura hat ihren zweiten Sohn Hugo weggegeifun, weil Gorgo ihr weissagte, daß er am Tod ihres Erstgeborenen Carlos schuldig geben, weil Gorgo ihr weissagte, daß er am Tod Carlos, die von ihrer Verwandtschaft werden würde. Im Stück freunden sich Hugo und Carlos, die von ihrer Verwandtschaft nichts ahnen, miteinander an; Hugo und Carlos' Frau Elvire verlieben sich ineinander; nichts ahnerfill in rasende Eifersucht. Hugos zeitweilig auftretender Entsagungswille Carlos verfalle in rasende Eifersticht. Helvire weissagt, sie werde bald wird von Gorgo systematisch unterminiert, indem sic Blyie wess sis Witwe und in einer zweiten Ehe glücklich werden, und Hugo glauben mach, Elvire werde von Carlos mißhandelt. Während Elvire den einzigen Ausweg in Entsagung wercher (Selbstmord oder Ruickzug ins Kloster) sieh, faßt morden. Als Carlos von dem nach Jahren zurückgekehrten Jeronimo erfahrt, Hugo se sein Bruder, versucht er, die Versöhnung einzuleiten, und lädt Hugo zu einem Fest ein Diese Einladung nimmt Hugo als Beweis für Gorgos Behauptung, Carlos wolle ihn Diese Einladung nimmt Kloster, Gorgo wird direk ermorden, und tötet Carlos auf der Jagd. Elvir

nach dem Mord von einem Blitz erschlagen.

Während die Willensfreiheit der männlichen Figuren sich in ihren Entscheidungen Wert ist die der Frau ausschließlich moralischer Natur. Für sie geh und Handlungen außert, ist die der Trau ausschließlich ming realen Einfluß auf ih es im Stück nur darum, ihre Seele zu retten oder zu verieren, realen Einthß auf ih Schicksal im Diesseits hat sie nicht. Das wird zunächst an Elvires Dilemma demonstriert: Elvire wurde mit 13 Jahren an Carlos zwangsverheiratet. Carlos, wie sie vor vollendete Tatsachen gestellt, verliebt sich glüicklicherweise in sie, denn „Geist und Lie-

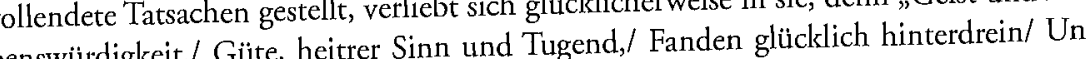
benswürdigkei,/ Güte, heitrer Sinn und Tugend,/ Fanden glucklich hinterdrein/ Unbekannt sich selber ein“ (33); sie dagegen empfindet für ihn nur "Stiller Neigung freundlich Regen" (33). Elvire ist in ihrer Ehe nicht glücklich, denn sie leidet an einer Kon Betty Friedan als Hausfrauenkrankheit diagnostiziert Krankheit, die noch 1962 von Betry Fredan als Hains inse Einsamkeit in unerfullbaren Wurde: sie ist unausgefüllt und mit starkem Symbolgehalt. Ihr erster Wunsch ist ein Paradiesvogel,
„Welcher nie an Zweigen hangt,/ Fußlos, nie den Grund berühret,/ Sondern ewig in der Luft/ Schwebt, genährt von Actherduft" (40). Carlos muß ihr darauf mitteilen, daß es solche Vögel nicht gibt, da er auf der Suche nach ihnen nur tote gefunden hat. Ihren Traum vom Paradiesvogel erklärt er zum Trick eines Betrügers: „ein Mann, der Glaubens werth,/[...]/ Hat betheuernd mich belehrt,/ List'ge hätten uns betrogen/ Und dem Thierchen, schön geputzt,/ Todt die Füße abgestutzt" (41); sein sententiöser Verweis an Elvire lautet: „Thorheit ist vergebnes Sehnen“ (41). Elvire, der so die Fliigel gestutzt werden, nimmt Abschied von ihren Träumen überhaupt: „Ach! mit allen $\mathrm{Pa}$ radiesen/ Hier mag's wohl ein Mährchen seyn!“ (41) Der Paradiesvogel, der nie den Boden berührt, ist ein offensichtliches Symbol für Elvires Bewußtsein, daß die Ehe, die sie am Boden festhält, ihr nicht genügt. „In dem tiefsten Herzen hege/ Ich ein brennendes Verlangen/ Etwas, etwas zu erlangen,/ Was ich nicht zu nennen weiß,/ Und höchst schmerzlich doch vermisse" (42).

In diesem Zustand befindet sie sich, seit ihr Sohn Otto zu alt ist, um ihr die ausschließliche Selbstdefinition als Mutter zu erlauben: sobald der Sohn sie nicht mehr völlig in Anspruch nimmt, stellt sich das Gefühl der Nutzlosigkeit ein, das diese Selbstdefinition als Traum entlarvt. Denn „nun ist's, als wär' ich wach;/ Leer der Platz an meinem Herzen/ Wo er einschlief unter Scherzen/ [...]/ Und nun möcht' ich was ersinnen,/ Was durch Neuheit mich erfreut" (43, Hervorhebung der Autorin). Carlos versucht sie zu beruhigen, indem er ihre Verzweiflung zur Laune degradiert: „Laß, sie werden bald verrinnen,/ Diese Nebel, theures Weib“ (43). Da Elvire auf die Rolle der Hausfrau und Mutter beschränkt ist, ist Carlos' Meinung nach ihr „brennendes Verlangen/ Etwas, etwas zu erlangen" nur innerhalb dieser Rolle erfüllbar - durch ein neues Baby, das ihr "für den Wildfang,/ Der nicht mehr beym Mütterlein/ Bleiben will, Ersatz gewähren" wird (43). Die Darstellung von Elvires Eheunglück widerspricht ihrer späteren Ansicht, ihr Dilemma bestünde in ihrer Liebe zu Hugo; ihr irdisches Schicksal wurde bereits in ihrem 13. Lebensjahr entschieden. Das einzige, was ihr bleibt, ist für die ewige Seligkeit vorzusorgen, in der Hoffnung, daß sich diese nicht auch als Märchen entpuppt. So entsagt sie ihrer Liebe zu Hugo und zu ihrem Sohn, indem sie freiwillig ins Kloster geht. An ihrer Entsagung scheitert auch der letzte Verführungsversuch Gorgos, die an Elvire feststellt, was für alle Frauen des Stückes gilt: ihr Glücksanspruch, der Wunsch nach dem Paradies auf Erden, ist nicht nur ein Ding der Unmöglichkeit, sondern steht auch in direktem Gegensatz zur Hoffnung auf das Paradies im Himmel. "Fleuch zur Rulhstatt, müdes Reh!/ Du hast Kraft noch, wie ich seh',/ Bist auf Dornen jetzt gebettet,/ Doch die Seele ist gerettet" (165, Hervorhebung der Autorin).

Für Gorgos Schwester Ruffina gilt Ähnliches: Ruffina hat dieselbe Geschichte wie Gorgo, hat aber irdischen Versuchungen (der Versuchung, den Tod der Mutter zu rächen), in der Hoffnung auf das ewige Leben entsagt. Ruffinas Auftritte beschränken sich auf Versuche, Gorgo zur Umkehr zu bewegen und ihre üblen Machenschaften zu entkräften. Ihre Seele schließlich rettet sie, indem sie Carlos gegenüber Elvires Unschuld am Ehebruch beweist und diesen so zu seinem letzten Versuch veranlaßt, die Katastrophe abzuwenden. Carlos will sie für die gute Nachricht reich belohnen, aber 
sie lehnt ab: „Kein Geschenk von Laurens Sohne!/ Bess'rcr Lohn wird mir zu Theil;/ sie lehnt ab: „Kein Geschenk v" (180, Hervorhebung der Autorin).

Gorgo dagegen geht den umgekehrten Weg: für die Befriedigung ihres irdischen Cectirfnisses verkauft sie ihre Seele dem Teufel; ihr einziger Wunsch ist, die Op(he fer ihrer Rache mit sich in die Hölle zu ziehen. Dabei betrachtet sie sich keineswegs als fer ihrer Rache mit sich in desicksals, sondern lediglich als dessen Werkzeug: „meine autonome Schöpferin des Schicksals, sondern lediglich als dessen Werkect " Hand/ Soll es vorlaut nicht entscheiden;/ Staunend leg' ich meine Rechte/ Zu den Füßen höh'rer Mächte“ (36). Gelingen oder Mißlingen ihrer Rache hängt letztendlich Fußen hörien von der Willensfreiheit der männlichen For strophe führt, ist Gorgo bcreit nachzuhelfen. Gorgo übernimmt die Rolle des Chors, der das Handeln anderer Figuren kommentiert, und ist in diesem Sinne eine neutrale Figur: sie personifiziert die Versuchung, der die anderen unterliegen, und überläßt ihFigur: sie personifiziert die Veterich sowohl als nen die Entscheidung, ob sie ihr nachgeben oder nicht. So kann sie sich sowohl als Dienerin des Himmels $(36,72)$ als auch der Hölle bezeichnen (208). Ihr Versuch, die anderen Figuren zur Aufgabe des Seelenheils zu bewegen, ist im Kontext des Stückes eine durch weibliche" Rache, denn auf Erden ist, wie sic aus der Geschichte ihre eine durchaus "weibliche Rache, denn auf Erde ist wares, sondern auch die Gerechunschuldig ermordeten Mutter weiß, nicht nur das Panadics, sonden auch dic Gerechtigkeit ein Märchen. Im Himmel vermutet sie, wie andere Figuren des Stücks, sowoh das Paradies als auch eine Gerechtigkeit; auf Erden aber herrschen, zumindest für Frau-

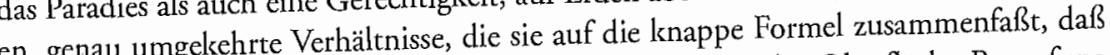
, nur' Unschuldige sterben. Der Toge insele Folge ihrer Unschuld, denn als echte für ein Verbrechen, ist im Gegenteil eine direke Fou Hexe hätte sie sich helfen können. "Nimmer litt es uns der Autorin)

nicht gewesen", klärt sie Ruffina auf (84, Hervorhebung der Autorin). Im Bewußtsein dieser umgekehrten iril sie sich auf dem Weg zur Unschuld befinden. ren, die für ihre Rache anfällig sind, weil sie sich auf dem Weg zur Unscher wird umDer Einsiedler Jeronimo, der sein Verbrechen an Gorgos Mutter bereut, wird umgehend von Gorgo vergiftet; Carlos' Einsicht und Reue ermöglichen scinen Tod, da gehend von Gorgo vergittet; Gorgo seine Einladung an Hugo diesen gegenthe garlos zitierten weiblichen len kann. Je mehr die männlichen Figuren sich den von Carlos zitienten weiblichen Eigenschaften Elvires (Güte, Tugend) nähern, desto hilfloser und anfälliger werden sie für Gorgos Rache. Während allerdings die Unabhängigkeit des männlichen Willen auch von Gorgo häufig betont wird (z. B. 205), scheint diese Möglichkcit für Frauen icht 7 exictent für Frauen die Hoffnung auf das himmlisch nicht zu existion seits und im Jenseits durch ein und dieselbe Handlung hervorgerufen wird. Hugo z. B. (irdisches als auch himmlisches Glück durch falsche Ausübung verscherzt sich sowohl irdisches als auch seiner Willenskraft, denn sein Mor er „lebend verzweifeln“ (208). Die Wahl zwischen auf Erden - wie Gorgo weiß, muß er „ebend verzweifeln (208). Dugo tötet Carlos irdischem und himmlischem Glück stellt sich nicht für Mầnner - Hugo tötet Carlos nicht in der Hoffnung auf irdisches Glück, sondern als Vergeltungsakt ${ }^{28}-$; Elvires irdinicht in der Hoffruch aber, die Verbindung mit Hugo, kann nur durch Opferung der himmlischen Seligkeit erreicht werden.
Artners Idee, daß für Frauen irdischer Glücksanspruch mit himmlischer Seligkeit grundsätzlich unvereinbar ist, könnte vieles erklären, so z. B. den häufigen Tod der weiblichen Unschuld in Trauerspielen von Frauen und die Diabolisierung weiblicher Unabhängigkeitsbestrebungen. Die Versuche der Frau, ihr eigenes Schicksal zu becinflussen, äussert sich meist in Rachebedürfnis (Gorgo), oft an einem untreuen Liebhaber (Thons Bertha in Adelheit von Rastenberg), und werden angemessen bestraft. Dicse Strafe für das Übertreten weiblicher Schranken wird unter Umständen als so selbstverständlich und bar jeder Tragik dargestellt, daß das Stück nicht einmal mehr den Namen der Tragödie erhält - man erinnere sich an Christiane von Bredens "Drama" Faustina. Aber hinter dieser Teilung des weiblichen Charakters steht überall das Bewußtsein der Abhängigkeit der Frau, der demnach nur die Wahl bleibt, sich gegen das Unausweichliche zu wehren - und folgerichtig unterzugehen - oder sich, wie Elvire, in cin Schicksal zu ergeben, über das sie keine Kontrolle hat.

\section{D. ÜBER DIE ABHÄNGIGKEIT DES WeIBES: Günderrode, Droste-Húlshoff}

In einigen wenigen Stücken wird der Versuch gemacht, weibliche Unabhängigkeitsbedürfnisse nicht zu diabolisieren. Bezeichnenderweise handelt es sich hier um nicht zur Aufführung bestimmte Lesedramen. Die meisten dieser Stücke sind Fragmente geblieben - ich nehme an: bewußt, da die fragmentarische Form in den Stücken selbst angelegt ist. Es handelt sich hier um Szenen, Ausschnitte, die tragisch enden müßten, wenn es mit rechten Dingen zuginge. Gerade gegen die Weltordnung aber, die bestimmt, was die „rechten Dinge" sind, wenden sich die Autorinnen; sie bieten lediglich tragisches „Material" - Bruder- oder Königsmord - und brechen das Stück an dem Punkt ab, an dem die Entscheidung zwischen menschlicher Autonomie und Unabwendbarkeit des Schicksals gefällt werden müßte.

Thema dieser Fragmente ist die Frage, ob der Mensch dem Schicksal gegenüber autonom ist, und ob - für Frauen eine logische Weiterführung der Frage - diese Autonomie, wenn sie für Männer existiert, auch für Frauen gilt. Karoline von Günderrode (1780-1806) scheint diese Frage für Männer und Frauen unterschiedlich zu beantworten: während den Männern der Zweifel des ungewissen Ausganges zugestanden wird, ist das Schicksal der Frauen an dem Punkt, an dem das Stïck abbricht, meist entschieden, da ihr Schicksal nach wie vor von dem der Männer abhängt. ${ }^{29}$ Dabei sind die Frauenfiguren ihrer Stücke oft selbständiger und entschlossener als die männlichen Heroen, deren Kampf mit dem Schicksal sich oft im Bruch sozialer und legaler Normen äußert.

In Magie und Schicksal (1805) wird der philosophische Konflikt, der sich durch das Stück zicht, zunächst an Vater und Sohn exemplifiziert: Unterwerfung unter das auch durch Magie unergründliche Schicksal (Alkmenes) steht gegen den menschlichen Willen, das eigene Schicksal „Von der Gestirne Einfluß unberïhrt" (Gesammelte Werke II, 131) zu bestimmen (Ligares). Schon allein der Glaube an die Unabwendbarkeit des 
Schicksals oder an menschliche Selbstbestimmung diktiert das Handeln der Figuren: Schicksals oder an malbbruders Timandras ab Ligares wird von seiner geliebten Ladika zugunsten seines Hänüber, indem er Timangelehnt und demonstriert scine Autonom die Unbeeinflußbarlkeit des Schicksals durch den dras ermordet. Alkmenes' Glaube an die Unbeeinfußbarkeit des Schekals duru den Menschen bestätigt sich in seiner Unfähigkeit, das vorausgesehene Unheil abzuwenden: Ligares findet das von ihm versteckte magische Szepter, das er, whe Alkmenes fürchtet, Verderblich [...] mißbrauchen" (151) würde, und benutzt es zum Mord an Timenten besteht in einem Timandras. Ligares Versuch, das Schicksal auf seine Seite zu zwingen, besteht in enio Bruch sämtlicher sozialer und moralischer Normen: bevor er limandras hinteich und mit magische

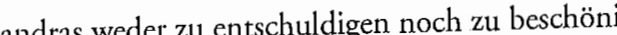
Ligares versucht den Mord anl Timandras Weltgeschehens (164) und ist von keinerlei gen; im Gegenteil sieht er ihn als Abbild des ist, der an die Rache des Schicksals glaubt Reue geplagt, da Reue eine Reaktion dessen ist, der an die Rache des Schiclsals glube (165). In seinem Autonomieglauben vergißt er allerdings, daß er zwar Einfluß auf das eigene Schicksal nehmen kann, nicht aber auf die Reaktion anderer. So erwist sich seine simplistisch gezogene Konsequenz im Bezug auf Ladikä - „Jetzt darf ich hoffen, ja, sie wird mich lieben“ (164) - als Trugschluß. Sein Glaube an die Möglichkeit der (a) derd an Timandras) 列 den Zweck (Ladikäs Liebe zu erringen) nicht erreicht, vor all Ladikä. Der Erfolg seines nicht nur versucht, das Schicksal zu zwingen, sonder Negierung des ihren ab. Seine verAutonomiebestrebens hängt letztendlich von der Negierung des ih frühte Siegesgewißheit - „Erkämpfet hab’ ich sie, sie ist nun mein./ Auf Erden mach sie keiner mehr mir streitig" (165) - wird von Ladikä gründlich gedämpft; an ihrer sie keiner ne die eigene Unabhängigkeit, bis er unbeirrten Ablehnung zerbrockelt sein Glawbe an die eigene Unabiangichtige Liebschließlich auf derselben Ebcne reagiert wie viele abgelehnte und ohnmächtige Liebhaber der Tragödie: er beschimpft und bedroht sie, klagt sie der Untreue an und bitte haber der Tragon schlieilich um Gnade (1e er Ladikä gegenüber seiner Autonomie dem Schicksal gegenuber, sondem eine Tat, die ce Ladik gegenter abstreiten oder damit rechtfertigen muß, sie habe durch ihre Weigerung, ihn zu lieben, "Schlimm'res noch an mir gethan" (173). In seiner ersten und letzten Begegnung mi "Schlimmies seiner Mutter Cassandra kann er die Tat ihr gege

Von Stückes ändert sich seine Haltung dem Schicksal gegenVor Auseinandersetzung mit Alkmenes will er sich noch „selber fühüber merklich. In der Auseinan len als des Schicksals Herr (131), aber bereits vor de Mor Schicksal nicht mehr als seinen Untergebenen, sondern als Kollaboran, der ih Schich Zu rechter Zeit spielst du mir in die Hände,/ Was Rache mir und Rettung noch verspricht" (162). Nach der Szene mit Ladikä bezeichnet er sich als vom Schicksal abhängig, in

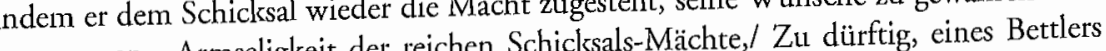
zu versagen. „Armseligkeit der reichen Su erfüllen!“ (175) Am Ende des Stückes heißen Wunsch/Mit einer Gabe göttlich zu crfullen! (175) Am Ende des Stuckes wird das Schicksal zur Triebfeder seiner Handlungen, er selbst nur zum ausführenden
Organ: „es hat mich zum Verbrechen/ Des Schicksals Wille deutlich selbst geführt,/ Und seine Winke hab' ich nur vollzogen:/ Drum denke, daß ichs nur gezwungen that" (181):

Dieser Abgang Ligares', mit dem das Stück endet, scheint eher ein letzter Versuch der Rechtfertigung als „positiv und auf die noch zu bewältigende Zulsunft gerichtet" (Kastinger Riley 110); auch daß „,von Ligares' weiterem Schicksal [...] nichts angedeutet" (110) wird, scheint nur bedingt zutreffend. Denn Ladikäs Ablehnung, die seinen Mord sinnlos macht, führt zu einem inneren Tod Ligares', dessen Konsequenz ein realer Selbstmord sein könnte - zumindest spricht er diese Möglichlkeit bereits in der Szene mit Ladikä an (174). In der Begegnung mit Cassandra ist er „wie Todte starr, wie Gräber kalt" (179); die physischen Merkmale, deren Abwesenheit er schon bei Timandras als Todesursache diagnostiziert - „Das Triebwerk seines Herzens ist zerstört" (164) -, fehlen auch bei ihm: „Es ist kein Herz in diesem Busen mehr" (179). Sein Versuch der Selbständigkeit bleibt auch für ihn in der legalen und gesellschaftlichen Interpretation verhaftet, ein Mord, „ein schrecklich Wort" (180), das er seiner Mutter gegenüber nicht aussprechen kann und dessen Konsequenz vorgezeichnet scheint. „Begraben sey mit mir das Schreckenswort. -/ Leb wohl denn, Mutter! lebe wohl auf immer!/ Und was $\mathrm{du}$ ferner auch vernehmen magst,/ So denke, daß Verzweiflung mich getrieben,/ Und fluche mir nicht, was ich auch gethan" (180). Ob er damit lediglich auf seine Tat an Timandras anspielt oder auf seine Absicht, sich „verzweiflend wüthend selbst" (174) zu morden, bleibt offen; die sich häufenden ominösen Anspielungen gegen Ende des Stückes lassen den letzteren Schluß jedenfalls zu.

Für Frauen scheint Selbständigkeit nur auf einer einzigen Ebene zu existieren, die allerdings auf gesellschaftlicher Ebene kaum wohlwollender interpretiert wird als der Mord beim Mann: in der Möglichkeit, einen ungeliebten Mann zu verlassen. Sowohl Cassandra als auch Ladikä haben diese Möglichkeit in Anspruch genommen und dadurch die Umstände mitgeschaffen, die den Brudermord ermöglichen: Ladikä erregt Ligares' Eifersucht, indem sie Ligares zugunsten Timandras' verläßt; daß Ligares unwissend den eigenen Bruder tötet, wird dadurch ermöglicht, daß Cassandra Alkmenes verlassen hat, als Ligares noch ein Säugling war. Während die männlichen Figuren des Stückes (Alkmenes, Ligares) ihr Selbst im Bezug auf das Schicksal definieren, definieren beide Frauen sich im Bezug auf die Männer. Cassandra lebt in ewiger Erinnerung an den „Tag, da ich den Gatten so verrieth,/ Da aller heil'gen Pflichten ich vergessend/ Mich in des fremden Mannes Arme warf" (138); ihr Schuldbewußtsein macht ihr diesen Tag zur "Stunde des Entsetzens" (138). Ladikä definiert sich völlig über Timandras und erinnert sich mit ebensolchem Schauder an ihre Verbindung mit Ligares, da sich ihr Selbst nicht über seine Liebe definieren ließ:

Mir schauert, denk' ich seiner Liebe nur.

Wohl mir! daß ich dem schlimmsten Traum erwachet,

In dem ich thörigt wähnend mich betrog,

Ich lieb' ihn. Nein! ich hab ihn nie geliebet;

Als ich es glaubte, war ich selbst mir fremd;

Doch in Timandras hab ich mich gefunden (159). 
Da ball von Timandras, abhängt, gründet sich ihr Schicksalsglaube auf den unsicheren Besitz dieses Mannes. „Versöhnet sind dic Götter, denn sie haben/ Timandras mir, den liebsten Sohn, geschenkt" (142), mein Cassandra laurz vor der Szene, in der Ligares den Plan zum Mord an Timandras entwirft. Kurz nach Timandras' Tod erwartet Ladikä ihn sehnsüchtig: „Schön ist es zwar ersehnen, hoffen, träumen,/ Doch seliger ein ruhiger Besitz" (169). Nachdem Timandras als Selbstdefinition Ladikäs wegfällt, bleibt ihr nur noch, Ligares abzuweisen, da er ihr keine Möglichleeit der Neudefinition bietet; Cassandra erfährt bi zum Schluß nichts vom Tod ihres Sohnes und verliert auch den zweiten Sohn Ligares zum Schle Möglichkeit der Selbstdefinition als Mutter. Von beider Schicksal wird am Ende des Stückes tatsächlich nichts angedeutet, aber angesichts der Tatsache, daß TiEnde des Stückes tatsachlich Faktor beider nicht mehr existiert, scheint das relativ überflüssig.

Ein umgekehrter Prozeß, der von Abhängigkeit zur Selbstbestimmung, scheint sich in Nikator (1806) zu vollziehen. Nikator, der Feldherr des Königs Egestis, bezeichnet sich am Anfang des Stückes als Getriebener ohne eigene Kontrolle (Gesammelte Werke II Werk des Schicksals darstellt:

Das launenhafte Glück zeigt sich mir hold,

Der Zufall will sich mir gewogen stellen,

Und ich weiß selber nicht, wie mir geschieht;

Von Schlacht zu Schlachten werd' ich fortgezogen,

Das Schicksal treibt mich fort in seinen Kreisen

Und ihm befehlend dien' ich ihm als Knecht.

Wir möchten gern uns Herrn des Zufalls stellen,

Doch er gewinnt und er verliert die Schlacht.

Der Steuermann beherrschet nicht die Woge,

Sie reißt ihn fort in ihrem wilden Drang (188).

Die Möglichkeit, sich in dieser Weise weiter treiben zu lassen, wird ihm genommen, als der König ihm die geliebte Adonia verweigert, um sie selbst zu heiraten. An dieser Stelle bleiben Nilkator zwei Möglichkeiten: die eine ist der völlige Rückzug, da nach Stelle blo dieser Ablehnung „nichts des kranken Herzens Wünsche mehr reizt (191) - was gleichzeitig bedeutet, die Weltgeschichte unbeeinflußt ihren „ernsten Schritt“ weitergehen zu lassen: „Ich greife nicht in ihres Rades Speichen,/ Und meine Thaten dring gehe Möglichkeit ist dic, das Schicksal nicht als unabich ihr nicht auf (192). Die andere Möglichleit ist dic, das Schick Re wendbar zu betrachten, sondern zu versuchen, es selbst zu stetion. Diese Moglic wird zunächst im König dargestellt, dessen Tyrannei darin besteht, daß er sich unbekümmert über Sitte, Gesetz und öffentliche Meinung hinwegsetzt, um sein Ziel zu (a) erreichen (194) und sich zum Herrn der Schöpfung aufwirft. "was mir angehöret, Das reiß’ ich fort in meiner eignen Bahn;/ Ich spende Glück und Gunst nach Wohlgefallen,/ Denn mein Geschöpf ist alles um mich her" (194)
In diesem Sinne ist er wahrhaft autonom und kann Gehorsam [..] im ganzen Sinn" (195) verlangen - und gerade dieses Selbstbewußtsein, dieser Wille, das eigene Schicksal zu formen, erweckt in Nikator dieselbe Seitc. Denn als das königliche Machtbewußtsein ihm von Esla in Form des unwiderruflichen Befehls überbracht wird, Adonia auszuliefern, erwacht sein Widerspruchsgeist: „Unwiderruflich! wenn es mir beliebet./ Geb' ich sie nicht, was bleibt ihm dann zu thun?“ (195) In einer Nachahmung des königlichen Selbstbewußtseins setzt er nun Laune gegen Laune, Welle gegen Fels (196); seines „Busens heiliges Gebot", dem er nun gehorcht, ist der Widerstand gegen eben die königliche Gewalt, deren Imitation sie ist. „Eh mag ich Königen die Treue brechen,/ Als der Natur, die mir im Herzen spricht" (200). Auch der König empfindet diese Usurpation seiner Majestät: „er hat den Tod verdienet;/ Verhöhnet hat er meine Majestät" (206). Diese Usurpation ist um so gefährlicher, als sie sich auf reale Macht gründet, denn das Heer ist auf Nikators Seite. „Drum glaubt' er des Gehorsam sich entlassen,/ Und thuet stets, was ihm, nicht mir, gefällt" (206), vermutet Egestis.

Nikators und Egestis' beiderseitiger Haß gründet sich auf das Wissen, daß beide eigenständig handeln und sich nicht vom anderen beeinflussen lassen; mehr noch als der Besitz Adonias ist daher beider Ziel, den anderen zu besiegen. In der Auseinandersetzung zwischen Nikator und Egestis führt dementsprechend jeder das an, was die eigene Autonomic gegenüber der des anderen rechtfertigt: der König die Pflicht des Gehorsams, die Nikator an ihn bindet, Nikator den Rat des eigenen Herzens, der ihn von diesem Gehorsam entbindet (208). Als der König seine Machtstellung durch das Todesurteil Nikators demonstriert, ersticht Nikator ihn. Damit ist sein Ziel, sich gegenüber der Macht Egestis' zu behaupten, erreicht: „Ich bin bereit zu sterben,/ Denn was ich wollte, hab' ich nun erreicht" (211). Das Ende des Stückes bleibt offen, weil alle anderen Ziele, die man Nikator unterstellen könnte - der Besitz Adonias oder auch nur zu überleben - seiner Unabhängigkeitsdemonstration gegenüber vergleichsweise nebensächlich sind. Aus den Worten der Soldaten, mit denen das Stück schließt das Überleben Nikators zu lesen (Kastinger Riley 116), ist begründet, aber m. E. optimistisch; sein Leben ist nach ihrer Aussage sowohl zeitlich begrenzt - „bis wir ihn vernommen haben“ - als auch von ihrem Urteil abhängig: „wenn er sich rechtfert'gen kann" $^{\prime \prime}(211)$.

Sowohl Adonia als auch die Königin versuchen gleichfalls, ihr Schicksal in die Hand zu nehmen, haben dabei aber mit einer Schwierigkeit zu kämpfen, der Nikator nicht unterliegt: mit ihrer Abhängigkeit vom Mann, die sich im Verlust ihrer realen Macht (Besitz) äußert. Die Königin, deren Macht an ihren Mann gebunden ist, sinkt durch die Verbannung "vom Thron zur Niedrigkeit" (204); in Adonias Liebeserklärung an Nikator steht der Verlust ihres Herzens in seltsamer Nachbarschaft mit dem ihrer Macht.

Das Diadem entwand'st Du meinem Haupte,

Und meinem Busen raubtest du das Herz.

Der Purpur fiel herab von meinen Schultern

Der Hoheit Glanz zerrann, wie Morgenthau; 
Da badet' ich die Brust in Lieblingsträumen,

Und unverwundbar ward sie dem Geschick.

Ich stieg vom 'Thron' und hab es nicht empfunden;

Denn in dem Schauen war der Sinn entrückt (198 f).

Nach dem Verlust ihrer realen Macht definiert sie sich völlig durch ihre Liebe - „Denn ich bin ewig meine Liebe selbst“ (199) -, und Nikator kann mit Recht behaupten: „sie ist mein, sie hat sich mir gegeben" (199).

$\mathrm{Da}$ die Frauen sich über die männlichen Figuren definieren, folgt daraus, daß beide Da die Tratcksal durch Becinflussung der Männer in die Hand zu nehmen. Adonia verhindert die Auseinandersetzung zwischen Nikator und dem König zunächst, indem sie sich eine Aussprache mit dem König vorbehält.

Die Liebe siege, nicht die blut'ge Macht.

Ich dulde nicht, daß Du mich so behauptest,

Denn hassenswerth soll unser Bund nicht seyn.

Ich geh' zum König, was das Schicksal sinne;

Ich bleibe Dein, vertraue meinem Muth

Und meiner Liebe; viele sind's der Pfade,

Die alle führen zum gewissen Ziel,

Und einen find' ich $(200 \mathrm{f})$.

Aber weit entfernt, einen dieser Pfade suchen zu können, geschweige denn zu finden, verbringt Adonia das gesamte Gespräch mit dem König damit, sich gegen dessen „wilde Gluth" (202) zu wehren - und reagiert schließlich, wie Ladilä, mit der einzigen de Gluth ih bleibt: der unbedingten Ablehnung (203). Während Adonia verMöglichleeit, die ihr bleibt: der unbedingten Ablehnung (203). Wöhrend Adonia vergeblich versucht, Nilkator vom König zu erhalten, versucht die Königin, mit Nikators Hilfe die Ehe zwischen Egestis und Adonia und dadurch ihre Verbannung zu verhinHern. Im Bewußtsein ihrer Hilflosigkeit ohne männliche Unterstützung machen beide dern. Im Bewußtsein ihrer Hilflosigkeit ohne män Frauen die Männer zu ihren Handlungsträgern. Nach dem Versuch der Einflußnahme auf die handelnden Männer verschwinden beide Frauen aus dem Stück - denn da Adonia ihre „Liebe selbst“ ist, ist ihr Schicksal von dem Nikators abhängig, und die beiden Möglichkeiten der Königin - mit ihrem Mann zu fallen oder selbst die Macht zu übernehmen - werden nicht weiter erörtert.

Obwohl bei Günderrode die Möglichlkeit, das eigene Schicksal zu bestimmen, nu fir Männer zu existieren scheint, sind die Frauen keineswegs passiv. Aber ihre Handfür Mânner zu existiercn schent, sind dic Frä lungsmöglichkeiten sind eingeschränkt durch ihre Situation, die Abhängigkeit der Frauen allgemein, die Günderrode selbst tief empfunden hat (Kastinger Riley $93 \mathrm{f}$ Frederitsen, Frederiken, „Die Frü Stücke. Solange diese Abhängigkeit (die hängigkeit liegt das Revolutionäre ihrer Stǘcke. Solange diese Abhangigkeit (die Cassandras und Ladikäs von Timandras, die Adonias und der Königin vom König) und die entsprechende Selbstdefinition (die Cassandras und Ladikäs über Timandras, die Adonias über Nikator, die der Königin über den König) bestehen bleibt, handeln
Frauen nicht nur durch Männer, sondern bleiben auch in ihrem negativen Handlungsspielraum gefangen. Dieses Muster - positive Handlung des Mannes, negative Hand lung der Frau - zieht sich durch viele Stücke Günderrodes: während die Männer ihre Kraft daran wenden, etwas zu erreichen, versuchen die Frauen meist, etwas zu verbindern.

Sowohl Ladikä als auch Adonia sind der Knochen, um den sich zwei Männer streiten; während Ligares, Nikator und Egestis um den Besitz der Frau lämpfen und ihre Besitzphantasien oft in mörderischen und kannibalistischem Vokabular äußern (Magie und Schicksal 172, Nikator 202), wenden die Frauen alles daran, nicht besessen zu werden - daher besteht der Höhepunkt ihrer Unabhängigkeit in ihrer entschiedenen Abweisung der Männer. Die einzige Frau bei Günderrode, die dieses Muster umkehrt, ist Hildgund in dem gleichnamigen Fragment (o. J.), die ihr Ziel, den Mord an Attila, dadurch zu erreichen versucht, daß sie ihn zum Schein heiratet (Gesammelte Werke I, 102 und 105). Aber auch hier bleibt der Erfolg des Unternehmens zweifelhaft; das Fragment endet nicht, wie Magie und Schicksal und Nikator, nach vollbrachter Tat, sondern mit Hildgunds Entschluß (108). In Mahomed, der Prophet von Mekka (o. J.), dem einzigen offensichtlich vollendeten Stück Günderrodes, sind die weiblichen Figuren nur Nebenrollen und vom Mann abhängiger denn je: am Ende des Stückes erreicht Mahomed sein Ziel; von den beiden Frauenfiguren, die beide kein Ziel und keine Definition außerhalb des männlichen Heros haben, stirbt eine; die andere wird von Mahomed dazu verurteilt, im Andenken eines ungeliebten Liebhabers zu leben (Gesammelte Werke I, 225) - sie wird also in eine Art inneres Kloster geschickt. Daß es Frauen möglich sei, ihr eigenes Schicksal zu beeinflussen, deutet Günderrode nur in Hildgund an, und auch hier hängt der Erfolg der weiblichen Pläne von einer zumindest scheinbaren Unterwerfung unter den männlichen Willen ab.

Diese Abhängigkeit der Frau vom Mann stellt Annette von Droste-Hülshoff in ihrem Trauerspielfragment Bertha oder die Alpen (1814) als anerzogen dar. Das Stück ist ca. zur Hälfte vollendet und enthält keine Handlung; die ersten anderthalb Akte, völlig ohne Interpunktion geschrieben, bestehen in einer Charakterisierung der Figuren durch Erörterung der gesellschaftlich vorgeschriebenen weiblichen und männlichen Rollen. Einander gegenüber stehen sich zwei Familien: Reichsgraf und Reichsgräfin mit ihren Töchtern Bertha und Cordelia und ihrem Sohn Ferdinand; der Minister; Bruder des Reichsgrafen, und die Ministerin mit ihrer Tochter Laurette; sowie die entsprechenden Bewerber um die Hand der einen oder anderen Tochter - Edward Felsberg, ein reisender Musilkus, der sich in Bertha verliebt; Graf Reihersdorf, aufgrund politischer Motive Anwärter auf Berthas Hand; und Graf Hellbronn, Cordelias Verlobter. Außer diesen Figuren, die insgesamt die Familiensphäre des Stückes ausmachen, existiert nur noch eine wichtige Figur aus der politisch-höfischen Sphäre, Marco Godowesi, der gemeinsam mit dem Reichsgrafen und dem Grafen Reihersdorf einen politischen Umsturz plant. Die Figurenkonstellation des Stückes könnte man folgendermaßen schematisieren: 
Tabelle 1. Figurenschema zu Droste-Hülshoffs Bertha.

\begin{tabular}{|c|c|c|c|}
\hline \multicolumn{2}{|c|}{ POLITIK } & FAMILIE & KUNST \\
\hline Familie 1: & Reichsgraf & $\begin{array}{l}\text { Reichsgräfin } \\
\text { Cordelia } \\
\text { Ferdinand }\end{array}$ & Bertha \\
\hline Familie 2: & & $\begin{array}{l}\text { Ministerin } \\
\text { Laurette }\end{array}$ & \\
\hline Heiratskandid & $\begin{array}{l}\text { aten: } \\
\text { Graf Reihersdorf }\end{array}$ & Graf Hellbronn & Edward Felsberg \\
\hline Randfigur: & Marco Godowesi & & \\
\hline
\end{tabular}

Jeder Charakter ist einem Bereich zugeordnet - Familic, Politik, oder Kunst - ; Probleme ergeben sich da, wo eine Figur versucht, sich in zwei Bereichen zu bewegen. So z. B. beim Minister, der von den umstürzlerischen Plänen seines Bruders zwar nichts z. B. beim Minister, der ahnt, aber dessen Machtgier milstraut, und dessen politische Ulathe die als Frau auf die derspruch zu seinen privaten Eusiker Edward liebt und sich Familiensphäre eingeschrankt ist and bei dem Künstler Edward selbst, der sich durch seine unglückliche Liebe zu Bertha zur Familiensphäre hingezogen fühlt. Diesc drei Figuren sind die einzigen in dieser Weise "geteilten" Figuren des Stückes - und deres genau in diese Teilung besteht ihr Un Unglück, indem sie sich erfolgreich auf einen Bereich konzentrieren: sowohl für den Reichsgrafen als auch für den Grafen Reihersdorf zählen nur politische Pläne; Graf Hellbronn hat außer seincr Liebe zu Cordelia keine Funktion und anscheinend auch keine Aufgabe und gehört somit ausschließlich in die Familiensphäre.

Von den geteilten Figuren steht Bertha im Mittelpunkt, da ihre Zweiteilung nicht, wie die Edwards und des Ministers, durch die Umstände bedingt ist, sondern durch wie die Edrem der intelligenten Frau. ${ }^{30}$ Das Stück dreht sich hauptsächdas unausbleibliche Dilemma der intelligenten Frau. Das Stick drel sich haschlich um Berthas Zwiespalt zwischen ihrer im Stück oft zitierten Intelligenz (Dramatische Versuche 148), ihrem Geist $(68,118)$, ihrem Verlangen zu denken (67), und ihrem Bewußtsein, daß die gesellschaftliche Doktrin der Weiblichkeit ihr verbietet, ihre Gabewußtsein, daß die gesellschaftliche Doktrin der Wendeiner Weise zu nutzen. Bereits in der ersten Szene wird verdeutlicht, daß Berthas Unglück nicht in ihrer unglücklichen Liebe zu Edward besteht, sondern in der Teilung zwischen zwei Bereichen: Cordelia stickt fröhlich an einem Rahmen, Bertha spielt melancholisch auf ihrer Harfe. Cordelia erklärt Berthas Zerrissenheit mit Hilfe ihres eigenen Glücks der ungeteilten Weiblichkeit: „nimmer war so heiter dein Gemüth/ Wie meins das keine bange Sorge kennt/ Und nur im Kreise holder Häuslichkeit/ Für sich und seine stillen Pflichten lebt“ (66). Daß Cordelias „stilles muntres
Wesen“, im Gegensatz zu Berthas "hohem ernsten Geist", das Glück ausmacht, is auch Bertha bewußt, die die Ungeteiltheit der Schwester beneidet, aber nicht in diese Kindlichkeit zurücklkehren kann. „O Theure oft seh ich dein ruhges frommes unschuldsvolles stilles Wandeln/ Mit trüben Blicken an und möchte gerne/ Dir gleichthun aber ach ich kann es nimmer/ Mein Geist ist unstät und hinweggezogen/ Wird er gewaltsam wie von Meereswogen" (68). Cordelia legt schließlich den Finger auf Berthas Wunde: Bertha ist eine Frau mit Männerwünschen, die unter der Unerfüllbarkeit ihrer Wünsche leidet.

$\mathrm{Zu}$ männlich ist dein Geist strebt viel zu hoch

Hinauf wo dir kein Weiberauge folgt

Das ists was ängstlich dir den Busen engt

Und dir die jugentliche Wange bleicht

Wenn Weiber über ihre Sphäre steigen

Entfliehn sie ihrem eignen bessern [Lücke im Ms.]st

Sie möchten aufwärts sich zur Sonne schwingen

Und mit dem Aar durch duftge Wolken dringen

Und stehn allein im nebelichten Thal

Wenn Weiber wollen sich mit Männern messen

So sind sie Zwitter und nicht Weiber mehr

Zwar bist du Bertha klüger viel wie ich

Denkst tiefer bist viel älter auch an Jahren

Doch glaube diesesmahl nur meinen Worten

Das gute Weib ist Weiblich aller Orten (68).

Berthas Bestreben, sich mit Männern zu messen, das sic zu einem Zwitterwesen macht, wird hier durch ihre Beschäftigung mit der Harfe (Kunst) statt mit der Nadel (Häuslichkeit) symbolisiert. Dementsprechend zielen Cordelias Rat („Laß deine Hand die feine Nadel führen“, 69) und Warnung („O deine Harfe o die mordet dich“, 70) darauf ab, Bertha in dic holde Häuslichlkeit zurückzulocken. Der Unterschied zwischen Bertha und Cordelia ist hauptsächlich erziehungsbedingt, denn Cordelia lernte „Im Kloster zu Trient wo ich erzogen" die Kunst des Stickens (77), während Bertha zuhause von ihrer Mutter erzogen wurde, die ihr "das Reich der Töne" (78) zugänglich machte. Wie wichtig angemessene Indoktrination durch Erziehung ist, zeigt sich nicht nur am symbolischen Unterschied zwischen Nadel und Harfe, sondern auch an Cordelias in klösterlicher Stille erlernter Fähigkeit, die grosse Welt der Männer durch ihre selbstgebaute kleine Welt zu ersetzen: da die Frau nicht an dieser Welt teilnchmen kann, besteht die einzige Möglichkeit des Seelenfriedens für sie in freiwilligem Selbstausschluß aus dieser Welt.

Muth und edle Freyheit ziert den Mann

Allein dem Weibe ziemet Sittsamkeit

So sagte oftmahls die hochwürdge Frau [die Äbtissin, S. K.] 
$[\ldots]$

Da baut ich meine eigne kleine Welt

In meinem Zimmer achtend nicht den Sturm

Der draußen brauste wenns nur ruhig war

In meinem Reiche ich bey meinem Rahmen

Und so erhielt ich meine Seelenruh (92 f).

Daß Bertha andererseits diese Fähigkeit völlig abgeht, zeigt sich an verschiedenen Diskussionen im Familienkreise, so z. B., als Ferdinand symbolisch durch dic Gabe eines Schwertes und Pferdes zum Mann erklärt wird. Auf die Aussicht, daß ihr Bruder demnächst hinaus ins feindliche Leben muß, reagiert Cordelia mit Angst, Bertha mit neidvoller Begeisterung (111-3). Dieses Leben allerdings ist Frauen verschlossen, da ihnen zwar die Fähigkeit gegeben ist, es sich zu wünschen (Herz, Phantasie, Leidenschaft, Begeisterung), nicht aber die Fähigkeit, sich darin auch zu bewegen (Geist, Vernunft, Verstand). Während der Mann beides besitzt und in dieser Weise naturlicherweise „geteilt" ist, ist der Frau nur die emotionelle Seite gegeben, die in sinnenzerstörende "geidenschaft ausartet, wenn sie sie nicht in der von Cordelia beschriebenen Weise unLeidenschaft auset, wa den unwiderterdrückt. Das alles wird Bertha von der Reichsgräfin erklärt, die damit den unwiderleglichen Beweis liefert, daß nur der Mann - aufgrund sciner „natürlichen“ Zweiteilung in Herz und Geist - imstande sei, in beiden Welten zu leben.

Zu der verzehrend wilden Flame die

Am innern Mark des Lebens zehret wächst

Die sanfte Wärme die das Herz belebt

Wenn nicht ein starker Geist sie treu bewach

In ernste Schranken zwängend ihre Macht

Sie wirkt verschönernd in des Mannes Hand

Und wirkend bringt das Große sie hervor

Denn sieh nicht zu vergleichen ist dem Sinn

Des zarten Weibes wohl des Mannes Geist

Der zwiefach in sich selbst getheilt so auch

Im Lauf der Dinge herrschend zwiefach wirkt

Ein innrer Drang treibt mächtig ihn und heiß

$\mathrm{Zu}$ großen Thaten, zu der Helden Preis

Wic zu des Bildes Glanz des Liedes Kraf

Indeß ein ernster Genius ihn stark

Zurückreißt droht dem Schwindelnden Gefahr

Und eisig cinschließt seine Flammenglut (122 f). ${ }^{31}$

Allerdings hat selbst die Reichsgräfin, die Bertha in wohlgesetzter Rede in die weiblichen Schranken der Machtlosigkeit zurückweist, ihre Zweifel an der institutionalisierten Abhängigkeit der Frau. Denn sie ist im Begriff, Bertha zu informieren, daß sie mi dem Grafen Reihersdorf verheiratet werden soll, vor dem ihr selbst graut. Sie wird durch diese geplante Zwangsehe an ihre eigene erinnert, zu der ihre Eltern, die meinten, „Nur in des Glückes Arme mich zu führen“ (129), sie ebenfalls gezwungen hatten. „Zum wütgen 'Tiger habt ihr mich gesellt/ Ihr die ich Eltern nannte kein Erbarmen/ In eurer Brust endloser Marter gabt/ Ihr kalt mich hin" (129). Mit dieser Einschätzung der Ehe als „endlose[...] Marter" ist die letzte Lebensmöglichkeit der Frau erschöpft auch das Kloster wurde in einem vorangegangenen Gespräch zwischen Bertha, Cordelia und Laurette als Gefängnis interpretiert (92) -, und die Fiktion der weiblichen Glücksmöglichkeit als ungeteiltes, da nur halb lebendes Wesen bricht zusammen. Denn dieses „Glück“ ist kein wahres Glück, sondern lediglich Abwesenheit von Leid die nur durch Enthumanisierung der Frau erreichbar ist - durch den Tod oder durch die Redulktion der Frau zum ewigen Kind. Bertha spricht diese Erkenntnis aus, als ihre Amme Katherine ihr ihr Leid um ihren früh verstorbenen Sohn klagt: „Sey/ nicht traurig gute Mutter vielem Schmerz/ Ist er entgangen und eine karge Lust/O ruhte in der Gruft ich oder auch/ An deiner Brust ein zart unmündig Kind/ Des eignen Thuns mir unbewußt da wär/ Ich vielem Leid entflohn" (135 f).

Diese Verkindlichung der Frau, die ihren Ehrgeiz im Zaum hält, wird an Cordelia exemplifiziert, als sie sich mit dem Grafen Hellmann verlobt: von da ab existiert sie im Stück nur noch im Diminutiv („Cordchen“, „Bräutchen“, 162). Da die weibliche Abhängigkeit in der Ehe endgültig wird, hat sich weiblicher Ehrgeiz darauf zu beschränken, eine möglichst vorteilhafte Ehe zu schließen. In diesem Zusammenhang sprich der Reichsgraf häufig von Berthas „erhabnen Geist“ (155, 199, 201); „eher schaut/ Nach Königskronen wie nach niedern Heerd/ Thr glühendes Verlangen" (155). Wo sich weiblicher Ehrgeiz in anderer Form äußert, wird er von den Männern als „Eitelkeit und Hochmuth" rezipiert (154), als Eigenschaften, die jeder Frau eigen sind, die aber glücklicherweise nicht viel Unheil in der Welt anrichten können, denn dazu fehlt ihnen - siehe Reichsgräfin - der Verstand. In diesem Sinne äußern sich mehrere männliche Figuren des Stückes, am deutlichsten Marco Godowesi: „ja so sind die Weiber/ Voll Lug und Trug die schlimmsten Männer sind/ Nur die Kopie von ihrer Falschheit hätte/ Der Himmel ihnen mehr Verstand verliehen/ Sie kehrten um das Weltall" (154).

Bertha oder die Alpen (die Alpen sind Edwards Heimat und stehen symbolisch für Berthas Traum von Höhe, Weite, Freiheit) ist ein Trauerspiel ohne Ende, da das Ende für Frauen vorgegeben ist. Denn da die Männer, in Godowesis brutalem Klartext, ihre Vormachtstellung dadurch erhalten, daß sie die. Frau in die Abhängigkeit zwingen, bleiben der Frau nur drei Lebensmöglichkeiten: das Kloster, ein „Kerker“, des „Gitters enge Räume" (92); die „endlose[...] Marter" der Ehe (129); oder Cordelias Lösung der Selbstreduktion zum Kleinkind, das, „Des eignen Thuns mir unbewußt“ (136), zwar nicht glücklich, aber zumindest „vielem Leid entflohn" (136) ist. Das Problem, das in anderen Trauerspielen von Frauen durch den Tod der Frau "gelöst" wird, wird hier auf philosophischer Ebene durchgespielt. Gegenüber anderen Dramatikerinnen geht DrosteHülshoff einen wichtigen Schritt weiter: während in früheren Stücken von Frauen die gefährliche Leidenschaft des Weibes ihr „Problem“ war - so zumindest dic männlichen Protagonisten -, ist es jetzt ihr Verstand. Während in früheren Stücken das „Problem“ 
der Frau mitsamt der Frau selbst durch ihren Tod beseitigr wurde, wird sie hier nicht . mit dem physischen lod, sondern mit dem Entzug jeglicher Lebensmogh bleiben straft. Berthas Tragik besten unbewußt/unwerden, und in der Tatsache, daß es ihr unmoggich ist, sich somiffene Möglichlect der wissenden Kind zu reduzieren, daß sie die von Cordelia ergriffene Mogichkeit der Flucht in den Kerker (Kloster) oder ins Elend (Ehe) nachleben könnte. In der von Droste-Hülshoff geschilderten Situation dient ihr Verstand nur dazu, ihr ihr Elend Droste-Hulshoff gen Wenige Dramatikerinnen haben das Dilemma der Frau so klar gebewußt zu machen. Wenige Dramatikerinnen haben das Dilem erellschaftlichen Zwängen sehen wie Droste-Huulshoff. Abees die Erläuterung der Hinunterlag wie ihre Heldin, ist die Aufdecking diennlich wie bei Gündertergründe des Dilemmas, eine Eigenschaft des Lesedramas - ähnlich wie bei Günderrode.

In den späteren zur Aufführung bestimmten Dramen von Frauen wird das Problem meist wieder auf der simplifizierten Ebene der Tragödien des 18. Jahrhunderts behandelt; diese Tradition, in der die Heldin des Trauerspiels ihre Unabhängigkeitsbestredelt; diese Tradition, in der dïnnliche Pläne - mit dem Leben bezahlen muß, setzt sich durch durch das 19. Jahrhundert fast unverandert fort. Bis zum Ende din Taurspielen von bleibt der Tod der weiblichen Unschuld das haungste Th Frauen - die extremsten Fälle finden sich in Mathilde Wesendoncks Genovefa und Elsa Bernstcins Milost Pan (1894). Wo eine Frau auf ihrer Willensfreiheit besteht, d. h. sich

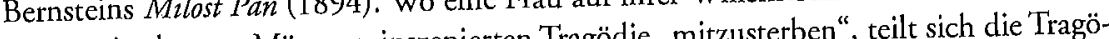
weigert, in der von Männern inszenierten Tragodie "mitzuster dientradition: teilweise entsteht aus dieser Idee ein Lesedrama, in dem gerade dic Tatsache, daß der Frau ihre Willensfreiheit vorenthalten wird, als tragisch dargestellt wird (Günderrode, Drostimmten Dramen wird das Gunderrode, Droste-Hutshoff). In zuch weibliches Unabhängigkeitsbestreben meist (Ther Bau sind die Pläne de ins Diabendonck, Bernstein); selten sterben sie an Männer (bei Schlegel, Thon, Gottsched, Wesendonck, Berst Scitern verurteilt sind den Folgen eigener Taten, die immer schon im Voraus zum Scheitern verch, Huber) (bei Breden). Vor diesem Schicksal rettet sie weder die Vorsehung (Gotsched, Huber) noch die eigene Tugend: die Idee, daß Frauen, ob Hexen oder Hellige, zum Tode verurteilt sind und ihr Schicksal weder durch Tugend noch Laster abwenden konnen, findet sich häufig (z. B. bei Schlegel und Thon). Dafür gibt es letztendlich nur eine ErWärung die in einigen Tragödien von Frauen genannt wird: nämlich die, daß Frauen klärung, die in einigen Tragodicn von tioll keinen Einfluß auf ihr Schicksal haben in ihrer Abhängigkeit vom Mann prinzipiell keinen Einfuß auf thr Schicksal haben (Günderrode, Droste-Hülshoff). Oft wird die weibliche Abhängigkeit vom Mann auf die Idee der weiblichen Abhängigkeit von der Welt der Männer erweitert (Artner, Droste-Hülshoff). Dementsprechend bricht das Konzept dieser Welt für Frauen häufig zusammen: die Gesetze der Männerwelt scheinen für Frauen nicht zu gelten. Daraus erkärt sich die häufige Umkehrung der dramatischen Weltordnung, wie das Versagen der Vol Laster (Gottsched, Schlegel, Thon).

Allen nicht geschichtlichen Trauerspielen von Frauen sind zwei Aspekte gemeinsam: das Bewußtsein der Abhängigkeit der Frau und die Abwesenheit von Lösungsvorschlägen.
Denn alle Lösungsvorschläge, ob philosophischer (Friedrich Schiller) oder politischer (Georg Büchner, Gerhart Hauptmann) Natur, basieren auf der Vorstellung einer Welt, die im Prinzip funktioniert und an der nur einiges verbessert werden muß. In Trauerspielen von Frauten, und das scheint der Hauptpunkt ihrer Tragödien zu sein, existiert diese Welt nicht oder nur für männliche Charaktere, da die Möglichleeir der Einflußnahme auf diese Welt auf Männer beschränkt ist.

$\mathrm{Da} ß$ es wesentlich mehr historische als nicht historische Trauerspiele gibt, überrascht nach dem Gesagten kaum: der größte Teil der historischen Tragödien von Frauen beschäftigt sich mit Frauen, die Geschichte machten oder es versuchten. 
KAPITEL V

VERGESSENHEIT, DAS IST DER WAHRE TOD!

HISTORISCHE DRAMEN ZUR GESCHICH'TE DER FRAU, MIT EINEM NACHWORT AUCH ZUR GESCHICH'TE DES MANNES

Von den historischen Stücken von Frauen des 19. Jahrhunderts - im 18. Jahrhundert sind keine ermittelt - gehören die historischen Trauerspiele auf einen besonderen Platz, schon allein wegen der Themarik, die sie von Geschichtsdramen unterscheidet. In historischen Stücken geht es meist um Männer - um Rudolph von Habsburg und historischen Stücken geht es meist um Männer - um Ron Habsburg, o. J., und Ferdinand der Zweyte, 1816); Mazarin und Peter von Szápár (in Birch-Pfeiffers gleichnamiaen 1849 und 1831). Hermann den Cherusker und Johann von Finnland Cobann, Herzog von Finnland 1810); (Franul von Weißenthurn: Hermann, 1813; Johann, Herzog Friedrich den Großen (Mathilde Wesendonck, 1828-1902: Friedrich der Große, 1871), Kaiser Karl V. (Laura Steinleins [1826-1901] gleichnamiges Drama, 1857); und Heinrich I. (Luise Zeller, 1823-1889: Heinrich des I. Söhne, 1873) -; seltener um weibliche historische Figuren wie Elisabeth I. oder Anna von Österreich (Birch-Pfeiffers Elisabeth, 1841; und Anna von Oestreich, 1845); Anna von Cleves (Elisabeth Müller, 1827 1898: Anna von Cleve, 1881); Königin Radegundis (Wilhelmine von Wickenburg 1845-1890: Rudegudis, 1879); ode Maria Theresia (Amalie von Liebhaber 17791845-1890: Radegundis, 1879); oder Maria Thessia (Amalie von Liebhaber, 17791845 , in ihrem gleichnamigen Drama, o. J.). Dagegen konzentrieren sich historische Trauerspiele weiblicher Autoren auf Frauen. Behandelt wurden u. a. Charlotte Corday (bei Engel Christine Westphalen, 1758-1840; und Elisabeth vom Berge, 1839-1909, in den gleichnamigen Tragödien, 1804 und o. J.); Marie Roland (Ebner-Eschenbachs gleichnamiges Trauerspiel, 1867); Marie Antoinette (in vom Berges Marie Antoinette, o. J.); Maria Stuart (Ebner-Eschenbach, Maria Stuart in Schottland, 1860); Anna Boleyn (Elisabeth von Rumänien [1843-1916] und Marie von Kremnitz [1852-1916]: Anna Boleyn, 1886); Johanna Gray (Karoline Ludecus, 1757-1827, in Johanne Grays 1806; und Rosalie Schönfließ, 1799-1845, Johanna Gray, 1839); Vittoria Accorambon (Auguste Götze, 1840-1908, in ihrem gleichnamigen Trauerspiel, 1890); Beatrice Cenci (Steinleins Das Haus Cenci, 1861; und bei Johanna Holthausen, 1812-1875, in Bea(Steinleins Das Haus Cenci, 1861; und bei Johanna Holthausen, 1812-1875, in Bea1865); Beatrice von Schwaben (Henriette Strauss, 1845 - nach 1882: Beatrice, o. J.); und Christine von Schweden (vom Berges gleichnamige Tragödie, 1873). Die Behandlung männlicher historischer Figuren ist dagegen in historischen Trauerspielen von Frauen relativ selten. Beispiele: Pichlers Heinrich von Hohenstauffen, 1813; Elise Schmidts (1824-?) Macchiavelli und Peter der Große, beide o. J.; Kempners Antigonos, 1880, und Rudolf der Zweite, 1896; Birch-Pfeiffers Ulrich Zwinglis Tod, 1837; und von Liebhabers Octavianus Augustus, o. J.

Schon aus dieser Zuordnung männlicher Figuren in die Geschichte und weiblicher ins historische Trauerspiel läßt sich auf die Geschichtsauffassung der Verfasserinnen spekulieren: der Eingriff in die Geschichte wird für Frauen häufiger zur Tragödie als für Männer. Zwischen geschichtlichen Dramen über männliche bzw. über weibliche Figuren findet sich ein weiterer wichtiger Unterschied: die Dramen über Frauen aus der Geschichte behandeln häufig relativ unbekannte historische Frauenfiguren. Während die Biographie einer Elisabeth I. oder Maria Stuart z. B. besser dokumentiert ist als die anderer Hauptpersonen historischer Dramen (Anna Boleyn, Charlotte Corday, Marie Roland), ist über viele andere so gut wie nichts belkannt, wie z. B. über Vittoria Accoramboni, Beatrice Cenci, Beatrice von Schwaben, Anna von Cleves und Königin Radegundis. Daher ist das Ziel historischer Dramen über weibliche Helden oft ein anderes als das von Geschichtsdramen, in denen Männer behandelt werden: im Bezug auf weibliche Protagonisten geht es oft darum, eine historische Lücke zu füllen. Die Falkten und Daten, an die sich die Autorinnen meist streng halten, sind aus der männlichen Geschichtsschreibung übernommen und befassen sich häufig nur mit dem historischen Umfeld oder den männlichen Helden dieser Geschichte; die Geschichte der Frau dagegen ist oft nur im Mythos überliefert und muß ergänzt werden. Viele dieser Trauerspiele und einige der Historien können nur dem Namen nach als historisch gelten, da sie sich auf die weitgehend unbekannte Geschichte der Frau konzentrieren.

Dieses Kapitel beschäftigt sich hauptsächlich mit historischen Stücken von Frauen, in denen versucht wird, diese unbelkannte Geschichte der Frau aufzuarbeiten, nachzuerzählen oder nachzuerfinden. Denn wo die Autorinnen historischer Stücke sich mit der Geschichte männlicher Figuren beschäftigen, behandeln sie sie ähnlich wie ihre männlichen Zeitgenossen: entweder wird die Geschichte des Helden zu patriotischen Zwecken glorifiziert (wie in den Stücken Franul von Weißenthurns, Pichlers und Wesendoncks), oder der Held opfert sein privates Glück zum Wohle des Volkes (bei Elise Schmidt). Dagegen steht hinter der Behandlung historischer Frauenfiguren meist eine andere Motivation der Autorin, nämlich die, sie vor der Vergessenheit zu bewahren, oder das von der Geschichtsschreibung verzerrte Bild der Heldin zu korrigieren.

\section{A. Historische Tragödien}

Beides wurde verschiedentlich auch in geschichtlichen Traktaten von Frauen versucht, u. a. von Ida Klokow, Louise Otto-Peters und Ida von Düringsfeld. Ihre Versuche, historische Frauen vor Vergessenheit zu bewahren, beschränken sich meist auf die Aufarbeitung biographischer Fakten und bewegen sich in demselben nebulösen Niemandsland zwischen Geschichte und Sage wie die der Dramatikerinnen. Wie diese füllen die Geschichtsschreiberinnen die Lücken in den wenigen Quellen, die ihnen zur Verfügung standen, mit populärgeschichtlichen Vermutungen aus, z. B. mit der Beschreibung der äußeren Erscheinung und Kleidung der historischen Heldin oder Spekulationen bezüglich ihrer Motive. Aber gerade diese Spekulationen sind das Wichtigste an ihrer Geschichte, denn ihnen liegt daran, 
mit unserer weiblichen Hand und Auffassung diese Lebensbilder zu entwerfen, weil die Männer gerade die Frauen am wenigsten richtig beurtheilen und ihnen mindestens nicht nachempfinden können, die von der Sehnsucht geleitet wurden aus dem beschränkten Familienkreis heraus zu treten, in den man mit Gewalt sie bannen wollte. [...] daher kommt es denn, daß sie den Frauen für ihre Handlungen ganz andere Motive unterschicben als diejenigen sind, welche sie wirklich haben. Einmal ganz von der Annahme beherrscht, daß die Frauen nur eine Naturaufgabe hätten, eine Culturaufgabe aber ihnen nur mittelbar zu theil geworden, durch die Macht ihres Einflusses auf den Mann, schieben dann jene Männer als Historiker selbst den Frauen, welche auf irgend einem Gebiet, sei es auf dem des Wissens oder der That Ture leisteten auch meist ganz falsche Motive unter. Eine Jungganz falsche Motive unter. Eine Jungfrau von Orleans wird da entweder ganz geleugnet oder zu einem Werkzeug der Pfaffen gestempelt, eine Charlotte Cordais soll sich nur deshalb für die französische Republik geopfert haben, weil sie einen Girondisten geliebt und was dergleichen absichtliche oder absichtslose Geschichtsfälschungen mehr sind (Otto-Peters, Einflußreiche Frauen $11 \mathrm{f}$, Hervorhebungen der Autorin).

Worum es also geht, auch in vielen Geschichtstragödien von Frauen, ist die Darstellung der Handlungsweise der historischen Heldin als unabhängig, als ihr Versuch, unabhängig von der ihr aufoktroyierten oder unterstellten „weiblichen Bestimmung auch der allgemein menschlichen Bestimmung gerecht zu werden" (Otto-Peters, Einflußreiche Frauen 12). In historischen Tragödien von Frauen handelt die Heldin immer aus edlen Motiven. Wo sie politisch aktiv wird, treibt sic ihr politischer Idealismus (in Westphalens Charlotte Corday, Ebner-Eschenbachs Marie Roland, Kempners Berenize). Einige Tragödien behandeln die Frau als Opfer der Geschichte (Elisabeths von Rumänien und Kremnitz' Anna Boleyn, Strauss' Beatrice); in diesem Fall werden ihre Motive auf die Privatebene verlegt, sind aber nicht minder edel (in Anna Boleyn heiratet Anna Heinrich nicht aus Herrschsucht, sondern aus Liebe). Wo die Geschichte berühmter Mörderinnen wiedererzählt wird, ist die Angeklagte unschuldig, auch wenn ihre Unschuld in der Geschichtsschreibung nicht eindeutig erwiesen ist (Götzes Vittoria Accoramboni, Steinleins Dds Haus Cenci). Daß die Autorinnen meist historische Figuren wählen, deren Geschichte mit ihrer Ermordung (Vittoria Accoramboni, Beatrice yon Schwaben) oder auf dem Block endet (Beatrice Cenci, Anna Boleyn, Charlotte Corday, Marie Roland, Maria Stuart), verstärkt nur noch den Eindruck des Nachrufs, der hier entsteht: versucht wird nicht, den weiblichen Eingriff in die Geschichte als erfolgreich darzustellen, sondern ihn durch Erläuterung ihrer Motive zu erklären oder zu rechtfertigen.

\section{REVOLUTIONÄRINNEN}

a. Westphalen.

Engel Christine Westphalen (1758-1840) übernimmt in Charlotte Corday (1804) aus ungenannten Quellen dieselben Aspekte wie später Klokow, Düringsfeld und Otto-
Peters; insbesondere dic Charakterisierung Charlottes als politische Schwärmerin, Charlottes fingierte Flucht nach England, die Mordszene, die Gerichtsszene (die sich in den späteren historischen Biographien fast wörtlich wiederfindet), und die Beschreibung ihrer Hinrichtung. Die Autorin ändert die geschichtlichen Umstände in zwei wichtigen Punkten: Charlottes Verbindung zu Barbaroux und dem girondistischen Abgeordneten Duperret entfallen, so daß Charlottes Plan nicht in den Verdacht der Beeinflussung durch andere geraten kann. Zum andern ist bei Westphalen Charlottes Mutter noch am Leben, ${ }^{32}$ so daß Charlotte zwei Vorbilder vor Augen hat: der Mutter schwermütige und des Vaters mutige Ergebenheit in ein Schicksal, das Charlotte zu ändern versucht. Wähıend der Vater glaubt, sie durch Zerstreuing, durch Beschäftigung mit „weiblichen" Dingen (Natur, Mode, Pracht des englischen Hofes) von den politischen Geschehnissen ablenken zu können $(20,51,55 \mathrm{f})$, kennt die Mutter sie besser, denn sie sah „immer,/ Wie nur ihr [Charlottes, S. K.] Sinn nach grossen Bildern strebte,/ Den stets das Gröste, Edle an sich zog,/ Mit durstender Begier es selbst zu üben“ (10). Der Vater hält ihre politische „Schwärmerei“ deshalb für heilbar, weil er sie als Auswuchs einer überhitzten Mädchenphantasie interpretiert, die „Das Schauderhafte grässlicher und wilder" (19) malt, als es tatsächlich ist; echten Heroismus hält er bei der Frau für unnatürlich (84). Die Mutter dagegen alzzeptiert das Entsetzliche der politischen Realität, aber hält Frauen für weniger befähigt, es zu ertragen, als „Ein Männerherz, vertrauter mit der Stärke" (25). Was sie hier versteckt ausspricht, ist, daß gerade Charlottes „weibliche" Qualitäten (Weichherzigkeit und Mitleid, 9) sie anfälliger für diese Realität machen, als die meisten Männer es wären - und zugleich unfähiger, dieser Realität zu steuern. „Nur ist das Grösste nicht für unsern Sinn [den der Frauen, S. K.]./ Das Ungeheure können wir nicht fassen./ Es schreckt uns, gleich Phantomen. - So ergriffen/ Fühlt sich Charlotte" (25).

Diese Diagnose stellt die Mutter zu einem Zeitpunkt, an dem Charlotte, weit entfernt, vor dem Ungeheuren zu kapitulieren, ihren Entschluß, Marat zu töten, bereits gefaßt hat. Was Charlotte von ihren Eltern und von ihrem Bruder Antoine trennt, ist ihre unterschiedliche Auffassung von menschlichem Willen versus dem des Schicksals. Für Eltern und Bruder steht der Wille des Menschen gegen, für Charlotte im Einklang mit dem des Schicksals. Während also für ihre Familie der einzige Weg, der Vorsehung zu gehorchen, in untätiger Ergebung in ihr Los besteht, hält Charlotte umgekchrt ihre eigenen Pläne für den Ausdruck des göttlichen Willens. Ihrer Auffassung nach schwingt sich der Mensch dadurch zur Größe auf, daß er "seine Kraft dem Schicksal“ (36) leiht. Diese Größc aber steht in direktem Widerspruch zu der der Frau angewiesenen Sphäre und kann nur durch Aufgabe dieser Abhängigkeit errungen werden. "Willst du aus deines Daseyns engem Kreise,/ Dem stillen Wirken leichterfüllter Pflichten,/ Hinaus dich wagen in das Weite - Freie?" (38), lautet Charlottes beklommene Frage an sich selbst; die sic gleich darauf selbst beantwortet: „Dem Grössern fügt das Klein're willig sich -/ Dem Höhern weichet scheu das Niedere“ (38); der Vaterlandsliebe weicht die zur Familie (42). Daß Charlottes Entschluß nicht nur cine irrige Verwechslung des cigenen Willens mit dem Gottes ist, sondern Erfüllung der „ewigen Gesetze" (158), bestätigt der Chor, der jeden Akt kommentierend 
schließt: „Ausgerïstet hat ein Gott mit Stärke,/ Wen er schuf, ihr Wollen zu vollbringen" (159).

Die philosophische Auseinandersetzung zwischen Charlotte und ihrer Familie, die sich durch die ersten anderthalb Alste zieht, wird später zwischen Lagarde und Luchs wieder aufgenommen. Wie Charlottes Eltern und Bruder hält Lagarde die Vorschung für allmächtig und menschliche Einmischung für Übertretung ihrer Gesetze (101), während Luchs der Ansicht ist, die Vorsehung brauche einen Menschen, der ihre Pläne ins Werk setzt (102). Wie Charlotte hat auch Luchs den Entschluß gefaßt, Marat zu töten, da er, wie sie, Marat für den Hauptschuldigen, an den Morden der Revolution torenter der die anderen Revolutionäre nur als Trittbrett auf dem Weg zur Diktatur benutzt (118-20). Des Chors ominöse Worte (,Schrecklich hauset das Laster", 121) beziehen sich eindeutig auf Marat, den "Verbrecher", (123), der "die Reiche der Erde verschlingen" (122) möchte. Aber bereits in der nächsten Szene (III, 1) wird Marats postulierte Schreckensherrschaft verhindert. In ihrem ersten Auftritt seit ihrem Abschied von den Eltern und ih rem endgültigen Entschluß, Marat zu töten, führt Charlotte ihr Vorhaben hinter de Szene aus. Erst Szene aus. Erst nach der Tat kommen ihr zum spruch/ Erscheint mein Ich mit meinem innern Selbst" (129, Hervorhebungen de Autorin). Die Tat, die ihr Ich ausmacht, widerspricht dem innerem Selbst (Mitleid, Weichherzigkeit) der Charlotte, die „Mitleidig oft cin zartes Leben schützte,/ Nicht einmal einen Wurm zu töten wagte" (129). Dieser Widerspruch zwischen ihrer Tat und ihrem Charakter ist nur durch ihre Abhängigkeit vom göttlichen Willen erklärbar, und in der Erkenntnis ihrer Rolle als Werkzeug des Schicksals spricht sie sich selbst von der Anklage des Mordes frei: „O, ew'ge Güte! ja, es war Dein Werl" (129, Hervorhebung der Autorin).

$\mathrm{Ob}$ eine Frau einer solchen Tat fähig ist, ist Thema eines großen Teils der darauffolgenden Diskussion. Weil Luchs sich als Frau verkleiden wollte, um leichter an Marat heranzukommen, glaubt er dem Gerücht, ein Mann in Frauenkleidung hätte Mara ermordet (148). Als er schließlich erfährt, daß Charlotte dic Täterin ist, weigert er sich, das Ungeheure zu glauben - weil er Charlotte und ihre „wciblichen“ Qualitäten kennt: das Ungeheure zu glauben - weil er Charlotte und ihre „weiblichen "Charlotte? - Corday? - Nein! unmöglich! nein!/ Die holde Santmuth! - diese Hin mentern auf ihre Größe; die Bewunderung ihrer Größe bringt Luchs zu dem Entschluß, Charlotte zu befreien, Lagarde zu dem, sie vor Gericht zu verteidigen. Vor Gericht ${ }^{33}$ gesteht sie die Tat sofort, nennt als Motiv ihre Vaterlandslicbe $(167,169,170 \mathrm{f})$ und zeigt sich empört über den Verdacht, sie sei eine gedungene Meuchelmörderin (173). Ebenso empörend wie der Vorwurf des gemeinen Mordes ist für sie die Annahme, sie sei lediglich ausführender Arm einer Verschwörung gewesen - die Unabhängigkeit ihrer Tat ist ihr ebenso wichtig wie die Reinheit ihrer gewer - Am Gängelband des Motive. Darüber belehrt sie den Vorsitzenc fremden Wollens, glaubst Du,/ Sei ich, geleitet, - gleich dem Kind' - mechanisch? (Mit Hoheit:) Du kennst Dich auf des Menschen Wollen schlecht!/ Schlecht auf die Kraft, die in sich selbst dic Stütze/ Zu jedem grossen Unternehmen findet!" (172) Nur diese zwei Faktoren - Reinheit ihrer Motive und absolute Eigenständigkeit - machen ihre Tat nicht zum Mord, sondern zum heroischen Versuch, „Dem Vaterlande Frieden neu zu geben" (171).

Aus dieser Philosophic erklärt sich Charlottes Zufriedenheit mit Lagardes Verteidigungsrede, in der sie - oberflächlich gelesen - keineswegs positiv erscheint. Lagarde sucht ihre Rechtfertigung gerade in ihrem Geständnis und in ihrer Weigerung, sich zu entschuldigen - $d$. h, er bestätigt ihre Eigenständigkeit - und schließt seine Rede mit einem Plädoyer auf Unzurechnungsfähiglkeit: „Nicht diese hohe Ruh' ist ihr natürlich,/ [...]/ Nicht ist natürlich die erhabene/ Verläugnung ihrer selbst [...]/ Der Fanatismus falscher Politik,/ Er war es, der den blut'gen Dolch ihr lieh" (174). Seine These von Charlottes „Unnatur" (und das heißt auch: von der postulierten „Natur" der Frau abweichend) bestätigt ihre Auffassung ihrer selbst als Werkzeug des Schicksals. Indem er ihren politischen "Fanatismus" anspricht, bestätigt er ihre eigene Rechtfertigung des Mordes durch ihre Vaterlandsliebe, ihren politischen Idealismus. Mit Hilfe dieser Motive begründet schließlich auch Lagarde seine Auffassung von Charlottes Unschuld und Größe. „O warum konnt' ich nicht die Unschuld retten?/ Ein Opfer nur der Tyrannei entziehn?" llagt er nach gefälltem Urteil, und fährt fort: „Die That ist strafbar; doch die grosse Absicht/ Verdient den Lorber, nicht das Blutgerüst" (177)

Von da an ist das Stück eine Apotheose auf Charlottes Größe. Als Luchs ins Gefängnis eindringt und Charlotte anfleht, mit ihm die Kleider zu tauschen und zu fliehen, lehnt Charlotte ab, denn "die Charlotte, / Die Sie vorhin so gross, so göttlich nannten" (188), „Dic nehmliche Charlotte kann das nicht" (189). Luchs interpretiert ihre Weigerung - „schön [...], so herrlich, gross und göttlich“ - als Weigerung, von dieser Größe etwas abzugeben: „Ihr grosses Herz - es will von seiner Grösse/ Auch nicht den Schimmer mit dem Freunde theilen" (189). Als Luchs versucht, sie an ihrer menschlich-weiblichen Seite zu packen, indem er sie an ihre Familie erinnert, antwortet sie entsprechend: „Wo hoher Zweck den Busen stärker hebt,/ Zu Götter-Kraft der Seele Wollen steigert;/ Da muss das Einzelne dem Ganzen weichen,/ [...]/ Unwichtig scheinet unser Dascin, arm;/ Bedeutend wird es, wo es wirken kann" (190).

Charlottes "Götter-Kraft" setzt sich auch über die letzten irdischen Bedenken hinweg („So weiht' ich mich und jenes zarte Band/ Dem Vaterland zum unbedingten Opfer", 190) und zwingt schließlich auch Luchs zur Anbetung. „Wer wagt' es noch sie weiter zu bestürmen? -/ Wer, dieser Grösse Schranken zu bezeichnen?/ Verbrechen schelt' ich - Wahnsinn - mein Bestreben,/ Aus jenen Regionen Dich zu locken" (196). So stirbt Charlotte, der "Engel" (196, 217, 218, 219, 220, 221), die „Heilige“ $(217,221,231)$, die „Göttin“ $(196,217,221,232)$, die dem Vaterland „Die Wunden heilen wird, ihm Ruhe bringt" (221), „den Heldentod der Grösse" (209). Luchs faßt den Entschluß, zu besingen, „Was nie ein Mund besang, [...]/ Mit starken Tönen, einzig ihrer würdig" (231), kann ihn jedoch nicht ausführen, ${ }^{34}$ denn kurz nach Charlottes Heldentod werden er und Charlottes Bruder Antoine verhaftet. Mit dieser Verhaftung endet das Stück, und aus gutem Grund. Denn durch die Verhaftung ihrer einzigen Freunde, die direkt nach Luchs' Entschluß, ihre Geschichte zu erzählen, erfolgt, wird Charlottes große Tat der Vergessenheit oder dem verzerrenden Urteil der 
Nachwelt preisgegeben - und dieser Vergessenheit entgegenzuwirken, ist ein Ziel des Stückes.

Ob Charlottes Tat den gewünschten Erfolg hat (dieser Erfolg wird vom Chor am Ende des vierten Aktes prophezeit, 201), ist letztendlich unwichtiger als die Reinheit ihrer Motive, die der Genius der Wahrheit am Ende des Stückes verkündet: „Sie fiel, cin Opfer ihrer hohen Tugend,/ Der Menschheit Glück war ihr erhab'nes Ziel!" (234) ein Opfer ihrer hos im Kontext des Diese Motive heiligen nicht nur den Mord, sondern auch - und hs ist im Kontext des Stückes ebenso wichtig - iht Sich-Hinwegsetzen über den weiblichen Handlungsspielraum, ihre Negierung weiblicher Pflichten. Denn „Ihr edles Herz, es kämpfte, gross im Stillen, Den Kampf der Pflichten mit des Schicksals Willen" (234), und die Pflichten Stillen,/ Den Kampf der Pfichten mit des Schicksals Wer Frau, dem innen unterliegen. Wofür hier letztendlich plädiert wird, ist das Recht der Frau, „dem innern bessern Rath" zu gehorchen (235); ihr Recht, sich nicht, wie Charlottes Eltern und Antoine, in das Unabwendbare zu ergeben, sondern das eigene Schicksal - und unter Antoine, in das Unaber Dasein auch der Frau Umständen auch die Geschichte - selbst zu steuern. Denn clas Dasein auch der Fra wird nur da „bedeutend“, „wo es wirken kann“, und aus dieser Philosophie crklärt sich Charlottes Apotheose: nicht wie sie handelt, sondern daßs sic handelt, macht Charlotte zur Heldin und ihr Leben nacherzählenswert.

\section{b. Ebner-Eschenbach}

Ebner-Eschenbachs Marie Roland (1867) ${ }^{35}$ ist mit ähnlichen Attributen ausgestattet wie Westphalens Corday: ihr Handlungswille und ihre unbedingte Hingabe an die große Aufgabe ermöglichen ihre schließliche Apothoose im Tod. Marie regiert die golne Annenminister Roland. girondistische Partei konkurenzos durch Ihre Vormachtstellung als der Kopf der Partei wird zu Beginn des Stickes wiederholt hervorgehoben: nach ihr wird zuerst gefragt (3), wo sie gemeinsam mit ihrem Mann auftritt, wird sie zuerst gegrüßt (4), ihr werden sämtliche Entscheidungen überlassen we festsellt, schreibt sie für ihren Mann, „Und spricht für ihn, we Gensonne lakonisch feststelt, schreibe sie fire ihen und handelt wohl für ihn" (3). Die bedrohliche Macht der Jakobiner wird von den Girondisten mit Resignation beantwortet, die sich bei Roland bis zur Lebensmüdigkeit steigert: „O nähm' ein End' dies Zagen und dies Bangen/ Um uns und Alles, was uns theuer ist!/ Ich bin der Müh' zu ringen um mein Leben/ So herzlich satt!" (5) Marie dagegen ruft die Girondisten mit Hinweis auf ihre politischen Ziele ins Leben zurück.

Wer spricht von Sterben, eh' sein Werk vollbracht?

Galt's nur allein das Unrecht zu vernichten,

Als Ihr den Bau der Monarchie gestürzt? -

Es galt wohl mehr! es galt das Recht zu gründen,

Ein neu Gesetz im neuerstand'nen Reich.

Die große Arbeit ist noch ungethan;

Sie fordert Euch (5).

Wie immer stimmen die Mitglieder der Partei ihr sofort begeistert zu. Vergniaud, der darauf ein Bündnis mit Danton vorschlägt, überläßt Marie die Entscheidung:
„Entscheide Du [...]/ Du bist die Seele der Gironde, und stets/ Erschien Dein Wunsch ihr ein Gesetz" (5). Maries Ablehnung dieses Vorschlags bestimmt die der Partei (6); als gleich darauf Lodoïska, Louvets Geliebte, die Versammlung unterrichtet, sie sollten auf Befehl Marats im Konvent ermordet werden, ist es wieder Marie, die sie zur Flucht bewegt und einen kompletten Schlachtplan entwirft. Die Zustimmung der anderen setzt sie voraus: "Ihr seid doch einverstanden?" (8)

Maries unwidersprochene Machtstellung beruht auf einem Selbstbewußtsein, das den männlichen Mitgliedern der Partei fehlt, auf dem Wissen, daß der Mensch über sich selbst hinauswachsen kann. „Erhebt Euch über Euer eig'nes Selbst -/ Das kann der Mensch in großen Augenblicken,/ O traut Euch's zu!“" (8) Wie Westphalens Corday handelt sie aus politischem Idealismus: „Geht hin, - erkämpft dem Volk/ Wonach es fiebernd und vergeblich ringt:/ Den Frieden in der Freiheit!" (8) Ihr Idealismus und das Bewußtsein der eigenen Größe erzwingt die Zustimmung der anderen, die sich bis zur Anbetung steigert: „Du Herrliche, vor deren Geist auf Knieen/ Der meine liegt, nimm ihn in Dienst und Pflicht!" (8) fleht Barbaroux stellvertretend für alle.

Aber das Bild Maries als Herrscherin über die Gironde ist gebrochen: zum einen durch die Tatsache, daß auch sie irren kann - sic bestimmt Lanthenas, der sich später. als Verräter entpuppt, zum Führer des entscheidenden Schlages gegen die Jakobiner ${ }^{36}$ zum anderen durch ihre Konflikte auf privatem Gebiet. Sie liebt Buzot und hat Roland nur geheiratet, um sich politischen Einfluß zu verschaffen. Gegen ihre Liebe zu Buzot muß sie ankämpfen, weil sie, dic Vorkämpferin des Scheidungsicechts für Frauen in Frankreich, ${ }^{37}$ dieses Recht nicht für sich in Anspruch nehmen kann, denn dadurch würden ihre politischen Motive in Zweifel gezogen. Ihre Verachtung für Lodoïska erklärt sich aus ihrer eigenen krampfhaften Entsagung: Lodoïska hat ihren Mann für Louvet verlassen und lebt mit Louvet ohne kirchlichen Segen. Während Marie Lodoïska beneidet und ihren Neid mit ihrer moralischen Überlegenheit bemäntelt, sieht Lodoïska zu Maries Tugend in ähnlicher Anbetung auf wie die Girondisten zu ihrer Entschlossenheit. Um sich ihre Verehrung für sie zu erhalten, muß Lodoïska der Atheistin Marie einen Glauben unterstellen, denn vor Maries gottloser Selbständigkeit graut ihr. "Sie sagten doch: Ihr glaubtet nicht an Gott;/ Auf Eurer stolzen Höhe stündet Ihr/ Durch eig'ne Kraft allein; da schaudert' ich. $-/$ [...]/ Nun aber - ach - nun seh' ich's klar: Ihr glaubt -/ Lebend'ger, frömmer; stärker nur als ich“ (12). In diesem Glauben sieht Lodö̈ska den Grund für Maries Tugend und ihr Glück, denn in dieser Welt, so meint sie, „Sind glücklich nur, die edel sind wie Du“ (12). Lodoïskas Irrtum ruft bei Marie die ersten Zweifel an ihrer eigenen Stärke hervor, denn diese Stärke beruht nicht nur auf ihrer Ablehnung eines Glaubens, sondern auch auf der Unterdriickung aller menschlichen Gefühle. Für Marie Antoinette kann sie kein Mitleid empfinden; im Gegenteil fühlt sie beim Anblick ihres Unglücks nur „Bewunderung der ewig waltenden/ Und ewig siegenden Gerechtigkeit“ (14, Hervorhebung der Autorin). Ihr ganzes Gefühl konzentriert sich auf die Mitglieder der Gironde, die versuchen, ihre politischen Ideale zu verwirklichen. „Ihnen/ Gehört jedwedes liebende Gefühl,/ Das meine vielbestürmte Seele sich/ Im harten Kampfe dieser Zeit bewahrt./ Ich habe keines für die Andern mehr" (14). Marie kann sich ihre politische Handlungsfähigkeit nur durch 
diese Unterdrüclaung ihrer „weiblichen" Gefühle erhalten; gleichzeitig hängt ihr Glaube an die Ehrlichkeit ihrer Motive davon ab, daß sie ihren eigenen Glücksanspruch aufgibt: die Gesetze, denen sie das Handeln anderer unterwirft, gelten auch für sie.

Danton, in diesem Stück der kaltblütigste Revolutionär, sieht gerade die postulierte weibliche Unfähigkeit, ihre Leidenschaften ihrer Vernunft zu unterwerfen, als Beweis für ihre politische Unfähigkeit. Die Gironde sieht er als „Immer heißblïtig und enthusiastisch wie die Frau, die Euch inspiriert"; Marie selbst nicht als politische Alktivistin, sondern als Sirene, die die Männer ins Verderben lockt. „Warum wählt Ihr keinen Mann zu Eurem Führer? Diese Frau richtet Euch zu Grunde - sie ist die Circe der Revolution" (18). Ähnlich äußert er sich in seiner Szene mit Marie, in der er versucht, sie - und damit die Gironde - zum Bündnis mit ihm zu bewegen. Denn das allgemeine Beste braucht einen Führer, und zwar „einen Mann/ Zum mindesten! ... Kein Weib und keinen Träumer" (22). Danton überzeugt sie fast, indem er sie bei ihrer „weiblichen" Seite packt - bei ihrer Angst um die Girondisten. Kurz darauf läßt Danton die Maske des Republikaners fallen und erklärt seine Absicht, eine Diktatur zu errichten, und Marie lehnt das Bündnis entsetzt ab.

Auf diese Ablehnung reagiert Danton, indem er versucht, Maries politischen Idealismus zu zerstören - und ihre Überzeugung, daß dieser Idealismus ihre Handlungsweise rechtfertigt. Was „sie zerfließen macht,/ All' Deine Herrlichkeit" (23), ist die Tatsache, daß Maries Einfluß sie für die 'Taten der Mitglieder ihrer Partei verantwortlich macht. In diesem Sinne lastet Danton Marie sowohl die Gefahr, in der die Girondisten schweben, als auch den Tod des Königspaares an, für dessen Verurteilung die Gironde stimmte. Hinter seinem Vorwurf steht die Auffassung, daß nicht die Absicht, sondern der Ausgang über die Berechtigung politischen Handelns entscheidet, und dieser Logik kann sich Marie nicht entziehen. Die Verantwortung für das Schicksal ihrer Genossen nimmt sie an - „Ich bin verflucht! - bin Eure Mörderin!“ (26) -, aber das bedeutet keincswegs, daß sie ihre Stellung als Feldherrin der Gironde aufgibt. Vielmehr befiehlt sie den Girondisten, zu fliehen und in den Provinzen Heere anzuwerben. Obwohl sie sich darüber im klaren ist, daß sie damit einen Bürgerkrieg einleitet, sicht sie ihre Handlungsweise nach wie vor durch das politische Ziel gerechtfertigt - und darin sieht sie den Unterschied zwischen sich und Danton: „Wir haben recht gethan, wir thuen recht!.../ Unwürd'ger Zwcifel, Höllenqual der Reue,/ Wie Staub aus meinen Locken schüttl' ich Euch/ Und Euer Gift aus meiner reinen Seele!" (27, Hervorhebungen der Autorin)

Aber der von Danton erweckte Zweifel bleibt; ihre frühere Selbstaufgabe für da politische Ziel wird ersetzt durch ihr privates Rachebedürfnis, durch ihren Wunsch, es Danton „zu zeigen“ (27). Sie träumt davon, durch ihre Hinrichtung das Volk zum Aufruhr gegen die Jakobiner zu bewegen, aber ihr Traum scheitert an Rolands Entschluß, an ihrem Todestag Selbstmord zu begehen. Roland bringt sie dadurch in den Kreis weiblicher Pflichten zurück; sie fühlt sich „Gebunden! fest geschmiedet ewig an/ Die Pflicht! ... Ohnmächtig Weib!“ (28) - und damit endet ihre Rolle als politischer Kopf der Partei. Wie in Charlotte Corday wird ihre Rolle als politisch Handelnde abgelöst durch die der verklärt Leidenden: in der nächsten Szene wird sie verhaftet, es folgt eine rührende Abschiedsszene von Tochter und Gesinde, und in der darauffolgenden Szene ist sie bereits verurteilt. Auf das Todesurteil reagiert sie ähnlich wie Westphalens Corday, sie empfindet es als Apotheose. „Sie selber drücken - sie mit eig'nen Händen/ Den Siegeskranz verklärend auf mein Haupt!" (32)

Bevor sie allerdings ihren Siegeszug antreten kann, muß sie von verschiedenen Illusionen Abschied nchmen. Lodoïska berichtet vọn der Niederlage der Girondisten und von der Opposition des Volkes gegen sie, und bietet ihr, ähnlich wie Luchs in Charlotte Corday, die Möglichkeit, durch Kleidertausch mit ihr zu entfliehen. ${ }^{38}$ Marie lehnt ab allerdings aus anderen Gründen als Charlotte. In Lodö̈skas gottesgläubiger Aufopferung erkennt sie ihre eigene Selbstherrlichkeit, sie erkennt ihren Allmachtswahn, der jedes menschliche Gefühl in ihr auslöschte. Thre gesamte politische Alktivität erscheint ihr plötzlich in einem anderen Licht:

Wie anders bin ich, als ich mir erschien! -

Ich hab' gehaßt, und nicht das Schlechte nur;

Das Gute auch, sobald es mich belkämpfte.

In meinem Stolz unbeugsam, rückssichtslos,

Ließ neben mir und Denen, die ich liebte,

Ich keine Größe gelten, kein Verdienst,

Der Thorheit Wahn, das Wanken zager Schwäche,

Galt mir für Schuld, im Blute nur zu sühnen!

Verachtungswerth war mir der Irrende,

Und ein Verbrecher jeglicher Bethörte

So trug ich bei zum Sturze der Monarchen,

Und kein Gefühl des Mitleid's rührte mich,

Als sie schon lagen unter uns'ren Füßßen... (35).

Was Marie hier verdammt, ist nicht ihre politische Aktivität, sondern ihre private Unerbittlichkeit und Gefühllosigkeit, die sie zur Ausführung ihrer politischen Pläne für unerläßlich hielt. Wenn der Royalist Beugnot ihr diese Mitleidslosigkeit verzeiht, in der Annahme, sie ginge „beklagend Euer Werk" in den Tod, irrt er: „[...] nicht unser Werk! - nur uns're Schuld./ Das Werk ist göttlich - Menschen führen's aus" (36). Die Erzichung ihrer Tochter, die sie Lodoïska anvertraut, soll dieser sowohl die entschlossene Seite, die zum Handeln befähigt, als auch die gefühlvolle, die ihr die moralische Grundlage zum Handeln gibt, vermitteln. "Sie werde klug, entschlossen, klar und fest, / Vor Allem aber - wohlwollend und gut!" "(36) ${ }^{39} \mathrm{Da}$ ihr selbst diese Seite fehlt, hält sie ihren Tod für „Versöhnung, denn er ist gerecht" (36). Aber an ihre politischen Ideale glaubt sie nach wie vor; ,[...] dieser Kampf, [...]/ Ihn hat entflammt ein heiliges Gefühl:/ Der Durst nach Recht in Millionen Herzen" (36). So kann für Marie am Ende des Stückes eine ähnliche Apotheose erfolgen wie für Westphalens Charlotte: „Ihr Irrthum stirbt mit ihrem Menschendasein,/ Was ewig von ihr lebt, ist ihre Größe“ (36). 
2. OPFER

a. Elisabeth von Rumänien und Kremnitz.

Außer der politisch alktiven Heldin, deren Größe verherrlicht wird, spielt die Frau in historischen Tragödien von Frauen eine weitere wichtige Rolle: den des Opfers der Geschichte. Die Heldinnen dieser Trauerspiele haben weder politischen Einfluß noch machen sie Anspruch darauf; vicle erhalten ihre Position in der Geschichte durch ihre Verbindung mit dem Mann, dem sie schließlich zum Opfer fallen. Statt auf der Selbständigkeit der Frau und der Rechtfertigung ihrer Handlungen liegt hier die Betonung auf ihrer Unschuld. Was diese geschichtlichen Frauenfiguren (Anna Boleyn, Vittoria Accoratoni) won den Heldinnen nicht historischer Tragödien unterscheidet, ist ihre anfängliche Charakterisierung als selbständig Handelnde; ihr Fall wird meist darauf zurückgeführt, daß sie diese Selbständigkeit aufgeben. Ein solcher Fall ist Anna Boleyn $^{40}$ (1886) von Elisabeth von Rumänien (1843-1916) und Marie von Kremnitz (1852-1916). Annas entscheidender Fehler ist die Tatsache, daß sie in der Ehe mit Heinrich die Unabhängigkeit aufgibt, die dieser an ihr respekstiert. Heinrichs Verhältnis zu Frauen ist im Stück durch die Angst vor unabhängigen Frauen und durch das Bedürfnis, diese Selbständigkeit zu vernichten, charakterisiert. Gegenüber seiner ersten Frau, Katharina von Aragon, heuchelt er Achtung, weil sie sich seinen Plänen widersetzt (5-9) und betrauert sie nach ihrem Tod in den höchsten Tönen der Verzweiflung $(86 \mathrm{f})$. An Anna ist er interessiert, solange sie sich ihm gegenüber ablehnend oder kritisch verhält. Die „Löwin“ (22) Anna erweckt in ihm gleichermaßen den Wunsch, sie zu besitzen - „Mein muß sie werden, sollten Welten bersten“ (22) - und den, sie zu vernichten: Zerpressen möcht ich ihren spröden Leib,/ Das goldne Haar zerreißen, ihre Brust/ Aufschlitzen, wälzen mich in ihrem Blute./ Todt soll sie sein, o wär' sie nie gewesen!“ (15) Die Unabhängigkeit, die diese Mordgelüste in ihm erweckt und die Anna gleichzeitig vor ihm retten könnte, gibt sie auf, indem sie „sein“ wird: „Der Mann,/ Dem ich mich schenke, sei mein Herr, mein Meister" (40).

Diese Herrschaft des Mannes über die Frau sieht sic als so unbedingt, daß sie, ana$\log$ zu Heinrichs kannibalischer Vision, dem Mann gegebenenfalls das Recht zugesteht, die Frau zu vernichten. „Wär' ich auch/ Nur eine Stunde ihm zum Gliick gewesen,/ Wie gerne stürb' ich bittern Tod dafür" (41). Wie die Frau für den Mann stirbt, lebt sie auch ausschließlich durch ihn; sie „will die schwere Last ihm nur erleichtrern, Will selig sein, so lang' ich ihn nur stütze“ (41). Was Wyatt als den Weg ,zur Schlachtbank" erkennt (41), sieht Anna als Erwählung durch ein gütiges Geschick (38, 41) zur Größe (42). Ihre Selbstaufgabe bestätigt sie im Gespräch mit Heinrich, das zu neun Zeholn von ihr beherrscht wird und in dem sie ihm ihre frühere ablehnende Haltung als „Stolz“ erklärt, der „erst/ Gebrochen werden “ mußte (42 f). Jetzt aber ist sie "ganz besiegt", sie gibt sich "Gefangen hin in Eure liebe Hand,/ Will sie mir gnädig sein?" (42) Wo der "Göttergleiche“ um die „Magd“ (43) freit, kann keine Gleichheit in der "Ehe herschen; was Anna a "Traung unsrer Seelen" (42) bezeichnet, besteht schlicht in ihrem Entschluß, sich von ihm vereinnahmen zu lassen. „Ich kenne keinen Willen mehr als Euren,/ Kein Leben außer Eurem theuren Sein,/ Ja, keinen Gott, als den Thr nennt den Euren“ (43). Heinrichs Antwort ist bezeichnend: ihre Selbstaufgabe bedeutet für ihn einen Sieg auf privater Ebene, den er auf die politische ausdehnen will, indem er sein Land auf ähnliche Weise unterwirft wie sie. ${ }^{H} \mathrm{Hätt}$ ich Euch nie geliebt, wählt' ich doch Euch/ Zur Königin, zur Mutter meiner Erben,/ Weil nie ein Weib an diese Größe reichte./ Ein Licht, von Euch erstrahlend, wird mein Land/ Erhellen" (43).

Erste Zweifel an ihrer selbstgewählten Abhängigkeit kommen Anna, als Mary, Katharinas und Heinrichs Tochter, sie auf dem Weg von der Kirche öffentlich verflucht Aus Heinrichs Worten an Mary geht auch für Anna deutlich hervor, wovon ihr neuer Status als Königin abhängt: nämlich von dem als Mutter seines männlichen Erben. Heinrichs Gewißheit, daß sie "Den Erben Englands/ [...] jetzt unterm Herzen" trage (55), führt zu ihrer Angst, „nur" eine Tochter zur Welt zu bringen. Dazu gesellt sich bereits in der nächsten Szene die Angst vor Heinrich, denn mittlerweile hat sie ihren naiven "Glauben an des Königs Heiligkeit" (60) angesichts seiner politischen Morde verloren. Da sie gegen die einmal erkannte Realität, das „entsetzlich Loos [...]/ Der Königin“ (59) nicht mehr angehen kann, bleibt ihr nur; sich in die frühere „sel'ge Blindheit" (60) zurückzuwünschen. Heinrich dagegen verachtet sie für ihre Abhängigkeit, für ihre Metamorphose von der „Löwin“ zum Weib. „Ein Weib bleibt doch ein Weib! Seitdem sie mein,/ Da zittert sie, die unerschrocken sonst/ Mit Wort und That gekämpft" (61). Als Heinrich schließlich den Justizmord in die Wege leitet, indem er falsche Zeugen besticht, die Annas Untreue bezeugen sollen, bringt Annas Rolle als Weib sie aufs Schafott. Ihr Bruder George versucht, Anna zur Flucht zu bewegen, sie aber lehnt diesen Plan unter Hinweis auf ihre weibliche Aufgabe ab: „[...] ich bin nur/ Die Königin, der künft'gen Erben Mutter,/ Ich stehe fest, wo Gott mich hingestellt" (89). Um ihrer weiblichen Rolle gerecht zu werden, versucht Anna, Heinrich zu rechtfertigen, indem sie seine Schuld übernimmt:

Er ist seit zarter Jugend König, ist

Gewohnt, Verantwortung für was ihn reut

Auf Andere zu werfen; darum bin

Ich ja sein Weib, um auch das Böse, wic

Das Gute treu mit ihm, dem Herrn, zu theilen.

Ich fühl' es schon, daß eigentlich nur ich

Im Unrecht war; seit vielen Jahren habe

Ich Alles stets mit ihm getragen, feig

Hab' ich gehandelt, als ich ihn verließ,

Ich reizte ihn, ja, ich bin schuld an Allem (90).

Auf privater Ebene ist diese Schuldübertragung von Heinrich auf Anna für sie nicht aufrechtzuerhalten; nach außen hin werden ihre Worte Wirklichkeit: Anna erwischt ihren Gatten in flagranti mit Jane Seymour, er klagt sie des Ehebruchs an, um seinen eigenen zu vertuschen, und Anna erkennt, daß sie „Für meines Gatten Sünden büßen" muß (92). Obwohl Annas Widerstandsgeist kurz vor ihrem Tod wiedererwacht - im 
Tower lehnt sie Heinrichs Angebot, sich durch ein falsches Geständnis vom Todesurteil

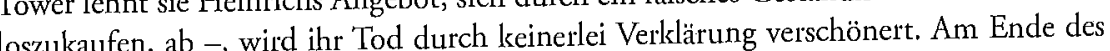
Stïckes steht eine letzte bittere Auseinandersetzung mit Heinrich, in der ihr Lebens. Seine wille endgültig gebrochen wird; ihr Widerstand gegen ihn ist nutzlos geworden. Seine durchaus ernstzunehmende Drohung, ihre Tochter Elisabeth zu ermorden, beantwortet sie mit der ohnmächtigen Drohung, ihn zu töten; das Bewußtsein ihrer Machtlosigkeit fuihrt zu ihrem völligen Zusammenbruch. „Ist/ Das Leben denn noch nicht verronnen? Herr;/ Befreie mich; ich kann die Bürde nicht/ Mehr tragen; Hab Erbarmen!“ Die Glocken, die zur Hinrichtung läuten, begrüßt sie erleichtert: „Dem men Gott sei Dank, ich bin erlöst!“ (111) Aber Anna sieht hier nicht den Himmel offen stehen, sondern sich nur von einem Leben befreit, das sie nicht länger ertragen kann; am Ende ihres Lebens steht keine Apotheose, sondern schiere Lebensmüdigkeit.

Die mögliche Inspiration für dieses Stück legen die Autorinnen Anna in den Mund: Ich seh die Jahre fliehen, [...]/ Und nur die harten Facten bleiben stelın,/ Die grause "That, daß ich den Tod erlitten;/ Wird jemand glauben, daß ich keines Fehls/ Je schuldig? Und was macht es mir, wenn ich/Vermodert bin, ob nach Jahrhunderten/ Gerecht mir wird die Welt?" (104 f) Ähnliche Zitate finden sich in historischen Tragödien von Frauen häufig; aus diesen Bemerkungen und aus der Tatsache, daß die Unschuld der wreiblichen Opfer der Geschichte sich immer am Ende des Stückes erweist, könnte man auf eine Motivation vieler Autorinnen schließen: die Rechtfertigung historischer Frauenfiguren vor der Nachwelt.

\section{b. Steinlein}

Ein beliebtes Thema historischer Tragödien ist z. B. die Behandlung berühmter Mordverdächtiger In diesen Tragödien geht es um Frauen, die wegen Mordes zum Tode verurteilt wurden und deren Geschichte so lückenhaft überliefert ist, daß die Autorinnen nur wenige Daten und Fakten zur Hand hatten. Um diese Lücken zu füllen, waren sie meist gezwungen, die Geschichte ihrer Heldin mit Hilfe der wenigen Daten und der itu dieser Stücke liegt in dem Faktor der Rechtfertigung: egal, ob die Geschichtsschreibung auf Schuld oder Unschuld der Angeklagten erkennt - auf der Bühne ist sie immer unschuldig.

So behandelte Laura Steinlein (1826-1901?) 1861 in ihrer Tragödie Das Haus Cenci die Geschichte der Beatrice Cenci, ${ }^{41}$ von der die Geschichtsschreibung nur wenig zu berichten weiß: sie wurde von ihrem Vater gefangengehalten und mißhandelt und des (im Bett ermordet zwei bezahlten Attenstem in Bett ermordet wurde. Für diese Tat wurde sie 1599 von Papst Clemens VIII. zum Tode verurteilt und hingerichtet. Einige Berichterstatter nehmen eine Vergewaltigung Beatrices durch hren Vater an (Klokow 182), andere nicht (Durant/Durant $252 \mathrm{f}$ ). Einig ist sich die Geschichtsschreibung, mit Ausnahme von Klokow, der einzigen weiblichen Berichterstatterin, im. Bezug auf Beatrices Schuld: in allen anderen Quellen hat Beatrice in Verhältnis mit Ölimpio Calvetti (Durant/Durant 253, Ricci 128-30) oder mit dem Monsignore Guerra (Remarkable Women 7 f; „Relation“ 95-9; Beyle 206) und stiftet ihren Liebhaber zum Mord an. Klokow dagegen hält es für „ziemlich sicher erwiesen [...], daß dieselben [Beatrice und ihre Geschwister, S. K.] durch ränkevolle Verleumdungen die Opfer eines Justizmordes geworden sind" (182). Bei Klokow schließlich wird Beatrice gemeinsam mit ihrem Bruder und einer älteren Schwester hingerichtet (182), in allen anderen Quellen mit ihrem Bruder und ihrer Stiefmutter Lucrezia.

Aus dieser mythologisch-spekulativen Historie übernahm Steinlein nur die von Anna erwähnten „harten Facten“, d. h. die wenigen Punkte in Beatrices Geschichte, die durch verschiedene gleichlautende Überlieferungen als einigermaßen erwiesen gelten können: die Gefangenschaft Beatrices und ihrer Geschwister, den Mord und die Hinrichtung. Bei Steinlein hat Beatrices Vater, Francesco Cenci, im Verein mit seiner langjährigen Geliebten Marghitta seine erste Frau Angela ermordet (sowohl die Geliebte als auch der Mord an Angela sind Steinleins Erfindung) und mißhandelt seine Kinder, weil sie ihn an sie erinnern. Aus Beatrices Liebschaft mit Calvetti oder Guerra wird ihre Liebe zu Guido Reni, der sie malt und bei dem sie Unterricht nimmt; aus der möglichen Mordgehilfin Lucrezia wird die liebevolle Stiefmutter, die unter der Zerrissenheit der Familie leidet und Vater und Kinder miteinander aussöhnen will. Der Mord an Cenci wird der Geliebten Marghitta angelastet, die sich so für den Verrat Cencis an ihr rächt. Beatrice, durch die ungeheure Grausamkeit und die inzestuösen Anträge ihres Vaters reichhaltig gerechtfertigt, will sich und ihre Geschwister zwa ebenfalls befreien, indem sie ihren Vater tötet, findet aber nicht die Kraft dazu und will stattdessen Selbstmord begehen. Sie wird mit dem Giftbecher überrascht, ihr Vater to gefunden; Marghitta beeilt sich darauf, ihr den Mord anzulasten, und Beatrice und ih Bruder werden des Mordes angeklagt und überführt.

Ähnlich wie Anna Boleyn leistet Beatrice ihrem Vater keinerlei Widerstand. Francescos Plan, sie durch den erzwungenen Malunterricht bei Reni „zur Demuth [zu] füh ren“, „den Übermuth zu brechen“ (26), ist reichlich überflüssig: im Gegensatz zur Wur ihres Bruders Giacomo reagiert Beatrice auf die Grausamkeit ihres Vaters mit einer Angst und Passivität, in der sie ihren einzigen Schutz vor weiterer Mißhandlung sieht. "Wenn Du des Vaters Grausamkeit erkannt,/ Und je gefühlt, wie er zu strafen weiß Du dächtest nie an Rache", erklärt sie Giacomo (16). Ihrem Bruder ist ihre Ergebenheit unbegreiflich: „Beatrice!/ Ist's möglich? regt in Deinem Busen kein/ Gefühl sich das, von aller Schmach getroffen,/ Dein Blut empört und auf zu wildem Haß/ Die Seele reizt? Das nicht allmächtig drängt/ Die grauenhafte Fessel abzustreifen?" (16). Sie aber kann sich ohne männliche Unterstützung nicht zu der Energie, die der wilde Haß erfordert, aufraffen: „Doch... doch... wärst du mir nah und er... mein Freund..." (16). Diesem Freund, Guido Reni, gegenüber, definiert sie sich selbst als „ein Nichts" (32), findet aber durch seine Liebe ins Leben zurück (33). Diese Neudefinition als „Deine Beatrice“ (33) gibt ihr die zeitweilige Kraft zum Widerstand gegen ihren Vater; ihr neues Selbstverständnis als „sein... Reni’s ..." (33) widerspricht ihrem früheren als Besitz des Vaters, den dieser beliebig mißhandeln kann. Diese Änderung zeigt sich deutlich in dem folgenden Austausch zwischen Beatrice und dem Grafen Cenci. 
Graf. Auf, Püppchen, kromm! ich habe Lust zu spielen...

(er zerrt Beatrice, die sich cben im Hintergrund vom Boden erheben wollte, in den Vordergrund.)

Und tanzen sollst Du... tanzen...

BEATRICE (springt auf, ihm sich entwindend.) Meint Graf Cenci

Ich lasse mit mir spielen? - O, die Zeit

Reift jede Frucht. - Hier ist es aufgegangen

Das selige Bewußtsein eignen Werths,

Und das Bewußtsein heil'ger Menschenrechte.

Seht eine Römerin und... Jungfrau... Graf.

GRAF. Ist das das schwache, demuthsvolle Kind?

BEATRICE. Hier hat ein neues All sich mir erschlossen,

Hier hat urew'ger Liebe Himmelsstrahl

Das schon vom Sturm zerpeitschte, schwanke Rohr

$\mathrm{Zu}$ neuem Dasein aufgerichtet (51, Hervorhebungen der Autorin).

Dem Grafen scheint dieser plötzliche Widerstand unvereinbar mit dem Charakter des schwachen, demutsvollen Kindes, das er kennt; er löst das Identitätsproblem dadurch, $\mathrm{da} ß \mathrm{er}$ in Beatrice seine verstorbene Frau Angela sieht. "Was schwirrt vor meinen Augen ... Beatrice?/ Nein!... Beatrice nicht... sie ist es - sie - / Ist Angela in ihrer ganzen Hoheit/ Und Würde“ (52). Obwohl sein schließlicher Ausruf „Mein Kind!" (52) auch Angela gelten könnte, glaubt Beatrice sich wiedererkannt und fliegt ihm in die Arme. Durch diese Aussöhnung mit dem Vater erhält sie Rang und Namen, gewissermaßen ihr Selbst zurück; aber da sic sich weiterhin als Renis Beatrice empfindet, kann sie sich nicht mehr mit diesem Selbst identifizieren. „ich kenne/ Mich selbst nicht mehr. Wie soll ich an den Wechsel,/ Der von des Elends tiefster Stufe mich/ Zu irdischer Glückseligkeit erhoben,/ Auch glauben? - Bin ich's? - Bin ich's nicht, Reni?" (67) Auch Reni kann die glückselige Beatrice nicht als „seine“ erkennen. „RENI. Ihr seid Contessa Beatrice Cenci./ BEATRICE. Nicht Dein, Reni? Nicht Deine Beatrice?" (67, Hervorhebungen der Autorin) Da sie begreift, daß ihre Rolle als Renis Beatrice von ihrer Hilflosigkeit abhängt, verspricht sie ihm, diese Abhängigkcit baldmöglichst wiederherzustellen - nachdem sie ihrem Vater zuliebe die glückliche Contessa gespielt hat.

[...] sollte ich den ersten, ersten Wunsch Ihm weigern? Nein! - Ist er erfüllt, Reni, Fort mit dem Prunk, den Edelsteinen. - Dir

Will ich ja leben, Dir allein. Von Dir

Empfang' ich das Gewand, das Dir gefallt,

Und meines Hauptes funkelnder Juwel,

[...] ist Deine Liebe,

Dein Glück - vor ihm fällt aller Tand der Welt

In Staub. Bist du zufrieden? (68)
Was Beatrice hier versucht, ist, zwei Herren zu dienen, von denen sich jeder ein anderes Bild von ihr macht - das Bild der Herrscherin (Vater) steht gegen Renis Heiligenbild $(70 \mathrm{f})$. Dieser Versuch bricht erst dann zusammen, als sie begreift, daß der Graf ihr eine Rolle aufdrängt, die sie nicht spielen kann: die ihrer Mutter Angela. Wie Anna Boleyn verinnerlicht Beatrice seine Schuld und verliert damit die Möglichkeit der Selbstidentifizierung als (unschuldig) mißhandelte Tochter; ebensowenig kann sie nun Renis Heiligenbild entsprechen.

Der Widerspruch zwischen den ihr aufgezwungenen Rollen - Heilige und Herrscherin/ Angela, Renis Beatrice und Francescos Tochter - ist ein Ergebnis ihrer Freiheit, denn während ihrer Gefangenschaft war sie ungeteilt, sic war Francescos grundlos mißhandelte Tochter; an ihrer Unschuld war kein Zweifel möglich. Für Beatrice bedeutet ihre frühere Unfreiheit Unschuld, Reinheit, Identität; ihre jetzige Freiheit sieh sie als gleichbedeutend mit Zerrissenheit, Zweifel, Schuld. Ihre Sehnsucht nach dem Ende der Zerrissenheit äußert sich dementsprechend in der nach dem Gefängnis, die sie ihrem chemaligen Gefangenenwärter Pietro gegenüber ausspricht.

\section{[...] als Du mich gefangen hieltest, da}

Warst Du ein Mensch... ein Mensch? Nein, nein, Pietro,

Du warst ein Engel, mir herabgesandt,

Du warst ein Gott der Liebe, des Erbarmens.

Seitdem Du aber mein Gefängniß mir

Erschlossen hast, mich in die Welt gestoßen,

Und ich, ein harmlos Kind, der langentbehrten,

Der süßen Freiheit in die Arme sank -

Du, ungewarnt, den heißen Durst zu stillen,

Des Daseins goldig flimmernden Pokal

Mich an die unentweihte Lippe setzen,

Den Höllentrunk mich kosten ließest - bist...

Ich kann nicht sagen was Du bist (74 f, Hervorhebung der Autorin).

Nur in der Gefangenschaft kann Beatrice gleichzeitig vor dem väterlichen Verführer Schutz finden, die Zweifel an ihrer eigenen Identität vermeiden und sich selbst als unentweiht empfinden. In der Freiheit aber bringt sie das Bewußtsein der eigenen Unschuld nicht auf. Der Unterschied zwischen ihrem Plan, den Vater zu töten, und dem ihres Bruders Giacomo beruht darauf, daß ihr scin Selbstbewußtsein, seine eigenständige Identität fehlt: anders als sie ist er sich bewußt, daß er im Recht ist und aus Selbstverteidigung handelt. Giacomo plant die Tat, um sich selbst zu retten (78), Beatrice zur Rettung anderer (89); fiir Giacomo sind Mord und Selbstmord Alternativen - er will sich töten, wenn sein Plan fehlschlägt -, für Beatrice dagegen ist der Selbstmord eine unausweichliche Konsequenz des Mordes am Vater (81). Während Giacomo an der Tat nur dadurch gehindert wird, daß Marghitta ihm zuvorkommt, ändert Beatrice ihren Vorsatz: nachdem sie den Giftbecher gefüllt hat, belauscht sie ein Gebet ihrer Stiefmutter für sie und fühlt sich durch die Vorsehung an der Ausführung 
ihres Planes zurückgehalten. In rapider Aufeinanderfolge versucht sie nun zwei Neudefinitionen ihrer selbst: die Rückkehr in die Rolle der unschuldig Mißhandelten durch Selbstmord und die Rückkehr in den Besitz Renis durch Flucht. Aber diese Weg ist ihr "verschlossen“, sie bleibt "Gefangen" (91) und wird von ihrer Familie ohnmächtig gefunden. Das „erklärend Wort" (95), zu dem sie wiederholt aufgefordert wird, bringt sie nicht heraus; ihren Tod versteht sie als ihre letzte Möglichkeit, „das unbefleckte Kleid/ Der heil'gen Unschuld wieder zu erringen" (106).

Das Motiv der Rechtfertigung der historischen Heldin vor der Nachwelt ist hier wesentlich stärker ausgeprägt als bei Westphalen, Ebner-Eschenbach und Elisabeth/ Kremnitz: Beatrice bringt Reni von seinem Entschluß, mit ihr zu sterben, durch eine hypothetische Frage ab, hinter der sich ein Auftrag verbirgt. „Wenn Reni/ Vom Schicksal auserlesen, uns're Schmach/ Und unsern Tod zu sühnen? Wenn durch ihn/ Verkündung kommenden Geschlechtern würde,/ Sie - vor der Welt entehrt, in Schmach gerichtet, / Sie wären schuldlos?" (110) Und Reni nimmt den Auftrag an, er verspricht ihr Rechtfertigung durch ein Bild, einer Botschaft an die Zukunft. In diesem Bild verspricht er,

soll für Nachwelt, kommende Geschlechter

Und für Jahrhunderte in Flammenschrift

Das Zeugniß stehn - sie: Beatrice Cenci,

War nimmermehr Verbrecherin! - Ich schaue:

Licht wird's vor meinem Seelenauge, licht -

Ich seh' Dein Volk, Nationen fern und nah,

In Scharen dicht gedrängt, in Andacht wallen

Hin zu dem Bilde einer Heiligen.

Ich seh' sie Weihrauch streu'n, Dir huldigen,

Ich seh' ihr Aug' von Thränen überfluthet,

Für die Dir angethane Schmach Erhebung

Fordern - und für Dein ungemess'nes Leid

Abbitte thun (110 f, Hervorhebung der Autorin).

Die Annahme, daß Steinleins Stück von ähnlichen Motiven inspiriert wurde, liegt nahe.

c. Götze.

Während Beatrice als Sinnbild der mißhandelten mädchenhaften Unschuld dargestellt wird, ist die Heldin in Auguste Götzes (1840-1908) Vittoria Accoramboni ${ }^{42}$ (1890) durch das hartnäckige Bestehen auf ihrer Unabhängigkeit teilweise für ihr tragisches Schicksal mit verantwortlich. Im Bezug auf Vittorias Leben ist die Geschichtsschreibung ebenso lückenhaft wie im Falle Beatrice Cenci: nach der Ermordung ihres ersten Mannes, Francesco Peretti, heiratete sie Paolo Orsini, den Duce von Bracciano, der zusammen mit ihrem Bruder Marcello den Mord begangen haben soll, um diese Heirat zu ermöglichen (Beyle 158; Martinengo Cesaresco 138; Bax 48-50). John Symonds und Bax nehmen eine Komplizität Vittorias bei der Tat an (John Symonds 161; Bax 115). Weder Vittoria noch Orsini wurden gerichtlich belangt, da der Kardinal Montalto, der Onkel des Ermordeten, eine gerichtliche Untersuchung verhinderte. Trotz eines päpstlichen Dekrets, das Vittoria eine zweite Eheschließung verbot, heirateten Vittoria und Orsini mehrfach (Boklund 17; Bax 67 und 99; Martinengo Cesaresco 142; John Symonds 165). Nach dem Tod des Duce wurde Vittoria von ihrem Schwager Lodovico Orsini ermordet, da dieser vergeblich gegen die unstandesgemäße Heirat seines Bruders Einwände erhoben hatte und Vittorias beträchtliche Erbschaft in die Familie zurückbringen wollte (Bax 160 f; Martinengo Cesaresco 148 f; John Symonds 167).

In Götzes Stück verliebt sich Vittoria in den Kardinal Montalto, später Papst Sixtus V; aber ihre ehrgeizige Mutter Tarquinia will ihr durch die Ehe mit Orsini, dem Herzog von Bracciano, die Herzogskrone aufsetzen. Vittoria setzt ihren ganzen Stolz darein, den Herzog vor den Augen Montaltos und der Welt abzulehnen, wird aber daran durch den Widerstand der Noblen von Rom gehindert, die ihre Verbindung mit dem Herzog aus Standesgründen ablehnen und seinem Antrag durch ein päpstliches Dekret zuvorlkommen. So um ihren Triumph gebracht und öffentlich bloßgestellt, schwört Vittoria Luigi Orsini, dem Sprecher der Noblen, Rache. Sie verspricht Montaltos Neffen Francesco Peretti die Ehe, wenn er ihr Luigis Verbannung erwirkt; dieser tut es durch den Einfluß seines mächtigen Onkels, und Vittoria heiratet ihn zwar widerwillig, aber durch ihr Wort gezwungen. Vittoria liebt Montalto weiter, ohne von seiner Gegenliebe zu wissen, und leidet unter den kleinlichen Eifersüchteleien ihres Mannes, der ihr sogar den Umgang mit Künstlern verübelt. Unterdessen schmiedet Tarquinia mit Hilfe ihres älteren Sohnes Marcello und Orsinis, der Vittoria nach wie vor in seinen Besitz bringen will, weiter an ihren ehrgeizigen Plänen für Vittoria. Marcello bringt Vittoria bei Francesco in den Verdacht der Untreue und lockt ihn in eine Falle. Francesco wird ermordet, der Verdacht fällt auf Vittoria. Vittoria gibt jeden Rechtfertigungsversuch auf, als auch Montalto sie für schuldig hält; sie flieht und ist von da an völlig in der Hand ihrer Mutter. Tarquinia und Orsini entführen sie auf Orsinis Schloß und zwingen sie zur Ehe mit Orsini. Montalto rechtfertigt Orsini öffentlich, um Vittoria zu schützen, obwohl er von beider Schuld überzeugt ist. Als er zum Papst gewähl wird, verurteilt er Orsini zum Tode; Vittoria wird von ihrem Mann zu ihm geschickt, um seine Begnadigung zu erwirken. Die Szene zwischen Vittoria und Montalto ist die Aufklärungs- und Aussöhnungsszene des Stückes: Vittoria überzeugt Montalto von ihrer Unschuld; beide gestehen sich ihre Liebe und entsagen. Montalto begnadigt Orsin auf Vittorias Bitten hin, aber bevor Vittoria mit der Freudenbotschaft zurückkehrt stirbt Orsini. Am Ende des Stückes wird Vittoria von Luigi, dem durch ihre Schuld Verbannten, der sich aus Verzweiflung einer Räuberbande angeschlossen hat, ermordet.

Wie Steinlein rechtfertigt Götze ihre Heldin nicht nur durch falstische Änderungen und Uminterpretationen der bekannten Geschichte (frei erfunden sind die LuigiHandlung, Vittorias unglüclliche Liebe zu Montalto, und ihre erzwungene Ehe mit Orsini), sondern vor allem durch die Charakterisierung ihrer Heldin. Anders als Steinleins Beatrice ist Vittoria hochbegabt, intelligent und ehrgeizig, wenn auch in anderem Sinne als ihre Mutter. Während deren Ehrgeiz auf Macht abzielt, liegt Vittoria an einer 
Demonstration ihrer persönlichen Unabhängigkeit. Sie läßt sich weder von ihrer Mutter in die Ehe zwingen - „Ich bin die freic Herrin meiner Hand/ Und meines Herzens, Mutter, merk' es wohl“ (17) -, noch von ihrem besorgten Bruder Flaminio überreden, eine Frau brauche den Schutz des Mannes (17 f). Ihre Freiheit versteht sie als die Unabhängigkeit vom Mann; den Ausdruck ihrer Freiheit sieht sie in der Anbetung der Männer, die sie zu nichts verpflichtet.

[...] laßt mir meine Freiheit,

Und laßt mich sorgenlos und voll genießen

Dies schöne Leben unbegrenzter Macht.

Vittoria kann alles, was sie will!

[...]

Ich sehe sie so gern zu meinen Füßen,

Die Großen Roms, Herzoge und Barone

[...]

Das ist mir Leben und Genuß des Lebens;

Nicht aber das, mein eigen Selbst zu opfern

Und eines Gatten folgsam Weib zu sein (19).

In ihrem ersten Gespräch mit Montalto versucht er, ihr genau diese Folgsamkeit aufzuzwingen: „Ihr sollt des holden Reichthums,/ Mit dem Natur verschwenderisch Euch schmückte,/ Euch nur bewußt sein, um damit den Einen, / Um Euren Gatten weiblich zu beglücken" (21); bis dahin aber soll sie "den holden Schatz/ Von anmuthvoller Frauenschöne" (22) sorgfältig verstecken, statt ihn auf Festen zur Schau zu tragen. Mit diesem Argument versucht Montalto, Vittoria dazu zu bewegen, das Fest zu verlassen und auf ihren Triumph, den Antrag Orsinis, zu verzichten, denn „Was auch vielleich an glänzendem Triumphe/ Des Festes Königin verliert, das wird/ Das sittig holde Weib dabei gewinnen" (22). Aber seine Bevormundung erweckt Vittorias Stolz, sie glaubt an ihre unbegrenzte Macht über sein „schwach Geschlecht“ (23) und hält an ihren Plänen fest. Montaltos Einfluß aber macht sich in ihrem folgenden Monolog bemerkbar: vor ihrem Gespräch mit Montalto ging es ihr um eine öffentliche Demonstration ihrer Unabhängigkeit, jetzt liegt ihr zusätzlich daran, daß Montalto Zeuge ihrer Entschlossenheit wird. Daß ihr dieser 'Triumph genommen wird, bedeutet für sie eine öffentliche Blamage, eine Negierung ihrer Freiheit; um sich zu rächen, verkauft sie sich „nur von Rachegefühl durchglüht, ohne Besinnen und Schwanken" (Bühnenanweisung, 34) an Francesco. Dessen Schwäche - sie bezeichnet ihn wiederholt als „Knaben“ (40) äußert sich in seiner lächerlichen Besitzerpose und kleinlichen Eifersucht. „Sobald Du mein, will ich mein Kleinod wahren,/ Vor aller Andern Blicken es verschließen!“ (41). Vittoria scheint trotz ihres Ehrenworts unwillig, sich in dieser Form einschließen zu lassen - aber wieder werden ihre letzten Zweifel von Montalto beseitigt. Sein Dank dafür, „Daß Ihr dem Rath gefolgt und Euch vermählt" (53), gibt den Ausschlag: Vittoria fügt sich in ein System, in dem die Frau ohnmächtig ist und der Mann, gemäß Flaminios Annahme, als ihr Beschützer fungiert. Auf dem Weg zur Kirche reicht sie
Montalto „wie ein Kind folgsam und willenlos ihre Hand“; sie „schwankt einen Augenblick, so daß sie sich auf ihn stützen muß" (Bühnenanweisung 53). Montalto begrüßt diese physischen Symptome ihrer Unfreiheit mit Jubel: „So recht, stützt Euch auf mich, Vittoria,/ Und wie in dieser Stunde thut es immer!“ (54) Damit ist Vittorias Metamorphose vom unabhängigen Mannweib zum machtlosen Weibchen vollzogen.

Wie vollkommen diese Umwandlung ist, zeigt sich in ihrem Gespräch mit dem Maler Zuccari, der sich noch an die unverehelichte Vittoria aus dem vorigen Jahr erinnert.

ZuCCARI. Damals erschient ihr meinem Auge stolzer -

VITTORIA (leise für sich). Und glüicklicher!

ZUCCARI (in seiner Rede fortfahrend).

Doch nicht so schön, als heut';

Noch fehlte Eurem Antlitz das, was oft

Das häßlichste verschönt; der Zug der milden

Und sanften Weiblichkeit; jetzt, da Ihr liebt - - (56).

Bei dieser Metamorphose gewinnt das „sittig holde Weib“, gemäß Montaltos Vorhersage im ersten Alkt, und zwar auf Kosten ihres Glücks. Da Vittoria die „Aufgabe" der Frau in der Ehe - „Dich zu beglücken und mein ganzes Sein/ Dem Deinen anzuschließen" (61) - Francesco gegenüber nicht erfüllen kann, überträgt sie einen Teil ihrer ehelichen Pflichten auf Montalto. „[...] seinen großen Plänen wurdet Ihr/ Verständnißvoll Gefährtin. - [...] auch sonst/ Noch folgt ihm Eurer Seele kühner Flug" (57), lautet die Einschätzung des Baumeisters Fontana. Da Vittoria weder in der Ehe noch in der Welt einen Handlungsspielraum hat, lebt sie "still hier nur mit ihren Büchern“ (67). Montalto dagegen reagiert auf seine unglückliche Liebe mit verstärktem politischem Ehrgeiz: als Anwärter auf die Tiara greift er „mit reiner Hand/ Nach jener Frucht der unumschränkten Mach" " (68, Hervorhebung der Autorin). Für Vittoria, die in der Ehe gezwungen wird, sich auf die von Zuccari zitierten Weiblichkeitsattribute einzuschränken, wird derartiger Ehrgeiz zur Sünde. Montalto gegenüber beichtet sie ihr Unabhängigkeitsbedürfnis, als handele es sich um cine Todsünde: „Du würdest schaudern, sähest Du dies Herz/ [...]/ Entsetzensvolle Dinge stehen drin./ [...]/ Da steht der Ehrgeiz, brennend, unzufrieden/ Mit meinem stillen Loos in Deinem Haus,/ Ergeht er sich in sünd'gen Hoheitsträumen" (73).

Vittorias Verhängnis, die Flucht, die sie am Mord Francescos schuldig erscheinen läßt, ist das Ergebnis einer Wechselwirkung zwischen ihrer früheren Unabhängigkeit und ihren jetzigen Versuchen, diese Freiheitswünsche zu unterdrücken: ihre „weibliche" Seite, ihre Abhängigkeit von Montaltos Ansichten, nimmt ihr jede Möglichkeit, sich ihm gegenüber zu verteidigen, als er sie des Mordes beschuldigt (85). Andererseits macht gerade ihre frühere Selbständigkeit sie zur Hauptverdächtigen - in den Augen der männlichen Protagonisten. „Das sieht ihr ähnlich!“, heißt es da unter anderem, „Dies Weib ist stets den eig'nen Weg gegangen!" (87) Nach Vittorias einmütiger Verurteilung durch die öffentliche Meinung und ihrer Entführung durch Orsini und Tarquinia 
gehen ihre und Montaltos Wege zunehmend auseinander: Montalto steigt zum Papst auf, Vittoria versinkt in völlige Apathie. „Die Kraft der starken Seele war gebrochen./ So schleppte man sie hin zum Traualtar" (98).

Aus dieser Apathie erwacht sie erst, als sich ihr die Möglichkeit bietet, sich Montalto gegenüber zu rechtfertigen. Orsini, von Montalto zum Tode verurteilt, schickt sie zu Montalto, um bei ihm seine Begnadigung zu exflehen, und gesteht ihr seinen Anschlag auf Francescos Leben und die Tatsache, daß er selbst sie in einem Brief an Montalto des Verbrechens beschuldigte. Vittoria sieht Montaltos Verhalten durch diesen Brief als völlig gerechtfertigt; ihre eigene Unfähigkeit, sich ihm gegenüber zu verteidigen, interpretiert sie als Trotzrealktion, die sie jetzt durch Demut wiedergutmachen will (115). So sehen sich Vittoria und Montalto als Bittstellerin und Papst wieder, er auf der Höhe der Macht, sie in der tiefsten Machtlosigkeit: „Nicht hoch - nicht hehr - ein sündig schwaches Weib/ Erschein' ich hier" (122). Daß Montalto angesichts dieser endlich unterwürfigen Vittoria in Versuchung gerät, ist verständlich; aber gerade ihre nun verinnerlichte weibliche Rolle dilktiert ihr Verhalten: sie entsagt mit dem Hinweis auf seine große Zulkunft, seine Aufgabe in der Welt. Denn was für die Frau ein Lebensinhalt ist, die Liebe zum Mann, ist für den Mann lediglich „dieser Stunde Rausch“ (128), aus dem er erwachen muß, um seine Bestimmung zu erfüllen. „Wenn Du erwachst - und Du wirst bald erwachen, / Denn Liebe füllt des Mannes Sein nicht aus -/ Wirst Du mi starker und mit reiner Hand/ Das Werk, zu dem Dich Gott beruft, beginnen" (128) Damit verweist sie Montalto auf seine „glanzerhellte[n] Bahnen“, seine „heil'ge Sendung" (131)

Vittorias Aufgabe dagegen - die Pflicht, den Mann zu seiner zurückzuführen -, ist damit erfüllt: „Das Höchste, was das Leben bieten kann,/ Genoß ich in dem sel'gen Augenblick!" (129, Hervorhebung der Autorin) Da die Liebe, wie hier deutlich impliziert, das Sein der Frau ausfüllt, bleibt Vittoria nach ihrer Entsagung weder Wunsch noch Aufgabe übrig; ihr einziger Wunsch ist der nach Vernichtung - „Wär' dieser Tag, nach welchem mir die Welt/ Nichts, nichts mehr bieten kann, mein letzter auch!" (138) - und Vergessenheit: „daß meine Spur verwehe" (137). Ihre Ermordung durch Luigi, für sie die Sühne für ihre Schuld ihm gegenüber (141), wird für Montalto zum Anstoß für weitere politische Pläne, die ihm außerdem Befriedigung seiner privaten Gefühle versprechen. „Der Papst hält morgen fürchterlich Gericht!/ In Kurzem sei von der Briganten Horden/ Das Land gesäubert; Keiner darf mehr leben!/ So räch' ich Deinen Tod, Vittoria!" (147) Durch Vittorias Tod wird der Riß in Montalto, der Zwiespalt zwischen privatem Glücksanspruch und politischem Ehrgeiz, geheilt; seine Privatrache wird zur Sache Roms; Montaltos Licbe zu Vittoria geht in dem Entschluß des Papstes, in ihrem Geist [zu] regieren" (148), auf.

Anders als Steinlein, Elisabeth von Rumänien und Kremnitz, die sich auf die Rechtfertigung ihrer Heldinnen durch Darstellung ihrer Unschuld konzentrieren, sprich Götzes Tragödie einen weiteren Aspelkt an: die Tatsache, daß der Frau historisch die Möglichkeit der Verbindung von privatem Glück und öffentlicher Wirksamkeit nich gegeben war, selbst wenn sie, wie Vittoria, sowohl den Willen als auch die Fähigkei dazu besitzt. In allen historischen Tragödien sind der private und der öffentliche
Bereich für die Frau einander direkt entgegengesetzt und schließen sich gegenseitig aus. Wo die Frau in historischen Tragödien von Frauen auf Selbständigkeit Anspruch macht, bezahlt sie sie mit dem Verlust ihres privaten Glüclssanspruchs (Vittoria Accoramboni) oder ihres Gefühlslebens (Marie Roland). Wo dagegen ihre geschichtliche Rolle mit ihrer "weiblichen" (als Frau, Tochter, Untertanin) übereinstimmt, ist sie auf politisch-öffentlichem Gebiet machtlos (Das Haus Cenci, Anna Boleyn). Die Idee, daß eine Frau imstande ist, ihre "weibliche Bestimmung" zugunsten ihrer politischen Handlungsfreiheit oder privaten Unabhängigkeit zu opfern, wird verschiedentlich auf die Bühne gebracht, oft mit mildernden Zusätzen, die diesen Entschluß vertretbar erscheinen lassen oder ins Nachhinein „berichtigen“: Vittoria erkennt ihre Unabhängigkeitsbestrebungen als unverzeihlichen Stolz; Ebner-Eschenbachs Marie Roland urteilt ähnlich über ihre unweibliche Härte; Westphalens Corday wird zur Auserwählten bzw. zum Werkzeug des Schicksals - ähnlich wie Schillers Jungfrau von Orleans.

Hinter dieser Verfahrensweise - die Darstellung selbständiger Heldinnen unter Anführung mildernder Umstände - könnnte man ein taktisches Manöver vermuten, dem nicht unähnlich, das die Autorinnen von Bildungstraktaten gebrauchten. Denn wo die Sympathien der Autorinnen liegen, ist eindeutig: wo die Heldin der Tragödie in der privaten Ebene verhaftet bleibt, stirbt sie als bekllagenswertes Opfer der Geschichte (Beatrice Cenci, Vittoria Accoramboni, Anna Boleyn, Beatrice von Schwaben in Henriette Strauss' Beatrice). Wo sie dagegen die Folgen ihrer politischen Handlungen mit dem Leben bezahlt, erfolgt ihre Apotheose, die Verherrlichung ihrer Größe (Charlotte Corday, Marie Roland). Worin die Tragödie der Figur besteht, ist ebenso davon abhängig, ob sie als Heldin oder Opfer auftritt: in Westphalens Charlotte Corday und EbnerEschenbachs Marie Roland besteht die Tragödie der Heldin in ihrem Ende, das ebenso wie ihre politischen Taten das Ergebnis ihrer eigenen Entscheidung ist, denn sowohl Charlotte als auch Marie wird noch im Gefängnis die Möglichkeit der Flucht geboten. In den Tragödien, in denen die Heldin der Geschichte geopfert wird, besteht ihre Tragödie in der vorgegebenen oder selbstgewählten Ausweglosigkeit ihrer Situation, in der Tatsache, daß sie die Möglichleit der Handlungsfreiheit entweder nicht haben (Das Haus Cenci, Beatrice) oder zugunsten des Privatbereichs aufgeben (Vittoria Accoramboni, Anna Boleyn).

\section{B. Historische Dramen}

\section{KÖNIGINNEN UND SOLCHE, DIE ES WERDEN SOLLTEN}

Die Idee, daß Frauen nur unter Ausschluß der Privatsphäre Geschichte machen können - sowohl ihre eigene als auch Weltgeschichte -, zicht sich auch durch historische Stücke von Frauen: ähnlich wie in Charlotte Corday und Marie Roland wird hier die Entscheidungsfreiheit der Frau durch Ausschaltung des Privatbereichs gesichert. Anders als historische Tragödien über Frauen, die meist einen guten Teil der Lebensgeschichte der Heldin zeigen oder nacherzählen, wird hier nur ein kurzer Ausschnit 
behandelt: die Heldin steht am Kreuzweg zwischen privater Abhängigkeit und öffentlicher Wirksamkeit; gezeigt wird nur ihre Entscheidung - der Rest ist Geschichte.

\section{a. Birch-Pfeiffer}

Charlotte Birch-Pfeiffers Elisabeth (1841) behandelt die Geschichte Elisabeths von England vor ihrer Thronbesteigung; bis zur letzten Szene spielt das Stück zur Zeit de Regierung Mary Tudors. Die Autorin hält sich dabei genau an die historischen Gegebenheiten und erfindet zwei wichtige Faktoren: Elisabeths Liebe zu Eduard Courtney und die zeitliche Übereinstimmung zwischen Courtneys Tod und Elisabeths Thronbesteigung. ${ }^{43}$

Maria steht völlig unter dem Einfluß des Bischofs und Staatskanzlers Gardiner, der der katholischen Kirche ihre ehemalige Vormachtstellung in England wiederverschaffen will. Gardiner intrigiert gegen Elisabeth, weil er in ihr eine mögliche kiunftige Regentin sieht, die sich weder von der katholischen Kirche noch von ihm regieren lassen würde. Maria dagegen haßt Elisabeth, weil sie ihr die Liebe des Volkes und die Eduard Courtneys, den sic kürzlich von jahrelanger Haft im Tower begnadigt hat, entzieht. Maria läßt Eduard durch Gardiner ihre Hand und Krone antragen; dieser lehnt b, und Maria schwört sowohl ihm als auch Elisabeth Rache. Beide werden verhaftet und in den Tower gebracht; unterdessen suchen Gardiner und Maria eifrig nach Mög lichkeiten, Elisabeth und Eduard pro forma des Hochverrats zu überführen, um ihre Hinrichtung vor dem Volk rechtfertigen zu können. Denn das Volk befindet sich im Aufruhr gegen Maria, die inzwischen Philipp von Spanien geheiratet und die Inquisition in England eingeführt hat.

Im Tower kommt es zu einem ersten Gespräch zwischen Elisabeth und Eduard, in dem Eduard ihr seine Liebe gesteht. Unter dem Druck der öffentlichen Meinung wird es schließlich unumgänglich, beide aus dem Tower zu befreien; Gardiner setzt daraufhin den nächsten Plan ins Werk: er versucht, Elisabeth zu bewegen, ihr Erbrecht auf Englands Thron aufzugeben und den König von Frankseich zu heiraten. Eduard dagegen soll ihm, durch die Freiheit verführt, durch echte Rebellion den Vorwand liefern, den er braucht. Elisabeth lehnt Gardiners Angebot ab und wird auf Schloß Ricot gebracht; dort sieht sie Eduard wieder, der sich entschlossen hat, England zu verlassen, und von ihr Abschied nimmt. Mit dieser Abschiedsszene endet das Stück; die Folgen des Abschieds zeigt Birch-Pfeiffer im Nachspiel: die Thronbesteigung Elisabeths, der nach dem Tode Gardiners, Marias und Eduards nichts mehr im Wege steht.

Elisabeth wird zu Beginn des Stückes als eine Frau dargestellt, die sowohl Anlagen zur "Frau“ als auch zur Herrscherin besitzt: ihr Todfeind Gardiner beschreibt sie eher als Weib mit Geist - „ein seltner Bund/ Von Geist und Körperreiz, von Witz und Lau-

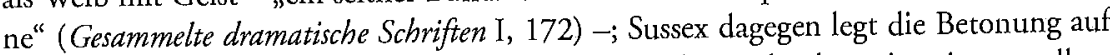
Elisabeths Intelligenz und Gelehrsamkeit und erwähnt nebenher, sie sei trotz allem "Weib" geblieben. In seiner Darstellung ist sie:

Gereift in Allem, was den Geist erhebt

Zur höchsten Stufe merischlicher Vollendung.
Tief eingedrungen in des Wissens Schacht

Ist ihre nimmer ruh'nde Lernbegier;

Die todten Sprachen, wie die lebenden

Spricht sie, beschämend ihre eignen Lehrer,

Und keiner Zierde, die das ächte Weib

Soll schmücken, hat sie sich entäußert, um

Sich der Gelehrsamkeit streng zu befleißen.

Ich kenne keine Frau, in der sich so

Die schönen Künste und das tiefste Wissen

Vereinen mit der keuschen Züichtigkeit,

Der holden Schaam, der makellosen Sitte (173).

Was Sussex über Elisabeth sagt, wird im Stück Punkt für Punkt bestätigt: ihre Perfektion im Bezug auf die schönen Künste stellt sie unter Beweis, indem sie Marias Hof durch Gesang verschönert; der Gelehrsamkeit befleißt sie sich auf ihrem Schloß - dort liest sie Sophokles. Die Zierden des „ächten Weibes“ (Züchtigkeit, Scham, Sitte) demonstriert sie dagegen keineswegs in einem wie immer gearteten Verhältnis zu einem Mann, sondern in ihrer Bescheidenheit (192) und Mäßigkeit bei Hofe, wo sie in schlichtem Weiß erscheint (183) und allen Lobeshymnen auf ihren Gesang mit ihrer Selbsteinschätzung als „Stümperin“ und „Krähe“ begegnet (184f). Ihre „weiblichen“ Eigenschaften bestimmen außerdem ihre politische Haltung Maria gegenüber: obwoh Maria sie auf alle nur erdenkliche Art herabsetzt, erkennt sie sie als Königin an, der sie unbedingten Gehorsam schuldet. Maria erscheint als das genaue Gegenteil Elisabeths: kalt und finster; überladen mit Samt, Seide und Schmuck, schwenkt sie demonstrativ den Rosenkranz und verwendet im Gespräch mit jedem außer Gardiner den Pluralis Majestatis (189). Maria, obwohl Herrscherin, existiert im Stück nur als „Frau“; ihre Motive sind die der eifersüchtigen Frau, ihre Handlungen zielen auf Befriedigung eines privaten Rachebedürfnisses ab. Auf politischem Gebiet ist sie vollkommen von Gardiner beherrscht und unfähig, selbständig zu regieren. Diese Unfähigkeit bestätigt sie erneut durch ihre Ehe mit Philipp II., in der sie effektiv ihre politische Funktion aufgibt: ein Untertan spricht im vierten Akt von „Philipps Thron" (300), nicht etwa dem Marias.

Marias wichtigste Funktion im Stück ist die, zu demonstrieren, daß gerade ihre Unterwürfigkeit Gardiner gegenüber die Schreckensherrschaft der Inquisition ermöglicht, und daß gerade ihre Abhängigkeit von ihrer „weiblichen“ Rolle, exemplifiziert in ihrem Antrag an Eduard, Gardiners Herrschaft über sie befestigt. Da Maria in ihren privaten Gefühlen - Liebe, Eifersucht, Rachebedürfnis - verhaftet bleibt, sieht sie nur die Wahl zwischen selbstgewählter Abhängigkeit (von Eduard) und widerwilliger (nach außen hin von Philipp, tatsächlich von Gardiner). Auf eine kurze Formel gebracht, verhindert ihre Abhängigkeit von Männern ihre politische Entscheidungsfreiheit; indem die Königin sich dem Mann unterwirft, setzt sie ihr Land der Tyrannei aus. Thr Beispiel vor Augen, kann Gardiner die politische Unfähigkeit der Frau verallgemeinern: „Die Frauen - selbst die Königinnen - bleiben/ Doch immer Frauen“ (176). 
Elisabeth dagegen ist zur fähigen Herrscherin prädestiniert, denn für sie gibt es „keinen Maaßstab, der/ Den andern Weibern paßt" (219). Die Unabhängigkeit, die sie zur geborenen Herrscherin macht, wird durch drei Elemente im Stück gefährdet: auf politischer Ebene durch Gardiners und Marias Pläne, sie entweder hinzurichten oder zu verheiraten; auf privater Ebene durch Elisabeths Liebe zu Eduard. Im Gegensatz zu Maria hat sie aber in Liebesdingen "früh sich schon beherrschen lernen“ (218), so daß es nicht einmal ihrer Erzieherin und Vertrauten Ashley gelingt, sie im Bezug auf Eduard auszuhorchen. Obwohl sie Eduard liebt, beurteilt sie ihn weitgehend im Bezug auf sein politisches Handeln (288-93; 361-3). In der Gefängnisszene weicht sie ihm aus, solange sie vermutet, daß er sie zu einem Liebesgeständnis drängen will - bis er sie solange sie vermutet, daß er sie zu einem Liebeständnis dăngen will bis er sic beruhigt: „Nichts verlang' ich von der Jungfrau,/ Das ihre keusche Brust, ihr Herz enthülle;/ Nicht frag' ich, ob Du liebst. Frag' ich die Gotheit,/ Wenn im Gebet zu ih empor ich blicke,/ Ob sie mit Liebe die Anbetung lohnt?" (290 f, Hervorhebungen der Autorin) Was er dagegen von ihr verlangt, ist den Glauben an seine Untertanentreue, und nachdem Elisabeth ihm diesen Glauben bestätigt hat, zieht Eduard sich ohne weitere Ansprüche in den Tower zurïck (291). Gardiners Versuch, sie zur Ehe mit dem König von Frankreich zu bewegen, erkennt sie als seinen Plan, „der Vergessenheit mich [zu] überliefern -/ Mein Erbrecht - meinen Kronanspruch [zu] vernichten" (314) $\mathrm{Da}$ dieser Machtverlust, diese Vergessenheit ihrem Tod gleichläme, ist ihr ebenso bewußt wie ihrem Widersacher Gardiner und dessen Werkzeug Beddingfield. Beddingfield vermutet, wenn man sie nur erst nach Frankreich schaffen könne, „So wird vergessen sie und ungefährlich“; Gardiner erkennt: „Vergessenheit, das ist der wahre Tod!“ (301, Hervorhebung der Autorin)

Die Angst vor der Vergessenheit überfällt Elisabeth in der Regel dann, wenn sie vermutet, daß ihre Hinrichtung kurz bevorsteht; in einer solchen Szene hadert sic mit Gott, den sie anklagt, „Daß Du mich jetzt [...]/ Ruhmlos und schnell vergessen, aus der Bahn/ Die Du mir in der Wiege vorgezeichnet,/ Hinwegnimmst [...]/ gleich dem Veilchen,/ Das unbemerkt ein roher Fuß zertritt“ (332). Denn der ihr „bestimmte[...] Zweck“" ist keineswegs, unbemerkt zertreten zu werden, sondern „Erhabenes zu schaffen":

Dies Auge - das mit scharfen Adlerblicken

Des Völkerschicksals Gang, die Weltgeschicke

Geprüft, belauscht, und sich vermessen schon,

Der fernsten Zukunft Früchte zu erkennen,

$[\ldots]$

Dies Auge sollte jetzt im Tod sich schließen,

Bevor sein Wink ein Werk hervorgerufen,

Auf dem es, brechend, noch mit Stolz verweilt? (332

Hervorhebungen der Autorin)

Da aber nach ihrem Glauben „nichts Erschaff'nes zwischen Erd' und Himmel/ Sich zwecklos in der eig'nen Bahn bewegt" (332), hält sie eine solche Verschwendung ihrer
Fähigkeit zum Erhabenen für unmöglich. Was Beddingfield in ominösem Ton auf ihre Ablehnung des Heiratsplans erwidert - „So nehmt denn Euer Loos; Ihr habt's ge-

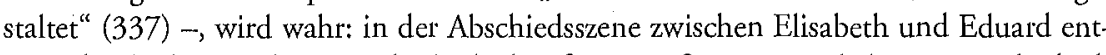
sagen beide ihrer Liebe, um Elisabeths künftige Größe zu ermöglichen. Wie Elisabeth weiß Eduard, daß die Verbindung mit dem Mann, das alltägliche Schicksal der Frau, sie von allem Außerordentlichen ausschließt: „Geschlechtslos ist der Geist, der in Di wohnt; / Er darf dem Alltagsloose nicht verfallen, / Das sich an der Geschlechter Schwäche knüpft“ (348). Elisabeth gibt ihm recht: „Das Dasein ist nicht werth, durchlebt zu werden, / Wenn großen Geistern es zum mächt'gen Wollen/ Nicht auch die Vollmach zum Vollbringen bietet./ Die Vollmacht aber - was kann anders sie,/ Als Kron' und Szepter sein?" (349, Hervorhebungen der Autorin) Das Alltagslos der Frau ist mit dieser Aufgabe nicht nur unvereinbar, sondern steht im Gegensatz dazu: „Verloren wäre England, würd' ich Dein!“" (351)

Letztendlich ist es Eduard, der in dieser Szene die Rolle des traditionellen „Weibes übernimmt: wie Vittoria Accoramboni entsagt er heroisch, weil er es nicht über sich bringt, „Die Tochter Englands aus den lichten Höhen/ Herab zu mir in's enge Thal zu zieh'n" (348), weil der „Sonnenaufgang Deiner Größe" (351) nur durch seine Entsagung Wirklichkeit werden kann. Wie Vittoria Accoramboni stirbt er, weil seine Aufgabe damit erfüllt ist - genauer: weil er sich ebenso über Elisabeth definiert wie Vittoria über Montalto. Eduard stirbt, weil er nur in ihr leben kann; bei seinem Abschied von Elisabeth trennt er sich

Vom Licht der Sonne - von jedwedem Hoffen,

Vom Athemzug, vom Pulsschlag [m]eines Lebens,

Von Dir, Elisabeth - denn Licht und Hoffen

Und Athemzug und Pulsschlag bist Du mir!

Ich werde leben - doch der Pflanze Sein

Wenn ich Von Dir in ew'ge Nacht nun gehe,

Bin sterbend ich - ob auch der Leib bestehe! (347, Hervorhebung der Autorin)

Elisabeth dagegen überlebt als Herrscherin, in ihr stirbt nur die Frau. Die von Eduard übernommene weibliche Rolle gibt sie auf, weil sie mit ihren Plänen nicht vereinbar ist. „Was zu dem Mann das Weib allmächtig zieht,/ In mir ist's todt!“ (352) Was Eduard gegenïber als ewiger Treueschwur geäußert wird, ist gleichzeitig eine politische Entscheidung, ein Zeichen, daß sie die von Maria gelernte Lektion verstanden hat: „Als Jungfrau steigt Elisabeth in's Grab!" (352, Hervorhebung der Autorin)

Eduards Pflanzendasein wird kurz vor ihrer Thronbesteigung im Nachspiel beendet. Im Kontext des Stückes ist sein Tod notwendig, damit, in Cecils Worten an Elisabeth, „ein neues Leben Dir beginne,/ Damit kein Traumbild - nicht ein Schatten mehr/ Sich dränge zwischen Dich und Deine Größe" (368). Elisabeth, nun endgültig gezwungen, "stärker, als ihr ganz Geschlecht" (371) zu sein, erleidet bei der Todesnachricht einen kurzen Rückfall in die Weiblichkeit: „Die Größe ist ein Götterbild - von Stein!l (In Thränen ausbrechend): Nur einmal - einmal laßt noch Weib mich sein!“ (371, 
Hervorhebungen der Autorin) Aber ihre Verzweiflung ist von kurzer Dauer; direkt darauf kündigt ihr das Glockengeläute den Tod Marias an. Elisabeths „Züge verlklären sich allmälig in begeisternder Ahnung" (Bühnenanweisung 372), noch bevor der Zug der Noblen eintritt, um ihr die Krone anzubieten. Nun hat sie die Gelegenheit, „Ein Blatt der Weltgeschichte“ zu beschreiben (373). Ihre Pose am Ende des Stückes bestätigt die Richtigkxeit ihrer Entscheidung: „Sie steht hoch aufgerichtet, mit stolzem Selbstbewrußsein, und hält die Krone empor" (Bühnenanweisung 374), als der Vorhang fällt.

Was Birch-Pfeiffer hier aufs Theater bringt, ist in Dramen männlicher und zum groBen Teil auch weiblicher Autoren unerhört: eine Frau, die ihre "Weiblichlkcit“ zugunsten ihrer politischen Handlungsfreiheit aufgibt, die dafür nicht einmal mit dem Tod bestraft wird und die am Ende des Stückes auch nicht die Spur von Reue zeigt. In Dramen von Frauen ist, wie wir gesehen haben, die Unvereinbarkeit von weiblichem Privatglück, die nur durch Abhängigkeit zu erkaufen ist, und öffentlicher Handlungsfreiheit ein ständiges Thema. In Dramen von Männern wird dieses Thema leicht abgewandelt: hier geht es meist um die Unvereinbarkeit von Weiblichkeit und Macht überhaupt, woraus häufig der Schluß gezogen wird, daß Frauen zur Ausübung politischer Macht nicht befähigt sind. Wo Frauen in Dramen männlicher Autoren ihre „Weiblich-

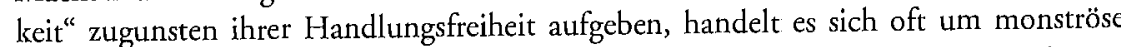
Zwitterwesen, die die Unnatürlichleit solchen Tuns klar zu Tage legen - man erinnere sich nur an Schillers wenig schmeichelhafte Darstellung von Elisabeths Geschlechtslosigkeit in Maria Stuart. In Dramen von Frauen wird die Machtübernahme oder Unabhängigkeit von Frauen als problematisch - nie als unnatïrlich - dargestellt. Beispiele, in denen die Entscheidung der Frau zugunsten ihrer Unabhängigkeit - und das heißt auch hier: Geschlechtslosigkeit durch Aufgabe der „weiblichen“ Rolle - in dieser Weise gefeiert wird, finden sich auch bei ihnen selten. Birch-Pfeiffer beschreibt das Uncrhörte anhand von Elisabeths Beispiel und kann es sich erlauben, denn die Geschichte, die einzige Institution, deren Urteil sich auch ihre Heldin unterwirft - „Die Nachwelt ist's, die über Kön'ge richtet!" (374) - bestätigt Elisabeths Entscheidung. Letztendlich läßt sich Schillers Idee von der Unnatürlichkeit weiblicher Macht in seinem Stück nur dadurch aufrechterhalten, daß er seine Elisabeth mit all den negativen Charaktereigenschaften ausstattet, die Birch-Pfeiffer ihrer Maria Tudor zuschreibt. Birch-Pfeiffer dagegen laann Elisabeths Entscheidung, Erhabenes zu schaffen, schon deshalb so positiv darstellen, weil sie auf das - historisch gut dolkumentierte - goldene Zeitalter unter Elisabeth I. nur hinzuweisen braucht.

b. Müller.

In historischen Dramen anderer Autorinnen steigen die Heldinnen nicht zu Elisabeths Größe auf, aber sie erhalten sich ihre persönliche Unabhängigkeit, indem sie eine ähnliche Entscheidung fállen wie sie. Ihnen wird in der Regel dieselbe Falle gestellt wie Anna Boleyn; aber indem sie an der entsprechenden Stelle den Antrag des Mannes ablehnen, entgehen sie Boleyns Verhängnis. Elisabeth Müllers (1827-1898 ${ }^{44}$ Anna von Cleve oder Die Gürtelmagd der Königin (1881) ist die Gegengeschichte zu Elisabeths von Rumänien und Kremnitz' Anna Boleyn, und zwar durch eine Verdrehung geschichtlicher Tatsachen: die historische Anna von Cleve soll von Heinrich VIII nach England bestellt worden sein, weil er sich in ihr Bild verliebte; sie wurde kurz darauf verstoßen, weil sie diesem Bild nicht entsprach. ${ }^{45}$ Bei Müller versucht Anna selbst, mit allen Mitteln der Ehe mit dem mittlerweile berüchtigten König zu entgehen. Zu diesem Zweck heckt sie mit ihrer Amme Gertrud einen Plan aus: statt ihrer soll die Näherin Walburg, die Anna täuschend ähnlich sieht, die Rolle der Braut übernehmen; Anna selbst soll ihre Zofe spiclen. Walburg, die uneheliche und nicht anerkannte Tochter des Herzogs von Cleve und der Gürtelmagd der Herzogin, ist mit diesem Plan einverstanden, weil sie mit ihrem Stand unzufrieden ist und sich in Machtträumen wiegt. Heinrich ist von der wenig anmutigen und ungebildeten Walburg tief enttäuscht und macht sofort Pläne, sie wieder loszuwerden; Anna dagegen findet an Heinrichs Hof einen Freund wieder: Hans Holbein, der das Bild malte, das an Heinrichs Heiratsplänen schuld ist, und der sich bei dieser Gelegenheit in Anna verliebte. Als Heinrich die Ehe mit Walburg löst und sie auf ein Schloß verbannt, folgt Anna ihr als ihre Gürtelmagd. Schließlich flieht Walburg, unwillig, ihre Rolle länger zu spielen, und Anna muß die Rolle der verstoßenen Königin übernehmen.

Der gesamte erste Aufzug dient dazu, Heinrich als genau das darzustellen, was Anna in ihm vermutet: ein „Ungeheuer - ja, das ist er!/ Der seine Frauen mordet, sie verstößt, / Nach seiner Willkür " (22). Ihren Bruder, den Herzog Wilhelm, fleht sie an, ihn nicht zu dieser Ehe zu zwingen; er aber verkauft sie aus Gründen der Staatsraison: er braucht ein Bündnis mit Heinrich, um seine politischen Händel zu schlichten. Gegen diesen Zwang, das „Beweinenswerthe[...] Loos der Fürstentöchter“ (27) lehnt Anna sich auf:

Ein Seelenhandel ist's -, im besten Fall

Gibt man sie einem Fürsten, herzensfremd;

Und einem Mann, den nie ihr Auge schaute,

Muß reichen sie zum ew'gen Bund die Hand. $[\ldots]$

Sie hat das Recht nicht, Herz und Hand zu schenken

Dem, den sie liebt, aus eig'ner freier Wahl.

Ja, selber ihre Freiheit zu bewahren,

Ist nicht erlaubt ihr; niemand fragt danach,

Ob würdig, ob unwürdig der Gemahl.

$[\ldots]$

Ein willenloses Wesen, - ein Artikel

Ist sie, mit der dic Staatskunst Handel treibt (27, Hervorhebung der Autorin).

Nach einer langen Debatte, in der Wilhelm versucht, Heinrichs Justizmorde, die Anna als „plumpe Heuchelei“ (23) durchschaut, zu rechtfertigen, beendet Wilhelm das Gespräch durch simplen Zwang: "Wenn ich befehle, hast Du zu gehorchen" (26). Da er als Mann, meint, die Wirklichkeit besser beurteilen zu können als sein grillenhaftes, da 
weibliches Gegenüber, bleibt ihm nichts anderes übrig, als das Machtwort zu sprechen, das sie zu ihrem Glück zwingt.

Genug des Unsinn's jetzt, der Ueberspanntheit! Willst auf vernünft'ge Gründe Du nicht hören, So muß ein Machtwort enden allen Streit.

So sind die Weiber! Zwingen muß man sie

Zu ihrem eig'nen Glück; doch ist's gescheh'n,

Und nicht zu ändern mehr die schlimme Sache,

Sind mit dem Schicksal sie meist wohlzufrieden.

Drum wirst auch Du Dich fügen, Anna! Traun,

Es wird am brit'schen Hof Dir schon gefallen (28, Hervorhebung der Autorin).

Anna allerdings weiß es besser und ist nicht gewillt, sich als Artikel der Staatskunst verschachern zu lassen. Gertruds Plan scheint ihr der einzige Ausweg, da sie auch von ihrer Mutter keine Unterstïtzung zu erwarten hat:

[...] ihres Sohnes Größe

Geht über Alles ihr; für seine Wohlfahrt

Scheint ihr kein Opfer allzuschwer zu sein,

[...]

So fordert sie ein Gleiches auch von mir;

Und scheltet störrisch mich und eigensinnig,

Da ich die Sache anders sehe an.

[...]

Von Mutterliebe schwillt das Herz ihr nur,

Wenn sich's um Wilhelm, meinen Bruder handelt

(31, Hervorhebungen der Autorin).

Annas Entschluß, nicht zu heiraten, ist in ihrer Angst vor dem Ungeheuer Heinrich und in ihrem Willen, unabhängig zu bleiben, begründet, nicht in ihrer Liebe zu einem und in ihrem Willen, unabhängig zu bleiben, begründet, nicht in ing and abgewiesener Bewerber (33), auf kindliche Träume vom Märchenprinzen (32) und auf einen Tanz mit einem echten Prinzen, der ihrem Traumbild entspricht (32). Aber diese Träume vom Märchenprinzen verwechselt sie nicht mit ihrer Realität; auf Gertruds Vermutung, sie würde lieber diesen Prinzen heiraten als den „finstern engeländ'schen König“ (33), antwortet sie kühl: „Der Prinz begehrt nicht mein,/ Er hätte anders längst um mich geworben“ (33). Anstatt auf Rettung durch diesen imaginären Märchenprinzen zu hoffen - der nach dieser Szene nicht wieder erwähnt wird -, besteht Anna auf der Freihei der eigenen Wahl und auf ihrer. Weigerung, sich als willenloses Wesen zwangsverheiraten zu lassen. Gertrud begründet im Gespräch mit Walburg Annas Verzicht auf die Königswürde damit, „Daß keinem Andern sie gehören will,/ Als dem Geliebten, den ihr Herz erkoren,/ Wo nicht, sie will entsagen lebenslang/ Jedwedem Ehebunde" (44)
Um der Zwangsehe zu entgehen, ist Anna durchaus bereit, „irgendwo verborgen“ zu leben, „Zwar nicht im Fürstenglanz, so doch in Ruh"“ (37), und sich von ihrer Hände Arbeit zu ernähren: das „Scepter reizt mich nicht,/ Und gern vertausch' ich es um meine Freiheit,/ Sei's auch die Freiheit nur der Löhnerin“ (38).

Der Löhnerin Walburg scheint der Tausch ebenso vorteilhaft: sie fühlt sich vom Schicksal übervorteilt, denn auch sie ist "eine Herzogstochter nach dem Blute" (40, Hervorhebung der Autorin). Anders als Anna verliert Walburg sich in ihren Träumen; ihre Vorstellung vom Leben der Prinzessin könnte aus Grimms Märchen stammen. „Das wär' ein Leben voller Lust und Wonne:/ In Glanz und Freude schwelgen jeden Tag;/ In Sammt und Seide geh'n, Juwelen tragen,/ Und Leckerbissen, statt der magern Suppe -/ Was Alles ich nur wünsch' und haben mag $-/[\ldots] /$ Und keine Noth und Langeweile mehr!" (40) In diese Märchenträume mischt sich eine sehr reale Machtgier: „Und dann vor Allem - herrschen! - herrschen!/ Ein Höflingstroß, zu jedem Dienst bereit,/ Sich beugend vor mir, nach den Augen sehend,/ Bei meinem Stirnerunzeln schon zerknirscht -,/ Und eine Dienerschaar, des Winks gewärtig, -“ (40).

Aber Walburgs Träume erweisen sich nach ihrer Ehe mit Heinrich auf beiden Ebenen als Märchen: reale politische Macht hat sie nicht; und das Leben voller Lust und Wonne verkehrt sich in Walburgs Sklaverei unter den Regeln einer Etikette, die sie nicht versteht. Ihre anfängliche Naivität - „Kann ich nicht thun und lassen was ich will,/ Wofür dann bin ich Königin?“ (59) - verwandelt sich allmählich in die Erkenntnis dessen, was sie mit ihrem früheren Leben verloren hat: „Mein Leben dort [in Cleve, S. K.] war heiter und war frei" (60). Walburg wird von ihren Hoffartsträumen so gründlich kuriert, daß sie schließlich ihre frühere Dürftigkeit als Glück erkennt (71). Als Heinrich sie verstößt, ist sie so weit, „Daß ich mich glücklich schätze, noch so wohlfeil/ Mich loszukaufen wieder von dem Joch,/ Das mich erdrückte unter gold'nen Fesseln“ (69). Aber auch in der Verbannung wird sie ,auf Tritt und Schritt bewacht [...] Wie eine Staatsgefang'ne“ (70); sie will wieder "heim, nach Cleve, kehren,/ In meine Hütte! Arm zwar, aber frei“ (68). Anna versucht, sie daran zu hindern; ihrer Ansicht nach sind sie beide gleich schuldig. „Denn die Versuchung, die Dir nahte, fand/ Nur allzu williges Gehör. - Bekennen/ Laß' drum uns ehrlich, frei: Wir fehlten beide,/ Und beide müssen sühnen wir die Schuld" (71 f, Hervorhebungen der Autorin). Walburg aber ist anderer Meinung: sie schiebt Anna die Schuld zu, weil diese sie in ihren Illusionen belassen hat. Walburgs Ansicht nach hat Anna sie in eine Ehe geschickt, vor der ihr selbst graute, ohne einen Versuch zu machen, ihr die Schrecken dieser Ehe zu schildern. „Was wußte ich von König Heinrich denn,/ Als Gertrud mich zu diesem Schritt beschwatzte?/ Mir sagt' man nur, er sei ein mächt'ger Fürst;/ Daß er ein Wüth'rich sei, verschwieg man weislich./ Ihr aber wußtet's, - leugnet es nur nicht!" (72, Hervorhebungen der Autorin) Dieses Argument ist auch für Anna nicht von der Hand zu weisen: das Recht, das sie für sich selbst in Anspruch nimmt, das Recht der freien Wahl, ist Walburg vorenthalten worden, da diese ihre Wahl unter Voraussetzung falscher' Tatsachen getroffen hat. Thre Entscheidung, sich gegen die Zwangsehe zu wehren, kann Anna nach wie vor vertreten; was sie schuldig macht, ist „Nicht, daß ich überhaupt mein Recht vertrat,/ Die üble Wahl des Gatten zu verwerfen,/ Nein, daß 
ich selber wählte üble Mittel// Mich zu entzichen dem verhaßten Bund./ Die Mittel waren's" (80, Hervorhebungen der Autorin). Denn diese Mittel bestanden darin, die Ehe, die Unfreiheit, der sic entgehen wollte, auf dem Rücken einer anderen Frau abzuladen. Deshalb alkzeptiert sie Walburgs Urteil, das die Verhältnisse umkehrt: Walburg erhält ihre Freiheit zurück, Anna trägt die Gefangenschaft für beide.

Während Anna ihre Schuld an Walburg zugibt und ihre Gefangenschaft als Sühne dafür ansieht, ist ihr Bruder zu solcher Einsicht völlig unfähig. Als sie ihm kurz vor Ende des Stückes das ganze Komplott gesteht, versucht sie gleichzeitig, ihm klarzumachen, daß sein Plan, sie zu ihrem „Glück“ zu zwingen, die Ursache allen Übels ist:

Denn Deine Härte war das kleine Korn,

Aus dem der Baum des Unheil's üppig aufschoß;

[...]

Und seine Früchte - wirst Du mit mir theilen,

Wie Du auch theilst die Schuld, die ich beging.

Selbstsüchtig, wie Du bist, in Deinem Trotz,

Schiebst Du auf mich allein die ganze Fehle (78).

Das tut er, indem er sie verstößt - auf der Oberfläche, weil er ihren Betrug als Schandfleck auf dem Wappen der Clever sieht $(77 \mathrm{f})$, tatsächlich, weil Annas Verhalten ihn politisch lächerlich gemacht hat: denn inzwischen hat er den Kaiser und sämtliche deutschen Fürsten zusammengerufen, um sich an Heinrich für die Verstoßung seiner Schwester zu rächen. Seine Hauptsorge ist die um seinen guten Ruf: „Was wird der Kaiser, was die Fürsten all'/ Vom Clever denken, dem sie sich verbanden/ Zu Schutz und Trutz, wenn heim er kehrt, ein Lämmlein,/ Dem unterwegs die Wolle ward geschoren!" $(70)$

Annas Sühne", ihre Gefangenschaft für Walburg und der brüderliche Fluch, haben beide eine Kehrseite. In ihrem Verhältnis zu ihrem Bruder hat sich durch den Fluch objektiv nichts geändert, denn durch ihre Flucht ,sagt' ich selbst mich los/Von allen Banden“; damals "Schien mir's nicht schwer, das Vaterhaus zu meiden,/ Wo man so kalt und lieblos mir gesinnt" (79). Wilhelms Fluch nimmt ihm dic Autorität, sie beliebig weiterzuverhciraten und entbindet sie offiziell von der Pflicht des Gehorsams ihm gegenüber. Auch wenn Anna ihre Gefangenschaft mit allen Anzeichen der Reue antritt, ist dieses Gefängnis der Ehe mit Heinrich zweifellos vorzuziehen, denn „nicht groß ist die Gefahr", wie Walburg erklärt, und Besuche Heinrichs hat sie nicht zu fürchten (73). Auch wenn sie am Ende des Stuickes ihre Handlungsweise verdammt "Die Schuld erlöset nicht" (80) - objektiv gesehen war sie durchaus effeltiv: die Ehe mit Heinrich hat sie ihr erspart. In der letzten Szene wird angedeutet, daß Annas Gefangenschaft nur eine temporäre sein könnte: Holbein ermutigt sie mit der Hoffnung, "daß schön're Tage Euch noch blüh'n:/ Nach finstern Wolken, heit're Sonnenblicke“; und Anna nimmt diesen ihr von Gott gesandten Freund als „Zeichen [...] seiner Huld,/ Die der Verlaß'nen gnädig sich erbarmet" (82). Ob Gott sich erbarmt oder nicht, läßt das Stück offen; immerhin wird hier eine Hoffnung ausgedrückt, die in der
Ehe mit Heinrich vergeblich wäre. Was Anna bleibt, ist die Möglichlkeit der Befreiung, eine Möglichkeit, die am Ende des Stückes nähergerückt scheint als am Anfang.

\section{c. Wickenburg.}

Eine ähnliche Momentaufnahme im Leben einer historischen Figur zeigt Wilhelmine von Wickenburg (1845-1890) in ihrem Einakter Radegundis (1879). Der Entscheidungsmoment zwischen Ehe und Unabhängigkeit wird in ihrem Stück wesentlich dramatisiert, wieder durch eine Änderung der Geschichte. Radegundis (520?-587) war eine Nonne, die im Gallien des sechsten Jahrhunderts als Heilige verehrt wurde und deren Leben von zwei zeitgenössischen Biographen, Schwester Baudovinia und dem Dichter Venantius Fortunatus (ca. 536-600), beschrieben wurde. Diesen Chroniken zufolge heiratete sie $538 \mathrm{n}$. Chr. gezwungenermaßen den fränkischen König Clothar Radegundis war scine fünfte Frau - und verließ ihn 552 unter dem Schutz des Bischofs Medardus, um ins Kloster zu gehen. ${ }^{46}$ Wickenburg unterschlägt Radegundis vierzehnjährige Ehe; bei ihr ist die Eheschließung und Radegundis' Entschluß das Werk eines Tages. Wickenburgs Clothar ist ein ähnlich brutaler Tyrann wie Heinrich VIII. in der Darstellung Elisabeths, Kremnitz' und Müllers. Wie in der Chronik wird Radegundis zur Ehe mit ihm gezwungen ("Vita S. Radegundis Reginae“ 498 f). An Clothars Hof muß sie sich nicht nur gegen die Brutalität des Königs wehren, sondern auch gegen die Intrigen der verlassenen Ingundis (so hieß Clothars dritte Frau). Sie lernt Venantius Fortunatus kennen; beide verlieben sich ineinander (Fortunatus' Bericht zufolge lernte er sie erst im Kloster kennen). Thre Liebe zu Fortunatus ist der Grund, mit dem sie Medardus überzeugt, dic Ehe zu lösen; Clothar läßt sich von Ingundis überreden, sie gehen zu lassen. Fortunatus schließlich entsagt seiner Liebe und weiht ihr ein „Erinnern/ Begehrlos und wie ein Gebet so rein“ (66).

Durch ihre Entscheidung emanzipiert sich Radegundis von der Ergebung in ihr Schicksal, die ihr reihum gepredigt wird - unter anderem von der Äbtissin, die sie Clothar ausliefert, und von Medardus. Obwohl Radegundis von der Ermordung früherer Königinnen durch Clothars verlassene Frauen gehört hat, hofft die Äbtissin, ihre Schönheit und Güte würden sie vor gleichem Schicksal bewahren. Andernfalls, so tröstet sie die Äbtissin, sei es sinnlos, sich gegen das ihr bestimmte Schicksal aufzulehnen; im Gegenteil: „der Weiseste ist der,/ Der ohne Furcht, geduldig es erwartet" (4, Hervorhebung der Autorin). Auch Medardus predigt ihr eine wenig anzichende Lebensphilosophie: ihr Hochzeitstag - „Der heiligste im Leben eines Weibes“ - ist der, „Wo Du zum Opfer bringst des Magdthums Freiheit/ Und nach der Schrift, dem Manne unterthänig,/ Ihm Treue und Gehorsam schwören willst" (23 f). Radegundis’ Verhängnis scheint doppelt unentrinnbar, weil sie, wic Anna Boleyn, „Dein ganzes Leben einem Manne weihst,/ Der doppelt Dein Gebieter ist: Als Gatte/ Und König!" (25) Dieser künftige Gebieter poltert auf die Bühne, beleidigt die Äbtissin, droht, seine Hunde auf sie zu hetzen, versichert Radegundis, sie könne ihm nicht entkommen, stellt ihr Venantius vor und überläßt diesem die weitere Werbung (6-12). Bis nach der Hochzeit tritt Clothar nicht mehr in Erscheinung, danach besteht ein Großteil seiner Beschäftigung mit ihr darin, daß er versucht, sie zum Trinken zu zwingen $(40 \mathrm{f}, 55)$. 
Was Clothar vor allem von ihr verlangt, ist blinden Gehorsam und Anpassung an seine Lebensart.

Das Weib, das ich zur Gattin mir erkoren

Zu leben lern' es auch nach meiner Art!

Ich brauch' ein Weib, das in den Wald mir folgt,

Das in dem Sattel besser sich behagt,

Als auf dem Betstuhl zwischen Kirchenwänden,

Das mir die Sonne von der Stirne scheucht

Und nach der Heimkehr mir die Tafelfreuden

Mit Lachen und mit frohem Plaudern würzt (43).

$\mathrm{Zu}$ alledem ist Radegundis denkbar ungeeignet; Radegundis' wcibliche Qualitäten, von Ventius unverhohlen bewundert - „diese holde Scheu“, "der höchste Reiz des Weibes", der "Zauber/ Der Schüchternheit" (10) -, gehen Clothar auf die Nerven: er hört nur "Gewimmer" (6) und hat es schnell satt, "Hier diesen beiden scheuen blauen Augen/ Durch meine Nähe Thränen zu erpressen" (11).

Gegenüber den Zwängen, denen Radegundis ausgesetzt ist - symbolisiert durch Clon sanktioniert von Medardus und der Äbtissin - ist Venantius der einzige, der ihr eine andere Lebensphilosophie als die der Ergebung in das Unabwendbare zu bieihr eine andien ten hat, nämlich den, ,suße[n] Glaube[n] an des Lebens Pracht (22). Diesen Glauben hat Radegundis verloren, denn der Frühling ihres Lebens geht direkt in den Herbst über: bereits als Kind wurde sie Clothars Kriegsbeute, fand kurze Zuflucht im Kloste und wird jetzt ausgeliefert, da Clothar sie heiraten will. ${ }^{77}$ Für sie ist das Kloster die ein-

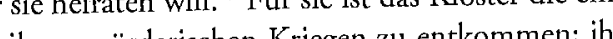
zige Möglichkeit, der Außenwelt und ihren mörderischen Kriegen zu entkommen; ih "Frühling", der Beginn ihres Lebens, besteht in der Erinnerung an den Krieg; die Ehe mit Clothar sieht sie als den „Herbst", das Ende ihres Lebens.

Der Lenz ist Anfang und der Herbst ist Ende,

Doch blütenarm ist einer, wic der andre;

Der sagt: ,Noch nicht!' und jener sagt: ,Nicht mehr!

Und mir, mir rief das Leben zu: ,Nicht mehr!'

Eh' das ,Noch nicht!' verklungen war und ehe

Noch mit der Lerche fröhlichem Geschmetter

Es an mein trunknes Ohr gelklungen: Jetzt!' (20 f)

Venantius denkt anders, weil er nicht an die unbedingte Ergebung in das Unabwend-

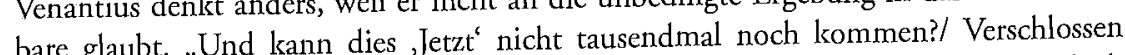
bare glaubt. „Und kann dies ,Jetzt nicht tausendmal noch kommen?/ Verschlossen sind noch ungezählte Knospen/ An Eures Lebens reichem Blütenstrauch!/ Laßt doch den Glauben Euer Herz erfüllen/ An einen Sonnenstrahl, der sie erschließt"' (21) Damit rät er ihr keineswegs zur Rückkehr ins Kloster, denn „auch die Erde fordert ihre Rechte/ Und will, daß ihre Kinder glauben sollen/ An eine Seligkeit in ihrem Herzen " (21). Dieses „Jetzt" aber ist für Radegundis nicht realisierbar; für sie existiert nur der
Unterschied zwischen Krieg (Außenwelt) und Frieden (Kloster) (41). Nicht das Kloster, sondern das Leben außerhalb ihrer Zelle, die Ehe mit Clothar, ist für sie gleichbedeutend mit der ihr von Medardus und der Äbtissin anbefohlenen Ergebung.

Das Leben im Kloster bedeutet für sie nicht Entsagung, sondern die Flucht vor de Zwang, der ihr in der Ehe angetan würde - gegen die ihr angebotene Stellung der Königin hat sie nichts einzuwenden, nur gegen den Mann, durch den sie diese Stellung erhält. In einer Welt, von Menschen wie Venantius bevölkert, könnte es ihr durchaus „gefallen,/ Die Stirne mit der Krone mir zu schmücken,/ Zu heißen dieses Landes Königin“ (14). So aber beherrscht sie „Die Sehnsucht [...] nach meiner Klosterzelle“ (15). Was Venantius' ihr von des Lebens Blütenpracht vorschwärmt, bringt ihr ihre Version dieses Traumes, den Frieden, wieder zu Bewußtsein: „Nach Frieden trachtet meine arme Secle/ Und Liebe ist das Ende alles Frieden " (56). Radegundis ist weder imstande, Venantius' blütenreichem Weg zu folgen - da er ihr keinen Frieden verspricht noch laann sie sich Clothar „ergeben“ (57); was bleibt, ist ihre eigene Alternative, zu der sie Medardus schließlich überredet. Sowohl ihre Entscheidung als auch ihr Weg sind ihre eigenen; was sie Venantius verdankt, ist, daß er ihr die Alternative bewuß machte - indem er Medardus' und der Äbtissin unbedingter Ergebungsphilosophie ein Leben entgegensetzte, wie es sein könnte. „Du hast den Blick in's Leben mir erschlossen,/ Nimm meinen Dank, daß Du's bei Zeiten thatst!" (66)

Der Frieden, den sie findet, ist wahrscheinlich ein bedingter. Clothar entläßt sie mit einer Drohung: „Auch die Klostermauern/ Sind einem guten Schwert nicht undurchdringlich!" (65 f) Diese Drohung ist historisch untermauert: nach den Chroniken versuchte Clothar mehrere Male vergeblich, Radegundis aus dem Kloster zurückzuholen ihr Kloster wurde schließlich 587 n. Chr. (nach Radegundis' Tod) von fränkischen Truppen zerstört. Aber wie in den meisten historischen Stücken über Frauen geht es hier nicht um den Ausgang, sondern um den Moment der Entscheidung zwischen privater Abhängigkeit und öffentlicher Wirksamkeit. Alles andere wird dem Urteil der Nachwelt überlassen - und die historische Radegundis war eine der berühmtesten Heiligen ihrer Zeit.

C. Nachwort auch zur Geschichte des Mannes Pichler, Franul, von Weissenthurn, Wesendonck, Schmidt

Geschichtliche Dramen und Tragödien über männliche Figuren sind grundsätzlich von anderen Motiven beherrscht. Zunächst besteht bei Männern wie Peter dem Großen, Macchiavelli, Ulrich Zwingli und Hermann dem Cherusker weniger die Notwendigkeit, sie vor Vergessenheit zu bewahren. Viele historische Stücke von Frauen über Männer entstanden in den Jahren nach Napoleons Abzug, zwischen 1813 und 1817, und sind von patriotischen Themen geprägt: meist geht es um die Beschwörung versunkener deutscher (d. h. hier: deutsch-österreichischer) Größe; der Charalster dieser Stïcke ist oft ein direkter Appell an die deutsch-österreichische Nation, sich dieser Größe wieder bewußt zu werden. Beispiele sind Caroline Pichlers (1769-1843) 
Heinrich von Hohenstauffen, König der Deutschen (1813), Ferdinand der Zweyte, König von Ungarn und Böbmen (1816), Germanicus (1813) und Rudolph von Habsburg (o. J., zuerst veröffentlicht 1818) und Johanna Franul von Weißenthurns Johann, Herzog von Finnland (1810) und Hermann (1813). Wo diese Helden untergehen, sterben sie durch Verrat und Meuchelmord (Heinrich von Hohenstaufen und Germanicus); alle

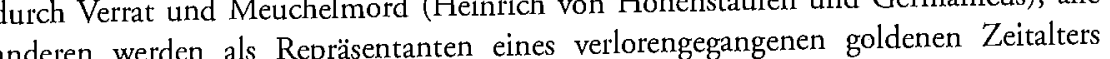
auf Phänomen wieder auf, so z. B. in Wesendoncks Friedrich der Große (1871). Um die

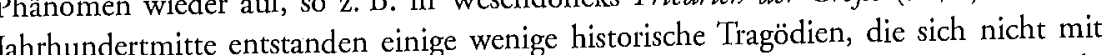
deutschen oder germanischen Helden beschäftigen (Elise Schmidts (1824- ?) Peter der deutschen oder germanischen Helden beschaftigen (Lise Sch Dramen wird die Macht Große und sein Sohn und Macchiavelli, beide o. J.). In diesen Dramen wird die Macht der männlichen Potentaten ebensowenig angetastet; dargestellt wird, welche Opfer sie fordert. Ähnlich wie Götzes Montalto sind Peter der Große und Macchiavelli gezwunfordert. Xhnlich wie Gôn Mandlungsfreiheit ihr Privatglück zu opfern: Peter läßt seinen gen, ihrer politischen Handlungsfreiheit ihr Privatglek zu opfern: Peter laß seinen Sohn wegen Hochverrats hinrichten; Macchiavelli kompromittiert seine politischen Überzeugungen, um sich seine Handlungsfreiheit zu erhalten. Aber in beiden Fällen wird der Held des Dramas durch die Umstände zu seinem Opfer gezwungen; der prinzipielle Widerspruch zwischen Politischem und Privatem, der die Entscheidung der historischen Heldin bestimmt, existiert hier nicht.

Daß diese aus der männlichen Dramentradition bekannte Behandlung männlicher Geschichte als weitaus harmloser empfunden wurde als die Bearbeitung der unterdrückten oder verfälschten Geschichte der Frau, zeigt ein Blick auf die Pseudonyme der Autorinnen. Sämtliche mir zugänglichen historischen Dramen über Männer wurden unter dem vollen Namen der Autorin veröffentlicht; dagegen benutzten Autorinnen von Dramen, die sich mit der Geschichte einer Frau befassen, weitaus häufiger Pseudonyme. Unter ihrem Namen veröffentlichten meines Wissens nur Birch-Pfeiffer Ebner-Eschenbach, Kempner und Wickenburg. Hinter einem neutralen Pseudonym verbargen sich Elisabeth von Rumänien und Marie Kremnitz (Dito und Idem), Auguste Götze (A. Weimar) und Elisabeth Müller (E. Meruell); Engel Christine Westphalen veröffentlichte donyme finden sich (Arthur Freese für Laura Steinlein und Franz Siking für Henriette Strauss). Darin liegt vielleicht ein Paradox, vielleicht auch nur ein Ausdruck des Geschichtsbewußtseins der Verfasserinnen, das ihre Stücke inspirierte: gerade Autorinnen deren Hauptinteresse es war, die unterdrückte Geschichte anderer Frauen aus der Versenkung zu holen, begaben sich selbst in die Anonymität.
KAPITEL VI

Pygmalions Erben: Dramen Über Kưnstler und Musen

Wie historische Stücke sind Künstlerdramen ein Genre des 19. Jahrhunderts; ebenso wie in historischen Stücken behielten sich die Autorinnen das Recht vor, die Geschichte des Künstlers oft recht frei nachzuerzählen. Während die Frau in der dramatisierten Geschichte eine wichtige, wenn auch meist tragische Rolle spielt, fehlt sie in der Kunstgeschichte fast völlig: von 14 ermittelten Künstlerdramen zwischen 1806 und ca. 1890 behandelt nur ein einziges - mir nicht zugängliches - eine Künstlerin: Emilic von Binzers (1801-1891) Karoline Neuber, 1847 veröffentlicht unter dem Pseudonym „Ernst Ritter". Mit dieser einzigen Ausnahme geht es in Künstlerdramen von Frauen um männliche Künstler: um Petrarca (in Westphalens gleichnamigem Stück, 1806); Fra Bartolomeo (Birch-Pfeiffer, Fra Bartolomeo der Maler, oder Das Stift zu Worms, 1829); Rembrandt (Caroline Bernsteins [1797-1838] Rembrandts Meisterstiick, 1834); Gutenberg und Rubens (Birch-Pfeiffer, Johannes Guttenberg, 1834; und Rubens in Madrid, 1836); Dürer (Caroline Piersons [1811-1899] Meister Albrecht Dürer, 1840); Michelangelo (Gisela Grimms [1827-1889] Trost in Thränen, 1857); Byron (Schmidt, Der Genius und die Gesellschaft, o. J.); Platen und Molière (Auguste Cornelius' [18261891] Platen in Venedig, 1865; und König und Dichter, 1865); Mozart (Maria Arndts' [1823-1882] Mozart als Ehestifter, 1869); Schiller (Ebner-Eschenbach, Doctor Ritter, 1869); Goethe (Levi, Aus Goethes lustigen Tagen, 1876); und Pietro Manolo (Elisabeth von Rumänien, Meister Manole, 1892).

Warum selbst künstlerisch tätige Frauen sich augenscheinlich nur für männliche Künstler interessierten, ergibt sich aus ihrer Behandlung der Künstler. und aus ihrer Darstellung der Entstehung männlicher Kunst: wie sich herausstellt, hatten dic Autorinnen mehr Interesse an der Muse des Künstlers als an diesem selbst. Diese Muse aber ist, wie ihre neun griechischen Vorgängerinnen, per definitionem weiblich; durch den Musenkult verschafft die Frau dem Manne - und nicht umgekehrt - die nötige Inspiration. Die Darstellungen der Musen und Künstler gleichen sich in ihren Dramen erstaunlich, denı dieses Verhältnis erlaubt nur wenige Möglichkeiten. Der Künstler ist fast überall ein leidender (einzige Ausnahme ist Mozart in Maria Arndts' Lustspiel Mozart als Ehestifter). Sein Leiden besteht überall sonst in einer unglücklichen Liebe; teilweise ist er zusätzlich mit einer Ehefrau, einer verständnislosen Anti-Muse, geplagt (Piersons Dürer; Schmidts Byron, Birch-Pfeiffers Gutenberg). Der Künstler entsagt seiner Liebe zugunsten seiner Kunst (Cornelius, Platen in Venedig; Birch-Pfeiffer, Johannes Guttenberg und Rubens in Madrid; Ebner-Eschenbach, Doctor Ritter; Pierson, Meister Albrecht Dürer; Schmidt, Der Genius und die Gesellschaff; Westphalen, Petrarca; Elisabeth von Rumänien, Meister Manole). Entsagen muß er, da seine Liebe meist schon anderweitig vergeben ist (Westphalen, Schmidt, Pierson, Birch-Pfeiffers Rubens, Cornelius' Platen). Der Künstler löst das Problem, indem er seine Liebe zu der Frau auf die Kunst überträgt (Westphalen, Ebner-Eschenbach, Birch-Pfeiffers Rubens, Cornelius' 
Platen); aus seiner Geliebten wird seine Muse (Westphalen, Birch-Pfeiffers Rubens, Cornelius' Platen, Pierson). Die Rolle der Frau als Muse des Künstlers aber schließ Consch aus, denn die Muse ist nichts anderes als das Bild des Künstlers - im wörtlichen oder übertragenen Sinne.

Dieses Bild hat nichts mit dem Original selbst zu tun: wie Pygmalion macht sich der Künstler ein Bild der Frau, verliebt sich in seine eigene Schöpfung und belebt sic nach Gutdünken. Um sich dieses Bild erhalten zu können, d. h. um sicherzugehen, daß sein Bild (Muse) von der Realität (Frau, Mensch) unbeeinträchtigt bleibt, muß die Muse für den Künstler unerreichbar bleiben. Während ihr Bild in seiner Kunst weiter" ${ }^{*}$ " kostet der realen Frau ihre Transformation zur Muse meist das Leben: sie stirbt "lebt Westphalen, Schmidt, Elisabeth von Rumänien), verschwindet spurlos (in BirchPfeiffers Rubens), oder geht ins Kloster (Pierson); oder das Ende des Stückes garantiert die Unerreichbarkeit der Muse für den Künstler auf weniger brutale Weise (EbnerEschenbach, Cornelius' Platen).

\section{A. SChriftSTeller: WeStPHAlen, SCHMidT}

Viele Künstlerdramen von Frauen nehmen diesen Prozeß erstaunlich wörtlich: dargestellt wird die Vollendung des männlichen Kunstwerks/Künstlers durch Abbildung bzw. Verbildlichung der Frau. In Engel Christine Westphalens Petrarca $(1806)^{48}$ sieht Petrarca Laura zum ersten Mal in der Kirche: er betrachtet, von Andacht hingerissen, Petraild de er wie die Mutterdas Bild der Madonna; gleich darauf falle sein Blick auf Laura, de ex wie die Mutergottes als Bild, als „Engel“ sieht und seinem Freund Francesco gegenüber mit ähnlichen Begriffen beschreibt (9-12). Dieses Bild ist sein „süsser Traum“ (12), der, „in tichen sich ergiesst" (14); und hat, wie Petrarca selbst gesteht, mir verschlossen, mit der realen Laura weniger zu tun als mit seinem Bild: wenn seine Lieder göttlich sind, hat „Die Liebe, dieser Göttlichkeit, allein,/ Die Seele der Empfindung angeind, " (14). Francesco, im Glauben, Petrarca rede von einer menschlichen Liebe, hauch!" (14). Francesco, in Gluben, Petraca sieht darin eine gewisse Gefahr für die verheiratete Laura. „Du denkst nur dich , wirft er Petrarca vor, "doch nicht ein and'res Herz,/ Das, ruhig itzt, einst schuldbewusster, schlägt,/ Durch deiner Flamme rasche Gluth entzündet" (15). Aber Petrarca sieht nur sein Bild und dieses Bild ist das der göttlichen Muse, die selbstverständlich über solche irdischen Anwandlungen erhaben ist.

Den Geist, der dieser Lichtgebornen ward,

Hat, frevelhaft, ein Schatte nie verdunkelt!

Der angebornen Grösse nahet keiner! -

Den zarten Sinn beschützt sein eignes Wesen! -

[...]

Sie zeigt die Harmonie der ew'gen Schönheit,

Die nie ein fremder Misslaut unterbricht (16f).
Laura, die Muse, ist Sinnbild der ewigen Harmonie, die in den Liedern des Dichters Petrarca wiederkehrt; für diese Inspiration opfert der Dichter die irdische Realität gern „Zu wahrer Göttlichkeit wird immer mehr/ In ihrer Nähe mein Gemüth geläutert./ Und wenn, was irdisch ist, die klare Flamme/ - Im Kämpfen mit der Neigung, mit der Pflicht -/ Zerstört, es sei!" (17) Was Petrarca bei der Vergöttlichung seiner Dichtung im Wege steht, ist Lauras reale Existenz als Frau: noch sind diese Kämpfe zu bestehen, noch finden sich irdische Elemente in seiner Verehrung für sie.

Die irdischen Elemente seiner Liebe, d. h. der Teil seiner Verehrung, der sich auf die Frau bezieht, werden auch für Laura zum Problem. Laura versteht sich als Petrarcas Muse, aber in anderem Sinne als der Dichter. Sie sieht ihre Aufgabe darin, Petrarca zum Dichter zu erziehen, sein "Genius" zu sein (33); für sie bedeutet die Muse nich etwa einen Gegenstand, der in seinen Gedichten verklärt wird, sondern die Erzieherin des Schwärmers zum Dichter. Petrarcas Leidenschaft, die sie in seinen Gedichten wiederfindet, hindert ihn an der dichterischen Vollendung - sie sieht ihn, mit Colonnas Worten, ,aus hohen Regionen,/ Wo frei sich nur der freie Geist bewegt,/ Durch Leidenschaft gelenkt herniedersinken,/ Ihr ew'ger Sklave" (193). Gleichzeitig hindert seine Leidenschaft sie daran, die erzieherische Aufgabe der Muse zu erfüllen, weil sie sie auf ihr eigenes Bild beschränkt und dieses Bild in seine Dichtung bannt. Petrarcas Gefühle empfindet sie als „Schwärmerei“ (27), als „Krankheit“, aber dieses „Feuer“ wird, so glaubt Laura, „bald verglimmen./ Nicht göttlicher Natur muß es verlodern" (28) Die Dichtung, die aus diesem irdischen Fener entsteht, beurteilt sie fast mitleidig: „ich nenn' es Laune,/ Wenn mich die Wahl der schönen Lieder trifft./ Den Dichter reißt ein Gegenstand dahin;/ Rasch fühlt er sich gelaunt, ihn zu besingen:/ [...] So wird dic Sterbliche durch ihn zum Engel" (34). Die dichterische Vollendung in Petrarca ist ihrer Ansicht nach nur durch eine Liebe möglich, die „dem Geistigen allein" gehört (29); nur eine solche Liebe kann „Begeistern sein Gefühl zur höchsten Höhe,/ Das SittlichSchöne zur Vollkommenheit" (33). Mit anderen Worten sieht Laura Petrarcas Werdegang als Dichter darin, daß er seine Leidenschaft für sie als Frau überwindet und sie als Muse - in ihrem Sinne - erkennt. In diesem erzieherischen Einfluß auf Petrarca liegt ihre Hoffnung auf Unsterblichkeit; sie will lieber als sein Genius verewigt werden als als Engel, dessen Bild sich durch seine Dichtung zieht. „Und wenn die Nachwelt ihn, bewundernd, ehrt;/ Wenn, spät, die Dankbarkeit aus Marmor spricht:/ So nenne sie den Namen seiner Laura/ Als Genius, dem Glücklichen geboren!“ (33)

Im ersten Alkt führt die Verlesung eines Gedichts Petrarcas "An Laura“" (35 f) ${ }^{49}$ zu einer Diskussion zwischen Laura, ihrem Mann Fernando und ihrer Freundin Rosa über die Aufgabe der Dichtkunst. Während Laura an dem Bild, das Petrarca von ihr malt (Engel, besungener Gegenstand) kein Interesse zeigt, findet Fernando das Bild unvollkommen: „Die äussre Charis malt der Dichter gern;/ Die innre [...]/ Sieht er mit seinen tausend Augen seltner" (39). Während seine Kritik an Petrarcas Gedicht darauf abzielt, daß Petrarca nicht die ganze Wahrheit sagt, sieht Lauras Freundin Rosa gerade in der halben Wahtheit die Anziehungskraft der Dichtung: für sie ist Dichtkunst eine angenehme Täuschung, die Darstellung einer Welt, in der alle negativen Züge ausgespart sind. 
Ich horche gern dem Rauschen eines Bachs -

Ich horch' ihm geist'ger aus des Dichters Munde

Mir winkt ein reiches Feld, ein dunkler Wald -

An seiner Seite sind die Schatten kühler.

Denn keine Sonne brennt auf meinen Scheitel,

Und keine Schlange naht sich meiner Ferse.

Er sondert fein (40).

Diese Ästhetisierung der Realität ist nach Lauras Auffassung die gleiche subtile Unwahrheit wie die, durch die die Sterbliche zum Engel wird, und diese Unwahrheit wirft wo du mit geist'gen Worten Wahrheit sie Petrarca in der folgenden Szene vor. "Wo du mit geïh Lob den festen Sinn nennst; - .... nicht, schmeich, bewundernd, gern mein Ohr gehört" (47). Was Laura als erschütterst - / Hat dich, bewundernd, gern mein Ohr gehort (47). Was Laura als Wahrheit, als „reine[...] Göttlichlkeit“ (50) empfindet, meint Petrarca lediglich durch die dichterische Übertreibung ihrer Reize erreichen zu können (52-5). Für ihn ist sein Dichtung der Versuch, Lauras Anerkennung zu erhalten, Lauras Stilisierung zum Engel, und ein emotionelles Ventil, weil er mit der Realität, in der Laura durch ihre Ehe für ihn unerreichbar ist, nichts anfangen kann.

Zu grausam, Laura, trübst du mir mein Glück.

Du störest einer süssen Täuschung Frieden,

[...]

Kann ich der Wahrheit huld'gen, den das Schicksal,

Im Zauberspiel beglückter Phantasicen

Ans bittersïsse Leben einzig fesselt,

Ein Unrecht zu vergüten, das ihm ward? - (lebhaft):

Könnt' ich in Liedern nicht Gefühl verströmen,

So wäre dieser Busen längst zersprungen! (56)

Durch Lauras Weigerung, der Gegenstand seiner beglïckten Phantasieen zu sein, Wies bleibt ihm nur ein Weg, sich diese Tauschung zu enhaltent Laura. Er weigert sich, den Abend mit ihr zu verbingen, und steift allein im Wald umher. Seine Einsamkeit ermöglicht ihm, sich die Erfüllung seiner Liebe (65 f) und ihre Gesellschaft (66) herbeizuphantasieren; seine Träume sind ihrer Gesellschaft vorzuziehen, da die wirkliche Laura ihnen nicht widersprechen kann. Solange er von ihr zuziehen, da die wirkliche Laura phantasiert, "Seh' ich sie, mich selbst vergessend;/ Funle so der/Innigst sich zufrieden Seele mit dem Irrthum,/ Den sie selbst im Wahn geschaffen,/ Innigst sich zufrieden findet" (67). Aus dem Tagtraum wird eine Vision - ihr Bild erscheint Petrarca in eifindet nem Bach, in einem Baum, und auf einer Wo in die Erfüllung seiner Liebe durch die Frau herder Muse aur: wahrend er vorher die seinem Bild beiphantasierte, träumt ẹr jetzt ihren Tod, die Besird ung zur Muse, der Traum wird der Muse im Wege steht. Durch ihren Traumtod wird Laura zur Muse, der Traum wird zum Gedicht, das Petrarca Francesco vorsingt: „In Melodieen schwebt er um mein Ohr,/ Die Trauer-Töne mit den freud'gen mischen" (86). Da dieses Bild der Muse au der Abwesenheit (Tod) der Frau beruht, flieht Petrarca, als Francesco ihm erklärt, Laura befinde sich in der Nähe, mit dem Schwur, sie nicht wiederzusehen (92 f). Aus dem Gespräch mit Francesco, insbesondere aus den Bühnenanweisungen, wird deutlich, daß Petrarca von nun an mit der lebendigen und lebenslustigen Laura nichts mehr anfangen kann -- was er für seine Dichtung braucht, ist die sterbende.

FRANCESCO. Bald ist sie hier - $[\ldots]$

Petrarca (erschrocken). Wie? Laura?

Francesco. Ja! Fernando mit ihr, Rosa Sie wollen hier der kühlern Luft geniessen.

Petrarca (seufzend). So muss ich fliehn! - Du maltest sie so reizend, (furchtsam forschend) Ist ihre Wange nicht ein wenig blass?

FRANCESCO (zuversichtlich). Nein! ich betheur' es dir, so blühend sah Ich niemals sie als eben diese Tage!

Petrarca (trauernd). Nicht blass? - Truibt nicht ihr Aug' ein kaleines Wöllkchen? Francesco (wie vorhin). Es ist noch heit'rer als des Himmels Blüthe.

Petrarca (kalt). So will ich sie nicht sehn (91-3).

Um sie nicht mehr sehen zu müssen, faßt Petrarca den Entschluß, nach Verona zu gehen, um dort seine dichterische Begabung dem Vaterland zur Verfügung zu stellen; jetzt empfindet er Laura als Fessel, die die Ausführung dieses längst gefaßten Planes verhinderte (101). Daß dieser Sieg der neugefundenen Pflicht über seine Liebe (104) lediglich eine weitere Phantasie ist, wird an der Rolle deutlich, die er jetzt Laura zuschreibt - nämlich die der verlassenen Frau, die ihn nach seinem Tod beweint und ihre Hartherzigkeit bereut. Laura erscheint hier im Bild eines männlichen Freundes, der ähnlich trauert:

Mit nassem Blick - ja, mit der Sehnsucht Wïnschen,

Der hier den Busen kalt für uns verschloss;

Ach! nicht zu schätzen schien, was er besass:

Ein Herz voll kindlich reiner, edler Liebe,

Das für ihn schlug - das nun im Grab verstummt;

Das keine Reue aus der Asche weckt.

So wird auch einmal Laura mich beweinen (102 f).

Solange Petrarca sich mit der echten Laura befaßt, besteht die Gefahr, daß sie seinen Phantasieen über sie nicht entspricht. Als Laura kurz darauf die Bühne betritt, flieht Petrarca eilig (106); bei einem Fest im päpstlichen Palast beschwört er den Kardinal Colonna, ihn nach Verona zu senden, bzw. ihn von Laura zu entfernen: „Ich muss sie fliehn, um meine Qual zu enden" (123).

Während Petrarca Anstalten trifft, sein Bild von Laura vor negativer Beeinflussung durch das Original zu retten, muß Laura sich auf demselben Fest gegen weitere Ver- 
bildlichungen wehren. Prinz Carl von Luxemburg hat Gefallen an ihr gefunden und ribtent ihm denselben und rihm inre "Schönheit als "Meisterwerk" (133); Laura unterstellt ihm denselben deic das Werk der eig nen Phantasic "(133). Als der Prinz siegegen ihe Willen kow er sie dem Klatsch des Hofes aus (133-5); aber erstaunlicherweise finden sowohl Fernando als auch Petrarca sein Verhalten vertretbar: Fernando sieht Laura, ganz wic der Prinz, als Meisterwerk, als Bild. Zu einer Szene, dic Laura den Annäherungen eines Prinz, als Meisterwerk apMann plaudirte fast, - Der ganze Sal/ Geiren sittsam niederschlugst, / Sie zürnend halb, und Blick nicht wehren./ Als du die Augen singm nesches halb beschämt erhobst,/ Da hätte dich Siena malen sollen" (136). Für Petrarca ist es ebenso verständlich, daß der Prinz sich im Anschauen dieses Bildes verliert: „Der Prinz ist zu entschuld'gen. Sage, Laura,/ Kann man der Macht der Augen widerstehn?" (137) ist $\mathrm{zu}$ entschuld gen. Sage, Laura,/ Kann man der Macht der Augen widersteh" wichtig In dieser kurzen Szene wird Petrarcas Verbildlichung Lauras verallgemeinert: wichtig sind nicht die Gefühle der real existierenden Laura, sondern lediglich, was der Prinz sieht.

In Potrarcas Abschiedsszene von Laura versucht er zum letzten Mal, Laura in sein in seinem Gedicht „An Vauclusens Quelle"50 beklagt sie, wie in seine früheren Phantasie, seinen Tod und bereut ihre Hartherzigkeit (156 f); wie in seinem Alt

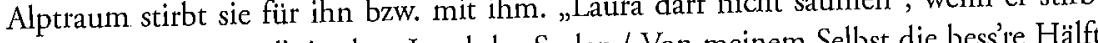
denn „ohne sic, würd', in dem Land der Seelen, fehlen!“ (157) Im Elysium strahlt sie "ätherischer" (158); ihr Tod gibt dem gequälten Dichter endlich Frieden, da er die ungestörte Perfelstion seines Bildes garantiert: „So sucht' ich Frieden, fand ich Wohlgefallen" (159). Laura ist begreiflicherweise entsetz über diese ästhetische Mordphantasie und sieht seine Entfernung als das einzige Mittel, un seiner Krankheit zu heilen. Diese Gelegenheit bictet sich, als Petrarca von Tic Dichterkronen angeboten werden: die Annahme diese Rom, Neapel und Paris dic Dichterkronen angeboten werden: die Ans Ehrung bedeutet für Laura gleichzeitig die Trennung von Petrarca und die offzielle Anerkennung Petrarcas als Dichter - die Erfuillung ihrer Aufgabe als Muse nach ihre Definition. Obwohl Petrarca schließlich auf ihre Bitten hin die Ehrung annimmt, existiert die Muse Laura für ihn nach wie vor nur als Bild. Laura wirc Petrarca durch ein physisches Bild ersetzt, das Fernando Petrarca beim Abschied überreicht. Wie sein Traum im Wald ist dieses Bild dem Original vorzuziehen, denn es " Winspruch etheben zu können. kann von ihm nach Gutdunken „, Zugunsten des Bildes schließt er die Realitat ihre Verbildlichung, ohne daß er sic auch nur hört.

Petrarca [...] (mit Entzücken). O theures, schönes Bild (Er drückt es an die Lippen). O nie gefühlte hohe Götterwonne!
(Er drückt es an die Brust). Dich will ich wie Pygmalion beseelen! (Er betrachtet es unverrüickt). Ihr Augen sollt mir seel'ge Licbe lächeln, Den glücklichsten Unsterblichen begeistern!
Ihr sollt mir traurig blicken! - Ich will wähnen,

Ein Seufzer hebe diesen schönen Busen,

Ein Sehnsuchts-Seufzer um den fernen Freund.

LaURA (zürnend). Petrark!

ROSA (zu Laura). Du zürnst umsonst! Er hört dich nicht.

(bittend). Er hört dich nicht! Du zürnst ihm doch vergebens!

Petrarca (wie vorhin). Dich süssen Ton, das Ohr berauschend, sollt

Ihr frischen Lippen mir, entzückend, nennen!

LAURA (wie vorhin). Petrark! Petrark!

Rosa (wie vorhin). O stille, Laura! still.

Petrarca (wie vorhin). Du seid'nes Haar, du sollst mir schwellend schweben,

Von meiner Seufzer leisem Hauch bewegt

Ihr Züge sollt von Ihr das Leben leihn,

Und um den Sieg mit ihr im Kampfe streiten! - (199-201)

Gegen ihr eigenes Bild kommt Laura nicht mehr an. Über dem Bild vergißt der Dichter sowohl das Original als auch sämtliche anderen Anwesenden: als Francesco ihn zum Aufbruch mahnt, läuft er ohne Gruß und Abschied zur Tür und kommt gleich darauf, Entschuldigungen stammelnd, zurück (201).

Nach der Trennung zwischen Muse und Dichter bleibt nur, diese Trennung zur permanenten zu machen. Laura verfällt nach Petrarcas Abschied in Schwermut und gibt sich Todesahnungen hin (219-21). Ihr Verfall wird auf der Oberfläche durch Petrarcas große Aufgabe gerechtfertigt, durch seine Bestimmung, Italien zur chemaligen Größe zurückzuführen $(240 \mathrm{f})$. Petrarca ist auf dem Weg vom Schwärmer zum Dichter Colonna beschreibt ihn als ewig melancholischen Poeten, der im Bewußtsein seiner Bestimmung eine Dichterkrone trägt, die "Ihn selbst gewiss am wenigsten beglïclkt (241), und der seiner Aufgabe sein Lebensglück opfert: „Er wird ein Opfer! wird es uns zum Wohl“ (241). Genau dieses Konzept drückt Petrarca in seinem Gedicht „An Laura" ${ }^{\text {"51 }}$ aus (251). Mit Petrarcas Erkenntnis seiner Bestimmung zum Dichtẹ verliert Laura ihre Funktion als erzieherische Muse und stirbt nach der Verlesung des Gedichts (251 f).

Für Petrarca, der sich während dieser Szene in Rom auf die Dichterkrönung vorbereitet, hat eine Änderung in seinem Bild stattgefunden: das physische Bild ersetzt Laura nicht mehr; es ist nur ein "kaltes Bild, das ich beseelen wollte", ein „schlechtes Conterfei der schönsten Züge" (262). Seine Phantasieen über Laura empfindet er als tyrannisch, weil er keine Kontrolle mehr über sie hat: die Phantasie „spielt gebieterisch/ Den Meister über mich! - In stillen Nächten/ Heisst sie mir Laura tausendmal erscheinen,/ Und immer sind die Scenen melancholisch,/ Die sie zu ihren Traumgebilden wählt" (263). Laura ist nicht mehr die ausschließliche Inspiration seiner Dichtung, nach ihrem Tod gewinnt Petrarca zusätzliche Anstöße, dic den wahren Dichter vom Schwärmer unterscheiden: das Bewußtsein der Möglichkeiten und der Aufgabe der Dichtung. Die Möglichkeiten werden ihm von einem Blinden demonstriert, der durch seine Lieder seine Blindheit vergißt (268-272); die Aufgabe konstatiert Petrarca selbs 
in seiner Dankrede bei der Krönung. Durch die Dichtkunst, so Petrarca in seiner ing in einer Vision als Paradies auf Erden zeigt (281 f).

Während der Feier hat Petrarca ein neues Traumgesicht, das ihm Lauras Tod anzeigt Werendigkeit ihres Todes für ihre Verewigung als Muse verdeutund licht. In seinem Traum stirbt Laura einen asthetischen Tod uncer Blürer

klängen: der Genius senkt seine Fackel, Laura entschläft lächelnd

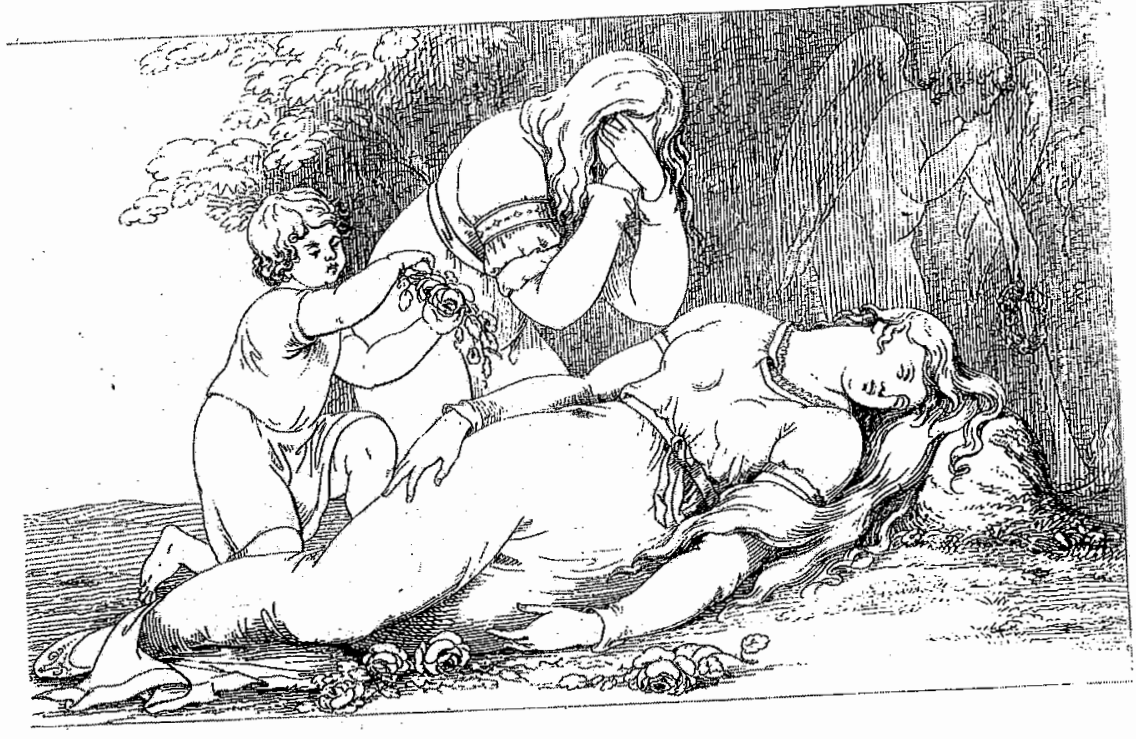

Abbildung 1. Petrarcas Laura. Aus: Westphalen, Petrarca, 254

Angesichts dieses Traum-Bildes bleibt kein Platz für die Trauer um den Menschen, das Original des Bildes; vielmehr fühlt Petrarca sich vergeistigt: „Mir war nicht weh - mir Original des Bild diese dichtewar so wohl - so leicht!" (29) In seiner Phantasie als Psyche erscheint und ihm ihre Liebe rische Interpretation des Todes, indem sie ihm als Psyche erscheint the the Liebe zu vergesteht (301 f). Da der Dichter durch ihren Tod gezwungen ist, diese Liebe zu vergeistigen, wird Lauras Bild endlich zur wahren Dichtung und Petrarca zum Dichter: Mit sel'gem Lächeln flog die Liebe, freier,/ Mit dir, zur höhern Göttlichkeit erlesen“ (305).

In Elise Schmidts (1824-?) Der Genius und die Gesellschaft (o. J.) zerbricht der DichIn thise Schider Tatsache, daß ihm eine derartige Inspiration fehlt. Byron ist ter Byron an der Tatsache, daß ihm eine dertion (erst der fiunfte Akt zeigt ihn beim ein Misanthrop, implizit künstlerisch untätig (erst der funfte Akt zeder Interesse an Schreiben). Von seiner Weltverachtung durchdrungen, hat er weder Interesse an Künstlerruhm noch daran, Englands Größe durch seine eigene wiederauferstehen zu Künstlerruhm noch daran, Englands Große durch seine
lassen (52). Seine Frau Arabella dagegen ist ganz. Gesellschaftsdame und zeigt keinerlei
Verständnis für seine Dichtung. ${ }^{53}$ Indirelkt macht Byron seinc verständnislose AntiMuse Arabella sowohl für seine fehlende Inspiration als auch für dic Oberflächlichkeit der Gesellschaft verantwortlich.

Eine Ehe wie die meinige ist ein jämmerlicher Zustand! Hemmt und dämmt mi alle Gefühle und Gedanken! - Ach, die Weiber, die Weiber verderben die Gesellschaft! Sie sollten sich gar nicht in die Societät hineinmengen. Sie sollten sich nur um ihr. Hauswesen kümmern und sich gut herausfüttern und kleiden (15).

Für Byron ist sein putzsüchtiger Hausteufel nicht nur die Quelle allen persönlichen Unglücks, sondern auch der Stein auf seinem Weg zum Künstlertum. Denn der Künstler muß zwar hinaus ins feindliche Leben, aber "nach allem Sturmgelaufe kommt doch ein Jeder zurïck, wie ich, und sucht ein Herz" (15, Hervorhebung der Autorin) - er sucht „Linderung durch weibliche Sanftmuth“ (16). Für Byron sind persönliches Glück und Künstlerruhm nicht unvercinbar - darin unterscheidet sich das Stück von der allgemeinen Darstellung der Künstlerproblematik -, sondern vielmeh zwei Seiten derselben Medaille. Sowohl Privatglück als auch Künstlertum ist dem Manne nur zugänglich durch Inspiration durch das Weib. Der unglückliche Ehemann ist demnach auch auf künstlerischer Ebene in einer trostlosen Situation.

Man könnte ihm raten und sagen: Stürze dich in die Geschäfte! Ersäufe dich in Arbeit! Nach einer Größe ringt der Mensch. Kannst du nicht glücklich in deinem Hause sein, so werde groß in deinem Volke, ein Sulla, oder ein Washington! Gleichviel! Aber - aber! Der häusliche Fluch hängt sich an und schleppt uns nach. Der Fluch des Zurïckgestoßen-, des Unverstandenseins! O Weiber! Weiber! die Größe der Welt liegt in euren Herzen! Ich sag' euch, bildet eure Herzen aus! (16, Hervorhebungen der Autorin)

Was Byron hier anzudeuten scheint, ist einfach, daß jeder Mann ein potentieller Künstler ist - und jede Frau, zumindest idealiter, die ihn ergänzende Muse. Byrons Muse besteht in der Erinnerung an seine unglückliche Liebe Mary ${ }^{54}$ er lebt „mit dem unvergeßlichen Bilde meiner ersten Liebe noch im Kopf und Herzen", physisch repräsentiert durch ein Medaillon (16). Als die Schauspielerin Clara ${ }^{55}$ ihn besucht, um seine Protektion zu erbitten, überträgt er diese Funktion auf sie, weil sie Marys Bild sprechend ähnlich sieht: er verliebt sich augenblicklich in ihr Bild und fühlt sich durch dieses Bild zum ersten Mal seit langem inspiriert.

Sie sind ein Genius, das fühle ich! Ihr Wesen gießt eine Milde, eine Klarheit aus über mein Wesen. Mir ist wohl in Ihrer Nähe. Meine Jünglingsjahre steigen vor mir herauf mit ihren herrlichsten Träumen. Ich sehe Annesly-Hall, Newstead-Abbey. - Ich schreibe wieder an dem schönen Gedichte, über dem später mein Herz verblutet is (19, Hervorhebung der Autorin).

Aber Byron muß der Versuchung widerstehen, weil er der Gesellschaft nicht die Gelegenheit geben will, ihn des Ehebruchs zu bezichtigen. So erklärt er Clara, er könne sie 
nicht wiedersehen, und we bider mittlerweile nicht wiedersella, miteinander identizier teils auforund einer geschmacklosen Wette. Brummel, seines Zeichens Modekönig von teils aufgrund einer geschmacklosen Wette. Brtmmel, seines Zeichens Modek olingen London und Arabellas ständiger Besucher, hat mit ihr gewettet, daß es ihm gelingen würde, Ophelia ihren Strohkranz abzuschmeicheln; Arabella hält eine solche Sittenlosigkeit selbst bei einer Schauspielerin für unmöglich (21-3). Byron rettet Clara vor Brummels Avançen, wofür er denselben Preis verlangt und erhält (24), und wird bei seiner Liebeserklärung von Brummel überrascht.

In dieser Szene erweist sich Clara eindeutig als die Stärkere und widerlegt damit das Szenche in deutlichem Bild, daß Byron sich von seiner Muse macht. Ihre Entschlossenhit steht in deuthem Gegensatz zu seiner Vorstellung von weiblicher Sanftmut. Byron bestürmt sie mit Liebeshymnen, verwechselt sie verschiedentlich mit Ophelia (24) und fordert Geständnisse hom von ihr; Clara liebt Byron ebenfalls, ohne sich ein Geständnis abpressen zu lassen, unch entschließt sich später zur Entsagung, weil sie der Welt beweisen will, daß auch Schauspielerinnen ehrbare Frauen sein können (28). Byron verliert bei Brummels Auftrit völlig die Nerven, er wettert und tobt und fordert Brummel zum Duell; Clara dagegen
erklärt Brummel den Sachverhalt, verwahrt sich gegen seine Andeutungen und schickt beide aus dem Zimmer:

Die schließliche Vergeltung für Byrons Zuneigung - von seiten Arabellas und, von ihr inszeniert, auch von Seiten der Öffentlichkeit - richtet sich nicht gegen ihn, sonihr inszeniert, atch von Schließt sie dern gegen Clara. Als Arabella von Casche Haussuchung bei ihrem sofort auf ein Verhältnis. Ihren Verdacht bestatigt eine rasche Tassuchung bei ihren Mann: in einem Kästchen findet sie Marys Bild und Claras Strohkranz. Thre Rache setzt sie mit Brummels Hilfe ins Werk, denn der ist „der Mann dazu, einige Menschen selfen, ohne Haß, bloß zum Zeitvertreib“ (37). Durch Brummels in elend nachen zu helfen, ohe nächsten Auftritt ausgeder Gesellschaft tonangebenden Einfluß wird Clara bei ihrem năchsten Auftit ausgezischt; als Byron für sie eintritt, trifft ihn dasselbe gesellschaftliche Verdanmungsurte (53 f). Aus diesen Vorgängen und aus dem Schicksal seines Freundes, des Schrift$53 \mathrm{f}$. . Aus diesen
stellers Sheridan, der inzwischen zum Alkoholiker verkommen ist, schließt Byron erstellers Sheridan, der inzwischen zum Alkoholiker verkom Künstlern gegenüber. Seine neut auf die Undankbarkeit der Gesellschaft ihren großen Künstlern gegenüber. Seine Lösung besteht darin, die Gesellschaft und ihre Sitten und Gesetze zu negieren und mit Clara das Land zu verlassen; Clara dagegen sieht darin eine Bestätigung des gesellmit Clara das Land zu verlassen; Clara dagegen sieht dare Unglück alles folgende Unrecht schaftlichen Urteils. Byron meint, durch vergangenes Unglück alles folgende Unrecht im voraus gesühnt und jetzt seinen Himmel verdient zu haben (62); Clara dagegen läßt sich auch durch seine emotionalen Erpressungsversuche nicht zum Nachgeben zäßt sich auch durch seine emotionalen zouf und auf die öffentliche Verurteilung Claras folgt die private. Arabella wirft ihr in harten Worten die Verführung Byrons vor und läßt ihr keine Möglichleit der Verteidigung; Clara verliert schließlich den Verstand $(66 \mathrm{f})$.

Indem Clara sich hier; entsprechend Byrons früherer Verwechslung der SchauspieleIndem Cla Byrons rin mit ihrer Rolle, mit Ophelia identifiziert, entspricht sie zum ers sie „so schuldlos
Vorstellung von seiner Muse; durch den Verlust ihres Verstandes wird sing und unverpfuscht wie der erste Schöpfungstag" (68). Das Bild, das sich hier bietet, ist ein anderes als das der intelligenten, mutigen und lebendigen Clara von früher: das der „Byronic Heroine" - schwach-sinnig, sanft-mütig, sterbend.

Angesichts dieses Bildes kann Byron Arabella darüber aufklären, daß er nicht die Frau geliebt habe, sondern das Bild. „Ich liebte dieses Mädchen, wie man ein Heiligenbild liebt, ein Ideal, eine Erinnerung - [...] Keine irdische Beziehung war zwischen uns!" (69, Hervorhebung der Autorin) Arabella bereut ihre Tat und straft sich selbst durch ewige Trennung von ihrem Mann.

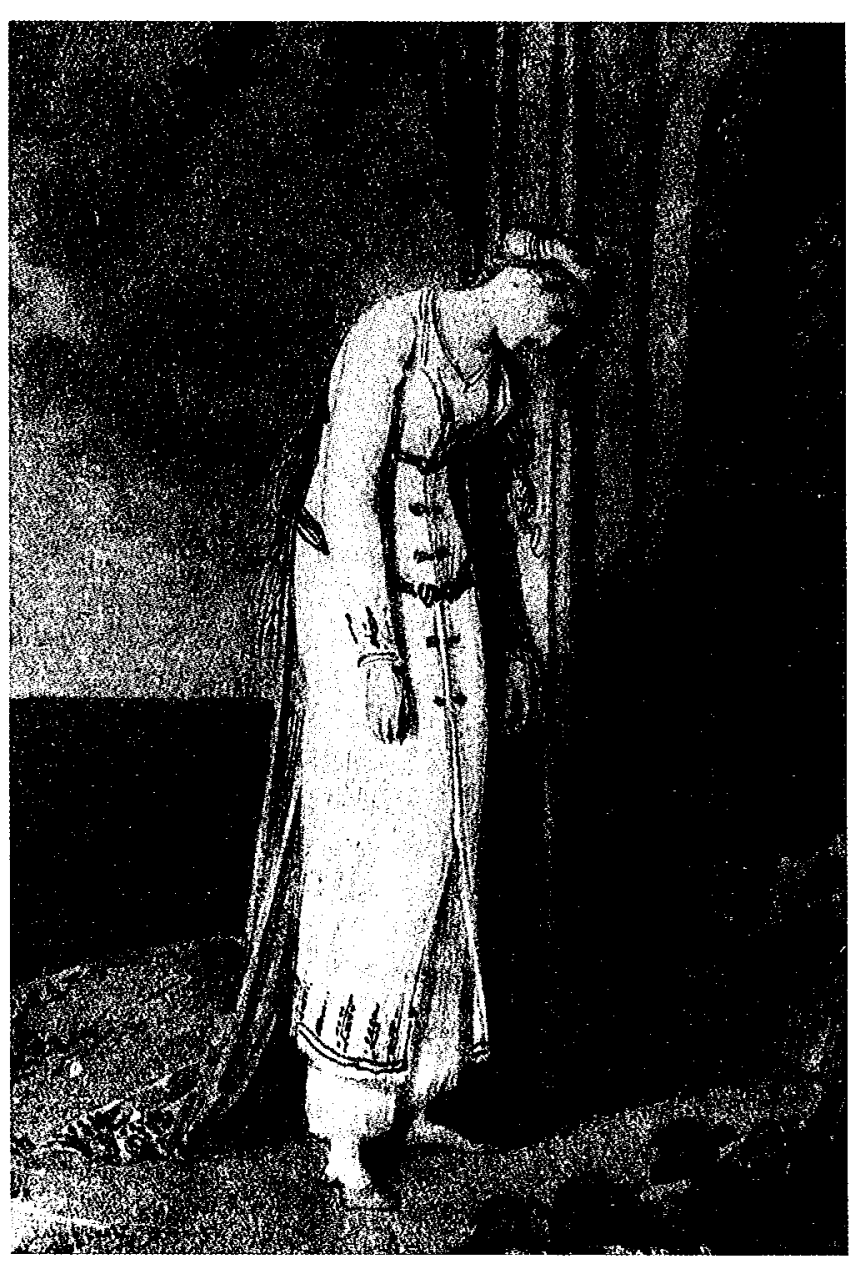

Abbildung 2. Richard Westall: „The Byronic Heroine“. Wasserfarbe. Aus: Symonds/Quennell, „To Lord Byron“. Titelbild. 
Der gesamte fünfte Alkt spielt teils an der englischen Küste, teils in Griechenland, und behandelt Byrons Leben nach seiner Trennung von der Muse. Ein guter Teil des Aktes ist angefüllt mit Selbstmordgedanken und bittersten Ausbrüchen gegen die grausame Gesellschaft (70-9); immerhin inspiriert der Gedanke an Clara ihn zu zwei Gedichten, (an schließlich ein Schiff nach Griechenland anlegt, fühlt sich eins an jede Frau (80 ). Als schließlich ein Schiff nach Griechenland anlegt, fuhl sich Byron von einer plötzlichen Sehnsucht nach Hellas und von dem unwiderstehlichen Bedürfnis ergriffen, für die Freiheit des Griechenvolkes zu fechten (82), und wird „bei dem ersten Versuche ein Held zu sein" (84), tödlich verwundet. ${ }^{56}$

Kurz vor seinem Tod erhält Byron die Nachricht von der Genesung seiner Muse. Kurz vor sein ihm unwillkommen ist oder nicht, ist aus der Szene schwer feststellOb die Nachricht ihm unwillsommen eine Umkehrung des üblichen Verhältnisses zwibar - jedenfalls stellt diese Wendung eine Umkehrung des üblichen Verhălnisses zwschen Künstler und Muse dar: der Künstler stirbt, die Muse überlebt. Die Gesundung der Muse findet nach ihrer Trennung vom Künstler statt und scheint mit dem Tod des Künstlers in Verbindung zu stehen: der Diener, der die Nachricht überbringt, stellt diesen Zusammenhang zumindest zeitlich her Erreichet Euch die Kunde einer theuren -

Byron. Wie?

DiEnER Genesung von Miß Clara.

BYron (wendet sich um). Still! Stör' mich nicht! (84)

Byrons Tod wird durch seine Vision einer ganzen Armee von astartischen Schönheiten versüßt: die Jungfrauen des Dorfes, die sich vergeblich um ihn bemühen, belegt er mit versu Namen von Figuren aus seiner eigenen Dichverschiedenen mythischen Narte, Haide und tung (Braut von Abydos, Donna Julia, Mirfiegt; seine letzte Schlußfolgerung zieht e Olympia). Aber auch diese Vision vertiegt; seine lezin scine Konsequenz" (86) plötzlich mit klarem Blicls" (85): „der Tod - das ist die einzige Konsequenz (86). Anders als für Petrarca versagt die Muse für Byron; hier endet die Laufbahn und da Anders als für Petrarca versagt die reale Welt folgt.

\section{B. Maler: Birch-Pfeiffer, Pierson}

Die Identifikation der Frau als Muse mit einem geistigen und physischen Bild wird noch deutlicher in Künstlerdramen, in denen Maler behandelt werden. In Birch-Pfeiffers Rubens in Madrid (1836) ist Rubens von dem Gedanken besessen, Ellenas Bild zu malen. ${ }^{57}$ Ellenas Ehemann Enrico haßt Rubens, weil Ellena ihre Bewunderung für den malen.' Ellenas thibt, und weil Rubens bei König Philipp in höherer Gunst steht. Als Künstler offen zugibt, und weil Rubens bei König Phillpp in höherer Gist ste Aaßt Rubens eine diplomatische Sendung angetragen wird, um die Enrico sich bewirbt, faßst dieser den Entschluß, den Künstler in Mißkredit zu bringen. Er läßt Rubens' Lehrdieser den Entschluß, dort kllenas Bild 168 zu malen. Auf öffentlicher Ebene soll dadurch Rubens' Kunst durch die größere des Lehrers verdunkelt werden; auf privater Ebene will Enrico Rubens dadurch zur Verzweiflung bringen, daß ein anderer statt seiner Ellenas Bild malt. Rubens erfährt von Enricos Plan, besticht van Oort, auf halbem Weg umzukehren, und malt Ellena in der Maske seines ehemaligen Lehrers. Ellena, die ihm nur widerwillig das Modell liefert, erkennt Rubens schließlich an seinem Werk und weigert sie sich von da an, ihm Modell zu stehen. Enrico wird von seinem Freund Garzia von van Oorts Umkehr benachrichtigt; Rubens wird entdeckt und flieht mit dem fast vollendeten Bild. Enrico kann den Gedanken nicht ertragen, Ellenas Bild in den Händen eines anderen zu wissen, und befiehlt Ellena, ihr Bild von Rubens zurückzufordern. Auf Ellenas Bitten fordert die Königin die Herausgabe des Bildes; als Rubens sich weigert, trägt Ellena selbst dem Maler ihre Bitte vor, und Rubens gibt ihr schließlich das Bild. In der letzten Szene muß Rubens den Zorn des Königs besänftigen, der sich hintergangen fühlt - Rubens hat auch ihm den Adam van Oort vorgespielt -; aber gerade die Schlauheit und Selbstbeherrschung, die Rubens in seiner Intrige demonstriert, beeindrucken den König mehr als Enricos rasende Eifersucht. Rubens erhält die von Enrico begehrte Diplomatenstelle in England, Enrico wird von Ellena verlassen, von der Majestät persönlich daran gehindert, Rubens zu ermorden, und mit einer minder begehrenswerten Sendung nach Rom abgespeist.

Daß Ellenas Bild für beide Männer wichtiger ist als das Original, zeigt sich zu Beginn des Stückes: Enrico würde sie eher töten, als sie von Rubens malen zu lassen (Gesammelte dramatische Schriften II, 12 und 23); für Rubens ist sie "ein Gemälde,/ Wie es die mächt'ge Meisterin Natur/ Allein zu schaffen wagen durfte“ (21). Wie Petrarca wird Rubens von seinem Freund Gomez vor den Folgen seiner Leidenschaft gewarnt; aber Rubens' Ideal bezieht sich nicht auf die Person Ellena: im Gegenteil zerstört die Erinnerung daran, daß es sich hier um eine Person handelt, die Perfelktion seiner Vision.

Sie ist mein Ideal! Hoch schwebt sie mir

Ob der Region gemeiner, ird'scher Wünsche!

Ich will auch nicht daran erinnert sein,

$\mathrm{Da}$, staubgeboren, sie das Loos des Staubes,

Begehrend und begehrt, soll theilen - nein -

So tief will ich aus meinen Himmeln nicht

Zur schmutz'gen Erde niederstürzen! (22)

Um dieses Bild malen zu können, würde er alles opfern (24); der Gedanke, daß ein anderer ihr Bild malt, versetzt ihn in Raserei $(26 \mathrm{f})$, bis ihm der rettende Gedanke kommt, van Oort das Bild abzukaufen (28). Seine eigene Besessenheit erklärt Rubens mit seiner ewigen Unzufriedenheit mit seiner eigenen Kunst, mit der ständigen Diskrepanz zwischen Gedanke und Ausführung. Wie den Bildern seiner Schüler fehlt seinen eigenen Werken der Sinn des Höheren, das überirdische Element, das den Unterschied zwischen Stümperei und Kunst ausmacht (31-4). Rubens verallgemeinert den 
Une Kunst und zu dem Unterschied zu dem zwischen niederlandischer und italienischer Kung', des Vaters zwischen Hausbackenheit und Leidenschaft. „Der Mutter leuchtend Aug', des Vaters Züge,/ Der Schwester Lächeln - das sind die Gestirne", die dem niederländischen Maler leuchten (38); in Italien dagegen wird der Künstler von anderen Leidenschaften inspiriert: „Hätt' in Italien ich das Licht erblickt, / Hätt' ich den ersten Liebesblick gewechselt, / Den ersten Kuß mit einem röm'schen Weibe -/ [...] dann wär' die Welt mein eigen!" (38, Hervorhebungen der Autorin)

Vergleich zwischen sich selbst und dem größten italienischen Maler, Raphael, Im Vergleich zwischen sehlt, ist die Muse. „Ja, Raphaelzeigt sich das Manko in Rubens' Kunst. Was Rubens feht ' der Fornarina./ (Plötzlich der war des Himmels Meister,/ Er fand ihn in dem Aug ( der Niederländer wohl mir glühend): Ich kenn' auch solch ein Auge, das vermöchte,/ Den Niedcrländer wohl mir auszutreiben" (38 f, Hervorhebung der Autorin). Rubens wagt das lebensgefährliche Spiel willig (46), um seine Kunst zu vervollkommnen; die Muse, die ihn zur Vollkommenheit inspirieren soll, ist „Das Ideal, dem ich abgöttisch huld'ge“ (59). In Rubens' Vorstellung wird Ellena dadurch gewissermaßen zweigeteilt: für seine Zwecke ist sie Vorstllo Nicht Händedruck, nicht Kuß, nicht Liebesseufzer/ Ersehne ich - ihr himmelklares "Nicht Hanndedrel Bild/ Allein ist's, was ich ihr entreißen will" (59). Das himmelklare Bild der Muse Ellena kann nur durch die Frau Ellena zerstört werden - wenn es der Frau beispielsweise einfiele, sich in ihn zu verlieben. Denn „Wenn sie vergäße, was sie selbst sich schuldet, Dann sänke sie von meinem Ideal/Zum Alltagsweib herab; und keine Kraft/ Bedürft' ich mehr, mich vor mir selbst zu schützen!" (60)

Durch diese Entmenschlichung wird Ellena sowohl von Rubens als auch von Enrico Werkzeug erniedrigt: Rubens benutzt sie zur Vervollkommnung seiner Kunst Enrico, um sich an Rubens zu rächen, indem er sie zwingt, dem vermeintlichen van Enrico, um sich an Ruber Oort Modell zu stehen. Elch nur durch eine Erpressung Enricos dazu bewegen, in diese schmerzlich und läßt sich nur durch cinc Erpressng Ench Weise über sich verfügen zu lassen; die einzige Freiheit, die ihr bleibs, ist die, ihr eigenes Bild nicht sehen zu müssen (84). Der Künstler allerdings zeigt kein Interesse an nes Bild nicht sehen zü müs's mich, ob ihr mein Bild gefällt" (85) -: wichtig ist nicht ihrem Urteil - „Was kümmert's mich, ob

Rubens' Inspiration wird schließlich durch die Entdeckung gefährdet, daß Ellena Rubens' Is leine Zweiteilung Ellenas kann nur bedingt aufrechterhalten wer-

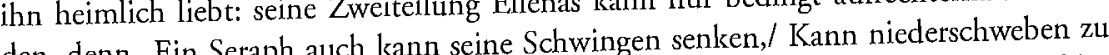
den, denn „Ein Seraph auch kann seine Schwingen senken,/ Kann Kiedesch in Gefahr, der blüh'nden Erde"; und mit der sinkenden Muse gerat auch der Kunnsler in Gefahr, schmählich der Materie [zu] verfallen" (92). Während der Sitzungen wird dem Maler „schmählich der Materie [zu] verfallen (92). Wuse ist, sondern im Gegenteil eine immer deutlicher, daß sein Modell keine passive Muse ist, sondern " Gegentil cine Frau mit eigenem Kunstverstand, die spricht, als wäre sic „vom Fach“ (97). Mit diesem Kunstverstand erkennt sie schließlich Rubens in seinem Werk; was sic nicht wiederKunstrct ist sich selbst. „Ich soll das sein? - O nimmer! Es ist ähnlich,/ Ich fühl' es, erkennt, ist sich selbst. "Ich soll das sein? - O nimmer! Es ist ahnin). In dieser Szenc ähnlich, dennoch bin ich's nicht" (102, Hervorhebungen der Autorin). In dieser Szene erfährt das Verhältnis zwischen Muse und Künstler eine merklliche Änderung. Ellenas erfahrt das Verhäl den Künstler Rubens (für ihr Bild) weicht der Enttäuschung über 170 den Menschen, det imstande ist, sie in dieser Weise zu benutzen und zu kompromittieren; der Maler dagegen muß erkennen, daß seine Muse ein Mensch ist, der durch seine Handlungen gefährdet wurde (104).

Als der falsche van Oort kurz darauf an den Hof zitiert wird, glauben beide, die Maskerade sei entdeckt; aber Rubens folgt dem Befehl, weil seine Flucht Ellena kompromittieren würde (106). Ellena weigert sich zwar, Rubens weiter zu sitzen, bevor seine Identität entdeckt wird, kann sich aber vor Enricos späteren Beschuldigungen der Komplizität mit Rubens nur dadurch retten, daß sie sich bereiterklärt, von diesem das Bild zurückzufordern. Während Ellena ihre menschliche Würde nur dadurch erhalten kann, daß sie ihr Bild von Rubens zurückerhält, geht es Enrico nach wie vor nur um das Bild, darum, „Daß er [Rubens, S. K.] im Anschau'n dieser Reize schwelgt,/ Die ich vor jeden Sonnenstrahls Berühren/ Verbergen möchte" (132). Auch Rubens, entdeckt und beim König in Ungnade, nimmt die Folgen leicht: „sieh' hier mein Bild“, triumphiert er Velasquez gegenüber, „Gerettet hab' ich's, weiter wollt' ich nichts!" (136)

An die möglichen Konsequenzen für Ellena wird er zwar erinnert, setzt sich aber relativ leichtfertig darüber hinweg, denn „Auf dieses Weibes/ Erhab'ner Stirn, in diesem reinen Auge/ Ruht solch ein Glanz der fleckenlosen Unschuld,/ Daß selbst Enrique ihr willenlos gehorcht" (138). In dem angesichts von Enricos Brutalität naiven Glauben, Ellena werde „sich selbst zu schützen wissen“ (138), verweigert er der Königin die Herausgabe des Bildes. Als Ellena selbst auftritt, um ihm dieselbe Bitte vorzutragen, erklärt Rubens ihr den veränderten Wert, den das Bild inzwischen für ihn erhalten hat. Zu Beginn des Stückes war das Bild für ihn lediglich die Möglichkeit, seine Kunst zu perfelktionieren, indem er sie zum Engel stilisierte. Inzwischen aber ist der Maler durch seine Leidenschaft zu der Frau Ellena in Versuchung geführt worden und hat diese irdische Liebe heroisch überwunden - und das Bild ist die Dolsumentation seines Sieges über sich selbst, der Beweis, daß er sich vom Menschen zum Künstler aufgeschwungen hat. Dafür, daß Ellena ihm dieses Bild abverlangen kann, gibt es nach Ansicht des Künstlers nur eine mögliche Erklärung: mangelndes Verständnis der Muse. Diese Vermutung äußert er ihr gegenüber in anklagendem Ton:

Begreift das Opfer Ihr, das ich gebracht?

Habt Ihr bedacht, welch eine Riesenkraft

Der Leidenschaft, anbetender Abgött'rung

Mir Stärke gab in diesem heißen Kampe?

Ihr habt es nicht, sonst wär't Ihr nicht gekommen,

Den Preis des schwersten Siegs mir zu entreißen!

(151, Hervorhebung der Autorin)

Aber Ellena besteht auf ihrer Forderung, und Rubens ergeht sich in den bittersten Ausbrüchen des unverstandenen Genies: „Verstanden glaubt' ich mich, erfühlt, empfunden./ O, bitt're Täuschung, allzu kühner Wahn! (Er verhüllt das Gesicht)" (153). Als Ellena ihn darüber auflklärt, daß Enrico das Bild als Beweis ihrer Unschuld fordert daß der Besitz des Bildes also ihre einzige Überlebensmöglichkeit darstellt -, reagiert 
Rubens mit einer kleinlichen Tifersucht die der Envicos gleichkommt: er kann den (153). Gedanken nicht ertragen, daß der verhaßte Gegner Ellenas Bild besitzen soll (153). Ellena bleibt schließlich nur eine Möglichkeit, das Bild zu erhalten: der Ruckeall in ihre Musenrolle. Sie spielt sie, indem sie Rubens auf seine glänzende Laufbahn verweist und sie mit der eigenen freudelosen Zukunft vergleicht; das Bild fordert sie jetzt als
Erinnerungsstück an seine Liebe. So kann Rubens ihr das Bild schließlich geben, denn ihm bleibt „das Bewußtsein, daß sie liebend selbst/ Ein heil'ges, unentweihtes Götterbild" ist (157).

So verinnerlicht Rubens Ellenas Bild; Ellena wird zu seiner ewigen Muse. Ellena verschwindet damit aus dem Stück; der Rest des Stückes behandelt den Beginn der von schwindet damit aus dem Stuck, der Rest des Stües bünstlers, und RuEllena prophezeiten glänzenden Laufbahn des Diplomaten und Künstlers, und Rubens' Spiel ist „Gewonnen" (175). Daß Rubens sich selbst ku teuer erkauft scheint, is des Glïcks" (174) empfindet, daß ihm sein Glück jetzt zu teuer erkauft schir se nicht mehr als eine Begleiterscheinung seiner Vollendung als Künstler: wie wil gesehen
haben, betritt der echte Künstler seine glänzende Laufbahn nicht triumphierend, sondern melancholisch.

Caroline Piersons (1811-1899) Meister Albrecht Dürer (1840) hat viele Elemente it Birch-Pfeiffers und Schmidts Stücken gemeinsam. Wie Rubens ist Dürer mit seimit Birch-P ner Kunst ewig unzufieden; was e auf di Leinwand Zeit im Geiste trug" (3). Was ihm glanz nur von dem Gebilde,/ Das ich seit langer Zeit im Geist "(5), die en fehlt, ist die Verlalärung der „Maler-Kunst" durch „Maler-Poesie (5), die er in Italie beobachten konnte. Wie Birch-Pfeiffers Rubens identifiziert Dürer Italien mit Leiden-

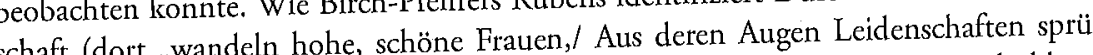
schaft (dort „wandeln hohe, schöne Fauen,/ Aus dic hen") und Deutschland mit holder Häuslichkeit („Indeß, die blauen Augen hold gesenkt,/ Die deutsche Frau die goldne Spindel dreht") (7). Wie Schmidts Byron ist senkt,/ Die deutsche Fau die gentDürer von einer hăustichen Anti-Muse geplagt seine Fou sche Hausfrau mit weinerlicher Stimme und ewigen Geldsorgen, der jedes Verstândnis für die Kunst abgeht - für sie ist Malerei lediglich eine Frage der Gewandfarbe (11) -, und die während des Stückes ununterbrochen aus dem Zimmer oder zum Schweigen und die während des Stuckes ununterbridts Stück ist Agnes die Frau in Dürers Leben, verwiesen wird. Wie Arabella in Schmidts Stück ist Agnes die Tran in Duess Leben, die „die holde Muse/ Mit ihren ew'gen Fragen“ verscheucht (12); wie Byron kann Düdie "die holde Mein schönes Bild bewahrt" (14). rer sie nicht lieben, weil sein „Herz/ Noch Dieses Bild ist das seiner ehemaligen Geliebten, auch f). Eins dieser Madonnenbilder zu scinen schönsten Madonnenbildern inspiriert (14 f). Eins dieser Madonnenbilder schickt er zu einem von Kases Bildes - nach der Beschreibung der Autorin das nebenberg; in der Madonna dieses Bildes - nach der Wie Byron ist Dürer in Versuchung, sein stehende ${ }^{59}$ - erkennt Clara sich wieder (25). Wie Byron ist Dürer in Versuchung, scin Lebensglück durch Scheidung und Neuverheiratung zu erringen; aber Clara lehnt diesen Vorschlag ab, weil sie sich selbst als Muse seiner Kunst sieht: „Soll ich nicht mehr [...]/ Der erste, helle Morgenstern Euch sein?" (27) Diese. Funktion würde sie als [...] / Der erste, helle Mër hellen Stern, / Wie Ihr mich nennt, herab zur Düres Erde ziehen?" (28) Clara weich weiß, daß nur die reine bzw. vergeistigte Liebe der 172

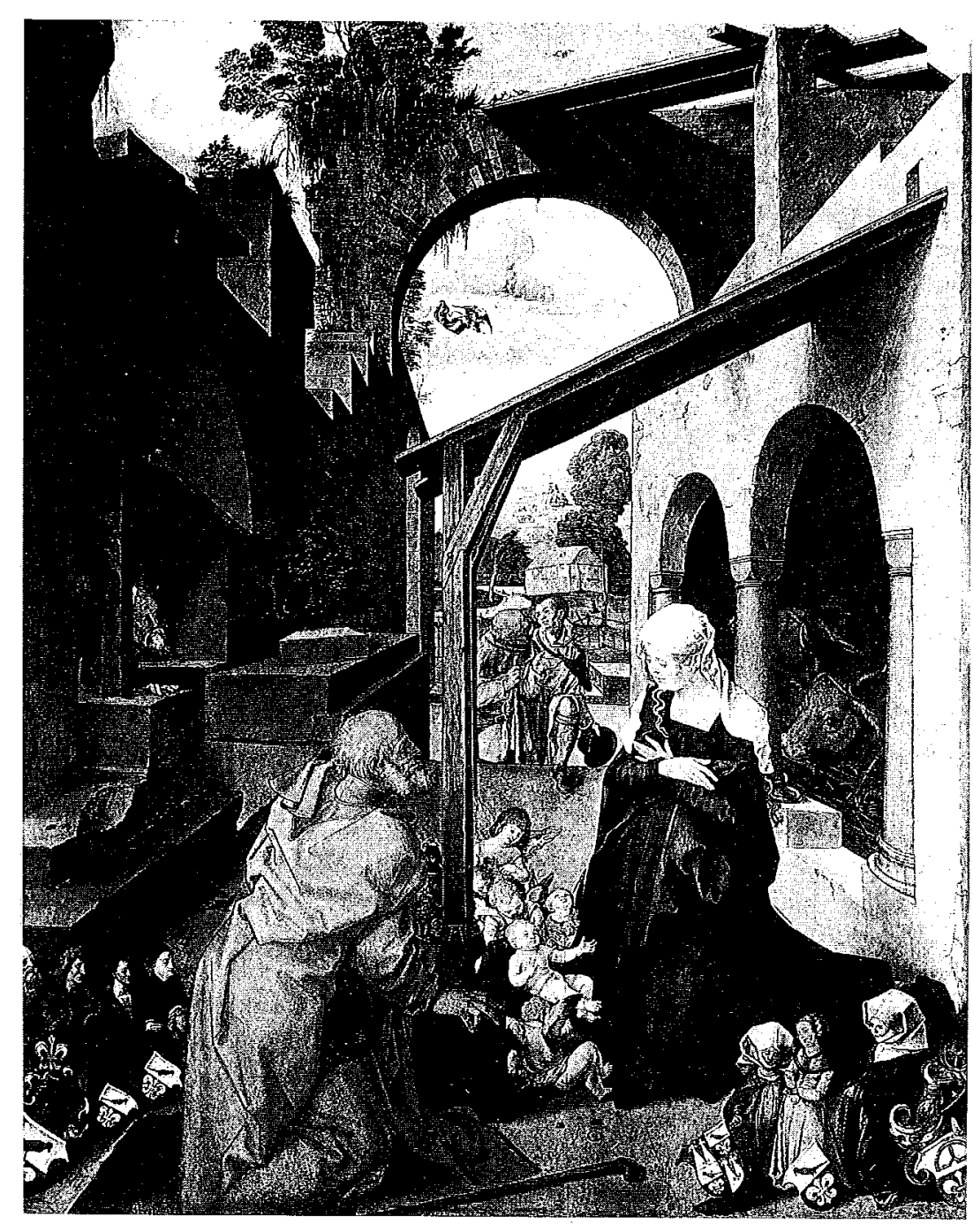

Abbildung 3. Albrecht Dürer: Christi Geburt. Mittelbild des Paumgartnerschen Altars. Öl auf Holz. Alte Pinakothek München

Entsagung seine Werke angemessen inspirieren kann. „Die Lieb’ allein, die echte, reine Liebe,/ Ist Leitstern [...], und je herrlicher;/ Je reiner Liebe lebt im Künstlerherzen,/ Je klarer werden seine Werke sein!" (29 f) Clara beschließt ihr Leben im Kloster (30), Dürer dagegen setzt alles daran, für seine Künstlerehre und zu Deutschlands Ruhm die Malerkrone des Wettbewerbs zu erringen (31). 
Dieses Vorhaben wird ihm durch die Eifersucht des italienischen Malers Guglielmo Dieses Vorhaben wid häßen Maler erkennt, weil seine Bilder von erschwert, der in Dürer neidisch rö s" sind, während Guglielmo selbst nur imstande ist, „Erdenlust" zu malen (36). Guglielmo versucht, Dürers Bild zu vernichten, indem er das Gesicht der Madonna entstellt, denı die Verklärung ist im Gesicht der Madonna, identisch mit dem der Muse, ausgedrückt. Die Zerstörung dieser Verklärung (der reinen" bzw. "höher'n schöner'n Liebe") kann nur auf eine einzige Art und Weise

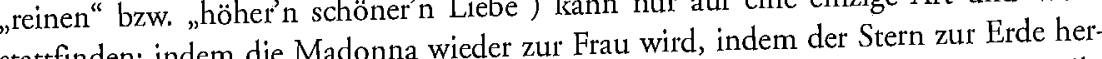
stattfinden: indem die Madonna wieder zur Trau . hinzuftigen will, ist "Dic Glut der Sinne diesen sanften Augen, Bild vom Original selbst um den milden Mund“ (36). Vor dieser Entstellung wird das Bild vom Originl selbst gerettet: Clara unterbricht Guglielmo kurz vor der Austührung des bösen Plans, hüll das Bild in ihren Schleier - „damit kein Staub der Erde es berühre" - und läßt es auf dic Burg bringen (38).

Guglielmos zweite Atracke auf Dürer richtet sich gegen den Maler selbst. Er überGürer tief Gedanken - Dürer plant ein neues Bild, gedenkt seiner ersten Lierascht Dürer tief in Gedanken - Durer plant en nespräch "Mit meiner Muse" (59) be und befindet sich nach eigener Aussage im Gesprach „Mit meiner Muse (59) und verwundet ihn mit einem Messer. Dürer weigert sich, ihn anzuzeigen, und zwing Guglielmo so, seine menschliche Größe ebenso anzuerkennen wic seine kïnstlerische Guglielmo so, seine menschit

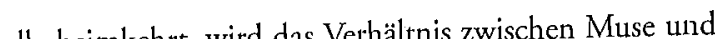

Bevor Clara in ihre Klosterzelle heimkehrt, wird das Verhal wh war't die holde Musc Künstler verewigt: Dürer schwört seiner Muse ewige Treuc. "Whr wart dic holde Musc meines Lebens,/ Ihr bleibet sie!" (74, Hervorhebung der Autorin) In dieser Treue zu seiner Muse sieht Dürer die einzige Möglichkeit der Vollendung seiner Kunst: „alle meine Bilder, hehr und rein,/ Sind Deines holden Bildes Wiederschein./ Getreu die Muse jedem Künstler bliebe,/ Blieb' er getreu der ersten, reinen Liebe“ (75, Hervorhebung der Autorin). Nach ihrem Abschied führt Dürer die Notwendigkeit der Tren作 nung auf die bekannte Künstlerproblematils zurück, nämlich auf die Unverenterente „Vielleicht von Ruhm und Glück - auch hier ist der leiden Kunst hellstralend aufgegangen, / Zwe ist mir aus meines Herzens Leid/ Der Stern de Kunst hellstalend aufgegangen,/ Zwei Kränze werden keinem dargereicht:/ Es will der Ruhm nicht bei der Liebe prangen./ Dir, heil'ge Kunst, will ich mich ganz ergeben“ (77 f, Hervorhebung der Autorin). Die Richtigkeit dieses Entschlusses wird sofort bestätigt: im Traum erscheint Dürer „Clara, Richtigkeit dieses Entschlusses wird sofort bestü als Muse gekleidet", und bekränzt das von den anderen neun Muen ungen standbild in Nürnberg (79); direkt darauf folgt die Bekrañzung Dürers durch Kaiser Maximilian (80 f), begleitet von der unumgänglichen Apotheose des Künstlers aus Allerhöchstem Munde (81)

\section{ARCHITEKT: ELISABETH VON RUMÄNIEN}

Wie das Verhältnis zwisçhen Muse und Künstler aussieht, wo es nicht künstlerisch verklärt wird, zeigt sich in Elisabeths von Rumänien Meister Manole (1892) ${ }^{60}$ In Elisa- beths Stück soll Pietro Manolo, ein italienischer Baumeister, im Auftrag von Neagoie Bassarab, dem Fürsten von Muntenia, eine Kirche bauen. Für den König bedeutet dieser Bau die Absolution vergangener Schuld; für Manole wird der Bau selbst zum Fluch: die Mauer der Kirche stürzt jedesmal ein, sobald sie vollendet ist. Durch diesen ständigen Rückschlag verliert er die Gunst seines Fürsten und die Kontrolle über seine überdies schlechtbezahlten Arbeiter, die glauben, er stünde mit dem Teufel im Bunde. Dimitri, ein Ratgeber des Fürsten, versucht, Manole zu vernichten, weil er sich vergeblich um Manoles Frau Maria Giannetta beworben hat, und weil er sich beim Fürsten zugunsten Manoles zurückgeserzt sieht. Daher verbreitet er unter den Arbeitern den Aberglauben, dic Mauer würde stehen, wenn ein Mensch hineingemauert würde. Gleichzeitig erzählt er Giannetta, der König habe ihren Mann zum Tode verurteilt, und bringt sie dazu, beim König für Manole zu bitten. Von diesem Bittgang unterrichtet er wiederum Manole und macht ihn glauben, Giannetta habe sich für seine Begnadigung dem Fürsten, der tatsächlich versucht, Giannetta zu verführen, verkauft. Im Zweifel an der Treue seiner Frau und unter dem Druck der Arbeiter mauert Manole seine Frau lebendig in die Mauer ein; nach der Vollendung der Kirche verfällt er in Wahnsinn und stirbt.

Giannetta wird von Anfang an von den Beteiligten indirekt für den Mißerfolg des Unternehmens verantwortlich gemacht: die Maurer werfen Manole vor, er veruntreue das zu ihrer Bezahlung bestimmte Geld, um seine Frau herauszuputzen (6); Dimitri flößt dem Fürsten denselben Verdacht ein (14). Für Manole besteht eine noch direktere Beziehung zwischen Giannetta und dem Bau: Giannetta versucht wiederholt, ihn zum Abbruch der Arbeit oder zum Glauben an die eigene Größe zu bewegen. Manole dagegen ist ein „Mann, der länger nicht/ Mehr tragen will, daß er der Kunst geweiht" (28). Aber ebensowenig kann er den Bau unvollendet lassen, denn „Ich bin an diesen Ort gebannt, o Fluch/ Dem Ehrgeiz, Fluch dem kühnen Schauen!“ (26) Während Manole seine Kunst als Fluch empfindet, betrachtet er seine Frau als Kunstwerk, das er vor aller Augen verstecken will. "Gleich einem Kirchenschatz will ich dich hüten, $/$ Wenn sie dich nennen, ist mir's schon ein Fluch./ Wenn sie dich sehen, möcht' ich sie vergiften" (31). Schon bevor er von Dimitris Plan erfährt, spricht er Giannetta gegenüber davon, seinen Schatz in die Kirche einzumauern: „reiß” es aus/ Der Brust das Herz, und wirf's hinunter in/ Den Schutt, den Schlamm der Fundamente, wo/ Zu Stein es wird, zertreten wird, zermalmt" (26). In Manoles Gespräch mit dem Hirten Busuioc wird Giannetta implizit mit der Mauer identifiziert. Busuioc bewacht die Baustelle, „Weil bald die Mauer fällt" (30); von da kommt das Gespräch auf Giannetta; Manole versucht vergeblich, herauszubekommen, wer seinen Schatz durch Klatsch entheiligt hat, und spricht beiseite den Verdacht aus: „Hat man als Netz den Knaben hergestellt,/ Darein sie fallen soll?" Busuioc beantwortet die Vermutung mit dem Ausruf: „Ja, fallen, fallen!" Bei seinen Worten stürzt „Die Mauer im Hintergrunde [...] mit lautem, lang anhaltendem Donnergetöse ein" (31).

Busuioc ist, ohne es zu wissen, tatsächlich das Netz, in das Giannetta fallen soll, denn vor dieser Szene hat Dimitri ihm eingeschärft, Manole auszurichten, die Mauer hiclte, wenn „Was Lebendiges, das spricht" hineingemauert würde (32). „Was 
Wendiges, das spricht" bedeutet keineswegs einfach ein menschliches Wesen, sondern

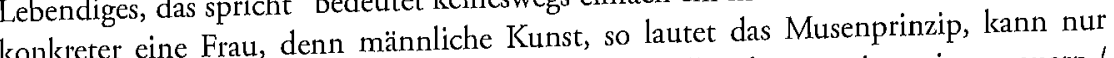
durch Opferung ciner Frau belebt werden. Manole soll „schwören, jene einzumauern,/ durch Oplerung ein. Fittagszeit erscheint./ Von euren Frauen, Die dort [an der Baustelle, S. K.] zuerst zur Mittagszeit enscher euren Kindern, Schwestern" (44). Auf der Baustelle wird Manole der Plan in ahn Worten unterbreitet; jetzt geht es um die erste von den „Frauen, Schwestern, Töch-

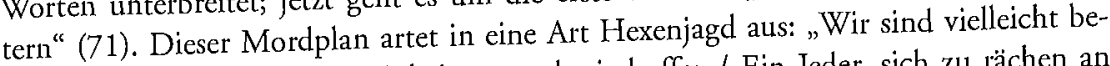
"rof ", mutmaßt einer der Arbeiter, „und wir hoffen,/ Ein Jeder, sich zu rächen an W Wanole interpretiert: "Ihr glaubt, der Himmel wird in Cin strafbedürftig Weib als Erste senden?" (73) Die Arbeiter "glauben's“ in der Hoffnung auf Gottes Beistand „Beim fromm geleistetem Schwur tauchen mehrere Personen - glücklicherweise Männel, die nich behelligt werden dürfen - auf der Baustelle auf (75); die erste Frau, die Manole in de Ferne auftauchen sieht, ist seine eigene.

Manole fleht zu Gott, ihr. Hindernisse in den Weg zu legen (ein Gewitter und eine Überschwemmung); aber Giannetta langt bei ihm an, obwohl seine Gebete erhört werden (79 f). Nun geht Manole daran, seinen Schwur zu erfüllen. Zunächst versucht er, den (79 $)$ Nu bewegen, in die Mauer hinabzusteigen; als das Glanneta der wo vollenden fehlschlägt, begründet er sein Verlangen mit zwei Mor ihm kein Opfer zu groß (84) und sie vor dem König zu schützen. Für sein Werk ist ihm kein Opfer zu goß (84) Giannetta dagegen will er vor dem Fürsten „erretten, [...] beschituen, so/ Verbergen, daß er nie dich mehr erreicht" (85). Seine Liebe, vor der Giannetta inzwischen graut, ist eine besitzerische. Sie will „dich ganz verhüllen [...], daß/Kein Sonnenstrahl dich

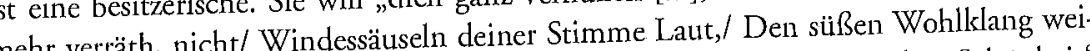

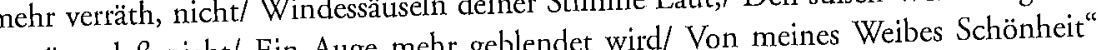
terträgt, daß nicht/ Ein Auge mehr geblendet wird/Von meines Weibes Schönheic (85 f). Jetzt befállt Giannetta die Angst, denn in der vorigen Nacht - in derselben, in der die Mauer einstürzte - wurde sie von einem „wüste[n] Traum“ gewarnt. „Ich sah

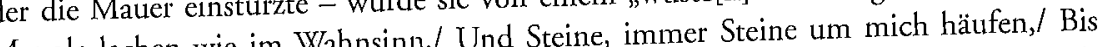
Manole lachen wie im Wahnsinil, " selbst ich nicht mehr rufen konnte (40). Sie flch Lufs Leugnen (87). Schließlich steigt sie lebendig einzumauern; Manole verlegt sich aufs Leugnen (87). Schlicßlich steigt Giannetta freiwillig in die Mauer, um ihren ehelichen Gehorsam zu dem Gian "Sie sollen Alle seh n, daß ich, Mert, mein Hüter!" (88) Mein banges Herz bezwinge und gehorche,/ Mein Herr, mein Hort, mein Huter ( Manole mauert Giannetta daraufhin ein, begleitet von thren ununterbrochenen Bitten und Hilferufen; schließlich fordert er seine Arbeiter zum Reden, Singen und Schreien auf, um ihre Stimme zu übertönen (91-4).

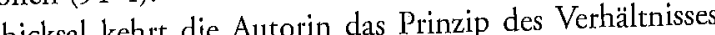
Anhand von Giannettas Schicksal keht die Aulo in das Pinge das Bild steht hier zwischen Muse und Künstler um: anstatt zum Bild zu erstarren stellvertretend für die Muse, den Kirchenschatz, den Manole wor alle Augen Giannetta kann -, wird Giannetta zur Stimme der protestierenden Fal. Anders als in Giannettas Angsttraum, in dem sie auch ihre Stimme verliert, meldet sich diess ununterbrochen zu Wort; sie begleitet Manole durch den Rest des Stückes und treib ihn schließlich in den Wahnsinn: er findet nirgends „Stille vor dem Ton“ (95), er kann weder leben noch sterben mit ihrem „Ruf/ In meinem Ohr“ (96 f). Sein Werk hält er für eine „Stümperei“: „Es ist Staub,/ Ein Haufen Steine ward's und etwas Gold, / Da mit die Kinder meinen, daß es glänze" (98). Da Giannetta sich weigerte und sich auch nach ihrem Tod noch weigert, die stumme Muse seiner Kunst zu sein, wird ihr Bild für Manole schließlich zum Gegensatz zu dem seiner Kunst. Manole stirbt unter diesen gegensätzlichen Visionen: die "glückliche[...] Vision" (108) der Kirche, die er bauen will, beschreibt er "in vollkommenem Selbstvergessen und. künstlerischer Freude“ (104), mit „kindlichem Eifer und Entzücken" (105); seine Vision von Giannetta dagegen ist für ihn das „höchste[...] Entsetzen“ (105), eine „Hölle in der Brust“ (109)

Elisabeth nimmt hier den Prozeß, der in vielen Künstlerdramen von Frauen beschrieben wird, lediglich etwas wörtlicher: die Frau opfert sich der Kunst des Maestro oder wird von diesem geopfert; sie gibt gezwungen oder freiwillig zugunsten ihrer Scheinexistenz als Muse, meist repräsentiert durch ein Bild, ihre reale Existenz als Frau auf. In vielen Künstlerdramen wird die Verbildlichung der Muse für und durch die Kunst des Maestro mit den für die Verklärung dieser Kunst notwendigen ästhetischen Verzierungen versehen; bei Elisabeth entfällt die Ästhetisierung der Kunst. Statt in Stanzen oder auf die Leinwand wird die Muse in eine Mauer verbannt. Was bleibt, ist eine deutlichere Darstellung dessen, was sich in den bereits behandelten Dramen oft hinter dem Glorienschein der Kunst versteckt: der Mord an der Muse. Die zur Muse verbildete Frau stirbt (Westphalen, Elisabeth), sie geht ins Kloster (Pierson) oder verschwindet im Olivenwald (Birch-Pfeiffer); wo die Muse als Frau überlebt - sei es auch nur in der Einbildung des Maestro -, stirbt der Künstler. Auf die eine oder andere Art wird die Frau, die das Vorbild zum ästhetischen Bild des Künstlers liefert, aus dem Wege geräumt, um seine durch dieses Bild inspirierte Kunst nicht zu gefährden. Dieser Pygmalionkomplex ist den meisten in Dramen von Frauen dargestellten Künstlern gemeinsam, egal, ob die Autorin ihren Künstler als geteilte oder als ideale Figur darstellt (wie Pierson ihren Dürer): der Weg des männlichen Künstlers zur künstlerischen Vollendung geht immer über die Leiche einer Frau. 


\section{KAPITEL VII}

\section{Die Emanzipation Vom Mythos der MachtLosigkeit:}

\section{MYTHOLOGISCHE DRAMEN UND BIBELBEARBEITUNGEN}

Dramatische Bearbeitungen mythologischer und biblischer Stoffe sind bei weiblichen Dramatische Bearbeitungen mythesen wearbeitungen nur noch wentlich sind, Autoren relativ selten. Da von diesen Bearbeitungen nur noch weibt, sind vereinzelte fällt es hier schwerer, Zusammenhänge zu rekonstruieren: was bleibe, sind verallenfalls Erscheinungen eines Phänomens, die die Geschichte weiblicher Dramather allenflls ergänzen.

Zeitlich beschränkt sich dieses Phänomen weitgehend auf zwei Zeiträume: auf die Jahre zwischen 1792 und 1812, ein Zeitpunkt, der in etwa mit dem Höhepunkt der Klassik übereinstimmt, und auf die Jahre zwischen dem Deutsch-Französischen Krieg Klassik übereinstimmt, und auf die Jahre und dem ersten Weltkrieg (1870-1910). Die Stoffe deschließlich der griechischen und dem 18. und frühen 19. Jahrhundert entstammen ausschließlich der griechischen und römischen Mythologic; die späteren behandeln 'Themen aus der griechischen, römirömischen Mythologic; dien ${ }^{61}$ Während in der früheren Tradition verschiedentlich auch schen und germanischen. ${ }^{6}$ ährend in der fruhenstruieren (so z. B. in Caroline von versucht wird, klassische Mythen stilistisch zu rekonstruieren (so z. B. in Calvigs [1776 Wolzogens [1763-1847] Der leukadische Fels, 1792; und Amalie von Helvigs [17761831] Die Schwestern auf Corcyra und ihrer Zyklusdichtung Die Tageszeiten, beide 1812 veröffentlicht), konzentriert sich die spätere fast ausschließlich auf die Behand1812 veroffentlicht), konzentriert sich dich lung einzelner Figuren aus bekannten Mychen. Bchandelo we (bei Charlotte von Stein, 1742-1827, in Dido, 1796, und Johanna Holtar 1875, in ihrem gleichnamigen Stück, 1874); Romulus und Remus (Johanna Sedelmayr, 1811-1853, in ihrem gleichnamigen Drama, 1837); Odysseus (Maria Anna

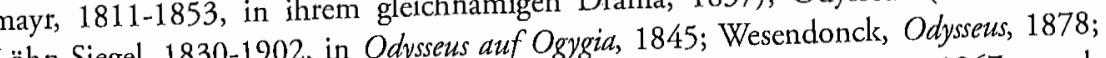
Löhn-Siegel, 1830-1902, in Odysseus auf Ogygia, 1845; Wes Harder, vor 1867 - nach und Bernstein, Nausikad, 1906); Hippolyta (bei Pautrius (Holthausen, Demetrius, o. J.); 1899, in ihrem gleichnamigen Stück, 187-?); Demetrius (Holthausen, Demetrius, o. J.); Antigonos (Friederike Kempner, 1836-1904, Antigonos, 1880); Oedipus (Gertrud
Prellwitz, 1869-1942, Oedipus oder das Rätsel des Lebens, 1896); und Achill (Elsa Bernstein, Achill, 1910)

Aus der (Amalie von Liebhaber, Heldenepils dramatisch bearbeitet: Kriemhild und Siegfried (Aman (Wesendonck, Gud1779-1845, Chric

run, 1868).2 Dramatische Bearbcitungen der zweiten Hälfte des 19. Jahrhunderts; auch hier konzeln biblischen Figur. Beispiele oft auf die Nacherzählung der Geschichte einer einzelnen biblischen Figidts (Daten sind Henrictte von Stolbergs (1751-1832) Moses (1788); nicht ermittelt) Dramatische Bearbeitung einiger Theile der beiligen Geschichte (1827) nicht ermittelt) Dramatische Bearbeitung einiger Theile der (1828); Elise Schmidts Judas Ischariot Friederike Ellmenreichs (1777-1845) Moses (1828); Elise Schmidts Judas Ischarto
(1848); Henriette Reuschs (1834-1902) Das Rosenwunder (1863), und Die Errettung des Moses (1867); Emilie Ringseis' (1831-1895) Märtyrertragödie Sebastian (1868); Emilie von Binzers (1801-1891) Ruth (1868); Luise von Plönnies' (1803-1872) Maria Magdalena (1871); und David (zuerst veröffentlicht 1874); Katharina Diez' (1809-1882) Jephthas Opfer (1875); Marie Eugenie delle Grazies (1864-1931) Sau

(1885); Elsa Bernsteins Mutter Maria (1900); Louise Gutbiers (1834-1904) Eleazar (o. J.); und Anna Krafts (1863 bis nach 1913) Saul (o. J.).

Dieses Kapitel soll einige Dramen vorstellen, die weitgehend bekannte mythologische und biblische Stoffe behandeln, und die Motivation der Autorinnen bei der Wahl des Stoffes untersuchen. Denn Mythologie - hier ist der in der Bibel überlieferte Mythos mitgemeint - unterscheidet sich von anderen Stoffen durch ihr Alter, die häufige Abwesenheit eines Autors, und durch die ehrwürdige Behandlung, die ihr zuteil wird. Bei Mythologic handelt es sich um sogenannte "Timeless Legends" (Hamilton, Titelblatt), die selbst die Grundlage für einen großen Teil der westlichen Literatur bieten. Aber die Überlieferung von Mythen ist keineswegs nur eine literarische; ein vereinzeltes Beispiel dafür ist ihre Manifestation in der Umgangssprache, auch in der des 18. und 19. Jahrhunderts (Sisyphus- oder Herkulesarbeit, Achillesferse, Damoklesschwert, Sirenengesang, Prokrustesbett, spartanische Kost, Tantalusqual, Gordischer Knoten). Mythologie, nicht nur die biblische, hat religiöse Untertöne; sie erklärt die Entstehung der Welt und etabliert sich solchermaßen als die erste Literatur, als Ursprung der Literatur. Dieser Status der Mythologie als Ur-Literatur führt häufig zu einer unterschiedlichen Haltung des Lesers der Mythologie gegenüber; Mythologie erhält einen Status, den andere Literatur nicht hat. Der Mythos ist „zeitlos“, „ewig“; er steht an der Quelle sowohl der Literatur als auch der Religion, er ist relativ unangreifbar und vor allem einzigartig: man spricht nicht von verschiedenen Mythologien eines Volkes, sondern von der Mythologie bzw. dem Mythos.

Ein hervorstechendes Merkmal vieler Mythen - z. B. des griechischen, römischen, germanischen und alttestamentarischen - ist die Unerbittlichkeit des Schicksals und die Machtlosigkeit des Menschen gegenüber dem Willen Gottes oder der Götter. Dazu nur einige Beispiele. Im Nibelungenlied is die Unausweichlichkeit des furchtbaren Endes das Motiv, das sich durch das gesamte Epos zicht; die Anspielungen auf die schließliche Katastrophe beginnen mit der ersten Strophe und reißen nicht mehr ab. Durch diese ständigen Wiederholungen wird auf die Katastrophe in einer Weise vorbereitet, die - ähnlich wie in Homers Ilias - vermuten läßt, diese Katastrophe sei der Höhepunkt oder sogar die Basis des gesamten Epos. Dabei wird zwar oft erklärt, welches spezifische Element die Katastrophe herbeiführt, aber nicht, warum. Dieses Element kann eine Handlung, ein Gedanke oder die Existenz einer Person sein:

Ez wuohs in Búrgónden ein vil édel magedîn daz in allen landen niht schœeners mohte sîn, Kriemhilt geheizen: si wart ein scone wîp.

dar umbe muosen degene vil verlíesén den lîp (2). 
Für die Schrecken am Ende gibt es letztendlich keinen realen Grund. In Sophokles Könir Oedipus erfüllt Oedipus das furchtbare Orakel gerade dadurch, daß er alles darKeinen Vater töten und seine Mutter heiraten, verläßt er sein Zuhause und die Menschen, die er für seine Eltern hält; unterwegs gerät er an seinen Vater und tötet ihn in einem Zornanfall, ohne ihn zu erkennen; spägerăt er an seinen Vater und tott ihn in ennem Zorna wollt, wird schuldig gemacht, und zwar gerade dadurch, daß er versucht, unschuldi u bleiben. Für dieses Motiv gibt es in der griechischen Mythologic unzählige Beispiele, un des Orestes, der von einem Gott zur Rache an seiner Mutter angehalten und yon anderen furchtbar für dieselbe Tat bestraft wird (Acschylos, The Libation Bearers 269-277; 1048-1063; und The Eumenides). Von dem Gott des Alten Testaments werte vert: Jehovah werden Lohn und Strafe auf oft ebenso uneinsichtige Art und Weise vertcilt: Jehovah ist, ähnlich wie die Götter Griechenlands, eine dem Menschen nicht durchschaubare und daher, nach menschlichem Ermessen, willkürliche Mischung aus Erbarmen und Strafe. Hauptsächlich aber ist er, wie die Bewohner des Olymp, ein „eifernder Gott (II. Mose 20,5), der oft auch da straft, wo das Vergehen nach unserem moralischen Empfinden vertretbar scheint (Sauls Schonung der Amalekiter). Fest steht zweierlei, und das gilt für alle genannten mythologischen Richtungen: was Gott bzw. ein Gott und mit menschlicher Moral nicht viel zu tun - und wem die Götter zürnen, der hat verspielt.

\section{A. Mythologie: von Stein, Bernstein, Prelliwitz, Wesendonck}

Gegen diesen Aspekt der Mythologie wenden sich viele Autorinnen in ihren Bearbeitungen, indem sie entweder das furchtbare Ende des Mythos in ein erträglicheres abtungen, indem sie entischen Aspekt einschieben, der im Original nicht existiert, ode wandeln, einen moralischen Aspekt einschieben, der im Original nicht existiert, oder indem sie dem Menschen in ihrem Drama eine größere Eigenständigkeit zugestehen als das Original. In der ersten Richtung werden Geschichten aus der Mythologie in enger Anlehnung an das Original nacherzählt und lediglich die tragischen Aspekte des Originals etwas gemildert. Ein Beispiel ist Mathilde Wesendoncks Gudrun (1868), eine Ber Heldenepos: der Tod der verräterischen Hergart ist geBearbeitung des geichnamigen strichen, die brutale Ermordung der bösen Königin Gerhild aus dem Original wer im Original überlebt und mit Gudruns Freundin und Leidensgenossin Hildbug tet wird, in der Schlacht $(187,191,204)$. Gertrud Prellwitz' (1869-1942) Oedipus oder das Rätsel des Lebens (1896) gibt die Geschichte des Oedipus mit wenigen Abweichun-

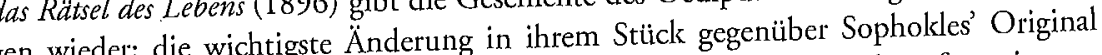
gen sur findet sich am Ende: bei Sophokes blend wissentlich begangenes Verbrechen, übergibt Kreon die Regierung über Theben und verläßt die Stadt, geführt von seinen Töchtern Ismene und Antigone (Oedipus the King 1297-1530). Bei Prellwitz ruft Oedipus seine Untertanen zum Kampf gegen das King 1297-1530). Bei Prellwittliche Schiclssal auf und wird vom Gott Apollo, in lichte Schleier gehüllt, zum
Olymp erhoben (139). ${ }^{63}$ Schon allein die Tatsache, daß der Oedipus dieser Bearbei tung zwar fällt, aber sich nicht (in sein vorgezeichnetes Schicksal) ergibt und in dieser Auflehnung von Apoll bestätigt wird, verweist auf ein wichtiges Merkmal einiger mythologischer Bearbeitungen: auf die Unabhängigkeitsbewegung des Menschen in dieser "neuen "Mythologie.

Teilweise werden dabei Varianten alter Mythen, in denen der Mensch seine Unabhängigkeit von göttlichem Willen oder äußeren Zwängen unter Beweis stellt, wiederaufgearbeitet, wie in Charlotte von Steins (1742-1827) fünfaktigem Trauerspicl Dido (1796). Interessanterweise sind diese Varianten nicht mehr die, die wir heute kennen in der Reverenz vor dem Mythos geht häufig die Tatsache unter; daß es teilweise verschiedene Mythologien - unterschiedliche Varianten desselben Stoffes - gibt, und daß es die Rezeption des Lesers ist, die entscheidet, welche Variante zur vorherrschenden wird. Der Stoff der Dido von Karthago z. B. ist in zwei Varianten überliefert: in einer mittlerweile verschollenen Quelle und in Vergils Aeneis. Nach der ersten Variante erscheint Dido, von ihrem Bruder aus ihrem Königreich Tyrus vertrieben, bei König Hjarbas und bittet ihn um soviel Land, wie sie mit einer Ochsenhaut umspannen könne. Der sagt zu, da er meint, ein so kleines Stück Land gut entbehren zu können. Daraufhin zerschneidet Dido die Haut in dünne Streifen, verlängert die Streifen durch Einweichen in Wasser und umspannt damit ein riesiges Stück Land, das sie vom König beansprucht und erhält. Auf diesem Land baut sie ihre Stadt Karthago. Nach langer erfolgreicher Regierungszeit begeht sic Selbstmord, weil sie sich vor den Nachstellungen des Königs Hjarbas, der sie zur Ehe mit ihm zwingen will, nicht mehr schützen kann, und weil sie ihre Herrschaft nicht mit ihm teilen will (Meyer). Bei Vergil spielt sich die Geschichte anders ab: Aeneas, der Held seiner Geschichte, landet nach seiner Flucht aus Troja in Karthago. Unter dem Einfluß der Venus, Aeneas' Mutter, verliebt Dido sich in Aeneas und tut alles, um ihn bei sich zu halten. Aber Aeneas ist von Jupiter dazu bestimmt, ein neues Königreich in Latium (später Rom) zu gründen, und setzt seine Reise auf dessen zornige Vorhaltungen fort. Bei Aeneas' Abreise erstich sich Dido und verbrennt sich auf einem eigens dafür errichteten Scheiterhaufen (Aeneis).

Von Stein, deren Stück auf der ersten Variante des Mythos aufbaut, ${ }^{64}$ geht damit gegen die von Vergil überlieferte Version an, die meist mit dem Dido-Mythos identifiziert wird. In ihrem Stück droht der machtgierige König Jarbes Dido mit einem Feldzug, wenn sie sich weigert, ihn zu heiraten. Da Didos Ratgeber keinen Ausweg aus dem Dilemma sehen und das Volk nach ihrer Aussage das Opfer von seiner Königin verlangt, entschließt sich Dido, zugunsten ihres Bruders abzudanken. Dido verläßt Karthago und zieht sich zu einem Einsiedler ins Gebirge zurück; sie zieht dabei nur ihre Freundin Elissa und ihren Vertrauten und Priester Albicerio ins Vertrauen. Mittlerweile marschiert Jarbes in Karthago ein und versucht, Elissa und Albicerio zu zwingen, Didos Aufenthaltsort zu verraten. Albicerio weigert sich und wird zum Tode verurteilt; in der fuihrerlos gewordenen Stadt bricht revolutionsartiges Chaos aus. Dido erfährt von der Bedrängnis ihres Volkes und ihrer Freunde, kehrt zurïck und begeht öffentlich Selbstmord - in der bei Vergil beschriebenen Weise. 
Hinweise auf die Motivation des Stückes und zur Beantwortung der Frage, inwiein fern der mythologische Stoff dis Molitischen Vorgänge und in der Zweiteilung de im Stück: in der Darstellung der politischen Vorgange und in der Za mythologischen Dido in die Figuren Dido und Elissa. Blissa, in der Sage lediglich ein anderer Name für Dido, wird im Stück zu Didos bester Freundin. Sie ist Didos alte ego, der Königin treu ergeben und die einzige Figur außer Albicerio, der Dido unbedingt vertraut. Während aus verschiedenen Anspielungen deutlich wird, daß z. B. Albicerios Errebenheit Dido gegenüber auf seiner heimlichen Liebe zu ihr beruht, hat Fil Elissa, anders als alle anderen File noch Didos Flucht dung zu Dido wird nirgends erläutert. Thre Rolle ist vor allent die, nach Didos Flucht in Karthago zurückzubleiben, um die Flucht der Königin zu decken, denn won ihrer Anwesenheit schließen sämtliche anderen Figuren des Stückes wie selbstverständlich auf die Didos (511). In Karthago widersteht Elissa allen Versuchungen, denen Dido

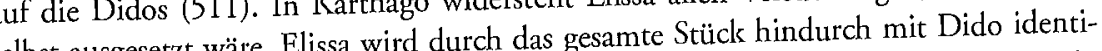
Cil der Tit sido - das Prinzip der Treue sich der Treue, vor allem - durch ihre Idente ist das eine der Eigenschaften, die Dido als selbst gegenüber. Wie

Herrscherin legitimiert. $\quad$ Didos dargestellt. $\mathrm{Zu}$ Auf politischer Ebene wird Didos Reich als eine Art anilke über ihre Regierungszeit: Beginn des Stückes zieht die Königin selbst eine Art Resume tibe ihre Regierungreit

Es blühet alles um mich herum, alles ist im Wohlstand, mein Volk, meine Seemacht, alle Handthierungen; es dringt keine Stimme des Mangels mehr zu meinem ( A meine Hülfe, es ist nirgends eine dringende Noth, auch Oh. An WW

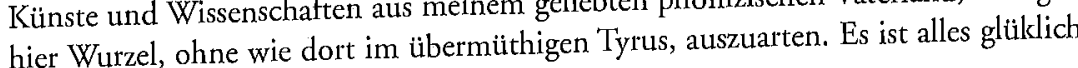
(491).

Dido selbst wird als vorausschauende und entschlußkräftige, aber gütige Herrscherin dargestellt, die ihren Beratern zwar eine Stimme zugesteht, aber notfalls durchaus imstande ist, selbständige Entscheidungen zu treffen (494). Jarbes dagegen, der selbsterklärte Anwärter auf ihre Hand und damit auf die Herrschaft über Karthago, ist ein korrupter Monarch, in dessen Reich es keineswegs so paradiesisch zugeht wie in Didos . Jarbes glaubt weder an die Tugend noch an die Götter, will sich Didos Reichtïmer geJich auf persönlicher Ebene als liebesunfähig (497). 列 Im politischen Kontext des Stick fä denn persönliches Verhaten ihres Volkes unterzuordnen (491), ist sie auch imstande, die ist, ihr privates Glück dem ihres Volkes unterzuordnen ( politische Macht zum Besten ihres Volkes aufzugeben; Jarbes' Gefuhle dagegen beschränken sich auf Herrschsucht - sowohl auf privater als auch auf politischer Ebene. schränken sich auf Die Liebe, die Dido ihrem Volk und ihrem Jarbes nicht: „Dieses glüklich gepriesene Gefühl des Herzens haben mir die Götter versagt, Sklavinnen sind alles, was ich begehre, und in der Liebe sind meine schönen afrikanischen Pferde mir die nächsten am Herzen“ (497). Seine Werbung um Dido ist ein Feldzug: „ich falle ins Land ein mit Gewalt, und sie, oder auch nicht sie, ihre Schätze, die ich haben will, sind meiı" (497); das Ziel des Feldzuges ist die Unterwerfung der Königin: „Zu meinen Füsen will ich die stolze Frau liegen sehen“ (516). Auf politischer Ebene ist sein Verhalten analog: er fällt in das Land ein, versucht, verschiedene von Didos Getreuen zu bestechen, verleitet die Bestechlichen zum Verrat und verurteilt die Unbestechlichen zum Tode.

Wie das Regiment des Jarbes - in krassem Kontrast zu dem Didos - aussähe, wird im Stück mehr als deutlich gemacht; trotzdem wird wiederholt erklärt, das Volk verlange von Dido das Opfer der Ehe mit Jarbes (493). Erstaunlicherweise wird weder vor noch nach Jarbes' Einmarsch das oft zitierte von Dido abgefallene "Volk", die Einwohner Karthagos, die „sich von dem Jetulischen Barbaren, dem Goldsüchtigen Jarbes befehlen lassen" (523), auf der Bühne gezcigt. Im Gegenteil: wo Angehörige des Volkes auf der Bühne erscheinen, tun sie es mit Treuebezeugungen für die Königin, und zwar Mitglieder sämtlicher Stände: der Rat (509), Albicerio, der im Stück die kirchliche Institution vertritt (505), die Bürger (518 f), die Sklaven (521), die Kaufleute (523) und die Wache bzw. das Militär (527 f). Selbst ein Feldherr des Jarbes läßt sich von Didos 'Tugend und Jarbes' Laster überzeugen und fällt von Jarbes ab (517 f),

Einzige Ausnahme in diesem Bild der Volkstreue sind die drei Gelehrten Ogon, Dodus und Aratus. Diese drei stehen stellvertretend für die Intelligentia des Landes (Ogon ist Poet, Dodus Philosoph und Aratus Geschichtsschreiber); sie sind gleichzeitig die einzigen, die Jarbes' Bestechungsversuchen unterliegen. Ogon hält die Gelehrten für die Vollendung der Menschheit und alle anderen für "das Gewürme, das unbemerkt zertreten wird" (495) und hat seine ehemaligen Ideale zugunsten der Völlerei aufgegeben (495 f). Dodus propagiert heimlich die Revolution $(496)^{65}$ und ist der erste, der seinem neuen Herrn Jarbes zur Gewaltanwendung rät (524). Aratus versucht, Elissa auf Jarbes' Seite zu ziehen, indem er ihr schmeichelt (505 f) und wirft sich später zum Sprachrohr des Volkes auf (527 und 531). Wogegen die Gelehrten sich besonders wehren, ist das Regiment einer Frau. Die Rhetorik, mit der sie ihre Gründe vortragen, dient einmal mehr dazu, sie lächerlich zu machen.

Donus. Lange genug haben wir das Pfund unsers Genies, das uns die Götter zum Wohl der Völker verliehen, unter dieses Frauen-Regiment vergraben müs$\operatorname{sen}[\ldots]$.

JARBES. Ein Mann weiß scharfsinniger zu unterscheiden.

OGON. Gewiß! Denn auch der mittelmäsigste Dichter findet ein Weib, das ihm huldigt, ob ich mich gleich von der Königin dieses nicht rïhmen kann. [...] ich gestehe, daß ich mich gern loben höre, es mag von Güte, Schmeichelei oder Albernheit herrühren, ich sehe nicht gern hinter den Vorhang (502 f).

Bei aller Lächerlichkeit stellen doch die Gelehrten die ernstzunehmendste Gefahr für das Land dar, da es ihnen, wie im Stück impliziert wird, gelingt, einige Bürger zum 
Abfall von Dido zu überreden (527). Didos letzte Amtshandlung vor ihrem Selbstmord ist demgemäß die Verbannung der drei Gelehrten (531).

Dommentar der Autorin zur FranzösiDie polition gëllich, wird aber von 列 den Ereignissen uberrannt, die einzigen Anănger deinen schlechten Tausch; es ersetz Letztendlich macht das Volk bei diesem Unsturz ein sachierigen und unfähigen eine gütige und kompetente Herrscherin durch einen mach giengen und unf Potentaten. Von Stein scheint es zum einen darum zu gehen, die negativen AuswinunPen desturzes darzustellen; andererseits aber macht sie den Unterschied zwischen gen des Umsturzes darzustig an Geschlechtscharakteristika fest. Die Wichtigkeit persönDido und Jarbes eindeutg an Gesche harakterDich lichen Gegensätze keinesweg sollen, wird im Stück wiederholt betont. So bricht Elissa gemeiner verstanden werden sollen, wirk

bei der Nachricht, daß Jarbes mit Heeresmacht anruckt, in eine Anshlecht.
sich nicht an Jarbes richtet, sondern an das gesamte männliche Geschlo

zerstörendes Geschlecht! ohne euch wär uns die Kriegslust unbelkannt. Warum Thesensucht, um den ruhigen gabst du Natur! den Männern dieses Treiben, ding Gang nach einem bess

Elissas Worte können als Kurzformel für das ganze Stück stehen: der ruhige Gang nach inem besseren Ziele, den Dido in ihrer Regierungszeit angetreten hat, wird von Jarbes

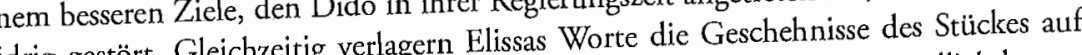
Weiberregiment letztendlich besser. die allgemeine Ebene: das Volk hat es unter einem Welbel zu beantworten. Warum

Die Frage nach der Wahl des Stoffes scheint sich hier selbst zu beantworten. Warum die Autorin auf einen mythologischen Stoff verfiel, braucht hier nicch erhutert zu werden - das taten viele Autorinnen und Autoren der Klassik. Aber der Dido-Stoff ist in desselben Mythos gegen-

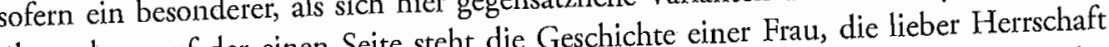
uiberstehen: auf der einen Seite steht die Geschichte einer Thu, dic liebe He und Leben aufgibt als ihre persönliche Unabhängigkeit, auf der anderen Seite der Mythos von der Frau, die sich nicht einmal aus eigenem Antrieb, sondern unter dem Einfluß der Venus in einen Mann verliebt und sich tötet, als ihr Geliebter sie verläßt. Eürönliche und die politische - erwies sich der urFür von Steins Geschichte - die personliche mindo-Mythos als wesentlich geeigneter als die sprüngliche und heute fast unbel

bekanntere Dido aus der Aeneis.

Eines der Themen, die von Stein in ihrem Stück anschneidet, ist ein wiederkeh rendes Motiv in vielen Mythologiebearbeitungen, nämlich die Fähigkeit zu lieben als moralisches $\mathrm{Maß}$ des menschlichen Charakters. In der Mythologie dagegen we handelnden Figuren cher mit einer Charaktereigenschaft, Fähigkeit oder ăußerem herkal identifiziert $($ Achill $=\mathrm{Kraft}$; Helena $=$ Schönheit; Odysseus $=$ List und GeMerkmalide duld; Philoktetes = Neid); ethisch-noralische Wen die sich gegenüber dem Original unwichtig. Um so krasser sind die Veränderungen, die sich gegenüber dem Origina ergeben, wenn dieser Aspelkt zum vorherrschenden gemacht wird - selbst wenn der Original-Mythos inhaltlich fast genau beibehalten wird.

Eine der interessantesten mythologischen Bearbeitungen dieser Art ist Mathilde Wesendoncks Odysseus (1878), die zwei Episoden aus Homers Odyssee behandelt, Odysseus' Abenteuer auf Calypsos Insel und das nachfolgende bei den Phäakern. Die Odyssee berichtet von der zehnjährigen Irrfahtt des Odysseus nach Beendigung des Trojanischen Krieges, die Odysseus erdulden muß, weil er sich die Feindschaft des Meergottes Poseidon zugezogen hat und dieser ihn an der Heimfahrt hindert. Während dieser Irrfahrt landet Odysseus u. a. auf der Insel der Nymphe Calypso, die sich, wic früher Circe, in ihn verliebt und versucht, ihn bei sich zu behalten. Odysseus wird schließlich mit Hilfe seiner Beschützerin Athene aus seiner Gefangenschaft befreit: auf Athenes Betreiben hin schickt Zeus Hermes zu Calypso mit dem Befehl, Odysseus zu entlassen (Homer, Odyssee V, 1-270). Dic Episode bei den Phäakern ist die letzte vor Odysseus' Heimkehr: Odysseus wird an der Küste des Phäalkerlandes schiffbrüchig und dort von der Königstochter Nausilkaa, der Athene im Traum den Gedanken eingegeben hat, zum Strand zu gehen, aufgefunden. Sie kleidet ihn soweit ein, daß er sich ihren Eltern mit der Bitte um Hilfe zu Füßen werfen kann. Am Hof wird Odysseus freundlich aufgenommen, ohne daß er sich zu erkennen gibt; bei einem Festgelage wird er erkannt und erzählt daraufhin dem Königspaar ausführlich seine Abenteuer (bei Homer umfaßt diese Erzählung vier Gesänge von insgesamt 24). Die Phäaker schicken ihn mit einem mit Geschenken beladenen Schiff nach Hause, müssen aber dafür die Rache des unversöhnlichen Poseidon in Kauf nehmen, der das Schiff auf der Rückfahrt in einen Felsen verwandelt (VI, 1 bis XIII, 187).

Beide Episoden werden von der Autorin fast unverändert übernommen - mit zwei nur scheinbar geringfügigen Abweichungen: in der Kalypso-Episode verlegt sie den Akzent auf Kalypsos selbstsuichtige Liebe und baut ein moralisches Lernerlebnis für die Göttin ein; in der Episode bei den Phäakern verlieben sich Nausikaa und Odysseus ineinander. Dem Bild der unbeirrbaren Treue, das Homer von Odysseus zeichnet - er umschreibt seinen Helden mit Vorliebe als den „herrlichen Dulder“ -, fügt Wesendonck einen weiteren Aspekt hinzu: Odysseus wird in ihrem Stück zum moralischen Lehrmeister der weiblichen Figuren.

Was Kalypso von Odysseus lernt, ist die Fähigkeit zu entsagen. Zu Beginn des Stülkkes erwartet sie Erwiderung ihrer Liebe aus Dankbarkeit, als ihr schuldigen Tribut also, kann aber Odysseus weder mit Hinweis auf diese Dankbarkeitspflicht überreden noch mit der Unsterblichlkeit verlocken. Denn Odysseus hat an dem Himmel, den sie ihm bietet, weniger Interesse als an irdischer Liebe; die einschüchternde Schönheit und Macht der Göttin crinnern ihn nur stärker an die Eigenschaften, die er mit Penelope verbindet, nämlich „Weiblichlseit und treue Liebe" (23). Anders als bei Homer läß Kalypso Odysseus schließlich deshalb ziehen, weil sie gegen seine Willensstärke nicht ankommt: letztendlich ist es „nicht Zeus' Gebot, das ich erfülle,/ Wenn ich Odysseus auf das Meer entsende,/ Es ist des Mannes unbeugsamer Wille,/ Der hier die Göttin zwingt" (32). Dieser Machtdemonstration des Mannes der Frau gegenüber folgt ein weiteres Stadium in der moralischen Entwicklung der Göttin: während sie ihren 
Geliebten in der Odyssee nur widerwillig entläßt, begreift sie bei Wesendonck ihre EntGeliebten in der ihre Liebe beweisen; da Liebe hier mit Entsagung identifiziert wird, lernt Kalypso dirch Odysseus und die Entsagung, die er von ihr verlangt, lieben. Kalypso bestätigt ihre Umwandlung von der hehren Göttin zum liebenden Weib:

Ich kannte nur ein $I c h$ - ein göttlich Ich-

Bedürfnißlos und wunschlos wie mich selbst!

Du kamst - und ich erkannt in Dir ein Du

Und dieses $D u$ erhöhte mir mein Ich,

Ach mehr! Ich mußt' es allzubald erkennen,

Daß keine Seligkeit des eignen Ich

Den Wunsch aufwiegt im heißgeliebten Du! (37, Hervorhebungen der Autorin)

Während die mächtige Göttin Kalypso im Vorspiel von Odysseus zu dem Ideal der White "Weiblichkeit und treuen Liebe "bekehrt wird „Die Liese Stückes, Nausikaa, Odysseus" der Pflicht!“, 38), gerät in dem dreiaktigen Hauptteil des Stückes, Nausikaa, Odysseus eigene Treue ins Wanken, weil er eben diesem Ideal in Nausikaa wiederbegegnet. Nausikaa ist Homer treu nachgezeichnet: sie ist cin sehr junges Mädchen, die ihre Zeit mi Wäschewaschen und Ballspielen verbringt, aber im Vergleich mit ihren Altersgenos-

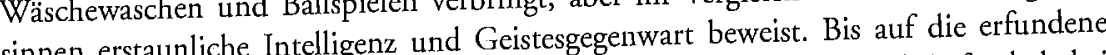
sinnen erstaun Liebesgeschichte zwischen Nausike Wie im Vorspiel ist auch dicse Liebesgeschichte den Phäakern genau wie im Original. Wie im Vorspien ist auch dicse Lieb (58), danach eine Entsagungsgeschichte: Nausikaa verliebt sich auf den ersten Blick (58), danach wird auf ihre Gefühle nicht weiter eingegangen.

Odysseus dagegen gerät erst beim Abschied zum ersten Mal - und relativ unvermuBis zum tert tet - in Versuchung. Bis zum letzten Akt wir für den Zuschauer einigermaßen überund auch jetzt kommt diese Entwicklung für den Zuschauer einigermaßen unorraschend. Am Tage seiner Abreise beschreibt Odysseus in einem dreiseitigen Monolog den Tagesanbruch, wobei er, ganz nach dem griechischen Vorbild, die Natur personifziert: „Getragen von der Morgenröte Flügeln,/ Schwebt' Eos goldgelockt zu mir heran " (97) Auf die ausführliche Beschreibung der Morgenröte folgt die des Sonnenaufgangs (97). Auf die ausführliche Beschreibung der Mirbt der Tag, ein jugendlicher Freier/ Mit sciner personifizierten Schöpfung: „Dann wirbt der Tag, ein jugendlicher Freier/ Mit Flammenblicken um die keusche Erde,/ Die abgewendet halb, nach Jungfrau'n Art, Erröthet und verhüllt die lieblichste Geberde!" (98) Von der Naturbeschreibung verErröthet und verhull die Beschreibung der Stadt, ihrer Bewohner, Einrichtungen, und fällt Odysseus auf eine Beschreibung der Stadt, ihrer Bewoher, Einnichen seinen Gastdem Treiben der Einwohner (99), geht über zu Dankbarkeitsbezengungen seinen Gastgebern gegenüber und erwähnt die ihm erwiesenen Wohltaten (99 f), worauf er die gebern gegenüber und erwaht (100). Je länger er bleibt, das fühlt er, desto schwerer Bitterkeit des Abschieds beklagt (100). Je länger er blibt, Entflieh'n, bevor die hoilde wird der Abschied; schließlich sieht er sich gezwungen, zu "Entfieh'n, bevor die holde Lichtgestalt/ Von Himmelsschöne und von Erdengüte,/ Mich fest zur Stelle bannt, Nausikaa!" (100) Nach dieser etwas epischen Einleitung fällt hier zum ersten Mal ihr Nausikaa!" (100) Nach dieser etwo Kenntnis Name; andererseits ist dieses Gefühl, von dem der Zuschauer erst jetzt in Kenntnis gesetzt wird, stark genug, um das Endziel der Odyssee - die Heimkehr des Odysseus in Frage zu stellen. Denn auf den Gedanken an Penelope ist Odysseus erstaunlicherweise noch nicht gekommen, und das Verlangen nach Ithaka, das ihn der mächtigen Kalypso gegenüber zu beharrlichem Widerstand inspirierte, ist plötzlich verschwunden:

Mein Ithaka! Wie machte sonst Dein Name

Die Brust erbeben mir in brünst'ger Sehnsucht!

Wo sind die Schwingen die mich heimwärts tragen?

Wie ist gehemmt der Fuß, die Seele voller Zagen,

Und auf den Lippen Laute, wie von Klage? (100)

Als Nausikaa direkt darauf die Bühne betritt, verfällt Odysseus der Versuchung der "Weiblichkeit“. Nausikaa deutet etwas weniger beredt als die herrischere Kalypso ihre Liebe an, und Odysseus erklärt sich durch „der süßen Lippen Stammeln" (103) überwunden:

[...] Ließ Götterreiz mich kalt,

Mocht' ich Kalypso's Lockung widersteh'n,

Und Kirke's schlimmem Zauber mich entwinden,

Mocht' ich Seirene's süßem Sang entgeh'n,

Der grausen Skylla Schreckniß überdauern,

Wo lebt der Mann, den nicht der Lenz bezwingt,

Wenn ihm Dein Auge, wie die Mainacht tief,

Mit wehmutsfeuchtem Pfeil die Brust durchdringt,

Daß er vergeht vor Wonn- und Weheschauern? (104)

Die Gegensätze zur holden „Weiblichkeit", vor der Odysseus vergeht, sind die weiblichen Schreckbilder des Mythos: eine Nymphe (Calypso), zwei Zauberinnen, die ihre Künste vornehmlich dazu anwenden, Männer ins Verderben zu locken (Circe und die Sirene), und ein Seeungeheuer weiblichen Geschlechts mit sechs Hundeköpfen, das in einer Meerenge nichtsahnenden Seefahrern auflauert und sie verschlingt (Slcylla). Aber all diese Gefahren sind nun überwunden; Odysseus und Nausikaa erklären cinander ihre Liebe und schwelgen kurz in dem neuen Gefühl, bis die Ernüchterung folgt: Odysseus „besinnt sich plötzlich“ (106) auf Penelope und erklärt Nausikaa, er sei bereits verheiratet (107).

Die darauffolgende Entsagung hat auf Nausikaa dieselbe Wirkung wie früher auf Kalypso: die der Läuterung zu Höherem. Nach kurzem Verzweiflungsausbruch erklärt sie sich als "gereift an dieser schwersten Stunde/ Und von der Kindheit Traum emporgetragen/ Durch Deine Liebe zu der Menschheit Höh'n!“ (109, Hervorhebung der Autorin) Wie im Falle Kalypso ist Entsagung gleichbedeutend mit Liebe und daher mit Glück; für Nausilkaa wiegt „dieser Augenblick voll hoher Liebe/ Zu dir [...] Ewigkeiten auf von Erdenglück" (110). So kann Odysseus zwar schmerzerfüllt, doch mit beruhigtem Gewissen scheiden: „Erinnjen wandeln sich in Eumeniden“ (111) ${ }^{66}$ Was 
er Nausilkaa zurückläßt, ist „Der Männerwürde bohes Ideal“ (112, Hervorhebung der Autorin), ähnlich wie seine Standhaftigkeit Kalypso zu einer neuen Achtung vor dem Menschengeschlecht bekehrt: „ahnungsvoll gesteht's der Götterbusen:/ Ein Großes muß es um die Menschbeit sein!" (38, Hervorhebung der Autorin)

Obwohl sich hier, diesmal eingehüllt in eine Toga, einmal mehr das aus unzähligen Stiicken bekannte Bild der Frau als hold und widerspruchslos entsagende Weiblichkeit Stuicken bekance Bild der Pran als hald und wien präsentiert, scheint es wichtig, eins festzuhalten: das Große, das um die Menschheit ist, ist keineswegs ein Großes, sondern ein Ethisch-Moralisches, nämlich eben die Liebesfähigkeit auf privater Ebene, die schon von Stein auf die Bühne brachte. Interessanterweise ist diese menschliche Qualität im Vorspiel der einzige Faktor, der Odysseus vor der Göttin rettet: ihre spätere Menschlichkeit (Entsagung, Liebe) steht im Gegensatz zu ihrem sie Odysseus zwingen könnte. Die zu ihrem gottichen Göttin als Göttin wäre genau das, was sie in der Mythologie ist: das tünentich geworSchicksal des Menschen. Durch Liebe vermenschlicht, ist Kalypso ungefährlich gewor

den und bietet Odysseus seine einzige Chance, dem Verhängnis zu entkommen.

In späteren Mythologiebearbeitungen gehen die beiden genannten Themen (Unabhängigkeit des Menschen dem Schicksal gegenüber und die Einführung ethischmoralischer Faktoren) ineinander über: oft werden die sogenannten „menschlichen“ Faktoren zum Ausdruck der menschlichen Unabhängigkeitsbestrebungen. Was die Menschen den Göttern, die sie beschützen und bedrohen, entgegenhalten, ist das, was sie von ihnen unterscheidet (Liebe, Moral, Ethil, Glïcksansprïche).

Ein Beispiel ist das oben bereits genannte Schauspiel Oedipus oder das Rätsel des Lebens von Gertrud Prellwitz: hier steht die Befreiung Thebens von der Sphinx als stellyertretend für den menschlichen Glücksanspruch überhaupt. Oedipus befindet sich, wie vorher sein Vater Laios, auf der Suche nach dem "Glück" (37); das ständige ses Stiickes ist das Licht (symbolisiert durch Apoll, den Gott des Gegensatzpaar des Stickes ist das Tiche (sybering Lichts) und die Nacht (symbolisiert durch die Sphinx). Das Licht steht gleichzeitig fü die Eigenständigkeit des Menschen und dic Nacht für die Unentrinnbarkeit de Schicksals; das im Titel angesprochene Rätsel des Lebens, das Oedipus zu lösen versucht, ist eine direlate Auseinandersetzung mit dem mythologischen Prinzip der absoluten Souveränität des Schicksals. Denn die in der Mythologie vorgesehene Lösung de Rätsels schließt jede menschliche Kontrolle über das eigene Schicksal aus.

Ist das die Lösung? - „Tückischen Mächten unentrinnbar verfallen, wchrlos verfallen", - ist das die Lösung? - Grauen und Entsetzen dic Wahrheit der Welt?! [... Ist dat dem Streben nach Gottheit frevler Mächte ein Ist das die Lösung? „Der Mensch mit dem Streben nach Gottheit for Wach [...] Schicksal -! Schicksal - ! (38, Hervorhebungen der Autorin)

Während bei Sophokles das Schicksal selbstverständlich souverän regiert, sieht Oedipus hier am Ende des Stückes „das Licht! Was durch die Nacht geht, Freunde, das dunkle Schicksal, das ist ja verhüllt der Gott des Lichts!" (138) Bei Prellwitz kann die Nacht besiegt werden, und zwar durch eigenständiges menschliches Handeln, wie
Oedipus' Aufruf am Ende des Stückes andeutet: „Meine Brüder, kämpft! Ringt euch hinan! Dringt durch die Hüllen, dringt zu dem Licht!" (139)

\section{B. Biblische Dramen: Kraft, delle Grazie}

Der menschliche Glücksanspruch im Gegensatz zu oder unabhängig vom göttlichen Willen ist ein Thema, das auch in Bearbeitungen biblischer Geschichten auftaucht und dort ist es wesentlich brisanter als in Bearbeitungen griechischer Mythologie. Von den oben angeführten biblischen Dramen waren mir nur zwei zugänglich, Anna Krafts (1863-nach 1913) Saul (o. J.) und Maria Eugenie delle Grazies (1864-1931) Saul (1885). Diese gegensätzlichen Bearbeitungen desselben Stoffes sind eine weitere Auseinandersetzung mit dem Mythos von der Unkontrollierbarkeit des Schicksals. Diejenige der beiden Bearbeitungen, in der das menschliche Schicksal, vom Menschen selbst nicht beeinflußbar; von Gott bestimmt wird, hält sich relativ genau an die im 1. Buch Samuel erzählte Geschichte; dagegen verlangt die Version, die für menschliche Autonomie plädiert, eine radikale Änderung des Originals.

Im 1. Buch Samuel verlangt das Volk Israel in Auflehnung gegen die Führung Jehovahs einen menschlichen König, worauf der Prophet Samuel den Erwählten Gottes, Saul, zum König salbt. Saul führt mehrere erfolgreiche Kriegszïge; auf dem Feldzug gegen die Amalekiter bricht er Gottes Gebot, das ihn dazu anhält, das Volk Amalek völlig zu vernichten: „verschone sie nicht, sondern töte Mann und Frau, Kinder und Säuglinge, Rinder und Schafe, Kamele und Esel" (I. Samuel 15, 3). Saul dagegen verschont den König Agag und die besten Rinder und Schafe, um die Tiere Gott zu opfern. Daraufhin wendet sich Gott von Saul ab und läßt ihm durch Samuel, der in Erfüllung des göttlichen Gebots Agag eigenhändig tötet, seine Absetzung ankündigen. Von da ab ist Saul von einem vom Herrn geschickten bösen Geist besessen $(16,14)$. Zur Besänftigung dieses bösen Geistes läßt Saul David zu sich kommen, damit ihn dieser mit seinem Harfenspiel beruhigt. David stellt sich gegen Sauls Willen dem Kampf mit Goliath und besiegt ihn, wofür er, gemäß Sauls früherem Versprechen, Sauls Tochter Michal zur Frau erhält, nicht ohne vorher einen Brautpreis von 200 philistinischen Vorhäuten zu erlegen $(18,25-27)$. Sauls Eifersucht auf Davids Macht und Popularität im Volk wächst; er versucht vergeblich, seinen Sohn Jonathan zum Mord an David anzustiften und zwingt David schließlich zur Flucht. Auf der Verfolgung Davids gerät Saul zwei Mal in Davids Hände; David schont ihn beide Male; jedes Mal bereut Saul und erklärt David zu seinem Nachfolger (24, 5-22 und 26, 7-22). In einem neuen Krieg der Philister gegen Israel werden Sauls Söhne getötet; er selbst begeht Selbstmord. Sein Waffenträger überbringt David die Krone und erkennt ihn als König Israels an, wofür ihn dieser im Schmerz um Saul und seine Söhne töten läßt (II. Samuel 1, 7-26).

Die Geschichte von Saul und David ist nicht nur die Geschichte menschlicher Auflehnung und göttlicher Strafe, sondern auch eine Machtdemonstration des rächenden Gottes, der „die Missetat der Väter heimsucht bis ins dritte und vierte Glied an den 
Kindern derer die mich hassen" (II. Mose 20, 5). Von Sauls einstiger Macht bleibt Kindern derer, die mich hassen (Il. Mose 20, nichts übrig, nichts davon geht auf seine Angehörigen über. Seine (David ergeben Tochter Michal, die David durch eine List vor Sauls Nachstelltngen daher keinen Anteil an Davids Flucht mit einem anderen Mann verheiratet und Davids Königtum; David selbst heiratet auf seinen Feldzügen zwei Mal (I. Samu 39-44) Sauls Söhne fallen allesamt in der Schlacht, auch der treue Jonathan, der mit 39-44). Sauls Söhne fallen alles tut, um ihn vor Saul zu schützen $(20,1-23)$. Sauls proDavid befreundet ist und alles tut, um ihn vor Saul zu sch minentester Höfling Doeg, früher ausführendes Organ seiner grausamsten und ingerechtesten Befehle (die Tötung Achimelechs und der Priester von Nob, 22, 7-22) verschwindet nach Davids Machtiibernahme aus der Geschichte. Ob die Figuren nach verschichelech) oder nicht (Saul, ) Doeg), har letzendich kein gehört, geht unter, gemẩ demselben götlch Gaul nicht wegen seiner Missetaten, und Säuglinge" der Amalekiter anordnet. Daß Saul nicht wenen seiner Mid mach sondern wegen seiner Übertretung des göttlichen Gebots gerichtet wird, mach sein Beib von Endor klar; sie beschwört den Geist des Propheten sein Besuch bel dem Samucl heraut, der ihm sein Ende ane Hern nicht gehorcht und Mordversuche an David, sondern "Weil du der Stimme des Herrn $(28,18$; Hervorhebung im seinen Text).

fte Berbeitung dieser Geschichte hat eine im Prolog erklärte religiöse Anna Krafts Bearbeitung dieser Geschichte hat eine im Prolog Welt ein ernstes Motivation: Saul ist für sie ein von Gott statuiertes Exempel, „der Welt ein ernstes Mahnen" (Prolog, unpag.). Sauls Beispiel verdeutlicht die Folgen menschich legt: „Ich lehnung gegen den Gott, dem die Autorin im Prolog folgendes in den Mund legt: "Ich

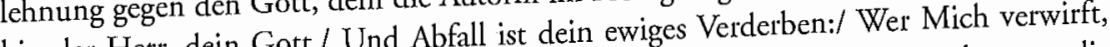
bin der Herr, dein Gott,/ Und Abfal die der muß des Todes sterben!" Angesichts dieses Sch die Rücklkehr zur Herde; dementspreUnterwerfung unter den göttlichen Willen und die Rlickeehr zind Unter chend ist das erklärte Ziel des Stúck tet auf dies Wort:/ Mög' euch ein Strahl aus Gott Augen führen/ Euch allen, die ihr achtet auf dies Wöh zum Hort!"

das Herz berühren, / Daß ihr aufs neue Ihn erwahht zum Hort $\mathrm{Zu}$ diesem Zweck erzählt die Autorin die Geschichte originalgetreu, leilweise wortgetreu, nach, unter Auslassung einiger weniger Details, die dem moralischen Empfinden der zeitgenössischen Zuschauer zu sehr widersprochen häten. David eind seine Michals Hand, ohne daß er 200 Vorhäute als Brautpreis beibringen muß, und sein späteren Mehrfachehen werden nicht ins Stück übernommen. Michal verschwinde spât nach ihrer aus dem Buch Samue ter AnkünMotiv der menschlichen Eigenmachtigkeit als Tods Wr Su en digung im Prolog, das vorherrschende des Stückes. We Sanuel zu Begin her hervorhebt, salbt er Saul nicht zu ziehet aus dem Staube dich empor/ Und setzet dich zu lichen Stellvertreter Gottes. „Er ziehet aus den Sest seines Volkes Fürsten./ Doch nie vergiß, daß Er der Konig ist,/ Des ewiges Gestir bleibt über dir/ Und deinem Regimente" (7). Als die Philister Israel den Krieg erkläber den Angriff beginnen noch die ausbrechende Panik in seinem
Heer beruhigen, weil er sieben Tage lang auf das Zeichen des Herrn warten muß, denı nur Gott darf das Zeichen zum Beginn des Kampfes geben (19-23).

Saul übertritt das Gebot und verteidigt sich Samuel gegenüber mit der Sorge eines souveränen Monarchen um sein Volk, d. h. er handelt in der irrigen Annahme, er hätte tatsächlich die Verantwortung für das Volk. „Nicht gerne überschreit' ich das Gebot,/ Doch greift ans Herz mir meines Volkes Jammer" (24). Samuel dagegen belehrt ihn in einer rhetorischen Frage über seine wahre Rolle: „ist/ Denn Saul ein Heidenfürst? [...]/ Ist Glaube nicht, Gehorsam dein Beru?" (25) Saul, weit entfernt, sein Vergehen zu erkennen und zu bercuen, reagiert mit weiterer Auflehnung: „Hab’ ich so übel denn gethan, da mich/ Dic Sorge fraß um mein geängstet Volk?/ Hart ist dein Wort, ein Gott des Zorns Jehovah,/ So Er durch dich mich also straft" (25). Sauls zweite Eigenmächtigkeit, die Schonung Agags und der Rinder, wird ebenfalls durch unter ethischen Gesichtspunkten verständliche Motive gemildert: anstatt Agag, wie befohlen, hinzurichten, macht er ihn zum Sklaven (39 f); die Rinder dagegen will er Gott opfern (40) Aber unter Samuels scharfen Augen entpuppt sich beides als fehlgeleitete Güte: bei Sauls Opferfreudigkeit handelt es sich um schlichte Raubgier, „Denn nur; was alt und schwach und schnöde war,/ Hast du verbannt; was fette Beute war,/ Hast du behalten" (41). Auch die Schonung Agags war fehl am Platze, denn Agag ist, wie Samuel weiß, König eines Volkes, das sich den Zauberkünsten der Hölle verschrieben hat. Mit diese Begründung ${ }^{67}$ rechtfertigt Samuel nicht nur den Mord an Agag, den er (hinter de Kulisse) tötet (43), sondern auch die völlige Vernichtung der Amalekiter: nur durch Vollziehung des Banns (d. h. Tötung der Männer und Frauen, Kinder und Säuglinge) kann der Herr das Volk Amalek retten - in jener Welt.

O Saul, wie ist dein Sinn verkehrt! So spricht

Der abgefall'ne König; weißt du nicht,

Daß Amalek, von Zaubergreueln trunken,

In finst'res Teufelswesen ist versunken?

Wie, ist es grausam, daß des Herrn Gericht

Einhält der Sünde Flut und unterbricht

Den Lauf zum ewigen Verderben? Güte

Und Gnade ist's, daß Amaleks Er hüte,

In jener Welt es rette. Das sei fern,

Daß es verloren sei! denn was dem Herrn

Verbannt ist, kehrt zurück in Seine Hand,

Und wird der Bann zu ew'gem Heil dem Land! (42, Hervorhebung der Autorin)

Da Saul weder dieser dem Menschen nicht recht einsichtlichen Logik widersprechen noch sein eigenes Tun entschuldigen kann, entschließt et sich zum Abfall von Gott und das heißt hier: zu eigenmächtigem Handeln. ,- wer soll/ Das Volk regieren? Einer nur kann's sein,/ Und Saul ist König! Saul soll herrschen, Saull Kann thun, was ihm gefällt!" ( $43 \mathrm{f}$, Hervorhebungen der Autorin) Von da ab verkommt Saul zu dem im Buch Samuel dargestellten machtbesessenen, eifersüchtigen und halb wahnsinnigen 
Tymnnen. Er unternimmt mehrere Mordanschläge auf David, läßt die gesamte PricTyannen. Er unternimmt mehre Mlucht geholfen sterschaft von Nob töten, weil der Priester Achimelech David auf der David verteidigt, hat, und bedroht schließlich sogar seine Sohn Jirekt aus dem $A T$ übernommen. Eine einzi-

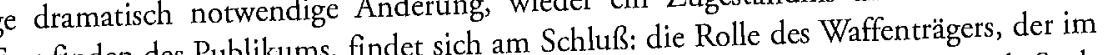

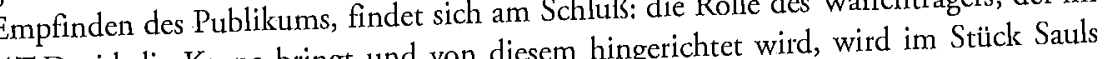
$A T$ David die Krone bringt und von dien Bösewicht am Ende mordlustigem Höfling Doeg übertragen (111), so daß auch diesen Bosemicht am Ende die verdiente Strafe ereilt.

Da die Autorin ihrer eigenen Aussage nach die Intention des Originals übernahm, Die im $A T$ beschriebenen Charaktere und Ereignisse weitgehend bei. Die . einzigen Anderungen, die sie vonahm, dienceren zeitgenössischen Moralvorstellungen anzugleichen. Zu diesem Zühne), ließ andere weg (die schiedene Episoden (Samuel tötet Agag nicht auf der Bühne), ließ andere Tötung der 200 Philister und Verwendung ihrer Vorhäute als Brautpreis, die Scheidung und Wiederverheiratung Michals, Davids polygamistische Eheschließungen) und erfand wieder andere dazu (die Darstellung der Amalekiter als dem Teufel verfallen, dic Hinrichtung Doegs am Ende). Wenn Kraft mit ihrem Saul eine Art literarische Bekeh-

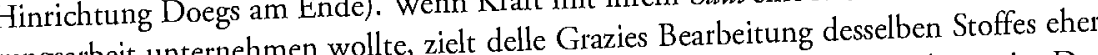
nem auf das Gegentell ab - und hat desciens de Autorin gesamte Stück ist ein einziges Pladoyer fur die Autonomic des Mensch; die Auroin Gibernat cinige Figuren und Teile der Handlung aurs de der nichts weniger als blasphemischen Geschichte dazu.

Eine der wichtigsten Abweichungen vom Buch Samuel ist die Liebesgeschichte zwi. der Tochter des besiegten Amalekiterkonigs Agag. Mit Melitia - die Figur ist ebenfalls eine Erfindung der Autorin - will Saul ein Reich der Liebe gründen, in betontem Gegensatz zu dem finsteren Reich Jehovahs, des Rachegottes. Das Stïck setzt nach Sauls Sieg über die Amalekiter ein; nach dem Feldzug also, auf (iesem dem Saul Melitta kennenlernte, sich in sie verliebte und sie heiratete. Aus diesen für Grund wird Saul von Samuel verflucht; nach Samuels Bericht's sach Jehovah,/ ,Zieh' Jehovah der Stein des Anstoßes. „Zieh hin, gelicbier Priest, s. hin und reiße meinen Diener Saul/ Erbarmungslos vom Herzen jener Heidin, Dic ihn durch freche Buhlerkünste fesselt" (6). Jene Heidin, die bei der ersten Begegnung von durch fecheidigt wird („Metze“, 9, 11, 16, 18; „DirSamuel und Achimelech ununterbrochen beleidige ne“, 10, 11, 14; „Buhlerin“, 11, 12), reagiert auf alle Anfechtungen als Modellall der Standhaftigkeit, sie versucht Samuels Zorn zu besänftigen und bietet ihm abwechselnd Stand haft Israels (17) an. Agag benimmt sich beihr Leben (11) und ihre Bekehrung zum scheiden, wic es sich in seinem Stand als Besiegter gehöt, und ist ansont besorgte Vater. Aber Samuels und Achimelechs Fanatismus ist so unerbittich, daß Agag den Schluß ziehen muß: „Im Herzen dieser Priester wohnt der Haß,/ Und von den Höhen dieses Himmels blickt/ Ein finst'rer Gott, der keine Liebe lkennt!" (12) Als Sere erregte Samucl ihn vor die Wahl, die Saul kurz die Krone zu verlieren. Saul aber empfindet keine
Gehorsamspflicht mehr dem finsteren Gott gegenüber, der keine Liebe kennt, umso weniger, als er selbst einmal gläubig auf seine Liebe vertraute.

Ich träumte von der Liebe eines Gottes,

Die alle Menschen väterlich umschließt

Und alle gramzerfress'nen Herzen tröstet.

Da bebte ich vor Wonne: mein Gemüt

Erstarkte im Gefühle dieser Hoffnung

Und meine thränenfeuchten Augen blickten

Vertrauensvoll zum Vater Israel's.

Doch als ich eure finst'ren Lehren hörte,

Erkannt' ich, daß der Lenker dieses Volkes

Ein Gott der Rache und des Hasses sei

Der nur das Kriechen feiler Sklaven liebt

Und alle Menschen schafft, um sie zu quälen (15 f).

Die Licbe, die Saul vergeblich bei diesem Gott suchte, findet er bei einem Menschen; die Konsequenz ist nicht nur sein Abfall von Gott, sondern eine direkte Kampfansage: Saul setzt sein Reich der Liebe gegen das finstere Reich des Sklavengottes.

[...] als ich in das Land der Feinde zog

Und dieses Weib erblickte, als mein Herz,

Befreit vom Dunkel eines bösen Wahnes,

Im Licht der Freiheit und der Liebe schwelgte,

Erst da erkannt' ich, daß mein Geist berufen,

Die Ketten eurer finst'ren Macht zu lösen

Und eurem wilden Schreckensgott zu trotzen! (16)

Auf diese Herausforderung reagiert Samuel, indem er „Den blutbefleckten Rachedolch Jehovah's" (16) gebraucht: er ersticht Agag, anders als bei Kraft, auf der Bühne (19). Saul, vom Volk daran gehindert, sich an Samuel zu vergreifen, muß sich mit einer erneuten Kampfansage begnügen. Den unvermeidlichen Konflikt interpretiert er als den zwischen Liebe und $\mathrm{Haß}$, aber auch als den zwischen Selbständigkeit und blindem Gehorsam. „An eurer Seite steht die finst're Rache,/ Der blinde Aberglaube eines Volkes,/ Das durch Jahrhunderte geknechtet ward,/ Doch über meinem stolzen Haupte schwebt/ Die Liebe mit dem gold'nen Freiheitsbanner!" (20)

Daß die Sympathien der Autorin auf Sauls Seite stehen, beweist die Uminterpretation sämtlicher aus dem $A T$ übernommener Figuren. Samuel, im $A T$ der gläubige Prophet Gottes, wird hier zum religiösen Fanatiker, der ununterbrochen Gottes rächende Blitze im Munde führt; Doeg, im Buch Samuel Sauls Untergebener, der nicht zögert, die grausamsten Befehle auszuführen, ist bei delle Grazie der treue Diener, der fest zu Saul hält und alles Übel von ihm und Michol fernzuhalten versucht. David, ursprünglich der unschuldige gottgläubige Hirtenknabe, entpuppt sich hier als Machtbesessener, der mit seinem Hirtendasein unzufrieden ist und dem jedes Mittel recht ist, sich die 
Trone aufzuserzen. Achimen Nebenfigur; rone aufzusetzen. Achimelech ist im er ist einer der wenigen Priester, die versuchen, Saul auf den Pfad des Rechts zurdecter- Hier führen, und wird von Doeg für seine Hilfeleistung Dotiven und zur Hauptfigur des wird er zum Gegenspieler Sauls aus persontichen Motiven und zur Hat Stückes. Er haßt Saul, weil er sich um seine Tochter Michol beworben hatte und abgelehnt wurde (8). Achimelechs Rachsucht macht ihn zum Mephistopheles des Stückes: (ällig unter seinem Einfluß; er setzt sämtliche sowohl Samuel als auch David stehen vollig unter seinem Einfußs er sezt shliche handelnden Figuren gegen Saul ein und pervertiert ihre Gefuhle - mit Vorliebe die positiven - für seine Zwecke. Da Achimelech als einziger nicht von moralischen Eingebungen oder Gefuihlen behindert ist (wic Samuel durch seinen Glauben, David gebungen oder Gefuhlen behichol, Michol durch ihre Liebe zu Saul und David und durch ihre Treue zu ihrer Mutter), ist er dazu durchaus imstande; umgekehrt sind die anderen Figuren gerade aufgrund ihrer moralischen Vorstellungen für Achimelechs Versuchungen anfällig. Achimelech, der nur seinem $\mathrm{Haß}$ und seiner Rache lebt, identifiziert sich gen anfallig. Achimelect, / Ich bin dein treuin dieser Hinsicht mit Gott : „O Adonal, gewalt ger Schreckensgott, / cr Diener: meine Bitze/ Zerschmet" (47, Hervorhebung der Autorin)

Qualen meiner Feinde!" (47, Hervorhebung der Autorin)

Wie die Charakterisierung der Figuren weicht auch die Handlung des Stückes von der im $A T$ erzählten Version beträchtlich ab: Achimelech hetzt Samuel und David gegen Saul auf und macht auch Michol, zu Beginn des Stückes eine liebende Tochter zu seinem Werkzeug. Achimelech benutzt ihre Liebe zu David, ihre Treue ihrer verstorzu seinem Werkzeug. Achimelech benutzt ihe Liebe zu selitta geschickt, um sie auf seine Seice zu ziehen.

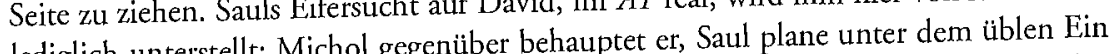
lediglich unterstellt; Michol gegenüber behauptet er, Saul plane tnter dem tublen tinfluß der bösen Heidin einen Mordanschlag auf Davids Leben (59 f). So - und indem flußs der bösen Herchol er ihr die Tat als "Wunsch Jehahs dazu, Melitta zu ermorden. Mittlerweile ist David mit Unterstützung philistinischer Streitkräfte ins Land einmarschiert, um sich nach der Salbung durch Samuel Sauls Krone mit Gewalt zu erobern. Samuel, durch die Ereignisse gezwungen, erklärt David König über Israel. In diese Zeremonie platzt Saul hinein; es kommt zur öffentlich zum König über Israel. In diese Zeremonic platz Sau hinging es kich Auseinandersetzung zwischen Saul und David, Samuel und Achimelech, in der sich das Volk auf die Seite Davids und der Priester schlägt (98 f). Um das Volk von seiner das Volk auf die Seite Davids und dët abergläubischen Furcht vor der gottlichen Rache zu helen, begeht Saul die gr denkbare Blasphemie: er zerreißt den Vorhang vor der Bundeslade und zeigt das Heiligtum dem Volk (103). Noch während alles auf den göttlichen Blitz wartet, der Saul ligtum dem niederstrecken soll, bringt Doeg Melittas blutubers begrüßt wird: „Großer Gott,/ Du Anblick, der von Samucl mit den feicrlichen Worten begrüist wird: "Großer Gott, Du hast gesiegt!" (106) Nachdem Saul von Doeg erfährt, daß seine Tochter seine Geliebte hast gesiegt: diese Art der Quälerei war von ermordet hat, crkennt auch er die Allo simple Blitz, denn sie entspricht den sadistidem Rachegott eher zu erwarten als der simple Blitz, denn se entiche dent schen Tendenzen, die Gott sowohl von Saul als auch von Samuel und Achinelech (s. o.) unterstellt werden. „Die Glut des Schmerzes sollte mich verzehren/ Und meine Jammerrufe sollten dich / Wie tausend Huldigungen süß erfreuen!" (107)
Mit Melittas Tod ist Sauls Reich der Liebe zu Ende; Saul kapituliert vor dem Gott des Zorns und verliert damit jede Funlstion im Stück: er ist „Verlassen auf der Welt allein - allein!" (109) Die einzige Alternative ist die, die ihm sein treuer Doeg vorschlägt. „[...] ermanne dich!/ Das Schwert spricht besser als die reichsten Thränen!/ Vernichte deine schadenfrohen Feinde/ Und pflanze auf das frühe Grab Melittas/ Da schwarze, blutbefleckte Rachebanncr!" (108 f) Aber diese Alternative stammt aus der anderen Welt, aus dem Reich des rächenden Gottes, gegen das Saul anzugchen versucht. Bereits die nächste Szene zeigt ihn als Sterbenden: Saul stirbt, nachdem er Michol verziehen hat, mit dem Wunsch nach dem „Reich der Liebe" bzw. dem "Gott der Liebe" auf den Lippen (124, Hervorhebungen der Autorin).

Sauls Reich bleibt eine Utopie, auch für die anderen Figuren des Stückes. Nach Sauls Tod umwirbt David Michol; Achimelech aber tritt zwischen sie und beanspruch Michol für sich bzw. für sein Reich der Rache. „Dies Weib gehört der Nacht, die sie umfangen,/ Gehört dem Wahnsinn, der ihr Haupt geküßt [...]./ Sie ist mein schönstes Opfer - hörst du? Ist/ Die reichste Krone meines ganzen Sieges,/ Ein Kleinod, das du nie besitzen wirst!" (128) Als Achimelech seinen Triumph in die Welt hinausposaunen will, ersticht David ihn (129). David, der neue Herrscher von Israel, wird aus beiden Reichen verbannt, aus dem der Liebe von Michol (126), aus dem Gottes von Samuel, da David mit Hilfe der Philister das Land eroberte (130 f). So ist auch David am Ende des Stückes „allein - allein [...]. Die Liebe/ Hat mich verlassen“ (132).

Sauls Kampf gegen den alttestamentarischen Gott ist ein weiteres Beispiel für die Tendenz, die sich in mythologischen Bearbeitungen verschiedener Autorinnen abzeichnet: der Kampf gegen die in der Mythologie überlieferte Vorstellung der menschlichen Machtlosigkeit. Von Steins Dido wehrt sich gegen ihr Schicksal in Form der ihr aufgezwungenen Ehe mit Jarbes und der Entthronung - und nicht zuletzt gegen Vergils Dido-Mythos. Oedipus, bei Sophokles das Paradebeispiel für die menschliche Hilflosigkeit dem eigenen Schicksal gegenüber, lsämpft bei Prellwitz gegen die vorgegebene Lösung des Rätsels. Bei Wesendonck entkommt Odysseus der Göttin Kalypso - und nicht mit Hilfe göttlicher Intervention -; die Versuchung, der er später ausgesetzt ist, ist eine selbstgewählte, über die er die Kontrolle behält. Während andere Autorinnen (Kraft und Wesendonck in Gudrun) sich darauf beschränken, die grausamsten Elemente der Originalmythen zu mildern oder auszusparen, geht es bei von Stein, Prellwitz, delle Grazie und in Wesendoncks Odysseus um die Behandlung des Mythos an sich. Ähnlich wie sich die Autorinnen historischer Stücke oft um eine Richtigstellung oder Ergänzung der belkannten Geschichte bemühen, versuchen sie, den Mythos - oder die damit verbundenen Vorstellungen - zu „berichtigen“. Dem Mythos vom Menschen als Spielball Gottes, des Schicksals oder der Götter wird hier eine Utopie entgegengesetzt, in der der Mensch versucht, die Kontrolle über sein Schicksal zu übernehmen und dazu notfalls auch den Kampf mit den Göttern aufnimmt. 


\section{KAPITEL VIII}

\section{ES WAR EINMAL/EINMAL WIRD ES SOWEIT SEIN:}

\section{MÄRCHEN UND ALLEGORISCHE UTOPIEN}

Zwischen Märchen und allegorischen Utopien gibt es im Bezug auf Arbeitsweise und Zien Föll durch die dargestellten FiguZlelsetung veschiedenc Pallen. In biden Fellen söllen wird eine Art ren und Vorgänge eine Moral vermittelt werden, und in beiden Fallen wird eine Art poetischer Gerechtigkeit geübt. Dic (positive) Utopic ist die literarische Suche nach Gerechtigkeit schlechthin; das Märchen vollzieht diese Gerechtigkeit am Ende Gecholisiert in der systematischen Verteilung von Lohn und Strafe. Beide spiclen symbolisiert in der systematischen Verteilung von Lohn und dem Gegensatz zwiim U-Topos, im literarischen Niemandsland. Beide arbeiten mit dem Gegensatz zwischen U-Topos und der bekannten Welt; erst durch diesen Vergleich erhält U-Topos seinen Status als goldenes Zeitalter. Sowohl im Märchen als auch in der Utopie gibt es seinen Status als goldenes Zeitalerschied herbeiführt: infolge einer Entscheidung, Probe ein Element, das diesen Unterschied herbeifuhrt: infolge ein. Dieses retrende Flement oder Tat wird aus einer fehlerhaften Welt das poetische Ideal. Dieses rettende Element in dramatischen Märchen ist die Liebe - die, man erinnere sich, im Lustspiel keineswegs diese Rolle spielt - ; in Utopien ist es - überraschenderweise - die Dichtkunst.

\section{A. Märchen Von der Zaubermacht der Liebe: Seyler, KRONes, GúnTHER, BERnstein}

Dramatisierte Märchen und Zauberspiele treten vereinzelt in beiden Jahrhunderten auf, sind aber hauptsächlich ein Genre des 19. Jahrhunderts. Das einzige mir bekannte Drama dieser Art im 18. Jahrhundert ist Friederike Seylers (1738-1789) Oberon, oder König der Elfen (zuerst erschienen 1792). Nachdem in der Spätromantilk das Interesse Konig der Elfen (zramatische Märchenbearbeitungen häuan Märchen wiedererwacht war, treten auch dramatische Maich figer auf. Beispiele sind Therese Krones' (1801-1830) musikalische Zauberspiele Syphide, das See-Fräulein (1828) und Der Nebelgeist und der Branntweinbrenner (1829) phide, das See-Frautein (1808-?) musikalische Romanze Finnette Aschenbrödel, oder: Rose und Auguste Ribics (1808-?) mer Bergönig oder: Hopsa, der Schuh (1830); Margarethe Bernbrunns (1788-1861) Der Begkonig oden Hopsa, der Retter aus Zauberbanden, ein romantisches Zaubermärchen mit Musik (1832); und Katharina Horschelts (Daten nicht ermittelt) Zauberballett Der Berggeist (o. J.). Diese und einige wenige andere (Ebner-Eschenbachs Die Prinzessin von Banalien, 1872 Bernsteins Königskinder, 1894; und die Festspiele der Elisabeth Krukenberg, 18671954, wie Märchenbilder und Prinz Frühling und Prinzessin Rose, beide o. J.) sind Originalmärchen.

Daneben finden sich Adaptationen bereits vorhandener Märchenstoffe, so z. B. Daneben finden sich Adaptationen bereits vorhanden (o. J.) nach 1001 Nacht, Sophie
Amalie von Liebhabers (1779-1845) Harun al Raschid Krickebergs (1770-1842) Klein Rothkäppchen (1819, nach Theaulon), Henriette Kühnes (1822-1894) Dramatisierte Märchen (1877), eine Sammlung von zehn Märchen nach Jakob und Wilhelm Grimm; Emilie von Ringseis' (1831-1895) Märchenspiel
Schneewittchen (1866) nach J. und W. Grimm; Dora Dunckers (1855-1916) Die Schneekönigin (1910) nach Hans Christian Andersen; Maria Günthers Märchenadaptationien der Grimmschen Märchen (Schneeweißchen und Rosenroth,1888; Goldmarie und Pechmarie, 1893; und Tischlein deck dich, Esel streck dich, Knïppel aus dem Sack, 1893); und die Originalmärchen derselben Autorin (Die kleinen Musikanten, 1896 und Der Kleinen Osterfabrt, 1900).

Von den genannten dramatisierten Märchen sind ca. die Hälfte Singspiele im Stil der Zauberflöte (Seylers Oberon, Krones' Sylphide und Nebelgeist, Ribics' Finnette Aschenbrödel, Bernbrunns Bergkönig, Horschelts Berggeist, Krickebergs Klein Rothkäppchen und Günthers Schneeweißschen und Rosenroth); andere wurden später vertont (wic Bernsteins Königskinder von Engelbert Humperdinck). Bezeichnungen wie „Romantisches Singspiel“" (Seyler), „Romantisches Zaubermärchen“ (Bernbrunn), „Romantisch komisches Zauberspiel mit Gesang " (Krones), „Zauberballett" (Horschelt), „Feenoper“ (Krickeberg), „Zauberspiel mit Gesang" (Ribics) sind häufig. Was an diesen gleichlautenden Bezeichnungen auffällt, ist die Verbindung zwischen Märchen, Musil und dem Begriff „romantisch“, den viele Autorinnen durch die Bezeichnung ihrer Stücke herstellen. Der Begriff „,romantisch“ hat hier, trotz des Stoffes, nichts mit der literarischen Epoche zu tun, sondern wird von den Autorinnen umgangssprachlich gebraucht; was das Wort auf dem Theaterzettel ankündigt, ist die Finfügung einer Liebesgeschichte. Obwohl der komische Aspelst seltener betont wird, wie in Krones' Bezeichnung ihrer Stücke als „komische Zauberspiele“, sind die meisten dramatischen Märchen Komödien: die einzigen Tragödien unter den obengenannten Märchendramen sind Liebhabers Harun al Raschid und Bernsteins Königskinder. Ein Grund für die Tatsache, daß viele Autorinnen sich bemühen, eine Verbindung zwischen dem Märchen, der Komödie und der Oper herzustellen, ist die überwiegende Beliebtheit der Komödie und der Oper beim Publikum, über die die Liebhaber und Autoren von Tragödien und „ernsthafteren" Stücken sich in beiden Jahrhunderten bitter beschweren. Wer die Verbindung zwischen Komödie, Gesang und bühnentechnischen Effelsten herstellte, d. h. Stücke schrieb wie die, die Paldamus etwas abfällig als „Delsorations- und Maschinendichtung" (275) bezeichnete, hatte einen Kassenschlager. Bei den meisten dieser Märchen handelt es sich tatsächlich um Stücke, die mit einem Auge auf die Bühnenwirksamkeit geschrieben sind: sie sind Singspiele, die das komödienhafte Element betonen und vor allem die Möglichkeiten der Dekoration und der Bühnenmaschinerie weidlich ausnutzen.

Die meisten dramatischen Märchen übernehmen Elemente aus dem Volksmärchen; wie aus der obenstehenden Liste ersichtlich ist, sind viele Adaptationen der Grimmschen Kinder- und Hausmärchen. Ein kurzer Vergleich zwischen Volksmärchen und dramatischen Märchen lohnt sich schon deshalb, weil viele Autorinnen dramatischer Märchen zwar vieles aus dem Volksmärchen übernehmen, thematisch aber oft von diesen Mustern abweichen. Im Volksmärchen - bei Grimm z. B. - zieht der Prinz oft aus, un die (gefangene, schlafende, anderweitig passive) Prinzessin zu befreien. Nicht so im Märchendrama: hier bestehen Prinzessin und Prinz, à la Zauberflöte, gemeinsam verschiedene Proben (Seyler, Oberon), die Prinzessinnen befreien ihre Prinzen (Günther, 
Schneeweißschen und Rosenroth), oder die Schwester des Prinzen befreit die Prinzessin (Ken Grimm geradezu unentbehrlich - sie

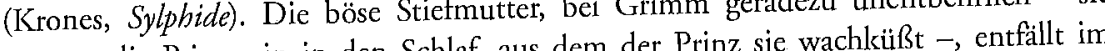
versetzt die Prinzessin in dendrama. Stattdessen sind die (immer männlichen) Widersacher böse Könige (Seyler), Zauberer (Krones) oder einfach komische Figuren, wie die unbequemen Freier bei Günther. Im Prosamärchen dient Magie meist dazu, dem Prinzen, Jüngling ode Dummling im entscheidenden Moment weiterzuhelfen (Muster: wenn der Prinz sich Dum und gewährt ihm drei Wünsche). Im dramatischen Märchen dagegen ist die Welt de Magie häufig bedroht oder zumindest in Unordnung geraten; das einzige, was die Ordnung wiederherstellen kann, ist cine bestimmte Entwicklung in der Welt der MenOrdnung wiederherstellen kann, ist cine bestimmte Entwickierigkeiten, und - an diesem Punkt beginnt meist das Märchen - deshalb schließen Vertreter der magischen Welt Punkt beginnt meist das Măchen - dist zweierlei: die Flfen mit Vertretern der Menschen einen Pakt. Dieser Pakt besage (Seyler, Günther) oder Seejungfrauen (Krones) versprechen den Menschen ihre Hilfe bei der Lösung ihrer Schwierigkeiten, machen dafür aber bestimmte Auflagen bzw. stellen die Menschen gleichzeitig auf die Probe. Wenn die Menschen diese Probe betehen folgt die Wiederherstellung der Ordnung sowohl in der menschlichen als auch - Werch Märchendrama auftretende Par ist keineswegs nur in der me heiraten und bis an ihr seliges Ende zu leben, sondern dazu auf der Bühne, um zu heiraten und bis an ihr seliges Ende zu leben, sondern übernimmt eine weit wichtigere Rolle: während die hilfreichen Geister, Elfen und Männlein des Vollksmärchens dazu da sind, dem Menschen zu Hilfe zu kommen, ist es hier genau umgelsehrt.

Märchen oft aus dem Volksmärchen

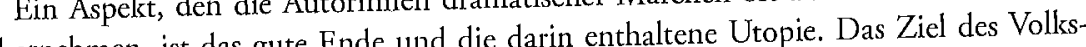
übernehmen, ist das gute Ende und diechzeit [... märchens ist identisch mit dem Ziel der Hauptfigur(en): "da wurde dien Dornröschen, KHM I, 291). Aber hinter der Hochzeit zwischen Prinz und Prinzessi verbirgt sich mehr, denn der Prinz erbt meistens auch das Königreich des Vaters (oder das des Schwiegervaters bzw. der nicht erbberechtigten Prinzessin). „[...] nach de Königs Tod erbte der Dummling das Reich und lebte lange Zeit vergnügt mit seiner Köngs " (a) oder nicht: mangelnder Stand des künftigen Herrschers lxann tatsählich ein Prinz ist oder nicht mange durchaus durch ethische Eigenschaften ersetzt werden. Damit sowohin der Ehe als auch im Reich das Glück gewährleistet ist, wird von der Prinzessin dasselbe erwarte. Die Güte des künftigen Königs (Naivität, gutes Herz) erweist sich im Verlauf der Geschichte; die der Prinzessin in ihrer Bercitschaft, ihn zu heiraten, selbst wenn er nicht von Stand ist. So z. B. in dem folgenden Märchenende:

Es war aber ein alter König im Land, vor dem mußt' er [Hans, S. K.] spielen, und der versprach. Als die aber hörte, daß sie so einen gemeinen Kerl im weißen Kittel heiraten sollte, sprach sie: „eh' ich das tät', wollt' ich lieber ins tiefste Wasser gehen."
Da gab ihm der König die jüngste, die wollt's ihrem Vater zuliebe gerne tun; und also bekam des Teufels rußiger Bruder [d. i. Hans, S. K.] die Königstochter und, als der alte König gestorben war, auch das ganze Reich (Des Teufels rußiger Bruder, KHM II, 193).

Die Botschaft dieses kurzen Abschnitts ist klar: nur mit der jüngsten Prinzessin kann Hans „lange Zeit vergnügt" leben. Das Reich belkäme er zwar auch durch eine Ehe mit der älteren, aber es wäre nicht das Märchenreich, das auf folgenden Elementen basiert: die moralischen Eigenschaften des Paares (Hans' gutes Herz, der Gehorsam der jüngsten Tochter) garantieren eine glückliche Ehe; die Ordnung im Haus wiederum garantiert die im Reich. Mit der Hochzeit zwischen Prinz und Prinzessin beginnt im Märchen ein goldenes Zeitalter auf politischer Ebene. Deshalb beenden Prinz und Prinzessin bei ihrer Heirat und Machtübernahme oft eine Tyrannei - die der bösen Stiefmutter (Schneewittchen, Aschenputtel), des Zauberers (Die Kristallkugel) oder des hinterlistigen Königs (Das tapfere Schneiderlein). Was folgt, ist das goldene Zeitalter, in dem das Glück des Herrscherpaares das der Untertanen garantiert. In der Hochzeit zwischen Prinz und Prinzessin ist immer eine (vergangene) politische Utopie impliziert.

Um genau diese Utopie, die Suche nach dem gütigen, weil glücklichen, Herrscherpaar, geht es in dramatischen Märchen. Dabei wird der real-politische Aspekt (Machtübernahme, Untertanen) genauso ausgespart wie im Volksmärchen; dargestellt wird nur die Liebesgeschichte zwischen Prinz und Prinzessin. Allein die Macht der Liebe, exemplifiziert am glücklichen Paar, ist der Garant für das goldene Zeitalter.

In vielen dramatischen Märchen führt das Versagen der Liebe im menschlichen Bereich zur Unordnung im Reich der Magie, so z. B. in Friederike Seylers Oberon, oder König der Elfen (1792). Das Stück ist eine Neubearbeitung ihres romantischen Singspiels Hiion und Amande (erschienen 1789) nach Wielands Oberon. In Seylers Märchen führt ein Zerwürfnis zwischen einem menschlichen Paar zum Zwist zwischen einem Elfenpaar. Oberon und Titania, die, ähnlich wie dic olympischen Götter, das Leben der Menschen beobachten und gegebenenfalls eingreifen, geraten in eine Meinungsverschiedenheit über die Rolle der Frau in der Ehe. Titania wird von Oberon verstoßen, weil er, sehr im Gegensatz zu ihr, die Tugend der Frau als die Bereitschaft versteht, sich endlos mißhhandeln zu lassen. Aus 'Titanias Bericht:

Ein alter reicher Thor hatte sich ein junges Weib zum Opfer gewählt. Lange ließ sie sich von ihm quälen, ohne auf Rache zu denken; (denn sie war tugendhaft) aber diese Tugend wankte, sie wählte sich einen jungen Liebhaber; und gab (meiner Meynung nach) dem alten Thoren seinen verdienten Lohn. Aber mein Gemahl dachte nicht so; er wollte sie bestrafen (148).

Weil Titania die Frau vor Oberons Rache schützte, verstößt Oberon sie mit dem Schwur, sic nicht cher wiederzusehen, als bis ein menschliches Paar die Existenz wahre Liebe, Treue und Tugend durch ausreichende Proben beweist, „Entschlossen eh den Tod in Flammen zu erwählen,/ Als Ungetreu zu seyn" (150). 
Das erwählte Paar ist Hüon, ein vom Hof Kaiser Karls verstoßener Prinz, und Amande, Tochter des Sultans von Bagdad. Hüon erhält von dem halb verrückten KaiAmant Barthaare des Sultans ser einen seltsamen Aufras. er socher Amande, die ihr grausamer und jähzorniger von Bagdad bringen und dessen Tochter Amande, die ihr grausamer und jahzorniger Vater zur Ehe mit einem ungeliebten Mann zwingen will, zu seiner Braut erklären. Oberon zeigt beiden das Bild des anderen im Traum und sorgt dafüi, daß sie sich in einander verlieben. Unterwegs nach Bagdad entdeckt Hüon im Wald einen Diene (Scherasmin), der als komisch-ängstlicher Antiheros (Prioritäten: Essen, Wein, Weib(Scherasmin), der als komisch-ângsticher chen), aber treuer Diener charakn und verteilt magische Geschenke sowie standesgemäße Hilfe bei dem Untenehmen Ermahnungen. Hüon nimmt er das Versprechen ab, immer der Tugend treu zu bleiben; Scherasmin rügt er, der König der Elfen, für seinen Glauben an „Kindermähren (163). Unter Oberons wohltätiger Aufsicht gelingt das Wagnis problemlos: Amande (163) Un Elfenkönigs versetzen jeden mögsinkt in Hüons Arme, die magischen Geschenke des Elfenkönigs versetzen jeden mög lichen Gegner in zeitweilige Paralyse, und Oberon erscheint schließlich persönlich, um seinem Schützling ein Kästchen zu überreichen, das die verlangten Zähne und Barthaare des Sultans enthält.

Oberon schickt beide Paare (Amandes treue Dienerin Fatime hat sich inzwischen zu Scherasmin gesellt) mit seinem Segen nach Hause und stellt dabei nur eine Bedingung

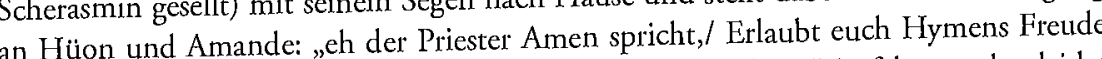
an Hüon und Amande: "h der Priester Amcr splcht / Eraubt euch Hymens Frete nicht!“ (184) Das Paar bricht den Schwur bereits auf der Heimfahrt und erleidet prompt Schiffbruch. In Tunis, an dessen Küste alle vier Beteiligten angeschwemmt prom Allmansor bedrängt, der um ihretwillen sogar werden, wird Amande von den ersten Blick in seine Sultanin Allmansaris verstößt. Die wiederum verliebt sich auf den ersten Blick in Hüon, den Scherasmin als Gärtner in den Palast schmuggelt. Sowohl der Bassa als auch die Sultanin sind von der standhaften Ablehnung Hüons und Amandes erbost genug, beide zum Feuertod zu verurteilen. Glücklicherweise erscheint in der letzten genug, beide zum Feuetod zu verur Sekunde - die Liebenden befinden sich bereits auf detm Scheiterhaufen - Standhaftigmacht dem Spuk ein Ende. Das Paar wird befreit und Tur dic bewesene Stacht: Titania keit mit dem ewigen Glück belohnt, das auch das Volksmärchen verspricht. Titania überreicht Amande Rosen, die nie verwelken, die „Ewig, so wie euer Glück, [... blühn“ (218). Weil das menschliche Paar die Liebesordnung auf der Erde wiederherbestell hat, darf Oberon sich nun endlich mit Titania wiedervereinigen, „von der ein gestellt hat, darf Oberon sich nun endlich mich sonst hätte" (218).

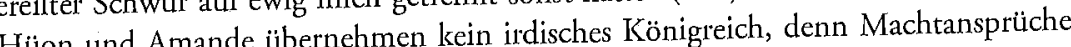
作 haben sion prinz und Prinzessin ersetzt wird, kann gime der bösen Königin durch das Reich von Prinz und Prinzessin ensetzt wid, kann das Reich der Liebe, in dem Hüon und Amande regieren, als Gegensatz zu den von korrupten Machthabern regierten irdischen Reichen gesehen werden. Alle irdischen Machthaber des Stückes reagieren auf die geringste Opposition mit Racheschwüren

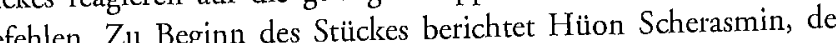
und Hinrichtungsbefehlen. Zu Beginn des Stiickes berichtee Hun Sches Sohn des Kaisers habe ihn ermorden wollen, worauf er ihn im Zweilsampf getöte habe. Darauthin habe Kaiser Karl ihm den Auftrag gegeben, den Sultan um Barthaare
Backenzähne und Tochter zu erleichtern - natürlich in der Hoffnung, Hüon werde die Fahrt nicht überleben. Scherasmins Kommentar: „Wenns der Kayser nicht wäre, - so würde ich fragen, obs im Oberstübchen bey ihm spuckte" (143). Im Reich des Sultans von Bagdad geht es kaum humaner zu. Dort tauschen der Sultan und sein erwählter Schwiegersohn Babekan im Konversationston Neuigkeiten von der letzten Christenverbrennung aus, und Babekan wünscht sich vom Sultan als Festspiel zur Hochzeit „ein[en] Scheiterhaufen, worauf du eine Kuppel solcher Christen-Sclaven braten läßt“ (179). Allmansor und Allmansaris schließlich, die Beherrscher von Tunis, reagieren auf Hüons und Amandes Weigerung, sie zu heiraten, analog, nämlich indem sie das Paar zum Scheiterhaufen verurteilen. Gegenüber diesen korrupten Potentaten repräsentieren Hüon und Amande die Utopie des gütigen Herrscherpaares. Angesichts dieser Tatsache kann das Reich, das ihnen zusteht, durch das Reich der Liebe ersetzt werden: das ewige Glück der tugendhaft Gebliebenen impliziert gleichzeitig das aller anderen Tugendhaften - das von Hüons imaginären Untertanen.

Für das thematische Schema, nach dem das von Menschen gegründete Liebesreich die Ordnung im Geisterreich wiederherstellt, lassen sich noch mehrere Beispiele anführen. Eines davon ist Maria Günthers Singspiel Schneeweißchen und Rosenroth (1888), eine freie Adaptation des gleichnamigen Grimmschen Märchens. Hier befinden sich die roten und weißen Rosenelfen, angeführt von ihren Königinnen Rosa und Blanka und deren Dienern Flink und Flott, in einer Art Kleinkrieg. Dieser Streit soll durch die Frage entschieden werden, welche der beiden Elfenschützlinge (Schneeweißchen als Protegée der weißen, Rosenroth als Schützling der roten Elfen) sich als tugendhafter erweist.

Die Tugendprobe besteht darin, die in einen Zwerg und einen Bären verzauberten Prinzen Heinz und Alberich durch „Lieb' und Treu' [zu] erlösen“ (7). Beide Schwestern verlassen ihr Zuhause, weil ihre Mutter sie zu Ehen mit den lächerlichen Freiern Hannes Taps und Roland Raps zwingen will, und werden von den Rosenelfen verschiedenen Versuchungen ausgesetzt. Schneeweißchen und Rosenroth beweisen ihre Tugenden, indem sie widerspruchslos jahrelang bei den mißgestalteten (und sie mißhandelnden) Prinzen dienen. Der Höhepunkt ihres Opfermuts, d. h. der verlangten "Lieb' und Treu'", erfolgt in der Schlußszene, in der Schneeweißchen sich bereiterklärt, den häßlichen Zwerg zu heiraten (wie die jüngste Königstochter in Des Teufels rußiger Bruder), und Rosenroth für ihren Bären gar ihr Leben wagt. Es folgt das traditionelle Märchenende (Donnerschlag und Verwandlung, Hochzeit, Apotheose) - und die Wiederherstellung des Friedens im Reich der Elfen:

FLoTT. Wir aber, die so lang' im Streit gelegen, Wir rothen Elfen -

FLINK, Und wir ander'n, weißen -

FLOTT. Umarmen uns versöhnt - (Allseitige Umarmung)

FLINK. $\quad$ Freunde uns heißen (44).

Wie bei Seyler ist die Abfolge der Geschehnisse eine Wechselwirkung: die Liebe der Mädchen bewirkt die Versöhnung im Geisterreich, die Elfen lohnen es ihnen mit "Heil 
und Segen" (44). Impliziert in der Hochzeit der prinzlichen Paare ist das Glück ihrer (antelisiert durch den bösen Zauber) (auch hier imaginären) Untertanen: das Unrech (sy lisiert durch die Doppelhochzeit). endet mit der Gründung des Liebesreiches (symbolisiert durch te Donzentrieren, wie in

Nur in Märchen, die sich mehr auf die komischen Aspekte konzentrern, wie in Therese Krones' (1801-1830) musikalischem Zauberspiel Sylphide, das See-Fraulein (1828), betreten die Untertanen die Bühne. Gleichzeitig aber verliert hier die magisch Sphäre an Wichtigkeit: die magische Welt ist in keiner Weise bedroht, und Sylphide,

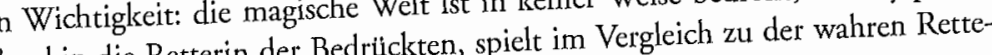
nach außsen hin die Retterin der Bebentle. rin Nettchen nur eine Nebenrolle.
Das Unrecht, das Sylphide berichtigen will, ist folgendes: ein böser Magier hat den jungen Gutsherrn August und seine Schwester Nettchen auf ene einame Insel jungen Gutsherrn August un bannt, sich in Augusts Schloß Insel schmachten, hält der Magier Jetta auf dem Schloß August und Nettchen auf der Insel sch ihm gefangen und versucht, sie zur' Ehe mit ihm zu wingen. Sylphide beron seine Schützlinge, August, beschenkt sie mit ähnllichen magischen Gaben wie Obchen unerkannt als Köund setzt sie in ihrem Heimatdorf ab. Dort verdingt sich Nettchen unetkannt als Ko chin bei dem Gutsverwalter Eustachius Wolferl und seiner Schwe kundschaftet die Lage aus. Sie erfährt von einem Aufruf an August, sich innerhalb von drei Tagen zu melden; andernfalls würde das Gut an den Magier verkauft, der gleichdrei Tagen zu melden; ande Heirat mit Jetta bekanntgibt. August gibt sich daraufhin zeitig seine bevorstehende Her schleunigst zu erkennen und nimmt den Dörflern das Versprechen abern erfolglos das Befreiung seiner Braut zu helfen. August bestürmt mit den Bauen eschlimmste.

Schloß; nur das rechtzeitige Erscheinen Sylphides verhindert dis Schlin erwählten Ritter; Jetzt greift Nettchen ein: zusammen mit Eustachius Wolferl, hrem dort Jetta von der will sie als Wandermusikanten verkleidet aufs Schloß ziehen ungelangt, verständigt sic bevorstehenden Rettungsaktion unterrichten. Auf der Burg angel Schlußszene des Don Jetta und bringt August heimlich ins Schlo1s. Ahnlich wie in der Schlßss Giovanni treffen August und der Magier aufeinander, Wolferl erschießt den Magier und August zerbricht seinen Zauberstab, worauf die Furien den Magier in die Tiefe und Aus Solferl und ziehen. Das Stück ender Königreiches -, Nettchen mit einem Gut bedenkt - eine Abwandlung des Jetta/August und Nettund der obligator.

Stücke bei Seyler und Günther nur eingeschoben - bei Der komische Aspekt des Stückes, bei Seyler und Günther nur die lächerlichen Seyler durch den komischen Diener Scherasmin, bei Ginn der Elfen - ist hier wesentFxeier Taps und Raps und durch die mutwilligen Streiche der. Platz eingeräumt als der lich ausgeprägter. Den komischen Dorfszenen wird weit mehe Pu August. Sylphide, fast tragischen, weil gefährdeten Liebesgeschichte zwischen Jetta und August. Sylph Ebedie im Verlauf des Stückes nur selten in Erscheinung tritt, Befreiung der Geschwister; nen. Dreimal erscheint sie als magische Retterin (bei der Befreiung der bei der Schlacht gegen den Magier und bei ihrer Abschiedsrede), bei der Schlacht gegen den Mof gemacht, das andere Mal

Figur: in einer Szene wird ihr von zwei Dort davor, von Anastasia eingesperrt zu werden.
In dieser Szene wird deutlich, daß Sylphide keineswegs als magisch-mächtiges Wesen à la Oberon gemeint ist, sondern eher als komische Figur mit übernatürlichen Fähigkeiten, die ab und zu nachhilft, wo die Menschen allein nicht weiterkommen. Sie tritt als italienische Bildhändlerin auf, liefert in geradebrechten Deutsch-Italienisch eine äußerst komische Beschreibung von Anastasia und dem Gerichtsdiener Cyprian und verscheucht die beiden schließlich mit Hilfe von acht aus dem Boden gestampften „Salamimännern“ (40). Sylphide schafft im Grunde nur die Voraussetzung z.ur Befreiung Jettas (durch die Befreiung Nettchens und Augusts); der größte Teil der Rettungsarbeit selbst wird von Nettchen - nicht August - ïbernommen. Nach Augusts gescheitertem Angriff auf die Burg planen die Männer sofort den nächsten, Nettchen aber widerspricht und übernimmt das Kommando. „Ich habe mir etwas anders ausspintisiert, schlagt das fehl, so können wir immer noch grob werden" (55). Was Nettchen sich ausspintisiert, hat immer Erfolg; dagegen scheint August, der Held der Geschichte, bei aller männlichen Entschlossenheit völlig unfähig, den Gang der Dinge zu beeinflussen. Im Vergleich zu allen anderen Figuren des Stiickes scheint August eine Figur aus einer anderen Welt.

Das ist durchaus beabsichtigt: August ist eine Tragödienfigur, die sich in die Komödie verirrt hat. Der Unterschied zwischen August als Tragödienfigur und Nettchen als Komödienfigur ist schon allein an der Sprache erkennbar. Nettchen spricht im Komödienton und im Wiener Dialekt, August die Sprache der Tragödie und Hochdeutsch. Nur eine Szene zur Illustration: während Nettchen sich ausfïhrlich über die Dummheit der Männer lustig macht, betritt August mit allen Anzeichen tragischer Verzweiflung die Bühne.

NeTtChen. Aha! Da ist auch so ein Herr der Schöpfung! Gestern hat er alles zusammenreißen wollen und heut' geht er herum wie ein Hendel, das den Nipf hat. (Laut.) Nun, wie hast du geschlafen auf dein verunglücktes Abenteuer?

August. Ach liebe Schwester, ich konnte kein Auge schließen; der Unmut und der Durst nach Rache verscheuchten allen Schlaf. O verzweiflungsvolle Lage! (55 f)

Jetta ist Augusts weibliches Gegenstück: ihre Rolle beschränkt sich darauf, ihre Tugend gegen den Magier zu verteidigen und dem abwesenden August ihre Treue zu schwören. Im Stück wird die Liebesgeschichte der Tragödienfiguren August und Jetta schnellstmöglich abgehandelt und so oft wie möglich von der Komödie unterbrochen. Der August-Jetta-Handlung stehen z. B. zwei komische Liebesgeschichten gegenüber, der von Nettchen, die recht forsch Eustachius Wolferl zu ihrem Ritter erkürt, und der von Wolferls Schwester Anastasia, im Volksmund die "Gestrenge Frau“, die den Schulmeister Cajetan Schippelberger umwirbt. Daneben gibt es zahlreiche Dorfszenen, in denen der Schulmeister seinen Schülern das Einmaleins einprügelt, die Richterstochter Röschen ihren Peter heiratet, oder Nettchen von verschiedenen Dörflern umworben wird. 
Der gesamte Ton des Stückes ist auf Wortwitze angelegt: der Schulmeister beobachtet die Sterne und behauptet stolz von sich, er sei „alle Tage sternhagelvoll“ (12); Anatet die Stem ihren Gänsen und wird unterrichtet, ihr stasia fragt bei ihrer Anlunft als erstes nach ihren Gansen und wird untenteh die geBruder habe "befohlen, wir sollen keine einzige Gans schlach "e, dami, wenn die gestrenge Frau wieder zurückkommt, alle Gäns beisammen seyn" (21, Hervorhebung der Autorin). Die Werbung zwischen Anastasia und ihrem Schulmeister ist eine Parodie

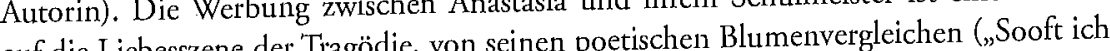
auf die Liebeszzene dïmchen oder an einer Klatschrose vorbeiging, fielen Sie mir immer ein“, $27 \mathrm{f}$ ) bis zu ihrer Reaktion („O! Wie die holde Schamröte meine Wangen umein , 27 , 27), Quasi als Warnung davor, die August-Jetta-Handlung zu ernst zu nehflattert!", 27). Quasi als Warnung davor, die August-Je the men, schiebt die Autorin zwischen den ersten Angriff auf die Burg und die endgültige Befreiung eine Szene ein, in der der Schulmeister seine Zöglinge abfragt. Wie in allen Bertspielen nicht gespart. Auf die Frage, komischen Szenen des Stickes wird hier an Worting Steffel: Mordelementl Kreuzelewie die vier Elemente heißen, antwortet der Prüfling Steffel: "Morele ment! Giftelement! Sternelement!" (64) Noch peinlicher wird die Sache, als Anastasia auftritt und der Schulmeister versucht, sie mit dem Wissen seiner Zöglinge zu beeinauftict und der Schinder sind. Z B. de drucken. „[...] ich versichere, es ist zun Staunen, wie brav dic King Große ist in der Mathematilk äußerst geschickt, werden es gleich selbst horen. He, Seppel! Aus der Mathematik, von der Analysierung der vorkommenden Gegenstände. Wa ist eine Analyse?" Antwort: „Dic Annaliese ist unsern Richter sein erstes Kuhmensch, mit der der Herr Schulmeister immer so freundlich ist, wenn's ihm die saure Milch bringt" (64 f).

Die Befreiungsgeschichte bzw. das magische Element und die Dorfgeschichte bzw. as komische Element werden bei Krones am Ende des Stückes auf ähnliche Weise verbunden wie in anderen Märchen: durch die Vereinigung der Liebespaare und die Gründung des Reiches der Liebe. Weil die Untertanen in Krones' Stück mindesten Grtind eine ebenso prominente Rolle spielen wie das bedrohte Liebespaar, muß die Autorin am Ende des Stückes klarstellen, was andere Autorinnen - in absentia der Untertanen - unausgesprochen lassen können, nämlich daß das Volk vom Liebesglück des Herrcherpaares profitiert. Daher die Versprechungen des wieder in seine Rechte eingescherpaares profitiert. Daher die Versprechingen des wieder in seine Rechte engesetzten Gutsherrn August und des frischgebackenen Gutsherrn Wolferl am Ende des Stückes.

Alt.e. Wir gratulieren! Wir gratulieren!

AUCuST. Ich danke euch! Ich erlasse euch alle Abgaben auf ein ganzes Jahr.

WOLFERL. Und ich auf sechs Wochen.

AlLE. Juche! Es leben die neuen Brautleute! (82)

Die Moral von der Geschicht ist dieselbe wie bei Seyler und Günther: die Liebe des Herrscherpaares garantiert das Glück der Untertanen, indem sie die Schreckensherrschaft des Magiers beendet.

Der Glaube an die Allmacht der Liebe, den schon Krones durch ihre Komödienhandlung persifliert, bricht in Elsa Bernsteins Königskinder (1894) völlig zusammen.
Bernsteins „deutsches Märchen“ etabliert sich schon im Personenverzeichnis als generisches Märchen; ihre namenlosen Figuren (der Königssohn, die Gänsemagd, der Spielmann, die Hexe etc.) stehen stellvertretend für die Typen des traditionellen Märchens. Zu Beginn des Stückes versucht die Hexe vergeblich, die Gänsemagd, die sie bei sich gefangenhält, zu einem Hexenkind zu erziehen, aber all ihre Bemühungen scheitern an deren Naivität und Güte. Während der Lebenszweck der Hexe der ist, den Menschen nach Kräften zu schaden, fühlt die Gänsemagd eine ihr selbst unerklärliche Zuneigung zu dem ihr völlig unbekannten Menschengeschlecht.

GÄNSEMAGD. [...] Laß mich ein Sommerjahr Ins Thal zu den Menschen gehn.

Müssen schön sein und freundlich und hold. Oft gehst du hinunter,

Kommst wieder und bist gar munter.

Hab' eine solche Gunst zu ihnen.

HEXX. Große Gunst hab’ ich ihrem Gold.

Denkst du, ich gehe die krummen Gassen,

Um sie zu lieben? Um sie zu hassen! (14 f)

Dic Gänsemagd besitzt genau die unbegrenzte Liebesfähigkeit, durch die im Märchen die Prinzessin mit ihrem Prinzen das Reich der Liebe begründet. Das erkennt auch die Hexe resigniert: „Da mach' nun einer 'ne Hexe d'raus!" (14) Ihr letzter Versuch, ihr ungeratenes Hexenkind zu erziehen, besteht darin, daß sie sie ein Brot backen läßt, das von beiden mit Zaubersprüchen beschworen wird.

GänSEMAGD. [...] Da ist das Brot.

(Schwingt es dreimal mit beiden Händen über den Kopf und spricht dazu.)

Wer davon ißt, mag das Schönste seh'n,

So er wünscht, sich zu gescheh'n.

[...]

HeXe. Nun sieh dir mit klugen Augen an,

Was du geknetet.

Es wird nicht hart, es wird nicht alt,

Verliert nicht seine schlimme Gewalt.

Wer es hälften ißt, stirbt ganzen Tod.

GÄNSEMAGD. Und das Sprüchlein, das ich drüber gebetet?

Hexe. [...] Macht keinem die Wangen wieder rot,

Hat er ausgeduldet (16).

Den Machtkampf zwischen Liebe und Tod gewinnt die Hexe: ihr Fluch ist stärker als der liebevolle Bann der Gänsemagd. Aber noch besteht Hoffnung: wie im Volksmärchen erscheint der Königssohn, sobald die Hexe den Rücken wendet, um im Wald 
nach giftigen Kräutern zu suchen. Der Königssohn hat sich auf die Wanderschaft bechen sich draußen bewähren will. Denn seiner Auffassung nach ist ein König nicht jemand, dem ein Königreich in den Schoß fällt, sondern jemand, der erst

Hungert und durstet und härtet die Glieder,

Gebirge hinan, zu Thale wieder,

Im Bärenkampf wird er stark und kühn.

Die Wunden heilen, die Narben erblühn.

O der Gefahr unbändige Lust!

Mächtig bewußt

Wächst es ihm erst aus der Brust

Im brausenden Morgenwind:

Königskind! Echtes Königskind! (25)

Die Gänsemagd, von seiner Euphoric hingerissen, schwört ihm ewige Liebe und will mit ihm ziehen, wird aber vom Bann der Hexe zurückgehalten, und der Königssohn, der ihre Unfähigkeit als Treuebruch versteht, verläßt sie zornig und beschimpft sie: "Königsblut und Bettelblut/ Sollen es nicht miteinander wagen" (31). Da die Gänse"Königs magd, im Bezug auf menschliche Herantasien des Königssohnes, lkleidet sie ihren Freivom Königtum kennt, nämlich die Phantasien des Königssohnes, kleidet

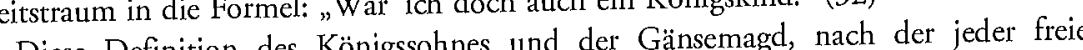

Diese Definiton des Königssohnes und der Gän Mensch ein Königskind ist, wird in der darauffolgenden Szene durch cine prosaischere ersetzt. Die Stadt Hellabrunn sendet der Hexe eine Delegation von drei Bürgern Holzhacker, Besenbinder und Spielmann. Ihr Auftrag, in den sarkastischen Worten des Spielmannes:

Müde ihrer gemästeten Freihei

Sind die Bürger der Hellastadt.

Korn und Wein

In faulem Frieden gedeihn,

Schier spinnt sich zu Golde das Stroh,

Jeder Gulden heckt sich zur Dreiheit,

Die Reichen sind feist, die Bettler sind satt.

Aber sie fühlen sich nicht froh

In der flachen Freude ihrer Tage und Feste.

Es fehlt das Beste.

[...]

Nichts Großes geschieht.

Jeder hat einen Herd, keiner hat einen Thron.

[...]

Finen Thron! Den wollen sie jetzt erbauen -
Die Königssehnsucht treibt sie zur Frohn -

Dinem Herrscher sich anvertrauen,

Einem Königssohn

Oder Königstöchterlein.

Aber ein Königssproß muß es sein.

Ein blutgeborener

Kronerkorener;

Stark, freudig und hochgesinnt,

Ein Königskind! ( $45 \mathrm{f}$ )

Trotz ihres märchenhaften Wohlstandes wollen die Bürger einen Herrscher über sich darauf reagiert die Hexe zunächst mit Unglauben und dann mit einer Warnung. Als die Abgeordneten, mit Ausnahme des Spielmanns, trotzdem auf ihrem Anliegen bestehen, erhalten sie das gewünschte Orakel: „Wenn morgen dic Mittagsglocken schlagen,

[...]/ Der Erste, der schlendert zum Stadtthor herein,/ Sei es ein Schalk/ Oder braune Wechselbalg,/ Der mag euer König sein" (49). Damit ziehen Besenbinder und Holzhacker glücklich und in der Hoffnung auf reichen Botenlohn ab; nur der Spielmann bleibt zurück, weil er die Gänsemagd am Fenster gesehen hat. Allein ihr Anblick überzeugt ihn, wen er hier vor sich hat: „Holdselig, wie mildes Morgenlicht./ Wie sollte der eine Krone stehn" (51). Als er versucht, die Gänsemagd dazu zu überreden, sich aus dem Bann der Hexe zu befreien, konfrontiert die Hexe die Gänsemagd mit der Geschichte ihrer Elterm:

Dein Vater, der hat vor sechzehn Jahren

Mit dem Feldstein den geilen Jungherrn erschlagen,

Und die Henkerstochter mit roten Haaren

Dic hat dich im Schoße getragen.

Hatte dem Jungherrn sich verwehrt,

Hat sich dem Henkersknechte bescheert,

In der Todesnacht,

Eh’ der Mörder zum Galgen gebracht (54).

Was die Hexe übersieht: in ihrer Moritat verborgen ist die Geschichte zweier Liebender, die für ihre Liebe sterben. So kann der Spielmann am Ende der Geschichte „mit gewaltigem Jubel“ ausrufen: „Zwei Königsmenschen, voll Kraft und Gewalt,/ Gaben dir Atem und Erdengestalt./ [...]/ Die Henkerstochter, der Henkersknecht/ Waren königsecht/In ihrem Lieben und Leiden" (54 f). Wie bei Seyler und Günther ist hier die Liebe des Paares das Zeichen ihrer Königswürde. Die Gänsemagd befreit sich aus dem Bann der Hexe, indem sie ihre Eltern um ein Zeichen bittet - unter Beschwörung der Liebe: "Wie ihr euch liebtet, so lieb” ich ihn“ (56). Ihr Ziel ist jetzt "ihn wiedersehn“, „ihn erreichen" (56).

Während die Gänsemagd durch ihre Liebe zum Königskind wird, versucht der Königssohn dasselbe Ziel zu erreichen, indem er sich in Demut übt. Den „rechten 
Königssinn" (69) will er sich erwerben, indem er sich für ein Jahr bei dem geizigen Wirt als Schweinehirt verdingt. Aber das Volk, das sich mittlerweile auf die für zwölf Uhr prophezeite Ankunft des Königs vorbereitet, hat andere Vorstellungen von einem König.

Und kommen wird er, dahergefahren,

Daß die Räder sich biegen

Auf einem Wagenthron -

In dreimal siebenhundert Jahren

Erzählt man den Kindern davon.

Und hat Kisten und Truhen

Mit Gewanden und silbergeschmiedeten Schuhen,

Und lkarfunkelt von Steinen und dickem Geschmeide - (87)

Im Volksmund machen die Kleider den König, oder in der trefflichen Kurzformel des Im Volksmat Go sehnsüchtig erSchneiders: "Guter Stand/ wartet, ist keineswegs ein echter Herrscher, sondern ein „Drohnenkönig", wie die Hexe schon vorher festgestellt hat (48), eine Repräsentationsfigur, die es jedem recht macht und jeden Stand bereichert.

RATSHERR. Er braucht nicht denken. Denken doch wir

SCHNFIDFr El soll sich hübsch Kleider nähen lassen!

RATSERAU. Uns schenkt er vielschlitzige Handschuh zur Zier:

RATSFrÄulein. Oft läßt er sich sehen auf Marlıt und Gassen.

MäDCHEN. Auf dem Anger springt er mit uns den Reihn.

WIRT. Bei mir kauft er wohlfeil seinen Wein.

Besenbinder. Beim vierzehnten Kind steht er mir Pate. [...]

HOLZHACHER Ich hacke für ihn - nein, ich hack' nicht mehr Holz.

Mich macht er zu seinem Lieblingsrate (89 f).

Die Erwartungen des Vollees werden, zumindest was das Aussehen des neuen Monar Die Enwartie Gänsemagd in die Stadt einzieht, in chen betrifft, herb enttauscht, als Schlag zwöf dieżne Begleitung des Spielmannes, umgeben von ihren Gänsen und mit ciner Krone auf dem Kopf. Das Voll verwandelt sich prompt in einen Lynchmob; der Königssohn, der sie in Scer Stadt geprügelt; der Spielmann, der sie Schutz nimmt, wird mit ihr zusarnmen aus der Stähnenbild bis anerkennt, in den Turm geworfen. Am Ende der Szene lect sich das Buhnenbild bis auf ein Kind, das weinend protestiert: „Das ist der König und seine Frau gewesen!" (98)

Der dritte Alst spielt im tiefsten Winter und liefert den endgültigen Beweis für die Machtlosigkeit der Liebe gegenüber der Gier und Blindheit der Bürger. Die Hexe ist 列 den; ihre Hütte im Wald bewohnt jetzt der Spielmann, der sich aus der menschlichen den; ihre Hütte im Wald bewohnt jetzt duch ing Gemeinschaft ausgeschlossen hat. Dort sucht ihn eine Delegation aus der Stadt auf, bestehend aus dem Holzhacker, dem Besenbinder und einem Kind - demselben, das die Königskinder erkannt hat. Holzhacker und Besenbinder agieren als Abgesandte der seit der Vertreibung der Königskinder verarmten Stadt, in der die Kinder den Erwachsenen den Gehorsam verweigern. Während die Erwachsenen den Spielmann bitten, die aufrührerischen Kinder zu beruhigen, flüstert das Kind ihm den Auftrag der Kinder zu: er soll ihnen helfen, die Königskinder wiederzufinden. Der Spielmann macht sich mit den Kindern auf die Suche, und Holzhacker und Besenbinder besetzen die Hüttc. Kurz darauf erscheinen Königssohn und Gänsemagd, beide halb verhungert und frierend. Der Königssohn bittet den Holzhacker und den Besenbinder um Essen und Unterkunft; beides wird ihm verweigert. Schließlich verkauft er das letzte, was er hat - seine Krone - und erhält dafür das Brot, das die Gänsemagd zu Beginn des Stückes unter Anleitung der Hexe gebacken hat. Sowohl der Fluch der Hexe als auch der Spruch der Gänsemagd gehen in Erfüllung: die Königskinder sterben nach einer Vision dessen, was sie sich am meisten wünschen - den Frühling -, die Gänsemagd mit der Beschwörungsformel auf den Lippen, mit der sie die ganze Szene hindurch versucht, den Tod abzuwehren: „Der Tod kann nicht kommen - ich liebe dich" (116, $117,123)$.

Was Königssohn und Gänsemagd zu Königskindern macht, ist ihre Fähigkeit zu lieben, dieselbe Eigenschaft, die in allen anderen Märchen das Paar zu Herrschern über das von ihnen gegründete Reich der Liebe setzt. Aber im Gegensatz zu anderen Märchen, in denen das Volk entweder ganz ausgespart oder zu komischen Figuren reduziert wird, zeigt Bernstein, wogegen dieses Ideal angehen muß: gegen die Gier des Besenbinders und des Holzhackers, die sich um den Botenlohn für den Gang zur Hexe streiten und den Königskindern Brot und Unterkunft verweigern; gegen die Dummheit der Bürger, von denen sich jeder einen König nach seinem eigenen Vorteil zimmert; gegen den Geiz des Wirtes, der den Königssohn umsonst als Schweinehirt für sich arbeiten lassen will und bei unbezahlter Zeche mit dem Schuldturm droht; gegen die kleinliche Grausamkeit der Wirtstochter, die die Mägde schlägt; gegen die mörderische Mentalität der Masse, die die Königskinder aus der Stadt prügelt, den Spielmann körperlich mißhandelt und im Turm gefangensetzt. Mit Ausnahme der Königskinder; des Spielmannes und der Kinder hat jede Figur des Stückes nur den eigenen Vorteil im Auge. Während das traditionelle Märchen der Liebe die Macht zugesteht, die Welt zu crneuern, hat sie bei Bernstein nicht einmal die Fähigkeit, sich selbst zu erhalten: die alte Märchenformel der Gänsemagd von der alles besiegenden Liebe zerbricht an der Lieblosigkeit anderer:

\section{B. Die Utopie von der Allmacht der DichtKunst: NeUber, DELLE GRAZIE}

Die Idee, daß die Poesie das goldene Zeitalter herbeiführt, ist bekannt, u. a. von Schiller, Goethe und sämtlichen Frühromantikern. Bei schreibenden Frauen ist diese Utopie seltener; daß die Dichtkunst - immer impliziert: die eigene Dichtkunst - eine 
derartige Wirkung haben könnte, scheint für Frauen schwerer glaubhaft als für MänVon der. Menge der angefuihrten Dramatikerinnen verbanden nur zwei den Prozeß ner. Gran soziale Reform der Welt; bei Neuber um die ästhetische des Theaters. Beide Autorinnen vermitteln ihre Utopie im allegorischen Stil.

Karoline Neubers (1697-1760) Ein deutsches Vorspiel (1734) ist eines von mehreren Karoline Neubers (1697-1760) Ein deutsches Vorspiel (1734) ist eines von mentide.
Vorspielen und Vorreden, in denen sie ihre reformatorischen Bestrebungen verteidigte. Ziel dieser Bühnenreform, theoretisch ausgearbeitet von Johann Christoph Gottsched, Ziel dieser Ber Schauspiele durch Einführung der drei Einheiten und Verse (nach französischem Muster meist Alexandriner), die Abschaffung obszöner Äußerungen, Zoten, Witze und grober Unwahrscheinlichkeiten auf der Bühne (dahe J. Chr. Gottscheds Empfindlichkeit gegen Opern, Possen, sogenannte Haupt- und . Chr. Gottscheds En Harlekin). Das neue Theater schuf Staatsaktionen, und selbstverständlich gegen den Harlekin). Das neue Theater schuf eine Hierarchie zwischen Tragödie und Komödie, in der die Tragödie das favorisierte Genre war, und sollte eine stark didaktisch-moralische Seite haben - wie Neuber selbs oft betont: die Guten im Guten bestärken, die Bösen bessern. Während J. Chr. Gottsched es bei dem theoretischen Konzept bewenden ließ und als Beispiel einige Tragödien schrieb, blieb es Neuber überlassen, seine Theoric in die Praxis zu übersetzen.

Für eine Wanderbühne, die an jedem neuen Spielort ihr Publikum anziehen mußte, war das ein schwieriges Unternehmen. Possen und Haupt- und Staatsaktionen waren die bevorzten Genres der Wandertheater, der Harlekin die beliebteste Figur auf der Bühne, und die Zeit für Proben knapp bemessen. Viele der aufgeführten Stücke beBühne, und die Zeit ferr Proben standen nur zum Teil aus einstudiertem Material, der Rest we Technik, die bei Alexandrinerdramen nicht anwendbar war. In der Praxis bedeutete J. Chr. Gottscheds Programm ein Risilso für die Truppe: einerseits mußten die Schauspieler wesentlich mehr Zeit für Proben aufwenden und konnten daher weniger Stücke (a) aufführen, andererseits erwies sich der neue Anspruch des 'The Belehrung statt Unterhaltung - in vielen Fällen als weniger rentabel als die Witze des verachteten Harlekin.

Die Gottsched-Neubersche Theaterreform war Teil einer utopischen Bewegung: die Terbeiführung des goldenen Zeitalters durch die Verbesserung des Menschen von der Bühne herab. Für Neuber, die dieses Programm auf der Bühne verfechten sollte, gesell列 te sich eine zweite, praxisbezogenere Utopie dazu, namich die, mit diesem Plogramm auf der Bühne überleben zu können. Das Deutsche Vorspiel war nicht das einzige Stück, in dem sie das Unternehmen verteidigte; später nahm sie den Kampf mehrfach wieder in dem sie das Un Weißheit wider die Unwissenauf - wie in dem verlorengegangenen Vorspiel Die von der We Jheit wider die Unwissenheit beschützte Schauspielkunst (1736) und in Die Verehrung der Volkhommenheit durch die gebesserten teutschen Schauspiele (1737). Alle drei Vorspiele waren außerdem Ge-

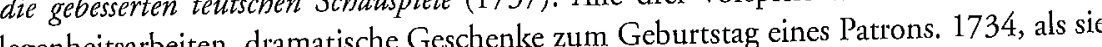
legenheitsarbeiten, dramatische Geschenke zun Geura das Deutsche Vorspiel schrieb, ließ dieser Paron Privileg - die Erlaubnis, in Leipzig zu spielen - dem Schauspieler Müller, der bis 1733 Prileg 210 leben ihrer Truppe gefährdet, sondern auch das ihrer Reformbestrebungen, denn Müller, seiner alten Rolle getreu, war gegenüber Possen, Haupt- und Staatsaktionen und dem Harlekin skrupelloser als Neuber.

Aus ihrem Streit mit Müller um das sächsische Privileg macht Neuber im Deutschen Vorspiel eine utopische Allegorie: wenn die Leipziger Behörden und der König sich auch auf Harlekin Müllers Seite schlagen - in ihrer Allegorie bestätigt Apoll persönlich ihre Utopie vom Erzichungstheater. Den Weg vom persönlichen Erlebnis - dem verlorenen Streit um das Privileg - zur Theaterutopie, in der das Besserungstheater das Unterhaltungstheater ersetzt, legt sie, kryptisch formuliert, in der Vorrede zurück: Them ihres Vorspicls ist „theils bekannte Geschichte, theils unbekannte Gedichte" (Vorrede, 3). Gemeint ist vermutlich die Geschichte des Privilegstreites; die unbekannten Gedichte könnten Verstragödien sein. „Das Werk ist in Reimen abgefasset. Ob die Verse rein, und die Gedanken richtig sind; werden diejenigen wissen, die es verstehen" (3). Das ist deutlicher: indirekt distanziert sich Neuber von Müller, dem Harlekin, dem "alten" Theater; indem sie sich dem Urteil derer unterwirft, die von der regelmäßigen Tragödie etwas verstehen. Es folgen die obligatorischen Entschuldigungen der weiblichen Schriftstellerin dafür, daß sie es wagt, etwas zu veröffentlichen. Wie sie alle hat auch Neuber einen zwingenden Grund dafür, daß sie es dennoch tut, in diesem Falle den, daß „sie ihre eigene Rolle auf, und vor der ganzen Welt zu spielen genöthiget wird" (4). Ihre Rolle auf der Welt: die Rolle der Theaterreformerin. Ihre Rolle vor der Welt (d. h.: auf dem Theater): die Rolle der Theaterreformerin Melpomene im Deutschen Vorspiel, die Neuber selbst spielte.

Zum besseren Verständnis des Stückes folgt eine Aufzählung des Personenverzeichnisses aus dem Original mit Erläuterung der allegorischen Bedeutung jeder Figur:

Melpomene: Muse der Tragödie. Gespielt von Karoline Neuber.

Thalia: Muse der Komödie

Euphrosyne: die Heiterkeit, eine der Grazien

Vigilantia: die Wachsamkeit

Apollo: der Gott der Künste. Ihm unterstehen die neun Musen.

Tharsus: die Kühnheit

Themis: das Recht, die göttliche Gerechtigkeit (im Gegensatz zu Dike, der irdischen Gerechtigkeit)

Arcte: die Vortrefflichkeit

Alethea: die Wahrheit

Obsequenz: die Willfährigkeit, Nachgiebigkeit. Gespielt von Johann Neuber.

Sedulius: der Fleiß

Meletander: unklar. Wahrscheinlich die Nachdenklichkeit (von griechisch "melet" = die Nachdenklichkeit oder der Muse Melete = das Nachdenken). "Ander" = der Mann (griechisch). Eventuell eine Anspielung auf die Dichtkunst: griechisch „Meleteian“ (am Fluß Meleteos geboren) ist eine poetische Umschreibung für Homer, der an diesem Fluß geboren war. 
Silenus: $\quad$ Gott der Erde. Manchmal Sohn oder Bruder des Pan oder Sohn des Hermes. Silenus ist mit Pan und Bacchus verwandt und wird häufig als jovialer, dicklicher, ständig betrunkener Mann dargestellt. Als als joviale, dicllicher silenus sein Lehrmeister, später wurde er sein Bacchus jung war, war Silenus sein Leher treuer Anhänger. Da Silenus in der Regel zu betrunken ist, um gehen zu können, reitet er auf einem Esel.

Pseudolus: Lügenmaul (aus einer Komödie von Plautus).

Im Stück planen Silenus und Thalia, Melpomene das Privileg an Apollos Musenhof zu Im Stuick planen entziehen, denn Thalia sieht ihre Kunst durch Me Kunst sind eine ziemlich vollstänAufzählung von Melpomenes Bedingungen an die Kunst

dige Darstellung des Gottsched-Neuberschen Programms:

Ich soll die Leute nicht mit Possen mehr betrügen,

Und nicht mit leichter Müh viel Geld in Kasten kriegen;

Ich soll, nach ihrer Art, in strengen Regeln gehn,

Und jede Leidenschaft recht aus dem Grund verstehn.

Der Teufel plagt sie doch! den Leuten weiß zu machen

Man müßt im Lustspiel nicht, so, wie ein Bauer lachen

Und auf dem Schauplatz dürft kein Possenreißer seyn.

[...]

In jedem Schauspiel soll kein leerer Possen stehn,

Und auch kein Zötgen nicht; der Harlekin soll schweigen (5 f).

Und das alles einzig zur Besserung des Lasters („Der Pöbel dürfte nicht noch mehr verdorben seyn;/ Er wär der Beßrung werth“, 6) und zur Festigung der Tugend („Man

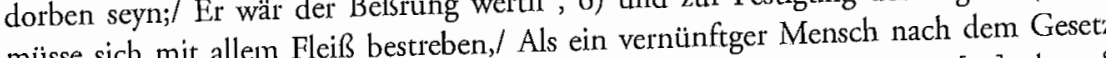
müsse sich mit allem Fleißß bestreben,/ Als ein vernüntger Menche Gesetze [zu] plagen" zu leben“, 7). Thalia, nicht gewillt, „sich so gezwängt mit dem Gesetze [zu] plagen (7), beschließt vielmehr zusammen mit Silenus, Melpomene bei Apoll zu verleumden, (7), beschlißst weiß, won redlich klugen Leuten/ Gar unterstïtze obwohl diese, wie Thalia wohl weiß, „,on redich Sedulius und Obsequenz, dic alle wird" (7). Diese redlich klugen Leute sind Tharsus, Sedulius und Obsequenz, dic alle der verzagten Melpomene eifrig zureden, ihr Vertrauen in Apollos Gerechtigkeit zu serzen, und Alethea, die ihr verspricht, im rechten Moment für sie zu sprechen. Abe Melpomene fühlt sich verstoßen und "in lauter Ungenaden" (10). Trotz der Unterstützung der anderen wird sie vor Apollos Thron von Vigilantias Mißtrauen erneut so cingeschüchtert, daß Themis und Alethea dem Gott ihre Sache vortragen müssen. Kur vor dem göttlichen Urteilsspruch betritt Pseudolus die Bühne und versucht, Apollo (a) Frau erboßt!/ Du glaubst gegen Melpomene aufzuhetzen: „sey ja recht sehr auf diese Frau ent nicht, was das Thier für mich für Schaden bringet, / Und wie sie, mir zum Trotz, von guten gut

Themis und der Alethea, gibt

Trotzdem überläßt Apoll die Entscheidung der Themis und läßt an Thalia und
Melpomene ihren angestammten Platz am Musenhof zurück und lät
Silenus den Auftrag ergehen, sich zu bessern. Das ist insofern wichtig, als Thalia, die Komödic, keineswegs von Melpomene, der'Tragödie, aus dem Musentempel vertrieben wird: nach Apollos Ausspruch hat sie ihren Platz unter den Musen zwar nicht verdient, aber sie darf trotzdem bleiben - vorausgesetzt, die erhoffte Besserung tritt ein. An dieser Besserung der Thalia arbeitet auch Melpomene, indem sie ihr bereitwillig ihre Hilfe anbietet: „das was dir gehört, gewiß das gönn ich dir./ Ich will dich noch darzu mit vielen Freuden lehren,/ Wie du dich rühmlich, wohl und redlich solst ernähren" (23). Obwohl auch Sedulius, Tharsus, Themis und Alethea ihre mahnenden Stimmen der Melpomenes hinzufügen, bleibt Thalia unbelehrbar. „Ich brauch so hohe Gaben,/ So grosse Einsicht, nicht. Mein Nutzen ist mein Recht" (26 f). So schließen Melpomene und Thalia einen unsicheren Nichtangriffspakt, nach dem beide nebeneinander existieren - Melpomene zur Verbesserung, Thalia zur Unterhaltung der Menschen - und bei dem, gemäß der zeitgenössischen Realität, Thalia sich noch gesünder befindet als Melpomene. Während Thalia noch ausreichend Energie aufbringt, um über das ihr angetane Unrecht schreien zu können, ist Melpomene „matt, und kan nichts weiter thun, Als einen treuen Wunsch [...]: Gott geb dem König Sieg, und beßre seine Feinde,/ Erhalte Stadt und Land, und segne meine Freunde!" (27 f)

Melpomenes Abschiedsworte, gleichzeitig Neubers Abschied an die Stadt Leipzig, sprechen wieder das Besserungsmoment an, die Beschwörungsformel der geplanten Reform. In einem guten Teil des Vorspiels geht es um nichts anderes: fast ein Viertel des gesamten Textes entfällt auf die vergeblichen Überzeugungsversuche von Tragödie, Fleiß, Kühnheit, Recht und Wahrheit an die Komödie, sich von der Tragödie bessern zu lassen. Das war drei Jahre vor Neubers spektakulärer Verbrennung des Harlekin. Hier schließt der utopische Besserungsglaube auch den Harlekin noch ein: „Aus einem Zotenreißer sollte eine didaktische Figur werden" (Heckmann 120).

Neubers Kampf um die Reform der deutschen Bühne war weit mehr als nur der Kampf um das materielle Überleben ihrer Truppe. Sie sah sich als Vorkämpferin eines großen utopischen Programms, das der Erziehung und Verbesserung des Menschen von der Bühne herab, das zunächst auf der Bühne verwirklicht werden und von da einen moralischen Siegeszug um die Erde antreten würde. Für Neuber, die Theaterleiterin, Schauspielerin und Theaterschriftstellerin, die ihr ganzes Leben beim Theater verbracht hatte, schien überdies der Weg zur Erzichung des Menschen über die Bühne der offensichtlichste und erfolgversprechendste. Für sie war die Reform des Theaters nicht nur Mittel zum Zweck, sondern bis zu einem gewissen Grade identisch mit der Reform der Welt. Zweifellos hätte sie den Erfolg des neuen Besserungstheaters als Zeichen der erhofften Besserung des Zuschauers interpretiert. Deshalb ordnet sie auf dem Theater ästhetische Kriterien den moralischen unter und möchte selbst - mitsamt ihren Reformbestrebungen - unter Anwendung derselben Kriterien bewertet werden nicht an dem Urteil von Theaterfachleuten oder -kritikern ist Neuber interessiert, sondern an "dem Urtheile dererjenigen, die da richtig denken“ (Vorrede, 4). Wie Neuber selbst in ihrer Rolle als Melpomene „ihre eigene Rolle" spielte, besteht für sie eine enge Beziehung zwischen der Welt und den Brettern, die die Welt bedeuten - die geplante moralische und ästhetische Besserung des Theaters ist gleichbedeutend mit der 
moralischen der Welt. Wie in der Welt das Laster mit der Tugend im Kampf liegt, so stehen im Theater Unterhaltung und Obszönität gegen moralisches Beispiel und Besstehen im Theater Unill sie bessern. Sowohl in der Welt als auch auf dem Theater bleibt sie „beydes, der guten und bösen Welt verpflichtet: Der guten; weil sie es würdig ist; der bösen, weil sie an ihrer Besserung nicht zweifelt" (Vorrede, 4).

Die einzige utopische Allegorie nach Neuber hofft nicht auf Reform, sondern auf Revolution. Marie Eugenie delle Grazies (1864-1931) Moralische Walpurgisnacht (1896) ist wie Neubers Stück ein Vorspiel, ein „Satyrspiel vor der Tragödie“. Dramatis (1896) ist wie Neubers Ste - dargestlt von personae: die Heuchelei, das Eigentum, die Humanitat, die Ehe dargestell von einem Mann und einer Frau, die mit Schlangen ancinander gefesselt sind -, die Gerechtigkeit, die Wissenschaft, die öffentliche Meinung, der Kritiker, der Dichter, die Art iuberall (5). Delle Grazies Allegorie spricht für sich Arbeiter. Zeit. die Gegenwar, Ort iberll (5). Delle Grazies Allegorie spricht fur sich selbst. In einer unterirdischen Grotte sitzt die Heuchelei auf dem Thron, außer dem Dichter und den Arbeitern finden sich sämtliche Personen des Stückes - alle maskiert Dichter und den Arbeitern Heuchelei" ein (8). Vor Beginn der Festivität berichtet das - zum "Gottesdicnst der Heren Eigentum von schlimmen Vorgängen auf der Erde - „Denk nur, die Armen ruhren sich!/ Sie wollen nicht mehr werken und schaffen,/ Nicht mehr für mich erringen, erraffen" (11 f) - aber die Gerechtigkeit hat die Aufrührer mit Pulver und Blei zum rast Zeichen, daß das Fest der Heuchelei erneut beginnen kann, Schweigen gebracht. Zum Zeichen, daß das Fest der Heuch cli en befiehlt die Heuchelei den Anwesenden, die Masken abzunehmen. Diese muhen sich vergeblich: die Masken sind ihnen angewachsen - „Ein neuer Teil von unsrem Sein (15). Das Phänomen erklärt der Akademiker mit "Darwins prächt'ger Theorie“ (15) (15). Das Phänomen erklärt der Akcaniker mit „Daw Nietzsche Aus dem akadevom Gesetz der Anpassung, moralisch untermauert von Niezzche. Aus dem akademischen Diskurs, in dem er der Heuchelei darlegt, daß so aus Verstellung Natur gemorden sei, zieht sie erfreut den Schluß, daß die so geschaffene Natur sich ruhig ans den Sch mystisch DunTageslicht wagen dürfe. "Zum letztenmal vereint euch hier/ Der Höhle

kel -/ Die nächste Orgie feiern wir/ Kühn in des Tag's Gefunkl! (19) Im frohen Reigen singt jeder der Anwesenden ein Led, das sente Roll beschribs das Eigentum fungiert als Mörder, die Gerechtigkeit als Richter des Menschen; die Humanität und die öffentliche Meinung dienen dazu, das Komplott zu bemänteln die Ehe zeugt im Dienste des Eigentums Kinder "Zwischen Ekel und Verrat" (24); di Wissenschaft har ihre Braut, die Wahrheit, für die Mätresse Pfründe verlassen. Nur de Kritiker findet, seiner Rolle gemäß, an der allgemeinen Heiterkeit ctwas auszusetzen und warnt die Heuchelei, daß ihr Reich von kurzer Dauer sein könnte, „Den uusenthron/ Naht der Lümmel Revolution" (26). Der Kritiker heg diese Vermutung, seit die Dichter, ehedem „Der Menschheit Scheuleder gegen die Wahrheit" (26), sich weigern, die Zustände im Reich der Heuchelei ästhetisch zu bemänteln: "nun brüllen sic nach Klarheit“ (26); „Die Bande lärmt und wird fatal“ (28). Den Kririker, der unfähig ist, die aufrührerischen Dichter ins alte Fahrgleis (28). Den Kritiker, überrieselt's kalt" beim Gedanken daran, was die Dichter jetzt schreiben.
KritTKER, Zuvörderst schildern sie die Frauen, So wie sie sind!

EHE. $\quad$ O Schmach und Grauen

Dic künftigen Mütter!

KRITIKER (verlegen). Ja seht, im Vertrauen

Gesagt: auch diese sind manchmal - Frauen!

ALLE. Hihi -

HeUCHELEI, Dann aber sagt man's nicht --

Wer brächte Solches in ein Gedicht?! (30 f)

Während die Gesellschaft noch lautstark ihr Entsetzen über die aufrührerische Dichterzunft äußert, zersplittert dic Grotte, es wird Licht, und es erscheint - wie auf Stichwort - der Dichter. Er zerbricht das Szepter der Heuchelei und berichtet, auf der Erde habe inzwischen die Wahrheit ihre Fesseln gesprengt; er demaskiert die hilflos gewordene Heuchelei und richtet eine Aufforderung an den Rest der Gesellschaft: „Folg' wer mir folgen darf und mag,/ Hinauf an seine gold'ne Sonne!" (37) Die erste, die begeistert dieser Aufforderung folgen will, ist das „Weib" - ein Teil der Ehe. Es folgt eine der vielen vielsagenden Nebenszenen: „DAS WeIB. Die Fesseln herab! Hinauf? Laß mich -/ Der MAnN. Haha, wähnst du, ich hielte dich? (Lüstern.)/ Da draußen all die blüh'nden Frauen..." (37). Am Ende der Szene stürzen beide auf den Dichter zu: "Nimm uns hinauf:" (39) Der aber lehnt ab und verurteilt die Ehe dazu, vergessen in der Grottc zu sterben - zusammen mit der Heuchelei und dem Eigentum. Die Mitglieder der Gesellschaft, die oben gebraucht werden, sind die Gerechtigkeit, die Wissenschaft und die öffentliche Meinung. Auch der Kritiker darf mit nach oben, obwohl nach ihm nicht gefragt wurde, denn der Dichter erkennt ihn als die andere Seite seiner selbst - und definiert mit folgender Wendung sowohl sich selbst als auch den Kritiker als allegorische Figuren: „Gieb mir die Hand,/ Noterbe aller Phantasie - Verstand!“ (43)

Oben zieht ein Arbeiterheer mit roten Fahnen vorbei; das Lied von der Auferstehung der Wahrheit, das sie singen, ist eine wörtliche Analogie zur Auferstehung Christi und räumt mit der einzigen allegorischen Figur auf, die nicht in der Grotte vertreten war: der Religion.

Die Wahrheit ist erstanden,

Befreit von Todesbanden -

Der Trug hat keinen Stachel mehr,

Der Stein ist weg - das Grab ist leer!

Seht ihrer Wunden Male

Aufblüh'n im Sonnenstrahle -

O Duldermut, o Siegesglück,

Weit weichen Nacht und Kreuz zurïck! (43)

Neubers allegorische Reform und delle Grazies allegorische Revolution haben ein Element gemeinsam: das utopische Element, das schon ein Teil des alten Märchens ist. 
Das Erstaunliche an beiden utopischen Konzepten, der rückwärtsgewandten des MärDas er Allegorie, ist, daß sie in der dramatischen Prochens und Komödien, die duktion von Frauen so selten vorkon das Märchen von der Zaubermacht der Liebe vehement abstreiten, finden sich nur ca. 30 Märchen, die versuchen, sie zu behaupten. Angesichts der ungeheuren Bühnenwirksamkeit dramatischer Märchen ist das einigermaßen überraschend. Noch seltene ist die bei männlichen Schriftstellern recht populäre Utopic von der Allmacht der Dich Dichtkunst: Neuber und delle Grazie sind meines Wissens die einzigen Dame heitalter heraufzubeschwören.

Die Grïnde für die Seltenheit von dramatischen Utopien lassen sich nur vermuten. So holbstzweifel vicler Autorinnen hier eine Rolle spielen. Diese Zweifel am eigenen Schriftstellertum (Maske? Zweite Natur?), die in fast spielen. Diese Zweifel am eigcilon scheinen mit einem so unbejedem Vorwort, in jedem Epilog ausgedrückt werden, scheinen dingten Glauben an die Dichtkunst, wie ihn Neubers und delle Grazies Utopien voraussetzen, kaum vereinbar. Eine mögliche Antwort auf die Frage, warum Märchen a obwohl selten - so viel häufiger auftreten als Utopien, Gendet sich bei einem Getevergleich. Die allegorische Utopie verhält sich der Gegenwart gegenüber wesentich krritischer als die Utopic des Märchens. Letztendlich steht es dem Leser frei, ein Märchen als Utopie zu lesen. Die Utopie des Märchens ist impliziert und rückwärtsgechen als Utopie zu lesen. Die Utopie des Märhe wandt; das glückliche Ende des Märchens - d. h. Prinz und Piinzessin heiraten, wenn sie nicht, wie bei Bernstein, gestorben sind - deutet auf das goldene Zeitalter ihre Regierung voraus. Für den Leser des Märchens aber ist das glückliche Zeitalter, das Ende des Mäch an Vorzeit, denn das Ganze spielt Ende des Märchens anbricht, nicht erlebte graue Vor " sich „vor langer langer Zeit“ ab, „wo das Wünschen noch geholfen hat (Der Froschkönig oder der eiserne Heinrich, KHM I, 35), oder gar "als Gott noch selbst auf Erden wandelte" (Die Kornähre, KHM II, 232). Das Märchen impliziert einen Kontrast zwiWerte (der Zeit, in der das Wünschen nicht mehr hilft); die allegori-

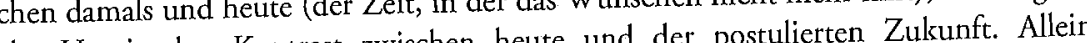
sche Utopie den Kontrast zwischen heute und de pertulientent sic dadurch, daß die allegorische Utopie die Zukunft als Bezugspunkt setz, etabliert sic sich als Kritik an der Gegenwart. Eine Utopic ist eine literarische Revoluciong sie behauptet, die real existierende Welt sei ohne diese Umwälzung ungerecht, unvollkommen ofertende Welt und ersetzt sie men oder schlechthin unertriglich; sie veen durch ihren U-Topos. Implizit oder ausdrücklich präsentient sich jede Utopie vor dem Hintergrund einer im wahrsten Sinne des Wortes vernichtenden Kritik an der gegenwärtigen Realität. Und Kritik auf dem Theater, das ist ersichtlich aus den einhundertfünf nicht ermutigt.

\section{KAPITEL IX}

\section{UND DIE MORAL, VON DER GESCHICHT...}

\section{KINDERTHEATER}

\section{A. Braun, Hölder, Hofmann, von Sydow, Franz}

Kindertheater ist tatsächlich Theater für Kinder. Theater für Kinder ist ein fester Bestandteil der Kinder- und Jugendliteratur des frühen 19. Jahrhunderts - ca. 1820 bis 1850 -; die Verfasserinnen waren oft hauptberuflich Erzieherinnen. Thre Stücke, die meist in Sammlungen von vier bis zehn Stücken erschienen, sind sehr kurz (Spielzeit höchstens eine Stunde), verlangen wenige Requisiten, spielen meist in einem Wohnzimmer, in dem sie auch aufgeführt werden sollten, und führen hauptsächlich Kinderrollen im Personenverzeichnis. Die Stücke richten sich ausnahmslos an die

Kinder des Adels und des gehobenen Bürgertums und spielen in entsprechendem Milieu.

Sinn der Stücke ist fast überall ein erzieherischer, wie die teilweise ebenfalls an die Kinder gerichteten Vorworte bezeugen. Wilhelmine von Sydow (1789-1867), die einzige Autorin, die unter einem Pseudonym schrieb, bemerlst zur Zielsetzung ihrer Dramen

Was Euch die kleinen Schauspiele andeuten [...], umfaßt keinen andern Zweck, als Euch die Vorzüge des Guten und die Nachtheile des Bösen in vielfarbigen Lebensbildern vor die Seele zu führen. Mögen sie Euere Liebe für die Tugend erhöhen, Euer Zartgefühl beleben, Eueren Abscheu vor dem Laster verstärken helfen, und Euch nebenher eine heitere Unterhaltung gewähren! - Dann ist meine Absicht erfüllt (Vorwort III $\mathrm{f}$ ).

Ähnlich äußert sich Luise Hölder (keine Lebensdaten) in der Vorrede zu ihrem zweibändigen Werk Neues Kinder-Theater:

Die lebendigere dramatische Darstellung so mancher Fehler und Unarten der Kinder macht einen tieferen und bleibenderen Eindruck als bloße Erzählungen; durch die Aufführung solcher kleiner Schauspiele wird das Gedächtniß geübt, und sie sind zugleich eine treffliche Uebung in der Declamation (Vorrede 4).

Diesen letzteren Aspelkt betont auch von Sydow: „die kleine Bemühung eines längeren Memorirens wird [...] Euerem Gedächtnisse nur Vortheil bringen" (Vorwort v). Kitty Hofmann (?- nach 1834) nennt als Anlaß für die Veröffentlichung ihrer Kinderdramen den „Wunsch, die kleinen Weltbürger für sittliches Vergnügen aufzuregen, und sie dadurch moralisch zu bilden" (Vorerinnerung, 7). 
Die moralische Bildung adliger und bürgerlicher Kinder wird in den Stücken hauptar sachlich durch drei Methoden angestrebt. die Darstellung lasterhafter rende Darstellung gur bestraft werden. In die erste Kadeiner Rangen, die am Ende entweder gebser tegorie fallen eine Reihe von Stücken, in denen die Tugenden guter Kinder (Gehorsam, Fleiß, Mitleid, Lerneifer, Bescheidenheit) am Ende des Stückes durch außergewöhnliches Glück belohnt werden, z. B. indem ein verlorener Sohn oder Bruder wiewönnliches Click beloht dergefunden und in den Schoß der Familie zurtickgebracht wird. In Withe Sydows Die Überraschung (1830) läuft der fleißige und wahrheitsliebende Pfarcerssohn Fritz von zuhause weg, um seinem Freund, dem Seiltänzer Anselmo, in der Not beizuFirz rons von Wehlau ist, der vor Jahren von einer wandernden Zigeunertruppe entethrt wurde. Der Husarenrecrut (1830), der zwölfjährige Rino Ennst, zieht den in der Schlacht verwundeten Rittmeister von Fall unter Lebensgefahr unter Leichen hervor und bringt ihn nach Hause, wo seine Mutter und Schwester dem Vaterlandsverteidiger. ind ser Gerettete als Bruder des liebevolle Pflege angedeiher leim vor Jahren wegen seiner bürgerlichen Heirat Familienvaters, der von beider Oheim zurickerhält. enterbt wurde und nun von dem dankbaren Bruder Adelstitel c Auf ähnliche Weise - immer als direkte Folge einer guten Tat der Kinder - finden sich Auf ahnliche Wrüder in von Sydows Das Angebinde (1830) und Hofmanns verlorene Söhne oder Brüder

die Familie vor dem finanziellen Ruin. In von Sydows Das Festspiel (1830) gerät der Forstrat von Haller unverschuldet Ruin. In von Sydows Dird in adligen Kreisen in die Ungnade seines Fursten, verfall in bitteeste Anmut und wird in adigen Kreisen geschnitten. Auch im tiefsten Elend bietet die Familie ein musterhafes Bild der Frömmigkeit, der Sauberkeit und des Fleißes; die Kinder überbieten sich in ihrer Hingabe an die Eltern und sparen sich das Essen vom Munde ab, um ihnen eine Freude machen (Eunom 75 77). Izuischen wird in Adelskreisen ein Festspiel zu Ehren zu machen (Eunomia 75-77). Inzwischen wird in Adelskreisen ein Fich des Fürsten geplant; das Mädchen, das die Hauptrolle spiclen soll, wird plotzlich krank, und in der ganzen Stadt kann kein besserer Ersatz für sie gefunden werden als die anmutige und wohlerzogene Tochter der ausgestoßenen Familie, Bianka. Bianka cie anme erobert durch dic Ausfuhrung ihrer Rolle das Herz des furstlichen Paares im Sturm; die Rechtfertigung des Vaters und dessen Erhebung zu Stand und Ehren folgen auf dem Fuße.

In Kindliche Liebe (1830) treten eine ganze Reihe guter Kinder als rettende Enge uf: Oswald der Sohn des ebenfalls unschuldig in Ungnade gefallenen und inzwischen auf: Oswald, der Soln dellingen, macht sich heimlich mit einer Bittvöllig verarmten Hauptmanns von Wellingen, ma schrift an den Fürsten auf den Weg. Da er sein Fruhstick an seine hungers schwister abgetreten hat, wird ihm schwach vor Hunger, glücklicherweise erbarmt sich der Cärtnerssohn Ludwig und schenkt ihm eine Ananas, die er selbst erst vor kurzem der Gärtnerssohn Ludwig und schenlt ihm eine Anas von den Fürstentöchtern Marie und Sidonie erhalten hat, Osald wird vom Gartner mit der Ananas, die für die fürstliche Tafel bestimmt war, erwischt und ins Gefängnis gesteckt, wo er bleibt, bis die Kinder (Marie, Sidonie und Ludwig) sich dem Fürsten zu Füßen werfen und das Mißverständnis aufklären. Bei dieser Gelegenheit wird auch Oswalds Vater; der Hauptmann von Wellingen, gerechtfertigt und wieder in seine Ämter eingesetzt, ebenso Elise, die Nichte der Familie und ehemalige Erzieherin der Fürstentöchter. Sie wurde durch die Intrigen der Frau von Halden, die es auf ihre Stellung abgesehen hatte, in einen selbstverständlich unbegründeten Verdacht gebracht, verlor ihre Stellung und pflegte seitdem die verarmte Hauptmannsfamilic aufopferungsvoll. Der Verdacht wird nun ebensoschnell aus der Welt geräumt wie ihre Konkurrentin (die in der letzten Szene an einem Schlag stirbt), und Elise kann ihre Gouvernantenstelle wieder übernehmen.

In Agnes Franz' (1794-1843) Der Rosenstock (veröffentlicht 1845 in ihrem Vermiächtniß an die Jugend) schenken Paul und Lieschen, die Kinder der armen Witwe Klaus, ihr Letztes her: auf die Bitten des jungen Grafen Ferdinand überlassen sie ihm die Geburtstagsgeschenke für ihre Mutter, einen Rosenstock und ein Bild, damit dieser seiner kranken Schwester eine Freude machen kann. Die Schwester wird gesund, und die arme Familie aus Dankbarkeit von gräflichen Gnaden zeitlebens versorgt. In den Stïkken der Isabella Braun (1815-1886) werden die Kinder verarmter Familien von Figuren aus dem Feenreich auf spezifische Tugenden hin getestet: in Das Hutzelmännchen (o. J., veröffentlicht 1865) erweist sich Marie als mitleidige Seele, worauf das Hutzelmännchen ihre Familie von ihrem materiellen Elend erlöst. In Der Mutter Geburtstag (o. J., veröffentlicht 1865) erfinden die gute Fee Florida und das Waldmännlein mehrere Proben für die Kinder Marie und Heinrich und testen sie auf Gehorsam, Fleiß und Mitleid. Selbstverständlich bestehen auch sie sämtliche Proben und werden entsprechend belohnt.

Hinter diesen Stücken steckt weit mehr als nur die offensichtliche Moral für Kinder, die da behauptet, daß gute Taten immer ihren wohlverdienten, wenn auch hier reichlich übertriebenen Lohn finden. Der Tugend wird hier die Arbeit relativ leicht gemacht, schon wegen der Abwesenheit von Bösewichtern (die nur in der Vergangenheit existieren und meist an dem Unglück der tugendhaften Familie schuld sind) oder auch nur von mittelmäßigen Charakteren. Die tugendhaften Figuren beherrschen die Bühne und sehen einander erstaunlich ähnlich. An der Sprache und Ausdruckssweise der Figuren z. B. sind weder Alters- noch Standesunterschiede feststellbar. Die Kinder sprechen im selben Ton wie die Erwachsenen, die Bauern oft in demselben wie die Fürsten. In Die Überraschung z. B. berichtet Fritz in achtseitiger wohlgesetzter Rede von seinem Wiedersehen mit Anselmo (Eunomia 23-31), worauf dieser, mit gleicher Ausführlichkeit und Eleganz, die Erzählung übernimmt (35-47). Abgesehen davon, daß von Sydow den Gedächtnissen der ca. zwölfjährigen Schauspieler hier doch einiges mehr zumutet als „die klleine Bemühung eines längeren Memorirens“, sprechen die Kinder die Sprache der Erwachsenen. Aus Anselmos Bericht über sein Abenteuer in der Räuberhöhle:

Klopfenden Herzens überschritt ich die Schwelle; ein großer, in dem Gemache aufgestellter Schrank erregte zuerst meine Aufmerksamkeit. Wähnend, daß er die mir so merkwürdigen Schätze enthalte, machte ich ihn auf; doch wie erstaunte ich, 
denselben mit Nichts als einer Menge der verschiedenartigsten Kleidungen, die eine förmliche Maskengallerie bildeten, angefüllt zu sehen (37).

Anselmos bei den Zigeunern zweifellos vernachlässigte Erziehung hat seiner Beredtheit keinen Abbruch getan. Sätze wie der folgende aus Anselmos Erzählung sind in Kinderdramen (auch aus Kindermunde) keine Seltenheit:

Während mir in meinem dunklen Verstecke der Angstschweiß in dicken Tropfen über Stirn und Wangen herab rann, und ich meine Neugierde in die tiefste Hölle verwünschte, konnte ich, nachdem der Klausner hinausgegangen war, und alle Zugänge der Hütte, nebst dem Eingange des Gartens, in dessen Mitte sie lag, von innen verschlossen hatte, bei seiner Rückkehr aus der Fortsetzung des Gespräches vernehmen, daß jener Masetto kein Anderer war, als der listige Marionettenspieler, den Du, mein Vater, noch zwei Tage vorher zu meiner Belustigung auf unserem Schlosse spielen ließest (39, Hervorhebung der Autorin).

Hierarchie und Autorität (die Erwachsener über Kinder, die Adliger über Nichtadlige) haben in Kinderdramen keinerlei Einfluß auf den Stil. Dadurch, daß die Kinder und die Erwachsenen, die Bauern und die Fürsten exakt dieselbe Sprache sprechen, wird eine gewisse Konformität der verschiedenen. Figuren hergestellt, eine Art stilistische Gleichberechtigung, die sich auf alle tugendhaften Figuren erstreclst (die Sprache des Lasters dagegen unterscheidet sich erheblich von der der Tugend). Dieser Gleichklang der tugendhaften Figuren, egal welchen Alters, egal von welchem Stand, deutet auf ein wichtiges Merkmal der Kinderdramen hin: der Standesunterschied an sich wird, wie der Altersunterschied, als ein natürlicher dargestellt; wo immer die Tugend regiert, herrscht die erwähnte im Stil ununterbrochen beschworene Gleichheit. Wo Schwierigkeiten auftreten, die in irgendeiner Weise standesbedingt sind, handelt es sich um Mißverständnisse, die dank der Milde der Großen baldmöglichst behoben werden. In der Welt der Tugend, in die Bösewichter nur in der Vergangenheitsform Zutritt haben, existieren Armut, Hunger, Unrecht, Korruption (alles Probleme, die in diesen Stücken angesprochen werden) nur als Mißverständnis.

$\mathrm{Zu}$ dieser heilen Welt gehört auch die überwiegend positive Darstellung des Adels. Wo ein Fürst sich eines Unrechts schuldig macht, ist er immer von Untergebenen hintergangen worden und gleicht das Unrecht durch wahrhaft königliche Milde wieder aus, sobald er den wahren Sachverhalt erfährt (von Sydows Das Festspiel und Kindliche Liebe). Der Baron in von Sydows Überraschung ist ein vom Unglück geschlagener Vater und der beste Freund der Pfarrersfamilie; der junge Graf in Franz' Rosenstock ist zwar der Besitzer des Hauses, in dem die arme Witwe samt Kindern lebt, weiß aber nicht, daß sie auf die Straße gesetzt werden, wenn sie den Mietzins nicht aufbringen, und hilft, sobald er es erfährt. Wo Angehörige anderer Stände die Bühne betreten, handelt es sich um edle Arme (besagte Witwe mit Kindern) und lustig-tölpelhafte Bauern (Töffel in Die Überraschung), die die Großen der Welt um ihren Glanz beneiden, aber von deren schweren Regierungssorgen keine Ahnung haben (Kindliche Liebe, in Eunomia, $177 \mathrm{f}$ ). Die Welt, in der die Tugend unfehlbar und auf so exorbitante Weise belohnt wird, ist eine gradualistische, in der jeder mit seinem Schicksal zufrieden ist. Wenn Großmut und Milde die Tugenden des Adels sind, so sind Bescheidenheit und Genuigsamkeit die Tugenden der niederen Stände. Die letzte Szene in Die Überraschung, in der der Baron den Bauern Töffel dafür entlohnt, daß er Fritz und Anselmo aus dem Wald geführt hat, ist in dieser Hinsicht bezeichnend.

Baron. [...] Sprich, guter Töffel, wie kann ich Dir lohnen? Gott hat mich mi Glücksgütern gesegnet; deine Aeltern sind arm. Sage mir, für welchen Stand Du Neigung empfindest! Willst du ein Landmann werden, ein Handwerker, oder strebt Dein Sinn nach etwas Höherem? Du zeigst einen hellen Verstand, willst Du studiren? eine Kunst lernen? Alles, was Du begehrest, soll mein beglücktes Herz Dir gewähren!

Töfrel. Die letzte Gnade thäte allzugroß für mich seyn, gnädiger Herr! Mein Vate sagt: Jeder müsse seinem Stand getreu bleiben, wenn er vernünftig sei, und es gäbe jetzt so viel studirte Herren, daß es bald an Schuhmachern fehlen würde, ihnen die Sohlen zu liefern, die sie zerreißen thäten, wenn sie zu den Prinzen und Räthen liefen, welche ihnen Brod und Amt verschaffen sollten. Wollen Sie mich glücklich machen, gnädiger Herr, so dingen Sie mich bei unserem Nachbar Zimmermann auf die Lehre (48, Hervorhebung der Autorin).

Die große Tugend, die hinter allen dargestellten kleinen Tugenden wie Fleiß, Gehorsam, Milde, Mitleid etc. steht, heißt Ergebung in das Schicksal. Die verarmten Adligen, die die Bühne bevölkern, haben sich mit ihrem unverdienten Unglück ebenso abgefunden wie die echten Armen. In beiden Fällen geht diese Erziehung zu gottgläubigedelmütiger Resignation auf die Kinder über; und aus dieser Erziehung entsprießt die rettende Tat. Daß in Stücken, in denen dieses Weltbild gezeichnet wird, weit mehr vermittelt werden soll als nur die moralische Erziehung zu Fleiß und Gehorsam, liegt auf der Hand.

Andere Stücke konzentrieren sich weniger auf die Erziehung der Kinder zu sozialem Gehorsam als auf die Ausbildung zu Einzeltugenden. In diesen Stücken wird häufiger mit dem Kontrast gearbeitet: tugendhafte und lasterhafte Kinder werden miteinander verglichen, oder die „Fehler und Unarten der Kinder", die Hölder in ihrer Vorrede erwähnt, werden durch Rüge oder Bestrafung verbessert. In Kitty Hofmanns Die Angebinde oder Familienliebe (1824) zerstört der Wildfang Ostar die Geburtans Die Angedie der brave Sohn Denis in mühevoller Kleinarbeit für die Mutter gebastelt hat. Er zeigt sich aber so reuig, daß er mit einer Rüge und der Moral aus dem Munde der Großmutter davonkommt, die besagt, „daß einer Mutter - auch ohne Geschenke - das schönste Angebinde der Fleiß und der Gehorsam ihrer Kinder sind" (Theater für Kin$\operatorname{der} 27 \mathrm{f}$ ). Fleiß und Gehorsam sind genau die Tugenden, die Sohn Denis vertritt und um die man bei Oskars wildem Übermut fürchten muß. In Die Wundergaben (1824) heilt Sophie, eine Freundin der Madam Walter, deren vier Kinder in Verkleidung einer 
Tee Fee von verschiedenen Unarten (Faulheit, Naschsert ihnen verschiedene Geschenke überreicht, die bei Rückfall in ihre Unart ihre Gewisverlieren würden. Die Kinder erliegen der nächsten Versuchung; ihr schlech Wirkung: sen ersetzt die fehlende Zauberkraft der Geschenke und tut die erwünschte Wirkung. ausführliche Reue und Geloben baldiger Besserung.

Eitelkeit ist ein in Kinderdramen oft geheiltes Übel, von dem ausschließlich Mädhen befallen werden. In Isabella Brauns Nach der neuesten Mode (o. J., veröffentlicht chen befallen werden. In Isabella Brauns 1865) heilt Baron von Schwandorf seine putzsüchtigen Tochter Elsbeth und Marie von ihrer Eitelkeit, indem er seinen Diener Johann dazu anhält, einen italienischen von ihrer Eitelket, inder macht das Theater mit und tut so, als könne er die Affentheaterbesizer zu spiclen. Der macht das Theater mit underscheiden. Er will sie für Mädchen wegen ihrer bunten Kleidung nicht von Affen unterscheiden. Er will sie für sein Theater kaufen, versetzt die Mädchen in Todesangst und läßt die Maske len, als beide in schlichten Hauskleidchen vor ihm stehen (Moral: „der schönste len, als beide in schlichen Hescheidenheit"; Kleine Theaterstücke Schmuck eines Mädchens [ist] die Einfachheit und Bescheidenheit; Kleine Theatersicke 62, Hervorhebungen der Autorin). Dasselbe Laster rügt Luise Hölder an Elise in Der Zauberspiegel (1822): der Zauberspiegel, das Geschenk einer hier echten Fee, zeigt Elise ihr Bild im Alter von 60 und 70 Jahren sowie ihren eigenen Grabstein. Durch die Darstellung der Vergänglichkeit ihrer eigenen Schönheit ernüchtert, wandelt sich Elise von de spricht. Von Sydows Die geheilte Thorheit (1830) ist eine leichte Abwandlung desser(1830) ist eine leichte Abwandlung desselben Themas: Eweline, die Nichte der mit einer Anzaht mes Landrätin Weiler, hat sich durch den übermäßigen Konsum von Romanen so sehr in ihren Hochmut verstiegen, daß sie jeden Umgang mit ihren Altersgenossinnen verweigert und schließlich sogar mit dem Grafen Lebeau nach Paris flichen will. Glücklicher. weise stammt der Licbesbrief des Grafen, der sie zur Flucht bewegt, won ihrem Bruder Theobald, der ihr auf diese Weise ihren Hochmutsteufel austreibt. Die Lektion, die er Eweline in aller Ausführlichkeit und wohlgesetzten Worten erteilt, richtet sich an alle:

O Ihr leichtgläubigen Mädchen, die Ihr Euch in Euerer Eitelkeit so gern mit jeder Oan Euch ein artiger Fant im Drange der Langeweile faden Schmeichele bristet, die Euch cin artiger Tant im Dange der Langeweile addressirt, oft nur darum addressirt, um zu sehen, wie Ihr Euch dabei benehmen werdet; wüßtet Ihr, wie diese nämlichen Herren, die Euch heute die süßesten Sachen vorschwatzen, morgen in ihrem vertrauten Zirkel Euerer Einfalt spotten, Sachen vorschwatzen, und jede Sommersprosse Euerer Haut, die sie Euch in's Gesicht als Schöneitsmerkmal preisen, - jede Schleife Eueres Anzuges, die sie vor Eueren Ohren als Muster des feinsten Geschmackes, jeden unbedeutenden Einfall, den sie als die Probe Eueres

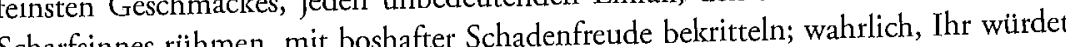
Scharfsinnes rühmen, mit boshafter Schadenfreude bekriteln; wah lch thr wïte Euch beschämt von dannen schleichen, und statt Euch auf alle lichen Künste der Coquetterie zu legen, Euer Streben auf eine edlere, in sich selbst belïckende Ausbildung richten! - Und nun Ihr vollends, Beklagenswerthe, die Ihr beglückende Ausbildung tichten! - Und nun thr vollends, Bek hie das ganze Heil Eueres Lebens den Vorspiegelungen eines Lasterhaften hinwerfet, wie ich nur eben, um Dich zu bessern, die Rolle eines solchen übernahm, was habt Ihr zu erwarten? (Eunomia 275, Hervorhebungen der Autorin)
Auf solch wohlformulierte Vorhaltungen kann Eweline nicht anders als zerknirscht reagieren und wird, durch Reue geläutert, wieder in den Schoß der Familie aufgenommen.

Auch die berüchtigte (weibliche) Neugier und Schwatzhaftigkeit wird zur Zielscheibe des Erzichungsdramas. In Hölders Die Neugierige (1821) belauscht Brigitte eine geplante Geburtstagsüberraschung; in dem Fortsetzungsstück Brigitte, oder Sie fallt mit der Thïr zum Haus hinein (1822) glaubt sie, eine Katastrophe zu beobachten, Mit der ersten Meldung verdirbt sie ihrer Schwester fast die Überraschung, mit der zweiten erschreckt sie sie zu Tode. Glücklicherweise hat Brigitte alles nur halb aufgeschnappt und gibt es ungeprüft weiter (wofür sie am Ende der Stücke angemessen beschämt wird), so daß sich die Geburtstagsïberraschung als stark unter- und die Katastrophenmeldung als stark übertrieben erweist. Strenger verfährt von Sydow mit ihrer Metha in Die Schwätzerin (1830), die durch ihre Unbedachtsamkeit fast zwei Familien miteinander verfeindet, eine Verlobung verhindert und mehrere Personen durch üble Nachrede in Verruf bringt. Nachdem die Familien sich versöhnt haben, die Verlobung zustandegelsommen ist und die reuige Metha ausführlich Besserung gelobt hat, wird sie in ein Erziehungsheim geschickt, wo ihrer Schwatzhaftigkeit hoffentlich der Zügel angelegt werden kann.

Gegenüber diesen vielen Verbesserungs- und Belehrungsdramen sind abschreckende Beispiele, in denen das Laster in seinen schwärzesten Farben gemalt und angemessen gestraft wird, seltener; aber sie existieren durchaus. Zwei Beispiele sind Luise Hölders Der ungezogene Knabe oder Beispiel einer schlechten Erziehung (1822) und das Fortsetzungsdrama Was Hänschen nicht lernt, lernt Hans nimmermehr (1822). Das im ersten Stück dargestellte Hänschen ist in jeder Hinsicht unverbesserlich: er mißhandelt das Dienstmädchen, spielt den Nachbarn alle nur erdenklichen bösen Streiche, schwänzt die Schule und zeigt nirgends auch nur die geringsten Anzeichen von Reue. Seine Schulkameraden erteilen ihm schließlich eine Lektion, nicht etwa, um ihn bloßzustellen, sondern - in der Art guter Kinder - in der Hoffnung, daß Hans von seinem Vater „einen derben Verweis wegen seiner Unwissenheit bekommen und sich vielleicht bessern [wird]; was wir von Herzen wünschen" (Neues Kinder-Theater II, 71). Hans reagiert allerdings nicht, wie erhofft, mit Reue und Besserung, sondern mit Trotz: „Ich brauche eure Moral nicht“ (89). Am Ende des Stückes wird Hans von der Schule verwiesen und aus dem Kreis seiner Spielkameraden ausgeschlossen, denn „Von deinem Umgang hat man wenig Ehre" (99). Im Fortsetzungsstück findet sich der vier Jahre ältere Hans in einer Klasse von viel jüngeren Knaben wieder, die ebenfalls wenig Interesse am Umgang mit dem „bösen und unwissenden Knaben“ (II, 113) zeigen. Das gesamte Stück behandelt Hans' Eintrittsexamen in die Schule, wobei er kläglich versagt und am Ende des Stückes ganz hinten in der Klasse sitzen muß. Hans' im Nachtrag berichtetes Ende ist, wie nicht anders zu erwarten, eins mit Schrecken: Hans ist keiner geistigen Anstrengung mehr fähig, schafft die Schule nicht und läuft weg, verliert sein Vermögen durch Unglücksfälle und wird Soldat. Da aber auch die Erziehung zum Gehorsam bei Hans lkläglich versagt hat, desertiert er, muß Spießruten laufen und stirbt schließlich „im größten Elend“" (Nachtrag, II 133). 
Anders als in den Verbesserungsdramen, die in der Regel mit der Reue und Einsicht An

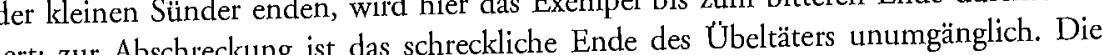
ert; zur Abschreckung ist das schroch erläutert zu werden: so geht's den Kindern, dic Moral von der Geschicht braucht nicht elautert zu will überhören. Hinter der Mora die in den früheren Dramen erteilten Lehren mutwillig überhören. Hinter der Moral für Kinder verbirgt sich selbstverständlich eine für Mütter, denn Hans ist nicht einfach in ungchorsamer und fauler Knabe, sondern - wie im 'Titel beigefügt - ein „Beispiel iner schlechten Erziehung". Hänschens Mutter ist eine nachgiebige weinerliche Frau, die ihn zum Schulgang zu zwingen, und ihn auch bei seinen böswilligsten Streichen in 作 Schutz nimmt. Threm Sohn gegenuber spricht sie in fast un elterliche Autorität versagt, wendet sie Bestechung an (50 f). Auch dic Kinder, die den Besserungsversuch unternehmen, kennen die Nachgiebigkeit der Mutter; ihrer Aussage nach ist der Vater, der in keinem der beiden Stücke die Bühne betritt, die einzige Hoff(6) Über die wohlverdiente Rüge des Nachbarn tröstet die Mutter (96) ihren Sohn hinweg (96); als Hamen verlassen wird, zieht auch die Mutter daraus keine Lehre Stattdessen „Drückt [sie] Hänschen weinend an sich“ und tröstet ihn: "Wenn dich auch alles verläßt, so bleibt dir doch deine Mutter" (99).

Im Fortsetzungsstück machen sich Hans' neue Mitschüler ausgiebig über seine Mutter lustig: Christoph berichtet von „dem herzzerbrechenden Abschied “ (114), be dem die Mutter "weinte, hu! hu! daß mir Hören und Sehen verging" (115) und schließlich dem Unfug die Krone aufsetzt: „Als sie denn lange genug an seinem Halse gewimmer dem Unfug die Kron an hatte, bat sie unsern Lehrer, doch ja ihren lieben Sohn nicht zu sehr mit Len anzustrengen, damit es seiner Gesundheit nicht schade“ (116). Aus dem kann ja nichts werden, denkt sich der Zuschauer (und die Zuschauerin); bzw. wird ihm (und vor allem den, denkt sich der Zülich klargemacht, daß die Mutter für die Verlotterung ihres Sohnes ihr) unmißverstanndich llargemacht, daß die $M$ un die Hauptverantwortung trägt. Kein Wunder, daß die Strafe, die den ungerene Hans trifft, auch seine Mutter nicht verschont: Hans stirbt „im größten Elend“, und Seine Mutter, die sich nun selbst als die Ursache seines Unglïcks ansah, folgte ihm "Seine Mutter, die sich nun selbst as dech" (Nachtrag, 133).

Die wicklung der Kinder verantwortlich ist (und sich daher auch ausschließlich der Erziewicklung der Kinces negativen Beispiel demon-

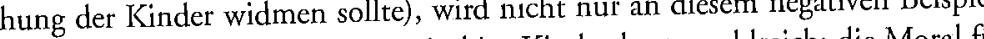
striert. Hinweise auf die Mütter sind im Kindertheater zahlreich; wird ebenso ausgiebig betont wie die für Kinder. Auf eine kurze Formel gebracht, ist eine gute Mutter die, die ganz für ihre Kinder lebt, sie zu Tugend, Fleiß und Gehorsam en Kinder (durch Listen oder Autorität) im Keime erstickt, 等 danken es ihnen durch Ausrufe wie etwa den folgenden:

Wir wissen es, theuerste Mutter! welche Opfer Sie uns brachten: daß Sie das angeWerließen, um uns in der Stadt auszubilden. Unsern Vater hatten 224 wir früh verloren; Sie, geliebteste Mutter! sorgen wie ein solcher für uns (Hofmann, Gewinn durch Verlust, in Theater fur Kinder 160).

Die Mutter fühlt sich durch die Liebe ihrer Kinder für alles entschädigt: „Süß ist die Mutterpfliçht für solche Herzen wie die eurigen" (160); sie lebt "der Vervollkommnung meiner Söhne, die mir durch gute Sitten, Fleiß und Herzensgüte lohnen“ (161). In Brauns Der Mutter Geburtstag wollen die Kinder "auch so mild,/ Fleißig und Gehorsam werden" wie die Mutter (Kleine Theaterstïcke 122, Hervorhebungen der Autorin). Von Sydow läßt die Kinder in Die geheilte Thorheit dankbar ausrufen: „Wohl uns, daß wir eine Mutter besitzen, die Scherz und Ernst so herrlich zu verbinden weiß, und nebst der würdigen Erzieherin uns gleichzeitig eine heitere liebevolle Freundin ist" (Eunomia 254). Ida in Das Angebinde und Bianka in Das Festspiel sind sich darüber im klaren, daß sie alle ihre Fähigkeiten (die im Festspiel die Familie vor dem Ruin rettet) nur der Mutter verdanken. Auch Väter zeigen sich Müttern gegenüber dankbar; so Herr von Wildau in Das Angebinde, der die gelungene Überraschung der Kinder mit Dank an die Gattin quittiert: „Amalie! Dieß ist Dein Werk! Du gabst mir diese guten Kinder; Du lehrtest sie, mich zu beglücken!" (Eunomia 122, Hervorhebung der Autorin) In Kindliche Liebe widmen Marie und Sidonie ihrer verstorbenen Mutter einen kurzen Nachruf, in dem sie als perfelkte Mutter und Fürstin beschrieben wird

Ach! mit unsrer theuren fürstlichen Mutter sanken unsere liebsten Freuden in die Gruft; wie zart, wie liebreich und doch so würdevoll, wußte sie die Forderungen unseres Standes mit denen des Herzens und eines heiteren ungezwungenen Lebens zu verbinden. Ihre Größe zeigte sie nur; wenn es galt, dem höchsten Unrechte Schranken zu setzen; ihre Milde dem Strauchelnden, und ihre Huld dem Leidenden! (Eunomia $173 \mathrm{f}$, Hervorhebung der Autorin)

Worauf das alles hinauswill, ist deutlich. Kindertheater ermahnt nicht nur die Kinder zu Fleiß, Gehorsam, und Untertanentreue, sondern bietet außer dem Rollenmodell für Kinder auch eins für Frauen - das der aufopferungsvollen Mutter und Hausfrau, die ganz im Kreis der Familie aufgeht und dafür dereinst den überschwenglichen Dank der wohlerzogenen Kinder ernten wird. 


\section{KAPITEL X}

\section{DurCH DIE HINTERTÜR: SCHLUSSWORT}

Für die meisten der hier behandelten Autorinnen bedeutete Bühnenschriftstellerei, bzw. Berufsschriftstellerei überhaupt, ein zweifaches Risiko: ein finanzielles (das sie mi bzw. Berufschifste Risiko versuchten vichren männlichen Kollegen teilten) und ein soziales. Das soziale Risilso versuchten vicle durch Benutzung von Pseudonymen, Anonymität oder pseudonymes Verhalten zu umgehen. Das finanzielle Risiko dagegen schien unüberwindbar: Mir ist keine Autorin (a) Autorinnen waren sozial und finanziell abgesichert und schrieben nicht aus Erwerbsgründen (Amalie von Sachsen, Elisabeth von Rumänien, Katharina II.). Für vicle andere war Schreiben lediglich die zweite Berufswahl: Auguste Götze war hauptberuflich Konzertsängerin; Elise Schmidt Rezitatorin; Charlotte Birch-Pfeiffer Schauspielerin. Wilhelmine von Hillern begann erst nach ihrer Heirat zu schreiben, als sie ihre Karriere als Schauspielerin aufgeben mußte; Elisabeth Müller war Lehrerin, bis sie sich aufte a Schären Stand als freie Schriftstellegrund veränderter ökonomischer Verhältnisse den prekären Stand als freie Schriftstellerin leisten konnte. Für sie und unzählige andere (meist Schauspielerinnen) war der nicht schriftstellerische Beruf die Erwerbstätigkeit; die zweite Karriere lief nebenbei.

Die Tatsache, daß die dramatische Produltion weiblicher Autoren dennoch so verbreiret ist, läßt sich vor allem auf zwei Elemente zurückführen: auf die Verbindung vieler Autorinnen zum Theater (durch ihren Hauptberuf als Schauspielerin) und auf männliche Protektion. Einige Autorinnen wurden von männlichen Schriftstellern oder Kännliche "entdeckt“" oder protegiert. Andere erhielten durch ihre Bekanntschaft, Freundschaft oder the mit einem meist bekannteren Schriftsteller oder Künstler eine Verbindung zu literarischen Kreisen oder zum Theater. Beispiele sind Mathilde Wesendonck und Richard Wagner, Annette von Droste-Hülshoff und Levin Schücking, Elise und Gottfried August Bürger, Charlotte und Friedrich Schiller, Charlotte von Stein und Friedrich Schiller, Charlotte von Stein und Johann Wolfgang von Goethe, Theres Krones und Fendinand Ra Krones und Ferdinand Rainund, Adelheid Reinbold und Johann Christoph Gottsched, Karoline Neuber und Johann Christoph Gottsched Christiane Karoline Schlegel und Christian Fürchtegott Gellert. Im kleinen Kreise bedeuteten diese Verbindungen zwar eine Anregung zum Schreiben und oft auch ein Unterstützung der schriftstellerischen Tätigkeit, aber das allgemeine soziale Vorurteil gegen schreibende Frauen galt auch für eine „Freundin Goethes und Schillers aus Heige " (Peudonym für Karoline Paulus). Die Anzahl der in Anhang B angeführten Pseudonyme (315 Autorinnen, 265 Decknamen), mit der diesem Vorurteil Rechnung getragen wurde, beweist es.

Über Pseudonyme, Anonymität und pseudonymes Verhalten wurde in Kapitel I berichtet; das dort Gesagte braucht hier nicht wiederholt zu werden. Wichtig an Pseudonymität und Anonymität allerdings ist die psychologische Motivation, aus der ein Werk ohne oder unter einem falschen Verfassernamen veröffentlicht wird, denn sie ha einen nicht zu unterschätzenden Einfluß auf das Werk selbst. Hinter einem Pseudonym steht meist der Wunsch, durch ostentative Anpassung etwaigen Verfemungen zu entgehen, aber auch die Hoffnung Verf Zuteil. (Ich erinnere in diesem Zusammenhang an offensichtliche Pseudonyme wie „Tochter der Karschin“, d. i. Karoline von Klencke, und „Enkelin der Karschin“, d. i. Wilhelmine von Chézy.) In diesem Falle hätte die Autorin sowohl den Schein (und ihren guren Ruf) gewahrt als auch das erreicht, was die meisten Autorinnen und Autoren erreichen wollen: die Anerkennung ihrer Werke. Weiblichen Autoren eine andere Motivation zu unterstellen als mung lichen, nur weil sie in der Regel behaupten, das Werk sei "nur zum Zeitvertreib" entstanden, halte ich für verfehlt. Die häufigen Beteuerungen weiblicher Dramatiker in dieser Hinsicht müssen in den meisten Fällen als Zugeständnis an die Vorurteile gegen weibliche Auter weibliche Autoren gelesen werden. Zusammen mit den tertür; die Frauen den Zugang zur Literatur ermöglichte; die Möglichkeit, trotz de sozialen Vorurteile zu veröffentlichen, war nur gegeben, wenn der Schein der Anpassung gewahrt blieb.

Dasselbe Phänomen kann man in den meisten ihrer Werke beobachten: hinter de ostentativen Anpassung finden sich subversive Elemente. Die Uminterpretation the matischer Traditionen ist in Dramen von Frauen weitaus häufiger als unlaritische Ǘ nahme der Tradition od on Vorstellungen kritiklos aufrechterhalten werden, ist das Kindertheaer; offene Opposition findet sich nur in einigen wenigen politischen Allegorien und Tragödien, die nicht zur Aufführung bestimmt waren. Viel häufiger wird die dramatische Tradition des jeweiligen Genres pro forma aufrechterhalten und im Text negiert. So endet z. B. auch hier die Komödie mit einer Heirat oder Verlobung, ohne daß dieses Ende mit dem traditionellen Happy End der Komödie gleichgesetzt werden laann. In Lust- und Schauspielen des 18. Jahrhunderts ist das Glüick des schließlich vereinten Paares äußerst zweifelhaft, weil es durch Unwahrscheinlichkeiten herbeigeführt werden muß oder durch ein tragisches Ereignis überschattet wird. In Komödien zwischen 1800 und 1850 schaffen die Autorinnen die Zwangsehe ab; ihre weiblichen Figuren werden zunehmend unabhängiger (sowohl in finanzieller als auch in intellektueller Hinsicht) und wählen sich ihre Partner selbst. Oft hängt hier die Wahl des Partners von der Frage ab, wieviele Freiheiten der Zukünftige der Frau gewähren wird. Nur wenn davon ausgegangen werden kann, daß der Mann der Frau genügend Spielraum läßt (indem er ihr z. B. eine Bildung gestattet oder zukommen läßt), komm Spielraum laßst (indem er ihs z. B. cine Bildung gestattet oder zukommen läßt), lkommt die Ehe zustande. Zwischen 1850 und 1900 behandeln viele Komödienautorinnen das neue Dilemma der Frau, die Wahl zwischen Ehe und Beruf. Eine spätere Heirat ist auch hier nicht ausgeschlossen, aber die Eheschließung der weiblichen Hauptfigur wird zunehmend zur Möglichlseit anstatt zur Notwendigkeit. Das große Glück am Ende der Komödie erfährt hier eine neue Behandlung: nur selten wird davon ausgegangen, daß eine Frau sowohl einen Beruf ausïben als auch eine glückliche Ehe flihren kann; viel öfter werden Beruf und Ehe als unvereinbar und gie Ehe nache Ehe führen kann; viel interpretiert. Andere Autorinnen stellen ihre weibliche Hauptfigur vor die Wahl 
zwischen Ehe und Beruf, aber keine dieser beiden Möglichkeiten repräsentiert das Glïck. Das Happy End der Komödie in Form einer Eheschließung am Schluß des Glück. Das Happy End der Kurch nichts ersetzt. ann Aavechterhalten und durch die Hintertür unterwandern, lassen sich in den meisten anderen Genres nachweisen. Die Tragödie übernimmt, wie die Komödie, das

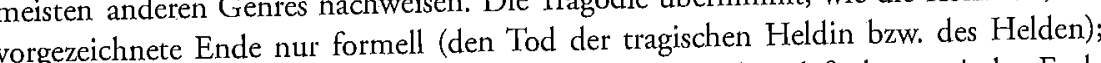
vorgezeichnete Ende nur formell (den Tod dragischen Held ${ }$ gegen die Genretradition verstößt vor allem die Tatsache, daß das tragische Ende letztendlich unbegründet und ethisch nicht zu rechtfertigen ist. Im 18. Jahrhundert versagt die Vorsehung, auf die die tugendhaften Heldinnen und Helden sich fest verlassen; Tugend und Laster werden gleichermaßen bestraft. Später werden weibliche und männliche Figuren einander vor allem in einer Hinsicht entgegengesetzt: wahrend der männliche Held sein Schicksal durch einen wic immer gearteten Fehlentschluß verdient (der Aristotelische gemischte Charakter), haben die weiblichen Figuren keine (ïn der mänlichen Helden oder Kontrolle über ihr Schicksal und sterben an den Plänen der männliche an von ihnen geschaffenen Umständen. In einigen wenigen Lesedramen wird dies Abhängigkeit der weiblichen Figuren (nicht der Tod der Heldin) zum Thema der Tragödie. Diese Tragödien waren nicht zur Aufführung bestimmt und sind Fragmente geblieben; das Ende ist vorgegeben und braucht nicht berichtet zu werden. In allen Trä̈̈len fällt das völlige Fehlen von Lösungsvorschlägen auf: während in TrauerspicTragodiche Entscheidung des Helden len männlicher Autoren meist deieten weibliche Autoren keine Alternative zum Tod der Heldin an.

Dagegen findet sich in historischen Dramen das thematische Gegenstïck zu der Dagegen findet sich in hechicksal haTragödientradition, in der die Protagonistinnen keinen Einfuß auf der geschichtlichen ben. Dargestellt wird die Handlungs undeln historische Frauenfiguren; neu gegenüber der Tradition historischer Dra Was in geschichtlichen Dramen, die männliche Protagonisten behandeln, vorausgesetz wird - Recht des Helden, Geschichte zu formen -, muß gerechtfertigt werden, sobald der Heros eine Frau ist. Diese Verteidigung der Entschei rischen Heldin ist das Hauptthema des Genres. Die historische Mission bzw. die Autonomie der Heldin rechtfertigt ihr Abweichen von dem vorgezcichneten Lebensweg der Frau sowie ihre politische Alstivität. Wo die historische Tragödic Verbrecherinnen au der Geschichte behandelt, werden sie als unschuldige Opfer der Geschichte dargestell - gleichgültig, ob die Geschichtsschreibung sie schuldig spricht oder nicht. Wenn die Helder Geshichte auftritt, folgt die Apotheose; wenn als Opfer, die Betonung inschuld. In allen Fällen wird die Handlungsweise der Protagonistin Wo dic Autorinnen männliche Helden der Geschichte behandeln, folgerechtfertigt. Wo die Autorinnen măhnliche Heschichtsdramas: beschriegen sie mehr oder weniger der vorgegebenen Tradition des Geschichtsichen Grïnden ben werden Aufstieg und/oder Fall des Helden, der oft aus patio auf die Bühne beschworen wird - und über dessen Berechtigung zu geschichtlichem Handeln die Autorin kein Wort zu verlieren braucht.
In Künstlerdramen liegt die Betonung nicht auf der Apotheose des Künstlers oder der Kunst, sondern auf der Beziehung zwischen Künstler und Muse. Wohl deshalb behandeln Künstlerdramen von Frauen, mit wenigen Ausnahmen, ausschließlich männliche Künstler. Durch die Darstellung des Verhältnisses zwischen Künstler und Muse wird die thematische Tradition gleichzeitig aufgearbeitet und negiert. Übernommen wird der Teil der Tradition, in dem der männliche Dichter, Maler oder Sänger sich durch die Inspiration der Muse zu den Höhen der Kunst aufschwingt; negiert wird die Tradition dadurch, daß auch die Konsequenzen für die Muse gezeigt werden. In Künstlerdramen geht der Weg zur Kunst immer über die Leiche der Muse, im wörtlichen oder im übertragenen Sinne. Überlebt dic Muse, so stirbt der Künstler. Ein Aspelkt der Fairneß dem dargestellten Künstler gegenüber liegt vielleicht darin, daß er oft zusätzlich durch seine Kunst charakterisiert wird; d. h. gezeigt wird nicht nur der Weg zur Kunst - mit äußerst negativen Auswirkungen auf die Muse -, sondern auch das Resultat. (Sowohl Pierson als auch Birch-Pfeiffer stellen in ihren Stücken die Bilder der dargestellten Maler auf die Bühne; Westphalen läßt ihren Helden Petrarca ausführlich mehrere seiner Gedichte zitieren.)

Ähnlich wie viele Geschichtsdramen versuchen, die historische Heldin vor der Nachwelt zu rechtfertigen, wird in dramatischen Bearbeitungen von Mythologie und Bibelgeschichten häufig eine „Berichtigung" der mythologischen Vorlage vorgenommen. Wogegen die meisten Autorinnen angehen, ist die in den Mythen überlieferte Vorstellung von der Allmacht des Schicksals und der daraus folgenden Ohnmacht des Menschen. In ihren Mythologiedramen setzen die menschlichen Protagonisten den Göttern ethische und moralische Eigenschaften entgegen und machen Anspruch auf Autonomie gegenüber dem Schicksal oder dem göttlichen Willen. Während der Mythos selbst inhaltlich unangetastet bleibt, weigern sich die menschlichen Protagonisten, die Allmacht Gottes, der Götter oder des Schicksals anzuerkennen.

Diese Talstik der Reinterpretation der dramatischen Tradition, die dabei gleichzeitig aufrechterhalten und negiert wird, läßt sich in den meisten Dramen von Frauen nachweisen. In Bildungstraktaten von Fraulen findet sich ein verwandtes Phänomen: im 18. Jahrhundert plädieren die Autorinnen für eine höhere Bildung der Frau - keineswegs zum Broterwerb, sondern lediglich zur Herzens- und Geistesbildung; im 19. Jahrhundert verlangen sie eine berufliche Ausbildung und entsagen dafür ostentativ, sozusagen als Gegenleistung, allen Ansprüichen auf das Wahlrecht. Teilweise wird diese Mischung aus Anpassung und Widerstand auf der Bühne personifiziert, so z. B. durch die unabhängigen und intelligenten Frauenfiguren der Komödien des 19. Jahrhunderts, die innerhalb des vom Onkel oder Vater inszenierten patriarchalischen Spiels die passive Tugend spielen, um ihre Zwecke zu erreichen. Die literarische Tradition von Frauen ist eine defensive; für sie gab es nur einen Weg zur Bühne: den durch die Hintertür der Anpassung an das soziale Vorurteil gegen schreibende Frauen (durch Pseudonym) und an literarische Traditionen (im Stück selbst).

Trotz der sozialen Gegebenheiten, die einen solchen diplomatischen Seiltanz nötig machten, und trotz der Tatsache, daß dramatische Schriftstellerei allein in keinem Fall ihre Frau ernährte, war dic dramatische Produltion von Frauen umfangreicher, als hier 
dargestellt werden konnte. Abgesehen von den genannten Genres gibt es noch mehrere, die aus verschiedenen Gründen hier nicht ausführlich behandelt werden können. Von einigen dieser Genres waren mir keine Stücke zugänglich (dramatisierte SprichVon einigen dieser Genres waren mir kelne Stucke zugang (dir wörter, Festspiele). Bei wieder anderen (Opern und Singspiele) fehlte mir der musikalische Hintergrund, um sie angemessen bearbeiten zu können. Weiterhin fanden sich unzählige Bearbeitungen und Übersetzungen, die hier nicht aufgenommen wurden, weil diese Untersuchung sich auf Originalstücke beschränkt, obwohl bei vielen diese Bearbeitungen und Übersetzungen $\mathrm{m}$. E. der berechtigte Zweifel besteht, ob es sich trotz der Bezeichnung - um ein Originaldrama handelt oder nicht.

Von heiten; heute sind die meisten völlig unbekannt. Einige Dramatikerinnen sind berühmt geblieben, meist für schriftstellerische Leistungen auf anderen Gebieten (Ebnerrühmt geblieben, meist fülshem durch ihre Verbindung mit einem bekanten Eschenbach, Droste-Hulloff), durch ihre Verind (Charlotte von Stein) oder aufgrund ihrer historischen Bedeut Von den Hunderten der in Anhang B genannten Autorinnen sind heute nur drei hon deä für ihre Tätigkeit als Dramatikerin bekannt: Karoline Neuber, Luise Gottsched und Karoline von Günderrode. Für die Diskrepanz zwischen der Vielzahl dramatischer Autorinnen und der geringen Anzahl derer, die posthum einige Anerkennung erhielten, kann man dic weitverbreitete Anonymität der Autorinnen teilweise nung erhielten, kann maten den Zugang zur Literatur gestattete, schloß gleichzeitig die erhoffte öffentliche Anerkennung aus und erschwert noch heute den Blick hinter die Kulissen.

\section{ANMERKUNGEN}

Vorwort

1 Karin Wurst, Hg., Frauen und Dramen im 18. Jahrbundert (1770-1800), Köln \& Wien 1991. Die Anthologie enthält vier Dramen: Sophie Albrechts Theresgen, Marianne Ehrmanns Leichtsinn und gutes Herz, Christiane Karoline Schlegels Duval und Charmille und Wilhelmine von Gersdorfs Die Zwillingsschwestern.

Kap. I

2 Für vollständige Angaben der zitierten Texte und weiterführenden Literatur siehe das Literaturverzeichnis am Ende der Arbeit.

3 So zum Beispiel bei Elise Levi, deren Stücke unter ihrem Mädchennamen (Henle) erschienen; bei Friederike Sophie Seyler, die zwei ihrer Dramen unter ihrem ersten Ehenamen veröffentlichte (Hensel); bei Caroline (oder Karoline) von Günder(r)ode; bei Amalie von Helvig (oder Hellwig) bzw. Amalie von Imhof(f); bei Caroline Bernstein (oder Bornstein?); u. v. a.. Wo ich vor diesem Namensproblem stand, habe ich mich (oft ziemlich willkürlich) für einen Namen oder eine Schreibweise des Namens entschieden; habe aber in Anhang B sämtliche zur Auswahl stehenden Möglichkeiten angegeben.

4 Dieselbe Verdoppelung aufgrund verschiedener Namen konstatiert Alice Kahler Marshall für englischsprachige Schriftstellerinnen aller Genres ab 1600.

5 So auch Leporins Gründliche Untersuchung. Hier versichert Leporins Vater in seinem Vorwort zu ihrer Abhandlung, sie habe sie „nicht in der Absicht, selbige an das Licht zu stellen, verfertiget, vielmehr hat sie solches auf alle Weise abzuwenden versucht" $(\$ 11)$, und rettet so den guten Ruf seiner Tochter. Sie dagegen macht sich in ihrem Vorwort mehr Sorgen darum, daß einige ihrer Leser glauben könnten, es "Wäre dieses Werckchen nicht meine eigene Arbeit" (unpag.).

Kap. 2

6 Weitere Beispiele aus Küstners Abrechnungen: Hoftheater München 1822: 114000 Gulden Gesamteinnahme und 78000 Gulden Subvention (Vierunddreißig Jahre 96 f); Hoftheater Darmstadt 1830: 40000 Gulden Kasseneinnahme und 60000 Gulden Zuschuß (65); Hoftheater Dresden 1848: 30-40 000 Taler Zuschuß, 90100000 Taler Einnahme und 140000 Taler Ausgaben (346). 1 Taler Mitte des 18. Jahrhunderts $=$ ca. 1.5 Gulden (Vierunddreißig Jabre 340). Zur Subvention von Hoftheatern vgl. auch Paldamus 85-7; Brachvogel, Die Königl. Oper 459; Kindermann, Theatergeschichte 537 und 734 f; Krause 253.

7 Diese Angaben stammen aus Schröders Aufzeichnungen zu verschiedenen Aufführungen. So zum Beispiel am 18. 8. 1777: „Leseprobe zu ,Diamant"; am 19. 8.: 
Wieder Leseprobe zu ,Diamant“"; 20. 8.: „Probe zu ,Diamant““; 20. 8.: „Dia"Want" nicht gefallen" (zit. in Paul Hoffmann, 265). In diesem Falle fand also die einzige Probe vor der Aufführung am Tag der Vorstellung statt.

$8 \mathrm{Zu}$ diesen Abgaben gehörte in Wien ab 1671 auch eine Abgabe für das Zuchthaus in der Leopoldstadt, die erst 1782 aufgehoben wurde. Bis dahin zahlte jeder durch Wien ziehende Schauspieler einen Groschen an das dortige Zuchthaus, das sich durch diese Beiträge der "deutschen Actoribus" ausgezeichneter Einnahmen erfreute. Vgl. von Weilen/Teuber I, 114-19.

9 Gemeint ist wahrscheinlich 1731. Friedrich Wilhelm I. starb 1740, und Eckenbergs Anfrage ergäbe meht Sinn, wenn sie vor der Erteilung des Privilegs stattgefunden hätte.

10 Kabale und Liebe war wegen der fürstlichen Mätresse (Kindermann, Das Burgtheater 30) und der Klagen des Kammerdieners über den Menschenhandel mit hessischen Soldaten (Laube, Das Burgtheater 77) verboten, Fiesco wegen des revohessischen Soldaten (Lauber Worte "Verschwörung" im Titel und „Freiheit" in der letzten Szene (Kindermann, Das Burgtheater 35), Romeo und Julia wegen Bedenklichkeiten bezüglich des vierten Gebots und wegen der Leichenzüge und Kirchhöfe im Stück (von Weilen/Teuber II, 39). 1859 wäre das Schillerfest am Burgtheater fast ausgefallen, weil Wallensteins Lager wegen des Kapuziners vom Spiclplan gestrichen wurde; nur ein persönlicher Appell an den Kaiser rettete das Stück samt Kapuziner (Laube, Das Burgtheater 368 f).

11 Thespis und Sylpho sind fiktive Namen. Die Klammern bezeichnen die Leerstellen des Vertrags.

$12 \mathrm{Vgl}$ auch die Angaben im Almanach fuir Freunde der Schauspielkunst, nach denen Schauspieler an den meisten Theatern als Schauspicler und Sänger engagiert waren: 1836: 201-11 und 253; 1839: 246-57, 284, 328, 356, $370 \mathrm{f}, 375,396,407 ; 1842$ $10,124,151,160,169,172,197,200,202,216,219,228,236,244,254,272$, $274,279,292 \mathrm{ff}, 320,332,334,357 ; 1844: 431,497 ; 1846: 54 \mathrm{f}, 104,129,211$; 1848: 318, 384; 1851: 124; 1852: 110, 182, 224, 250, 266, 369

$13 \mathrm{Fl} .=$ Gulden, $\mathrm{Kr}$. = Groschen .

Kap. $3 \mathrm{~A}$

14 Zur Sozialgeschichte der Frau vgl. u. a. Weber-Kellermann, Dohm, Joeres/Maynes, Riemer/Fout, Fout, und Frevert besonders 15-25 und 40-51.

15 Hier gemeint ist Luise Gottsched, wie auch im folgenden. Die oft übliche Me thode, männliche Autoren mit dem Nachnamen, weibliche dagegen mit dem Vorthode, männliche Autoren mit dem lichen Schriftstellern und trägt vieles zu ihrer Unsichtbarkeit bei. Während Johann Christoph Gottsched mit größter Selbstverständlichlzeit als „Gottsched“ bezeichnet wird (so, als gäbe es nur einen), wird Luise Gottsched als "Luise" bzw. „die Gottschedin" umschrieben; viele Kritiker fühlen sich heute noch wohler mit „Fra Gottsched“. Im folgenden werden alle Autorinnen, auch die Schwestern, Ehefrau- en und Namensgenossinnen berühmter Männer, lediglich mit dem Nachnamen bezeichnet: Gottsched $=$ Luise Gottsched, Schiller $=$ Charlotte von Schiller, Schlegel = Christiane Karoline Schlegel.

16 Bei Zitaten aus Dramen in Sammlungen oder Gesamtausgaben wird hier, wie auch im folgenden, die Sammlung und der Band nur beim ersten Zitat angegeben. Jedes darauffolgende Zitat aus demselben Drama bezieht sich, soweit nicht anders angegeben, auf dieselbe Ausgabe.

Kap. 3 B

17 Das hier dargestellte Bildungsideal ist identisch mit der Bildung der meisten Frauen des Adels und gehobenen Bürgertums, d. h. - in den meisten Fällen -: identisch mit der der Autorinnen.

18 Eine bessere Ausbildung war eine der ersten Forderungen von Frauen vor der feministischen Bewegung, und viele Autorinnen vorfeministischer Bildungstraktate plädierten für eine bessere Erziehung der Frau mit dem Argument, eine gebildete Frau sei eine bessere Hausfrau und Mutter. Vgl. dazu u. a. Holst 76f, 95 und $127 \mathrm{f}$ Gleim in der Anmerkung auf S. 134 f, 133 und 237; Woltmann, Ueber Natur, Bestimmung, Tugend und Bildung 413; Homberg, Gedanken über Erziehung 243, 247, 249 f; Laddey 312 und 349 f; Gerhard 337-40.

19 Ganz anders die Heldinnen ihrer historischen Schauspiele, (Elisabeth, 1841; Anno von Oestreich, 1845; Die Marquise von Villette, 1844; u. a.), die wesentlich unabhängiger auftreten. Vgl. dazu Kap. V.

20 Eines ihrer erfolgreichsten Stücke, Dorf und Stadt (1847), war eine Bearbeitung von Auerbachs Novelle Die Frau Professorin. Birch-Pfeiffer veröffentlichte das Stiick mit der Anmerkung „Mit freier Benutzung der Auerbachschen Erzählung Die Frau Professorin“. 1848 verklagte Auerbach sie, seine Erzählung plagiiert zu haben, und verlor den Prozeß, weil das damalige Urheberrecht ein Plagiat als direkte Übernahme von zwei Dritteln des Wortlauts definierte. Da Auerbach nicht nachweisen konnte, daß Birch-Pfeiffer zwei Drittel seiner Novelle wörtlich zitiert hatte, ging die Autorin frei aus. Hes hält Birch-Pfeiffers Stück für ein relativ selbständiges Werk (89), vor allem wegen der weitreichenden Änderungen, die die Autorin an der Novelle vornahm. Diese Änderungen entsprechen denen gegenüber anderen Romanyorlagen der Autorin: Umarbeitung der Charaktere und ein versöhnliches Ende. Sowohl Auerbach als auch Birch-Pfeiffer beschreiben unüberbrückbare Differenzen zwischen zwei Ehepartnern. Bei Auerbach erfolgt am Ende die Scheidung, bei Birch-Pfeiffer die Versöhnung. Vgl. Hes 79-89.

21 Im Roman Rochester.

22 Beide angeführten Zitate sind fast wörtlich aus dem Roman übernommen. Während Birch-Pfeiffer sich im Glöckner die Mühe machte, die Figur des Phöbus umzuschreiben, übernahm sie hier Brontës Figur fast unverändert: Rochesters Werbung um Jane ist von demselben brutalen Volzabular geprägt wie die Rowlands. Bei Brontë allerdings kann diese Brutalität als Realktion auf erfahrenes Leid 
verstanden werden (Rochesters unglückliche Ehe, die Wahnsinnige im Turm, seine Blindheit und Trennung von Jane): so, so könnte Jane im Roman verständnisvoll resümieren, klingt die Sprache eines Vielgeprüften. Bei Birch-Pfeiffer fehlt dieser restinien, kird durch nichts erklär gesamte Hintergrund; Rowlands Haltung Jane gegenuber wir durch nichs crkart oder modifiziert - und das allein reicht durchaus zur Relativierung des Happy Ends.

Kap. $3 \mathrm{C}$

23 Vgl. dazu Karoline von Woltmann, Ueber Natur, Bestimmung, Tugend und Bildung; Minna Pinoff; Louise Büchner, Die Frauen; Elsbeth Krukenberg, Die Frauenbewegung, und Tinette Homberg, Gedanken über Erziehung, besonders 213-72.

24 Meines Wissens vor 1850 nur in Elise Bürgers Die antike Statue aus Florenz (1829).

25 Dieses simple Ablenkungsmanöver erscheint umso wahrscheinlicher angesichts der

25 Dieses simple Ablenkungsmanöver erscheint umso wahrscheinlicher angesichts der ren indem sie beispielsweise „nur" das Hochschulstudium für die Frau forderten, ren, In

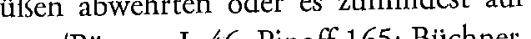
die lange Bank schoben. Vgl. dazu u. a. Lange/Bäumer I, 46; Pinoff 165; Büchner; Die Frauen 268, 270 und 275; Troll-Borostyáni, Die Mission 123-26 und 159-63; Lewald, Osterbriefe 136; Krukenberg, Die Frauenbewegung $264 \mathrm{ff}$.

26 Diese Szene wurde inspiriert von einem Erlebnis der Autorin in einer Buchhandlung in Münster, die sie in ihrem Tagebuch berichtet. Vgl. Christaller $70 \mathrm{f}$.

Kap. 4

27 Johann Christoph Gottsched sah die Bestrafung des Lasters in der Tragödie als unerläßlich und besonders effektiv, wenn die Laster des mittleren Charakters gestraft würden. Denn gerade dadurch werde „dic Tragödie den allermeisten Zuschauern erbaulich: weil nämlich die meisten Menschen von eben der Art sind, als er; das ist, einestheils Mitleiden mit ihm; andernweder recht gut, noch recht böse. Mant hat einestheils Mar kein Laster ungestraft läßt" (Critische Dichtkunst 608).

28 Artner stellt in der Vorrede fest, daß Hugo „im Moment des Mordes keineswegs daran denkt, sich dadurch in Elvirens Besitz zu setzen, sondern nur, in der Wuth des Zorn's und der Verachtung gegen Carlos, diesen des schmählichsten Todes würdig glaubt" (ix).

29 Kastinger Riley nimmt eine gleiche Autonomie der weiblichen und männlichen Figuren dem Schicksal gegenüber an. Vgl. „Zwischen den Welten“, 114-18.

$30 \mathrm{Zu}$ autobiographischen Elementen in Bertha vgl. Bauer Pickar $109 \mathrm{f}$ und 123.

31 Gleichlautend äußert sich Hegel sechs Jahre später über den Unterschied zwischen den Geschlechtern: „das eine Geschlecht [ist] der Unterschied in sich selbst [...], während das andere die neutrale Einheit darstellt. Das Trennende, Entzweiend fällt auf die Seite des Mannes [...]. Die andere Seite ist die der Frau, deren Charak- ter überhaupt ist, die innere Harmonie des Geistigen und Sittlichen überhaupt zu bewahren. [...] Das eine Geschlecht stellt dic geistige Form in ihrer einfachen Gediegenheit dar, während das andere Geschlecht den Gegensatz, das Auseinandergehen der Einheit darstellt" (136 f). Auch die Schlußfolgerung der Reichsgräfin ist die Hegels: „So kommt dem Mann [...] der Erwerb wesentlich zu; und dann die Objektivität [...], die Arbeiten im Staat und in der Wissenschaft und die Zwecke der Kunst" (137).

Kap. 5

32 Marie-Jaqueline de Corday d'Armont, née de Gautier, starb 1782, also bereits 11 Jahre vor dem Zeitpunkt, an dem das Stück ansetzt. Ebenfalls erfunden sind Cordays erste Reise nach Paris, bei der der Anblick politischer Greuel sie zur Aktivität anfeuert; Adam Luchs' persönliche Bekanntschaft mit ihr, Luchs' Pläne, Marat zu ermorden und Corday zu befreien, die Gefängnisszene mit Luchs, und die Szenen mit ihrer Familie. Vor ihrer Reise nach Paris befand sich Corday bei ihrer Kusine, Madame de Bretteville, in Caen. Bei Westphalen spielt außerdem Simonne Evrard, Marats Geliebte, keine Rolle; sie wird durch die Haushälterin Anne ersetzt. Möglicherweise erschien es der Autorin, deren Sympathien eindeutig auf Cordays Seite standen, unangebracht, Marat durch Erwähnung seines Privatlebens auf persönlicher Ebene darzustellen. Vgl. Dobson 9 und 11, Cher $71 \mathrm{f}, 89 \mathrm{ff}$, $100 \mathrm{f}$ und 123; Corday 17 f, 103 und 167-71; Shearing 142.

33 Die gesamte Gerichtsszene einschließlich Lagardes Verteidigungsrede entspricht den Gerichtsalkten der Verhandlung fast wörtlich. Vgl. Vatel $3 \mathrm{ff}$ und 39-53.

34 Auch hier weicht die Autorin von den historischen Tatsachen ab: Luchs, der Corday nicht persönlich kannte, verfaßte noch vor seiner Hintichtung einen Essay über sie, in dem er ihren Mord rechtfertigte und sie selbst verherrlichte. Vgl. Shearing 259-265; Cher 154; Corday 167-71.

35 Die Autorin hält sich ziemlich genau an historische Gegebenheiten, nimmt aber einige wichtige Änderungen vor. U. a. erfunden sind Marie Rolands Irrtum im Bezug auf Lanthenas, ihre Stellung als Vorkämpferin für das Scheidungsrecht der Frau, die erste Szene mit dem Grafen Beugnot, die Szene mit Lodoïska im Gefängnis, und vor allem die entschieden religiöse Note und die Bewunderung für Marie Antoinette, die Ebner ihr in den letzten Szenen beilegt. Rolands Mitgefangener Beugnot, der sic in Ebners Darstellung zur Religion und Anerkennung des Königtums bekehrt, berichtet zwar in seinen Memoiren von politischen Auseinandersetzungen mit ihr, gibt aber keinerlei Hinweise darauf, daß Roland ihre Ansichten in irgendeiner Weise gemildert hätte, schon gar nicht als Ergebnis seiner Vorhaltungen (Beugnot 159-64). Vgl. auch Bernardin, Les Idees Religieuses 160 f; May 261, 265, 274, 278, 280 f; Abbot 258 f; Birch 3, 512 f.

36 Diese Episode ist exfunden. Lanthenas soll in Roland verliebt gewesen sein und mit ihr gebrochen haben, als er von ihrer Liebe zu Buzot erfuhr. Er lief bereits 1792 zur Bergpartei über. Vgl. May 248. 
37 Wahrscheinlich ebenfalls eine Erfindung der Autorin. 1792 erhielten Frauen in Frankreich zum ersten Mal das gesetzliche Scheidungsrecht; dieses Recht wurde 1814 yom Chambre des Introuvables wieder abgeschafft. Das Scheidungsrecht für Frauen wurde erst 1884 in Frankreich wiedereingeführt (O'Faolain 308, 315). Ob Marie Roland in irgendeiner Weise für die Gesetzgebung von 1792 verantwortlich war, ist aus keiner Biographie zu entnehmen.

38 Dieses Angebot wurde Roland nicht von Lodoïska, sondern von ihrer Freundin Henriette Cannet gemacht. Vgl. Abbot 258 f; May 274.

39 Ebenfalls nicht historisch. Rolands Tochter wurde schon vor Rolands Hinrichtung in ein Internat gebracht. Briefe Rolands an ihre Tochter und an die Internatsleiterin betonen eher den Aspekt der Erziehung zur Befähigung zur Arbeit als den der moralischen Erziehung. Vgl. Roland, Mémoires II, 385 und 413.

40 Ähnlich wie Westphalen und Ebner-Eschenbach nahmen die Autorinnen einige historische Änderungen vor, die für sich selbst sprechen. Erfunden sind Marys Fluch beim Kirchgang, Henrys gespielte Trauer bei der Nachricht von Katharinas Tod, die Tatsache, daß Anna Henry beim Ehebruch überrascht, und die Gefängnisszene zwischen Anna und Henry. Die wichtigste charakterliche Änderung bezieht sich auf Annas Unterwürfigkeit Henry gegenüber während ihrer Ehe, die in Biographien und historischen Quellen ausnahmslos bestritten wird (z. B. Bruce 272; Ives 338). Fortgelassen wurde im Stück die Aussage (und die Figur) Marc Smetons, der zusammen mit Brereton, Wyatt, Norris, Page, Weston und Annas Bruder George beschuldigt wurde, mit Anna Ehebruch begangen zu haben, und der sich als einziger der Angeklagten schuldig bekannte. Da dieses Geständnis unter Anwendung der Folter erzwungen wurde, wird seine Echtheit heute von Bruce 301). Der Grund für diese letzte Änderung ist offensichtlich: Smetons Aussage hätte die klare Darstellung von Annas Unschuld im Stïck erheblich kompliziert.

41 Dieser Stoff wurde verschiedentlich dramatisiert, u. a. von Shelley und Artaud.

42 Vittoria Accoramboni erhielt ihren Spitznamen "The White Devil“" von Websters gleichnamigem Stück über sie (1612). Obwohl Vittoria in Websters Stück eher eine Nebenfigur ist und völlig unklar bleibt, wodurch sie diesen Spitznamen erhält scheint er sich teilweise besser durchzusetzen als ihr eigener. So beispielsweise in C. Bax' The Life of the White Devil, einer historischen Biographie über Vittoria Accoramboni.

43 Edward Courtenay (ca. 1526-1556) wurde 1538 auf Befehl Heinrichs VIII. mi seiner Familie verhaftet und 1553 yon Mary Tudor begnadigt. Er wurde als möglicher Prinzgemahl für Mary und nach ihrer Heirat mit Philipp II. für Elisabeth in Erwägung gezogen. 1554 nahm er an Thomas Wyatts Rebellion teil, die Elisabeth auf den Thron setzen wollte. Er wurde erneut verhaftet und schließlich verbannt. Er starb 1556, also zwei Jahre vor Elisabeths Thronbesteigung, im Exil in Italien. Hinweise auf eine Liebesgeschichte zwischen ihm und Elisabeth oder auf ein mögliche Teilnahme Ėlisabeths an Wyatts Rebellion finden sich nirgends. Vgl
Erickson, The First Elizabeth 112 und 155 f; Plowden 11 f, 53-7 und 69 f; Smith 49 und 55; Ridley 52-6 und 68.

44 Friedrichs' Datenangabe für die Autorin ist 1866-1932; sie bezeichnet sie als "Jugendschriftstellerin“; als Pseudonym nennt sie „E. Meruéll“. Im National Union Catalog ist Elisabeth Müller mit den Daten 1827-1898 und demselben Pseudonym verzeichnet. Anna von Cleve wurde unter diesem Pseudonym veröffentlicht; aufgrund der Daten ist anzunehmen, daß das Stück von Elisabeth Müller (1827-1898) stammt (zu weiteren Angaben über die Autorin siehe Anhänge A und B). Da Anagramme als Pseudonym üblich waren, kann die Möglichkeit, daß beide Autorinnen dasselbe Pseudonym benutzten, nicht ausgeschlossen werden.

$45 \mathrm{Zu}$ dieser Episode vgl. Morrison $163 \mathrm{f}$ und Hume 324. Heinrichs Ehe mit Anna war auf der Oberfläche eine von Thomas Cromwell arrangierte politische Vernunftehe: der Herzog von Cleve war überzeugter Lutheraner, und der König brauchte einen Alliierten gegen den Papst und Frankreich. Sechs Monate nach der Eheschließung ließ Heinrich sich von ihr scheiden; Anna erhob keine Einwände. Cromwell wurde kurz nach der Scheidung hingerichtet; wessen er beschuldigt wurde, ist unklar. Vgl. Hume 348-55; Morrison 170; Ridley 28; Erickson, The First Elizabeth 49; „Four Original Documents" 1-24.

46 Vgl. Fortunatus, "Vita S. Radegundis Reginae“ 498-502, und Carminum 178-81. Schwester Baudovinias Biographie der Radegundis war mir nicht zugänglich.

47 Diese Biographie entspricht Fortunatus' Bericht, abgesehen von Radegundis' Aufenthalt im Kloster. Vgl. Carminum $179 \mathrm{f}$ und „Vita S. Radegundis Reginae“ $498 \mathrm{f}$.

Kap. 6

48 Wie aus den ausführlichen Anmerkungen und Erläuterungen der Verfasserin hervorgeht, war sie sowohl mit Petrarcas Biographie als auch mit seiner Dichtung genau vertraut. Die Änderungen, die sie vornimmt, sprechen für sich. Die wichtigste Abweichung ist eine zeitliche: die zeitliche Übereinstimmung der zwei Ereignisse, die (im Stück) aus dem dichterischen Schwärmer einen Poeten machen, nämlich Petrarcas Dichterkrönung und Lauras Tod, ist erfunden.

Wer Petrarcas Laura war, ist unbekannt; die meisten Biographen Petrarcas nehmen mit dem Abbé de Sade, dessen Mémoires pour la vie de Petrarque eine Hauptquell Westphalens war, Laura de Noves als Original des Bildes an. Laura de Noves soll Petrarca 1327 in einer Kirche in Avignon „erschienen“ sein. Seit 1325 war sie mit Hugo de Sade, einem Edelmann aus Avignon, verheiratet (bei Westphalen heiß ihr Mann Fernando; der Name Hugo wird auf Lauras Sohn übertragen). Laura de Noves starb 1348; Petrarca bekam bereits 1340 das Angebot der Dichterkrönung von Paris und Rom und wurde 1341 in Rom zum Poeta laureatus gekrönt. Vgl. Sade I, 26-9, 370-9 und 383-7; Friedrich Schneider 82 f; Bergin 14, 43, 54 und $74 \mathrm{f}$; Hollway-Calthrop 33-7, 97-9 und 137; Willkins $8 \mathrm{f}, 25-7$ und $76 \mathrm{f}$; Wulff 3 .

49 Dieses Gedicht ist eine leicht abgeänderte Übersetzung von Petrarcas 126. Sonett („In qual parte del cielo"). Wo die Autorin solche Übersetzungen im Text zitiert, 
nahm sie häufig dem Original gegenüber leichte Änderungen vor. Meist handelt es (a) Bezüge auf erfundene Ereignisse im Drama. Aller Wahrscheinlichkeit nach sind die Übersetzungen die der Autorin.

50 Canzone Nr. 27 („Chiare, fresche“).

51 Canzone Nr. 30 ("Oltra quell" alpe").

52 Laura de Noves, dic Frau, die in der Literatur mit Petrarcas Laura identifizier wird, starb an der Pest.

3 Um das Dilemma des Künstlers anhand der Antimuse (und Ehefrau) Arabella und Uuse (und Geliebten) Clara zu illustrieren, nahm die Autorin beträchtliche der Muse (und Geliebten) Clara zu illustren vor. Anabella Milbanke heirateAnderungen gegenüber den historischen Tatsachen vor. Aie warf Byron Trunksucht, te Byron 1815 und bestand 1816 auf einer Trenntng. Sie wart Byron Trunksuch Ehebruch, Drohung und Mißhandlung vor und erwähnt einen Anfall Byrons im Drury Lane Theater (Longford $87 \mathrm{f}$ ), eine Episode, die Schmidt für ihre Zweck abwandelt (Genius $53 \mathrm{f}$ ). Byron weigerte sich beharrlich, auf die Trennung einzuabwandelt (Genius $53 \mathrm{f}$ ). Byron weigerte sich beharrlich, auf dic 76 ).

gehen (Trueblood 7 , Loworth, Byrons erste Liebe (1803). Laut Sekundärliteratur

4 Gemeint ist Mary Chaw versuchte Chaworth 1814, die Beziehung zu Byron wied Longford 69.

Derional für Clara ist Claire Clairmont, die Byron erst nach der Das historische Origla kennenlernte. Clairmont schrieb ihm anonyme Briefe, in Trennung von Anabella lken denen sie um ein persönliches Treffen und um eine Empfehlung Byrons an das Drury Lane Theater bat (Grylls 53-7; Symonds/Quennell 202 f; Gordon 109; Origo 15-17). Anders als im Stück war Clairmont keine Schauspielerin; in der Literago 15-17). Anders als in Stick benutzte, um Byron tur wird diese Bitte in der Regel als kennenzulernen. Als Byron 1816 England verließ, folgte Clairmont ihm nach Genf. 1817 bekam sie ein Kind von ihm, worauf Byron sich endgültig von ih Genf. 1817 beksam sie ein Kritert, in denen e trennte. In der Literatur werden häufig Briefstellen Byrons zitier, in denen er Clairmont und seine Affäre mit ihr äußerst verächtlich beschrcibt. Vgl. Trueblood 16; Longford 104-106; Maurois, Byron 353-5; Grylls 63 und 75; Symonds/Quen16; Longford 104-106; Maurois, nell $206 \mathrm{f}, 212,214 \mathrm{f}, 216 \mathrm{f}, 224 \mathrm{f}$; 160 ; $22,31-33,57 \mathrm{f}, 89$ und $99 \mathrm{f}$.

56 Byron war an den griechischen Freiheitskämpfen beteiligt und starb 1824 in Missolunghi an einer Krankheit, nicht an den Folgen einer Kampfhandlung. Vgl Trueblood 17 und Gordon 245.

7 Die Handlung des Stückes sowie die entsprechenden Figuren (Ellena und Enrico) sind eine freie Erfindung der Autorin. Historisch sind lediglich die Angaben übe seort, seine Freundschaft mit Velasquez und der Rubens' Lehrjahre bei Adam van Noort, seine Frundschaf mutens war 1628 in zeitliche Rahmen, in den Birch-Pfeiffer ihr Stück einfugt, Rubens war 1628 in Madrid und wurde 1629 von Philipp IV. auf eine diplomatische Mission nach Madrid und wurde England geschickt, um dort Friedensverhandlungen mit Che auf eine Liebesgeschichtc lon 54 f; Stevenson 68-70 und Warnke 217). Hinweise auf eine Liebesgeschich in Madrid finden sich auch nicht in Rubens' Briefen aus diesen Jahren (Ruben 258-332).
58 Die Liebesgeschichte mit Clara, im Stück Willibald Pirkheimers Schwester, ist eine Erfindung der Autorin, ebenso wie der Malerwettbewerb in Nürnberg, Dürers Ehrung, und die Guglielmo-Handlung. Pirkheimer hatte mehrere Schwestern, die alle Nonnen waren (Panofsky 270; Timken-Zinkann 55); eine Clara Pirlsheimer wird nirgends erwähnt. Die Darstellung der Agnes Dürer als verständnisloser Hausteufel ist Bestandteil fast jeder Dürer-Biographie.

59 Im Jahre 1517, in dem nach Angaben der Autorin das Stück spielt, malte Dürer keine Madonnenbilder. Das im Stück geschilderte Gemälde beschreibt die Autorin folgendermaßen: „Joseph, ein Greis, und Maria, von Engeln umgeben, mit ihrem, vor ihren Füßen auf einem Kissen ruhenden, Kinde" (Anmerkung 6). Das einzige Bild Dürers, das dieser Beschreibung entspricht, ist seine "Christi Geburt", das Mittelstück des Paumgartnerschen Altars, aus dem Jahre 1500.

60 Der hier beschriebene Baumeister Pietro Manolo war nach Angaben der Autorin eine historische Figur, über die mir leider keine Literatur zugänglich war. Der Stoff zu ihrem Stück stammt aus „einer alten Ballade“ (Meister Manole, Vorwort v). Manolo soll vom Fürsten Neagoie Bassarab beauftragt worden sein, eine Kirche zu bauen, da dieser versucht habe, „durch Kirchenbauten von seinem Geschlecht den Fluch abzuwenden, den seine Vorgänger durch zahllose Greuelthaten darauf gehäuft" (Vorwort v).

Kap. 7

61 Ein Beleg für die Faszination vieler Autorinnen mit klassischer Kultur; keineswegs nur eine Begleiterscheinung der deutschen Klassik, ist die Anzahl der Bearbeitungen griechischer und römischer Geschichte, wie z. B. Elsa Bernsteins Themistokles (1897); Caroline Pichlers (1769-1843) Germanicus (1813); Friederike Ellmenreichs (1777-1845) Libretto Der letzte Tag von Pompeiji (o. J.); Emilie von Ringseis' (1831-1895) Die Sibylle von Tibur (1858); Lodoiska von Blums (1841-1927) Das Leben Neros (o. J.); und Gisela Grimms (1827-1889) Das Herz der Lä̈s (1857).

62 Da sich bei vielen dieser Bearbeitungen - und tatsächlich bei einigen der Stoffe die Unterscheidung zwischen Mythos und Geschichte verwischt, stellt sich hier die Frage nach den Auswahlkriterien für dieses Kapitel. Dieser Abschnitt beschäftigt sich ausschließlich mit literarischen Mythen. Dagegen werden Dramen über historische Persönlichkeiten, die später zu mythologischen Figuren erhoben wurden (Nero, Caligula, Themistolkes, Hermann der Cherusker) hier ebenso ausgespart wie Komödien der Frühaufklärung (beispielsweise von Gottsched oder Neuber), die zwar den antiken Lokus benutzen, tatsächlich aber einen anderen Zweck velfolgen als den der Behandlung des mythologischen Stoffes.

Für die Zwecke dieses Kapitels werden dramatische Bibelbearbeitungen ebenso behandelt; d. h. die Bibel wird als der Stoff, der ihnen zugrundeliegt - als Literatur verstanden.

63 Die hier zitierte Ausgabe ist die von 1898, wie auch im folgenden 
64 Das Stück hat außerdem einen zweiten wichtigen Hintergrund: den des Weimarer Hofes. Eine Besprechung des Stückes in der Augsburger Allgemeinen Zeitung (Nr. 246, 3. 9. 1863) nennt die folgenden Weimarer Persönlichkeiten als mögliche Vorbilder für Figuren des Stückes: Jarbes $=$ Karl August, Dido = Herzogin Luise, Albicerio $=$ Herder, Aratus $=$ Bertuch, Ogon $=$ Goethe, Elissa $=$ von Stein, Dodus $=$ Knebel (Goethes Briefe, hg. Schöll, Anmerkungen, II, 686). Inwiefern dieser Verdacht der Intention der Autorin entspricht, ist mir nicht nachprüfbar, da von Stein sich nirgends über eine mögliche Verwandtschaft zwischen diesen Persönlichkeiten und ihren Figuren äußert. Im Falle Ogon-Goethe allerdings ist eine etwaige Übereinstimmung mit lebenden Personen und Ereignissen alles andere als zufällig: Ogons für ihn wenig schmeichelhafte Äußerungen auf der Bühne entstammen zum großen Teil - manchmal wörtlich zitiert - Goethes Briefen an von Stein.

65 Eventuell eine Anspielung auf Knebel. Vgl. die Anmerkungen in Goethes Briefe, hg. Schöll, II 687.

66 D. h.: die Rachegöttinnen verwandeln sich in „die Wohltätigen“, die Verteidigerinnen des Menschen vor dem göttlichen Tribunal. Das Zitat ist eine Anspielung auf die Freisprechung des Orestes vor dem Gericht der Pallas Athene, in dem Athene Orestes von der Blutschuld freispricht und auf diese Weise die Erinnyen, die Rachegöttinnen, in die Eumeniden verwandelt (Hamilton, 248). Von den Erinnyen Verfolgte nannten sie oft Eumeniden, um ihren Zorn zu besänftigen.

67 Diese Episode ist nicht im Buch Samuel überliefert, sondern von der Autorin aus leicht ersichtlichen Gründen eingefügt: die darauffolgende Tötung Agags durch Samuel ist aus dem $A T$ übernommen; da die Autorin das Konzept eines rächenden, aber gerechten Gottes auf die Bühne bringen wollte, brauchte sie fuir den Mord eine zusätzliche Rechtfertigung als nur Samuels unbedingten Gehorsam.

Kap. 8

68 Dic Dokumente zu dem Privilegienstreit zitiert Reden-Esbeck ausführlich; siehe Caroline Neuber, 118-169. Für eine kurze Zusammenfassung sowie eine Auseinandersetzung mit Neubers Vorspielen und Vorreden siehe Heckmann. 


\section{A. Kurze Biographien der behandelten Autorinnen}

Amalie Prinzessin von Sachsen. Geb. 10. 8. 1794 in Dresden als älteste von sieben Kindern, Vater Prinz Max v. S., Mutter Prinzessin ? von Parma (?-1804). Nach dem Tod ihrer Mutter 1804 wurde A. v. S. von ihrer Tante, der Prinzessin Therese v. S., unter strengster Hofetikette erzogen. Musikunterricht bei Kapellmeister Joseph Schuster. A. v. S. fing früh an zu komponieren und schrieb mit 16 Jahren ihre erste Oper1813-1815 im Exil in Prag. Ab 1816 Kompositionsunterricht bei Carl Maria von Weber. Zwischen 1813 und 1835 komponierte A. v. S. zahlreiche Opern, Kantaten und kleinere Gesangsstücke, die alle bei Hof unter Mitwirkung ihrer Geschwister aufgeführt wurden. 1817 wurde ihr erstes Drama (Die Abentheuer der Thorenburg) anonym im Hoftheater aufgeführt; die Aufführung war ein Mißerfolg. König Friedrich August sah ihre schriftstellerische Betätigung als Bruch der Etikette; die Vorstellung von 1817 blieb die letzte öffentliche Aufführung eines ihrer Stücke bis zu seinem Tod 1827. Mehrere ihrer Stücke wurden in Privatvorstellungen im Prinzenpalais gegeben (Der Krönungstag, 1823; Mesru I, 1824; Mesru II, 1826; alle unter dem Pseudonym „A. Heiter"); der König besuchte keine dieser Vorstellungen, obwohl der gesamte Hof anwesend war. 1829 wurden beide Stücke am Hoftheater aufgeführt. 1833 sandte sie ihre erste Komödie (Lïge und Wabrheit) anonym an das Berliner Hoftheater, das Stïcls wurde erfolgreich aufgeführt und machte aus A. v. S. über Nacht eine populäre Komödienautorin. Ihre gesamte dramatische Produlttion (ca. 30 Stücke) stammt aus den folgenden elf Jahren (1834-1845); in diesen Jahren „beherrschte A. das Lustspielrepertoire ihrer Zeit" (Goedeke NF, 211). Viele ihrer Stücke wurden in verschiedene Sprachen übersetzt (Englisch, Französisch, Ungarisch, Russisch und Italienisch); in Paris führte ein Bühnendichter eigene Werke unter ihrem Namen auf.

A. v. S. blieb als einzige ihrer Familie zeitlebens unverheiratet, lebte zurückgezogen und beschäftigte sich fast ausschließlich mit ihrer musikalischen und schriftstellerischen Tätigkeit und mit Reisen. 1825 unternahm sie eine Reise nach Madrid, bis 185 zehn Reisen nach Italien. Aus ihrem Tagebuch ist nichts über persönliche Erlebnisse zu entnehmen; auch die Persönlichkeiten, mit denen sie zusammentraf, erwähnt sie nur kurz (Napoleon I., Louis Philippe, Napoleon III., Karl August, Pio Nono, Goethe, Karl Gutzkow). Engeren Kontakt unterhielt sie nur mit dem Hofrat Winkler (Pseud. Theodor Hell), dem sie ihre Stücke zur Durchsicht schickte. 1851 Erkrankung am grauen Star, 1853 Augenoperation und Erblindung. 1855 wurde ein Auge durch eine zweite Operation wiederhergestellt. Gest. 18. 9. 1870 in Pillnitz

Während die zeitgenössische Kritilk über A. v. S. wohlwollender urteilte als beispielsweise über Birch-Pfeiffer, wird die Autorin von späteren Kritikern meist als seichte Lustspielautorin gesehen, deren Stücke nach dem ruhmvollen Jahrzehnt 1834-1844 zu Recht vergessen wurden. Wohlwollend-abfällige Besprechungen ihrer Stücke wie die Goedekes („Arbeiten [...] epigonischen Charalkters", "Gemisch zwischen Verstandestätigkeit und schwächlicher Romantik“, „allzu einfach“, „eintönig“, „Probleme werden nicht behandelt", NF 211) sind die Regel. Goedeke nahm die Erfolglosigkeit der 
späteren Aufführungen ihres Oheims (Dresdner Hoftheater, 1871 und 1887) als Beweis für seine Sicht der Autorin als literarische Eintagsfliege: „die Zeit der Stücke Amalie Heiters war dahin" (NF 212).

Werke: Dramatische Werke siehe Anhang B. Gelegenheitsdichtungen, 1815. Im Nachlaß (Dresden): Briefe an Theodor Hell (Pseud. f Karl Winkler). Briefe an J. L. Deinhardstein. Prosaschriften (Erzählungen, Märchen, Geschichten). Gedichte. Tagebücher und Reisetagebücher, u. a. "Journal d'émigration à Prague". Mehrere Übersetzungen.

Literatur: K. Herloßsobn und H. Marggraff, Allgemeines Theater-Lexikon, 1846, I. Almanach fur Freunde der Schauspielkunst 12, 1848, 121 f. K. Th. v. Kiustner, Vierund dreißig Jahre meiner Theaterleitung, 1853, 121, 319. H. Lawbe, Das Burgtheater, 1868, 137. R. Waldmüller, Lebensskizze, in: A. v. S., Dramatische Werke, 1873-4, I vixxxiI. K. Goedeke, A. M. F. A. Prinzessin v. S., in: Allgemeine deutsche Biographie 1875, I. R. Waldmüller, Aus den Memoiren einer Fürstentochter, 1883. K. Goedeke, Grundriß zur Geschichte der deutschen Dichtung aus den Quellen, 2. Aufl. 1884 1966, XI/1 und NF, H. Groß, Deutsche Dichterinen und Schriftstellerinen in Wort und Bild, 1885, I 218-23. E. Kilian, Beiträge zur Geschichte des Karlsruher Hoftheaters, $1893,32,51,54,58,61,64,82,119$. A. Eloesser, Das bürgerliche Drama, 1898, 198-200. S. Pataky, Lexikon deutscher Frauen der Feder, 1898, I. A. v. Weilen und O. Teuber, Die Theater Wiens, 1899-1906, II C 100. C. Ponader, Prinzessin A. v. S. (Diss. Würzburg), 1923. W. Kunze, „A. M. F. A., Herzogin zu S.“, in: Neue Deutsche Biographie, 1953-1980. E. Devrient, Eduard Devrient aus seinen Tagebüchern, 1964, 93, 149-151. E. Devrient, Geschichte der deutschen Schauspielkunst, 1967, II 309, 354. W. Kosch, Deutsches Literatur-Lexilkon, 3. Aufl. 1968-1990. H. Denkler, Restauration und Revolution, 1973, 118, 193, 197-202. E. Friedrichs, Die deutschsprachigen Schriftstellerinnen des 18, und 19. Jahthunderts, 1981. R. Cowen, Das deutsche Drama im 19. Jahrhundert, 1988, 57, 62 f. V. Richel, The German Stage, 1767-1890, A Directory of Playwrights and Plays, 1988, 3. H. Laube, Heinrich Laubes ausgewählte Werke, o. J., IX 368 f. M. Fürstenau, Die musikalischen Beschäftigungen der Prinzes$\sin$ A. v. S., o. J.

Artner, Marie Therese von. Geb. 19. 4. 1772 in Schnitau (später Sempte bei Neutra, Ungarn) als älteste von vier Töchtern. Vater der österreichische Rittmeister Leopold v. A., Mutter Magdalena v. Hubert. 1779 Umzug nach Ödenburg [heute Sopron in Ungarn]. Zwischen 1779 und 1781 schrieb sie ihr erstes Gedicht, ein gereimtes Gebet an ihren Vater: Ihre Ausbildung kann als typisch für die Erziehung von Mädchen gegen Ende des 18. Jahrhunderts angesehen werden: M. T. v. A. erhielt privaten Anfängerunterricht in den verschiedensten „weiblichen" Fächern (Zeichnen, Malen, Musik, Religion, Schreiben, Briefstil, Französisch), der in der Regel auf ein bis drei Jahre beschränkt blieb. Schindel führt ihre dürftige Erziehung auf „Häusliche Geschäfte“ (I, 16) zurück. Später lernte sie gut genug Italienisch, um italienische Dichtung lesen zu könzurück. Später lernte sie gut genug Italienisch, um hauptsächlich durch Freundschaften mit anderen Frauen, von denen viele selbst schrieben, unterstititzt. Diese literarischen
Freundschaften begannen sehr früh - ca. 1782/3 - und hielten bis an ihr Lebensende an. Mit ca. 12 oder 13 Jahren Freundschaft mit Doris v. Conrad (später Donner) und Marianne v. Tiell (später die Schriftstellerin M. Neumann v. Meissenthal); mit der letzteren schrieb M. T. v. A. Gedichte. 1784 Tod der vierjährigen Schwester Josephe; aus M. T. v. A.s Trauer und ihrer Lektüre von Klopstocks Messias entstanden Oden im Stil des Göttinger Dichterbundes.

Von nun an schien M. T. v. A. entschlossen, ihre dichterische Begabung selbst zu schulen. Sie las hauptsächlich Epen und entschloß sich 1786 zu einem Epos über Conradin von Schwaben. Vier Jahre lang sammelte sie unermüdlich geschichtliche Materialien und schrieb 14 Gesänge, bevor sie den Plan 1790, vielleicht unter dem Druck ihrer Familie, aufgab. Dieses Epos blieb, bis auf die später von der Zensur verbotene Schlacht von Aspern, ihr letztes; M. T. v. A. schrieb später fast ausschließlich Dramen und Gedichte. Ihre Mutter war von ihrem schriftstellerischen Ehrgeiz nicht begeistert: „die häusliche Sphäre, als die Hauptbestimmung des Weibes, im Auge haltend, hielt sie Theresen früh zum Fleiß in weiblichen Beschäftigungen an" (Schindel I, 19). Das Schreiben war M. T. v. A. nur in ihrer Freizeit erlaubt, die knapp genug bemessen war, da sie inzwischen zur Erzieherin ihrer drei jüngeren Schwestern bestellt worden war und „bei dem geringsten ihr erwartenden Geschäft abgerufen“ wurde (I, 20). Schindel berichtet, daß M. T. v. A., als ihre Mutter ihr das nötige Licht für Nachtarbeit verweigerte, Wachsreste sammelte, um nachts schreiben zu können (I, 20). Als M. T. v. A mit 14 Jahren die Pocken bekam, wurde diese Krankheit ihrer dichterischen Beschäftigung zugeschrieben, und „alle ihre Freunde vereinigten sich mit der Mutter, sie von ihrer Lieblingsbeschäftigung abzuziehen" (I, 20). In ihrer ersten gemeinsamen Gedichtsammlung (Feldblumen, veröff. unter den Pseudonymen „Nina“, d. i. M. v. Tiell, und „Theone“, d. i. M. T. v. A.) schrieb Marianne v. Tiell an sie: „O möchte die Geburt von deinen Geisteskindern,/ Theone, dieses Jahr nicht deine Kräfte mindern!/ Sonst müßten alle, die dich kennen,/ Sie kleine Muttermörder nennen" (zit. Schindel I, 21).

M. T. v. A. enttäuschte ihre Eltern weiter durch ihre Weigerung zu heiraten (Schindel I, 22). Als ihre Mutter 1796 starb, übernahm M. T. v. A. den Haushalt, die Erzichung der Geschwister und die Pflege des kränkelnden Vaters. 1799 Tod des Vaters. 1800 erschien M. T. v. A.s und Marianne v. Tiells erste Gedichtsammlung Feldblumen pseudonym und erhielt in Deutschland gute Kritiken, wurde aber in Ungarn nur wenig bekannt. Um dieselbe Zeit Freundschaft mit der Schriftstellerin Maria v. Zay. 1802 lebte M. T. v. A. mit ihrer Schwester Wilhelmine und ihrer Freundin Doris Donner, die 1803 starb; von da an lebte sie abwechselnd bei Wilhelmine v. A. und Maria v. Zay in Freiburg, Ungarn und Wien. 1803 Reise mit M. v. Zay nach Freiburg; dort lernte M. T. v. A. Jacobi kennen, der eine Art literarischer Mentor für sie wurde. 1804 Reise mit ihren Schwestern Amalie und Wilhelmine nach Straßburg, Landau, Worms, Mainz und Frankfurt. 1806 veröffentlichte sie, wieder anonym, eine zweite Gedichtsammlung; 1810-12 schrieb sie ein Epos über die Schlacht von Aspern. Fragmente des Epos erschienen 1812 in Hormayr's Historisches Archiv und 1819, auf Empfehlung von M. T. v. A.s Freundin Caroline Pichler (siehe dort), in Therese Hubers 
„Morgenblatt“. Das gesamte Epos wurde nicht gedruckt, weil der Staatsminister Graf "Metternich den Druck des Werkes, wahrscheinlich wegen des historischen Stoffes, verbot.

1811 verlor M. T. v. A. aufgrund eines neu erlassenen Finanzgesetzes die Hälfte ihvermögens. Ab 1814 enge Freundschaft mit der Schriftstellerin Caroline res geerbten Vermogens. Ab 1814 enge 1816 begann sie ihr Trauerspiel Die That, das ein Pichler, die bis zu ihrem Tod daucte. Jahr später erschien; später revidierc sie ihre fither veroffentlichen Gedichte, von denen 1818 eine neue Ausgabe gedruckt wurde. $1827 \mathrm{zog}$ sie zu ihrer Schwester Wilhelmin nach Agram, die ihrer eigenen Gesundheit wegen cine Stütze in ihrem häuslichen nach A. ". wurde dort selbs Walten bedurfe "(Pichler, Denhwintigeiten 11,25$)$. M. T. v. A. Wurde dort selbst krank und verschlimmerte ihre Krankheit durch häufiges Hin- und Herreisen zwischen ihrer Schwester und M. v. Zay. M. T. v. A. starb am 25. 9. (11?) 1829 in Agram

Werke: Dramatische Werke siehe Anhang B. Conradin von Schwaben, Epos (unedr.), 1786-1790. Feldblumen, auf Ungarns Fluren gesammelt, von Minna [Pseud. gedr.) furr: Mariante Nen Theone, 1806. Die Schlacht von dichtsaminlung, 2 Bde., 18010-12. Gedichte, 2 Bde, 1818. Stille Größe, 1824. Rogneda Aspern, Epos (ungedr.), 1810-12. Gedichte, 2 Bde., 1818. Stil Größ, 1824. Rogned und Wladimir, 1824. Briefe über einen Theil von Kroatien, 1830. Briefe an Caroline Pichler, veröff. 1830. Sappho an Phaon, Heroide, o. J. Beiträge (meist Gedichte) in Iris, 1805; Hormayr's Historisches Archiv, 1812; Minerva, 1820; Aglaja, 1820.

Literatur: $C$. W. O. A. w. Schindel, Die deutschen Schriftstellerinnen des neunzehnen Tichler, „T. v. A.“, in: C. Pichler, Zerstreute Blätter aus meinem Schreibrische, 1836, I 191-208. K. Herloßsohn und H. Marggraff, Allgemeines

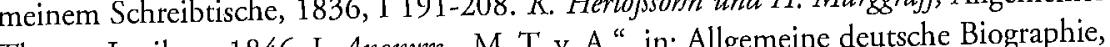
Theater-Lexikon, 1846, I. Anonym, „M. T. v. A.“, in: Allgemeine deutsche Biographie, 1875, I. H. Groß, Deutschlands Dichterinen und Schriftstellerinen, 2. Aufl. 1882, 35. K. Goedeke, Grundriß zur Geschichte der deutschen Dichtung aus den Quellen, K. Goedeke, Grundriß zur Geschichte deß Deutsche Dichterinen und Schriftstelleri2. Aufl. 1884-1966, VII und XI/2. H. Groß, Deutsche Dichterinen und Schriftstellerinen in Wort und Bild, 1885, I 160-63. S. Pataky, Lexilkon deutscher Frauen der Feder, 1898, II. C. Pichler, Denkwürdigkeiten aus meinem Leben, 2 Bde., 2. Aufl. 1914. K. Vancsa, „M. T. A..", in: Neue Deutsche Biographie, 1953-1980. L. Hirschberg, Hg., Ker Taschengoedeke, 1961, 19. W. Kosch, Deutsches Literatur-Lexikon, 3. Aufl. 1968 . Friedrichs, Die deutschsprachigen Schriftstellerinnen des 18. und 19. Jahrhunderts, 1981.

Bandemer, Susanne von. Geb, 2. 3. 1751 in Berlin (v. Frencklin oder v. Franklin). Vater Captain von Frencklin Mutter ?, Onkel möglicherwcise Benjamin Franklin Vater Captain (s. Slessarev, „S. v. B. and Benjamin Franklin“). Heiratete um 1766 den preußischen Major v. B. und ließ sich scheiden; heiratete (wann?) Graf Kurt Ludwig v. Bohlen und ließ sich scheiden. Über ihre Ehen existieren verschiedene Interpretationen: Friedrich nimmt in beiden Fällen eine Scheidung an; nach Slessarev starb S. v. B.s erster Mann, worauf S. v. B. sich „heimlich mit einem Grafen von Bohlen vermählt[e], der diese Worbing allein ließ" („S. v. B.s BeiVer wieder an; sie kehrte vielleicht „zum ersten Mann zurück" (Friedrichs). S. v. B. lebte in Frankfurt/M., Koblenz und Stettin und schrieb vorwiegend Gedichte und Dramen. Befreundet mit Wieland, Ramler, Herder, Anna Luisa Karsch. Briefwechsel mit Sophie von La Roche 1794-1797. Gest, 30. 12. 1828 in Koblenz.

Werke: Dramatische Werke siehe Anhang B. Poetische und prosaische Versuche d. Fr. v. B., 1787. Klara von Bourg, eine wahre Geschichte im letzten Zehntel des abscheidenden Jahrhunderts [z. T. autobiographisch?], 1798. Gedichte, 2 Bde., 1801. Neue vermischte Gedichte, 2 Bde., 1802. Gedichte und prosaische Kleinigkeiten, 2 Bde., 1811. Zerstreute Blätter aus dem letzten Zehntheil des abgeschiedenen Jahrhunderts, 1821. Beiträge (meist Gedichte) in: Berliner Musenalmanach, 1791/2; Rammlers Fabellese, o. J.; Wielands Neuer Teutscher Merkur, 1792; Müchlers Egeria, 1802; Frauenzimmer-Almanach, 1812.

Literatur: C. W. O. A. v. Schindel, Die deutschen Schriftstellerinnen des neunzehnten Jahrhunderts, 1823, I. $H$. Groß, Deutschlands Dichterinen und Schriftstellerinen, 2. Aufl. 1882, 27. K. Goedeke, Grundriß zur Geschichte der deutschen Dichtung aus den Quellen, 2. Aufl. 1884-1966, V. S. Pataky, Lexikon deutscher Frauen der Feder; 1898, IT. A. v. Hanstein, Die Frauen in der Geschichte des Deutschen Geisteslebens des 18. und 19. Jahrhunderts, 1900, II 320-3. L. Hirschberg, Hg., Der Taschengoedeke, 1961, 30. H. Slessarev, „S. v. B. and Benjamin Franklin“, in: American Notes and Queries IV, 10 (Juni 1966), 149 f. H. Slessarev, „S. v. B.s Beitrag zur Entwicklung des Briefromans", in: Goethe Jahrbuch, Neue Folge 30, Weimar, 1968, 132-7. W. Kosch, Deutsches Literatur-Lexilkon, 3. Aufl. 1968-1990. E. Friedrichs, Die deutschsprachigen Schriftstellerinnen des 18. und 19. Jahrhunderts, 1981.

Berlepsch, Emilie von (in Lexika auch: Harms, E.). Geb. 26. 11. 1757 in Gotha (v. Oppeln; auch: v. Oppel, v. Appel). Vater Vizekanzler zu Altenburg und SachsenGotha Carl Georg August von Oppeln, Mutter ?. Heiratete (wann?) den Hofgerichtspräsidenten und Landrat Friedrich Ludwig Freiherrn v. B. (gest. 1818) aus Hannover und lebte in Hannover, Göttingen und Weimar. 1797 ging sie mit Jean Paul, „den sie heiraten wollte" (Kosch), nach Leipzig, und lebte danach zeitweilig in der Schweiz und in Schottland. Auf ihren Wunsch wurde ihre Ehe (wann?) geschieden. 1801 heiratete sie den Domänenrat August Heinrich Ludwig Harms in Redefin (Mecklenburg) und lebte von da ab wieder in der Schweiz, später in Hannover und Schwerin. E. v. B. starb am 27. 7. 1830 in Lauenburg.

Außer ihrem Drama Eginhard und Emma schricb E. v. B. Lyrik, Essays und Reisebeschreibungen. Jean Paul bezeichnete ihre Bemerkungen als „das Beste in deutscher Sprache und Seele, was je eine Deutsche geschrieben " (zit. Kosch).

Werke: Dramatische Werke siehe Anhang B. Drei Theaterreden, in: Reichards Theaterkalender, 1785. Sammlung kleiner Schriften und Poesien, 3 Bde., 1787. Gedichte im Göttinger Musenalmanach und in Wielands Neuer Teutscher Merkur; 1791. Ein Gedicht an Herder und ein Nachruf auf Herder, in: Neuer Teutscher Merkur, 1791. Einige zum Glück der Ehe nothwendige Eigenschaften und Grundsätze, Aufsatz, in: Neuer Teutscher Merkur, 1791. Sommerstunden, 15 Bde., 1795. Einige Bemerkungen 
zur richtigen Beurteilung der erzwungenen Schweizer Revolution, 1799. Caledonia (Schilderung der Hochgebirge von Schottland), 4 Bde., 1802-4. Verschiedene Briefe über Rheingegenden und Holsteinsche Gärten im Hannöverschen Magazin, o. J.

Literatur: G. Chr. Hamberger und J. G. Meusel, Das gelehrte Teutschland oder Lexikon der jetzt lebenden teutschen Schriftsteller; 1796-1834, I, IX, XI, XIII. C. W. O. A. v. Schindel, Die deutschen Schriftstellerinnen des ncunzehnten Jahrhunderts, 1823, I. H. Groß, Deutschlands Dichterinen und Schriftstellerinen, 2. Aufl. 1882, 52. S. Pataky, Lexikon deutscher Frauen der Feder, 1898, II. L. Hirschberg, Hg., Der Taschengoedeke, 1961, 43. W. Kosch, Deutsches Literatur-Lexikon, 3. Aufl. 1968-1990. E. Friedrichs, Die deutschsprachigen Schriftstellerinnen des 18. und 19. Jahrhunderts, 1981. R. Dawson, „E. v. B.“, in: E. Frederiksen, Hg., Women Writers of Germany, Austria, and Switzerland, 1989, $29 \mathrm{f}$.

Bernstein, Elsa (in Lexika und Sekundärwerken auch: Rosmer, Ernst). Geb. 28. 10. 1866 in Wien (Porges). Vater der Musikschriftsteller Heinrich Porges (?-1900), Mutter?. In ihrer frühen Jugend zog die Familie nach München um, weil ihr Vater von Ludwig II. nach München berufen wurde. Dort war E. B. kurzfristig Schauspielerin (am Hoftheater?), mußte ihre Karriere jedoch wegen eines Augenleidens aufgeben. (am Hoftheater?), mußte ihre Karriere jedoch wegen eines Augenleidens autgeben. schrieb sie ihr erstes Drama (Wir Drei), dem bis 1910 noch 11 Dramen folgten. E. B. war hauptsächlich Dramatikerin (außer Dramen veröffentlichte sie nur einige Novellen); ihre Stücke wurden häufig und erfolgreich aufgeführt. Ihr Märchendrama Königskinder (1895) wurde von E. Humperdinck vertont.

E. B. veröffentlichte fast alles, was sie schrieb - eine Ausnahme ist ihr Schauspie Johannes Herkner, das sie 1904 unter ihrem Mädchennamen herausgab - unter dem Pseudonym „Ernst Rosmer“ und wird, von zwei Ausnahmen abgesehen, in Sekundärwerken unter ihrem Pseudonym geführt. Häufiges Thema ihrer Dramen, die oft einen naturalistischen Ton anschlagen, ist das Dilemma der Frau zwischen Beruf und Ehe (z. B. in Dämmerung, Milost Pan, Maria Arndt, Wir Drei): viele ihrer weiblichen Dramenfiguren sind berufstätige Frauen (Ärztinnen, Schriftstellerinnen, professionelle Musikerinnen), die sich vor die Wahl gestellt sehen, entweder ihre Hoffnung auf menschliche Beziehungen (Ehe, auch Freundschaften) oder ihren Beruf aufzugeben E. B. selbst hörte fast vierzig Jahre vor ihrem Tod auf zu schreiben; ihr letztes Werk stammt aus dem Jahre 1910. Sie starb am 2. 7. 1949 in Hamburg-Eimsbüttel.

Werke: Dramatische Werke siehe Anhang B. Madonna, Novellen, 1894. Merete, 1902.

Literatur: E. Brausewetter, „Ernst Rosmer", in: E. Brausewetter, Meisternovellen deutsher Frauen, 1897, I 279-88. F Mehring, „Ernst Rosmers Dämmerung“, in Die neue Zeit, Wochenschrift der deutschen Sozialdemokratie 11 (1892/3), 2. T. Lessing, „Ernst Rosmer", in Die Gesellschaft, 1898. H. Landsberg, „Enst Rosmer“, in Nord und Süd, 1899. A. Maucke, "Ernst Rosmer", in Das neue Jahrhundert (1899), 50. S. Kleth Ernst Rosmers Mutter Maria“, in Die Frau 8 (1901). L. Weber, „Ernst Rosmers Mutter Maria“, in Der Kunstwart 14 (1901), 7. A. Kerr, „Ernst Rosmer“, in A. Kerr, Das neue Drama, 1905. T. v. Scheffer, „Ernst Rosmers Achill“, in Xenien, 1913. K. Wiener
Die Dramen E. B.s, Diss. (Wien), 1923. P. Witkop, „E B., eine Münchner Dramatikerin", in Münchner Neueste Nachrichten (1926), 299. E. Friedrichs, Die deutschsprachigen Schriftstellerinnen des 18. und 19. Jahrhunderts, 1981. D. Kafitz, Grundzüge einer Geschichte des deutschen Dramas von Lessing bis zum Naturalismus, 1982, II 323 f. M. Giesing, „Theater als verweigerter Raum, Dramatikerinnen der Jahrhundertwende in deutschsprachigen Ländern", in: Frauen - Literatur - Geschichte, Schreibende Frauen vom Mittelalter bis zur Gegenwart, 1985, 240-59. G. Brinker-Gabler, „Ernst Rosmer", in G. Brinker-Gabler, K. Ludwig, A. Wöffen, Hg., Lexilkon deutschsprachiger Schriftstellerinnen 1800-1945, 1986.

Birch-Pfeiffer, Charlotte. Geb. 23. 6. 1800 in Stuttgart (Pfeiffer). Vater Domänenrat ? Pfeiffer; Mutter ?. 1806 Umzug der Familie nach München, 1809 Erblindung des Vaters. Als Kind las C. B.-Pf, ihrem Vater, ein ehemaliger Karlsschüler und Mitschüler Schillers, dessen Werke vor; sie übernahm dabei seine Schillerbegeisterung und entwickelte eine eigene für die Bülnne. 1813 überwand sie mit Hilfe der Fürsprache des Königs Max Joseph den Widerstand ihrer Eltern gegen ihren Plan, Schauspielerin zu werden, und trat am 13. 6. im Hoftheater am Isartor zum ersten Mal auf. Ihr Erfolg verschaffte ihr eine feste Anstellung an der Münchner Bühne (bis 1826); Gastspielreisen 1818-1823 in Stuttgart, Karlsruhe, Mannheim, Darmstadt, Frankfurt, Wien, Kassel, Hannover, Berlin, Dresden und Hamburg.

1825 heiratete sie den dänischen Diplomaten Dr. Christian Andreas Birch (1795 1868), der um ihretwillen seine diplomatische Laufbahn abbrach und durch C. B.-Pf, Vermittlung eine Anstellung bei der Hoftheaterintendanz in München erhielt. 1826 gab C. B.-Pf. ihre Stelle in München auf und unternahm weitere Gastspielreisen (bis 1827) nach Hamburg, Danzig, Königsberg, Riga, Petersburg, Reval, Breslau, Leipzig und Prag. 1827-1830 feste Anstellung in Wien (Theater an der Wien). Dort schrieb sie 1828 ihr erstes Drama (Herma oder die Söhne der Rache), dem bis 1868 über hundert Theaterstiicke und Operntexte folgten (ihre gesammelten dramatischen Werke enthalten nur 74 Stücke). C. B.-Pf. schrieb ihre Stücke im Schnellverfahren, oft im Zeitraum von nur acht Tagen. 1830 neue Gastspielreisen in Budapest, Brünn, Breslau und Berlin; fester Wohnsitz in München mit jährlichen Gastspielreisen ab 1830. 1836 Geburt der Tochter Wilhelmine (siehe W. v. Hillern). Bei einem Gastspiel in Zürich 1837 ging Beurer; der Direktor des Stadttheaters, durch und ließ das Verlustunternehmen im Stich, worauf C. B.-Pf. das Theater übernahm und trotz finanzieller Schwierigkeiten und Personalmangel mehrere erfolgreiche Vorstellungen auf die Bühne brachte. Sie wurde darauf Intendantin in Zürich, obwohl ihre Bedingungen weit weniger annehmbar waren als die ihrer zehn Mitbewerber um die Theaterleitung. Bis 1842 leitete sie das Theater mit großem Erfolg (Theaterchronils 1842: „Geht B.-Pf., so können wir wohl mit Recht sagen: ,Wir haben ein Theater gehabt'."Zit. Hes 7). Ab 1844 Schauspielerin am Königlichen Hoftheater in Berlin unter Küstners Theaterleitung; C. B.-Pf. trat hier, wic auch auf Gastspielreisen, häufig in ihren eigenen Stücken auf. Auftritte in Zürich und Berlin auch als Sängerin. Krankheit ab 1863; gest. 25. 8. 1868 in Berlin. 
C. B.-Pf. war, trotz negativer Kritilken ihrer schauspielerischen Leistungen und ständiger Verrisse ihrer Stücke, bis an ihr Lebensende eine erfolgreiche Schauspielerin und erwies sich in Zürich als kompetente Intendantin; neben diesen zwei Berufen war sie wohl die produktivste und erfolgreichste Bühnenschriftstellerin des 19. Jahrhunderts. Die meisten ihrer Stücke wurden überall in Deutschland aufgeführt, waren in der Regel stets ausverkauft und so populär, daß fast 30 Jahre lang behauptet wurde, sie „beherrsche" mit ihren Stücksen das deutsche Theater. Sowohl Küstner als auch Laube wurden heftig angegriffen, weil sie den Stücken der C. B.-Pf. zuviel Raum auf ihren Bühnen einräumten; Küstner verteidigt sich mit der Behauptung, er führe jährlich nur zwei neue Stücke von ihr auf, und vergißt dabei zu erwähnen, daß sie in der Regel nu zwei Stücke im Jahr schrieb. 1846 hatte C. B.-Pf. genug von den ständigen Attacken auf sie und wollte nur noch „auf ausdrückliche Aufforderung der Intendanz“ Stücke zur Aufführung einreichen: „Ich bin es müde, mir vorwerfen zu lassen, daß ich die Berliner Bühne beherrsche, daß man nichts gibt als meine Stücke usw. So groß auch hier das Feld ist, werde ich es für eine Zeit ganz allein denen überlassen, die überzeugt sind, daß meine Arbeiten nur durch Protektion das Repertoire behaupten und denen das ,vox populi" nur dann etwas gilt, wenn es ihre eigenen Kinder erhebt" (zit. Hes 16). Aber dieser Entschluß war kurzlebig; wenig später nahm sie sich vor, ,auf jede Philippika gegen mich - mit einem Stück zu antworten. [...] Sie kriegen mich doch nicht unter" (zit. Hes 17).

Außer auf ihren Erfolg führte C. B.-Pf. viele dieser Angriffe auf den Umstand zurück, daß sie „Unterrock trage“ (zit. v. Weilen 1917, 11), und veröffentlichte verschicdene Stücke unter männlichen Pseudonymen (Franz Fels, Waldherr). Ein Zeichen ihres ungeheuren Erfolges waren die vielen Nachahmungen und Parodien ihrer Stücke. 1853 beklagt sie sich bei Laube, H. Volzmann habe ihre Waise aus Lowood plagiiert; ihre Pfeffer-Rösel wurde in ihrem Erscheinungsjahr verschiedentlich parodiert (als Pfeffer-Dösel im Josefstädter Theater, als Die Rösel im Pfeffer in Ofen, als Die Paprika-Lisel in Preßburg, alle 1829). 1842 wurde nach der Erstaufführung ihres Stückes Nacht und Morgen in Zürich das Souffleurbuch zu ihrem Stück gestohlen; C. B.-Pf. schützte sich vor unrechtmäßigen Aufführungen durch einen Hinweis auf ihr Druckrecht in der Leipziger Allgemeinen Theaterchronik. C. B.-Pf. war eine so imposante Figur, daß verschiedentlich Zeitgenossen mit Hinweis auf sie charakterisiert wurden (Laube wurde als „cine B.-Pf. mit Schnurr- und Knebelbart" bezeichnet).

Trotz der fast lebenslangen Verrisse ihrer Stücke durch die Kritik und persönlicher Angriffe anderer Theaterschriftsteller und -direktoren auf sie war sie selbst für ihre neidlose Anerkennung der Leistungen anderer Schriftsteller und Schauspieler bekannt. Sie unterstïtzte und protegierte jüngere Kollegen und ging so weit, ihre Tantiemen mit verarmten Kollegen zu teilen (Felix Dahn über C. B.-Pf.: „sic war eine kleine ,Schillerstiftung für sich allein!", zit. Hes 18). Die Versöhnlichkeit ihrer Stücke, die auch anderen auffiel (Hes 10), wurde darauf zurückgeführt, daß C. B.-Pf. direkt für die Aufführung schrieb und sich sowohl dem Publikumsgeschmack als auch der Zensur anpassen mußte: ernsthafte Konflikte hätten das Publikum abgestoßen und die Aufführung ihrer Stücke gefährdet. Viele ihrer Stücke wurden am Wiener Burgtheater aufgeführt, wo die Zensur am strengsten war. C. B.-Pf. in einem Brief an Emil Devrient: „Ich habe unter acht Stücken immer nur eines durch die Wiener Zensur gebracht" (zit. v. Weilen 1917, 12).

Wie in der zeitgenössischen Kritik wurde C. B.-Pf. auch von späteren Biographen und Herausgebern ihrer Werke als Trivialliteratin dargestellt, vermutlich aus denselben Gründen: wegen ihres großen Erfolges als Bühnenschriftstellerin und ihrer ungeheuren Produktivität. Der Autorin wohlgesonnene Biographen vertreten dieses Urteil mit dem Hinweis auf C. B.-Pf.s Selbsteinschätzung ihrer Stücke als „wieschte[s] Theatergeschreib" (zit. Hes 13)

Werke: Dramatische Werke siehe Anhang B. Burton Castle, Roman, 2 Bde, Berlin,

3. Aufl. 1854. Gesammelte Novellen und Erzählungen, 3 Bde., Leipzig, 1863-65.

Literatur: G. Chr. Hamberger und J. G. Meusel, Das gelehrte Teutschland oder Lexikon der jetzt lebenden teutschen Schriftsteller, 1796-1834, XXII, 1. K. Herloßssohn und H. Marggraff, Allgemeines Theater-Lexilkon, 1846, I. Almanach für das Königliche Hoftheater in Stuttgart, 1846, 90-103. H. Th. Rötscher, Dramaturgische Slsizzen und Kritiken, 1847, 78-83 und 92-96. Almanach fir Freunde der Schauspielkunst 12, 1848, 122 f. $K$. Th. v. Kïstner, Vierunddreißig Jahre meiner Theaterleitung, 1853, $138 \mathrm{f}$, 250-2, 275-278, 294, 309, 318 f. F. Chr. Paldamus, Das deutsche Theater der Gegenwart, 1856-7, I 271. Album des Königl. Schauspiels und der Königl. Oper zu Berlin unter der Leitung von $A$. W. Iffland, $K$. Grafen v. Brühl, W. Grafen v. Redern und K. Th. v. Kiustner, Für die Zeit von 1796 bis 1851, 1858. H. Th. Rötscher, Kritiken und dramaturgische Abhandlungen, 1859, 101-117. H. Laube, Das Burgtheater, 1868, 141, 144, 247, 249 f. Förster, „C. B.-Pf.", in: Allgemeine deutsche Biographie, 1875, II. F J. v. Reden-Esbeck, Deutsches Bühnen-Lexilkon, 1879. H. Groß, Deutschlands Dichterinen und Schriftstellerinen, 2. Aufl. 1882, 43. K. Goedeke, Grundriß zur Geschichte der deutschen Dichtung aus den Quellen, 2. Aufl. 1884-1966, XI/1. H. Groß, Deutsche Dichterinen und Schriftstellerinen in Wort und Bild, 1885, I 253-66. E. Kilian, Beiträge zur Geschichte des Karlsruher Hoftheaters, 1893, 32, 51, 54, 58, 61, 64, 67, 70, $73,76,79,82,85,88,93,95,98,102,106,119$. A. Eloesser, Das bürgetliche Drama, 1898, 200-206. S. Pataky, Lexikon deutscher Frauen der Feder, 1898, I. R. Lothar, Das Wiener Burgtheater, 1899, 59. A. v. Weilen und O. Teuber, Die Theater Wiens, 18991906, II C 40, 100, 128-132, 171-180. H. Laube, Theaterkritiken und dramaturgische Aufsätze, 1906, Einl. xxxIV und xLvI, 182, 375-384. P. Stein, Deutsche Schauspieler, Eine Bildnissammlung, 1908, II. E. Müller, Eine Glanzzeit des Zürcher Stadttheaters; C. B.-Pf. (Diss. Zürich), 1911. E. Hes, C. B.-P. als Dramatikerin, 1914. A. v. Weilen, C. B.-P. und H. Laube im Briefwechsel, 1917. A. v. Weilen, K. Gutzkow und C. B.-Pf., 1918. M. Martersteig, Das deutsche Theater im neunzehnten Jahrhundert, 2. Aufl. 1924, 444 f. H. Hettner, Das moderne Drama, 1924, 108. H. Doerry, Das Rollenfach im deutschen Theaterbetrieb des 19. Jahrhunderts, 1926, 25, 26, 78. P. Schlenther, Theater im 19. Jahrhundert, 1930, 39, 44, 134. R. Ziersch, C. B.-Pf. als Darstellerin (Diss. München), 1930. K. Richter, C. B.-Pf., in: Neue Deutsche Biographic, 1955. L. Hirschberg, Hg., Der Taschengoedeke, 1961, 48. G. v. Wilpert, Deutsches Dichterlexikon, 1963. E. Devrient, Eduard Devrient aus seinen Tagebüchern, 1964, 244-255, 
275-279, 340, 360. E. Devrient, Geschichte der deutschen Schauspiellzunst, 1967, II 119, 309, 342, 354-356. W. Kosch, Deutsches Literatur-Lexikon, 3. Aufl. 1968-1990. H. Denkler, Restauration und Revolution, 1973, 119-122, 205-207, 337. E. Friedrichs, Die deutschsprachigen Schriftstellerinnen des 18. und 19. Jahrhunderts, 1981. D. Kafitz, Grundzüge einer Geschichte des deutschen Dramas von Lessing bis zum Naturalismus, 1982, II 276-80. R. Cowen, Das deutsche Drama im 19. Jahrhundert, 1988, 3, 37, 47-51, 95, 99, 123, 167, 180, 182 f. V. Richel, The German Stage, 1767-1890, A Directory of Playwrights and Plays, 1988, 16-18. R. van Stiprian, „C. B.-Pf.“, in: E. Frederiksen, $H_{g}$, Women Writers of Germany, Austria, and Switzerland, 1989, $31 \mathrm{f}$. K. v. Holtei, Vierzig Jahre Lorbeerkranz und Wanderstab, o. J., 334-6, 454 f. H. Laube, Heinrich Laubes ausgewählte Werke, o. J., VIII 30, 117 f, 190; IX 259, 349.

Braun, Isabella. Geb, am 12. 12. 1815 in Jettingen bei Mindelheim (Bayern). Vater ? B., Rentenverwalter des Grafen Schenk von Stauffenberg, Mutter ?. Ein Bruder, eine jüngere Schwester. 1827 Tod des Vaters und Umzug I. B.s mit ihrer Mutter nach Augsburg. Dort besuchte I. B. das Institut der Englischen Fräulein. Ihre Mutter trat nach dem Tod des Sohnes mit ihrer jüngeren Tochter in eine Herrenhutergemeinde ein I. B. trennte sich von ihr und lebte in der Folge bei einem Onkel. 1837 wurde sie Lehrerin an der Volksschule in Neuburg an der Donau. Als das Institut 1848 an eine klösterliche Leitung übergeben wurde, mußte I. B. die Schule verlassen.

Ein Jahr später schrieb sie Bilder aus der Natur, das unter der Proteltion von Christoph von Schmid im selben Jahr veröffentlicht wurde. Von da ab konzentrierte I. B. sich auf ihre Karriere als Jugendschriftstellerin. 1851 veröffentlichte sie Bilder aus der deutschen Geschichte und Kleine Geschichten, den Kindern erzählt, ein Jahr später Helden des Christentums, 1853 Aus dem Kinderleben und der Sommerzeit und Für die lieben Kinder. 1854 Umzug nach München; im selben Jahr veröffentlichte sie sechs weitere Kinderbücher. In München führte sie einen Salon, in dem sich viele Dichter, Künstle und Gelehrte aus adligen und bürgerlichen Kreisen trafen, u. a. Katharina Diez und die Prinzessinnen Alexandra und Therese von Bayern. Seit 1855 war I. B. die Herausgeberin der Jugendblätter fiir christliche Unterhaitung und Belehrung. Freundschaft mi der Familie von Knebel-Döberitz und dem Maler Kaspar Scheuren; häufige Reisen u. a. nach Düsseldorf und Oldenburg.

I. B. hatte als Jugendschriftstellerin einen ausgezeichneten Ruf und wurde verschiedentlich geehrt und protegiert, u. a. von dem Prinzen Ludwig von Bavern, dem Herzog Maximilian von Bayern, der ihr die große goldene Medaille für schriftstellerische Verdienste verlich, und von König Ludwig II. Ludwig II. verlieh ihr die Ludwigsmedaille für Kunst und Wissenschaft und eine Schriftstellerpension. Durch den Erfolg ihrer Bücher machte I. B. Kinder- und Jugendliteratur zu einem anerkannten literarischen Genre. In den letzten Jahren schwere Krankheiten. I. B, starb am 2. 5. 1886 in München.

Werke: Dramatische Werke siehe Anhang B. Bilder aus der Natur, 1849. Bilder aus der deutschen Geschichte, 1851. Kleine Geschichten, den Kindern erzählt, 1851. Helden des Christentums, 1852. Aus dem Kinderleben und der Sommerzcit, 1853. Für die lieben Kinder, 1853. Die Kinderstube im Elternhause, 1854. Ein Liedergruß für gute Kinder, 1854. Erwins Bilderbuch, 1854. Frühlings-Bilder für gute Kinder, 1854. Mutterliebe und Muttertreue, 1854. Das liebe Brot, 1854. Das Vater Unser in Erzählungen für Jung und $A l t, 1854$. Geschichten für liebe Kinder, 1855. Im Kinderkreise, Erzählungen und Gedichte, 1855. Im grünen Walde, Bilder aus der Natur, 1856. Lebensbilder, 1856. Ein lustiges Kinderbüchlein, 1857. Dorfgeschichten für kleine Knaben und Mädchen, 1857. Freuden und Leiden aus dem Kinderleben, 1857. Wahre Geschichten, 1857. Des Großvaters Erzählungen, 1858. Gesammelte Erzählungen für die Jugend, 2 Bde., 1858/9 (1861 unter dem Titel: Aus der Jugendzeit, II Scherz und Ernst). Die zwölf Monate des Jahres, 1859. Der Christbaum, 1860. Durch Leid zu Freud, 1860. Heinrich Findelkind, oder: Die Gründung des Hospizes auf dem Arlberg, 1860. Festbüchlein, 1861. Namenbüchlein, 2 Bde., 1861-3. Der Kinder Zeitvertreib, 1862. Die Uhr, 1862. Frühlingsspiele, 1862. Kinderbeschäftigungen, 1862. Der Jahrmarkt, 1862. Kinderleben, 1862. Das Elternhaus, 1863. Die guten Kinder, 1863. Ein Jahr aus dem Kinderleben, 1863. Die alten Bekannten, 1863. Allerlei, 1864. Mancherlei, 1868. Das Kreuz, 1869. Unsere Kleinen, 1870. Aus meiner Jugendzeit, 1871. Großvaters Erzählungen, 2. Aufl, 1874. Der Mädchen liebstes Buch, Erzählungen, 1877. Gesammelte Erzählungen, 12 Bde. (enthält: I: Aus Dorf und Stadt [3 Errz.]; II: Guten Abend [4 Erz.]; III: Mancherlei [4 Erz.]; IV: Reich und Arm [4 Erz.]; V: Heimatlos [3 Erz.]; VI: Aus alter und neuer Zeit [3 Erz.]; VII: Dorfgeschichten; VIII: Jung Erlebtes [5 Erz.]; IX: Vier Wochen lang, Aus der fröhlichen, seligen Weihnachtszeit; X und XI: Aus meiner Jugendzeit [2 Abteilungen à 8 Erz.]; XII: Regenbogen), 1879-91. Charles Dickens, genannt Boz, ein Lebensbild, 1880. Das Geheimnis des Schreibtisches, 1880. Lieb und Treu, Novellen, 1884. Freudenbüchlein, 1887. Gesammeltc Erzählungen, 1891. Glückwünschbüchlein, 3. Aufl., 1891. Für stille Stunden, Gedenkbuch, 1893.

Literatur: H. Groß, Deutschlands Dichterinen und Schriftstellerinen, 2. Aufl. 1882 118 f. H. Groß, Deutsche Dichterinen und Schriftstellerinen in Wort und Bild, 1885 II 78-91. L. Morgenstern, I. B., 1889. S. Pataky, Lexikon deutscher Frauen der Feder, 1898, I. H. Holland, „I. B.", in Allgemeine deutsche Biographie, 1903, XIVII. F. Brimmer, Lexikon der deutschen Dichter und Prosaisten vom Beginn des 19. Jahrhunderts bis zur Gegenwart, 6. Aufl. 1913, I. M. S. Filchner, I. B. und die Jugendblätter, 1915. H. Holland, "I. B.", in: H. Holland, Lebenserinnerungen eines ncunzigjährigen Altmüncheners, 1921. W. Kosch, Deutsches Literatur-Lexikon, 3. Aufl. 1968-90. E. Friedrichs, Die deutschsprachigen Schriftstellerinnen des 18. und 19. Jahrhunderts, 1981.

Breden, Christi(a)ne von (in Lexilka auch: Christen, Ada). Geb. 6. 3. 1839 in Wien (Friderik). Vater der Kaufmann ? Friderik, Mutter ?. Der Vater war an der 1848er Revolution beteiligt und wurde „schwer verurteilt" (Brümmer); die Familie verlor ihr Vermögen. Mit 15 Jahren ging C. v. B. zum Theater und war Mitglied an verschiedenen Wanderbühnen in Ungarn.

1864 heiratete sie den ungarischen Stuhlrichter und Großgrundbesitzer Siegmund von Neupauer, der im 2. Jahr ihrer Ehe wahnsinnig wurde und starb. In dieser Zeit - 
zwischen 1864 und 1866 - entstanden ihre ersten Gedichte. Ihr erster Gedichtband, zwischen 1864 und 1866 Lieder einer Verlorenen, wurde mit der Unterstützung von Filiärschriftsteller Adalveröffentlicht. 1873 heiratete sie den Ritcmeister a. D. und Miliărschrifteller Adalmar v. B. (?-1903), der ihre schriftstellerische Tätigkeit unterstutzte. Ab ca. 1870 schrieb C. v. B. Gedichte, Novellen, Erzählungen, vier Dramen und zwei Romane und veröffentlichte regelmäßig unter dem Pseudonym „Ada Christen“. Sie führte einen Saverfor on, in dem einge gere Krankheit um di Jah . starb am 19.5.1901 in Wien.

und Berchtesgaden. C. v. B. starb am 19. 5. 1901 in Wien. Trotz einer Reihe von Veröffentlichungen ist die Autorin so obskur geblicben, daß die meisten Biographen sich weder auf ihren Namen noch auf thre Lebenscran können. In Lexika erscheint sie unter folgenden Angaben: Christi(a)ne von Breden 6. 3. 1839 - 19.5. 1901 (Friedrichs), Christine von Breden, 6.3.1844 - 19. 5. 1901

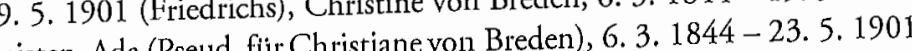
(Brim Kosch, Garland/Garland), und Chrsther Werke: Dramatische Werke siehe Anhang B. Lieder einer Velore 1868. Aus der Asche, Neue Gedichte, 1870. Schatten, Gedichte, 1873. Ela, Roman, 1873. Vom Wege, Skizzen, 1874. Aus dem Leben, Skizzen (enthält: Käthes Federhut: Wie Gretel lügen lernte; Rahel; Im Armenhaus; Irrlichter; Zu spät); 1876. Aus der Tiefe, Neue Gedichte, 1878. Unsere Nachbarn, Neue Skizzen, 1884. Jungfe 年, Ausgewählte Werke, hg. W. A. Ham mer, 1911.

Groß Deutschlands Dichterinen und Schriftstellerinen, 2. Aufl. 1882, Literatur: H. Groß, Deutschlands Dichterinen und Scerterinen in Wort und Bild, 1885 $136 \mathrm{f}$. $H$. Großs, Deutsche Dichterinen und Schriftstellerinen in Wort III 168-79. S. Pataky, Lexikon deutscher Frauen der Feder, 18 . Jahrhunderts bis zur kon der deutschen Dichter und Prosaisten vom Beginn des 19. Jah. Gegenwart, 6. Aufl. 1913, I. W. Kosch, Deutsches Litexatur-Lexikon, 3. A G. Brinker-Gabler, „Ada Christen“, in: G. Brinker-Gabler, Hg., Deutsche Dichterinnen G. Brinker-Gabler, "Ada Che vom 16. Jahrhundert bis zur Gegenwart, 1978, 219-22. E. Friedichs, Die deuts chigen Schriftstellerinnen des 18. und 19. Jahthunderts, 1981, $H$. $M$ Schumd, The Oxford Companion to German Literature, 2. Aufl. 1986, 138. P. K. Schwarz, „Ada Christen", in: E. Frederiksen, Hg., Women Writers of Germany, Austria, and Switzerland, $1989,46 \mathrm{f}$

Cornelius, Auguste. Geb. am 17.7. 1826 in Darmstadt. Vater der Schauspieler Kar C., Mutter die Schauspielerin Fricderike C. geb. Schirmer. Ein Bruder (der Komponis Peter C 1824-1874). Wegen des unsteten Familienlebens (ihr Vater verbrachte aus (ber 列 eine lïckenhafte Ausbildung, später war sie boll ins ünglich Opernsängerin wervervollständigen. 1843 Tod des Vaters. A. C. wollte ursprünglich Opernalngerin werden und erhielt durch Meyerbeers Vermittlung ein Stipendium für eine Gesangsausbildung vom König von Preußen. Nach einer Krankheit blieb ihre Stimme geschädigt, und sie mußte ihre Pläne aufgeben.
1865 veröffentlichte sie ihre ersten Dramen (König und Dichter und Platen in Venedig), denen bis 1891 noch sechs Dramen, ein Gedichtband und viele Jugendschriften folgten. Einige ihrer Schriften veröffendichte sie unter dem Pseudonym "Paul Dido". Interessant an ihrem Werk ist die ausschließliche Spezialisierung auf ein Genre: bis 1877 schrieb sie Dramen, gefolgt - nach einer siebenjährigen Pause - von einem Gedichtband (Lose Blätter, 1884); von 1885 bis zu ihrem Lebensende schrieb A. C. Kinder- und Jugendbücher. 1874 Tod des Bruders. Ab 1878 lebte sie als freie Schrifistellerin in Berlin/Charlottenburg. Dort starb A. C. am 30. 11. 1891.

Werke: Dramatische Werke siche Anhang B. Lose Blätter, Gedichte, 1884. Das Kind, wie es weint und lacht, 1885. Glückliche Kinderzcit, 1886. Das Riesenkind, Märchen, 1887. Der Kobold, Märchen, 1887. Goldmäuschen, Märchen, 1887. Der Struwwelpeter oder Lustige Geschichten für Kinder, 1887. Der neue Struwwelpeter, 1887. Kleine Erzählungen für Knaben und Mädchen, 1888. Peter Stehauf und andere lustige Geschichten, 1889/90. Wo ist der Kuchen? und andere drollige Geschichten für Kinder, 1895. Lustige Geschichten für Kinder, 1902. Der kleine Fischer und Anderes, Lehrreiche Geschichten für Knaben, 1911. Schnatterkäthchen und anderes, Lehrreiche Geschichten für Mädchen, 1911.

Literatur: H. Groß, Deutschlands Dichterinen und Schriftstellerinen, 2. Aufl. 1882, 141. S. Pataky, Lexikon deutscher Frauen der Feder, 1898, I. F. Brimmer, Lexikon der deutschen Dichter und Prosaisten vom Beginn des 19. Jahrhunderts bis zur Gegenwart, 6. Aufl. 1913, I. W Kosch, Deutsches Literatur-Lexikon, 3. Aufl. 1968-90. E. Friedrichs, Dic deutschsprachigen Schriftstellerinnen des 18. und 19. Jahrhunderts, 1981

Delle Grazie, Marie Eugenie. Geb. 14. 8. 1864 in Weißkirchen in Ungarn. Vater der venezianische Bergbaudirektor Caesar d. G., Mutter ? (Deutsche). Mindestens ein Bruder oder eine Schwester. M. E. d. G. verbrachte ihre Kindheit in Bersaska, einem Gebirgsdorf in Ungarn, wo ihr Vater Bergwerksdirektor war. 1872 Tod des Vaters. 1874 zog ihre Mutter mit ihren Kindern nach Wien um. Dort besuchte M. E. d. G. die Bürgerschule, später die Lehrerinnenbildungsanstalt zu St. Anna. Wegen Krankheit konnte sie den Lehrerimnenberuf nicht ausüben. 1882 veröffentlichte sie ihren ersten Gedichtband und erhielt ein Jahr später ein Literaturstipendium vom Kuratorium der Schwestern-Fröhlich-Stiftung; lebte seitdem als freie Schriftstellerin in Wien. 1886/7 Reise nach Italien. Zwischen 1882 und 1906 schrieb sie vorwiegend Gedichte und Dramen (und einige wenige Erzählungen); danach folgte die Wende zur Prosa: bis 1930 folgten viele Romane, Erzählungen und Novellen. Am belsanntesten war sie für ihre Italienischen Vignetten, ein Gedichtband (1897), ihr Robespierre-Epos (1894) und ihr naturalistisches Bergarbeiterdrama Scblagende Wetter (1899). Ihr Drama Der Schatten wurde $1901 \mathrm{im}$ Wiener Burgtheater aufgeführt. Nach der Teilnahme am Eucharistischen Kongreß in Wien bekehrte sie sich 1912 zum Katholizismus. M. E. d. G. starb am 18. 2. 1931 in Wien.

M. E. d. G. war eine anerkannte, häufig und enthusiastisch rezensierte und mehrfach ausgezeichnete Schriftstellerin (1901 Bauernfeldpreis für ihr Drama Der Schatten, 
1916 Ebner-Eschenbachpreis für ihren Roman Das Buch der Liebe). Ungewöhnlich an 1916 Ebner-Eschenbachpreis fur ihren Rroste-Hülshoff M. E. d. G. ist, daßs sic, wier-Eschenbach) sich zu Beginn ihrer literarischen Karriere auf Dramen (und Lyrik) konzentrierte, sich später aber ausschließlich Prosagenren zuwandte - ihr letztes Drik) kor Drama stammt aus dem radikale Weise politische Themen und griff soziale MißBerst unkonventionelle und radikale Weise politische Themen und griff soziale Mirstände an, wie die Ausbeutung der Bergarbeiter in Schlagende Wetter. Häufige Themen ihrer Dramen sind persönliche Unabhängigkeit versus soziale, politische, oder religiöse Unterdrückung.

Thr politisch brisantes Drama Moralische Walpurgisnacht, ein Satyrspiel vor der Tragödie (1896) und ihr blasphemisches Drama Saul (1885) wurden meines Wissens seltedie (185) und hr beichter in die gegen Jahrhundertende sehr gesuchte ner rezensiert als Texte, die sich leicher in die gegen Jahr Hermann "deutschnationale" Literatur einordnen ließen. Beim Erscheinen ihres Epos Hermann das den Sieg Hermanns des Cheruskers über die Römer beschreibt, regnete es begeidas den Sieg Hermen sterte Kritiken, von denen ca. die Halfie anzunëfentlichte sic unter Abkürrzung ihre männlicher Verfasser (viele ihrer Schriften veroffentichte sic unter Abuinzung ithrer Vornamen). Fast alle dieser Rezensionen - die interessanterweise im Anhang zu der Ausgabe ihres Stückes Saul abgedruckt sind - beeilen sich, festzustellen, M. E. d. G. sei Ausgabe ihres Stückes Saul abgedruckt sind-beilen sich, festante dieser „jugendfrische - trotz ihres Namens - eine Original-Deutsche. Nur so konnte dicser "jugendfische Dichter mit dem trotz welschen Namens gut deutschen Herzen" (Staatsanzeiger fur Württemberg, 22. 7. 1883) dem ideologischen Feldzug gegen „die Welschen" (damals Rom heute Frankreich und Italien) einverleibt werden; und ihr Hermann-Epos wurde Rom, Mannheit und römische in diesem Sinne rezensiert. "Vortrefflich sind deutsche Mannte und Schlaftheit, deutsche Geradheit und römische Hinterlist, deutsche Tapferk römische Feigheit, deutsche Liebe und römische Wollust, deutsches Gemüth und südlicher Affect, deutscher Idealismus [...] und nackter südlicher Realismus, der im lich Afrect deynich Sch 12 1883). Nach 19. 12. 1883). Nach Menung eines anderen Rezensenten sagt hier die Vetfasserin, selbst halbe Italienerin, die deutsche Invasion in Italien voraus (A. Jung in Gotsschalls Blatter für literarische Unterhaltung, 30. 8. 1883: „Sie ahnt, daß d"

dem entzückenden Italien ihr eigentliches Heim finden werden").

Gegenüber dem Chor der Begeisterung für M. E, d. G.s Hermann-Epos, diesem Gerenter fromme, hochgestimmte Germania" (Staatsanzeiger für Würt„Lobgesang auf die freie, fromme, hochgestimm temberg, 22. 6. 1883), findet sich für ihr radikales Drama Saul meines Wrussens geleeine einzige positive Stimme: die Heinrich Laubes, der das Stuck als Maite des Stückes

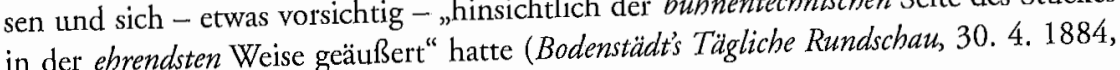
Hervorhebungen d. Verf.).

M. F Säliche Werke, trotz Titel nur eine Auswahl ihres Gesamtwerks, erM. E. d. G.s Sämtliche Werke, trotz Titel nur eine Auswahl indes Gesafgelegt.

schienen 1903-4 in neun Bänden und wurden danach nicht wieder aufgelegt.

Werke: Dramatische Werke siehe Anhang B. Gedichte, 1882. Hermann, deutsches Helden-Gedicht in 12 Gesängen, 1883. Gedichte lung aus dem ungarischen Haidelande, 1885. Italienische Vignetten, 1892. Der Rebell,
Erzählung, 1893. Bozi, Erzählung, 1893. Robespierre, ein modernes Epos, 1894. Liebe, Erzählungen, 1902. Vom Wege, Geschichten und Märchen, 2 Sammlungen, 1907. Traumwelt, Erzählungen, 1907. Heilige und Menschen, Roman, 1909. Vor dem Sturm, Roman, 1910. Gottesgericht und andere Erzählungen, 1912. Wunder der Seele, Erzählung, 1913. Zwei Witwen, Novelle, 1914. Das Buch des Lebens, Erzählungen und Humoresken, 1914. Die blonde Frau Fina und andere Erzählungen, 1915. Das Buch der Liebe, Roman, 1916. O Jugend!, Roman, 1917. Donaukind, Roman, 1918. Eines Lebens Sterne, Roman, 1919. Die Seele und der Schmetterling, Novelle, 1919. Der frühe Lenz, Erzählung, 1919. Homo..., Der Roman einer Zeit, 1919. Dic Blumen der Acazia, Erzählung, 1920. Der Liebe und des Ruhmes Kränze, Roman auf die Viola d'amour, 2 Bde., 1920. Die weißen Schmetterlinge von Clairvaux, Novelle, 1925. Matelda, Novelle, 1926. Unsichtbare Straße, Roman, 1927. Titanic, cine Ozean-Phantasie, 1928. Sommerheide, Novelle, 1928. Das Buch der Heimat, Erzählung, 1930. Die Empörung der Seele, Roman, 1930.

Literatur: Kein Verfassername, „Rezension über M. E. d. G.s Hermann“, Hamburger Nachrichten Nr. 126, 30. 5. 1883, in: M. E. d. G., Saul, Anhang, unpag. Kein Verfassername, „Rezension über M. E. d. G.s Hermann", in: Sacher-Masoch, Auf der Höhe, Juli 1883, in: M. E. d. G., Saul, Anhang, unpag. E. Grûn , "Rezension über M. E. d. G.s Hermann", Deutsche Kunst- und Musikzeitung Nr. 25, 12. 7. 1883, in: M. E. d. G., Saul, Anhang, unpag. Kein Verfassername, „Rezension über M. E. d. G.s Hermann“, Staatsanzeiger für Württemberg Nr. 167, 22. 7. 1883, in: M. E. d. G., Saul, Anhang, unpag. A. Jung, „Rezension über M. E. d. G.s Hermann“, Gottschall's Blätter für literarische Unterhaltung N. 35, 30. 8. 1883, in: M. E. d. G., Saul, Anhang, unpag. Kein Verfassername, „Rezension über M. E. d. G.s Hermann“, Neue Illustirte Zeitung (Wien) Nr. 1, 1. 10. 1883, in: M. E. d. G., Saul, Anhang, unpag. Kein Verfassername, „Rezension über M. E. d. G.s Hermann“, Die Heimat, Illustrirtes Familienblatt Nr. 1, 1. 10. 1883, in: M. E. d. G., Saul, Anhang, unpag. Kein Verfassername, „Rezension über M. E. d. G.s Hermann", Deutsche Zeitung Nr. 4270, 21, 11. 1883, in: M. E. d. G., Saul, Anhang, unpag. F Wrubel,, "Rezension über M. E. d. G.s Hermann", Literarischer Merkur Nr. 5, 1. 12. 1883, in: M. E. d. G., Saul, Anhang, unpag. Kein Verfassername, „Rezension über M. E. d. G.s Hermann“, Tagesbote aus Mähren und Schlesien Nr. 290, 19. 12. 1883, in: M. E. d. G., Saul, Anhang, unpag. Kein Verfassername, „Rezension über M.E.d. G.s Hermann", Vossische Zeitung Nr. 1, 1.1.1884, in: M.E.d. G., Saul, Anhang, unpag. Kein Verfassername, "Rezension über M. E. d. G.s Hermann", Bodenstedt's Tägliche Rundschau Nr. 101, 30. 4. 1884, in: M. E. d. G., Saul, Anhang, unpag. A. Bölte, „Rezension über M. E. d. G.s Hermann“, Wiesbadener Zeitung Nr. 136, 13. 6. 1884, in: M. E. d. G., Saul, Anhang, unpag. A. v. B. G. (Pseud. für ?), „Rezension über M. E. d. G.s Hermann“, Brehmer's Von Pol zu Pol, internationale Revue, Neue Folge 1, 1884, in: M. E. d. G., Saul, Anhang, unpag. H. Groß, Deutsche Dichterinen und Schriftstellerinen in Wort und Bild, 1885, III 495-99. E. Brausewetter, „M. E. d. G.“, in: E. Brausewetter, Meisternovellen deutscher Frauen, 1897, I 163-72. B. Minz, M. E. d. G. als Dichterin und Denkerin, 1902. H. Widmann, M. E. d. G., 1903. F. Milleker, M. E. d. G, Ihr Leben und ihre Werke, 1921. A. Wengraf, M. E. d. G., 
1932. M. Zenner, M. E. d. G., Diss. (Wien), 1932. G. Brinker-Gabler, „M. E. d. G.“, in: G. Brinker-Gabler, Ho. Deutsche Dichterinnen vom 16. Jahrhundert bis zur Gcin: G. Brinker-Gabler, Hg., Deutsche Dicherinne vo (1864-1931), eine österreichische genwart, 1978, 233-6. M. Flaschberger, M. E. d. G. (1864-1931) (Graz), 1979. E. Friedrichs, Die deutschsprachigen Schriftstellerinnen des 18. und (Graz), 1979. E. Friedrichs, Die detscher M. E. d. G.", in G. Brinker-Gabler, K. Ludwig, A. Wöffen, Hg., Lexikon deutschsprachiger Schriftstellerinnen 1800-1945, 1986.

Droste-Hülshoff, Annette (eigentl. Anna Elisabeth) von. Geb. 10. 1. 1797 auf Schloß Hülshoff bei Münster (Westphalen). Vater Clemens August Freiherr v. D.-H., Mutter Therese geb, von Haxthausen. Drei Geschwister (Jenny, eigentl. Marianne, geb. 1795, Werner Konstantin, geb. 1798, Ferdinand Wilhelm, geb. 1800). Die Mutter war eine "tüchtige Hausregentin“ (Busse 12) und eine Autorität auf dem Gebiet adliger Etikette; Busse berichtet, daß sämtliche Edelfräulein der Nachbarschaft zu ihr ins Haus gete; Busse berich

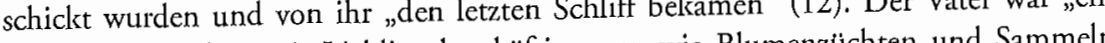
eher träumerischer, mit Lieblingsbeschäftigungen wie Blumenzüchten und Sammeln merkwürdiger alter Geschichten beschäftigter Mann" (Brinker-Gabler, Lexikon). A. v mour D.-H. erhicht dic fur adlige Madchen ubliche Buichen und Französisch konzentrierte auf Latein, Griechisch, Musik, Mathematik, Zeichnen und Französisch konzentrierte und ausführlicher gewesen zu sein scheint als im Falle ihrer Schwester; später lernte sie (im Selbstunterricht?) Niederländisch, Italienisch und Englisch.

A. v. D.-H. fing früh an, Gedichte zu schreiben und zu komponieren - beides zum Zeitvertreib, nicht zur Veröffentlichung. Ihr erstes Gedicht, das "Lied vom Hähnchen" (ca. 1804/5), versteckte sie auf dem Dachboden. 1813 Kontakt zum Bökendorfe Kreis durch die Brüder ihrer Mutter, die mit den Brüdern Grimm befreundet waren. Kreis durch die Brüder ihrer Mutter, Wilhelm Grimm kennen und sammelte auf seine Bitte Dut Kinder- und Hausmärchen. Außer zu diesem mrojekt lieferte sie auch Beiträge zu August v. Haxthausens Volksliedersammlung und zu Ludwig Uhlands Alten hoch- und niederdeutschen Volksliedern und berichtet, sie habe allen alten Weibern des Kirchspiels dic Cour gemacht" (zit. Busse 22)

Um dieselbe Zeit erfuhr sie erste Unterstïtzung ihrer literarischen Arbeit durch den Hainbunddichter und Professor Anton Matthias Sprickmann, der ihr Bücher zur LekHainbunddichter und Professor Anton Matthias Sprickmann, der ihn lernte sie 1813 die türe emptahl und thren Stil in Gedichten being - kennen. Nach seinem Umzug nach Dichterin Kartha, oder die Alpen. Breslau 1814 Briefwechsel mit Sprickma 1814 ihe Drama Berba A. v. D.-H. wurde in diesem Jahr schwer krank und litt vor allem unter der ihr aufgezwungenen gesellschaftlichen Einengung, die auch ihre literarische Tätigkeit betraf; gezwungen schreiben durfe sic, nach wie vor, nur zum Zeitverteib, eine etion ihrer Werke kam für das adlige Fräulein nicht in Frage. Gegen diese Situation lehnt sie sich häufig in ihren Werken auf, u. a. in Bertha und dem Gedicht „Unruhe“: „Fesseln will man uns eignen Ferde,/ Unsre Sehnsucht nennt man Wahn und Traum!" Um 1820 persönliche Krise; Arbeit an dem unvollendeten Roman Ledwina.
Die Eintönigkeit auf Hülshoff wurde durch Reisen nach Köln und Bonn (1825, 1828, 1830/1) unterbrochen. Dort lernte sie August Wilhelm v. Schlegel und Kar Simrock kennen; Freundschaft mit Sibylle Mertens-Schaffhausen und Adele Schopenhauer. 1826 Tod des Vaters und Umzug mit Mutter und Schwester Jenny nach Rüschhaus, dem Witwensitz der Mutter. Dort lebte A. v. D.-H. teils mit ihnen, oft allein, wenn Mutter und Schwester verreist waren. 1829 Tod des Bruders Ferdinand. 1829-34 Arbeit an „Das Hospiz auf dem Großen Sankt Bernard“. 1830 erste Bekanntschaft mit Levin Schücking, den seine Mutter auf das Gymnasium in Münster schickte und ihm einen Empfehlungsbrief an A. v. D.-H. mitgab. Als Katharina Schücking 1831 starb, empfand A. v. D.-H. deren Bitte, ihren Sohn zu unterstützen, als Vermächtnis. 1835-7 Aufenthalt bei Jenny, die inzwischen geheiratet hatte, in der Schweiz; Brieflxontakt mit dem blinden Philosophieprofessor Christoph Bernhard Schlüter, der ihr - wie zuvor Sprickmann - Lesematerial schickte und sie u. a. dazu drängte, Das Geistliche Jahr zu vollenden.

1837 bestand sie zum ersten Mal auf einer Veröffentlichung ihrer Gedichte und nahm Kontakt zu einem Verlag auf; die Ausgabe kam wegen eines Zerwürfnisses zwischen Verleger und Herausgeber nicht zustande. Im selben Jahr Arbeit an „Die Schlacht im Loener Bruch“. Durch Schlüters Vermittlung wurde der Gedichtband 1838 veröffentlicht - anonym und trotz des Widerstandes ihrer Familie -; die Ausgabe fand trotz lobender Rezensionen u. a. von Gutzkow, Jakob Grimm, Freiligrath und Schücking nur geringen Absatz (Hüffer 154). Außer den abwertenden Bemerkungen ihrer Familie und Bekannten über den Band erfuhr dic Autorin bei dieser Gelegenheit in einer Buchhandlung in Münster, Gedichte würden sowieso nur wegen des hübschen Einbandes gekauft. Diese Episode, die ihr Stoff für die Schlußszene in ihrem Drama Perdu! (1840) lieferte, erzählt sic in ihrem Tagebuch (70 f),

Freundschaft mit Elise Rüdiger, geb. v. Hohenhausen, und Levin Schücking, der nach dem Studium 1838 nach Münster zurückkehrte. In einem literarischen Zirkel traf sie ihn wieder und versuchte zunächst, ihm durch Vermittlung eine Stelle zu verschaffen. Ihre enge Freundschaft mit - und Liebe zu - Schücking hatte wahrscheinlich einen besonderen Grund: Schücking war der erste, der sie auf literarischem Gebiet ernst nahm. Von ihrer Familie, die sie in ihrem Tagebuch als ihre „Plagegeister" bezeichnet (zit. Busse 110), wurde sie, verstärkt nach dem Erscheinen ihres erfolglosen Gedichtbandes, mit guten Ratschlägen und abwertender Kritik verfolgt. Ständiger Kontakt mit Schücking und literarische Produktivität. 1841 Reise zur Meersburg, die ihr Schwager v. Laßberg gekauft hatte; auch dort Kontakt mit Schücking, der die Bibliothel ihres Schwagers ordnete.

Der Großteil ihres Werkes stammt aus diesen Jahren, u. a. der Zyklus "Heidebilder" und Die Judenbuche, 1839 vollendet sie Das Geistliche Jahr. Auch ihre einzigen nichtposthumen Veröffentlichungen, ihr literarischer Erfolg zu Lebzeiten, fällt in diese Jahre: 1842 wurde Die Judenbuche (der Titel stammt nicht von ihr) veröffentlicht, 1844 der zweite Gedichtband, beide durch Schückings Vermittlung. Von dem Erlös für den Gedichtband konnte A. v. D.-H. sich immerhin ein Anwesen kaufen, ihr „Fürstenhäusle“ in der Nähe von Meersburg. Nach der Trennung von Schücking 1842 führte 
sie mit ihm einen Briefwechsel, der, da A. v. D.-H. immer noch unter der Aufsicht ihrer Mutter stand, etwas angestrengt das "Sie“ wahrte. Bruch der Beziehung nach Scer Schückings Verheiratung 1843 und seiner Hinwendung zum Jungen Deutsch. Dort starb A. v. D.-H. am 24. 5. 1848.

Als unverheiratete Adlige stand A. v. D.-H. zeitlebens unter der Aufsicht der GroßAls unverheiratete Adlige stand A. verau, die schon von Zeitgenossen als „Deutschlands größte Dichterin" gefeiert wurde, fand erst zehn Jahre vor ihrem Tod statt, und auch diese nur gegen die ausdrückliche Opposition der Mutter, die erst später - nach auch diese dem Erscheinen der Judenbuche - nachließ. „Mama söhnt sich mit meinem Dichterberuf aus, seit ich erfolgreich bin" (Tagebuch, 24. 6. 1842, 203). Jedes Wort, das sie schrieb, wurde von literarischen Mentoren gedreht und gewendet und von ihrer Familie bekrittelt.

Schücking, dem man schon für seine posthume Ausgabe ihrer Werke dankbar sein muß, regte sie zwar durch Anerkennung ihrer Leistungen zu weiterer Arbeit an, „Aber doch - selbst gegen ihn muß ich mich oft wehren" (Tagebuch, 16. 5. 1841, 87). In einem Brief an Schücking vermutete sie, daß seine Zuneigung von ihren literarischen Errungenschaften abhing, „denn Du bist cin hochmüthiges Thier und hast Einen doch Eur licb, wenn man was Tüchtiges ist und leistet" (Brief an L. Schücking vom 4. 5. nur lieb, we 1842, zit. Zobeltitz 333). Oft mußte sie sich seinen Vorstellungen anpassen, manchmal auf Befehl dichten. Eine in ihrem Tagebuch aufgezeichnete Konversation zwischen ihr und Schücking: „Dichten Sie mir etwas vor, Mütterchen. - ,Pascha! Ich bin doch inr

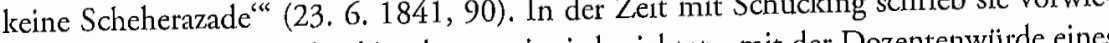
gend Gedichte, denn Schücking hatte, wie sie berichtet, „mit der Dozentenwürde eines gend Gedichte für Literatur" beschlossen, das Lyrische sei ihr „eigentliches Feld“ (Tagebuch, 5. 1. 1841, 152).

Die vier Leben, von denen sie in ihrem Tagebuch schreibt - das Leben als adliges Fräulein, ihr Berufsleben als Schriftstellerin, ihr Leben mit Schücking, und "mein ge heimes Leben mit Gott" (15. 8. 1842, $211 \mathrm{f})$ - empfand sie selbst als unvereinbar. Die Gründe beschreibt sie in ihrem frühen Drama Bertha offen, in unzähligen Gedichten versteckt (vgl. z. B. „Der lkranke Aar", „Am Turme“): die Schriftstellerin blieb für ihre nächste Umgebung, Schücking vielleicht ausgenommen, lediglich ein adliges katholis lisches Fräulein, das nebenbel schiteb. Den Regeln, die ciner Fran ima einer Adligen im Besonderen das Schreiben untersagten, tat A. v. D. H. Gentge, in dem sic sich in die Schriftstellerin und das adlige Fräulein zerteilte. Nicht ohne lakoding hoh Dichterthron herabgestiegen, habe meine blauen Strümpfe ausgezogen und habe für Luise ein paar Pantoffeln gestickt" (Tagebuch, 31. 12. 1843, 241). Und nicht ohne das klare Bewußtsein, daß das lebenslange Dilemma zwischen blauen Strümpfen und Pantoffeln für einen daß das lebenslange Dich existiert hätte. Ein wiederkehrender Wunsch in ihrem Tagemännlichen Dichter nicht existiert hätte. Ein wiederkehrender Wän

buch: „Ach, wäre ich ein Mann! (Tagebuch, Marz 1842, 185)

Werke: Dramatische Werke sicho sammlung und zu Ludwig Ublands Alten hoch- und niederdeutschen Volksliedern, 1813. Walter, Episches Gedicht, 1818. Ledwina, Romanfragment, 1820. Das Hospiz auf dèm Großen Sankt Bernard, Episches Gedicht, 1829-34. Des Arztes Tod, Episches Gedicht, o. J. Des Arztes Vermächtnis, Episches Gedicht, 1834. Musik zu zwei Opern, Babilon; Die seidenen Schuhe, vor 1837. Musik zu 24 Liedern, o. J. [um 1837?]. Die Schlacht im Loener Bruch, Episches Gedicht, 1838. Gedichte, 1838. Das geistliche Jahi, 1839. Beiträge zu Freiligratbs/Schückings Das malerische und romantische Westfalen, 1840. Beiträge zu Schiickings Der Dom zu Köln, 1841. Westfalen 1795 oder Bei uns zu Lande auf dem Lande, 1841. Der Geierpfiff, Ballade, 1841. Bilder aus Westfalen (spätere Version von Westfalen 1795?), 1841-?. Der Spiritus familiaris des Roßtäuschers, Episches Gedicht, 1842. Die Judenbuche, Erzählung, 1842. Gedichte, 1844. Posthum: Das geistliche Jahı, 1851. Letzte Gaben, Nachgelassene Blätter, 1860. Lieder mit Pianofortebegleitung, 1877. Briefe der ..., 1877. Gesammelte Schriften, 3 Bde., 1878. Ergänzungen ... zu den Ausgaben ihrer Werke, 1909. Briefe, 1909. Nachlese, Ungedruckte Verse und Briefe, 1934. Lieder und Gesänge, 1954. Gesammelte Schriften, hg. L. Schilcking, 3 Bde., 1878-9. Gesammelte Werke, 4 Bde., 1884-78. Sämtliche Werke, 6 Bde., 1912. Sämtliche Werke, 4 Bde, 1925-30. Tagebuch, hg. H. Christaller, 7. Aufl. 1926. Briefe, Gesamtausgabe, 2 Bde., 1944. Sämtliche Werke, 1952. Historisch-kritische Ausgabe, Werke, Briefwechsel, 5 Bde., 1978-82.

Literatur (Auswahl): L. Schücking, A. v. D.-H., ein Lebensbild, 1862. J. Claassen, A. v. D.-H., Ein Denkmal ihres Lebens und Dichtens, 1879. R. König, A. v. D.-H., Ein Lebens- und Literaturbild, 1882. H. Groß, Deutschlands Dichterinen und Schriftstellerinen, 2. Aufl. 1882, 62 f. $H$. Groß, Deutsche Dichterinen und Schriftstellerinen in Wort und Bild, 1885, I 233-40. L. Jacoby, A. v. D.-H., Deutschlands Dichterin, 1890. H. Keiter, A. v. D.-H., Deutschlands größte Dichterin, Ein Lebensbild, 1890. J. Schwering, Die Dichterin der roten Erde, 1902. W. v. Scholz, A. v. D.-H., 1904. G. Reuter, A. v. D.-H., 1905. B. Pelican, A. Freiin v. D.-H., Ein Bild ihres Lebens und Dichtens, 1906. B. Strauss, A. v. D.-H., Ihre dichterische Entwicklung und ihr Verhältnis zur englischen Literatur, 1909. H. Hüffer, A. v. D.-H. und ihre Werke, 3. Aufl. 1911. P. Schulz, Die Weltanschauung der A. v. D.-H., 1911. M. Krass, Bilder aus A. v. D.s Leben und Dichtung, 1915. A. Freund, A. v. D.-H. in ihren Beziehungen zu Goethe und Schiller und in der poetischen Eigenart ihrer gereiften Kunst, 1915. M. Silling, A. v. D.-H.s Lebensgang, 1917. W. v. Scholz, D.-H., 1922. C. Busse, A. v. D.-H., 3. Aufl. 1923. A. Jïngst, A. v. D.-H., Eine westfälische Dichterin, 1924. H. Christaller, Hg., Das Tagebuch der A., Ein Stück aus dem verborgenen Leben der A. v. D.-H., 7. Aufl. 1926. C. v. Droste zu Hiilshoff, Professor C. B. Schlüter und A. v. D.-H., 1926. K. Milblhoff, A. v. D.-H., Ein Lebensbild, 1926. O. Scheiwiller, A. v. D.-H. in der Schweiz, 1926. E. Hollweg, Von der getrosten Verzweiflung, Welt, Mensch und Gott in den Dichtungen der D., 1928. F Castelle, A. v. D.-H., 1929. E. Arens u. K. Schulte-Kernminghausen, D.-Bibliographie, 1932. H. Eggart, A. v. D.-H., Ein Dichterleben, 1934. T. Schneider, Im Banne der D., 1934. A. v. D.-H., Briefe, in: F. v. Zobeltitz, Hg., Briefe deutscher Frauen, 1936, 319-45. T. Ramsay, A. v. D.-H., 1938. R. Schneider, Zur Zeit der Scheide zwischen Tag und Nacht, Der Lebenskampf der D., 1940. 
M. Brauns, A. v. D.-H, 1941. J. Müller, Natur und Wirklichkeit in der Dichtung der M. Brauns, A. v. D.-H., 1941. J. Muller, Natur und Wingest, Bilder aus Leben und A. v. D.-H., 1941. M. Krass, Du hast mich über viele Dichtung der D., 1947. L. Linnhoff, A. v. D.-H., 1947. W. Rink, A. v. D.-H., ein Leben neben der Zeit, 1948. R. Schneider, Aar mit gebrochener Schwinge, Clemen Brentano, A. v. D.-H., 1948. M. Weinand, Die große Dichterin A. v. D.-H., eine Sich Herke, 1948. M. Lavater-Sloman, Einsamkeit, Das Leben der A. v. D.-H., 1950. T. Steinbiüchel, A. v. D.-H. nach 100 Jahren, 1950. C. Heselhau A. v. D.-H., Das Leben einer Dichterin, 1951. M. Schulte-Kemminghausen, A. im Aü Walter, D., Bilder aus ihrem Leben, 1957. W. Hollerer, ZwiRüschhaus, 1951. I. E. Wulter, D., Bille ans ihrem schen Klassik und Moderne, Lachen und Weinen in der Dichtung einer Ubergangszeit, 1958. E. Gössmann, „A. v. D.-H., Die Frau in der Auseinandersetzung mit ihrem Selbst", in. E Gössmann, Die Frau und ihr Auftrag, 1961, 99-139. L. Hirschberg, Hg., Selbst, ln: E Gasmamm Dic Fin Der Taschengoedeke, 1961, 121. E. Staiger, A. v. D.-H., 2. Aufl. 1962. M. Braukmann A. v. D.-H., Ein Lebensbild, 1963. H. Thiekotter, A. v. D.-H., Eine Auswahlbibliographie, 1963. J. Nettesheim, Wilhelm Junkmann und A. v. D.-H., Nach den Briefen de D. $D$. und neuen Quellen, 1964. H. Franck, A., Das Leben der A. v. D..H., R. 1965 . M. Mare, A. v. D.-H., 1965. P. Berglar, A. v. D.-H. in Selbstzeugnissen und Bilddokumenten, 1967. J. Nettesheim, Die geistige Welt der Dichterin A. D. zu H., 1967 G. G. Hantzschel, Traditon und Orginalitat, Allgorische Da H.s, 1968. W. Nigg, Glanz der ewigen Schönheit, A. v. D.-H. 1797-1848, 1968. W. Nigg, Wallfahrt zur Dichtung, 1968. W. Woesler, A. v. D.-H., 1969. G. Hadntzsche W. No " in: Hermand u. M. Windfuhr, Hg., Zur Literatur der Restaurations„A. v. D. H. ", in: J Hermerk und Leben, 1971 . cpoche 1815-1848, 1970, 151-201. C. Heselhaus, A. v. D.-H. Werk und Leben, 1971. B. Kortlander, Studien und Materialien zum Briefwechsel der D., 1973. A. Brall, Vergangenheit und Vergänglichkeit, Zur Zeiterfahrung und Zeitdeutung im Werk A.s v. gangertänder, A. v. D.-H. und die deutD.-H., 1975. R. Schneider, A. v. D.-H., 1977. B. Kortander, A, w. D. -H, und die de sche Literatur, Kenntnis, Beurteilung, Beeinflussung, 1979. A. Bauer Pickar, „A. v. D.H.s Reich der goldenen Phantasie“", in: M. Burkhard, Hg., Gestaltet und Gestaltend, H.s Reich del goldenen Posler, Hg., Modellfall der ReFrauen in der deutschen Literatur, 19. Jahrhundert, 3 Bde., 1980. I. Brender, „A. v. D. H. 1797-1848", in: $H$. Schultz, Hg., Frauen, Porträts aus zwei Jahrhunderten, D.-H. 1797- vo D.-H., 1981. H. Schultz, 1981, ve . D.-H., 1981. Form als Inhalt, Vers- und Sinnstrukturen bei J. v. Eichendorff und A. v. D.-H., 1981 . E. Friedrichs, Die deutschsprachigen Schriftstellerinnen des 18. und 19. Jahrhunderts, 1981. W. Gössmann, "Trunkenheit und Desillusion, Das poetische Ich der D., , in: Zer Zeitschrift für deutsche Philologie 101 (1982), Leben zwischen Auflehnung und Gehorsam, 1982. M. E. Morgan, A. v. D.-H., A Biography, 1984. W. Gossmann, A. v. D.-H.: Ich und Spiegelbild, Zam Wersandnis der Dichterin und ihres Werkes, 1985. G. Brinker-Gabler, Hg., „A. v. D.-H. , in: G. Brinker-Gabler, Hg., Deutsche Dichterinnen vom 16. Jahrhundert bis zur Gegenwart, 1986, 165-73. G. Brinker-Gabler, „A. v. D.-H.“, in: G. Brinker-Gabler, K. Ludwig, A.Wöfen, A. Woffen, Hg., Lexilche Drama im 19. Jahrhundert, 1988, 13 f. I. Roebling, „Heraldik des Unheimlichen, A. v. D.-H. (1797-1848), Auch ein Porträt", in: G, Brinker-Gablen, Hg., Deutsche Literatur von Frauen, 2 Bde., 1988, II 41-68. M. Burkhard, „A. v. D. H.", in: E. Frederiksen, Hg., Women Writers of Germany, Austria, and Switzerland, $1989,56 \mathrm{f}$.

Ebner-Eschenbach, Marie von. Geb. 13.9.1830 in Zdislawice/Mähren (von Dubsky). Vater Franz Graf von Dubsky, Mutter Maria geb. von Vockel.'Tod der Mutter zwei Wochen nach der Geburt. Eine ältere Schwester (Friederike; aus erster ode zweiter Ehe des Vaters?); später mehrere Schwestern und Brüder aus der dritten (ca. 1830-33) und vierten Ehe (1840 bis zum Tod der vierten Frau 1869) ihres Vaters. M. v. E.-E. lebte in ihrer Jugend abwechselnd in Zdislawice und Wien und wuchs unter der Obhut ihrer Großmutter, ihrer beiden Stiefmütter und zahlreicher Gouvernanten und Lehrer auf. Ihre Ausbildung empfand sie selbst als lückenhaft: dic für adlige Töchter übliche Erziehung (Französisch, Sticken, Klavier) reichte ihr nicht aus. Dic Erzieherinnen und Gouvernanten wechselten ständig; die Ausbildung beschränkte die Mehrzahl der Fächer, die sie interessierten, auf Jungen. Ihren größten Wunsch - Griechisch und Latein zu lernen, um die Klassiker im Original lesen zu können - behielt sie weislich für sich; „sie wäre ganz einfach für verrückt angesehen worden“ (Alkemade 100). Noch 1906 beneidet sie Lessing um seinen Lateinunterricht: „Er freilich, er lernte sie [die Klassiker, S. K.] in ihrer Sprache kennen, der Glückliche. Weil er ein Bub war, durfte er das" (Meine Kinderiahre, zit. Gladt 37). In den ersten Jahren ihrer Ehe nahm sie daher Nachhilfeunterricht, wo sie sich unsicher fühlte, u. a. in deutscher Grammatik und Syntax.

M. v. E.-E. begann früh zu schreiben; ihre ersten literarischen Versuche wurden von der Familie unwillig aufgenommen, denn eins „stand von vornherein fest, daß ,unsereins' keine Künstlerin werden dürfe" (Allkemade 99). Und genau das wollte sie - und nicht nur irgendeine Künstlerin: „ein Shakespeare des neunzehnten Jahrhunderts wollte sie werden, sie wollte „entweder nicht leben oder die größte Schriftstellerin alle Zeiten und Völker sein" (Alkemade 20). Schriftstellerin bedeutete für sie zunächst: Dramatikerin. M. v. E.-E.s unbescheidene Pläne waren das Resultat zweier wichtige Ereignisse: ihrer Burgtheaterbesuche ab 1839, von denen sie „völlig berauscht“ (Gladt 11) nach Hause kam, und ein Geschenls ihrer zweiten Stiefmutter zum 12. Geburtstag eine Ausgabe von Schillers Sämtlichen Werken. Mit 14 Jahren plante sie die Reformation der deutschen Bühne. Ein Jahr später schrieb sie an ihrem ersten historischen Schauspiel, dem Henri Cinq-Mars, an dem sie zwei Jahre arbeitete, bis sie ihre Entwürfe - bis auf zwei noch erhaltene - verbrannte. Ihre Stiefmutter schickte einige ihrer Gedichte an Franz Grillparzer und bat um eine Beurteilung; dieser antwortete höflich und etwas ausweichend, aber doch ermutigend.

1843 Tod der Großmutter. Bereits 1844 stand fest, daß sie ihren Vetter, Moritz v. E.-E., heiraten würde, was sie, pünktlich mit erreichter Volljährigkeit, 1848 auch tat. Mit ihm zog sie im selben Jahr nach Klosterbruck/Mähren, wo ihr Mann an der Militärakademie unterrichtete. 1856 Umzug nach Wien und regelmäßiger Umgang in jüdischen Salons; zahlreiche Freundschaften, u. a. mit Weilen, Laube, Hahn, Grillparzer, 
Paul Heyse (die letzten zwei fungierten auch als literarische Berater), E. Devrient; später mit der Schriftstellerin Elisabeth Glück (Pseud.: Betty Paoli) und Ida Fleischl.

Ihr Mann hatte gegen ihre schriftstellerische Tätigkeit zunächst nichts einzuwenden, und sie versuchte sich weiter im Drama. Ab 1859 trieb sie historische Studien für ihr Drama Maria Stuart; das sie in drei Wochen schrieb; das Stück wurde 1860 gedruckt, 1861 am Wiener Burgtheater aufgeführt und stand bis 1863 auf dem Spielplan. 1861 1861 am Wiene Künstlerdrama Die Arbeit an einem Drama über Jacobäa von Jülich-Cleve und das Künstlerdrama Die Schauspielerin sowie das Drama Marie Roland; ihr Quellenstudium zu diesem

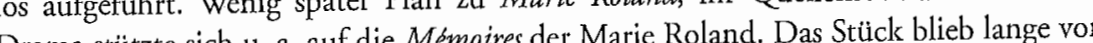
Drama stïtzte sich u. a. auf die Memackes der der Wiener Zensur verboten: „Wegen des Revolutionsmilieus und der Zitierung Marie Antoinettes [die Schwester Josephs II., des Kaisers von Österreich, S. K.] war an eine Auffür der Weimarer Hofbühne mit mäßigem Erfolg aufgeführt. Weitere dramatische Arbeiten: Die Veilchen (1863), acht Mal am Burgtheater gespielt; Das Geständnis, zunächst von Iaube für eine Aufführung am Burgtheater abgelehnt und 1867 in Prag aufgevon Laube fir eidfralein (1867-70); Doctor Ritter führt; Die Selbstsïchtigen, Untrö̈.h (1869), mehrfach erfolgreich aufgeführt, Männertreue (1873), 1874 gedruckt, 1875 in Gotha aufgeführt.

Von den insgesamt 21 Dramen der M. v. E.-E. wurden 13 aufgeführt und/oder erschienen im Druck. Fast 30 Jahre lang versuchte M. v. E.-E. den Durchbruch auf der Bühne; eine teilweise Anführung ihrer Dramen - eine vollständige findet sich in $A n$ Bang $B$ - schien mir schon deshalb notwendig, weil ihre Dramen in keiner Ausgabe (8) ihrer gesammelten oder sämtlichen Werke aufgenommen wurden. Die Aufnahme ihrer Dramen zu Lebzeiten war für die Autorin eine Enttäuschung: infolge äußerst abfälliger Rezensionen über ihr Drama Das Geständnis wollte ihr Mann, der selbst wenige Jahre später (1874) vorzeitig pensioniert wurde, ihr das Schreiben verbieten, worauf sich Freunde der M. v. E.-E. für sie ins Mittel legen mußten. Ihr Lustspiel Untröstlich unterschrieb sie nicht mehr, wie ihre früheren Stücke, mit dem kurzen (und geschlechtsneutralen) „Eschenbach“; nicht einmal Anonymität war ihr sicher genug: das Stück neutralen) "Eschenbach"; nicht einmal Anonymitat war ihr sicher

1873 durchlitt die Autorin eine mittelmäßige Aufführung ihres Waldfräuleins am Wiener Stadttheater. Der Abend war ein gesellschaftliches Ereignis ersten Ranges, komplett mit berittener Polizei; von der Satire auf den Wiener Hofadel versprach man sich einen Theaterskandal, der ihr erspart blieb. Trotzdem erinnert sie sich an diesen Tag als an einen der qualvollsten Tage meines Lebens" (zit. Gladt 45). In den kurz Tag ans an einen, der qualvols darauf einsetzenden Rezensionen brach ein Sturm der Enntustes dammungsurteil, das wechselweise die Hauptfigur des Stückes und die Autorin tra auf eine kurze Formel gebracht werden lsann: Blaustrumpf. Was der Autorin selbst ein Rätsel war: „Ich weiß [...] nicht, wie ich zu der persönlichen Gehässigkeit komme, die mir in allen Journalen ohne Ausnahme bewiesen wird“" (zit. Gladt 48).

Nachdem Untröstlich, ihr letztes Drama, trotz Anonymität erbarmungslos verrissen worden war, gab M. v. E.-E. ihren dramatischen und bühnenreformatorischen Ehrgeiz zunächst auf und zog sich auf das weniger der Öffentlichkeit ausgesetzte Gebiet der Prosa zurück. 1875 erschien ihr erster Band mit Erzählungen; mit dem Genrewechsel erfolgte ein bemerkenswerter Themenwechsel: von der Sphäre der baute tragédie (Maria Stuart, Marie Roland, Schiller, historische Dramen und Dramen, die sich fast ausschließlich in der höfischen Sphäre bewegen) zieht M. v. E.-E. in literarischer Hinsicht aufs Dorf. Ihre Novellen hatten einen bescheidenen Erfolg; zumindest wurde die Autorin nicht mehr angefeindet. Prosa blieb bis zu ihrem Tod ihr "festes" Genre, obwohl sich auch hier der Erfolg erst spät einstellte: 1883 mit ihren Dorf- und Schloßgeschichten.

Die Erfolglosigkeit ihrer Dramen hat sie nie verwunden. 1878 schreibt sie, nach der ungünstigen Rezension auf ihre Erzählung Bozena, erbittert: „Es geht mir mit meinen Erzählungen, wie es mir mit meinen Dramen gegangen ist. Die ersten errangen einen ehrenvollen Erfolg, die nachfolgenden bereiteten mir Enttäuschungen auf Enttäuschungen. - Ich habe ein Ende gemacht mit dem Schreiben von Theaterstücken, ich werde hoffentlich die Kraft haben, mit der Schriftstellerei überhaupt ein Ende zu machen." Viel später zitiert sie sich selbst und fügt hinzu: „Die ersehnte Kraftprobe wurde nicht abgelegt" (Aus einem zeitlosen Tagebuch, 118). Die Kraftprobe gelang auch im Drama nicht vollständig; um mit einem an sie gerichteten Wort von Paul Heyse zu sprechen: ihr letztes dramatisches Wort war noch nicht gesprochen (Brief von P. Heyse an M. v. E.-E., 24. 12. 1883; zit. Alkemade 264). Nach unzähligen Erzählungen wagte M. v. E.-E. sich 1891 wieder an ein Lustspiel (Ohne Liebe, 1898 am Burgtheater aufgeführt); es folgen noch mehrere Einakter, die die Autorin diplomatisch als „dialogisierte Novellen“ bezeichnet: Am Ende (1897; Auff. am Burgtheater 1900), Es wandelt niemand ungestraft unter Palmen (1900), Der Sportsmann (1902), Genesen (ca. 1902), Zwei Frauen und Zwei Schwestern, beide o. J.

1879 ließ sie sich als Uhrmacherin ausbilden; sie betrieb das Handwerk und sammelte Uhren von 1880-1913. Freundschaft mit Louise von François ab 1880 bis zu deren Tod 1893. 1894 Tod der langjährigen Freundin Elisabeth Glück, 1898 Tod ihres Mannes und Italienreise, 1899 Tod ihrer Freundin Ida Fleischl. Gegen Ende des Jahrhunderts wurde die jetzt durch ihre Novellen bekannte Autorin vielfach gefeiert und geehrt. Im Todesjahr ihres Mannes erhielt sie das „Ehrenzeichen für Kunst und Wissenschaft", den höchsten österreichischen Zivilorden; 1900 Emennung zum Ehrendoktor der Philosophie an der Universität Wien; es gab Gedenktage zu ihren 70. und 80. Geburtstagen. Ab 1903 Freundschaft mit der Schriftstellerin Enrica von HandelMazzetti. M. v. E.-E. starb am 12. 3. 1916 in Wien.

M. v. E.-E., wie Annette von Droste-Hülshoff häufig als „Deutschlands größte Schriftstellerin“ bezeichnet, kam wie diese erst spät zu Ruhm, erst nach langem Kampf gegen ihre adlige Familie, gegen gehässige Kritiken und das in ihrem Fall oft und deutlich formulierte Bewußtsein, dieser Gehässigkeit als schreibende Frau ausgesetzt zu sein. Aus ihrer Rückschau im Altweibersommer (1909): „Berühmt möchte ich sein“, sagst du und weißt nicht, was du redest. Berühmt sein heißt, mit nackten Füßen über ausgestreute Glasscherben dahinschreiten" (Sämtliche Werke IX, 162).

Werke: Dramatische Werke siehe Anhang B. Frühe Gedichte. Aus Franzensbad, Sechs Episteln von keinem Propheten, 1858. Die Prinzessin von Banalien, Märchen, 
1872. Erzählungen (enthält: Ein Spätgeborener; Chlodwig; Die erste Beichte; Die Großmutter; Ein Edelmann), 1875. Bozena, Die Geschichte einer Magd, Erzählung, 1876. Aphorismen, 1880. Neue Erzählungen (enthält: Ein kleiner Roman; Die Freiherren von Gemperlein; Lotti, die Uhrmacherin; Nach dem Tode), 1881. Dorfund Schloßgeschichten (enthält: Der Kreisphysikus; Jakob Szela; Krambambuli; Die Resel; Die Poesie des Unbewußten), 1883. Zwei Komtessen (enthält: Komtess Muschi; Komtesse Paula), Erzählungen, 1885. Neue Dorf- und Schloßgeschichten (enthält: Die Unverstandene auf dem Dorfe; Er läßt dic Hand küssen; Der gute Mond), 1886. Das Gemeindekind, 1887. Ein kleiner Roman, Erzählung, 1889. Miterlebtes (enthält: Wieder die Alte; Ihr Traum; Erlebnis eines Malers; Wiener Geschichten; Der Muff; Die Kapitalistinnen), 1889. Die Unverstandene auf dem Dorfe, Erzählung, 1889. Lotti, die Uhrmacherin, Erzählung, 1889. Unsühnbar, Erzählungen in 2 Bden., 1891. Margarete, Erzählung, 1891. Parabeln, Märchen und Gedichte, 1892. Drci Novellen (enthält: Oversberg, Aus dem Tagebuche des Volontärs Ferdinand Binder; Der Nebenbuhler; Bettelbriefe), 1892. Glaubenslos?, 1893. Erinnerungsblätter an Louise von François, 1894. Das Schädliche; Die Totenwacht, 2 Erzählungen 1894. Rittmeister Brand; Bertram Vogelweid, 2 Erzählungen, 1896. Komteß Muschi; 1894. Rittmeister Brand; Bertram Vogelweid, 2 Erzählungen, 1896. Komte Fine Vision; Schattenleben; Verschollen), 1897. Wiener Kinder, 1897. Oversberg, Aus dem Tagebuche des Volontärs Ferdinand Binder, Novellen, 1898. Bettelbriefe, Novelle, 1898. Hirzeprinzchen, Märchen, 1900. Krambambuli; Der gute Mond, 2 Erzählungen, 1901. Aus Spätherbsttagen, 2 Bde. (enthält: I: Der Vorzugsschüler; Maslans Frau; Fräulein Susannens Weihnachtsabend; II: Uneröffnet zu verbrennen; Die Reisegefährten; Die Spitzin; In letzter Stunde; Ein Original; Die Visite), 1901. Agave, Roman, 1903. Die arme Kleine, Erzählung, 1903. Ein Spätgeborener, Erzählung, 1903. Die Freiherren von Gemperlein, Erzählung, 1904. Die unbesiegbare Macht (enthält: Der Erstgeborene; Ihr Beruf), 1905. Meine Kinderjahre, 1906. Aus meinen Schriften, ein Buch für die Jugend, 1907. Altweibersommer, Erzählung, 1909. Ein Buch, das gern ein Volksbuch werden möchte, 1909. Die erste Beichte, 1910. Der Kreisphysikus, Aus den Dorf- und Schloßgeschichten, 1910. Vixen und andere Tiergeschichten, 1913. Meine Erinnerungen an Grillparzer, Aus einem zeitlosen Tagebuch, 1916. Stille Welt, Erzählungen, 1916. Posthum: Briefwechsel mit G. Frenssen, 1917. Briefe an Erica von Handel-Mazzetti, Der Dichterinnen stiller Garten, 1918. Chlodwig, Erzählung, 1919. Letzte Worte, Aus dem Nachlaß, 1923. Der Vorzugsschüler, 1924. Maslans Frau; Uneröffnet zu verbrennen, 1924. Kinderjahre einer Dichterin, Aus den Jugenderinnerungen der M. v. E.-E., 1927. Unveröffentlichte Parabeln aus dem Nachlaß, 1946/7. Aus ungedruckten Briefen an Dichter, 1946/7. Der Nachlaß, Bei meinen Landsleuten, 1947. Briefwechsel mit F.v. Saar, 1957. Briefwechsel mit J. Breuer, 1969.

Literatur (Auswahl): H. Groß, Deutschlands Dichterinen und Schriftstellerinen, 2. Aufl. 1882,126 f, 266. H. Groß, Deutsche Dichterinen und Schriftstellerinen in Wort und Bild, 1885, II 340-53. L. Morgenstern, „M. Freifrau v. E.-E.“, in: L. Morgenstern, Dic Frauen des 19. Jahrhunderts, 1891, III 220-2. G. Reuter, M. v. E.-E., 1904.
T. Klaiber, "M. v. E.-E.", in: T. Klaiber, Dichtende Frauen der Gegenwart, 1907. E. Riemann, Zur Psychologie und Ethik der M. v. E.-E., 1913. M. Necker, M. v. E.-E. nach ihren Werken geschildert, 1916. $F v$. Saar, „Begegnungen mit M. v. E.-E.“, in: F. v. Saar, Sämtliche Werke, 1918, XII. A. Bettelheim, M. v. E.-E.s Wirlken und Vermächtnis, 1920. E. M. O'Connor, M. v. E.-E., 1928. J. Mühlberger, M. v. E.-E., 1930. R. Latzke, Die Ethil der Frau M. v. E.-E., 1931. M. Alkemade, Die Lebens- und Weltanschauung der Freifrau M. v. E.-E., mit sechs Tafelbeilagen und dem Briefwechsel Heyse und E.-E., 1935. R. Latzke, „M. v. E.-E.“, in: E. Castle, Geschichte der deutschen Literatur in Österreich-Ungarn im Zeitalter Franz Josephs I., 1935, I 1036-66. G. Bdumer, "Stille Weisheit", in: G. Badumer, Gestalt und Wandel, 1939. I. Slama, M. v. E.-E. und das Burgtheater, Diss, Wien, 1944. E. Felbinger, M. v. E.-E.s dramatische Arbeiten, Diss., Wien, 1947. A. Siernsen, „M. v. E.-E.“, in: Der Weg ins Freie, 1950. I. Mühlberger, M. v. E.-E., ein Gedenkblatt, 1957. M. v. E.-E., Aus einem zeitlosen Tagebuch, in: M. v. E.-E., Sämtliche Werke, 1960/1, IX 77-141. M. v. E.-E., Altweibersommer, in: $M . v . E_{.}-E_{.}$, Sämtliche Werke, 1960/1, IX 143-99. F Braun, „M. v. E.-E., ein Lebensbild“, in: $M . v . E .-E$., Sämtliche Werke, 1960/1, IX 215-34. K. Benesch, Die Frau mit den hundert Schicksalen, Das Leben der M. v. E.-E., 1966. G. Fussenegger, M. v. E.-E. oder der gute Mensch von Zdislawitz, ein Vortrag, 1967. V. Aschenbrenner, „M. v. E.-E., Ein Gedenken zum 50. Todestag", in: Sudetendeutscher Kulturalmanach, 1967. K. Gladt, „Kindliche Begeisterung und Theaterleidenschaft", in: M. v. E.-E., Das Waldfräulein, hg. K. Gladt, 1969, 11-35. R. C. Cowen, „M. v. E.-E.“", in: Handbuch der deutschen Literaturgeschichte, 197.0, 2. Abt. IX. J. Vesely, "Tagebücher legen Zeugnis ab, Unbekannte Tagebücher der M. v. E.-E.“, in: Österreich in Geschichte und Literatur 15 (1971), 211-41. I. Aichinger, „Harmonisierung oder Skepsis? Zum Prosawerk der M. v. E.-E.“, in: Österreich in Geschichte und Literatur 16 (1972), 483-95. J. Vesely, „M. v. E.-E., F. v. Saar, J. J. David, Wechselseitige Beziehungen", in: Germanistica Pragensia (1976), 119-29. M. Kubelka, M. v. E.-E., 1980. E. Endres, „M. v. E.-E. 1830-1916“, in: H. J. Schultz, Hg., Frauen, Porträts aus zwei Jahrhunderten, 1981, 114-26. H. Harriman, „M. v. E.-E. in feminist perspective“, in: Modern Austrian Literature 18 (1985), 1, 27-38. G. Brinker-Gabler, Hg., „M. v. E.E.", in: G. Brinker-Gabler, Hg., Deutsche Dichterinnen vom 16. Jahrhundert bis zur Gegenwart, 1986, 229-31. G. Brinker-Gabler, „M. v. E.-E.", in: G. Brinker-Gabler K. Luduig, A. Wöffen, Hg., Lexikon deutschsprachiger Schriftstellerinnen 1800-1945, 1986. K. Goodman, "The Cases of Lewald and E.-E.“, in: K. Goodman, Dis/Closures, Women's Autobiography Between 1790 and 1914, 1986, 147-85. R. Cowen, Das deutsche Drama im 19. Jahthundert, 1988, 183 f, 188. V. Richel, The German Stage, 1767-1890, A Directory of Playwrights and Plays, 1988, 36. J. Blackwell, „M. v. E. E.“, in: E. Frederiksen, Hg., Women Writers of Germany, Austria, and Switzerland, $1989,62-4$.

Elisabeth Königin von Rumänien (in Sekundärwerken häufig: Syiva, Carmen; Carmen Sylva). Geb. am 29. 12. 1843 in Neuwied (von Wied). Vater der Fürst Hermann zu Wied-Neuwied, Mutter Marie Prinzessin von Nassau. Zwei Brüder (Wilhelm, 
1845-?, und Otto, 1850-1862). Ihre Mutter war gelähmt und litt unter ständigen Herz- und Starrkrämpfen; ihre Großmutter geisteskrank. E. v. R. erhielt früh (ab dem 4. Lebensjahr) einen ausführlichen Unterricht, u. a. in Englisch, Französisch, Italicnisch, Latein, Philosophic, Kirchengeschichte, Religion, Mathematik, Physik, Geschichte und Hauswirtschaft. Außerdem wurde E. v. R. zur Krankenpflege und Landwirtschaft angehalten; sie erhielt Unterricht im Buchbinden und half bei der Ente mit. Dagegen wurde ihr die Beschäftigung mit Musils und das Lesen von Romanen mit Hinweisen auf die Geistesgestörtheit ihrer Großmutter streng untersagt (ihren ersten Roman, Gustav Freytags Soll und Haben, las sie mit 19 Jahren).

Aus demselben Grund untersagte ihre Mutter ihr das Schreiben, so daß E. v. R. mit Hilfe eines verständnisvollen Italienischlehrers heimlich ihre schriftstellerischen $\mathrm{Be}$ dürfnisse ausleben mußte. Der Kontalst mit Ernst Moritz Arndt, der häufig Gast ihrer Eltern war, entwickelte diese Bedürfnisse weiter; mit acht Jahren schrieb sie erste Gedichte, mit 14 plante sic cin Drama und einen Roman. 1862 Tod des Bruders Otto. Um dieselbe Zeit wurde ihr erlaubt, den Musikunterricht wiederaufzunchmen; um verlorene Zeit nachzuholen, spielte E. v. R. ca. sieben Stunden täglich Klavier. Besuch bei ihrer Tante, Therese von Oldenburg, in Neapel in der ersten Hälfte der 60er Jahre. Hier unterrichtete E. v. R. ihren Vetter und ihre Kusine in Englisch und im Rechnen und faßte den Entschluß, Lehrerin zu werden. Reise nach St. Petersburg und Tod des Vaters Mitte der 60er Jahre; Rückkehr nach Neuwied, wo sic mit ihrer Mutter, ihrem Bruder Wilhelm und ihrer Lehrerin Fanny Lavater lebte.

1869 heiratete sie den Fürsten des frisch geschaffenen Fürstentums Rumänien, den Prinzen Kar(o)1 (1839-1914), einen ehemaligen preußischen Gardeoffizier. Eine'Tochter (Marie, 1870-1872 oder 1874). Zu Beginn seiner Regierung hatte Karol derartige Schwierigkeiten mit dem Etat und mit der Anerkennung des neuen Fürstentums durch die Großmächte (Rumänien war damals türkische Provinz), daß er öfter den Gedanken an Abdankung äußerte. E. v. R. lernte schnell Rumänisch, setzte sich für eine Verbesserung des rumänischen Schulwesens ein und gründete verschiedene wohltätige Institute (u. a. einen Armenverein, eine Krankenschwestern- und eine Handarbeitsschule). Häufige Erktrankungen am Sumpffieber und sechswöchige Kur in Italien 1872. Kurz nach ihrer Rückkehr, im April 1872 (Wolbe) oder 1874 (Brümmer) Tod der Tochter.

Während einer neuen Kur in Frankreich gab sie dem russischen Diplomaten W. von Kotzebue (ein Enkel des gleichnamigen Dichters?) ihre deutschen Übersetzungen von rumänischen Volksliedern und Legenden zur Beurteilung. Auf sein ermutigendes Urteil hin fing sie an, sich selbst als Schriftstellerin zu bezeichnen: „Du bist doch eine Dichterin!" (Tagebucheintragung, zit. Wolbe 82) Unter dem Pseudonym "C. Wedi", einem Anagramm ihres Mädchennamens (E. von Wied), schrieb sie zunächst mehrere Erzählungen und Gedichte und übersetzte rumänische Gedichte und Legenden. 1877 Unabhängigkeitserklärung Rumäniens und kurze Beteiligung am russisch-türkischen Krieg (während dessen E. v. R. sich als freiwillige Krankenschwester betätigtc); ein Jahr später erkannten die Großmächte die Unabhängigkeit Rumäniens an, und aus dem Fürstentum Rumänien wuirde das Königreich Rumänien.
Von 1881 bis ca. 1897 Freundschaft und literarische Zusammenarbeit mit der Frau ihres Leibarztes, Marie (Mite) von Kremnitz (siehe dort), die E. v. R. als Vorleserin anstellte. 1881 gab v. Kremnitz E. v. R.s Übersetzungen unter dem Titel Rumänische Dichtungen heraus. Um diese Zeit kreierte E. v. R. ein neues Pseudonym, „Carmen Sylva" (Waldgesang); unter diesem Namen veröffentlichte sie die meisten ihrer späteren Werke. Als literarische Einflüsse nennt sie Dickens, Uhland, Heine und Mörike. E. v. R, schrieb jahrelang so viel (auf Deutsch, Rumänisch, Französisch und später auch auf Englisch), daß sic regelmäßig unter Krämpfen in der Hand litt; ihre Lieblingserfindung nach eigener Aussage war die Schreibinaschine. Dieses Pensum bezahlte sie mit Krankheiten (Herzneurose, Nervenzusammenbruch); aber sie hatte Erfolg: ihre Werke wurden regelmäßig veröffentlicht und in mehrere Sprachen übersetzt; ihre Dramen aufgeführt und ihre Gedichte vertont. Ihr Ehrgeiz war es, Dramatikerin zu werden: sie wollte ursprünglich 16 rumänische Volkslegenden dramatisieren. Von dem geplanten Zyklus entstand nur ein Drama, Meister Manole (1892).

Um 1890 mußte E. v. R. drei Jahre im Exil, zunächst in Venedig, verbringen, weil sie sich in die Politilk einmischte: sie wollte über die Opposition des Königs und verschiedener fürstlicher Familien hinweg den Thronerben Ferdinand mit ihrer Hofdame Helene Vacarescu verheiraten. In Venedig Kontakt zu Richard Voß. In Exil wurde ihr die Schriftstellerei untersagt und ihr Briefwechsel überwacht. Offiziell wurde eine Krankheit E. v. R.s vorgeschützt, wegen der sie in Kur hätte fahren müssen; und tatsächlich wurde E. v. R. in Italien krank. In den Bukarester Zeitungen wurden die Nachrichten von ihrem schlechten Gesundheitszustand übertrieben, um ihre lange Abwesenheit zu rechtfertigen. 1893 Rücklkehr nach Rumänien.

1897/8 Entfremdung von M. v. Kremnitz und deren Umzug nach Berlin. 1905/6 schwere Krankheit des Königs, während der E. v. R. ihn ununterbrochen pflegte. 1905 verhinderte E. v. R. eine Hungersnot in Rumänien durch Gründung einer Seidenzucht, mit der sie eine neue Einnahmequelle für die Bauern schaffte. 1907 gründete E. v. R. ihre Blindenstadt in Bulkarest, die "Vatra Luminoasa" (,Leuchtender Herd“) deren Zweck es war, Beschäftigungen für Blinde zu finden, mit denen sie ihren Lebensunterhalt verdienen konnten. Um diese Zeit wurde die Königin selbst augenkrank; schrieb aber trotz einsetzender Blindheit und Staroperationen weiter (u. a. den Roman Des Schicksals Meister). Freundschaft mit dem Komponisten August Bungert. In dem Krieg mit Bulgarien (1913) betätigte E. v. R. sich erneut als Krankenschweste und schuf eine weitere Stiftung für bedürftige und lrriegsgeschädigte Familien. Im selben Jahr Bauchfellentzündung und Kur in Constanza; E. v. R. war in diesem Jahr sech Monate lang bettlägerig. Bei Ausbruch des ersten Weltkrieges Opposition der Rumänen sowohl gegen E. v. R. als auch gegen Karol (wegen ihrer deutschen Abstammung) 1914 Tod ihres Mannes und Umzug nach Arges bei Bukarest. Winter 1915/16 Tumor und Lähmung; trotzdem arbeitete sie weiter, ließ sich Charles Dickens vorlesen und zorrigierte die Aussprache ihres Vorlesers. Gest. am 2. 3. 1916 in Arges.

E. v. R. war eine schr erfolgreiche Schriftstellerin (sie schrieb Romane, Dramen, Erzählungen, Novellen, Märchen, Gedichte und zahlreiche Übersetzungen rumänische Literatur) und eine passionierte Sozialarbeiterin. Außer den oben erwähnten Wohl- 
fahrtseinrichtungen gründeteE. v. R. noch mehrere Institute, u. a. Altersheime, Frauenvereine, Web- und Stickereischulen, und unterstützte - gegen ihre eigene Überzeugung vercine, We und Sick ihre Werke gingen an die Armen. Für ihre literaxischen Errungenschaften und kulturpolitischen Bemühungen wurde E. v. R. mit Ehrendoktorwürden von verschiedenen Universitäten in Rumänien und anderen Ländern ausgezeichnet.

Werke: Dramatische Werke siehe Anhang B. Stürme, Erzählungen (enthält: Sappho; Über den Wassern; Schiffbruch), 1881. Rumänische Dichtungen (Übers.), hg. M. v Kremnitz, 1881. Die Hexc, zu der Statue von Carl Cauer, 1882. Leidens Erdengang, ein Märchenkreis, 1882 (7. Aufl. 1908). Gedanken einer Königin, 1882 (erste Aufl.: ein Märchenkreis, 1882 (7. Aufl. 1908). Gedanken einer Kom Amboß, 1890). PeleschMärhen, 1882. Jehovah, die Geschichte des Ewigen Juden, 1883. Ein Gebet, Novelle, 1883. Aus zei Welten, Roman [mit M. u Kremnitz], 1883 (7. Aufl. 1901). Aus Carmen Sylvas Königreich (Pelesch-Märchen und Durch die Jahrhunderte), 2 Bde., 188387. Handzeichnungen, Novellen, 1884. Mein Rhein, Gedichte, 1884. Meine Ruh', Gedichte, 1884 (3. Aufl., 5 Bde., 1901). Durch die Jahrhunderte, Balladen und RoGedichte, manzen aus der rumänischen Geschichte von Decebal bis König Carol I., Zweiter Teil Buch, mit faksimilierten Gedichten, 1886. Stürme, Ronan, 1886. Es klopft, Novelle, 1887. Feldpost, Briefroman [mit M. v. Kremnitz], 1887 (4. Aufl. 1903). In der Irre, Novellen [mit. M. v. Kremnitz], 1888 (4. Aufl. 1901). Islandfischer, Novellen von P. Loti [übers. mit $M$. v. Kremnitz], 1888. Pelesch im Dienst, ein Märchen, 1888. Rache und andere Novellen [mit M. v. Kremnitz], 1888 (2. Aufl. 1889). Lieder aus dem Dimbowitzatal (Übers.), gesammelt von H. Vacarescu, 1889. Defizit, Roman, 1890. Die Sphinx, gedichtet, geschrieben, gemalt von Carmen Sylva (vertont von Bungert), 1890. Handwerkerlieder, 1891. Heimat!, Gedichte, 1891. Meerlieder, 1891. Weihnachtskerzchen von Pallanza, Gedichte, Sentenzen, Gedanken, 1891. Bukarest (in: Die Hauptstädte der Welt), 1892. Eine Kindergeschichte, Novelle [mit M. v. Kremnitz], o. J. Monsieur Hampelmann, Kindererzählungen (gleichzeitig auf deutsch, englisch, französisch und rumänisch), 1898. In beiden Masken, Tragikomödie von $P$ de Saintfranzösisch und rumänisch), 1898. In beiden Masken, Tragikomodie von P. de SaintNeue Gedichte, 1900. Märchen einer Königin, 1901. Es ist vollbracht!, Das Leben des Prinzen Otto, 1902. Unter der Blume, Rheinweinlieder, 1903. Geflüsterte Worte, 5 Bde., 1903-12. In der Lunca, Rumänische Idylle, 1904 (2. Aufl. 1905). Rheintochters Donaufahrt, Erinnerungen und Reiseeindrücke, 1905. Das Sonnenkind und andere Märchen, 1906. Mein Penatenwinkel, Lebenserinnerungen, 1908. Briefe ciner einsamen Königin, 1916. Des Schicksals Meister, Roman, o. J. Buch der Seele, o. J: Mehrere Aufsätze in Zeitschriften.

Literatur: $M$. v. Kremnitz, Carmen Sylva [Pseud. für: E. v. R.], 1882. H. Groß, Deutschlands Dichterinen und Schriftstellerinen, 2. Aufl. 1882, 213 f. H. Groß, Deutsche Dichterinen und Schriftstellerinen in Wort und Bild, 1885, III 148-58. N. v Stackelberg, Aus C. Sylvas [Pseud. für: E. v. R.] Leben, 1885. S. Pataky, Lexikon deutGo Königreich, Tales from the

\section{0}

Carpathian Mountains by Carmen Sylva [Pseud. für: $E . v, R ., 1900$. [E. v. R. , Geflüsterte Worte von Carmen Sylva [Pseud. für: $E . v . R$ ], 2 Bde., 2.-3. Aufl. 1905-7. F. Brïmmer, Lexikon der deutschen Dichter und Prosaisten vom Beginn des 19. Jahrhunderts bis zur Gegenwart, 6. Aufl. 1913, II. E. v. R., „Briefe der Königin Elisabeth von Rumänien (Carmen Sylva) an einen deutschen Gelehrten", Mitgeteilt von Prof. Dr. Arthur Kleinschmidt, in: Westermanns Monatshefte 120 (Berlin: 1916), 393-400. [E. v. R.], Carmen Sylva [Pseud. für: E. v. R.], Briefe einer cinsamen Königin, [1916?] $[E, v, R]$, Aus den Briefen Carmen Sylvas [Pseud. für: E. v. R.], 1920. E. Wolbe, Carmen Sylva [Pseud. für: E. v. R.], Der Lebensweg einer einsamen Königin, 1933. P. Lindenberg, Plauderstunden mit Carmen Sylva [Pseud. für: E. v. R.], 1941. W. Kosch, Deutsches Literatur-Lexilkon, 2. Aufl. 1949-58. E. Friedrichs, Die deutschsprachigen Schriftstellerinnen des 18. und 19. Jahrhunderts, 1981. V. Richel, The German Stage, 1767-1890, A Directory of Playwrights and Plays, 1988, 146. [E. v. R. $]$, From Memory's Shrine, The Reminiscences of Carmen Sylva [Pseud. für: E. v. R.] (H. M. Queen Elisabeth of Roumania), übers. Edith Hopkirk, o. J.

Franul von Weißenthurn, Johanna von (in Lexika häufig: Weißenthurn, Johanna Franul von). Geb. 16.2. 1772 in Koblenz (Grünberg) als älteste von sechs Kindern. Vate Benjamin Grünberg (1724-1781), Mutter Anna Rausch (1756-?). Ihr Vater wurde entgegen den Wünschen seines Vaters Offizier und später Schauspieler bei der Kurzschen Gesellschaft, wo J. F. v. W. ab 1777 im Ballett mitwirkte, 1781 Tod des Vaters. Ihre Mutter heiratete im selben Jahr den Schauspieler Johann Andreas Teichmann. Teichmann stellte mit seinen Stiefkindern ein Kindertheater zusammen, das hauptsächlich die Stücke aus Christian Felix Weißes Kinderfreund aufführte und ganz Deutschland bereiste.

J. F. v. W. erhielt keine formale Ausbildung (mit zehn Jahren konnte sie weder lesen noch schreiben), sondern verbrachte ihre gesamte Jugend als Schauspielerin, Sängerin und Tänzerin und mit der Versorgung ihrer Geschwister. Mit zehn Jahren übernahm sie den Unterricht ihrer Geschwister und überwachte das Einstudieren der Rollen. 1787 (Schindel; Goedeke: 1783) wurde die Truppe von dem Münchner Hoftheaterintendanten eingeladen, auf dem Schloß zu spielen; J. F. v. W. erhielt bei dieser Gelegenheit ein festes Engagement am Münchner Hoftheater. 1788 Engagement an der Gesellschaft Wilhelm in Baden bei Wien; 1789 Engagement am Wiener Burgtheater, wo sie bis 1842 eine erfolgreiche und oft ausgezeichnete Schauspielerin war.

1791 heiratete sie den Patrizier F. v. W. aus Fiume gegen den Widerstand seiner Familie und holte selbständig ihre versäumte Ausbildung nach. 1796 begann sie zu schreiben; ihre gesammelten dramatischen Schriften umfassen ca. zehn Bände. Von zeitgenössischen Rezensenten bekam sie überwiegend positive Kritiken sowohl für ihre schriftstellerischen als auch ihre schauspielerischen Leistungen; später dagegen wurde sie als Trivialliteratin rezipiert (Schlenther 115: „Das deutsche Repertoire stak damals [in den 1840er Jahren, S. K.] in den Sümpfen der Kotzebueschen und Weißenthurnschen Niederung"; Martersteig bezeichnet sie als eine der meistgespielten dramatischen Autoren während des „Tiefstand[s] der dramatischen Produktion“, 233). J. F. v. W.s 
Dramen waren so erfolgreich, daß sie verschiedentlich verdächtigt wurde, sie in $\mathrm{Zu}$ sammenarbeit mit einem ungenannten männlichen Mitverfasser geschrieben zu haben; viele ihrer Stücke wurden in andere Sprachen übersetzt (Englisch, Französisch, Dänisch, Russisch, Polnisch, Italienisch) und überall in Deutschland aufgeführt - „bis auf einige wenige, die des geschichtlichen Inhalts wegen die Censur nicht passirten“ (Schindel II, 414).

1817 Tod des Mannes. 1842 zog J. F. v. W, sich von der Bühne zurück; Gesundheitsreisen nach Ischl und Reichenau. Krankheit um 1845 (Schlaganfall, Wassersucht) J. F. v. W. starb am 17.5. 1847 in Wien.

Werke: Dramatische Werke siehe Anhang B. Die arme Lisel, Erzählung, 1816. Ein Morgen im Schloßhof, 1816. Graf Lohrenburg, Roman, 1819. Die Schifferin, Gedicht, 1824. Adele, oder das Crucifix, Erzählung. Über meine Schreiberei, Aufsatz, o. J. Meine Ansicht über den Verfall der dramatischen Bühnenerzeugnisse, Aufsatz, o. J. Schauspielerleben vor hundert Jahren, Fragment einer Autobiographie, o. J. Verschicdene Gelegenheitsgedichte. Beiträge in den folgenden Zeitschriften; Der Sammle (1809/1815, 1826); Mimigardia (1810/1); Thalia (1810/1); Bäuerles Allgemeine Theater-Zeitung (1824); Fortuna (1824-31, 1838, 1840); Huldigung den Frauen (1827); Erheiterungs-Bade-Almanach für Damen (1827); Telegraph (1836/8); Die Presse (1840)

Literatur: G. Chr. Hamberger und J. G. Meusel, Das gelehrte Teutschland oder Lexikon der jetzt lebenden teutschen Schriftsteller, 1796-1834, XX. C. W. O. A. v. Schindel, Die deutschen Schriftstellerinnen des neunzehnten Jahuhunderts, 1823, II. A. Klingemann, Kunst und Natur, 1823-8, 1 299, II 253, 274, 296 und 323. F. Zim mermann, Neue dramaturgische Blätter, 1827-8, I 304, T. und K. $A$. West, Gesammelte Schriften, 1829, IV 101-7. Almanach fuir Freunde der Schauspielkunst IV, 1839, 101-7. K. Herioßsobn und H. Marggraff, Allgemeines Theater-Lexikon, 1846, VII. Almanach für Freunde der Schauspielkunst XII, 1848, 58-62. L. Tieck, Kritische Schriften, 184852, III 34 f. K. Th. v. Kistner, Vierunddreißig Jahre meiner Theaterleitung, 1853, $120 \mathrm{f}$ 316. H. Laube, Das Burgtheater, 1868, 89. J. Kürschner, ,J. F. v. W.", in Allgemeine deutsche Biographie, 1878, VII. $H$. Groß, Deutschlands Dichterinen und Schriftstellerinen, 2. Aufl. 1882, 35. K. Goedeke, Grundriß zur Geschichte der deutschen Dichtung aus den Quellen, 2. Aufl. 1884-1966, XI/2. H. Groß, Deutsche Dichterinen und Schriftstellerinen in Wort und Bild, 1885, I 164-68. A, Eloesser, Das bürgerliche Drama, 1898, 197 f. S. Pataky, Lexikon deutscher Frauen der Feder, 1898, II. A. v. Weilen und O. Teuber, Die Theater Wiens, 1899-1906, II B 196, II C 32, 37, 53, 82, 100 und 114. H. Devrient, Archiv für Theatergeschichte, 1904-5, II 170 f. P. Stein, Deutsche Schauspieler, Eine Bildnissammlung, 1908, II. K. L. Costenoble, C. L. Costenoble's Tagebücher von seiner Jugend bis zur Übersiedlung nach Wien (1818), 1912, I 201, 204 206, 208, 210 f, 229, 232; II 9, 32, 36, 41, 50 und 137. M. Martersteig, Das deutsche Theater im neunzehnten Jahrhundert, 2. Aufl. 1924, 233. J. du Toit, J. v. W. (Diss. Göttingen), 1924. P. Schlenther, Theater im 19. Jahrhundert, 1930, 115. G. Gugitz, „J. F. v. W.", in Neue Deutsche Biographie, 1961. G. v. Wilpert, Deutsches Dichterlexikon, 1963. W. Kosch, Deutsches Literatur-Lexikon, 3. Aufl. 1968-1990. E. Friedrichs,
Die deutschsprachigen Schriftstellerinnen des 18. und 19. Jahrhunderts, 1981. V. Richel, The German Stage, 1767-1890, A Directory of Playwrights and Plays, 1988, 158-9.

Franz (eigentl. Franzlyy), Agnes. Geb. 8. 3. 1794 in Militsch (Schlesien). Vater der Regierungsrat F., Mutter ?, geb. v. Hahn. Zwei jüngere Schwestern (Clara, Adelheid). A. F. erhiclt eine vorwiegend religiöse Erziehung und las als Kind viel; ihr Leseeifer wurde von den Eltern unterstützt, ebenso ihre künstlerischen und musikalischen Anlagen; sie zeichnete, malte und spielte Klavier. Mit kaum sechs Jahren begann sie, Gedichte zu schreiben („Das Fest Aurorens“, 1800), 1801 Tod des Vaters und Umzug der Familie von Militsch nach Steinau. Dort besuchte A. F. die Elementarschule; wo sie eine - ihrem Empfinden nach - unzureichende Ausbildung erhielt.

Mit 13 Jahren hatte A. F. auf einer Reise einen Unfall; seitdem war sie verwachsen und kränklich. Irgendwann zwischen 1807 und 1813 lebte sie mit Mutter und Schwestern auf dem Landgut ihres Onkels in Ober-Arnsdorf bei Schweidnitz; dort schrieb sie ihre ersten Kompositionen (Lieder), die sie später vertonte, und Erzählungen. Ab 1818 schrieb sie regelmäßig Gedichte. Vor Kriegsausbruch flol die Familie nach Landeck. 1813 erließ sie einen Aufruf an die Schlesierinnen, den Kampf gegen Napoleon (finanziell) zu unterstützen. Seit 1816 Briefwechsel mit ihrer (seit diesem Jahr verheirateten) Schwester Clara, mit der sie eng befreundet war. Zwischen 1816 und $1822 \mathrm{Ar}$ beit an ihrem Roman Angela; in diesen Jahren erschien eine Gedichtsammlung von ihr:

Nach dem Tod ihrer Mutter 1822 machte A. F. mehrere Gesundheitsreisen; danach lebte sie bei ihrer Schwester Clara in Wesel, Siegburg bei Bonn und Brandenburg a.d. H. Freundschaft mit Julie v. Großmann, die nach ihrem Tod ihren vierbändigen Nachlaß herausgab und eine Lebensbeschreibung von ihr schrieb, und dem Hofrat Winkler (Pseudonym: Theodor Hell), „der sie ehelichen wollte“ (Goedeke X, 582). In Wesel gründete A. F. eine Arbeitsschule für Mädchen aus den niederen Ständen, der sie lange vorstand. Mit ihrer (inzwischen verwitweten) Schwester kehrte A. F. 1837 nach Schlesien zurück. Dort ließen sich beide in der Nähe der jüngsten Schwester Adelheid nieder. In Breslau war A. F. Vorsteherin einer Armenschule und half ihrer Schwester Clara bei der Erziehung ihrer drei Kinder. Später, nachdem der Mann ihrer jüngsten Schwester Adelheid gestorben war, tat sie dasselbe für sie; nach Adelheids Tod adoptierte sie deren vier Kinder. Nach wiederholten Krankheitsanfällen starb A. F. am 13. 5. 1843 in Breslau.

A. F. schrieb Theaterstücke für Kinder, Jugendbücher, Lustspiele, Romane, Sagen, Erzählungen, Lieder und unzählige Gedichte. Zeit ihres Lebens litt sie unter ihrer ungenügenden Ausbildung; ihre Weseler Schule zielte vor allem darauf ab, jungen Fraue "durch Erlernung nützlicher Kenntnisse die Mittel zu einem ehrlichen Fortkommen in der Welt" zu bieten (Anon., „A. F., eine Lebensskizze“ 18). Besonders kraß empfand sie ihren Bildungsmangel im Bezug auf ihre schriftstellerische Tätigkeit: schreiben, ohne durch eine formelle Ausbildung dazu "berechtigt" worden zu sein, empfand sie als Wagnis, obwohl sic zeitlebens eine ungeheuer produktive Schriftstellerin war. A. F in einem Gedicht (Titel nicht genannt) über ihre Un-Bildung und die daraus folgende Unsicherheit beim Schreiben: 
Oft sehnt' ich mich nach Lehr' und Rath

Der manche mir noch dunkle Stelle

Des Pfades, den ich kühn betrat,

Mit sanftem Lichte mir erhelle.

Doch, ach! es fand sich keine Hand,

Mich in den lichtern Tag zu leiten,

Und, was das Herz nicht selbst verstand,

Das sah ich nimmer freundlich deuten! (Zit. in „Lebensskizze“, 15)

Werke: Dramatische Werke siehe Anhang B. Gedichte 1800: Das Fest Aurorens, 1800 Gedichte 1818: Die Liebe; Tugend, Religion, Liebe; Religion; Theilnahme, Mitleid und Barmherzigkeit; Weltseele; Ergebung; Sternennacht; Geduld; Bei einer Hyacinthe, die über dem Wasser blüht; Aepfelblüthe; Reinigkeit; Die vollendete Schöpfung; Charaden; Kindespflicht; Wohlthat des Schmerzes; Versöhnlichkeit; Gewalt der Natur; Der trauernde Knabe; Das deutsche Mädchen; Schmerz und Verdruß; Innres Leben; Gebet; Stilles Bewußtsein; Das Veilchen; Die Rosen; Die Weihnachtsfeier. Gedichte 1819: Entstehung der weißen Rose; Morgengesang; Psyche; Die Spinnerinnen; Die Logogryphe; Charade; Der Spielleute Schwanenlied; Das Epheu; Homonyme; Die Lerche; An dic Hoffnung; Glühwürmchen; Stille Freude; Heimweh; Geheimes Walten; Irdische und himmlische Liebe, eine Zeichnung von G. v. Kügelgen; Der Jüngling zu Nain; Simeon; Unsre Heimat, an Theophania [Pseud. für: Pauline von Brochowska]; Die beiden Anhöhen. Gedichte 1820: Künstlers Glaube; Werth der Zeit; Quell des Guten; Bitte; Himmlischer Seegen; Die Ruhe; Des Sängers Heilung; Des Künstlers Tod; Das Meer; Werny; Liebe der Kinder; Der Zackenfall; An Theophania [d. i. Pauline v. Brochowska]; Buchwald; Die Vestalinnen; Sappho; Ernst und schweigend, wie Gewittergrauen. Gedichte 1821: Die Stimme der Natur; Die Winterfreuden; Was mir bleibt; Fröhlicher Wechsel; Ahnung der Unsterblichkeit; Elbfahrt; Gottvertrauen; Herbstblumen; Der Schiffer; Ganymed; Das Silesier Thal; Der Heimsuchung Heil. Gedichte 1822: Der Frühlings-Engel; Ein Tag im Glatzer-Gebirge den 5. Mai 1822. Gedichte 1823: Laura; Die Wahl. Gedichte 1824: Die Schwingen des Lebens; Irrthum der Liebe, ,Die Erde eilt, daß sie sich festlich kleide.' Gedichte 1825: Der Vorzug; Parodie auf Schillers Glocke. Gedichte 1826: Das Brautkleid, meiner Schwester an ihrem Vermählungstage; Das treue Herz; Könnt' ich dein vergessen? Gedichte 1827: Marienblümchen; Liebe Nähe ,Ich weiß es nicht, wie mir geschehen.' Gedichte 1828: Die Schöpfung des Menschen, Mythe nach Hygin. Gedichte 1830: Der Christbaum, An der 'Tanne Wipfel flimmert'. Gedichte 1831: Die Gäste; Schlaf ein!, Sonettenkranz. Gedichte 1841: Sehnsucht, An des Stromes lichten Wellen'; Die Beterin.

Milon, Idylle, 1818. Die goldne Spindel, Sage, nacherzählt, 1818. Die Trauer-Birke, Idylle, 1819. Biblische Gemälde (6), 1819. Das Versprechen, Sage, 1819. Cölestine Mandolini, Erzählung, 1821. Der Charfreitag, Erzählung, 1821. Das Grab auf dem Eulengebirge, poetische Sage, 1821. Der Lorbeerkranz, Parabel, 1821. Geist und Gemüth, eine Erzählung, 1821. Sonnenhold, romantisches Gedicht in vier Gesängen,
1821. Himmlische Liebe, eine Erzählung, 1822. Agrigonien, 1822. Glycereon, Sammlung kleiner Erzählungen und Romane (enthält: Phantasie und Wirklichkeit; Huldine; Quintin Messy; Moroi), 1823. Der Wettstreit, Skizze aus den Zeiten der Meisterschulen des 14. Jahrhunderts, 1823. Das Mädchen aus dem Schlesier-Thal, Erzählung, 1823. Camillo, Erzählung, 1823. Parabeln, 1823. Zehn Reime für einen, Erzählung, 1823. Sappho und Alcäus, 1823. Des Abends Triumph, 1825. Wolfgang und Althea, oder die getrennte Welt, Erzählung, 1825. Erzählungen und Sagen (enthält: Gefühl und Empfindlichkeit; Himmlische Liebe; Wlasinka, böhmische Vollkssage; Die Hahnkrähe, schlesische Volkssage; Der Wettstreit; Die Höhle von Benidoleig, Poetische Erzählung in 2 Gesängen), 1825. Gedichte, 2 Bde., 1826. Die heilige Maria war; Parabel, 1827. Trost des Glaubens, Epistel, 1827. Der Vormund, Erzählung, 1828. Jugendliebe, aus den Papieren eines Reisenden, 1828. Parabeln, 1829. Der Christbaum, 1829. Volkssagen (enthält: Die Jungfrau vom Lurley; Der Treuenfels; Die Brüder; Welen, der Vogelsteller; oder: die Entstehung der Burg Boskowitz; Isolde, oder: die Entstehung von Adersbach), 1830. Angela, eine Geschichte in Briefen, Roman, 4 Bde., 1831. Gefühlserinnerung, Erzählung, 1832/3. Cyanen (enthält: Wolfgang und Althea; Weltsinn und Gemüth; Das Mädchen aus dem Schlesier-Thal; Elfriede, oder: das Christbäumchen; Vier weitere Geschichten, u. a. Die Heimatlosen; Novelle von Elise), 2 Bde., 1833. Stundenblumen, eine Sammlung Polterabend-Scenen und andere Festgedichte, 6 Bde., 1833. Die Überraschung am Jahrmarkte, Erzählung, 1834. Gedichte, 2. Aufl., 2 Bde., 1836-7. Gedichte, 8 Bde. (enthält: Religiöse Gedichte; Vermischte Gedichte; Gemüth; Betrachtung; Erzählende Gedichte; Aphorismen), 1837. Andachtsbuch für die Jugend reiferen Alters, 1838. Gebete für Kinder, 1838. Führungen, Bilder aus dem Gebiete des Herzens und der Welt, 1840. Buch für Kinder (enthält: Kinderlust; Kinderschatz; Kindertheater), 2 Bde., 1840. Neue Sammlung von Parabeln, 1841. Aus dem Nachlaß: Literarischer Nachlaß, 4 Bde., 1845. Mein Vermächtniß an die Jugend, 1845. Buch für Mädchen, 1850. Buch der Kindheit und Jugend, 1850. Die Wahl, Novelle, o. J. Betty, Novelle, o. J. Polterabendscherze und Spenden für Familienfeste, 4 Bde, o. J. A. fs Leben und brieflicher Nachlaß, o. J. Die Perlen und andere Erzählungen (übers. ins Englische: The Pearls, and other tales, 1857). Viele Gedichte und Parabeln als Beiträge zu einem für wohltätige Zwecke bestimmten Buch und zu Zeitschriften.

Literatur: $C . W . O . A, v$. Schindel, Die deutschen Schriftstellerinnen des neunzehnten Jahrhunderts, 1823, I und III. J. v. Großmann, „A. F, eine Lebensskizze“, in: Damenconversationslexicon, 1843, IV 225. Kein Verfassername [J. v. Großmann?], „A. F., eine Lebensskizze", in: $A$. F, A. F.s Vermächtniß an die Jugend, 1845, 1-23. H. Groß, Deutschlands Dichterinen und Schriftstellerinen, 2. Aufl. 1882, 90 f. K. Goedeke, Grundriß zur Geschichte der deutschen Dichtung aus den Quellen, 2. Aufl. 18841966, X, XI/1. H. Groß, Deutsche Dichterinen und Schriftstellerinen in Wort und Bild, 1885, I 224-28. L. Hirschberg, Hg., Der Taschengoedelke, 1961, 160. W. Kosch, Deutsches Literatur-Lexilkon, 3. Aufl. 1968-1990. E. Friedrichs, Die deutschsprachigen Schriftstellerinnen des 18. und 19. Jahrhunderts, 1981. 
Götze Auguste. Geb am 24.2. 1840 in Weimar. Vater der Sänger und spätere Gesangsprofessor Franz G., Mutter die Schauspielerin Karoline Müller. A. G. erhielt eine sorgfältige literarische und musikalische Ausbildung. Von 1853-1859 war sie Schauspielerin und Sängerin. Zwei Jahre lang (1861-1863) war sie Mitglied an verschiedenen Bühnen ( $u$. a. in Weimar, Hamburg und Würzburg), konzentrierte sich aber danach ausschließlich auf ihre Karriere als Konzertsängerin. Exfolgreiche Konzertreisen durch Deutschland, England, die Niederlande und die Schweiz. 1865 Umzug nach Dresden, wo sie sich weiter künstlerisch betätigte und 1874 Gesangslehrerin am Dresdener Konservatorium wurde. 1875 gründete sie dort eine Gesang- und Opernschule

Um diese Zeit erwachte ihre alte Neigung zum Theater wieder; ab Ende der 70er Jahre betätigte sie sich als Bühnenschriftstellerin. 1878 schrieb sie ihr erstes Drama (das Trauerspiel Susanna Mountfort); diesem Stück folgten in den nächsten 20 Jahren 13 weitere. A. G. schrieb ausschließlich Dramen, viele unter dem Pseudonym „A. Weimar", und widmete sich ansonsten ihrer Gesangsschule, die sie bei ihrem Umzug nach Leipzig 1889 dorthin verlegte. Vom Großherzog von Sachsen erhielt sie den Titel einer Kammersängerin. A. G. starb am 29.4.1908 in Leipzig.

Werke: Dramatische Werke siehe Anhang B.

Literatur: H. Groß, Deutschlands Dichterinen und Schriftstellerinen, 2. Aufl. 1882, $141 \mathrm{f} . H$. Groß, Deutsche Dichterinen und Schriftstellerinen in Wort und Bild, 1885, III 90-5. S. Pataky, Lexilkon deutscher Frauen der Feder, 1898, I. F. Brümmer, Lexikon der deutschen Dichter und Prosaisten yom Beginn des 19. Jahrhunderts bis zur Gegenwart, 6. Aufl. 1913, II. W. Kosch, Deutsches Literatur-Lexikon, 3. Aufl. 1968-90. E. Friedrichs, Die deutschsprachigen Schriftstellerinnen des 18. und 19. Jahrhunderts, 1981.

Gottsched, Luise Adelgunde Victorie. Geb. 11.4.1713 in Danzig (Kulmus), Vater der Danziger Arzt und Gymnasialprofessor Johann Georg Kulmus (1680-1731), Mutter Katharina Dorothea Schwenk (?-1734). Ein Bruder (aus Kulmus' erster Ehe) und eine Schwester; mehrere Schwestern aus seiner zweiten Ehe starben früh. L. G. erhiel von ihren Eltern eine für ihre Zeit ungewöhnliche Ausbildung, u. a. in Englisch, Französisch, Geographie, Musik, Philosophie, Mathematik, Religion und Poesie. Beide Eltern waren musikalisch und ermutigten ihre Beschäftigung mit Musik (sie spielte Klavier und Laute und komponierte); ihre akademischen Unternehmungen wurden eher unterstützt als ihre häuslichen: einer Anekdote zufolge verbrannte ihr Vater ih Klöppelzeug, damit sie sich nicht ihre Augen verderben könnte, und hielt sie stattdessen dazu an, seine lateinischen medizinischen Traktate abzuschreiben.

L. G. begann früh, Gelegenheitsgedichte zu schreiben; 1725 schrieb sie eine Ode zum Namenstag ihrer Großmutter und ein "Sinngedicht auf die Kommunionandacht" zum Namenstag ihrer Großmutter und ein "Sinngedicht auf die Kommunionandacht
ihrer Mutter, 1726 eine "Elegie" zum Namenstag ihrer Mutter, 1727 eine Ode auf Menschikoff, 1728 eine Ode über "das Unglück der Geldgeizigen", das sie ihrem mit Finanznöten geplagten Vater zum Trost überreichte. 1728 übersetzte sie Mme. de Lafayettes La Princesse de Clèves (1678). Obwohl ihre Übersetzung gut genug war, veröffentlicht zu werden, weigerte L. G. sich - nach Johann Christoph G.s Aussage -, weil es sich um einen Roman handelte. Johann Christoph G. erhiclt einige ihrer frühen Gedichte durch Bernhardi und las "ganz entzückt die geisterfüllten Lieder" (zit. Schlenther 10); er bat ihre Eltern (entweder 1727 oder 1729) um die Erlaubnis, mit ihr einen Briefwechsel führen zu dürfen, und erhielt sie. Sporadischer Briefwechsel mit Johann Christoph G. ab 1727.

1729 lernte L. G. ihn persönlich kennen, danach regelmäßiger Briefwechsel, in dem Johann Christoph G. von Anfang an die Erzieherrolle übernahm: er „suchte sie dadurch, mehr und mehr in dem Geschmacke an den Wissenschaften und freyen Künsten zu befestigen: zu welchem Ende er sie dann allmählich mit allerley deutschen und französischen Büchern, die ihrer Fähigkeit gemäß waren, versorgete" (Johann Christoph G., „Leben“, unpag. Der Autor spricht in seiner Lebensbeschreibung der L. G. von sich selbst in der dritten Person.). Schon hier drängt sich eine (vielleicht Johann Christoph G. gegenüber unfaire) Vermutung auf: der Professor erzieht sich eine gebildete Gattin, die ihm bei seinen späteren Arbeiten helfen kann.

1731 starb L. G.s Vater. Im selben Jahr übersetzte L. G, auf Johann Christoph G.s Betreiben die „Betrachtungen über das Frauenzimmer" der Mme. de Lambert aus dem Französischen (gedruckt 1734), 1735 Mme. de Gomez' "Triomphe de l'Éloquence" und Addisons Cato. 1734 faßte: Johann Christoph G. - nach seiner Aussage - den Plan, sich „mit einer so geschickten Person näher zu verbinden: deren Briefe ihm ihren fähigen Geist mehr und mehr verrathen hatten“ („Leben“). Aus L. G.s Briefwechsel ist dagegen ersichtlich, daß solche Pläne bereits seit 1731 bestanden, aber L. G. schob die Hochzeit wiederholt hinaus und begründete ihr Zögern mit dem Tod des Vaters (1731), dem Tod der Mutter (1734), und dem Krieg in Sachsen. 1734 floh L. G. mit ihrer Mutter vor der Belagerung von Danzig; in ihrer Abwesenheit wurde ihr Haus durch Bomben zerstört. Allerdings schienen auch andere Gründe in ihrer Weigerung mitzuspielen; ihre Briefe, in denen sie die Hochzeit hinausschieben oder sogar den Briefwechsel abküirzen will, sind zahlreich (Briefe I, $12 \mathrm{f}, 1731 ; 42 \mathrm{f}, 1732$; $45 \mathrm{f}, 1732$; 50-3, 1733; 53-5, 1733; 86 f, 1734; 92 f, 1734; 97-9, 1734; 100, 1734; 107, 1734; 114-6, 1734; 120-3, 1734; 130 f, 1734); ihre ständige Beschwörungsformel Johann Christoph gegenüber ist „Gelassenheit".

Obwohl sich in diesem (zensierten) Briefwechsel nur wenige Hinweise auf persönliche Differenzen mit Johann Christoph G. finden, gibt es doch zwei: einmal vermutete L. G. seine Untreue, ein Verdacht, der sich um 1754 bestätigte. Dieser Brief ist nicht in die Ausgabe ihrer Briefe aufgenommen; die Situation ist ersichtlich aus ihrem Brief vom 3. 5.1732 an Johann Christoph G., in dem sie sich für ihren Verdacht entschuldigt (Briefe I, $17 \mathrm{f}$ ). Beim anderen Mal kam Johann Christoph G. das Gerüicht zu Ohren, L. G. habe die Blattern gehabt und sei völlig entstellt worden, und er verlangte schriftlich Auflkärung (Brief an Johann Christoph G. vom 4. 9. 1734, Briefe I, 12731). Nach Friedensschluß und dem Tod ihrer Eltern waren sowohl ihre materiellen Mittel als auch ihr Reichtum an Ausflüchten erschöpft; sie heiratete Johann Christoph G. am 19.4. 1735 und zog mit ihm nach Leipzig.

Hier wurde sie zu seiner "fleißigen Helferinn", deren Aufgabe darin bestand, seine wissenschaftliche und literarische Arbeit zu fördern. Zu diesem Zweck hörte sie mit 
ihm Vorlesungen über „alle Theile der Weltweisheit“, der Rede- und Dichtkunst, „an der Thüre ihres Zimmers sitzend, welches an seinen Hörsaal stieß“ (Johann Christoph G., „Leben") und nahm auf Betreiben ihres Mannes Lateinunterricht. 1736 schrieb sie Die Pietisterey im Fischbein-Rocke nach Bougeants La Femme Docteur, das Stück er regte Aufsehen und wurde in einigen Städten verboten. 1738 die Satire Triumph der Weltweisheit. Mit der Erlaubnis ihres Mannes nahm sie Unterricht im Komponieren (bei Krebs, einem Schüler Johann Sebastian Bachs) und schrieb verschiedene Kantaten und eine Suite. Ihre Kompositionen wurden verschiedentlich anerkannt (die Komponisten Gräf und Mitzler widmeten ihr Sammlungen). 1739-43 plante ihr Mann eine Übersetzung von Addisons und Steeles Spectator und schob dabei L. G. den Löwenanteil der Arbeit zu. „Hauptsächlich machte ich dabey auf meine fleißige und arbeitsame Gattin Rechnung, die theils zu dieser Arbeit alle Lust und Fähigkeit hatte, theils ihre Nebenstunden nicht besser anwenden konnte“ (Johann Christoph G., „Leben“). So übersetzte L. G. in ihren „Nebenstunden" den größten Teil der Wochenschrift; eine Arbeit, die sich beide ursprünglich teilen wollten - aber ihr Mann war zu beschäftigt. Immerhin nahm sie ihre Arbeit für sich in Anspruch: sie unterschied ihre Übersetzungen von denen der anderen beiden Mitarbeiter durch Sternchen.

1740 die Satire „Horatii“ (anon. veröff.). 1741 Übers. zweier Briefe von de Chatelet und Mairan; im selben Jahr übersetzte sie Barbiers Cornelia für Johann Christoph G.s Deutsche Schaubühne. Auch bei diesem Projekt rechnete ihr Mann "hauptsächlich" auf sie - und zu Recht: kein Band enthält weniger als zwei Stücke von L. G. Für die Schaubilhne lieferte sie ihm Das Gespenst mit der Trommel (Übers. von Destouches' Le Tambour nocturne), Alzire (übers. von Voltaires gleichnamigem Stück), Der Verschwender (Übers. von Destouches' Le Dissipateur), und Der poetische Dorffunker (Übers. von Destouches' La Fausse Agnes), alle 1741; 1742 folgten Der Menschenfeind (Ưbers. von Molières Le Misanthrope) und Die Widerwillige (Übers. von Dufresnys L'esprit de contradiction), 1744 Der Lockenraub, eine Übersetzung von Popes The Rape of the Lock, und die Originalstücke Die ungleiche Heirath, Die Hausfranzösinn, und Panthea, ihre einzige Tragödie; 1745 Das Testament und Der Witzling. Die meisten ihrer Stücke und dramatischen Übersetzungen und Bearbeitungen wurden an Höfen, bei der Schönemannschen und bei der Neuberschen Truppe mit Erfolg aufgeführt.

Von 1741-4 übersetzte sie 330 der 635 Artikel in Johann Christoph G.s Ausgabe von Peter Bayles Historisch-kritischem Wörterbuch, ebenfalls unter der Anleitung ihres Mannes, der sich „also eine Gehülfinn aus ihr bereitete" (Johann Christoph G., „Leben“); ihr Mann zwang sie nach vollendeter Arbeit, „die vier Bände dreimal Zeile für Zeile durchzulesen" (Schlenther 24). Nebenbei rezensierte sie, schrieb Satiren auf katholische Lobreden und Leichenpredigten und weitere Übersetzungen; sie besorgte den Haushalt ihres Mannes „ohne Geräusch aufs ordentlichste“ („Leben"), katalogisierte und beschriftete seine Bibliothel und führte seinen Briefwechsel mit anderen Gelehrten, „wenn ich mit Geschäfften zu sehr überhäufet war" (,Leben").

1744 Mitarbeit an Johann Christoph G.s U'bers. von Leibniz' Theodizee. 1745 Übers. von Addisons The Guardian. 1746-7 katalogisierte sie Stücke für Johann Christoph G.s Nöthiger Vorrath, trieb Quellenforschung und bibliographierte - er war zu sehr mit "anderen alkademischen Arbeiten beschäfftiget" („Leben“). Obwohl Johann Christoph G. zugab, daß er ihr "fast den ganzen Stoff" verdankte („Leben“), wurde das Projekt unter seinem Namen veröffentlicht. Nebenbei schrieb sie Titel für seine Bibliothek.

Um diese Zeit verfaßte sie eine Geschichte der lyrischen Dichtkunst seit Ottfried; trotz geplanter Veröffentlichung fand sich kein Verleger; und sie verbrannte das Werk kurz vor ihrem Tod. 1747 Die gestürzten Freimäurer (Ưbers. von Pereaus Les Francsmaçons écrasés und L'ordre des francs-maģons trahi), anon. veröff.; 1748 Paisan parvenu (Übers. von Marivaux’ Paysan parvenu), anon. veröff.; 1749 Neue Sammlıng auserlesener Stïcke (Übers. verschiedener Prosastïcke von Pope, Newton, Eachard et, al.).

Ab 1748 arbeitete sie an Johann Christoph G.s Deutscher Sprachkunst mit; sie lieferte ihm die etymologische Grundlage für das Werk und las das gesamte Werk Korrelstur. 1749-57 Übers. der Geschichte der königlichen Akademie; 1752 Übers. der Volständigen Sammlung aller Streitschriften zwischen Maupertuis, König, Voltaire et. al.; 1753 Übers. der Cenie der Mme. de Graffigny und Der kleine Prophet von Bömischbroda (Übers. von F. M. Grimms Le petit prophet de Boebmischbroda); 1753-4 Übers. der Königlichen Akademie der Aufschriften aus dem Französischen; nebenbei schrieb sie das Goldastische Manuskript (ein Foliant!) für Johann Christoph G.s Gebrauch ab. 1755 das Vorspiel Der beste Fürst; 1756 Des Abts Terrasson Philosophie (Übers. von Jean Terrassons La philosophie applicable à tous les objets); 1757 Nachrichten, die zum Leben der Frau von Maintenon gehörig sind (Übers. von de La Beaumelles Memoires pour servir à l'histoire de Madame de Maintenon); 1758 Übers. von Beausobres Gedanken über die Glïckseligkeit.

1758-9 schrieb sie verschiedene Aufsätze im Handlexikon oder Kurzgefasstes Wörterbuch der schönen Wissenschaften und freyen Künste; ihre Beiträge bezeichnete sie wieder mit einem Sternchen. 1760 schrieb sie die Satire Briefe, die Einführung des englischen Geschmacks in Schauspielen betreffend (anon. veröff.) und übersetzte 1761 J. F. von Bielfelds Institutions politiques. Nach ihrem Tod erschienen verschiedene Gedichte von ihr und ihr Briefwechsel.

Obwohl L. G. nur für einen Bruchteil ihrer Arbeit Anerkennung erhielt (vieles wurde anonym oder unter dem Namen ihres Mannes veröffentlicht), wurde sie berühmt. Sie galt als die gebildetste Frau Deutschlands und nahm 1749 an öffentlichen wissenschaftlichen Diskussionen teil. Wegen ihres Ruhmes konnten die G.s wornehmen Umgang“ („Leben“) pflegen, d. h.: Umgang mit dem Adel. Johann Christoph G. berichtet ausführlich von einer Audienz L. G.s bei Maria Theresia im Jahre 1749. 1755 beehrte der Kurprinz von Dresden das Paar mit Eintrittskarten für eine Aufführung ihrer Ungleichen Heirath, die der Kurprinz angeordnet und dafür das ursprünglich geplante Stück abgesetzt hatte; die G.s durften sogar auf dem für Adlige reservierten Balkon sitzen. Teilweise profitierte Johann Christoph G. mehr von ihrem Ruhm als sie selber; er beschreibt z. B., daß er in Wilhelmstal mit dem Landgrafen Wilhelm speisen durfte, während L. G. mit der übrigen Gesellschaft „aus der Herrschaftlichen Küche mit Speisen versorget" wurde („Leben"). Ähnliches berichtet er von einer Reise nach Geismar, wo er mit dem Erbprinzen dinierte und L. G. „versorget“ wurde. 
Daß ein Pensum wie das oben beschriebene nicht spurlos an der "fleißigen Gehülfinn" vorbeigehen konnte, stand zu erwarten. Im Sommer 1752/3 hatte L. G. das Tertianfieber; jetzt gönnte ihr ihr Mann - nach eigener Aussage - eine Pause. Die meisten der Ehrungen von Adligen fanden auf Erholungsreisen statt, auf denen L. G. ihre ruinierte Gesundheit reparieren sollte. Seit 1760 war sie ernsthaft krank; ihre Mitarbeit an Johann Christoph G.s Übersetzung von Bielfelds Lehrbegriff der Staatskunst wa „Das einzige, wozu ich sie noch bewegen konnte" („Leben“). Ihr Mann hatte mit dem Verleger das Erscheinen der beiden Bände auf den Winter 1760 festgesetzt, und die Zeit wurde knapp. So ließ L. G. „sich auch dießmal im Winter 1760 willig finden " („Leben“), obwohl sie schon nicht mehr schreiben konnte: die Übersetzung mußte sie diktieren.

Die letzten zwei Jahre war L. G. ein physisches Wrack; sie konnte nicht mehr schreiben und kaum noch essen oder trinken, hatte ständige Ohnmachten und unterzog sich häufigen Aderlässen. Das letzte halbe Jahr vor ihrem Tod verließ sie das Haus nich mehr. In einem Brief an ihre Freundin Dorothea Henriette von Runckel, mit der sie seit 1752 befreundet war (und die später ihre Briefe herausgab), macht sie ihr literarisches Sklavendasein bei Johann Christoph G. indirekt für ihre Krankheit verantwortlich. „Fragen Sie nach der Ursache meiner Krankheit? Hier ist sie: Acht und zwanzig Jahre ununterbrochene Arbeit, Gram im Verborgenen und sechs Jahre lang unzählige Thränen" (Brief vom 4. 3. 1762, Briefe III, 167 f). Nach wiederholten Schlaganfällen und teilweiser Lähmung starb L. G. am 26. 6. 1762 in Leipzig.

L. G. ist häufig für eine Frau gehalten worden, die fest daran glaubte, „daß die Hauptaufgabe einer Frau die Ehe und die Kinder seien“ (Sanders, „Ein kleiner Umweg“, 170). Jede Biographie beschäftigt sich ausführlich mit ihren Klagen über ihre eigene Kinderlosigkeit und ihrem Widerstand gegen die "Gelehrsamkeit" von Frauen (ihre abfälligen Bemerkungen über die Promotion der Naturforscherin Laura Bassi, ihre eigene Weigerung, der Leipziger Deutschen Gesellschaft beizutreten, ihre ständige Furcht, als gelehrte „Pedantin“" zu gelten). Aber es gibt durchaus Anzeichen dafür, daß diese Bemerkungen eher eine (nicht ganz neidlose) Schutzreaktion gewesen sein könnten; daß L. G. sich selbst als ernstzunehmende Schriftstellerin verstand und nicht nur als die „Helferinn" ihres Mannes, und daß sie sich nach der ihr gebührenden Anerkennung sehnte. In der oben erwähnten Audienz bei Maria Theresia, die sie in einem Brief an Frl. Thomasius beschreibt, antwortet sie auf die Frage der Kaiserin, wie sic so gelehrt geworden sei: „ich wünschte es zu seyn, um des Glückes, welches mir heute begegnete, und wodurch ganz allein mein Leben merlswürdig [d. h.: bemerkenswert, S. K.] werden würde, nicht so gar unwerth zu seyn" (zit. in Johann Christoph G., "Leben"). Spricht sie hier von der Audienz selbst oder allgemeiner von der Anerkennung ihrer Leistungen? Einen Briefwechsel mit der ostentativ feministischen Schriftstellerin Sidonie Hedwig Zäunemann lehnt sie zwar ab, aber mit einer bewundernden Bemerkung, in der die stille Hoffnung mitschwingt, daß vielleicht deren Extremismus meh Erfolg hätte als ihre eigene Moderation. „Ich wünsche, daß uns einst Dein Griffe überzeuge,/ Daß auch ein Weiberkiel, trotz Männer-Federn steige" (Kleinere Gedichte 109).
Ihre „Acht und zwanzig Jahre ununterbrochene Arbeit" kamen hauptsächlich ihrem Mann zugute; die Rezeption beider Autoren, abgesehen von jüngsten Selsundärwerken, beweist es. Schon in ihrem Todesjahr schrieb Walz in seinem Nachruf auf sie: „Die Feder sinkt, die lauten Seufzer stöhren/Den Klageton. Doch was erhebt/ Schnell unser Herz? O sanfter Trost! wir hören/ Der Vorsicht Ruf: Ihr Gatte lebt" (zit. in: Kleinere Gedichte 484). Ihr Gatte lebte bis 1766 und heiratete kurz nach L. G.s Tod wieder

Werke: Dramatische Werke siehe Anhang B. Ode zum Namenstag der Großmutter, 1725. Sinngedicht auf die Kommunionandacht ihrer Mutter, 1725. Elegie zum Namenstag ihrer Mutter, 1726. Ode auf Menschikoff, 1727. Ode über das Unglück der Geldgeizigen, 1728. Die Prinzessinn von Cleves (Übers. v. Mme. de Lafayettes La Princesse de Clèves, 1678), 1728. Der Frau von Lambert Betrachtungen über das Frauenzimmer (Übers. v. Mme de Lambert), 1731 (gedruckt 1734). Das glückliche Rußland am Geburtstage Ihro Kaiserl. Majestät Anna Ixyanowna (Ode), 1733. Triumph der Beredsamkeit (Úbers. v. Mme. de Gomez' "Triomphe de l'Éloquence“), 1735. Triumph der Weltweisheit, 1738. Eine Suite und mehrere Kantaten, (1738/9?). Der Zuschauer (Mitarbeiterin; Übers. v. Addisons und Steeles Spectator), 1739-43. Horatii, 1740 (anon.). Zwo Schriften, welche von der Frau Marquise von Chatelet und dem Herrn von Mairan, das Maaß der lebendigen Kräfte in den Körpern betreffend, sind gewechselt worden (Übers.), 1741. Der Lockenraub (Übers. von Popes'The Rape of the Lock), 1744. Historisches und kritisches Wörterbuch (Mitarbeiterin; Übers. v. Peter Bayles Historisches und kritisches Wörterbuch), 1741-4. J. Chr. Gottsched, Theodizee (Mitarbeiterin, Übers. von Leibniz'Theodizec), 1744. Der Aufseher oder Vormund (Ưbers. yon Addisons The Guardian), 1745. J. Chr. Gottsched, Nöthiger Vorrath (Mitarbeiterin), 1746-7. Die gestürzten Freimäurer (Übers. von Pereaus Les Francs-maçons écrasés und Lordre des francs-maçons trahi), 1747 (anon). Geschichte der lyrischen Dichtkunst seit Ottfried, ca. 1747. Ueber die Gelehrsamkeit des Frauenzimmers, in: Die Vernünftigen Tadlerinnen, 1747-8. Ueber Arbeit und Müßiggang, in: Die Vernủnftigen Tadlerinnen, 1747-8. Weitere Aufsätze in derselben Zeitschrift, 1747-8. Paisan parvenu (U'bers. von Marivaux' Paysan parvenu), 1748 (anon.). J. Chr. Gottsched, Deutsche Sprachkunst (Mitarbeiterin), 1748-?. Neue Sammlung auserlesener Stücke (Übers. verschiedener Prosastücke von Pope, Newton, Eachard et. al.), 1749. Geschichte der königlichen Akademic der Aufschriften und schönen Wissenschaften zu Paris (Übers.), 1749-57. Vollständige Sammlung aller Streitschriften über das vorgebliche Gesetz der Natur von der kleinsten Kraft in den Wirkungen der Körper (die zwischen dem Präsidenten von Maupertuis in Berlin, dem Prof. König in Holland, dem Herrn von Voltaire u. a. gewechselt worden), Übers. 1752. Der kleine Prophet von Bömischbroda (Übers. von F M. Grimms Le petit prophet de Boehmischbroda), 1753. Der Königlichen Akademie der Aufschriften und schönen Wissenschaften zu Paris ausfiihrliche Schriften (Übers.), 1753-4. Des Abts Terrasson Philosophie (Übers. von Jean Terrassons La philosophie applicable à tous les objets), 1756. Nachrichten, dic zum Leben der Frau von Maintenon gehörig sind (Übers. von de La Beaumelles Memoires pour servir à l'histoire de Madame de Maintenon), 1757. Gedanken über die Glückseligkeit (Übers. v. Beausobre), 1758. Handlexilkon oder Kurzgefasstes Wörterbuch der schönen 
Wissenschaften und freyen Künste (Mitarbeiterin); 1758-9. Briefe, die Einführung des englischen Geschmacks in Schauspielen betreffend, 1760 (anon.). Des Freyherrn von Bielefeld Lehrbegriff von der Staatskunst (Übers. v. J. F. von Bielfelds Institutions politiques), 1761. Der Frau L. A. V. G., geb. Kulmus, sämmtliche Kleinere Gedichte, 1763. Briefe der Frau L. A. V. G. gebohrne Kulmus, 3 Bde., 1771-2. Weitere Rezensionen, Satiren und Übersetzungen.

Literatur: J. Chr. Gottsched, Nöthiger Vorrath zur Geschichte der deutschen Dramatischen Dichtluunst, 1757, unpag. J. Chr. Gottsched, „Leben“, in: L. G., Sämmtliche Kleinere Gedichte, 1763, unpag. Almanach der deutschen Musen, 1772, 48 f. J. G. Meusel, Lexilkon der vom Jahr 1750 bis 1800 verstorbenen teutschen Schriftsteller, 1802-1816, IV. K. Herloßsohn und H. Marggraff, Allgemeines Theater-Lexikon, 1846, IV. R. E. Prutz, Vorlesungen über die Geschichte des deutschen Theaters, 1847, $259 \mathrm{f}$ Th. Mundt, Dramaturgie, oder Theorie und Geschichte der dramatischen Kunst, 1848, 407 f. Th. W. Danzel, Gottsched und seine Zeit, 1855, 142-4, 167. [T. Robinson], Deutschlands Schriftstellerinnen bis vor hundert Jahren, von Talvj [Pseud.] 1861, 115-34. H. Groß, Deutschlands Dichterinen und Schriftstellerinen, 2. Aufl. 1882, 23 f. K. Goedeke, Grundriß zur Geschichte der deutschen Dichtung aus den Quellen, 2. Aufl. 1884-1966, III/2. H. Groß, Deutsche Dichterinen und Schriftstellerinen in Wort und Bild, 1885, I 28-43. P. Schlenther, Frau G. und die bürgerliche Komödie, 1886. H. Devrient, Johann Friedrich Schönemann und seine Schauspielergesellschaft, 1895, 29; 74 [Anm. 112]; 90; 179; 182; 182 [Anm. 297]; 219 f [Anm. 359]; 232 f; 233 [Anm. 384]; 49; Anh. XXIII, 328; Anl. XXXVII, 349-54; Anh. XXXVIII, 356; Anh. XXXIX, 358-65. H. Devrient, Die Schönemannsche Truppe in Berlin, Breslau, Danzig und Königsberg 1742-1744, Diss. (Jena), 1895, 12, 28, 40 48, 50 f, 53-6. S. Pataky, Lexilkon deutscher Frauen der Feder, 1898, I. A. v. Hanstein, Die Frauen in der Geschichte des Deutschen Geisteslebens des 18. und 19. Jahrhunderts, 1900, I 113, 117-26, 129-31, 141-5, 147-52, 154-8, 163, 165, 169, 183, 186, $196 \mathrm{f}, 199,211,234,265-8,270,272,274 \mathrm{f}, 279,284 \mathrm{f}, 289,294,304-6,308 \mathrm{f}$, 311 f, 321, 330; II 51-3, 60, 70 f, 77, 79, 94, 103, 106, 188, 194, 196, 202, 204, 217 , $238,247,262,265,273,359,365,377,437$. F. Brüggemann, Hg., Gottscheds Lebensund Kunstreform in den zwanziger und dreißiger Jahren, Gottsched, Breitinger, die G.in, die Neuberin, 1935. H. A. Ploetz, „Ein Lebensbild, A. G. geb. Culmus (17131762)“, in: Geistige Arbeit II, 15 (1935), 12. H. Kindermann, Theatergeschichte der Goethezeit, 1948, 271 und 275. S. E. Schreiber, The German Woman in the Age of Enlightenment, 1948, 41-88. L. Hirschberg, Hg., Der Taschengoedeke, 1961, 207 f, G. v Wilpert, Deutsches Dichterlexikon, 1963. W. Kosch, Deutsches Literatur-Lexilson, 3. Aufl. 1968-1990. V. Richel, L. G., A Reconsideration, Diss. (Yale), 1968. R. H. Sanders, The Virtuous Woman in the Comedies of the Early German Enlightenment, Diss. (SUNY Stony Brook), 1970, 9-15, 51-94. R. H. Sanders, „Ein kleiner Umweg, Das literarische Schaffen der L. G.", in: B. Becker-Cantarino, Hg., Die Frau von der Reformation zur Romantik, 1980, 170-94. E. Friedrichs, Die deutschsprachigen Schriftstellerinnen des 18. und 19. Jahrhunderts, 1981. F. J. v. Reden-Esbeck, Caroline Neuber und ihre Zeitgenossen, 1881 (Neudruck 1985), 85 f. Arnd Bohm, „Authority and Authorship in L. A. G.'s Das Testament", in: R. Schade, Hg., Lessing Yearbook XVIII (1986), 129-40. B. Becker-Cantarino, „Bildung, Schreiben und Selbständigkeit, Christiana Mariana von Ziegler, die G.in, Sidonie Hedwig Zäunemann, die Karschin", in: B. Becker-Cantarino, Der lange Weg zur Mündigkeit, Frau und Literatur (15001800), 1987, 259-78. R. P. Dawson, „Frauen und Theater, Vom Stegreifspiel zum bürgerlichen Rührstück“, in: G. Brinker-Gabler, Hg., Deutsche Literatur von Frauen, 2 Bde., 1988, I 425 f. M. Heuser, „Den Musenchor mit neuer Ehre zieren, Schriftstellerinnen zur Zeit der Frühauflklärung", in: G. Brinker-Gabler, Hg., Deutsche Literatur von Frauen, 2 Bde., 1988, I 302-7. V. Richel, The German Stage, 1767-1890, A Directory of Playwrights and Plays, 1988, 51 f. B. Becker-Cantarino, "L. A. V. G.", in: E. Frederiksen, Hg., Women Writers of Germany, Austria, and Switzerland, 1989, 86.

Günderrode, Karoline von. Geb. 11. 2. 1780 in Karlsruhe. Vater Regierungsrat, badischer Kammerherr und Schriftsteller Hektor Wilhelm v. G., Mutter Luise Dorothea Agatha v. G. Sechs jüngere Geschwister, von denen drei Schwestern früh starben. 1786 Tod des Vaters und Umzug von Karlsruhe nach Hanau. 1797 wurde sie aus finanziellen Gründen im Cronstetter-Hynspergischen Stift für (verarmte) adlige Damen in Frankfurt/M. aufgenommen, obwohl die Stiftsregeln ein Mindestalter von 30 Jahren voraussetzten. K. v. G. fühlte sich im Stift isoliert und unternahm häufig Reisen zu Freunden und Verwandten.

Ihr besonderes Interesse, das sich vielfach in ihrem Werk äußert, galt der Mythologie und frühgesellschaftlichen, östlichen und matriarchalischen Kulturen; sie war vielseitig gebildet und belesen und bewies großen schriftstellerischen Ehrgeiz. Enge Freundschaft und ausführlicher Brieflkontakt mit Bettina Brentano (später von Arnim), die sie in Frankfurt kennenlernte; ihr Bruder Clemens bewarb sich erfolglos um K. v. G. Freundschaft mit Karoline Leonhardi, Susanne von Heyden, Pauline und Lotte Servière und Lisette Mettingh (später von Esenbeck). Seit 1799 unglückliche Liebe und Briefkontalst zu Carl von Savigny, den sie auch nach dessen Heirat mit Gunda Brentano (1804) fortsetzte. Seit 1804 Liebesbeziehung zu dem verheirateten Philologen und Mythologen Friedrich Creuzer, den sie in Heidelberg kennenlernte

1804 Veröffentlichung ihrer Gedichte und Phantasieen unter dem Pseudonym Tian durch Vermittlung von Nees von Esenbecks; 1805 veröffentlichte sie ihre Dramen Udobla und Mahomed in Creuzers und Carl Daubs Studien. 1806 folgten Poetische Fragmente unter dem Pseudonym Ion. Auf Creuzers Anraten brach sie 1806 ihre Bezichung zu B. v. Arnim ab. Als Creuzer sich von ihr trennte, beging K. v. G. am 26. 7. 1806 in Winkel am Rhein Selbstmord.

Obwohl K. v. G. seit einigen Jahren als Schriftstellerin ernstgenommen wird, gibt es noch keine ausführliche biographische Studie über sie. Der romantische Hintergrund ihres Todes scheint einen unvoreingenommenen Blick auf ihr Leben zu erschweren und eher zu filktiven Bearbeitungen anzuregen (wie die von Steffen und Wolf). Aber auch bei biographisch intendierten Werken handelt es sich häufiger um Filktion als um eine Aufarbeitung ihres Lebens; schon B. v. Arnims zweibändiges Werk Die Gïnderrode (1840) enthält (bewußt) fiktive Elemente, und L. Hirschbergs „Mährchen von der 
schönen Günderode" (1906) ist, dem Titel entsprechend, eine subjektiv-fiktive Huldigung mit wenig Informationsgehalt. Biographische Materialien beschäftigen sich hauptsächlich mit ihren „empfindsamen, stark melanchol. Zügen“ (v. Wilpert), ihrem Selbstmord und den Gründen für ihren Selbstmord (Rohde, Preisendanz, Burwick). Wissenschaftliche Studien über ihr Werk sind noch seltener als biographisch-filktive Nacherzählungen ihres Lebens.

Werke: Dramatische Werke siehe Anhang B. Briefe an Bettina Brentano. Briefe an Carl und Gunda v. Savigny. Gedichte und Phantasien, 1804. Briefe an F. Creuzer, 1804-6. Poetische Fragmente, 1806. Melete, 1806. Gesammelte Dichtungen, 1858. Melete von Ion, 1906. Gesammelte Werke, 3 Bde., 1920. Gesammelte Werke, 3 Bde., 1970. Der Schatten eines Traumes, Gedichte, Prosa, Briefe, hg. C. Wolf, 1981

Literatur: G. Chr. Hamberger und J. G. Meusel, Das gelehrte Teutschland oder Lexikon der jetzt lebenden teutschen Schriftsteller, 1796-1834, XVII. C. W. O. A. v. Schindel, Die deutschen Schriftstellerinnen des neunzehnten Jahrhunderts, 1823, I. $B$. v. Arnim, Die G., 2 Bde., 1840. H. Groß, Deutschlands Dichterinen und Schriftstellerinnen, 2. Aufl. 1882, 37 f. K. Goedeke, Grundriß zur Geschichte der deutschen Dichtung aus den Quellen, 2. Aufl. 1884-1966, VI. L. Geiger, K. v. G. und ihre Freunde, 1895. E. Rohde, F. Creuzer und K. v. G., 1896. S. Pataky, Lexilson deutscher Frauen der Feder, 1898, I. L. Hirschberg, „Das Mährchen von der schönen Günderode“, in: K. v. G., Gesammelte Wcrke, 1970, I rX-XxI. E. Regen, Die Dramen K. v. G.s, 1910. K. Preisendanz, Die Liebe der G., F. Creuzers Briefe an K. v. G., 1912. O. Heuschele, K. v. G., 1932. M. Matheis, K. v. G., 1934. K. v. G., Briefe, in: F. v. Zobeltitz, Hg., Briefe deutscher Frauen, 1936, 177-82. R. Wilhelm, Die G., Dichtung und Schicksal, 1938. R. Steffen, K. v. G., eine Tragödie, 1946. W. Howeg, K. v. G. und Hölderlin, Diss. Halle, 1953. A. Naumann, K. v. G., Diss. Berlin, 1957. L. Hirschberg, Hg., Der Taschengoedeke, 1961, 224. G. v. Wilpert, Deutsches Dichterlexikon, 1963. W. Kosch, Deutsches Literatur-Lexikon, 3. Aufl. 1968-1990. C. Wolf; Kein Ort. Nirgends, 1979. R. Burwick, „Liebe und Tod im Leben und Werk der G.", in: German Studies Review 3 (1980), 207-24. F. Hetmann [d. i. H. C. Kirsch], Drei Frauen zum Beispiel, Simone Weil, Isabel Burton, K. v. G., 1980. E. Friedrichs, Die deutschsprachigen Schriftstellerinnen des 18. und 19. Jahrhunderts, 1981. C. Wolf, „Der Schatten eines Traumes, K. v. G., cin Entwurf", in: Lesen und Schreiben, 1981, 225-83. G. Brinker-Gabler, $H g$, ,K. v. G.“, in: G. Brinker-Gabler, Ho, Deutsche Dichterinnen vom 16. Jahrhundert bis zur Gegenwart, 1986, 159-63. G. Brinker-Gabler, „K. v. G.“, in: G. BrinkerGabler, K. Ludwig, A. Wöffen, Hg., Lexikon deutschsprachiger Schriftstellerinnen 1800-1945, 1986. H. Kastinger Riley, „Zwischen den Welten. Ambivalenz und Existentialproblematilk im Werk C. v. G.s", in: H. Kastinger Riley, Die weibliche Muse, Sechs Essays über kzinstlerisch schaffende Frauen der Goethezeit, 1986, 91-119, 197-203. E. Frederiksen, „K. v. G.", in: E. Frederiksen, Hg., Women Writers of Germany, Austria, and Switzerland, 1989, 87-9.

Günther, Marie (in Lexika auch: Brauer, Marie). Geb. am 29.5. 1854 in Lübeck. Vater der Schauspieler Leoopold G. (1825-1902), Mutter Minna Schulz-Wiek. Mit
12 Jahren schrieb sie einige Stücke fiir ihr Puppentheater. Ihre Mutter bildete M. G. zur Sängerin aus. M. G. machte Konzertreisen durch Deutschland und trat mit großem Erfolg in Rostock, Hamburg, Kassel, Neustrelitz und Altenburg auf. Aus gesundheitlichen Gründen verließ sie (Anfang der 70er Jahre?) die Bühne und lebte bei ihrem Vater in Schwerin. Von 1873 bis 1893 äußerst produltive dramatische Schriftstellerin (sie schrieb insgesamt 31 Lustspiele und dramatische Märchen in ebensovielen Jahren).

1891 Heirat mit dem Schweriner Hofschauspieler Oskar Brauer; die Ehe wurde 1895 geschieden. Nach dem 'Tod ihres Vaters 1902 zog M. G. nach Wiesbaden um; dort sind alle Unterlagen verbrannt. Weitere biographische Angaben nicht crhältlich; Todesdatum unbelkannt [1916?].

Werke: Dramatische Werke siehe Anhang B.

Literatur: S. Pataky, Lexilkon deutscher Frauen der Feder, 1898, I. F. Brïmmer, Lexikon der deutschen Dichter und Prosaisten vom Beginn des 19. Jahrhunderts bis zur Gegenwart, 6. Aufl. 1913, III. W. Kosch, Deutsches Literatur-Lexilkon, 3. Aufl. 196890. E. Friedrichs, Die deutschsprachigen Schriftstellerinnen des 18. und 19. Jahrhunderts, 1981. V. Richel, The German Stage, 1767-1890, A Directory of Playwrights and Plays, 1988, 55.

Hillern, Wilhelmine von. Geb. am 11.3. 1836 in München (Birch). Vater der Schriftsteller Christian Birch (1795-1868), Mutter die Schauspielerin und Dramatikerin Charlotte Birch-Pfeiffer (1800-1868, siehe dort). Sorgfältige Erziehıng im Elternhaus durch Hauslehrer und Kontakt mit vielen Künstlern und Wissenschaftlern, die regelmäßige Gäste der Eltern waren. Ihre Mutter, selbst eine berühmte dramatische Schriftstellerin, Schauspielerin und Theaterdirektorin, erlaubte ihr erst mit 12 Jahren den ersten Theaterbesuch, der W. v. H. so beeindruckte, daß sie sich entschloß, selbst Schauspielerin zu werden.

Erster Auftritt 1854 in Gotha als Julia; danach Gastspiele u. a. an den Hoftheatern in Braunschweig, Karlsruhe und Berlin, an den Stadttheatern Frankfurt/M. und Hamburg und ein festes Engagement am Hof- und Nationaltheater Mannheim. Ihre kurze Laufbahn als Schauspielerin war schr erfolgreich; Groß berichter, „dass sie schon im Begriffe stand eine deutsche Rachel zu werden" $(1882,131)$

1857 Heirat mit dem badischen Kammerherrn und Hofgerichtsdirektor Hermann v. H., Abgang von der Bühne und Umzug nach Freiburg i. Br. Drei Töchter; u. a. die Schriftstellerin Hermine Diemer (1859-1924). Regelmäßiger Umgang mit Mitgliedern der Freiburger Universität und Beginn ihrer schriftstellerischen Tätigkeit.

Ihr erster Roman (Doppelleben, 1865) war cin Erfolg; ihm folgten bis 1903 noch viele Romane und Erzählungen und einige Lustspiele. Viele ihrer Romane erreichten mehrere Auflagen. 1880 dramatisierte sie ihren erfolgreichsten Roman, Die Geier-Wally (1875). Das Stück wurde auf vielen deutschen Buihnen aufgeführt, in acht Sprachen übersetzt und mehrfach verfilmt, u. a. 1956 als Heimatfilm. 1882 Tod des Mannes und Umzug nach Oberammergau. Ihr letztes Werk, der Roman Ein Sklave der Freiheit stammt aus dem Jahre 1903; 1904 Übertritt zur katholischen Kirche. 1911 Umzug nach Hohenaschau bei Prien/Chiemsee. Dort starb W. v. H. am 25. 12. 1916 
Werke: Dramatische Werke siehe Anhang B. Doppelleben, Roman, 2 Bde, 1865. Ein Arzt der Seele, Roman, 4 Bde., 1869 (5. Aufl. 1906). Aus eigener Kraft, Roman, 3 Bde., 1872 (3. Aufl. 1896). Dic Geyer-Wally, eine Geschichte aus den Tiroler Alpen, 2 Bde., 1875. Höher als die Kirche, eine Erzählung aus alter Zeit, 1877. Ernestine, Roman, 1879. Und sie kommt doch, Erzählung aus einem Alpenkloster des dreizehnten Jahrhunderts, 3 Bde., 1879 (6. Aufl. 1907). Jugendträume, 1881. Der Skalde, Episches Gedicht, 1882. Friedhofsblume, Novelle, 1883. Am Kreuz, ein Passionsroman aus Oberammergau, 2 Bde., 1890 (2. Aufl. 1900). 's Reis am Weg, Geschichte aus dem Isarwinkel, 1897. Ein alter Streit, Roman aus dem bayrischen Volksleben der sechziger Jahre, 1898. Der Gewaltigste, Roman, 1901. Ein Sklave der Freiheit, Roman, 1903.

Literatur: H. Groß, Deutschlands Dichterinen und Schriftstellerinen, 2. Aufl. 1882, 131 f. $H$. Groß, Deutsche Dichterinen und Schriftstellerinen in Wort und Bild, 1885, II 477-84. S. Pataky, Lexikon deutscher Frauen der Feder, 1898, I, R. v, Gottschall, Die deutsche Nationalliteratur des 19. Jahrhunderts, 7. Aufl. 1902, IV 341-45. F. Brümmer, Lexilkon der deutschen Dichter und Prosaisten vom Beginn des 19. Jahrhunderts bis zur Gegenwart, 6. Aufl. 1913, III. H. Spiero, Geschichte der deutschen Frauendichtung, 1913, 60 f. T. Fontane, Plaudereien über das Theater, 1926. W. Kosch, Deutsches Literatur-Lexikon, 3. Aufl. 1968-90. E. Friedrichs, Die deutschsprachigen Schriftstellcrinnen des 18, und 19. Jahrhunderts, 1981. J. Blackwell, „Die nervöse Kunst des Frauenromans im 19. Jahrhundert oder Der geistige Tod durch kränkende Handlung", in: R. Berger et. al. (Hg.), Frauen, Weiblichkeit, Schrift, 1985, 145-54. G. Bisterfeld, „W. v. H.", in G. Brinker-Gabler, K. Ludwig, A. Wöffen, Hg., Lexikon deutschsprachiger Schriftstellerinnen 1800-1945, 1986. V. Richel, The German Stage, 1767-1890, A Directory of Playwrights and Plays, 1988, 68. J. Blackwell, „W. v. H.“, in: E. Frederiksen, Hg., Women Writer's of Germany, Austria, and Switzerland, 1989, $103 \mathrm{f}$

Hölder, Luise. Geb. wann? (Ende des 18. Jahrhunderts) in Fürth in Bayern. Sie war Kinder- und Jugendschriftstellerin und lebte in oder bei Nürnberg. Todesdatum und -ort unbekannt. Weitere Angaben trotz ihres umfangreichen Werkes nicht erhältlich.

Werke: Dramatische Werke siehe Anhang B. Des jüngeren Robinson Rückreise nach seinem Eilande, in Begleitung seiner Kinder, 1821. Neue Gesellschaftsspiele und Unterhaltungen, 1823. Die Familie Edmund oder die Weltgeschichte im Kleinen, 1823 (unter dem Pseud. L. Hold). Leben und Taten des ... Don Quixote von la Mancha von Mich. Cervantes, zur Unterhaltung und Belustigung der Jugend [nach Tiecks Übers.] neu bearbeitet, 1824. Kleine Kindergeschichten, Fabeln und Erzählungen, 1824. Geschichtlicher Erntelsranz, 1824 (unter dem Pseud. L. Hold). Dic ErzichungsSchule in anziehenden, munteren und lehrreichen Unterhaltungen, 2 Bde., $1824 \mathrm{f}$ (unter dem Pseud. L. Hold). Kurze naturhistorische Fabeln und Erzählungen, 1826. Allerlei Schauspiele, Erzählungen, Märchen, sinnreiche Gespräche und Gedankenspiele, 1832. Andere Jugendschriften, oft unter dem Pseud. Luise Hold.

Literatur: G. Chr. Hamberger und J. G. Meusel, Das gelehrte Teutschland oder Lexilkon der jetzt lebenden'teutschen Schriftsteller, 1796-1834, XXII 2. C. W. O.A v. Schindel, Die deutschen Schriftstellerinnen des neunzehnten Jahrhunderts, 1823, I und III. K. Goedeke, Grundriß zur Geschichte der deutschen Dichtung aus den Quellen, 2. Aufl. 1884-1966, X und XI/2. W. Kosch, Deutsches Literatur-Lexikon, 3. Aufl. 1968-1990. E. Friedrichs, Die deutschsprachigen Schriftstellerinnen des 18, und 19. Jahrhunderts, 1981

Hoffmann, Bertha. Geb, am 5. 2. 1816 in Prester bei Magdeburg (Flügel). Vater der Baurat ? Flügel, Mutter ?. Ihre Jugend verlebte sie in Angermünde. Geh. Dezember 1845 den Baurat Friedrich H. Die Wintermonate verbrachte sie in Berlin, die Sommermonate im Riesengebirge. Außer einem Märchen (ihr erstes Werk, 1860), zwei Gedichtbänden und einer Liedersammlung verfaßte sie ausschließlich dramatische Werke. Gest. 1892 in Berlin.

Werke: Dramatische Werke siehe Anhang B. Was den Kindern gefällt, Märchen, 1860. Wartburg, Gedichte, 1868. Kriegs- und Sicgeslieder, 1871. Bilderlese, Gedichte, 1875.

Literatur: H. Groß, Deutschlands Dichterinen und Schriftstellerinen, 2. Aufl. 1882, 142. S. Pataky, Lexilkon deutscher Frauen der Feder, 1898, I. F Brïmmer, Lexikon der deutschen Dichter und Prosaisten vom Beginn des 19. Jahrhunderts bis zur Gegenwart, 6. Aufl. 1913, III. W. Kosch, Deutsches Literatur-Lexikon, 3. Aufl. 1968-90. E. Friedrichs, Die deutschsprachigen Schriftstellerinnen des 18. und 19. Jahrhunderts, 1981.

Hofmann, Kitty (in Lexika auch: Hoffmann, K.). Geb. wann? (von Blei). Lebte 1834 (und 1826?) in Agram. Keine weiteren Angaben erhältlich.

Werke: Dramatische Werke siehe Anhang B. Auf das allerhöchste Jubelfest der fünfzigjährigen Priesterweihe ... des Herrn Agramer Bischof Maximilian Verhovacz am 1. Jänner 1826. Auf das allerhöchste Jubelfest der fünfzigjährigen Priesterweihe ... des Herrn Agramer Bischof Alexander von Agalovich am 30. Dezember 1834.

Literatur: K. Goedeke, Grundriß zur Geschichte der deutschen Dichtung aus den Quellen, 2. Aufl. 1884-1966, XI/2 und XII. W. Kosch, Deutsches Literatur-Lexilon, 3. Aufl. 1968-1990. E. Friedrichs, Die deutschsprachigen Schriftstellerinnen de 18. und 19. Jahrhunderts, 1981.

Huber, Christiane Friederike. Geb. wann? (1721, 17. 5. 1729, 1730?) in Zittau (Lorenz). Vater Schauspieler Johann Friedrich Lorenz, Mutter ?. Sie war Schauspielerin Debüt in Wien 1741. Von da zog sie mit ihren Eltern nach Danzig und spielte dort bei Sellier; 1744 spielte sie, wahtscheinlich bis 1748, bei Karoline Neuber in Leipzig. Dort lernte sie Lessing kennen „und trat mit ihm in nähere Beziehungen“" (Stein); sowoh Stein als auch Hanstein vermuten, daß sie seine Jugendgeliebte war. Sie ging 1748 nach Wien, wohin Lessing ihr gefolgt sein soll, bevor er nach Berlin ging, und war dort bis zu ihrem Tod 1799 am Hoftheater fest angestellt. 1751 heiratete sie den Schauspieler Joseph Karl H. (1726-1760) und ander Weidner. C. F. H. war eine sehr erfolgreiche Schauspielerin; Sonnenfels, Eva König 
(damals Lessings Verlobte) und Anna Luisa Karsch schrieben begeisterte Kritiken von ihren Auftritten. König über ihre Darstellung der Claudia Galotti: „Sie hat meines Erachtens in der größten Vollkommenheit gespielt. Wenigstens ich habe in meinem Leben keine Rolle so ausführen sehen und bei keiner das empfunden, was ich be ihr empfand" (Brief an G. E. Lessing, 15. 6. 1772, zit. Stein). 1788 erhielt C. F. H. zu ihrem 40jährigen Jubiläum als erstes Hoftheatermitglied die große goldene Ehrenmedaille C. F. H. starb am 14. 11. 1799 (wo?). Nach J. H. Müller „wären, sie zu ersetzen, drei Schauspielerinnen nötig" (zit. Stein).

Hanstein ist der einzige ihrer Biographen, der ihre schriftstellerische Tätigkeit auch nur erwähnt; er berichtet, C. F. H. habe sich nicht nur als Schauspielerin, sondern auch als "Bearbeiterin von Dramen [...] großen Ruf erworben“ und „dic „Miß Sara Lessing's sonderbar umfrisiert für die Bühne“ (I, 221). Über ihr Drama, ihre dramatischen Bearbeitungen und etwaige sonstige schriftstellerische Tätigkeit sind nirgends Angaben zu finden.

Werke: Dramatische Werke siehe Anhang B. Weitere Werke?

Literatur: K. Herloßsohn und H. Marggraff, Allgemeines Theater-Lexilkon, 1846, II. A. v. Hanstein, Die Frauen in der Geschichte des Deutschen Geisteslebens des 18. und 19. Jahrhunderts, 1900, I 221 und II 103 f, 228, 391. P. Stein, Deutsche Schauspieler, Eine Bildnissammlung, 1908, I. F. J. v. Reden-Esbeck, Caroline Neuber und ihre Zeitgenossen, 1881 (Neudruck 1985), 273

Kraft, Anna Friederike (Fricda; in Lexilka auch: Kraft, Frieda). Geb. am 10. 6. 1863 in Berlin. Vater der Pfarrer der Judenmission, später dér Zionsgemeinde Julius Adolf Gottlieb K. (1825-1913), Mutter ?. Lebte bis 1876 in Berlin und besuchte dann zwci Jahre lang ein französisches Pensionat. Dort begann sie, sich für französische Lustspiele zu begeistern, und schrieb nach ihrer Rücklkehr nach Berlin selbst mehrere Komödien in französischer Sprache. Ca. Beginn der 80er Jahre begann sie, religiöse Gedichte und Epen zu schreiben, ab 1884 religiöse Dramen. Von ihren Dramen erschienen nur drei im Druck (unter dem Pseudonym „Werner Kraft"); der Rest ihrer Schriften ist nicht nachweisbar. 1913 lebte sie in Berlin; im selben Jahr starb ihr Vater. Ihr eigenes Todesdatum ist unbekannt; weitere Lebensdaten nicht erhältlich.

Werke: Dramatische Werke siehe Anhang B. Religiöse Gedichte und Epen, ca. 1880-1884.

Literatur: S. Pataky, Lexikon deutscher Frauen der Feder, 1898, I. F. Brïmmer, Lexikon der deutschen Dichter und Prosaisten vom Beginn des 19. Jahrhunderts bis zur Gegenwart, 6. Aufl. 1913, IV. W. Kosch, Deutsches Literatur-Lexilkon, 3. Aufl. 196890. E. Friedrichs, Die deutschsprachigen Schriftstellerinnen des 18. und 19. Jahrhunderts, 1981.

Kremnitz, Marie (Mite) von. Geb. 4. 1. 1852 in Greifswald (von Bardeleben). Vater der Professor der Chirurgie Heinrich Adolf von Bardeleben, Mutter ?. 1868 Umzug nach Berlin, wohin ihr Vater als Universitätsprofessor berufen worden war. Erste Hälfte der 70er Jahre Heirat mit dem Arzt v. K. 1875 Umzug nach Bukarest, wo ihr Mann der Arzt der Königsfamilie war. Seit Anfang der 80er Jahre war sie Vorleserin der Königin Elisabeth von Rumänien (siehe dort); Freundschaft mit Elisabeth und literarische Zusammenarbeit ab 1881. Unter den Pseudonymen „Dito und Idem" verfaßten beide ein Drama (Anna Boleyn, 1886), das häufig Elisabeth allein zugeschrieben wird (bei Kosch und Brümmer nicht als M. v. K.s Arbeit verzeichnet).

Ihre eigenen Werke veröffentlichte M. v. K. unter dem Pseudonym „George Allan“. In den frühen $80 \mathrm{er}$ Jahren veröffentlichte sie die Biographien des rumänischen Königspaares, die der Königin Elisabeth unter deren Pseudonym (Carmen Sylva, 1882). Zumindest bei einem Werk war dic Anonymität der Verfasserin nicht freiwillig: ihre König-Karol-Biographie durfte sie auf Befehl des Königs nur anonym veröffentlichen, so daß viele Zeitgenossen annahmen, das Werk sei von dem König selbst (Wolbe $131 \mathrm{f}$ ). 1897 Tod ihres Mannes, 1898 Umzug nach Berlin. Gest. am 18. 7. 1916 in BerlinWilmersdorf.

Werke: Dramatische Werke siehe Anhang B. Hg. von Elisabeth von Rumänien, Rumänische Dichtungen, 1881. Neue rumänische Skizzen, 1881. Fluch der Liebe, Novelle, 1881. Rumänische Märchen, 1882. Aus der rumänischen Gesellschaft, 1882. Carmen Sylva [Pseud. für: Elisabeth von Rumänien], Biographie, 1882 (2. Aufl. 1903). Ein Fürstenkind, Roman, 1883. Aus zwei Welten, Briefroman [mit Elisabeth von Rumanien], 1883 (7. Aufl. 1901). Astra, Briefroman [mit Elisabeth von Ruminien], 1886 (6. Aufl. 1903). Feldpost, Briefroman [mit Elisabeth von Rumänien], 1887 (4. Aufl. 1903). In der Irre, Novellen [mit Elisabeth von Rumänien], 1888 (4. Aufl. 1901). Islandfischer; Novellen von $P$. Loti [übers. mit Elisabeth von Rumanien], 1888. Rache und andere Novellen [mit Elisabeth von Rumänien], 1888 (2. Aufl. 1889). Eine Kindergeschichte, Novelle, [mit Elisabeth von Rumänien], o. J. Ausgewanderte, Roman, 1890. Elima, Novelle, 1894. Zwischen Kirche und Pastorat, Novelle, 1894. Sein Brief, Roman, 1896. In beiden Masken, Tragikomödie von $P$. de Saint-Victor (Übers. mit Elisabeth von Rumänien), 3 Bdc., 1899-1900. Herr Baby, Kindergeschichte, 1901. Am Hofe von Ragusa, Roman, 1902. Mann und Weib, Roman, 1902. Fatum, Erzählung, 1903. König Karol von Rumänien, Lebensbild, 2. Aufl. 1903. Maria, Fürstin Mutter zu Wied, Lebensbild, 1904. Eine Hilflose, Roman, 1906. Mutterrecht, Novelle, 1906. Was die Welt schuldig nennt, 1907. Der rote Streif, Erzählung, 1908. Die Getäuschten, Roman, 1909. Ist das - das Leben?, Roman, 1909. Laut Testament, Roman, 1911. Das Geheimnis der Weiche, Erzählung, 1913. Die Kammerwahl, eine rumänische Zustandsburleske mit H. Kienzl frei nach J. L. Caragiales' Der verlorene Brief, 1917.

Literatur: H. Groß, Deutschlands Dichterinen und Schriftstellerinen, 2. Aufl. 1882, 214. H. Groß, Deutsche Dichterinen und Schriftstellerinen in Wort und Bild, 1885, III 158 f. S. Pataky, Lexikon deutscher Frauen der Feder, 1898, I. F. Brümmer, Lexilkon der deutschen Dichter und Prosaisten vom Beginn des 19. Jahrhunderts bis zur Gegenwart, 6. Aufl. 1913, IV. E. Wolbe, Carmen Sylva [Pseud. für: Elisabeth von Rumänien], Der Lebensweg einer einsamen Königin, 1933, 122-28, 131, $134 \mathrm{f}$ und $136 \mathrm{f}$. W. Kosch, Deutsches Litcratur-Lexikon, 3. Aufl. 1968-90. R. Grebing, M. v. K. (18521916), eine Vermittlerin rumänischer Kultur in Deutschland, 1976. E. Friedrichs, Die deutschsprachigen Schriftstellerinnen des 18. und 19. Jahrhunderts, 1981. 
Krones, Therese. Geb. am 7. 10. [11?] 1801 in Frcudenthal/Schlesien. Vater der Kürschnermeister Joseph K. (?-1839), Mutter ?. Ein Bruder (Joseph Franz, 1797-?). Ihr Vater war ein leidenschaftlicher Liebhaber des Theaters und in seiner Freizeit der Leiter einer Liebhaberbühne; 1806 gab er seinen Beruf auf und gründete mit Einverständnis seiner Frau sein eigenes Wandertheater. Von 1806 bis 1821 zog T. K. mit dem Theater ihrer Eltern quer durch Deutschland und Österreich und spielte hauptsächlich Rollen in Komödien. Ein Bingraph berichtet, auf einer dieser Wanderungen seien ihrem Vater beide Füße erfroren, so daß er bis an sein Lebensende bettlägerig und von 'T. K.' Pflege abhängig gewesen sei (Reden-Esbeck). Der Vater versuchte wiederholt (1809, 1810, nach dem Wiener Kongreß 1816) und vergeblich, in Wien eine feste Anstellung als Schauspieler zu bekommen. T. K. erhielt eine Ausbildung als Sängerin und war kurzfristig Mitglied an den Theatern in Brünn, Ölmütz, Graz, Laibach, Temesvár, Preßburg und Agram.

1821 spielte sie in Ödenburg [d. i. Sopron in Ungarn] die Ophelia, dort „entdeckte" sie Ferdinand Raimund, damals fest engagierter Schauspieler am Leopoldstädter Theater in Wien und Gastschauspieler an demselben Theater in Ödenburg wie T. K. Er versprach T. K., sich für sie am Leopoldstädter Theater zu verwenden. Auf seine Empfehlung hin spielte T. K. dort am 11. 10. 1821 als Gast und wurde am 14.11. desselben Jahres fest angestellt. Dort machte sic große Karriere als Schauspielerin; sie bekam fast immer begeisterte Kritiken und wurde zu einem Publikumsliebling Wiens; vor allem wegen ihr und Raimund, der später auch der Bühnenschriftsteller des Theaters wurde, wurde das Theater als "klassische Volksbühne" (Rabenlechner 90) berühmt. T. K. spielte in jedem neuen Stück Raimunds die Hauptrolle, immer mit großem Erfolg.

1826 lernte sie den russisch-polnischen Edelmann Severin von Jaroszynski (17891827) kennen, der in Wien zur Schule gegangen war, in Polen Geld veruntreut hatte und vor den polnischen Behörden wieder nach Wien geflohen war, wo er sich einen erfundenen Grafentitel zulegte. Die Beziehungen zwischen T. K. und Jaroszynski waren bald der Gegenstand des allgemeinen Theater- und Stadtklatsches. Im Februar 1827 verübte Jaroszynski einen Raubmord an seinem ehemaligen Mathematiklehrer Johann Kontad Blank und wurde wenige Tage später - im Beisein T. K.' - verhaftet. Bei der folgenden Gerichtsverhandlung mußte T. K, wiederholt Aussagen über ihre Beziehungen zu Jaroszynski machen und wurde zur Zielscheibe vieler Spottlieder, die in Wien kursierten.

Das'Theater allerdings hielt in dieser Krise zu ihr: am 16. 3. gab das Leopoldstädter Theater Bäuerles Kabale und Liebe, eine Parodie auf das Schillersche Stück; als Benefizvorstellung für T. K. - mit T. K. in der weiblichen und Raimund in der männlichen Hauptrolle. Die Vorstellung war sehr erfolgreich; die Kritilken der schauspielerischen Leistungen ' $T$. K.' waren enthusiastisch wie immer. Bis zu Jaroszynskis Hinrichtung im August 1827 trat T. K. außer in Bäuerles Stück in mindestens vicr neuen Stücken auf (vgl. Rabenlechner 99-101), was auf eine ununterbrochene Tätigkcit hindeutet, obwohl verschiedene Raimund-Biographien von einer ;monatelangen Pause" der Schauspielerin sprechen (Rabenlechner $101 \mathrm{f}$, Anm. 1; ebenso bei Herloßsohn und Marggraff); laut Reden-Esbeck wollte sie sogar ins Kloster gehen.
Ende 1827 Arbeit an Sylphide, das See-Fräulein, das im Februar 1828 als Benefizvorstellung für T. K. am Leopoldstädter Theater aufgeführt wurde. T. K. spielte Nettchen, Raimund Eustachius Wolferl. Das Stück war ein voller Erfolg: selten bekam eine Schauspielerin, die sich nach etablietter Schauspielerkarriere als Bühnenschriftstellerin versuchte, für ihr erstes Stück so enthusiastische Kritiken. Bis Ende des Jahres wurde das Stück allein am Leopoldstädter Theater 66 Mal aufgeführt - das sind immerhin eine bis zwei Aufflihrungen pro Woche - und bis 1844 häufig an derselben Bühne wiederholt; auch an anderen österreichischen und deutschen Theatern wurde Sylphide ein Kassenschlager.

Im Sommer 1828 ernsthafte Krankheit, die T. K. veranlaßte, ihr Testament zu machen. 1829 schrieb sie ein weiteres dramatisches Märchen, Der Nebelgeist und der Branntweinbrenner (uraufgeführt mit Raimund in der Rolle des Branntweinbrenners); ein Jahr später die Travestie Kleopatra. Beide Stücke wurden am Leopoldstädter Theater ohne Erfolg aufgeführt und äußerst negativ rezensiert. Am 23. 1. 1830 verließ T. K. wegen schwerer Differenzen mit dem neuen Direktor des Theaters die Leopoldstädter Bühne und ging als Gastschauspielerin ans Theater an der Wien. Im Sommer desselbon Jahres mußte sie wegen einer Krankheit eine Erholungsreise nach Marienbad machen, die nicht die erhoffte Wirkung hatte. T. K. starb am 28. 12. 1830 in Wien.

Der Rummel um den Publikumsliebling T. K. ging über 100 Jahre nach ihrem Tod weiter: ' $T$. K. wurde das Thema zahlreicher Volksstücke, Operetten, Filme und Lokalromane (u. a. Haffners Operette T. K., 1854; Haffners und Pfundhellers Operette Severin von Jaroszynski, 1862; Bäuerles Roman T. K., 1854; Fallss T. K., die schöne Volkssängerin, 1902; Krenns und Ludassys Operette Die tolle Therese, 1913; von Bernaus Roman Bridderlein fein, 1916; Geyers Die große Leidenschaft der T, K., 1937; Schulss Im Banne des Schicksals, 1941, und Thimigs, Ritters und Grohs Film Brüderlein fein, 1942). Zu ihrem 100. Todestag 1930 wurde T. K. enterdigt und in ein Ehrengrab im Wiener Zentralfriedhof überfühıt.

Trotz ihres Ruhmes als Schauspielerin und der Verehrung, die ihr als Wiener Publikumsliebling zuteil wurde, wurde T. K. unfair beurteilt, was ihre schriftstellerischen Leistungen betraf. Die Kritiken ihrer letzten beiden Stücke sind ebenso vernichtend, wie die ihrer Sylphide begeistert waren - ob verdientermaßen oder nicht, läßt sich nicht mehr feststellen: weder Der Nebelgeist noch Kleopatra sind erhalten. Was das letzte Stück betrifft, kann man beim Lesen der Kritiken - wie der folgenden aus dem Sammler vom 16. 3. 1829 - auf den Gedanken verfallen, nicht die Qualität des Stückes sei an dem Mißerfolg schuld gewesen, sondern das Thema: „Das Thema der Weiberhertschaft hat man schon zum Ekel und allzeit besser variiert gesehen als in dem Stück der Dlle. Krones" (zit. Rabenlechner 117). Der Erfolg der Sylphide, des Kassenschlagers der Saison, war nicht zu bezweifeln - wohl aber T. K.' Autorschaft: verschiedentlich wurde das Stück ihrem Bruder Joseph zugeschrieben (vgl. Stein). Veröffentlicht wurde Sylphide - das einzige ihrer Werke, das noch erhältlich ist - erst 120 Jahre nach dem Tod der Autorin, in Rabenlechners Ausgabe von 1947.

Werke; Dramatische Werke siehe Anhang B. 
Literatur: K. Herloßsohn und H. Marggraff, Allgemcines Theater-Lexikon, 1846, V. F. J. v. Reden-Esbeck, Deutsches Bühnen-Lexilkon, 1879. H. Groß, Deutschlands Dichterinen und Schriftstellerinen, 2. Aufl. 1882, 109 f. K. Goedeke, Grundriß zur Geschichte der deutschen Dichtung aus den Quellen, 2. Aufl. 1884-1966, XI/2. S. Pataky, Lexikon deutscher Frauen der Feder, 1898, I. P. Stein, Deutsche Schauspieler, Eine Bildnissammlung, 1908, II. M. Enzinger, Die Entwicklung des Wiener Theaters vom 16. zum 19. Jahrhundert, 1918/19, I 306 und 375. M. Martersteig, Das deutsche Theater im ncunzehnten Jahrhundert, 2. Aufl. 1924, 289 f. M. M. Rabenlechner „T. K. und ihre dramatischen Arbeiten", in: T. K., Sylphide, das See-Fräulein, 1947, 86-120. W. Kosch, Deutsches Literatur-Lexikon, 3. Aufl. 1968-1990. E. Friedrichss, Die deutschsprachigen Schriftstellerinnen des 18. und 19. Jahrhunderts, 1981.

Levi, Elise (in Lexika auch: Henle, Elise). Geb. am 10. 8. 1832 in München (Henle). Vater der Sensal Benedikt Henle, Mutter ?. Nichte (Friedrichs) oder Schwester (Brümmer, Kosch) der Schriftstellerin Henriette Ottenheimer (1807-1883). Im Juli 1853 heiratete sie den Bijouteriefabrikanten Leopold L. und zog nach Eßlingen in Württemberg. Eine Tochter. Musikalische und schriftstellerische Tätigkeit ab ca. Mitte der 60er Jahie.

E. L. schrieb Gedichte, Novellen und Erzählungen, war aber hauptsächlich dramatische Schriftstellerin. Thr Lustspiel Aus Goethes lustigen Tagen sollte 1876 am Stuttgarter Hoftheater aufgeführt werden, wurde aber aus bürokratischen Gründen abgesetzt. Diese Ereignisse lieferten ihr den Stoff zu ihrem Lustspiel Durch die Intendanz (1878), das sie zu einem Wettbewerb einsandte. Das Stück wurde ausgezeichnet; danach wurden die meisten ihrer Dramen auf zahlreichen Bühnen aufgeführt. 1879 Heirat ihrer Tochter und Umzug E. L.s nach München, wo sie bei ihrer Tochter und deren Mann lebte. 1889 Umzug nach Frankfurt/M. zu ihrer Schwester. Gest. am 18. 8. 1892 in Frankfurt/M.

Werke: Dramatische Werke siehe Anhang B. Hut ab, Satire, vor 1869. Beim Volksfest, Skizze, vor 1869. Das zweite Jägerbatallion, Novelle, um 1869. Die Wacht am Rhein, Erzählung, 1870. Was soll ich deklamieren?, Sammlung von Gedichten zum Vortrag, den deutschen Mädchen und Frauen gewidmet, 3 Bde., 1885-89 (6. Aufl. 1903). Wer will Französisch lernen?, Eine Gabe für unsere Kleinen, 1893.

Literatur: $H$ Groß, Deutschlands Dichterinen und Schriftstellerinen, 2. Aufl. 1882, 127 f. $H$. Groß, Deutsche Dichterinen und Schriftstellerinen in Wort und Bild, 1885, II 398-405. S. Pataky, Lexikon deutscher Frauen der Feder, 1898, I. F Brïmmer, Lexikon der deutschen Dichter und Prosaisten vom Beginn des 19. Jahrhunderts bis zur Gegenwart, 6. Aufl. 1913, IV. W. Kosch, Deutsches Literatur-Lexikon, 3. Aufl. 196890. E. Friedrichs, Die deutschsprachigen Schriftstellerinnen des 18. und 19. Jahrhunderts, 1981. V. Richel, The German Stage, 1767-1890, A Directory of Playwrights and Plays, 1988, 64

Müller, Elisabeth. Geb. 1827 (wo?) als Tochter eines Kaufmanns. Erhielt cine gute Ausbildung. Nach der zweiten Verheiratung ihres Vaters verließ sie das Elternhaus und besuchte eine Lehrerinnenbildungsanstalt, wo sie das Staatsexamen machte. Lehrerin an Privat- und öffentlichen Schulen im In- und Ausland, „bis verändertc Verhältnisse es ihr ermöglichten, sich ganz ihrer Neigung zur Schriftstellerei hinzugeben" (Brümmer). Ab 1881 freie Schriftstellerin in Freiburg i. Br. Sie verfaßte mehrere Dramen (unter dem Pseudonym „E. Meruéll“) und Märchen, einen Roman und eine Biographic über Peter Rosegger. 1895 Umzug nach Stuttgart. Gest. am 6. 3. 1898 in Stuttgart.

Werke: Dramatische Werke siehe Anhang B. Das Märchen auf der Wanderschaft, 1881. Taube und Habicht, Roman, 1883. Neue Märchen für die liebe Jugend, 1892. Vom Hirtenstab zur Feder, ein Lebensbild von P. K. Rosegger, o. J.

Literatur: F Brümmer, Lexikon der deutschen Dichter und Prosaisten vom Beginn des 19. Jahrhunderts bis zur Gegenwart, 6. Aufl. 1913, V. E. Friedrichs, Die deutschsprachigen Schriftstellerinnen des 18. und 19. Jahrhunderts, 1981 (unter ihrem Pseudonym E. Meruell, das Friedrichs einer anderen gleichnamigen Autorin zuschreibt).

Neuber, Friederike Karoline. Geb. 9. 3. 1697 in Reichenbach/Vogtl. (Weißenborn). Vater der Rechtsanwalt Daniel Weißenborn (?-1722), Mutter Anna Rosine Wilhelm (?-1705). 1702 Umzug der Familie nach Zwickau, dem Heimatort des Vaters. K. N.s Vater war für die körperliche Mißhandlung seiner Frau stadtberüchtigt und „soll sogar die Schuld an ihrem frühzeitigen Tod [...] getragen haben" (Reden-Esbeck 2). Über K. N.s frühe Jugend und Ausbildung geben nur zwei Quellen Auskunft; eine ist das Urteil ihrer Zeitgenossen, die sie als ungewöhnlich gebildete Frau bezeichneten. Aus ihren Briefen ist ersichtlich, daß sie fließend Französisch und etwas Latein sprach.

Die zweite Quelle bezüglich ihrer Jugendjahre sind die Gerichtsakten eines Prozesses im Jahre 1712, in denen sowohl K. N. als auch andere Beteiligte aussagen, ihr Vater habe sie körperlich schwer mißhandelt und wiederholt gedroht, sie zu erschießen. Der Prozcß behandelte die Klage des Vaters gegen den Studenten Gottfried Zorn, der bei ihm Schreiberdienste genommen hatte und mit dem K. N. im April 1712 - nach einer Morddrohung ihres Vaters - das Weite gesucht hatte. Der Vater verklagte Zorn, K. N. entführt und geschwängert zu haben; beide wurden auf sein Betreiben hin verhaftet und blieben 13 Monate lang in Haft. Zorn konnte jedoch nicht wegen Verführung Minderjähriger belangt werden, da K. N. vor Gericht aussagte, sie habe ihn zur Flucht angestiftet. Obwohl K. N. in verschiedenen Briefen an das Zwickauer Stadtgericht den Wunsch äußerte, im Gefängnis bleiben zu dürfen, wurde sie nach Beendigung des Verfahrens wieder nach Hause geschiclst.

1717 lernte sie den Primaner Johann N. (1697-1759) kennen und floh mit ihm endgïltig; im selben Jahr ließen beide sich in Weißenfels bei der Spiegelbergschen Wanderbühne als Schauspieler anwerben. Am 5. 2. 1718 heirateten beide in Braunschweig. K. N. erwarb sich schnell einen Ruf als namhafte Schauspielerin und begünstigte schon, bevor sie J. Chr. Gottsched kennenlernte, Übersetzungen französischer Alexandrinertragödien vor den üblichen improvisierten Komödien. Nach einigen Jahren bei verschiedenen Wanderbühnen kam sie 1724 mit der Haakschen Gesellschaft nach Leipzig. 
Dort lernte sie Johann Christoph Gottsched kennen, der versuchte, sie für seine reformatorischen Ideen zu gewinnen. Mitte der 20er Jahre, nach dem Tod der Direktorin Sophie Haak und der Auflösung ihrer Truppe, entschloß K. N. sich, ihre eigene Schauspieltruppe zu gründen, und bemühte sich um Haaks sächsisches Privileg, d. h. das verbriefte Recht, in Sachsen Stücke aufzuführen. Das Privileg wurde ihr 1727 erteilt. K. N. stand in regem Austausch mit J. Chr. Gottsched und bemühte sich um eine Erweiterung des Repertoires "regelmäßiger" Stücke (d. h. von Stücken, die die drei Einheiten beachteten, vor allem Verstragödien), obwohl ein guter Teil auch ihres Spielplans aus Possen und improvisierten Stuicken bestand. Die von J. Chr. Gottsched angestrebte Kostlimtreue konnte K. N. sich aus finanziellen Gründen nicht erlauben; aber das Konzept der Literatur auf dem Theater nahm sie durchaus ernst.

Wie viele spätere Theaterwissenschaftler war K. N. der Ansicht, eine Bühnenreform dieser Art könne nur dann Erfolg haben, wenn die Vorurteile gegen den Schauspielerstand beseitigt würden. Schon deshalb hielt K. N. auf strengste Disziplin in ihrer Truppe; ihr Einfluß auf ihre Schauspieler ging weit über die üblichen Rechte und Pflichten des Theaterdirektors hinaus. Sie zwang ihre Schauspieler dazu, ihre Rollen zu lernen, setzte regelmäßige Proben an und bestand auf pünktlichem Erscheinen - bei Wandertheatern ein recht ungewöhnliches Verfahren. Nebenbei überwachte sie den sittlichen Lebenswandel ihrer Truppenmitglieder. Die unverheirateten Schauspieler nahm sie in Kost, um etwaige Abstecher ins Wirtshaus zu verhindern; ledige Schauspielerinnen nahm sie als Pflegetöchter ins Haus; Liebschaften irgendwelcher Art wurden nich geduldet: sie „trieb die jungen Leute unnachsichtlich auseinander oder in die Ehe" (Reden-Esbeck 75).

Bis 1734 spielte die Neubersche Truppe zu Messezeiten regelmäßig in Leipzig, unterbrochen von Gastspielreisen u. a. nach Frankfurt a. M., Hamburg, Blankenburg, Merseburg, Hannover, Dresden, Nürnberg, Augsburg, Wolfenbüttel, Braunschweig, Salzdahlum, Lübeck, Weißenfels, Freiberg, Wittenberg und Lüneburg. Im Repertoirc standen französische Verstragödien, erste deutsche Nachahmer desselben Musters - wie J. Chr. Gottscheds Sterbender Cato-, K. N.s eigene Stücke und Vorspiele, und, um das Publikum zu halten, improvisierte Possen mit dem Harlekin in der Hauptrolle. K. und Johann N. beklagten sich in diesen Jahren häufig über den Mangel an Verstragödien. An denen, die es gab, wurde ununterbrochen verbessert und gefeilt. So wurde beispielsweise häufig ein Stück umstudiert, wenn eine neue Bearbeitung oder Übersetzung erschien. Das war eine beachtliche Zusatzarbeit für die Truppe, besonders wenn man das bei Wanderbühnen übliche Pensum bedenkt: von April bis Dezember 1735 gab die Neubersche Gesellschaft in Hamburg 203 verschiedene Vorstellungen (Reden-Esbeck 107-10).

Obwohl K. N. in viclen verschiedenen Städten spielte, betrachtete sie Leipzig als ihren Stlitzpunkt: dort hatte sie in der Regel den größten Erfolg, und J. Chr. Gottsched, der theoretische Mitarbeiter ihter Reformbestrebungen, war dort Professor. 1733 wurde ihr ihre Spielerlaubnis in Leipzig streitig gemacht: der Schauspieler Joseph Ferdinand Müller, Schwiegersohn der ehemaligen Direktorin und Privilegsinhaberin Sophie Haak, nahm das Privileg, das nach deren Tod an K. N. übergegangen war, für sich in Anspruch. Es folgte ein langwieriger und feindseliger Streit mit unzähligen Eingaben und Bittschriften von beiden Seiten an den Dresdener Hof, die Landesregierung und den Stadtrat. Aus den erhaltenen Eingaben beider Parteien geht in etwa folgendes hervor: K. N., die im Leipziger Fleischhaus ihr Theater aufgeschlagen hatte, versuchte, ihr Privileg erneuern zu lassen; Müller dagegen verlangte das ausschließliche sächsische Privileg - d. h. die Garantie, daß seine Truppe als einzige die Erlaubnis hätte, in Leipzig zu spielen - und das Recht, im Leipziger Fleischhaus zu spielen. Müller begründete seine Forderung damit, daß zwei Schauspieltruppen sich in Leipzig nicht ernähren könnten. K. N., die augenscheinlich seine Konkurrenz weniger fürchtete als er die ihre, widersprach heftig und erfolgreich: nach zahlreichen Briefen und Bittschriften konnte sie im Mai 1734 ihre Bühne wieder eröffnen.

Am 19. Mai traf ihr Mann, sicher ohne K. N.s Wissen und gegen ihren Willen, ein erstaunliches Abkommen mit Müller: er versprach, schriftlich und notariell beglaubigt, „in ehelicher Vormundschafft seines Eheweibes Fridericen Carolinen“ (zit. Reden-Esbeck 152), das Theater nach Ende der Spielzeit zu räumen, wenn Müller seine Klage zurückzöge. Am 9. Juni bat K. N. den Leipziger Rat, dieses Ablommen rückgängig zu machen; es folgten viele Briefe desselben Inhalts an sämtliche Gönner und schließlich an den König. Ihre Begründung ist immer dieselbe: die Vormundschaft des Ehemannes über die Ehefrau erkannte sie nicht an; vielmehr bestand sie darauf, daß ein Vertrag nur die vertragschließenden Personen beträfe, ,und gehet mich daher dasjenige, weßen sich mein Ehemann mit Müllern vermeintlich verglichen, meiner Seits nicht das geringste an" (Brief rom 30. 6. 1734 an König Friedrich August, zit. Reden-Esbeck 162). Der endgültige Bescheid vom Juli 1734 sprach das Privileg samt Fleischhaus Müller zu; K. N. durfte nur zu Messezeiten in Leipzig spielen. In dieser Zeit, kurz nach dem Vergleich zwischen Müller und ihrem Mann, schrieb K. N. ihr Deutsches Vorspiel, das im Juni aufgeführt wurde.

Von Leipzig zog die Truppe zunächst nach Braunschwcig und spielte danach u. a. in Hamburg, Kiel, Lübeck, Hannover, Frankfurt/M. und Straßburg. Der Briefwechsel mit J. Chr. Gottsched und die Reformbemiihungen der Truppe hielten an. In Hamburg hatte die Truppe mit ihren Verstragödien zunächst einen solchen Erfolg, daß K. N. hoffte, Hamburg könnte für sie ein neuer Stützpunkt werden; aber der Erfolg flaute rasch ab. Die Truppe machte Schulden und K. N. schricb ihren Mißerfolg der Sensationslust der Hamburger Zuschauer zu, die - ihrer Meinung nach - ihre delklamierten Schauspiele weniger schätzten als Harlekinsburlesken. In der Ankïndigung ihrer Abschiedsvorstellung im Dezember 1735 widmete sie dic Aufführung „Allen Denen/ Die uns oft und gerne gesehen haben/ Die uns nicht haben sehen können/ Die uns nicht haben sehen dürfen und/ Die uns nicht haben sehen wollen" (zit. RedenEsbeck 191) und stieß damit den Hamburger Bürgermeister so vor den Kopf, daß die Vorstellung noch am selben Tag vom Senat verboten wurde.

1736 erhielt K. N. das Schleswig-Holsteinische Privileg und bedankte sich mit ihrem Vorspiel Die von der Weißheit wider die Unwissenheit beschüttzte Schauspielkunst. 1737 bewarb sie sich gleichzeitig um das Hamburger Privileg und um eine Spielerlaubnis in Leipzig zu Messezciten. Das Hamburger Privileg wurde abgeschlagen; die 
Erlaubnis, zur Leipziger Messe zu spielen, erhielt sie. Diese Erlaubnis setzte sie sofort in bitterste Konkurrenz zu dem derzeitigen Privilegsinhaber Müller. Nach ciner Aufführung bei Hofe erhielt sie ihr Prädikat „Hofkomödiantin“ wieder; mietete das Opernhaus und bewarb sich erneut um die Erlaubnis, in Leipzig außerhalb von Messezeiten spielen zu dürfen.

Auch jetzt noch war die Reform des deutschen Theaters Gegenstand ihrer Vorspiele: 1737 schrieb sie ein Vorspiel, in dem der Harlekin in aller Form von der Bühne verbannt wurde; in Der alte und neue Geschmack (1738) ist der neue Geschmack ein „junger wohlerzogener Mensch“, der alte ein Bauer (Theaterzettel, zit. Reden-Esbeck 232). 1738 verlor sie die Schauspielerin, dic dic Liebhaberinnen spielte, und mußte daher das Fach selbst übernehmen. $1739 \mathrm{kam}$ es zu einer Auseinandersetzung mit J. Chr: Gottsched, weil K. N. sich weigerte, eine von ihm verlangte Änderung im Spielplan durchzuführen: sie sollte die bereits einstudierte Stüvensche Übersetzung von Voltaires Alzire durch die Übersetzung von Luise Gottsched (siche dort) ersetzen.

Nach der Leipziger Messe ging sie nach Hamburg und durchlebte dort eine erfolglose Spielzeit. Dort erreichte sie eine Einladung nach St. Petersburg, was sie wieder veranlaßte, den Hamburger Bürgern von der Bühne herab die Meinung zu sagen. Der Magistrat verbot ihr darauf, die Stadt wieder zu betreten. Als K. N. nach Rußland ging, trennte sich einer ihrer Schauspieler, Johann Friedrich Schönemann, von ihr und gründete seine eigene Schauspieltruppe - das wurde die Truppe, die J. Chr Gottsched nach dem Verlust der Neuberschen protegierte, bzw. die er dazu bestimmte, seine Theorien auf der Bühne zu verfechten. So kam es, daß K. N. 1741 bei ihrer Rückkehr nach Leipzig dort eine neue konkurrierende Truppe vorfand. Sie erhiel zwar die Erlaubnis, außerhalb der Messezeiten zwei Mal wöchentlich zu spielen, aber die Konkurrenzsituation hatte sich nun verstärkt: Müller war immer noch sächsischer Hoflomödiant, und Schönemanı spielte unter J. Chr. Gottscheds Protektion in Leipzig.

Diese Protektion des Gegners, verschiedene Anfeindungen, vielleicht auch das Bedürfnis, sich an J. Chr: Gottsched für die vorher erfahrene Bevormundung zu rächen, veranlaßten K. N., J. Chr. Gottsched öffentlich lächerlich zu machen - zunächst in einer Parodie des Sterbenden Cato. Nach mehreren öffentlichen Feindseligkeiten von beiden Seiten ließ K. N. im Olstober 1741 eine selbstverfaßte Satire auf J. Chr. Gottsched aufführen (Der allerkostbarste Schatz, in dem J. Chr. Gottsched durch den Tadler dargestellt wird), die sogar wiederholt wurde, obwohl J. Chr. Gottsched alle Hebel in Bewegung setzte, um die Aufführung zu verhindern.

Im selben Jahr stellten die Universitäten von Leipzig und Wittenberg ein Gesuch an das Konsistorium in Dresden, in dem sie sich über die negativen Auswirkungen von Glücksspielen und öffentlichen Schauspielen auf ihre Studenten beschwerten - und das unter direkter Bezugnahme auf die Truppen K. N.s und Müllers. Das Gesuch, das die Einschränkung der Schauspiele verlangte, wurde zweimal erneuert, 1742 und 1744 (in diesem Jahr unterstützt von der Landesregierung und von Dresden bewilligt). K. N. ging es auch bei zeitlich uneingeschränktem Spielplan finanziell nicht gut: 1742 bat sie die Stadt Leipzig zum ersten Mal, ihr die Abgaben zu erlassen; im darauffolgenden
Jahr löste sic ihre Gesellschaft auf und zog sich mit Johann N. nach Oschatz zurück, weil sie hoffte, daß ihr Mann dort eine Anstellung belkommen könnte.

Diese Hoffnung schlug fehl, und K. N. war schon 1744 wieder in Leipzig, gründete eine neue Truppe - die meisten ihrer früheren Mitglieder spielten auch jetzt wieder be ihr - und nahm den bürokratischen Kampf um die Spielerlaubnis in Leipzig wiede auf. Die erhielt sie zwar, aber unter starken Einschränkungen: inzwischen hatte das obenerwähnte Leipziger Dekret alle Glücksspiele verboten und die Aufführung von Theaterstücken auf Mcssezeiten beschränlkt. K. N. protestierte, aber ihr Gesuch um Spielerlaubnis außerhalb der so festgesetzten Zeit wurde erst 1745 gewährt - jetzt durfte sie wöchentlich ein Stück aufführen. K. N. war damit nicht zufrieden und erreichte tatsächlich durch Bittschriften an ihren alten Gönner, den Grafen Brühl, daß die Einschränkung im Juni 1745 durch Kabinettsbefehl widerrufen wurde.

Ein Jahr lang spielte K. N.s Truppe konkurrenzlos - Schönemann hatte einen neuen Papierkrieg um das Privileg mit ihr verloren - und ohne zeitliche Einschränkung dennoch machte die Truppe weiter Schulden. 1746 wurde ihr das Spielen in der Adventszeit, ein Jahr später Aufführungen an Sonn- und Feiertagen untersagt. Mit dieser Beschränkung konnte die Truppe nicht überleben; und K. N., der Bitt- und Protestbriefe müde, widersetzte sich dem Befehl diesmal in der Praxis. Nachdem sie wiederholt wegen ihrer Ankündigungen auf Theaterzetteln bei ihren Sonntagsaufführungen erwischt worden war, hörte sie auf, ihre Vorstellungen anzukündigen, spielte abet weiter: Erst 1748, dem Uraufführungsjahr von G. E. Lessings Jungem Gelehrten auf der Neuberschen Bühne, wurde K. N. wegen einer unerlaubten Theatervorstellung vor den Magistrat geladen. Statt selbst zu erscheinen, schickte sie dem Magistrat ihren Schauspieler Wolfram, der Folgendes aussagte: „So viel er wüste, wäre nicht öffentlich, sondern nur privatim und weil etl. neue Acteurs darzu gekommen, exercitii gratia gespielet worden; des wegen man auch Kein Geld vor die entrée genommen" (zit. RedenEsbeck 308).

1749 kam Schönemann nach Leipzig zurück. K. N. sah die Konkurrenzsituation, die dadurch entstand, als ernste Gefahr für das Überleben ihrer Truppe und bewarb sich sofort um das ausschließliche sächsische Privileg, das ihr auch zunächst bewilligt wurde. Als sich aber herausstellte, daß die N.s ihre Abgaben an die Stadt seit Jahren nicht bezahlt hatten, wurde das Gesuch nachträglich abgeschlagen, Die verlangten 800 Reichstaler konnte die Truppe nicht aufbringen, und alle Bitt- und Protestschriften der energischen Prinzipalin blieben erfolglos: K. N. verlor das ausschließliche Privileg und ihre Bühne im Fleischhaus. $\mathrm{Zu}$ der finanziellen Katastrophe trat eine weitere: 1749 verließ sie ihr bester Schauspieler, Johann Heinrich Koch, gründete seine eigene Schautspieltruppe und bewarb sich um den Titel des Hofkomödianten, 1750 gefolgt von demselben Gesuch, das K. N. ein Jahr zuvor an die Stadt Leipzig gerichtet hatte: dem um das ausschließliche sächsische Privileg. In den nun folgenden erneuten Papierkrieg mischte sich auch Schönemann, der versuchte, sich seine Spielerlaubnis zu sichern diesmal gegen Koch, nicht gegen K. N. Koch erhielt das ausschließliche Privileg und kam mit Schönemann zu einem Vergleich, in dem er ihm gegen Abgaben eine beschränkte Spielerlaubnis erteilte. 
K. N. mußte ihre Truppe auflösen und - mit 53 Jahren - wieder Schauspielerin werden, um sich zu ernähren. Sie spielte - nach brieflichen Äußerungen von Zeitwenosen ziemlich erfolglos - u. a. in Frankfurt, Wien und Dresden. Zu Beginn des dritten schlesischen Krieges 1756 waren K. N. und ihr Mann völlig ruiniert. Ein Dr. Löber, königlicher Leibarzt in Dresden, nahm beide bei sich auf; als sein Haus kurz darauf berschen Familie und den N.s das Haus. Johann N. starb 1759. 1760 wurde das Haus von einer Bombe getroffen; die Löbers flohen mit K. N. in das Dorf Laubegast. K. N. wurde hier schwer krank und starb am 29. oder 30.11. 1760

Im Leben der K. N. gibt es zwei hervorstechende Elemente, den ständigen Überlebenskampf auf der Bühne und ihre reformatorischen Ideale. K. N. war eine äußerst kompetente und, wie aus den vielen Briefen und Eingaben an die Leipziger Regier'ung hervo spielerin und Bühnenschriftstellerin und eine langjährige Förderin jüngerer Kollegen. Viele junge Schauspieler, die später zeitgenössische Berühmtheiten wurden, traten bei ihr zuert us, Brïckner, Heydrich, Hübler, Kohlhardt, Mylius, Schönemann, Schröter, Suppig, Uhlig, Weidner, Withöff, Klotzsch, Wolfram und Toskani. Unter den Erstlingswerken, die auf ihrer Bühne zuerst gespielt wurden, befand sich Lessings Junger Gelehrter, ebenso protegierte K. N. andere junge Bühnenschriftsteller wie Gellert, Christian Felix Weiße und Johann Elias Schlegel.

Thre Bemühungen um eine Reform der deutschen Bühne bestanden keineswegs nu in einer Anwendung von J. Chr. Gottscheds Theorien, sondern auch, wie oben beschrieben, in umfassenden praktischen Änderungen der täglichen Routine auf dem Theater. Die meisten ihrer Vorrede, Vorspiele und Schauspiele stehen im Dienst diese Bühnen reichen Theaterstücken gedruckt: in Abwesenheit jeglicher Druck- oder Aufführungsrechte wären ihre Stücke Freiwild für jede andere Truppe gewesen. Nicht nur ihre, fas jede Wanderbühne der Zeit war ständig auf der Jagd nach neuen Stücken, und so hiel K. N. Wre igenen Wersche Vorspiel, das SchiK. N. ihre eigenen Werke unter Verschluß. Bis auf drei (das Deutsche Vorspiel, das Seha-
ferfest und Die Verehrung der Vollkommenheit durch die gebesserten teutschen Schauspiele) sind alle ihre Stücke verlorengegangen.

Wahrscheinlich liegt es an dieser Tatsache und an den Themen ihrer Stücke (häufig allegorische Kommentare zu den Zuständen des deutschen Theaters und Darstellungen ihrer eigenen reformatorischen Bemühungen), daß K. N., die Bühnenreformatorin, häufiger gewürdigt wurde als K. N., die Schriftstellerin. Als Bühnenreformatorin aber wurde sie berïhmt; spätere Biographen sehen sie, wie Reden-Esbeck, als „Reaber wurde sie berühmt; spätere Biographen sehen sie, wie Reden-Esbeck, als "Repräsentantin einer neuen Epoche" (255): K. N. wurde hauptsächlich rezipiert als die
Wegbereiterin für das Theater Lessings, Schillers, und Goethes - unter auffälliger Un-

terschlagung ihrer eigenen schriftstellerischen Errungenschaften.

Die meisten Werke über K. N., die schon ihrer Energie wegen eine illustre Figur ist, K N. ihre Werke kaum Bezug genommen wird. So wird u. a. häufig berichtet, die schwer kranke K. N. habe in Laubegast umziehen müssen, da der erstc Hausherr den Tod einer Komödiantin in seinem Haus verhindern wollte. Der berïhmtesten und am häufigsten wiedererzählten Aneldote zufolge mußte ihr Sarg über die Friedhofsmauer geschoben oder geworfen werden, weil der Pfarrer dem Leichnam der Komödiantin den Zutritt zum Friedhof nicht gestattete. (Für beide Anelkdoten gibt es letztendlich keine konkreten Anhaltspunkte.) Auch Reden-Esbecks Neuber-Biographie, die gerade wegen seines ausführlichen Quellenstudiums wertvoll ist, nimmt auf ihre Werke überhaupt keinen Bezug: dem Autor war keines ihrer Stücke zugänglich.

K. N. ist eine unübersehbare Figur in der deutschen Theatergeschichte und war es schon zu Lebzeiten. Sie wurde diffamiert, falsch repräsentiert, in ihrer Bedeutung verkleinert und lächerlich gemacht, aber übersehen wurde sie nicht. Bereits 1743 erschien eine Persiflage auf sie, Friedrich Siegmund Meyers Leben und Thaten der [...] Friederica Carolina N.in. Dieses spöttische "Heldengedicht" blieb nicht die einzige literarische Darstellung ihres Lebens: dasselbe Thema bearbeiten u. a. Emilie von Binzers Drama $K . N$, veröffentlicht unter dem Pseudonym „Ernst Ritter" und 1847 in Wien aufgeführt; Hartwigs Vierakter Die N.in (o. J.); Mosenthals Drama Die deutschen Comödianten (1863); Meynerts theatralisches Zeitgemälde Harlekins Rache (1840); von Panhuys Adagio Ach Liebste Madame N.in! (um 1870); Emil Junghans' allegorische Erzählung Hanswursts Autodafee (1874); Seebergs Schauspiel Harlekins Tod ... Die N. in (1928); Weisenborns Stück Die N.in (1935); Olly Bocheims [Pseud. für: Olga George] Roman Philine (1935) und der darauf basierende Film Komödianten von G. W. Pabst (1941); Welckers Künstlerroman Frau C. N. in (1935); Heide Wendlands Komödianten ohne Maske (1957); Lore Mallachows Im Morgenlicht (1960); Katharina Rothärmels Hörspiel Ich war die N.in (1979); Charlotte Thomas' Erzählung Die Prinzipalin (1981) und Irmela Brenders Lebenszeugnisse-Lebensstationen, Die N.in (Manuskript zu einer Radiosendung, Süddeutscher Rundfunk Stuttgart, Januar/Februar 1981).

Auch auf wissenschaftlicher Ebene wurde, wie bereits erwähnt, ihr Leben häufiger gewürdigt als ihr Werk: während die Quellen, die über ihre Biographie Auskunft geben, aufgearbeitet wurden - u. a. von Reden-Esbeck -, müssen die meisten ihrer Stücke als verlorengegangen angesehen werden.

Werke: Dramatische Werke siehe Anhang B. Trauergedicht auf den Tod ihres Vaters, 1722. Rede der Lucretia an ihren gemahl Tarquinium Collatinum, 1727. Glückwunschgedicht zum Geburtstag der Kaiserin Elisabeth Christine, 1727. An ein Frauenzimmer; an ihren nahmenstag, um 1727?. Glïclwunschgedicht zum Geburtstag der Herzogin Luise, 1729. Glückwünschungs-Gedichte zur Huldigung des Herzogs Ludwig Rudolf von Braunschweig-Wolfenbüttel, 1731. Bey der hohen Vermählung Jhr. königl. Hoheit Printz Friedrichs, Königlichen Cron-Printzens in Preussen, mit Der ... Printzessin Elisabeth, aus dem ... Hause Braunschweig-Lüneburg-Bevern, in Saltzthal am 12. Juny 1733 überreicht, 1733. Widmungsverse in einer Ausgabe von Senecas Dialogen, 1733. Widmungsverse in einer Ausgabe von Petrarcas Troststiegel in Glïck und Unglïck, 1733. Widmungsverse in einer Ausgabe der Christlichen Sitten-Lehr, 1733. Gereimte Bittgesuche an die Herzogin von Braunschweig, die Kurfürstin von 
Sachsen, die Königin von Polen und den Grafen Brühl, 1734. Bey dem Ableben des Durchlauchtigsten Fürsten und Herrn H. Ludwig Rudolf regier. Hertzogs zu Braunschweig, eine Trauerrede, 1735. Glückwunschgedicht an Antonette Amalie, 1735. Gliickwunschgedicht an den Herzog Ferdinand, 1735. Bey dem Geburts-Feste Jhr. Königl. Hoheit ... Carl Friderichs Erbens zu Norwegen, Herzogs zu Schleswig, Holstein, 1736. Bey dem hohen Geburts-Feste Ihr. Königl. Majestät Ludovici XV., Eine Glückwünschungs-Ode, 1737. Poetische Ansprache an den König von Polen und Kurfürsten von Sachsen, Friedrich August II., 1737. Gedicht an den Reichsgrafen von Brühl, 1737. An dem hohen Geburtsfeste Sr. Königl. Majestät beyder Sicilien, Eine Glückwünschungs-Ode, 1738. An dem hohen Namens-Feste ... Carl Friedrichs, regier. Hertzogs zu Schleswig-Hoistein, Eine Glüclswünschungs-Ode, 1738. Bittgedicht an den Rat zu Leipzig, 1738. Abschiedsrede in dramatischer Form, 1740. Bittgedicht an den Grafen von Hennicke, 1749. O Künstler, Gedicht, 1756. Geburtstagsgedicht. der kleinen Ernestine Charl. Wilhelm. Löber gewidmet, 1758. Dankgedichte, 1758-9.

Literatur: J. F. Löwen, Geschichte des deutschen Theaters (1766) und Flugschriften über das Hamburger Nationaltheater (1766/67), 24-31, 55, 103 f. Gallerie von Teutschen Schauspielern und Schauspielerinnen der ältern und neuern Zeit nebst J. F. Schinks Zusïtzen und Berichtigungen, hg. R. M. Werner, 1783. J. F. Schiitze, Hamburgische Theater-Geschichte, 1794, 209-44. J. G. Meusel, Lexilkon der vom Jahr 1750 bis 1800 verstorbenen teutschen Schriftsteller, 1802-1816, X. H. Blïmner, Geschichte des Theaters in Leipzig, Von dessen ersten Spuren bis auf die neueste Zeit, 1818, 30 f, 44-76, 270 f. $K$. Th. v. Küstner, Rüclsblick auf das Leipziger Stadttheater, 1830, $104 \mathrm{f}, 283$ K. Herloßsohn und H. Marggraff, Allgemeines Theater-Lexikon, 1846, V. R. Prutz, Vorlesungen über die Geschichte des deutschen 'Theaters, 1847, 233-59, 279-85, 297. Th. Mundt, Dramaturgie oder Theorie und Geschichte der dramatischen Kunst, 1848 408. Th. W. Danzel, Gottsched und seine Zeit, 2. Aufl. 1855, 132, 134 f. H. Laube, Das Burgtheater, 1868, 6 f. L. Otto[-Peters], „F. N.“, in: L. Otto[-Peters], Einflußreiche Frauen aus dem Volke, 1869, 162-170. K. Bauer, Komödianten-Fahrten, Erinnerungen und Studien von Karoline Bauer, 1875, 276-302. A. E. Brachvogel, Das alte Berliner Theater-Wesen bis zur ersten Blüthe des deutschen Dramas, 1877, 85-90, 170-2. K. Goedeke, Grundriß zur Geschichte der deutschen Dichtung aus den Quellen, 2. Aufl. 1884-1966, III/2. I. Brüning, Le Théatre en Allemagne, Son Origine et ses Luttes (1200-1700), 1887, 183-234. H. Devrient, Die Schönemannsche Truppe in Berlin, Breslau, Danzig und Königsberg 1742-1744, 1895, 14, 70 f, 92 f, 104. A. Richter, „Vorrede zu F. C. N.s Ein Deutsches Vorspiel", in: Deutsche Litteraturdenkmale des 18. und 19. Jahrhunderts Nr, 63, Neue Folge 13 (1897), III-XVI. S. Patdky, Lexikon deutscher Frauen der Feder, 1898, II. R. Lothar, Das Wiener Burgtheater, 1899, 15. A. v. Weilen und O. Teuber, Die Theater Wiens, 1899-1906, II A 82 f. A. v. Hanstein Die Frauen in der Geschichte des Deutschen Geisteslebens des 18. und 19. Jahrhunderts, 1900, I 104-13, 139, 140, 166, 221, 224, 226, 227, 229, 230, 235, 238, 239, 304; II 51, 56, 65, 391. C. H. Schmid, Christian Heinrich Schmids Chronologie des deutschen Theaters, 1775 (Nachdruck 1902), 39-48, 60-64, 68, 70, 73-76, 82, 89, 91 f, 95, 108, 113. P. Stein, Deutsche Schauspieler, Eine Bildnissammlung, 1908, I
H. Landsberg und A. Rundt, Hg., Theater-Kalender auf das Jahr 1911 (1912), 57. H. Daffis, "Theater und Schauspielkunst im alten Berlin", in: H. Landsberg und A. Rundt, Hg., Theater-Kalender auf das Jahr 1912 (1913), 122. M. Martersteig, Das deutsche Theater im neunzehnten Jahthundert, 2. Aufl. 1924, 70-74, 148, 150. F. Brilggemann, Hg:, Gottscheds Lebens- und Kunstreform in den zwanziger und dreiBiger Jahren, Gottsched, Breitinger, die Gottschedin, die N.in, 1935. H Sasse F. C N., Versuch einer Neuwertung, Diss. Freiburg, 1937. H. Kindermann, Theatergeschichte der Goethezeit, 1948, 64-95, 189, 266-70, 277-86, 395-407, 442, 518-21. L. Scholz und R. Daunicht, Die N.in, Materialien zur Theatergeschichte des 18. Jahrhunderts, in: Studienmaterial für die künstlerischen Lehranstalten Heft 2, 1956 H. Zïllchner, Das Wirken von F. C. N.in, Hof-Comoediantin, in Dresden, 1960 L. Hirschberg, Hg., Der Taschengoedeke, 1961, 457. G. v. Wilpert, Deutsches Dichterlexikon, 1963. H. Devrient, Johann Friedrich Schönemann und seine Schauspielergesellschaft, 1895 (Nachdruck 1978), 21 f, 25, 70, 104, 130, 153 f, 303-5. E. Friedrichs, Die deutschsprachigen Schriftstellerinnen des 18. und 19. Jahrhunderts, 1981 F v. Reden-Esbeck, C. N. und ihre Zeitgenossen, 1881 (Nachdruck 1985). W. Günther "Nachwort", in: F. J. v. Reden-Esbeck, C. N. und ihre Zeitgenossen, 1985. H. Heckmann, "Theaterkritik als Unterhaltung, Die Vorreden und Vorspiele der N.in“, in R. Schade, Hg., Lessing Jahrbuch XVIII (1986), 111-27. B. Becker-Cantarino, „Prinzipalin und Theaterautorin, C. F. N.“, in: B. Becker-Cantarino, Der lange Weg zur Mündigkeit, Frau und Literatur (1500-1800), 1987, 310-7. G. zu Putlitz, „F. K. N.“ in: J. M. von Gayette-Georgens und H. Kletke, Hg., Frauen-Album, Charakterbilder aus alter und ncuer Zeit, o. J., 189-98.

Pernet, Luise Hedwig von. Geb. 22. 2. 1742 in Schleswig (von Kemmerer), Vater Marcus Andreas Kemmerer (1702-1782), Mutter Johanna Eleonora von Schildberg. Von 1760 bis 1765 lebte sie in Husum und zog dann mit ihrer Mutter nach Graz Dort heiratete sie 1765 Johann Heinrich v. P., k. u. k. Auditor im Infanterieregiment Baden-Durlach. 1770 veröffentlichte sie ihr komisches Trauerspiel Seline zusammen mit einer Sammlung Fabeln und Erzählungen mit einer Widmung an Maria Theresia. Ihr Mann wurde wiederholt versetzt (1771 nach Wien, 1777 nach Freiburg i. Br., 1779 nach Hermannstadt); es ist anzunehmen, daß L. H r. P. 1785 zog sie nach Wien und von da mit ihrem Mann in die Niederlande. 1790 rschienen ihre Neuen Vermischten Gedichte, 1795 eine Neuauflage desselben Bandes. Von 1794 bis zur Pensionierung ihres Mannes lebte sie in Wien. L. H. v. P. starb am 4. 1.1801 in Budapest.

Über ihre literarische Tätigkeit ist weiter nichts bekannt; wegen ihrer Fabeln bezeichnet Goedeke sie als „Nachahmerin Gellerts“ (VI, 530). 1894 erschien eine gekürzte Neuausgabe ihrer Fabeln und Erzählungen unter einem seltsamen Motto: $M e$ ine liebe Frau von Kemmeter [fälschl. für: Kemmeter],/ Näh' sie lieber Hemmeder!" (Zit. Goedeke VI, 531)

Werke: Dramatische Werke siehe Anhang B. Fabeln und Erzählungen, 1770. Ode auf die Vermählung ... der Herzogin Este, 1771. Beiträge zu Riedlers Wochenschrift 
Der Einsiedler, 1773. Neue vermischte Gedichte, 1790. Verschiedene Gelegenheitsgedichte und Beiträge zu Zeitschriften.

Literatur: G. Chr. Hamberger und J. G. Meusel, Das gelehrte Teutschland oder Lexikon der jetzt lebenden teutschen Schriftsteller, 1796-1834, VI. K. Goedeke, Grundriß zur Geschichte der deutschen Dichtung aus den Quellen, 2. Aufl. 1884-1966, IV/1 und VI. A. v. Hanstein, Die Frauen in der Geschichte des Deutschen Geisteslebens des 18. und 19. Jahrhunderts, 1900, II 246. L. Hirschberg, Hg., Der Taschengoedeke, 1961, 480. E. Friedrichs, Die deutschsprachigen Schriftstellerinnen des 18. und 19. Jahrhunderts, 1981.

Pichler, Caroline. Geb. 7. 9. 1769 in Wien (von Greiner). Vater der Hofrat Franz von Greiner, Mutter Karoline (Charlotte?) von Hieronymus. Zwei ältere Brüder und eine jüngere Schwester starben früh; ein Bruder (Franz Xaver, 1772-1804). C. P. war nach eigener Aussage als Kind „ein ziemlich wildes Mädchen“ („Überblick meines Lebens", Denkwitrdigkeiten II, 401) und erhielt zum Teil dieselbe Ausbildung wie ihr Bruder, u. a. - für Mädchen recht ungewöhnlich - Lateinunterricht. Außerdem Unterricht in Französisch, Italienisch, Englisch, Zeichnen, Geometrie, Musik. C. P. las mit Leidenschaft Milton, Klopstock, Herder, Voß und Geßner, und beschäftigte sich nur in ihren „Mußestunden mit Lesen, Dichten und Musik“ („Überblick“, 401). Denn „Meine Mutter, die über der Bildung des Geistes die viel nöthigere zur Häuslichkeit nicht vergessen hatte, hielt mich streng dazu an, lehrte mich diese lieben und als die erste und wichtigste Bestimmung des Weibes betrachten, und bewahrte auf diese Weise meinen Charalkter vor mancher falschen Richtung" (Überblick", 401).

Sie fing früh (mit ca. 15 Jahren) an zu schreiben, zunächst Lieder und Balladen, Über'setzungen aus anderen Sprachen, und um 1791 die Gleichnisse. Ihre Eltern unterhielten einen lebhaften literarisch-politisch-philosophischen Salon (Gesellschaftskonzerte, Theaterabende, Abendgesellschaften, gelehrte Kränzchen), in dem der gesamte österreichische Adel und andere Größen (u. a. Mozart) ein- und ausgingen. 1791/2 gründete ihr Bruder zusammen mit Freunden einen ähnlichen Kreis, in dem selbstgeschriebene Aufsätze diskutiert wurden. C. P. gab ihrem Bruder einige ihrer Aufsätze über Gegenstände, „die nicht außer meiner Sphäre lagen“, („Überblick“, 403), zur Diskussion mit, ohne sie zu unterzeichnen und ohne selbst in dieser Gesellschaft zu erscheinen. Durch diesen Verein lernte sic den späteren Regierungsrat Andreas P. kennen, den sie 1796 heiratete. 1797 Geburt einer Tochter. Nach dem Tod ihres Vaters im Juni 1798 zog C. P. mit ihrem Mann, ihrem Bruder und dessen Frau zu ihrer Mutter in eine Vorstadt von Wien.

1800 gab sie, unter Anregung ihres Mannes, die Gleichnisse heraus, dic u. a. von Klopstock und Nicolai günstig beurteilt wurden. C. P. wurde mit diesem Buch mit einem Schlag berühmt; ihr plötzlicher Ruhm hatte zwei Auswirkungen: er „erweckte in mir die Lust, mich an etwas anderm zu versuchen und einen kleinen Roman zu schreiben" („Überblick“, 405), und er machtc die Wiener Gesellschaft auf sie aufmerksam. Einige Ergebnisse ihres neuen literarischen Selbstbewußtseins waren der Roman
Olivier (1802 anonym erschienen, 1804 unter ihrem Namen neu veröffentlicht), Leonore (1803) und dic Idyllen (1804).

Das Resultat ihrer Bekanntheit war ein reges gesellschaftliches Leben. Von 1802 bis 1824 führte sie einen ähnlichen Salon wie zuvor ihre Eltern, ihr Haus wurde (zwei bis drei Mal in der Woche) zum Treffpunkt der "feinen bürgerlichen Kreise, des niederen Adels und der literarischen und künstlerischen Größen" (Blümml XIV). Es gab Deklamations-, 'Theater- und Musikabende, fast alle mit politischem Unterton: in C. P.s Salon wurde Politik diskutiert, der Opposition gegen Napoleon flammender Ausdruck verlichen, der „Fall ihres Vaterlandes aufs tiefste" beklagt (Blümml XIV) und nach österreichisch-nationalen Stoffen für die Dichter des Zirkels gesucht

C. P. selbst verstand sich als österreichische Nationaldichterin; viele, wenn nicht die meisten, ihrer Werke behandeln Stoffe aus der österreichischen Geschichte und nehmen direkten Bezug auf den napoleonischen Krieg. In ihrem Fall kann ihr Patriotismus auch persönliche Gründe gehabt haben: ihre Mutter wurde als verwaiste Fünfjährige von Maria Theresia persönlich protegiert und erzogen und wurde später ihre Vorleserin; als sic v. Greiner heiratete, machte die Kaiserin diesen zum Hofrat und Geheimen Referendar. Jedenfalls war C. P. zeitlebens eine standfeste Patriotin; besonders ihre Stücke drehen sich häufig um ein Thema: Österreichs versunkene (und wiederkehrende) Größe.

1804 'Tod des Bruders. 1806-8 Arbeit am Agathokles, der 1808 erschien; im selben Jahr veröffentlichte sie ihren vierbändigen Roman Frauenwürde. 1810 Die Grafen von Hohenberg. Um diese Zeit äußerte ihr. Mann den Wunsch, „daß ich einmal etwas Dramatisches zu schreiben versuchen sollte"; sie gab „dem Wunsch, ihm Freude zu machen" ("Überblick“, 407 f), nach und schrieb Germanicus, der 1812 am Wiene Hoftheater aufgefih rt wurde. Der Erfolg ermutigte sie zu ihrem Trauerspiel Heinrich von Hohenstauffen (aufgeführt 1813).

Freundschaft mit Johanna Franul v. Weißenthurn (siehe dort), Maria v. Zay, Marianne v. Neumann-Meißenthal, Dorothea Schlegel und Marie Therese von Artner (siehe dort). 1815 Tod der Mutter. Bekanntschaft mit Dorothea und Friedrich Schlegel, die sie 1815 kennenlernte, Mme. de Staël, Grillparzer, Oehlenschlaeger, Caroline von Woltmann, Wilhelm von Humboldt, Theodor Körner; Henriette Herz. Weitere Veröffentlichungen - alle unter ihrem Namen: 1816 das Drama Ferdinand II, 1817-21 drei Bände mit Erzählungen, 1818 ein Band mit ihren Dramen, 1821 der zweibändige Roman Die Nebenbuhler, 1822 ein Band mit Aufsätzen, und bereits 1820 eine Ausgabe ihrer sämtlichen Werke - in 53 Bänden.

Ab 1824 wurden C. P.s Gesellschaften kleiner, privater und seltener; von da ab lebte sie zurückgezogen und schrieb. Die Wiener Gesellschaft hatte sich ihrem Empfinden nach so verändert, daß sie sich nur noch schwer in ihr bewegen konnte; sie spricht in den Denkwïrdigkeiten von einer ,stiefgewordenen Welt" (II, 385). Auch ihre Schriften wurden immer introvertierter: Bereits in den dreißiger Jahren schreibt sie häufig Erinnerungswerke. 1836-43 erschienen ihre Zerstreuten Blatter aus meinem Schreibtische, cine Aufsatzsammlung über Literatur, Mode, Erziehung und eine Biographie einer verstorbenen Freundin, der Autorin Marie Therese v. Artner. 1837 Tod des Mannes. 
Dieses Ereignis sieht sic als das Ende ihrer literarischen Beschäftigung: "Gedichtet im eigentlichen Sinn habe ich nichts mehr" (Denkwïrdigkeiten II, 378).

Nach dem Tod ihres Mannes zog sie zu ihrer Tochter (inzwischen verh. v. Pelzeln) und ihren Kindern nach Wien. 1839-41 erschienen die Zeitbilder, eine ähnliche Essaysammlung, die auch eine Beschreibung des „alten" Wien enthält. Das letzte, woran sie arbeitete, waren ihre Memoiren, die zweibändigen Denkwürdigkeiten aus meinem Leben, deren Erscheinen (1844) sie nicht mehr erlebte.

Die Angaben über ihren Tod sind widersprüchlich: Blümml spricht diskret von einer „schwere[n], wenn auch nicht unvermutet eingetretene[n] Krankheit [im Mai 1843], von der sie nicht mehr genesen sollte" (xxIV). Seinen Angaben nach beschäftigte sie sich noch in dieser zweimonatigen Krankheit mit Literatur und Wissenschaften, „aber der Körper versagte seine Dienste und am 9. Juli 1843, einem Sonntag, verließ ihre Seele die gebrechliche Hülle" (xxy; ebenso Wolf, der ihren Tod einer "Erschöpfung" zuschreibt, Nachwort, Denkwiirdigkeiten II, 390). Notiz bei Elisabeth Friedrichs: "gest. 9. 7. 1843 (Freitod) in Wien" (so auch bei Groß 1882 und Brinker-Gabler).

C. P. hatte vor allem zwei Ziele: sie wollte für ihre literarischen Leistungen anerkannt werden - sie ist die einzige mir bekannte Autorin, die zu Lebzeiten zweimal ihre gesammelten Werke veröffentlichte -, und sie wollte wegen ihrer schriftstellerischen Tätigkeit nicht diffamiert werden. Ihr literarischer Ruhm war kurzlebig - ca. 20 Jahre $\rightarrow$; und die Angriffe, denen fast jede schreibende Frau ausgesetzt war, verschonten auch sie nicht. Aus Angst vor solchen Attacken verschanzte sie ihre bemerkenswerte Anzahl von Veröffentlichungen, die meisten unter ihrem Namen, hinter steten Hinweisen auf die „wahre" Rolle des Weibes: „nähmlich Gattinnen, Hausfrauen, Mütter im edelsten Sinne zu werden" (Zerstreute Blätter 66).

Um diese Rolle geht es u. a. in ihrem Roman Frauenwürde. Sie, die erfolgreiche Schriftstellerin, schrieb häufig mahnende Traktate gegen die weibliche Ver-Bildung zu Schriftstellerinnen. Eine literarische oder wissenschaftliche Bildung ließe ,jeder Frau, die wirklich eine Frau, das heißt: Gattinn, Mutter und Hauswirthinn im echten Sinne ist", keine Zeit mehr, „um das Wichtigste zu lernen und zu üben, was sie wissen soll nähmlich die Kenntniß des Hauswesens, der Küche und der echten bäuslichen Arbeiten" (Zerstreute Blatter $62 \mathrm{f}$, Hervorhebungen der Autorin). Ihren eigenen (zu?) oft wiederholten Beteuerungen nach war sie „nun einmahl der festen Überzeugung [...], das Übergewicht, nicht bloß an körperlicher, sondern auch an Geisteskraft und vorzüglich an Dauer und Tiefe derselben, sey von der Natur, und also von Gott, dem männlichen Geschlechte verliehen. Aus dieser Ursache gebührt dem Manne auch das herrschende Wort im Hause, nicht bloß weil er das Geld verdient [...], sondern weil er in der Regel der Verständigere ist" (Zerstrente Blätter 147).

Trotzdem mußte einer ihrer Nekrologisten sic nach ihrem Tod zunächst einmal "won dem Vorwurf, ein Blaustrumpf gewesen zu sein“, reinigen (Blümml XXVI). In den ersten zwei Jahrzehnten des 19. Jahrhunderts eine bekannte und gesuchte Schriftstellerin, war sie bereits 1843, in ihrem Todesjahr, eine literarische Kuriosität. 1913 berichtet Blïmml, der Herausgeber einer Neuauflage ihrer Denkwiirdigkeiten, man habe sie nicht ganz übersehen können; immerhin umfaßten ihre sämtlichen Werke ganze
53 Bände. Also tauchte ihr Name, „mit einigen nichtssagenden Phrasen umgeben, noch hie und da" in Literaturgeschichten auf (Blümml XxIX f). Fast 80 Jahre später sind Blümmls ironische Bemerkungen noch eine ziemlich aklkurate Beschreibung de Forschungslage.

Werke: Dramatische Werke siehe Anhang B. Gleichnisse, 1791 (veröff. 1800). Abendlied einer Hirtin, 1798. Der Blumenstrauß, eine Idylle, 1802. Der Sänger am Felsen, eine Idylle, 1802. Idyllen, 1803. Leonore, Roman, 2 Bde., 1804. Ruth, ein biblisches Gemälde in drei Idyllen, 1805. Frauenwürde, Roman, 4 Bde., 1808. Agathokles, Briefroman aus der Antike, 3 Bde., 1808. Ueber die Tropfsteinhöhle zu Blasenstein, 1809. Stille Liebe, 1809. An meinen Arzt und Freund bei Uebersendung eine Lavendelkissens, Gedicht, 1809. Ueber den Volksausdruck in unserer Sprache: ein ganer Mann, 1809. Ueber die Bildung des weiblichen Geschlechts, 1810 . Cremsmiunster Erzählung, 1810. Die Grafen von Hohenburg, 2 Bde., 1811. Eduard und Malvina, 1811. 'Zuleima, Gedicht, 1811. Der Markgräfin Schleier oder Ursprung des Kloster Neuburg bei Wien, 1811. Biblische Idyllen, 1812. Argelia, 1812. Erzählungen, 2 Bde. 1812. Olivier, oder Die Rache der Elfe, Roman, 1812. Klage auf den 'Tod H. J. Edlen von Collin, 1812. Sämmtliche Werke, 24 Bde., 1813-20. Das gefährliche Spiel, Erzählung, 1814. Ein Gedicht, Titel nicht ermittelt, 1814. Ueber eine Nationallkleidung der deutschen Frauen, 1815. Das befreite Deutschland, Cantate, 1815. Bei Anhörung des Mozart'schen Requiem, 1815. Mein erstes Sonett im April 1805, 1815. So war es nicht gemeint, Erzählung, 1816. Der Husarenofficier, Erzählung, 1817. Ueber Mode und Coquetterie, 1817. Neue Erzählungen, 3 Bde., 1817-20. Die Berggeister, 1818. Horimirz, eine böhmische Sage, 1818. Die goldene Schaale, 1819. Der Einsiedler auf dem Montserrat, Erzählung, 1819. Rüdiger der Normann, erster Graf von Sicilien, 1819. Überblick meines Lebens, 1819. Der Corsar, Erzählung von Byron (übers.), 1820. Das Schloß im Gebirge, 1820. Im Frühling, Gedicht, 1820. Lebewohl, Ged. von Byron (übers.), 1820. Auf ein weißes Blatt, Gedicht, 1821. Tasso's Klage, Ged. von Byron (übers.), 1821. Freundschaftliche Briefe, 1821. Die Nebenbuhler, Roman, 2 Bde., 1821. Ueber die Stoa und das Christenthum, 1822. Wahre Liebe, Erzählung, 1822. Die Walpurgisnacht, Erzählung nach einer Sage, 1822. Ueber die Art der geselligen Unterhaltung, 1822. Kleine prosaische Aufsätze, 1822. Der Postzug, Erzählung, 1823. Briefe über die Art der geselligen Verhältnisse, 1823. Charakteristilk der verewigten Louise Brachmann, 1823. Der Bluträcher, 1824. Die Belagerung Wiens, 3 Bde., 1824. Quentin Messis, Erzählung, 1824. Die Stieftochter, Erzählung, 1824. Ueber Wahrheit itn Erkennen, Denken und Empfinden, 1824. Die Schweden in Prag, 3 Bde., 1827. Sämmtliche Werke, 60 Bde. (enthält: I-II: Leonore; III-V: Agathokles; VI-VII: Die Grafen von Hohenburg; VIII: Olivier; IX-X: Die Nebenbuhler; XI-XIV; Frauenwürde; XV-XVII: Die Belagerung Wiens; XVIII-XX: Die Schweden in Prag; XXI: Idyllen; XXII-XXIII: Gedichte; XXIV-XXV: Prosaische Aufsätze; XXVI-XXVIII: Dramatische Dichtungen; XXIX-XLI: Kleine Erzählungen [Das Schloß im Gebirge; Der junge Maler; Stille Liebe; Die Walpurgisnacht; Die Geschwister; Der entwendete Schuli; Das gefährliche Spiel; Die Frühverlobten; Der Badeaufenthalt; Falkenberg: Wahre Liebe; Der Pflegesohn; Argalya; Das Kloster auf Capri; Sie war es dennoch; Das vergebliche 
Opfer; Alt und neuer Sinn; Der Amethyst; Eduard und Malvina; Zuleima; So wars nicht gemeint; Der Graf von Barcelona; Schloß Wiernitz; Karls des Großen Jugendliebe; Das Ideal; Abderachman; Der Husarenoffizier; Das Spital; Der schwarze Fritz; Die goldne Schale; Der Einsiedler auf dem Monserrat; Horimicz; Quentin Messis; Die Stieftochter; Der Bluträcher; Der Postzug; Johannes Schoreel; Der Wahlspruch; Der Teppich]; XLII-XLIV: Die Wiedereroberung von Ofen; XLV: Henriette von England; XIVI-XLIX: Friedrich der Streitbare; L: Kleine Erzählungen [Der Gluickswechsel; Das XLVI-XLIX: Friedrich der Streitbare; L: Keine Erzählungen [Der Gluckswechsel; Das Blätter; LVI-LVIII: Zeitbilder; LIX-LX: Zerstreute Blätter, Neue Folge), 1828-44. Die Wiedereroberung von Ofen, 3 Bde., 1829. Friedrich der Streitbare, 4 Bde., 1831 Denkwürdigkeiten aus meinem Leben, 2 Bde., 1844. Volksweisen deutscher Kirchenlieder, veröff. 1851. Beiträge zu vielen Zeitschriften.

Literatur: G. Chr. Hamberger und J. G. Meusel, Das gelehrte 'Teutschland oder Lexikon der jetzt lebenden teutschen Schriftsteller, 1796-1834, XIX. C. W. O. A. v. Schindel, Die deutschen Schriftstellerinnen des neunzehnten Jahrhunderts, 1823, II. C. $P$, Zerstreute Blätter aus meinem Schreibtische, 1836. C. P., Zeitbilder, 1839. K. Herloßsohn und $H$. Marggraff, Allgemeines 'Theater-Lexikon, 1846, VI. H. Groß, Deutschsohn und H. Marggraff, Allgemeines 'Theater-Lexikon, 1846, VI. H. Groß, DeutschGeschichte der deutschen Dichtung aus den Quellen, 2. Aufl. 1884-1966, V und XI/2. H. Groß Deutsche Dichterinen und Schriftstellerinen in Wort und Bild, 1885, I 13746. L. Morgenstern, „C. P.“, in: L. Morgenstern, Die Frauen des 19. Jahrhunderts, 1889 II 35-53. S. Pataky, Lexikon deutscher Frauen der Feder, 1898, II. H. Devrient, Archiv für Theatergeschichte, 1904-5, II 175 f. T. Pupini, K. P.s Romane, Ein Beitrag zur Geschichte der Unterhaltungsliteratur, 1910. E. K. Bliimml, „Einleitung", in: C. P, Denkwürdigkeiten aus meinem Leben, 2 Bde., 1914, I vil-LxxxvII. C. P, Denkwürdigkeiten aus meinem Leben, 2 Bde., 1914. C. P. "Überblick meines Lebens (1819), “in: C Penkwürdigkeiten aus meinem Leben, 2 Bde., 1914, II 393-410. K. Glossy C, P, Denkwürdigkeiten aus meinem Leben, 2 Bde, 1918. E. Waldhäusl, C. P.s Stel"Hor meronderer Berücksichtigung ihrer Novellenlung zur zeit, 1936. G. Prohaszka, Der literarische Salon der. K. P., 1946. A. Neunteufel-Metzler, K. P. und die Geschichte ihrer Zeit, 1949. L. Hirschberg, Hg., Der Taschengoedeke, 1961, 487. G. Wilpert Deutsches Dichterlexikon, 1963. K Wache, K. P., die Dichterin AltWiens, 1966. E Sengle, Das historische Drama in Deutschland, 1969, 118 f, 135, 137. B. Becker-Cantarino, „C. P. und die ,Frauendichtung “", in: Modern Austrian Literature 12 (1979) 3/4, 1-23. B. Bittrich, „Österreichische Züge am Beispiel der C. P.", in: Lite12(1979) 3̈̈treich-Österreichische Literatur, 1981, 167-89. E. Friedrichs, Die deutschsprachigen Schriftstellerinnen des 18. und 19. Jahrhunderts, 1981. G. BrinkerGabler, „C. P.“, in G. Brinker-Gabler, K. Ludurig, A. Wöffen, Hg., Lexikon deutschsprachiger Schriftstellerinnen 1800-1945, 1986. V. Richel, The German Stage, 1767-1890, A Directory of Playwrights and Plays, 1988, 115. M. Wallach, „K. P.", in: E. Frederiksen, Hg., Women Writers of Germany, Austria, and Switzerland, 1989, 179
Pierson, Caroline (in Lexika auch: Hahn, R. Edmund), Geb, am 6. 1. 1811 in Zittau/ Sachsen (Leonhardt). Vater der sächsische Hauptmann ? Leonhardt, Mutter ?. Thre Mutter starb kurz nach ihrer Geburt, der Vater, der sich bald darauf wieder verheirate hatte, in einem Feldzug gegen Rußland. Ihre Stiefimutter heiratete den sächsischen Hauptmann Dreverhoff und adoptierte C. P. C. P. erhielt eine gründliche Schulbildung und aufgrund ihres früh crkannten Improvisationstalentes eine Ausbildung im Versbau. Sie schrieb, trotz stiefelterlicher Opposition, viele Gedichte. C. P. hatte eine gute Stimme und wäre beinahe Sängerin geworden, gab aber ihrer literarischen Karriere den Vorzug.

Umzug nach Dresden Anfang der 30er Jahre. Hier wurde sie von Friedrich Kind und Ludwig Tieck protegiert, erhielt Kontakt zu literarischen Kreisen und fing an zu schreiben. Ihre erste Veröffentlichung waren "ihre Jugendgeschichte" (Groß 1882, 117 Titel nicht ermittelt) und cin Gedichtband (Liederkranz, 1834), von denen viele Gedichte vertont wurden, und mehrere Opernlibretti. 1836 Heirat mit dem Dichter und Maler Johann Peter Lyser (1804-1859). Zwei Töchter. Um 1839 beschäftigte sie sich mit dem Leben der Anna Luisa Karsch und schrieb an einer Biographie üher sie. 1840 veröffentlichte sie ihr erstes Theaterstück, das Künstlerdrama Meister Albrecht Dürer.

Seit 1840 trat sie mit ungeheurem Erfolg als Stegreifdichterin auf (u. a. in Wien, Berlin, Dresden, Hamburg, Leipzig, Prag, Budapest und Frankfurt/M.) und wurde in der Folge fast an alle Höfe gerufen. Ehrungen an den Höfen von Berlin, Wien, Hannover, Dessau, Bernburg und Budapest. 1842 Scheidung. 1844 Heirat mit dem Komponisten Henri Hugo P. (1815-1873) und Ende ihrer Karriere als Stegreifdichterin „auf Wunsch ihres Gatten“ (Brümmer). Mindestens drei Söhne.

Mit ihrem Mann lebte sie in Wien, Mainz, Würzburg, Stuttgart, seit 1846 in Hamburg und später in Leipzig. Thre Ehejahre bedeuteten auch in schriftstellerischer Hinsicht eine Unterbrechung: zwischen 1842 und 1864 hat sie nichts veröffentlicht. $A b$ 1865 , d. h. „erst nachdem ihre Kinder erwachsen waren“ (Brümmer), schrieb sie in rascher Aufeinanderfolge viele Romane und Novellen, immer anonym oder unter dem Pseudonymen „R. E. Hahn" oder "R. Edmund Hahn“. 1873 Tod ihres Mannes und Umzug nach Dresden, wo zwei ihrer Söhne eine Buchhandlung besaßen.

Die Feier ihres 60jährigen Jubiläums als Dichterin 1886 legt den Beginn ihrer literarischen Tätigkeit in das Jahr 1826 und deutet auf frühere, inzwischen verschollene Werke hin (ihr erstes nachgewiesenes Werk wurde 1833 veröffentlicht). 1892 zog sie nach Coswig bei Dresden zu ihrem Sohn Reginald, der dort eine Heilanstalt („Lindenhof") leitete, und starb dort am 2. 4. 1899.

C. P. war hauptsächlich Prosaschriftstellerin. Außer Meister Albrecht Dürer verfaßte sie mehrere Opernlibretti und noch zwei Stücke; die historischen Dramen Starhemberg (1865) und Der letzate Jagiello (1895), ihr letztes Werk.

Werke: Dramatische Werke siehe Anhang B. Frühe Gedichte, ca. 2. Hälfte der 1820er Jahre. Encyclopädie der sämmtlichen Frauenkünste (mit C. Seifer), 1833 (2. Aufl. 1837). Ein autobiographisches Werk, Titel nicht ermittelt, 1834. Liederkranz, 1834. Charakterbilder für deutsche Frauen und Mädchen (enthält: Die Verwahrlosete; Lea; Die weiße Locke; Die beiden Perlenschnüre; Die Malerin; Buch der Lieder), 
1838. Beiträge in Abendländische Tausend und eine Nacht, hg. J. P. Lyser, 1838/9. Herbstgabe, Taschenbuch auf die Jahre 1839-41, 1838-40 (2. Aufl. unter dem Titel: Zehn Novellen, 3 Bde., 1842). Beiträge in Abendländische Einhundert und eine Nacht, hg. J. P. Lyser, 1840. Ludwig Pauli als Künstler dargestellt, 1842. Novellen (enthält: Getrennt und doch vereint; Das Leben im Waldschlosse; Lebensschattierungen; Imanuel; Konradin), 1842. Goldene Fibel oder Kurzweilige Mährlein, belehrende Fabeln und Geschichtchen, 1843. Novellen (mit F. Iffalz), 1864. Das Dokument, Roman, 1865. Der Verschwundene, 1866. Das graue Haus in der Rue Richelieu, Roman, 1867. Hohenzollern und Welfen, Roman, 3 Bde., 1867-9. Tat und Gedanken, Novelle, 1868. Bilder aus der Dichter- und Künstlerwelt, 1870. Schloß Hrawodar, Roman, 3 Bde., 1870. Die Sklaverei der Liebe, Roman, 2 Bde., 1872. Stephanie, Roman, 2 Bde., 1873. Die falsche Gräfin, Roman, 1873. Der Zögling des Diplomaten, Roman, 3 Bdc., 1876. Zu früh vermählt, Roman, 1876. Ein Jah.r in der großen Welt, Roman, 2 Bde., 1879. Schöne Frauen, Roman, 2 Bde., 1881. Im Park zu Rodenstein, Roman, 2 Bde., 1881. Die beiden Gräfinnen, Roman, 2 Bde., 1884. Die Geheimnisse des Waldschlosses, Roman, 2 Bde., 1885 (4. Aufl. 1894). Ehen werden im Himmel geschlossen, Roman, 1886. Das Erbfräulein, Roman, 2 Bde., 1889. Gustav Kühne, sein Leben und Briefwechsel mit Zeitgenossen, 1890. Die Unbelsannte, Roman, o. J.

Literatur: H. Groß, Deutschlands Dichterinen und Schriftstellerinen, 2. Aufl. 1882, 117 f. H. Groß, Deutsche Dichterinen und Schriftstellerinen in Wort und Bild, 1885, II 40-3. S. Pataky, Lexikon deutscher Frauen der Feder, 1898, II. Fr Brimmer, „K. P.", in: Allgemeine deutsche Biographie, 1907, LIII. F Brïmmer, Lexikon der deutschen Dichter und Prosaisten vom Beginn des 19. Jahrhunderts bis zur Gegenwart, 6. Aufl 1913, V. W. Kosch, Deutsches Litcratur-Lexikon, 3. Aufl. 1968-1990. E. Friedrichs, Die deutschsprachigen Schriftstellerinnen des 18. und 19. Jahrhunderts, 1981

Prellwitz, Gertrud. Geb. 5. 4. 1869 in Tilsit. Oberlehrerinnenprüfung in Königsberg wo sie eine Zeitlang als Lehrerin tätig war: Ab 1898 als Dramatikerin, Erzählerin und Essayistin tätig; verfaßte viele patriotische und religiöse Schriften. Seit 1901 war sie Oberlehrerin in Berlin, seit 1905 in Mittel-Schreiberhau (Schlesien) und seit 1910 in Woltersdorf bei Erkner (Mark). Philosophie- und Theologiestudium an der Universität von Köniosberg, danach freie Schriftsteilerin. 1915 Amerikareise. Zuletzt wohnhaft in Oberhof (Thüringen) und Blankenburg (Harz). Den Oberhof in Thüringen hatte sie als Jugendheim gestiftet. Gest. 13. 9. 1942 in Oberhof (Thüringen).

Werke: Dramatische Werke siehe Anhang B. Weltfrömmigkeit und Christentum, 1901. Der religiöse Mensch und die moderne Geistesentwicklung, Sieben Vorträge, 1905 (2. Aufl, unter dem Titel: Unsere neue Weltanschauung, 1921). Vom Wunder des Lebens, Dichtung, 1909. Die Legenden vom Drachenkämpfer, Dichtung, 1912. Durch welche Kräfte wird Deutschland siegen?, Religiöser Vortrag, 1915. Von de Durch Seligwerden hinieden, 9 Brieschaffenden Liebe des Lichts in uns, Eine Anleitung zum (enthält: I: Vorfrühling, cin Spiel; II. Neue Zeit, Den jungen Gottsuchern gewidmet; III: Flammenzeichen), 1920-26. .
Jugend, dem Volke zu spielen, 1921. Vom heiligen Frühling, Aufsatz, 1921. Gottesstimmen, Gedicht (entstanden 1896-99), 1921. Das Osterfeuer, eine Erzählung aus der Welt des Armannentums (entstanden 1917), 1921. Ruth, Buch von Deutschlands Not und von Deutschlands Jugend, Erzählung, 1921. Schaffende, Novelle, 1922. Vom Frühlingsschaffen, 8 Spruchkarten, 1923. Des Deutschen Willens Weg, 1923. Des Deutschen Willens Ziel, 1923. Der lebendige Quell, ein Spruch-Jahrbuch aus G. P.' Werken, zusammengestellt von W. Plaut, 1924. Baldurs Wiederkehr, Lcgende, Eine Schauung vom Völkerschicksal, 1924. Sonne über Deutschland, Roman, 1926. Das eigene Ich, Roman, 1926. Das Geheimnis hinter Liebe und Tod, 3 Novellen, 1929 Meine Kindheitserinnerungen, 1929/30. Lebensanfänge, Erinnerungen aus Kindhei und Jugend, 1930. Treue, Roman, 1930. Die Kastanienlkönigin, Sternenlegende, 1931. Pfingstflammen, Roman in Tagebuchform, 1932.

Literatur: Ff Brümmer, Lexikon der deutschen Dichter und Prosaisten vom Beginn des 19. Jahrhunderts bis zur Gegenwart, 6. Aufl. 1913, V. W. Kosch, Deutsches Literatur-Lexikon, 3. Aufl. 1968-1990. E. Friedrichs, Die deutschsprachigen Schriftstellerinnen des 18. und 19. Jahrhunderts, 1981. G. Brinker-Gabler, "G. P.", in G. BrinkerGabler, K. Ludwig, A. Wöffen, Hg., Lexikon deutschsprachiger Schriftstellerinnen $1800-1945,1986$.

Reitzenstein, Sophie Mariane von. Geb. 1. 3. 1770 (Weikard). Vater Staatsrat und Direktor des Medizinalwesens in Fulda D. Adam Melchior Weikard. 1823 heiratete sic den Kreisrat v. R. in Nenndorf bei Bayreuth. Gest. 13, 1. 1823 in Nemmersdorf (Bayern). Weitere Angaben nicht erhältlich.

Werke: Dramatische Werke siehe Anhang B.

Literatur: C.W. O. A. v. Schindel, Die deutschen Schriftstellerinnen des neunzehnten Jahrhunderts, 1823, II. H. Groß, Deutschlands Dichterinen und Schriftstellerinen, 2. Aufl. 1882, 35. K. Goedeke, Grundriß zur Geschichte der deutschen Dichtung aus den Quellen, 2. Aufl. 1884-1966, V. E. Friedrichs, Die deutschsprachigen Schriftstellerinnen des 18. und 19. Jahrhunderts, 1981. V. Richel, The German Stage, 1767-1890, A Directory of Playwrights and Plays, 1988, 124

Rupp, Victoria von. Geb. um 1755 in Prag (Raudnitzky), gest. um 1824 in Prag. Sic bezeichnete ihre Dramen als Übersetzungen (Pseud.: Miß Jennys Übersetzerinn); die meisten Bibliographen glaubten ihr (Hanstein, Friedrichs). Keine weiteren Angaben erhältlich.

Werke: Dramatische Werke siehe Anhang B.

Literatur: G. Chr. Hamberger und J. G. Meusel, Das gelehrte Teutschland oder Lexikon der jetzt lebenden teutschen Schriftsteller, 1796-1834, VI und XIX. C.W. O.A v. Schindel, Die deutschen Schriftstellerinnen des neunzehnten Jahrhunderts, 1823, II. H. Groß, Deutschlands Dichterinen und Schriftstellerinen, 2. Aufl. 1882, 27. K. Goedeke, Grundriß zur Geschichte der deutschen Dichtung aus den Quellen, 2. Aufl. 1884-1966, V. S. Pataky, Lexikon deutscher Frauen der Feder, 1898, II A. v. Hanstein, Die Frauen in der Geschichte des Deutschen Geisteslebens des 18. und 
19. Jahrhunderts, 1900, II 252. E. Friedrichs, Die deutschsprachigen Schriftstellerinnen des 18. und 19. Jahrhunderts, 1981

Schlegel, Christiane Karoline. Geb. 7. 12. 1739 in Dresden (Lucius), ein älterer Bruder (geb. 1736/7), eine jüngere Schwester (Friederike Auguste, geb. 1748). Vater der kurfürstlich-sächsische Geheimsekretär Karl Friedrich Lucius, Mutter Christiane Sophie Franz. Da der Vater häufig Berufsreisen unternahm, wurden die Kinder weitgehend von der Mutter oder von Hauslehrern unterrichtet. Die Mutter ermutigte die Kinder zum Lesen; C. K. S. lernte Französisch (wahrscheinlich von einem Hauslehrer) und später Englisch und Italienisch im Selbstunterricht.

1760 schrieb C. K. S. an den von ihr sehr verehrten Gellert, der ihre Briefe beantwortete; daraus enstand ein Briefwechsel, der bis zu Gellerts Tod (1769) anhielt (Teile des Briefwechsels sind in Gellerts Gesammelten Werken veröffentlicht). Zu eben diesem Zweck bat Gellert sie um Abschriften seiner Briefe an sie, damit die Briefe, „wenn sie einst auf die Nachwelt kommen sollten, sich in gehöriger Ordnung befänden" (Schindel II, 252). Gellert verwies eine andere Korrespondentin, mit der er selbst keine Briefe wechseln wollte, an C. K. S., die später mit ihr gut befreundet war, und hatte einmal sogar vor, C. K. S. mit einem seiner Freunde, einem Kantor, zu verheiraten. Briefwechsel außerdem mit Jacobi; Freundschaft mit Christian Felix Weiße. Nach Gellerts Tod bearbeitete sie ihren Briefwechsel mit Gellert zusammen mit Schlegel, Heyer und Cramer zur Herausgabe.

Am 6. 10. 1774 heiratete sie den Pastor M. Gottlieb S. in Dresden und zog mit ihm nach Burgwerben. 1777 erfuhr sie durch ihre Schwester von einem in Dresden verübten Mord; dieser Mordfall war die Grundlage zu ihrem Trauerspiel Düval und Charmille, das sie in wenigen Tagen schrieb. Sowohl Schindel als auch Hanstein nchmen an, daß C. K. S. nicht an eine Veröffentlichung dachte, als sie das Stück an Weiße schickte, „um sein Urtheil darüber zu hören“ (Schindel II, 256), dieser aber gab es prompt heraus - nach Rücksprache mit der Verfasserin, ,in deren Sinne dieß eigentlich nicht lag" (II, 256).

1778 trat ihr Vater von seiner Stelle zurück; beide Eltern wohnten yon da ab bis zu ihrem Tod (1783 Tod des Vaters, 1786 Tod der Mutter) bei C. K. S. in Burgwerben. Ihr Bruder war (wann? vor 1778) gestorben; ihre Schwester starb 1780 an den Folgen einer Gcburt. 1796 adoptierten die Schlegels eine Pflegetochter. 1813 starb ihr Mann. C. K. S. zog mit ihrer Pflegetochter nach Weißenfels und 1814 nach Dresden. In diesen Jahren Bekanntschaft mit v. Schindel. 1822 unterzog sie sich einer Operation an ihrem Fuß. C. K. S. starb am 21. 8. 1833 in Dresden. Außer ihrem Briefwechsel und ihrem Trauerspiel übersetzte sie aus dem Englischen und dem Französischen.

Werke: Dramatische Werke siehe Anhang B. Briefwechsel mit Gellert, 1775. Unterricht eines Vaters für seine Kinder über Natur und Religion, Übers. (von Abr. Trembley, Instructions d'un père à ses enfants sur la nature et la réligion), 1776-80. Der empfindsame Träumer, Übers. (von P. Blanchard, aus dem Französischen), 1799. Frohe Gedanken über die Glückseligkeit eines religiösen Lebens, Übers. (von D. Harwoods Delights of a Religious Life), 1781.
Literatur: G. Chr. Hamberger und J. G. Meusel, Das gelehrte Teutschland oder Lexikon der jetzt lebenden teutschen Schriftsteller, 1796-1834, VII und XX.C.W. O.A v. Schindel, Die deutschen Schriftstellerinnen des neunzehnten Jahrhunderts, 1823, II. H. Groß, Deutschlands Dichterinen und Schriftstellerinen, 2. Aufl. 1882, 25. K. Goedeke, Grundriß zur Geschichte der deutschen Dichtung aus den Quellen, 2. Aufl. 1884-1966, V. S. Pataky, Lexikon deutscher Frauen der Feder, 1898, II. A. v. Hanstein, Die Frauen in der Geschichte des Deutschen Geisteslebens des 18. und 19. Jahrhunderts, 1900, II 238-246, 249-252. L. Hirschberg, Hg., Der Taschengoedeke, 1961, 580. E. Friedrichs, Die deutschsprachigen Schriftstellerinnen des 18. und 19. Jahrhunderts, 1981. K. Wurst, Hg., Frauen und Drama im 18. Jahrhundert, 1991, 58-69.

Schlichtkrull, Aline von. Geb, am 20.11. 1832 in Silenz (Rügen), Vater der Edelmann und Gutsbesitzer ? v. S., Mutter ?. Sie ging gegen den Willen ihres Vaters nach Berlin, um sich fortzubilden, und lebte dort von 1845-47. Danach Rückkehr zu ihre Familie nach Engelswacht bei Stralsund; hier schrieb sie ihre (unveröffentlichte) $G_{e}$ schichte der deutschen Literatur.

1850 Rückkehr nach Berlin und Eintritt in das Marx-Kullak-Sternsche Konservatorium. Da ihr Vater sie finanziell nicht hinreichend unterstützte, erteilte sie Musilunterricht und trieb nebenbei historische und poetische Studien. In diesen Jahren schrieb sie viele mehrbändige Romane, eine Novellensammlung und zwei Dramen, von denen eines (der Schwank Wie ein Staat gerettet wird) erst nach ihrem Tod veröffentlicht wurde. Freundschaft mit der Schriftstellerin und Rezitatorin Elise Schmidt (siche dort), bei deren Vorträgen sie eigene Kompositionen vortrug Krankheit ab Mitte der 50er Jahre und wiederholte Badereisen von 1858-1862. A. v. S. starb am 5. 3. 1863 in Berlin.

Werke: Dramatische Werke siehe Anhang B. Geschichte der deutschen Literatur, vor 1850. Eine verlorene Seele, Roman, 4 Bde., 1853. Chapelle Gaugain, Roman in $2 \mathrm{Ab}$ teilungen (I: Der Kardinal Richelieu; II: Cordelia), 7 Bde., 1855-57. Morton Varney, Roman, 2 Bde., 1855. Kompositionen, Titel nicht ermittelt, ca. 1855-63. Der Agitato von Irland, Roman, 4 Bde., 1859. Laterna Magika, Novellen, 1860. Berühmte Männer des Constitutionalismus, o. J.

Literatur: H. Groß, Deutschlands Dichterinen und Schriftstellerinen, 2. Aufl. 1882, 130. S. Pataky, Lexikon deutscher Frauen der Feder, 1898, II. F Brümmer, Lexikon de deutschen Dichter und Prosaisten vom Beginn des 19. Jahrhunderts bis zur Gegenwart, 6. Aufl. 1913, VI. W. Kosch, Deutsches Literatur-Lexikon, 2. Aufl. 1949-1958. E. Friedrichs, Die deutschsprachigen Schriftstellerinnen des 18. und 19. Jahrhunderts, 1981.

Schmidt, Elise. Geb. 1. 10. 1824 in Berlin. Vater der Kaufmann ? S., Mutter ?. E. S, entwickelte ein frühes Interesse am Theater und begann mit 12 Jahren dramatisch Studien. Mit 14 Jahren trat sie zum ersten Mal auf und wurde sofort am Theater in Dessau als Schauspielerin angestellt. Später spielte sie u. a. in Berlin (Königsstadt), Frankfurt/O., Stettin, Preßburg, Prag, Lemberg, am Hoftheater in München und 
längere Zeit in Wien. Nach 1848 wurde sie nach Breslau gerufen. Ein Jahr später verließ sie die Bühne und wurde freie Schriftstellerin.

$\mathrm{Ab} 1855$ bereiste sie Europa mit Vorlesungen griechischer Dramen (u. a. las sie in Berlin, Hamburg, London, Frankfurt/M., München, Leipzig, Königsberg und Danzig); mit diesen Vorlesungen wurde sie berühmt. Freundschaft und Zusammenarbeit mit der Schriftstellerin und Komponistin Aline von Schlichtkrull (siche dort), die bei diesen Vorlesungen ihre Kompositionen vortrug. Nach dem Tod ihrer Freundin gab E. S. ihre Karriere als Rezitatorin auf und zog nach Berlin, später nach Potsdam, 1872 nach Berka an der Ilm, wo sie als freie Schriftstellerin lebte. Abgesehen von zwei mehrbändigen Romanen schrieb E. S. hauptsächlich Theaterstücke und Bearbeitungen gricchischer Dramen. Todesdatum und -ort unbekannt.

Werke: Dramatische Werke siehe Anhang B. Roman in Wien, 2 Bde., 1864. Zeitgenossen, Roman (Fortsetzung von: Roman in Wien), 3 Bde., 1866.

Literatur: H. Groß, Deutschlands Dichterinen und Schriftstellerinen, 2. Aufl. 1882, 126. H. Groß, Deutsche Dichterinen und Schriftstellerinen in Wort und Bild, 1885, II 294-303. S. Pataky, I exikon deutscher Frauen der Feder, 1898, II. F. Brimmer, Lexikon der deutschen Dichter und Prosaisten vom Beginn des 19. Jahrhunderts bis zur Gegenwart, 6. Aufl. 1913, VI. W. Kosch, Deutsches Literatur-Lexikon, 2. Aufl. 19491958. E. Friedrichs, Die deutschsprachigen Schriftstellerinnen des 18. und 19. Jahrhunderts, 1981. V. Richel, The German Stage, 1767-1890, A Directory of Playwrights and Plays, 1988, 134

Seyler, Friederike Sophie (in Lexilka häufig: Hensel, F. S.; Seiler, F. S.). Geb. 1738 in Dresden (Sparmann). Vater der Generalstabsarzt Sparmann, Mutter ?. Nach der Scheidung der Eltern (1740er oder frühe 1750er Jahre) ging die Mutter ins Kloster und übergab die Fürsorge für F. S. S. einem Onkel, dessen tyrannische Behandlung ihr so unerträglich war, daß sie weglief und sich in den Schutz einer Verwandten begab. Als diese 1753 starb, sah F. S. S. sich den Mißhandlungen ihres Onkels erneut ausgesetzt. 1754 wollte ihr Onkel sie zu einer Heirat zwingen, worauf sie zum Theater ging; im selben Jahr spielte sie bei der Kirschschen Truppe.

1755 heiratete sie den Schauspieler Hensel und ging Ende des Jahres mit ihm zur Schuchschen Truppe, von dort $1757 \mathrm{zu}$ Ackermann nach Hamburg. 1757 trennte sie sich von ihrem Mann und ging trotz einjährigen Vertrags mit Ackermann für drei Monate nach Wien. Reisen bis 1765 nach Frankfurt/M., Hildburghausen und Wien. Wegen einer Krankheit faßte sie kurzfristig den Entschluß, ihre Schauspielerlaufbahn aufzugeben, kehrte jedoch 1765 nach Hamburg zurück. und spielte wieder bei Ackermann.

Wegen Schwierigkeiten mit ihrer Kollegin Karoline Schulze entschloß sich ihr langjähriger Verehrer, der Schauspieldirektor Abel S., „für sie ein Theater zu schaffen, auf dem sie, ohne Rivalität zu befürchten, herrschen könnte" (Stein I, 19) und gründete 1767 das Hamburger deutsche Nationaltheater, an das Lessing als Dramaturg berufen wurde. Enge Zusammenarbeit mit Konrad Ekhof bis ca. 1775. Als das Theater ein Jahr später geschlossen wurde, spielte F. S. S. in Abel S.' Truppe u. a. in Hannover, am
Weimarer Hoftheater, das die Truppe 1775 verlassen mußte, weil das Schloß samt Bühne abbrannte, und in Gotha. 1777 [1772?] ließ sie sich von Hensel scheiden und heiratete Abel S. 1780 löste dieser seine Truppe in Frankfurt auf; von 1783-1792 leitete er das Hoftheater in Schleswig. F. S. S. starb am 22.11. 1789 in Schleswig.

F. S. S. war eine der berühmtesten und, zeitgenössischen Rezensionen zufolge, eine der großartigsten Schauspielerinnen ihrer Zeit. Lessing lobt ihre schauspielerischen Leistungen in der Hamburgischen Dramaturgie in den höchsten 'Tönen und war besonders begeistert von ihrer Darstellung der Sara Sampson (,Man kann von der Kunst nichts mehr verlangen, als was Madame Henseln in der Rolle der Sara leistet", HD 13 , 176); Iffland zerfloß bei derselben Vorstellung „in Tränen“ (Theatralische Laufbahn 10) und bezeichnete F. S. S. als cines seiner größten Vorbilder (13).

F. S. S. wurde oft für ihre Empfindlichkeit im Bezug auf ihre schauspielerischen Leistungen kritisiert; die Streitigkeiten mit Karoline Schulze, deren Resultat die Gründung des Hamburger Nationaltheaters war, wird von vielen Biographen als Beispiel ihres extremen Konkurrenzverhaltens angeführt. Über ihre Darstellung der Hauptrolle in der Cenie der Mme. de Graffigny in der Übers. von L. Gottsched (siehe dort) schrieb Lessing: „Kein Wort fällt aus ihrem Munde auf die Erde. Was sie sagt, hat sic nicht gelernt; es kömmt aus ihrem eignen Kopfe, aus ihrem eignen Herzen. Sie mag sprechen, oder sie mag nicht sprechen, ihr Spiel geht ununterbrochen fort. Ich wïßte nur einen einzigen Fehler; aber es ist ein sehr seltner Fehler; ein sehr beneidenswürdiger Fehler. Die Aktrice ist für die Rolle zu groß. Mich dünkt einen Riesen zu schen der mit dem Gewehre eines Kadetts exerzieret" (HD 20, 202). Trotz dieser zweifellos gutgemeinten Rezension war F. S. S. über den letzten Satz so entrüstet, daß Lessing danach auf eine Besprechung der Leistungen der Schauspieler in der $H D$ verzichtete. Ihre Dramen wurden wesentlich seltener und negativer rezensiert als ihre schauspielerischen Leistungen.

Werke: Dramatische Werke siehe Anhang B. Ein Gedicht in Reichards Theaterkalender, 1775.

Literatur: J. F. Löwen, Geschichte des deutschen Theaters (1766) und Flugschriften über das Hamburger Nationaltheater (1766/7), 81. Almanach der deutschen Musen auf das Jahr 1771, 82 f. Almanach der deutschen Musen auf das Jahr 1772, 71 f, 140-144. H. L. Wagner, Briefe die Seylerische Schauspielergesellschaft und Ihre Vorstellungen zu Frankfurt am Mayn betreffend, 1777, 8 f, 42, 48 f, 87, 98-101, 119, 166, 202, 235. Gallerie von Teutschen Schauspielern und Schauspielerinnen der ältern und neuern Zeit nebst J. F. Schinks Zusätzen und Berichtigungen, hg. R. M. Werner, 1783. J. F. Schütze, Hamburgische Theater-Geschichte, $1794,328 \mathrm{f}$ und 333 f. J. G. Meusel, Lexikon de vom Jahr 1750 bis 1800 verstorbenen teutschen Schriftsteller, 1802-1816, XIII K. Herloßssohn und H. Marggraff, Allgemeines Theater-Lexikon, 1846, IV, R. E. Prutz Vorlesungen über die Geschichte des deutschen Theaters, 1847, 294 f. A. E. Brach vogel, Das alte Berliner Theater-Wesen bis zur ersten Blüthe des deutschen Dramas, 1877, 200-2 und 222. FJ. v. Reden-Esbeck, Deutsches Bühnen-Lexikon, 1879. H. Großs, Deutschlands Dichterinen und Schriftstellerinen, 2. Aufl. 1882, $24 \mathrm{f}$ $K$. Goedeke, Grundriß zur Geschichte der deutschen Dichtung aus den Quellen, 
2. Aufl. 1884-1966, V. A. W. Iffland, Ueber meine theatralische Laufbahn, 1886, Vorwort (von H. Holstein) vil, xx; 10, 13, 46-8. S. Pataky, Lexikon deutscher Frauen de Feder, 1898, II. A. v. Weilen und O. Teuber, Die Theater Wiens, 1899-1906, II A $84 \mathrm{f}$. A. v. Hanstein, Die Frauen in der Geschichte des Deutschen Geisteslebens des 18. und 19. Jahrhunderts, 1900, II 436. Chr. H. Schmid, Chronologie des deutschen Theaters [1775], 1902, 114-224. A. W. Iffland, A. W. I.s Briefe an seine Schwester Louise und andere Verwandte (1772-1814), 1904, 33, 35, 38, 175 und 261. H. Devrient, Archiv für Theatergeschichte, 1904-5, II 74-8. A. W. Iffland, A. W. I.s Briefe meist an seine Schwester nebst anderen Alktenstücken und einem ungedruckten Drama, 1905, $204 \mathrm{f}$. P. Stein, Deutsche Schauspieler, Eine Bildnissammlung, 1908, I. A. Eloesser, Hg., Aus der großen Zeit des deutschen Theaters, Schauspieler-Memoiren, 1911, $36 \mathrm{f}$. H. Landsberg und A. Rundt, Theater-Kalender auf das Jahr 1911 (1912), 148. H. Landsberg und A. Rundt Theater-Kalender auf das Jahr 1912 (1913), 101-113. K. Ekhof und Anna Amalia von Weimar, Ungedruckte Briefe, in: Bühne und Welt 15 (1913). P. Schlenther, Theater im 19. Jahrhundert, 1930, 2. H. Kindermann, Theatergeschichte der Goethezeit, 1948, 125-152, 312-320, 426-428, 431, 437, 441 und 449-454. L. Hirschberg, Hg., Der Taschengoedeke, 1961, 617. G. E. Lessing, Hamburgische Dramaturgie (Frankfurt: 1967), 4., 13. und 20. Stück, S. 140 f, 176 und 202. E. Friedrichs, Die deutschsprachigen Schriftstellerinnen des 18. und 19. Jahrhunderts, 1981. V. Richel, The German Stage, 1767-1890, A Directory of Playwrights and Plays, 1988, 64.

Stein, Charlotte Albertine Ernestine von. Geb. 25.12. 1742 in Eisenach (von Schardt). Vater Hofmarschall Christian Wilhelm von Schardt, Mutter Concordia ElisaSchardt). Vater Hofmarschall Christian W lhelm von Schardt, Mutter Concordia E. v. S. war für den Dienst bei Hofe vorgesehen; ihre Erzichung war eine entsprechende: Französisch, Klavier, Gitarre, Zeichnen und die üblichen feineren Handarbeiten" (Hanstein II, 422). Mit 15 Jahren wurde sie Hofdame der Herzogin Anna Amalia in Weimar.

Am 8. 5. 1764 heiratete sie den Herzoglich Weimarschen Stallmeister Friedrich Freiherr v. S. (1735-1793) und zog nach Kochberg bei Rudolstadt. Sieben Kinder; vier Töchter starben früh; drei Söhne (Karl, Ernst, Fritz). Aufgrund seines Berufes lebte ih Mann meistens am Weimarer Hof und befand sich oft auf Reisen, entweder als Begleiter des Herzogs oder auf Pferdekäufen. Freundschaft mit Wieland.

1775 lernte sie Goethe in Weimar kennen und war mit ihm bis zu seiner Abreise nach Italien (1786) eng befreundet. Scine Liebesbriefe an sie (ihre Antworten sind nicht erhalten) gaben Anlaß zu endlosen Spekulationen; meist wird Goethe als der jugendlich Verliebte und C. v. S. als die mütterlich Beratende dargestellt, die vielleicht seine Zuneigung erwiderte, aber die Beziehung entweder aus Angst vor dem Klatsch oder aus idealistischen Entsagungsmotiven auf freundschaftlicher Bbene hielt. Es gibt auch Anzeichen dafür, daß sie sich über Goethes leidenschaftliche Briefe cher amüsierte: 1776 schrieb sie Rino, ein kurzes Schauspiel, in dem sie sich über Goethes Liebeleien am Weimarer Hof lustig macht. Am Ende des Stückes stellen die Hofdamen nach kurzer Konversation fest, daß jede einen gleich großen Packen Liebesbriefe von RinoGoethe besitzt; und Gerthrut (d. i. C. v. S.) resumiert: „Gleichgültig ist er mir eben nicht,/ Doch weiß ich nicht ob er oder Werther mir spricht" (Goethes Briefe I, 398).

Bis 1786 hielt C. v. S. engen Kontakt mit Goethe; dieser Kontakt scheint sich mit vollem Einverständnis ihres Mannes in eine Art Halbehe ausgewachsen zu haben, die Kühn als „Familiengemeinschaft mit Güteraustausch für Küche und Haus“ beschreibt (I, 182). C. v. S. schickte ihm regelmäßig Mahlzeiten und pflegte ihn während verschiedener Krankheiten; Goethe teilte „alle wirtschaftlichen Sorgen [...] mit ihr, lieh ihrer Mutter Geld, besorgte Obstbäume für Kochberg, verrichtete manche Geschäfte des Haushalts, die dem Hausvater zustehen, machte sich ïber Steins wirtschaftliche Lage Gedanken, übernahm Besorgungen, half, wo er konnte" (Kühn I, 183). Wenn Goethe verreiste, bekam C. v. S. die Schlüssel zu seiner Wohnung. C. v. S. übergab Goethe sogar die Erziehung ihres Sohnes Fritz.

Als Goethe 1786 nach Italien reiste, brach sie den Kontalkt ab; ihr Sohn zog wieder zu ihr. Sie schrieb Goethe, sie wolle den Brieflkontakt nicht länger fortsetzen, und forderte ihre Briefe von ihm zurück. Obwohl sie später wieder schriftlichen Kontalkt zu ihm aufnahm, war das Verhältnis von da ab ein gespanntes. Freundschaft mit Charlotte von Lengefeld (später Schiller), Herzogin Luise, Karl von Knebel. 1787 starb ihr Sohn Ernst an der Auszehrung. 1788 wurde ihr Mann gichtkrank; bis zu seinem Tod 1793 pflegte sie ihn. In Briefen klagt sie häufig über seine „Hypochondrie“, die sie ans Haus fesselte; sie hätte gern Charlotte Schiller in Jena besucht, ,aber wohin mit dem Stein" (zit. Kühn II, 47). Nach dem Tod ihres Mannes lud C. v. S. häufig Freunde und Verwandte zu sich ein; sie zeichnete, schrieb, war eine begeisterte Reiterin, und beschäftigte sich mit Philosophie, Astronomie und den Naturwissenschaften. Häufige finanzielle Schwierigkeiten, da sie ihren Sohn Fritz finanziell unterstützte.

1796 schrieb sic ihr Drama Dido, dessen Figuren eventuell Persönlichkeiten des Weimarer Hofes nachgezeichnet sind (der Dichter Ogon = Goethe). Sie schickte das Manuskript im selben Jahr an Charlotte Schiller; mit der Bitte, es ihrem Mann zur Einsicht zu geben (,Schillern wird's leeinen Spaß machen, denn wie kann dem Meister sowas gefallen", Brief von C. v. S. an Charlotte Schiller, zit. Kühn II, 177). Wider Erwarten war Schiller von dem Stück begeistert, wollte es in Hamburg aufführen lassen und die Verhandlungen für den Druck und Honorar für sie übernehmen. C. v. S. wcigerte sich; das Stück wurde erst 1867 gedruckt - im Anhang einer Ausgabe von Goethes Briefen an C. v. S. Schon Neujahr 1798 schrieb sie an einer neuen Komödie (Neues Freiheitssystem oder die Verschwörung gegen die Liebe); cine Bühnenbearbeitung des Freiherrn Felix von Stein wurde 1867 in der Deutschen Schaubuibne gedruckt. Endo 1800 zwei weitere Komödien; eine davon, Die zwei Emilien, wurde 1803 anonym durch Schillers Vermittlung veröffentlicht.

Um die Jahrhundertwende wieder regelmäßiger, meist gesellschaftlicher, Kontakt mit Goethe. 1802 Tod der Mutter, 1803 Tod ihrer Schwester Luise von Imhoff. Um 1803 Mitwirkung am Liebhabertheater in Weimar, auf dem sie einmal auftrat; einma wurde bei ihr. Gocthes Iphigenie mit ausschließlich weiblicher Besetzung aufgeführt. Seit 1805 war C. v. S. häufig krank, kurzsichtig und halb taub. 1806 völliger Bankrot 
wegen Plünderung durch französische Truppen, bei der C. v. S. ihren gesamten Besitz verlor. C. v. S. starb am 6. 1. 1827 in Weimar.

Werke: Dramatische Werke siehe Anhang B. Briefe an Goethe, 1775-1786. Briefe an Charlotte Schiller; ca. 1780-1827. Weitere Briefe. Verschiedene Gelegenheitsgedichte. Literatur: H. Groß, Deutschlands Dichterinen und Schriftstellerinen, 2. Aufl. 1882, 25. J. W. v. Goethe, Briefe an Frau von Stein, 2 Bde., 1883/5. H. Groß, Deutsche Dichterinen und Schriftstellerinen in Wort und Bild, 1885, I 69-75. S. Pataky, Lexikon deutscher Frauen der Feder, 1898, II. A. v. Hanstein, Die Frauen in der Geschichte des Deutschen Geisteslebens des 18. und 19. Jahrhunderts, 1900, II 223, 421-39. Paul Kühn, Die Frauen um Goethe, Weimarer Interieurs, 2 Bde., 1911/2. W. Bode, C. v. S., 1920. W. Bode, Goethe in vertraulichen Briefen seiner Zeitgenossen 1749-1803, 1921. L. Voss, Goethes unsterbliche Freundin (C. v. S.); eine psychologische Studie an der Hand der Quellen, 1922. C. Kahn-Wallerstein, "C. v. S. und Christiane von Goethe", Goethe-Kalender 1932, 108-137. C. v. S., Briefe, in: F. v. Zobeltitz, Ho., Briefe deutscher Frauen, 1936, 65-84. W. Hof, Wo sich der Weg im Kreise schließt, Goethe und C. v. S., 1957. K. R. Eissler, Goethe, A Psychoanalytic Study, 1775-1786, 1963. G. v. Wilpert, Deutsches Dichterlexilkon, 1963. E. Friedrichs, Die deutschsprachigen Schriftstellerinnen des 18. und 19. Jahrhunderts, 1981. R. Browning, Hg., Selections from Goethe's Letters to Frau von Stein 1776-1789, 1990.

Steinlein, Laura (in Lexika auch: Arthalis, Freese). Geb. 24. 8. 1826 in Friedefeld/ Pommern (Freese). Vater der Rittergutsbesitzer ? Freese, Mutter ?. Häufige Krankheiten in früher Jugend und regelmäßige Erziehung in einer Berliner Schule erst mit 11 Jahren. Im Elternhaus ausführliche Beschäftigung mit Musik und Literatur. Ca. 1844 schrieb sie ihre erste Novelle, die später preisgekrönt wurde (eventuell die Novelle Aus deutschem Hause, veröffentlicht 1890).

Mitte der 40er Jahre verheiratete sie sich mit dem Berliner Landwirt Franz S. (ca. 1821-1902) und zog mit ihm nach Neuenhagen bei Freienwalde; später auf sein Gut Stolpe bei Berlin und 1887 nach Berlin, wo er eine Bierbrauerei übernahm. Unregelmäßige schriftstellerische Tätigkeit (zwischen 1861 und 1890 erschien kein Werk von ihr), wohl wegen „der aufreibenden Pflichten, welche ihr die Leitung eines großen Hauswesens auferlegte" (Brümmer). Meist unter den Pscudonymen "Arthalis“, „A. Freese" oder "Arthur Freese" schrieb L. S. einen Roman, einige Novellen und mehrere Dramen und wurde für ihre schriftstellerischen Leistungen zwei Mal ausgezeichnet. Ihr Mann starb 1902; ihr eigenes Todesdatum ist unbekannt (1901? nach 1902?).

Werke: Dramatische Werke siehe Anhang B. Eine frühe Novelle (identisch mit: Aus deutschem Hause?), ca. 1844. Die letzten Blüten, Roman, 1851. Aus deutschen Hause, Preisgekrönte Novelle, 1890 (2. Aufl. 1890). Mark Ravensberg, Historische Erzählung, 1891.

Literatur: F Brimmer, Lexikon der deutschen Dichter und Prosaisten vom Beginn des 19. Jahrhunderts bis zur Gegenwart, 6. Aufl. 1913, VII. W. Kosch, Deutsches Literatur-Lexikon, 2. Aufl. 1949-1958. H. Groß, Deutschlands Dichterinen und Schriftstellerinen, 2. Aufl. 1882, 127. S. Pataky, Lexikon deutscher Frauen der Feder, 1898
II. E. Friedrichs, Die deutschsprachigen Schriftstellerinnen des 18. und 19. Jahrhunderts, 1981.

Sydow, Wilhelmine von. Geb. 26. 11. 1789 in Thumitz/Oberlausitz (von Criegern) Vater der dänische Hauptmann Karl Friedrich v. Criegern, Mutter ?, geb. v. Kracht Mindestens eine Schwester. W. v. S. heiratete am 6. 12. 1809 den späteren preußischen Hauptmann Friedrich Wilhelm v. S., der selbst Schriftsteller war. Sie selbst begann erst 1822 zu schreiben; in den folgenden 40 Jahren folgten unzählige Aufsätze, historische Romane, Theaterstücke für Kinder, Jugendbücher, Kochbücher, Erzählungen, Novellen und Epen. Fast alle ihre Werke veröffentlichte sie unter den Pseudonymen "Isidore Grönau", „Frau Isidore“ oder anonym, so daß Schindel 1823 nur vermuten kann, "nachfolgende, unter dem Namen Isidore Grönau verfaßte Aufsätze in Zeitschrifteı, wodurch sie ihre geistige Ausbildung beurkundete", (II, 352, Hervorhebung des Verfassers) seien von ihr. In Sondershausen war sie lange die Vorsteherin eines wohltätigen Frauenvereins. 1823 lebte sie in Erfurt; dahin zog sie auch nach dem Tod ihres Mannes (1845) wieder und lebte bei ihrem ebenfalls verwitweten Sohn Oskar; später bei ihrer Tochter in Schleusingen (Thüringen). Dort starb sie am 25. 6. 1867.

W. v. S. war eine äußerst vielseitige Autorin; die im Rahmen dieser Arbeit vorgenommene Analyse ihrer Stücke kann ihr als Autorin nicht gerecht werden.

Werke: Dramatische Werke siehe Anhang B. Aussaat und Lohn, Erzählung, in: Allgemeine Mode-Zeitschrift, 1822. Glaube und Schicksal, Erzählung, in: Allgemeine Mode-Zeitschrift, 1822; auch in: Friedrich v. Sydow, Erzählungen und Gemälde, 1823 und Die Biene, 1823. Züge aus der englischen Geschichte, nach dem Französischen, in: Allgemeine Mode-Zeitschrift, 1822. Die Familie Heimo, oder Bilder der Freude, belehrende Unterhaltung für die Jugend, in einer ungenannten Veröffentlichung ihres Mannes, 1822. Die Täısschung, Erzählung, in: Allgemeine Mode-Zeitschrift, 1823 Das Vermächtniß, Erzählung, in: Allgemeine Mode-Zeitschrift, 1823; auch in: Philippis Merkur, 1823. Vergeltung, Erzählung, in: Friedrich v. Sydow, Erzählungen und Gemälde, 1823. Die Blutschuld, oder Leben und Liebe, eine Criminalgeschichte, 1824 Siegmar, Erzählung, in: Huldigung den Frauen, 1825. Die Grafen von Nordheim, oder das Räthsel der Friedburg, in: Sammlung von Romanen und Erzählungen deutscher Schriftstellerinnen, 1825. An Fanny Tarnow, in: Abendzeitung, 1827. Verlus und Ersatz, Erzählung, in Tolds Fortuna, 1829. Opferblumen, Ausgewählte Erzählun gen (enthält: Heldensinn und Minneglück; Die Blutschuld; Siegmar; Das Vermächtniß; Die Geprüften), 1829. Kunigunde, Königin von Böhmen, Historisch-romántisches Gemälde aus dem 13. Jahrhundert, 1830. Die Inselfahrer, ein Roman aus de Wirklichkeit, 1831. Drei Erzählıngen, der belehrenden Unterhaltung der Jugend aller Stände bestimmt (enthält: Glück folgt der Tugend nach; Nur nicht verzagt, oder: Die edle Schweizer-Familie; Susanne Reisacher), 1834. Drei Erzählungen (enthält: Die drei Freundinnen; Die Freiheits-Jünger; Joseph der Pompier), 1834. Ein Beitrag in Louise Marezolls Frauen-Zeitung, 1838. Die Verirrten, ein Roman für die Gegenwart, 2 Bde 1843. Arwid, der Mann von Welt und feinen Sitten, 2. Aufl. 1850. Johann Adolph, der letzte Herzog von Sachsen-Weißenfels, Historischer Roman, 3 Bde., 1852. Palme 
und Lorbeer, ein anglo-indianisches Zeitbild aus den zwanziger Jahren, 3 Bde., 1858. Die Marketenderin, Volkserzählung, 1859. Allgemeines Koch- und Wirtschaftsbuch, 2 Bde., 7. Auff. 1859. Die Belagerung von Stralsund, Historischer Roman, 2 Bde., 1861. Der Krieg um Schleswig-Holstein, Epos, 1864. Olivia, Novelle, veröff, 1880. Weitere Schriften über den Frauenvercin, Gärtnerei und "den Theetisch" (Goedeke IX, 336).

Literatur: C. W. O. A. v. Schindel, Die deutschen Schriftstellerinnen des neunzehnten Jahrhunderts, 1823, II. K, Goedeke, Grundriß zur Geschichte der deutschen Dichtung aus den Quellen, 2. Aufl. 1884-1966, IX. H. Groß, Deutschlands Dichterinen und Schriftstellerinen, 2. Aufl. 1882, 88. S. Pataky, Lexikon deutscher Frauen der Feder, 1898, II. E. Friedrichs, Die deutschsprachigen Schriftstellerinnen des 18. und 19. Jahrhunderts, 1981.

Teutscher, Maria Antonia, Geb. 13. 6. 1752 in Wien. Sie war bis 1780 Schauspielerin am Wiener Hoftheater, wo sie am 1.4.1769 in der Rolle der Gräfin Olsbach debütierte. M. A. T. beschäftigte sich außerdem mit Porzellanmalerei und war eine leidenschaftliche Leserin; ihre Bibliothek war so umfangreich, daß mehrere ihrer Biographen sie ausdrücklich erwähnen. M. A. T. verließ 1780 das Wiener Theater und heiratete einen „italienischen Negotianten“" namens Gorini (Gallerie). Am 12.4. 1782 spielte sie in Leipzig Rutland in Graf Essex, das Stiick war ein Mißerfolg und M. A. T. mußte die Gesellschaft bald wieder verlassen. M. A. T. starb am 9.1. 1784 in Wien.

Werke: Dramatische Werke siehe Anhang B. Mehrere Aufsätze in Riedls Wochenschrift Der Einsiedler.

Literatur: Gallerie von Teutschen Schauspielern und Schauspielerinnen der ältern und neuern Zeit nebst J. F. Schinks Zusidtzen und Berichtigungen, hg. R. M. Werner, 1783. G. Chr. Hamberger und J. G. Meusel, Das gelehrte Teutschland oder Lexilson der jetzt lebenden teutschen Schriftsteller, 1796-1834, VIII. C. W. O. A. v. Schindel, Die deutschen Schriftstellerinnen des neunzehnten Jahrhunderts, 1823, II. $H$. Groß, Deutschlands Dichterinen und Schriftstellerinen, 2. Aufl, 1882, 28. K. Goedeke, Grundriß zur Geschichte der deutschen Dichtung aus den Quellen, 2. Aufl. 1884-1966, IV/1. S. Pataky, Lexikon deutscher Frauen der Feder, 1898, II. A. v. Weilen und O. Teuber, Die Theater Wiens, 1899-1906, II A 147, II B 8 f. E. Friedrichs, Die deutschsprachigen Schriftstellerinnen des 18. und 19. Jahrhunderts, 1981. V. Richel, The German Stage, 1767-1890, A Directory of Playwrights and Plays, 1988, 147.

Thon, Eleonore Sophie Auguste (in Lexika auch: Rödern, E.). Geb. wann? 1753 in Eisenach (Röder), getauft 29. 10. 1753. Vater herzoglicher Kammersekretär von Sachsen-Weimar, August Friedrich Röder, Mutter ?. E. T.s Patin Frau v. Schlotheim, die Obergouvernante der Prinzessin v. Sachsen-Gotha, übernahm mit Erlaubnis der Eltern E. T.s Erziehung, die sowohl Schindel (II, 368) als auch Groß (32) als ungewöhnlich gründlich bezeichneten. 1782 heiratete E. T. den sachsen-weimarischen Geheimrat Johann Karl Salomon T.; ein Sohn (Heinrich Christian Kaspar).

Ein Jahr später erschien ihr erstes Werk, der dreibändige Roman Julie von Hirtenthal. E. T. schrieb außerdem Gedichte, Aufsätze, Übersetzungen, eine Erzählung und ein Drama und veröffentlichte meistens entweder anonym oder unter dem Pseudonym Jenny. 1796 zog sie sich eine Fußlähmung zu; während des folgenden Jahres breitete sich die Paralyse über ihren ganzen Körper aus. Die letzten zehn Jahre ihres Lebens verbrachte $\mathrm{E}$. T., vom Nacken abwärts gelähmt, ,auf einem für sie besonders eingerichteten Sessel" (Schindel II, 369). E. T. starb am 22. 4. 1807 in Eisenach.

Werke: Dramatische Werke siehe Anhang B. Julie von Hirtenthal, eine Geschichte, 3 Bde., 1780-83. Briefe von Karl Leulkfort, 1782. Mariane von Terville, eine Erzählung, 1798. Beiträge (meist anon. oder pseudon. Gedichte, Aufsätze und Übersetzungen in Musenalmanachen und Zeitschriften), u. a. in Olla Patrida (1788-90), Cahiers de lecture, und in Bertuchs Weimarsches Modejournal.

Literatur: G. Chr. Hamberger und J. G. Meusel, Das gelehrte Teutschland oder Lexikon der jetzt lebenden teutschen Schriftsteller, 1796-1834, VIII, X, XXI. C. W. O.A v. Schindel, Die deutschen Schriftstellerinnen des neunzehnten Jahrhunderts, 1823, II. H. Groß, Deutschlands Dichterinen und Schriftstellerinen, 2. Aufl. 1882, 32. K. Goedeke, Grundriß zur Geschichte der deutschen Dichtung aus den Quellen, 2. Aufl. 1884-1966, IV/1. L. Hirschberg, Hg., Der Taschengoedeke, 1961, 663. E. Friedrichs, Die deutschsprachigen Schriftstellerinnen des 18. und 19. Jahrhunderts, 1981.

Titzenhofer, Sophie Eleonore von (in Lexilka auch: Tietzenhofer, S. E. v.; Kortzfleisch, S. E. v.). Geb. 27. 12. 1749 in Groß-Jänowitz bei Licgwitz in Schlesien (Wundsch). Vater Major Wundsch, Mutter ?. Auf Wunsch der Mutter, die sich weigerte, Schlesien zu verlassen, nahm der Vater seinen Abschied vom sächsischen Militär und zog nach Schlesien.

S. E. v. T. zeigte schon früh Anlagen und Neigung zum Dichten, erhielt aber keine formelle Ausbildung, „da ihre Mutter bei der Erziehung mehr die Bildung im Hauswesen und in weiblichen Arbeiten als eigentlichen Beruf des weiblichen Geschlechts im Auge hatte" (Schindel II, 370). S. E. v. T. bildete sich selbst, begann zu schreiben und veröffentlichte anonym „einige kleine Versuche“ (Schindel II, 371), nebenbei zeichnete und malte sie. Heiratete (wann?) den preußischen Rittmeister von Kortzfleisch und ging mit ihm nach Oberschlesien, „wo häusliche Beschäftigungen ihr nur wenige Zei zur Lectüre übrig ließen" (Schindel II, 371), von da nach Breslau und Berlin. Dor sammelte der Konsistorialrat D. Dietrich ihre Gedichte und gab sie in 2 Bden. heraus.

1805 starb ihr Mann; vor 1810 heiratete sie den preußischen Hauptmann von T. 1810 ließ sie in Berlin einen Band ihrer Schriften drucken, der Erlös ging an Soldatenwaisen. 1812 wurde ihr Mann nach Graudenz versetzt und starb dort 1813 an einem Nervenfieber. S. E. v. T. bekam die Krankheit ebenfalls, überlebte und ging nach Breslau, wo sie von ciner kleinen Witwenpension lebte und Schriften schrieb und veröffentlichte, deren Erlös verwundeten Soldaten zugute kam. S. E. v. T. starb am 18. 6. 1823 in Olbersdorf bei Breslau.

Werke: Dramatische Werke siehe Anhang B. Poetische Versuche eines adelichen Frauenzimmers an ihre Freunde, 1776. Gedichte, 1792. Frühere Gedichte, 1792. Vermischte Aufsätze in Poesie und Prosa, 1792/3. Aufsätze in der Berliner Monatsschrift 1792. Gedicht am Sarge Friedrichs II., an den Kronprinzen von Preußen, o. J. 
Literatur: G. Chr. Hamberger und J. G. Meusel, Das gelehrte Teutschland oder Lexikon der jetzt lebenden teutschen Schriftsteller, 1796-1834, XXI. C. W. O. A. v. Schindel, Die deutschen Schriftstellerinnen des neunzehnten Jahrhunderts, 1823, II. K. Herloßssohn und $H$. Marggraff, Allgemeines Theater-Lexikon, 1846, VII. H. Groß, Deutschlands Dichterinen und Schriftstellerinen, 2. Aufl. 1882, 26 f. K. Goedeke, Grundriß zur Geschichte der deutschen Dichtung aus den Quellen, 2. Aufl. 1884-1966, V und VII. H. Groß, Deutsche Dichterinen und Schriftstellerinen in Wort und Bild, 1885, I 76-9. S. Pataky, Lexikon deutscher Frauen der Feder, 1898, II. E. Friedrichs, Die deutschsprachigen Schriftstellerinnen des 18. und 19. Jahrhunderts, 1981.

Wesendonck, Mathilde. Geb. 23. 12.1828 in Elberfeld (Luckemeyer). Vater der Kommerzienrat Karl Luckemeyer, Mutter ?. Umzug nach Düsseldorf; Erziehung dort und später in Dünkirchen. Geh. 1848 den Kaufmann Otto W., Teilhaber eines Seidenhauses in New York, dessen Geschäfte er in Deutschland führte. Lebte zunächst in Düsseldorf. 1850 Amerikareise, 1851 Umzug nach Zürich. Dort lernte sie Richard Wagner kennen, mit dem sie seit 1853 befreundet war. 1857 baute Otto W. eine Villa bei Zürich und kaufte ein Haus in der Nähe, das er umbauen und einrichten ließ und Richard Wagner als "Asyl“ anbot.

Ihr erstes Werk war eine Gedichtsammlung von fünf Gedichten (1857/8), dic Wagner vertonte. 1858 zog Wagner aus und verließ Zürich; reger Briefwechsel bis 1863.1865 veröffentlichte sie ihre Märchen und Märchenspiele, von da ab regelmäßige schriftstellerische Tätigkeit (vorwiegend Dramen und mythologische Stoffe, Sagen, Märchen und Legenden). 1872 Umzug nach Dresden. Reise nach Kairo im Winter 1881/2 und Umzug nach Berlin 1882. 1896 Tod ihres Mannes. M. W. starb am 31.8. 1902 auf ihrem Landsitz in Traunblick bei Altmünster (Salzkammergut).

Werke: Dramatische Werke siehe Anhang B. Fünf Gedichte, vertont von $R$. Wagner, 1857/8. Märchen und Märchenspiele, 1864 (Neuausg. 1900). Naturmythen, 1865. Deutsches Kinderbuch in Wort und Bild, 1869. Patriotische Gedichte, 1870. Gedichte, Volksweisen, Legenden und Sagen, 1875. Der Baldurmythus, 1875. Alte und neue Kinderlieder, 1900.

Literatur: $H$. Groß, Deutschlands Dichterinen und Schriftstellerinen, 2. Aufl. 1882, 142. H. Groß, Deutsche Dichterinen und Schriftstellerinen in Wort und Bild, 1885, II 468 f. S. Pataky, Lexikon deutscher Frauen der Feder, 1898, II. R. Wagner, Richard Wagner to M. W., 1905. E. Kreouski und E. Fuchs, Richard Wagner in der" Karilkatur, 1907, 164-70. J. Kapp, Richard Wagner und die Frauen, Eine erotische Biographie, 1912, 96, 106, 109, 114, 116 f, 119, 121, 126, 128, 141 f, 145, 168, 200. F. Brïmmer, Lexikon der deutschen Dichter und Prosaisten vom Beginn des 19. Jahrhunderts bis zur Gegenwart, 6. Aufl. 1913, VII. W. Kosch, Deutsches Literatur-Lexilkon, 2. Aufl. 1949-1958. E. Friedrichs, Die deutschsprachigen Schriftstellerinnen des 18. und 19. Jahrhunderts, 1981. R. Wagner, 'Tagebuchblätter und Briefe an M. W. 1853-1871, o. J.
Westphalen, Engel Christine. Geb. 8. 12. 1758 in Hamburg (von Axen). Vater Kaufmann und Bürgerkapitän Jacob von Axen, Mutter Catharina Maria, geb. Albers. Laut Schindel erhielt sie eine gute Ausbildung, fühlte sich „am stärksten [von ...] den Wissenschaften angezogen" (II, 421) und begann früh Gedichte zu schreiben. Thre ersten literarischen Versuche wurden von dem Beichtvater ihrer Mutter ermutigt.

1785 heiratete sie den Kaufmann und späteren Senator Ernst Friedrich Johann W. (1757-1833). Fünf Kinder, von denen nur ein Sohn und zwei Töchter überlebten. Kontalst mit Wissenschaftlern und Schriftstellern; während der Französischen Revolution war ihr Haus ein Sammelplatz französischer Flüchtlinge und wurde u. a. von Louis Philippe, Dumouriez und Bernadotte besucht. Wahtscheinlich erhielt sie durch diese Kontakte die Anregung zu ihrem Revolutionsdrama Charlotte Corday (1804).

Ihre frühen Gedichte erschienen unter dem Pseudonym Angelika, spätere anonym; die ersten Gedichte unter ihrem Namen wurden 1809 veröffentlicht. Auch ihre beiden Dramen (Charlotte Corday und Petrarca, 1806) erschienen anonym. Daß sie bei der Veröffentlichung des zweiten Stückes auf das erste hinweisen konnte (Petrarca erschien unter dem Pseudonym: „Von der Verfasserin der Charlotte Corday“), läßt auf einen gewissen Erfolg des früheren Dramas schließen.

1809 wurde ihr Mann Mitglied des Hamburger Rates. 1812 Reise mit ihrem Mann und ihrer jüngsten Tochter durch Deutschland und die Schweiz. Sie war eine eifrige Unterstützerin verschiedener Wohltätigkeitsstiftungen und erhielt 1815 eine Gedenkmünze der Stadt Hamburg. Der Ertrag ihrer Gesidnge der Zeit (1815), rund 580 Taler, ging an den Frauenverein. Die zwei obengenannten Dramen blieben ihre einzigen; später veröffentlichte sie ausschließlich Gedichte, die 1809/11 in einer dreibändigen Sammlung erschienen (ein vierter Band erschien 1835 unter dem Titel Neuere Gedichte). 1833 Tod des Mannes. E. C. W. starb am 10, 5. 1840 in Hamburg.

Werke: Dramatische Werke siehe Anhang B. Gemälde aus dem Leben des Menschen, ein Gedicht in neun Briefen, 1805. Gedichte, 4 Bde., 1809-35. Kleine Gedichte, Denkmäler, Elegien und Idyllen, 3 Bde., 1809/11. Gesänge der Zeit, 18I5. Neuere Gedichte, 1835. Erbauungslieder, 1835. Viele einzeln gedruckte Gelegenheitsgedichte und Gedichte in Zeitschriften, u. a. in Halems Irene (1804); Mabnckes Gesangbuch für Freimaurer (1804); Morgenblatt (1809); Lotz' Originalien (o. J.); Abendzeitung (1825); Krïgers Deutschlands Ehrentempel (o. J.).

Literatur: G. Chr. Hamberger und J. G. Meusel, Das gelehrte Teutschland oder Lexikon der jetzt lebenden teutschen Schriftsteller, 1796-1834, XIV und XX. C. W. O. A v. Schindel, Die deutschen Schriftstellerinnen des neunzehnten Jabrhunderts, 1823, II K. Herloßsobn und H. Marggraff, Allgemeines Theater-Lexikon, 1846, VII. H. Groß Deutschlands Dichterinen und Schriftstellerinen, 2. Aufl. 1882, 29. K. Goedeke, Grundriß zur Geschichte der deutschen Dichtung aus den Quellen, 2. Aufl. 1884-1966, VII. $H$. Groß, Deutsche Dichterinen und Schriftstellerinen in Wort und Bild 1885 , 99 f. M. Mendheim, „E. C. W.“, in: Allgemeine deutsche Biographie, 1897, XLII. S. Pataky, Lexilon deutscher Frauen der Feder; 1898, II. L. Hirschberg, Hg., Der Taschengoedeke, 1961, 712. E. Friedrichs, Die deutschsprachigen Schriftstellerinnen des 18. und 19. Jahrhunderts, I981. 
Wickenburg, Wilhelmine Gräfin von. Geb. am 8. 4, 1845 in Ofen (Almásy). Vater der Geheimrat und Präsident der ungarischen Hofkammer Moritz Graf von Almásy, Mutter ?. Sorgfältige Elziehung im Elternhaus. 1855 Umzug nach Wien, Kontakt mit Julie Rettich und Friedrich Halm. Erste Gedichte 1865, die 1867 veröffentlicht wurden. Durch diesen Gedichtband lernte sie Albrecht Graf v. W. kennen, den sie 1867 heiratete. Bis 1881 häufige Reisen und schriftstellerische Tätigkeit. W. v. W. verfaßte Epen, Dramen, Erzählungen und viele Gedichte; mit ihrem Mann schrieb sie Nymphidia, eine Bearbeitung nach Michael Drayton. Ihre Dramen wurden verschiedentlich aufgefühtt; so u. a. 1882 das Lustspiel Ein Abentewer des Dauphin (1881) am Wiener Burgtheater. 1885 Umzug nach Gries bei Bozen. Dort starb W. v. W. am 23. 1. 1890 an Influenza. Thr Mann gab im selben Jahr Gedichte aus ihrem Nachlaß heraus.

Werke: Dramatische Werke siehe Anhang B. Gedichte, 1865 (3. Aufl. 1882). Neue Gedichte, 1869. Emanuel d'Astorga, Erzählendes Gedicht, 1872. Erlebtes und Erdachtes, Gedichte, 1873. Der Graf von Remplin, Erzählung in Versen, 1874. Marina, Erzählendes Gedicht, 1875. Mahnruf an dic Deutschen in Österreich, Poem, 1886. Nymphidia, eine Nachdichtung aus dem Englischen des Michael Drayton (mit A.v Wickenburg), o. J. Übersetzungen ungarischer Volkslieder, o. J. Letzte Gedichte, aus dem Nachlaß hg. von A. v. Wickenburg, 1890.

Literatur: H. Groß, Deutschlands Dichterinen und Schriftstellerinen, 2. Aufl. 1882, $137 f$ Groß Deutsche Dichterinen und Schriftstellerinen in Wort und Bild, 1885 III 197-206. A. Scblossar, „W. Gräfin W.-Almásy“, in: Allgemeine deutsche Biographie, 1897. XLII. S. Pataky, Lexikon deutscher Frauen der Feder, 1898, II. F Brïmmen Iexikon der deutschen Dichter und Prosaisten vom Beginn des 19. Jahrhunderts bis zur Gegenwart, 6. Aufl. 1913, VII. W. Kosch, Deutsches Literatur-Lexikon, 2. Aufl. 1949-1958. E. Friedrichs, Die deutschsprachigen Schriftstellerinnen des 18. und 19. Jahrhunderts, 1981. V Richel, The German Stage, 1767-1890, A Directory of Playwrights and Plays, 1988, 161.

Young, Betty. Geb. 24. 5. 1832 in Budapest (Mück). Lebte in Wien. Erstlingswerk das Drama Die rote Liesl (1865). Schrieb bis 1881 mehrere Komödien, einige Erzählungen und Novellen und einen Roman. Gest, am 26. 9. 1887 in Wien. Weitere Angaben nicht erhältlich.

Werke: Dramatische Werke siehe Anhang B. Frau Othello - Mädchenträume, Erzählungen, 1870. Blaue Brillen, Novelle, 1872. Ein Vierteljahrhundert, Roman, 2 Bde., 1881.

Literatur: H. Groß, Deutschlands Dichterincn und Schriftstellerinen, 2. Aufl. 1882, 140 f $F$ Brimmer Lexikon der deutschen Dichter und Prosaisten vom Beginn des 19. Jahrhunderts bis zur Gegenwart, 6. Aufl. 1913, VIII. W. Kosch, Deutsches LiteraturLexikon, 2. Aufl. 1949-1958. E. Friedrichs, Die deutschsprachigen Schriftstellerinnen des 18, und 19. Jahrhunderts, 1981
B. LISTE DER AUTORINNEN, DRAMATISCHEN WERKE UND PSEUdONYME*

Ackermann, Sophie Charlotte. 1714 - 1793 (Hamburg). Geb. Biercichel. Verh. Schröder:

„Vorspiele und Stücke, dic niemals im Druck erschienen" (Dawson, „Frauen und Theater", 425).

Adlersfeld, Eufemia von. 1854 (Ratibor/Oberschlesien) - 1941 (München). Geb. Ballestrem di Castelleng, Gräfin:

Jadwiga. Dramatisierte Novelle. 1880.

Komtesse Katthe. Schwank in 3 A. Mit Heinrich Stobitzer. 1897. \{D-HHU-T, DKöTM\}

Ein Meteor. Drama in 5 A. 1880. \{D-EWA, MH; Vorkriegsnachweise in: D-BPS, DBSR, D-FUB, D-KaMB, D-LUB, D-MüS, D-SPL, D-SpSP, D-WS, A-KIÖ, AWN, CH-ZZ\}

Adliches Frauenzimmer in Schlesien = Pseudonym für: Titzenhofer, Sophic Elconore von

* Diese Liste ist keineswegs vollständig und soll lediglich einen Überblick über die verbreitete dramatische Tätigkeit deutschsprachiger Autorinnen geben. Sie umfaßt alle ermittelten Dramatikerinnen, deren erstes Drama zwischen 1700 und 1899 verfaßt, veröffentlicht oder aufgeführt wurde, und alle dramatischen Werke (auch nach 1900 verfaßte oder anderssprachige Dramen) dieser Autorinnen. Die Namensliste umfaßt Pseudonyme, Geburts- und Ehenamen.

Die angegebenen Werke beschränken sich auf dramatische Werke, selbst dann, wenn die betreffende Autorin, was in der Regel der Fall ist, auch in anderen Genres geschrieben har. Die Liste der dramatischen Werke umfaßt Opernlibretti, Übersetzungen und Bearbeitungen; desgleichen dialogisierte Novellen, Prologe, Szenen und sonstige Randgenres. Wo unklar war, ob das betreffende Werk ein Drama ist oder nicht, wurde es hier nicht angeführt, es sei denn, es bestand Grund zu der Annahme, daß es sich um ein dramatisches Werk handelt. Solche „zweifelhaften" Dramen sind entsprechend bezeichnet.

Die Jahreszahlen bezeichnen jeweils das Jahr, in dem das betreffende Werk meines Wissens verfaßt oder zum ersten Mal gedruckt, aufgeführt oder erwähnt wurde.

Wo die Quelien unterschiedliche Angaben bieten, sind abweichende Angaben zu Namen und Daten in Klammern angegeben.

Wo die Standorte zu ermitteln waren, sind sie jeweils in geschwungenen Klammern - \{\} - angegeben. Wo die Standorte zu ermitteln waren, sind sie jeweils in geschwungenen Klammern - \{\} - angegeben.
Das Siglenverzeichnis der Bibliotheken befindet sich am Ende der Liste. Die deurschsprachigen Länder (Deutschland, Osterreich, Schweiz) und Großbritannien sind mit D, A, CH, GB gekennzeichnet; nicht gekennzeichnete Kürzel bezeichnen Standorte in den USA und Kanada. Für Deutschland wurden trotz der Unsicherheit auch die Vorkriegsnachweise angegeben-vielleicht lassen sich auf diesem Wege Werke nachweisen, die sonst verlorengingen. Die Standorte beziehen sich nur auf den Text des jeweiligen Dramas und bezeichnet nicht unbedingt die angegebene Ausgabe oder Sammlung.

Für das Theatermuseum der Universität K.öln ist inzwischen ein achtbändiger Bestandskatalog von Hunderten von Schauspieltexten erarbeitet worden, komplett mit theaterhistorischen Anmerkungen, aus denen überdies hervorgeht, welche Texte für die Aufführung bearbeitet wurden (Schauspieltexte im Theatermuseum der Universitatt zu Köln, bearb. Roswitha Flatz, 8 Bde. u. Register, München, London, New York, Paris 1988-89). 
Amalie Marie Friederike Auguste, Prinzessin von Sachsen. 1794 (Dresden) - 1870 (Pillnitz). Pseudonyme: Amalie, Amalie Heiter, A. Serena, Verfasserin von „Lüge und Wahrheit":

Die Abentheuer der Thorenburg. Schauspiel in 5. A. 1817

Agamemnon, König von Argäus. Tragödic in 1 A. O. J.

L'Americana. Oper in 2 A. 1820.

Der alte Herr. Lustspiel in 2 A. 1841. (Dramatische Werke VI, 1874.) \{D-BDS, DBHU, D-BUB, D-DeLL, D-FrU, D-FSU, D-GSU, D-HUL, D-KöTM, D-TUB, D-TUB-G, D-WeiZdK, D-WHLB, D-WüU, D-ZCW, CH-BSU, GB-LBL, DLC, MdBE, MdBPF

Alter und Jugend. Lustspiel in 4 A. O. J. \{D-MBS

Die Ankunft des Ulysses. Schauspiel in 3 A. O. J.

Der Arme lebt vom Pläneschmieden. Lustspiel in $4 \mathrm{~A}$. Freie Bearb. nach Calderon. O. J.

Der Baron. Lustspiel in 2 A. O. J.

Die Brïutigamswabl. Lustspiel in 4 A. O. J.

Die Braut aus der Residenz. Lustspiel in 2 A. 1834. (Original-Beiträge I, 1836.) \{DBDS, D-BFU, D-BHU, D-BUB, D-DeLL, D-FGM, D-FrU, D-FSU, D-HUL, DKöTM, D-LKM, D-MBS, D-MrU, D-OLB, D-PaU, D-WeiZdK, D-WHLB, DZCW, A-WÖN, CH-BSU, CH-SGK, GB-LBL, MB, PU, TNJ\}

Der Brief aus der Schweiz. Schauspiel in 5 A. 1845.

Der Brudermord. Gedicht von Saavedra. Übers. O. J.

Capitain Fimewald. Lustspiel in 4 A. 1840. (Original-Beitrage VI, 1842.) \{D-BFU, D-BHU, D-BSPK, D-BUB, D-DeLL, D-FGM, D-FrU, D-FSU, D-GSU, D-HUL, D-KöTM, D-LKM, D-MBS, D-MüS, D-WeiZdK, D-WHLB, D-ZCW, A-WÖN, CH-BSU, GB-LBL, MB, PU, TNJ\}

La casa disabitata. Musikalische Farce in 1 A. 1835.

Der Condottiere. Opernlibretto. O. J.

Die Danaiden. Romantisches Drama in $2 \mathrm{~A}$. O. J.

Una Donna. Oper: Partitur: Um 1810.

Dramatische Werke. 6 Bde. 1873. \{D-BHU, D-BUB, D-FrU, D-GSU, D-KöTM, D-PaU, D-WüU, GB-LBL, Bde. 1-4 in D-WHLB

L'écolier de l'enfer et l'élève du ciel. Conte invraisemblable et effroyable dédié à Mme. de Bleszinska née de Prosor. O. J.

Elisa ed Ernesto. Musikalisches Drama in 2 A. 1823.

Elisabeth. Trauerspiel. Um 1820.

Elvira. Oper in 2 A. Übers. aus dem Italienischen. 1821.

Elvira. Maurisches Trauerspiel. Um 1820.

Engelbert's Abschied. Schauspiel in 1 A. O. J.

Die Engländer in Cairo. National-Gemälde in 4 A. O. J.

La fedeltà alla prova. Musilkalisches Drama in 2 A. 1826.

Die Feuersbrunst. Drama in 6 A. O. J.

Il figlio pentito. Musilkalisches Drama in 3 A. 1831. 
Fluch und Vergeltung oder das Losungswort. Trauerspiel in 4 A. O. J.

Folgen einer Gartenbeleuchtung. Lustspiel in 3 A. (Original-Beitrige VI, 1842.) (DBDS, D-BFU, D-BHU, D-BUB, D-DeLL, D-FGM, D-FrU, D-FSU, D-GSU, DHUL, D-KöTM, D-LKM, D-MBS, D-MrU, D-MüS, D-WeiZdK, D-WHLB, DZCW, A-WÖN, CH-BSU, GB-LBL, MB, PU, 'TNJ\}

Fräulein Sybille. Lustspiel in 2 A. 1847.

Das Fräulein vom Lande. Lustspiel in 5 A. 1836. (Original-Beiträge IV, 1839.) (DBDS, D-BFU, D-BHU, D-BUB, D-DeLL, D-FGM, D-FrU, D-FSU, D-GSU, DHUL, D-KöTM，D-LKM，D-MBS, D-MrU，D-OLB，D-PaU，D-WeiZdK，DWHLB, D-ZCW, A-WÖN, CH-BSU, GB-LBL, MB, PU, TNJ\}

Die Fürstenbraut. Schauspiel in 5 A. 1836. (Original-Beiträge II, 1837.) (D-BDS, D-BFU, D-BUB，D-DeLL，D-FGM，D-FrU，D-FSU，D-GSU, D-HUL，DKöTM, D-LKM, D-MBS, D-MrU, D-OLB, D-PaU, D-WeiZdK, D-WHLB, DZCW, A-WÖN, CH-BSU, CH-SGK, GB-LBL, MB, PU, TNJ\}

Das Gastrecht. Ein sehr vortreffliches Ritterspiel und angenehmste Tragödie in $4 \mathrm{~A}$. O. J.

Der Gedächtnißtag. Schauspiel in 3 A. O. J.

Das Geheimnis. Szenische Cantate. 1818.

Der geschäftige Vetter. Lustspiel in 4 A. O. J.

Der Graf von Beaujolais. Schauspiel in 5 A. (Dramatische Werke I, 1873.) (D-BDS, D-BHU, D-BUB, D-FrU, D-FSU, D-GSU, D-HUL, D-KöTM, D-LKM, D-OLB, D-PaU, D-TUB, D-TUB-G, D-WeiZdK, D-WHLB, D-WüU, A-WÖN, CHBSU, GB-LBL, DLC, MdBE, MdBP\}

Graf von Toulouse. Schauspiel. Um 1820.

Eine große Enttäuschung. Gedicht von Saavedra. Übers. O. J.

Die Heimkehr des Sohnes. Schauspiel in 4 A. 1841. (Original-Beitráge VI, 1842. ) \{D-BFU, D-BHU, D-BSPK, D-BUB, D-DeLI, D-FGM，D-FrU，D-FSU， DGSU, D-HUL, D-KöTM, D-LKM, D-MBS, D-MüS, D-WeiZdK, D-WHLB, DZCW, A-WÖN, CH-BSU, GB-LBL, MB, PU, TNJ\}

Das Jawort der Mädchen. Lustspicl in $3 \mathrm{~A}$. O. J.

Johanna von Montfaucon. Schauspiel in 5 A. O. J.

Der Kanonenschußß. Dresdner Lokalposse in 1 A. Partitur. 1828.

Konradin. Trauerspiel in 5 A. O. J.

Der Krörungstag. Lustspiel in 5 A. 1823 [Groß, Deutschlands Dichterinen und Richel, The German Stage: 1829]. (Dramatische Werke I, 1873.) (D-BDS; D-BHU, D-BUB, D-FrU, D-GSU, D-HUL, D-KöTM, D-LKM, D-OLB, D-PaU, D-TUB, D-TUB-G, D-WeiZdK, D-WHLB, D-WüU, A-WÖN, CH-BSU, GB-LBL, DL,C MdBE, MdBP\}

Der Landwirth. Lustspiel in 4 A. 1836. (Original-Beiträge II, 1837.) \{D-BDS, DBFU, D-BUB, D-DeLL, D-FGM, D-FrU, D-FSU, D-GSU, D-HUL, D-KöTM, D-LKM, D-MBS, D-MrU, D-OLB, D-PaU, D-WeiZdK, D-WHLB, D-ZCW, AWÖN, CH-BSU, CH-SGK, GB-I,BL, MB, PU, TNJ\}

Leonore oder der Triumpl kindlicher Liebe. Schauspiel in 4 A. O. J.
Lugge und Wahrbeit. Schauspiel in 4 A. 1833 [Richel, The German Stage: 1834]. (Original-Beitrige I, 1836.) \{D-BDS, D-BFU, D-BHU, D-BUB, D-DeLL, D-FGM, DFrU, D-FSU, D-HUL, D-KöTM, D-LKM, D-MBS, D-MrU, D-OLB, D-PaU, DWeiZdK, D-WHLB, D-ZCW, A-WÖN, CH-BSU, GB-LBL, MB, PU, TNJ\} Der Majoratserbe, Lustspiel in 4 A. 1838. (Original-Beitrige IV, 1839.) \{D-BDS, DBFU, D-BHU, D-BUB, D-DeLI, D-FGM, D-FrU, D-FSU, D-GSU, D-HUL, DKöTM, D-LKM, D-MBS, D-MrU, D-OLB, D-PaU, D-WeiZdK, D-WHI,B, DZCW, A-WÖN, CH-BSU, GB-LBL, MB, PU, TNJ\}

Il Marchesino. Musilkalisches Drama in 2 A. 1833.

Medea. Trauerspiel in $1 \mathrm{~A}$. O. J.

Mesru, König von Baktriana. Schauspiel in 2 Abteilungen und 5 A. 1824 [Goedeke und Richel, The German Stage: 1829; Groß, Deutschlands Dichterinen: 1830]. (Dramatische Werke I, 1873.) (D-BDS, D-BHU, D-BUB, D-FrU, D-GSU, D-HUL, DKöTM, D-LKM, D-OLB, D-PaU, D-TUB, D-TUB-G, D-WeiZdK, D-WHLB, D-WüU, A-WÖN, CH-BSU, GB-LBL, DLC, MdBE, MdBP\}

Der Mörder. Schauspiel, 1844.

Das neue Schauspiel. Lustspiel in $2 \mathrm{~A}$. O. J.

Die Neuvermählte. Oper in $2 \mathrm{~A}$. Frei bearb. nach Scribes Lune de miel. O. J.

Le Nozze funeste. Oper. 1816.

Der Oheim. Schauspiel in 5 A. 1835. (Original-Beiträge I, 1836.) (D-BDS, D-BFU, D-BHU, D-BUB, D-DeLL, D-FGM, D-FrU, D-FSU, D-HUL, D-KöTM, DLKM, D-MrU, D-MBS, D-OLB, D-PaU, D-WeiZdK, D-WHLB, D-ZCW, AWÖN, CH-BSU, CH-SGK, GB-LBL, MB, PU, TNI\}

Original-Beiträge zur deutschen Schaubühne. 6 Bde. 1836-8. (D-BUB, D-DeLL, DFGM, D-FrU, D-FSU, D-LKM, D-MBS, D-WHLB, D-ZCW, A-WÖN, CHBSU, GB-LBL, MB, PU, TNJ; Bde. 1 u. 3 in D-KöTM; Bde. 2, 4, 6 und NF in DGSU; Bde. 1-5 in D-MrU, Bde. 1 und 3-6 in D-BHU, Bde, 1, 2, 5 u. 6 in CHSGK]

Ottfeld's Erben. Schauspiel in 5 A. 1848.

Der Pflegevater. Schauspiel in 4 A. 1837. (Original-Beiträge IV, 1839.) (D-BDS, BUB, D-DeLL, D-FGM, D-FrU, D-FSU, D-GSU, D-HUL, D-KöTM, D-LKM, D-MBS, D-MrU, D-OIB, D-PaU, D-WeiZdK, D-WHLB, D-ZCW, A-WÖN, CH-BSU, GB-LBL, MB, PU, TNJ\}

Pflicht und Liebe. Schauspiel in 2 A. 1839. (Original-BeitrigeV, 1841.) \{D-BFU, DBHU, D-BUB, D-DeLL, D-FGM, D-FrU, D-FSU, D-GSU, D-HUL, D-KöTM, D-LKM, D-MBS, D-MrU, D-WeiZdK, D-WHLB, D-ZCW, A-WÖN, CH-BSU, CH-SGK, GB-LBL, MB, PU, TNJ\}

Il Prigioniere. Oper: 1817.

Regine. Lustspiel in 5 A. 1843. (Dramatische Werke VI, 1874.) \{D-BDS, D-BHU, D-BUB，D-DeLL，D-FrU，D-FSU，D-GSU，D-HUL，D-KöTM，D-TUB，DTUB-G, D-WeiZdK, D-WHLB, D-WüU, D-ZCW, CH-BSU, GB-LBL, DLC, $\mathrm{MdBE}, \mathrm{MdBP}\}$

Die Sieben vor Thebae. Parodic in 1 A. 1815. 
Der Siegelring. Schauspiel in 4 A. 1843. (Dramatische Werke VI, 1874.) (D-BDS, DBUB, D-BHU, D-DeLL, D-FrU, D-FSU, D-GSU, D-HUL, D-KöTM, D-TUB, D-TUB-G, D-WeiZdK, D-WHLB, D-WüU, D-ZCW, CH-BSU, GB-LBL, DLC, MdBE, MdBP\}

Die Siegesfahne. Operette in 1 A. Partitur: Vor 1834.

Six Dramas. [Übers. von sechs Dramen: The Uniformed Girl. The Heir of Scharfeneck. The Irresolute Man. Capitain Firnewald. The Son's Return. The Young Lady from the Country.] (London, Parker 1848). \{D-DUB, D-GiU, GB-LBL\}

Späte Reue. Trauerspiel in 6 A. nebst einem Vorspiele. O. J.

Die Stieftochter, Lustspiel in 4 A. 1839. (Original-Beitrage V, 1841.) \{D-BFU, DBHU, D-BSPK, D-BUB, D-DeLL, D-FGM, D-FrU, D-FSU, D-GSU, D-HUL, D-KöTM, D-LKM, D-MBS, D-MrU, D-WeiZdK, D-WHLB, D-ZCW, A-WÖN, CH-BSU, CH-SGK, GB-LBL, MB, PU, 'TNJ\}

Sultan Saladin oder Fatime in Aegypten. Schauspiel in 4 A. O. J.

Die Täuschungen. Lustspiel in $5 \mathrm{~A}$. (Dramatische Werke $\mathrm{I}$, 1873.) \{D-BDS, D-BHU, D-BUB, D-FrU, D-GSU, D-HUL, D-KöTM, D-LKM, D-OLB, D-PaU, D-TUB, D-TUB-G, D-WeiZdK, D-WHLB, D-WüU, A-WÖN, CH-BSU, GB-LBL, DLC, $\mathrm{MdBE}, \mathrm{MdBP}\}$

Ein Tag auf dem Lande. Lustspiel in 2 A. O. J.

Ein Tag in der Hauptstadt. Schauspiel in 3 A. O. J.

Theseus und Ariadne. Posse. O. J.

Le tre Cinture. Oper. 1817.

Die Unbelesene. Lustspiel in 4 A. 1838. (Original-Beiträge $V$, 1841.) (D-BFU, DBHU, D-BSPK, D-BUB, D-DeLL, D-FGM, D-FrU, D-FSU, D-GSU, D-HUL, D-KöTM, D-LKM, D-MBS, D-MrU, D-WeiZdK, D-WHLB, D-ZCW, A-WÖN, CH-BSU, CH-SGK, GB-LBL, MB, PU, TNJ\}

Undank ist der Welt Lohn. Posse in 4 A. O. J.

Der Unentschlossene. Lustspiel in 4 A. 1837. (Original-Beiträge III, 1838.) \{D-BFU D-BHU，D-BSPK，D-BUB，D-DeLL，D-FGM，D-FrU，D-FSU，D-HUL，DKöTM, D-LKM, D-MBS, D-MrU, D-OLB, D-PaU, D-WeiZdK, D-WHLB, DZCW, A-WÖN, CH-BSU, GB-LBL, MB, PU, TNJ\}

Die unglückliche Verwechselung. Operette in 1 A. O. J.

Vecchiezza e gioventù. Musilkalisches Drama in 2 A. 1828. \{D-MBS\}

Der Verlobungsring. Lustspiel in 4 A. 1835. (Original-Beiträge II, 1837.) (D-BDS, D-BFU, D-BUB, D-DeLL，D-FGM，D-FrU，D-FSU，D-GSU，D-HUL，DKöTM, D-LKM, D-MBS, D-MrU, D-OLB, D-PaU, D-WeiZdK, D-WHLB, DZCW, A-WÖN, CH-BSU, CH-SGK, GB-LBL, MB, PU, TNJ\}

Vetter Heinrich. Schauspiel in 5 A. 1837. (Original-Beiträge III, 1838.) (D-BFU, DBHU, D-BSPK, D-BUB, D-DeLL, D-FGM, D-FrU, D-FSU, D-HUL, D-KöTM D-LKM, D-MBS, D-MrU, D-OLB, D-PaU, D-WeiZdK, D-WHLB, D-ZCW, AWÖN, CH-BSU, GB-LBL, MB, PU, TNJ\}

Die Wittwe. Schauspiel. Um 1820.

Der Zauberspruch. Schauspiel. Um 1820.
Der Zögling. Lustspiel in 4 A. 1836. (Original-Beiträge III, 1838.) (D-BFU, DBSPK, D-BUB, D-DeLL, D-FGM, D-FrU, D-FSU, D-HUL, D-KöTM, D-LKM, D-MBS, D-MrU, D-OLB, D-PaU, D-WeiZdK, D-WHLB, D-ZCW, A-WÖN, CH-BSU, GB-LBL, MB, PU, TNJ\}

Zulika. Orientalisches Lustspiel. Um 1820.

Zwei Nächte auf dem Schlosse Castel Franco. Trauerspiel. Um 1820.

Amalie Louise $=$ Pseudonym für: Liebhaber, Amalie Luise von.

Ambrosius, Anna Cäcilie = Fabricius, Anna Cäcilie .

Angelika $=$ Pseudonym für: Westphalen, Engel Christine.

Anhalt-Zerbst, Sophie Auguste Prinzessin von = Katharina (II.) Alexejewna, Kaiserin von Rußland.

Anneke, Mathilde Franziska. 1817 (Gut Levringhausen bei Blankenstein/Ruhr) 1884 (Milwaukee, Wisconsin). Geb. Giesler. Gesch. von Tabouillot. Pseudonym: Mathilde Franziska:

Oithono, oder Die Tempelweihe. Drama in 4 A. 1844.

Annette Elisabeth = Pseudonym für: Droste-Hülshoff, Annette von.

Anonyma. ?-?:

Ortinde oder die königliche Rache. Ein dramatischer Versuch in 4 A. Von einem Frauenzimmer. 1792. [Versuch einer Frauenzimmerbibliothek; Eintrag 469.]

Appel (fälschlich für: Oppeln), Emilie von = Berlepsch, Emilie von.

Apranzow, Wilhelmine = Beringer, Wilhelmine

Arens von Braunrasch, Auguste. ? (Mainz) - 1902 (Wiesbaden). Geb. von Braunrasch. Pseudonyme: Julius Rasch, Max von Pleiner: Aus Eifersucht. Lustspiel. 1882.

Der Bürgermeister. Volksstück in 4 A. O. J. \{D-MS\}

Ein Kampf ums Glïck. Lustspiel in 4 A. 1882. \{D-MS\}

Arndts, Maria. 1823 (München) - 1882 (München). Geb. Vespermann. Verh. Görres. Pseudonym: Carl Pauss:

Drei Bilder aus Raphaels Jugendleben. O. J. (Dramen für das christliche Haus. 186469.) (A-WUB, GB-LBL\}

Dreizehnlinden-Festspiel. Festspiel in 7 Bildern. Partitur [Text von Friedrich Wilhelm Weber]. 1893. \{D-BUB, DCL\} 
Mozart als Ehestifter. Lustspiel in 3 A. 1869. (Dramen fir das christliche Haus IV, 1869.) \{A-WÖN, GB-LBL, IEN; Vorlkriegsnachweis für: D-MBS, A-WN\}

Ostern in 5 Bildern. 1869. (Dramen fir das christliche Haus. 1864-69.) \{GB-LBL, Vorkriegsnachweis für: D-MBS\}

Ein Passionsspiel in 5 Bildern. 1864. (Dramen fir das christliche Haus II, 1864.) \{AWÖN, GB-LBL, Vorkriegsnachweis für: D-MBS, A-WN\}

Die Schule Murillos. 1864. (Dramen fur das christliche Haus. 1864-69.) \{GB-LBL, Vorkriegsnachweis für: D-MBS\}

Arnim, Gisela von = Grimm, Gisela

Arnold, Hans = Pseudonym für: Bülow, Babette von

Arnold, Franz = Pseudonym für: Mayreder, Rosa.

Arthalis = Pseudonym für: Steinlein, Laura

Artner, Marie Therese von. 1772 (Schnitau, später Sempte bei Neutra, Ungarn) 1829 (Agram). Pseudonym: Theone:

Das Fest der Tutgend. Schäferspiel mit Chören in 1 A. 1798.

Rettung und Lohn. Lustspiel in 1 A. 1823.

Rogneda und Wladimir. Trauerspiel in 3 A. 1824. \{D-DonFFH, A-WÖN, Vorkriegsnachweis für: A-WN\}

Stille Größe. Schauspiel in 3 A. 1824. \{A-WÖN, Vorkriegsnachweis für: A-WN\}

Die That. Trauerspiel in $5 \mathrm{~A}, 1817$. (D-ASS, D-BDS, D-BHU, D-BrU, D-BS, DBSPK, D-BUB, D-DeLL, D-DonFFH, D-DUB, D-FGM, D-GF, D-GSU, DHUL, D-KaMB, D-LKM, D-MarSN, D-OLB, D-SML, D-WeiZdK, D-WoHA, ALBS, A-WÖN, A-WUB, GB-LBL, CtU, IEN, NcU, NN; Vorkriegsnachweise für: D-BU, D-BUB, D-HSUB, A-WN\}

Theseus auf Kreta. Heldenoper. 1792.

Auguste $=$ Pseudonym für: Danne, Auguste.

Auguste $=$ Pseudonym fïr: Pichler, Caroline

Auguste $=$ Pseudonym fiur: Zitz, Katharina Rosa Therese Pauline Modesta

Auguste Pauline $=$ Pseudonym für: Zitz, Katharina Rosa Therese Pauline Modesta

Augustin, Marie Freifrau von. 1807 [Groß, Deutschlands Dichterinen: 1810] (Wcrschetz/Banat) - 1886 (Wien). Geb. Regelsberg von Thurnberg. Pseudonym: Marie von Thurnberg:

Die Sausenburger Klamm. Schauspiel. 1846. \{D-GSU, Vorkriegsnachweis für: DHLHD\}
Aurelie = Pseudonym für: Baudissin, Sophie von.

Axen, Engel Christine von = Westphalen, Engel Christine von,

B., Louise = Pseudonym für: Brachmann, Louise.

B., S. v. = Pseudonym für: Bandemer, Susanne von.

B., Susanne von = Pseudonym für: Bandemer, Susanne von.

B., Wilhelmine $=$ Pseudonym für: Bornstedt, Wilhelmine von

Bajovar, Josef = Pseudonym für: Baltz, Johanna.

Ballestrem di Castelleng, Eufemia Gräfin = Adlersfeld, Eufemia von.

Baltz, Johanna. 1847 (Arnsberg/Westfalen) - 1918 (Arnsberg). Pseudonymc: Helene Busch, Josef Bajovar:

Am Webstubl der Zeit. Historisches Drama. 1902.

Auf roter Erde. Festspicl. 1890. \{D-BDS, D-WLM

Die Brücke zum Ruhme. Historisches Drama. 1903.

Die heilige Elisabeth, Landgräfin von Thüringen. Festspiel. 1891. \{D-FSU\}

Im goldenen Kranze. Festspiel. 1908. \{D-KöTM\}

Des Kaisers Kronenschmied oder: Getreu den Hohenzollern. Bismarcl-Festspiel zum 1. April 1895. 1895. \{D-KaMB\}

Die Leoniden. Festspicl. 1907. \{D-BDS\}

Lissas Christfest. Komödie nach einem englischen Motiv. 1898. \{D-BSPK, D-FSU\} Preußen-Frauen in großer Zeit, 1813. Festspiel. 1913.

Psyche. Schauspiel. 1907

Sarabrucca. Historisches Drama. 1903.

Siegfried von Santen und Kriembilde. Festspiel. 1893.

Die schöne Else. Drama. 1883.

Die Stadt am Torstein. Historisches Drama. 1902.

Unter der Turnereiche. Festspiel. 1891. \{D-BDS, D-BSPK\}

Die Zaubermuschel. Festspiel. 1893.

Bandemer, Susanne von. 1751 (Berlin) - 1828 (Koblenz). Geb. von Frencklin (v. Franklin?). Pseudonyme: S. v. B., Susanne v. B:

Knapp Edmund oder die Wiedervergeltung. Schauspiel in 4 A. 1800. \{D-FFDH, DFGM, D-FTT, D-HLHD

Sidney und Eduard, oder Was vermag die Liebe? Schauspiel in 3 A. 1792. (D-ASS, D BSPK, D-GSU, D-KöTM, A-LBS, A-WÖN, GB-LBL, MH, MU (Mikrofilm) OU; Vorkriegsnachweise für: D-BPS, D-BSR, D-HHB, D-NeLB, A-WN\} 
Baßerin, Sabine Elisabeth Oelgard von. Um 1715 oder 1716 - 1790 (vielleicht in Dalwitz/Mecklenburg)

Unveröffentlichte dramatische Werke [Dawson, „Frauen und Theater“ 425].

Baudissin, Caroline Adelheid Cornelia Gräfin von. 1759 oder 1760 (Dresden) 1826 (Knoop bei Kiel). Geb. Gräfin Schimmelmann:

Die Dorfgesellschaft. Drama. 1791. \{D-KUB; Vorkriegsnachweise für: D-HHB, DWeiLB]

Nicht genannte Trauerspiele [Groß, Deutschlands Dichterinen 30].

Baudissin, Sophie Gräfin von. 1813 (Dresden) - 1894. Geb. Kaskel. Pseudonym: Aurelie, Tante Aurelie, Gowenz:

Theater fir die Jugend. Zum Auffihren im Familienkreise. 1876. (D-FSU\}

Baumer, Sophie $=$ Albrecht, Sophie

Baur [auch Bawr], Alexandrine Sophie von, Comtesse de Saint Simon, 1776 (Stuttgart) - ? Geb. Goury de Champgrand:

Charlotte Brown. Komödie in 1 A. 1835. \{D-FSU

Les chevaliers du Lion. Melodrama in 3 A. 1804. \{D-FSU, D-MBS\}

Der ProzeßS oder Die Folgen einer Maskerade. Lustspiel in 1 A. nach d. Französischen. Um 1815.

Le suit d'un bal masqué. Komödie in 1 A. 1813. \{D-BHU, D-FSU, D-KaMB, DKöTM\}

Baußnern, Marie von = Vaselli, Marie von

Bawr, Alexandrine Sophie von = Baur, Alexandrine Sophie von.

Bechtolsheim [Groß, Deutschlands Dichterinen: Bechtoldsheim], Julie Freifrau von. 1751 [Groß, Deutschlands Dichterinen: 1747; National Union Catalog: 1752] (Gut Stedten bei Erfurt) - 1847 (Eisenach). Geb. Freiin von Keller. Pseudonym: Psyche: Festspiel zum Empfang der Kaiserin Maria von Rußland in Eisenach 1818. \{CtY\}

Beck, Luise. 1789 (Mannheim) - 1857 (Stuttgart). Pseudonym: Ludwig Becker: Morgen gewifs! Romantisches Idyll in 1 A. 1825. (D-BDS, D-HHU-T, D-KöTM) Opfertrene. Drama in 3 A. 1825. \{D-KöTM\}

Der Pfeil. O. J.

Das Schloß in den Pyrenäen. Schauspiel in 4 A. 1828. \{A-WÖN\}

Becker, Ludwig = Pseudonym für: Beck, Luise.

Beckmann, Mathilde = Raven, Mathilde
Bentheim-Steinfurth, Caroline Ferdinandine Marie Elisabeth Reichsgräfin von. 1759 (Burgsteinfurt) - 1834 (Burgsteinfurt):

Trauerspiele und Gelegenheitsgedichte. Unveröff.

Berg, Amalie von = Pseudonym für: Ludecus, Karoline Johanne Amalie

Berg, Luise $=$ Pseudonym für: Woltmann, Karoline von.

Berge, Elisabeth vom. 1838 (Ober-Ullersdorf bei Sorau/Brandenburg) - 1909 (Bernried/Oberbayern):

Alexei. Trauerspiel in 5 A. 1888. \{D-FSU\}

Charlotte Corday. Trauerspiel. O. J.

Christine von Schweden. Tragödie. 1873. \{D-BSPK, D-GSU, D-LKM, D-WeiZdK, $\mathrm{NN}\}$

Heinrich IV. Trauerspiel in 5 A. 1880. (D-BDS, D-BUB, D-GSU, fehlt an OClW] Heinrich von Kleist. Trauerspiel. 1902. \{D-BHU\}

Konradin. Drama. O. J.

Marie Antoinette. Drama. O. J

Pausanias. Trauerspiel in 5 A. 1885. \{D-BSPK, D-FSU, D-LKM\}

Bergen, Alexander $=$ Pseudonym für: Gordon, Marie.

Beringer, Wilhelmine [Minna] Karoline Friederike. 1790 (Berlin) - 1844 (Berlin). Verh. Grantzow. In Lexika häufig: Apranzow:

Die Rückkehr aus dem Freiheitskampfe. Ein lkeines Schauspiel. 1814

Berlepsch, Emilie von. 1755 [Groß, Deutschlands Dichterinen: 1757] (Gotha) - 1830 (Lauenburg). Geb. von Oppeln (auch: von Oppel, von Appel). Verh. von Harms (oder Harmes):

Eginhard und Emma. Eine dramatische Skizze. (Sammlung kleiner Schriften und Poesien. 1787.) (D-BFU, D-BSPK, D-DSB, D-GSU, D-HHSU, D-HUL, D-LKM, DMrU, D-OLB, D-RS, D-WeiZdK, A-GUB, GB-LBL, MU (Milkrofilm), NiP\}

Bernbrunn, Margarethe. 1788 (München) - 1861 (Ischl/Oberösterreich). Geb. Lange. Bühnenname: Margarethe Carl, Pseudonyme: Margarethe Carl, Adalbert Prix: Das Abenteuer in Venedig, oder: Der Teutsche in Moskau. Romantisches Schauspiel in 4 A., frei nach dem Französischen. 1838.

Der Bergkönig, oder: Hopsa, der Retter aus Zauberbanden. Romantisches Zaubermärchen in 2 A. mit Musilk. 1832.

Die drei gefahrvollen Nächte, oder: Der Sklavenmarkt in Saint-Pierre. Schauspiel in 6 Abteilungen, frei nach dem Französischen. 1840.

Die Gabe, für sich einzunehmen, oder: Artour.de Montpensier. Vaudeville in 3 A., frei bearb. nach dem Französischen. 1843. 
Herr und Diener, oder: Das gebeimnisvolle Haus. Schauspiel in 5 A., frei nach dem Französischen. 1839.

Das Irrenbaus zu Dijon, oder: Wabnsinn und Verbrechen. Schauspiel in $3 \mathrm{~A}$. frei nach dem Französischen. 1831

Palmerin oder der Ritterschlag. Romantisches Schauspiel in 3 A. frei nach dem Französischen. 1825

Der Reisewagen des Flüchtlings. Schauspicl in 4 A. 1837.

Das Spielhaus zu Langenschwalbach, oder: Der Demant-Ring. Romantisches Schauspiel in 4 A. 1836.

Bernhardi, Sophie $=$ Knorring, Sophie von

Bernstein [Groß, Deutschlands Dichterinen: Bornstein], Caroline. 1797 (Berlin) 1838 (Berlin). Pseudonym: E. Karoli:

Das eingebrachte Stündchen oder Gellert im Schlafrock. Lustspiel in Versen und 1 A. 1831. \{D-BDS\}

Jedem das Seine. Lustspiel in Versen und 3 A. 1832. \{D-BSPK, A-WÖN\}

Der Johannessegen. Dramatischer Scherz in Versen und 1 A. 1833.

Rembrandts Meisterstiick. Dramatisches Charalktergemälde in Versen und 1 A. 1834.

Bernstein, Elsa. 1866 (Wien) - 1949 (Hamburg-Eimsbüttel). Geb. Porges. Pseudonym: Ernst Rosmer:

Achill. Tragödie in 3 A. 1910. \{D-BFU, D-FSU, D-HHU-T, D-HUB, D-KöTM, D-LDB [Mikrokarte], A-WÖN, A-WUB, CtY, DLC, NjP, NN\}

Dämmerung. Schauspiel in 5 A, 1893. \{D-BFU, D-BHU, D-FSU, D-HHSU, D HHU-T, D-KöTM, D-LDB [Mikrokarte], D-MüS, D-RoU, D-WHLB, CH-SGK, CU, NIC, NjP, NN, PPT\}

Dagny. Drama. 1904.

Johannes Herkner. Schauspiel in 5 A. 1904. \{D-BHU, D-FSU, D-LDB [Mikrokarte], D-MüS, A-WÖN, MH, NBuG, NjP, NN, OCU\}

Kingly Children. A fairy opera in three acts. 1911. \{GB-LBL\}

Könizskinder. Märchendrama in 3 A. 1894. (D-BFU, D-BHU, D-BUB, D-ES, DFrU, D-FSU, D-GSU, D-HHSU, D-HHU-T, D-KaMB, D-KöTM, D-KöUSB, DLDB [Mikrokarte], D-MarSN, D-MrU, D-MüRS, D-MüS, D-OLB, D-WeiZdK D-WHLB, D-WuS, A-WÖN, A-WUB, CH-BSU, CH-SGK, GB-LBL, DLC, PU; als Opernlibretto in D-ChS, D-DeLL, D-DUB, D-EWA, D-FrU, D-LDB [Mikrokarte], D-SPL

Maria Arndt. Schauspiel in 5 A. 1908. \{D-BFU, D-FSU, D-GSU, D-LDB [Mikrokarte], A-GUB, A-WON, A-WUB, GB-LBL, DLC, NIC, NN, OCU\} Milost Pan. (Madonna.) 1894. \{D-BUB, A-WÖN, NIC, PPULC\}

Mutter Maria. Legendendrama in 5 Wandlungen. 1900. \{D-BFU, D-BHU, D HHU-T, D-HUL, D-KöTM, D-KöUSB, D-MarSN, D-WeiZdK, A-WÖN, GBLBL, CLSU, KyU, MH, NBuG, NIC, NjP, NN\}
Nausikad. Tragödie, 1906. \{D-BFU, D-BHU, D-BiSL, D-FSU, D-HHU-T, LDB [Mikrokarte], A-WUB, GB-LBL, IEN, IU, MH, NjP, NN, WaU\} Schicksal. Schauspiel in 4 A. 1919. \{D-KöTM\}

Tedeum. Komödie in 5 A. 1896. \{D-BFU, D-BHU, D-FSU, D-GSU, D-HHSU, D-HHU-T, D-KöTM, D-KöUSB, D-LDB [Mikrokarte], D-MarSN, D-WeiZdK, D-WHLB, A-WÖN, GB-LBL, MH, NIC, NjP, NN, OU, PBm, PU\}

Themistokles. Tragödie in 5 A. 1897. \{D-BFU, D-BHU, D-FrU, D-FSU, D-GSU, D-KöTM, D-KöUSB, A-WÖN, CH-SGK, GB-LBL, MH, NjP, NN, OCU, PSC, PU\}

Wir drei. Drama in 5 A. 1891. (D-BHU, D-BUB, D-FSU, D-GSU, D-HHSU, DKöTM, D-KöUSB, D-LDB [Mikrokarte], D-MüS, D-WHLB, A-WÖN, A-WUB, $\mathrm{NIC}\}$

Berthold, Franz $=$ Pseudonym für: Reinbold, Adelheid

Beulwitz, Caroline von $=$ Wolzogen, Caroline Friederike Sophie Auguste von

Biehl, Charlotte Dorothea. 1731-1788:

Comödien und Lustspiele. 3 Bde. 1760

Der zärtliche Ehemann. Lustspiel in 5 A. 1765. \{D-BDS\}

Biereichel, Sophie Charlotte $=$ Ackermann, Sophic Charlotte.

Binzer; Emilie Henriette Adelheid Freifrau von. 1801 (Berlin) - 1891 (München). Geb. von Gerschau. Pseudonym: Ernst Ritter:

Die Gauklerin. Drama nach Königs Roman Williams Dichten und Trachten. O. J. \{AWÖN\}

Karoline Neuber. Drama. 1847. \{A-WÖN\}

Ruth. Biblisch-idyllisches Schauspiel. 1868

Birch, Charlotte $=$ Birch-Pfeiffer, Charlotte

Birch, Wilhelmine $=$ Hillern, Wilhelmine von

Birchpfeiffer, Ch. = Birch-Pfeiffer, Charlotte.

Birch-Pfeiffer, Charlotte. 1800 (Stuttgart) - 1868 (Berlin). Geb. Pfeiffer. Pseudonytme: Ch. Birchpfeiffer, Franz Fels, Waldherr:

Alles fir andere. Lustspiel in 1 A. 1848. (D-BDS, D-FSU, D-GSU, D-HeS, DHHU-T, D-KaMB, D-KöTM, D-KöUSB, D-LDB [Mikrokarte], D-SPL, A-WUB, CH-CGK, IU, NNU-W, PPULC, PU, WU\}

Alte Liebe rostet nicht oder Welche von den dreien? Schwank in 1 A. 1831. \{D-FSU, D-GSU, D-KöTM\} 
Ein alter Musikant Drama in 1 A. 1852. \{D-BDS, D-FSU, D-GSU, D-HeS, DHHU-T, D-HLHD, D-KöTM, D-WeiZdK, A-WÖN, CH-CGK\}

Die Anglikaner und die Puritaner. Große Oper in 5 A. 1838. (D-MBS\}

Anna, Königin von Frankreich. Schauspiel. Vor 1851.

Anna von Oestreich. Intrigenstück in 5 A. und einem Nachspiel. 1845 [Groß, Deutschlands Dichterinen: 1850]. [D-BDS, D-FSU, D-GSU, D-HHU-T, DHLHD, D-KöTM, A-WÖN\}

Auf dem Oberhof. Anderer Titel für: Kaiser Karls Schwert. \{D-BDS\}

Die beiden Meister. Schauspiel in 5 A. nach F. Kind. 1829.

Der beste Arzt. Schauspiel in 4 A. 1838. \{D-FSU, D-GSU, D-KöTM\}

Ein Billet. Schauspiel in 5 A. 1847. [Nach Richel, The German Stage identisch mit: Ein Brief:] \{D-BDS, D-FSU, D-GSU, D-HHU-T, D-KöTM, A-WÖN\}

Ein Brief. Schauspiel. 1843. [Nach Richel, The German Stage identisch mit: Ein Billet.] \{D-FGM, D-MarSN, CH-BSL\}

Der Cassationsrat. Lustspiel in 1 A. 1864. \{D-BFU, D-BoU, D-FSU, D-GSU, DHeS, D-KöTM, D-MarSN, D-WeiZdK\}

Eine deutsche Pariserin. Anderer Titel für: Onkel und Nichte. \{D-BDS, D-FSU, DGSU, D-HHU-T, D-KöTM, D-MüS\}

Der Döhrner Turm, oder Hannovers Spartaner. Drama in 3 A. 1830.

Dorf und Stadt. Schauspiel in 2 Abteilungen und 5 A. nach Auerbach. 1847 [Groß, Deutschlands Dichterinen: 1863]. \{D-BDS, D-BFU, D-BS, D-ENU, D-FSU, D GSU, D-HHU-T, als Regiebuch in D-HLHD; D-HUL, D-KaMB, D-KöTM, DLDB, D-MüS, D-WS, A-ISA, A-WÖN, A-WUB, AAP, DLC-P4, ICRL, MB, NN, NNC, RPB, WU

Edith. Schauspiel in 4 A. nach Flygare-Carlén. 1855. \{D-BDS, D-FSU, D-GSU, DHHU-T, D-KöTM, A-WÖN\}

Elisabeth. Historisches Originaldrama in 5 A. und einem Nachspicl. 1841. (Gesammelte dramatische Schriften I, 1847.) (D-FSU, D-GSU, D-KöTM, D-LKM, DMüRS, D-MüS, A-WÖN, GB-LBL, CtY, NNU-W\}

Die Englander in Paris. Posse in 4 A. 1833. \{D-BDS, D-FSU, D-GSU, D-HHU-T D-KöTM\}

Eine Familie. Schauspiel in 5 A. und einem Nachspiel. 1846. \{D-BDS, D-FSU, DGSU, D-HHU-T, D-KöTM, als Regiebuch, durchschossen, in D-HLHD; AWÖN, A-WUB\}

Ferdinand Avelli, der Flüchtling, oder Der Leichenräuber. Schauspiel in 3. A. 1830. [Umgearbeitet auf: Die Flucht nach London.] [D-BDS, D-FSU, D-GSU, D-KöTM D-MüS

Die Flucht nach London. Umarbeitung von: Ferdinand Avelli.

Das Forsthaus. Schauspiel in 2 Abteilungen und 4 A. 1850. (D-BDS, D-FSU, DGSU, D-HHU-T, als Regiebuch, durchschossen, in D-HLHD; D-KöTM, AWÖN\}

Fra Bartolomeo der Maler, oder Das Stift zu Worms. Schauspiel in 3 A. 1829.

Fräulein Höckerchen. Lustspiel in 3 A. 1858. (D-BDS, D-FSU, D-GSU, D-HHU
T, D-KöTM, D-MarSN, D-MüS, A-WÖN\}

Die Fräulein von St. Cyr. Lustspiel in 5 A. 1844.

Francis Johnston. Schauspiel in 5 A. 1848. (D-FGM, D-HHU-T, D-KöTM, AWÖN\}

Die Frau in Weiß. Drama in 3 Abteilungen und 5 A. nach W. Collis. 1866. \{DBDS, D-FSU, D-GSU, D-HHU-T, als Regiebuch, durchschossen, in D-HLHD; D-KöTM, D-MüS, A-WÖN\}

Eine Frau aus der City. Schauspiel in 4 A. 1852. (D-BDS, D-FSU, D-GSU, DHHU-T, D-MüS\}

Der Friedensschluß. Vorspiel in 1 A. zu: Der Döhrner Turm. 1830.

Gasthausabenteuer. Posse in 3 A. 1848. \{D-FSU, D-GSU, D-KöTM, D-MüS

Gesammelte dramatische Schriften. 3 Bde. 1847. (D-LKM, D-MüRS, GB-LBL, CtY, NNU-W; Bd. 1 in D-KöTM\}

Gesammelte dramatische Werke. 23 Bde. 1863-1880. (D-BDS, D-FSU, D-GSU, DKöTM, A-LBS, A-WUB, GB-LBL, CU, GEU, MB, NN, WU; Bde. 1, 2 u. 7 in DHHU-T; Bde. 2-4, 7, 14-16, 20 u. 21 in A-GUB; Bd. 11 in D-BoS; Bd. 15 u. 16 in D-HeS; Bd. 9 in CH-BSL)

Der Glöckner von Notre-Dame. Romantisches Drama in 6 Tableaus nach V. Hugo. 1830 [Richel, The German Stage: 1837; Groß, Deutschlands Dichterinen: 1838]. (DBFU, D-BSPK, D-DSB, D-ENU, D-FSU, D-GSU, D-HHU-T, D-HUL, DKaMB, D-KöTM, D-LDB, D-MüS, A-ISA, A-WÖN, A-WUB, GB-LBL, MB, NN, WU\}

Der Goldbauer. Schauspiel in 4 A. 1860. \{D-BFU, D-ENU, D-FSU, D-GSU, DHHU-T, als Regiebuch, durchschossen, in D-HLHD; D-HUL, D-KöTM, DKöUSB, D-LDB, D-MüS, D-SPL, A-ISA, A-WÖN, A-WUB, GB-LBL, MB, NN, WU\}

Graf von Falkenberg. Schwank in 1 A. O. J. \{D-BDS, D-BFU, D-BH, D-BoU, DFSU, D-GSU, D-HeS, D-LDB\}

Graf Waltron. Schauspiel in 4 A. 1845. \{D-ENU, D-KöTM, D-SPL, A-WUB\}

Die Grille. Ländliches Charakterbild in 5 A. nach G. Sand. 1856 [Groß, Deutschlands Dichterinen: 1860]. (D-BDS, D-BH, D-BS, D-DeLL, D-ENU, D-FSU, DGSU, D-HeS, D-HHU-T, als Regiebuch, durchschossen, in D-HLHD; D-HUL, D-KaMB, D-KöTM, D-LDB, D-MüS, D-MüU, D-WHLB, A-ISA, A-GUB, AWÖN, A-WUB, CH-CGK, DLC-P4, LNHT, MB, WU]

Die Großfiirstin. Romantische Oper in 2 Abtheilungen und 4 A. mit Ballett. 1850. \{D-BDS\}

Großvater und Enkelkind oder Die Wanderungen. Schauspiel in 4 Abteilungen und 6 A. nach C. Dickens. 1843. \{D-FSU, D-GSU, D-KöTM\}

Die Günstlinge. Schauspiel in 4 A. 1834. (D-HHU-T, D-KöTM\}

Gunst und Liebe: Schauspiel in 5 A. 1836.

Herma oder die Söbne der Rache. Gemälde der Vorzeit nach van der Velde in $5 \mathrm{~A}$. 1828. \{D-BDS, D-BoU, D-FSU, D-GSU, D-KöTM\}

Der Herr Studiosus. Charaktergemälde in 1 A. nach Levin Schücking. 1866. \{D- 
FSU, D-GSU, D-HHU-T, D-HUL, D-KöTM, D-MüS, D-TS, A-WÖN

Hinko, genannt: Der jüngere Sohn. Drama in 5 A. und einem Vorspiel nach L. Storch. 1834. \{D-BUB, D-FSU, D-GSU, D-HHU-T, D-KöTM\}

Iffland. Zeitbild in 3 Abteilungen und 4 A. 1858. \{D-BHU, D-FSU, D-GSU, DKöTM, D-MarSN, D-MüS, A-WÖN\}

Im Walde. Ländliches Charaktergemälde in 4 A. nach G. Sand. 1849. \{D-FSU, DGSU, D-HHU-T, D-KöTM, A-WÖN

In der Heimat. Schauspiel in 5 A. 1865. (D-BDS, D-BH, D-FSU, D-GSU, DHUL, D-KöTM, D-MarSN, D-MüS, A-WÖN\}

Johannes Guttenberg. Schauspiel in 3 Abteilungen und 5 A. 1834. (D-BDS, DDelL, D-FSU, D-GSU, D-HHU-T, D-KöTM, D-MarSN, D-MBS, D-MüS, DWLM, A-WÖN, CH-BSL, IEN\}

Junge Alte. Lustspiel in 1 A. 1865. \{D-BDS, D-FSU, D-GSU, D-KöTM, DMarSN, D-MüS, A-WÖN, NN\}

Kaiser Karls Schwerdt oder Der Leyerkaspar. Schauspiel in 5 A. nach Immermann. 1849. \{D-BDS, D-FSU, D-GSU, D-KöTM, D-MüS\}

Der Kaiser und der Seiler. [Vorspiel in 1 A. zu: Steffen Langer.] 1841. \{D-KöUSB, DMüS, CH-LZ, IEN, MB, WU\}

Karl der Große vor Pavia. Drama. O. J.

Katharina II. und ibr Hof. Schauspiel in 4 A. [Neubearbeitung von Die Günstlinge.]. 1863. \{D-BDS, D-FSU, D-GSU, D-KöTM, A-WÖN\}

Ein Kind des Glücks. Charakterlustspiel in 5 A. 1860. (D-BDS, D-FSU, D-GSU, DHHU-T, als Regiebuch, durchschossen, in D-HLHD; D-KöTM, A-WÖN, GBLBL, WU\}

König und Freiknecht. Schauspiel. 1834.

Königin Bell. Schauspiel in 2 Abteilungen und 5 A. nach Kavanagh. 1863. \{D-BDS, D-FSU, D-GSU, D-HHU-T, D-HUL, D-KöTM, A-WÖN, IU, NN\}

Die Lady von Worsley Hall. Schauspiel in 2 Abteilungen und 5 A. 1854 (Hes und Richel, The German Stage: 1855). (D-BDS, D-FSU, D-GSU, D-HHU-T, DKöTM, D-MüS, A-WÖN\}

Der Leichenräuber. Drama in 3 A. O. J. \{D-KöTM

Der Leiermann und sein Pflegekind. Volksstück in 3 Abteilungen und 5 A. 1859. (DBFU, D-BUB, D-ENU, D-FSU, D-GSU, D-HHU-T, D-HUL, D-KaMB, DKöTM, D-LDB, D-MüS, D-SPL, D-WHLB, A-WUB, DLC-P4, MB, WU\}

Der Liebe Streit. Festspiel zur Feier der Ankunft Seiner Majestät Otto des Ersten Königs von Griechenland. 1836. \{D-BSPK, D-MBS, GB-LBL\}

Das Mädchen und der Page oder Der Park zu Saint Valerie. Schauspiel in 4 A. 1830 \{D-FSU, D-GSU, D-KöTM\}

Magdala. Drama in 3 A. und einem Vorspiel. 1851. \{D-BH, D-FSU, D-GSU, DHHU-T, A-WÖN\}

Marguerite oder Die Macht des Zufalls. Schauspiel in 5 A. nach C. Birch [d. i. Charlotte Birch? Christian Birch?]. 1855. \{D-BDS, D-FSU, D-GSU, D-KöTM, DMarSN, A-WÖN\}
Maria di Gonsalvo. Romantisches Schauspicl in 5 A. 1829. (D-FSU, D-GSU, DKöTM\}

Die Marquise von Villette. Schauspiel in 5 A. 1844. (Gesammelte dramatische Werke II, 1863.) (D-BDS, D-BH, D-FSU, D-GSU, D-HHU-T; als Regiebuch, durchschossen, in D-HLHD; D-KöTM, D-LKM, D-MüRS, D-MüS, A-WÖN, GBLBL, CtY, NNU-W\}

Mazarin. Historisches Schauspiel in 4 A. 1849 [Groß, Deutschlands Dichterinen: 1852]. \{D-BDS, D-FGM, D-FSU, D-GSU, D-HHU-T, D-KöTM\}

Müllers Töchter. Drama.

Mutter und Sohn. Schauspiel in 2 Abteilungen und 5 A. nach Bremer, 1843. \{DFSU, D-GSU, D-HHU-T, D-HLHD, D-KöTM, A-WÖN, NN\}

Mutter und Tochter. Schauspiel in 4 A. 1844. (Gesammelte dramatische Schriften I, 1847; Gesammelte dramatische Werke IX, 1866.) \{D-FSU, D-GSU, D-HHU-T, DKöTM, D-LKM, D-MüRS, D-MüS, A-LBS, A-WÖN, GB-LBL, CtY, CU, GEU, $\mathrm{MB}, \mathrm{NN}, \mathrm{NNU}-\mathrm{W}, \mathrm{WU}\}$

Nacht und Morgen. Drama in 4 Abteilungen und 5 A. nach Bulwer. 1842. (D-BDS, D-BFU, D-BH, D-DeLL, D-ENU, D-FSU, D-GSU, D-HHU-T, als Regiebuch, durchschossen, in D-HLHD. D-KaMB, D-KöTM, D-KöUSB, D-MüS, D-SPL, AISA, A-WUB, CH-BSL, CH-LZ, GB-LBL, WU\}

Natalie. Schauspiel in 5 A. 1862.

Nelly oder Die Wanderungen. Schauspiel in 6 A. 1843. \{D-HHU-T, D-KöTM, CHBSL\}

Onkel und Nichte. Lustspiel in 5 A. 1836. (D-BDS, NNU-W, PPULC)

Peter von Szápár. Historisches Schauspiel in 5 A. 1831. \{D-BoU, D-FSU, D-GSU, D-KöTM, D-MüS

Der Pfarrherr. Schauspiel in 5 A. 1848. (D-BDS, D-FGM, D-FSU, D-GSU, DHLHD, D-KöTM, D-MüS, A-WÖN\}

Pfeffer-Rösel, oder Die Frankfurter Messe im Jahire 1297. Schauspiel in 5 A. 1829 [Groß, Deutschlands Dichterinen: 1833]. (D-BDS, D-BoU, D-BS, D-FSU, D-GSU, D-HLHD, D-HUL, D-KöTM, D-LKM, D-WHLB, A-WÖN, NRU\}

La Réole. Oper in 3 A. Libretto [Musik von Gustav Schmidt]. 1862. [D-BUB, D$\mathrm{MrU \}}$

Revanche. Lustspiel in 2 A. 1865. (D-BDS, D-FSU, D-GSU, D-HUL, D-KöTM D-MüS, A-WÖN\}

Ein Ring. Intrigenstück in 5 A. 1851. \{D-BDS, D-BH, D-FSU, D-GSU, D-HHUT; als Regiebuch, durchschossen, in D-HLHD, D-Kö'TM, A-WÖN\} Die Ritter von Malta oder Die Kraft des Firmans. Romantisches Drama in 6 A. nach de Madeleine. 1836. \{D-BoU, D-FSU, D-GSU, D-MüS\}

Robert der Teufel oder die Stimme von Burgund. Romantisches Ritterschauspiel in 4 A. nebst einem Vorspiel Die Verbannung. Vor 1849. \{D-KöTM\}

Rose und Röschen. Schauspiel in 4 A. 1853. [D-FSU, D-GSU, D-HHU-T, DHLHD, D-KöTM, A-WÖN\}

Die Rose von Avignon. Romantisches Schauspiel in 4 A. 1850. \{D-FGM, D-FSU, D- 
GSU, D-KöTM, D-MüS, A-WÖN\}

Rubens in Madrid. Schauspiel in 5 A. 1836 [Groß, Deutschlands Dichterinen: 1839]. (Gesammelte dramatische Schriften I, 1847.) (D-BDS, D-BHU, D-BoU, D-DeLL, D-FSU, D-GSU, D-HHU-T, als Regiebuch in D-HLHD; D-KöTM, D-LKM, DMBS, D-MüRS, D-SchOS, D-SiFH, D-WeiZdK, A-WÖN, CH-BSL, GB-LBL, $\mathrm{CtY}, \mathrm{NNU}-\mathrm{W}\}$

Sämtliche Werke. 1876. \{Bd. 15 in CH-CGK

Santa Chiara. Große romantische Oper in 3 A. 1854. \{D-BHU, D-KL, D-SPL, GB-LBL\}

Der Schatz des Webers. Schauspiel in 5 A. 1862. \{D-KöTM\}

Der Scheibentoni. Nationalschauspiel in 4 A. und einem Vorspiel nach Spindler. 1834. \{D-FSU, D-GSU, D-KöTM\}

Schlo/3 Greifenstein [auch: Greiffenberg] oder Der Samtschuh. Romantisches Schauspiel in $5 \mathrm{~A}$. nebst einem Vorspiele. 1828. (D-BDS, D-FSU, D-GSU, D-HLHD, D-KöTM, D-MüS; unter dem Titel: Das Schloß Greiffenstein oder: der Kampf für Frawenehre in D-SPL; A-WÖN, GB-LBL

Schön Clärchen. Schauspiel in 4 A. nach C. Spindler. 1830.

Simon. Schauspiel in 5 A. nach Tieck. 1843. (Gesammelte dramatische Schriften I, 1847.) (D-BDS, D-FSU, D-GSU, D-KöTM, D-LKM, D-MüRS, GB-LBL, CtY, NNU-W]

Ein Sonderling und seine Familie. Lustspiel in 5 A. 1848. \{D-BDS, D-FSU, D-GSU, D-KöTM, D-MüS\}

Steffen Langer aus Glogau oder Der hollandische Kamin. Lustspiel in 4 A. und einem Vorspiel. 1841. \{D-BFU, D-BH, D-FSU, D-GSU, D-HHU-T, D-HUL, D-KaMB, D-KöTM, D-KöUSB, D-LDB，D-MüS, D-SPL, A-WÖN, A-WUB, CH-BSL, CH-LZ, IEN, MB, WU\}

Eine Sylvesternacht. Schauspiel in 2 Abteilungen und 4 A. nach Eliot. 1862. (DFSU, D-GSU, D-KöTM, D-MüS\}

Die Taube von Cerdrons. Drama in 5 A. 1830 [Goedeke] oder 1833 [Kosch, Hes]. \{D-BDS, D-FSU, D-GSU, D-KöTM, D-MüS\}

Das Testament eines Sonderlings. Schauspiel in 5 A. nach C. Dickens. 1867. (D-BDS, D-BH, D-BUB, D-DeLL, D-FSU, D-GSU, D-HHU-T, D-HUL, D-KöTM, AWÖN\}

Thomas Thyrnau. Schauspiel in 5 A. nach dem gleichnamigen Roman. 1844 [Groß, Deutschlands Dichterinen: 1847]. \{D-BDS, D-FSU, D-GSU, D-HHU-T, als Regiebuch, durchschossen, in D-HLHD; D-KöTM, A-WÖN\}

Eine Tochter des Sïdens. Schauspiel in 5 A. nach Kavanagh. 1862. [D-BDS, D-FSU, D-GSU, D-KöTM, D-MüS, NN\}

Ein Trauschein. Schauspiel in 5 A. 1855.

Trudchen. Schauspiel in 3 Abteilungen und 5 A. 1831. \{D-FSU, D-GSU, DKöTM, D-MüS\}

Ulrich Zwinglis Tod. Historisches Trauerspiel in 5 A. 1837. (Gesammelte dramatische Werke IX, 1866.) (D-BDS, D-FSU, D-GSU, D-HHSU, D-KöTM, D-MarSN, D-
MüS, A-LBS, A-WÖN, CH-BSL, CH-LZ, CH-WiS, GB-LBL, CU, GEU, IEN, $\mathrm{MB}, \mathrm{NN}, \mathrm{WU}\}$

Vatersorgen. Komisches Zeitgemälde in 3 A. 1849. \{D-BDS, D-FSU, D-GSU, DHeS, D-KöTM, A-WÖN, CH-CGK

Die Verbannung. Vorspiel zu Robert der Teufel. O. J. \{D-KöTM\}

Die verhängißßvollen Wechsel. Drama. O. J.

Das Vermächtnis. Vorspiel zu Waldemars Traum. 1831.

Die Waise aus Lowood. Schauspiel in 2 Abteilungen und 4 A. nach C[urrer]. Bell [= Pseud. für: Charlotte Brontë]. 1853 [Groß, Deutschlands Dichterinen: 1856]. \{DBDS, D-BH, D-BoU, D-DeLL, D-ENU, D-FSU, D-GSU, D-HeS, D-HHU-T, als Regiebuch, durchschossen, in D-HLHD; D-HUL, D-KaMB, D-KöTM, DKöUSB, D-LDB, D-MïS, D-PEA, D-SPL, A-GUB, A-ISA, A-WÖN, A-WUB, GB-LBL, MH, MB, NNC, WU\}

Waldemars Traum. Historisch-romantisches Schauspiel in $5 \mathrm{~A}$. mit einem Vorspiel (Das Vermächtnis). 1831. \{D-BoU, D-FSU, D-GSU, D-HeS\}

Die Walpurgisnacht. Dramatisches Volksmärchen in 4 A. 1830. (Gesammelte dramatische Werke IX, 1866.) \{D-BDS, D-FSU, D-GSU, D-KöTM, D-MüS, A-LBS, AWÖN, CU, GEU, MB, NN, WU\}

Der Wartturm. Großes romantisches Schauspiel nach Blumenhagen. 1829. Wer ist sie? Schauspiel in 4 A. 1868. [D-BoU, D-FSU, D-GSU, D-KöTM, D-MüS, D-WeiZdK, A-WÖN

Wie ist das zugegangen. Lustspiel. O. J. (D-BDS, D-BH, D-DonFFH, D-MüS\} Wie man Häuser baut. Lokales Zeitgemälde in 4 A. 1851. (D-BDS, D-FSU, DGSU, D-HHU-T, D-HLHD, D-KöTM, A-WÖN

Die Witwe. Schauspiel in 4 A. 1836.

Zufallslaunen. Drama.

Zulima. Vorspiel in 1 A. zu Schloß Greifenstein oder Der Samtschuh. 1829. \{DKöTM\}

Blei, Kitty von $=$ Hofmann, Kitty.

Blum, Lodoiska von, 1841 (Schloß Caczevice/Russ. Polen) - 1927. Pseudonym: Enst von Waldow:

Eine Badereise. Lustspiel. O. J.

Die Entfïhrung. Lustspiel in 2 A. 1863. \{D-FSU\}

Das Leben Neros. Lustspiel. O. J.

Magdalena. Schauspiel. O. J.

Maria von Ungarn. Trauerspiel. O. J.

Eine romantische Dichterschule. Lustspiel. O. J.

Blumenhagen, Anna Wilhelmine Elisabeth = Sostmann, Anna Wilhelmine Elisabeth.

Bock, Annie = Neumann-Hofer, Annie 
Böhmer, Caroline $=$ Schlegel-Schelling, Caroline.

Bölte, Amalie (Amely) Charlotte Elise Marianne. 1811 [Groß, Deutschlands Dichterinen: 1814] (Rhena/Mecklenburg) - 1891 (Wiesbaden):

Der Edelhof. Schauspiel in 4 A. 1865. \{D-BDS, A-WÖN\}

Boos, Josephine. Um 1829:

Olga, oder die moskowitische Waise. Trauerspicl in 5 A. Übers. [?] 1829. (D-MrU\}

Borch, Marie von. 1853 (Hamburg) - 1895 (Berlin):

Comödie der Liebe. Komödie von Henrik Ibsen. Übers. 1889. \{D-BHU, D-FSU, DHUB, D-WüU\}

Es war einmal oder Der Prinz von Nordland. Märchenkomödie in 5 A. von Holger Drachmann. Übers. O. J. \{D-KöTM\}

Frau Inger auf Östrot. Drama von Henrik Ibsen. Übers. O. J. \{D-KaMB, D-KöTM\} Die Frau vom Meer. Schauspiel in 5 A. von Henrik Ibsen. Übers. O. J. \{D-KöTM, D-LDB\}

Gespenster. Familiendrama in 3 A. von Henrik Ibsen. Übers. 1884. \{D-BUB, DDonFFH, D-DSB, D-EWA, D-FSU, D-HHU-T, D-HUB, D-HUL, D-KaMB, DKöTM, D-LDB, D-MrU, D-MüS, D-WeiZdK, D-WüU, A-SUB, GB-LBL

Hedda Gabler. Schauspiel in 4 A. von Henrik Ibsen. Übers. O. J. (D-KaMB, DKöTM, D-LDB\}

Henrik Ibsens gesammelte Werke. Übers. 1890. \{D-FSU, GB-LBL\}

Eine ideale Frau. Schauspiel in 3 A. von Marco Praga. Übers. 1892. (D-KöTM)

König Midas. Schauspiel in 4 A. von Gunnar Heiberg. Übers. um 1890. (D-FSU, D-HUB, D-KöTM\}

Die Kronprätendenten. Historisches Schauspiel in 5 A. von Henrik Ibsen. Übers. O. J. \{D-KaMB, D-KöTM, D-LDB $\}$

Nordische Heerfahrt. Schauspiel in 4 A. von Henrik Ibsen. Übers. 1890. \{D-DSB D-EWA, D-FSU, D-HHU-T, D-KöTM, D-LDB，D-MüS，D-SPL，D-WeiZdK, GU\}

Ein Puppenheim. Drama von Henrik Ibsen. Übers. 1900. (Henrik Ibsens Sämtliche Werke in deutscher Sprache VI, Berlin 1903.) \{D-BHU, D-KöTM, D-WüU\}

Rosmersholm. Drama von Henrik Ibsen. Übers. 1887. (D-BFU, D-BHU, D-FSU, D-KöTM, GB-LBL\}

Ein Volksfeind. Drama von Henrik Ibsen. Übers. O. J. \{D-BHU $\}$

Die Wildente. Schauspiel in 5 A. von Henrik Ibsen. Übers. 1887. (D-BFU, D-BHU, D-FSU, D-KöTM, GB-LBL\}

Bormann, Julie. ?-?:

Westfalens Freiheitsringen. 1805-14. (D-WLM\}
Bornstedt, Wilhelmine von. 1776 (Drewen/Priegnitz, Brandenburg) - 1855 (Engelholm, Schweden). Geb. von Klitzing. Pseudonym: Wilhelmine B:

Theobald und Marie oder der reinsten Liebe schönster Sold. Drama in 3 A. 1826. \{DHUL

Bossi von Löwenglau, Katharina Reichsfreiin von = Hesse, Katharina von.

Brachmann, Louise Caroline Marie. 1777 (Rochlitz/Sachsen) - 1822 Halle/Saale). Pseudonyme: Klarfeld, Sternheim, Louise B:

Eigensinn und Schicksal. Dramatisches Gedicht in 2 A. 1826. \{D-WeiZdK

Der schöne Zirkel, oder Zilge aus dem Portrait einer geistreichen Dame. Dramatische Skizze. 1807.

Bracht, Hedwig = Kiesekamp, Hedwig.

Brackel, Ferdinande (Fernande) Maria Theresia Freifrau von. 1835 (Schloß Welda bei Warburg/Westphalen) - 1905 Paderborn). Pseudonym: E. Rudorff:

Die Ehestandspädagogen. Schwank. 1877.

Brandl, Friederike $=$ Ellmenreich, Friederike.

Brauer, Marie $=$ Günther, Marie

Braun, Friederike $=$ Robert, Friederike

Braun, Isabella. 1815 (Jettingen, Krs. Günzburg/Bayr. Schwaben) - 1886 (München): Allerneuestes Theaterbilderbuch. Ein plastisches Bilderbuch mit beweglichen Figuren in 4 theatralischen Aufzügen. Nebst einleitenden Versen und 4 Lustspielen für die liebe kleine Jugend. 1883. [Enthält vier Lustspiele.] \{D-BiU, D-BoU, D-FSU, DReuS\}

Die Heimkehr. Festspiel. O. J. (Kleine Theaterstïcke für die Jugend II, 1865.) \{D$\mathrm{LDB}, \mathrm{CU}\}$

Das Hutzelmännchen. Ein Weihnachtsspiel. O. J. (Kleine Theaterstïcke für die Jugend II, 1865.) \{D-LDB, CU\}

Kleine Theaterstïcke für die Jugend. 2 Bde. 1865. \{D-LDB, CU\}

Der Mutter Geburtstag. Festspiel in 2 A. O. J. (Kleine Theaterstiucke fur die Jugend II, 1865.) \{D-LDB, CU\}

Nach der neuesten Mode. Lustspiel in 1 A. O. J. (Kleine Theaterstïcke fir die Jugend

- II, 1865.) \{D-LDB, CU\}

Das Namenstagsgeschenk. Festspiel. O. J. (Kleine Theaterstücke für die Jugend I, 1865; Neues Kindertheater, 1881.) \{D-LDB\}

Neues Kindertheater. Sammlung von Theaterstücken. 1881.

Der St. Nikolausabend. Singspiel. O. J. (Kleine Theaterstïcke fir die Jugend I, 1865; 
Neues Kindertheater, 1881.) \{D-LDB\}

Ein Waldmärchen. Dramatisches Singspiel. O. J. (Kleine Theaterstücke für die Jugend I, 1865; Neues Kindertheater, 1881.) \{D-LDB\}

Der Zombi. Drama. O. J. (Kleine Theaterstücke fir die Jugend II, 1865.) \{D-LDB, $\mathrm{CU}$

Zur Genesungsfeier. Festspiel in 2 A. O. J. (Kleine Theaterstïcke für die Jugend I, 1865.) $\{\mathrm{D}-\mathrm{LDB}\}$

Braun, Lily. 1865 (Halberstadt) - 1916 (Berlin-Zehlendorf). Geb. von Kretschman. Verh. von Gizycki:

Madeleine Guimard. Lyrische Oper in 3 A. O. J. (Gesammelte Werke, Berlin/Grunewald: Klemm, o. J., V.) \{D-BDS, D-BFU, D-BHU, D-FSU, D-HeSB, D-HHSU, $\mathrm{D}-\mathrm{MrU}\}$

Mutter Maria. Tragödie in 5 A. 1913. Gesammelte Werke, Berlin/Grunewald: Klemm, o. J., V.) \{D-BDS, D-BFU, D-BHU, D-FSU, D-HeSB, D-HHSU, DHHU-T, D-KöTM, D-MrU, GB-LBL\}

Brauneck, Luise von $=$ Krockow, Luise Gräfin.

Braunrasch, Auguste von $=$ Arens von Braunrasch, Auguste.

Breden [Groß, Deutschlands Dichterimen: Bredow], Christiane [Groß, Deutschlands Dichterinen: Christine] von. 1839 [Groß, Deutschlands Dichterinen, Garland/Garand: 1844] (Wien) - 1901 (Wien). Geb. Friederik. Verh. von Neupauer. Pseudonym: Ada Christen:

Ein armer Spinner. Lustspiel in $2 \mathrm{~A}$. frei bearb. von A. Christen [ident. mit Ada Christen?]. 1861. \{D-KöTM\}

Faustina. Drama in 5 A. 1871. \{D-KöTM, D-MarSN, A-WÖN, A-WUB, IEN\} Fraulein Pascha. Lustspiel. 1899

Hypnotisiert. Lustspiel. 1898

Wiener Leut'. Drama. (Adaptation ihres Romans Jungfer Mutter.) 1893.

Bredow-Goerne, Adele Elisa Gräfin von. 1830 (Posen) - 1885 (Gut Goerne bei Friesack). Geb. von Gansauge:

Diana von Lavergne. Trauerspiel in 5 A. 1875. \{D-BSPK, D-WeiZdK, NN\}

Ein Fenster beim Einzuge. Lustspiel in 1 A. 1871. (D-BDS, D-HHU-T, GB-LBL, $\mathrm{NN}\}$

Freie Wahl. Trauerspiel. 1872. \{D-BDS, D-WeiZdK\}

Gute Freunde. Lustspiel. 1871. \{D-BDS, A-WÖN\}

Hypathia. Trauerspiel. 1877. \{D-BSPK, D-WeiZdK, A-WÖN\}

Juana von Castilien. Trauerspiel. 1877.

Der Lauf der Welt. Lustspiel. 1871. \{D-WeiZdK, A-WÖN\}

Ein verlorener Sohn. Trauerspiel in 5 A. 1873. \{D-BDS, D-WeiZdK, NN\}
Brentano, Marianne von $=$ Ehrmann, Marianne

Brentano, Sophie $=$ Mereau, Sophie

Briest, Karoline $=$ Motte-Fouqué, Karoline de la.

Brinkmann, Auguste = Danne, Auguste

Brochowska, Pauline Maria Juliane von. 1794 (Dresden) - 1853 (Spanien). Pseudonyme: Lina, Theophania:

Libella. Romantische Oper in 2 A. Libretto. 1828. \{D-BDS

Der rothe Domino. Komische Oper in 2 A. Libretto. 1837.

Die Siegesfahne. Operette in 1 A. Libretto. Vor 1834.

Brunn, Adalbert $=$ Pseudonym für: Druskowitz, Helene von.

Buch, Ida von = möglicher Geburtsname für: Görner, Ida.

Bülow, Babette (Clara Bertha Friederike) von. 1850 (Breslau) - 1927 (Arendsee/ Mecklenburg). Geb. Eberty. Pseudonym: Hans Arnold:

Geburtstagsfreuden. Schwank in 1 A. 1884. \{GB-LBL\}

Theorie und Praxis. Lustspiel. 1890

Zwei Friedfertige. Schwank. 1891.

Bültzingslöwen, Johanna Sophie Friederike von. 1770 (Dewitz bei Stargard/ Mecklenburg) - ?. Geb. von Gentzkow [Goedeke: Genskow]:

Die Vergeltung. Trauerspiel in 5 A. 1820. \{D-BSPK, D-CorFB, D-FGM, D-WHLB\}

Bürck, Adelheid Babette Emilie = Eberhardt-Bürck, Adelheid Babette Emilie.

Bürger, Elise [Marie Christiane Elisabeth]. 1769 (Stuttgart) - 1833 (Frankfurt a. M.) Geb. Hahn. Pseudonyme: Theodora, Pilgerin nach dem Heimatlande. Veröffentlichte auch anonym.:

Adelheit Gräfinn von Teck. Ritterschauspiel in 5 A. 1799. (D-BDS, D-BHU, D FGM, D-HHS, D-HLHD, D-MBS, D-WeiZdK, A-LBS, A-SUB, A-WÖN, GBLBL, MU (Mikrofilm)\}

Die antike Statue aus Florenz Scherzspicl. 1829. (D-FGM, D-FSU, D-HHSU, DKöTM, D-LDB, D-MarSN, A-WÖN, MiD, außerdem ,in verschiedenen Bibliotheken, Hamburg, Frankfurt a. M., Berlin u. a." [von Hoff 217.]]

Das Bouquet. (Samtliche theatralische Werke I, 1801.) \{D-HLHD, D-MüU, AWÖN\}

Die Heirathslustigen. (Sämtliche theatralische Werke I, 1801.) (D-HLHD, D-MüU, A-WÖN\} 
Klara von Montalban. Drama in 5 A. nach Frau von Genlis. O. J. Veröff, 1819. [Bei von Hoff wiederholt: „Montablan“.] [D-KöTM, Handschriften in D-ASS und DFFDH

Sämtliche theatralische Werke I. 1801. \{D-HLHD\}

Schein und Wabrheit. Eine dialogisierte Geschichte. 1799. \{CH-CGBB\}

Die schwäbische Bäuerin. O. J. Veröff. 1819.

Die Überraschung. Familiengemälde in 1 A. 1801. (D-HL, D-HLHD, D-MBS

Acht weitere Dramen. Titel nicht ermittelt (Kinder 178).

Bürstenbinder, Elisabeth. 1838 (Berlin) - 1918 (Schloß Labers bei Meran). Pseudonyme: E. Werner, Elisabeth Werner:

Aberglaube. Lustspiel in 3 A. 1880. \{D-WeiZdK, NN\}

Bufalo della Valle Zagrabia, Emilia Johanna Constantia Catharina Marchesa del. 1828 [Groß, Deutschlands Dichterinen: 1818] (Hamburg) - nach 1882 (Rom?). Geb. Schmidt. Pseudonyme: Emilie dell'Buffallo, Moderatus Diplomaticus:

Die Deutschen und Engländer im Mond. Humoristisches Lustspiel in 3 A. 1873. \{GB-LBL

Konradin von Hohenstaufen. Drama. 1871. \{D-WciZdK, NN\}

Buffallo, Emilie dell' $=$ Pseudonym für: Bufalo della Valle Zagrabia, Emilia Marchesa del.

Buller, Jeanette (Jenny). 1795 (Reval) - 1850 (Reval)

Der Becher. Trauerspiel in 5 A. nach E. T. A. Hoffmann. 1828.

Busch, Helene = Pseudonym für: Baltz, Johanna

Calafati, Marie $=$ Gordon, Marie

Calisch, Marie Elisabeth Helene Freiin von = Zay von Csömör, Marie Elisabeth Helene Freiin von.

Callot, Magdalena (Madeleine) Freiin von, 1774 (Weimar, Eger oder Wien) - 1847 [Groß, Deutschlands Dichterinen: nach 1830] (Wien). Geb. von Wagmuth [Goedeke: Wachmuth]:

Die Ballnacht zu Gumpelwitz, oder: Das Wiedersehen. Schwank. 1826

Carl, Margarethe $=$ Bühnenname für: Bernbrunn, Margarethe.

Ceconi, Ricarda $=$ Huch, Ricarda

Ceres = Pseudonym für: Getsdorf, Wilhelmine von
Champs, Julie Charlotte Dorothea des = Richthofen, Julie Charlotte Dorothea Freifrau Prätorius von.

Chézy, Wilhelmine von. 1783 (Berlin) - 1856 (Genf). Geb. von Klencke [Friedrichs: Klenke]. Verh. von Hastfer. Pseudonyme: Helmina, Helmine, Sylvander, Sylvandra, Enkelin der Karschin:*

Eginhard und Emma. Spiel mit Gesang. 1817. \{Handschrift in D-ASS; D-FFDH, D-HHSU, D-SML; unter dem Titel Emma in D-FrU?\}

El galan Fantasma (von Pedro Calderón de la Barca). Bearbeitung von Szenen für die Bühne. 1817.

Euryanthe. Große romantische Oper in 3 A. (Libretto.) 1824. \{D-BCHS, D-BDS, D-BFU, D-BHU, D-BoU, D-BS, D-DeLL, D-DSB, D-DUB, D-ENU, D-FSU, D-FTT, D-FrU, D-HHSU, D-HUL, D-LKM, D-MüS, D-SML, D-SPL, D-ZR, AWÖN, A-WUB, CH-LZ, GB-LBL, DLC-P4, ICN, LNH, MB, NN]

Der neue Narziß. Lustspiel in 1 A. 1824 . \{D-ZCW\}

Rosamunde. Schauspiel. 1823. \{D-MrU\}

Die Silberlocke im Briefe. Schauspiel in 3 A., frei nach Calderón de la Barca. 1815

\section{$\{\mathrm{D}-\mathrm{WeiZdK}\}$}

Weiße Hände kränken nicht. Schauspiel. O. J.

Der Wunderquell. Dramatische Kleinigkeit in 1 A. 1824. [Geänderter Titel für: Der neue Narzißs.]

Beiträge zu: Polterabendspiele. Hg. Kralowsky, Berlin 1818.

Christ, Jean $=$ Pseudonym für: Gutbier, Louise Jeanette Christiane.

Christen, $\mathrm{Ada}=$ Pseudonym für: Breden, Christiane von

Christlieb, Theophyle $=$ Pseudonym für: Zitz, Katharina Rosa Therese Pauline Modesta.

Cohn, Clara $=$ Viebig, Clara.

Collin, Rosalie von. 1773 (Wien) - 1832 (Wien):

Don Carrizales. Lustspiel nach Cervantes. 1823. \{D-GSU, D-LKM, A-WÖN\}

Consbruch, Henriette Artemisia Marianne = Montenglaut, Henriette Artemisia Marianne von.

Conze, Elisabeth $=$ Krukenberg, Elisabeth

Cornelius, Auguste Charlotte Sophie Agnes. 1826 (Darmstadt) - 1891 [National Union Catalog: 1890] (Berlin/Charlottenburg). Pseudonym: Paul Dido:

* D-MSDA besitzt nicht näher bezeichnete Dramen der Autorin. 
Der Arzt wider Willen. Prosakomödic in 3 A. von Molière, Übers. O. J. (Molières Sämmtliche Werke in zwei Bänden. 1871.) (D-EWA, D-HUL, D-LDB, D-SPL Eine blinde Frau. Lustspiel. 1866. (D-BDS\}

Der Bürger als Edelmann. Lustspiel in 5 A. von Moliere. Übers. O. J. (Molieres Sämmtliche Werke in zwei Bänden. 1871.) (D-ENU, D-EWA, D-HUL, D-LDB, D SPL]

Don Juan, oder der steinerne Gast. Prosakomödie in 5 A. von Molière. Übers. O. J. (Molières Sämmtliche Werke in zwei Bänden. 1871.) \{D-EWA, D-HUL, D-LDB, D SPL

Dramatische Studien. Lustspiel in 1 A. frei nach dem Französischen. 1867. \{D-BDS, D-KaMB\}

Der eingebildete Kranke. Lustspiel in 3 A. von Molière. Übers. O. J. (Molieres Sämmtliche Werke in zwei Bänden. 1871.) \{D-EWA, D-FSU, D-HUL, D-MüU, DLDB, D-SPL, A-SUB\}

Er will auf die Bïhne. Lustspiel. 1867. (D-BDS, A-WÖN\}

Die erkannten Götter. Lustspiel. 1867. (D-BDS, A-WÖN\}

Die erzwungene Heirath. Lustspiel in 1 A. von Molière. Übers. O. J. (Molières Sämmtliche Werke in zwei Bänden. 1871.) (D-EWA, D-HUL, D-LDB, D-SPL Die Fïrsten als Brautwerber. Lustspiel in $5 \mathrm{~A}$. von Molière. Übers. O. J. (Molières Sämmtliche Werke in zwei Bänden. 1871.) (D-EWA, D-HUL, D-LDB, D-SPL\}

Der Geizige. Lustspiel in 5 A. von Molièrc. Übers. 1875. (Molières Sämmtliche Werke in zwei Bänden. 1871.) (D-DSB, D-EWA, D-HUL, D-LDB, D-SPL, A-SUB, AWÖN\}

George Dandin, oder der betrogene Ehemann. Lustspiel in 3 A. von Molière. Übers. O. J. (Molières Sammtliche Werke in zwei Bänden. 1871.) (D-EWA, D-HUL, DLDB, D-SPL\}

Die Gezierten. Lustspiel in $1 \mathrm{~A}$. von Molière. Übers. 1880. (Molières Sämmtliche Werke in zwei Bänden. 1871.) \{D-DSB, D-EWA, D-HUL, D-LDB, D-SPL\} Goethe en Italie. 1867. (D-BDS\}

Die Graffin von Escarbagnas. Lustspiel in $1 \mathrm{~A}$. von Molière. Übers. O. J. (Molières Sämmtliche Werke in zwei Bänden. 1871.) (D-EWA, D-HUL, D-LDB, D-SPL\}

Herr von Pourceaugnac. Ballettkomödie in 3 A. von Molière. Übers. O. J. (Molieres Sämmtliche Werke in zwei Bänden. 1871.) \{D-EWA, D-HUL, D-LDB, D-SPL\}

Das Impromptu von Versailles. Prosakomödic in $1 \mathrm{~A}$. von Molière. Übers. O. J. (Mo-

lières Sämmtliche Werke in zwei Bänden. 1871.) \{D-EWA, D-HUL, D-LDB, D-SPL\} König und Dichter. Schauspiel in 4 A. 1865. \{D-DSB, D-HHU-T, D-KaMB, DKöTM, D-LKM, D-MüU, D-SML, D-SPL, A-WÖN, MH, ViU\}

Der Liebhaber als Arzt. Lustspiel in 3 A. von Molière. Übers. O. J. (Molières Sämmtliche Werke in zwei Bänden. 1871.) (D-EWA, D-HUL, D-LDB, D-SPL\}

Nur ein Held. Schwank in 1 A. 1877. \{A-WÖN, NN\}

Platen in Venedig. Lustspiel in 1 A. 1865. (D-BHU, D-BUB, D-HHU-T, DKöTM, D-KoS, D-LKM, D-SPL, D-WHLB, A-WÖN, A-WUB, CH-BSU, ICN, $\mathrm{MH}\}$
Scapins Schelmenstreiche. Lustspiel in 3 A. von Molière. Übers. O. J. (Molières Sämmtliche Werke in zwei Bänden. 1871.) (D-EWA, D-HUL, D-LDB, D-SPL\} Die verbängnisvolle Perriucke. Lustspiel in 3 A. nach A. de Musset. 1867. \{D-ENU, D-HHU-T, D-KöTM, D-LKM; unter dem Titel: Die vergängnißsvolle Perrïcke in D-SPL; A-WÖN, A-WUB, MH\}

Wilhelm der Eroberer, Lustspiel in 1 A. frei nach einem fremden Stoffe. 1862. \{GBLBL\}

Weitere Öbersetzungen von Molières Dramen [Groß, Deutschlands Dichterinen $141]$.

Crané, Caroline $=$ Eichler, Caroline.

Criegern, Wilhelmine von $=$ Sydow, Wilhelmine von.

Croissant-Rust, Anna. 1860 (Bad Dürkheim/Pfalz) - 1943 (Pasing bei München). Geb. Rust:

Der Bua. Oberbayrisches Volksdrama in 4 A. 1897. \{D-BHU, D-KöTM\}

Der standhafte Zinnsoldat. Drama. 1896. \{D-BHU, D-BSPK\}

Cronstain, Henriette Artemisia Marianne von $=$ Montenglaut, Henriette Artemisia Marianne von.

D., Catharina Helena = Dörrien, Catharina Helena

D., Elisabeth = Pseudonym für: Grube, Elisabeth.

D. . . H. . ., v. = Pseudonym für: Droste-Hülshoff, Annette von.

Danne, Auguste. Um 1855. Geb. Brinkmann. Pseudonym: Auguste:

Das Beerenlieschen oder Die guildene Kette. Weihnachtsmärchen in 2 A. mit Gesang und Tanz. 5. Aufl. 1898. (D-KöTM)

De liutt Heckenros. Plattdeutscher Schwank. O. J. \{D-HHU-T\}

Leicht auffuhrbare Stiucke. (Hirts Theater für die Jugend.) 1877.

Daphne = Pseudonym für: Fuchs, Anna Rupertina.

Delle Grazie, Marie Eugenie. 1864 (Weißkirchen, Ungarn) - 1931 (Wien):

Arme Seelen. Drama. Vor 1904. \{D-BFU, D-FSU\}.

Donawwellen. Einalkter. O. J. ( $Z u$ spatt. 1903.) \{D-BFU, D-BHU, D-FSU, DKöTM, A-GUB, A-WUB, CH-DBG, IU, MH\}

Goldener. Drama. 1901.

Moralische Walpurgisnacht. Ein Satyrspiel. 1896. (D-BFU, D-BHU, D-FSU, DKöTM, D-MüU, D-WeiZdK, A-GUB, A-WÖN, A-WUB, IEN, MH, TU\} Mutter. Einakter. O. J. (Zu spät. 1903.) \{D-BFU, D-BHU, D-FSU, D-KöTM, AGUB, A-WUB, CH-DBG, IU, MH\} 
Narren der Liebe. Lustspiel in 4 A. 2. Aufl. 1904. \{D-MüU, D-WeiZdK, A-WÖN, A-WUB, IEN, NN\}

Sämtliche Werke. 9 Bde. 1903-4. \{D-LKM, D-MüU\}

Saul. Tragödie in 5 A. 1885. \{D-BFU, D-BHU, D-BSPK, D-ENU, D-GSU, DKöTM, D-KöUSB, D-LKM, A-GUB, A-WÖN, A-WUB, CH-DBG, CH-ZZ, GB-LBL, DLC, IEN, MH, NN\}

Der Schatten. Drama in einem Vorspiel und 3 A. 1901. \{D-BFU, D-ENU, D-ES, D-FSU, D-KaMB, D-KöTM, D-MüS, A-GUB, A-WÖN, A-WUB, MH, NhD\} Schlagende Wetter. Drama in 4 A. 1899/1900. [D-BFU, D-BHU, D-DoFHI, DENU, D-FSU, D-KöTM, D-MarSN, D-MüU, A-GUB, A-WÖN, A-WUB, CHDBG, NNC\}

Schwàne am Land. Drama. 1902. \{A-WÖN, A-WUB\}

Sphinx. Einakter. O. J. (Zu spät. 1903.) \{D-BFU, D-BHU, D-FSU, D-KöTM, AGUB, A-WUB, CH-DBG, IU, MH\}

Ver Sacrum. Drama. 1906. \{D-BUB, D-KöTM, A-WÖN, A-WUB\}

Vinetta. Einakter. O. J. ( $Z u$ spát. 1903.) (D-BFU, D-BHU, D-FSU, D-KöTM, AGUB, A-WUB, CH-DBG, IU, MH\}

$Z u$ spät. Vier Einalkter. 1903. (D-BFU, D-BHU, D-FSU, D-KöTM, D-WeiZdK, A-GUB, A-WÖN, A-WUB, CH-DBG, IU, MH\}

Dery, Juliane $=$ Pseudonym für: Deutsch oder Decsy, Juliane.

Descy, Juliane $=$ Deutsch, Juliane

Deutsch (auch Decsy), Juliane. 1864 (Baja/Ungarn) - 1899 (Berlin). Pseudonym: Juliane Dery:

Das Amulett. Lustspiel. 1891.

Es fiel ein Reif. Drama in 1 A. 1896. \{D-FSU\}

Pusztastïrme. Lustspiel. O. J.

D'Schand. Volksstiuck in 6 Bildern. 1894. \{D-FSU

Die selige Insel. Dramatisches Idyll. 1897. \{D-FSU, D-LKM

Die sieben mageren Jabre. Drama. 1896.

Die sieben mageren Kïhe. Komödie in 3 A. 1897. \{D-FSU\}

Der Stärkere. Lustspiel. O. J.

Die Verlobung bei Pignerols. Lustspiel. 1891.

Devrient, Therese. 1803 - 1882:

Ein Lustspiel, Titel nicht genannt [E. Devrient, Eduard Devrient aus seinen Tagebiichern 547]

Dido, Paul $=$ Pseudonym für: Cornelius, Auguste .

Dievenow = Pseudonym für: Kühne, Julie Mathilde.
Diez, Elisabeth = Grube, Elisabeth.

Diez, Katharina, 1809 (Netphen/Westphalen) - 1882 (Netphen):

Frithjof. Tragödie in $5 \mathrm{~A}$. nach Tegner. 1879. \{D-BSPK, D-BUB, D-DUB, D-FrU, D-SiFH, D-SiSiM, D-TS, D-WeiZdK\}

Jephthas Opfer: Trauerspiel in 5 A. mit einem Vorspiel. 1874. \{D-BSPK, D-BUB, DDUB, D-KaMB, D-KöUSB, D-SiSiM, GB-LBL

Dito $=$ Pseudonym für: Elisabeth von Rumänien.

Dönniges, Margarete von = Keyserling, Margarete Gräfin von.

Dörrien (auch Doerrien), Catharina (auch Katharina) Helena. 1717(Hildesheim) 1795 (Dillenburg/Hessen) [Kosch 3: Wittenberg]:

Der Besuch. Ein kleines Schauspiel furr junge Frauenzimmer. 1759. [D-BSPK, DFGM, A-WÖN, A-WUB

Dohm, Hedwig. 1833 (Berlin) - 1919 (Berlin). Geb. Schlee: Die Ritter vom goldenen Kalb. Lustspiel in 1 A. 1879. (D-BDS, D-GSU, DWeiZdK, GB-LBL

Der Schuß ins Schwarze. Lustspiel in 1 A, 1878. \{D-BDS, D-EWA

Der Seelenretter. Lustspicl in 1 A. 1875. \{D-BDS, D-BUB, D-WeiZdK, A-WÖN, A-WUB, NN\}

Vom Stamme der Asra. Lustspicl nach dem Spanischen. 1876. \{D-BDS, D-HHU-T, D-KöTM, D-TS, D-WeiZdK, A-WÖN, GB-LBL\}

Dornheim = Pseudonym für: Schwarzburg-Sondershausen, Mathilde Fürstin von

Dressel, C. = Pseudonym für: Dressel, Clara.

Dressel, $\mathrm{Carl}=$ Pseudonym für: Dressel, Clara.

Dressel, Clara. 1850 (Stettin) - nach 1912. Pseudonyme: C. Dressel, Carl Dressel: Der Allerweltsfreund. Lebensbild in 4 A. 1885. \{D-BSPK, D-SiS\}

Droste-Hülshoff, Annette von. 1797 (Schloß Hülshoff bei Münster i. W.) - 1848 (Meersburg/Bodensee). Pseudonyme: v. D. . . H. ..., Annette Elisabeth: Babilon. Libretto. O. J. (Historisch-kritische Ausgabe XIII/1, 1982.) \{U. a. an: DBFU, D-DUB, D-FrU, D-FSU, D-GSU, D-MöS, D-MrU, D-TUB-G, A-GUB, $\mathrm{CH}-\mathrm{AK}, \mathrm{CH}-\mathrm{ZDS}, \mathrm{OCU}\}$

Bertha oder die Alpen. Trauerspiel in 3 A. [Fragment]. 1814. (Historisch-kritische Ausgabe VI/1, 1982.) \{U. a. an: D-ASU, D-BDS, D-BFU, D-BGS, D-BoU, D-BS, DDeLL, D-DoU, D-DU, D-DUB, D-ENU, D-ES, D-EU, D-EWA, D-FrU, DFSU, D-GÖ, D-GSK, D-GSU, D-HBFU, D-HHSU, D-HUL, D-KaMB, D- 
KöTM, D-LDB, D-MarSN, D-MaU, D-MöS, D-MrU, D-MüS, D-MüU, D-PaU, D-PBH, D-PS, D-PUB, D-SHH, D-SiU, D-SO, D-SS, D-SWA, D-TUB, DTUB-G, D-WeiZdK, D-WüSMH, D-WuU, D-SG, A-GUB, CH-AK, CH-FTK, CH-SZ, CH-ZDS, AU, CU, DLC, ICarbS, IEN, IU, KAS, MH, MiEM, MiU, $\mathrm{MtU}, \mathrm{NcD}, \mathrm{NcU}, \mathrm{NhD}, \mathrm{NjR}, \mathrm{NN}, \mathrm{NNC}, \mathrm{ODW}, \mathrm{OU}, \mathrm{PBm}, \mathrm{PSC}, \mathrm{PSt}, \mathrm{PURPB}$, $\mathrm{TxU}, \mathrm{ViU}\}$

Der blaue Cherub. Libretto. (Historisch-kritische Ausgabe XIII/1, 1982.) \{U. a. an: DBFU, D-FrU, D-GSU, D-MöS, D-MrU, D-TUB-G, A-GUB, CH-AK, OCU\}

Dramatische Versuche. (Gesammelte Werke, hg. Elisabeth v. Droste-Hülshoff, 3 Bde., Paderborn: Schöningh, 1900-6.) \{D-BFU, D-BHU, D-FrU, D-FSU, D-HUL, D$\mathrm{MrU}\}$

Dramatisches. (Gesammelte Schriften, hg. L. Schücking, Bd. 3, Stuttgart: Cotta, 1899.) \{U. a. an: D-BFU, D-BHU, D-BoU, D-HUB, D-HUL, D-LDB, D-SU\} Der Galeerensklave. Schauspiel. [Fragment]. Vor 1837. \{U. a. an: D-DeLL, D-DUB, D-GÖ, D-GSK, D-MöS, D-PS, D-SHH, D-SWA, D-SG, OCU\}

Hedwig und Sophie oder Verzweiflung und Rache. [Fragment]. (Historisch-kritische Ausgabe VI/1, 1982.) \{U. a, an: D-BDS, D-BFU, D-BoU, D-BS, D-DoU, D-DU, D-DUB，D-ENU，D-EU，D-FrU，D-FSU，D-GSU，D-HBFU，D-HHSU，DMarSN, D-MaU, D-MöS, D-MrU, D-MüU, D-PaU, D-PUB, D-SiU, D-SO, DSS, D-TUB, D-TUB-G, D-WeiZdK, D-WüSMH, D-WuU, A-GUB, CH-AK, CH-FTK, CH-SZ, CH-ZDS, AU, DLC, ICarbS, MiEM, MtU, NcD, NhD, NjR, NN, ODW, PSC, PSt, TxU, ViU\}

König Erich/Gustav Wasa. Oper. [Fragment]. O. J.

Perdu! oder Dichter, Verleger und Blaustrimpfe. Lustspiel in 1 A. 1840. (Historischkritische Ausgabe VI/1, 1982.) \{U. a. an: D-AS, D-ASU, D-BDS, D-BFU, D-BGS, D-BHS, D-BHU, D-BoU, D-BS, D-CS, D-DeLL, D-DoU, D-DU, D-DUB, DENU, D-ES, D-EU, D-EWA, D-FrU, D-FS, D-FSU, D-GÖ, D-GSK, D-GSU, DHBFU, D-HHSU, D-HUL, D-KaMB, D-KöTM, D-LDB, D-LeS, D-MarSN, DMaU, D-MöS, D-MrU, D-MüS, D-MüU, D-PaU, D-PBH, D-PS, D-PUB, DSHH, D-SiU, D-SO, D-SS, D-SU, D-SWA, D-TUB, D-TUB-G, D-WeiZdK, DWüSMH, D-WuU, D-SG, A-GUB, CH-AK, CH-FTK, CH-SZ, CH-ZDS, AU, CU, DLC, ICarbS, IEN, IU, KAS, MH, MiEM, MiU, MtU, NcD, NcU, NhD, NjR, NN, NNC, OCU, ODW, OU, PBm, PSC, PSt, PU, RPB, TxU, ViU\}

Das Rathsel oder Wie viele Pfund Freyer gehen auf 1 Pfund Nehmer. Antwort: Keins denn sie fliegen alle davon. [Fragment]. (Historisch-kritische Ausgabe VI/1, 1982.) \{U. a. an: D-BFU, D-BoU, D-BS, D-DeLL, D-DoU, D-DU, D-DUB, D-ENU, DEU, D-FrU, D-FSU, D-GSU, D-HBFU, D-HHSU, D-MarSN, D-MaU, D-MöS, D-MrU, D-MüU, D-PaU, D-PUB, D-SiU, D-SO, D-SS, D-TUB, D-TUB-G, DWeiZdK, D-WüSMH, D-WuU, A-GUB, CH-AK, CH-FTK, CH-SZ, CH-ZDS, AU, DLC, ICarbS, MiEM, MtU, NcD, NhD, NjR, NN, ODW, PSC, PSt, TxU, ViU\}

Scenen aus Hülshoff. [Fragment]. (Historisch-kritische Ausgabe VI/1, 1982.) \{U. a. an: D-BFU, D-BoU, D-BS, D-DeLL, D-DoU, D-DU, D-DUB, D-ENU, D-EU, D-
FrU, D-FSU, D-GSU, D-HBFU, D-HHSU, D-MarSN, D-MaU, D-MöS, DMrU, D-MüU, D-PaU, D-PUB, D-SiU, D-SO, D-SS, D-TUB, D-TUB-G, DWeiZdK, D-WüSMH, D-WuU, A-GUB, CH-AK, CH-FTK, CH-SZ, CH-ZDS, AU, DLC, ICarbS, MiEM, MtU, NcD, NhD, NjR, NN, ODW, PSC, PSt, TxU, $\mathrm{ViU}\}$

Die Wiedertäufer. Trauerspiel mit Musik [Fragment, nicht erhalten]. Um 1837. (Etwas Musik und Motive in Historisch-kritische Ausgabe XIII/1, 1982.) \{U. a. an: D-BFU, D-DUB, D-FrU, D-FSU, D-GSU, D-MöS, D-MrU, D-TUB-G, CH-AK, OCU\}

Musik und etwas Text zu einer geplanten Oper Johann von Leiden. Um 1837.

Druskowitz (von Calagis), Helene von. 1858 (Hietzing bei Wien) - 1918 (MauerÖhling bei Salzburg). Pseudonyme: E. René, Erna, Adalbert Brunn, Sacrosanct, H. Foreign, H. Sakkorausch:

Aspasia. Lustspiel in 5 A. 1889. \{D-KöTM\}

Dramatische Scherze. 1889. \{D-Kö'T'M, CH-ZZ\}

Einsamkeit - das einzige Glück. Dramatischer Scherz. 1889. (Dramatische Scherze. 1899.) \{D-KöTM, CH-ZZ\}

Die Emancipations-Schwarmerin. Lustspiel in 5 A. 1889. (Drarnatische Scherze. 1899.) $\{\mathrm{D}-\mathrm{KöTM}, \mathrm{CH}-\mathrm{ZZ}\}$

Er dozirt. Dramatischer Scherz. 1889. (Dramatische Scherze. 1899.) \{D-KöTM, $\mathrm{CH}-\mathrm{ZZ}$ \}

International. Lustspiel. 1891. \{D-BDS, D-KöTM, D-WeiZdK\}

Die Pädagogin. Lustspiel in 3 A. 1890. \{D-BDS, D-FSU, D-KöTM, D-WeiZdK\}

Der Präsident vom Zither-Club. Original-Posse in 4 A. Um 1890. \{D-BSPK\}

Sultanin und Prinz. Trauerspicl in 5 A. 1881. \{D-WeiZdK, A-WUB, CH-ZZ\}

Unerwartet. Dramatischer Scherz. 1889. (Dramatische Scherze. 1899.) \{D-KöTM, $\mathrm{CH}-\mathrm{ZZ}\}$

Dubsky, Marie Gräfin von = Ebner-Eschenbach, Marie Freifrau yon.

Düdemsee, Elfriede von der $=$ Hyno, Elfriede von .

Dumpf (auch Dumpff), Karoline $=$ Stahl, Karoline.

Duncker, Dora. 1855 (Berlin) - 1916 (Berlin):

Assarpai. Oper in 3 A. Libretto. 1895. \{DLC, MB, MH\}

Ermte. Schauspiel, 1902

Freund der Frauen. Lustspiel von Alexandre Dumas. Übers. 1891. \{D-EWA\} Gesiuhnt. Volksschauspiel. 1905.

Gewitterschauer. Lustspiel. 1891.

Gustav Wöhrmann. Schauspiel. 1903. \{D-BHU, D-WeiZdK, A-WÖN\}

Der heilige Berg. Opernlibretti. 1911.

Hexen-Lied. Opernlibretto. 1899. 
Im Schatten. Schauspiel. 1899. \{D-WeiZdK\}

Die kleine Hoheit. Lustspiel in 3 A. 1913. \{D-BDS, D-BH, D-HHU-T, D-KöTM,

DLC)

Maria Raimund. Schauspiel. 1895.

Nelly. Lustspiel. 1884. (D-DeLL, D-KöTM, D-WeiZdK\}

Die neue Geliebte. Einakter. 1908.

Die neue Zeit. Volksstück. 1909.

Ruth. Schauspiel in 4 A. 1891. \{D-HHU-T, D-KöTM\}

Die Schneekönigin. Märchenspiel mit Vorspiel und 3 A. nach H. C. Andersen. 1910.

\{D-BHU, D-KöTM, D-LDB [Mikrokarte], A-WÖN, DLC, NN\}

Sphinx. Schauspiel in 4 A. 1881. (D-BSPK, D-KöTM, D-WeiZdK\}

Sylvia. Schauspiel. 1883. \{D-HHU-T, D-WeiZdK\}

Um ein Haar. Plauderei in 1 A. 1886. \{Als Regiebuch in D-HHU-T; D-KöTM\}

Vor Tores Schluß. Versspiel [?]. 1904.

Wir tanzen durchs Leben. Posse. 1911.

Dungern, Julie von. 1822 (Augsburg) - 1886 (Mannheim):

Ein untröstlicher Wittwer. Lustspiel in 3 A. von O. Feuillet. Freie Bearb. 1869. \{DKöTM, D-WeiZdK, NN]

E. T. P. A. = Pseudonym für: Maria Antonia Walpurgis, Kurfürstin von Sachsen.

Eberhardt-Bürck, Adelheid Babette Emilie. 1836 (Schönau bei Heidelberg) - 1914 (Karlsruhe). Geb. Bürck:

Hildegarde. Drama nach einer Rheinsage. 1876. \{D-BSPK, CH-BSL, CH-LZ\}

Maria die Kleidermacherin (oder: Maria. Die Kleidermacherei.) Drama [?]. 1885. FFehlt an DLC und OCl\}

Eberty, Babette $=$ Bülow, Babette von

Ebner-Eschenbach, Marie Freifrau von. 1830 (Zdislawice, Mähren) - 1916 (Wien). Geb. Dubsky:*

Am Ende. Szene in 1 A. 1900. (Samtliche Werke I, o. J.) \{D-BDS, D-BFU, D-BHU, D-BiR, D-BoS, D-BoU, D-BUB, D-CS, D-DeLL, D-DoB, D-DoU, D-DSB, DES, D-FTT, D-HeS, D-HUB, D-KöTM, D-LDB, D-MaU, D-MSDA, D-MüS, DNeKW, D-PBH, D-PS, D-RDPH, D-RoU, D-RS, D-TUB-G, D-WeiZdK, DWüU, D-WuS, A-GUB, A-WÖN, A-WUB, CH-LZ, CH-ZDS, GB-LBL, AU, CLSU, GEU, ICarbS, ICN, KyU, MdU, MiU, NcU, NhD, NRU, OrPR, PSt, PU, $\mathrm{RPB}, \mathrm{ScU}, \mathrm{TU}, \mathrm{ViU}, \mathrm{WaWW}, \mathrm{WU}\}$

Aphorismen, Erzäblungen, Theater. [Wien: Böhlau, 1988]. \{D-FrU, D-LKM\}

Doctor Ritter: Dramatisches Gedicht in 1 A. 1869. \{D-BDS, D-HeBO, D-KöTM, D-MarLA, D-MarSN, D-SiS, D-WeiZdK, A-WÖN, A-WUB\}

* D-MSDA besitzt nicht näher bezeichnete Dramen der Autorin.
Es wandelt niemand ungestraft unter Palmen. Dram. Sprichwort. 1900. $\{\mathrm{NhD}\}$ Genesen. Dialogisierte Novelle. Um 1902. \{D-WeiZdK, NhD\}

Das Geständnis. Drama. 1864

Die Heimkehr. Anderer Titel von: Mutter und Braut.

Henri de Cinq-Mars. Historische Tragödie. Um 1845.

Ihre Schwester: Drama? (Deutsche Rundschau 117, 1903) \{D-ABTH, D-DoB, DDUB, D-DZB，D-ES，D-KöUSB，D-MöS，D-MüU，D-TS，D-WeiZdK，DWHLB, D-WüU, D-WuS, A-WÖN\}

Jacobäa von Jülich-Cleve. Fragment. Um 1863.

Männertreue. Lustspiel in 3 A. 1873. (Der Merker 3, 1912.) (D-DoB, D-DUB, DMarLA, A-WÖN

Maria Stuart in Schottland. Historische Tragödie. 1860. (D-BDS, D-WeiZdK, AWLA, A-WÖN\}

Marie Roland. Trauerspiel in 5 A. 1867. (D-MarLA, D-MarSN, D-WeiZdK, AWÖN, A-WUB\}

Mutter und Braut. 1861.

Ohne Liebe. Dialogisierte Novelle. 1898. (Sämtliche Werke II, o. J.) \{D-BiR, D-BoU, D-BoS, D-CS, D-DeLL, D-DoB, D-DSB, D-ES, D-EWA, D-FTT, D-KaMB, DKöTM, D-LDB, D-MaU, D-MüS, D-NWS, D-PS, D-RDPH, D-RS, D-SHL, DTUB-G, D-TüU, D-WeiZdK, D-WüU, D-WuS, A-GUB, A-WÖN, CH-LZ, CHZDS, GB-LBL, AU, GEU, ICarbS, ICN, KyU, MdU, MiU, NcU, NhD, NRU, OrPR, PSt, PU, RPB, ScU, TU, ViU, WaWW, WU, WW]

Obne Liebe. Lustspiel in 1 A. 1891. (D-HUB, D-LDB, D-MarSN, D-WeiZdK, AWÖN, ICU, WU

Die Prinzessin von Banalien. Dramatisches Märchen. 1872. \{D-BHU, D-BoU, DBUB, D-BZL, D-DeLL, D-DoU, D-ES, D-FTT, D-LDB, D-MSDA, D-MüS, DWS, A-GUB, A-SUB, A-WNS, A-WÖN, A-WUB, CH-LZ, GB-LBL

Richelieu. Fragment. Um 1845.

Die Schauspielerin. Künstlerdrama in 3 A. 1861.

Die Selbstsiichtigen. Lustspiel in 3 A. 1867-70.

Ein Sportsmann. Dialogisierte Novelle in 1 A. 1902. (D-BDS, D-WeiZdK, NhD) Untröstlich. Lustspiel in 1 A. Um 1874.

Die Veilchen. Lustspiel in 1 A. 1864. \{D-MarLA, D-MarSN, D-WeiZdK, A-WÖN, A-WUB\}

Das Waldfräulein. Lustspiel in 3 A. 1873. \{D-FSU, D-MarSN, A-GUB, InU\}

Zwei Frauen. Drama. Nach 1902. \{D-WeiZdK\}

Zwei Schwestern. Drama in 1 A. Nach 1902.

Eckert = Pseudonym für: Kautsky, Min(n)a.

Egbert, W. = Pseudonym für: Grieben, Ferdinande.

Egerváry, Marianne = Neumann von Meißenthal, Marianne. 
Ehrmann, Marianne. 1755 [Kosch: 1735] (Rapperswyl/Züricher See?) - 1795 (Stuttgart). Geb. von Brentano. Bühnenname: [Maria Anna Antonia] Sternheim. Pseudonyme: Verfasserin der Amalia, Verfasserin der Philosophie eines Wcibes:

Graf Bilding, eine Geschichte aus dem mittleren Zeitalter. Dialogisierte Geschichte. 1788. \{GB-LBL\}

Leichtsinn und gutes Herz oder die Folgen der Erziehung. Schauspiel in 5 A. 1786. (Neuausg. hg. Wurst 1991.) \{D-KöTM, D-TS\}

Eichler, Caroline. 1856 (Regensburg) - ? Geb. Crané. Gesch. Häußer (Pataky: Häusser):

Der Bergschreck. Volksstück mit Gesang in 4 A. (Musik v. Hermann Müller.) 1887. 's Resei. Genrebild aus dem Gebirge. [Drama?]. 1884.

Elisa = Pseudonym für: Recke, Elisa von der.

Elisabeth $=$ Pseudonym für: Grube, Elisabeth .

Elisabeth Pauline Ottilie Luise, Königin von Rumänien. 1843 (Neuwied) - 1916 (Arges bei Bukarest). Geb. Fürstin Wied. Pseudonyme: Carmen Sylva, C. Wedi, Dito:

Am Verfalltag. Drama in 1 A. O. J. (Frauenmut. 1890.) \{GB-LBL\}

Anna Boleyn. Historische Tragödie (mit Kremnitz, Marie von). 1886. (D-BDS, DBUB, D-FSU, D-LGS, D-LKM, D-MarSN, D-WeiZdK, A-WÖN, PPLT\}

Die beiden Masken. Drama von Paul de Saint-Victor. Übers. 1899/1900. \{D-BDS, D-RoU, GB-LBL\}

Dämmerung. Schauspiel in 1 A. 1889. (Frauenmut. 1890.) \{GB-LBL\}

Frauenmut. Dramensammlung. 1890. (D-BDS, D-BoU, D-BUB, D-HUB, DKöUSB, D-LH, D-LKM, GB-LBL

Geschreckt und geneckt. Lustspiel in 1 A. O. J. Übers. ihres Revenants et revenus von Carl von Stengel. \{Handschrift in D-SiS

Herrn Daniels Wittwen. Schwank in 1 A. O. J. (Frauenmut. 1890.) \{GB-LBL

Die Jungfrau von Orléans. Opernlibretto. O. J.

Louise. Dramatische Dichtung in 1 A. O. J. (Frauenmut. 1890.) $\{\mathrm{GB}-\mathrm{LBL}\}$

Marioara. Drama in 3 A. O. J. (Frauenmut. 1890.) \{GB-LBL\}

Meister Manole. Schauspiel. 1892. (D-BHU, D-BUB, D-HUB, D-LKM, DMarSN, D-WHLB, A-WÖN, GB-LBL, CU, IaU\}

Mitra. Drama [?], [Zusammen mit Marie von Kremnitz?]. 1887. [A-WUB]

Revenants et revenus. Drama. O. J. \{D-SiS\}

Ullranda. Drama in 1 A. Um 1890. (Frauenmut. 1890.) \{D-FSU, D-KöTM, GBLBL

Ullranda und andere dramatische Dichtungen. 1890. (Anderer Titel von: Frauenmut.) \{D-BoU, D-BUB, D-HeS, D-KöUSB, D-MarSN, GB-LBL

Zwei Dramenfragmente. Titel nicht ermittelt (Wolbe 207).

Weitere Stücke in Zusamimenarbeit mit Marie yon Kremnitz?

\section{Elise $=$ Pseudonym für: Recke, Elisa von der}

Ellmenreich, Friederike Christiana. 1777 [Goedeke: 1775] (Köthen/Anhalt) - 1845 (Schwerin i. M.). Geb. Brandl. Gesch. Mayer. Veröffentlichte auch anonym: Beatrice di Tenda, oder Das Castell von Binasco. Große Oper in 4 A. nach Felice Romani. Libretto. 1839.

Die beiden Nächte. Oper in $3 \mathrm{~A}$. frei nach Bouilly und Scribe. Libretto. 1830. \{DBS\}

Die beiden Witwen, oder Der Kontrakt [Goedeke: Kontrast]. Lustspiel in 1 A. 1822 (Lustspiele. Frei nach dem Französischen bearbeitet. 1827.) \{A-WÖN\}

Das beste Loos ein Mann. Lustspiel in 1 A. 1827. (Lustspiele. Frei nach dem Französischen bearbeitet. 1827.) \{A-WON\}

Der Blitz. Komische Oper in $3 \mathrm{~A}$. nach Planard und Saint-Georges. Libretto. 1836. \{D-BDS, D-ENU, D-FSU, D-SPL, A-WÖN\}

Die Braut. Oper in 3 A. nach Scribe. Libretto. 1832. \{D-FrU\}

Der Deserteur. Oper in 1 A. Libretto. O. J.

Emma, oder Das unbedachtsame Versprechen. Ländliche Oper in 3 A. nach Planard. Libretto. 1825. \{D-ASS, D-RoU\}

Die Englidnder auf Reisen. In 1 A. 1848.

Der entfiibrte Offizier. Lustspiel in 1 A. 1823. (Lustspiele. Frei nach dem Französischen bearbeitet. 1827.) \{A-WÖN\}

Fiorella. Oper in 3 A. nach Scribe. Libretto. O. J.

Die Fremde. Oper in 2 A. Libretto von Felice Romani. Übers, 1832. [D-BS, DFGM, D-WoHA]

Die Gesandtin. Komische Oper in 3 A. Frei nach Scribe. Um 1836.

Der Großpapa. Lustspiel in 1 A. nach Scribe und Mélesville [Pseud. für: Anne Honoré Joseph Bon Duveyrier]. 1824. (Lustspiele. Frei nach dem Französischen bearbeitet. 1827.) \{A-WÖN\}

Ein Hausirer. Oper in 3 A. Libretto. Frei nach dem Französischen. 1828.

Heirath vor hundert Jahren. Lustspiel mit Gesang in 1 A. nach dem Französischen. 1852.

Die Jüdin. Große Oper in 5 A. nach Scribe. Libretto. 1845. [D-BSPK, D-FSU, DHHSU, D-SPL, D-WoHA, A-WÖN\}

Das Konzert am Hofe. Komische Oper in 1 A. nach Scribe und Mélesville [Pseud. für: Anne Honoré Joseph Bon Duveyrier]. Libretto. 1825. Musik von Auber: \{Handschrift in D-ASS; D-BS\}

Die Kreuzritter in Ägypten. Große heroische Oper in 2 A. Libretto von Gaetano Rossi. Übers. 1807? \{D-BSPK, D-FrU\}

Leocadia. Lyrisches Drama in 3 A. nach Scribe. 1825. \{D-ASS, D-RoU\}

Der letzie Tag von Pompeji. Oper in 2 A. nach Pottola. Libretto. O. J.

Die Männerlotterie. Ursprünglicher Titel von: Das beste Loos ein Mann. Marie. Oper in 3 A. nach Bayard und Saint-Georges. Libretto. 1832. \{D-FGM\} Der Maurer (und der Schlosser). Oper in 3 A. nach Scribe. Libretto. O. J. \{D-DeLL; 
unter dem Titel: Maurer und Schlosser in D-KaMB; D-SPL, A-WÖN; Gesänge aus der Oper in D-ZR\}

Michel und Christine. Lustspiel in 1 A. 1827. (Lustspiele. Frei nach dem Französischen bearbeitet. 1827.) \{A-WÖN

Die Montecchi und Capuleti. Anderer Tïtel für: Romeo und Julie. \{Unter diesem Titel in CH-BSL\}

Moses. Große Oper in 4 A. Libretto. Übers. aus dem Französischen. 1828. \{Arien und Gesänge aus der Oper in D-DGM

Die Nachtwandlerin. Große Oper in 2 A. nach Felice Romani. Libretto. 1838. \{DDeLL, D-KöUSB, D-SPL, A-WÖN\}

Die Nachtwandlerin. Lustspiel in 2 A. nach Scribe. 1825. (Lustspiele, Frei nach dem Französischen bearbeitet. 1827.) \{D-BHU, D-BSPK, D-HUL, D-MBS, A-WÖN, AWUB, CH-LZ\}

Der Postillon von Lonjumeau. Komische Oper in 3 A. nach Leuwen und Brunswick. Libretto. 1837. \{D-FrU, D-SPL, D-WoHA, CH-BSL\}

Die Puritaner. Oper in 3 A. nach Pepoli. Libretto. 1836. \{D-BSPK, D-FGM, DMBS\}

Röschens Aussteuer, oder Das Duell. Lustspiel in 3 A. nach einer französischen Oper. 1823. (Lustspiele. Frei nach dem Französischen bearbeitet. 1827.) (D-HHU-T, AWÖN\}

Romeo und Julie. Oper in $2 \mathrm{~A}$, und 4 Abteilungen nach Felice Romani. Libretto. 1837. \{D-BS, D-FrU, CH-LZ; in CH-BSL unter dem Titel: Die Montecchi und Capuleti\}

Der Schnee, oder Der neue Eginhard. Oper in 4 A. nach Scribe und Delavigne. Libretto. 1824.

Der Seeräuber. Oper in 2 A. nach Felice Romani. Libretto. 1830.

T. F oder der Enthusiast. Posse in 1 A. nach dem Französischen. 1843

Der Vampyr. Posse in 1 A. nach Scribe und Mélesville [Pseud. für: Anne Honoré Joseph Bon Duveyrier]. 1827. (Lustspiele. Frei nach dem Französischen bearbeitet. 1827.) $\{$ A-WÖN\}

Der Währwolf. Oper in 1 A. nach Scribe und Mélesville [Pseud. für: Anne Honoré Joseph Bon Duveyrier]. Libretto. Musik von Johann Strauß. 1832.

Die weiße Dame. Komische Oper in 3 A. nach Scribe. Libretto. O. J. \{D-BDS, D-

BS, D-ENU, D-EWA, D-FSU, D-HHSU, D-MrU, D-RoU, D-SPL, D-WeiZdK,

D-WoHA, A-WÖN; Gesänge und Arien aus der Oper in D-DGM, D-ZR\}

Zampa, oder Die Marmorbraut. Oper in 3 A. nach Mélesville [Pseud. für: Anne

Honoré Joseph Bon Duveyrier]. Libretto. 1832. \{D-BHU, D-BSPK, D-DeL,L, D-

EWA, D-FGM, D-FSU, D-KaMB, D-SPL, A-WÖN\}

Emilie $=$ Pseudonym für: Zitz, Katharina Rosa Therese Pauline Modesta

Emmeline $=$ Pseudonym für: Zitz, Katharina Rosa Therese Pauline Modesta.

Enders, August $=$ Pseudonym für: Zitz, Katharina Rosa Therese Pauline Modesta.
Enkelin der Karschin = Pseudonym für: Chézy, Wilhelmine von

Erna $=$ Pseudonym für: Druskowitz, Helene von.

Ernest, Marie von = Vaselli, Marie von.

Eschstruth, Nataly Auguste Amalie Hermine von. 1860 (Hofgeismar) - 1939 (Schwerin). Verh. von Knobelsdorff-Brenkenhoff:

Der Eisenkopf. Schauspiel. 1884.

In des Königs Rock. Drama. 1882

Der kleine Rittmeister. Schauspiel. 1883. (Die Sturmnixe und andere Dramen. 1895.)

\{D-BDS, GB-LBL

Die Obotriten. Drama. O. J. (Die Sturmnixe und andere Dramen. 1895.) \{GB-LBL\}

Die Ordre des Grafen von Guise. Schauspiel in 1 A. 1884.

Pirmasenz oder: Karl August's Brautfahrt. Lustspiel in 3 A. 1883. (A. Kühlings VolksSchaubuihne 55; Die Sturmnixe und andere Dramen. 1895.) (D-BDS, D-HPi, D$\mathrm{MrU}, \mathrm{D}-\mathrm{Pi}, \mathrm{GB}-\mathrm{LBL}\}$

Sie wird geküßt. Schwank in $4 \mathrm{~A}$. Mit Hermann Anderten. 1888. \{D-HHU-T, DKöTM\}

Die Sturmnixe. Schauspiel. 1883. (Die Sturmnixe und andere Dramen. 1895.) \{GBLBL\}

Die Sturmnixe und andere Dramen. 1895. \{GB-LBL\}

Eugenie $=$ Pseudonym für: Zitz, Katharina Rosa Therese Pauline Modesta.

Euphrosyne $=$ Pseudonym für: Krickeberg, Sophie Friederike

F, Eleonore $=$ Pseudonym für: Gersdorf, Wilhelmine von.

F., L. v. = Pseudonym für: François, Louise von.

Faber, Luise $=$ Hölder, Luise

Fabricius, Anna Cäcilie. 1747 [Kosch: 1771] (Flensburg) - 1820 (Kiel). Geb. Ambrosius:

Heinrich der Vielgeliebte oder Die Würde der Protestanten. Schauspiel. 1802. \{DWoHA\}

Fahrig, Clara. 1848 (Ronneburg bei Altenburg) - 1905 (Loschwitz bei Dresden). Geb. Gerhard. Pseudonyme: A. L., Alma Leschivo:

Don Juan d'Austria. Schauspiel. 1884. \{D-BSPK\}

Julius von Braunschweig. Historisches Schauspiel. 1884. \{D-BSPK\}

Keine Ehe ohne Liebe. Lustspiel. 1884 
Fallsen [auch Falsen], Christine de $=$ Harboe, Christine von.

Fanny = Pseudonym für: Tarnow, Franziska Christiane Johanna Friederike.

Fasching, Anna. 1847 (Dienten/Österreich) - 1919 (Straßwalchen/Österreich):

Theaterstücke oder Bearbeitungen von Dramen für Kinder- und Mädchenbühnen (Feichtlbauer 153)

Fels, Franz $=$ Pseudonym für: Birch-Pfeiffer, Charlotte.

Felz, Catharina Salome $=$ Link, Catharina Salome

Festner, Auguste Sophie = Schröder, Auguste Sophie.

Fick, Maria Sophie Christiane von $=$ Plessen, Maria Sophie Christiane von,

Fink, Luise Charlotte von $=$ Krause, Luise Charlotte.

Fittchersvogel $=$ Pseudonym für: Grimm, Gisela.

Fittchersvogel, Marilla = Pseudonym für: Grimm, Gisela

Flamm, Wilhelmine. 1845 (Bad Cannstadt/Württemberg) - 1922 (Pfullingen/ Württemberg). Geb. Link:

Liebesränke. Lustspiel in 3 A. 1882. \{D-FSU, D-SiS\}

Das verhängnißßvolle Schloß oder der Wandschrank als Brautwerber. Schwank in 1 A nach einer alten Humoreske. O. J. \{Handschrift in D-SiS\}

Yrsa. Dramatisches Gedicht in 5 A. 1881. \{D-BSPK, D-FSU; unter dem Titel Ursa in D-KöTM

Flügel, Bertha = Hoffmann, Bertha.

Fölsch, Auguste von $=$ Goldstein, Auguste Freiin von.

Förster, Maria Laura. 1817 (Dresden-Neustadt) - 1856 (Dresden):

Nicht genannte Dramen [Groß, Deutschlands Dichterinen 154].

Foreign, H. = Pseudonym für: Druskowitz, Helene von.

Forstenheim, $A .=$ Pseudonym für: Hirschler, Anna.

Forstenheim, Anna = Pseudonym für: Hirschler, Anna

Forster, Helene von. 1859 (Nürnberg) -1923 (Nürnberg). Geb. Schmidemer (Pataky: Schmidmer):

Das Burgweiblein. Festspiel. 1902.
Im Hause Martin Behaims. Drama. 1907.

Zweiter Bayrischer Frauentag in Nürnberg. Festspiel zum 13, 4. 1901. \{D-BDSV\}

Eine kleine Komödie „zu einer Feier des 'Peynesischen Blumenordens'“ (Pataky I,

221). Um 1893/4.

Forster, Therese $=$ Huber, Therese.

Fouqué, Karoline de la Motte = Motte-Fouqué, Karoline de la

François, Marie Louise von. 1817 (Magdeburg) - 1893 (Trier). Pseudonyme: L. v. F, F. v. L.:*

Der Posten der Frau. Lustspiel in 5 A. 1881. \{D-BHU, D-FSU, D-LKM, D-MarSN, D-TS, A-WÖN, TNJ\}

Frank, Ulla = Pseudonym füı: Wolff, Ulla.

Frank, Ulrich = Pscudonym für: Wolff, Ulla.

Franklin, Susanue von = Bandemer, Susanne von.

Franul von Weißenthurn, Johanna Rahel Theresia Veronika. 1772 [Groß, Deutschlands Dichterinen: 1773] (Koblenz) - 1847 [Groß, Deutschlands Dichterinen: 1845] (Hietzing bei Wien). Geb. Grünberg. Pseudonym: Johanna Weißenthurn:

Adelheid, Markgräfinn von Burgau. Romantisches Schauspiel in 4 A. 1806. (Schauspiele IV, 1810.) (D-BUB, D-CorFB, D-DeLL, D-FSU, D-GSU, A-WÖN, AWUB, CH-BSU, GB-LBL, MH, PU, WaU, WU\}

Agnes van der Lille, oder: Grausamkeit und Kindespflicht. Schauspiel aus dem niederländischen Befreiungskriege in $5 \mathrm{~A}$. nach einer Skizze bearb. 1819. (Schauspiele X, 1822.) (D-BUB, D-CorFB, D-DeLL, D-GSU, A-WÖN, A-WUB, CH-BSU, TNJ, WU\}

Alles aus Freundschaft. Lustspiel in 1 A. 1839. (Schauspiele XV, 1848.) \{D-BDS, DBUB, D-CorFB, D-DeLL, A-WÖN, A-WUB, TNJ, WU\}

Beschämte Eifersucht. Lustspiel in 3 A. 1801. (Schauspiele II, 1810.) (D-BSPK, DBUB, D-CorFB, D-DeLL, D-FSU, D-GSU, D-KöTM, D-KoS, D-MBS, A-WÖN, A-WUB, CH-BSU, GB-LBL, MH, PU, WaU, WU\}

Die Bestürmung von Smolensk. Romantisches Schauspiel in 4 A. 1808. (Schauspiele VI, 1810.) \{D-BSPK, D-BUB, D-CorFB, D-DeLL, D-FSU, D-GSU, A-WÖN, AWUB, CH-BSU, GB-LBL, IEN, MH, PU, WaU, WU\}

Der Bevollmächtigte. Lustspiel in 1 A. 1840 . Ungedr.

Die bezahlte Schuld. Sittengeschichte aus dem vorigen Jahrhundert in 4 A. 1845. Ungedr.

* Eine Ausgabe ihrer Gesammelten Werke, von der mir nicht bekannt ist, ob sie Dramen enthält, befindet sich in D-HUB, D-KH und CH-SZ. 
Der Brautschleier. Lustspiel in 1 A. 1832. (Schauspiele XIV, 1836.) (D-BUB, DCorFB, D-DeLL, D-GSU, A-WÖN, A-WUB, TNJ, WU\}

Die Burg Gölding. Romantisches Schauspiel in 5 A. 1826. (Schauspiele XII, 1829.) ' D-BDS, D-BH, D-BUB, D-CorFB, D-DeLL, D-GSU, A-WÖN, A-WUB, TNJ, WU\}

Clementine. Anderer Titel für: Die Versöhnung. \{D-BUB, D-DeLL, A-WUB\} Das Consilium. Lustspiel in 1 A. 1817. (Schauspiele X, 1822.) (D-BSPK, D-BUB, D-CorFB, D-DeLL, D-DUB, D-GSU, A-WÖN, A-WUB, TNJ, WU\}

Deutsche Treue. Schauspiel in 1 A. 1803. (Schauspiele I, 1810.) (D-ASS, D-BUB, DCorFB, D-DeLL, D-FSU, D-GSU, A-WÖN, A-WUB, CH-BSU, GB-LBL, MH, PU, WaU, WU\}

Die Drusen. Schauspiel in 4 A. O. J. [vor 1800]. (Schauspiele II, 1810.) \{D-BSPK, D-BUB, D-CorFB, D-DeLL, D-FSU, D-GSU, A-WÖN, A-WUB, CH-BSU, GBLBL, MH, PU, WaU, WU

Die Ehescheuen. Lustspiel in 1 A. 1808. (Schauspiele V, 1810.) (D-ASS, D-BSPK, DBUB, D-CorFB, D-DeLL, D-FSU, D-GSU, D-HHU-T, D-KöTM, D-KoS, AWÖN, A-WUB, GB-LBL, MH, PU, WaU, WU\}

Die Englanderin. Lustspiel in 1 A. 1824. (Schauspiele XI, 1826.) (D-BUB, DCorFB, D-DeLL, D-GSU, A-WÖN, A-WUB, TNJ, WU\}

Die Erben. Lustspiel in 4 A. 1803. (Schauspiele III, 1810.) \{D-ASS, D-BDS, D-BH, D-BUB, D-CorFB，D-DeLL, D-FSU，D-GSU, D-KoS, D-MBS，A-WÖN, AWUB, GB-LBL, MH, PU, WaU, WU\}

Die erste Liebe. Lustspiel in 3 A. 1808. (Schauspiele VI, 1810.) (D-BSPK, D-BUB, D-CorFB，D-DeLL，D-FSU, D-GSU, A-WÖN, A-WUB, CH-BSU, GB-LBL, MH, PU, WaU, WU

Der erste Schritt. Lustspiel in 4 A. 1833. (Schauspiele XIV, 1836.) (D-BDS, D-BUB, D-CorFB, D-DeLL, D-GSU, A-WÖN, A-WUB, TNJ, WU\}

Es spukt. Lustspiel in 2 A. 1810. (Schauspiele VII, 1817; Neueste Schauspiele I, 1823.) \{D-BUB, D-CorFB, D-DeLL, D-GSU, D-KöTM, A-WÖN, A-WUB, CH-BSU, WU\}

Die Fremde. Schauspiel in 5 A. 1838. (Schauspiele XV, 1848.) (D-BDS, D-BUB, DCorFB, D-DeLL, A-WÖN, A-WUB, TNJ, WU\}

Das Friihstïck. Lustspiel in $1 \mathrm{~A}$. nach dem Französischen. 1810. (Schauspiele IV, 1810.) (D-BDS, D-BUB, D-CorFB, D-DeLL, D-FSU, D-GSU, A-WÖN, AWUB, CH-BSU, GB-LBL, MH, PU, WaU, WU\}

Die Geprïften. Lustspiel in 5 A. 1834. (Schauspiele XIV, 1836.) (D-BDS, D-BUB, D-CorFB, D-DeLL, D-GSU, A-WÖN, A-WUB, TNJ, WU\}

Das Gut Sternberg. Lustspiel in 4 A. 1816. (Schauspiele IX, 1821.) \{D-BDS, D-BH D-BUB, D-CorFB, D-DeLL, D-GSU, D-KöTM, A-WÖN, A-WUB, CH-BSU, TNJ, WU\}

Ein Haus zu verkaufen. Lustspiel in 1 A. nach Duval. 1801. (Schauspiele I, 1810.) (D-ASS, D-BUB, D-CorFB, D-DeLL, D-FSU, D-GSU, A-WÖN, A-WUB, CHBSU, GB-LBL, MH, PU, WaU, WU\}
Hermann. Geschichtliches Schauspiel in 5 A. in Jamben. 1813. (Schauspiele VIII, 1817; Neueste Schauspiele II, 1823.) (D-BUB, D-CorFB, D-DeLL, D-GSU, AWÖN, A-WUB, CH-BSU, WU\}

Johann, Herzog von Finnland. Schauspiel in 5 A. 1810. (Schauspiele VII, 1817; Neueste Schauspiele I, 1823.) (D-BDS, D-BUB, D-CorFB, D-DeLL, D-GSU, DKöTM, A-WÖN, A-WUB, CH-BSU, WU\}

Kindliche Liebe. Schauspiel in 5 A. 1802. (Schauspiele I, 1810.) \{D-ASS, D-BSPK, D-BUB, D-CorFB, D-DeLL, D-FSU, D-GSU, A-WÖN, A-WUB, CH-BSU, GBLBL, MH, PU, WaU, WU\}

Künstler-Dank. Dramatische Szene. 1815. (Schauspiele VIII, 1817; Neueste Schauspiele II, 1823.) \{D-BUB, D-CorFB, D-DeLL, D-GSU, A-WÖN, A-WUB, CHBSU, WU\}

Das letzte Mittel. Lustspiel in 4 A. 1820. (Schauspiele XI, 1826.) (D-BUB, DCorFB, D-DeLL, D-GSU, D-HHU-T, D-KöTM, D-SPL, D-WHLB, A-WÖN, AWUB, ICRL, TNJ, WU, fehlt an MH und ViU\}

Liebe und Entsagung. Schauspiel in 3 A. 1801. (Schauspiele II, 1810.) (D-BSPK, DBUB, D-CorFB, D-DeLL, D-FSU, D-GSU, A-WÖN, A-WUB, CH-BSU, GBLBL, MH, PU, WaU, WU

Des Malers Meisterstick. Lustspiel in 2 A. 1831. (Schauspiele XIV, 1836.) \{D-BDS, D-BUB, D-CorFB, D-Del.L, D-GSU, D-KöTM, A-WÖN, A-WUB, TNJ, WU\} Ein Mann hilft dem andern. Lustspiel in 1 A. 1822. (Schauspiele XV, 1848.) (DBDS, D-BH, D-BUB, D-CorFB, D-DeLL, D-DonFFH, D-HHU-T, D-HUB, DWeiZdK, A-WÖN, A-WUB, GB-LBL, MH, TNJ, WU\}

Das Manuskript. Lustspiel in 5 A. 1826. (Schauspiele XIII, 1832.) (D-BDS, D-BUB, D-CorFB, D-DeLL, D-GSU, A-WÖN, A-WUB, TNJ, WU\}

Das Mißverständniß. Lustspiel in 1 A. 1804. (Schauspiele III, 1810.) (D-ASS, DBDS, D-BUB, D-CorFB, D-DeLL, D-FSU, D-GSU, D-KoS, A-WÖN, A-WUB, GB-LBL, MH, PU, WaU, WU

Das Nachspiel. Lustspiel in 1 A. Freie Bearb. 1800. (Schauspiele II, 1810.) (D-BDS, D-BUB, D-CorFB, D-DeLL, D-FSU, D-GSU, D-KöTM, A-WÖN, A-WUB, CHBSU, GB-LBL, MH, PU, WaU, WU\}

Pauline. Schauspiel in 5 A. 1825. (Schauspiele XIII, 1832.) \{D-BUB, D-CorFB, DDeLL, D-GSU, A-WÖN, A-WUB, TNJ, WU\}

Die Pilgerin. Lustspiel in 4 A. 1822. (Schauspiele XII, 1829.) (D-BDS, D-BUB, DCorFB, D-DeLL, D-GSU, A-WÖN, A-WUB, TNJ, WU\}

Die Radikalkur. Lustspiel in 3 A. 1805. (Schauspiele IV, 1810.) (D-ASS, D-BSPK, D-BUB, D-CorFB, D-DeLL, D-FSU, D-GSU, D-KöTM, D-MBS, A-WÖN, AWUB, CH-BSU, GB-LBL, MH, PU, WaU, WUY

Des Rathsherren Töchterlein. Lustspiel in 4 A. 185-?. (NN\})

Die Reise nach Amerika. Schauspiel in 1 A. 1824. (Schauspiele XI, 1826.) (D-BH, DBUB, D-CorFB, D-DeLL, D-GSU, A-WÖN, A-WUB, TNJ, WU\}

Die Reise nach Paris. Lustspiel in 4 A. 1828. Ungedr.

Der Reukauf. Lustspiel in 2 A. 1802. (Schauspiele I, 1810.) (D-ASS, D-BSPK, D- 
BUB, D-CorFB, D-DeLL, D-FSU, D-GSU, A-WÖN, A-WUB, CH-BSU, GBLBL, MH, PU, WaU, WU\}

Ruprecht, Graf zu Horneck. Trauerspiel in 5 A. 1820. (Schauspiele X, 1822.) \{DBUB, D-CorFB, D-DeLL, D-GSU, A-WÖN, A-WUB, TNJ; WU\}

Die Schweitzerbiutte am Rheinfall. Lustspiel in $1 \mathrm{~A}$, nach einer wahren Begebenhei im Jahre 1813. 1814. (Schauspiele VII, 1817; Neueste Schauspiele I, 1823.) \{D-BDS, D-BUB, D-CorFB, D-DeLL, D-GSU, D-KöTM, A-WÖN, A-WUB, CH-BSU, WU\}

Die Schwestern St. Janvier. Schauspiel in 5 A. nach einer wahren Begebenheit aus den Schreckenstagen auf St. Domingo. 1822. (Schauspiele IX, 1821.) \{D-BUB, DCorFB, D-DeLL, D-GSU, D-KöTM, A-WÖN, A-WUB, CH-BSU, 'TNI, WU

La Selva d'Hermanstadt. Melodramma. [Übersetzung ihres deutschen Originals Der Wald bey Herrmannstadt.] 1827. \{GB-LBL\}

Sie bilft sich selbst. Lustspiel in 4 A. 1842. (Schauspiele XV, 1848.) \{D-BDS, D-BUB, D-CorFB, D-DeLL, A-WÖN, A-WUB, TNJ, WU\}

So lohnt sich die Kunst. Vorspiel zum 4. Olst. 1829. (Schauspiele XII, 1829.) \{DBDS, D-BUB, D-CorFB, D-DeLL, D-GSU, A-WÖN, A-WUB, TNJ, WU\}

Die stille Braut. Alpensage in 1 A. 1842. (Schauspiele XV, 1848.) (D-BDS, D-BUB, D-CorFB, D-DeLL, A-WÖN, A-WUB, TNJ, WU

Das System. Lustspiel in 1 A. 1842. Ungedr.

Totila, König der Gothen. Schauspiel in 5 A nach Federici. 1804. (Schauspiele III 1810.) \{D-ASS, D-BUB, D-CorFB, D-DeLL, D-FSU, D-GSU, A-WÖN, A-WUB, GB-LBL, MH, PU, WaU, WU\}

Der Traum. Lustspiel in 1 A. 1824. (Schauspiele XI, 1826.) (D-BUB, D-CorFB, DDeLL, D-DUB, D-GSU, A-WÖN, A-WUB, TNJ, WU\}

Unterthanenliebe. Schauspiel in $2 \mathrm{~A}$. (Schauspiele IV, 1810.) \{D-BSPK, D-BUB, DCorFB, D-DeLL, D-FSU, D-GSU, A-WÖN, A-WUB, CH-BSU, GB-LBL, MH, PU, WaU, WU\}

Die Väter. Schauspiel in 5 A. 1844. Ungedr.

Versöbnung. Schauspiel in 3 A. nach Pelletier-Volméranges, 1806. (Schauspiele V, 1810.) (D-ASS，D-BUB，D-CorFB，D-DeLL，D-FSU，D-GSU，D-KöTM，AWÖN, A-WUB, GB-LBL, MH, PU, WaU, WU\}

Das Waisenhaus. Schauspiel in 2 A. O. J. (Schauspiele VI, 1810.) (D-BUB, DCorFB, D-DeLL, D-FSU, D-GSU, A-WÖN, A-WUB, CH-BSU, GB-LBL, MH, PU, WaU, WU\}

Der Wald bey Herrmannstadt. Romantisches Schauspiel in 4 A. nach dem Französischen. 1807. (Schauspiele V, 1810.) \{D-ASS, D-BUB, D-CorFB, D-DeLL, D-FSU, D-GSU, D-KöTM, D-KöUSB, D-MBS, A-WÖN, A-WUB, GB-LBL, MH, PU, WaU, WU\}

Welche ist die Braut? Lustspiel in 5 A. 1813. (Schauspiele VIII, 1817; Neueste Schauspiele II, 1823.) \{D-BUB, D-CorFB, D-DeLL, D-GSU, D-MarSN, A-WÖN, AWUB, CH-BSU, WU

Welcher ist der Bräutigam? Lustspiel in 4 A. 1816. (Schauspiele IX, 1821.) (D-BDS,
D-BUB, D-CorFB, D-DeLL, D-GSU, D-KöTM, A-WÖN, A-WUB, CH-BSU, TNJ, WU\}

Wer Herzen behält, hat nichts verloren. Schauspiel in 2 A. [Auch unter dem Titel: Unterthanenliebe] 1806. (Schauspiele IV, 1810.) \{D-BUB, D-CorFB, D-DeL.L, DGSU, A-WÖN, A-WUB, CH-BSU, GB-LBL, MH, PU, WaU, WU\}

Franz, Agnes Louise Antoinette Eleonore Constanze. 1794 (Militsch/Schlesien) 1843 (Breslau). Eigentl. Franzky. Veröffentlichte teilweise anonym:

Agnes Franz' letzie Geburtstagsfeier. Schauspiel. (Vermächtniß an die Jugend. 1845.) \{D-BHU, GB-LBL, MH, NN, PPG\}

Beiträge [dramatische?] zu Julie von Großmanns Feierabende fuir gute Kinder. 1844. $\{\mathrm{D}-\mathrm{KaMB}\}$

Buch für Kinder. 2 Bde. Sammlung von Dramen, Festspielen und Parabeln und Märchen, 1840. \{D-BHU, MH\}

Das gestörte Winzerfest. Liederspiel in 2 A. O. J. \{D-BDS, D-BHU, D-KöTM

Der Glückwunsch. Dramatisierte Charade in 3 Abteilungen. 1825.

Kinderschatz. [Neudruck von: Buch fur Kinder.] 1841. \{A-GUB\}

Kindertheater. 1840. \{D-CorFB, D-DUB, D-FTT, GB-LBL\}

Polterabends-Scenen. 1823. \{D-BUB\}

Der Roman. Lustspiel in $1 \mathrm{~A}$. und gereimten Alexandrinern. 1828.

Der Rosenstock oder das goldene Blatt. Drama in $1 \mathrm{~A}$. O. J. (Vermächtniß an die Jugend. 1845.) \{D-BHU, GB-LBL, MH, NN, PPG\}

Stundenblumen. Eine Sammlung Polterabend-Scenen und andere Festgedichte. 1833. \{D-BHU, D-BSPK, D-BUB, D-DoB, D-ES, D-KöUSB

Die Verlobte. Schauspiel in 3 A. aus dem Nachlaß. 1845. \{D-BDS, D-BHU, DKöTM\}

Franzky, Agnes = Franz, Agnes

Freese, $A .=$ Pseudonym für: Steinlein, Laura

Freese, Arthur $=$ Pseudonym für: Steinlein, Laura

Freese, Laura $=$ Steinlein, Laura

Freiberg, Günther von = Pseudonym für: Pinelli-Rizzutto, Ada.

Frencklin, Susanne von = Bandemer, Susanne von.

Freundin Gocthes und Schillers aus Heidelberg $=$ Pseudonym für: Paulus, Karoline.

Friederichs, Adelheid Anna. 1859 (Bremen) - 1932 (Bremen): Hilda und Antonius. Drama. 1880. \{D-BSPK, D-SiS, A-WÖN\} 
Friederil, Christiane $=$ Breden, Christiane von .

Friederike $=$ Pseudonym für: Robert, Friederike

Friedländer, Regina $=$ Frohberg, Regina

Fritsch, Franziska. 1823 oder 1828 (Markt Bibart/Bayern) - 1904 (Riedenburg bei Salzburg). Geb. Ruf. Pseudonym: Fr. Staufen

Heli. Tranerspiel in 5 A. 1882. \{D-BSPK, D-FSU\}

Die Sprachreiniger. Lustspiel. 1892. \{D-BSPK\}

Frölich [auch Fröhlich], Henriette. 1768 (Zehdenick/Havel) - 1819 [Groß, Deutschlands Dichterinen: nach 1819; Steiner: 1833] (Berlin). Geb. Rauthe. Pseudonym:

Jerta. Veröffentlichte auch anonym:

Das Rosenmädchen. Lustspiel in 5 A. Um 1805.

Frömmichen, Sophie, 1767 (Helmstedt) - ?:

Schauspiele für Kinder. 1803. (D-BS, D-WoHA\}

Frohberg, Regina. 1783 (Berlin) - 1850 [Goedeke und Groß, Deutschlands Dichterinen: nach 1858] (Berlin). Geb. Salomo [Goedeke: Salomon]. Angenommener Name: Saling [Goedeke: Saaling]. Verh. Friedländer:

Alter und Jugend. Lustspiel in $5 \mathrm{~A}$. nach Le Vieillard et les jeunes gens. O. J. (Theater II, 1818.) \{D-DonFFH, GB-LBL\}

Der Geschaffige. Lustspiel in 1 A. nach d'Harleville. 1812. (Theater I, 1818.) (DDonFFH, A-WÖN, GB-LBL

Der Jïngling von 60 Jahren. Lustspiel in 1 A. nach dem Französischen. 1826.

Onkel und Neffe. Lustspiel in 3 A. nach Demoustier. 1816. (Theater I, 1818.) (DDonFFH, GB-LBL\}

Der Page und das Pasquill. Schauspiel in 1 A. O. J.

Rosalie oder sie besinnt sich anders. Lustspiel in $1 \mathrm{~A}$. nach dem Französischen. O. J. (Theater II, 1818.) \{D-DonFFH, GB-LBL\}

Die Schwiegersöhne. Lustspiel in 4 A., frei bearb. nach Étienne. O. J

So bezahlt man seine Schulden. Lustspiel in 3 A. nach Andrieux, 1815. (Theater I, 1818.) \{D-DonFFH, A-WÖN, GB-LBL\}

Theater. 2 Bde. 1818. \{GB-LBL; Bd. 1 in: D-DonFFH\}

Das unvermuthete Zusammentreffen oder: So ridcht sich eine Deutsche. Lustspiel in $1 \mathrm{~A}$ nach einem französischen Vaudeville. 1815. (Theater II, 1818.) (D-DonFFH, GBLBL\}

Fuchs, Anna Rupertina. 1657 (Elbing) -1722 (Sulzbach/Thüringen). Geb. Pleitner. Pseudonyme: Die Fuchsin, Daphne:

Hiob. In einer dramatischen Reprisentation. 1714
Fuchs von Bimbach, Regina = Güthner, Regina

Fuchsin, die = Pseudonym für: Fuchs, Anna Rupertina.

G., L. A. V. = Pseudonym fïr: Gottsched, Luise Adelgunde Victoria.

G., L. von = mögliches Pseudonym für: Schücking, Louise.

G., Louise von = Pseudonym für: Schücking, Louise.

G., W. v. = Pseudonym für: Gersdorf, Wilhelmine von.

Gall, Louise von = Schücking, Louise

Gansauge, Adele Elisa von = Bredow-Goerne, Adele Elisa Gräfin von.

Gellert, Christina. ? - ?:

Übersetzungen von Shakespeare-Dramen.

Gêne, Sans = Pseudonym für: Hill, Anna.

Genée, Elise. ? - ?:

Infanterie und Cavallerie. Schwank. 1872. (D-BDS\}

Gensike (auch Gensicke, Gensiken), Wilhelmine. 1779 (Weimar) - 1822 (Dresden). Geb. Herz. Pseudonyme: W. W., Wilhelmine Willmar:

Das Angebinde. Lustspiel in 1 A. und Alexandrinern. 1819. (Schmetterlinge I, 1819.) [D-CorFB, GB-LBL $\}$

Finden und Wiederfinden. Lustspiel in 2 A. und in Versen. 1814. (Schmetterlinge III, 1821.) \{D-CorFB, GB-LBL

Das verlassene Haus. Schauspiel in 1 A. 1819. (Hyancinthen. 1819.)

Gentzkow [Genskow], Johanna Sophie Friederike von = Bültzingslöwen, Johanna Sophie Friederike von.

Georgi, Amadeus = Pseudonym für: Georgi, Amanda.

Georgi (auch Georgie), Amanda. 1858 (Jever/Oldenburg) - nach 1901. Pseudonym: A. Georgi von der See, Amadeus Georgi:

Hypathia. Drama. 1893.

Saul und Jonathan. Dramatische Charakterzeichnung in 5 A. 1892. \{D-BDS, DBSPK, D-KöTM, D-LKM\} 
Georgi von der See, A. = Pseudonym für: Georgi, Amanda.

Germül, Charlotte von = Pseudonym für: Glümer, Charlotte von.

Gerschau, Emilie Freiin von = Binzer, Emilie Freifrau von.

Gersdorf, Wilhelmine Charlotte Eleonore von. 1768 (Oberbellmannsdorf/ Niederlausitz) - 1847 [Groß, Deutschlands Dichterinen: nach 1836] (Dresden). Geb. von Gersdorf. Pseudonyme: Eleonore F., W. v. Morgenstern, F. P. E. Richter, J. van der Hall, W. v. G., Glycere, Minna, Ceres, Verfasserin der Familie Stolberg. Veröffentlichte auch anonym:

Dialogen, auch fiir die Bühne brauchbar. 1794. \{Unter dem Titel Neue Schauspiele in D-LKM; A-WÖN\}

Dragoner Karl oder Nichts ist so böse, es ist zu etwas gut. Schauspicl in $2 \mathrm{~A}$. mit Gesang. 1791. (Glycerens Blumen-Kranz II, 1791.) \{D-GOB\}

Edgar und Emma. Duodrama. O. J. (Museum für Frauenzimmer. 1796.$)$

Elina die Circassierin. Dialogisierte Geschichte. 1818. \{D-BSPK, A-WÖN\}

Der erste April. Dramatische Kleinigkeit. O. J. (Der Freimuithige fiir Deutschland. 1819.)

Esther Raphael oder die Proselytin. Dialogisierte Familiengeschichte. 1797. \{D-HUL\} Die Familie Walberg. Dramatische Bearbeitung. 1792 [Groß, Deutschlands Dichterinen: 1784]. \{D-GOB\}

Die Gaben der Peri. Romantisches Drama nach einer englischen Dichtung des Sir Thomas Moore, in 3 A. (Dramatische Blïthen der Ceres.) 1832. (D-BDS, DHLHD\}

Die Horatier und Curatier. Dramatische Skizze aus der römischen Geschichte. O. J. (Museum für Frauenzimmer. 1796.)

Lenette oder der Fall edler Seelen. Ein dialogisiertes Familiengemälde in 3 A. 1791. (Glycerens Blumen-Kranz II, 1791.) \{D-GOB, D-HUL\}

Meg Merrilies, die Zigeunerin, oder Guy-Mannering der Sterndeuter. Schauspiel nach W. Scott. 1818. \{GB-LBL, TNJ\}

Mnemosyne oder meine Erinnerungen. 1797. [Enthält nicht genannte Schauspiele.] \{D-BSPK\}

Neue Schauspiele von der Verfasserin der Familie Stolberg. [Anderer Titel für: Dialogen.] 1795. \{D-LKM

Der Ring. Ein dramatischer Versuch in 2 A. 1791. (Glycerens Blumen-Kranz I, 1791.) $\{\mathrm{D}-\mathrm{GOB}\}$

Die Rose aus Paldstina oder das Gelïbde der Mutter. Trauerspiel in 5 A. in freien Versen. (Dramatische Blïthen der Ceres.) 1817. \{D-BDS, D-HLHD\}

Der Sold der Sünde. Drama [?]. O. J. \{D-HUL\}

Die Zwillingsschwestern oder die Verschiedenheit des Glücks. Familiengemälde in 3 A. 1797. (Mnemonsyne oder meine Erinnerungen II, 1797; Neuausg. hg. Wurst 1991.)
Giers, Johanna. ? - ?:

In zwölfter Stunde. Drama nach ciner Novelle von Fr. Spielhagen. 1880.

Giesler, Mathilde Franziska = Anneke, Mathilde Franziska.

Gizycki, Lily von = Braun, Lily.

Glück, Elisabeth Barbara Babette. 1815 [oder 1814] (Wien) - 1894 (Baden bei Wien). Pseudonym: Betty Paoli:

Didier. Schauspiel in 3 A. von Pierre Berton. Übers. 1868. \{D-KöTM, Vorkriegsnachweise in: A-GUB, A-WN, A-WUB?

Gringoire. Schauspiel von Banville. Übers. 1872. \{A-GUB, Vorkriegsnachweise in: A-GUB, A-WN, A-WUB\}

Glümer, Charlotte von. 1799 (Schöppenstedt/Niedersachsen) - 1839 [Groß, Deutschlands Dichterinen: 1841] (Weissenburg/Elsaß). Geb. Spohr. Pseudonyme: Charlotte von Germül, G. Telto [Groß, Deutschlands Dichterinen: Tolstoy]:

Die Fehde der Gegenkönige Ludwig von Baiern und Friedrich von Oesterreich. Schauspiel. 1832. [D-BS, D-MBS

Die graue Nonne von Clemence's Grab. Drama [?]. 1832. \{D-MBS\}

Die Waldenser in Böhmen. Drama [?]. \{A-WÖN\}

Falls nicht mit einem der obengenannten identisch: ein weiteres nicht genanntes Schauspiel, von Tieck in der Handschrift gelesen und abgelchnt, um 1830. [Goedeke X, 406-8.]

Glümer, Claire von. 1825 (Blankenburg/Harz) -1906 (Dresden-Blasewitz): Claudia. Schauspiel in 3 A. von George Sand. Übers. O. J. \{D-KöTM\}

Glycere $=$ Pseudonym für: Gersdorf, Wilhelmine von.

Göppcl, Luise von = Krockow, Luise Gräfin.

Görner, Ida. 1830 - 1888. Geb. von Buch [?]:

Die Großmutter. Schauspiel in 5 A. und 6 Tableaux. Freie Bearb. 1864. \{D-BDS, DKöTM\}

Héloïse Péranquet. Drama in 4 A. von Durantin. Übers. 1866. \{D-FSU\}

Jeder Vogel baut sein Nest. Lustspiel in 1 A. nach dem Französischen. 1864. \{DHHU-T; in D-BDS unter dem Titel: Jeder baut sein Nest.\}

Der Marquis von Villemer. Schauspiel von George Sand. Übers. O. J. \{D-BDS, DWuS, A-WÖN\}

Unsere Alliirten. Lustspiel in 3 A. nach dem Französischen. 1864. (D-BDS, DHHU-T, D-KöTM, A-WÖN\}

Weitere Übersetzungen französischer Dramen [Groß, Deutschlands Dichterinen 143]. 
Görres, Maria $=$ Arndts, Maria

Götze, Auguste. 1840 (Weimar) - 1908 (Leipzig). Pseudonym: A. Weimar: Alpenstürme. Drama in 1 A. 1886. \{D-HHU-T, D-KöTM, D-WeiZdK\} Im Bann auf Helgoland. Schauspiel. 1893.

Demetrius. Trauerspiel nach Schillers Entwurf mit Benutzung von Scenen der Gustav Kühneschen Bearbeitung in 5 A. 1897. \{D-BSPK, D-BUB, D-FGM, DGSU, D-KaMB, D-LKM, D-MarSN, D-WeiZdK, D-WHLB, A-WUB\}

Eine Diplomatin. Lustspiel in 4 A. 1882. \{D-HHU-T, D-KöTM, D-LKM, DWeiZdK\}

Esther, oder die Liebe zum Volke. Schauspiel. O. J.

Gräfin Osmon. Drama. 1884

Eine Heimfahrt. Drama. 1882. \{D-WeiZdK\}

Hohe Liebe. Lustspiel. 1884.

Magdalena. Schauspiel in 4 A. 1879. \{D-KöTM, D-LKM

Nur kein Blaustrumpf. Lustspiel in 1 A. 1881. \{D-HHU-T, D-KöTM, D-WeiZdK\} Schloß Raveneck. Schauspiel. 1886.

Susanna Mountfort. Trauerspiel in 5 A. 1878. \{D-WeiZdK, A-WÖN\}

Vittoria Accoramboni. Trauerspiel in 5 A. 1890. \{D-BSPK, D-HUL, D-KöTM, D-

LKM, D-WeiZdK, ICRL, IEN\}

Die weiße Frau. Lustspiel. 1884.

Wera. Schwank. 1884.

Zwei Mal Christnacht. Dramatisches Märchen in 8 Bildern. 1885. (D-LKM, DWeiZdK\}

Golder, Johann = Pseudonym für: Zitz, Katharina Rosa Therese Pauline Modesta.

Goldmann, Anna = Hirschler, Anna

Goldstein, Auguste Friederike Freiin von. 1764 (Breslau) - 1837 (Breslau). Geb. von Wallenrodt. Verh. von Fölsch. Pseudonym: Auguste von Wallenheim:

Dramatisch bearbeitete Szenen zur Unterhaltung fir Freunde romantischer Lektüre. 1798.

Die Glïcksritter oder Die Liebe steht ihren Günstlingen bei. Lustspiel in 4 A. 1783. \{A-WÖN\}

Klara von Lauenstein. Ein Schauspiel aus den Ritterzeiten nach Walafried in 5 A. für die Bühne bearb. (Neueste deutsche Schaubilhne für 1806 VI). (D-ASS, D-MBS unter dem Titel: Klara von Leuenstein; D-RS unter dem Titel: Klara und Gottfried; GB-LBL\}

Sammlung theils dialogisitter Geschichten, theils Erzäblungen. 1798.

Der todte Nebenbuhler. Lustspiel in 1 A. 1806.
Gordon, Marie. 1812 (Wien) - 1863 (Triest). Geb. Calafati. Pseudonyme: Alexander Bergen, Marie Saphir, Max Stein:

Der arme Marquis. Schauspiel nach dem Französischen. 1862. [A-WUB]

Aus Liebe sterben! Lustspiel. 1864. \{A-WUB\}

Ein Autograph. Lustspiel in 1 A. Nach dem Französischen. 1860. \{D-BDS, DKöTM\}

Er hat das Pulver erfunden. Lustspiel. 1868. \{A-WUB\}

Eine Gardinenpredigt. Nach dem Englischen. 1868. (D-BDS, D-HHU-T, DWeiZdK, A-WON, A-WUB\}

Der Gesandtschafts-Attaché. Lustspiel. 1864. [A-WUB\}

Gewohnheiten. Lustspiel in $1 \mathrm{~A}$. nach dem Französischen. 1863. (D-BDS, DKöTM

Der Graf und die Schirmemacherin. Charakterbild. 1862. \{A-WUB\}

Die Henne und ihre Kiüchlein. Nach dem Französischen. 1865.

Herkules als Schutzmann. Lustspiel in 1 A. 1863. \{D-BDS, A-WUB\}

Ein junger Gelehrter. Lustspiel. 1860. (D-BDS, A-WUB\}

Kleine Mißverständnisse. Lustspiel. 1867. \{A-WUB, GB-LBL\}

Ein Kostkind auf dem Lande. Posse in 1 A. nach dem Englischen. 1861. \{D-BDS, DWeiZdK\}

Ein liebenswïrdiger Mensch. Lustspiel in 1 A. nach dem Französischen. O. J. \{DBDS\}

Männlich oder weiblich? oder ihr Bruder und ihre Schwester. Lustspiel in 1 A. nach dem Französischen Mein Fräulein Bruder. O. J. [Identisch mit: Mein Fräulein Bruder:] $\{\mathrm{D}-\mathrm{LDB}\}$

Mein Album. Lustspiel in 1 A. nach dem Französischen. O. J. \{D-BDS

Mein Fräulein Bruder. Lustspiel in 1 A. 1862. [Identisch mit: Männlich oder weiblich? $\{\mathrm{D}-\mathrm{BDS}, \mathrm{A}-\mathrm{WUB}\}$

Meine Nichte und mein Bär. Posse. Nach dem Französischen. [Auch unter dem Titel: Mein Bär und meine Nichte.] 1862. \{A-WÖN, A-WUB\}

Montjoye. Drama [?] von O. Feuillet. Übers. O. J.

Der Mord in der Kohlmessergasse. Nach dem Französischen. 1860. \{D-BDS, D-BH, D-ENU, D-HHU-T, D-HUL, D-KöTM, A-GUB, A-WÖN, A-WUB, GB-LBL

Der neue Don Quixote. Lustspiel. Nach dem Französischen. 1861. \{D-HHU-T, AWÖN, A-WUB\}

Nur Mutter. Lustspiel in $2 \mathrm{~A}$. nach dem Französischen. 1862. \{D-BDS, D-HHU-T, D-KöTM, A-WUB\}

Der Prinz von Arkadien. Drama [?] von Saint-Georges. Übers. Um 1865. \{D-EWA\} Regen und Sonnenschein. Lustspiel in $1 \mathrm{~A}$. von Léon Gozlan. Übers. 1862. (D-BDS\} Der schöne Fleischhauer. Lustspiel in 1 A. 1862. \{D-HHU-T, A-WUB\}

Die Schrift an der Wand. Drama in 3 A. Frei nach dem Englischen. Mit I. Ch. Wages [Pseud. für: A. W. Hesse]. 1860. \{D-BDS, D-HHU-T\}

Der Schulmeister. Drama in 5 A. von Paul Meurice. Übers. O. J. \{D-BDS

Schwesterliebe. Nach dem Englischen. 1865. \{D-BDS, D-BH, A-WÖN, A-WUB\} 
Secretar und Koch. Nach dem Englischen. 1868.

Der Sohn des Giboyer. Drama in 5 A. von Emilie Augiers. Übers. 1865. \{D-BDS\} Ein solider Ehemann. Nach dem Englischen. 1868. (D-BDS, A-WÖN, A-WUB\} Umrzec z mitosci. Komödie. 1870. \{A-WUB

Ein ungeschliffener Diamant. Posse in 1 A. nach dem Englischen. 1859. (D-HHU-T D-KaMB, D-KöTM, A-WÖN, A-WUB\}

Der Veilchenstrauß. Lustspiel in $1 \mathrm{~A}$. von Henri Thiery. Übers. O. J. \{D-BDS\}

Eine Vorlesung bei der Hausmeisterin. Posse in 1 A. nach dem Französischen. 1860 \{D-ENU, D-HHU-T, D-KöTM, D-LDB, A-WÖN, A-WUB\}

Zwei Witwen. Lustspiel nach dem Französischen des F. Malleville. 1865.

Ubers. von ,über 60 französische[n] und englische[n] Dramen“ [Groß, Deutschlands Dichterinen 116].

Viele andere nicht genannte Stücke [Groß, Deutschlands Dichterinen 116]

Gottsched, Luise Adelgunde Victoria. 1713 (Danzig) - 1762 (Leipzig). Geb. Kulmus [auch Culmus]. Pseudonym: L. A. V. G. Veröffentlichte auch anonym:

Alzire, oder die Amerikaner. Drama von Voltaire. Übers. 1741. (D-ASU, D-BHU, D-BSPK, DeLL, D-FGM, D-KöTM, D-LKM，D-RSB，D-TS, A-WÖN, CHCGBB, GB-LBL,

Der beste Fürst. Vorspiel. 1755. (Sämmtliche Kleinere Gedichte. 1763.) (D-BDS, DBFU，D-BHU，D-BUB，D-FGM，D-HUB，D-KaMB，D-MBS，D-OLB，D WeiZdK, A-GUB, GB-LBL, CtY, CU, IU, MdBJ, NIC, NNU-W]

Cenie, oder die Großmuth im Unglïcke. Moralisches Stück in 5 A. von Françoise de Grafigny. Übers. 1753. \{D-ASB*, D-BS, D-DeLL, D-DiSB, D-FGM, D-KöTM D-MBS, D-TS, D-WeiZdK, D-WoHA, A-GUB, MU (Mikrofilm)\}

Cornelia, Mutter der Gracchen. Trauerspiel in 5 A. von Marie Anne Barbier. Übers. 1741. \{D-ASU, D-BHU, D-DiSB; D-DeLL, D-FGM, D-HHU-T, D-KöTM, D WeiZdK, A-WÖN, CH-CGBB, MU (Mikrofilm)\}

Das Gespenst mit der Trummel. Lustspiel in 5 A. Bearb. nach Addison/Destouches. 1741. (Die Lustspiele der Gottschedin II, 1908-9.) (D-ASU, D-BDS, D-BFU, DBHU, D-DeLL, D-HHSU, D-HHU-T, D-KaMB, D-KöTM, D-KöUSB, D-LDB, D-LKM, D-SchOS, A-WÖN, CH-CGBB, GB-LBL, IU, MnU, NN, TxHR\}

Die Hausfranzösinn, oder die Mammsell. Lustspiel in 5 A. 1744. (Die Lustspiele der Gottschedin I, 1908-9.) (D-ASU, D-BDS, D-BFU, D-BHU, D-DeLL, D-HHSU, D-HHU-T, D-KaMB，D-KöTM，D-KöUSB，D-LDB，D-LKM，D-MBS，DSchOS, D-SML, IU, MnU, NN, TxHR\}

Kato. Trauerspicl von Addison. Übers. 1735. \{D-DSB, D-FGM, D-HG, D-MBS, D-RoU, D-WeiZdK, D-WoHA, CH-CGBB, GB-LBL\}

Die Lustspiele der Gottschedin. 2 Bde. 1908/9. \{D-BFU, D-BHU, D-HHSU, DHHU-T, D-KaMB, D-LDB, D-LKM, D-SchOS, IU, MnU, NN, TxHR

Im Katalog der Bibliothek steht das Stück verzeichnet unter dem Namen der Verfasserin (v. Graphigny) und unter dem Tirel: Lenie, oder die Grossmutter im Ungluich.
Der Menschenfeind. Lustspiel in 5 A. von Molière. U'Ubers. 1742. (Die Lustspiele der Gottschedin II, 1908-9.) (D-ASU, D-BDS, D-BFU, D-BHU, D-DeLL, D-HHSU, D-HHU-T，D-KaMB，D-KöTM，D-KöUSB，D-LDB，D-LKM，D-MBS，DSchOS, CH-CGBB, GB-LBL, IU, MnU, NN, TxHR

Panthea. Trauerspiel in 5 A. 1744. \{D-ASU, D-BSPK, D-BHU, D-DeLL, D-FGM, D-HHSU, D-HUB, D-KöTM, D-MBS, D-SML, D-TS, A-GUB, A-WÖN, CH CGBB, CH-SZ, GB-LBL, MdBJ, MU (Mikrofilm)]

Die Pietisterey im Fischbein-Rocke, Oder Die Doctormäßige Frau. Lustspiel in 5 A. nach Bougeants La Fernme Docteur. 1736. (Die Lustspiele der Gottschedin I, 1908-9.) \{D-ASU, D-BCHS, D-BDS, D-BFU, D-BHU, D-ChS, D-DUB, D-FrU, D-FSU, D-GF, D-HG, D-HHSU, D-HHU-T, D-HUB, D-KaMB, D-KöTM, D-KöUSB, D-LDB，D-LKM，D-MarSN，D-MBS，D-MrU，D-MüS，D-MüU，D-RoU，DSchOS, D-SML, D-TüU, D-WeiZdK, D-ZCW, A-WÖN, A-WUB, CH-BSU, CH-FTK, GB-LBL, CtY, CU, IU, MnU, NcU, NN, OCU, OClW, TxHR\} Der poetische Dorfjunker. Lustspiel in $5 \mathrm{~A}$. von Destouches. Übers. mit Veränderungen 1741. (Die Lustspiele der Gottschedin II, 1908-9.) \{D-ASU, D-BDS, D-BFU, DBHU, D-DeLL, D-HHSU, D-KaMB, D-KöTM, D-KöUSB, D-LDB, D-LKM, DMBS, D-SchOS, A-WÖN, CH-CGBB, GB-LBL, IU, MnU, NN, TxHR\}

Das Testament. Lustspiel in 5 A. 1745. (Die Lustspiele der Gottschedin I, 1908-9.) (DASU, D-BCHS, D-BDS, D-BFU, D-BHU, D-ChS, D-DeLL, D-DHO, D-DUB, D-ENU, D-ES, D-FTT, D-HHSU, D-HHU-T, D-KaMB, D-KöTM, D-KöUSB, D-LDB, D-LKM, D-MBS, D-SchOS, D-SML, D-SPL, D-TS, CH-BSU, CHCGBB, CH-FTK, GB-LBL, ICRL (Mikrokarte), IU, MnU, NN, OOxM, OU, TxHR\}

Die ungleiche Heirath. Lustspiel in 5 A. 1744. (Die Lustspiele der Gottschedin I, 1908-9.) (D-ASU, D-BDS, D-BFU, D-BHU, D-DeLL, D-HHSU, D-HHU-T, DKöTM, D-KöUSB, D-LDB, D-LKM, D-MBS, D-SchOS, CH-CGBB, TxHR, IU, $\mathrm{MnU}, \mathrm{NN}, \mathrm{OCIW}$

Der Verschwender, oder die ebrliche Betrïgerinn. Lustspiel in 5 A. von Destouches. Übers. 1741. (Die Lustspiele der Gottschedin II, 1908-9.) (D-BDS, D-BFU, DBHU, D-DeLL, D-HHSU, D-HHU-T, D-KaMB, D-KöTM, D-KöUSB, D-LDB D-LKM, D-SchOS, CI-CGBB, GB-LBL, IU, MnU, NN, TxHR\}

Die Widersprecherin. Anderer Titel von: Die Widerwillige. \{D-BHU, D-KöUSB, DLDB, D-LKM, D-SchOS, A-WÖN, CH-CGBB, GB-LBL, IU, MnU, NN, TxHR\} Die Widerwillige. Lustspiel in $1 \mathrm{~A}$. nach Dufresnys L'esprit de contradiction. Bearb./ übers. 1742. (Die Lustspiele der Gottschedin II, 1908-9.) (D-ASU, D-BDS, D-BFU, D-BHU, D-DeLL, D-HHSU, D-HHU-T, D-KaMB, D-KöTM, D-KöUSB，DLDB, D-LKM, D-SchOS, IU, MnU, NN, TxHR\}

Der Witzling. Nachspiel in 1 A. 1745. (Die Lustspiele der Gottschedin I, 1908-9.) (DASU, D-BDS, D-BFU, D-BH, D-BHU, D-BiU, D-BoU, D-BUB, D-DeLL, DDoU, D-DUB, D-EFH, D-ENU, D-ES, D-FrU, D-FS, D-FSU, D-GiU, DHHSU, D-HHU-T, D-HUL, D-KaMB, D-KöTM, D-KöUSB, D-LDB, D-LKM, D-MarSN, D-MBS, D-MrU, D-MüS, D-MüU, D-PaU, D-SchOS, D-SML, D- 
SPL, D-TUB-G, D-WHLB, A-GUB, CH-BSU, CH-CGBB, CH-LZ, GB-LBL, IU, MnU, NN, OCU, TxHR\}

Goury de Champgrand, Alexandrine Sophie $=$ Baur, Alexandrine Sophie von.

Gowenz = Pseudonym für: Baudissin, Sophie von.

Gramm, Friederike Louise von $=$ Stolberg, Friederike Louise Gräfin .

Grans, Agnes Charlotte Elise. 1828 (Leipa bei Lauer, Schlesien) - nach 1888. Geb. ?: Eselfritze von Ems. Drama. O. J.

Stumme Liebe. Lustspiel. O. J. \{D-BDS\}

Die Tochter des Lootsen. Schauspiel. 1863. \{A-WÖN\}

Über den Ozean. Drama aus der englisch-indischen Gesellschaft. 1858. \{A-WÖN\}

Grantzow, Wilhelmine = Beringer; Wilhelmine.

Grave, Agnes le = Pseudonym für: Holthausen, Johanna.

Gravell, Charlotte. ? - ?:

Eine Schule der Ehe. Ein Lebensbild. 1874.

Greiner, Caroline von $=$ Pichler, Caroline.

Grieben, Ferdinande. 1844 (Angermünde/Brandenburg) - ? Pseudonym: W. Egbert: Knalleffekte der Natur. Lustspiel in 4 A. 1881. \{D-HHU-T, D-KöTM, D-WeiZdK\}

Grimm, Gisela. 1827 (Berlin) - 1889 (Florenz). Geb. von Arnim. Pseudonyme: Allerleih Rauh, Fittchersvogel, Marilla Fittchersvogel:

Alt-Schottland. Drama in $5 \mathrm{~A}$. und einem Vorspiel. 1890. \{D-BFU, D-BHU, DBUB, D-FGM, D-FrU, D-FSU, D-HUB, D-KaMB, D-KöTM, D-TS, D-WeiZdK, ICarbS, ICRL, IU, KyU, MH\}

Dramatische Werke. 4 Bde. 1857-75. (D-BDS, D-BHU, D-FGM, D-GSU, DWeiZdK, A-WÖN, GB-LBL, CtY, CU, ICarbS, NN, PPG

Das Herz der Laïs. Drama in 1 A. 1857. (Dramatische Werke I, 1857-75.) (D-BDS, D-BHU, D-BUB, D-FGM, D-GSU, D-WeiZdK, A-WÖN, GB-LBL, CtY, CU, ICarbS, NN, PPG\}

Ingeborg von Dänemark. Drama in 3 A. O. J. (Dramatische Werke I, 1857-75.) (DBDS, D-BHU, D-BUB, D-FGM, D-GSU, D-WeiZdK, A-WÖN, A-WUB, GBLBL, CtY, CU, ICarbS, NN, PPG

Das Licht. Festspiel. 1870. \{D-BSPK, D-FGM, D-WciZdK, MH, OCIW\}

Das Steinbild der Cornelia. 1865. (Dramatische Werke III, 1857-75.) (D-BDS, DBHU, D-BUB, D-FGM，D-GSU，D-MüU，D-SML，D-WeiZdK，D-WüU，AWÖN, GB-LBL, CtY, CU, ICarbS, NN, PPG\}
Trost in Thränen. Drama in 5 A. 1857. (Dramatische Werke II, 1857-75.) \{D-BDS, D-BHU, D-BUB, D-FGM, D-GSU, D-WeiZdK, A-WÖN, GB-LBL, CtY, CU, ICarbS, NN, PPG\}

Wie es unterdessen Daheim war. Dramatische Erzählung. 1875. (Dramatische Werke IV, 1857-75.) \{D-BDS, D-BHU, D-BS, D-BUB, D-FGM, D-GSU, D-WeiZdK, A-WÖN, GB-LBL, CtY, CU, ICarbS, InU, NN, OClW, PPG\}

Gröben, Elisabeth Gräfin von der. Um 1882:

Blanka und Rosalinde. Schauspiel in 4 A. O. J. (Dramatisierte Marchen. 1877.) \{DFSU\}

Blaubart. Schauspiel in 3 A. O. J. (Dramatisierte Märchen. 1877.) \{D-FSU\} Christmärchen. Schauspiel in 2 A. O. J. (Dramatisierte Märchen. 1877.) (D-FSU\} Dornröschen. Schauspiel in 3 A. und einem Bilde. O. J. (Dramatisierte Märchen. 1877.) \{D-FSU\}

Dramatisierte Märchen. 1877. \{D-FSU\}

Fallada. Schauspiel in 3 A. O. J. (Dramatisierte Marrchen. 1877.) \{D-FSU\}

Der Froschkönig. Schauspiel in 2 A. O. J. (Dramatisierte Märchen. 1877.) \{D-FSU\} Die Geschwister. Schauspiel in 3 A. O. J. (Dramatisierte Märchen. 1877.) \{D-FSU\} Hänsel und Gretel. Schauspiel in 4 A. O. J. (Dramatisierte Marchen. 1877.) \{D-FSU\} Die Höckernasigen. Lustspiel in 3 A. O. J. (Dramatisierte Märchen. 1877.) \{D-FSU\} Kinder- und Puppentheater. [15 dramatisierte Grimmsche Märchen. Identisch mit: Dramatisierte Märchen?\}. 1877. \{D-FSU; unter dem Titel Illustriertes Kinder- und Puppentheater in A-WÖN\}

König Drosselbart. Schauspiel in 4 A. O. J. (Dramatisierte Märchen. 1877.) \{D-FSU\} Die Rose des Zaubergartens. Schauspiel in 4 A. O. J. (Dramatisierte Marchen. 1877.) $\{$ D-FSU $\}$

Rothkäppchen. Schauspiel in 2 A. O. J. (Dramatisierte Märchen. 1877.) \{D-FSU\} Rumpelstilzchen. Schauspiel in 2 A. O. J. (Dramatisierte Marchen. 1877.) \{D-FSU\} Das unsichtbare Königreich. Schauspiel in 3 A. O. J. (Dramatisierte Märchen. 1877.) \{D-FSU\}

Das Wasser des Lebens. Schauspiel in 3 A. O. J. (Dramatisierte Märchen. 1877.) \{DFSU\}

Grönau, Isidore $=$ Pseudonym für: Sydow, Wilhelmine von .

Großmann, Julie Florentine von. 1790 (Freistadt/Mähren) - 1860 (Dresden). Geb. Menzel:

Feierabende für gute Kinder. [Enthält zwei Dramen.] 1844. \{D-KaMB\}

Grotthuss, Elisabeth (Elise) Freiin von. 1820 (Dürben/Kurland) - 1896 (Wien): Der Magnetiseur. Lustspiel in 3 A. 1876. (D-BSPK, A-WÖN, A-WUB\} Zwei Onkel aus Amerika. Lustspiel in 5 A. 1875. (D-BSPK) 
Grottluss, Sara Freifrau von. ? (Berlin) - 1828 (Oranienburg). Geb. Meyer. Verw. Wulff:

Nicht genannte Dramen [Groß, Deutschlands Dichterinen 30],

Grube, Elisabeth (Betty). 1801 [1803?] (Netphen/Sieg) - 1871 (Düsseldorf). Geb. Diez. Pseudonyme: Elisabeth, Elisabeth D:

Dramen. 1864. \{D-WeiZdK, GB-LBL\}

Jakobaea von Baden. Trauerspiel in 5 A. 1864. (D-BiSL, D-BUB, D-DUB, DSiSiM, D-WeiZdK

Die Lützower. Historisches Schauspiel, 1864. [D-BiSL, D-BUB, D-DUB, D-SiSiM, D-WeiZdK\}

Wittekind der Sachsenherzog. Historisches Schauspiel in 5 A. 1864. \{D-BiSL, DBUB, D-DUB, D-KöUSB, D-SiSiM, D-WeiZdK]

Grünberg, Johanna = Franul von Weißenthurn, Johanna.

Gudewill, Anny = Kistner, Anna.

Günderrode [auch Günderode], Karoline [auch Caroline] von. 1780 (Karlsruhe) 1806 (Winkel a. Rh.). Pseudonyme: Tian, Ion:

Edda-Fragment. O. J. (Gesammelte Werke III, 1970.) \{U. a. an: D-ABTH, D-BDS, D-BFU, D-BHU, D-BiU，D-BoU，D-BSPK，D-BUB，D-CorFB，D-DeLL，DENU, D-FGM, D-FSU, D-HHSU, D-HUB, D-HUL, D-KaMB, D-KoS, D-LDB, D-MaU, D-MrU, D-MüS, D-MüU, D-SPL, D-TUB-G, D-WHLB, A-GUB, CHLZ, CH-SZ, CH-ZDS, GB-LBL, MU, TxU\}

Hildgund. O. J. (Gesammelte Werke I, 1970.) \{U. a. an: D-ABTH, D-BFU, D-BHU, D-BiU, D-BoU, D-BSPK, D-BUB, D-CorFB, D-DeLL, D-ENU, D-FGM, DFSU, D-HHSU, D-HUB, D-HUL, D-KaMB, D-KoS, D-LDB, D-MaU, D-MrU, D-MüS，D-MüU，D-SchOS，D-SPL, D-TUB-G, D-WHLB, A-GUB, CH-AK, CH-LZ, CH-SZ, CH-ZDS, GB-LBL, MU, TxU\}

Immortalia. Ein Dramolet. O. J. (Gesammelte Werke I, 1970.) \{U. a. an: D-ABTH, D-BFU，D-BHU，D-BGS，D-BiU，D-BoU，D-BSPK，D-BUB，D-CorFB，DDeLL, D-DoU, D-ENU, D-FGM, D-FSU, D-GSK, D-GuSK, D-HHSU, DHUB, D-HUL, D-KaMB, D-KoS, D-LDB, D-MrU, D-MüRS, D-MüS, D-MüU, D-PBH, D-SPL, D-TUB-G, D-SG, D-WHLB, A-GUB, CH-LZ, CH-SZ, CHZDS, GB-LBL, MU, TxU

Der Kanonenschlag oder das Gastmabl des Tantalus. Ein heroisches komisches tragisches Schauspiel. O. J. (Gesammelte Werke III, 1970.) \{U, a an: D-ABTH, D-BFU, D BHU, D-BiU, D-BoU, D-BSPK, D-BUB, D-CorFB, D-DeLI, D-ENU, D-FGM, D-FSU, D-HHSU, D-HUB, D-HUL, D-KaMB, D-KoS, D-LDB, D-MrU, DMüS, D-MüU, D-SPL, D-TUB-G, D-WHLB, A-GUB, CH-LZ, CH-SZ, CHZDS, GB-LBL, MU, TxU
Magie und Schicksal. In 3 A. 1805. (Gesammelte Werke II, 1970.) \{U. a. an: DABTH, D-BFU, D-BHU, D-BiU, D-BoU, D-BSPK, D-BUB, D-CorFB, D-DeLL, D-DUB, D-ENU, D-FGM, D-FSU, D-HHSU, D-HUB, D-HUL, D-KaMB, DKoS, D-LDB, D-LKM, D-MaU, D-MrU, D-MüS, D-MüU, D-SchOS, D-SPL, DTUB-G, D-WHLB, A-GUB, CH-AK, CH-LZ, CH-SZ, CH-ZDS, GB-LBL, MU, $\mathrm{TxU}\}$

Mahomed, der Prophet von Mekka. O. J. (Gesammelte Werke I, 1970.) \{U. a. an: DABTH, D-BFU, D-BHU, D-BiU, D-BoU, D-BSPK, D-BUB, D-CorFB, D-DeLL, D-ENU, D-FGM, D-FSU, D-HHSU, D-HUB, D-HUL, D-KaMB, D-KoS, DLDB, D-MrU, D-MüS，D-MüU，D-SchOS，D-SPL，D-TUB-G，D-WHLB，AGUB, CH-AK, CH-LZ, CH-SZ, CH-ZDS, GB-LBL, MU, TxU\}

Mora. O. J. (Gesammelte Werke I, 1970.) \{U. a. an: D-AB'TH, D-BFU, D-BHU, DBiU, D-BoU, D-BSPK, D-BUB, D-CorFB, D-DeLL, D-ENU, D-FGM, D-FSU, D-HHSU, D-HUB, D-HUL, D-KaMB, D-KoS, D-LDB, D-MrU, D-MüS, DMüU, D-SPL, D-TUB-G, D-WHLB, A-GUB, CH-LZ, CH-SZ, CH-ZDS, GBLBL, MU, TxU\}

Nikator. Eine dramatische Skizze in 3 A. 1806. (Gesammelte Werke II, 1970.) \{U. a. an: D-ABTH, D-BFU, D-BHU, D-BiU, D-BoU, D-BSPK, D-BUB, D-CorFB, DDeLL, D-DUB, D-ENU, D-FFDH, D-FGM, D-FSU, D-HHSU, D-HUB, DHUL, D-KaMB, D-KoS, D-LDB, D-MrU, D-MüS, D-MüU, D-SPL, D-TUB-G, D-WHLB, A-GUB, CH-LZ, CH-SZ, CH-ZDS, GB-LBL, MU, TxU\}

Udohla. In 2 A. 1805. (Gesammelte Werke II, 1970.) \{U. a. an: D-ABTH, D-BFU, D-BHU，D-BiU，D-BoU，D-BSPK，D-BUB，D-CorFB，D-DeLL，D-ENU，DFFDH，D-FGM，D-FSU，D-HHSU，D-HUB，D-HUL，D-KaMB，D-KoS，DLDB, D-MrU, D-MüS, D-MüU, D-SchOS, D-SPL, D-TUB-G, D-WHLB, AGUB, CH-AK, CH-LZ, CH-SZ, CH-ZDS, GB-LBL, MU, TxU\}

Günther, Adele Minna = Osterloh, Adele Minna.

Günther, A. [identisch mit: Osterloh, Adele Minna?]. ? - ?: In Hemdsärneln. Schwank in 1 A. 1892. \{GB-LBL\}

Günther, Marie. 1854 (Lübeck) - 1916 [?]. Verh. Brauer: Antons Erben. Schwank. 1899.

Die beiden Hausärzte. Lustspiel in 4 A. 1889. (Theaterstïcke. 1892.) (D-WeiZdK, IEN\}

Das Bild der Schwiegermutter. Schwank in 1 A. Ca. 1880. (D-BDS, D-DeLL, DWeiZdK\}

Christian Ludewig und sein Hof-Komödiant. Charaktergemälde in 4 A. 1892. (DSML, D-WeiZdK, D-WHLB, A-WÖN

Christinchen. Modernes Märchen in 5 Bildern. 1896. [Drama?] [D-SML, DWHLB\}

Ein Dienstbotenstreik. Schwank. 1898. \{D-WeiZdK\} 
Dilettanten und Kïnstler. Lustspiel in 4 A. 1892. (Theaterstücke, 1892.) \{D-KöTM, D-SML, D-WHLB, IEN\}

Durch die Karten. Lustspiel in 1 A. 1874. (Theaterstücke. 1892.) \{D-BHU, IEN\} Eifersuichtig auf sich selbst, oder: Das graue Männlein. Lustspiel in 4 A 1879 . (DSML\}

Die Feuerprobe. Lustspiel in 1 A. 1881. \{D-WeiZdK\}

Die Flagge deckt die Waare. Schwank in 3 A. 1885. \{D-SML, D-WeiZdK, A-WÖN, NN\}

Goldmarie und Pechmarie. Dramatisches Märchen nach J. und W. Grimm in 3 A. 1882. \{D-BDS, D-SML, D-WeiZdK, D-WHLB, A-WÖN\}

Das graue Männchen. Lustspiel. 1885. \{D-BSPK\}

Jeder nach seinem Geschmack. Lustspiel in 1 A. 1880. \{D-HHU-T, D-WeiZdK, AWÖN\}

Die kleine Exzellenz. Lustspiel in 1 A. 1898. (D-KöTM\}

Kleine Sünden. Lustspiel. 1878.

Die kleinen Musikanten. Dramatisches Märchen in 2 A. 1896. \{D-HHU-T, D KöTM, D-SML, D-WeiZdK

Der Kleinen Osterfahrt. Dramatisches Märchen. 1900. \{D-WeiZdK\}

Mama muß heiraten. Lustspiel in 1 A. 1874. [Richel, The German Stage: In Zusammenarbeit mit L. Günther.] \{D-HHU-T\}

Der neue Stiftsarzt. Lustspiel in 4 A. 1883. [Richel, The German Stage: In Zusammenarbeit mit L. Günther.] \{D-BH, D-BSPK, D-HHU-T, D-KöTM, D-SML, D WeiZdK, A-WÖN, IEN\}

Der neue Theaterarzt. Schwank. 1898. \{D-HHU-T, D-SMI

Olgas Toto. Schwank in 3 A. 1896.

Papa Windbeutel [Pataky I: Papas Windbeutel]. Lustspiel in 4 A. 1887. \{D-SML\}

Der rätselhafte Liebhaber. Schwank in 3 A. 1887. \{D-SMI, GB-LBL\}

Sammelfieber. Lustspiel in 4 A. 1887. (Theaterstïcke, 1892.) (D-HHU-T, D WeiZdK, IEN\}

Schneeweißchen und Rosenroth. Märchen mit Gesang und Tanz in 3 A. frei nach J. und W. Grimm. 1888. (Theaterstücke. 1892.) \{D-WeiZdK, D-WHLB, IEN\}

Sinnlich-Übersinnliches. Dramatischer Zyklus. 1903. \{D-SML\}

Theaterstiicke. 1892. \{IEN\}

Tischlein deck dich, Esel streck dich, Knüppel aus dem Sack. Dramatisches Märchen nach J. und W. Grimm in 3 A. 1893. \{D-SML, D-WHLB\}

Till Eulenspiegels Jugendstreiche. Schwank. 1902.

Die Töchter des Kommerzienrats. Lustspiel in 4 A. 1884. [Richel, The German Stage Pataky I: In Zusammenarbeit mit L. Günther.] \{D-BDS, D-HHU-T, D-KöTM, DSML, D-WeiZdK, D-WHLB, A-WÖN, GB-LBL

Eine Tochter, die ibre Mutter verheiraten will. [Anderer Titel für: Mama muß heiraten:] Lustspiel in $1 \mathrm{~A}$. Mit Leopold Günther, 1874. \{D-KöTM\}

Der Weihnachtsmann. Lustspiel in 1 A. 1873.

Weltfriede. Lustspiel in 3 A. 1896. \{D-SML, D-WeiZdK\}
Wem gehört's? (Anderer Titel für: Olgas Toto.)

$Z u$ boch hinaus. Volksstück in 4 A. 1895. \{D-SML

Güthner, Regina (Nina) Henriette Wilhelmine. 1835 (Schloß Bimbach bei Gerolzhofen/Bayern) - 1905 (München). Geb. Fuchs von Bimbach. Pseudonym: Nina von Waldburg:

Die Wabl. Dramatische Kleinigkeit in 1 A. 1879. \{D-HHU-T, D-WeiZdK, AWUB; fehlt an $\mathrm{MH}$ \}

Guischard, Wilhelmine Konstanze. 1826 [Groß, Deutschlands Dichterinen: 1833] (Kolberg/ Pommern) - 1896 (Berlin): Bekehrt. Schauspiel in 5 A. 1887. \{D-FSU\}

Jedico. Historisches Drama in 5 A. 1896. \{Unter dem Titel Ildico in: D-FSU; DRoU\}

Der letzte Capy. Schauspiel in 4 A, und einem Vorspiel. 1896. \{D-RoU\} Parisina. Tragödie in 5 A. 1879. \{D-BSPK, D-GSU, D-WeiZdK, OCIW\}

Gutbier, Louise Jeanette Christiane. 1834 (Heßberg bei Hildburghausen/Thüringen) - 1904 (Coburg). Geb. Hoffmann. Pseudonyme: Jean Christ, Jean-Christ: Eleazar. Drama. 1895. \{D-BDS, D-BHU, D-LKM, D-WeiZdK, A-LBS, A-WÖN\} Im Bann der Schuld. Drama. O. J.

Napoleon I. Drama. O. J. \{D-LKM, D-WeiZdK\}

H., E. = Pseudonym für: Paulus, Karoline.

H., E. v. = Pseudonym für: Rüdiger, Elise.

H., Freiin v, = Pseudonym für: Rüdiger, Elise.

Häbler, Friederike Johanna = Lohmann, Friederike Johanna.

Häusser, Caroline $=$ Eichler, Caroline.

Häußer, Caroline = Eichler, Caroline.

Hahn, Elise $=$ Bürger, Elise.

Hahn, R. Edmund = Pseudonym für: Pierson, Caroline.

Hain [auch Hayn], Juliane [auch Juliana]. 1758 (Budapest) - ? Verh. Mihule. Pseudonym: Verfasser des Dichterlings:

Der Dichterling oder: Solche Insekten giebts die Menge. Lustspiel in 1 A. 1781. \{D-

HHU-T, A-WÖN 
Der gleichgiltige Ehemann. Il marito indolente. Scherzhaftes musikalisches Drama. 1784. [Ital. und deutsch.]

Das Listige Stubenmädchen oder der Betrug von Hinten. Lustspiel in 3 A. 1784. \{AWON\}

Halein, Katharina Rosa Therese Pauline Modesta $=$ Zitz, Katharina Rosa Therese Pauline Modesta.

Hallka, Alexander $=$ Pseudonym für: Ledochowska, Maria Theresia von.

Hall, J. van der = Pseudonym für: Gersdorf, Wilhelmine von.

Handel-Mazzetti, Enrica Freiin von. 1871 (Wien) - 1955 (Linz). Pseudonym: Marien Kind:

Des Christen Wunderschau in der heiligen Nacht. Weihnachtsspiel. 1910. (Weihnachtsund Krippenspiele. 1912.) \{D-BDS, D-BHU, D-FSU, D-KöTM\}

Christkindleins Abschied. Krippenspiel. 1912. (Weihnachts- und Krippenspiele. 1912.)

\{D-BDS, D-BHU, D-FSU, D-Kö'TM

Geistige Werdejabre. Dramen und Epen. 1911-12. \{D-BDS\}

Das Haus der Gräfin Kiesel. Vor 1910. \{D-KöTM\}

Der heilige Alexius. Spiel in 1 A. und 8 Bildern. O. J. \{D-KöTM\}

Ich kauf ein Mohrenkind. Weihnachtsspiel. 1912. (Weihnachts- und Krippenspiele. 1912.) \{D-BDS, D-BHU, D-FSU, D-KöTM\}

In terra pax, hominibus bonae voluntatis! Weihnachtsspiel in $3 \mathrm{~A} .1899$. (Weihnachtsund Krippenspiele. 1912.) \{D-BDS, D-BHU, D-FSU, D-KöTM\}

Einer Klosterschülerin mutig Wort. Schauspiel in 2 A. O. J. \{D-KöTM\}

Lasset die Kleinen zu mir kommen. Dramatischer Versuch. Vor 1886.

Die Leiden eines Kindes. Weihnachtsspiel. 1912. (Weihnachts- und Krippenspiele. 1912.) (D-BDS, D-BHU, D-FSU, D-KöTM\}

Nicht umsonst. Historisches Schauspiel in 5 A. 1892

Pegasus im Joch oder die verwunschenen Telegramme. Lustspiel. 1895

Sankt Aloysius. Spiel in 8 Bildern. 1891. [Identisch mit: Der beilige Alexius?] (DKöTM\}

Sophie Barat erkennt ihren Beruf. Spiel in 1 A. 1910. \{D-KöTM\}

Talitha, das Hirtenmädchen an der Krippe. Weihnachtsspiel in 2 A. 1895. (Weihnachts- und Krippenspiele. 1912.) \{D-BDS, D-BHU, D-FSU, D-KöTM\}

Die wiedereröffnete Himmelsthür. Osterspiel. 1894. \{D-KöTM\}

Weihnachts- und Krippenspiele. 1912. \{D-BDS, D-BHU, D-FSU, D-KöTM\}

Verschiedene „Schauspiele, in denen es sehr abenteuerlich zuging“ (Pataky I, 310).

Um $1880 / 81$.

Harboe, Christine Johanne von. 176-? (Hadersleben/Jütland) - ? Geb. de Fallsen [auch Falsen]. Veröffentlichte anonym:
Allzuviel an einem Tage. Lustspiel in 2 A. 1785. \{A-WÖN\}

Juliane oder die Belohnung der Tugend. Lustspiel in 3 A. 1784. \{Unter dem Titel: Juliane oder das rübrende Beispiel der Tugend in A-WÖN; TNJ\}

Harder, Pauline Baronin von. Vor 1867 (Breslau) - nach 1899. Pseudonym: Paul Iné: Auf Ehrenwort. Original-Schauspiel in 5 A. Um 1880. \{D-FSU\}

Fata Morgana. Schauspiel in 5 A. O. J. \{D-KöTM\}

Gela. Original-Lustspiel in 4 A. O. J. \{D-SiS\}

Gerettet! Drama in 4 A. 1904. \{NN\}

Der Günstling. Lustspiel. O. J.

Hilde. Lustspiel in 4 A. 1883. \{D-BHU\}

Hippolyta [Pataky I, 313: Hyppolita]. Drama. 187-?. \{D-KöUSB, D-WeiZdK, AWÖN, CU, NN\}

Oceanide. Lustspiel. 1881. \{D-WeiZdK\}

Rouge et Noir, oder: Die Opfer der Spielbank. Schauspiel in 5 A. mit teilweiser Benutzung der Novelle von Hans Wachenkusen. 1868. [D-BUB, D-KöTM\}

Schloß Sedlitz. Schauspiel. O. J.

Schwabenheim oder Mittel zum Zwecke. Lustspiel in 4 A. O. J. \{D-MarSN\} Simiensky oder: Fürs Vaterland. Drama in 5 A. Nach 1863. \{D-BUB\}

Die Sphinx. Schauspiel in 5 A. 1870 . \{D-BUB\}

Ein versagter Kuss. Lustspiel. O. J.

Harkort, Henriette = Kühne, Henriette.

Harmes, Emilie von = Berlepsch, Emilie von.

Harms, Emilie von $=$ Berlepsch, Emilie von .

Harrer, Marie $=$ Uttech, Marie.

Hartl [Groß, Deutschlands Dichterinen: Hartl-Milius], Philomene [Groß, Deutschlands Dichterinen: Philomele]. 1851 [Groß, Deutschlands Dichterinen: 1852] (München) - 1928 (München). Geb. Waschmitius. Schauspielername: Ph. Mitius. Pseudonym: Hartl-Mitius:

Am Wend'lstoan. Drama. 1881.

Am Wetterstein. Vollksstïck. 1889. [Identisch mit: Am Wend'lstoan?]

Annerl vom Grundlhof. Drama. 1882.

Die Auserwählte. Schauspiel. 1904.

s goldene Kalbel. Volksstück. 1901.

Der Neuentdeckte. Posse [mit L. Klein]. 1904.

Onkel Troneck. Drama. 1879.

Der Protzenbauer. Gebirgsposse mit Gesang und Tanz in 4 A. 1880. \{D-MüS, DWeiZdK, A-WÖN 
Sherlock Holmes im Gebirge. Posse. 1906

Die schöne Milibäuerin vom Tegernsee. Volksstück. 1900.

Sommerfreuden. Lustspiel. 1881.

Der Verstoßene. Drama. O. J.

Die Zauberwurzel. Bauernposse. 1906

Zirkusleut. Ländliches Spiel. 1907.

Hartl-Mitius = Pseudonym für: Hartl, Philomene.

Hasenclever, Sophie. 1824 (Berlin) - 1923 (Düsseldorf). Geb. von Schadow:

Aus den Charakteren, eine Reihenfolge. O. J. (Handschriftlich nachgelassen.) \{Urschrift und eine Abschrift in D-DHHI\}

Badebekanntschaften. O. J. (Ursprünglich unter dem Titel: Die Überraschung. Handschriftlich nachgelassen.) \{Eine Reinschrift in D-DHHI\}

Drickes und Frau Kdsen treten auf. O. J. (Handschriftlich nachgelassen.) \{D-DHHI\} Er will Ruhe haben. Lustspiel in 2 A. O. J. (Handschriftlich nachgelassen.) (Eine Reinschrift in D-DHHI\}

Die Geschwätzige. (Aus den Charakteren, eine Reihenfolge.) O. J. (Handschriftlich nachgelassen.) \{Urschrift und eine Abschrift in D-DHHI\}

Häusliche Märchen. O. J. (Handschriftlich nachgelassen.) \{D-DHHI

Hochzeitsscherz. O. J. (Handschriftlich nachgelassen.) \{D-DHHI; Anfang fehlt\}

Die Neugierige. (Aus den Charakteren, eine Reihenfolge.) O. J. (Handschriftlich nachgelassen.) \{Urschrift und eine Abschrift in D-DHHI\}

Die Sentimentale. (Aus den Charakteren, eine Reihenfolge.) O. J. (Handschriftlich nachgelassen.) \{Urschrift und eine Abschrift in D-DHHI\}

So lernt man Frauen kennen. Lustspiel in 1 A. O. J. (Handschriftlich nachgelassen.)

\{Eine Abschrift in D-DHHI\}

Der Troubadour in der Westentasche. 1892. (Handschriftlich nachgelassen.) \{Eine Abschrift in D-DHHI

Die Verlobungsvisite. O. J. (Handschriftlich nachgelassen.) \{Eine Abschrift in DDHHI\}

Was sind Männer werth? Lustspiel in 3 Abt. O. J. (Handschriftlich nachgelassen.) \{Eine Abschrift in D-DHHI

Wirtshaus zum Goldadler. O. J. (Handschriftlich nachgelassen.) \{D-DHH

Ein neues Stück, kein Titel. 1891. (Handschriftlich nachgelassen.) \{D-DHHI\}

Einakter ohne Titel. O. J. (Handschriftlich nachgelassen.) $\{\mathrm{D}-\mathrm{DHHI}\}$

Hasslacher, Bertha = Ackermann-Hasslacher, Bertha

Hastfer, Wilhelmine von = Chézy, Wilhelmine von.

Hebenstreit, Christiane Benedikte Eugenie = Naubert, Christiane Benedikte Eugenie.
Heinrichs, Emilie. 1823 (Schleswig) - 1901 (Braunschweig). Geb. Schmidt. Pseudonym: E. v. Linden:

Ein deutscher Held. Lustspiel. 1859.

Heiter, Amalie $=$ Pseudonym für Amalie, Prinzessin von Sachsen .

Helene Kordelia = Pseudonym für: Kiesekamp, Hedwig.

Helene Kornelia $=$ Pseudonym für: Kieselkamp, Hedwig.

Helmina $=$ Pseudonym für: Chézy, Wilhelmine von .

Helmina = mögliches Pseudonym für: Klencke, Karoline Luise von.

Helmine $=$ Pseudonym für: Chézy, Wilhelmine von .

Hermine = Pseudonym für: Laddey, Emma.

Helvig [auch: Hellwig], Amalie von. 1776 (Weimar) - 1831 (Berlin). Geb. von Imhof [auch Imhoff]:

Die Geister des Sees. In Musik gesetzt von Joseph Woelfl. Um 1800. (D-DUB, DHUL\}

Die Schwestern auf Corcyra. Dramatische Idylle. 1812. \{D-ASS, D-ASU, D-BDS, DBFU, D-BHU, D-BUB, D-DGM, D-DUB, D-FGM, D-GS, D-GSU, D-HUB, D-LKM, D-LR, D-MBS, D-TS, D-WeiZdK, A-WUB, GB-LBL, CtY, IU, MH, $\mathrm{PBm}\}$

Die Tageszeiten. Ein Zyklus griechischer Zeit und Sitte in 4 Idyllen. 1812. \{D-BHU, D-DUB, D-FGM, D-GF, D-GSU, D-LDB, D-LR, D-MBS, D-TS, D-WeiZdK, AWUB, GB-LBL, CtY, IEN, IU, MH

Hempel, Karoline Luise $=$ Klencke, Karoline Luise von.

Henle, Elise = Levi, Elise

Henoch d'Albert, Pauline. ? - ?

Das Blumenmädchen. Schauspiel in 2 A. 1867. \{A-WÖN, GB-LBL, NN\}

Henrich, Hedwig = Wilhelmi, Hedwig.

Hensel, Friederike Sophie $=$ Seyler, Friederike Sophie

Herrigau, Willibert von = Pseudonym für: Löhn-Siegel, Maria Anna.

Herz, Wilhelmine $=$ Gensicke, Wilhelmine, 
Hesse, Katharina von. 1756 (München) - nach 1804. Geb. Reichsfreiin von Bossi von Löwenglau. Verh. Gräfin Morazani:

Prinz Egid von Bretagne. Originalschauspiel in $4 \mathrm{~A}$. Aus der französischen Geschichte bearbeitet. 1798. \{D-HUB, D-MBS, D-WüU, A-WÖN\}

Mehrere nicht genannte Trauer- und Lustspiele [Groß, Deutschlands Dichterinen 28].

Heyne, Therese $=$ Huber, Therese.

Hildeck, Leo = Pseudonym für: Meyerhof, Leonie.

Hill, Anna. 1860 (Frankfurt/M.) - 1912 (Frankfurt). Geb. Klees. Pseudonym: Sans Gêne:

Diana. Schwank in $1 \mathrm{~A} .1887$. (D-HHU-T, D-KöTM

Erlkönig. Schwank in 4 A. 1900 . \{D-HHU-T\}

Ich suche eine Stelle als Köchin! Lustspiel. 1891.

In der neuen Heimat. Festspiel für Kolonialvereine. 1908.

In Feindesland. Szene aus dem deutsch-französischen Kriege. [Drama?] 1899.

Kompromittiert. Lustspiel. 1889.

Der rote Schornsteinfeger. Schwank. 1905.

Hillern, Wilhelmine von. 1836 (München) - 1916 (Hohenaschau bei Prien/Chiemsee). Geb. Birch:

Die Augen der Liebe. Lustspiel in 3 A. 1878. \{D-BDS, D-ENU, D-FSU, D-GOB, D-HHU-T, D-KöTM, D-KöUSB, D-MüU, D-WeiZdK, A-WÖN, ICMILC, ICRL, MH]

Der Autographensammler. Lustspiel in 1 A. 1870. \{D-HHU-T, A-WÖN\}

Die Geier-Wally. Schauspiel in 5 A. 1880. [Dramatisierung ihres eigenen gleichnamigen Romans von 1875]. [D-BCHS, D-CorFB, D-DonFFH, D-ENU, D-FrU, D-FTT, D-KöTM, D-MarSN, D-TS, A-WÖN, GB-LBL\}

Guten Abend. Dramatischer Scherz in 1 A. 1872. (D-BDS, D-BUB, D-FSU, DKöTM, A-WÖN, GB-L,BL, NN\}

Guten Abend, Bluette. Anderer Tïtel von: Guten Abend.

Die Klötze von Rofen. Vorspiel zu Die Geier-Wally. 1880.

La Wally. Oper. 1922. \{D-FSU, GB-LBL\}

Hirschfeld, Ulla $=$ Wolff, Ulla

Hirschler, Anna. 1846 (Agram) - 1889 (Vöslau). Geb. Goldmann. Pseudonyme: A. Forstenheim, Anna Forstenheim

Caterina Cornaro. Historisches Drama. 1875

Der Wau-Wau. Lustspiel unter Benutzung von Spindlers Der Bräutigam von Otabaiti 1882.
Hobe, Charlotte von. 1792 (Chemnitz bei Neubrandenburg) - 1852 (Malchow/ Mecklenburg):

Dramatische Dichtungen. 1822. \{D-SML

Dit Einsiedlerinn am Hofe. Monodrama. Um 1830? (D-NeKW\}

Der Gondelfuihrer. Drama in 2 Abteilungen. O. J. (Dramatische Dichtungen. 1822.)

\{D-SML\}

Propertia. Trauerspiel in 5 A. O. J. (Dramatische Dichtungen. 1822.) \{D-SML\}

Hölder [auch Hoclder], Luise [auch Louise] Friederike Wilhelmine. 1763 (Stuttgart) 1843 (Aalen/ Württemberg). Geb. Faber. Pseudonym: Luise Hold:

Allerlei Schauspiele. 1832. [Enthält nicht genannte Schauspicle.]

Die arbeitsamen Kinder. Lustspiel in 1 A. (Kleine Schauspiele. 1835.) (A-GUB, AWÖN\}

Die Bescherung am St. Thomastage. Nachspiel in $2 \mathrm{~A}$. [Fortsetzung von Die arbeitsamen Kinder.] (Kleine Schauspiele. 1835.) [A-GUB, A-WÖN]

Das bestrafte Verbrechen. Schauspiel in 1 A. (Kleine Schauspiele. 1835.) \{A-GUB, AWÖN\}

Die bestraften Wildfange. Lustspiel in 1 A. (Neues Kinderthedter I, 1821.) \{IU, NN\} Bet' und arbeite, Gott bilft jederzeit. Lustspiel in $1 \mathrm{~A}$. (Dramatisierte Sprüchwörter. 1838.) \{D-MBS, OCl\}

Brigitte, oder Sie fallt mit der Thür zum Haus binein. Schauspiel in 1 A. (Neues Kindertheater II, 1822.) \{IU, NN\}

Der Denkzettel. Lustspiel in 1 A. O. J. (Die Familie LindorfIII, 1828.) \{D-HUL, D$\mathrm{KaMB}\}$

Dramatisierte Spriichwörter. 1838. \{D-MBS, OCL

Ehrlich währt am länosten. Schauspiel in 4 A. O. J. (Die Familie Lindorf IV, 1828.) \{D-HUL, D-KaMB $\}$

Die Familie Lindorf. 4 Bde. 1828. \{D-HUL, D-KaMB

Der Fingerring. Schauspiel in 2 A. O. J. (Die Familie Lindorf III, 1828.) (D-HUL, D-KaMB\}

Der Geburtstag. Lustspiel in 3 A. O. J. (Kleine Schauspiele, 1835; Die Familie Lindorf I, 1828.) \{D-HUL, A-GUB, A-WÖN\}

Die guten Kinder sind der Eltern größter Segen. Schauspiel in 3 A. (Dramatisierte Spriichwörter. 1838.) \{D-MBS, OCl\}

In der Not erkennt man den Freund. Schauspiel in 2 A. (Dramatisierte Sprïchwörter. 1838.) $\{\mathrm{D}-\mathrm{MBS}, \mathrm{OCl}\}$

Kleine Schauspiele. 1835. (A-GUB)

Der Maskenball. Lustspiel in 2 A. (Kleine Schauspiele. 1835.) \{A-GUB, A-WÖN\} Die Modedame. Lustspiel in 1 A. (Kleine Schauspiele. 1835.) \{A-GUB, A-WÖN\}

Die Morgenstunde hat Gold im Munde. Lustspiel in 1 A. (Dramatisierte Spruichwörter. 1838.) $\{\mathrm{D}-\mathrm{MBS}, \mathrm{OCl}\}$

Die Nacht im Walde. Schauspiel in 2 A. (Kleine Schauspicle. 1835.) (A-GUB, AWÖN\} 
Das Namensfest. Lustspiel in 3 A. (Kleine Schauspiele. 1835.) \{A-GUB, A-WÖN\} Neue Gesellschaftsspiele und Unterbaltungen. Dramensammlung [?] für Kinder. 1824. \{D-FSU\}

Die Neugierige. Lustspiel in 2 A. (Neues Kindertheater I, 1821.) \{IU, NN\}

Die nengierige Pauline. Schauspiel in 1 A. (Kleine Schauspiele. 1835.) (A-GUB, AWÖN\}

Der Schein trügt. Schauspiel in 2 A. (Dramatisierte Sprüchwörter. 1838.) (D-MBS, OCl\}

Der Schwarzkiunstler. Schauspiel in 1 A. (Kleine Schauspiele. 1835.) (A-GUB, AWÖN\}

Der ungezogene Knabe oder Beispiel einer schlechten Erziehung. Schauspiel in 1 A. (Neues Kindertheater II, 1822.) \{IU, NN\}

Der verlorne Sohn. Schauspiel in 4 A. O. J. (Die Familie Lindorf IV, 1828.) \{DHUL, D-KaMB]

Die versäumte Lustreise. Schauspiel in 1 A. (Kleine Schauspiele. 1835.) (A-GUB, AWON\}

Das Vogelschießen. Lustspiel in 3 A. (Newes Kindertheater I, 1821.) $\{\mathrm{IU}, \mathrm{NN}\}$

Was der Mensch wert ist, widerfahrt ihm. Schauspiel in $1 \mathrm{~A}$. (Dramatisierte Sprüchwörter, 1838.) \{D-MBS, OCl\}

Was Hänschen nicht lernt, lernt Hans nimmermehr. Lustspiel in $1 \mathrm{~A}$. [Fortsetzung von Der ungezogene Knabe.] (Neues Kindertheater II, 1822.) \{IU, NN\}

Was man in der frühen Jugend treibt, auch später gerne hängen bleibt. Schauspiel in 1 A. (Dramatisierte Spriichwörter: 1838.) \{D-MBS, OCl\}

Wer hoch steht, der sehe sich wobl vor, daß er nicht falle. Schauspiel in $1 \mathrm{~A}$. (Dramatisierte Sprichwörter. 1838.) \{D-MBS, OCl\}

Wie die Alten, so die Jungen. Drama in 2 A. (Dramatisierte Sprüchwörter. 1838.) \{D$\mathrm{MBS}, \mathrm{OCl}\}$

Die Zauberflasche. Schauspiel in 3 A. O. J. (Die Familie Lindorf I, 1828.) (D-HUL, D-KaMB

Die Zauber-Glocke. Schauspiel in 1 A. O. J. (Die Familie Lindorf II, 1828.) \{DHUL, D-KaMB

Der Zauberspiegel. Schauspiel in 2 A. (Neues Kindertheater II, 1822.) \{IU, NN\}

Zuerst getan, hernach bedacht, hat manchen in groß Leid gebracht. Lustspiel in $1 \mathrm{~A}$. (Dramatisierte Sprüchwörter. 1838.) [D-MBS, OCl\}

Hoffmann, Bertha Wilhelmine. 1816 (Prester bei Magdeburg) - 1892 (Berlin). Geb. Flügel:

Der böhmische Mägdekrieg. Drama. 1871.

Eine böse Sieben. Dramatisches Märchen. 1870

Cillis Weg zur Bühne. Schauspiel. 1873.

Der Corbeille oder Französische Liebe. Genrebild in 4 A. 1891. \{D-BUB\}

Ekkehard. Schauspiel in $4 \mathrm{~A}$. nach V. Scheffel. 1889. \{IEN\}

Die erbaute Hochzeit. Lustspiel in 5 A. 1880. \{D-BUB\}
Der Galgenvogel. Lustspiel. 1892.

Gustav Adolf. Trauerspiel. 1888.

In Tilsit. Historisch-dramatische Skizze. 1885. \{D-BUB\}

$J a$, oder Die Königin der Nacht. Lustspiel in 2 A. 1892. \{IEN\}

Margarete Minden. Trauerspiel. 1886.

Napoleon Bonaparte. Trauerspiel. 1884

Pantinia. Schwank. 1879

Der Ritter. Schauspiel. 1880.

Schön Else. Schauspiel. 1888

Der Strobkranz. Schauspiel in 4 A. 1889. \{IEN\}

Das zwölfte Paar. Schwank in 2 A. 1890. \{D-BSPK, D-BUB\}

Mehrere nicht genannte Dramen [Groß, Deutschlands Dichterinen 142].

Hoffmann, Kitty = Hofmann, Kitty

Hoffmann, Louise Jeanette Christiane = Gutbier, Louise Jeanette Christiane.

Hoffmeier, Hedwig = Hülle, Hedwig.

Hofmann, Anne Margarethe. ? (Frankfurt/M.) - ?:

Nicht näher bezeichnete Schauspiele [Schindel III, 167].

Unveröffentlichte dramatische Werke [Dawson, „Frauen und Theater" 424].

Hofmann (Friedrichs: Hoffmann), Kitty. ? - nach 1834 (Agram?). Geb. von Blei: Die Angebinde oder Familienliebe. Dramolet in 1 A. (Theater für Kinder. 1824.) \{NN\}

Gewinn durch Verlust. Schauspiel in 2 A. (Theater fir Kinder. 1824.) $\{\mathrm{NN}\}$ Die kleine Aschenbrödel. Schauspiel in 3 A. (Theater fiur Kinder. 1824.) \{NN Die Wundergaben. Szenenreihe. (Theater für Kinder. 1824.) \{NN\}

Hohenhausen, F. v. = Pseudonym für: Rüdiger; Elise.

Hohenhausen, Elise Friederike Freifrau von = Rüdiger, Elise

Hohenlohe, Sophie Prinzessin von $=$ Sophie, Prinzessin von Sachsen-Hildburghausen .

Holberg, Eleutheria = Pseudonym für: Paulus, Karoline.

Hold, Luise $=$ Pseudonym für: Hölder, Luise

Holderieder, Christiane Benedikte Eugenie $=$ Naubert, Christiane Benedikte Eugenie 
Holthausen, Johanna (Jeanette). 1812 (Cleve) - 1875 (Breslau). Geb. Schugt. Pseudonym: Agnes le Grave:

Beatrice di Cenci. Drama. O. J.

Dido. Tragödie. 1874. \{D-BSPK, D-KöUSB\}

Fortsetzung des Demetrius von Schiller. O. J.

Horschelt, Katharina. Um 1814 (Prag)

Der Berggeist. Zauberballett. O. J.

Der Mechanikus. 1814.

Huber, Christiane Friederike. ? [1721, 1729, 1730?] - 1799. Geb. Lorenz. Veröffentlichte anonym?:

Cleveland dritter Theil, oder: Die redliche Untreu. Trauerspiel in 5 A. 1756. \{MU (Milkrofilm)\}

Eine Bearbeitung von Lessings Miß Sara Sampson. O. J. (Philipp Stein, Deutsche Schauspieler I).

Weitere dramatische Bearbeitungen (Philipp Stein, Deutsche Schauspieler I.)

Huber, Ludwig Ferdinand = Pseudonym für: Huber, Therese.

Huber, Therese. 1764 (Göttingen) - 1829 (Augsburg). Geb. Heyne. Verh. Forster. Pseudonyme: Ludwig Ferdinand Huber, Therese:

Der alte Junggeselle. Lustspiel. (Neueres französisches Theater III, 1797.) \{D-BDS, DKöTM, A-WÖN\}

$D u$ und $D u$. Lustspiel. (Neueres französisches Theater I, 1795.) (D-BSPK, D-ChS, DFGM, D-GSU, D-HHU-T, D-KöTM, A-WÖN\}

Du und Sie. Lustspiel in 3 A. Bearb. (Neueres französisches Theater II, 1796.) \{DBSPK, D-GSU, D-HHU-T, D-KöTM, A-WÖN, CH-BSL]

Eitelkeit und Liebe. Lustspiel in 3 A. Bearb. (Neueres französisches Theater I, 1795.) \{D-BSPK, D-ChS, D-FGM, D-GSU, D-HHU-T, D-KöTM, A-WÖN, CH-BSL; MU (Mikrofilm)

Emilie, oder Die Spieler. Lustspiel in 5 A. Bearb. nach Montesquicu. (D-KöTM, AWON, MU (Mikrofilm)

Emilie von Varmont. Nach Louvet. 1794. (In Neueres französisches Theater?)

Der Friedensstifter. Lustspiel in $5 \mathrm{~A}$. (Neueres französisches Theater II, 1796.) \{DBSPK, D-FGM, D-GSU, D-HHU-T, D-KöTM, A-WÖN\}

Das heimliche Gesicht. Trauerspiel. 1790. (D-BDS\}

Juliane. Lustspiel in 3 A. 1796. \{D-KöTM, A-GUB\}

Miftrauen und Liebe. Lustspiel in 3 A. (Neueres französisches Theater II, 1796.) \{DBSPK, D-GSU, D-HHU-T, D-KöTM, A-WÖN\}

Neueres französisches Theater. 3 Bde. 1796. \{D-GSU, Bde. 1 u. 2 in D-HHU-T\}

Selbstsucht. Schauspiel in 5 A. (Neueres französisches Theater II, 1796.) \{D-BSPK, DFGM, D-GSU, HHU-T, D-KöTM, A-WÖN\}
Tartuffe der zweite oder die schuldige Mutter. Schauspiel. (Neueres französisches Theater I, 1795.) \{D-BSPK, D-ChS, D-FGM, D-GSU, D-HHU-T, D-KöTM, A-WÖN\} Der Trostlose. Lustspiel, übers. aus dem Französischen. 1794. \{A-WÖN\}

Die ungeladenen Gäste. Possc. (Neueres französisches Theater III, 1797.) \{D-BDS, AGUB, A-WÖN\}

Die Verdïchtigen. Lustspiel. (Neueres französisches Theater III, 1797.) (D-FGM, DGOB, A-WÖN\}

Der verliebte Briefwechsel. Lustspiel. (Neueres französisches Theater III, 1797.) [Im National Union Catalog Ludwig Ferdinand Huber zugeschrieben.] [D-BSPK, AWÖN\}

Die Weiber. Lustspiel. (Neveres französisches Theater III, 1797.) \{D-FGM, A-GUB, A-WÖN

Zwei Poststationen. Posse in 3 A. (Neueres französisches Theater I, 1795.) \{D-BSPK D-ChS, D-GSU, D-HHU-T, D-KöTM, A-GUB, A-WÖN\}

Huch, Ricarda [Octavia?]. 1864 (Braunschweig) - 1947 (Schönberg/Taunus), Verh. Zecconi oder Ceconi. Pseudonym: Richard Hugo:

Der Bundesschwur. Lustspiel. 1891. [CH-ZZ

Dornröschen. Märchenspiel. 1902. (D-BDS, D-BHU; D-HHU-T, D-KaMB, CHZZ\}

Dramen. (Gesammelte Werke V, hg. W. Emrich, Köln: Kiepenheuer \& Witsch 1971.) (D-BFU, D-BoU, D-FSU, D-HHSU, D-KaMB, D-MrU, D-MüRS, CHZZ, GB-LBL\}

Evoë. Dramatisches Spiel in 5 A. 1892. \{D-BDS, D-BHU, D-FSU, D-HHSU, DKaMB, D-KöTM, D-LKM, D-MrU, CH-ZDS, CH-ZZ\}

Fastnachtspossen. 1897. (D-BFU, D-BoU, D-FSU, D-HHSU, D-KaMB, D-MrU D-MüRS, CH-ZZ, GB-LBL

Das Geburtstagsständchen. 1914. \{D-BFU, D-BoU, D-FSU, D-HHSU, D-KaMB, D-MrU, D-MüRS, CH-ZZ, GB-LBL\}

Das Spiel von den Zürcher Heiligen. 1895. \{D-KaMB, CH-ZDS, CH-ZZ\}

Tod und Muse. 1901. \{D-BFU, D-BoU, D-FSU, D-HHSU, D-KaMB, D-MrU, D MüRS, CH-ZZ, GB-LBL\}

Hülle, Hedwig. 1794 (Övelgönne/Oldenburg) - 1861 (Varel/Oldenburg). Geb. Hoffmeier [Groß, Deutschlands Dichterinen: Hofmeier]. Pseudonym: Ludwig März: Die Geheimnisse des Carnevals. Drama in 5 A. nach dem Französischen. 1847. Die Nase. Lustspiel in $1 \mathrm{~A}$. und Alexandrinern. 1831.

Das Kranzbinden. Sammlung von Kreuzbinde- und Polterabendszenen. 1835.

Hugo, Richard = Pseudonym für: Huch, Ricarda.

Husch, P. von = Pseudonym für: Montenglaut, Henriette Artemisia Marianne von. 
Husch, Paul von = Pseudonym für: Montenglaut, Henriette Artemisia Marianne von.

Hyno, Elfriede Freiin von der. Um 1829. Geb. von der Düdemsee:

Der falsche Zahn. Lustspiel. O. J.

I. K. M. d. K. a. R. [Abküurzung von: Ihre Kaiserliche Majestät die Kaiserin aller Reussen] = Pseudonym für: Katharina (II.) Alexejewna, Kaiserin von Rußland.

Ibsen, Sigurd. 1859-1930:

Baumeister Solneß. Drama in 3 A. von Henrik Ibsen. Übers. vor 1893. \{D-BDS, DBHU, D-KaMB, D-KöTM\}

Robert Frank. Drama in 3 A. (Übers. von Julius Elias.) 1914. \{D-BHU\}

Tempel der Erinnerung. Drama in 1 A. (Original norwegisch). 1918. \{D-BHU, DKöTM

Ickstatt, Marie Franziska (Fanny) von. 1767 oder 1768 (Ingolstadt) - 1785 (München):

Skizze zu einem vaterländischen Trauerspiel, Ludwig der Strenge. O. J. (Pfalzbaierisches Museum III, 1785.) \{D-IS\}

Idem = Pseudonym für: Kremnitz, Maric (Mitc) von.

Imhof, Amalie von = Helvig, Amalie von

Iné, Paul = Pseudonym für: Harder, Pauline von.

Ion = Pseudonym für: Günderrode, Karoline von

Irene $=$ Pseudonym für: Ruhkopf, Julie

Isidor = Pseudonym für: Mauritius, Frau von.

Jaich, Minna = Kautsky, Minna.

Jean-Christ $=$ Pseudonym für: Gutbier, Louise Jeanette Christiane

Jenny = Pseudonym für: Thon, Eleonore.

Jerta = Pseudonym für: Frölich, Henriette.

Jochheim, Amalie. 1839 (Groß-Steinheim bei Hanau) - 1874 (Darmstadt). Geb. Römheld:

Die Liebe macht alle gleich. Singspiel. O. J.

Eine Szene aus dem Zigeunerleben. Singspiel. O. J.
Jordan, Henriette $=$ Keller, Henriette

\section{Juling, Marie. ? - ?:}

Jahres Abschied. Eine kleine Aufführung zum „Sylvester" in 1 A. O. J.

K., C. = Pseudonym für: Klauczek, Katharina.

Karoli, E. = Pseudonym für: Bernstein, Caroline.

Karsch, Karoline Luise $=$ Klencke, Karoline Luise von.

Kaskel, Sophie $=$ Baudissin, Sophie von

Katharina (II.) Alexejewna, Kaiserin von Rußland. 1729 (Stettin) - 1796 (Zarslroje Selo, heute Puschkin). Geb. Sophie Auguste Prinzessin von Anhalt-Zerbst. Pseudonym: I. K. M. d. K. a. R.:

Der Betrüger. Lustspiel in 5 A. (Übers. ihres russischen Originals). 1786. (Drey Lustspiele. 1788.) (D-BUB, D-HG, D-KöUSB, D-WeiZdK, A-WÖN, GB-LBL\}

Oh diese Zeit! Komödic in 3 A. 1772.

Dramaticeskija socinenija. 4 Bde. [Petersburg: Imp. Akad. nauk, 1901]. \{D-FrU

Drey Lustspiele wider Schwärmerey und Aberglauben. 1788. \{D-BDS, D-BUB, DFGM, D-HG, D-KöUSB, A-WÖN, GB-LBL\}

Der Familienzwist, durch falsche Warnung und Argwohn. Lustspiel in 5 A. (Übers. ihres russischen Originals). 1789. (D-ASU, D-BHU, D-BoU, D-BSPK, D-FGM, D-KaMB, D-SML, D-WeiZdK, A-WÖN, MU (Mikrofilm)\}

Le flatteur et les flattés. Proverbe. 1798. (Théatre de l'Hermitage. 1799.) (D-BDS, DFSU, D-HHU-T, D-KöTM, D-PGS]

Il n'y a point de mal sans bien. Proverbe. O. J. (Théatre de l'Hermitage. 1799.) \{DBDS, D-FSU, D-HHU-T, D-KöTM, D-PGS\}

Imitation de Shakespear. Scène historique. 1788. (Theátre de l'Hermitage. 1799.) \{DBDS, D-FSU, D-HHU-T, D-KöTM, D-PGS

La rage aux proverbes. 1798. (Théatre de l'Hermitage. 1799.) (D-BDS, D-FSU, DHHU-T, D-KöTM, D-PGS

Der sibirische Schaman. Lustspiel. (Übers, ihres russischen Originals). 1786. (Drey Lustspiele. 1788.) (D-BDS, D-BUB, D-FGM, D-HG, D-KöUSB, D-WeiZdK, AWÖN, GB-LBL\}

Théatre de l'Hermitage. 2 Bde. 1799. \{D-BDS, D-FSU, D-HHU-T, D-KöTM, DPGS\}

Le tracassier. Proverbe. 1798. (Theâtre de l'Hermitage. 1799.) (D-BDS, D-FSU, DHHU-T, D-KöTM, D-PGS\}

Der Verblendete. Lustspiel in 5 A. (Übers. ihres russischen Originals). 1786. (Drey Lustspiele. 1788.) \{D-BDS, D-BUB, D-FGM, D-HG, D-KöUSB, D-WeiZdK, AWÖN, GB-LBL\} 
Les Voyages de Monsieur Bontemps. Proverbe. 1788. (Théatre de l'Hermitage. 1799 ) \{D-BDS, D-FSU, D-HHU-T, D-KöTM, D-PGS\}

Kautsky, Min(n)a. 1837 (Graz) - 1912 (Berlin/Friedenau). Geb. Jaich. Pseudonym: Eckert:

Madame Roland. Historisches Drama. 1878. \{D-BSPK, GB-LBL\}

Keller, Henriette. 1835 (Marburg/L.) - 1909 (München). Geb. Jordan: Eine glänzende Partie. Lustspiel in 3 A. O. J. \{D-BDS, D-HHU-T, D-KöTM Der kleine Benno. Lustspiel in 3 A. 1859. \{D-BDS, D-BH\} Ein Musterkind. Lustspicl in 3 A. 1859. \{D-HHU-T, D-KöTM\}

Keller, Julie Freiin von $=$ Bechtolsheim, Julie Freifrau von .

Kemmerer, Luise Hedwig Freiin von = Pernet, Luise Hedwig von.

Kempner, Friederike. 1836 (Opatow/Posen) - 1904 (Gut Friederikenhof, Krs. Namslau/Schlesien):*

Antigonos. Trauerspiel in 3 A. 1880. \{D-BHU, D-GSU, D-WeiZdK, A-WUB, GBLBL, OCIW\}

Berenize. Trauerspiel in 5 A. und Jamben. 1865. \{D-BSPK, D-WeiZdK, A-WÖN, $\mathrm{CtY}$

Der faule Fleck im Staate Dänemark oder eine lustige Heirat. Lustspiel in 1 A. 1888. (D-BDS, D-BHU

Jahel. Drama. 1886. \{D-BHU, D-BSPK

Rudolf der Zweite, oder der Majestätsbrief. Trauerspiel. 1896. (D-BDS, D-BHU, DBSPK, D-BUB, D-DSB, D-GSU, D-WeiZdK, A-WÖN, GB-LBL, CtY

Kerner, Pauline. ? - ?:

Lohn der Tugend. Ritterschauspiel. O. J.

Keyserling (auch Keyserlingk), Margarete Adelheid Gräfin von. 1846 (Berlin) - 1930 (Breslau). Geb, von Dönniges:

Auf Sturmeshöhen. Shakespeare-Drama. 1909.

Sordello. Historisch-dramatisches Gedicht. 1899. \{D-BSPK, GB-LBL

Ein Todesurteil. Einakter. 1908

Keyserlingk, Margarete Gräfin von = Keyserling, Margarete Gräfin von.

Khuenberg, Sophie von $=$ Kleinert, Sophie

* Eine Ausgabe ihrer sämtlichen Werke, von der mir nicht bekannt ist, ob sie Dramen enthält, befindet sich in D-BoU.
Kiesekamp, Hedwig Carolina Theodora Maria Huberta Philomene. 1844 (Heinrichenburg/Westfalen) - 1919 (Münster/Westfalen). Geb. Bracht. Pseudonyme: Helene Kornelia (oder Kordelia), L. Rafael:

Heinrich. Drama. 1898. \{D-LKM

Die Liebe siegt! Lustspiel. 1898.

Der Prinz kommt. Lustspiel. 1898. \{D-LKM\}

Kistner, Anna (auch Anny). 1834 (Celle) - 1911 (Hannover). Geb. Gudewill. Pseudonym: Anny Albert:

Ein Abenteuer. Lustspiel in 1 A. 1877. \{D-BDS, D-EWA

Ehestandspaddagogen. Schwank in 2 A. 1878. \{In D-BDS unter dem Titel: Die Ehestandspädagogen; D-EWA

Eine eroberte Schwiegermutter. Schwank in 1 A. 1883. \{D-BDS, D-HUL\}

Der Herr Graf. Lustspiel in 1 A. 1877. \{D-BDS, D-EWA, D-GSU, D-KöTM, NN\}

Hut ab. Dramatischer Scherz. 1883. (D-BDS, D-EWA, D-HHU-T, D-HUL, DWeiZdK\}

Kleine Hochzeitsreise. Lustspiel in 1 A. 1885. \{D-HUL

Ein letzter Versuch. Schwank in 2 A. O. J. \{D-L,DB\}

Ein Schatz firs Haus. Lustspiel in 1 A. 1882. \{D-BDS, D-HHU-T, D-SPL\}

Eine wie die andere. Polterabendschwank in 2 A. für drei Damen. 1878. \{D-EWA, D-HUL

Klarfeld = Pseudonym für: Brachmann, Louise

Klauczek, Katharina. 1833 [Groß, Deutschlands Dichterinen: 1836] (Prag) - 1858 (Prag). Pseudonym: C. K

Lady Hunyady. O. J.

Kleinert, Sophie. 1863 (Graz) - 1937 (Villach) oder 1917 (Linz). Geb. von Khuenberg. Verh. Valduga:

Ein krafftiger Junge. Schwank. 1905.

Wabrheit. Volksschauspiel in 3 A. 1897

„Ferner ungedr. Bühnenstücke“ (Kosch)

Klencke, Karoline Luise von. 1754 (Fraustadt/Posen) - 1802 (Berlin). Geb. Karsch. Verh. Hempel. Pseudonyme: Helmina [?], Tochter der Karschin:

Der ehrliche Schweizer. Schauspiel in 2 Handlungen. 1776. \{D-FGM, D-HG, D-

HUL, D-KöTM, D-WeiZdK

Die Grazien. Vorspiel. 1777. \{D-HUL\}

Der Ruhm. Prolog zum Geburtstag Prinz Heinrichs von Preußen. [1777?]

Klees, Anna = Hill, Anna.

Klencke [Friedrichs: Klenke], Wilhelmine von = Chézy, Wilhelmine von. 
Klingenfeld, Emma. 1846 (Nürnberg) - 1935:

Auf dem Heimwege. Charakterbild in 1 A. von Alexander Kielland. Übers. O. J. \{DKöTM\}

Autoris. Drama [?] von Henrik Ibsen. Übers. O. J. \{D-KöTM\}

Das Fest auf Solhaug. Drama von Henrik Ibsen. Übers. Um 1885. (D-DSB, D-ES, D-EWA, D-KöTM, GB-LBL\}

Ein Handschuh. Schauspiel in 3 A. von Björnstjerne Björnson. Übers. 1867. \{DLDB, D-MüU, A-SUB\}

Hedda Gabler. Drama von Henrik Ibsen. Übers. 1891. (D-BHU, D-EWA, D$\mathrm{KaMB}\}$

Die Helden auf Helgeland. Drama von Henrik Ibsen. Übers. O. J. \{D-KöTM, D$\mathrm{W} \ddot{\mathrm{uU}}\}$

Henrik Ibsens sämtliche Werke in deutscher Sprache. Übers. mit Christian Morgenstern u. a. 1898-1904. \{D-AÖB, D-BHU, D-BiS, D-BoS, D-BUB, D-ChS, DDeLL, D-DUB, D-DZB, D-ENU, D-ES, D-GSU, D-HHU-T, D-HLB, D-HUL D-KöUSB, D-MarSN, D-MüRS, D-MüU, D-SML, D-TüU, D-WHLB, D-WüU, D-WuS, A-WÖN, CH-WiS, CtY, CU, GU, NCD, NN, OkU\}

Die Herrin von Oestrot. Historisches Schauspiel in 5 A. von Henrik Ibsen. Übers. 1877. \{D-KöTM, D-RoU, D-WüU, GB-LBL\}

Das Hünengrab. Drama von Henrik Ibsen. Übers. O. J. \{D-KöTM, D-Ẅ̈U\}

Der König. Drama in 4 A. von Björnstjerne Björnson. Übers. O. J. \{D-DiSB, DDSB]

Nordische Heerfahrt. Trauerspiel in 4 A. von Henrils Ibsen. Übers. 1876. \{D-ChS, D-HHU-T, D-MüS, D-RoU, D-TüU, D-WüU, A-WÖN, GB-LBL, DLC, MsU (Miksrolsarte)\}

Olaf Liljekrans. Drama von Henrik Ibsen. Übers. O. J. \{D-KöTM, D-WüU\}

Romeo und Julia. Dramatische Symphonie von Hector Berlioz. Übers, 1900. \{D$\mathrm{MrU}\}$

Rotkäppchen. Oper in 3 A. Libretto. Bearb. 1902. \{GB-LBL\}

Die Stïtzen der Gesellschaft. Drama von Henrik Ibsen. Übers. O. J. \{D-BHU, DKöTM, D-WüU, GB-LBL\}

Klitzing, Wilhelmine von = Bornstedt, Wilhelmine von

Klokow, Ida, 1850 (Daber bei Stettin) - 1912 (Berlin): Ein gefahrlicher Nebenbuhler. Lustspiel. 1875.

König Heinrich und Bertha von Susa. Lustspiel in 3 A. 1898. \{D-BSPK, A-WÖN\}

Königin Bertha. Historisches Lustspiel in 3 A. 1898. \{D-BSPK\}

Mehrere nicht genannte Lustspiele [Groß, Deutschlands Dichterinen 270].

Klopstock, Margaretha (Meta). 1728 (Hamburg) - 1758 (Hamburg). Geb. Moller. Pseud.: Margaretha:

Der Tod Abels. Trauerspiel, 1757. (Hinterlaß3ne Schriften, Hamburg 1759.) \{D-ASU,
D-BFU, D-DeLI, D-DGM, D-DSB, D-ES, D-FBPT, D-FrU, D-FSU, D-FT'T, DHLB, D-HHSU, D-HUL, D-KaMB, D-LKM, D-MBS, D-MrU, D-PBH, DQSM, D-RoU, D-RS, D-RSB, D-SchOS, A-WÖN, CH-CGBB, CH-CGK, CHSZ, GB-LBL\}

Knauff, Marie. 1842 (Berlin) - 1895 (Berlin)

Auf dem Holzwege! Schwank in 4 A. 1887. \{D-HHU-T, D-KöTM, D-MarSN, DWeiZdK, NN\}

Durchs Loch im Vorhang. 1891. \{D-BSPK\}

Ein gemuitlicher Abend. Lustspiel in 1 A. 1890. \{D-BDS\}

Ellen. Lustspiel in 1 A. 1877. \{D-BDS\}

In der Sprechstunde oder die Skatbrïder. Lustspiel in 1 A. 1893.

Der Nachbar. Lustspiel in 1 A. 1888. \{D-BDS\}

Die Nachkur. Lustspiel. 1889.

Onkel Don Juan. Lustspiel in 1 A. 1873. (D-BDS, D-HHU-T\}

Redaktionsgeheimnisse. Lustspiel in 1 A. 1887. \{D-BDS, D-HHU-T\}

Die vergessenen Schuhe. Schwank. O. J. \{D-HHU-T, D-WeiZdK\}

Wer zuletzt lacht. Schwank in 1 A. 1871. (D-BDS, D-HHU-T, D-KöTM, AWÖN

Knobelsdorff-Brenkenhoff, Nataly von = Eschstruth, Nataly von.

Knorring, Sophie von. 1775 (Berlin) - 1833 (Reval). Geb. Tieck. Gesch. Bernhardi; Die Alte vom Bach. Romantisches Schauspiel. (Dramatische Phantasieen. 1804.) (DBDS, D-BHU, D-FGM, D-HHSU, D-MBS, D-WeiZdK, IU, MH\}

Die Brïder. Romantisches Schauspiel. (Dramatische Phantasieen. 1804.) (D-BDS, D-BHU, D-FGM, D-HHSU, D-MBS, D-WeiZdK, IU, MH\}

Donna Laura. Lustspiel in 3 A. 1821.

Dramatische Phantasieen. Drei romantische Schauspicle. 1804. \{D-BDS, D-BHU, D-HHSU, D-MBS, D-WeiZdK, IU, MH\}

Egidio und Isabella. Trauerspiel, 1807. [Rostorfs Dichtergarten.]

Der erste April. Singspiel in 1 A. nach dem Französischen. 1814.

Friblingszauber. Romantisches Schauspiel. (Dramatische Phantasieen. 1804.) \{DBDS, D-BHU, D-FGM, D-HHSU, D-MBS, D-WeiZdK, IU, MH\}

Die vernünftigen Leute. Lustspiel. (Bambocciaden. Berlin 1799.) \{D-MBS\} Außerdem "noch manche [...] Schauspiele" (Schindel I, 258).

Koch, F. S. = Pseudonym für: Krickeberg, Sophie Friederike.

Koch, Sophie Friederike $=$ Krickeberg, Sophie Friederike

Köbner, Johanne Juliane Wilhelmine. 1794 (Rendsburg) - 1868 (Hamburg). Geb. von Schröter: 
Dännemarks erster Souverain. Nationalschauspiel in 5 A. 1833.

Skizzen eines episch-dramatischen Gemäldes zur Jubelfeier der Einfuibrung des Christentums vor tausend Jahren in unser Vaterland. 1828.

König, Sophic. ? - ?:

Der Roman einer Soubrette. Drama. 1822. \{D-WeiZdK\}

Koppy, Isabella Johanna Eleonora von $=$ Wallenrodt, Isabella Johanna Eleonora von.

Kordelia, Helene = Pseudonym für: Kiesekamp, Hedwig.

Kornelia, Helene = Pseudonym für: Kiesekamp, Hedwig.

Kortzfleisch, Sophie Eleonore von = Titzenhofer, Sophie Eleonore von.

Kotzebue, Christiane Gertrude von. 1769 (Estland) - 1803 (Berlin). Geb. von Krusenstjern [Goedeke: Krusenstern]:

Der Hofmeister. Schauspiel in 5 A. für Eltern und Erzieher. Freie Übers. nach d'Églantine. 1800. \{D-RS\}

Kotzebue, Karoline Johanne Amalie = Ludecus, Karoline Johanne Amalie.

Kraft, Anna Friederike (Frieda) Dorothea Erika. 1863 (Berlin) - nach 1913. Pseudonym: Werner Kraft:

Agrippina. Drama aus der Zeit Jesu in 5 A. 1894. \{D-KöTM

Elisabeth von Brandenburg. Drama in 5 A. 1905. \{D-KöTM\}

Saul. Biblisches Drama in 5 A. O. J. \{D-BSPK, C-VU\}

Mehrere Lustspiele in französischer Sprache, ca. 1878-1880.

Weitere unveröffentlichte Dramen; Titel nicht ermittelt.

Kraft, Werner $=$ Pseudonym für: Kraft, Anna Friederilke

Krause, Luise Charlotte. 1785 (Klein Neundorf bei Löwenberg/Schlesien) - nach 1825. Geb. von Fink:

Dichtungen und dramatische Scenen. 1845. \{D-HUL\}

Dramatische Scenen zu Polter-Abenden. 1843.

Erzäblungen, Polterabendscherze, dramatische Scenen, Fest- und Gelegenheitsgedichte. 1830

Krederer, Josephine $=$ Scheffel, Josephine.

Kremnitz, Marie (Mite) von. 1852 (Greifswald) - 1916 (Berlin-Wilmersdorf). Geb. von Bardeleben. Pseudonyme: George Allan, Idem:
Anna Boleyn. Historische Tragödie (mit Elisabeth von Rumänien). 1886. (D-BDS, D-BUB, D-FSU, D-LGS, D-MarSN, PPLT\}

Die Kammerwabl. Rumänische Zustandsburleske in 4 A. Mit Hermann Kienzl frei nach J. L. Caragiales' Der verlorene Brief. 1917. \{D-BFU, D-KöTM, D-LDB\} Mitra. Drama [?]. [Zusammen mit Elisabeth von Rumänien oder Werk der letzteren?]. 1887. \{A-WUB\}

Weitere Stücke in Zusammenarbeit mit Elisabeth von Rumänien?

Kreopola [Pseudonym für wen?]. ? - ?:

Der Tischler, oder der unbekannte Schwager. 3 A. 1816.

Kretschman, Lily von $=$ Braun, Lily.

Krickeberg, Karl von = mögliches Pseudonym für: Krickeberg, Sophie Friederike.

Krickeberg, Sophie Friederike. 1770 (Hannover) - 1842 (Berlin). Geb. Koch. Pseudonyme: Euphrosyne, F. S. Koch. Mögliches Pseudonym: Karl von Krickeberg: Die Ehrenrettung. Schauspiel in 2 A. Freie Bearbeitung nach Théaulon. 1827. \{DBDS, NNU, NNU-W, PU\}

Das Heiratsgesuch. Lustspiel. 1823. \{Unter dem Verfassernamen „Karl von Krickeberg" an D-BH; in ADB XVII, 161 ihr zugeschrieben\}

Herr Lesperance, oder die Kunst, Stellen zu erlangen. Vaudeville in 1 A. nach Scribe. 1817.

Der Kammerdiener. Lustspiel in $1 \mathrm{~A}$. nach Scribe und Mélesville. 1824. \{D-KöTM\} Klein Rothkäppchen. Feenoper in 3 A. nach Théaulon. 1819. \{D-BDS

Die Odaliske. Lustspiel in 1 A. mit Tanz. Frei nach dem Französischen. 1821.

Philipp. Drama in $1 \mathrm{~A}$. frei nach dem Französischen. 1830. \{D-BDS, D-BH, DBUB, D-HHU-T, D-KöTM, A-WÖN\}

Robinson Crusö̈. Melodrama in 3 A. nach dem Französischen. 1827.

Das Schützenfest. Singspiel in 2 A. mit Tanz. Freie Bearb. nach dem Französischen. 1820.

Der Sollizitant, oder Die Kunst, ein Amt zu erhalten. Aufgef. 1831. [Bearb, von Herr Lesperance?]

Wer trägt die Schuld? Lustspiel in 1 A. nach Scribe. 1830. \{D-BDS, D-KöTM, AWÖN

Krockow, Luise Margarethe Regina Gräfin. 1749 (Mohrungen/ Ostpreußen) - 1803 (Krockow bei Danzig). Geb. von Göppel. Verh. von Brauneck: Eduard der Dritte. Trauerspiel nach Gresset. 1795 [oder 1757].

Krones, Therese. 1801 (Freudenthal/Sudeten) - 1830 (Wien): Cleopatra. Travestie mit Gesang in 2 A. 1830. Ungedr.

Der Nebelgeist und der Branntweinbrenner. Komisches Zauberspiel mit Gesang in 2 A. 1829. Ungedr. 
Sylphide, das Seefridulein. Romantisch-komisches Zauberspiel mit Gesang. 1828. \{DMarSN, A-GUB, GB-LBL, MH, NN, ViU\}

Krug, Charlotte Anne. 1806 (Leipzig) - 1877 (Dresden). Geb. Schnorr von Carolsfeld:

Ungenannte „zahlreiche Lustspiele für die Jugend“ [Groß, Deutschlands Dichterinen $114]$.

Krukenberg, Elisabeth (Elsbeth). 1867 (Giebichenstein bei Halle/Saale) - 1954 (Stammheim, Krs. Calw/Württemberg). Geb. Conze:

Ein Festzug. Festspiel für Polterabende. O. J.

Kleine dramatische Festspiele. Zu Polterabendaufführungen. 1873.

Màrchenbilder. Festspicl für Polterabende. O. J.

Prinz Frühling und Prinzessin Rose. Festspiel für Polterabende. O. J.

Ein Winzerzug. Festspiel für Polrerabende. O. J.

Weitere Festspiele [Groß, Deutschlands Dichterinen 140].

Krusenstjern, Christiane von $=$ Kotzebue, Christiane von .

Kühne, Henriette. 1822 (Siegburg) - 1894 (Hostervitz bei Dresden). Geb. Harkort Kinder- und Puppentheater. Dramatisierte Märchen [10]. 1877. \{A-WÖN, OCl\}

Kühne, Julie Mathilde. 1837 (Stettin) - nach 1898. Geb. Poll. Pseudonyme: Friedrich Masche, Martin Masche, Thure, Dievenow:

Aspasia. (Anderer Titel von: Die Emancipations-Schwadrmerin).

Die Badegesellschaft. Lustspiel. 1875.

Dramatische Scherze. Mit: Die Emancipations-Schwärmerin. O. J.

Elfriede Laub, oder Weib und Mensch. Drama. 1873.

Die Emancipations-Schwadrmerin. Lustspiel in 5 A. O. J

Gesammelte dramatische Werke. 1908. \{D-LKM\}

Das Rattenschloß, oder: Der Einzug der Franzosen in Berlin. Lustspiel. 1876. \{DBHU\}

Sie will wie er und er ihr Glïck. Lustspiel. 1882

Kulmann, Elisabeth. 1808 (St. Petersburg) - 1825 (St. Petersburg):

Zwei Tragödien von Alfieri. Übers. O. J. (Sämtliche Dichtungen. 1835). \{D-BDS, DBoU, D-BUB, D-FSU, D-HUB, D-HUL, D-MarSN, D-SML, D-WeiZdK, AWÖN, NjP\}

Trauerspiele von Oserow. Übers. O. J. (Sämtliche Dichtungen. 1835). \{D-BDS, DBoU, D-BUB, D-FSU, D-HUB, D-MarSN, D-SML, D-WeiZdK, A-WÖN, GBLBL, NjP\}

Kulmus [auch Culmus], Luise Adelgunde Victorie = Gottsched, Luise Adelgunde Victorie.
L., F. v. = Pseudonym für: François, Louise von.

L., Mara = Pseudonym für wen? ? - ?:

Der Wendewein. Schwank. 1830

La Motte-Fouqué, Karoline de = Motte-Fouqué, Karoline de la.

Laddey, Emma. 1841 (Elbing) - 1892 (München), Geb. Radtke. Pseudonym: Hermine:

Adele oder des Schicksals Wechsel. Drama. 1868.

Antonio. Drama. 1868

Lamprecht, Bertha Henriette Christine. 1800 [Groß, Deutschlands Dichterinen: 1822] Otterndorf bei Hamburg) - 1872 (Bergedorf bei Hamburg). Geb. Valett: Der arme Heinrich. Drama nach Hartmann von Aue. 1861.

Lange, Margarethe $=$ Bernbrunn, Margarethe .

Lazarus, Nahida Ruth Anna Maria. 1849 (Berlin) - 1928 (Meran). Geb. Sturmhoefel bzw. Schasler. Verw. Remy:

Constanze. Schauspiel in 5 A. 1879. \{D-BSPK, D-FSU, D-KöTM, D-WeiZdK\}

Domenico. Drama. 1884.

Die Grafen Eckhardstein. Schauspiel in 5 A. 1880. \{D-BSPK, D-KöTM, DWeiZdK

Nationale Gegensitzze. Schauspiel in 4 A. 1884. \{D-SiS

Die Rechnung ohne Wirt. Drama. 1870

Schicksalswege. Volksschauspiel. 1880.

Mehrere nicht genannte Lustspiele [Groß, Deutschlands Dichterinen 139].

Ledochowska, Maria Theresia Gräfin. 1863 (Loosdorf/Niederösterreich) - 1922

(Rom). Pseudonyme: Africanus, Alexander Halka:

Baronesse Mizi. Drama. O. J.

Die heilige Odilia. Drama. 1884. \{D-BSPK\}

König Ludwig der Heilige. Drama. 1889.

St. Aloysius wacht. Drama. O. J. \{D-BSPK\}

Von Hütte zu Hütte. Drama. 1912. \{D-BDS\}

Das Weinkörbchen. Drama. O. J. \{D-BDS\}

Zaida, das Negermiddchen. Volksdrama. 1889. (A-SMCA\}

Leisler, Luise $=$ Plönnies, Luise von.

Leitenberger, Johanna $=$ Wolf, Johanna 
Lengefeld, Caroline von $=$ Wolzogen, Caroline Friederike Sophie Auguste von.

Lengefeld, Charlotte von = Schiller, Charlotte von

Leonhardt, Caroline $=$ Pierson, Caroline

Leonhardt-Lyser, Caroline $=$ Pierson, Caroline.

Leony, Marie. 1852 (Züllichau) - nach 1913. Geb. ?:

Auf glatter Bahn. Lustspiel. 1905.

Fallstricke. Lustspiel. 1898

Das Geliubde. Lustspiel. 1902.

Das Glïck. Schauspiel. 1901.

Irrlichter. Schwank. 1908.

Eine kleine Separatvorstellung. Drama? 1902.

Romantisch. Lustspiel. 1908.

Unter falscher Flagge. Lustspiel. 1908.

Lessing, Karoline [Goedeke: Caroline] Helene Beata Friederike. 1779 (Breslau) 1834 (Altona). Geb. Meitzen:

Der Lesethee. Lustspiel. 1826.

Létang, Anna Baronin von. 1850 (Brüssel) - ? Verh. von Loos-Corswarem (oder LoozCorswarem):

Dem Manne ist alles erlaubt. Schauspiel in 4 A. 1882. \{D-FSU, D-KöTM, D-LKM\}

Levi, Elise. 1832 (München) - 1892 (Frankfurt a. M.). Geb. Henle: Der 18. Oktober. Schauspiel. 1871. \{D-BDS, D-HHU-T, D-WeiZdK\} Aus Goethes lustigen Tagen. Lustspiel in 4 A. 1876. \{D-BDS, D-BHU, D-DGM, DHHU-T, D-KaMB, D-KöTM, D-MüS, D-MüU, D-WeiZdK, A-WÖN, A-WUB, GB-LBL, MB\}

Backfischchens Theaterfreuden. Ein Geschenk fir große und kleine Frduleins. Lustspiel. 1887.

Ein Duell. Lustspiel. 1869.

Durch die Intendanz. Lustspiel in 5 A. 1878. (D-BDS, D-BSPK, D-ENU, D-HHUT, D-KaMB, D-KöTM, D-MüS, D-MüU, D-WeiZdK, A-WÖN, A-WUB, ICRL, $\mathrm{MH}, \mathrm{MsU}, \mathrm{NN \}}$

Entehrt. Schauspiel in 5 A. 1879. \{D-BDS, D-BUB, D-FSU, D-HHU-T, DKöTM, MB, NN\}

Der Erbonkel. Lustspiel in 5 A. 1887. \{D-BDS, D-ENU, D-FSU, D-HHU-T, DKöTM, D-LDB, D-WeiZdK, A-WUB, NN\}

Excentrisch. (Zeitgemäß. Excentrisch. Ruhebedïrfig. Drei Bühnenwerke.) 1890 (Neuausg. 1891).
Das Johanniskäferchen. (Rosa von Tannenburg. Der Ring. Das Johanniskäferchen. Drei Schauspiele für die Jugend frei nach C. v. Schmid ... bearb.) 1891

Liebesqualen. Lustspiel. 1881.

Manon. Opernlibretto. 1880.

Murillo. Opernlibretto. 1887. $\{\mathrm{MB}\}$

Percy. Drama frei nach Galen. O. J.

Der Ring. (Rosa von Tannenburg. Der Ring. Das Johanniskäferchen. Drei Schauspiele für die Jugend frei nach C. v. Schmid ... bearb.) 1891.

Rosa von Tannenburg. (Rosa von Tannenburg. Der Ring. Das Johanniskäferchen. Drei

Schauspiele für die Jugend frei nach C. v. Schmid ... bearb.) 1891.

Ruhebedürftig. (Zeitgemäß. Excentrisch. Ruhebedürftig. Drei Bühnenwerke.) 1890 (Neuausg. 1891).

Der Wiener in Stuttgart. Lustspiel in 5 A. 1879. (In D-BDS unter dem Titel: Die Wiener in Stuttgart.]

Zeitgemäß. (Zeitgemäß3. Excentrisch. Ruhebedürftig. Drei Bühnenwerke.) 1890 (Neuausg. 1891).

Der zweite September. Politisches Lustspiel. 1870.

Liebhaber, Amalie Luise Henriette von. 1779 [Goedeke und Groß, Deutschlands Dichterinen: 1781] (Wolfenbüttel) - 1845 (Betlin). Pseudonym: Amalie Louise:

Der Apfel von Balsora. Drama. O. J.

Arria und Patus. Trauerspiel in 3 A. O. J.

Asfendier. Trauerspiel in 5 A. O. J.

Chriemhild. Trauerspiel in 5 A. O. J.

Der Einsiedler. Posse in 3 A. O. J.

Die Erhebung des Hauses Braganza. Trauerspiel in 5 A. O. J.

Der Erznarr und der Sonderling. Lustspiel in 3 A. O. J.

Friedrich der Große. Vorspiel in 1 A. zu: Maria Theresia. O. J.

Harun al Raschid. Trauerspiel in 5 A. O. J.

Hermann und Thusnelda. Trauerspiel in $5 \mathrm{~A}$. O. J.

Iglu und Arasmin. Schauspiel in 3 A. O. J.

Maria Theresia. Drama in 4 A. O. J.

Octavianus Augustus. Trauerspiel in 4 A. O. J.

Serap und Malafride. Drama in 3 A. O. J.

Siegfried. Trauerspiel in 3 A. O. J.

Thur von Thurem. Drama in 3 A. O. J.

Lina $=$ Pseudonym für: Brochowska, Pauline von.

Linden, E. v. = Pseudonym für: Heinrichs, Emilie.

Link [auch Linck], Catharina Salome. 1695. (Straßburg) - nach 1743. Geb. Felz (Goedelke III/2; Gesammelte Frauenzimmergedichte: geb. Link). Verh. Witter: 
Polyeuctes ein Märtyrer. Christliches Trauerspiel von Corneille. Übers. 1727. \{DGSU\}

Link, Wilhelmine $=$ Flamm, Wilhelmine

Lipschitz, Gertrud. 1860 (Bonn) - ?:

Märchenerscheinungen im Kindestraum. Märchenspiel in 1 A. 1895. (D-BSPK, DKaMB, D-KöTM]

Litahorsky, Jean = Pseudonym für: Wolf, Johanna.

Litahorsky, Marie = Pseudonym für: Wolf, Johanna.

Löhn, Maria Anna = Löhn-Siegel, Maria Anna.

Löhn-Siegel, Maria Anna. 1830 (Naundorf bei Freiberg/Sachsen) - 1902 (Dresden). Geb. Löhn. Pseudonyme: Lork Alban, Willibert von Herrigau:

Bei $40^{\circ}$ R. Lustspiel, O. J.

Das falsche Jettchen. Dramatischer Scherz. O. J. \{D-WeiZdK\}

Gefahr über Gefahr. Lustspiel. 1858. \{D-WeiZdK\}

Hartmann von Siebeneichen. Drama [?]. O. J. \{D-WeiZdK\}

Iduna. Drama in 1 A. 1854 . \{D-BDS, D-HHU-T\}

Im Finstern. Original-Lustspiel. 1860. \{A-WÖN\}

Liebeständelei und Liebe. Lustspiel. O. J. \{D-WeiZdK

Luisa Strozzi. Trauerspiel in 5 A. 1861. \{D-BH, D-HHU-T, D-LKM, A-WÖN\}

Odowalsky. Schauspiel in 5 A. Freie Bearb. von Caroline Pichlers Roman Die Schweden vor Prag. O. J. \{D-BDS, NN\}

Odysseus auf Ogygia. Antikes Drama. 1845. \{D-LKM, D-ZCW, GB-LBL\}

Der Philosoph. Lustspiel. O. J.

Pindars Werke. Lustspiel. O. J.

Rechter und linker Flïgel. Lustspiel in 1 A. 1861. \{D-BDS, D-FSU, A-WÖN\}

Wahrscheinlich weitere Dramen [Groß, Deutschlands Dichterinen 129].

Lohmann, Friederike Johanna. 1749 (Wittenberg) - 1811 (Leipzig). Geb. Ritter. Verh. Häbler:

Der blinde Harfner. Schauspiel in 4 A. Bearb. nach Veit Weber [Pseud]. 1791. \{DASS, D-ASU, D-BSPK, D-MüU, MU (Mikrofilm)

Die Mühle an der Elbe. Schauspiel [?] nach einer Erzählung. O. J.

Loos-Corswarem, Anna von = Létang, Anna Baronin von.

Looz-Corswarem, Anna von = Létang, Anna Baronin von.
Lorenz, Christiane Friederike $=$ Huber, Christiane Friederike

Lorenz, P. = Pseudonym für: Schabelsky, Elisabeth (Elsa) Alexandrowna von.

Lucius, Christiane Karoline $=$ Schlegel, Christiane Karoline.

Luckemeier; Mathilde = Wesendonck, Mathilde.

Ludecus, Karoline Johanne Amalie. 1757 (Wolfenbüttel) - 1827[?] (Weimar?). Geb. Kotzebue. Pscudonym: Amalie von Berg [Goedeke, Kosch, von Hoff: Amalie Berg]: Johanne Gray. Trauerspiel in 5 A. 1806. \{D-BHU, D-BSPK, D-HL, A-WÖN\}

Luigi, Gola = Pseudonym für: Luis, Olga.

Luis, Olga. 1858 (Hamburg) - nach 1898. Pseudonym: Gola Luigi: Auf geradem Wege. Dramatische Skizze in 1 A. 1882. \{D-BSPK, D-HHSU\} Die Kunstdilettantin. Drama. Vor 1885.

Zu spadt! Dramatische Szene. Vor 1885.

Luise Friederike, Herzogin von Mecklenburg-Schwerin. 1722 - 1791. Geb. Prinzessin von Württemberg:

Liebhaber seiner Frau. Drama von Boissy. Übers. oder Bearb. 1754. \{D-SML\}

Luise Friederike, Prinzessin von Württemberg = Luise Friederike, Herzogin von Mecklenburg-Schwerin.

Lyser, Caroline $=$ Pierson, Caroline .

M., Isidor v. = Pseudonym für: Mauritius, Frau von.

M. R. S. = Pseudonym für: Reichardt-Stromberg, Mathilde.

Mädler, Minna von, 1807 [Goedeke und Groß, Deutschlands Dichterinen: 1804; Brümmer: 1809] (Hannover) - 1891 (Hannover). Geb. von Witte. Pseudonyme Minna, Minna Witte:

Die Flitterwochen. Lustspiel nach dem Französischen. O. J.

Die Mißverständnisse eines Abends. In $5 \mathrm{~A}$. Bearb. nach Goldsmiths She stoops to conquer. 1852.

März, Ludwig = Pseudonym für: Hülle, Hedwig.

Mai, Leo = Pseudonym für: Megerle von Mühlffeld, Therese. 
Maltzan, Malwine Luise Charlotte Hildegard Gräfin von. 1812 (Berlin) - 1899 (Charlottenburg):

Amphitryon. Lustspiel in 3 A. von Molière. Übers. O. J. (Molières Sämmtliche Werke in zwei Bänden. 1871.) \{D-EWA, D-HUL, D-LDB, D-SPL

Athalie. Drama von Racine. Úbers. Um 1875. (D-DiSB, D-DSB, D-ENU, DMüU, D-SML, D-WeiZdK\}

Bajazet. Drama von J. Racine. Übers. O. J. \{D-DSB, D-ENU\}

Der Cid. Drama von Corneille. Übers, 1873. \{D-BFU, D-DiSB, D-DSB, D-ENU, D-FSU, D-HHSU, D-LDB, D-MüU, D-RS, D-WeiZdK, D-WHLB, A-SUB, CHWiS\}

Don Garcia von Navarra, oder der eifersïchtige Prinz. Heroisches Lustspiel in 5 A. von Molière. Übers. O. J. (Molières Sämmtliche Werke in zwei Bänden. 1871.) \{DEWA, D-HUL, D-LDB, D-SPL

Die gelehrten Frauen. Lustspiel in 5 A. von Molière. Übers. O. J. (Molières Sämmtliche Werke in zwei Bänden. 1871.) (D-DiSB, D-DSB, D-EWA, D-HUL, D-LDB, D-SPL, D-WeiZdK, A-SUB\}

Liebeszwist. Lustspiel in $5 \mathrm{~A}$. von Molière. Übers. O. J. (Molières Sämmtliche Werke in zwei Bänden. 1871.) (D-EWA, D-FBPT, D-HUL, D-LDB, D-SPL, A-SUB\} Lucretia. Trauerspiel in 5 A. von Ponsard. Übers. 1875-79. [D-BS, D-ENU, D LDB\}

Melicerta. Heroisches Schäferspiel in $2 \mathrm{~A}$. von Molière. Übers. O. J. (Molières Sämmtliche Werke in zwei Bänden. 1871.) \{D-EWA, D-HUL, D-LDB, D-SPL\} Die Prinzessin von Elis. Lustspiel in 5 A. von Molière. Übers. O. J. (Molières Sämmt liche Werke in zwei Bänden. 1871.) (D-EWA, D-HUL, D-LDB, D-SPL

Sganarelle, oder der Habnrei in der Einbildung. Verskomödie in 1 A. von Molière. Übers. O. J. (Molières Sürnmtliche Werke in zwei Bänden. 1871.) (D-EWA, D-HUL, D-LDB, D-SPL,

Der Sicilianer, oder der Verliebte als Maler. Lustspiel in 1 A. von Molière. Übers. O. J. (Molières Sämmtliche Werke in zwei Bänden. 1871.) (D-EWA, D-HUL, DLDB, D-SPL\}

Der Unbesonnene, oder Immer zur Unzeit. Verskomödie in 5 A. von Molière. Übers. O. J. (Molières Sämmtliche Werke in zwei Bänden. 1871.) \{D-EWA, D-HUL, D LDB, D-SPL\}

Zaïre. Drama von Voltaire. Übers. Um 1875. \{D-FSU\}

Weitere Übersetzungen [Groß, Deutschlands Dichterinen 143].

Margaretha $=$ Pseudonym für: Klopstock, Margaretha

Maria = Pseudonym für: Plessen, Maria Sophie Christiane von.

Maria Antonia Walpurgis, Kurfürstin von Sachsen. 1724 (München) - 1780 (Dresden). Geb. Prinzessin von Bayern. Pseudonyme: E. T. P. A., Ermelinda Taléa: Demetrio. Übers. nach Metastasio. 1749. \{D-DeLL
Der Nothleidende. Schauspiel in 4 A. von Louis Sebastian Mercier. Úbers. 1773. \{D$\mathrm{KaMB}\}$

Der Sieg der Treue. Schäferspiel. 1767. \{In D-MBS unter dem Titel: Der Triumph der Treue; D-ZCW\}

Talestri regina delle amazzoni. Talestris, Königinn der Amazonen. Singspiel. [Ital. und deutsch.] 1765. [D-FSU, D-GSU, D-HHSU, D-HUL, D-MBS, D-WeiZdK, D-

WHLB, D-WoHA, nur ital. in A-WÖN; MU (Mikrofilm)\}

Il trionfo della fedeltà. Libretto. 1754. \{D-DSA, D-GSU, D-HUL, D-MBS, DWHLB, D-WoHA, A-WÖN, MiU, NN\}

Maria Antonia Walpurgis, Prinzessin von Bayern $=$ Maria Antonia Walpurgis, Kurfürstin von Sachsen.

Maria Aurora, Gräfin von Königsmark, 1668 - 1728: Schauspiel von den drei Töchtern des Cecrops. O. J

Maria v. = Pseudonym für: Zay von Csömör, Maria Elisabeth Helene Freiin von.

Marien Kind = Pseudonym für: Handel-Mazzetti, Enrica von.

Mariot, Emil = Pseudonym für: Mataja, Emilie

Marr; Elisabeth. Um 1828 (Heinrichswalde/Mecklenburg) - 1901 (Weimar). Geb. Sangalli. Pseudonym: Sankt Galli:

Eine Mutter. Schauspiel in 4 A. 1899. \{D-BSPK\}

Die Macht der Vorurteile. Drama. 1849. \{A-WÖN\}

Vater und Sohn. O. J. \{D-KöTM\}

Marriot, Emil = Pseudonym für: Mataja, Emilie.

Masche, Friedrich $=$ Pseudonym für: Kühne, Julie Mathilde

Masche, Martin = Pseudonym für: Kühne, Julie Mathilde.

Mataja, Emilie. 1855 (Wien) - 1938 (Wien). Pseudonym: Emil Mariot oder Marriot: Gretes Glïck. Schauspiel in 3 A. 1897. (D-BDS, D-BHU\} Der Heiratsmarkt. Schauspiel. 1894. \{D-BHU, GB-LBL\}

Mathilde Franziska = Pseudonym für: Anneke, Mathilde Franziska

Mautitius, Frau von. ? - ? Pseudonyme: Isidor, Isidor v. M: Leonora. Trauerspiel in 2 A. 1826. \{D-CorFB\} Die verfangliche Wette. Humoristischer Schwank, 183-? 
May, Sophie = Pseudonym für: Mayer, Sophie Friederike Elisabeth

Mayer, Friederike $=$ Ellmenreich, Friederike

Mayer, Sara $=$ Grotthuss, Sara Freifrau von.

Mayer, Sophic Friederike Elisabeth [Groß, Deutschlands Dichterinen: Meyer, Friderike Elise]. 1778 [Goedeke: 1788] (Berlin) - 1827 (Berlin). Pseudonym: Sophie May: Die Blumensprache. Charade in 3 Abteilungen. O. J. (Thalia II, 1823.) \{D-HUL, DTS, D-WeiZdK\}

Die Bïrgerkrone. Viersilbige Charade. O. J. (Thalia II, 1823.) (D-HUL, D-TS, DWeiZdK]

Polterabend-, Geburtstags- und Festspiele. O. J. (Thalia III, 1823.) (D-HUL, D-TS, D-WeiZdK\}

Die Posttasche. Charade in 3 Abteilungen. O. J. (Thalia II, 1823.) \{D-HUL, D-TS D-WeiZdK\}

Mayreder, Rosa. 1858 (Wien) - 1938 (Wien). Geb. Obermayer. Pseudonym: Franz Arnold:

Anda Renata. Ein Mysterium in 2 Teilen und 12 Bildern. 1934. \{D-FSU, D-LDB, CH-DBG)

Der Corregidor. Opernlibretto in 4 A. 1896. \{D-BFU, D-BHU, D-DeLL, D-ES, DFrU, D-HHSU, D-LDB, D-MrU, D-SPL, A-WÖN, CH-WiS, CH-SGK, CH-ZZ\}

Medem, Elisa Reichsgräfin von = Recke, Elisa von der

Megerle von Mühlfeld, Therese. 1813 (Preßburg) - 1865 (Wien). Geb. Pop von Popenburg. Pscudonym: Leo Mai:

Die Armen und die Elenden. Bilder aus dem französischen Volksleben. 1864. \{DBDS, A-WÖN, A-WUB]

Eine Bauernfamilie. Lebensbild nach einer Volkserzählung aus dem Oberlande. Um 1860. \{A-WÖN\}

Ein entlassener Striffling. Schauspiel. Vor 1848. \{D-BDS, A-WÖN\}

Der Graf von Monte Christo. Schauspiel. Vor 1848.

Im Dorfe. Ländliches Charaktergemälde. 1859. \{D-BDS, A-WÖN, A-WWUB\}

Die Obsthändlerin des Königs. Nach dem Französischen. 1853. \{D-BDS, A-WÖN A-WUB\}

Onkel Tom. Amerikanisches Zeitgemälde nach Beecher-Stowe. 1853. \{A-LBS, AWÖN, A-WUB\}

Die Straßentdnzerin von Paris. Drama? Dramat. Bearb.? 1860. \{A-WUB\}

Die Verlassene. Volksdrama in 5 A. Freie Bearb. nach dem Französischen. 1863. \{AWÖN, A-WUB, NN

Der Waldmichel. Drama? Dramat. Bearb.? 1861. \{A-WUB\}
Ein weiblicher Monte Christo 1859. \{D-HHU-T, A-WÖN, A-WUB\} Ein Wiener Kind. Volksstïck mit Gesang. 1858. \{A-WÖN\}

Zwei Pistolen. Volksdrama in 1 A. mit Gesang und Tanz. Freie Bearb. aus dem Ungarischen. O. J. \{D-BDS\}

Nach Groß insgesamt „(über 60) bühnengerechte Charaktergemälde, von denen viele nicht gedruckt sind" (Deutschlands Dichterinen 116).

Meitzen, Karoline Helene = Lessing, Karoline Helene

Mentzel, Elisabeth Katharina. 1847 (Marburg/L.) - 1914 (Frankfurt/M.). Geb. Schippel:

Alte Hausmittel. Charakterbild in 1 A. 1895. [D-FSU, D-GiU]

Kinder der Sïnde. Drama. 1911. \{D-BDS, D-BHU\}

Das Puppenspiel vom Erzzauberer Dr. Johann Faust. Tragödie in 4 A. und 8 Bildern. Bearb. nach alten Mustern. 1900. \{D-BHU, D-BSPK, D-FSU, D-HHSU, D HHU-T, D-MrU\}

Der Räuber. Volksstück in 4 A. 1894. \{D-FSU\}

Das Urteil Salomonis. Schauspiel. 1906.

Menzel, Julie Florentine $=$ Großmann, Julie Florentine von.

Mereau, Sophie. 1770 (Altenburg) -1806 (Heidelberg). Geb. Schubert. Verh. Brentano:

Scenen aus einem Trauerspiele. 1805. \{D-BSPK\}

Meruell, E. = Pseudonym für: Müller, Elisabeth (1827-1898).

Meruell, E. = mögliches Pseudonym für: Müller, Elisabeth (1866-1932) [s. Anm. zu: Müller, Elisabeth, 1827-1898].

Meyer, Sara $=$ Grotthuss, Sara Freifrau von

Meyerhof, Leonie. 1858 (Hildesheim) - 1933 (Frankfurt/M.). Pseudonym: Leo Hildeck:

Abendsturm. Schauspiel. 1899.

Die Erben des Genius. Tragische Farce in 3 A. O. J. \{D-KöTM

Feuertaufe. Lustspiel. 1888.

Sie hat Talent. Lustspiel in 1 A. 1888. \{D-AmSP, D-HHU-T\}

Ungleiche Pole. Lustspiel. 1887. \{D-BDS\}

Zuerst komm' ich! Vier Einakter. 1914. \{D-FSU\}

Meynier, Luise Magdalene. 1766 (Erlangen) - nach 1820 Coquetterie und Liebe. Lustspiel. O. J. (Lustspiele. 1802.) 
Die furchtsamen Mädchen. O. J. (Kinderspiele in Erzäblungen und Schauspielen. 1801.)

Der Geburtstag. O. J. (Kinderspiele. 1801.)

Kinderspiele in Erzablungen und Schauspielen. 1801.

Kleine dramatische Kinderromane. 2 Bde. 1802. \{D-RSB

Das Liebhabertheater. Lustspiel. O. J. (Lustspiele. 1802.)

Lustspiele. 1802.

Der militairische Empfang des Onkels. O. J. (Kinderspiele. 1801.)

Die Modedame. O. J. (Kinderspiele. 1801.)

Prosit das neue Jahr! O. J. (Kinderspiele. 1801.)

Die U'berraschung. O. J. (Kinderspiele. 1801.)

Das Weihnachtsfest oder die doppelte Bescherung. O. J. (Kinderspiele. 1801.)

Meysenbug, Malwida Amalia Wilhelmina Tamina von, 1816 (Kassel) -1903 (Rom). Pseudonym: Verfasserin der Memoiren einer Idealistin. Veröffentlichte auch anonym:

Der Segen der heiligen Katharina. Drama. 1886/7. (D-DeNWS, handschriftlich in D-WeiZdK\}

Michaelis, Caroline $=$ Schlegel-Schelling, Caroline

Mihule, Juliane = Hain, Juliane

Mindermann, Marie Christiane. 1808 [Groß, Deutschlands Dichterinen: 1809] (Bremen) - 1882 (Bremen):

Dramatische Kleinigkeiten. 1867. (D-HeS\}

Marion. Charakterbild in 1 A. O. J. (Dramatische Kleinigkeiten. 1867.) \{D-HeS\}

Das Testament des Onkels. Lustspiel in 2 A. O. J. (Dramatische Kleinigkeiten. 1867.)

$\{\mathrm{D}-\mathrm{HeS}\}$

Minna = Pseudonym für: Gersdorf, Wilhelmine von.

Minna = Pseudonym für: Mädler, Minna von.

Minna = Pseudonym für: Zay von Csömör, Maria Elisabeth Helene Freiin von.

Miß Jennys Übersetzerinn = Pseudonym für: Rupp, Victoria von.

Mitius, $\mathrm{Ph},=$ Schauspielername für: Hartl, Philomene.

Moderatus Diplomaticus = Pseudonym für: Bufalo della Valle, Emilia Marchesa del.

Mödinger, Sophie $=$ Alberti, Sophie

Moller, Margaretha $=$ Klopstock, Margaretha
Montenglaut, Henriette Artemisia Marianne von. 1767 [Goedele: 1768] (Böhme bei Hannover) - 1838 (Prag). Geb. von Cronstain. Verh. Consbruch. Verh. Müller. Schauspielername: Emilie Willer [auch: Villiers]. Pseudonyme: P. von Husch, Paul von Husch:

Dramatische Werke. 2 Bde. 1830. \{D-ASU, D-GSU, D-HUL; Bd. 2 in D-KöUSB\} Die einfache Begebenheit. Lustspiel in 1 A. Freie Übers. nach Scribe und de Courcy. O. J. (Dramatische Werke II, 1830.) \{D-ASU, D-GSU, D-HUL, D-KöUSB\}

Der Magiker und das Ungehener. Romantisches Melodrama in 3 A. O. J. (Dramatische Werke II, 1830.) \{D-ASU, D-GSU, D-HUL, D-KöUSB\}

Merope. Trauerspiel in $5 \mathrm{~A}$. von Voltaire. Übers. 1827.

Der Pirat. Schauspiel in $5 \mathrm{~A}$. und Jamben nach Walter Scott. O. J. (Dramatische Werke I, 1830.) \{D-ASU, D-EWA, D-GSU, D-HUL\}

Probeszenen aus Die Schule der Alten. Lustspiel von Delavigne. Übers. 1824.

Der Sansfagon. Lustspiel in 3 A. nach Seldrin [Severin?]. O. J. (Dramatische Werke II, 1830.) \{D-ASU, D-GSU, D-HUL, D-KöUSB\}

Die Sitzung im Wirthshause. Posse mit eingelegten Gesängen nach dem französischen Vaudeville La carte à payer. O. J. (Dramatische Werke II, 1830.) \{D-ASU, DGSU, D-HUL, D-KöUSB\}

Morazani, Katharina Gräfin von = Hesse, Katharina von

Morgenstern, W. v. = Pseudonym für: Gersdorf, Wilhelmine von.

Motte-Fouqué, Karoline de la. 1773 (Neunhausen/Mark) - 1831 (Neunhausen). Geb. Briest. Verh. von Rachow oder Rochow. Pseudonym: Serena: Die Belagerung von Ancons. [Drama? Minerva.] 1815. \{D-ZMM\} Kloster Mariafelde. Einige Scenen [aus Dramen? Minerva.] 1818. \{D-ZMM\}

Müchler, Karoline $=$ Woltmann, Karoline von.

Mück, Betty = Young, Betty.

Mühlbach, Luise $=$ Pseudonym für: Mundt, Klara

Müller, Elisabeth, 1827 [Friedrichs: 1866, Luzern] - 1898 (Stuttgart) [Friedrichs: 1932, Ruswil, Ktn. Luzern].* Pseudonym: E. Meruell:

Die abweichenden Daten sind ein Resultat der Tatsache, daß dasselbe ungewöhuliche Pseudonyn zwei verschiedenen Autorinnen zugeschrieben wurde. Insgesamt sind vier Autorinnen unter diesen Namen verzeichnet, davon zwei unter diesem Pseudonym:

Muiller, Elise, 1782 (Bremen) -?, Dramatikerin

Müller, Elisabeth, 1827-1898 (Stuttgart), Pseud. E. Meruell, Dramatikerin und Lehrerin Müller, Elisabeth, 1866 (Luzern) - 1932 (Ruswil/Ktn. Luzern), Pseud. E. Meruéll, Lehrerin und 
Anna von Cleve oder Die Gürtelmagd der Königin. Drama in 5 A. 1881. \{D-BDSV, D-KöUSB, Handschrift in D-SiS; D-WeiZdK, IEN]

Ein Haar am Handschubknopf. Lustspiel. 1887. \{D-BSPK\}

Otto der Große. Drama. 1881. \{D-BSPK, D-GSU, D-WeiZdK\}

Müller, Elise. 1782 (Bremen) - ?:

Die Kostgängerin im Nonnenkloster. Schauspiel in 4 A. 1797. \{D-BSPK, D-FGM, DGF, D-WeiZdK, A-WÖN, GB-LBL\}

Prell und Louise, oder Was vermag die Liebe nicht? Schauspiel in 3 A. 1797.

Müller, Henriette Artemisia Marianne = Montenglaut, Henriette Artemisia Marianne von.

Müller, Klara = Mundt, Klara.

Mundt, Klara. 1814 (Neubrandenburg) - 1873 (Berlin). Geb. Müller. Pseudonym: Luise Mühlbach:

Mademoiselle Clairon. Schauspiel. 1861. \{D-BHU\}

Novellen und Scenen. 2 Bde. 1845. [Enthält dramatische Szenen?] \{D-ASU, GBLBL\}

Ein Vormittag in Sanssouci. Historisches Lustspiel in 2 A. 1859. \{D-BSPK, als handschriftliches Manuskript in: D-HHU-T; D-KöTM, GB-LBL\}

Naubert, Christiane Benedikte Eugenie. 1756 (Leipzig) - 1819 (Leipzig). Geb. Hebenstreit. Verh. Holderieder:

Elisabeth ... oder die Bürgermeisterin. Lustspiel. 1808. \{D-LKKM\}

Nauen, Maria Wilhelmine = Schmidt, Maria Wilhelmine.

Netter, Henriette $=$ Strauss, Henriette.

Nettner, Henriette $=$ Strauss, Henriette

Jugendautorin

Müller, Elisabeth, 1885 (Langnau/Ktn. Bern) - 1977 (Hünibach bei Thun), Lehrerin, Jugendautorin und Dramatikerin.

Die Tatsache, daß keine der Autorinnen verheiratet war, d. h. daß sie nicht durch Mädchennamen unterscheidbar sind, die Gleichheit des Pseudonyms (zwei E. Meruells, wobei sich nicht ausschließen läßt, daß beide Autorinnen dasselbe Pseudonym benutzten) und die Gleichheit der Professionen (drei Lehrerinnen, zwei Jugendschrifsstellerinnen) erschwert die Unterscheidung Aufarund der I (drens-

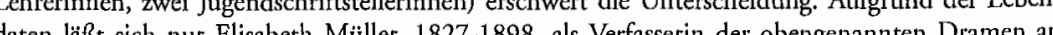
(anter nehmen.
Neuber, Friederike Karoline. 1697 (Reichenbach/Vogtl.) - 1760 (Laubegast bei Dresden). Geb. Weißenborn:

Der allerkostbarste Schatz. Ein deutsches Vorspiel. 1741.

Der alte und neue Geschmack. Vorspiel. 1738.

Die dankbaren Schäfer. Vorspiel. 1735.

Ein deutsches Vorspiel. 1734. (D-BFU, D-BHU, D-BiU, D-BoU, D-BUB, D-DoU, D-ENU, D-EWA, D-FGM, D-FSU, D-GiU, D-GSU, D-HHSU, D-HHU-T, DHLHD, D-HUB, D-HUL, D-KaMB, D-KoS, D-LDB, D-LKM, D-MarSN, DMBS, D-MüRS, D-MüS, D-MüU, D-RoU, D-SU, D-TS, D-WeiZdK, D-WHLB, D-WS, D-WuS, A-GUB, A-WÖN, A-WUB, CH-AK, CH-BSU, CU, DLC, GU, ICRL, MB, MiU, NIC, NjP, OCIW, OCU, OrU, OU, PSt, PU\} Die grösste Gliickseeligkeit in der Welt. Vorspiel. 1737.

Die Herbstfreude. Vorspiel [nicht identisch mit: Das Schäferfest oder die Herbstfreude). 1736. \{D-WeiZdK, $\Lambda$-WÖN\}

Die Liebe der Unterthanen. Ein deutsches Vorspiel. 1741.

Die närrischen Grillen. Ein deutsches Schauspiel. 1746.

Die ruhige und geseegnete Wohnung der Weisheit, der Wabrheit, des Apollo, und des Mercurius. Vorspiel. 1735. [Von Reden-Esbeck Neuber zugeschrieben.]

Das Schäferfest oder die Herbstfreude. Lustspiel in Versen. 1753. \{D-ASU, D-BFU, D-DeLL, D-HG, D-HHU-T, D-HUL, D-KöTM，D-MBS，D-MöS，D-MüS，DTS, A-WÖN, CH-BSU, NN, OCU\}

Der Sieg der Vernunft - oder der Tod des Hans Wurst. Vorspiel. 1737

Der Tempel der Vorsehung. Vorspiel. 1741.

Die Umstände der Schauspiel-Kunst in allen vier Jahres-Zeiten. Vorspiel. 1735.

Der Ursprung der Schauspiele. Vorspiel. 1738.

Die Verbindung der vier Jahres-Zeiten. Anderer Titel für: Die Umstände der Schauspiel-Kunst.

Die Verehrung der Vollkommenheit durch die gebesserten teutschen Schauspiele. Vorspiel. 1737. \{D-KaMB

Die von der Tugend getröstete und von dem Heldenmuth beschiutzte Guelphis. Vorspiel. 1735.

Die von der Weißheit wider die Unwissenheit beschïtzte Schauspielkunst. Vorspiel in Versen. 1736.

Das Vorspiel. Ein episches Gedicht. 1742. \{D-GOB\}

Die Zufriedenheit. Vorspiel. 1741

Ein Vorspiel. Titel nicht ermittelt. 1741. [Identisch mit: Das Vorspiel?]

Ein Epilog. Titel nicht ermittelt. Aufgeführt in Lübeck, 26. 11. 1734.

Wahrscheinlich noch mehrere ungedruckte Schauspiele.

Neumann von Meißenthal, Marianne. 1768 (Wien) - 1837 (Wien). Geb. von Tiell. Verw. Egerváry. Pseudonym: Nina. Veröffentlichte auch anonym: Die Colonie. Lustspiel. O. J.

Nina, oder Wahnsinn aus Liebe. Schauspiel mit Gesang. 1787. \{D-BSPK\} 
Neumann-Hofer, Annie. 1867 (New York) - nach 1905 (Berlin oder Frankfurt/M). Geb. Bock:

Dora Peters. Schauspiel. 1902.

Kollegen! Komödie in 1 A. 1895. \{Stark beschädigte Ausgabe in D-HHU-T\}

Marie Antoinette. Schauspiel. 1903

Die Montrefore. Drama frei nach Edgar Allan Poe. 1911.

Der nächste Tag. Schwank. 1907.

Die Schlangentänzerin. Schauspiel in 3 A. 1911. (D-KöTM\}

Spießgesellen. Drama. 1911.

Wotans Abschied. Komödie. 1911

Das Wunderkind. Komödie. 1903.

Neupauer, Christiane von $=$ Breden, Christiane von .

Nieberg, Mathilde. 1839 (Hamburg) - ? Geb. Wagner:

Es lebe der Geist! Schwank in 1 A. 1893. (Zur Kurzweil. 1908.)

Die erste Probe. Schwank in 1 A. 1894. (Zur Kurzweil. 1908.)

Frauenliebe. Drama in 3 A. 1894.

Das Hoftheater. Lustspiel in 4 A. O. J.

Im Freundeskreise. Dramensammlung von 15 Dramen. 1902

Klas Avenstaken oder Der Pfannkuchenberg. Kindermärchen in 3 A. mit Gesang und Tanz. O. J.

Pensionat für In- und Ausländer. Lustspiel in 3 A. 1908.

Perlen bedeuten Tränen. Volksmärchen aus alter Zeit in 3 A. nebst einem Vorspiel und einem Nachspiel. O. J.

Virginia Reel. Einakter. O. J. (Zur Kurzweil. 1908.)

"Wer ifst mit mir?" Einakter. O. J. (Zur Kurzweil. 1908.)

Zur Kurzweil. Vier Einalkter. 1908.

Nina = Pseudonym für: Neumann von Meißenthal, Marianne.

Obermayer, Rosa $=$ Mayreder, Rosa

Ochs, Elisabeth Philippine Amalie von = Hohenhausen, Elisabeth Philippine Amalie Freifrau von.

Odrich, Anna Natalie Emilie = Schlegel, Anna Natalie Emilie.

Oppel, Emilie von $=$ Berlepsch, Emilie von

Oppeln, Emilie von = Berlepsch, Emilie von.

Opzoomer, Adele. ? - ?:

Der Sturz des Hauses Alba. Drama. 1875. \{D-LKM\}
Osterloh, Adele Minna. 1857 (Dresden) - 1946 (Dresden). Geb. Günther: Der Andere. Lustspiel in 1 A. 1881

Ich deklamiere. Solospiel fuir eine Dame. O. J. \{D-KöTM

Ich denke dran. Solospiel für eine Dame. (Solospiele II. O. J.) \{D-HHU-T\}

Das Märchen vom Glück. Schauspiel in 4 A. 1900. \{D-FSU\}

Der Mann seiner Frau. Lustspiel in 5 A. 1883. \{Als Regiebuch in D-HHU-T; DKöTM]

Solospiele. 2 Bde. O. J. \{Bd. 2 in D-HHU-T $\}$

Der Wahrheitsmund. Operettenlibretto. Mit Heinrich Platzbecker. Musilk von Heinrich Platzbecker. 1914. \{Als Regiebuch in D-LDB\}

Otto-Peters, Luise. 1819 (Meißen) - 1895 (Leipzig). Geb. Peters. Pseudonym: Otto Stern:

Constantin der Große. Oper in 4 A. Um 1870. \{D-BDSV

Des Königs Aufruf. Vorspiel zu: Theodor Körner. 1867.

Die Nibelungen. Libretto. 1852.

Theodor Körner: Große vaterländische Oper in 5 A. und einem Vorspiel. 1867.

Oulot, B. = Pseudonym für: Suttner, Bertha von.

P., A. = Pseudonym für: Raupach, Pauline.

Paar, Mathilde Lisette Marie. 1849 (Kassel) - 1899 (Leipzig). Pseudonym: Josef Trieb:

Althessen. Dramatisches Gedicht mit lebenden Bildern. 1884. \{D-KaMB\}

Der Brautkranz. Lustspiel in 1 A. 1880. \{D-BDS, D-EWA\}

Der Bucbstabe des Gesetzes. Schauspiel in 4 A. 1898.

Chambre garnie. Lustspiel in 1 A. 1879. (Edmund Wallner, Hg.: Das Haus-Theater. 1879.) $\{\mathrm{D}-\mathrm{BDS}, \mathrm{D}-\mathrm{EWA}, \mathrm{D}-\mathrm{KaMB}, \mathrm{D}-\mathrm{WeiZdK}, \mathrm{NN}\}$

Der Champagnerpfropfen. Lustspiel. 1877.

Désirée. Schauspiel. 1895. \{D-LKM\}

Der Dombau zu Köln. Dramatisches Gedicht in 4 Abteilungen. 2. Aufl. 1881. \{DKaMB\}

Festgruß mit lebenden Bildern. Zur Feier des Musikfestes in Cassel. 1885. \{D-KaMB\} Frauenlist und Laune. Lustspiel in 4 A. O. J. \{Als Regiebuch in D-HHU-T; DKöTM\}

Die Geschwister. Schauspiel. 1891.

Helene. Schauspiel in 4 A. 1882. \{D-BSPK, D-KaMB

Die Hochzeit. Festspiel. O. J. \{D-BDS\}

Isolina Janson. Schauspiel. 1890.

Das Jahr und seine zwölf Monate. Fastnachtsscherz in 12 Scenen. 1882. \{D-EWA\} Johannistag, ein Sommermärchen. Dramatisches Märchen. 1879. \{D-EWA, D-LDB\} Des Königs Aufruf. Vorspiel zu: Theodor Körner. Libretto. 1867. \{GB-LBL\} 
Die Kreuzfabrer. Große Oper in 3 A. (Musik von Louis Spohr). Libretto. 1899. \{D$\mathrm{KaMB}\}$

Die Lebensfrage. Dramatisches Gedicht. 1879. \{D-EWA, D-LDB

Das Märchen. Dramatisches Gedicht in lebenden Bildern. 1882. \{D-KaMB\}

Ein Roman. Lustspiel in 1 A. 1879. (Edmund Wallner, Hg.: Das Haus-Theater. 1879.) \{D-BDS, D-EWA, D-WeiZdK, NN\}

Theodor Körner. Oper in 5 A. und einem Vorspiel Des Königs Aufruf. Libretto. 1867. \{GB-LBL\}

Ein Traum. Drama [?]. 1882. \{D-EWA\}

Verirrungen. Schauspiel in 5 A. 1882. \{D-KaMB\}

Die Wahrheit. Lustspiel in 1 A. 1875. \{D-KaMB, D-WeiZdK

Wilde Rose. Lustspiel. 1888.

Wintermärchen. Weihnachtsspiel für die Jugend. 1882.

Paoli, Betty = Pseudonym für: Glück, Elisabeth.

Pauline $=$ Pseudonym für: Zitz, Katharina Rosa Therese Pauline Modesta.

Paulus, Karoline Elisabeth Friederike. 1767 (Schorndorf/Württemberg) - 1844 (Heidelberg). Pseudonyme: E. H., Eleutheria Holberg, Freundin Goethes und Schillers aus Heidelberg. Veröffentlichte auch anonym:

Semiramis. Trauerspiel von Voltaire. Übers. 1811. \{A-WÖN, InU\}

Pauss, Carl = Pseudonym für: Arndts, Maria

Perin von Gradenstein, Josephine Freifrau von. 1779 (Brüssel) - 1856 (Wien). Geb. von Vogelsang. Veröffentlichte auch anonym:

L'amant d'Alicante. Heroisch-komisches Drama in 5 A. 1834

Linconséquent. Komödie in 5 A. 1828.

Rosemond. Tragödie in 5 A. 1826.

Telesilla. Tragödie in 5 A. 1827.

La terreur du ridicule. Komödie in 3 A. 1829.

Vanina. Tragödie in 5 A. 1831.

Pernet, Luise Hedwig Albertine von. 1742 (Schleswig) - 1801 (Budapest). Geb. Freiin von Kemmerer:

Seline. Komisches Trauerspiel in Versen und 5 A. 1770. (Versuch in Fabeln und Erziahlungen, nebst einem comischen Trauerspiele in Versen. 1770.) (A-WÖN, MU (Mikrofilm)\}

Peters, Luise $=$ Otto-Peters, Luise

Petersen, Marie Louise Auguste. 1816 (Frankfurt/O.) - 1859 (Frankfurt/Oder): Die Irrlichter. Drama. 1856 [?]. \{D-BDS, D-BFU, D-BHU, D-BSPK, D-KaMB, D
$\mathrm{MrU}, \mathrm{GB}-\mathrm{LBL}$

The Will o' the Wisps. Drama. 1868. \{GB-LBL\}

Pfeiffer, Charlotte $=$ Birch-Pfeiffer, Charlotte

Pichler, Caroline [auch Karoline]. 1769 (Wien) - 1843 (Wien). Geb. von Greiner. Pseudonym: Auguste:*

Amalie von Mannsfeld. Schauspiel in 3 A. nach Mad. Cottin. O. J. (Dramatische Dichtungen, 1818; Sammtliche Werke XXI, 1822.) (D-ASS, D-BiU, D-BoU, DBUB, D-CorFB, D-DeLL, D-DUB, D-FGM, D-GF, D-RSB, D-TS, A-GUB, AWÖN, A-WUB, A-ZS, CSt, MH, NN, TxU, ViU, WU

Das befreyte Deutschland. Cantate in 2 Abteilungen. O. J. (Sämmtliche Werke XIX, 1822.) \{D-BiU, D-BoU, D-BUB, D-CorFB, D-DeLL, D-DUB, D-GF, D-RSB, D ZMM, A-GUB, A-WÖN, A-WUB, GB-LBL, CSt, MH, NN, TxU, ViU, WU\}

Die Bergsteiger. [Drama? Minerva.] 1818. \{D-ZMM

Cremsmïnster, Eine Legende. [Drama? Minerva.]. 1810. \{D-ZMM

Dramatische Dichtungen. 1815. \{D-WüU\}

Dramatische Dichtungen. 1818. \{D-BoU, D-DUB, D-FGM, D-SML, D-TS, AWÖN, A-WUB, A-ZS\}

Dramatische Dichtungen. 3 Bde. 1822. [= Sämmtliche Werke XIX-XXI.] \{D-BiU, DBoU, D-BUB, D-CorFB, D-HUB, D-MüU, D-PUB, D-RSB, A-GUB, A-WÖN, A-WUB, A-ZS, CSt, MH, NN, TxU, ViU, WU; Bd. 1 u. 2 in: D-DUB\}

Ferdinand der Zweyte, König von Ungarn und Böhmen. Historisches Schauspiel in 5 A. 1816. (Dramatische Dichtungen. 1818; Sämmtliche Werke XXI, 1822.) (D-ASS, D-BiU, D-BoU, D-BUB, D-CorFB, D-DeLL, D-DUB, D-FGM, D-GF, D-LDB, D-LKM, D-PUB, D-RSB, D-TS, D-WeiZdK, D-ZCW, A-GUB, A-WÖN, AWUB, A-ZS, CH-WiS, GB-LBL, CSt, InU, MH, NN, TxU, ViU, WU\}

Germanicus. Trauerspiel in 5 A. 1813. (Sämmtliche Werke XIX, 1822.) (D-BHU, DBiU, D-BoU, D-BUB, D-CorFB, D-DeLL, D-DUB, D-GF, D-HUL, D-PUB, DRSB, D-TS, D-WeiZdK, A-GUB, A-WÖN, A-WUB, A-ZS, CSt, MH, NN, TxU, $\mathrm{ViU}, \mathrm{WU}\}$

Heinrich von Hohenstauffen, König der Deutschen. Trauerspiel in 5 A. 1813. (Sämmtliche Werke XX, 1822.) \{D-BiU, D-BoU, D-BUB, D-CorFB, D-DeLI D-DUB, DGF, D-PUB, D-RSB, D-WüU, A-GUB, A-WÖN, A-WUB, A-ZS, CSt, MH, NN, TxU, ViU, WU

Mathilde. Tragische Oper in 3 A. O. J. (Sämmtliche Werke XX, 1822.) \{D-BiU, DBoU, D-BUB, D-CorFB, D-DeLL, D-DUB, D-GF, D-PUB, D-RSB, D-WüU, DZCW, A-GUB, A-WÖN, A-WUB, A-ZS, CSt, MH, NN, TxU, ViU, WU\} Neue dramatische Dichtungen. 1818. \{D-BHU, D-KaMB\}

Prolog zu Heinrich von Hohenstauffen. O. J. \{D-DeLL, A-WUB, CSt\}

* Eine Anthologie aus ihren sämtlichen Werken aus dem Jahre 1844, die wahrscheinlich auch Dramen enthält, befindert sich in D-ENU. 
Rudolph von Habsburg. Heroische Oper in 3 A. O. J. (Dramatische Dichtungen, 1818; Sämmtliche Werke XX, 1822.) (D-ASS, D-BiU, D-BoU, D-BUB, D-CorFB, D-DeLL, D-DUB, D-FGM, D-GF, D-PUB, D-RSB, D-TS, A-GUB, A-WÖN, AWUB, A-ZS, CSt, MH, NN, TxU, ViU, WU\}

Wiedersehen. Schauspiel in 2 A. 1814. (Sämmtliche Werke XIX, 1822.) (D-BiU, DBoU, D-BUB, D-CorFB, D-DeLL, D-DUB, D-GF, D-PUB, D-RSB, D-WüU, AGUB, A-WÖN, A-WUB, A-ZS, CSt, MH, NN, TxU, ViU, WU\}

Pichler, Luise $=$ Zeller, Luise

Pierson, Caroline Wilhelmine. 1811 [Groß, Deutschlands Dichterinen: 1814] (Zittau/ Sachsen) - 1899 (Lindenhof bei Coswig/Sachsen). Geb. Leonhardt. Verh. Lyser. Pseudonyme: R. Edmund Hahn, Caroline Leonhardt-Lyser:

Armida. Schauspiel in 5 A. 1879. (D-BDS\}

Bertha von Bretagne. Opernlibretto. 1835.

Konradin von Schwaben. Opernlibretto. 1834. (D-GOB\}

Leila. Opernlibretto. O. J.

Der letzte Jagiello. Historische Tragödie. 2. Aufl. 1895.

Meister Albrecht Dürer. Drama in 4 A. 1840 (2. Aufl. 1871). \{D-BDS, D-BHU, DBSPK, D-ENU, D-FGM, D-MBS, D-ZCW, IEN]

Starhemberg oder Die Bürger von Wien. Historisches Drama [Kosch 3. Aufl.; bei Brümmer in ADB LIII, 1907 als Roman]. 1865. (D-BDS, D-LKM)

Vorgestern und heute. Lustspiel [?] oder Opernlibretto, 1836.

Wahrscheinlich weitere Opernlibretti.

Pilgerin nach dem Heimatlande $=$ Pseudonym für: Elise Bürger.

Pinelli-Rizzutto, Ada. 1836 [National Union Catalog: 1840] (Berlin oder Frankfurt a. O.) - 1918. Geb. von Treskow. Pseudonym: Günther von Freiberg: Don Diego. Drama in 1 A. 1873.

Don Juan de Maraña. Monodrama. 1894. \{D-KöTM\}

Timandra von Korinth. Dramatisches Gedicht in 1 A. 1911. \{D-BHU, D-KöTM\}

Pleiner, Max von = Pseudonym für: Arens von Braunrasch, Auguste

Pleitner, Anna Rupertina = Fuchs, Anna Rupertina.

Plessen, Maria Sophie Christiane von. 1783 (Göhren bei Parchim/Mecklenburg) 1851 [Groß, Deutschlands Dichterinen: nach 1820] (Bützow/Mecklenburg). Geb. von Fick. Pseudonym: Maria:

Der Shawl. Lustspiel in 2 A. O. J.

Plönnies, Luise von. 1803 (Hanau) - 1872 (Darmstadt). Geb. Leisler: David. Biblisches Schauspiel in 5 A. 1873. \{D-BHU\}
Maria Magdalena. Geistliches Drama in 5 A. 1870. (D-BDS, D-BHU, D-BUB, DHUB, GB-LBL,

Ruth. Drama? 1869. \{D-ASB, D-BHU, D-KaMB, GB-LBL

Sawitri. Drama. 1862. \{D-BHU, D-FSU, CH-CGK, GB-LBL\}

Wittekind. Dramatisches Oratorium in 3 Abtheilungen. 1852. \{D-FSU\}

Poll, Julie Mathilde $=$ Kühne, Julie Mathilde

Porges, Elsa = Bernstein, Elsa.

Prechtler, Barbara. ? - 1843

Festspiele und „zahlireiche Dramen, von denen nichts im Druck erschien“ (Goedeke).

Prellwitz, Gertrud. 1869 (Tilsit) - 1942 (Oberhof/Thüringen):

Das Deutschlandlied. Für dic neue Jugend, dem Volke zu spielen. 1921. (D-BHU, D-HHU-T

Der Kaisertraum. Weihefestspiel. 1912. \{D-BHU, D-ENU, D-HHSU, D-HHU-T, D-HUB, D-KöTM, D-LDB, D-MüS, D-WeiZdK, NNC\}

Kleine Spiele. Für dic neue Jugend. O. J. \{D-L,DB\}

Die letzte Wala. Eine Wotanslegende. Weihespiel in 5 A. 1935. \{D-HHU-T, D-LDB, D-WeiZdK\}

Maienspiel. 1933. \{D-HHU-T, D-LDB\}

Michel Kohlhas. Trauerspiel in 5 A. 1904. \{D-BDS, D-BHU, D-HUB, D-KöTM, D-KöUSB, D-LDB, D-MüS, D-RoU, D-WeiZdK, CtY, MH, PSC, PSt, RPB\}

Oedipus oder das Rätsel des Lebens. Tragödie in 5 A. 1896. \{D-BHU, D-BSPK, DHHU-T, D-HUB, D-HUL, D-KöTM, D-LDB, D-LKM, D-LR, D-MrU, D-MüS, D-MüU, D-RoU, D-TüU, D-WeiZdK, MH, NNC, TNJ\}

Ostern. (Geplant oder vollendet als 3. Teil von Die Gefangenen.)

Seine Welt. Lustspiel in 5 A. 1911. (D-BHU, D-MüS, D-WeiZdK, NN, NNC, OrU\}

Die Tat. Drama in 3 A. 1912. \{D-BH, D-BHU, D-DUB, D-HHU-T, D-HUB, DKöTM, D-LDB, D-MüS, D-WciZdK, A-WÖN, MH, NN, NNC, TNJ\}

Vier Volksspiele. 1919

Was der Mensch säet, das wird er ernten. Straßenspiel. 1921. \{D-BHU, D-HHU-T, D-LDB, D-MüS, D-WeiZdK

Weltsonnenwende. Ein Mysterium. 1919. \{D-BHU, D-HHU-T, D-LDB, D-RoU\} Zwischen zwei Welten. Weihefestspiel in 5 A. 1899. \{D-BHU, D-FSU, D-HHU-T, D-HLHD, D-HUL, D-LDB, D-LR, D-MüS, D-RoU, CLSU, NNC

Prix, Adalbert = Pseudonym für: Bernbrunn, Margarethe.

Psyche $=$ Pseudonym fuir: Bechtolsheim, Julie Freifrau von 
Puttkamer (auch Puttkammer), Anna Lucie Karolien Alberta. 1849 (Groß-Glogau/ Schlesien) - 1923 (Baden Baden). Geb. Weise:

Kaiser Otto der Dritte. Schauspiel in 5 A. 1883. (D-BDS, D-BFU, D-BHU, DFSU, D-KöTM, D-LKM\}

Merlin. Schauspiel in 4 A. mit einem Vorspiel. 1912. (D-BDS, D-BHU, D-FSU, D-KöTM\}

R. = Pseudonym für: Robert, Friederike.

R., H. = Pseudonym für: Reusch, Henriette.

R., M. v. = Pseudonym für: Reitzenstein, Marie Freifrau von.

R., V. v. = Pseudonym für: Rupp, Victoria von.

R. S., M. = Pseudonym für: Reichardt-Stromberg, Mathilde.

Rachow, Karoline von = Motte-Fouqué, Karoline de la.

Radtke, Emma = Laddey, Emma

Rafael, L. = Pseudonym für: Kiesekamp, Hedwig.

Rasch, Julius = Pseudonym für: Arens von Braunrasch, Auguste.

Ratzbar, Sophie Eleonore $=$ Titzenhofer, Sophie Eleonore von

Raudnitzky, Victoria = Rupp, Victoria von.

Raupach, Pauline. Um 1848. Geb. Werner. Pseudonym: A. P. Der Bruderkuß. Dramatischer Scherz in 2 A. 1844. \{D-KöTM\} Ehemann und Junggeselle. Lustspiel in 4 A. 1846. \{D-KöTM\} Eine einfache Geschichte. Schauspiel in 2 A. 1865. \{D-KöTM\} Frage und Antwort. Dramatischer Scherz in 1 A. 1843. [D-KöTM] Die Frau im Hause. Spiel in 3 A. 1842. (D-BHU, D-KöTM) Die Grundsätze. Lustspiel in 5 A. O. J. (D-BDS, D-WeiZdK] Marie. Schauspiel in 4 A. 1845. \{D-BHU, D-KöTM\}

Noch ist es Zeit. Schauspiel in 3 A. 1842. (D-BDS, D-BHU, D-KöTM] Der Rückfall. Original-Lustspiel in 4 A. O. J. \{D-BDS\}

Stolz und Liebe. Schauspiel in 5 A. 1849. \{D-BDS, D-KöTM, A-WÖN\} Ein Wort des Fürsten. Schauspiel in 5 A. 1841. \{D-BHU, D-KöTM\} Weitere (dramatische?) Werke [Groß, Deutschlands Dichterinen 140].

Rauthe, Henrictte $=$ Frölich, Henriette.
Raven, Mathilde. 1817 (Meppen/Niedersachsen) - nach 1898 (Dresden). Geb. Beckmann:

Der erste April. Dramatischer Scherz. 1870. (Edmund Wallner, Hg.: Das Haus-Theater. 1874.) (D-BDS, D-EWA, D-TüU, D-WeiZdK, NN\}

Ein Geheimnis. Drama in 5 A. Um 1880. \{Unter dem Titel: Marie oder Ein Geheimnis in D-BSPK; D-FSU, D-HHU-T, A-WÖN\}

Der Herr Hofjunker: Lustspiel in 1 A. 1918. \{D-LDB, NN, PPT\}

Herz und Krone oder Wilhelm von Lecce. Trauerspiel in 5 A. 1845. \{D-BSPK; unter dem Titel: Wilhelm von Lecce in D-FSU, D-KöTM, D-WeiZdK\}

Der Zauberspiegel. Dramatischer Scherz. 1871. \{D-BDS, D-BH, D-EWA\}

Recke, Elisa[beth] Charlotte Konstantia von der. 1754 [Groß, Deutschlands Dichterinen: 1751] (Schönberg/Kurland) - 1833 (Dresden). Geb. von Medem. Pseudonyme: Elisa, Elise:

Familien-Scenen, oder Entwickelungen auf dem Masquenballe. Schauspiel in $4 \mathrm{~A}$. 1826. \{D-BHU, D-BSPK, D-DonFFH, D-EWA, D-FGM, D-FrU, D-GF, DHUB, D-HUL, D-TS, D-ZR, ICU\}

Regelsberg von Thurnberg, Marie von = Augustin, Marie Freifrau von.

Reichardt, Mathilde $=$ Reichardt-Stromberg, Mathilde

Reichardt-Stromberg, Mathilde. 1823 (Solingen/Rheinland) - 1898 (Rheinbreitbach bei Unkel). Geb. Reichardt. Pseudonym: M. R. S

Aspasia. Dramatisches Gedicht in 5 A. 1852

Reinbold, Adelheid. 1802 (Hannover) - 1839 (Dresden). Pseudonym: Franz Berthold:

Prinz von Massa. Dramatische Novelle. 1837. (Als Bd. II ihrer Novellen und Erzählungen, 1836-7.) \{A-WUB?\}

Reinhardt, Friederike. 1770 (Arnstadt) - 1843 (Jena). Geb. Wagner. Pseudonym: Lina Reinhardt:

Alte Liebe rostet nicht. Lustspiel in 1 A. O. J. (Dramatische Kleinigkeiten. 1835.) \{DGSU, D-MBS\}

Die Braut des Echo's. Lustspiel in 1 A. O. J. (Dramatische Kleinigkeiten. 1835.) \{DGSU, D-MBS\}

Cyrus. Dramatisches Gemälde in 2 A. O. J. (Festgabe in zehn neuen dramatischen Spielen fiur die deutsche Jugend. 1839.) (D-FrU, D-KöTM\}

Dramatische Kleinigkeiten. Sechs leicht auffuibrbare Lustspiele, jedes in einem Akte. 1835. \{D-GSU, D-MBS\}

Die Entfuibrung. Schauspiel in 1 A. O. J. (Festgabe. 1839.) (D-FrU, D-KöTM, DWeiZdK\} 
Die Folgen der Neugier. Schauspiel in 1 A. O. J. (Festgabe. 1839.) (D-FrU, DKöTM\}

Friedliebchens Traum. O. J. (Newes Kindertheater. 1841.) \{D-FSU, D-KöTM, DWHLB\}

Das Goldstück. O. J. (Neues Kindertheater. 1841.) \{D-FSU, D-KöTM, D-WHLB\} Der gutgemeinte Irrtum. Lustspiel in 1 A. O. J. (Dramatische Kleinigkeiten. 1835.) \{D-GSU, D-MBS\}

Der Gutschmecker. Lustspiel in 1 A. Frei nach dem Französischen. O. J. (Festgabe. 1839.) $\{\mathrm{D}-\mathrm{Fr} U, \mathrm{D}-\mathrm{KöTM}\}$

Der Hochmüthige und sein Verderber. Schauspiel in 2. A. O. J. (Festgabe. 1839.) (DFrU, D-KöTM\}

Der hölzerne Prophet. O. J. (Neues Kindertheater. 1841.) \{D-FSU, D-KöTM, DWHLB\}

Die Johannis-Braut. O. J. (Neues Kindertheater. 1841.) \{D-FSU, D-KöTM, DWHLB\}

Kindertheater, bestehend in achtzehn kleinen dramatischen Belustigungen zur leichten Auffibrung in Familienkreisen. 1834. \{D-FSU, D-WeiZdK\}

Die kleine Creolin. Schauspiel in 3 A. O. J. (Festgabe. 1839.) \{D-FrU, D-KöTM\} Der kleine Schornsteinfeger. Schauspiel in 2 A. O. J. (Festgabe. 1839.) \{D-FrU, DKöTM\}

Neues Kindertheater. 1841. \{D-FSU, D-KöTM, D-WHLB\}

Der Pelzrock. Lustspiel in 1 A. nach einem Gedicht von Schütze. O. J. (Dramatische Kleinigkeiten. 1835.) \{D-GSU, D-MBS\}

Die Perlenschnur. O. J. (Neues Kindertheater. 1841.) \{D-FSU, D-KöTM, D-WHLB\} Das Probejabr. Lustspiel in 1 A. O. J. (Dramatische Kleinigkeiten. 1835.) \{D-GSU, D-MBS\}

Die rettenden Engel. O. J. (Neues Kindertheater. 1841.) \{D-FSU, D-KöTM, DWHLB\}

Die Rückehr aus dem Bade. O. J. (Neues Kindertheater. 1841.) \{D-FSU, D-KöTM, D-WHLB\}

Schauspiele fir die Jugend. O. J. (Der deutsche Kinderfreund, 1. Abt. Bd. 5. 1837.) Schuld und Unschuld. O. J. (Neues Kindertheater. 1841.) \{D-FSU, D-KöTM, DWHLB\}

Das Schwabenmädel. Lustspicl in 1 A. O. J. (Festrabe. 1839.) \{D-FrU, D-KöTM\} Der Spiegel. Feenmärchen. Lustspiel in 1 A. O. J. (Festgabe 1839.) (D-FrU, DKöTM\}

Der St. Hubertus-Brunnen. Lustspiel in 1 A. O. J. (Dramatische Kleinigkeiten. 1835.) \{D-GSU, D-MBS\}

Der Traum. Dramatisierte Erzählung. O. J. (Festgabe. 1839.) \{D-FrU, D-KöTM\} Ueberraschungen. O. J. (Neues Kindertheater, 1841.) \{D-FSU, D-KöTM, D-WHLB Die Verwandlung. O. J. (Neues Kindertheater. 1841.) (D-FSU, D-KöTM, D-WHLB\} Vor hundert Jahren, jetzt und was immer bleibt. O. J. (Neues Kindertheater. 1841.) \{D-FSU, D-KöTM, D-WHLB\}
Die zwei Rothkäppchen. O. J. (Neues Kindertheater. 1841.) (D-FSU, D-KöTM, DWHLB]

Reinhardt, Lina = Pseudonym für: Reinhardt, Friederike

Reitzenstein, Marie Freifrau von. 1854 (Hannover?) - 1894 (Baden-Baden). Pseudonym: M. v. R:

Dragoner-Regiment Das Erste d. kgl. Deutschen Legion. Ein Kriegsbild in 5 A. 1891 \{D-DeLL\}

Die Haussuchung. Lustspiel in 4 A. 1892

Pfalzgraf Heinrich, Herzog Heinrich des Löwen Sohn. Vaterländisches Bild aus dem 12. Jahrhundert. [Drama?] 1892. \{D-CSB $\}$

Reitzenstein, Sophie Mariane von. 1770 - 1823 (Nemmersdorf/Bayern). Geb. Weikard [Goedeke: Weickard]:

Der gereiste Bräutigam. Lustspiel in 1 A. aus dem Französischen. 1791. (Theatralische Sammlung XV.) \{A-WÖN\}

Kleine Lustspiele. 1791. (D-ASU, D-BSPK\}

Die Kriegslist. Lustspiel in 1 A. 1792. \{D-KöTM\}

Das nächtliche Rendez-vous. Lustspiel in 1 A. aus dem Französischen. 1791. (Theatralische Sammlung XX.) \{D-DeLL, A-WÖN\}

Reue mildert Verbrechen. O. J.

Die seltene Beständigkeit. Lustspiel in 2 A. 1792. \{D-ASU, D-BHU, D-KöTM, MU (Mikrofilm)\}

Der seltsame Freier. Lustspiel. 1793

Der Vergleich. Lustspiel in 1 A. 1791. (Theatralische Sammlung XIV.) \{A-WÖN\}

Remy, Nahida = Lazarus, Nahida Ruth.

René, E. = Pseudonym für: Druskowitz, Helene von.

Reusch, Henriette. 1834 (Brilon/Westphalen) - 1902 (Bonn). Pseudonym: H. R: Die Errettung des Moses. Dramatisches Spiel für die weibliche Jugend. 1867. \{DBSPK, D-BUB, D-KöTM, GB-LBL]

Das Rosenwunder. Drama in 1 A. 1863. \{D-BDS, D-BHU, D-BUB, D-KöTM, DKöUSB, D-LDB, D-MöS\}

Reventlow, Friederike Louise Gräfin $=$ Stolberg, Friederike Louise Gräfin.

Rheinau, Sophie = Pseudonym für: Siebert, Anna

Ribas (auch Riba), Anna Antonie $=$ Thaler, Anna Antonie 
Ribics, Auguste. 1808 (Prag) - ? Geb. Schreiber:

Finnette Aschenbrödel, oder: Rose und Schuh. Zauberspiel mit Gesang in 3 A. 1830. Montbars, oder: Die Korsaren von den Antillen. Romantisches Drama mit Musik in 4 A. nach van der Veldes. 1834

Richa [Pseudonym für wen?]. ? - ?

Die alte Geige. Schauspiel in 1 A. 1820

Richter, F. P. E. = Pseudonym für: Gersdorf, Wilhelmine von.

Richthofen, Julie Charlotte Dorothea Freifrau Prätorius von. 1785 (Pillau/OstpreuBen) - 1840 (Berlin). Geb. des Champs:

Berenice, Königin von Syrien. Trauerspiel. O. J.

Die Leiden Medicis. Trauerspiel. O. J.

Zaide, Prinzessin von Oudipore und Nadir, oder das Verhängni $\beta$. Trauerspiel in $5 \mathrm{~A}$ O. J.

Ringseis, Emilie. 1831 (München) - 1895 (München):

Die Getreue. Dramatisches Märchenspiel. 1862. [D-BHU, D-BSPK, D-FTT, DFrU, D-GSU, D-LKM, D-MarSN, D-MüS, D-SiFH, D-TüU, A-WÖN, CH-AK, $\mathrm{CH}-\mathrm{LZ}, \mathrm{CH}-\mathrm{SZ}, \mathrm{GB}-\mathrm{LBL}$

Neue Gedichte und kleine Dramen. 1873. \{D-FBPT, D-FrU, D-MarSN, CH-LZ fehlt an KAS\}

Schneewittchen. Märchenspiel. 1866

Sebastian. Märtyrertragödie. 1868. \{D-BHU, D-BSPK, D-FSU, D-KöED, D KöUSB, D-MarSN, D-MüS, D-TüU, CH-LZ, GB-LBL\}

Die Sibylle von Tibur. Schauspiel in 3 A. 1858. [D-BSPK, D-DeLL, D-FSU, DFTT, D-GSU, D-HUL, D-MarSN, D-MüS, A-WÖN, A-WUB, CH-LZ, CH-SZ, GB-LBL, KAS

Veronica. Drama in $3 \mathrm{~A}$. [Lateinische Utbersetzung ihres gleichnamigen deutschen Originals.] 1858. \{GB-LBL\}

Veronika. Schauspiel in 3 A. 1854. (D-BHU, D-BSPK, D-BUB, D-DeLL, D DonFFH, D-FrU, D-GSU, D-HLB, D-HUL, D-KöTM, D-MarSN, D-MüS, DSPL, D-TüU, A-WÖN, A-WUB, CH-LZ, CH-SZ, CH-WiS, GB-LBL, ICRL

Ritter, Ernst $=$ Pseudonym für: Binzer, Emilie Freifrau von

Ritter, Friederike Johanna = Lohmann, Friederike Johanna

Robert, Friederike. 1795 (Böblingen bei Stuttgart) - 1832 (Baden-Baden). Geb. Braun. Pseudonyme: R., Friederike:

Schwank in niederschwäbischer Mundart (Titel nicht ermittelt).
Rochow, Karoline von = Motte-Fouqué, Karoline de la.

Röder, Eleonore $=$ Thon, Eleonore

Römheld, Amalie $=$ Jochheim, Amalie.

Rosalba = Pseudonym für: Zitz, Katharina Rosa Therese Pauline Modesta

Rosmer, Ernst = Pseudonym für: Bernstein, Elsa.

Rothenburg, Friederike Helene von = Unger, Friederike Helene

Rudorff, E. = Pseudonym für: Brackel, Ferdinande Freifrau von

Rüdiger, Elise Philippine. 1812 (Schloß Eschwege) - 1899 (Berlin). Geb. von Hohenhausen [Ochs?]. Pseudonyme: F. v. Hohenhausen, Freiin v. H., E. v. H:

Johann und Cornelius de Witt oder das ewige Edikt. Historisches Trauerspiel aus de Zeit Ludwigs XIV. 1847. \{D-BiSL, D-KöTM, D-WeiZdK, NN\}

Rüttimann-Meyer von Schauensee, Anna Maria. 1772 - 1856

Dramatische Versuche. O. J. \{Handschriftlich in CH-LSK

Ruf, Franziska $=$ Fritsch, Franziska

Ruhkopf, Julie. 1799 (Bielefeld) - ? Pseudonym: Irene: Brand. Drama von Henrik Ibsen. Übers. 1874. \{GB-LBL\} Kriegerisch. Drama. Um 1870. \{D-LGS\}

Rupp, Victoria (von). Um 1755 (Prag) - um 1824 (Prag). Geb. Raudnitzky. Pseudonyme: V. v. R., Miß Jennys Übersetzerinn:

Die gute Mutter. Lustspiel in 2 A. 1777/8. (Deutsche Schaubühne Bd. 126.) \{DBSPK, D-WeiZdK, A-WÖN

Jenny, oder Die Uneigennützigkeit. Drama in 2 A. 1777. (D-BSPK, D-DUB, D WeiZdK, A-WÖN, CtU, CU, InU\}

Marianne, oder Der Sieg der Tugend. Rührendes Lustspiel in 3 A. 1777. (Deutsche Schaubiihne Bd. 126.) \{A-WÖN, MU (Mikrofilm), CLSU\}

Rust, Anna $=$ Croissant-Rust, Anna.

S., M. R. = Pseudonym für: Reichardt-Stromberg, Mathilde.

Sacrosanct $=$ Pseudonym für: Druskowitz, Helene von 
Salkkorausch, H. = Pseudonym für: Druskowitz, Helene von.

Saling, Regina $=$ Frohberg, Regina

Salomo, Regina $=$ Frohberg, Regina.

Sangalli, Elisabeth = Marr, Elisabeth.

Sankt Galli = Pseudonym für: Marr, Elisabeth,

Sans Gêne = Pscudonym für: Hill, Anna.

Saphir, Marie $=$ Pseudonym für: Gordon, Marie.

Schabelsky, Elisabeth (Elsa) Alcxandrowna von. 1860 (Stupky/Gouvernement Jekaterinoslaw, Südrußland) - nach 1902. Pseudonyme: P. Lorenz, Egar Schugay:

Agrippina. Lustspiel. 1892.

Der berühmte Mann. Lustspiel. 1890. \{D-BDS, D-BHU, D-BSPK, D-CorFB, DHHSU\}

Bobi. Lustspiel. 1896.

Irrlichter. Schauspiel. 1893.

Modern. Schauspiel. Freic Bearb. nach Sardou. 1895.

Notwehr. Vollssstück in 4 A. 1894. \{D-BSPK, GB-LBL\}

Ein Revisor. Lustspiel in 5 A. von Nikolaj Gogol. Übers. 1895. \{D-KöTM\}

Wabrheit. Märchendrama in 7 Bildern. 1899. \{D-BDS, D-BHU, D-BSPK, D-FSU\}

Schadow, Sophie von $=$ Hasenclever, Sophie

Schardt, Charlottc von = Stein, Charlotte Freifrau von.

Schasler, Nahida Ruth = Lazarus, Nahida Ruth.

Scheffel, Josephine. 1805 [ADB: 1803] (Oberndorf/Neckar) -1865 (Karlsruhe). Geb. Krederer:

Lorle und Dorle. Lustspiel in schwäbischer Mundart. Um 1850. [Aufgeführt Anfang der 1850er Jahre am Karlsruher Hoftheater; ADB XXX, 779].

Schelling, Caroline $=$ Schlegel-Schelling, Caroline

Schellinger, Emilie = Schleifer, Emilie

Schilffarth, Henriette. 1839 (Schwabach) - ? Verh. Straub: Maximilian Emanuel, Churfürst von Bayern. Schauspiel in 4 A. Ungedr. O. J. \{Handschriftlich in D-SSchw\}
Schiller, Charlotte Luise Antoinette von. 1766 (Rudolstadt) - 1826 (Bonn). Geb, von Lengefeld:

Der verunglïckte 5. März 1802. Schwank. 1802.

Schimmelmann, Caroline Gräfin von = Baudissin, Caroline Gräfin von

Schippel, Elisabeth = Mentzel, Elisabeth.

Schlee, Hedwig $=$ Dohm, Hedwig

Schlegel, Anna Natalie Emilie. 1849 (St. Petersburg) - 1891 (Berlin). Geb. Odrich: An rechter Schmiede. Lustspiel. 1883.

Die Heirat auf Befehl. Lustspiel. 1883.

Schlegel, Caroline $=$ Schlegel-Schelling, Caroline

Schlegel, Christiane Karoline. 1739 (Dresden) - 1833 [Goedelke: 1832] (Dresden). Geb. Lucius. Veröffentlichte anonym:

Düval und Charmille. Bürgerliches Trauerspiel in 5 A. 1778. (Deutsche Schaubühne Bd. 141; Neuausg. hg. Wurst 1991.) \{D-DUB, D-FGM, D-GF, D-GSU, D-HUB D-HUL, D-ZCW, A-WÖN, CtY, MH\}

Übersetzungen aus dem Englischen und Französischen [Groß, Deutschlands Dichterinen 25].

Schlegel-Schelling, Caroline Dorothea Albertine. 1763 (Göttingen) - 1809 (Maulbronn). Geb. Michaclis. Gesch. Schlegel. Verw. Böhmer:

Die Höhle des Todes. Übers. aus dem Französischen. 1800. [Von Meusel und Goedeke ihr zugeschrieben, nicht von Muncker in Allgemeine Deutsche Biographie.] [D MBS, MB\}

Romeo und Julia. Von Shakespeare. Übers. mit A. W. Schlegel. 1797. \{D-FGM, DWeiZdK?

Weitere Shakespeare-Übersetzungen mit A. W. Schlegel.

Schleifer, Emilie. 1825 (Vöcklabruck/Österreich) -1878 (Salzburg). Geb. Schellinger Veröffentlichte anonym:

Ein Opfer der Liebe. Schauspiel in 4 A. 1858. \{A-SMCA\}

Schlichtkrull, Aline von. 1832 (Silenz/Rügen) - 1863 (Berlin): Liebe aus Laune. Lustspiel in 5 A. 1854. \{D-BDS, NN\} Wie ein Staat gerettet wird. Schwank in 4 A. O. J. [Erstveröffentlichung 1871]. $\{\mathrm{TN}\}$

Schmid, Dr. = Pseudonym für: Zitz, Katharina Rosa Therese Pauline Modesta 
Schmidemer, Helene $=$ Forster, Helene von

Schmidmer, Helene $=$ Forster, Helene von

Schmidt, Elise. 1824 [Groß, Deutschlands Dichterinen: 1827] (Berlin) - ? Agamemnon. Drama von Äschylos. Bearb. 1857.

Die Bacchantinnen. Drama von Euripides. Bearb. 1869.

Brandenburgs erster Friedrich. Historisches Schauspiel in 5 A. 1861. \{D-BDS, D$\mathrm{MrU}\}$

Drei Dramen. 1849-56. \{D-BDS, D-BHU, D-GSU, D-RUB, A-WÖN, GB-LBL, $\mathrm{NcCU}$ oder NcGU oder NcGW, NCU

Der Genius und die Gesellschaft. Schauspiel. (Drei Dramen. 1849-56). (D-BDS, DBHU, D-BSPK, D-FGM, D-GSU, D-RUB, D-WeiZdK, A-WÖN, GB-LBL, $\mathrm{NcCU}$ oder NcGU oder NcGW, NCU\}

Judas Ischariot. Dramatisches Gedicht in 5 Abtheilungen. 1848. \{D-BDS, D-BHU, D-BSPK, D-HHU-T, D-KöTM，D-KöUSB，D-LGS，D-SPL，D-WeiZdK，AWUB, MH\}

Judas Iskariot. Russische Übersetzung ihres gleichnamigen deutschen Originals. 1909. \{D-HHSU\}

Der Kauf der Mark Brandenburg. Geschichtlich-vaterländisches Schauspiel in 5 A. 1860. \{Als Manuskript in D-BSPK\}

Macchiavelli. Trauerspiel. (Drei Dramen. 1849-56). (D-BDS, D-BH, D-BHU, DGSU, D-RUB, A-WÖN, GB-LBL, NcCU oder NcGU oder NcGW; NCU\}

Odipus in Kolonos. Drama von Sophokles. Bearb. 1857.

Paganini. Melodrama. 1846

Peter der Große und sein Sohn. Schauspiel. (Drei Dramen. 1849-56). (D-BDS, DBHU, D-GSU, D-RUB, A-WÖN, GB-LBL, NcCU oder NcGU oder NcGW, $\mathrm{NCU}\}$

Prometheus. Drama von Äschylos. Bearb. 1855.

Stein und Napoleon. Drama. 1870.

Die Vögel. Drama von Aristophanes. Bearb. 1869.

Schmidt, Emilie = Heinrichs, Emilie

Schmidt, Emilie Johanna Constantia Katharina = Bufalo della Valle, Emilia Marchesa del.

Schmidt, Friderilke. Um 1824:

Dramatische Bearbeitung einiger Theile der heiligen Geschichte nebst mehreren Gelegenheitsgedichten von der blinden Friderike Schmidt. 1827. (D-WeiZdK\}

Schmidt, Maria Wilhelmine (Minna). 1781 (Berlin) - 1827 (Berlin). Geb, Nauen: Der Liebhaber als Gespenst. Komödie von Pedro Calderón de la Barca. Übers. 1816.
Schnorr von Carolsfeld, Charlotte $=$ Krug, Charlotte.

Schönfließ, Rosalie. 1799 (Königsberg/Preußen) - 1845 (Georgenburg bei Insterburg):

Clara oder die Frauenemancipation. 1843-4

Johanna Gray. 1839.

Der letzte der Abencerragen. 1840.

Schreiber, Auguste $=$ Ribics, Auguste

Schröder, Auguste Sophie. 1847 (Löbejün bei Halle/Saale) - nach 1905. Geb. Festner:

Die bekehrten Ungläubigen. Lustspiel. 1876.

Intriguen. Schauspiel. 1876

Nur eine Gastrolle. Lustspiel. 1881.

Verheiratet wider Willen oder irren ist menschlich. Lustspiel. 1876.

Wabn und Liebe. Lustspiel. 1882

Dramatisierte Märchen [Groß, Deutschlands Dichterinen 138].

Schröder, Emilie. ? (Berlin) - 1922:

Das Glas Wasser oder Ursachen und Wirkungen. Lustspiel in 5 A. von Scribe. Übers. O. J. \{D-BDS, D-DonFFH, D-DSB, D-DUB, D-ENU, D-KöED, D-MarSN, DSPL, D-WeiZdK, A-WÖN, CH-WiS, CH-SZ\}

Der Misanthrop. Drama von Molière. Übers. O. J. (Molières Sämmtliche Werke in zwei Bänden. 1871.) \{D-EWA, D-HUL, D-LDB, D-MüU, D-SPL\}

Die Plagegeister. Komödie in 3 A. von Molière. Übers. O. J. (Molières Sämmtliche Werke in zwei Bänden. 1871.) (D-BDS, D-EWA, D-HUL, D-LDB, D-PEA, DSPL, A-SUB

Psyche. Trauerspiel in 5 A. von Molière. Übers. O. J. (Molières Sämmtliche Werke in zwei Bänden. 1871.) \{D-EWA, D-HUL, D-LDB, D-SPL\}

Sämmtliche Werke von Molière. 2 Bde. Hg. (und teilweise übers.) 1871. (D-EWA, DHUL, D-LDB, D-SPL\}

Die Schule der Ehemannner. Lustspiel in $3 \mathrm{~A}$, von Molière. Übers. O. J. (Molières Sämmtliche Werke in zwei Bänden. 1871.) (D-DSB, D-EWA, D-HUL, D-LDB, DSPL, A-SUB\}

Die Schule der Frauen. Lustspiel in 5 A. von Molière. Übers. O. J. (Molières Sämmtliche Werke in zwei Bänden. 1871.) \{D-BDS, D-EWA, D-HUL, D-LDB, D-SPL, DWeiZdK\}

Tartuffe. Drama von Molière. Übers. O. J. (Molières Sämmtliche Werke in zwei Bänden. 1871.) \{D-BDS, D-ENU, D-ES, D-EWA, D-HUB, D-HUL, D-LDB，DMüU, D-SPL, A-SUB]

Übersetzungen von Racines Tragödien. Um 1884 
Schröder, Sophic Charlotte $=$ Ackermann, Sophie Charlotte

Schröter, Johanne Juliane von = Köbner, Johanne Juliane.

Schubert, Sophie $=$ Mereau, Sophie

Schücking, Louise Johanne Gerhardine Ulrike. 1815 (Darmstadt) - 1855 (Sassenberg bei Münster). Geb. von Gall. Pseudonym: Louise v. G:

Doctor Robin. Lustspiel in 1 A. Bearb. nach dem Französischen von L.v. G. (= Louise von G.?) 1843. \{D-KöTM\}

Die gnädige Frau. Lustspiel in 1 A. 1852. \{D-KöTM\}

Ich hab's gewagt. Lustspiel in 2 A. 1851. \{D-KöTM\}

Das lebende Bildnißs. Lustspiel in 3 A. Bearb. nach dem Französischen von L. v. G. (= Louise von G.?) 1843. \{D-KöTM\}

Die Memoiren des Satans. Lustspiel in 3 A. Bearb, nach dem Französischen. 1842

Von L. v. G. (= Louise von G.?) \{D-KöTM\}

Ein schlechtes Gewissen. Komödie in 1 A. 1842. \{D-KöTM\}

Weitere nicht genannte Lustspiele [Groß, Deutschlands Dichterinen 119].

Schugay, Egar = Pseudonym füı: Schabelsky, Elisabeth (Elsa) Alexandrowna von.

Schugt, Johanna = Holthausen; Johanna.

Schusellka-Brïning, Ida. 1817 - ?:

Frauengüte. Lustspiel in $1 \mathrm{~A} .1853$. \{D-BDS

Herzensadel. Lustspiel in 5 A. Nach dem Französischen. O. J. \{D-BDS Eine kleine Gefalligkeit. Lustspiel in 1 A. 1860. \{D-HHU-T, D-KöTM

Der Reichtum des Arbeiters. Lebensbild mit Gesang und Tanz in 2 A. Bearb. nach dem Französischen. 1852. \{D-HHU-T, D-KöTM, A-WÖN\}

Ein verlorener Vater. Bearb. nach Dumas' Charakterlustspiel. O. J. [Identisch mit: Vater und Sohn? \{A-WÖN\}

Vater und Sobn. Charakterlustspiel in 5 A. Freie Bearb. nach A. Dumas Sohn Le pere prodigue. [Identisch mit: Ein verlorener Vater?] O. J. \{D-BTM, D-KaMB\} Zwei Mütter. Schauspiel in 4 A. Nach dem Französischen. O. J. \{D-BDS\}

Schwarzburg-Sondershausen, Mathilde Fürstin von. 1814 (Hohenlohe-Öhringen/ Österreich) - 1888 (Salzburg). Pseudonyin: Dornheim:

Jadwiga, Königin von Polen. Drama. O. J.

Sedelmayr [Goedeke: Sedelmaier], Johanna Maria. 1811 [Groß, Deutschlands Dichterinen: 1801] (Salzburg) - 1853 (Salzburg):

Der Fischer am Gollinger Wasserfall. Drama. O. J. Joseph Speckbacher. Drama: O. J.
Romulus und Remus. Drama. 1837

Weitere nicht genannte Dramen [Groß, Deutschlands Dichterinen 115].

Sefried, Franziska Freiin von = Tauffkirchen-Engelburg, Franziska Gräfin von

Serena $=$ Pseudonym für: Motte-Fouqué, Karoline de la

Serena, $A .=$ Pseudonym für: Amalie, Prinzessin von Sachsen

Seyler, Friederike Sophie. 1738 (Dresden) - 1789 (Schleswig). Geb. Sparmann. Gesch. Hensel:

Die Entfuibrung, oder Die zärtliche Mutter. Drama in 5 A. nach Sheridan. [Neubearb. der Familie auf dem Lande.] 1771. [D-KöTM, MU (Mikrofilm), NN\}

Die Farnilie auf dem Lande. Drama in 5 A. 1770. (D-KöTM, GB-LBL, MU (Mikrofilm), NNC

Der Hinkende und der Stotternde. Lustspiel. Ungedr. O. J.

Hüon und Amande. Romantisches Singspiel in 5 A. nach Wielands Oberon. 1789.

(Theatralische Sammlung Bd. 81.) \{D-DonFFH, D-WoHA, A-WÖN, GB-LBL\}

Melanide. Schauspiel. Übers. aus dem Französischen. O. J.

Oberon, oder König der Elfen. Romantisches Singspiel in 3 A nach Wieland. [Neubearb. von Hüon und Amande.] Erschicnen 1792. (Deutsche Schaubibne Jg. 4, Bd. 11.) (D-ASS, D-BS, D-DonFFH, D-WeiZdK, A-WÖN, GB-LBL, ICRL, MB, MH, MU (Mikrofilm), OrU; als Operntextbuch in D-BSPK, D-FGM, D-FSU, D$\mathrm{KaMB}\}$

Siebert, Anna. 1846 (Köln) - ? Geb. ? Pseudonym: Sophie Rheinau: Mirzels Ritt auf dem Pegasus. Lustspiel. 1879.

Wendelin Deichselgrad in Köln. Lustspiel in 3 A. 1879. \{D-KöTM, D-KöUSB\}

Siegel, Maria Anna = Löhn-Siegel, Maria Anna

Siking, Franz $=$ Pseudonym für: Strauss, Henriette.

Sophie, Prinzessin von Hohenlohe $=$ Sophie, Prinzessin von Sachsen-Hildburghausen .

Sophie, Prinzessin von Sachsen-Hildburghausen. Anderer Name: Sophie von Hohenlohe. $1772-1790$

Die Dorffeyer. Schauspiel. O. J.

Sostmann, Anna Wilhelmine (Minna) Elisabeth. 1788 (Hannover) - 1864 (Hamburg). Geb. Blumenhagen:

Peter Vischer. Romantisch-dramatisches Gemälde aus Nürnbergs Vorzeit in 2 A. 1832. \{D-BSPK, D-DeLL, D-FTT, D-GF, D-MBS, A-LBS, A-WÖN, GB-LBL $\mathrm{InU}$ 
Sparmann, Friederike $=$ Scyler, Friederike

Spohr, Charlotte $=$ Glümer, Charlotte von.

Stahl, Karoline, 1776 (Gut Ohlenhoff/Livland) - 1837 (Dorpat). Geb. Dumpf (auch Dumpff):

Moralische Erzählungen, Schauspiele und Reisebeschreibungen fïr die Jugend. 1822. \{D-GSU\}

Staufen, Fr. = Pseudonym für: Fritsch, Franziska.

Stein, Charlotte Albertine Ernestine Freifrau von. 1742 (Eisenach) - 1827 (Weimar). Geb, von Schardt:

Dido. Trauerspiel in 5 A. 1796. (Goethes Briefe an Frau von Stein, 2. Aufl., 2 Bde., hg. Adolf Schöll, Frankfurt: 1883-5, Bd. 2.) \{U. a. an: D-ASS, D-BDS, D-BFU, DBHU, D-BSPK, D-DeLL, D-DGM, D-DSB, D-DUB, D-ES, D-FGM, D-GSU, D-HHU-T, D-HUB, D-HUL, D-KaMB, D-LDB, D-LKM, D-MarSN, D-MrU, D-MüS, D-MüU, D-WeiZdK, A-ZS, GB-LBL, CtY, CU, DLC, IU, MB, MH, MU, NcU, NIC, OCIW, OCU, PPG, PU, RPB

Neues Freiheitssystem oder die Verschwörung gegen die Liebe. Komödie in 4 Bildern. 1798. \{D-BS, D-DUB, D-HHU-T, D-KaMB, D-KöTM, D-LDB\}

Die Probe. Lustspiel in 5 A. 1809 . \{UU\}

Rino. Schauspiel in 3 A. 1776. (Goethes Briefe an Frau von Stein, 2. Aufl., 2 Bde., hg. Adolf Schöll, Frankfurt: 1883-5, Bd. 1.) \{U. a. an: D-FGM, MB, MU\}

Die zwei Emilien. Komödie. 1800. (D-ASS, D-DGM, D-FGM, D-FSU, D-GF, DGSU, D-MarLA, D-MarSN, D-MBS, D-SchOS, D-TüU, D-WeiZdK, A-WUB, CH-CGBB, CH-LZ

Vielleicht eine weitere Komödie. 1800.

Stein, Max = Pseudonym für: Gordon, Marie.

Steinlein, Laura. 1826 (Friedefeld, Krs. Randow/Pommern) - 1901 [nach 1902?]. Geb. Freese. Pseudonyme: Arthalis, A. Freese, Arthur Freese:

Gustav Wasa. Schauspiel in 5 A. 1891. (D-EWA, D-FSU, D-WeiZdK\}

Das Haus Cenci. Tragödie in 5 A. 1861. \{D-WeiZdK, CtU, NN\}

Kaiser Karl V. Drama in 5 A. 1857 (2. Aufl. 1881). \{D-BUB, OClW\}

Stephanic = Pseudonym für: Zitz, Katharina Rosa Therese Pauline Modesta.

Stern, Otto $=$ Pseudonym für: Otto-Peters, Luise.

Sternheim = Pseudonym für: Brachmann, Louise.
Stolberg, Friederike Louise Gräfin. 1746 (Kopenhagen) - 1824 (Pederstrup). Geb. Gräfin Reventlow. Verh. von Gramm:

Emil. Drama in 3 A. O. J.

Stolberg, Henriette Katharina Gräfin zu. 1751 (Bramstedt/Holstein) - 1832 (Peterswaldau bei Reichenbach/Schlesien):

Moses. Ein kleines Drama. 1788. \{D-MBS\}

Stosch, Karoline $=$ Woltmann, Karoline von.

Straub, Henriette $=$ Schilffarth, Henriette.

Strauss, Henriette. 1845 (Bühl/Baden) - nach 1882. Geb. Netter oder Nettner. Pseudonym: Franz Siking:

Barbarossatetralogie. Fünf Dramen um Friedrich I. [Entstanden? Geplant?]

Beatrice. Historische Tragödie in 5 A. O. J. \{D-BDS, D-KöTM, ICRL, MB\}

Diplomatenliebe. Drama. O. J.

Kaiser Friedrich I. Schauspiel in 5 A, und einem Vorspiel. Als zweiter Teil der Barbarossatetralogie. 1893. \{D-FSU, D-HUB, D-KöTM

Kaiser Heinrich IV. von Deutschland. Drama. O. J.

Ein König. Drama. O. J.

Schuld um Schuld. Drama. O. J.

Sewabi. Drama in 5 A. 1872. \{D-BSPK, D-KaMB, D-WeiZdKK\}

Sturmhoefel, Nahida Ruth = Lazarus, Nahida Ruth.

Suttner, Bertha von. 1843 (Prag) - 1914 (Wien). Pseudonym: B. Oulot: Babies siebente Liebe und anderes. Neue Folge der erzählten Lustspiele. 1905. \{D$\mathrm{KaMB}, \mathrm{D}-\mathrm{LKM}\}$

Ermenegildens Flucht. Erzähltes Lustspiel. 1905.

Erzählte Lustspiele. Neues aus dem High Life. 1889.

Franzl und Mirzl. Erzähltes Lustspiel. 1905.

Langeweile. Erzähltes Lustspiel. 1905.

Sydow, Wilhelmine von. 1789 (Thumnitz/Oberlausitz) - 1867 (Schleusingen/Thüringen). Geb. von Criegern. Pseudonym: Isidore Grönau:

Das Angebinde. Schauspiel in 2 A. O. J. (Eunomia. 1830.) (D-EWA, D-GF, DHUL, D-WeiZdK, UU\}

Eunomia. 1830. \{D-EWA, D-GF, D-HUL, D-WeiZdK, UU\}

Das Festspiel. Schauspiel in 3 A. O. J. (Eunomia. 1830.) (D-EWA, D-GF, D-HUL, D-WeiZdK, UU\}

Die geheilte Thorheit. Lustspiel in 1 A. O. J. (Eunomia. 1830.) (D-EWA, D-GF, D-

HUL, D-WeiZdK, UU\} 
Der Husarenrecrut. Schauspicl in 2 A. O. J. (Eunomia. 1830.) \{D-EWA, D-GF, DHUL, D-WeiZdK, UU

Kindliche Liebe. Schauspiel in 2 A. O. J. (Eunomia. 1830.) (D-EWA, D-GF, DHUL, D-WeiZdK, UU\}

Die Schwätzerin. Lustspicl in 1 A. O. J. (Eunomia. 1830.) (D-EWA, D-GF, DHUL, D-WeiZdK, UU\}

Die Überraschung. Schauspiel in 2 A. O. J. (Eunomia. 1830.) (D-EWA, D-GF, DHUL, D-WeiZdK, UU\}

Sylva, Carmen = Pseudonym für: Elisabeth von Rumänien,

Sylvander = Pseudonym für: Chézy, Wilhelmine von.

Sylvandra = Pseudonym für: Chézy, Wilhelmine von.

T., F. = Pseudonym für: Tarnow, Franziska Christiane Johanna Friederike.

Tabouillot, Mathilde Franziska von = Anneke, Mathilde Franziska.

Taléa, Ermelinda = Pscudonym für: Maria Antonia Walpurgis, Kurfürstin von Sachsen.

Tante Aurelie $=$ Pseudonym für: Baudissin, Sophie von

Tarnow, Franziska (Fanny) Christiane Johanna Friederike. 1779 [Groß, Deutschlands Dichterinen: 1783] (Güstrow/Mecklenburg) - 1862 (Dessau). Pseudonyme: Fanny, F. T:

Die Spanier auf Fühnen. Historisches Schauspiel in 4 A. Freie Bearb. 1827. \{DKöT'M, D-SML\}

Tauffkirchen-Engelburg, Franziska (Fanny) Gräfin von. 1802 (Schloß Buttenheim/ Bayern) - 1851 (Engelburg/Bayern). Geb. Freiin von Seefried:

Der Advokat. O. J.

Die beiden Trenk. O. J.

Graf Arco. O. J.

Graf Lauzun. O. J.

Telto, G. = Pseudonym für: Glümer; Charlotte von. [d. i. Umstellung von: Lotte G.]

Teutscher, Maria Antonia, 1752 (Wien) - 1784 (Wien):

Fanny, oder Die glïckliche Wiedervereinigung. Drama in 1 A. 1773. \{A-WÖN, MU (Milkrofilm), NN, PU\}

Thal Antonie $=$ Pseudonym für: Thaler, Anna Antonie.
Thaler, Anna Antonie. 1814 (Brünn) - 1875 (Wien). Geb. Ribas (auch Riba). Pseudonym: Antonie Thal:

Zwei nicht genannte Lustspiele [Groß, Deutschlands Dichterinen 182].

Theodora $=$ Pseudonym für: Bürger, Elise.

Theone $=$ Pseudonym für: Artner, Marie Therese von

Theophania = Pseudonym für: Brochowska, Pauline von.

Thercse $=$ Pseudonym für: Huber, Therese

Thon, Eleonore Sophie Auguste. 1753 [Goedeke: 1757; Groß, Deutschlands Dichterinen: 176?] (Eisenach) - 1807 (Eisenach). Geb. Röder [Groß, Deutschlands Dichterinen: Rödern]. Pseudonym: Jenny:

Adelheit von Rastenberg [Goedeke: Rosenberg]. Trauerspiel in 5 A. 1788. \{D-ASS, DASU, D-BSPK, D-DUB, D-FGM, D-GF, D-KUB, D-LKM, D-MarSN, D-SPL D-WeiZdK, A-SUB, A-WÖN, GB-LBL, MH, MU (Mikrofilm), TxU\}

Thure = Pseudonym für: Kühne, Julie Mathilde

Thurnberg, Marie von = Augustin, Marie Freifrau von.

Tian = Pseudonym für: Günderrode, Karoline von

Tieck, Dorothea. 1799 (wo?) - 1841 (National Union Catalog: 1851):

Die beiden Veroneser. Drama von Shakespeare. Úbers. O. J. \{D-KaMB, D-KöTM\} Coriolanus. Drama von Shakespeare. Übers. O. J. \{U. a. an: D-BDS, D-FSU, DHHSU, D-KöTM, OCU\}

Cymbeline. Drama von Shakespeare. Übers. O. J. \{D-BDS\}

Macbeth. Drama von Shakespeare. Übers, 1833, \{U, a, an: D-BDS, D-FSU, D HHSU, D-KaMB, D-KöTM, GB-LBL, OCU\}

Timon von Athen. Drama von Shakespeare. Übers. O. J.

Das Wintermärchen. Drama von Shakespeare. Übers. O. J. \{D-HHSU, D-KöTM\}

Weitere Shakespeare-Übersetzungen.

Tieck, Sophie $=$ Knorring, Sophie von.

Tiell, Marianne von = Neumann von Meißenthal, Marianne

Tina $=$ Pseudonym für: Zitz, Katharina Rosa Therese Pauline Modesta 
Titzenhofer, Sophie Eleonore von. 1749 (Groß Jänowitz bei Liegnitz/Schlesien) 1823 (Olbersdorf bei Breslau). Geb. von Wundsch. Verh. von Kortzfleisch. Gen. Ratzbar. Pseudonym: Adliches Frauenzimmer in Schlesien:

Das Landwehrkreuz in der Schlacht an der Katzbach. Drama. 1816.

Lausus und Lydie. Drama in 3 A. nach Marmontel. 1776. (Deutsche Schaubühne Bd. 102.) \{D-FGM, D-WeiZdK, A-WÖN, MU (Mikrofilm)\}

Osman und Bella. Schauspiel in 5 A. 1776. \{D-ASU, A-WÖN\}

Willhelm und Hannchen. Operette in 3 A. 1778. \{D-BSPK, D-FTT, D-GF, DWeiZdK, MU (Mikrofilm)]

Tochter der Karschin = Pseudonym für: Klencke, Karoline Luise von.

Treskow, Ada von $=$ Pinelli-Rizzutto, Ada.

Trieb, Josef = Pseudonym für: Paar, Mathilde

Ulrike. ? - ? [Identisch mit Ulrike Sophie?]:

Unglücklich durch Liebe und Konvenienz. Schauspiel in 4 A. 1788. (Deutsche Schaubiuhne Bd. 46.) \{GB-LBL\}

Ulrike Sophie, Herzogin von Mecklenburg-Schwerin. 1723 - 1813. [Identisch mit Ulrilke?]:

Der Undankbare. Lustspiel in 5 A. nach Destouches. 1756. \{D-HHSU, D-SML\}

Unger, Friederike Helene. 1741 [Groß, Deutschlands Dichterinen: 1751] (Berlin) 1813 (Berlin). Geb. von Rothenburg. Pseudonyme: Verfasserin des Julchen Grünthal, (Verfasser der offenen Fehde?):

Die Abenteuer einer Nacht, oder die zwey lebenden Toten. Lustspiel von Dumaniant, aus dem Französischen. 1789. \{D-EWA, D-FGM, GB-LBL\} Der adelsüchtige Bürger. Posse. 1788. \{D-BSPK, A-WÖN\}

Der Bethbruder, ein Lustspiel nach Moliere's Tartuffe, frey übersetzt. In 5 A. 1787. \{DFGM, A-WÖN\}

Figaros Hochzeit, oder der lustige Tág. Komödic von Beaumarchais. Übers. 1785. \{DFGM, D-WeiZdK\}

Die magnetische Wunderkraft, oder aller Welt zum Trotz doch ein Arzt. Lustspiel in 3 A. Freie Übers. 1789. [Auch Ludwig Ferdinand Huber zugeschrieben.] \{D-FGM, GB-LBL, MU (Mikrofilm)\}

Der Mondkaiser. Posse in 3 A. Aus dem Französischen. 1790. (D-FGM, D-HHSU, A-WÖN\}

Die offene Fehde. Lustspiel. Bearb. nach dem Französischen. 1789. [Auch Ludwig Ferdinand Huber zugeschrieben.]
Uttech, Marie. 1819 (Züllichau/Brandenburg) - 1870 (Fürstenwalde/Brandenburg). Geb. Harrer:

Die kleine Erzherzogin. Lustspiel nach dem Spanischen. 1869. \{D-WeiZdK\}

Valduga, Sophic $=$ Kleinert, Sophie

Valett, Bertha $=$ Lamprecht, Bertha

Vaselli, Marie von. 1858 (Breslau) - 1923. Geb. von Ernest. Verh. von Baußnern Briefmarken. Lustspiel. 1880. \{D-WeiZdK\}

Magdalena. Schauspiel in 1 A. 1878. AAls Regiebuch, durchschossen, in D-KöTM; D-WeiZdK\}

Mit dem Strome. Lustspiel in 4 A. 1878. AAls Soufflierbuch in D-KöTM; DWeiZdK, D-WHLB, A-WÖN, NN\}

Verena, Sophie $=$ Pseudonym für: Alberti, Sophie.

Verfasser der offenen Fehde $=$ mögliches Pseudonym für: Unger, Friederike Helene

Verfasserin der Amalia = Pseudonym für: Ehrmann, Marianne.

Verfasserin der Charlotte Corday $=$ Pseudonym für: Westphalen, Engel Christine.

Verfasserin der Familie Stolberg = Pseudonym für: Gersdorf, Wilhelmine von

Verfasserin der Memoiren einer Idealistin = Pseudonym für: Meysenbug; Malwida von. Verfasserin der Philosophie eines Weibes = Pseudonym für: Ehrmann, Marianne.

Verfasserin des Dichterlings $=$ Pscudonym für: Hain, Juliane

Verfasserin des Julchen Grünthal = Pseudonym für: Unger, Friederike Helene.

Verfasserin von „Lüge und Wahrheit" = Pseudonym für: Amalie, Prinzessin von Sachsen.

Vespermann, Maria $=$ Arndts, Maria.

Viebig, Clara. 1860 (Trier) - 1952 (Berlin.). Verh. Cohn:

Die Bäuerin. Drama. O. J. (Der Kampf um den Mann. 1905.) (D-BDS, D-BFU, DBHU, D-HHU-T, D-LKM, GB-LBL]

Barbara Holzer. Schauspiel in 3 A. 1897. (D-BDS, D-BHU, D-BSPK, D-HHU-'T, D-I,KM] 
Fräulein Freschbolzen. Drama. O. J (Der Kampf um den Mann 1905) (D-BDS, D BFU, D-BHU, D-HHU-'T, D-LKM, GB-LBL\}

Der Kampf um den Mann. Dramenzyklus. 1905. (D-BDS, D-BFU, D-BHU, DFSU, D-HHU-T, D-KöTM, D-LKM, GB-L,BL

Das letzte Glück. Schauspiel in 4 A. 1909. \{D-BDS, D-BHU, D-FSU, D-HHU-T, GB-LBL\}

Mutter: Drama. O. J. (Der Kampf um den Mann. 1905.) \{D-BDS, D-BFU, DBHU, D-HHU-T, D-LKM, GB-LBL\}

Pharisder. Komödie in 3 A. 1899. \{D-BDS, D-BHU, D-BSPK, D-FSU, D-HHUT, D-KöTM, D-LKM)

Pittchen. Komödie in 3 A. 1910. \{D-KöTM\}

Eine Zuflucht. Drama in 1 A. O. J. (Der Kampf um den Mann. 1905.) \{D-BDS, DBFU, D-BHU, D-HHU-T, D-KöTM, D-LKM, GB-LBL\}

Villiers, Emilie = Schauspielername für: Montenglaut, Henriette Artemisia Marianne von.

Viola $=$ Pseudonym für: Zitz, Katharina Rosa Therese Pauline Modesta.

Vogelsang, Josephine Freiin von = Perin von Gradenstein, Josephine Freifrau von.

W., W. = Pseudonym für: Gensike, Wilhelmine.

Wagmuth [Goedeke: Wachmuth], Magdalena = Callot, Magdalena (Madeleine) Freiin von.

Wagner, Mathilde $=$ Nieberg, Mathilde.

Waldburg, Nina von = Pseudonym für: Güthner, Regina.

Waldherr $=$ Pseudonym für: Birch-Pfeiffer, Charlotte

Waldow, Ernst von = Pseudonym für: Blum, Lodoiska von.

Wallenheim, Auguste von = Pseudonym für: Goldstein, Auguste von.

Wallenrodt, Auguste von $=$ Goldstein, Auguste Freiin von.

Wallenrodt, Isabella Johanna Eleonora von. 1740 (Uhlstädt/Thüringen) - 1819 (Lampersdorf bei Bernstadt/Schlesien). Geb. von Koppy:

Die Räuber. Trauerspiel in 5 A. fortgesetzt. (Auch unter dem Titel: Karl Moor und seine Zeitgenossen nach der Abschiedsscene am alten Thurm. [Fortsetzung von Schillers Die Räuber] 1801. [D-BHU, D-FGM, D-KöTM, D-MarSN, D-MaU, DWeiZdK, A-WÖN\}
Wartensleben, Charlotte Wilhelmine Isabelle Gräfin. ? - ? Die Dulderin. 1809. \{D-ZCW\}

Waschmitius, Philomene $=$ Hartl, Philomene

Wedi, C. = Pseudonym für: Elisabeth von Rumänien.

Weikard, Sophie Marianne $=$ Reitzenstein, Sophie Marianne von

Weimar, A. = Pseudonym für: Götze, Auguste.

Weise, Alberta = Puttkamer, Alberta.

Weißenborn, Friederike Karoline $=$ Neuber, Friederike Karoline

Weißenthurn, Johanna von $=$ Franul von Weißenthurn, Johanna

Weißenthurn, Johanna Franul von = Franul von Weißenthurn, Johanna

Werner, $\mathrm{E} .=$ Pseudonym für: Bürstenbinder, Elisabeth.

Werner, Elisabeth = Pseudonym für: Bürstenbinder, Elisabeth.

Werner, Pauline = Raupach, Pauline.

Wesendonck, Mathilde. 1828 (Elberfeld) - 1902 (Traunblick bei Altmünster/Salzkammergut). Geb. Luckemeier:

Alkestis. Dramatisches Gedicht in 4 A. 1881 (Neuausg. 1898). (D-BaRW, D-LKM, CH-GBPU\}

Aschenputtel. O. J. (Märchenspiele. 1864.) \{D-DeLL, D-DUB, D-KöTM, CH-BSL\} Edith oder die Schlacht bei Hastings. Trauerspiel. 1872. (D-BaRW, D-BHU, DBSPK, D-DeLL, D-GSU, D-KaMB, D-KöUSB, D-LH, D-LKM, D-MarSN, DSML, D-TüU, D-WuS, A-WÖN, CH-BSL, CH-BSU, ICN, InU, MB, NN, PU\} Friedrich der Große. Dramatische Bilder nach Franz Kugler. 1871. (D-BHU, DBSPK, D-HUL, D-KöTM, D-LKM, CH-BSL, CH-SGK, fehlt an DLC\}

Genovefa. Trauerspiel in 3 A. 1866. \{D-BaRW, D-BSPK, D-TüU, CH-AK, CHWiS, InU\}

Gudrun. Schauspiel in 5 A. 1868. \{D-BaRW, D-DeLL, D-FSU, D-KöTM, DKöUSB, D-LDB, D-LH, D-LKM, D-MarSN, D-MüRS, D-SML, A-WÖN, CHBSL, CH-BSU, CH-LZ, CH-ZDS, GB-LBL, MH, NN, PU\}

Kalypso. Vorspiel zu Odysseus. 1875. (D-BaRW, CaBVaU, C-VU\}

Märchenspiele. (Märchen und Märchenspiele.) 1864 (Neuausg. 1900). (D-DeLL, DDUB, D-KöTM, CH-BSL] 
Odysseus. Dramatisches Gedicht in 2 Theilen und einem Vorspiel. 1878. \{D-BaRW, D-HLB, D-MarSN, CH-GBPU, GB-LBL, CaBVaU, C-VU\}

Perseus. O. J. (Märchenspiele. 1864.) \{D-DeLL, D-DUB, D-KöTM, CH-BSL Rothkapppchen. O. J. (Märchenspiele. 1864.) (D-DeLL, D-DUB, D-KöTM, AWÖN, CH-BSL

Siegfried. (Marchenspiele. 1864.) \{D-DeLL, D-DUB, D-KöTM, CH-BSL\}

Westphalen, Engel [auch Engeline oder Eva] Christine. 1758 (Hamburg) - 1840 (Hamburg). Geb. von Axen. Pseudonyme: Angelika, Verfasserin der Charlotte Corday. Veröffentlichte auch anonym:

Charlotte Corday. Tragödie in 5 A. mit Chören. 1804. \{D-BDS, D-BHU, D-FGM, D-FrU, D-GSU, D-HHSA, D-HHSU, D-HUL, D-LKM, D-MBS, D-MüU, DSchOS, D-WeiZdK, GB-LBL, InU, NcU\}

Petrarca. Dramatisches Gedicht in 5 A. 1806. \{D-BDS, D-BHU, D-BS, D-DoB, D-FGM, D-GSU, D-HHSA, D-HHSU, D-HLB, D-MBS, D-TS, D-WeiZdK, DWoHA, A-WÖN, CtY, InU, NIC, ViW]

Wickenburg, Wilhelmine Gräfin von. 1845 (Ofen/Budapest) - 1890 (Gries bei Bozen). Geb. Almásy:

Ein Abenteuer des Dauphin. Lustspiel. 1880. \{D-BDS, D-MarSN, A-WÖN\}

Das Dokument. Schauspiel in 3 A. 1880. \{D-LKM, D-WeiZdK\}

Eudocia. Drama. 1880.

Radegundis. Dramatisches Gedicht in 1 A. 1879. \{D-BSPK, D-MarSN, A-WÖN, PU, ViU\}

Wickenburg-Almásy, Wilhelmine von = Wickenburg, Wilhelmine von.

Wied, Elisabeth Fürstin = Elisabeth von Rumänien

Wilhelmi, Hedwig Karoline Berta. 1833 (Mainz) - 1913. Geb. Henrich: Brigitte. Schauspiel. O. J.

Die Gefangenen, oder eine Intrigue am Hofe Ludwigs XVI. Lustspiel in 4 A. 1854. \{AWÖN]

Die Glocke von Almudaina. Drama. Bearb. nach dem Spanischen. 1865. \{D-BDS, A-WÖN

Maria Padilla. Historische Tragödie in 5 A. 1857. \{D-BSPK\}

Matthias. Trauerspiel in 5 A. 1857.

Eine Sünderin. Drama in 5 A. 1896. \{D-FSU, D-LKM, D-TüU

Der Türke in Petersburg oder wie Katharina Frieden schließt. Lustspiel in 5 A. 1854. Virginia. Trauerspiel. 1853. \{D-BSPK, NN\}

Willborn, Johanna. 1838 (Schwerin i. M.) - 1908 (Schwerin). Pseudonym: Julius Willborn:

Matthias. Trauerspiel, 1857. \{D-BSPK, GB-LBL, NN\}
Willborn, Julius = Pseudonym für: Willborn, Johanna.

Willer [auch Villiers], Emilie = Schauspielername für: Montenglaut, Henriette Artemisia Marianne von.

Willmar [Friedrichs: Willmer], Wilhelmine = Pseudonym fur: Gensike, Wilhelmine.

Witte, Minna von $=$ Pseudonym für: Mädler; Minna von

Witter, Catharina Salome = Link, Catharina Salome.

Wolf, Johanna. 1818 (Prag) - 1893 (Salzburg). Geb. Leitenberger. Pseudonyme: Jean Litahorsky, Marie Litahorsky:

Die Fiole Cagliostros. Lustspiel. Um 1860. \{A-WÖN\}

Veronika von Teschenitz. Historisches Trauerspiel. 1867. \{A-GUB\}

Wolff, Ulla. 1850 (Gleiwitz oder Wollstein/Posen) - 1924 (Berlin). Geb. Hirschfeld. Pseudonyme: Ulla Frank, Ulrich Frank:

Aus Paris. Lustspiel. 1879.

Der Herr Kollege. Schauspiel. 1876. \{D-BSPK

Ein Vampir. Schwank. 1876. \{D-BSPK\}

Woltmann, Karoline von. 1782 (Berlin) - 1847 (Berlin). Geb. Stosch. Verh. Müchler Pseudonym: Luise Berg:

Orlando. Trauerspiel. 1815. \{D-HS, D-KöTM\}

Wolzogen, Caroline Friederike Sophie Auguste von. 1763 (Rudolstadt) - 1847 (Jena). Geb. von. Lengefeld. Verh. von Beulwitz:

Der leukadische Fels. Schauspiel. 1792. (Neue Thalia 2, 1792.) (D-BoU, D-DeLL, D-DGM, D-DoB, D-DUB, D-ENU (Mikrofiche), D-KUB, D-MiiU, D-TS, DTüU, D-WeiZdK, D-WuS, A-GUB, MU\}

Wulff, Sara $=$ Grotthuss, Sara Freifrau von.

Wundsch, Sophie Eleonore von = Titzenhofer, Sophie Eleonore von

Young, Betty. 1832 (Budapest) - 1887 (Wien). Geb. Mück:

Ein amerikanisches Duell. Lustspiel in 1 A. 1872. (Wiener Theater-Repertoir Bd. 14 , Lfg. 266.) \{D-BSPK, A-WON, A-WUB, NN\}

* Ihr zweibändiger Literarischer Nacblaß, Leipzig. 1848/9, von dem mir nicht bekannt ist, ob er Dramen enthält, befindet sich in D-HIB und D-IDB. 
Die beiden Giftmischerinnen. Dramatischer Scherz. 1872. (Wiener Theater-Repertoir Bd. 14, Lfg. 264.) \{A-WÖN, A-WUB

Durch Champagner. Lustspiel. 1876. \{D-WeiZdK, A-WÖN, A-WUB\}

Ehemann auf Probe. Komödic. 1872. (Wiener Theater-Repertoir Bd. 14, Lfg. 269.) A-WÖN, A-WUB\}

Frau Othello. Komödie. 1869. \{D-BDS, A-WÖN, A-WUB\}

Mädchenträume. Komödie mit Gesang. 1869. (Wiener Theater-Repertoir Bd. 12 Lfg. 227.) \{A-WÖN\}

Nach der letzten Redoute. Komödie. 1869. (Wiener Theater-Repertoir Bd. 12 Lfg. 229.) \{D-BDS, A-WÖN, A-WUB\}

Die rote Liesl. Dramatisches Charakterbild mit Gesang in $6 \mathrm{~A}$. und einem Vorspiel 1865. \{D-BDS, D-Kö'TM, A-WÖN, A-WUB\}

Eine Selbstmörderin. Vorspiel zu: Die rote Liesl. \{D-KöTM\}

\section{Zäunemann, Sidonie Hedwig. 1714 (Erfurt) - 1740 (bei Plaue)}

Die von denen Faunen gepeitschte Laster. 1736 [Groß, Deutschlands Dichterinen 1739]. \{D-MrU, D-TüU, A-GUB, GB-LBL, CtY, IU, WaPS \}

Zay von Csömör, Maria Elisabeth Helene Freiin von. 1779 (Tóth-Próna, Ungarn) 1842 (Ödenburg = Sopron, Ungarn). Geb. von Calisch. Pseudonyme: Minna, Maria v:

Das Bild, oder die seltsame Geliebte. Lustspiel in 3 A. nach einer Erzählung. Um 1812. (Lustspiele. 1820.) \{D-DonFFH, A-WÖN\}

Die dankbare Tochter. Drama. O. J.

Die drolligen Wirte. Lustspiel. 1820 [?]. (Lustspiele. 1820.) \{D-DonFFH, A-WÖN\} Die geheilte Eifersucht. Lustspicl in 2 A. 1820 [?]. (Lustspiele. 1820.) \{D-DonFFH, A-WON

Der Schooßhund. Lustspiel in 2 A. 1813. (Lustspiele. 1820.) \{D-DonFFH, A-WÖN\} Der unsichtbare Liebhaber auf der Probe. Lustspiel. 1813.

Zecconi, Ricarda = Huch, Ricarda.

Zeller, Luise. 1823 (Wangen bei Göppingen/Württemberg) - 1889 (Stuttgart). Geb. Pichler:

Die Brïder, Vaterländisches Schauspiel in 4 A. 1887. \{D-KöTM\}

Heinrich des I. Söhne. Historisches Drama. 1873. \{D-WeiZdK\}

Luise Pichler's illustrirtes Theaterbiichlein. 4 Bde. 1870-?. \{GB-LBL, NN\}

Zianitzka, K. Ph. = Pseudonym für: Zitz, Katharina Rosa Therese Pauline Modesta.

Zitz, Katharina (Kathinka) Rosa Therese Pauline Modesta. 1801 (Mainz) - 1877 (Mainz). Geb. Halein. Pseudonyme: Tina, K. Ph. Zianitzka, Stephanie, Theophyle Christlieb, August Enders, Johann Golder, Dr. Schmid, Emmeline, Rosalba, Viola,
Auguste, Emilie, Eugenie, Pauline, Auguste Pauline:

Cromwell. Traucrspiel in 5 A. von Victor Hugo. Übers. 1833. \{D-DeLL, D-TS, AWÖN, GB-LBL\}

Der König macht sich lustig. Trauerspiel von Victor Hugo. Übers. O. J. \{D-DG, DSML, GB-L,BL\}

Marion de Lorme. Drama in 5 A. von Victor Hugo. Übers. 1833. \{D-DeLL, D-TS\} Triboulet oder des Königs Hofnarr. Trauerspiel in 5 A. nach Victor Hugos LLe Roi s'amuse. 1835. \{D-MS\}

Victor Hugos Sämtliche Werke. Übers. 1839. [Enthält: Der König macht sich lustig. Cromwell. $\{$ GB-L,BL\} 


\section{SIGLENVERZEICHNIS DER STANDOR'TE}

(für die USA und Kanada aus: National Union Catalog, Pre-1956 Imprints.)

Deutschland:

ABTH

$\mathrm{AmSP}$

$\mathrm{AÖB}$

AS

ASB

ASS

ASU

$\mathrm{BaRW}$

BCHS

BDS

BDSV

BFU

BGS

$\mathrm{BH}$

BHS

BHU

BiR

BiS

BiSL

$\mathrm{BiU}$

BoS

$\mathrm{BoU}$

BPS

$\mathrm{BrU}$

BS

BSPK

BSR

BTM

BU

BUB

BZL

$\mathrm{ChS}$

CorFB

$\mathrm{CS}$

CSB

DeLL

DeNWS
BTH Aachen

Staatliche Provinzialbibliothek Amberg

OB Aachen

Stadtbücherei Ahlen

Staatliche Bibliothek Ansbach (Schloßbibliothek)

Staats- und Stadtbibliothek Augsburg

Staats- und Universitätsbibliothek Augsburg

Richard-Wagner-Museum Bayreuth

Heinrich-Schulz-Bücherei, Berlin/Charlottenburg

Deutsche Staatsbibliothek, Berlin

Deutscher Staatsbürgerinnen-Verband, Berlin

Ereie Universität Berlin

Stadtbücherei Bergisch Gladbach

Humboldt-Universität Berlin; Zweigbibliothek Kunstwissenschaften

Stadtbibliothek Bad Hersfeld

Humboldt-Universität Berlin

Ratsgymnasium Bielefeld

Stadtbücherei Bielefeld

Stadtarchiv und Landesgeschichtliche Bibliothek Bielefeld

Universitätsbibliothek Bielefeld; FB Linguistik u. Literaturwissenschaft

Stadtbücherei Bochum

Universitätsbibliothek Bochum

Preußische Staatsbibliothek Berlin

Universitätsbibliothek Bremen

Stadtbibliothek Braunschweig

Staatsbibliothek Preußischer Kulturbesitz, Berlin

Stadtbibliothek der Reichshauptstadt Berlin

Theaterbibliothek in der "Möwe", Berlin

Universitätsbibliothelk Berlin

Universitätsbibliothek Bonn

Zentralinstitut für Literaturgeschichte, Berlin

Stadtbibliothek Chemnitz

Fürstliche Bibliothek Corvey

Stadtbibliothek Cuxhaven

Stadtbibliothelk Celle

Lippische Landesbibliothek Detmold

Nordrhein.-Westfälisches Staatsarchiv Detmold
DonFFH

DoU

DSA

DSB

DU

DUB

DZB

EFH

ENU

ES

EU

EWA

FBPT

FFDH

FGM

FriB

FrU

FS

FSU

FTT

FUB

GF

GiU

GÖ

GOB

GS

GSK

GSU

GuSK

HBFU

$\mathrm{HeBO}$

$\mathrm{HeS}$

$\mathrm{HeSB}$

HG
Dörres-Gymnasium, Düsseldorf

Goethe-Museum, Düsseldorf

Heinrich-Heine-Institut, Düsseldorf

Haus des Deutschen Ostens, Düsseldorf

Studienbibliothek Dillingen

Bibliotheken der Stadt Dortmund

Fritz-Hüser-Institut für deutsche und ausländische Arbeiterliteratur Dortmund

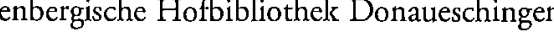

Universitätsbibliothek Dortmund

Staatsarchiv Dresden

Stadtbibliothek Dessau

Universitätsbibliothek Duisburg

Universitätsbibliothek Düsseldorf

Zentralbibliothek der Bundeswehr, Düsseldorf

Folkwang-Hochschule Essen

Universitätsbibliothek Erlangen-Nürnberg

Stadtbibliothek Essen

Universitätsbibliothek Essen

Wissenschaftliche Allgemeinbibliothel des Bezirkes Erfurt

Bibliotheken des Bischöflichen Priesterseminars und der Theologischen Fakultät Fulda

Freies Deutsches Hochstift, Frankfurt/M.

Goethe-Museum, Frankfurt/M

Bodenseebibliothek Friedrichshafen

Universitätsbibliothek Freiburg i. Br

Stadtbücherei Frankfurt/M

Stadt- und Universitätsbibliothel Frankfurt/M

Fürst Thurn und Taxis Hofbibliothek, Regensburg

Universitätsbibliothek Frankfurt/M.

Forschungs- und Landesbibliothek Gotha

Universitätsbibliothek Gießen

Offentliche Bibliothek Grimmen

Oberlausitzische Bibliothek Görlitz

Staatsbibliothek Göttingen

Stadt- und Kreisbibliothek Güstrow

Staats- und Universitätsbibliothek Göttingen

Stadt- und Kreisbibliothek Guben

BFU Hagen

Bücherei des deutschen Ostens, Herne

Stadtarchiv Heidelberg

Stadtbücherei Heidelberg

Gleimhaus, Halberstadt 
Staatsarchiv Hamburg

HHU-T Staats- und Universitätsbibliothek Hamburg

Theatersammlung, Universität Hamburg

Landesbibliothek Hannover

Bibliothek der Hansestadt Lübeck

Heimatmuseum Pirmasens

Staatsbibliothek Hannover

HSUB Universitätsbibliothek Halle/Saale

HUB Universitätsbibliothel Heidelberg

HUL Universitäts- und Landesbibliothek Halle/Wittenberg

IS Stadtbücherei Ingolstadt

KaMB Murhard'sche Bibliothek der Stadt Kassel

KL Lessing-Bibliothek Kamenz

KoS Stadtbibliothek Koblenz

KöED Erzbischöfliche Diözesan- und Dombibliothek Köln

KöTM Theatermuseum der Universität zu Köln

KöUSB Universitäts- und Stadtbibliothek Köln

KUB Universitätsbibliothek Kiel

KW Wessenberg-Bibliothek Konstanz

LDB Deutsche Bibliothek Leipzig

LeS Stadtbücherei Leichlingen

LGS Gräflich Solms-Laubach'sche Bibliothek, Laubach

LH Hohhaus-Bibliothelk Lauterbach

LKM Karl-Marx-Universität Leipzig

LR Ratsbücherei Lüneburg

LUB

MarLA

MarSN

$\mathrm{MaU}$

MBS

MöS

$\mathrm{MrU}$

MS

MSDA

MüRS

MüS

MüU

NeKKW

NeLB

NWS

Universitätsbibliothek Leipzig

Deutsches Literaturarchiv Marbach

Deutsches Literaturarchiv/Schiller Nationalmuseum Marbach

Universitätsbibliothek Mannheim

Bayrische Staatsbibliothek München

Stadtbücherei Mönchengladbach

Universitätsbibliothek Marburg/L.

Stadtbibliothek Mainz

Sudetendeutsches Archiv München

Stadtbücherei Mülheim a. d. Ruhr

Stadtbibliothek München

Universitätsbibliothek Münster

Karbe-Wagner-Sammlung Neustrelitz

Landesbibliothek Neustrelitz

Stadtbücherei Neustadt/Weinstr.
Landesbibliothek Oldenburg

Universitätsbibliothek Passau

Brandenburgische Hochschulbibliothek, Potsdam

Erzbischöfl.-Akademische Bibliothek Paderborn

Graf von Schönborn-Schloßbibliothek, Pommersfelden

Stadtbibliothek Pirmasen

Stadtbibliothek Plauen

Universitätsbibliothek Paderborn

Städtische Museen Quedlinburg

Bibliothek der PH Ruhr, Abt. Dortmund

Stadtbibliothek Reutlingen

Universitätsbibliothek Rostock

Stadt- und Kreisbibliothek Rudolstadt

Staatliche Bibliothek Regensburg

Universitätsbibliothek Regensburg

Bibliothek Otto Schäfer, Schweinfurt

Gemeindebibliothek Sandhausen

Stadt- und Kreisbibliothek „Heinrich Heine", Schmalkalden

Landeszentralbibliothek Schleswig-Holstein

Fürstlich Hohenzollernsche Hofbibliothek, Sigmaringen

Staatsarchiv Sigmaringen

Siegerland-Museum Siegen

Universitätsbibliothek Siegen

Mecklenburgische Landesbibliothek Schwerin

Stadtbibliothek Osnabrück

Pfälzische Landesbibliothek Speyer

Saarpfälzische Landesbibliothek Speyer

Stadtbücherei Solingen

Stadtbibliothek Schwabach

Universitätsbibliothek Stuttgart

Wissenschaftliche Allgemeinbibliothek Suhl

Stadtbibliothek Trier

Universitätsbibliothek Trier

Fachreferat Germanistik, Universität Trier

niversitätsbibliothek Tübingen

Landesbibliothek Weimar

Zentralbibliothek der deutschen Klassik Weimar

Hessische Landesbibliothek Wiesbaden

Westfälische Landesmuseum für Kunst und Kulturgeschichte, Münster Herzog-August-Bibliothek, Wolfenbüttel Stadtbibliothelk Worms

Stadtbücherei Würzburg (Max-Heim-Bücherei)

Universitätsbibliothek Würzburg 
Bibliotheca Bipontina, Zweibrücken

Museum Schloß Moritzburg, Zeitz

Ratsschulbibliothek Zwickau

\section{Österreich:}

GUB Universitätsbibliothek Graz

ISA Stadtarchiv Innsbruck

KIO Öffentliche Studienbibliothek Klagenfur

LBS Bundesstaatliche Studienbibliothek Linz

SMCA Museum Carolino Augusteum, Salzburg

SUB Universitätsbibliothek Salzburg

WLA Literaturarchiv Wien

WN Nationalbibliothek Wien

WNS Stadtbibliothek Wiener Neustadt

WÖN Österreichische Nationalbibliothek Wien

WUB Universitätsbibliothek Wien

ZS Stadtbibliothek Zofingen

\section{Schweiz:}

AK

BSL

BSU

CGBB

CGK

DBG

FTK

GBPU

LSK

LZ

SGK

SZ

WiS

ZDS

77

Aargauische Kantonsbibliothek Aargau

Schweizerische Landesbibliothek Bern

Stadt- und Universitätsbibliothek Bern

Bibliotheca Bodmeriana Cologny-Genève

Kantonsbibliothek Graubünden, Chur

Bibliothek Goetheanum, Dornach

Thurgauische Kantonsbibliothek, Frauenfeld

Bibliothèque publique et universitaire de Genève

Staatsarchiv des Kantons Luzern

Zentralbibliothek Luzern

Kantonsbibliothek (Vadiana) St, Gallen

Zentralbibliothek Solothurn

Stadtbibliothels Winterthur

Deutsches Seminar, Universität Zürich

Zentralbibliothek Zürich

\section{United Kingdom:}

Alabama

AAP

AFML

AMAU

AML

AU

Alaska

Aku

Arkansas

ArL

ArU

Arizona

AzTeS

$\mathrm{AzU}$

California

C

C-S

CBBD

CBGTU

CBPI

$\mathrm{CBPac}$

$\mathrm{CCC}$

$\mathrm{CCSC}$

CCamarSJ

CCovB

CFS

CFIS

CLCL

CLCM

CLI

CLL

CLO

CLS

CLSM

CLSU

CLU

CLU-C
Auburn University, Auburn

U. S. National Library of Medicine

Air University Library, Maxwell Airforce Base, Montgomery

U. S. National Library of Medicine

University of Alabama, University

University of Alaska Library, College

Little Rock Public Library

University of Arkansas, Fayetteville

Arizona State University, Tempe

University of Arizona, Tucson

California State Library, Sacramento

- Sutro Branch, San Francisco

Berkeley Baptist Divinity School, Berkeley

Graduate Theological Union, Berkeley

Pacific Lutheran Theological Seminary, Berkeley

Pacific School of Religion, Berkeley

Honnold Library, Claremont Colleges

Southern California School of Theology, Claremont

St. John's Seminary, Camarillo

California Baptist Theological Seminary, Covina

Fresno State College, Fresno

California State College at Fullerton

Los Angeles County Law Library

Los Angeles County Museum Library, Los Angeles

Immaculate Heart College, Los Angeles

Los Angeles County Law Library, Los Angeles

Occidental College, Los Angeles

Los Angeles State College of Applied Arts \& Sciences, Los Angeles

Southwest Museum, Los Angeles

University of Southern California, Los Angeles

University of California at Los Angeles

- William Andrews Clark Memorial Library 


\begin{tabular}{|c|c|}
\hline CLamB & Biola Library, La Mirada \\
\hline CLgA & Alma College, Los Gatos \\
\hline CLobS & California State College at Long Beach \\
\hline $\mathrm{CNoS}$ & San Fernando Valley State College, Northbridge \\
\hline CPFT & Fuller Theological Seminary, Pasadena \\
\hline CSa' & San Francisco Theological Seminary, San Anselmo \\
\hline CSdS & San Diego State College, San Diego \\
\hline CSf & San Francisco Public Library \\
\hline CSfM & University of California Medical Center, San Francisco \\
\hline $\mathrm{CSmH}$ & Henry E. Huntington Library, San Marino \\
\hline CSmyS & St. Mary's College, St. Mary's College \\
\hline $\mathrm{CSt}$ & Stanford University Libraries, Stanford \\
\hline CSt-H & - Hoover Institution on War, Revolution and Peace \\
\hline CSt-L & - Lane Medical Library \\
\hline CSt-Law & - Law Library \\
\hline CStbS & University of California, Santa Barbara \\
\hline $\mathrm{CU}$ & University of California, Berkeley \\
\hline $\mathrm{CU}-\mathrm{A}$ & - University of California, Davis \\
\hline CU-B & - Bancroft Library, Berkeley \\
\hline CU-CS & - Center for Chinese Studies, Berkeley \\
\hline CU-E & - East Asiatic Library, Berkeley \\
\hline CU-I & - University of California, Irvine \\
\hline CU-L & - Law Library, Berkeley \\
\hline CU-M & - University of California Medical Center, San Francisco \\
\hline CU-Riv & University of California, Riverside \\
\hline CU-RivA & - Agricultural Library \\
\hline CU-S & $\begin{array}{l}\text { - University of California, San Diego, La Jolla (einschließlich General } \\
\text { Library, Biomedical Library, Science and Engineering Library und } \\
\text { Scripps Institution of Oceanography Library }\end{array}$ \\
\hline CU-SC & - University of California, Santa Cruz \\
\hline \multicolumn{2}{|l|}{ Colorado } \\
\hline Co & Colorado State Library, Denver \\
\hline CoAT & Adams State College Library, Alamosa \\
\hline CoBBS & $\begin{array}{l}\text { U. S. Environmental Science Services Administration, Boulder Labora- } \\
\text { tories (einschließlich U. S. National Bureau of Standards Library, Boul- } \\
\text { der) }\end{array}$ \\
\hline $\mathrm{CoC}$ & Pikes Peak Regional District Library, Colorado Springs \\
\hline CoCA & U. S. Air Force Academy, Colorado Springs \\
\hline $\mathrm{CoCC}$ & Colorado College Library, Colorado Springs \\
\hline $\mathrm{CoD}$ & Denver Public Library \\
\hline CoDBR & U. S. Bureau of Reclamation, Denver \\
\hline CoDD & Dow Chemical Company, Rocky Flats Plant Library, Denver \\
\hline
\end{tabular}

CoDGS U. S. Geological Survey, Federal Center, Denver

CoDI Iliff School of Theology, Denver

CoDM Medical Society of the City and County of Denver

CoDMSC Metropolitan State College, Denver

CoDR Regis College, Denver

CoDStT Saint Thomas Seminary, Denver

CoDU University of Denver, Denver

CoF Fort Collins Public Library

CoFS Colorado State University, Fort Collins

CoG Colorado School of Mines, Golden

CoGD Dow Chemical Company, Rocky Flats Plant Library, Golden

CoGj Mesa County Library, Grand Junction

CoGrS Colorado State College, Greeley

CoGrW Weld County Library, Greeley

CoGuW Western State College, Gunnison

$\mathrm{CoHi} \quad$ Colorado State Historical Society, Denver

CoLH Loretto Heights College, Loretto

CoP McClelland Public Library, Pueblo

$\mathrm{CoU} \quad$ University of Colorado, Boulder

Connecticut

$\mathrm{CtHC}$

CtHT-W

CtHWatk

$\mathrm{CtHi}$

CtMW

$\mathrm{CtNlC}$

CtNowaB

$\mathrm{CtU}$

$\mathrm{CtW}$

CtWB

$\mathrm{CtY}$

CtY-AO

CAY-D

CtY-L

$\mathrm{CtY}-\mathrm{M}$

$\mathrm{CtY}-\mathrm{MHi}$

Connecticut State Library, Hartford

Hartford Seminary Foundation, Hartford

- Watkinson Library

Watkinson Library, Trinity College, Hartford

Connecticut Historical Society, Hartford

Wesleyan University, Middletown

Connecticut College, New London

Burndy Library, Norwalk

University of Connecticut, Storrs

Wesleyan University, Middletown

Silas Bronson Public Library, Waterbury

Yale University, New Haven

- American Oriental Society Library

- Divinity School Library

- Law Library

- Historical Library

District of Columbia

DA U. S. National Agricultural Library

DAL U. S. Army Library, Pentagon Building

DAS U. S. Dept. of Envirnmental Science Services Administration. Atmosphere Sciences Library, Silver Spring, MD 
DAU American University Library

DBRE Bureau of Railway Economics Library of the Association of Ametican Railroads

DBS U. S. National Bureau of Standards Library

DC U.S. Department of Commerce Library

DCU Catholic University of America Library

DCU-C - Clementine Library

DCU-H - Hyvernat Collection

DCU-IA - Ibero-American Collection

DDO Dumbarton Oaks Research Library of Harvard University

DE U.S. Office of Education Library

DF U.S. Bureau of Fisheries Library

DFM Franciscan Monastery Library

DFo Folger Shakespeare Library

DGS U. S. Geological Survey Library

DGU Georgetown University Library

DHC Holy Cross College Library

DHEW U.S. Department of Health, Education and Welfare Library

DHN Holy Name College Library

DHU Howard University Library

DHUD U. S. Department of Housing and Urban Development Library

DI U. S. Department of the Interior Library

DI-GS $\quad-$ Geological Survey Library

DL U. S. Department of Labor Library

DLC U. S. Library of Congress

DLC-P4 - Priority 4 Collection

DM U. S. Bureau of Mines Library (integriert mit DI)

DN U.S. Department of the Navy Library

DN-HO - Naval Oceanographic Office Library

DN-ONR - Office of Naval Research Library

DN-Ob - Naval Observatory Library

DN-RL - Naval Research Laboratory Library

DNA U. S. National Archives Library

DNAL U. S. National Agricultural Library

DNC Washington Cathedral Library

DNGA National Gallery of Art Library

DNIH U. S. National Institutes of Health Library, Bethesda, MD

DNLM U. S. National Library of Medicine

DNLM-HM History of Medicine Division Library, Cleveland, OH

DNR U.S. Office of Naval Records and Library

DNW U. S. National War College Library, Fort McNair

DOLM Our Lady of Mount Carmel College Library

DP

U. S. Patent Office Library
DPAHO Pan American Health Organization, Pan American Sanitary Bureau

DPSB

DPU

DS

DSC

DSI

Sanitary Bureau Library

Pan American Union Library

U. S. Department of State Library

Scottish Rite Supreme Council Library

Smithsonian Institute Library (einschließlich Sammlungen in: National Air Museum, Astrophysical Observatory, Bureau of American Ethnology, National Collection of Fine Arts, National Museum, Division of Radiation and Organisms und National Zoological Park Libraries)

DW U. S. Army War College Library, Ft. McNai

DWB U.S. Weather Bureau Library

DWHO-PSB World Health Organization, Pan American Sanitary Bureau Library

DWP Public Library of the District of Columbia

Delaware

DeGE

$\mathrm{DeU}$

University of Delaware, Newark

Florida

FMU

FTS

FTaSU

FU

FU-HC

FWpR

Georgia

GA

GAGT

GAGTh

GASC

GAT

GAU

GAuA

GColuC

GCuA

GDC

GDS

GDecA

GDecCT

GDoS

GEU

$\mathrm{GHi}$
Wilmington Institute and the New Castle County Free Library

University of Miami, Coral Gables University of South Florida, Tampa Florida State University, Tallahassee University of Florida, Gainesville - J. Hillis Miller Health Center Library Rollins College, Winter Park

Atlanta Public Library

Georgia Institute of Technology, Atlanta

Gammon Theological Seminary, Atlanta Georgia State College, Atlanta Georgia Institute of Technology, Atlanta Atlanta University, Atlanta Augusta College, Augusta

Columbus College, Columbus

Andrews College, Cuthbert

Columbia Theological Seminary, Decatur

Agnes Scott College, Decatur

Agnes Scott College, Decatur

Columbia Theological Seminary, Decatur

South Georgia College, Douglas

Emory University, Atlanta

Georgia Historical Society, Savannah 
Woman's College of Georgia, Milledgeville

Oglethorpe University, Oglethorpe University

University of Georgia, DeRenne Library

Hawaii

HU

HU-EWC

- DeRenne Georgia Library

- Georgia State College of Business Administration Library, Atlanta

University of Hawaii, Honolulu

Center for Cultural and Technical Interchange between East and West,

Honolulu

Illinoi

IC

ICA

ICF

ICF-A

ICHi

ICIP

ICJ

ICMILC

$\mathrm{ICMcC}$

ICN

ICRL

ICU

ICarbS

IEG

IEN

IEdS

IGK

IHi

ILS

IMunS

INS

IRA

IRivfR

Illinois State Library, Springfield

Chicago Public Library

Art Institute of Chicago, Chicago

Chicago Natural History Museum, Chicago

- Edward E. Ayer Ornithological Library

Chicago Historical Society, Chicago

Institute for Psychoanalysis, Chicago

John Crerar Library, Chicago

Center for Research Libraries, Chicago

McCormick Theological Seminary, Chicago

Newberry Library, Chicago

Center for Research Libraries, Chicago

University of Chicago, Chicago

Southern Illinois University, Carbondale

Garrett Theological Seminary, Evanston

Northwestern University, Evanston

Southern Illinois University, Edwardsville

Knox College, Galesburg

Illinois State Historical Library, Springfield

St. Procopius College, Lisle

Saint Mary of the Lake Seminary, Mundelein

Illinois State University, Normal

Augustana College Library, Rock Island

Rosary College, River Forest

University of Illinois, Urban

- Medical Sciences Library, Chicago

- Chicago Undergraduate Division, Chicago
$\mathrm{IaDL}$

IaDuC

$\mathrm{IaDuU}$

IaDuU-S

$\mathrm{IaDuW}$

$\mathrm{IaU}$

Idaho

IdB

IdPI

IdPS

IdU

Indiana

In

InAndC

InColls

InGo

InHi

InIB

InLP

InNd

$\mathrm{InOlH}$

InRE

InRenS

InStme

InU

Kansas

KAStB

$\mathrm{KHi}$

$\mathrm{KKcB}$

KMK

KStMC

KU

Ku-M

KWiU lowa State University of Science and Technology, Ames Luther College, Decorah

Loras College, Dubuque

University of Dubuque, Dubuque

- Theological Seminary Library

Wartburg Theological Seminary, Dubuque

University of Iowa, Iowa City

Boise Public Library

Idaho State University, Pocatello

Idaho State University, Pocatello

University of Idaho, Moscow

Indiana State Library, Indianapolis

Anderson College, Anderson

St. Joseph's College, Rensselaer

Goshen College Biblical Seminary Library, Goshen

Indiana Historical Society, Indianapolis

Butler University, Indianapolis

Purdue University, Lafayette

University of Notre Dame, Notre Dame

St. Leonard College Library, Dayton, Ohio

Earlham College, Richmond

St. Joseph's College, Rensselaer

St. Meinrad's College \& Seminary, St. Meinrad

Indiana University, Bloomington

Kansas State Library, Topeka

St. Benedict's College, Atchison

St. Benedict's College, Atchison

Kansas State Historical Society, Topeka

Central Baptist Theological Seminary, Kansas City

Kansas State University, Manhattan

St. Louis University, School of Divinity Library, St. Louis, Mo.

University of Kansas, Lawrence

- Medical Center Library, Kansas City

Wichita State University, Wichita 
Kentucky

Ky-LE

$\mathrm{KyBgW}$

$\mathrm{KyHi}$

KyLo

KyLoS

$\mathrm{KyLoU}$

$\mathrm{KyLx}$

$\mathrm{KyLxCB}$

KyLxT

KyMore'T

$\mathrm{KyU}$

KyWA

KYWAT

Louisiana

L-M

LHi

LNHT

LNT-MA

LU

LU-M

LU-NO

Library Extension Division, Frankfort

Western Kentucky State College, Bowling Green

Kentucky Historical Society, Frankfort

Louisville Free Public Library

Southern Baptist Theological Seminary, Louisville

University of Louisville, Louisville

Lexington Public Library

Lexington Theological Seminary, Lexington

Transylvania College, Lexington

Morehead State College, Morehead

University of Kentucky, Lexington

Asbury College Library, Wilmore

Asbury Theological Seminary, Wilmore

Louisiana State Library, Baton Rouge

Louisiana State Museum Library, New Orleans

Louisiana History Society, New Orleans

Tulane University Library, New Orleans

Tulane University, Latin American Library, New Orleans

Louisiana State University, Baton Rouge

- Medical Center Library, New Orlean

- Louisiana State University in New Orleans

Massachusetts

M Massachusetts State Library, Boston

MA Amherst College, Amherst

MB Boston Public Library

MBAt Boston Athenaeum, Boston

MBBC Boston College, Chestnut Hill

$\mathrm{MBCo} \quad$ Countway Library of Medicine (Harvard-Boston Medical Libraries)

MBHo

MBM

$\mathrm{MBMu}$

MBU

MBdAF

$\mathrm{MBr}$.

MBrigSt

$\mathrm{MBtS}$

$\mathrm{MCM}$

Massachusetts Horticultural Society, Boston

Massachusetts Horticultural Society, Boston

Countway Library of Medicine (Harvard-Boston Medical Libraries)

Museum of Fine Arts, Boston

Boston University

U. S. Air Force Cambridge Research Center, Bedford

Zion Research Library, Brookline

St. John's Seminary, Brighton

St. John's Seminary Library, Brighton

$\mathrm{MCR}$

Raddiffe College, Cambridge
$\mathrm{MH}-\mathrm{A}$

MH-AH

$\mathrm{MH}-\mathrm{BA}$

MH-FA

MH-G

MH-HY

MH-P

MH-PR

$\mathrm{MHi}$

MMe'T

MNF

MNS

MNoes

MNtcA

$\mathrm{MSaE}$

MShM

MU

MWA

MWAC

MWC

MWH

MWalB

MWelC

MWhB

MWiW

MWiW-C

Maryland

MdAN

$\mathrm{MdBE}$

MdBG

$\mathrm{MdBJ}$

MdBJ-G

$\mathrm{MdBP}$

MdBWA

$\mathrm{MdU}$

MdW
Smithsonian Institution, Astrophysical Observatory, Cambridge Boston College, Chestnut Hill

Harvard University, Cambridge

- Arnold Arboretum

- Andover-Harvard Theological Library

- Graduate School of Business Administration Library

- Fine Arts Library

- Gray Herbarium Library

- Harvard-Yenching Institute (Chinese-Japanese Library)

- Law School Library

- Peabody Museum Library

- Physics Research Library

Massachusetts Historical Society, Boston

Tufts University, Medford

Forbes Library, Northampton

Smith College, Northampton

Stonehill College Library, North Easton

Andover Newton Theological School, Newton Center

Essex Institute, Salem

Mount Holyoke College, South Hadley

University of Massachusetts, Amherst

American Antiquarian Society, Worcester

Assumption College, Worcester

Clark University, Worcester

College of the Holy Cross, Worcester

Brandeis University, Waltham

Wellesley College, Wellesley

Marine Biological Laboratory, Woods Hole

Williams College, Williamstown

- Chapin Library

U. S. Naval Academy, Annapolis

Enoch Pratt Free Library, Baltimore

Goucher College, Baltimore

Johns Hopkins University, Baltimore

- John Work Garrett Library

Peabody Institute, Baltimore

Walters Art Gallery, Baltimore

University of Maryland, College Park

Woodstock College, Woodstock 


$\begin{array}{ll}\text { Maine } & \\ \mathrm{MeB} & \text { Bowdoin College, Brunswick } \\ \mathrm{MeBa} & \text { Bangor Public Library } \\ \mathrm{MeU} & \text { University of Maine, Orono } \\ \mathrm{MeWC} & \text { Colby College, Waterville } \\ \mathrm{MeWaC} & \text { Colby College, Waterville } \\ \text { Michigan } & \\ \mathrm{Mi} & \text { Michigan State Library, Lansing } \\ \mathrm{MiAC} & \text { Alma College, Alma } \\ \mathrm{MiD} & \text { Detroit Public Library } \\ \mathrm{MiD}-\mathrm{B} & \text { - Burton Historical Collection } \\ \mathrm{MiDA} & \text { Detroit Institute of Arts, Detroit } \\ \mathrm{MiDU} & \text { University of Detroit, Detroit } \\ \mathrm{MiDW} & \text { Wayne State University, Detroit } \\ \mathrm{MiEM} & \text { Michigan State University, East Lansing } \\ \mathrm{MiEalC} & \text { Michigan State University, East Lansing } \\ \mathrm{MiGr} & \text { Grand Rapids Public Library } \\ \mathrm{MiH} & \text { Michigan College of Mining and Technology, Houghton } \\ \mathrm{MiHM} & \text { Michigan College of Mining and Technology, Houghton } \\ \mathrm{MiU} & \text { University of Michigan, Ann Arbor } \\ \mathrm{MiU}-\mathrm{C} & \text { - William L. Clements Library } \\ \mathrm{Minnesota} & \\ \mathrm{MnCS} & \text { St. John's University, Collegeville } \\ \mathrm{MnH} & \text { Minnesota Historical Society, St. Paul } \\ \mathrm{MnHi} & \text { Minnesota Historical Society, St. Paul } \\ \mathrm{MnRM} & \text { Mayo Clinic and Foundation Library, Rochester } \\ \mathrm{MnSJ} & \text { James Jerome Hill Reference Library, St. Paul } \\ \mathrm{MnSSC} & \text { College of St. Catherine, St. Paul } \\ \mathrm{MnU} & \text { University of Minnesota, Minneapolis } \\ \mathrm{Missouri} & \\ \mathrm{MoHi} & \text { Missouri State Historical Society, Columbia } \\ \mathrm{MoK} & \text { Kansas City Public Library } \\ \mathrm{MoKL} & \text { Linda Hall Library, Kansas City } \\ \mathrm{MoKU} & \text { University of Missouri at Kansas City, Kansas City } \\ \mathrm{MoS} & \text { St. Louis Public Library } \\ \mathrm{MoSB} & \text { Missouri Botanical Garden, St. Louis } \\ \mathrm{MoSC} & \text { Concordia Seminary Library, St. Louis } \\ \mathrm{MoSCS} & \text { Concordia Seminary Library, St. Louis } \\ \mathrm{MoSM} & \text { Mercantile Library Association, St. Louis } \\ \mathrm{MoSU} & \text { St. Louis University, St. Louis } \\ & \end{array}$

Montana

$\mathrm{MtBC}$

$\mathrm{MtBozC}$

$\mathrm{Mt} \mathrm{U}$

- School of Divinity Library, St. Louis

Washington University, St. Louis

University of Missouri, Columbia

\section{New York}

$\mathrm{N}$

NAIU

NAurW

$\mathrm{NB}$

NBB

NBC

NBM

NBPol

NBSU-M

NBiSU-H

NBronSL

$\mathrm{NBu}$

$\mathrm{NBuG}$

$\mathrm{NBuG}$

$\mathrm{NBuU}$

$\mathrm{NCH}$

$\mathrm{NCaS}$

NCorniC

NCoxHi

NFQC

NGrnUN

$\mathrm{NHC}$

$\mathrm{NHi}$

NIC

University of Mississippi, University

Montana State University, Bozeman

Montana State University at Bozeman

University of Montana, Missoula

New York State Library, Albany

State University of New York at Albany

Wells College, Aurora

Brooklyn Public Library, Brooklyn

Brooklyn Museum Libraries, Brooklyn

Brooklyn College, Brooklyn

Medical Research Library of Brooklyn Brooklyn

Sarah Lawrence College, Bronxville Buffalo

State University of New York at Buffalo

Hamilton College, Clinton

St. Lawrence University, Canton

um of Glass Library)

Queens College Library, Flushing

United Nations Library

Colgate University, Hamilton

New York Historical Society, New York
William Alexander Percy Memorial Library, Greenville

Mississippi State University, State College

Mississippi State University, State College

Polytechnic Institute of Brooklyn, Brooklyn

State University of New York, Downstate Medical Center Library,

State University of New York, Harpur College, Binghamton

Buffalo and Erie County Public Library, Buffalo

State University of New York, College at Buffalo

Grosvenor Reference Division, Buffalo and Erie County Public Library,

Corning Glass Works Library, Corning (einschließlich Corning Muse-

Greene County Historical Society, Inc., Coxsackie

Cornell University, Ithaca 
NJQ Queens Borough Public Library, Jamaica

NNGr

NNQC

NNRI

NNSU-M

NNU

NNU-W

NNUN

NNUN-W

NNUT

Newberry Library, Chicago

New York Public Library

American Bible Society, New York

Augustinian Historical Institute, New York

American Jewish Historical Society, New York

Association of the Bar of the City of New York, New York

New York Botanical Garden, Bronx Park, New York

Columbia University, New York

- Teachers College Library

Council on Foreign Relations, New York

City College of New York, New York

Engineering Societies Library, New York

Fordham University, New York

French Institure in the United States, New York

General Theological Society of the Protestant Episcopal Church, New York

Grolier Club Library, New York

Hispanic Society of America, New York

Hebrew Union College, Jewish Institute of Religion Library, New York New York Historical Society

Jewish Theological Seminary of America, New York

Jewish Institute of Religion, New York

Jefferson School of Social Science, New York (diese Bibliothek existiert nicht mehr)

American Museum of Natural History, New York

Metropolitan Museum of Art Library, New York

Pierpont Morgan Library

New York Academy of Medicine, New York

New York Medical College, Flower \& Fifth Avenue Hospitals, New York

New York Psychoanalytic Institute, New York

Pierpont Morgan Library, New York

Queens Borough Public Library, New York

Queens College Library, Flushing

Rockcfeller Institute for Medical Research, New York

State University of New York College of Medicine at New York City

New York University Libraries, New York

- Washington Square Library

United Nations Library, New York

Union Theological Seminary, New York

NNUT-Mc - McAlpin Collection
NNWML

NNZI

NNerC

NNiaU

NPV

$N R A B$

NRU

$\mathrm{NSchU}$

NSyU

NUt

NWM

NYPL

NYhI

Nebraska

$\mathrm{NbOC}$

$\mathrm{NbU}$

\section{Creighton University, Omaha}

University of Nebraska, Lincoln

North Carolina

Nc " North Carolina State Library, Raleigh

$\mathrm{Nc}-\mathrm{Ar} \quad$ North Carolina State Department of Archives and History, Raleigh

NcA Pack Memorial Public Library, Asheville

NcA-S - Sondley Reference Library

NcAS Sondley Reference Library, Asheville

$\mathrm{NcC} \quad$ Public Library of Charlotte \& Mecklenburg County, Charlotte

NoCC Charlotte College Library, Charlotte

$\mathrm{NcCl}$ Johnson C. Smith University, Charlotte

$\mathrm{NcCU} \quad$ University of North Carolina at Charlotte

$\mathrm{NcD} \quad$ Duke University, Durham

NcDurC North Carolina College at Durham, Durham

NcGU University of North Carolina at Greensboro

NcGW University of North Carolina at Greensboro

$\mathrm{NcGuG} \quad$ Guilford College, Guilford

$\mathrm{NcR}$

NcRR

NcRS

$\mathrm{NcU}$

NcWfC

NcWeSB

NcWilA
Olivia Raney Public Library, Raleigh

Richard B. Harrison Public Library, Raleigh

North Carolina State University at Raleigh

University of North Carolina, Chapel Hill

Wake Forest College, Winston-Salem

Southeastern Baptist Theological Seminary Library, Wake Forest Atlantic Christian College, Wilson 
North Dakota

NdFA

North Dakota State University, Fargo

NdHi State Historical Society of North Dakota, Bismarck

NdU University of North Dakota Library, Grand Forks

\section{New Hampshire}

Nh New Hampshire State Library, Concord

NhD Dartmouth College, Hanover

NhU University of New Hampshire, Durham

\section{New Jersey}

NjGbS

Glassboro State College, Glassboro

New Jersey Historical Society, Newark

NjMD Drew University, Madison

NjN Newark Public Library

NjNBR Rutgers-The State University, New Brunswick

NjNbS New Brunswick Theological Seminary, New Brunswick

NjNbT New Brunswick Theological Seminary

NjP Princeton University, Princeton

$\mathrm{NjP} T \quad$ Princeton Theological Seminary, Princeton

NjR Rutgers-The State University, New Brunswick

NjT Trenton Free Library, Trenton

\section{New Mexico}

$\mathrm{NmA}$

$\mathrm{NmU}$

Albuquerque Public Library, New Mexico

NmUpU New Mexico State University, University Park

Nevada

University of Nevada, Reno

Ohio

OAU

OAkU

OBerB

$\mathrm{OB} \mid \mathrm{C}$

OC

$\mathrm{OCH}$

OCHP
Ohio State Library, Columbus

Ohio University, Athens

University of Akron, Akron

Baldwin-Wallace College, Berea

Bluffton College, Bluffton

Public Library of Cincinnati and Hamilton County, Cincinnati

Hebrew Union College, Cincinnati

Historical and Philosophical Society of Ohio, Cincinnati

$\begin{array}{ll}\text { OCLloyd } & \text { Lloyd Library and Museum, Cincinnati } \\ \text { OCU } & \text { University of Cincinnati, Cincinnati } \\ \text { OCX } & \text { Xavier University, Cincinnati } \\ \text { OCl } & \text { Cleveland Public Library } \\ \text { OClCS } & \text { Case Institute of Technology, Cleveland } \\ \text { OClFC } & \text { Cleveland State University, Cleveland } \\ \text { OClJC } & \text { John Carroll University, Cleveland } \\ \text { OCIMA } & \text { Cleveland Museum of Art, Cleveland } \\ \text { OClSA } & \text { Cleveland Institute of Art, Cleveland } \\ \text { OCIW } & \text { Case Western Reserve University, Cleveland } \\ \text { OCIWHi } & \text { Western Reserve Historical Society, Cleveland } \\ \text { ODW } & \text { Ohio Wesleyan University, Delaware } \\ \text { ODa } & \text { Dayton and Montgomery County Library, Dayton } \\ \text { ODaStL } & \text { St. Leonard College Library, Dayton } \\ \text { ODaU } & \text { University of Dayton, Dayton } \\ \text { OEac } & \text { East Cleveland Public Library } \\ \text { OFH } & \text { Rutherford B. Hayes Library, Fremont } \\ \text { OGK } & \text { Kenyon College, Gambier } \\ \text { OHi } & \text { Ohio State Historical Society, Columbus } \\ \text { OKentC } & \text { Kent State University, Kent } \\ \text { OO } & \text { Oberlin College, Oberlin } \\ \text { OOxM } & \text { Miami University, Oxford } \\ \text { OSW } & \text { Wittenberg University, Springfield } \\ \text { OTU } & \text { University of Toledo, Toledo } \\ \text { OU } & \text { Ohio State University, Columbus } \\ \text { OWibfU } & \text { Wilberforce University, Carnegie Library, Wilberforce } \\ \text { OWicB } & \text { Borromeo Seminary, Wickliffe } \\ \text { OWoC } & \text { College of Wooster, Wooster } \\ \text { OWorP } & \text { Pontifical College Josephinum, Worthington } \\ \text { OYesA } & \text { Antioch College, Yellow Springs } \\ & \\ \text { Oklahoma } & \\ \text { Ok } & \text { Oklahoma State Library, Oklahoma City } \\ \text { OkEG } & \text { Graduate Seminary Library, Enid } \\ \text { OkS } & \text { Oklahoma State University, Stillwater } \\ \text { OkT } & \text { Tulsa Public Library } \\ \text { OkU } & \text { University of Oklahoma, Norman } \\ \text { Oregon } & \\ \text { Or } & \text { Oregon State Library, Salem } \\ \text { OrCS } & \text { Oregon State University Library, Corvallis } \\ \text { OrHi } & \text { Oregon Historical Society, Portland } \\ \text { OrP } & \text { Library Association of Portland, Portland } \\ & \end{array}$


Pennsylvani

PBL

$\mathrm{PBa}$

$\mathrm{PBm}$

PCA

PCC

PCamA

PCarlD

$\mathrm{PHC}$

$\mathrm{PHi}$

PJA.

PJAIG

PJB

PKsL

PLF

PLatS

PMA

$P P$

PPA

PPAN

PPAmP

PPAmS

PPAP

PPB

PPBC

PPC

PPCCH

PPCI

PPComm

PPD

PPDrop

PPEB

PPF

PPFr

PPFrankl

University of Oregon, Eugene

Lehigh University, Bethlehem storical Society, Rochester, N. Y.

Dickinson College, Carlisle

Haverford College, Haverford

Beaver College, Jenkintown

Allegheny College, Meadville

Free Library of Philadelphia

Athenaeum of Philadelphia

Franklin Institute, Philadelphia

Franklin Institute, Philadelphia
Mount Angel College, Mount Angel Abbey, Saint Benedict

Academy of the New Church, Bryn Athyn

Bryn Mawr College, Bryn Mawr

Samuel Colgate Baptist Historical Library of the American Baptist Hi-

Crozer Theological Seminary, Chester

Alliance College, Cambridge Springs

Historical Society of Pennsylvania, Philadelphia

Abington Library Society, Jenkintown

Alverthorpe Gallery, Rosenwald Collection, Jenkintown

Longwood Gardens, Kennett Square (Alle Bücher außer Werken über Botanils und Gartenbau verlegt nach DeGE)

Franklin and Marshall College, Lancaster

Saint Vincent College and Archabbey, Latrobe

Academy of Natural Sciences, Philadelphia

American Philosophical Society, Philadelphia

American Sunday School Union, Philadelphia

Apprentice's Free Library, Philadelphia

Philadelphia Bar Association, Philadelphia

Conion Library Catalogue of Pennsylvania, Philadelphia

College of Physicians of Philadelphis

Chestnut Hill College, Philadelphia

Curtis Institute of Music, Philadelphia

Commercial Museum, Philadelphia

Drexel Institute of Technology, Philadelphia

Dropsie College for Hebrew and Cognate Learning, Philadelphia

Eastern Baptist Theological Seminary, Philadelphia

Friends' Free Library of Germantown, Philadelphia
PPLas

Hahnemann Medical College and Hospital, Philadelphia Jefferson Medical College, Philadelphia

Library Company of Philadelphia

-, Ridgeway Branch

Lutheran Theological Seminary, Krauth Memorial Library, Philadelphia

La Salle College, Philadelphia

Mercantile Library, Philadelphia (existiert nicht mehr)

Chestnut Hill College, Philadelphia

Philadelphia Divinity School, Philadelphia

Philadelphia Divinity School, Philadelphia

Philadelphia Museum of Art

Presbyterian Historical Society, Philadelphia

Reformed Episcopal Church, Theological Seminary Library, Philadelphia

PPRF Rosenbach Foundation, Philadelphia

PPStC Philadelphia Divinity School, Philadelphia

PPT Temple University, Philadelphia

PPTU Temple University, Philadelphia

PPULC Union Library Catalogue of Pennsylvania, Philadelphia

PPWI Wistar Institute of Anatomy and Biology, Philadelphia

PPWE

PPeSchw

$\mathrm{PPi}$

Westminster Theological Seminary, Philadelphia

PPiCI

PPiD

PPiU

PRosC

PSC

PSC-Hi

PSt

PU
PV

PWCT

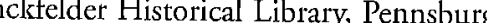

Carnegie Library of Pittsburgh

Carnegie Institute of Technology, Pittsburgh

Duquesne University, Pittsburgh

niversity of Pittsburgh, Pittsburgh

Rosemont College, Rosemont

Swarthmore College, Swarthmore

- Friends Historical Library

Pennsylvania State University, University Park

University of Pennsylvania, Philadelphia

Villanova College, Villanova

Puerto Rico

$\mathrm{Pr} U$

University of Puerto Rico, Rio Piedras

Rhode Island

$\mathrm{RHi}$

$\mathrm{RP}$

Rhode Island Historical Society, Providence

Providence Public Library 


\section{South Carolina}

$\mathrm{ScC}$

ScCleA

$\mathrm{ScGF}$

Charleston Library Society, Charleston

Clemson University Library, Clemson

$\mathrm{ScU}$

Furman University, Greenville

University of South Carolina, Columbia

\section{South Dakota}

Sd

SdRM

SdU

South Dakota State Library Commission, Pierre

South Dakota School of Mines and Technology, Rapid City

University of South Dakota, Vermillion

\section{Tennessee}

TKKL

TNDC

TNF

TNJ

TONS

TOU

TU

Texas

TxCM

TxCsA

TxDaDF

TxDaM

TxDaS

TxDa'Ts

TxFTC

TxHMC

TxHR

TxHST

TxHU

TxLT

TxSaT

$\mathrm{Tx} U$

Knoxville Public Library System

Disciples of Christ Historical Society, Nashville

Fisk University, Nashville

oint University Libraries (Vanderbilt University, George Peabody Col-

ege for Teachers and Scarritt College), Nashville

Oak Ridge Associated Universities, Oak Ridge

Oalk Ridge Associated Universities, Oak Ridge

University of Tennessee, Knoxville

Texas A \& M University, College Station

Texas A \& M University, College Station

DeGolyer Foundation Library, Dallas

Southern Methodist University, Dallas

Southwestern Medical College, Dallas

Dallas Theological Seminary and Graduate School of Theology, Dallas

Texas Christian University, Fort Worth

Texas Medical Center Library, Houston

Rice University, Houston

University of St. Thomas, Houston

University of Houston, Houston

Texas Technological College, Lubbock

Trinity University, San Antonio

University of'Texas, Austin $\begin{array}{ll}\text { TxU-M } & - \text { Medical School, Galveston } \\ \text { TxWB } & \text { Baylor University, Waco }\end{array}$

Utah

ULA

UU

Virginia

$\mathrm{Vi}$

ViAlTh

ViAsR

ViBlbV

ViFreM

$\mathrm{ViHaI}$

ViHarEM

ViLRM

ViLxW

ViRA

ViRM

ViRoH

$\mathrm{ViU}$

ViW

ViWC

Utah State University, Logan

Brigham Young University, Provo

University of Utah, Salt Lake City

Virginia State Library, Richmond

Virginia Theological Seminary, Alexandria

Randolph-Macon College, Ashland

Virginia Polytechnic Institute, Blacksburg

Mary Washington College of the University of Virginia, Fredericksburg

Hampton Institute, Hampton

Eastern Mennonite College, Harrisonburg

Randolph-Macon Woman's College, Lynchburg

Washington \& Lee University, Lexington

Richmond Academy of Medicine, Richmond

Medical College of Virginia, Richmond

Hollins College, Roanoke

University of Virginia, Charlottesville

College of William and Mary, Williamsburg

Colonial Williamsburg, Williamsburg

Vermont

$\mathrm{VtMiM}$

$\mathrm{VtNN}$

Middlebury College, Middlebury

Norwich University, Northfield

$\mathrm{VtU} \quad$ University of Vermont and Agricultural College, Burlington

Wisconsin

WBB

WHi

Beloit College, Beloit

State Historical Society of Wisconsin, Madison

WM Milwaukee Public Library

WMM Marquette University, Milwaukee

WU University of Wisconsin, Madison

Washington

WaChenE

WaE,

WaHi

$\mathrm{WaOB}$

Washington State Library, Olympi

Eastern Washington State College, Cheney

Everett Public Library

Washington State Historical Society, Tacoma

Washington State Department of Public Assistance, Ben Tidball Library 
Seattle Public Library

Pacific Northwest Bibliographic Center, Seattle

Spokane Public Library

Gonzaga University, Spokane

Tacoma Public Library

University of Puget Sound, Tacoma

University of Washington, Seattle

- Far Eastern Library

Walla Walla Public Library

West Virginia

Wv-Ar West Virginia Department of Archives and History Library, Charleston

West Virginia University, Morgantown

Wyoming

Wy

Wy-Ar

$\mathrm{WyC}$

WyU

Wyoming State Library, Cheyenne

Wyoming Archives and Historical Department, Cheyenne

Laramie County Carnegie Public Library, Cheyenne

University of Wyoming, Laramie

Canada:

An-C-LW University of Western Ontario, London

An-C-T

An-C-TU

An-C-V

Toronto Public Library, Toronto

University of Toronto, Toronto

Vancouver Public Library, Vancouver

An-C-Vic Victoria Public Library, Victoria

An-C-VU University of British Columbia, Vancouver

An-C-WlvA Arcadia University, Wolfville

C-V Vancouver Public Library, Vancouver

C-VicPr Provincial Library, Victoria

C-VU

CaACG

CaAEU

$\mathrm{CaB}$

CaBVa

$\mathrm{CaBVaU}$

$\mathrm{CaBVi}$

CaBViP

University of British Columbia Library, Vancouver

Glenbow Foundation Library, Calgary

University of Alberta, Edmonton

University of British Columbia, Vancouver

Vancouver Public Library, Vancouver

CaBViPA
CaNSWA

$\mathrm{CaOA}$

$\mathrm{CaOH}$

$\mathrm{CaOHM}$

$\mathrm{CaOKQ}$

$\mathrm{CaOLU}$

$\mathrm{CaOOCC}$

$\mathrm{CaOOG}$

$\mathrm{CaOON}$

$\mathrm{CaOONL}$

CaOTIM

CaOTP

$\mathrm{CaOTU}$

CaOTV

CaQMBN

CaQML

CaQMM

$\mathrm{CaQMU}$

CaQQLa

$\mathrm{CaT}$

CaTu

CaTU-V

$\mathrm{CaVU}$
University of Victoria Library, Victoria

Queen's University, Kingston

University of Western Ontario, London

La Bibliothèque de la Ville de Montréal, Collection Gagon, Montréal McGill University, Montréal

University of Manitoba, Winnipe

Acadia University, Wolfville, Nova Scotia

Public Archives Library, Ottawa

Hamilton Public Library, Hamilton

McMaster University, Hamilton

Queen's University, Kingston

University of Western Ontario, London

Public Archives Library, Ottawa

Carleton University, Ottawa

Geological Survey of Canada, Ottawa

National Science Library, National Research Council, Ottawa

National Library of Canada, Ottawa

Pontifical Institute of Medieval Studies Library, Toronto

Toronto Public Library, Metropolitan Bibliographic Center, Toronto

University of Toronto, Toronto

Victoria University, Toronto

La Bibliothèque Nationale du Québec, Montréal

Loyola College, Montréa

McGill University, Montréal

La Bibliothèque de l'Université de Montréal

Université Laval, Québec

Toronto Public Library, Toronto

University of Toronto, Toronto

Victoria University, Toronto

University of British Columbia, Vancouver 


\section{LITERATURVERZEICHNIS}

Abbott, John S. The History of Madame Roland. New York 1858

Abel, Elizabeth. Writing and Sexual Difference. Chicago \& London 1982

Aeschylos. Oresteia. Übers. und hg. Richard Lattimore. Chicago \& London 1953. [Enthält: The Libation Bearers, 91-131. The Eumenides, 132-71.]

Albrecht Dürer's Wohnhaus und seine Geschichte. In Wort und Bild dargestellt im Auftrag der Verwaltung der Albrecht-Dürer-Haus-Stiftung. Nürnberg 1896

Albrecht, Günther, Kurt Böttcher, Herbert Grainer-Mai und Paul Günther Krohn. Le xikon deutschsprachiger Schriftsteller. Von den Anfangen bis zur Gegenwart. 2 Bde. Kronberg/Ts. 1974

Album des Königl. Schauspiels und der Königl. Oper zu Berlin unter der Leitung von August Wilhelm Iffland, Karl Grafen von Bribhl, Wilhelm Grafen von Redern und Kar Theodor von Küstner. Für die Zeit von 1796 bis 1851. Berlin 1858

Alkemade, Mechtild. Die Lebens- und Weltanschaunng der Freifrau Marie von EbnerEschenbach. Mit sechs Tafelbeilagen und dem Briefwechsel Heyse und Ebner-Eschenbach. Graz \& Würzburg 1935

Allgemeine deutsche Biographie. Auf Veranlassung Seiner Majestät des Königs von Bayern hg. durch die Historische Commission bei der Königl. Akademie der Wissenschaften. 56 Bde. Leipzig 1875-1912

Allgemeiner deutscher Theater-Almanach für das Jahr 1822. Hg. Aug[ust]. Klingemann. Braunschweig 1822

Almanach der deutschen Musen auf das Jahr 1770. 2. Aufl. Leipzig, Berlin, Frankfurt 1770

Almanach der deutschen Musen auf das Jahr 1771. Leipzig 1771

Almanach der deutschen Musen auf das Jabr 1772. Leipzig 1772

Almanach fuir Freunde der Schauspielkunst auf das Jabr 1836. Hg. L. Wolff. Berlin 1837

Almanach fir Freunde der Schauspielkunst. 4. Jahrgang (1839) - 16. Jahrgang (1851) Jahrgänge 4-9: Hg. L. Wolff. Berlin 1840-45. Jahrgänge 11-16: Hg. A. Heinrich. Berlin 1847-52

Almanach fuir das Königliche Hoftheater in Stuttgart auf das Jahr 1846. Hg. Wilhelm Koffka. Stuttgart [1846]

Almanach fur Theater und Theaterfreinde auf das Jahr 1807 von August Wilhelm Iffland. Mit 12 Kupfern. Berlin 1807

Almanach fuirs Theater 1809 von Aug[ust]. Wilh[elm]. Iffland. Berlin 1809

Alston, Roy C. A Checklist of Women Writers 1801-1900. Fiction, Verse, Drama. London $1900 / 91$

Amalie, Prinzessin von Sachsen. Dramatische Werke der Prinzessin Amalie, Herzogin zu Sachsen. Im Auftrage Seiner Majestät des Königs Johann Sachsen aus dem Nachlasse vervollständigt und herausgegeben von Robert Waldmuiller [Edouard Duboc]. Bd. 1 (von 6 Bden.). Leipzig 1873.

[Enthält: Robert Waldmüller, „Lebensskizze“, vII-XXXII. Der Graf von Beaujolais, 1-100. Der Krönungstag, 101-196. Die Täuschungen, 197-291. Mesru, König von Baktriana I, 293-392. Mesru, König von Baktriana II, 393-476.
Die anderen 5 Bde. dieser Sammlung waren in zu schlechtem Zustand, um verliehen oder eingesehen werden zu können, und waren mir daher nicht zugänglich.]

- Original-Beiträge zur deutschen Schaubühne. 6 Bde. Dresden \& Leipzig 1836-42.

[Enthält: I: Liige und Wahrheit, 1-146. Die Braut aus der Residenz, 147-252. Der Oheirn, 253-420. II: Die Fürstenbraut, 1-140. Der Landwirth, 141-304. Der Verlobungsring, 305-438. III: Der Zögling, 1-164. Vetter Heinrich, 165-342. Der Unentschlossene, 343-443. IV: Der Majoratserbe, 1-140. Der Pflegevater, 141-282. Das Fraulein vom Lande, 283-454. V: Die Unbelesene, 1-126. Die Stieftochter, 127-288. Pflicht und Liebe, 289-398. VI: Capitain Firnewald, 1-162. Die Heimkehr des Sohnes, 163-292. Folgen einer Gartenbeleuchtung, 293-408.]

Anzelewsky, Fedja. Dürer. His Art and Life. Übers. Heide Grieve. New York 1981

Arens, Eduard. Droste-Bibliographie. Bearb. von Eduard Arens und Karl Schulte. Münster 1932

Arndts, Maria. Mozart als Ehestifter. Lustspiel in drei Acten von Maria Arndts (geb. Vespermann). Dramen für das christliche Haus. Bd. 4. Wien \& Gran 1869

Artaud, Antonin. The Cenci. Übers. Simon Watson Taylor. New York 1969

Artner, Marie Therese von. Die That. Trauerspiel in finf Akten. Leipzig 1817

Bab, Julius, Hg. Agnes Sorma. Ein Gedenkbuch. Zeugnisse ihres Lebens und ihrer Kunst. Heidelberg 1927

Bandemer, Susanne von. Sidney und Eduard, oder Was vermag die Liebe? Ein Schauspiel in drey Aufzuigen. Von Susanne von Bandemer, geb. von Franklin. Hannover 1792

Barbier, Marie Anne. Cornelia, die Mutter der Gracchen. Ein Trauerspiel. Aus dem Französischen der Madlle Barbier, übersetzt von L[uise]. A[delgunde]. V[ictorie]. G[ottsched]. Die deutsche Schaubiihne. Neue Aufl. Bd. 2. I.eipzig 1746. 163-230

Bauer, Karoline. Am Tage Rubm, am Abend Tridnen. Lebenserinnerungen der Schauspielerin Karoline Bauer. In Auswahl neu hg. von Susanne Förster. Zeulenroda, o. I.

- Die Berliner Hofbuibne vor einem halben Jahrhundert. Erinnerungen. O. O, o. J.

- Caroline Bauer and the Coburgs. Aus ihren Nachgelassenen Memoiren hg. und übers. Charles Nisbet. 2. Aufl. London 1887

- Karoline Bawer in ibren Briefen. Hg. Arnold Wellmer. Berlin 1878

- Komödianten-Fabrten. Erinnerungen und Studien. Hg. Arnold Wellmer. Berlin 1875 - Verschollene Herzensgeschichten. Nachgelassene Memoiren. Bearb. Arnold Wellmer. 3 Bde. Berlin 1880-1

Bauer Pickar, Gertrud. „Annette von Droste Hülshoff's ,Reich der goldnen Phantasie." Gestaltet und gestaltend. Frauen in der deutschen Literatur. Hg. Marianne Burkhard. Amsterdam 1980. 109-23

Bax, Clifford. The Life of the White Devil. London, Toronto, Melbourne, Sydney 1940 Becker-Cantarino, Barbara. „Caroline Pichler und die Fraulendichtung." Modern Austrian Literature 12 Nr. 3/4 (1979). 1-23

- Hg. Die Frau von der Reformation zur Romantik. Die Situation der Frau vor dem Hintergrund der Literatur- und Sozialgeschichte. Bonn 1980

- Der lange Weg zur Mündigkeit. Frau und Literatur (1500-1800), Stuttgart 1987

- „Von der Prinzipalin zur Künstlerin und Mätresse. Die Schauspielerin im 18. Jahr- 
hundert in Deutschland." Renate Möhrmann, Hg., Die Schauspielerin. Zur Kulturgeschichte der weiblichen Bübnenkunst. Frankfurt/M. 1989. 88-113

Behrens, Katia, Hg. Frauenbriefe der Romantik. Frankfurt/M. 1981

Belloc, Hilaire. Characters of the Reformation. New York 1938

Benger, ?. Memoirs of the Life of Anne Boleyn, Queen of Henry VIII. By Miss Benger, Author of Memoirs of Mrs. Elizabeth Hamilton, Jobn Tobin, etc. Philadelphia 1822

Benjamin, Walter. Ursprung des deutschen Trauerspiels. 2. Aufl. Hg. Rolf Tiedemann. Frankfurt/M. 1982

Bergin, Thomas G. Petrarch. New York 1970

Berglar-Schroer, Hans Peter. Annette von Droste-Hülshoff in Selbstzeugnissen und Bilddokumenten. Reinbek bei Hamburg 1967

Berlepsch, Emilie. Sammlung kleiner Schriften und Poesien von Emilie von Beriepsch, geb. von Oppel. 1. Theil, Göttingen 1787.

[Enthält: Eginhard und Emma, 159-212.]

Bernardin, Edith. Les Idées Religieuses de Madame Roland. Paris 1933

- Jean-Marie Roland et le Ministere de l'Intérieur (1792-1793). Paris 1964

Bernardo, Aldo S. Petrarch, Laura, and the Triumphs. Albany, N. Y. 1974

[Bernstein, Elsa]. Achill. Tragödie in drei Akten von Ernst Rosmer [Pseud.]. Berlin 1910

[-] Dämmerung. Schauspiel in funf Akten. Von Emst Rosmer [Pseud.]. Berlin, o. J.

[-] Johannes Herkner. Schauspiel von Elsa Porges (Ernst Rosmer [Pseud.]). Berlin 1904

[-] Königskinder, Ein deutsches Märchen in drei Akten von Ernst Rosmer [Pseud.]. 3. Aufl. Berlin 1897

[-] Maria Arndt. Schauspiel in fiinf Akten von Ernst Rosmer. [Pseud.]. Berlin 1908

[-] Milost Pan. In: Madonna. Von Ernst Rosmer [Pseud.]. Berlin 1894. 139-173

[-] Mutter Maria. Ein Totengedicht in füf Wandlungen von Ernst Rosmer [Pseud.]. Berlin 1900

[-] Nausikaa. Tragödie von Ernst Rosmer [Pseud.]. Berlin 1906

[-] Tedeum. Gemütskomödie in fünf Akten. Von Ernst Rosmer [Pseud.]. Berlin 1896

[-] Themistokles. Tragödie in fuinf Akten. Von Ernst Rosmer [Pseud.]. Berlin 1897

[-] Wir drei. Fünf Akte. Von Ernst Rosmer [Pseud.]. München, o. J.

Bettelheim, Anton. Marie von Ebner-Eschenbachs Wirken und Vermälchtnis. Leipzig 1920

Beugnot, Jacques-Claude. Mémoires du Comte Beugnot, Ancien Ministre (1783-1815), publiess par le Comte Albert Beugnot, son petit-fils [Hg.]. 3. Aufl. Paris 1889

[Beyle, Henry]. L'Abbesse de Castro. Les Cenci, Vittoria Accoramboni, Vanina Vanini, La Duchesse de Palliano. Par Stendhal [Pseud.]. Paris, o. J.

Die Bibel oder die ganze Heilige Schrift des Alten und Neuen Testaments nach der Übersetzung Martin Luthers. Stuttgart 1970

Bierbaum, Heintich. Karoline von Wolzogen aus ibren Werken und aus Briefen. Greifswald 1809

[Binzer, Emilie Henriette Adelheid von]. Mohnkörner. Gesammelte Erzählungen von Ernst Ritter [Pseud.]. 2 Bde. Pesth [d. i. Budapest] \& Leipzig 1846

[Birch, Una]. Madame Roland. A Study in Revolution by Mrs. Pope Hennessy (Una Birch). London 1917
Birch-Pfeiffer, Charlotte. Alles fur andere. Original-Lustspiel in einem Aufzug. Soufflierbuch mit einem Dekorationsplan und der vollständigen Regiebearbeitung. Leipzig, o. J.

- Dorf und Stadt. Schauspiel in zwei Abtheilungen und finf Aufzilgen, mit freier Benutzung der Auerbachschen Erzählung: „Die Frau Professorin. "Leipzig, o. J.

- Gesammelte dramatische Schriften. 2 Bde. Berlin 1847.

[Enthält: I: Die Marquise von Villette, 1-168. Elisabeth, 169-374. Simon, 375-523.

II: Rubens in Madrid, 1-175. Mutter und Tochter, 176-301.]

- Gesammelte dramatische Werke. Bd. 9. Leipzig 1866.

[Enthält: Die Walpurgisnacht, 1-84. Ulrich Zwinglis Tod, 85-175. Mutter und Tochter, 176-301.]

- Der Glöckner von Notre-Dame. Romantisches Drama in sechs Tableaus. Nach dem Roman des Victor Hugo frei bearbeitet. Leipzig [1899?]

- Der Goldbauer. Original-Schauspiel in vier Aufzügen. Soufflierbuch der Königlichen Schauspiele zu Berlin. Leipzig [1899?]

- Die Grille. Ländliches Charakterbild in fuinf Aufzilgen. Mit teilweiser Benutzung einer Erzadhlung von G. Sand. Halle/Saale, o. J.

- Johannes Guttenberg. Original-Schauspiel in drei Abtheilungen. Berlin 1836

- Junge Alte. Berlin 1865

- Der Leiermann und sein Pflegekind. Original-Volksstïck in drei Abtheilungen und finf Aufzügen. Leipzig, o. J.

- Mutter und Sohn. Schauspiel in 2 Abtheilungen und 5 Aufzuigen fir 9 Herren und 8 Damen. Für die Bühne neu eingerichtet von J. Wermann. Berlin [1909]. [Gebunden mit: Der Schuster als Prinz. Schwank in 3 Akten fir 7 Herren und 2 Damen nach Johann von Plötz. Für die Bühne neu bearbeitet von Demetrius Schrutz; und: Eine Spritztour nach Tirol. Schwank in 2 Akten fir 3 Herren und 3 Damen von Paul R. Lehnhard. Berlin, o. J.]

- Nacht und Morgen. Drama in vier Abtheilungen und füf Aufzügen mit freier Benutzung des Bulwerschen Romans. Soufflierbuch des Großherzoglichen Hoftheaters in Darmstadt. Leipzig, o. J.

- Onkel und Nichte. Lustspiel in fünf Aufzuigen. Deutscher Bühnenalmanach. Bd. 4. 1839. 145-242

- The Orphan of Lowood. A Drama in Two Parts and Four Acts. As Performed by Mme. Marie Seebach, and her Dramatic Company in New York and all the Principal Cities of the United States, under the Direction of J. Grau. New York 1870

- Pfeffer-Rösel, oder Die Frankfurter Messe im Jahre 1297. Schauspiel in fiinf Aufzïgen. Wien 1833

- Steffen Langer aus Glogau oder Der bolldndische Kamin. Original-Lustspiel in vier Aufzilgen und mit einem Vorspiele Der Kaiser und der Seiler. Soufflierbuch des Großherzoglichen Hoftheaters in Darmstadt. Leipzig, o. J.

- ,Twixt Axe and Crown. (Elisabeth Prinzessin von England.) A historical play in five acts. Adapted to the English Stage by Tom Taylor. New York, o. J.

- Die Waise aus Lowood. Schauspiel in zwei Abtheilungen und vier Aufzilgen. Mit freier Benutzung des Romans von Currer Bell [Pseud.]. Leipzig [1899?] 
- und Heinrich Laube. Charlotte Birch-Pfeiffer und Heinrich Laube im Briefwechsel, auf grund der Originalhandschriften dargestellt, von Alexander von Weilen [Hg.]. Schriften der Gesellschaft fir Theatergeschichte. Bd. 27. Berlin 1917

Bissing, Henriette von. Das Leben der Dichterin Amalie von Helvig. Berlin 1889

Blackwell, Jeannine. „Fractured Fairy Tales. German Women Authors and the Grimm Tradition." The Germanic Review LXI, 1 (Winter 1986). 162-174

Blaze de Bury, ?. Un Divorce Royal. Anne Boleyn. Paris 1890

Blümner, Heinich. Geschichte des Theaters in Leipzig. Von dessen ersten Spuren bis auf die neueste Zeit. Leipzig 1818

Bode, Wilhelm. Charlotte von Stein. Berlin 1920

- Goethe in vertraulichen Briefen seiner Zeitgenossen, 1749-1803. Berlin 1921

Böhlau, Helene. „Die Kummerfelden zieht mit ihrer Nähschule durch Alt-Weimar.“ Gesammelte Werke. 6 Bde. Berlin \& Wien 1915. II, 457-471

Bölty, Amely [d. i. Charlotte Elise Marianne]. Fanny Tarnow. Ein Lebensbild. Berlin 1865

Bohm, Arnd. „Authority and Authorship in Luise Adelgunde Gottsched's Das Testament." Lessing Yearbook. Bd. 18. Hg. Richard Schade. Detroit 1986. 129-140

Bohrer, Karl Heinz. Die Kritik der Romantik. Der Verdacht der Philosophie gegen die literarische Moderne. Frankfurt/M. 1989

Boklund, Gunnar. The Sources of the White Devil. Uppsala 1957

Bovenschen, Silvia. Die imaginierte Weiblichkeit. Exemplarische Untersuchungen zu kulturgeschichtlichen und literarischen Präsentationsformen des Weiblichen. Frankfurt/M. 1979

Brachvogel, A[lbett] E. Das alte Berliner Theater-Wesen bis zur ersten Blitthe des deutschen Dramas. Ein Beitrag zur Geschichte Berlins und des deutschen Theaters. Nach Originalquellen. Berlin 1877

- Die Königl. Oper unter Freiherrn von der Reck und Das Nationaltheater bis zu Iffland. Ein Beitrag zur Geschichte Berlins und des deutschen Theaters. Nach Originalquellen. Berlin 1878

- Theatralische Studien. Leipzig 1863

Brahm, Otto. Das deutsche Ritterdrama des 18. Jahrhunderts. Studien ïber Joseph August v. Törring, seine Vorgänger und Nachfolger. Straßburg 1880

Brall, Artur. Vergangenheit und Vergänglichkeit. Zur Zeiterfahrung und Zeitdeutung im Werk Annettes von Droste-Hiilshoff. Marburg 1975

Braun, Isabella. Kleine Theaterstücke für die Jugend. 2 Bde. Stuttgart, o. J.

[Enthält: I: Das Namenstagsgeschenk. Der St. Nikolausabend. Ein Waldmärchen. Zur Genesungsfeier. II: Der Zombi, 1-34. Nach der neuesten Mode, 35-62. Das Hutzelmännchen, 63-88. Der Mutter Geburtstag, 89-126. Die Heimkehr, 127-141.]

Brausewetter, Ernst. Meisternovellen deutscher Frauen. Mit Charakteristiken der Verfasserinnen und ibren Porträts. 2 Bde. Berlin \& Leipzig 1898

[Breden, Christiane von]. Faustina. Drama in funf Acten von Ada Christen [Pseud.]. Wien 1871

Bridel, Louis. Le droit des femmes et le mariage; études critiques de législation comparte. Paris 1893
Brinker-Gabler, Gisela, Hg. Deutsche Dichterinnen vom 16. Jahrhundert bis zur Gegenwart. Gedichte und Lebensläufe. Frankfurt/M. 1978

- Hg. Deutsche Literatur von Frauen. 2 Bde. München 1988

- „Die Schriftstellerin in der deutschen Literaturwissenschaft. Aspekte ihrer Rezeption von 1835 bis 1910." Unterrichtspraxis 9, 1 (1976). 15-28

- Karola Ludwig und Angela Wöffen. Lexikon deutschsprachiger Schriftstellerinnen 1800-1945. München 1986

Brion, Marcel. Dïrer. His Life and Work. Übers. James Cleugh. New York 1960 Brockbaus Enzyklopädie. 17. Aufl. 20 Bde. Wiesbaden 1968. Bd. 4

Brontë, Charlotte. Jane Eyre. Hg. Q. D. Leavis. Harmondsworth, Middlesex 1979

Bruce, Marie Louise. Anne Boleyn. New York 1972

Brümmer, Franz. Lexikon der deutschen Dichter und Prosaisten des neunzehnten Jahrbunderts. Dritte Ausgabe mit den Ergänzungen bis zum 1. Juli 1888. Leipzig, o. J.

- Lexikon der deutschen Dichter und Prosaisten vom Beginn des 19. Jahrbunderts bis zur Gegenwart. Sechste völlig neu bearbeitete und stark vermehrte Auflage. 8 Bde. Leipzig, o. J. [1913?]

Brüning, Ida. Le Theatre en Allemagne. Son Origine et ses Luttes (1200-1760). Paris 1887

Bruford, W. H. Germany in the Eighteenth Century: The Social Background of the Literary Revival. Cambridge 1935

Buck, Inge. „Zur Situation der Frauen am Theater im 18. Jahrhundert am Beispiel von Karoline Schulze-Kummerfeld (1745-1815). Eine Theatergeschichte von unten oder: Ein Porträt am Rande der Lessingzeit." Lessing und die Toleranz, in Hamburg vom 27.-29. Juni 1985. Sonderband zum Lessing Yearbook. Hg. Peter Freimarlk. München 1986. 313-25

Büchner, Louise. Die Frau. Hinterlassene Aufsätze, Abhandlungen und Berichte zur Frauenfrage. Halle 1878

- Die Frauen und ihr Beruf. 5. Aufl. Leipzig 1884

Bürger, Elise. Adelheid Gräfinn von Teck. Ein Ritterschauspiel in fün Aufzuigen. Von Elise Bïrger geborne Hahn. Neue Sammlung deutscher Schauspiele. Bd. 50. Grätz 1800

- Die antike Statue aus Florenz. Scherzspiel aus den im Besitze der Frankfurter Stadtbibliothek befindlichen unveröffentlichten Elise Bürger-Manuskripten. Frankfurt/M. 1929. [Nr. 116 von 300 numerierten Exemplaren.]

- Gedichte von Elise Bürger geb. Hahn. Als erster Band ihrer Gedichte, Reise-Blatter Kunst- und Lebensansichten. Hamburg 1812

Bulwer, Edward Lytton. Night and Morning. A Novel. New York [1883?]

Burkhard, Marianne, Hg. Gestaltet und gestaltend. Frauen in der deutschen Literatur. Amsterdam 1980

Burckhardt, Jacob. Erinnerungen aus Rubens. 3. Aufl. Basel 1918

Busse, Carl, Annette von Droste-Hülshoff. 3. Aufl. Bielefeld, Leipzig 1923

Byron, George Gordon. Lord Byron's Correspondence. Hg. John Murray. 2 Bde. New York 1922

Cardi, Carola. Das Kinderschauspiel der Aufklärungszeit. Eine Untersuchung der deutschsprachigen Kinderschauspiele von. 1769-1800. Frankfurt/M., Bern, New York 1983 
Case, Sue-Ellen. Feminism and Theatre. London 1988

Cassirer; Ernst. The Philosophy of the Enlightenment. Übers. Fritz A. Koelln und James

P. Pettegrove. Princeton, N. J. 1951

Chapman, John S. Byron and the Honourable Augusta Leigh. New Haven \& London 1975

Cher, Marie. Charlotte Corday and Certain Men of the Revolutionary Torment. New York \& London 1929

Chézy, Wilhelmine von. Neue auserlesene Schriften der Enkelin der Karschin. Herausgegeben auf Unterzeichnung zur Unterstïtzung verwundeter Vaterlandsvertheidiger. Heidelberg 1817

- Das stille Julchen. Correspondance d'Adalbert de Chamisso, fragments inédits. Lettres de Chamisso, Louis de la Foye, Helmina de Chézy, Varnbagen von Ense, Wilhelm Neumann, J. A. W. Neander, suivis de "Das stille Julchen" par Helmina de Chézy. Paris 1934. 275-335

- Unvergessenes. Denkwuirdigkeiten aus dem Leben von Helmina von Chézy, von ibr selbst erzählt. 2 Bde. Leipzig 1858. Faksimile-Neudruck: William T. Parsons, Hg. Collegeville, PA 1982

Christaller, Helene. Das Tagebuch der Annette. Ein Stück aus dem verborgenen Leben der Annette von Droste-Hülshoff. Basel 1926

Clairmont, Claire. The Joumals of Claire Clairmont. Hg. Marion Kingston Stocking. Cambridge, Mass. 1968

Clemenceau-Jaquemaire, Madeleine. The Life of Madame Roland. Übers. Laurence Vail. London, New York, 'Toronto 1930

Cocalis, Susan L. „Der Vormund will Vormund sein. Zur Problematilk der weiblichen Unmündigkeit im 18. Jahrhundert." Gestaltet und Gestaltend. Frauen in der deutschen Literatur. Hg. Marianne Burkhard. Amsterdam 1980. 33-55

- und Kay Goodman, Hg. Beyond the Eternal Feminine. Critical Essays on Women and German Literature. Stuttgart 1982

- Kay Goodman und Sara Lennox. "Women in German Language and Literature." Women in Print. Bd. 1. Hg. Joan E. Hartman und Ellen Messer-Davidow. New York 1982. $135-148$

Corday, Michel. Charlotte Corday. Übers. E. F. Buckley. New York 1931

Cornelius, Auguste. König und Dichter. Schauspiel in vier Aufzuigen. H[einrich] Th[eodor] Rötscher, Dramaturgische Probleme, Entwickelungen und Kritiken zur Förderung und Belehrung dramatischer Dichter und darstellender Künstler. Dresden 1865. Heft 2. 1-32

- Nur ein Held. Schwank in einem Aufzug nach einer allteren Idee von A. Cornelius. Wien 1877

- Platen in Venedig. Original-Lustspiel in einem Aufzuge. H[einrich] Th[eodor] Rötscher, Dramaturgische Probleme, Entwickelungen und Kritiken zur Förderung und Belehrung dramatischer Dichter und darstellender Künstler. Dresden 1865. Heft 3. 17-26

[Costenoble, Karl Ludwig.] Carl Ludwig Costenoble's Tagebïcher von seiner Jugend bis zur Ubbersiedlung nach Wien (1818). Hg. Alexander von Weilen. 2 Bde. Schriften de Gesellschaft für Theatergeschichte. Bd. 18 \& 19. Berlin 1912
Cowen, Roy C. Das deutsche Drama im 19. Jabrbundert. Stuttgart 1988

Danzel, Th. W., Hg. Gottsched und seine Zeit. Auszüge aus seinem Briefwechsel zusammengestellt und erläutert. Nebst einem Anhange: Daniel Wilhelm Trillers Anmerkungen zu Klopstocks Gelehrtenrepublik. Zweite wohlfeile Ausgabe. Leipzig 1855

Dashkova, Ekaterina. Am Zarenhofe. Memoiren der Fürstin Daschkoff. Nebst Briefen Katharinas der Zweiten und anderem Briefwechsel. 2 Bde. München 1918

- Memoiren der Fürstin Daschkoff. Zur Geschichte der Kaiserin Katharina II. Eingel. Alexander Herzen. 2 Bde. in 1. Hamburg 1857

Dauban, C. A. Etude sur Madame Roland et son temps, suivie des lettres de Madame Roland à Buzot et d'autres documents inédits. Paris 1864

Dawson, Ruth P. „The Feminist Manifesto of Theodor Gottlieb von Hippel (174196)." Gestaltet und Gestaltend. Frauen in der deutschen Literatur. Hg. Marianne Burkhard. Amsterdam 1980. 13-32

- „Frauen und "Theater. Vom Stegreifspiel zum bürgetlichen Rührstück." Deutsche Literatur von Frauen. 2 Bde. Hg. Gisela Brinker-Gabler. München 1988. I, 421-33

- „Im Reifrock den Parnaß besteigen. Die Rezeption von Dichterinnen im 18. Jahrhundert (am Beispiel von Philippine Gatterer-Engelhard)." Frauensprache-Frauenliteratur? Für und Wider einer Psychoanalyse literarischer Werke. Hg. Inge Stephan und Carl Pietzclker. Tübingen 1986. 24-9

Defrance, Eugène. Charlotte Corday e la Mort de Marat. Documents Inédits Sur i'bistoire de la Terreur, tirés des Archives Nationales de la Bibliothèque de la Ville de Paris, et notament des Bibliotheques Municipales de Caen et d'Alençon. Paris 1909

Delle Grazie, M[arie] E[ugenie]. Moralische Walpurgisnacht. Ein Satyrspiel vor der Tragödie von M. E. delle Grazie. Leipzig 1896

- Narren der Liebe. Lustspiel in vier Akten von M. E. delle Grazie. 2. Aufl. Leipzig 1905

- Saul. Tragödie in finf Acten von M. E. delle Grazie. Wien 1885

- Der Schatten. Drama in drei Akten und einem Vorspiel von M. E. delle Grazie. 2. Aufl. Leipzig 1902

- Schlagende Wetter. Drama in vier Akten von M. E. delle Grazie. 2. Aufl. Leipzig 1900

- Zu spät. Vier Einakter von M. E. delle Grazie. 2. Aufl. Leipzig 1903

Demmer, Sybille. Untersuchungen zu Form und Geschichte des Monodramas. Köln 1982

Denkler, Horst. Restauration und Revolution. Politische Tendenzen im deutschen Drama zwischen Wiener Kongreß und Märzrevolution. München 1973

Devrient, Eduard. Eduard Devrient aus seinen Tagebüchern. Berlin-Dresden 1836-1852. Hg. Rolf Kabel. Weimar 1964

- Geschichte der deutschen Schauspielkunst. 2 Bde. Hg. Rolf Kabel und Christoph Trilse. München \& Wien 1967

Devrient, Hans. Johann Friedrich Schönemann und seine Schauspielergesellschaft. Ein Beitrag zur Theatergeschichte des 18. Jabrhunderts. Hamburg \& Leipzig 1895. Neudruck: Theatergeschichtliche Forschungen. Bd. 9. Hg. Berthold Litzmann. Nendeln/ Liechtenstein 1978

- Die Schönemannsche Truppe in Berlin, Breslau, Danzig und Königsberg 1742-1744. Diss. (Jena). Hamburg 1895 
- Hg. Archiv für Theatergeschichte. 2 Bde. Berlin 1904-5

Dillon, Edward. Rubens. London 1909

Dixon, William Hepworth. History of Two Queens. Catharine of Aragon, Anne Boleyn. 2. Aufl. 2 Bde. London 1873

Dobson, Austin, Four Frenchwomen. New York, o. J.

Doerry, Hans. Das Rollenfach im deutschen Theaterbetrieb des 19. Jahrhunderts. Schriften der Gesellschaft fuir Theatergeschichte. Bd. 35. Berlin 1926

Dohm, Hedwig. Der Frauen Natur und Recht. 2. Aufl. Berlin, o. J.

Dohn, Walter. Das Jahr 1848 im deutschen Drama und Epos. Stuttgart 1912

Dosenheimer, Elise. Das deutsche soziale Drama von Lessing bis Sternheim. Darmstadt 1989 (Nachdruck der Ausgabe 1949)

Dotzler, Bernhard J. ..Seht doch wie ihr vor Eifer schäumet...' Zum männlichen Diskurs über Weiblichkeit um 1800." Jahrbuch der deutschen Schillergesellschaft XXX. Stuttgart 1986. 339-82

Droste-Hülshoff, Annette von. Die Briefe der Dichterin Annette von Droste-Hülshoff. Hg. und erläutert von Hermann Cardauns. Münster 1909

- Dramatische Versuche. Historisch-kritische Ausgabe. Werke, Briefwechsel. Hg. Winfried Woesler, bearb. Stephan Berning. Bd. VI, 1. Tübingen 1982

[Enthält: Perdu! oder Dichter, Verleger und Blaustrümpfe, 1-60. Bertha oder die Alpen, 61-224. Hedwig und Sophie oder Verzweiflung und Rache, 227-32. Das Räthsel oder Wie viele Pfund Freier gehn auf 1 Pfund Nehmer. Antwort: Keins denn Sie fliegen alle davon, 233-46. Scenen aus Hülshoff, 247-61.

- Perdul oder Dichter, Verleger und Blaustrümpfe. Sämtliche Werke. Hg. Clemens Heselhaus. 4. Aufl. München 1963. 1037-1101

Düringsfeld, Ida von. Das Buch Denkwürdiger Frauen. Lebensbilder und Zeitschilderungen. Festgabe für Mütter und Töchter. 4. Aufl. Hg. Ida Klokow. Leipzig 1891

Dumont, Louise. Vermächtnisse. Hg. Gustav Lindemann. Düsseldorf 1932

Duncker, Dora. Die Schneckönigin. Ein deutsches Märchenspiel in einem Vorspiel und drei Akten mit Zugrundelegung von Andersens "Schneekönigin“. Charlottenburg 1910

- und Hans Gaus. Die kleine Hoheit. Lustspiel in drei Akten. Berlin 1913

Dungern, Julie. Was sich schickt und den Leuten gefallt. Regeln des guten Tons firr Söbne und Töchter gebildeter Stände. Stuttgart 1866

Durant, Will und Ariel. The Age of Reason Begins. A History of European Civilization in the Period of Shakespeare, Bacon, Montaigne, Rembrandt, Galileo, and Descartes. 1558-1648. New York 1961

Duricux, Tilla. Eine Tür steht offen. Erinnerungen. Berlin-Grunewald 1954

- Spielen und Träumen. Berlin 1922. [Nr. 99 von 125 numerierten Exemplaren.]

Ebeling, Friedrich W. Gottfried August Bïrger und Elise Hahn: Ein Ehe-, Kunst- und Literaturleben. Leipzig 1868

Ebner-Eschenbach, Marie von. Am Ende. Mit: Das Gastmahl des Plato, von R. Specht O. O., o. J. [Angaben in: National Union Catalog, Pre-1956 Imprints. Bd. 154. 598.] - Bei meinen Landsleuten. Erzählungen, Novellen und Skizzen. Der Nachlaß der Marie von Ebner-Eschenbach in vier Bänden. Bd. 1. Hg. Heinz Rieder. Wien, o. J.
- Doctor Ritter. Dramatisches Gedicht in einem Aufzuge. Wien 1872

- Die erste Beichte, Der Muff, Die Sïnderin. Bearb. Kurt Sternelle. Hamburg 1958

- Letzte Worte. Aus dem Nachlaß herausgegeben von Helene Bucher mit einem Bildnis der Dichterin aus ibren letzten Lebensjahren. Wien, Leipzig, München 1923

- Männertreue. Der Merker 3, 1 (1912). Lith. Neudruck: Scarsdale, N. Y., o. J. 25-9, 72-4, 103-10, 143-8

- Marie Roland. Trauerspiel in fuinf Aufzïgen von M. von Eschenbach. Wien 1867

- Miterlebtes. Erzählungen. 4. Aufl. Berlin 1911

- Ohne Liebe. Lustspiel in 1 Akt. Bühnen-Bearbeitung gemäß der Auffuhrung im Residenz-Theater zu Berlin. Berlin, o. J.

- Sämtliche Werke. 6 Bde. Berlin \& Berlin-Grunewald, o. J.

[Enthält: I: Am Ende, 671-88. II: Ohne Liebe, 703-34.]

- Die Veilchen. Lustspiel in einem Aufzuge von M. von Eschenbach. Wien 1877

- Das Waldfräulein. Lustspiel in drei Aufzuigen. Erstdruck nach der Handschrift. Hg. Karl Gladt. Wien 1969

- und Enrica von Handel-Mazzetti. Der Dichterinnen stiller Garten. Marie von EbnerEschenbach und Enrica von Handel-Mazzetti. Bilder aus ihrem Leben und ihrer Freundschaft dargestellt von Johannes Mumbauer. Freiburg i. Br., o. J. [1918?]

Eisenberg, Ludwig. Großes biographisches Lexikon der deutschen Bühne. Leipzig 1903

Eissler, K. R. Goethe, A Psychoanalytic Study, 1775-1786. Detroit 1963

Ekhof, Konrad [und Anna Amalia von Weimar]. „Konrad Ekhof und die Herzogin Anna Amalia von Weimar. Ungedruckte Briefe." Bübne und Welt 15 (Hamburg 1913). $1-18,50-61$

[Elisabeth von Rumänien]. Aus den Briefen Carmen Sylvas. Hg. Werner Deetjen. Leipzig 1920

[-] Aus meinem Königreich. Tales from the Carpathian Mountains by Carmen Sylva [Pseud.]. Hg. Wilhelm Bernhardt. Boston 1900

- „Briefe der Königin Elisabeth von Rumänien (Carmen Sylva) an einen deutschen Gelehrten." Mitgeteilt von Prof. Dr. Arthur Kleinschmidt. Westermanns Monatsbefte 120 (Berlin 1916). 393-400

[-] Carmen Sylva [Pseud.]. Briefe einer einsamen Königin. München, o. J. [1916?]

- From Memory's Shrine. The Reminiscences of Carmen Sylva.[Pseud.] (H. M. Queen Elisabeth of Roumania). Übers. Edith Hopkirk. London, o. J.

[-] Gefliusterte Worte von Carmen Sylva [Pseud.]. 2.-3. Aufl. 2 Bde. Regensburg 1905-7

- Letters and Poems of Queen Elisabeth (Carmen Sylva) [Pseud.]. Hg. Henry Howard Harper. 2 Bde. Boston 1920

[-] Meister Manole. Trauerspiel in vier Aufzuigen von Carmen Sylva [Pseud.]. Bonn 1892

[-] Poems by Carmen Sylva [Pseud.], Queen of Roumania. Übers. A. H. Exner. London, o. J.

[-] Vom Amboß. Von Carmen Sylva [Pseud.]. Bonn 1890

[- und Marie von Kremnitz]. Anna Boleyn. Historisches Trauerspiel von Dito und Idem [Pseud.e]. Bonn 1886 
Eloesser, Arthur. Das bürgerliche Drama. Seine Geschichte im 18. und 19. Jahrhundert. Berlin 1898

- Hg. Aus der großen Zeit des deutschen Theaters. Schauspieler-Memoiren. München 1911

Ende, A[malie] von. „Neunhundert Jahre Frauendrama." Bühne und Welt. Zeitschrift fir Theaterwesen, Literatur und Kunst I/2. Berlin 1899. 1105-1111

Enzinger, Moriz. Die Entwicklung des Wiener Theaters vom 16. bis zum 19. Jahrhundert (Stoffe und Motive). 2 Bde. Schriften der Gesellschaft fir Theatergeschichte. Bd. $28 \&$ 29. Berlin 1918-9

Erickson, Carolly. The First Elizabeth. New York 1983

- Mistress Anne. New York 1984

Ewald, Alex[ander]. Charles, F. S. A. Stories from the State Papers. 2 Bde. London 1882

Feichtlbauer, Martin. Salzburgs hochdeutsche Literatur von 1850-1917 im Rahmen der deutschen Literaturentwicklung. Mitteilungen der Gesellschaft fuir Salzburger Landeskunde. Salzburg 1917

Fenyö, Iván. Albrecht Dürer. Übers. Ann Biener Tauber. Budapest 1956

Flaherty, Gloria. „Catherine the Great and Men." Lessing Yearbook. Bd. 18. Hg. Richard Schade. Detroit 1986. 141-150

Fortunatus, Venantius. A Basket of Chestnuts. Übers. Geoffrey Cook. Rochester, N.Y. 1981

- Carminum. Opera Poetica Libri VIII-XI. Berlin 1881. 178-270

- Opera Poetica. Berlin 1881

- „Vita S. Radegundis Reginae." Venantii Fortunati Pictaviensis Episcopi Opera Omnia. "Turnhout 1978. (Nachdruck der Ausgabe Paris 1850). 497-512

- und Decimus Magnus Ausonius. Die Moselgedichte des Decimus Magnus Ausonius und des Venantius Fortunatus. Hg. Carl Hosius. 3. Aufl. Marburg i. H. 1926

„Four Original Documents Relating to the Marriage of Henry VIII. to Anne of Cleves. 1539-40." A Collection of Eighteen Rare and Curious Historical Tracts and Pamphlets. Privately Printed. Edinburgh 1884-6. Sep. Pag.

Fout, John C., Hg. German Women in the Nineteenth Century. A Social History. New York \& London 1984

François, Louise von. Der Posten der Frau. Berlin, o. J.

- Der Posten der Frau. Lustspiel in fünf Aufzügen. Stuttgart 1881

- und Conrad Ferdinand Meyer. Louise von François und Conrad Ferdinand Meyer. Ein Briefwechsel. Hg. Anton Bettelheim. Berlin \& Leipzig 1920

Franul von Weißenthurn, Johanna. Die Bestürmung von Smolensk. Wien 1833

- Graf Lohrenburg. Wien 1819

- Das letzte Mittel. Lustspiel in vier Aufzügen. Zur Auffihrung eingerichtet von Carl Friedrich Wittrnann. Leipzig 1882

- Ein Mann hilft dem andern. Lustspiel in einem Aufzuge. Weimarisches dramatisches Taschenbuch. 1. Jahrgang. Hg. von Theodor Hell [Pseud. für Karl Theodor Winkler]. Weimar 1823

- Neueste Schauspiele. 2. Aufl. 2 Bde. [Schauspiele] Bd. $7 \& 8$ [=Neue Schauspiele Bd. \& 2]. Berlin 1823.
[Enthält: I: Johann, Herzog von Finnland, 1-106. Es spukt, 107-65. Die Schweitzerbiitte am Rheinfall, 166-95. II: Hermann, 1-122. Welche ist die Braut?, 123-246. Künstler-Dank, 247-65.]

- Die Radikalkur. Original-Lustspiel in drei Aufzügen. Wien 1833

- Schauspiele von Johanna Franul von Weißenthurn gebornen Grïnberg. 6 Bde. Wien 1810.

[Enthält: I: Kindliche Liebe, 1-124. Ein Haus zu verkaufen, 125-72. Der Reukanf, 173-236. Deutsche Treue, 237-70. II: Liebe und Entsagung, 1-92. Beschämte Eifersucht, 93-171. Das Nachspiel, 173-204. Die Drusen, 205-84. III: Die Erben, 1-123. Totila, König der Gothen, 125-212. Das Mißverständniß, 213-68. IV: Adelheid, Markgriffinn von Burgau, 1-99. Die Radikalkur, 101-88. Unterthanenliebe, 189-252. Das Frühstück, 253-96. V: Der Wald bey Herrmannstadt, 1-109. Versöbnung, 111205. Die Ehescheuen, 207-48. VI: Die Besturmung von Smolensk, 1-112. Die erste Liebe, 113-99. Das Waisenhaus, 201-55.]

Franz, Agnes. Agnes Franz' Vermächtniß an die Jugend. Breslau 1845.

[Enthält: Der Rosenstock, 232-48. Agnes Franz' letzte Geburtstagsfeier, 309-16.]

Die Frauenfrage in Deutschland. Bibliographie. 3 Bde. Bearb. Ilse Delvendahl. Deutscher Alkademikerinnenbund e.V. München, New York, London, Paris 1983-7

Frederilksen, Elke. „Die Frau als Autorin zur Zeit der Romantilk. Anfänge einer weiblichen literarischen Tradition." Gestaltet und gestaltend. Frauen in der deutschen Literatur. Hg. Marianne Burkhard. Amsterdam 1980. 83-108

- Hg. Die Frauenfrage in Deutschland 1865-1915. Texte und Dokumente. Stuttgart 1981

- Hg. Women Writers of Germany, Austria, and Switzerland. An Annotated Bio-Bibliographical Guide. New York, Westport, London 1989

Freicsleben, Gottfried Christian. Herrn Gottfried Christian Freieslebens, herzogl. sächsisch-gothaischen Raths und Bibliothekars, Kleine Nachlese, zu des berühmten Herrn Professor Gottscheds nöthigem Vorrathe zur Geschichte der deutschen dramatischen Dichtkunst. Leipzig 1760

Frevert, Ute, Hg. Bürgerinnen und Bürger. Geschlechterverbaltnisse im 19. Jahrhundert. Götringen 1988

- Frauen-Geschichte Zwischen Bürgerlicher Verbesserung und Neuer Weiblichkeit. Frankfurt/M. 1986

Friedan, Betty. The Feminine Mystique. New York 1971

Friedmann, Paul. Anne Boleyn. A Chapter of English History 1527-1536. 2 Bde. London 1884

Friedrichs, Elisabeth. Die deutschsprachigen Schriftstellerinnen des 18. und 19. Jabrhunderts. Ein Lexikon. Stuttgart 1981

- Literarische Lokalgrößen 1700-1900. Verzeichnis der in regionalen Lexika und Sammelwerken aufgefiuhrten Schriftsteller. Stutgart 1967

Froude, J. A. The Divorce of Catherine of Aragon. The Story as Told by the Imperial Ambassadors Resident at the Court of Henry VIII. New York 1891

Gallas, Helga, und Magdalene Heuser, Hg. Untersuchungen zum Roman von Frauen um 1800. Tübingen 1990 
Gallerie von Teutschen Schauspielern und Schauspielerinnen der altern und neuern Zeit nebst Jobann Friedrich Schinks Zusätzen und Berichtigungen. Wien 1783. Neuausg. Schriften der Gesellschaft für Theatergeschichte. Bd. 13. Hg. Richard Maria Werner. Berlin 1910

Garland, Henry und Mary. The Oxford Companion to German Literature. 2. Aufl. Oxford, New York 1986

Gayette-Georgens, Jeanne Marie von und Hermann Kletke, Hg. Frauen-Album, Charakterbilder aus alter und neuer Zeit. Berlin, o. J.

Gebhardt, Manfred. Mathilde Franziska Anneke. Madame, Soldat, Suffragette. Berlin 1989

Geitner, Ursula. „Passio Hysterica - Die alltägliche Sorge um das Selbst. Zum Zusammenhang von Literatur, Pathologie und Weiblichkeit im 18. Jahrhundert." Frauen Weiblichkeit - Schrift. Hg. Renate Berger, Monika Hengsbah, Maria Kublitz, Inge Stephan und Sigrid Weigel. Berlin 1985. 130-145

- Hg. Schauspielerinnen. Der theatralische Eintritt der Frau in die Moderne. Bielefeld 1988

Gerber, E. „Vorschläge zur Abhülfe des gegenwärtigen Theaterelends.“ H[einrich] Th[eodor] Rötscher, Dramaturgische Probleme, Entwickelungen und Kritiken zur Förderung und Belehrung dramatischer Dichter und darstellender Künstler. Dresden 1865. Heft 1. 29-38

[Gerhard, Caroline Similde]. Der deutschen Jungfrau Wesen und Wirken. Winke fitr das geistige und praktische Leben von Caroline S. J. Milde [Pseud.]. Leipzig 1882

Gerhard, Ute. Verhältnisse und Verhinderungen. Frauenarbeit. Familie und Rechte der Frauen im 19. Jahrhundert. Mit Dokumenten. Frankfurt/M. 1978

Gerstenberg, H[einrich]. Aus Weimars nachklassischer Zeit. Hamburg 1901

Gesammelte Frauenzimmergedichte. Frankfurt \& Leipzig 1764

Giesing, Michaela. „Theater als verweigerter Raum. Dramatilerinnen der Jahrhundertwende in deutschsprachigen Ländern." Frauen - Literatur - Geschichte. Schreibende Frauen vom Mittelalter bis zur Gegenwart. Hg. Hiltrud Gnüg und Renate Möhrmann. Stuttgart 1985. 240-59

Glaser, Horst Albert. Das bürgerliche Rührstück. Analekten zum Zusammenhang von Sentimentalitat mit Autorität in der trivialen Dramatik Schröders, Ifflands, Kotzebues und anderer Autoren am Ende des achtzehnten Jahrhunderts. Stuttgart 1969

Gleim, Betty [d. i. Elisabeth]. Ueber die Bildung der Frauen und die Behauptung ihrer Wïrde in den wichtigsten Verbältnissen ibres Lebens. Ein Buch für Jungfrauen, Gattinnen und Mittter. Leipzig 1814

Gnüg, Hiltrud und Renate Möhrmann, Hg. Frauen - Literatur - Geschichte. Schreibende Frauen vom Mittelalter bis zur Gegenwart. Stuttgart 1985

Goedeke, Karl. Grundriß zur Geschichte der deutschen Dichtung aus den Quellen. 2. Aufl. 15 Bde. in 20. Dresden 1884-1966

Gössmann, Elisabeth, Hg. Das woblgelahrte Frauenzimmer. München 1984

Goethe, Johann Wolfgang von. Faust. Eine Tragödie. Werke. 13. Aufl. 14 Bde. Hg. Erich Trunz. München 1986. III, 1-145
- Goethes Briefe an Frau von Stein. 2. Aufl. 2 Bde. Hg. Adolf Schöll. Frankfurt/ M. $1883-5$

- Selections from Goethe's Letters to Frau von Stein 1776-1789. Hg. und übers. Robert Browning. Columbia, S. C. 1990

- und Charlotte von Stein. Goethes Briefe an Frau von Stein. Mit dem Tagebuch aus Italien und Briefen der Frau von Stein. Hg. Richard Müller-Freienfels, 4 Bde, in 2. Berlin 1923-4

[Götze, Auguste]. Vittoria Accoramboni. Tragödie in fünf Aufzügen von A. Weimar [Pseud.]. Leipzig 1890

Goodman, Katherine. Dis/Closures. Women's Autobiography in Germany Between 1790 and 1914. New York, Bern, Frankfurt/M. 1986

[Goodrich, Samuel Griswold]. Lives of Celebrated Women. Boston 1845

Gordon, Armistead C. Allegra. The Story of Byron and Miss Clairmont. New York 1926 Gossmann, Wilhelm. Annette von Droste-Hülshoff. Ich und Spiegelbild. Zum Verstandnis der Dichterin und ibres Werkes. Düsseldorf 1985

Gottsched, Johann Christoph. Nöthiger Vorrath zur Geschichte der deutschen Dramatischen Dichtkunst, oder Verzeichniß aller Deutschen Trauer-Lust-und Sing-Spiele, die im Druck erschienen, von 1450 bis zur Halfte des jetzigen Jahrhunderts, gesammlet und ans Licht gestellet. Im Anhang Gottfried Christian Freieslebens Kleine Nachlese. Leipzig 1757 (1. Teil); 1765 (2. Teil). Neudruck New York \& Hildesheim 1970

- Versuch einer Critischen Dichtkunst. Unveränderter photomechanischer Nachdruck der 4., vermehrten Auflage, Leipzig 1751. Darmstadt 1962

Gottsched, Luise Adelgunde. Briefe der Frau Louise Adelgunde Victorie Gottsched gebohrne Kulmus. Hg. Dorothea Henriette von Runckel. 3 Bde. Dresden 1771-2

- Der Frau Luise Adelgunde Victoria Gottschedinn, geb. Kulmus, sämmtliche Kleinere Gedichte, nebst dem, von vielen vornehmen Standespersonen, Gönnern und Freunden beyderley Geschlechtes, Ihr gestifteten Ehrenmale, und Ibrem Leben, herausgegeben von Ihrem hinterbliebenen Ehegatten. Leipzig 1763

- Die Lustspiele der Gottschedin. Hg. Reinhard Buchwald und Albert Köster. 2 Bde. Leipzig 1908-9.

[Enthält: I: Die ungleiche Heirath, 1-124. Die Hausfranzösinn, 125-258. Das Testament, 259-392. Der Witzling, 393-440. Die Pietisterey im Fischbein-Rocke oder die doktormäßige Frau, 441-573. II: Das Gespenst mit der Trummel, oder der wahrsagende Ehemann, 1-120. Der Verschwender, oder die ehrliche Betrügerinn, 121-263. Der Poetische Dorfjunker, 265-392. Der Menschenfeind, 393-488. Die Widerwillige, 489532.]

- Panthea. Ein Trauerspiel in fünf Aufzügen. Von Luise Adelg. Vict. Gottsched. Wien 1752

- Die Pietisterei im Fischbein-Rocke oder Die doktormäßige Frau. Ein Lustspiel aus dem Jahre 1737. Gottscheds Lebens- und Kunstreform in den zwanziger und dreißiger Jahren. Gottsched, Breitinger, die Gottschedin, die Neuberin. Hg. F. Brüggemann. Leipzig 1935. 137-215

- Die Pietisterey im Fischbein-Rocke. Hg. Wolfgang Martens. Stuttgart 1968 
- Das Testament, ein deutsches Lustspiel in fünf Aufzulgen von Luise Adelgunde Victorine Gottsched. Joh. Christoph Gottsched und die Schweizer Joh. J. Bodmer und Joh. J. Breitinger. Berlin \& Stuttgart 1884. Nachdruck: Hg. Johannes Crüger. Darmstadt 1965. 252-337

- Der Witzling. Ein deutsches Nachspiel in einem Aufzuge. Komedia. Deutsche Lustspiele vom Barock bis zur Gegenwart. Berlin 1962. I, 1-37

Gouges, Olympe de. Les Droits de la Femme. A la Reine. Paris 1791

- Les Droits de la Femme par Olympe de Gouges. Übers. [ins Englische] Mary Hamilton Wright, O. O., 1938

- Euvres. Présenté par Benoîte Groult [Hg.]. Paris 1986

Graffigny, Françoise d'Issembourg d'Happencourt de. Cenie, oder die Großmuth im Unglïcke. Ein moralisches Stück, in fünf Aufziugen. Aus dem Französischen der Frau von Graphigny, ubersetzt von der Frau Gottschedinn zu Leipzig. Deutsche Schaubühne 4. Theil. Wien 1753

Grenz, Dagmar. Mädchenliteratur. Von den moralisch-belehrenden Schriften im 18. Jahr bundert bis zur Herausbildung der Backfischliteratur im 19. Jahrhundert. Stuttgart 198

[Grimm, Gisela]. Alt Schottland. Drama in finf Akten mit einem Vorspiel von Gisela von Arnim. Weimar, o. J. [1889?]

[-] Alt Schottland. Drama von Gisela von Arnim. 2. Aufl. Berlin 1890

[-] Dramatische Werke von Gisela von Arnim. 4 Bde. Berlin 1857-75.

[Enthält: I: Ingeborg von Dänemark, 1-280. Das Herz der Laïs, 281-320. II: Trost in Thränen. III: Das Steinbild der Cornelia. IV: Wie es unterdessen Daheim war.]

[-] Das Licht. Festspiel zum Geburtstag des Weisen. Berlin 1870

Grimm, Jakob und Wilhelm. Kinder- und Hausmärchen. 3 Bde. Hg. Ingeborg WeberKellermann. Frankfurt/M. 1984

Grimminger, Rolf, Hg. Deutsche Aufklärung bis zur Französischen Revolution 16801789. München \& Wien 1980

Groß, Heinrich, Hg. Deutsche Dichterinen und Schriftstellerinen in Wort und Bild 3 Bde. Berlin 1885

- Deutschlands Dichterinen und Schriftstellerinen. Eine literarhistorische Skizze. 2. Aufl. Wien 1882

Grote, Ludwig. Albrecht Dürer: A Biographical and Critical Study. Übers. Helga Harrison. Genf 1965

Grube, Karl. Die Meininger. Berlin \& Leipzig, o. J.

Grylls, R[osalie]. Glynn. Claire Clairmont, Mother of Byron's Allegra. London 1939

Günderrode, Karoline von. Gesammelte Werke. 3 Bde. Bern 1970.

[Enthält: I: Leopold Hirschberg, „Das Mährchen von der schönen Günderode“, IX-XXII. Immortalia, 38-46. Mora, 53-60. Hildgund, 89-108. Mahomed, der Prophet von Mekka, 121-228. II: Udobla, 87-123. Magie und Schicksal, 125-81. Nikator 183-211. III: Edda-Fragment, 45-63. Der Kanonenschlag, oder das Gastmahl des Tantalus, 85-98.]

[-] Magie und Schicksal. In drei Acten. Von demselben ['Tian, Pseud.]. Studien. Hg. Carl Daub und Friedrich Creuzer. Frankfurt \& Heidelberg 1805. I, 403-461
[-] Mahomed, der Prophet von Mekka. Poetische Fragmente von Tian [Pseud.]. Franlffurt 1805. 45-221

[-] Nikator. Eine dramatische Skizze in drei Acten von Tian [Pseud.]. Taschenbuch fiir das Jahr 1806. Der Liebe und Freundschaft gewidmet. Frankfurt [1806?]. 85-120

- Der Schatten eines Traumes. Gedichte, Prosa, Briefe, Zeugnisse von den Zeitgenossen. Hg. Christa Wolf. Darmstadt/Neuwied 1981

[-] Udobla. In zwei Acten. Von Tian [Pseud.]. Studien. Hg. Carl Daub und Friedrich Creuzer: Frankfurt \& Heidelberg 1805. I, 363-40

Günther, M[aria]. Die beiden Hausärzte. Lustspiel in 4 Aufzügen von M. Günther. Schwerin 1889

- Dilettanten und Künstler. Lustspiel in 4 Aufzügen von M. Günther. Schwerin 1892

- Durch die Karten. Lustspiel in 1 Akt von Maria Günther, Verfasserin von „Mama muß beirathen!" Berlin 1877

- Sammelfieber, Lustspiel in vier Aufzügen von M. Günther. Schwerin 1887

- Schneeweißchen und Rosenroth. Marchen mit Gesang und Tanz in drei Akten frei nach dem Grimmschen Märchen. Musik von Karl Mengewein. Schwerin 1888

- Theaterstücke. Berlin 1892.

[Enthält: Dilettanten und Künstler. Die beiden Hausdrzte. Sammelfieber. Schneeweißchen und Rosenroth. Durch die Karten. Sep. Pag.]

- und Leopold Günther. Der neue Stiftsarzt. Lustspiel in vier Aufzügen. Berlin, o. J.

Günzel, Klaus. Romantikerschicksale. Gestalten einer Epoche. München 1988

Guthke, Karl S. Das deutsche bïrgerliche Trauerspiel. Stuttgart: 2. Aufl. 1976

Häntzschel, Günter. „Annette von Droste-Hülshoff.“ Zur Literatur der Restaurationsepoche 1815-1848. Forschungsreferate und Aufsätze. Hg. Jost Hermand und Manfred Windfulır. Stuttgart 1970. 151-201

- John Ormrod und Karl N. Renner, Hg. Zur Sozialseschichte der deutschen Literatur von der Aufklärung bis zur Jabrbundertwende. Einzelstudien. Tübingen 1985

Hagemann, Carl. Aufgaben des modernen Theaters. Berlin \& Leipzig, o. J.

- Wilhelmine Schröder-Devrient. Wiesbaden 1947

Hamberger, Georg Christoph und Johann Georg Meusel. Das gelehrte Teutscbland oder Lexikon der jetzt lebenden teutschen Schriftsteller. 5. Aufl, 23 Bde. Lemgo 1796-1834. Reprografischer Nachdruck Hildesheim 1965-6

Hamilton, Edith. Mythology. New York \& Scarborough, Ontario 1969

Hanstein, Adalbert von. Die Frauen in der Geschichte des deutschen Geisteslebens des 18. und 19. Jahrhunderts. Leipzig, o. J. [1900? 1908?]

- „Frauenmoral und Herrenhalbheit. Offenes Schreiben an Dr. Käthe Schirmacher Verfasserin der Schrift: ,Herrenmoral und Frauenhalbheit'." Fragen des öffentlichen Lebens. Hg. Karl Schneidt und Dr. jur. Richard Wrede. Heft 6. Berlin 1896

[Harboe, Christine von]. Juliane. Ein Lustspiel in drei Aufzügen. Von dem Verfasser des beimlichen Gerichts [Pseud.]. Berlin 1794

Harris, Edward P. „From Outcast to Ideal: The Image of the Actress in EighteenthCentury Germany." German Quarterly 54 (1981), 177-87

Harrison, Robert Pogue. The Body of Beatrice. Baltimore \& London 1988 
Hartl-Mitius, [Philomene]. Bühnengeschichten von Hartl-Mitius. Dresden \& Leipzig 1901

- Theateriypen. 3 Bde. in 1. Leipzig 1887

Hausen, Karin. „Die Polarisierung der ,Geschlechtscharaktere - Eine Spiegelung der Dissoziation von Erwerbs- und Familienleben." Sozialgeschichte der Familie in der Neuzeit Europas. Hg. Werner Conze. Stuttgart 1976. 363-393

Heckmann, Hannelore. „Theaterkritik als Unterhaltung. Die Vorreden und Vorspiele der Neuberin." Lessing Yearbook. Bd. 18. Hg. Richard Schade. Detroit 1986. 111127

Hegel, Georg Friedrich Wilhelm. Philosophie des Rechts. Die Vorlesung von 1819/20 in einer Nachschriff. Hg. Dieter Henrich. Frankfurt/M. 1983

Heinrich VIII. von England und Anne Boleyn. The Love Letters of Henry the Eighth to Anne Boleyn: And Two Letters from Anne Boleyn to Cardinal Wolsey: With Her Last Letter to Henry the Eighth, and the King's Love Letter to Jane Seymour. Hg. Ladbroke Black. London 1933

Heller, Otto. "Women Writers of the Nineteenth Century." Studies in Modern German Literature. Sudermann, Hauptmann, Women Writers of the Nineteenth Century. Boston, New York, Chicago, London 1905. 230-296

Helvig, Amalie von. Die Schwestern von Lesbos. Die Tageszeiten. Die Schwestern auf Corcyra. Von Amalie von Hellwig, geb. von Imbof. Stockholm \& Upsala 1818

Henel, Heinrich. „Annette von Droste-Hülshoff." Festschrift für Bernhard Blume. Aufsätze zur deutschen und europäischen Literatur. Hg. Egon Schwarz, Hunter Hannum und Edgar Lohner. Göttingen 1967. 146-72

Henrich-Wilhelmi, Hedwig. Das Verhaltnis des Freidenkertums zur sozialen Frage. Leipzig 192-?.

- Vortridge. (Gehalten in Amerika in den Jahren 1887-1889). Milwaukee, Wis. 1889

Herloßsohn, K., H. Marggraff u. a., Hg. Allgemeines Theater-Lexikon oder Encyklopädie alles Wissenswerthen für Bühnenkïnstler, Dilettanten und Theaterfreunde unter Mitwirkung der sachkundigsten Schriftsteller Deutschlands. Neue Ausgabe. 7 Bde. in 3. Altenburg \& Leipzig 1846

Hermand, Jost und Manfred Windfuhr, Hg. Zur Literatur der Restaurationsepoche 1815-1848. Forschungsreferate und Aufsattze. Stuttgart 1970

Hes, Else. Charlotte Birch-Pfeiffer als Dramatikerin - ein Beitrag zur Theatergeschichte des 19. Jahrhunderts. Stuttgart 1914

Heselhaus, Clemens. Annette von Droste-Hülshoff. Werk und Leben. Düsseldorf 1971

Hettner, Hermann. Das moderne Drama. Aesthetische Untersuchungen. Hg. Paul Alfred Merbach. Berlin \& Leipzig 1924

Hetmann, Frederik. Die Frauen zum Beispiel. Die Lebensgeschichte der Simone Weil, Isabel Burton und Karoline von Günderrode. Weinheim \& Basel 1980

Hildebrandt, Irma. Vom Eintritt der Frau in die Literatur. Schreibend das Leben bewàltigen. München 1983

Hille, Curt. Aristophanes und die politische Komödie des 19. Jahrhunderts. Diss. Breslau. Leipzig 1907
- Die deutsche Komödie unter der Einwirkung des Aristophanes. Ein Beitrag zur vergleichenden Literaturgeschichte. Leipzig 1907

Hiller, C., Hg. Theater-Almanach der Königl. Haupt- und Residenz-Stadt Königsberg vom Jahre 1821. Königsberg 1822

Hillern, Wilhelmine von. Guten Abend. Dramatischer Scherz in 1 Akt. Berlin [1872]

Hippel, Theodor Gottlieb von. Über die bürgerliche Verbesserung der Weiber. Nachwort von Ralph-Rainer Wuthenow. Frankfurt/M. 1977

- Über die Ehe. Hg. Ewald Silvester [d. i. H. K. Heide]. Leipzig 1911

Hirschberg, Leopold. Der Taschengoedeke. Fotomechanischer Nachdruck, durchgesehen und erginzzt von Elisabeth Friedrichs. Stuttgart 1961

Hölder, Luise. Neues Kinder-Theater zur Unterhaltung und Belehrung durch Beispiele. 2 Bde. Nürnberg 1821-2.

[Enthält: I: Die Neugierige, 9-48. Die bestraften Wildfange, 49-86. Das Vogelschießen, 87-144. II: Der Zauberspiegel, 5-38. Der ungezogene Knabe, oder Beispiel einer schlechten Erziehung, 39-99. Was Hänschen nicht lernt, lernt Hans nimmermehr, 101 33. Brigitte oder Sie fallt mit der Thür zum Haus hinein, 135-59.]

Hof, Walter. Wo sich der Weg im Kreise schließt. Goethe und Charlotte von Stein. Stuttgart 1957

Hoff, Dagmar von. „Dramatische Weiblichkeitsmuster zur Zeit der Französischen Revolution: Dramen von deutschsprachigen Autorinnen um 1800.“ Die Marseillaise der Wciber: Frauen, die Französische Revolution und ihre Rezeption. Hg. Inge Stephan und Sigrid Weigel. Hamburg 1989. 74-88

- Dramen des Weiblichen. Deutsche Dramatikerinnen um 1800. Opladen 1989

- „Die Inszenierung des ,Fraucnopfers" in Dramen von Autorinnen um 1800." Frauen - Literatur - Politik. Hg. Annegret Pelz et. al. Hamburg 1988. 255-62

Hoffmann, B [ertha]. Ekkehard. Schauspiel in 4 Akten nach V. Scheffel von B. Hoffmann. Dresden, o. J.

- Ja, oder Die Königin der Nacht. Lustspiel in zwei Akten von B. Hoffmann. Halle/ Saale 1892

- Der Strohkranz. Schauspiel in 4 Aufzügen nach einer Idee aus dem Englischen von Berth. Hoffmann. Dresden, o. J.

Hoffmann, Paul F. Friedrich Ludwig Schröder als Dramaturg und Regisseur. Schriften der Gesellschaft fir Theatergeschichte. Bd. 52. Berlin 1939

Hofmann, Kitty. Theater fir Kinder. Von Kitty Hofmann, gebornen von Blei. Kaschau 1824.

[Enthält: Die Angebinde oder Familienliebe, 11-28. Die kleine Aschenbrödel, 29-85. Die Wundergaben, 86-112. Gewinn durch Verlust, 113-79.]

Hollerer, Walter. Zwischen Klassik und Moderne. Lachen und Weinen in der Dichtung einer Übergangszeit. Stuttgart 1958

Hollway-Calthrop, H. C. Petrarch. His Life and Times. London 1907

Holst, Amalia, geb. von Justi. Über die Bestimmung des Weibes zur höheren Geistesbildung. Neuausg. der Ausg. von 1802. 2. Aufl. Zürich 1984

Holtei, Karl von. Vierzig Jabre Lorbeerkranz und Wanderstab. Lebenserinnerungen. Berlin, o. J. 
Homberg, Tinette. Gedanken über Erziehung und Unterricht besonders des weiblichen Geschlechts und über weibliche Erziehungsanstalten. Nebst drei Anhängen. Mitgetheilt und ibren ehemaligen Schülerinnen zugeeignet. Berlin 1845

- Geschichte der schönen Literatur der Deutschen fuir Frauen. Von T. Homberg. Düsseldorf 1853

Homer. The Iliad of Homer. Übers. und hg. Richmond Lattimore. Chicago \& London 1967

- Odyssee. Nach der Übersetzung von Heinrich Voß. Paderborn, o. J.

Honegger, Claudia und Bettina Heintz, Hg. Listen der Obnmacht. Zur Sozialgeschichte weiblicher Widerstandsformen. Frankfurt/M. 1984

Hope, ?. The First Divorce of Henry VIII. As Told in the State Papers. By Mrs. Hope. London 1894

Horch, Hans Otto und Georg-Michael Schulz. Das Wunderbare und die Poetik der Frühaufklärung. Gottsched und die Schweizer. Darmstadt 1988

Huard, M. Adolphe. Mémoires sur Charlotte Corday. D'apres des Documentes authenthiques et inédits. Paris 1866

Huber, Christiane Friederike. Cleveland dritter Theil, oder: Die redliche Untreu. Ein Trauerspiel in fünf Aufzügen. Von Einer unbekannten Hand in Teutsche Verse gebracht, und heraus gegeben von Christiana Friderica Huberin. Wien 1756

Huber, Therese. Briefe der Therese Huber an Caroline Pichler. Hg. Ludwig Geiger. Jabrbuch der Grillparzer-Gesellschaft XVII (1907). 190-291

[-] Du und Sie. Ein Lustspiel in drey Aufzügen, bearbeitet von L. F. Huber [Pseud.]. Sammlung deutscher Lustspiele. Bd. 36. Grätz 1798

[-] Eitelkeit und Liebe. Ein Lustspiel in drei Aufzügen, nach dem Französischen bearbeitet von L. F. Huber [Pseud.]. Neue Sammlung deutscher Schauspiele. Bd 28. Grätz 1798

[-] Emilie, oder Die Spieler. Ein Lustspiel in fünf Aufzügen, nach dem Französischen des Montesquiou, [sic] bearbeitet von L. F. Huber [Pseud.]. Neue Sammlung deutscher Schauspiele. Bd. 39. Grätz 1799

Hüffer, Hermann. Annette von Droste-Hülshoff und ibre Werke. Vornehmlich nach dem literarischen Nachlaß und ungedruckten Briefen der Dichterin. 3. Aufl. Gotha 1911

Hugo, Victor. The Hunchback of Notre Dame. Übers. Walter J. Cobb. New York 1965

Hume, Martin. The Wives of Henry the Eighth and the Parts They Played in History. New York, o. J.

Ibsen, Henrik. Henrik Ibsens Sämtliche Werke in deutscher Sprache. 9 Bde. Hg. Georg Brandes, Julius Elias und Paul Schlenther. Übers. Christian Morgenstern, Emma Klingenfeld und Max Bamberger. Berlin, o. J.

- Nordische Heerfahrt. Schauspiel in vier Aufzügen von Henrik Ibsen. Übers. M[arie] von Borch. Leipzig 1890

Iffland, August Wilhelm. August Wilhelm Ifflands Briefe an seine Schwester Louise und andere Verwandte 1772-1814. Hg. Ludwig Geiger. Schriften der Gesellschaft fur Theatergeschichte. Bd. 5. Berlin·1904
- A.W. Ifflands Briefe meist an seine Schwester nebst anderen Aktenstücken und einem ungedruckten Drama. Hg. Ludwig Geiger. Schriften der Gesellschaft für Theatergeschichte. Bd. 6. Berlin 1905

- Fragmente über Menschendarstellung auf den deutschen Bühnen. Gotha 1785

- Ueber meine theatralische Laufbahn. Hg. Hugo Holstein, 1885. Heilbronn: 1886. Nachdruck: Nendeln/Liechtenstein: Kraus Reprint, 1968

- Theorie der Schauspielkunst fir ausübende Künstler und Kunstfreunde. 2 Bde. Berlin 1815

- und Johann Gottfried Seume. Über Schauspieler und Schauspielkunst. Ausgewählte Abhandlungen. Nachwort, Anmerkungen und Bibliographie von Kurt Böwe. Dresden 1954

Immermann, Karl. Werke in fünf Bänden. Hg. Benno von Wiese. Frankfurt/M. 1971-7 Ives, E. W. Anne Boleyn. Oxford \& New York 1986

James, G. P. R., Hg. Memoirs of Celebrated Women. 2 Bde. London 1837

Jansen, Lena. Karoline Pichlers Schaffen und Weltanschaung im Rabmen ibrer Zeit. Graz 1936

Jördens, Karl Heinrich. Lexikon der deutschen Dichter und Prosaisten. 6 Bde. Leipzig 1806-11

Joeres, Ruth-Ellen B. "The Ambiguous World of Hedwig Dohm.“ Gestaltet und Gestaltend. Frauen in der deutschen Literatur. Hg. Marianne Burkhard. Amsterdam 1980 255-76

- „Die Nebensächlichen. Selbstbehauptung durch Protest in den Schriften deutscher Schriftstellerinnen im 19. Jahrhundert." Frauensprache - Frauenliteratur? Für und Wider einer Psychoanalyse literarischer Werke. Hg. Inge Stephan und Carl Pietzcker. Tübingen 1986. 68-72

- und Marianne Burkhard, $\mathrm{Hg}$. Out of Line/Ausgefallen: The Paradox of Morality in the Writings of Nineteenth-Century German Women. Amsterdam 1989

- und Mary Jo Maynes, Hg. German Women in the Eighteenth and Nineteenth Centuries. A Social and Literary History. Bloomington, IN 1986

Kafitz, Dieter. Grundzige einer Geschichte des deutschen Dramas von Lessing bis zum Naturalismus. 2 Bde. Königstein/Ts. 1982

Kahn-Wallerstein, Carmen. Die Frau im Schatten. Schillers Schwägerin Karoline von Wolzogen. Bern \& München 1970

Kapp, Julius. Richard Wagner und die Frauen. Eine erotische Biographie. 1.-6. Aufl. Berlin 1912

Kastinger Riley, Helene M. „Zwischen den Welten. Ambivalenz und Existentialproblematik im Werk Caroline von Günderrodes." Die weibliche Muse. Sechs Essays über künstlerisch schaffende Frauen der Goethezeit. Columbia, S. C. 1986. 91-119

Katharina II. Erinnerungen der Kaiserin Katharina II. Von ihr selbst geschrieben. Nach Alexander Herzens Ausgabe neu hg. von G. Kuntze. Mit [...] einem Nachtrag aus den Erinnerungen der Fürstin Daschkoff. 12. Aufl. Stuttgart, o. J.

[-] Der Familienzwist, durch falsche Warnung und Argwohn. Ein Lustspiel in fuinf Aufzïgen. Von I[hrer]. K[aiserlichen]. M[ajestät]. d[er]. K[aiserin]. a[ller]. R[eussen]. Aus dem Russischen übersetzt. Berlin \& Stettin 1798 
Katharina II. und ibre Denkwürdigkeiten. München 1861

Katharina II. von Rußland. O. O., o. J. [Angaben aus: National Union Catalog. Pre1956 Imprints. Bd. 290. 389]

Katharine II. vor dem Richterstuble der Menschbeit. Größtentheils Geschichte. St. Petersburg 1797

Kayser, Gottlob. Vollständiges Bücherlexikon. Schauspiele. Leipzig 1836

Kempner, Friederike. Berenize. Tragödie in fünf Aufzügen und in Jamben. 2. Aufl. Leipzig 1865

Kesten, Hermann. „Albrecht Dürer, der Autor." Revolutionäre mit Geduld. Percha 1973. 43-74

Kiesel, Helmuth und Paul Münch. Gesellschaft und Literatur im 18. Jahrbundert. Voraussetzungen und Entstebung des literarischen Markts in Deutschland. München 1977

Kilian, Eugen, Hg. Beiträge zur Geschichte des Karlsruher Hoftheaters unter Eduard Devrient. Statistik des Repertoires nebst einem Auszug aus Eduard Devrients handschriftlichen Aufzeichnungen. Karlsruhe 1893

Kinder, Hermann, Hg. Bürgers unglückliche Liebe: Die Ehestandsgeschichte von Elise Hahn und Gottfried August Bürger. Frankfurt/M. 1981

Kindermann, Heinz. Das Burgtheater. Erbe und Sendung eines Nationaltheaters. Wien \& Leipzig 1939

- Hebbel und das Wiener Theater seiner Zeit. Wien 1943

- Theatergeschichte der Goethezeit. Wien 1948

Klein, Wilhelm. Der Preußische Staat und das Theater im Jahre 1848. Ein Beitrag zur Geschichte der Nationaltheateridee. Schriften der Gesellschaft für Theatergeschichte. Bd. 33. Berlin 1924

Klingemann, August, Hg. Beiträge zur Deutschen Schaubühne. Braunschweig 1824

- Kunst und Natur. Blütter aus meinem Reisebuche. Neuc Aufl. 3 Bde. Braunschweig 1823-8

Klokow, Ida. Die Frau in der Geschichte. Leben und Charakter der Frauen aller Zeiten, sowie deren Einfluß auf die Kulturgeschichte des Menschengeschlechts. Mitgabe für Frauen und Töchter gebildeter Stände. Leipzig \& Berlin 1881

Knevels, Wilhelm. Das moderne Drama. Gesicht unserer Zeit. Darstellung - Deutung Werbung. 2. Aufl. Braunschweig 1930

Knudsen, Hans. Methodik der Theaterwissenschaft. Stuttgart, Berlin, Köln, Mainz 1971

Köpke, Wulf. „Immer noch im Schatten der Männer? Therese Huber als Schriftstellerin." Der Weltumsegler und seine Freunde. Georg Forster als gesellschaftlicher Schriftsteller der Goethezeit. Hg. Detlef Rasmussen. Tübingen 1988. 116-132

Koopmann, Helmut. Freiheitssonne und Revolutionsgewitter. Reflexe der Französischen Revolution im literarischen Deutschland zwischen 1789 und 1840. Tübingen 1989

Kosch, Wilhelm. Deutsches Literatur-Lexikon; biographisch-bibliographisches Handbuch. 3. Aufl. 12 Bde. Stuttgart 1968-1990

- Deutsches Literatur-Lexikon; biographisch-bibliographisches Handbuch. 2. Aufl. 4 Bde. Bern 1949-1958
- Deutsches Theater-Lexikon; biographisches und bibliographisches Handbuch. Klagenfurt $1951 \mathrm{f}$.

Kraft, [Anna Friederike]. Saul. Biblisches Drama in fuinf Aufzuigen von Werner Kraft [Pseud.]. Brandenburg a. H., o. J.

Krause, Markus. Das Trivialdrama der Goethezeit 1780-1805. Produktion und Rezeption. Bonn 1982

Kreowski, Ernst, und Eduard Fuchs. Richard Wagner in der Karikatur. Berlin 1907

Krickeberg, Sophie Friederikc. Die Ehrenrettung. Schauspiel in zwei Aufzügen. Frei nach dem Französischen bearbeitet von Friederike Krickeberg geb. Koch. Almanach fiir Freunde der Schauspielkunst auf das Jahr 1836. Hg. L. Wolff. Berlin 1837. 140-193

Krones, Therese. Sylphide, das See-Frdulein. Romantisch-komisches Zauberspiel mit Gesang in zwei Aufzügen. Erstdruck mit einer Abhandlung über Therese Krones und ihre dramatischen Arbeiten von Michael Maria Rabenlechner. Wien 1947

Krukenberg, Elsbeth. Die Frau in der Familie. Leipzig 1910

- Die Frauenbewegung, ihre Ziele und ihre Bedeutung: Tübingen 1905

- Úber das Eindringen der Frau in männliche Berufe. Essen-Ruhr 1906

Krull, Edith. Das Wirken der Frau im frühen deutschen Zeitschriftenwesen. Diss. Berlin 1939

Kühn, Paul. Die Frauen um Goethe. Weimarer Interieurs. 2 Bde. Leipzig 1911-12

Küstner, Karl Theodor von. Rückblick auf das Leipziger Stadtheater. Ein Beitrag zur Geschichte des Leipziger Theaters, nebst allgemeinen Bemerkungen über die Bühnenleitung in artistischer, wie finanzieller Hinsicht. Leipzig 1830

- Taschen- und Handbuch für Theater-Statistik. 2. Aufl. Leipzig 1857

- Vierunddreißig Jahre meiner Theaterleitung in Leipzig, Darmstadt, München und Berlin. Zur Geschichte und Statistik des Theaters. Leipzig 1853

Kudrun. Hg. Karl Bartsch. 5. Aufl. Wiesbaden 1980

Kuhn, Annette und Gerhard Schneider, Hg. Frauen in der Geschichte. Bd. 1: Frauenrechte und die gesellschaftliche Arbeit der Frauen im Wandel. Fachwissenschafiliche und fachdidaktische Studien zur Geschichte der Frauen. 3. Aufl. Düsseldorf 1984

Laclos, Choderlos de. Des femmes et de leur éducation. EEuvres completes. Hg. Laurent Versini. Dijon 1979. 387-443

Laddey, Emma. Aus dem Reiche der Frau. Bilder aus dem Frauenleben. Stuttgart 1873

Lange, Helene. Higher Education of Women in Europe. Trans. and Accompanied By Cornparative Statistics By L. R. Klemm. New York 1890

- und Gertrud Bäumer, Hg. Handbuch der Frauenbewegung. 5 Bde. Berlin 1901-6. Nachdruck Weinheim \& Basel 1980

Lange, Victor. The Classical Age of German Literature, 1740-1815. New York 1982

Laube, Heinrich. „Briefe über das deutsche Theater.“ Heinrich Laubes dramaturgische Schriften. 4 Bde. in 1. Hg. Heinrich Hubert Houben. Leipzig, o. J. I, 15-62

- Das Burgtheater, Ein Beitrag zur Deutschen Theater-Geschichte. Leipzig 1868

- Das Burgtheater von 1848-1867. Separat-Abdruck aus der "Neuen Freien Presse“. Wien 1867

- Erinnerungen. Heinrich Laubes ausgewählte. Werke in zehn Bänden. Bd. 8 (18101840) \& 9 (1841-1881). Leipzig, o. J. 
- Georges Sand's Frauenbilder. Brüssel 1845

- Moderne Charakteristiken. 2 Bde. Mannheim 1835

- Das norddeutsche Theater. Ein neuer Beitrag zur Deutschen Theatergeschichte. Leipzig 1872

- Theaterkritiken und dramaturgische Aufsätze. Hg. Alexander von Weilen. 2 Bde. Schriften der Gesellschaft firr Theatergeschichte. Bd. 7 \& 8. Berlin 1906

- Das Wiener Stadt-Theater. Leipzig 1875

- [und Hermann Goja], Hg. Das Theaterbüchlein. Wien 1946

Lavater-Sloman, Mary. Einsamkeit. Das Leben der Annette von Droste-Hülshoff. Zürich 1961

Lehms, Georg Christian. Teutschlands Galante Poetinnen. Mit ibren sinnreichen und netten Proben; Nebst einem Anhang Auslandischer Dames, So sich gleichfalls durch Schöne Poesien Bey der curieusen Welt bekannt gemacht, und einer Vorrede. Daß das Weibliche Geschlecht so geschickt zum Studieren als das Männliche. 2 Bde. Frankfurt/M. 1715

Leporin, Dorothea Christina. Gründliche Untersuchung der Ursachen, die das Weibliche Geschlecht vom Studiren abbalten, Darin deren Unerheblichkeit gezeiget, und wie möglich, nöthig und nützlich es sey, Daß dieses Geschlecht der Gelahrtheit sich befleisse, umständlich dargeleget wird. Nebst einer Vorrede ihres Vaters D. Christiani Polycarpi Leporin, Med. Pract. in Quedlinburg. Berlin 1742. Nachdruck mit einem Nachwort von Gerda Rechenberg; Hildesheim/New York 1977

Lessing, Gotthold Ephraim. Werke. 3 Bde. Hg. Kurt Wölfel. Frankfurt/M. 1967

[Levi, Elise]. Durch die Intendanz. Preislustspiel in füf Aufzügen von E. Henle. Leipzig, o. J.

- Der Erbonkel. Lustspiel in fuinf Aufzuigen von E[lise] Henle. Leipzig [1889?]

Levine, Mortimer. The Early Elizabethan Succession Question 1558-1568. Stanford 1966

Lewald, Fanny. Erinnerungen aus dem Jahre 1848. 2 Bde. in 1. Braunschweig 1850

- Meine Lebensgeschichte. Hg. Gisela Brinker-Gabler. Frankfurt/M. 1980

- Osterbriefe fur die Frauen. Berlin 1863

Löhn-Siegel, [Maria] Anna. Aus der alten Coulissenwelt. Mein Engagement am Leipziger und Magdeburger Stadtheater in den Jabren 1847 und 1848. Leipzig 1883

- Theatererinnerungen und Vermischtes von Anna Löhn. Leipzig 1861

- Vom Oldenburger Hoftheater zum Dresdner. Letzte Theatertagebuchblatter. Oldenburg [1885]

Löwen, Johann Friedrich. Geschichte des deutschen Theaters (1766) und Flugschriften über das Hamburger Nationaltheater (1766 und 1767). Hg. Heinrich Stümcke. Berlin $\mathrm{o} . \mathrm{J}$.

Lohmann, Friederike. Der blinde Harfner. Ein Schauspiel in vier Aufzügen. Nach Veit Webers [Pseud.] Sagen der Vorzeit firr Theater bearbeitet. Theatralische Sammlung. Bd. 32. Wien 1792. 91-181

Longford, Elizabeth. The Life of Byron. Boston \& Toronto 1976

Lothar, Rudolph. Das Wiener Burgtheater. Leipzig, Berlin, Wien 1899
Madland, Helga Stipa, „An Introduction to the Works and Life of Marianne Ehrmann (1755-95): Writer, Editor, Journalist." Lessing Yearbook. Bd. 21. Hg. Richard Schade: Detroit 1989. 171-196

Maier, Elisa. Leitfaden zur Geschichte der deutschen Litteratur, bearbeitet für höhere Töchterschulen, weibliche Erziehungsanstalten und zum Selbstunterrichte. 6. Aufl. Dresden 1881 Marchand, Leslie A. Byron. A Biography. 3 Bde. New York 1957

- Hg. Lord Byron. Selected Letters and Journals. Cambridge, Mass. 1982

Mare, Margaret. Annette von Droste-Hülshoff. University of Nebraska Press, 1965

Marshall, Alice Kahler. Pen Names of Women Writers from 1600 to the Present. A Compendium of the Literary Identities of 2650 Women Novelists, Playwrights, Poets, Diarists, Journalists and Miscellaneous Writers. Camp Hill, PA 1985

Martens, Wolfgang. Die Botschaft der Tugend. Die Aufklärung im Spiegel der deutschen Moralischen Wochenschriften. Stuttgart 1968

- Literatur und Frömmigkeit in der Zeit der frïhen Aufklärung. Tübingen 1989

Martersteig, Max. Das deutsche Theater im neunzehnten Jahrhundert. Eine kulturgeschichtliche Darstellung. 2. Aufl. Leipzig 1924

- Die ethische Aufgabe der Schaubïhne. Eine Schillerrede. Leipzig 1912

Martinengo Cesaresco, Evelyn. Lombard Studies. London 1902

Martini, Fritz. Geschichte im Drama - Drama in der Geschichte. Spätbarock, Sturm und Drang, Klassik, Frührealismus. Stuttgart 1979

Mattenklott, Gert. Melancholie in der Dramatik des Sturm und Drang. Stuttgart 1968

Matthews, Brander. A Book about the Theater. New York 1916

Maurer, Doris. Annette von Droste-Hülshoff. Ein Leben zwischen Auflehnung und Gehorsam. Bonn 1982

Maurois, André. Byron. Übers. Hamish Miles. New York 1930

- Lord Byron et le Démon de la Tendresse. Paris 1925

May, Gita. Madame Roland and the Age of Revolution. New York \& London 1970

Mayer, F. Arnold. "Zensurakten aus Baden bei Wien." Archiv fur Theatergeschichte. Hg. Hans Devrient. 2 Bde. Berlin 1904-5. I, 18-29

Mayne, Ethel Colburn. The Life and Letters of Anne Isabella Lady Noel Byron. From Unpublished Papers. New York 1929

Mazade-Percin, Charles de. Deux Femmes de la Révolution. Paris 1866

McInnes, Edward. Das deutsche Drama des 19. Jabrhunderts. Berlin 1983

Meise, Helga. Die Unschuld und die Schrift. Deutsche Frauenromane im 18. Jahrhundert. Berlin \& Marburg 1983

Melchior-Bonnet, Bernardine. Charlotte Corday. Paris 1972

Melitz, Leo, Hg. Die Theatersticke der Weltliteratur ibrem Inbalte nach wiedergegeben. Hg. mit einer Einleitung zur Geschichte der dramatischen Literatur. 3. Aufl. 2 Bde. Berlin, o. J.

Merget, A. Geschichte der deutschen Jugendlitteratur. 3. Aufl. Berlin 1882

Meusel, Johann Georg. Lexikon der vom Jahr 1750 bis 1800 verstorbenen teutschen Schriftsteller. 15 Bde. Leipzig 1802-16. Reprografischer Nachdruck Hildesheim 1967-8 
Meyer, Reinhart, Hg. Bibliographica dramatica et dramaticorum, Kommentierte Bibliographie der im ehemaligen deutschen Reichsgebiet gedruckten und gespielten Dramen des 18. Jabrhunderts nebst deren Bearbeitungen und Übersetzungen und ibrer Rezeption bis in die Gegenwart. Tübingen 1986

- Das deutsche Drama des achtzehnten Jahrbunderts in Einzeldrucken. Das Repertoire bis 1755. München 1981

- Das deutsche Trauerspiel des 18. Jahrbunderts, Eine Bibliographie. Mit ca. 1250 Titeln, einer Einleitung sowie Verfasser- und Stichwortverzeichnis. München 1977

- „Von der Wanderbühne zum Hof- und Nationaltheater." Deutsche Literatur bis zur Französischen Revolution 1680-1789. Hg. Rolf Grimminger. München 1980. 186216

Meyers Konversations-Lexikon. Eine Encyklopädie des allgemeinen Wissens. 4. Aufl. 18 Bde. Leipzig 1888. Bd. 4

Möhrmann, Renate. Die andere Frau. Emanzipationsansätze deutscher Schriftstellerinnen im Vorfeld der Achtundvierziger Revolution. Stuttgart 1977

- Hg. Frauenemanzipation im deutschen Vormärz. Texte und Dokumente. Stuttgart 1978

- "Gibt es eine feministische Theater-, Film- und Fernsehwissenschaft?" Luise Pusch, Hg., Feminismus. Inspektion der Herrenkuluur. Ein Handbuch. Frankfurt/M. 1983 $82-100$

- „On the Cultural History of the Female Stage Artist. The Actress. Between Prostitution and Representation. "Übers. Patricia McAllister. Forum. A Women's Studies Peri odical 15, 1 (Fall 1989). 1-4

- "The Reading Habits of Women in the Vormärz." German Women in the Nineteenth Century. A Social History. Hg. John C. Fout. New York \& London 1984. 104-17

- Hg. Die Schauspielerin. Zur Kulturgeschichte der weiblichen Bühnenkunst. Franlıfurt/M. 1989

Moore, Thomas. Life of Lord Byron. With His Letters and Journals. 6 Bde. Boston, o. J.

Morgan, Mary E. Annette von Droste-Hiilshoff. A Biography. New York 1984

Morrison, N. Brysson. The Private Life of Henry VIII. New York 1964

Motekat, Helmut. Das zeitgenössische deutsche Drama. Einfiibrung und kritische Analyse. Stuttgart 1977

Motte-Fouqué, Caroline de la. Die Frauen in der großen Welt. Bildungsbuch bei'm Eintritt in das gesellige Leben. Berlin 1826

[Müller, Elisabeth]. Anna von Cleve oder Die Gürtelmagd der Königin. Drama in fünf Aufzügen von E. Meruell [Pseud]. Den Bühnen gegenïber Manuskript. Freiburg i. Bs: 188

Mundt, Theodor. Dramaturgie, oder Theorie und Geschichte der dramatischen Kunst. 2 Bde. in 1 . Berlin 1848

National Union Catalog. Pre-1956 Imprints. A Cumulative Author List Representing Library of Congress Printed Cards and Titles Reported By Other American Libraries. Compiled and Edited With the Cooperation of the Library of Congress and the National Union Catalog Subcommittee of the Committee of the Resources Cornmittee of the
Resources and Technical Services Division, American Library Association. 754 Bde Mansell 1968-81

Naunton, Robert. Fragmenta Regalia or Observations on Queen Elizabeth, Her Times \& Favorites. Hg. John S. Cerovski. Washington 1985

Nettesheim, Josefine. Die geistige Welt der Dichterin Annette Droste zu Hülshoff. Münster 1967

Neuber, Friederike Karoline. Ein deutsches Vorspiel (1734). Zur Feier ibres 200. Geburtstags 9. März 1897, mit einem Verzeichnis ihrer Dichtungen. Hg. Arthur Richter: Deutsche Litteraturdenkmale des 18. und 19. Jahrhunderts. Bd. 63, Neue Folge 13 Leipzig 1897. Neudruck Nendeln/Liechtenstein 1968. 1-28

- Das Schäfer Fest oder die Herbstfreude. Ein deutsches Lustspiel in Versen. Wien 1754 Nachdruck: Das deutsche Drama des 18. Jahrhunderts in Einzeldrucken. Hg. Reinhart Meyer, Bd. 5: Das Lustspiel 2. München 1981. 449-586

- Das Schäferfest oder Die Herbstfreude. Ein deutsches Lustspiel in Versen. Gottscheds Le bens- und Kunstreform in den zwanziger und dreißiger Jahren. Gottsched, Breitinger, die Gottschedin, die Neuberin. Hg. F. Brüggemann. Leipzig 1935. 216-294

Neunteufel-Metzler, Annemarie. Karoline Pichler und die Geschichte ibrer Zeit. Diss. [maschr.]. Wien 1949

Das Nibelungenlied. Hg. Helmut de Boor. 21. Aufl. Wiesbaden 1979

Niederle, Berta. Charlotte Wolter. Leben, Werden und Briefe der großen Tragödin. Berlin, Wien, Leipzig 1948

Nigg, Walter. Wallfahrt zur Dichtung. Zürich, Stuttgart 1966

O'Faolain, Julia, und Lauro Martines, $\mathrm{Hg}$. Not in God's Image. Women in History from the Greeks to the Victorians. New York, Hagerstown, San Francisco, London 1973

Origo, Iris. Allegra. London 1935

Otto[-Peters], Louise. Einflußreiche Frauen aus dem Volke, geschildert von Louise Otto. Leipzig 1869

- Das erste Vierteljahrhundert des Allgemeinen deutschen Frauenvereins gegründet am 18. Oktober 1865 in Leipzig. Auf Grund der Protokolle. Leipzig 1890

Paldamus, F[riedrich] C[hristian]. Das deutsche Theater der Gegenwart. Eïn Beitrag zur Wiirdigung der Zustände. 2 Bde. in 1. Mainz 1856-7

Panofsky, Erwin. The Life and Art of Albrecht Dürer. Princeton, N. J. 1955

Pataky, Sophie, Hg. Lexikon deutscher Frauen der Feder. Eine Zusammenstellung der seit dem Jahre 1840 erschienenen Werke weiblicher Autoren, nebst Biographien der lebenden und einem Verzeichnis der Pseudonyme. 2 Bde. Berlin 1898. Nachdruck Bern 1971

Paul, John E. Catherine of Aragon and Her Friends. New York 1966

Paullini, Christian Franz. Das Hoch- und Woblgelahrte Teutsche Frauen-Zimmer. Nochmahls mit mercklichem Zusatz vorgestellet. Frankfurt \& Leipzig 1705

- Philosophische Lust-Stunden; oder, Allerhand schöne, anmutige, rare, so nützlich-als erbauliche Politische, Physicalische, Historische $u$. d. Geist- und Weltliche Curiositäten. Männiglich zur beliebigen Ergötzung woblmeinend mitgetheilet. Frankfurt \& Leipzig 1709 
Paulsen, Wolfgang, Hg. Die Frau als Heldin und Autorin. Neue kritische Ansätze zur deutschen Literatur. Bern \& München 1979

[Paulus, Karoline]. Semiramis. Ein Trauerspiel von Voltaire in Jamben ilbersetzt. Von E. H. [Pseud.]. Mit: Natalie Percy. Eine Novelle. Frey bearbeitet nach den Confessions des Herrn von Pr, von E. H. [Pseud.]. Nürnberg 1811

[-] Briefe einer Freundin Goethes und Schillers aus Heidelberg. Hg. J. Miner. Wien 1888. 673-687

Pernet, Hedwig Luise von. Versuch in Fabeln und Erzählungen, nebst einem komischen Trauerspiel in Versen. Graz 1770.

[Enthält: Seline, ein komisches Trawerspiel, 65-174 ]

Petsch, Robert. Wesen und Formen des Dramas. Halle/Saale 1945

Petersen, Susanne. Marktweiber und Amazonen. Frauen in der Französischen Revolution. Dokumente, Kommentare, Bilder. Köln 1987

Petrarca, Francesco. For Love of Laura. Poetry of Petrarch. Übers. Marion Shore. Fayetteville 1987

Pfister, Kurt. Frauenschicksale aus acht Jahrhunderten. München 1949

Pfister, Manfred. Das Drama. Theorie und Analyse. München 1977

Pichler, Caroline. Briefe von Caroline Pichler an Therese Huber. Hg. Carl Glossy. Jahrbuch der Grillparzer-Gesellschaft III (1893). 269-365

- Denkwürdigkeiten aus meinem Leben. Mit einer Einleitung und zablreichen Anmerkungen nach dem Erstdruck und der Urschrift. Hg. Emil Karl Blümml. 2. Aufl. 2 Bde. München 1914

- Dramatische Dichtungen. Von Caroline Pichler, gebornen von Greiner. 3 Bde. in 1. Wien \& Leipzig 1829

- Dramatische Dichtungen. 3 Bde. Silmmtliche Werke, von Caroline Pichler, gebornen von Greiner. Neue verbesserte Aufl. Bd. 19-21. Wien 1822.

[Enthält: XIX: Germanicus, 1-154. Wiedersehen, 155-238. Das befreyte Deutschland 239-67. XX: Heinrich von Hohenstauffen, König der Deutschen, 1-154. Mathilde, 155-221. Rudolph von Habsburg, 223-74. XXI: Ferdinand der Zweyte, König von Ungarn und Böbmen, 1-164. Amalie von Mannsfeld, 165-264.]

- Ferdinand der Zweyte, König von Ungarn und Böhmen. Historisches Schauspiel in fünf Aufzügen. Von Caroline Pichler, gebornen von Greiner. Leipzig 1816

- Frauenwürde. Von Caroline Pichler, gebornen von Greiner. 4 Bde. Leipzig 1818

- Prolog zu Heinrich von Hohenstauffen, König der Deutschen, von Caroline Pichler, geb. von Greiner. Bey der zum Vortheile der veruundeten Oesterreichischen Krieger gegebenen Vorstellung dieses Trauerspiels auf dem k. k. Hoftheater nächst der Burg vorgetragen won Mad. Weissenthurn den 27. Oct. 1813. Wien 1813

- Zeitbilder, von Caroline Pichler, gebornen von Greiner. 2 Bde. Wien 1839-41

- Zerstreute Blätter aus meinem Schreibtische. 2 Bde. Wien 1836-43

Pierson, Caroline. Meister Albrecht Dïrer. Dramatisches Gedicht in vier Aufzügen von Caroline Pierson (Leonhardt-Lyser [Pseud.]). 2. Aufl. Stuttgart 1871

Pinoff, Minna. Reform der weiblichen Erziehung als Grundbedingung zur Lösung der socialen Frage der Frauen. Breslau 1867
Plönnies, Luise von. Mariken von Nymwegen. Berlin 1853

Ploetz, H. A. „Ein Lebensbild. Adelgunde Gottsched, geb. Culmus (1713-1762).“ Geistige Arbeit. Zeitung aus der wissenschaftlichen Welt II/15. Hg. G. Lüdtke und H. Sikorski. Berlin \& Leipzig 1935. 12

Plowden, Alison. Marriage With My Kingdom. The Courtships of Elizabeth I. New York 1977

Pope, Alexander, u.a. Neue Sammlung auserlesener Stücke, aus Popens, Eachards, Newtons und anderer Schriften ïbersetzt von Luisen Adelg. Vict. Gottschedinn, geb. Kulmussinn. Leipzig 1749

Prellwitz, Gertrud. Der Kaisertraum. Ein Weihefestspiel. Woltersdorf bei Erkner-Berlin 1916

- Michel Kohlhas. Ein Trauerspiel in 5 Akten. Freiburg i. Br. 1905

- Michel Kohlhas. Ein Trauerspiel in 5 Akten. Oberhof/Thüringer Wald 1922

- Oedipus. Ein Weihefestspiel in 5 Aufzuigen. Woltersdorf bei Erkner-Berlin, o. J.

- Oedipus. Ein Weihefestspiel in 5 Aufzügen. Neuausgabe. Woltersdorf bei Erkner-Berlin 1919

- Oedipus oder Das Ridtsel des Lebens. Tragödie in fünf Akten. Freiburg i. Br. 1898

- Seine Welt. Ein Lustspiel in 5 Akten. Woltersdorf bei Erkner-Berlin [1911?]

- Die Tat! Drama aus den Tagen von Tauroggen. 3 Akte. Woltersdorf bei Erkner-Berlin 1912

- Die Tat! Drama aus den Tagen von Tauroggen. 3 Akte. Oberhof'Thür. Wald 1922

- Zwischen zwei Welten. Eine Weltanschaunng im dramatischen Bilde. Fïnf Akte. Freiburg i. Br. 1901

- Zwischen zwei Welten. Weihefestspiel in füf Aufzuigen. Woltersdorf bei Erkner-Berlin 1899

Prohaszka, Gertrud. Der literarische Salon der Caroline Pichler. Diss. [maschr.]. Wien 1946

Prutz, Robert E. Vorlesungen über die Geschichte des deutschen Theaters. Berlin 1847

Pupini, Therese. Karoline Pichlers Romane. Ein Beitrag zur Geschichte der Unterhaltungsliteratur. Diss. [maschr.]. Wien 1910

Rabenlechner, Michael Maria, „Therese Krones und ihre dramatischen Arbeiten.“ Therese Krones, Sylphide, das See-Fräulein. Romantisch-komisches Zauberspiel mit Gesang in zwei Aufzügen. Erstdruck mit einer Abhandlung über Therese Krones und ibre dramatischen Arbeiten. Wien 1947. 87-120

Raven, M[athilde]. Der Herr Hoffunker. Lustspiel in einern Akt von M. Raven. Berlin, o. J. Recke, Elisa von der. Elisa von der Recke. Hg. Paul Rachel. 2. Aufl. 2 Bde. Leipzig 1902 - Familien-Scenen, oder Entwickelungen auf dem Masquenballe. Schauspiel in vier Aufzügen von Frau Elisa von der Recke, geb. Reichsgriffin von Medem. Zum Besten des Unterstïtzungsfonds fiir junge in Leipzig studirende Griechen. Leipzig 1826

- Herzens-Geschichten einer baltischen Edelfrau. Erinnerungen und Briefe. 4. Aufl. Memoiren-Bibliothek 5. Bd. 14. Stuttgart 1923

- Mein Journal. Elisas neu aufgefundene Tagebücher aus den Jahren 1791 und 1793/95. Hg. Johannes Werner. Leipzig [1927?] 
Reden-Esbeck, Friedr[ich] Joh[ann] von. Caroline Neuber und ihre Zeitgenossen. Ein Beitrag zur deutschen Kultur- und Theatergeschichte. Leipzig 1881. Nachdruck Leipzig 1985

- Deutsches Bühnen-Lexikon. Das Leben und Wirken aller hervorragenden'Bühnen-Leiter und Kiinstler vom Beginn der Schauspielkunst bis zur Gegenwart. Eichstätt \& Stuttgart 1879

Reichardt Stromberg, Mathilde. Frauenrecht und Frauenpflicht. Eine Antwort auf Fanny Lewald's Briefe „Für und wider die Frauen“. 3. Aufl. Leipzig 1883

[Reitzenstein, Marianne Sophie von]. Die seltene Beständigkeit. Ein Lustspiel in zwey Aufziigen, von Mariane Sophie Weikard. Deutsche Schaubithne. Bd. 9. Augsburg 1791. 383-440

„Relation of the Death of the Family of the Cenci." Percy Bysshe Shelley, The Cenci. A Tragedy in Five Acts. Hg. Alfred Forman und H. Buxton Forman. London 1886. 91-107

Remarkable Women of Different Nations and Ages. Boston 1858

Ricci, Corrado. Beatrice Cenci. Übers. Morris Bishop und Henry Longan Stuart. 2 Bde. New York 1925

Richel, Veronica C. The German Stage 1767-1890. A Directory of Playwrights and Plays. New York, Westport, London 1988

- Luise Gottsched. A Reconsideration. Diss. [maschr.]. New Haven, CT 1968

Ridley, Jasper. Elizabeth I.: The Shrewdness of Virtue. New York 1988

Riemer, Eleanor, und John C. Fout, Hg. European Women. A Documentary History 1789-1945. New York 1980

Ringseis, Bettina, Hg. Briefe von Herman und Gisela Grimm an die Schwestern Ringseis. Berlin 1905

Ringseis, Emilie. Die Sibylle von Tibur. Schauspiel in drei Aufzügen. 2. Aufl. Freiburg i. Br. 1896

- Veronika. Schauspiel in 3 Aufzügen. 3. Aufl. München 1859

[Robinson, Therese]. Deutschlands Schriftstellerinnen bis vor hundert :Jahren. Von Talvj [Pseud.]. Historisches Tagebuch. Bd. 32. Leipzig 1861. 1-141

Rötscher, H[einrich] Th[eodor]. Dramaturgische Probleme, Entwickelungen und Kritiken zur Förderung und Belehrung dramatischer Dichter und darstellender Kïnstler. Dresden 1865

- Dramaturgische Skizzen und Kritiken. Berlin 1847

- Dramaturgische und dsthetische Abhandlungen. Hg. Emilie Schröder. Leipzig 1867

- Kritiken und dramaturgische Abhandlungen. Leipzig 1859

- Die Kunst der dramatischen Darstellung. In ibrem organischen Zusammenhange wissenschaftlich entwickelt. 2. Aufl. Leipzig 1864

Roland de la Platière, Marie-Jeanne. Lettres Autographes de Madame Roland, addressées à Bancal-des-Issarts. Hg. Sainte-Beuve. Bruxelles 1836

- Lettres Inédites de Mlle. Phlipon/Mme. Roland adressées aux Demoiselles Cannet, de 1772 à $1780 . \mathrm{Hg}$. Auguste Breuil. 2 Bde. Paris 1841

- Mémoires de Madame Roland. Hg. Cl. Perroud. 2 Bde. Paris 1905
- The Works (Never Before Published) of Jeanne-Marie Phlipon Roland, Wife of the Exminister of the Interior; Containing Her Philosophical and Literary Essays, Written Previous to Her Marriage; Her Correspondence, and Her Travels. To Which are Annexed the Justificative Documents Relative to Her Imprisonment and Condemnation. Hg. L. A. Champagneux. London 1800

- und Jean-Marie Roland. Roland et Marie Phlipon. Lettres d'amour 1777 à 1780 . Hg. Claude Perrout. Paris 1909

Rosa, Angelika. Lebensschicksale einer deutschen Frau im 18. Jahrbundert in eigenhidndigen Briefen. Hg. Victor Kirchner. Magdeburg 1908

Rosenbaum, Heidi. Formen der Familie. Untersuchungen zum Zusammenhang von Familienverhältnissen, Sozialstruktur und sozialem Wandel in der deutschen Gesellschaft des 19. Jabrhunderts. Frankfurt 1982

Round, J. H. The Early Life of Anne Boleyn. A Critical Essay. London 1886

Ruben, Regina. Mathilde Franziska Anneke, die erste grosse deutsche Verfechterin des Frauenstimmrechts. Hamburg [1906]

Rubens, Peter Paul. Die Briefe des Peter Paul Rubens. Úbers. und hg. Otto Zoff. Wien 1918

Rullmann, Wilhelm, Hg. „Karl Moor und seine Genossen nach der Abschiedsszene beim alten Thurm. 'Von Frau von Wallenrodt. 1801." Die Bearbeitungen, Fortsetzungen und Nachabmungen von Schillers „Räubern." Schriften der Gesellschaft fuir Theatergeschichte. Bd. 15. Berlin 1910. 66-72

[Rupp, Victoria von]. Jenny, oder Die Uneigennützigkeit. Ein Drama in zween Aufzügen, von $V^{* * * *}$. v. $R^{*}$. [Pseud.]. Wien 1777

[-] Marianne, oder Der Sieg der Tugend. Ein rührendes Lustspiel in drey Aufzügen. Von Miß Jennys Übersetzerinn [Pseud.]. Frankfurt \& Leipzig 1777

[Sade, Jacques François Paul Aldonce de]. The Life of Petrarch. Collected from Memoires Pour la Vie de Petrarch by Mrs. [Susanna] Dobson [Hg. und Übers.]. 2 Bde. London 1805

Saine, Thomas P. Georg Forster. New York 1972

Sanders, Ruth Hetmanski. „Ein kleiner Umwegc. Das literarische Schaffen der Luise Gottsched." Die Frau von der Reformation zur Romantik. Die Situation der Frau vor dem Hintergrund der Literatur- und Sozialgeschichte. Hg. Barbara Becker-Cantarino, Bonn 1980. 170-94

- The Virtuous Woman in the Comedies of the Early German Enlightenment. Diss. New York 1975

Sangalli, Elisabeth. Weimar. Leipzig 1855

Sasse, Hannah. Friedericke Caroline Neuber, Versuch einer Neuwertung. Diss. Freiburg i Br. Endingen/Kaiserstuhl 1937

Satori-Neumann, Bruno Th. Die Frïhzeit des Weimarischen Hoftheaters unter Goethes Leitung (1791 bis 1798). Nach den Quellen bearbeitet. Schriften der Gesellschaft für Theatergeschichte. Bd. 31. Berlin 1922

Schade, Herbert, Hg. Albrecht Dürer. Kunst einer Zeitenwende. Regensburg 1971

Schaps, Regina. Hysterie und Weiblichkeit. Wissenschaftsmythen über die Frau. Franlffurt/ M. \& New York 1982 
Schebest, Agnese. „Mittheilung über unseren dramatischen Unterticht." H[einrich] Th [eodor] Rötscher, Dramaturgische Probleme, Entwickelungen und Kritiken zur Förderung und Belehrung dramatischer Dichter und darstellender Künstler. Dresden 1865. Heft 3. 45-55

Scheidemann, Uta. Louise von Frangois. Leben und Werk einer deutschen Erzählerin des 19. Jahrhunderts. Frankfurt/M., Bern, New York, Paris 1987

Schelle, Hansjörg, Hg. Christoph Martin Wieland. Nordamerikanische Forschungsbeitrilge zur 250. Wiederkehr seines Geburtstages 1983. Tübingen 1984

Scherr, Johannes. Geschichte der Deutschen Frawen. In drei Büchern nach den Quellen. Leipzig 1860

- Geschichte der Deutschen Frauenwelt. In drei Büchern nach den Quellen. 2. Aufl. 2 Bde. Leipzig 1865

Scheube, H. Die Frawen des achtzehnten Jahrbunderts. Culturgeschichtliche Zeit- und Lebensbilder. 2 Bde. in 1. Berlin 1876-77

Schiefer, Karl. Elise Bürger. Ein Beitrag zur deutschen Literatur- und Theatergeschichte. Diss. [maschr.]. Frankfurt/M. 1921

Schieth, Lydia. Die Entwicklung des deutschen Frauenromans im ausgehenden achtzehnten Jahrhundert. Ein Beitrag zur Gattungsgeschichte. Franlkfurt/M. 1987

Schiller, Charlotte von u. a. Charlotte von Schiller urd ibre Freunde. Auswabl aus ihrer Korrespondenz. Hg. Ludwig Geiger: Berlin, o. J.

Schiller, Friedrich von. Werke in drei Bänden. München 1984

Schindel, Carl Wilhelm August von. Die deutschen Schriftstellerinnen des neunzehnten Jabrhunderts. 3 Bde. Leipzig 1823

[Schlegel, Christiane Karoline]. Düval und Charmille. Ein bïrgerlich Trauerspiel in finf Aufzügen. Von einem Frauenzimmer. Hg. C. F. Weisse. Leipzig 1778

Schlegel, Friedrich. „Frau von Weißenthurns Lustspiel ,Es spulkt.“ Kritische Ausgabe. Bd. 3: Charakteristiken und Kritiken II (1802-1829). Hg. Hans Eichner. München, Paderborn, Wien 1975. 170

Schlenther, Paul. Frau Gottsched und die bürgerliche Komödie. Ein Kulturbild aus der Zopfzeit. Berlin: Wilhelm Hertz, 1886. Nachdruck Cleveland, OH, o. J.

- Theater im 19. Jahrbundert. Ausgewählte theatergeschichtliche Aufsätze. Hg. Hans Knudsen. Schriften der Gesellschaft für Theatergeschichte. Bd. 40. Berlin 1930

Schlichtkrull, Aline von. Wie ein Staat gerettet wird. Schwank in vier Akten. Berlin, o. J.

Schmid, Christian Heinrich, Hg. Anthologie der Deutschen. Frankfurt \& Leipzig 1770

- Christian Heinrich Schmids Chronologie des deutschen Theaters (1775). Hg. Paul Leg band. Schriften der Gesellschaft fir Theatergeschichte. Bd. 1. Berlin 1902

- Nekrolog oder Nachrichten von dem Leben und den Schriften der vornehmsten verstorbenen teutschen Dichter. 2 Bde. Berlin 1785

Schmidt, Elise. Drei Dramen von Elise Schmidt. Berlin 1856.

[Enthält: Der Genius und die Gesellschaff. Macchiavelli. Peter der Große und sein Sobn. Sep. Pag.]

Schmidt, Friedrich Ludwig. Dramaturgische Aphorismen. Hamburg 1820

- Dramaturgische Berichte. Hamburg 1834
- Hg. Neue Hamburger Bühne. Eine Sammlung der newesten Lustspiele. Hamburg \& Wien 1824

Schneider, Friedrich. Dante, Boccaccio, Petrarca. Zeulenroda 1938

Schneider, L. Geschichte der Oper und des Königlichen Opernhauses in Berlin. Berlin 1852

- Das Verdienst-Kreuz fir Frauen und Jungfrauen. Berlin 1872

Schönfließ, Rosalie, u. a., Hg. Der internationale Kongress fiur Frawenwerke und Frauen bestrebungen in Berlin, 19. bis 26. September 1896. Eine Sammlung der auf dem Kongress gehaltenen Vortrige und Ansprachen. Berlin 1897

Scholtz-Novak, Sigrid Gerda. Images of Womanhood in the Works of German Female Dramatists 1892-1918. Diss. Michigan 1973

Scholz, Wilhelm von. Droste-Hiulshoff. Stuttgart, Berlin 1922

Schrciber, S. Etta. The German Woman in the Age of Enlightenment. A Study in the Drama from Gottsched to Lessing. New York 1948

Schreyvogel, Josef. Josef Schreyvogels Tagebuicher 1810-1823. Hg. Karl Glossy. 2 Bde Schriften der Gesellschaft für Theatergeschichte. Bd. 2 \& 3. Berlin 1903

Schröder, Sophie. Briefe (1813-1868). Hg. Heinrich Stümcke. Schriften der Gesellschaft fiur Theatergeschichte. Bd. 16. Berlin 1910

- Sophie Schröders Briefe an ibren Sohn Alexander Schröder. Hg. Heinrich Stümcke. Schriften der Gesellschaft fur Theatergeschichte. Bd. 26. Berlin 1916

Schubert, Franz. Incidental Music for Rosamunde, Fürstin von Cypern, a play in four acts by Helmina von Chezy. New York 1961

- und Helmina von Chézy. Rosamunde. Schauspiel von Helmina von Chezy mit Musik. Franz Schubert, Opus 26. Klavierauszug. Leipzig 1928

- und Alexander Dean. Rosamunde. A Pastoral Opera in Two Acts. Based on the story of the original play by Wilhelmina von Chezy. New York Newark, Boston, Chicago, San Francisco 1928

Schütze, Gottfried. Lobschrift auf die Weiber der alten deutschen und nordischen Völker. Hamburg 1776

Schütze, Johann Friedrich. Hamburgische Theater-Geschichte. Hamburg 1794

- Satyrisch-d̈sthetisches Taschen- und Hand-Wörterbuch fir Schauspieler und Theaterfreunde beides Geschlechts. Nebst einem lehr- und scherzreichen Anhange. Hamburg 1800. Neudruck ho: Werner Otto. Wien, Köln, Graz 1984

Schultheis, W. Dramatisierung von Vorgeschichte. Beitrag zur Dramaturgie des deutschen klassischen Dramas. Assen 1971

Schultz, Alwin. Alltagsleben einer deutschen Frau zu Anfang des achtzehnten Jahrbunderts. Leipzig 1890

Schultz, Hans Jürgen, Hg. Frauen. Porträts aus zwei Jabrhunderten. Stuttgart \& Berlin 1981

Schulz, Gerhard. Die deutsche Literatur zwischen Französischer Revolution und Restauration. München 1983

Schulze-Kummerfeld, Karoline. Lebenserinnerungen. Hg. Emil Benezé. 2 Bde. Schriften der Gesellschaft fur Theatergeschichte. Bd. 23 \& 24. Berlin 1915 
Schumann, Sabine, „Das ,lesende Frauenzimmer.' Frauenzeitschriften im 18. Jahrhundert." Die Frau von der Reformation zur Romantik. Die Situation der Frau vor dem Hintergrund der Literatur- und Sozialgeschichte. Hg. Barbara Becker-Cantarino. Bonn 1980. 139-69

Schwanbeck, Gisela. Sozialprobleme der Schauspielerin im Ablauf dreier Jabrbunderte. Theater und Drama. Bd. 18. Berlin 1957

Sengle, Friedrich. Arbeiten zur deutschen Literatur 1750-1850. Stuttgart 1965

- Biedermeierzeit. Deutsche Literatur im Spannungsfeld zwischen Restauration und Revolution 1815-1848. 3 Bde. Stuttgart 1971-80

- Das historische Drama in Deutschland. Geschichte eines literarischen Mythos. Stuttgart 1969

Sergeant, Philip W. The Life of Anne Boleyn. New York 1924

[Seyler, Friederike Sophie]. Die Entfuhrung, oder Die zärtliche Mutter. Ein Drama, in fünf Aufzügen. Von Friederike Sophie Hensel. Neue Schauspiele 3. Pressburg \& Leipzig 1772

[-] Die Familie auf dem Lande, Ein Drama, in füf Aufzügen. Von Friederica Sophia Hensel. Braunschweig 1770

- Oberon, oder König der Elfen. Ein romantisches Singspiel in drey Aufzügen nach Wieland. Deutsche Schaubiithne 11. O. O., 1792. 135-220

Shearing, Joseph. The Angel of the Assassination. Marie-Charlotte de Corday d'Armont, Jean-Paul Marat, Jean-Adam Lux. A Study of Three Disciples of Jean-Jaques Rousseau. London \& Toronto 1935

Shelley, Percy Bysshe. The Cenci. A Tragedy in Five Acts. Hg. Alfred Forman und H. Buxton Forman. London 1886

Sherry, Ruth. Studying Women's Writing. An Introduction. London, New York, Melbourne 1988

Singer, Hans W. Albrecht Dürcr. München 1918

Slessarev, Helga. „Susanne von Bandemer and Benjamin Franklin." American Notes and Queries IV, 10 (Juni 1966), $149 \mathrm{f}$.

- „Susanne von Bandemers Beitrag zur Entwicklung des Briefromans." Goethe Jahrbuch. Neue Folge Bd. 30. Hg. Andreas B. Wachsmuth. Weimar 1968. 132-7

Smith, Lacey Baldwin. Elizabeth Tudor. Portrait of a Queen. Boston, Toronto 1975

Sopholkles. Sophocles I. Three Tragedies. Chicago \& London 1954.

[Enthält: Oedipus the King, 1-76. Oedipus at Colonus, 77-155. Antigone, 156-204.]

Sorel, Albert-Émile. Charlotte de Corday. Une arrière petite fille de Corneille. Paris 1930

Sørensen, Bengt Algot. Herrschaft und Zärtlichkeit. Der Patriarchalismus und das Drama im 18. Jahrhundert. München 1984

Spiero, Heinrich. Geschichte der deutschen Frauendichtung seit 1800. Leipzig 1913

Staiger, Emil. Annette von Droste-Hülshoff. 2. Aufl. Frauenfeld 1962

- "Rasende Weiber in der deutschen Tragödie des 18. Jahrhunderts." Stilwandel. Studien zur Vorgeschichte der Goethezeit. Zürich \& Freiburg 1963. 25-75

Stanton, 'Theodore, Hg. The Woman Question in Europe. A Series of Original Essays. New York: G. P. Putnam's Sons, 1884. Nachdruck Newx York 1970
Stein, Charlotte von. Dido. Goethes Briefe an Frau von Stein. 2. Aufl. 2 Bde. Hg. Adolf Schöll. Frankfurt/M. 1883-5. II, 488-534

- Rino. Goethes Briefe an Frau von Stein. 2. Aufl. 2 Bde. Hg. Adolf Schöll. Franlifurt/ M. 1883-5. I, 396-400

Stein, Philipp. Deutsche Schauspieler. Eine Bildnissammlung. 2 Bde. Schriften der Gesellschaft fur Theatergeschichte. Bd. $9 \& 11$. Berlin 1907-8

- Goethe als Theaterleiter. Berlin \& Leipzig, o. J.

Steiner, Gerhard. „Einleitung." Frölich, Henriette, Virginia oder Die Kolonie von Kentucky. Mehr Wahrheit als Dichtung. Berlin 1963

[Steinlein, Laura]. Das Haus Cenci. Preisgekrönte Tragödie in fünf Aufzuigen von Arthur Freese [Pseud.]. Frankfurt/M. 1867

Stephan, Inge. Literarischer Jakobinismus in Deutschland (1789-1806). Stuttgart 1976

- und Carl Pietzcker, Hg. Frauensprache - Frauenliteratur? Für und Wider einer Psychoanalyse literarischer Werke. Tübingen 1986

- und Sigrid Weigel. Die verborgene Frau. Sechs Beiträge zu einer feministischen Literaturwissenschaft. Berlin 1983

- Regula Venske und Sigrid Weigel. Frauenliteratur obne Tradition? Neun Autorinnenporträts. Frankfurt/M. 1987

Stevenson, R. A. M. Peter Paul Rubens. London 1898

Strauss, Bertha. Annette von Droste-Hülshoff. Ihre dichterische Entwicklung und ihr Verhältnis zur englischen Literatur. Leipzig 1909

[Strauss, Henriette]. Beatrice. Historische Tragödie in fünf Aufzügen von Franz Siking [Pseud.]. Leipzig, o. J.

Stümcke, Heinrich. Henriette Sontag. Ein Lebens- und Zeitbild. Schriften der Gesellschaft fuir Theatergeschichte. Bd. 20. Berlin 1913

Susmann, Margarete. Frauen der Romantik. Jena 1929

[Sydow, Wilhelmine von]. Eunomia, oder Der Spiegel des Herzens. Eine Sammlung moralischer Schauspiele zur belehrenden Unterhaltung fir die Jugend, von Isidore Grönau [Pseud.], Verfasserin der Grafen von Nordheim, der Opferblumen, Kunigunde u. s. w. Neustadt/ Orla 1830.

[Enthält: Die Überraschung, 1-50. Das Festspiel 51-114. Das Angebinde, 115-40. Die Schwätzerin, 141-70. Kindliche Liebe, 171-212. Der Husarenrecrut, 213-46. Die gebeilte Thorbeit, 247-76.]

[Symonds, Emily Morse] und Peter Quennell. „To Lord Byron": Feminine Portraits Based Upon Unpublished Letters 1807-1824 by George Paston [Pseud.] and Peter Quennell. London 1939

Symonds, John Addington. Italian Byways. London 1883

Szépe, Helena. "The Term Frauendichtung." Unterrichtspraxis 9, 1 (1976). 11-15

Szondi, Peter. Theorie des modernen Dramas (1880-1950). 10. Aufl. Frankfurt/M. 1974

- Die Theorie des bürgerlichen Trauerspiels im 18. Jahrhundert. Der Kaufmann, der Hausvater und der Hofmeister. Hg. Gert Mattenklott. Frankfurt/M. 1979

Tarbell, Ida M. Madame Roland. A Biographical Study. London 1896

Taschenbuch fuirs Theater. Mannheim: 1795. Mit: Theater Kalender. Mannheim 1795 
[Tesson de la Guérie, Jean]. Das dreyßigjährige Mädchen, ein Lustspiel in Einem Akt. Leipzig 1778

Teutscher, Maria Antonia. Fanny, oder Die glïckliche Wiedervereinigung. Ein Drama in einem Aufzuge. Wien 1773

Das Theater. Illustrierte Halbmonatsschrift. Redigiert von Christian Morgenstern. Berlin 1903-5. Kommentierte Falssimileausg. der Jahrgänge 1-2: Emsdetten 1981

Theater Kalender. Mannheim: 1795. Mit: Taschenbuch furrs Theater. Mannheim 1795

Theater-Kalender auf das Jahr 1911. Hg. Hans Landsberg und Arthur Rundt. Berlin, o. J. [1912]

Theater-Kalender auf das Jahr 1912. Hg. Hans Landsberg und Arthur Rundt. Berlin, o. J. [1913]

Theatralkalender fur Wien, fur das Jahr 1772. Verfasset von einigen Liebhabern der deutschen Schaubiïhne. Wien, o. J. [1773]

Thiekotter, Hans. Annette von Droste-Hülshoff. Eine Auswahlbibliographie. Münster 1963

Thon, Eleonorc. Adelheit von Rastenberg. Ein Trauerspiel in fün Aufzügen. Weimar 1788

Thorn, Eduard. Frauen um Dichter. Stuttgart 1933

Tieck, Ludwig. Kritische Schriften. 4 Bde. in 2. Leipzig 1848-52

Timken-Zinkann, R. F. Ein Mensch namens Dürer. Des Künstlers Leben, Ideen, Umwelt. Berlin 1972

[Titzenhofer, Sophie Eleonore von]. Lausus und Lydie. Ein Drama in drey Aufzügen, nach den moralischen Erzäblungen des Herrn Marmontel, verfasset von einern Adlichen Frauenzimmer in Schlesien. Breslau 1776

[-] Willhelm und Hannchen. Eine Operette in drey Aufzügen. Breslau 1778

Touaillon, Christine. Der deutsche Frauenroman des 18. Jahrhunderts. Bern, Frankfurt/ M., Las Vegas 1979

Trinkaus, Charles. The Poet As Philosopher. Petrarch and the Formation of Renaissance Consciousness. New Haven \& London 1979

Troll-Borostyáni, Irma von. Die Gleichstellung der Geschlechter und die Reform der Jugend-Erziebung. 2. Ausgabe des Buches der obgenannten Verfasserin "Im freien Reich". Zürich 1888

- Im freien Reich. Ein Memorandum an alle Denkenden und Gesetzgeber zur Beseitigung sozialer Irrtiumer und Leiden. Von Irma v. Troll-Borostyáni, Verfasserin von: „Die Mission unseres Jahrbunderts". Zürich 1884

- Katechismus der Frauenbewegung. 3. Aufl. Leipzig 1903

- Die Mission unseres Jahrbunderts. Eine Studie über die Frauenfrage. Pressburg \& Leipzig 1878

Trueblood, Paul G. Lord Byron. Boston 1977

Ueding, Gert. Klassik und Romantik. Deutsche Literatur im Zeitalter der Französischen Revolution 1789-1815. München \& Wien 1987

[Unger, Friederike Helene?]. Die magnetische Wunderkraft, oder aller Welt zum Trotz doch ein Arzt. Ein Lustspiel in drey Aufzüugen. Vom Verfasser der offenen Fehde. Aus dem Französischen frey übersetzt: Deutsche Schaubïhne. Bd. 2. Augsburg 1792. 121-204
Varnhagen von Ense, Rahel und Pauline Wiesel. Ein jeder machte seine Frau aus mir wie er sie liebte und verlangte. Ein Briefwechsel. Hg. Marlis Gerhardt. Darmstadt/ Neuwied 1987

Vatel, C., Hg. Dossiers du Procès Criminel de Charlotte de Corday, devant le Tribunal Révolutionnaire, Extraits des Archives Impériales. Versailles 1861

Vergil. The Aeneid. Übers. Robert Fitzgerald. New York 1983

Verzeichniß einiger jetztlebenden Deutschen Schriftstellerinnen und Ihrer Schriften. Journal von und fur Deutschland 1789, Theil II, 466; 1790, Th. I, 315; 1791, Th. I, 231

Vor und binter den Coulissen. Almanach erprobter Bühnenspiele, bumoristischer Polter abend-Masken, Theater-Mysterien, Schauspieler-Novellen und Anekdoten. Für 1844. Erster Jabrgang. Hg. Friedrich Adami. Berlin, o. J.

Voss, Lena. Goethes unsterbliche Freundin (Charlotte von Stein); eine psychologische Studie an der Hand der Quellen. Leipzig 1922

Waetzoldt, Wilhelm. Dürer und seine Zeit. 3. Aufl. Wien 1936

Wagner, Heinrich Leopold. Briefe die Seylerische Schauspielergesellschaft und Ibre Vorstellungen zu Frankfurt am Mayn betreffend. Frankfurt/M. 1777

Wagner, Maria, Hg. Mathilde Franziska Anneke in Selbstzeugnissen und Dokumenten. Franlufurt/M. 1980

Wagner, Richard. Richard Wagner to Matbilde Wesendonck. Hg. und übers. William Ashton Ellis. New York 1905

- Tagebucbblatter und Briefe an Matbilde Wesendonck 1853-1871. Eingeleitet und erläutert von Professor Dr. R. Sternfeld. Berlin, o. J.

Waldhäusl, Emma. Caroline Pichlers Stellung zur zeitgenössischen Literatur mit besonderer Berücksichtigung ibrer Novellendichtung. Diss. [maschr.]. Wien 1922

Waldmann, Emil. Albrecht Dürer. Sein Leben und seine Kunst. Leipzig, o. J.

Waldmüller, Robert. „Lebensskizze." Amalie von Sachsen, Dramatische Werke der Prinzessin Amalie, Herzogin zu Sachsen. Leipzig 1873. I, I-LVII

[Walpurgis, Maria Antonia]. Talestri regina delli amazzoni. Opera drammatica di E. T. P. A. [Pseud.]. Dresda nella stamperia regia: 1763. / Talestris, Königinn der Amazonen Ein Singespiel von E. T. P. A. [Pseud.]. Dresden 1763

Walter, Eva. Schrieb oft, von Màgde Arbeit müde. Lebenszusammenhänge deutscher Schriftstellerinnen um 1800 - Schritte zur bürgerlichen Weiblichkeit. Mit einer Bibliographie zur Sozialgeschichte von Frauen 1800-1914 von Ute Daniel. Hg. Annette Kuhn. Düsseldorf 1985

Warnke, Martin. Peter Paul Rubens. Life and Work. Übers. Donna Pedini Simpson. Woodbury, N. Y. 1980

Weber, Carl Maria von und Wilhelmine von Chézy. Euryanthe. Grosse romantische Oper in drei Aufzügen. Dichtung von Helmine von Chezy, geb.: Freyinn von Klencke, in Musik gesetzt von Carl Maria von Weber. Partitur: Berlin, o. J. Nachdruck: Farnborough, Hants. 1969

- [und Wilhelmine von Chézy]. Euryanthe. Große heroisch-romantische Oper in drei Akten von Carl Maria von Weber. Klavierauszug. Leipzig \& Berlin, o. J. [187-?] 
Weber-Kellermann, Ingeborg. Die deutsche Familie. Versuch einer Sozialgeschichte. 5. Aufl. Frankfurt/M. 1979

- Frauenleben im 19. Jabrhundert. Empire und Romantik, Biedermeier, Gründerzeit. München 1983

Webster, John. The White Devil. Hg. Travis Bogarr. San Francisco 1961

Weigel, Sigrid. Topographien der Geschlechter: Kulturgeschichtliche Studien zur Literatur. Reinbek bei Hamburg 1990

Weil, Rudolf. Das Berliner Theaterpublikum unter A. W. Ifflands Direktion (1796 bis 1814). Ein Beitrag zur Methodologie der Theaterwissenschaft. Schriften der Gesellschaft fur Theatergeschichte. Bd. 44. Berlin 1932

[Weilen, Alexander von und Oscar Teuber]. Die Theater Wiens. 2 Bde. Wien 1899-1906

Weinand, Maria. Die große Dichterin Annette von Droste-Hülshoff. Eine Sicht ihres Lebens und ihrer Werke. Essen 1948

Weller, Emil. Lexicon Pseudonymorum. Wörterbuch der Pseudonymen aller Zeiten und Völker oder Verzeichniss jener Autoren, die sich falscher Namen bedienten. 2. Aufl. Regensburg 1886

Wesendonck, Mathilde. Edith oder die Schlacht bei Hastings. Ein Trauerspiel. Stuttgart 1872

- Friedrich der Große. Dramatische Bilder (nach Franz Kugler). Berlin 1871

- Genovefa. Trauerspiel in 3 Aufziugen. Zürich 1866

- Gudrun. Schauspiel in 5 Akten. Zürich 1868

- Odysseus. Ein dramatisches Gedicht in zwei Theilen und einem Vorspiel. Dresden 1878 West, Thomas und Karl August. Gesammelte Schriften. 4 Bde. Braunschweig 1829

[Westphalen, Engel Christine]. Charlotte Corday. Tragödie in fünf Akten mit Chören. Hamburg 1804

[-] Petrarca. Ein dramatisches Gedicht in fuinf Akten. Von der Verfasserin der Charlotte Corday. Hamburg 1806

Wetzels, Walter D. „Schauspielerinnen im 18. Jahrhundert. Zwei Perspektiven: Wilhelm Meister und die Memoiren der Schulze-Kummerfeld." Barbara Becker-Cantarino, Die Frau von der Reformation zur Romantik. Die Situation der Frau vor dem Hintergrund der Literatur- und Sozialgeschichte. Bonn 1980. 195-216

Wickenburg, Wilhelmine von. Radegundis. Dramatisches Gedicht in einem Aufzuge von Wilhelmine Grafin Wickenburg-Almásy. Wien 1879

Wiese, Benno von. Deutsche Dramaturgie des 19. Jahrhunderts. Tübingen 1969

Wilkins, Ernest Hatch. Life of Petrarch. Chicago \& London 1961

Willcocks, M. P. Madame Roland or The Mirror of Men's Dreams. London 1936

Wilpert, Gero von. Deutsches Dichterlexikon. Biographisch-bibliographisches Handwörterbuch zur deutschen Literaturgeschichte. Stuttgart 1963

Winkler, Karl Theodor, Hg. Verzeichnisse der Darstellangen auf den vorzilglichsten Bühnen Deutschlands nebst andern das Theater betreffenden Gegenständen. Leipzig \& Dresden. No. 1-6 (Juli-Dezember 1815)

Wolbe, Eugen. Carmen Sylva [Pseud. für: Elisabeth von Rumänien, S. K.], Der Lebensweg einer einsamen Königin. Leipzig 1933
Wollstonecraft, Mary. A Vindication of the Rights of Woman. Hg. Carol H. Poston. 2. Aufl. New York \& London 1988

Woltmann, K[aroline] von. Deutsche Briefe. Leipzig 1834

- Ueber Natur, Bestimmung, Tugend ind Bildung der Frawen. Wien 1826

Wolzogen, Karoline von. Der leukadische Fels, Ein Schauspiel. Neue Thalia. Bd. 2, 5. \& 6. Stiick. Hg. Friedrich Schiller. Leipzig 1792. Neu verlegt Bern 1969

Women in Revolutionary Paris 1789-1795. Selected Documents. Hg. und übers. Darlene Gay Levy, Harriet Bronson Applewhite and Mary Durham Johnson. Urbana 8 Chicago 1979

Women Take Issue. Aspects of Women's Subordination. Women's Studies Group, Centre for Contemporary Cultural Studies, University of Birmingham $(\mathrm{Hg})$. London 1978 Wulff, Fredrik. Petrarch At Vaucluse 1337-1353. Lund 1904

Wurst, Karin, Hg. Frauen und Drama im achtzehnten Jahrbundert, 1770-1800. Köln \& Wien 1991.

[Enchält: Chistiane Karoline Schlegel, Düval und Charmille, 96-140. Sophie Albrecht, Theresgen, 141-87. Marianne Ehrmann, Leichtsinn und gutes Herz, 188-251. Wilhelmine von Gersdorf, Die Zwillingsschwestern, 252-91.]

Young, Betty. Ein amerikanisches Duell. Lustspiel in einem Aufzuge. Wien 1872

Young, Catherine. A Lady Who Loved Herself. The Life of Madame Roland. New York \& London 1930

Zäunemann, Sidonie Hedwig. Die von denen Faunen gepeitschte Laster. Frankfurt \& Leipzig 1739

Zimmermann, Friedrich Gottlieb. Friedrich Gottlieb Zimmermann's Dramaturgie. Erstes und kraftigstes Wirken in den Jahren 1817-1820, nebst einer charakteristischen Lebensskizze des Verfassers. Hg. Georg Lotz. 2 Bde. in 1. Hamburg 1840

- Neue dramaturgische Blatter. 3 Bde. Hamburg 1827-8

Zobeltitz, Fedor von, Hg. Briefe deutscher Frauen. Berlin 1936. 


\section{DANK}

allen, die mich beim Schreiben dieser Arbeit unterstützten und ermutigten - meinen Lehrerinnen und Lehrern, Freundinnen und Freunden, Kolleginnen und Kollegen. Zunächst und vor allem möchte ich Professor Susan Cocalis, meiner Doktormutter; für ihre fachliche Beratung und Ermutigung danken. Ihre wertvollen Ratschläge und ihr Enthusiasmus für das Thema gaben mir genug Rückenwind, um mich der einschüchternden Materialmenge zu stellen. Vieles, was in dieser Arbeit an Inspiration und Ausdauer steckt, verdanke ich ih:

Dank auch an John Landau für seine jahrelange und unermüdliche Unterstützung. John kennt die gesamte Arbeit dem Inhalt nach auswendig, ein Beweis für seine grenzenlose Geduld beim Zuhören. In der Endphase, als die Zeit knapp wurde, machte er sich oft mit mir in Bibliotheken auf die langwierige Suche nach mittlerweile verschollenen Autorinnen. Ohne Johns Hilfe wäre mir vieles schwerer gefallen, vieles hätte länger gedauert, und vor allem: einige Autorinnen, die John durch sein geradezu detektivisches Gespür für Pseudonyme entdeckte, hätte ich gar nicht gefunden.

Ich möchte mich auch bedanken bei:

Professor Klaus Peter und Professor Nina Scott an der University of Massachusetts/ Amherst, für ihre Hilfe und wertvollen Vorschläge;

Professor Werner Hoffmeister und Professor Susanne Zantop am Dartmouth College, und Iris Bork-Goldfield, für das Lesen von Teilen dieser Arbeit und kritische, aber freundliche Anmerkungen;

Professor Ruth Dawson an der University of Hawaii/Manoa, für wertvolle bibliographische Hinweise;

Patricia Carter und Marianne Hraibi, Interlibrary Loan Department, Dartmouth College, und Edla Holm, Interlibrary Loan, UMass/Amherst, für ihre Hilfe bei der Beschaffung der Primärliteratur

Weiterhin gilt mein Dank der University of Massachusetts/Amherst, die mir durch cin Stipendium die vorläufigen Recherchen zu dieser Arbeit ermöglichte; und John Murray Publishers Ltd, und dem Bildarchiv Preußischer Kulturbesitz, Berlin, für ihre freundliche Erlaubnis zur Reproduktion von Westalls Bild "The Byronic Heroine" und von Albrecht Dürers „Christi Geburt“.

Außerdem möchte ich mich bedanken bei all denen, die sich auf meine Anfrage hin die beträchtliche Mühe machten, mir Angaben über ihre Dramenbestände zu verschaffen: bei Dr. Heidi Ritter vom Germanistischen Institut der Universität Halle-Wittenberg, bei den Halleschen Studentinnen des Seminars zu Frauenbildern in Texten des 18. Jahrhunderts, und vielen Bibliotheken in Deutschland, Osterreich und der Schwciz:

in Deutschland:

die Stadtbücherei Ahlen,

die Staatliche Provinzialbibliothek dic Stadtbibliothek Bad Homburg v.

Amberg, das Richard-Wagner-Museum Bayreuth, die Stadtbücherei Bergisch Gladbach, die Deutsche Staatsbibliothek Berlin, die Staatsbibliothek Preußischer Kulturbesitz Berlin,

das Deutsche Historische Museum

Berlin,

die Universitätsbibliothek der Hum-

boldt-Universität Berlin,

der Deutsche Staatsbürgerinnen-Verband

$$
\text { Berlin, }
$$

die Theaterbibliothek in der "Möwe“, Berlin,

die Heinrich-Schulz-Bücherei Berlin/ Charlottenburg,

das Büro für stadtgeschichtliche Dokumentation Berlin

das Zentralinstitut für Literaturgeschichte Berlin,

das Wieland-Museum Biberach/Riß,

die Universitätsbibliothek Bielefeld, FB

Linguistils und Literaturwissenschaft,

das Stadtarchiv Biclefeld,

die Stadtbibliotheks Böblingen,

die Universitätsbibliothek Bonn,

die Stad thistorische Bibliothek Bonn,

das Zentrum für Kulturforschung Bonn,

die Stadtbibliothek Braunschweig,

die Stadtbücherei Brühl,

die Stadtbibliothek. Celle

die Stadtbibliothek Chemnitz,

die Stadtbibliothel Cuxhaven,

die Stadtbücherei Dachau,

das Stadtarchiv und Hessisches Staatsarchiv Darmstadt,

die Hessische Landes- und Hochschulbibliothek Darmstadt,

die Stadtbibliothek Dessau,

das Nordrhein-Westfälische Staatsarchiv Detmold,

die Studienbibliothek Dillingen a. d.

Donat,

die Fürstlich-Fürstenbergische Hofbibliothek Donaueschingen, die Universitätsbibliothek Dortmund,

das Fritz-Hüser-Institut für deutsche und ausländische Arbeiterliteratur Dortmund,

das Staatsarchiv Dresden

die Technische Universität Dresden,

das Haus des Deutschen Ostens Düsseldorf,

das Heinrich-Hcine-Institut Düsseldorf, das Goethe-Museum in Düsseldorf das Frauen-Archiv der Universität Düsseldorf,

die Wartburg-Stiftung Eisenach,

die Stadtbücherei Elmshorn „Carl von Ossietzky",

die Wissenschaftliche Allgemeinbibliothek des Bezirkes Erfurt,

die Stadtbücherei Erkelenz,

die Universitätsbibliothek Erlangen-

Nürnberg,

die Bibliothelk Folkwang-Hochschule

Essen

die Stadtbibliothek Essen,

die Landeszentralbibliothek Schleswig-

Holstein (Flensburg)

das Goethe-Haus in Frankfurt/M.

die Stadtbïcherei Frankfurt/M.,

die Universitätsbibliothek Freiburg i. Br.

dic Bodenseebibliothek Friedrichshafen,

die Bibliotheken des Bischöflichen

Priesterseminars und der Theologi-

schen Fakultät Fulda,

die Stadtbücherei Gelsenkirchen,

die Universitätsbibliothek Gießen,

die Oberlausitzische Bibliothelk Görlitz,

die Universitätsbibliothek Göttingen,

die Forschungs- und Landesbibliothek Gotha,

die Offentliche Bibliothek Grimmen,

die Stadt- und Kreisbibliothek Güstrow,

das Museum der Stadt Guistrow,

die Stadt- und Kreisbibliothek Guben,

die Siebenbürgische Bibliothek in

Gundelsheim/Neckar 
die Stadtbücherei Hagen,

das Gleimhaus in Halberstadt,

das Kreismuseum Haldensleben,

die Stadtbücherei Haltern,

das Staatsarchiv Hamburg,

das Zentrum für Theaterforschung der

Universität Hamburg,

die Stadtbibliothek Hameln,

das Stadtarchiv Heidelberg,

die Stadtbücherei Heidelberg,

die Universitätsbibliothek Heidelberg,

dic Bibliothek der Ehemaligen Universi-

tät Helmstedt,

die Stadtbibliothek Herford,

die Martin-Opitz-Bibliothek in Herne,

die Lessing-Bibliothek Kamenz,

die Stadtbibliothek Koblenz,

das Theatermuseum der Universität zu

Köln,

das Hochschulbibliothekszentrum des

Landes Nordrhein-Westfalen, Köln, die Wessenberg-Bibliothelk Konstanz,

die Gräflich-Solms-Laubach'sche

Bibliothek Laubach,

die Hohhaus-Bibliothek Lauterbach,

die Stadtbücherei Leichlingen,

die Deutsche Bibliothek Leipzig,

die Karl-Marx-Universität Leipzig,

die Stadt- und Bezirksbibliothek Leipzig

das Museum für Geschichte der Stadt

Leipzig,

die Bibliothek der Hansestadt Lübeck,

die Ratsbücherei Lüneburg,

die Stadt- und Bezirksbibliothek

Magdeburg,

die Akademie der Wissenschaften und

Literatur Mainz,

die Stadtbibliothek Mainz,

die Universitätsbibliothek Mannheim,

das Deutsche Literaturarchiv/Schiller

Nationalmuseum Marbach,

das Geheime Staatsarchiv Preußischer

Kulturbesitz in Merseburg, die Stadtbibliothek Mönchengladbach, die Stadtbücherei Mülheim a. d. Ruhr, das Sudetendeutsche Archiv München, die Stadtbibliothek München,

die Münchner Kammerspiele,

die Universitätsbibliothek Münster,

das Westfälische Landesmuseum für

Kunst und Kulturgeschichte, Münster die Staatliche Bibliothek Neuburg/Donau, dic Stadtbücherei Neustadt/Weinstr. das Karbe-Wagner-Archiv in Neustrelitz, die Kreisbücherei Northeim, die Landesbibliothek Oldenburg, die Stadtbibliothel Osnabrück, die Mitarbeiter/innen des Projektes

Corvey in Paderborn,

die Universitätsbibliothek Passau,

die Stadtbibliothek Pirmasens,

die Stadtbibliothek Plauen,

die Graf von Schönborn Schloßbibliothek Pommersfelden,

die Brandenburgische Landeshochschule in Potsdam,

die Städtischen Museen Quedlinburg, die Stadtbibliothek Radebeul-Ost,

die Fürst Thurn und Taxis Hofbibliothek Regensburg,

die Staatliche Bibliothek Regensburg,

die Universitätsbibliothek Regensburg,

die Stadtbibliothek Reutlingen,

die Universitätsbibliothek Rostock,

die Gemeindebibliothek Sandhausen,

das Landesarchiv Schleswig-Holstein in

Schleswig,

die Stadt- und Kreisbibliothek "Heinrich

Heine" Schmalkalden,

die Stadtbibliothek Schwabach,

die Bibliothek Otto Schäfer in

Schweinfurt,

das Stadtarchiv und -bibliothels

Schweinfurt,

die Mecklenburgische Landesbibliothek

Schwerin, das Siegerland-Museum Siegen,

die Fürstlich-Hohenzollernsche Hof-

bibliothek Sigmaringen,

das Staatsarchiv Sigmaringen,

die Hegau-Bibliothek Singen,

die Pfälzische Landesbibliothek Speyer,

die Universitätsbibliothek Stuttgart,

die Wissenschaftliche Allgemeinbibliothek Suhl,

die Stadt- und Kreisbibliothels Torgau,

die Universitätsbibliothek Trier,

das Fachreferat Germanistik der Universität Trier,

die Stadtbibliothek Trier,

die Universitätsbibliothek Ttibingen,

die Zentralbibliothek der Deutschen

Klassik, Weimar,

die Hessische Landesbibliothels Wies-

baden,

die Herzog-August-Bibliothek Wolfen-

biittel,

die Stadtbibliothek Worms,

die Universitätsbibliothek Würzburg,

die Stadtbücherei Würzburg (Max-

Heim-Bücherei),

die Stadtbibliothek Wuppertal,

das Museum Schloß Moritzburg in Zeitz

die Christian-Weise-Bibliothek Zittau,

der Bibliotheca Bipontina in Zweibrülk-

ken,

die Ratsschulbibliothek Zwickau,

in Österreich:

die Universitätsbibliothek Graz,

das Stadtarchiv Innsbruck,

die Bibliothek Oberösterreichisches

Landesmuseum Linz,

Außerdem schrieben viele, die hier unmöglich alle genannt werden können, mit Hinweisen auf weitere Autorinnen, Datenangaben und Werke, andere Bibliotheken, oder einfach mit Unterstützungsbezeugungen für meine Arbeit. Ihnen allen gilt mein herzlicher Dank. die Bundesstaatliche Studienbibliothek Linz,

die Universitätsbibliothelk Salzburg,

die Österreichische Nationalbibliothek Wien,

die Universitätsbibliothck Wien, die Stadtbibliothek Zofingen,

in der Schweiz:

die Aargauische Kantonsbibliothek

$$
\text { Aargau, }
$$

die Stadt- und Universitätsbibliothek Bern,

die Schweizerische Landesbibliothek

Bern,

die Bibliotheca Bodmeriana in ColognyGenève,

die Kantonsbibliothek Graubünden/ Chur,

die Bibliothek Goetheanum, Dornach, die Thurgauische Kantonsbibliothek

Frauenfeld,

die Bibliothèque publique et universitaire de Genève,

das Staatsarchiy des Kantons Luzern,

die Zentralbibliothek Luzern,

das Salzburger Museum Carolino

Augusteum,

St. Gallen,

die Zentralbibliothek Solothurn,

die Stadtbibliothek Winterthur;

die Zentralbibliothek Zürich,

und das Deutsche Seminar der Universi-

tät Zürich. die Stadtbibliothelk Wiener Neustadt,

die Kantonsbibliothek (Vadiana) in 
Kommunikation in Institutionen

1991, 176 Seiten, kartoniert.

lga Kotthoff

1992. 346 Seiten, gebunden.

Renate Baader

Dames de Lettre

Autorinnen des preziösen, hocharistokratischen

und »modernen « Salons (1649-1698)

Mlle de Scudéry - Mlle de Montpensier - Mme d'Aulnoy

1980. Romanistische Abhandlungen 5

ISBN 3476006093. gebunden.

Barbara Becker-Cantarin

Der lange Weg zur Mündigkeit:

Frau und Literatur (1500-1800)

1987. IX, 402 Seiten und 36 Seiten Abb., Leinen.

Christa Bürger

Leben Schreiben

Die Klassik, die Romantik und der Ort der Frauen

1990. VIII, 203 Seiten mit 22 Abb., engl. broschiert.

ISBN 3-476-00681-6

Catherine Clément

Die Frau in der Oper -

Besiegt, verraten und verikauft

Aus dem Französischen von Annette Holoch.

Mit einem Vorwort von Silke Leopold.

1992. 240 Seiten. 24 Seiten Abb,

ISBN 3-476-00785-5

Die Frau im Dialog

Studien zur Theorie und Geschichte des Briefes Herausgegeben von

Anita Runge und Lieselotte Steinbrügge

1991. VI, 242 Selten, kartonier

\section{Frauen Literatur Geschichte} Schreibende Frauen

vom Mittelalter bis zur Gegenwart Herausgegeben von

Hiltrud Gnüg und Renate Möhrmann

1985. XIV, 562 Seiten, Leinen
ISBN 3-476-00585-2

\section{J. B. Metzler Stuttgart}

Carola Hilmes

Ein Weiblichkeitstypus in der

nachromantischen Literatur

1990. XV1, 263 Selten, kartonlert.

ISBN 3-476-00691-3

Gudrun Kohn-Waechter

Das Verschwinden in der Wand

Destruktive Moderne und Widerspruch

eines weiblichen Ich in Ingeborg Bachmanns »Malina

Ergebnisse der Frauenforschung Band 28

ISBN 3-476.00836-, kartoniert.

Susanne Kord

Ein Blick hinter die Kulissen

Deutschsprachige Dramatlkerinnen

im 18. und 19. Jahrhundert

Ergebnisse der Frauenforschung Band 27

1992. 424 Seiten, kartoniert.

Christine Lehmann

Das Modell Clarissa

Liebe, Verführung, Sexualität und Tod

der Romanheldinnen des 18. und 19. Jahrhunderts

Metzler Studienausgabe
1991.217 Seiten, kartoniert.

ISBN 3-476-00748-0

Renate Möhrmann

Die andere Frau

Emanzipationsansätze deutscher Schriftstellerinnen

im Vorfeld der Achtundvierziger Revolution

1977. VI, 194 Seiten und 12 Kunstdrucktafeln, kartoniert.

ISBN 3-476-00353-1

Lieselotte Steinbrügge

Das moralische Geschlecht

Theorien und literarische Entwürfe über die Natur der Frau in der französischen Auflklärung Ergebnisse der Frauenforschung Band 11

1992. 160 Seiten, kartoniert.
ISBN 3-476-00834-7

J. B. Metzler Stuttgart 